\title{
ENTROPY PRINCIPLES IN THE PREDICTION OF WATER QUALITY VALUES \\ AT DISCONTINUED MONITORING STATIONS
}

BY

Agus Suprapto Kusmulyono

A Thesis Submitted to

the Central Queensland University

in Partial. Fulfilment of the Requirements

for the Degree of

DOCTOR OF PHILOSOPHY

VOLUME I

Department of Civil Engineering and Building James Goldston Faculty of Engineering Central Queensland University Rockhampton, Queensland, Australia 


\section{ABSTRACT}

This study examines an issue associated with the design and operation of water quality monitoring networks, namely, the situation, where, because of reductions in the budget allocated to water quality monitoring, or because the budget allocated to water quality monitoring is not increasing at the same rate at which the cost of operation of the network is increasing, or the need for a monitoring station is more acute in another location, one or more existing monitoring stations have to be discontinued. The particular question addressed in relation to this scenario is the development of an improved methodology for the prediction of water quality values at the discontinued stations.

The methodology proposed for the improved prediction of these water quality is derived from the information theory interpretation of the entropy principle, as formulated in terms of the Principle of Maximum Entropy (POME) and the Minimum Discrimination Information (MDI). The methodology itself is a nonlinear optimisation model in which an entropy function of the form $p_{i} l n p_{i}$, where $p_{i}$ represents the probability of event $x_{i}$, is maximised subject to a series of constraints on the form and statistics of the probability function from which the $p_{i}$ values are derived. An important feature of the probability distribution predictions provided by the model is that they are the 'most likely' distributions and therefore are unbiased, being affected only by the information which the user chooses to include in the constraints imposed on the optimisation, and on the historical values of the probability distributions which are incorporated into the non-linear objective function.

The approach is demonstrated by application to a series of water quality monitoring networks in Queensland, Australia. The model was evaluated on the basis of these cases in a verification step involving a comparison of the accuracy of the predictions provided by the entropy technique with the accuracy of the predictions available from a traditional regression based approach. The predictions from the entropy based approach were on average more accurate then those obtained from the regression approach $61 \%$ of the time.

The performance of the approach in terms of the accuracy of its predictions, the unbiased nature of those predictiors, and the fact that it requires the same type and anount of data as traditional regression techniques, indicates that the technique represents a significant advance in, the prediction of water quality values at discontinued water quality monitoring stations. 


\section{CONTENTS}

ABSTRACT

TABLE OF CONTENTS $i i$

LIST OF TABLES X

LIST OF FIGURES $\quad$ xiii

ACKNOWLEDGEMENT $\quad$ XV

CHAPTER

1 INTRODUCTION . . . . . . . . . . . . . . . . . . 1

2 LITERATURE REVIEW . . . . . . . . . . . . . . 6

2.1 Introduction . . . . . . . . . . . . . . . 6

2.1.1 Historical Background in the United States and Australia. . . . 6

2.1.2 General Background on Water
Quality Monitoring . . . . . . . 7

2.2 Water Quality Data Analysis . . . . . . . . 9

2.3 Water Quality Monitoring Networks . . . . . 16

2.4 Use of Entropy Theory in Water
Resources Engineering . . . . . . . 30

2.5 Conclusion . . . . . . . . . . . . . 31

3 APPLICATION OF THE ENTROPY PRINCIPLE TO

THE PROBLEM OF PREDICTION . . . . . . . . . . . 36

3.1 Shannon's Entropy (Information) Theory . . 37

3.2 The Principle of Maximum Entropy (POME) . . . . . . . . . . . . . . 4 41

3.3 The Principle of Minimum Discrimination Information (MDI) . . . . . 52

3.4 Demonstration of the Use of Entropy

3.5 Summary and Conclusion . . . . . . . . 62 
4.1 Problem Description . . . . . . . . . . . 64

4.2 Existing Methods . . . . . . . . 69

4.2.1 Regression Analysis . . . . . 69

4.3 The Proposed Entropy Based Method . 72

4.3.1 Problem Analysis . . . . . 72

4.3.2 The Entropy Based Model . . . . 75

4.3.3 Description of Terminology
Used in the Model . . . . . . . . 77

(i) Events . . . . . . . . . . 77

(ii) objective Function . . . . . . 81

(iii) Constraints . . . . . . . . . 83

4.3.4 Formulation . . . . . . . . 90

4.4 Discussion . . . . . . . . . . 106

5 APPLICATION OF THE TECHNIQUE $\quad$. . . . . . . 111

5.1 Database Description . . . . . . . . 112

5.2 Application of the Model . . . . . . . 121

5.2.1 Data Preparation . . . . . . . . 124

5.2.2 Data Analysis . . . . . . . . 128

a. Determining the Distribution . . . . 129

b. Discretization of the Variables . . . . 133

C. Development of the 'Information
Function' . . . . . . . . . . . . 134

d. Cases . . . . . . . . . . . . . 135

5.3 Results, Discussion and Computational
Problems . . . . . . . . . . 136

5.3.1 Results and Discussion . . . . . . 136

a. Case i Normally Distributed
Approximation . . . . . . 136

b. Case ii Non-Normal Distribution . . . 156 
c. Case iii Consideration of Observed Changes in the watershed that are, or may be, the Cause of Observed Changes in Water Quality Levels.

d. Case iv Dependency Between the Water Quality at Upstream Discontinued Stations . . . . 168

5.3.2 Discretization Problem . . . . . 173

5.3.3 Choice of the Period of Time Averaging . . . . . . . . . . .

5.4 The Use of Entropy Method for Identification of Locations of Causes of Changes in Observed Water Quality values

6 SUMMARY AND CONCLUSION . . . . . . . . . . 209 BIBLIOGRAPHY

\section{APPENDICES}

APPENDIX A

Table A.1(a) Water Quality Records in the Fitzroy River Basin

Table A.1(b) Water Quality Records in the Nogoa River Basin

Table A.1 (c) Water Quality Records in the Logan River Basin

Table A.2(a) Annual Mean Values of the water Quality Parameters from the Fitzroy River Basin . . . . . . .

Table A.2(b) Annual Mean Values of the Water Quality Parameters from the Nogoa River Basin

Table A.2(c) Annual Mean Values of the Water Quality Parameters from the Logan River Basin

Table A.3(a) Annual Mean Values of the Water Quality Parameters (grouped) from the Fitzroy River Basin 
Table A.3 (b) Annual Mean Values of the water Quality Parameters (grouped) from the Nogoa River Basin

Table A.3 (c) Annual Mean Values of the water Quality Parameters (grouped) from the Logan River Basin 250

Table A.4.1 Results of Assignment of Water Quality Values in the Fitzroy River Basin

Table A.4.1(a) 1 Yearly

Table A.4.1(b) 2 Yearly

Table A.4.1(c) 3 Yearly

Table A. 4.2

Results of Assignment of Water

Quality Values in the Nogoa

River Basin . . . . . . . . . 257

Table A.4.2(a) 1 Yearly . . . . . . . . . . . . . 257

Table A.4.2(b) 2 Yearly . . . . . . . . . . . . . 258

Table A.4.2(c) 3 Yearly . . . . . . . . . . . . . 259

Table A.4.2(d) 4 Yearly . . . . . . . . . . . 260

Table A.4.3 Results of Assignment of Water

Quality values in the Logan

River Basin . . . . . . . . . . 261

Table A.4.3(a) 1 Yearly . . . . . . . . . . . . . 261

Table A.4.3(b) 2 Yearly . . ............ . 262

Table A.4.3(c) 3 Yearly . . . . . . . . . . . . . 263

Table A.4.3(d) 4 Yearly . . . . . . . . . . . . . 264

Table A.5.1 Regression Coefficients for Various

Periods of Time in the Fitzroy

River Basin . . . . . . .

265

Table A.5.1(a) Between the Downstream Station

130003 and the Upstream

Station 130105

265

Table A.5.1(b) Between the Downstream Station

130003 and the Upstream

Station 130322

266

Table A.5.2 Regression Coefficients for Various

Periods of Time in the Nogoa

River Basin . . . . . . . . . 267

Table A.5.2(a) Between the Downstream Station

130209 and the Upstream

Station 130202 . . . . . . . . . 267

Table A.5.2(b) Between the Downstream Station

130209 and the Upstream

Station 130212

Table A.5.3 Regression Coefficients for Various

Periods of Time in the Logan

River Basin 
Table A.5.3(a) Between the Downstream Station

145008 and the Upstream.

Station 145010

269

Table A.5.3(b) Between the Downstream Station

145008 and the Upstream.

Station 145013

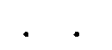

Table A.5.3 (c) Between the Downstream Station

145008 and the Upstream.

Station 145020

271

APPENDIX B

272

Table B.1.1

Comparison of the Use of Normal and

Log-normal Approach in the Fitzroy

River

273

Table B.1.1(a) 1 Yearly

Table B.1.1(b) 2 Yearly

Table B.1.1(c) 3 Yearly

273

273

273

Table B.1.2

Comparison of the Use of Normal and

Log-normal Approach in the Nogoa

River

Table B.1.2(a) 1 Yearly

Table B.1.2(b) 2 Yearly

Table B.1.2(c) 3 Yearly

Table B.1.2(d) 4 Yearly

274

274

274

275

275

Table B.1.3 Comparison of the Use of Normal and

Log-normal Approach in the Logan

River

Table B.1.3(a) 1 Yearly

............. . 276

Table B.1.3(b) 2 Yearly

Table B.1.3(c) 3 Yearly

Table B.1.3 (d) 4 Yearly

Table B.2.1 Comparison of the Results Obtained

by Using Knowledge about Changes in

the Watershed (Incorporated by

Changing the Prior Probability

Distribution at One Upstream Station

[Station 130105]) with those obtained

Ignoring that Knowledge [Fitzroy

River]

Table B.2.1(a) 1 Yearly

Table B.2.1(b) 2 Yearly

Table B.2.1(c) 3 Yearly

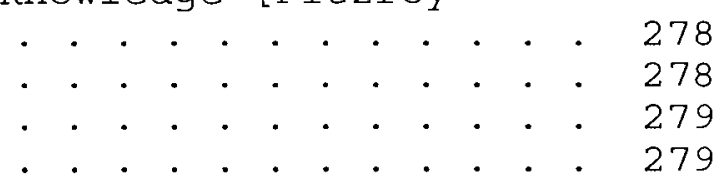

Table B.2.2

Comparison of the Results obtained

by Using Knowledge about Changes in

the Watershed (Incorporated by

Changing the Prior Probability

Distribution at One Upstream Station

[Station 130212]) with those Obtained Ignoring that Knowledge [Nogoa

River] 
Table B.2.2(a) 1 Yearly

Table B.2.2(b) 2 Yearly

Table B.2.2(c) 3 Yearly

Table B.2.2(d) 4 Yearly

Comparison of the Results obtained by Using Knowledge about Changes in the Watershed (Incorporated by Changing the Prior Probability Distribution at one Upstream Station [Station 145020]) with those Obtained Ignoring that Knowledge [Logan

River]

Table B.2.3(a) 1 Yearly

Table B.2.3(b) 2 Yearly

Table B.2.3 (c) 3 Yearly

Table B.2.3(d) 4 Yearly

Table B.3.1 Comparison of the Use of Independent and Dependent Data in the Fitzroy River

Table B.3.1(a) 1 Yearly

Table B.3.1(b) 2 Yearly

Table B.3.1(c) 3 Yearly

Table B.3.2 Comparison of the Use of Independent and Dependent Data in the Nogoa River

$\begin{array}{lll} & & \text { River } \\ \text { Table B.3.2(a) } & 1 \text { Yearly } \\ \text { Table B.3.2(b) } 2 \text { Yearly } \\ \text { Table B.3.2(c) } 3 \text { Yearly } \\ \text { Table B.3.2(d) } 4 \text { Yearly }\end{array}$

Table B.4.1(a) Station 130105

Table B.4.2(a) Station 130202

Table B.4.3(a) Station 145010

Table B.5.1

Hypothesis Testing for the water Quality values in the Fitzroy 
Table B.5.1(a) Station $130105 \quad$. . . . . . . . 312

Table B.5.1(b) Station $130322 \quad$. . . . . . . . . 314

Table B.5.1(c) Station $130003 \quad$. . . . . . . 316

Table B.5.2 Hypothesis Testing for the Water Quality Values in the Nogoa

River Basin . . . . . . . . . 318

Table B.5.2(a) Station $130202 \quad$. . . . . . . . . 318

Table B.5.2(b) Station $130212 \quad$. . . . . . . . . 320

Table B.5.2(c) Station $130209 \quad$. . . . . . . . 322

Table B.5.3 Hypothesis Testing for the water

Quality Values in the Logan

River Basin . . . . . . . . . 324

Table B.5.3(a) Station $145010 \quad$. . . . . . . . 324

Table B.5.3(b) Station $145013 \quad$. . . . . . . . 326

Table B.5.3(c) Station 145020 . . . . . . . . 328

Table B.5.3(d) Station 145008 . . . . . . . 330

Figure B.1(a) Assigned Probabilities at Station

130401 (Conductivity) . . . . 332

Figure B.1(b) Assigned Probabilities at Station

130401 (Dissolved Ions) . . . 333

Figure B.1(C) Assigned Probabilities at Station 130401 (Dissolved Solids) . . . 334

Figure B.1(d) Assigned Probabilities at Station 130401 (Hardness) . . . . . . . 335

Figure B.2(a) Plot of Regression Lines for

Different Period of Time over

which the Conductivity is

Averaged

Figure B.2(b) Plot of Regression Lines for

Different Period of Time over

which the Dissolved Ion is

Figure B.2(c) Plot of Regression Lines for

Different Period of Time over

which the Dissolved Solid is

Averaged

Figure B.2(d) Plot of Regression Lines for

Different Period of Time over

which the Hardness is

Averaged

Figure B.3(a) Plot of Water Quality values

in the Mackenzie River

(1 Yeariy Averaging) 
Figure B.3(b) Plot of water Quality Values

in the Mackenzie River

(2 Yearly Averaging) . . . . . 344

Figure B.3(c) Plot of Water quality Values

in the Mackenzie River

(3 Yearly Averaging) . . . . . . 348

Figure B.3(d) Plot of Water Quality Values

in the Mackenzie River

(4 Yearly Averaging) . . . . . . 352

APPENDIX C

The Saphiro-Wilk W Test . . . . . . . . . 357

Table C.1 Coefficients $a_{[i]}$ for the

Saphiro-Wilk Test for Normality . 359

Table C.2 Quantiles of the Saphiro-WILK W

Test for Normality (Values of $W$ such

that $100 \mathrm{p} \%$ of the Distribution

of $W$ is Less than $\mathrm{Wp}) \quad$. . . . . 360

Table C.3.1 Normality Test for Data from the

Fitzroy River Basin (Saphiro-Wilk

W Test) . . . . . . . 361

Table C.3.1(a) Station $130105 \quad$. . . . . . . . . 361

Table C.3.1(b) Station $130322 \quad$. . . . . . . . 362

Table C.3.2 Normality Test for Data from the Nogoa River Basin (Saphiro-Wilk

W Test) . . . . . . . . 363

Table C.3.2(a) station $130202 \quad$. . . . . . . . . 363

Table C.3.2(b) station $130212 \quad$. . . . . . . . 364

Table C.3.3 Normality Test for Data from the Logan River Basin (Saphiro-Wilk

W Test) ........ . 365

Table C.3.3(a) Station $145010 \quad$. . . . . . . . . 365

Table C.3.3 (b) Station $145013 \quad$. . . . . . . . . 366

Table C.3.3(b) Station $145020 \quad$. . . . . . . . . 367 


\section{LIST OF TABLES}

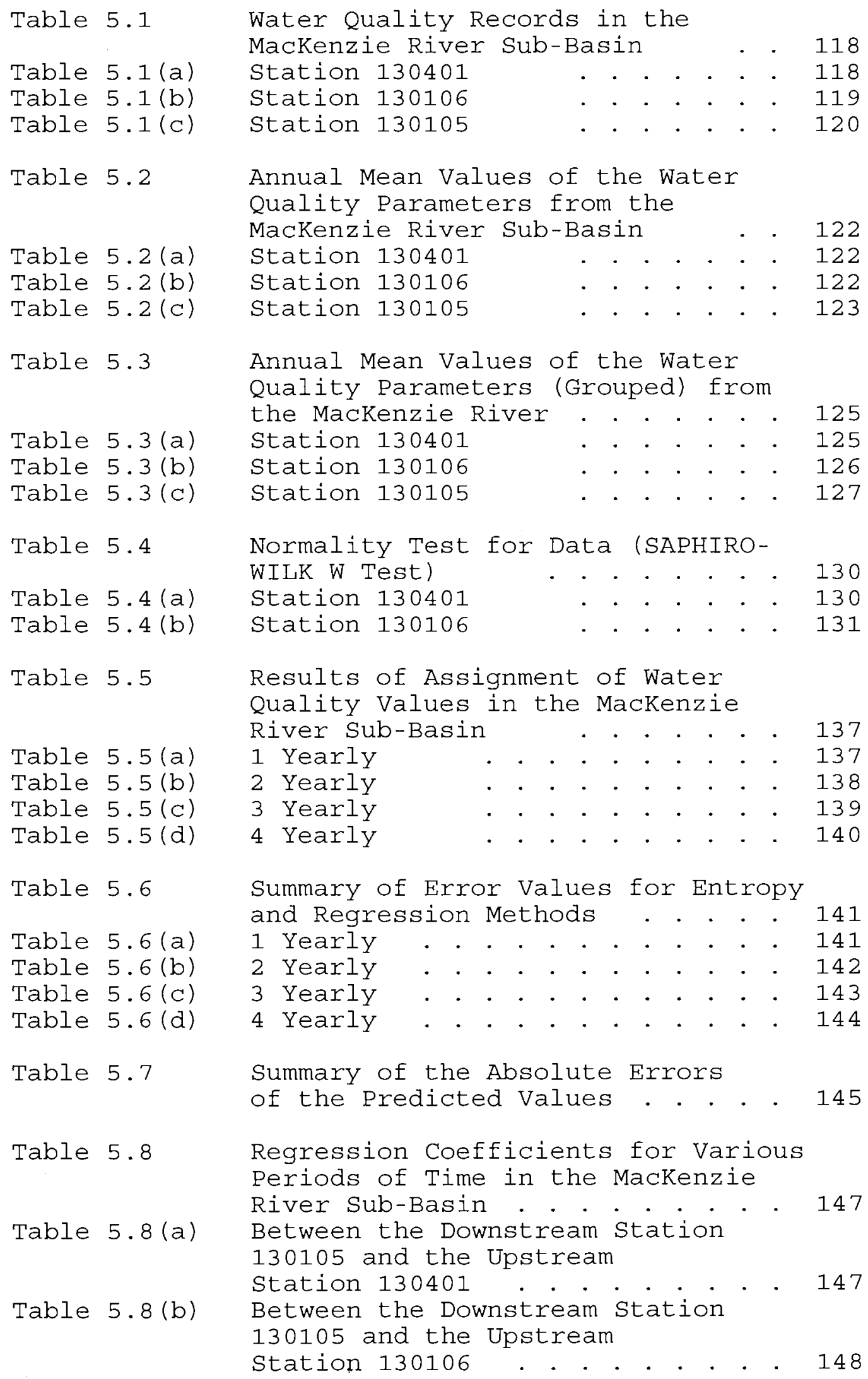




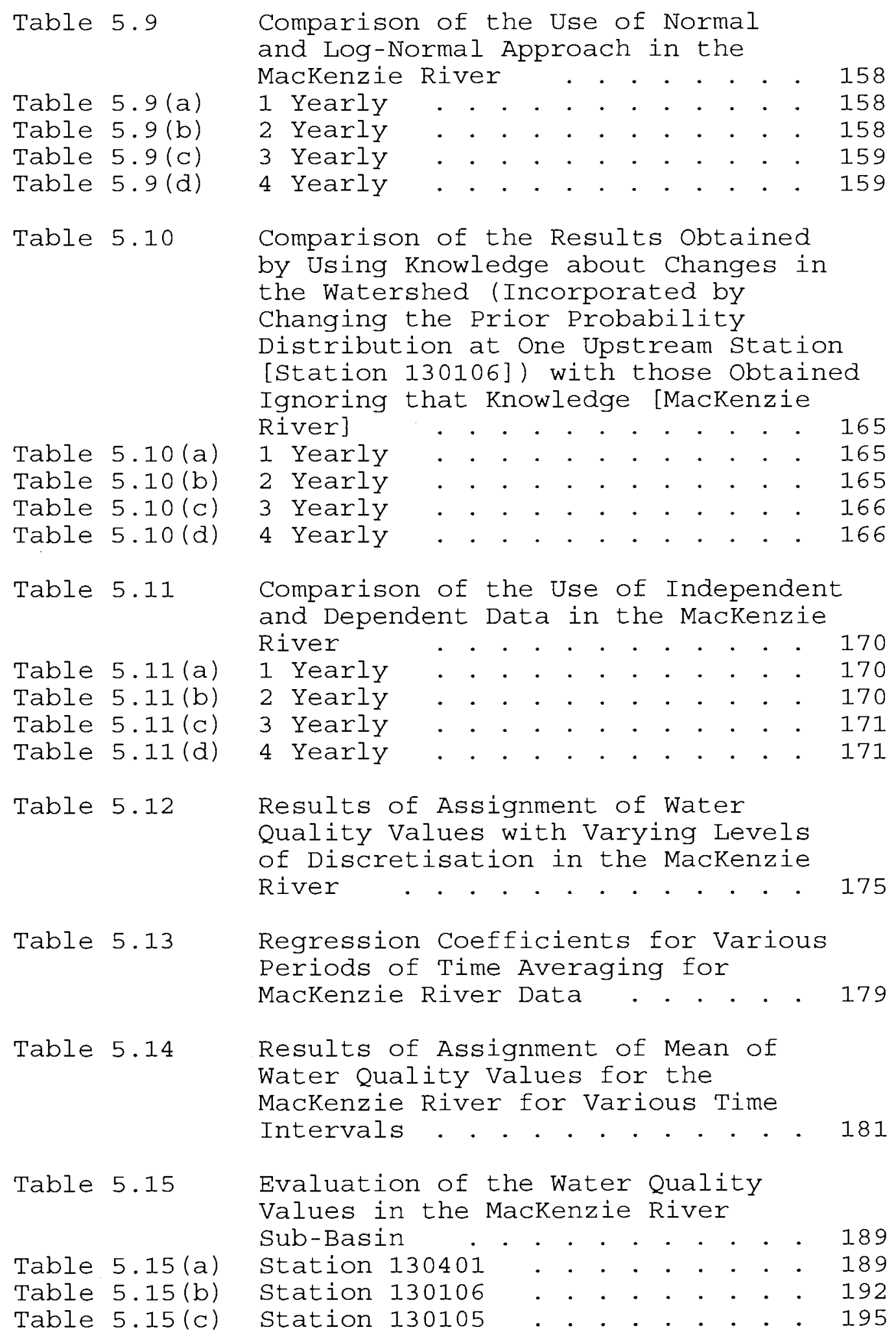


Table 5.16

Hypothesis Testing for the Water Quality Values in the MacKenzie

River Sub-Basin. . . . . . . . 202

Table 5.16(a) Station 130401... . . . . . . 202

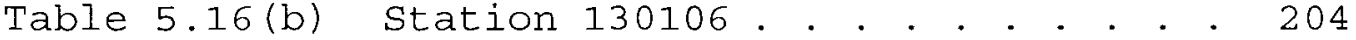

Table 5.16(c) Station 130105... . . . . . 206 


\section{LIST OF FIGURES}

Figure 3.1 Entropy Function for Two Possible

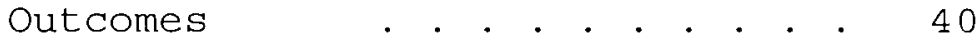

Figure 3.2(a) Maximising Entropy with the Constraint is the sum of the Probability is Equal 1

Figure 3.2(b) Maximising Entropy with the First Order Moment is Equal to the Median

Figure 3.2(c) Maximising Entropy with the First Order Moment is set Less than the Median . . . . . 48

Figure 3.2(d) Maximising Entropy with the First Order Moment is set Greater than the Median

Figure 3.2(e) Maximising Entropy with the First order and the second order Moment Specified

Figure 3.3(a) Probability Assignment for the Coin Problem with the Mean Value $=0.5$

Figure 3.3(b) Probability Assignment for the Coin Problem with the Mean Value $=0.6$

Figure 3.3(c) Probability Assignment for the Die Problem with the Mean value $=3.5$

Figure 3.3(d) Probability Assignment for the Die Problem with the Mean Value $=4.5 \quad$. . . . . . . . 60

Figure 4.1 Schematic of Explanatory Example. 66

Figure 4.2 Discretization of PDF to Determine the Candidate of Events . . . 80

Figure 4.3 Illustration of the Formulation of the Problem for Two Discontinued Monitoring Stations . . . . . . 96 
Figure 4.4

Figure 4.5
Illustration for the Simplified

Two Dimensional Formulation. . .

Figure for Explanation of

Relationship between Products of

Probability of Intervals of

Water quality Values that Give

Rise to Observed Downstream

Values

Figure 5.1(a) Location of Water Quality

Monitoring stations at the

MacKenzie River Sub-Basin

. 114

Figure 5.1(b) Location of Water Quality

Monitoring stations at the

Fitzroy River Basin

115

Figure 5.1(c) Location of Water Quality

Monitoring stations at the

Nogoa River Basin

.

.

Figure 5.1(d) Location of water quality

Monitoring stations at the

Logan River Basin . . . . . . . 117

Figure 5.2(a) Plot of Water Quality Values at

the Mackenzie River ( 1 yearly). . 152

Figure 5.2(b) Plot of Water Quality Values at

the Mackenzie River (2 yearly) . . 153

Figure 5.2(c) Plot of water Quality Values at

the Mackenzie River (3 yearly). . 154

Figure 5.2(d) Plot of water quality values at

the MacKenzie River (4 yearly). . 155 


\section{ACKNOWLEDGEMENT}

With a great appreciation and grateful, I acknowledge all people that helped make this research possible.

I would like to express my gratitude in particular to my supervisor, Professor I.C. Goulter for his guidance and encouragement during all phases of the study. Similar appreciation is also addressed to my co-supervisor Dr. D. Braddy for his support and guidance during my study.

My sincere thanks also go to Mr. Jim Davidson, Mr. Darron Irwin, Mr. Kevin Tickle, Mr. Francois Bouchart and $\mathrm{Mr}$. Suharyanto for their supports during my research work. Special thanks also addressed to the staff of the Queensland water Resources Commission and the Queensland Department of Environment and Heritage, who have provided the data for the purpose of this research.

Last but not least, I would like to express my appreciation to the AIDAB who has made this research 
possible with the financial support and to the Government of Indonesia who has given me the opportunity to accomplish this study.

\section{Declaration}

I hereby declare that this thesis is an original work, and I am the sole author of this thesis.

Agus S. Kusmulyono 


\title{
CHAPTER 1
}

\section{INTRODUCTION}

\begin{abstract}
Water quality monitoring is the activity of obtaining, analysing and interpreting quantitative information on the physical, chemical and biological characteristics of water via sampling and statistical analysis (Sanders et al., 1983). The objectives of water quality monitoring can generally be divided into three groups (Ward and Loftis, 1989). The first objective is to monitor the condition of the water body to determine baseline conditions. The second objective is to ascertain whether changes in water quality are occurring. The third objective is to observe the extreme conditions of the water body over a period of time. However, Duckstein et al. (1976) and Whitfield (1988) also highlighted another major objective, namely to observe the impacts on the water quality resulting, for example, from the introduction of water quality treatment measures or from projects and activities which have the potential to cause a deterioration in the quality of water.
\end{abstract}


One of the major issues in water quality monitoring is the cost of conducting the appropriate level of sampling that is to be undertaken on a routine basis. This cost is related to the variety and nature of the variables to be sampled, the number of locations of sampling (monitoring), and the frequency of sampling required to get the desired information within specified confidence limits. While the costs of monitoring are relatively easy to calculate, the benefits of water quality monitoring are more difficult to quantify. It is easy to argue that there are environmental benefits associated with water quality monitoring. However, it is not an easy task to quantify the benefit of knowing that water quality has increased to a certain level. The benefits of knowing that water quality has decreased to a certain level and remedial actions have to be taken are similarly difficult to quantify .

The difficulties associated with expressing the benefits quantitatively make analysis of the feasibility or desirability of a water quality monitoring network and monitoring program on a purely economic basis a very complex, if not impossible, task. Furthermore, the issues associated with expressing the economic benefits of water quality data can in turn mitigate against obtaining funding to support the continued operation and/or expansion of a water quality 
monitoring network. Difficulties in obtaining funding for establishment of a water quality monitoring network have been noted by a number of people involved in this field, e.g., Alpaslan et al. (1992).

In recognition of this problem, a number of studies have been directed at optimisation of the design of water quality monitoring networks so as to obtain the maximum amount of information for a given budget, or conversely to minimise the cost of obtaining a given amount of information. These efforts have been focused predominantly in determining the appropriate sampling frequencies (Sanders and Adrian, 1978; Loftis and Ward, 1980; Casey et al., 1983), the selection of locations for monitoring stations (sanders et al.. 1983; Lettenmaier et al.. 1984; Alpaslan and Harmancioglu, 1990), and the choice of variables to sample (sanders et al., 1983; ward et al, 1990; Alpaslan et al., 1992).

However, a more recent problem that is occurring in water quality monitoring, particularly in times of economic recession, is the discontinuation of existing water quality monitoring stations. These problems can arise directly as the result of actual declines in the budget allocated to water quality monitoring, or indirectly where the budget allocated to water resources is either 'static or increasing but the cost 
of operation is increasing more rapidly than the budget, resulting in an effective shortfall in funding.

\begin{abstract}
These conditions may lead to the decision to discontinue one or more water quality monitoring stations in a network. Even in the case of stable budgeting conditions there may be pressure to move a monitoring station from an existing location to another site where there is a greater need for water quality data. Regardless of the cause of the discontinuation of an existing station, the net result is the same, namely, loss of information about water quality at the site where monitoring has been discontinued. Accurate 'predictions' of the water quality at the discontinued sites are therefore highly desirable. It is this problem to which this thesis is directed.
\end{abstract}

The thesis proposes the use of the information theory of entropy as an improved method for predicting water quality values at water quality monitoring stations which have been in operation for a period of time sufficiert to define or establish the probability distribution of water quality values at that location but which have been subsequently discontinued for one reason or another, and for which water quality values are still desired.

The thesis initially discusses the current state 
of the art of water quality monitoring, water quality monitoring network design and water quality data analysis. A history of the use of entropy theory in water resources engineering is also provided. The principle of entropy, particularly as it is used in this thesis to predict water quality values, is then described.

Following this discussion of the theoretical background on the entropy based approach, the specific models used to predict the water quality values are formulated for a range of conditions. The various versions of the model are subsequently demonstrated by application to water quality monitoring networks in Queensland, Australia. Evaluation of the performance of the models is undertaken by comparing the results obtained from the models with those predicted using traditional regression techniques. Finally, the potential application of the model to the problem of identifying the locations of causes of observed changes (trend) in water quality is discussed. 


\section{CHAPTER 2}

\section{LITERATURE REVIEW}

\subsection{INTRODUCTION \\ 2.1.1 HISTORICAL BACKGROUND IN THE UNITED STATES AND AUSTRALIA}

In the United states, water quality monitoring/ management directed at pollution control began during the 1930s. (Interestingly, Federal laws on water pollution control were not actually passed in the United states until the 1940s and 1950s.) In 1965 the focus of water quality monitoring in the United states was on surface water quality. In 1972, the objective of monitoring was water quality management, i.e., to control discharges to streams by creating a discharge permit system (Ward et al., 1990). At the same time, in order to account for the stochastic nature of water quality variation, statistical considerations began to play an increasingly important role in the design of the networks and sampling programs.

In Australia, management of the water resources was started later than in the United states. The Australian water Resources Council was established in 
1962 with the primary objectives of conducting a comprehensive and continuous assessment of Australia's water resources, and the extension of measurement and research to aid in the planning of future development (Atlas of Australian Resources, 1967).

In the state of Queensland, the clean waters Act has been in operation since March 1973 with the aim of preserving, restoring and enhancing the quality of Queensland's water. The tasks of the water Resources Council, which has responsibility for administering the Act, are; to determine the conditions for licences; to undertake research and investigation into water quality; to set standards; to carry out surveillance of waste discharges; and to give advice and information to interested organisations and people. (Queensland Resources Atlas, 1980).

\subsubsection{GENERAL BACKGROUND ON WATER QUALITY MONITORING}

water quality monitoring is a complicated task. This complexity is related to a number of factors involved in the process of water quality monitoring, ranging from actual collection of the data to the process of translating the data into useful information. In the data collection process itself, factors such as selection of location of monitoring stations, selection of variables to monitor (sample), 
and selection of frequency of sampling have to be considered.

Ideally, monitoring is performed continuously. However, it is almost impossible to monitor all, or even a few, of the variables on a continuous basis. Sampling is, therefore, often the only viable alternative method for monitoring most water quality variables.

Previous research on water quality monitoring can be classified into two major categories. The first category is concerned with the actual collection of data describing the quality of water, i.e., design of water quality monitoring programs and water quality monitoring networks. The second category of research deals with the analysis of the data, i.e., extraction of as much information as possible from the data. It has been noted that large sets of data, often collected with considerable effort, do not always satisfy the objectives for monitoring (Ward et al., 1986). Unless the sampling programme is matched appropriately to the specified objectives for the water quality monitoring, the actual data collected may be inappropriate or at best only partially useful. In water quality monitoring, this case is designated as the 'data-rich information-poor syndrome' (Ward et al., 1986). 
In the following sections, previous research on water quality monitoring will be reviewed. Work on the analysis of water quality data will be examined first. Previous studies on the collection of the data and on the more complicated problems of design of the monitoring programs and the design of the network themselves will then be reviewed. Some applications of the entropy 'information' theory (on which the proposed model will be based upon) in a wide area of water resources problems, will also be presented.

\subsection{WATER QUALITY DATA ANALYSIS}

The primary objective of water quality data analysis is to extract information, i.e., determine the condition of the water body from collected data which are usually obtained by sampling. The values derived from the analysis can then be utilised to serve such objectives of water quality monitoring, as verifying compliance to specified standards, identifying trends, and detecting extreme values.

The problem of ascertaining whether water quality is complying with a specified standard has received some considerable attention in the literature. Schaeffer et al. (1980) and Herricks et al.(1985) discussed how to determine when violations occur. Berthouex and Hau (1991) reported on how to judge 
compliance using highly censored samples, while valiela and Whitfield (1989) examined the issue of designing monitoring strategies to determine compliance.

Determining when a violation does occur is a relatively complex task. One reason for this complexity is that, while the standard can be defined as a fixed value, the actual water quality values are generally determined on the basis of samples which are representative rather than absolute statements of the actual population. Any decision based on the values derived from the sampling must therefore recognise the statistical variability of both the population at large and the values derived from the sampling process. In their examination of assessment of compliance of water quality, Herricks et al. (1985), noted that regulatory authorities involved in water quality management must recognise the stochastic nature of data collected or reported to them. With respect to the process of addressing nor-compliance with water quality standards, Herricks et al. (1985) also noted that :

"Until both the natural systems and the harm done to them can be accurately measured, it may be inappropriate to impose penalties without regard to some form of fault".

A number of approaches have been proposed to address this problem of variability in the sample 
values. Schaeffer et al. (1980) developed a simple graphical method which takes into account process variability, average performance and type of sample collected (grab or composite) when determining violations. A method to estimate the probability that a single grab sample will violate a given stream standard was subsequently proposed by Loftis and Ward (1981) who also provided a procedure for determining the expected number of violations in a given number of samples from the cumulative density functions of water quality random variables themselves.

Berthouex. and Hau (1991) proposed a simple rule for judging compliance of effluent against effluent standards in the case when the effluent limit is set at a level below the limit of detection for the sampling method employed. Their rule was based on the binomial probability distribution and recognised the possibility of compliance even if a proportion of the samples were found to violate the effluent limit. In this latter case, effluent values observed to violate the limit are taken as a warning that initiates additional, more intensive monitoring. If the additional monitoring fails to detect further non-compliance within the time frame specified for the additional monitoring, the effluent is assumed to still be meeting the standards.

$$
\text { Another paper by Valiela and Whitfield }
$$




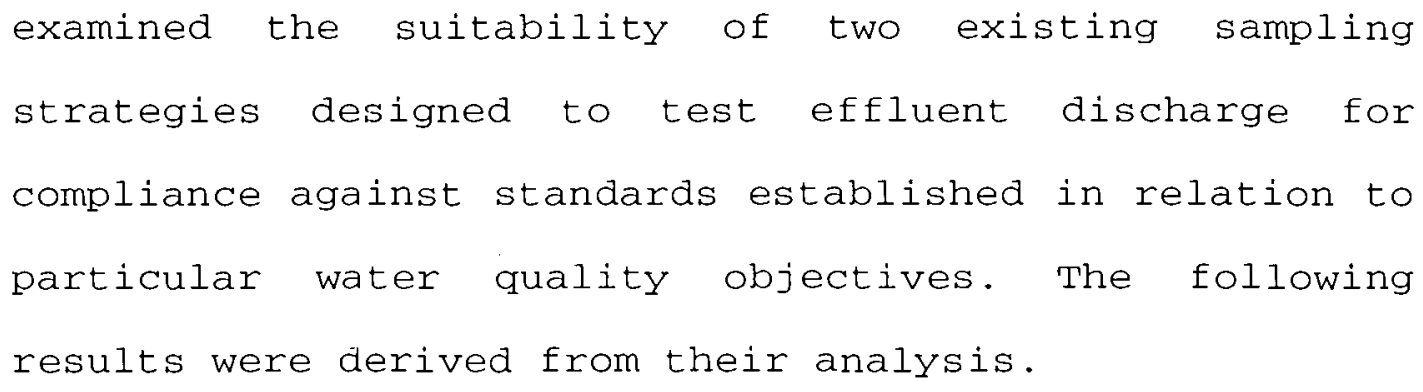

"For objectives based on long-term mean requirements, fixed frequency sampling at frequent intervals is most advantageous regardless of the underlying distribution of the data. For objectives that are based on maximum allowablè concentrations, effective sampling strategies increase the likelihood of detecting noncompliance. If data are highly autocorrelated or sharply seasonal in distribution, an exceedance-driven sampling strategy is more effective and efficient for detecting violations than fixed frequency sampling. However, data generated by exceedance-driven sampling provide biased estimates of mean and standard deviation."

In spite the importance of monitoring for determining compliance with a given standard, thereby assisting water quality control authorities in enforcing rules for maintenance of the quality of water, monitoring also serves a number of other purposes, such as, assessing the existing conditions in the water body and any short and long term trends that 
might be occurring in those conditions. Detection of trends, particularly those involving deterioration in water quality, is one of the main objectives in water quality monitoring. Appropriate monitoring assists in ensuring that conditions of decreasing water quality can be detected as early as possible, and any measures which might be implemented to maintain the water quality are put in place within an appropriate time scale.

The importance of detecting trends in water quality is indicated by the amount of research published on this particular subject. A number of papers by Hirsch et al. (1982), Hirsch and Slack (1984) and Belle and Hughes (1984) discussed techniques of trend analysis for water quality data. These papers noted that, due to such factors as non-normal distributions, seasonality, flow relatedness, missing values, values below the limits of detection and serial correlation, the analysis of water quality time series is complex. A range of methods to address that complexity were then proposed. The non-parametric test, known as the seasonal Kendall test, was demonstrated by Hirsch et al. (1982), as being applicable for data with seasonality, missing values, or values reported as 'less than'. Hirsch and slack (1984) subsequently modified this method to incorporate problems associated with data with sérial dependence. Two types of 
nonparametric tests for trends called intrablock methods and aligned rank methods were also introduced by Belle and Hughes (1984) about this time.

In a later study Hirsch (1988) discussed statistical methods and sampling designs to estimate step trends in surface water quality. That paper focused on the identification of a robust estimator appropriate to the data characteristics expected in water quality time series. Eight different existing estimators were evaluated to identify the robust estimator. The effectiveness of various existing sampling strategies were examined using Monte Carlo simulation coupled with application of the estimator.

An application of the trend detection method was reported by Alexander and Smith (1988) who used the Seasonal Kendall test for an investigation of the lead concentration in major rivers in the United states and observed the relationship between lead concentration and historical changes in gasoline-lead consumption. Lettenmaier et al. (1991) applied the same method and a related multivariate test to identify trends in stream quality in the continental United states for the period 1978-1987. Interestingly, the Lettenmaier et al. (1991) paper indicated that most of the stations with downward trends, i.e., decreasing concentrations in arsenic and cadmium concentrations were in the major population 
areas of the east and the midwest.

Selection of appropriate methods for trend tests has been discussed by Hirsch et al. (1991) and Harcum et a1. (1992). In the Harcum et al. (1992) paper, synthetic data were used in a simulation study to compare the power of selected methods for trend detection. The method used in that comparison were the Mann Kendall on deseasonalised data and the Seasonal Kendall (with and without correction for serial correlation).

Based on their experience with a wide variety of trend detection methods Hirsch et al. (1991) also provide guidance on the selection of existing statistical techniques for trend detection. The following issues were examined by Hirsch et al. (1991) in developing their guideline; step trend versus monotonic trend, parametric versus non parametric methods, concentration versus flux; effect of discharge, seasonal variability, and censored data.

It is important to note that in addition to the issues discussed above in relation to data analysis, the scale on which a conclusion will be derived should not be overlocked. It has been demonstrated by Loftis et al. (1991) that results of analysis of water quality data can vary significantly if different time scales 
are chosen. It is possible that a trend may be detected if one is interested in only a short time period. However, when a longer time period is considered, the existence of the trend suspected on the basis of a short term may no longer be evident. In conjunction with its effects on the detection of trends, the choice of the time scale will also affect the estimated value of the mean and have relevance as to the assumption of the independence of the data in the sample, i.e., data points collected over a short time scale with high frequency are likely to be more dependent than the same number of data points collected over a longer time scale. This importance of the spatial scale in estimating the condition of water body at a particular location was also noted by Loftis et al. (1991).

\subsection{WATER QUALITY MONITORING NETWORKS}

As noted earlier in their examination of issues related to the design and operation of water quality monitoring networks, ward et al. (1986) asserted that one of the problems in water quality monitoring systems is that of the "data rich but information poor" syndrome. In the same context, ward et al.(1986) argued that in order to have an effective monitoring system, it is necessary to view the problem as a complete system. Ward et al.(1986) then proposed a set of five steps which should be followed in the design of the 
monitoring network. These steps are (1) evaluate information expectation; (2) establish statistical design criteria; (3) design the monitoring network; (4) develop operating plans and procedures; and (5) develop information reporting procedures.

Before beginning design of the water quality monitoring network, it is essential to identify explicitly the objective(s) of the monitoring. In the first instance determination of this/these objective(s) involves the definition of the needs for the type of information expected from the monitoring system. Once the objectives; of the monitoring have been defined or agreed upon, the design of the monitoring network, including specification of the statistical criteria can be initiated. A good operational plan, including procedures for monitoring, then has to be established. Finally, but by no means the least, information reporting procedures have to be developed so that the information produced by the system will reach every user in the right format and within an appropriate time frame.

It should be noted that the nature and objectives of monitoring are dynamic, and therefore, periodic reviews of the stated design objectives for a particular network as they relate to the current situation are recommended (steele, 1987). In their 
comparison of the effectiveness of water quality monitoring using fixed stations and intensive surveys, Belle and Hughes (1983) concluded, not unexpectedly, that intensive surveys are effective only for studying short term fluctuations and are not appropriate for the evaluation of long term trends in water quality. Their study also supported the assertion of ward et al. (1986) that it is necessary to define the objectives before designing the network.

The following sections examine the following aspects of design; selection of sampling locations, sampling frequency and variables to sample. Note that the 'mechanical' processes involving in the actual sampling and the subsequent chemical, biological etc. analysis of the samples are not part of this study.

The selection of a sampling location in a river depends on two decisions; 1) where to take the sample from within a cross-section (micro-location), and 2) at which cross-section (along the length) of the river the sample should be taken (macro-location). The selection of the micro-location, must recognise the need for the sample to be representative of overall rather than local conditions in the water body at that crosssection. For example, the sample should be taken from the point in the cross-section where the solution is estimated to be completely mixed. A method for 
calculating the mixing length for straight channels where such sampling is appropriate has been proposed by Sanders et al. (1977) to address this issue.

In determining the macro-location for sampling, the following factors need to be considered: the objective(s) of the monitoring to be undertaken by stations in the network, accessibility of the location, how fast the results are expected and where detection with respect to a suspected potential source of pollution is to take place (Steele, 1987).

A method for the selection of macro-location based on the 'percent areal coverage' using basin centroids was presented by sanders et al. (1983). The 'percent areal coverage' in this method is defined as the number of sampling stations divided by the magnitude of the basin. Note that this definition only indicates that as more monitoring stations are installed the percent areal coverage will increase. However, it may not indicate the 'real' percentage of coverage of the basin, as might be expected. The method essentially consists of dividing the river network into sections with equal numbers of contributing tributaries.

The procedure itself is based on determining the 'centroid' of a river system. To determine this centroid, each exterior tributary lone which has no 
tributaries or one with a certain minimum mean flow is given a value of one. The value assigned to the stream at the confluence of each tributary with another tributary (or main stream) is determined by summing the values assigned to each of the streams which meet at that confluence point. Continuing the same process downstream, results in a value for the total of the contributing tributaries at each confluence and at the mouth of the river. Dividing this value by two, the centroid of the river basin is determined.

The sampling stations with the highest order (priority) are then located at the mouth of the river and in the section of the river where the centroid is located. A similar procedure can be applied to each section of the basin to allocate the higher order sampling stations. The result of the method is a location plan showing a hierarchy of monitoring stations, such that the stations with the highest rank can be built first, followed as funds become available, by stations with lower ranks. The cost, which is a function of the number of monitoring stations and their distance and accessibility, will of course be a consideration in the determination of the number and the macro-locations of monitoring stations under this process. Application of this method has been demonstrated by Alpaslan and Harmancioglu (1990) for the Gediz River basin in Turkey. 
The next and most important issue in data collection is the determination of sampling frequencies. This issue has been discussed intensively in many papers. Sanders and Adrian (1978), expressed its importance as follows:

"Sampling frequency is a very important
consideracion in the design of a water
quality monitoring network. A large portion
of the cost of operating a monitoring network
is related directly to the frequency of
sampling. In addition, the reliability and
utility of water quality data derived from a
monitoring network are likewise related to
the frequency of sampling."

The sampling frequency issue has also been identified by casey et al. (1983) as one of the most complex aspects of water quality network design and operation. From the perspective of the objective of monitoring, selection of sampling frequency becomes further complicated when multiple objectives have been identified for the monitoring program, a situation that is not uncommon. To detect extreme values, for example, frequent sampling must be conducted. On the other hand for detection of long term trends occurring over long periods of time, less frequent sampling would be more appropriate. From the statistical view point, design of the sampling programme, and in particular the frequency 
of sampling, can be considered on the basis of sampling theory, i.e., in terms of simple random sampling, systematic sampling, and stratified random sampling (Bruton, 1982).

Sanders and Adrian (1978) introduced a measure for determining sampling frequency based on the confidence interval of the mean of random component. Ward et al. (1979) also proposed a statistically based method to evaluate sampling frequencies in monitoring networks. The underlying principle of their procedure was to obtain uniform or equal information from all stations in the network. This goal was achieved by allocating the number of samples to be collected at a station as a function of the variations in the value of the water quality constituent of interest at that station, relative to the total variation for that constituent in the network.

Dunnette (1980) on the other hand, proposed the use of a water quality index to optimise the sampling frequency. This water quality index implicitly aggregates the relative importance of the various parameters to be sampled through a weighting process. and is therefore considered a good method for determining sampling frequency.

Loftis and ward (1980) subsequently presented 
another point of view for the determination of sampling frequency. They suggested that three factors have to be considered in determining sampling frequency, namely, i) random changes due to storms, rainfall, etc., ii) seasonal changes in temperature, rainfall, etc., and iii) serial correlation from sample to sample. From the analysis based on the width of the confidence interval around the sample mean and considering those three factors, three general regions of frequencies were identified, : 1) a region where serial correlation is dominant (the sampling frequency is greater than 30 times per year) ; 2) a region where the effects of seasonal variation and serial correlation tend to cancel each other out (the sampling frequency lies between 10 to 30 per year); and 3) a region where seasonal variation is dominant (the sampling frequency can be less than 10 per year).

While statistical analysis has an important role in determining the sampling frequency, it should be noted that, in many cases, it is the cost constraints that play the dominant role in the selection of sampling frequency (Sanders and Adrian, 1978). Therefore, a compromise between statistical considerations and budgetary limitations is generally needed in the: final determination of the sampling Erequency . 
The other major task in water quality monitoring is the selection of which parameters to sample. This task is very much dependent on the objectives of monitoring (ward et al., 1990). When the objective is to monitor conditions and observe long term trends, 'indicator' type of measurements would be sufficient. If the objective is for special investigation of a specific water quality problem, the parameters of concern should obviously be those related to the problem. When the objective of monitoring is to examine compliance, for example to a regulatory water quality standard, the parameters chosen for sampling must, at minimum, include all those listed in the standard.

For the situation where there is some choice of parameters to monitor, Sanders et al. (1983) suggest the specification of categories of water quality variables as a means of assisting in data collection planning and data analysis. Their study also suggested that the parameters to be monitored must be specified before the actual design of the water quality monitoring network and monitoring programme can be undertaken in a systematic fashion. This suggestion arises from both the natural or man made variations, that can occur in every water quality variable, the inability, due amongst other things to cost considerations, to consider all variables and their variations simultaneously, and the need to monitor the 
complete range of those parameters which are considered important .

Given the complexity of the design of water quality monitoring networks and monitoring programs described in the previous sections, it can be seen that the cost of establishing and operating a monitoring network can be very expensive. For a well designed network and monitoring programme, the greater quantity of data collected, the greater the information. It should be noted, however, in the light of this assertion that while more data will give more information, in a poorly designed network and monitoring programme, the increase in information associated with the collection of the additional data occurs at a slower rate than for a well designed network and monitoring programme. Furthermore, the increase in the cost associated with obtaining additional data, even for a well designed network and monitoring programme, may not always be justified by the increase in actual information gained. Generally, the availability of funding plays a dominant role in the establishment of a water quality monitoring network and monitoring programme. Therefore, financial issues cannot be overlooked in the design of water quality monitoring networks.

Constraints on' the budget can influence all 
aspects of the design of water quality monitoring networks, from selection of location of sampling stations (as it is related to the number of affordable stations), determination of sampling frequencies and selection of variables to sample. Not unexpectedly, given the importance of these financial issues, a number of studies have addressed the problem of 'optimal' design of water quality monitoring networks.

Heidtke and Armstrong (1979) presented a probabilistic sampling model for water quality management. The objective of their approach was to design an optimum sampling policy for detection of stream standard violation. Lettenmaier et al. (1984) proposed a method based on dynamic programming for systematic consolidation of an existing station water quality monitoring network. The method has been applied to the Municipality of Metropolitan seattle stream and river quality monitoring network, and resulted in a significant reduction in the number of monitoring stations with relatively little loss of information.

Palmer and Mackenzie (1985) developed an
interactive optimisation procedure, involving a
modified gradient search algorithm, to select designs
which maximise the statistical power of a network for a
specified budget or alternatively minimise the cost of
a network for a specified statistical power


requirement. The procedure was applied to aquatic monitoring in relation to a New England coastal power plant and showed that numerous solutions may exist for a specified power or cost, thereby providing the designer with many alternatives. Pinter and somlyody (1987) subsequently suggested a methodology for optimising the operation of a regional monitoring network being used for water quality management. The particular objective of their study was to provide a reliable estimate of the annual nutrient load of a lake. The model itself minimises the costs of operation of the annual monitoring system under obvious logical (physical) constraints and under constraints on the expected accuracy of the monitoring programme.

Caselton and Husain (1980), on the other hand, introduced a concept based on entropy theory to design a hydrologic data collection network, which might also be applicable in other situations such as water quality monitoring. The concept is based on viewing a hydrologic network as a communication channel which is dedicated to transmitting hydrologic information, and therefore, permits the network to be designed on the basis of its ability to convey hydrologic information. The objective in that paper, is to select $n$ permanent stations sites (where $\mathrm{n}$ is specified) from $m$ given locations, in a manner which maximises the information transmission measured with an entropy (measures of 
information) expression.

Most recently, Harmancioglu and Alpaslan (1992) re-examined the problem of multi-objective decision making in water quality monitoring network design and proposed a statistical procedure to evaluate the efficiency and cost-effectiveness of a network. The method was demonstrated by application to the Porsuk River in Turkey. This application indicated that their method has the capability of assessing the efficiency and cost-effectiveness of a network quantitatively. As such the method provides a rational basis for a reduction in either the frequency of sampling or the number of sampling stations.

However, research on optimisation of water quality monitoring networks has focused primarily on obtaining the optimal configuration of stations (Lettenmaier et al., 1984) and optimum sampling frequencies (Heidtke and Armstrong, 1979; Dunnette, 1980). Relatively little research has been directed at the problem of gain in information obtained by establishment of new station or the converse problem of loss of information about water quality at locations where water quality monitoring stations have been discontinued.

One of the existing methods for estimating values at a location where a station has been discontinued by 
interpolating data from surrounding stations is the Kriging method (Gambolati and Volpi, 1979). This method, however, does not appear to be applicable for the river network monitoring addressed in this thesis, since the physical characteristics of the problem are different. The Kriging method is applicable to spatial prediction of parameters where the nature of the parameter is changing gradualiy and continuously from one point to another e.g., water quality values or water levels at various locations across a lake; or piezometric levels or water quality values within an aquifer. The nature of a river network, however, is not a continuum; rather it has a skeletal structure with major 'discontinuities', i.e., a value at one point may not be significantly related to a value from other points which are separated by land masses and/or drainage basins. The kriging method is not therefore examined in this study.

Another method that may be applicable to the problem addressed in this thesis is 'traditional' regression analysis such as described in many statistical textbooks. Using this technique, values at the discontinued upstream stations can be derived by a function developed from the historical data from the discontinued station and other stations which were in existence during the monitoring period of the discontinued station "and which are still in operation. 


\subsection{USE OF ENTROPY THEORY IN WATER RESOURCES ENGINEERING}

Entropy 'information' theory has recently been applied widely in the field of water resources and hydrology. Sonuga (1972), Singh and Singh (1985), Singh et al. (1986) applied the principle to the derivation of frequency distributions. Sonuga (1976) also applied the concept to the derivation of functional rainfallrunoff relationships. Harmancioglu examined use of the entropy principle in the measurement of the information content of random process (Harmancioglu, 1981); evaluation of information transfer between hydrologic processes (Harmancioglu and Yevjevich, 1987); and assessment of recharge systems for a river basin (Harmancioglu and Baran, 1989). Amorocho and Espildora (1973) utilised the principle for assessment of hydrologic model performance while Chiu (1987,1988,1989,1991) and Chiu and Chiou (1986) applied the principle to velocity distributions in open channels. Awumah et al. $(1990,1991)$ on the other hand developed the principle for use in redundancy measures in water distribution network design.

These few examples demonstrate the versatility of the entropy concept in water resources and hydrology. This demonstrated versatility provided the basis for examination of the application of the entropy theory to 
the problem of prediction of water quality values at discontinued monitoring stations described in this thesis.

\subsection{CONCLUSION}

In this chapter, research in the area of water quality monitoring was presented. The issues discussed ranged from the relatively simple theoretical statistical aspects of sampling, to the more difficult and realistic cases wherein serial correlation and seasonal effects of water quality are addressed. The problem of the monitoring network design and operation was shown to have become increasingly complex as a greater range of the factors relevant to water quality monitoring were included.

A water quality monitoring network may have different users, each with a different objective for monitoring. However, geographic issues also contribute to the complexity. The more complex the configuration of the river system, the more complex the problem of designing a network to monitor the conditions in that network. Similarly the types of land use in the river basin will have an effect on the selection of the parameters to be sampled and perhaps on the selection of location of the sampling, i.e., the location of the water quality monitoring stations. 
The need for monitoring is itself growing with the increased emphasis on the environment. Effective environmental monitoring systems need to be in place in order to ensure that the environment is maintained to specified standards.

While the design of a monitoring system is in itself quite a complicated problem, financial considerations add to the complexity of designing effective and cost efficient networks. Furthermore, while the establishment of a good water quality monitoring system requires significant funding, the benefit of the monitoring itself is generally difficult to express in economic or quantitative terms. It is therefore not unusual for water quality monitoring to have a low priority in some countries, particularly in developing countries, where the budgets available for these activities are limited. Some form of optimisation procedure would therefore seem to be appropriate to cope with the problem of designing networks and monitoring programs so as to maximise the information (where information is a surrogate for benefits) able to be obtained for a specified budget. A number of studies have reported on different methodologies and models developed for this purpose and discussed their application to different aspects of water quality monitoring network design. 
The particular problem which is of interest in this thesis is the case of an effective reduction of the budget for monitoring network, where such reduction may require the discontinuation of sampling stations. The issue of reducing the number of sampling stations has been discussed as an issue in the optimisation of a water quality monitoring network (Lettenmaier et al., 1984; Palmer and Mackenzie, 1985; Harmancioglu and Alpaslan, 1992).

However, most of this work was directed at obtaining more reliable information from the existing network or ciesigning new and more reliable water quality monitoring networks/procedures. An exception to this generalisation is the work of Lettenmaier et al. (1984) which presented a systematic method for the reduction of sampling stations. Relatively little work focussed on the problems of limited budgets which might lead to a need to discontinue existing monitoring stations. Most of the previous research into water quality monitoring was directed at obtaining better information from established networks or designing new networks to obtain the maximum amount of information. The research described in this thesis is directed at the development of an improved methodology for prediction, within some limitations on the configuration of the network, of water quality values at these discontinued stations. 
Discontinuation of sampling stations is a real problem encountered in water quality monitoring networks. The reason for discontinuing stations in a particular river basin or monitoring network are often driven by financial considerations, either from a reduction in the budget allocated to water quality monitoring where such budget reduction might be absolute, or relative because the cost of the operation is increasing more rapidly than the increase in budget (or the budget is in fact static), or because the need for a monitoring station is more urgent in another basin. Either situation may require a station to be discontinued.

Faced with a situation of having to discontinue an existing station, the estimation of water quality values at a discontinued station represents a reasonable way of maintaining some information on the water quality condition at the discontinued station. Furthermore, if an effective method can be developed for estimation purposes, the design of a network can incorporate the possibility of station discontinuation, so that if budget reduction does occur, and some stations have to be discontinued, such discontinuation can take place with minimum reduction in the information able to be provided by the remainder of monitoring network. 
The method proposed in this thesis for prediction of water quality values at the discontinued stations is based upon information theory derived from entropy principles. The method is able to incorporate, prior knowledge about both existing (historical) conditions and changes in the watershed which may have caused changes in water quality observed at some downstream locations. The following chapters discuss the theoretical basis of the methodology and describe the application of the method to a series of case studies of water quality monitoring networks. The strength of the method, as demonstrated by the results from these case studies, is then discussed. 


\section{CHAPTER 3}

\section{APPLICATION OF THE ENTROPY PRINCIPLE TO THE PROBLEM OF PREDICTION}

The basic theory adopted in this thesis for prediction of water quality values at discontinued monitoring stations is Entropy (Information) Theory. The decision to consider entropy theory for prediction of water quality values at discontinued monitoring stations arises from one of the interpretations, or characteristics, of the entropy principle, wherein it can be used for the assignment, in an unbiased fashion, of probabilities to a range of events. This characteristic is applicable to the problem of estimating values of water quality at discontinued monitoring stations in that it provides a mechanism for assigning probabilities to a range of possible events (water quality values) at the location(s) of the discontinued monitoring station(s). These water quality 'events' and their associated (assigned) probabilities define, in turn, the distribution, and thereby the mean, of the particular water quality parameter at that location. Due to the' unbiased nature of the assignment 
of probabilities to each possible outcome, the estimated mean value derived from the assignment of probabilities to the range of possible events using the entropy principle will also be unbiased, i.e., depend only on the information available and no other assumptions.

Basic entropy theory and its extension to the frequency estimation (probability assignment) problem are described in the following sections.

\subsection{SHANNON'S ENTROPY (INFORMATION) THEORY}

Shannon's entropy based measure of information was formulated as follows. Define the probabilities of a set of $n$ possible events $1,2, \ldots, n$ (outcomes) to be $p_{1}$, $\mathrm{p}_{2}, \ldots, \mathrm{p}_{\mathrm{n}}$ respectively. Now consider a measure of uncertainty about the outcomes, say $\mathrm{H}\left(\mathrm{p}_{1}, \mathrm{p}_{2}, \ldots, \mathrm{p}_{n}\right)$. The measure of uncertainty proposed by Shannon (1948) on the basis of entropy consideration is as follows :

$$
H=-K \sum_{i=1}^{n} p_{i} \ln p_{i}
$$

where :

$\begin{aligned} \mathrm{H}= & \text { measure of information or measure of } \\ & \text { uncertainty } \\ \mathrm{K}= & \text { positive constant, whose value is }\end{aligned}$




determined by the units used
$\mathrm{p}_{i}=$ probability of possible event $i$
$[$ Since $\mathrm{K}$ is a constant for a given problem
(assuming use of the same units in each
application for that problem), $\mathrm{K}$ is omitted in
future uses of the entropy expression in this
thesis].

The above formula has the following characteristics :

a. $\mathrm{H}$ takes on its maximum value (equal to $\log \mathrm{n}$ ) when all events have the same probability or uncertainty, i.e., $p_{i}=1 / n$.

b. $\mathrm{H}$ takes on its minimum value (equal to 0 ) when there is absolute certainty about the events.

c. Any randomness in the probabilities will give a value of $\mathrm{H}$ between these two extremes.

d. $\mathrm{H}$ increases with increase in the number of possible events $n$.

The characteristic noted in point (a) indicates that, in the case of unbiased prediction such as that achieved through the use of entropy theory, the greater the uncertainty about the likelihood of the outcomes, i.e., the smaller the knowledge about the outcomes, the more uniform the probability of the events should be. In other words, entropy $\mathrm{H}$, as a measure of uncertainty about the outcomes in such a situation, will assume a 
larger value. Point (a) also indicates that entropy will take on its maximum value, reflecting the maximum level of uncertainty, when there is no knowledge about the outcomes of the event and hence every event will be assigned exactly the same probability (likelihood), i.e., every event for a process with $n$ outcomes is allocated the same probability $(1 / n)$.

The number of possible outcomes for an event also effects the maximum value of the entropy. The result of tossing a coin once only has two possible outcomes. The maximum entropy value for this case $(=0.693)$ will be lower, reflecting the reduced uncertainty about the outcomes than the maximum entropy value (=1.792) associated with the outcomes from tossing a die which has six possible outcomes. Based on those characteristics, the expression in Equation 3.1. can therefore be regarded as a measure of uncertainty.

By specifying $p_{i}$ as a proportion of the whole population with characteristics associated with a group i. this principle can also be used as a measure of diversity within a population. Consistent with the interpretation of larger values of entropy associated with the assignment of probabilities discussed in the previous paragraph, in this case, larger values of entropy will reflect a greater level of diversity 
within the population.

The behaviour of the entropy function for an event with two outcomes, $\mathrm{X}$ and $\mathrm{Y}$ is illustrated in graphical form in Figure 3.1. This figure shows that the entropy value becomes zero when one of the outcomes has a probability of one, i.e., $\mathrm{P}(\mathrm{X})$ or $\mathrm{P}(\mathrm{Y})=1$. The maximum value of entropy is reached when' $X$ and $Y$ have the same probability of occurrence, i.e., $P(X)=P(Y)=0.5$. AnY other combination of probabilities for the two outcomes results in an entropy value between these two extremes.

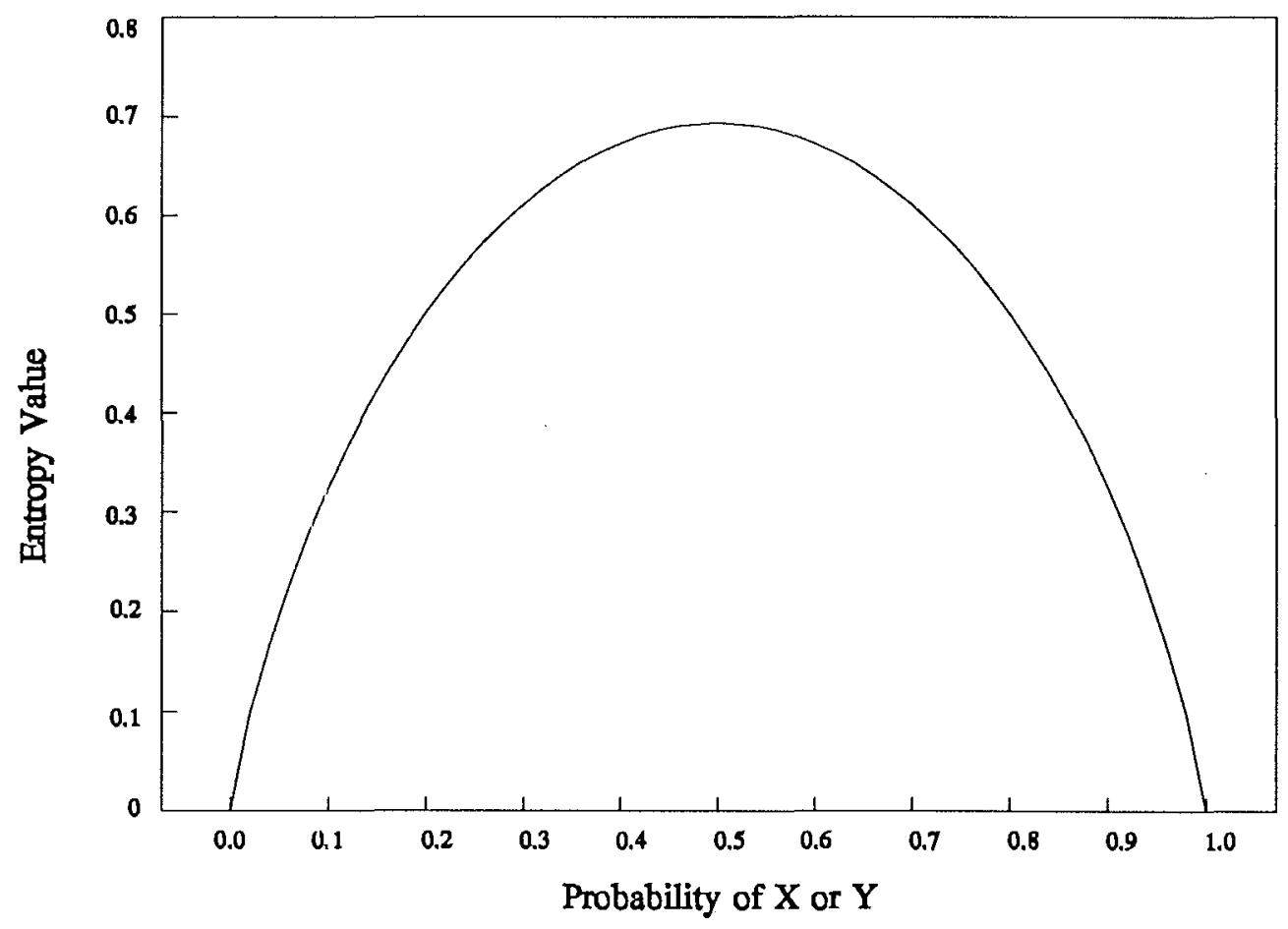

Figuns 3.1 Entropy Function for Two Possible Outcomes 


\subsection{THE PRINCIPLE OF MAXIMUM ENTROPY (POME)}

One of the characteristics noted for the entropy function as given in Equation 3.1 is that a uniform probability distribution will result in a maximum value of entropy for a set of events. Conversely, maximising the entropy function of Equation 3.1 (given no other constraints except that the sum of the probabilities of all the events must equal one to ensure specification of a complete probability distribution) results in an assignment of uniform probability to every event. In this 'reverse' application, the entropy principle can be used to derive probability distributions by maximising the entropy function subject to constraint(s) specifying any information which may be known about the events. Such information about the events might consist of knowledge that the outcomes of the events in questions are known to be normally distributed.

The mathematical expression for the simplest case of maximising entropy can be written as :

$$
\text { Maximise: } \quad H=-\sum_{i=1}^{n} p_{i} \ln p_{i}
$$

subject to :

$$
\sum_{i=1}^{n} p_{1}=1
$$


The constraint represented by Equation 3.3 ensures the development of a complete probability distribution. Solving the problem defined by Equations 3.2 and 3.3 . will result in a uniform probability distribution with $\mathrm{p}_{\mathrm{i}}=1 / \mathrm{n}$, where $\mathrm{n}$ is the number of possible events.

\begin{abstract}
The principle embedded in the maximisation involved in solving Equation 3.2 and 3.3 is known as the Principle of Maximum Entropy (POME) and was first introduced by Jaynes (1957). The basic concept in the POME is that, in assigning probabilities to possible events, the assignment should be as unbiased as possible, and should use, not unreasonably, only the information available.
\end{abstract}

The principle may be considered as an extension of "Laplace's Principle of Insufficient Reason " which states that equal probability should be assigned to all possible outcomes of a random experiment, if there is no information contradicting this assignment (Kapur, 1983).

The question might be asked as to why the probability distribution determined by POME should be the one accepted. This case for use of the entropy derived probability can be clarified by the following explanation. Suppose it is wished to assign 
probabilities to events $a, b, \ldots$ and there is no information at all about the likelihood of these events. There are numerous (infinite) possible combinations of probability values (distributions) for a certain number of possible events $n$. According to Laplace's Principle of Insufficient Reason, when there is no information at all, every event should be assigned an equal probability. This conclusion means that the outcome will have the maximum entropy value. Any other probability distribution in such a situation will have an entropy value less than that associated with the uniform distribution. However, the assignment of a distribution other than the uniform distribution which is associated with the maximum entropy is contradictory since there is no information available that can justify a reduction in the uncertainty and thereby a reduction in the entropy value for that case. Therefore, the probability distribution with the maximum entropy value should be the distribution selected.

It has also been shown by Jaynes (1968), that the probability distribution with the greatest entropy value derived from the results of a series of experiments under a given set of constraints is the probability distribution that can be realised in the greatest number of ways, i.e., it is the most likely 
probability distribution. Thus the most likely probability distribution derived from a set of experiments is that associated with the maximum entropy value.

In the situation where information is available about the likelihood of events, such information can be introduced in the entropy maximisation formulation through appropriate constraints. The addition of such constraints reduces the uncertainty about the likelihood of each outcome and thereby also reduces the value of the entropy. Each set of additional information, except where it is redundant, will progressively reduce the value of the entropy reflecting the fact each set of information also implies that there is less uncertainty associated with the likelihood. of each of the outcomes.

The addition of new information may, and in fact is likely to, change the probabilities assigned to the events, causing it to be no longer uniform. However, the probability distributions derived by the POME in the 'presence' of this new information (constraints) will still be the most uniform and unbiased possible, consistent with the information available.

Examples showing the assignment of probabilities 
to set of events under a range of different information about the process for a hypothetical problem are depicted in Figures $3.2(a)$ to $3.2(e)$. In these figures, $\mathrm{x}_{\mathrm{i}}$ can take on values from 1 to 16 inclusive and $\mathrm{n}=16$. Note that the differences in information about the process for each case are incorporated into the problem through the constraint(s) which are different for each case. The different information specified in each case are different values of observed (known) mean and in Figure $3.2(e)$ the observed (known) standard deviation. It can be seen in the figures that each set of information about the process, i.e., each set of constraints, results in different shapes for the resultant probability distributions.

It can also be seen in these figures that the probability distributions derived by the entropy principle can vary from a uniform distribution to a normal 'bell shaped' distribution. [The normal distribution is derived by the POME whenever observed or known means and standard deviations are specified in the formulation as indicated in the title of Figure 3. $2(e)]$. 


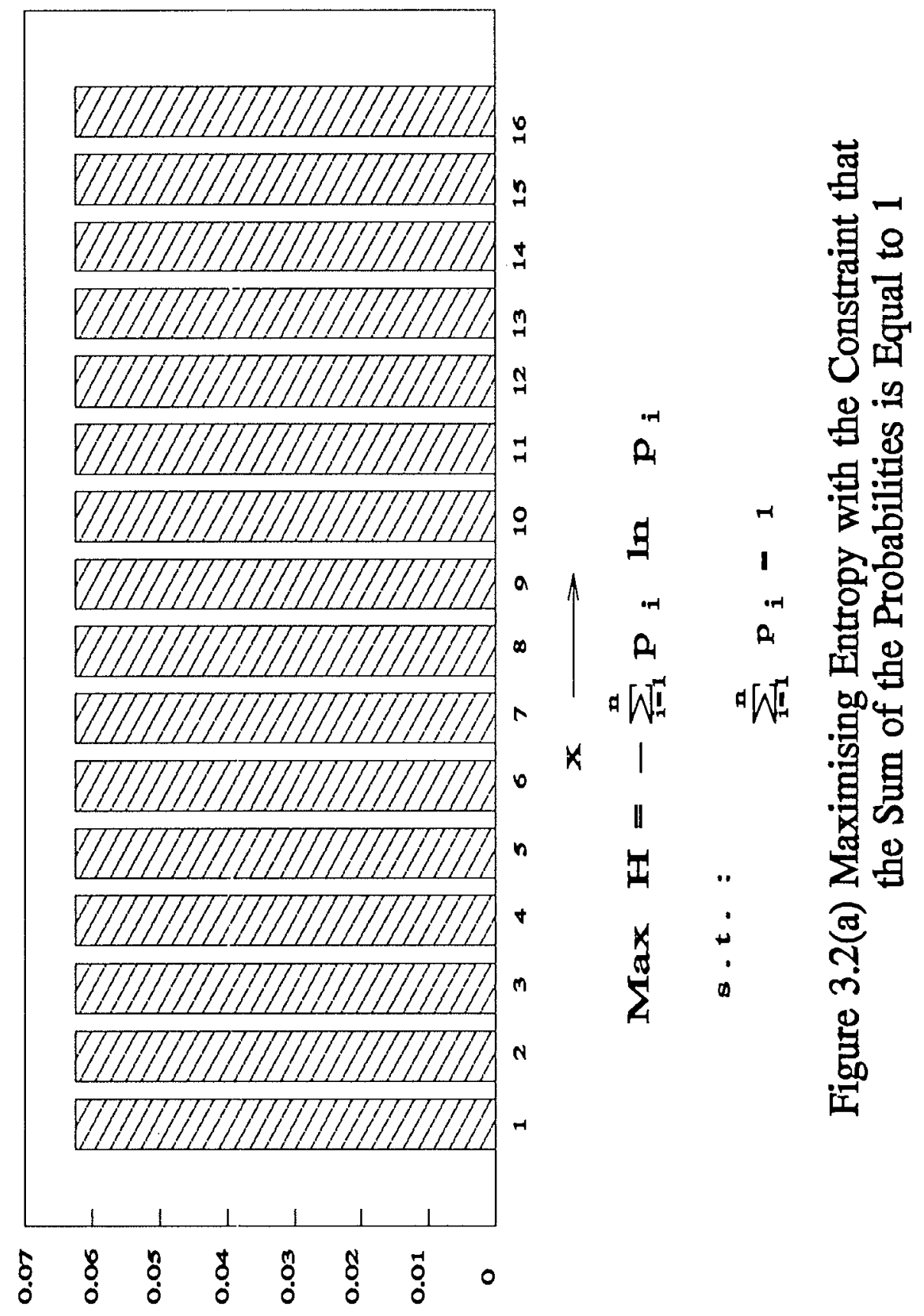




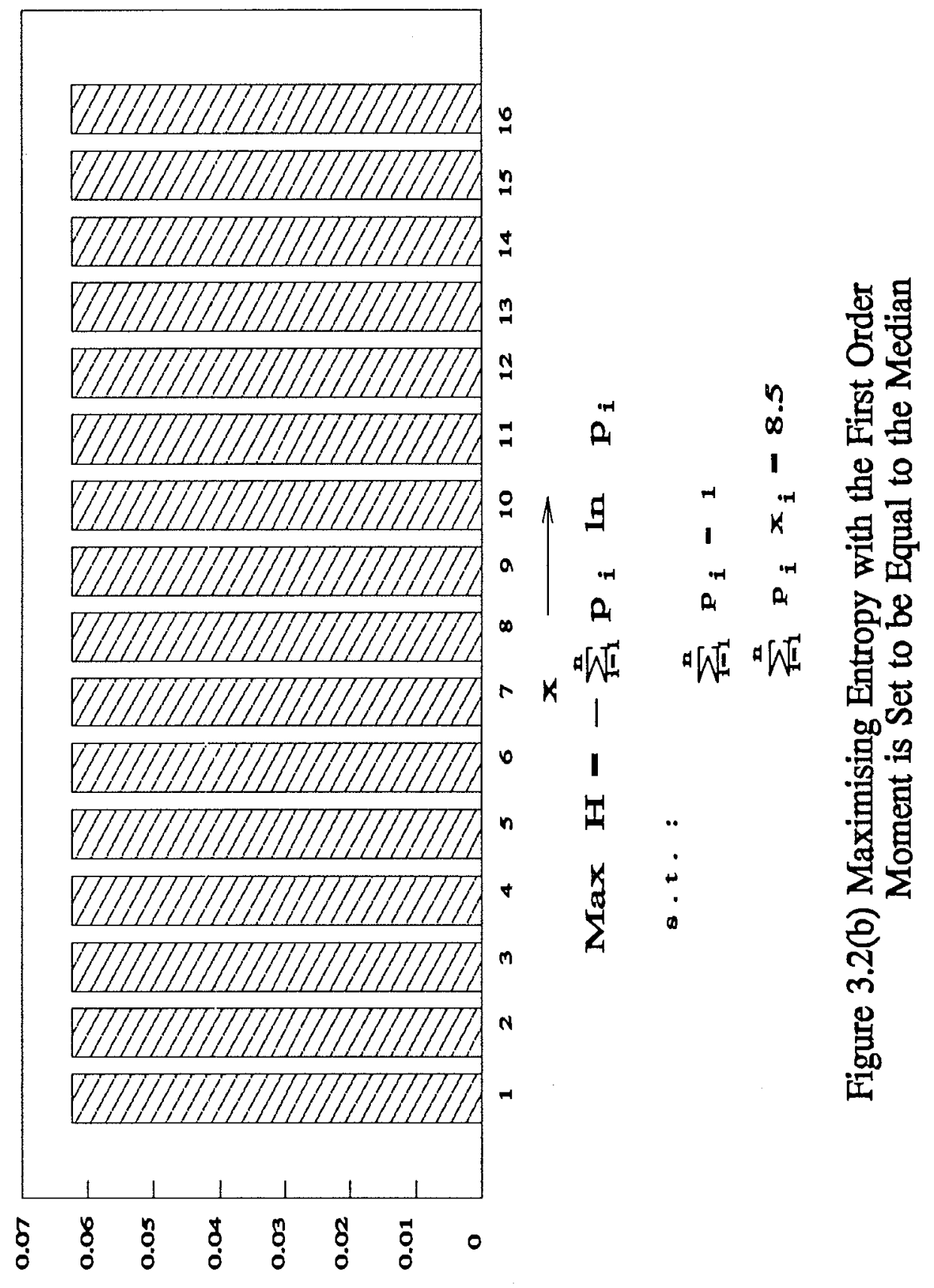




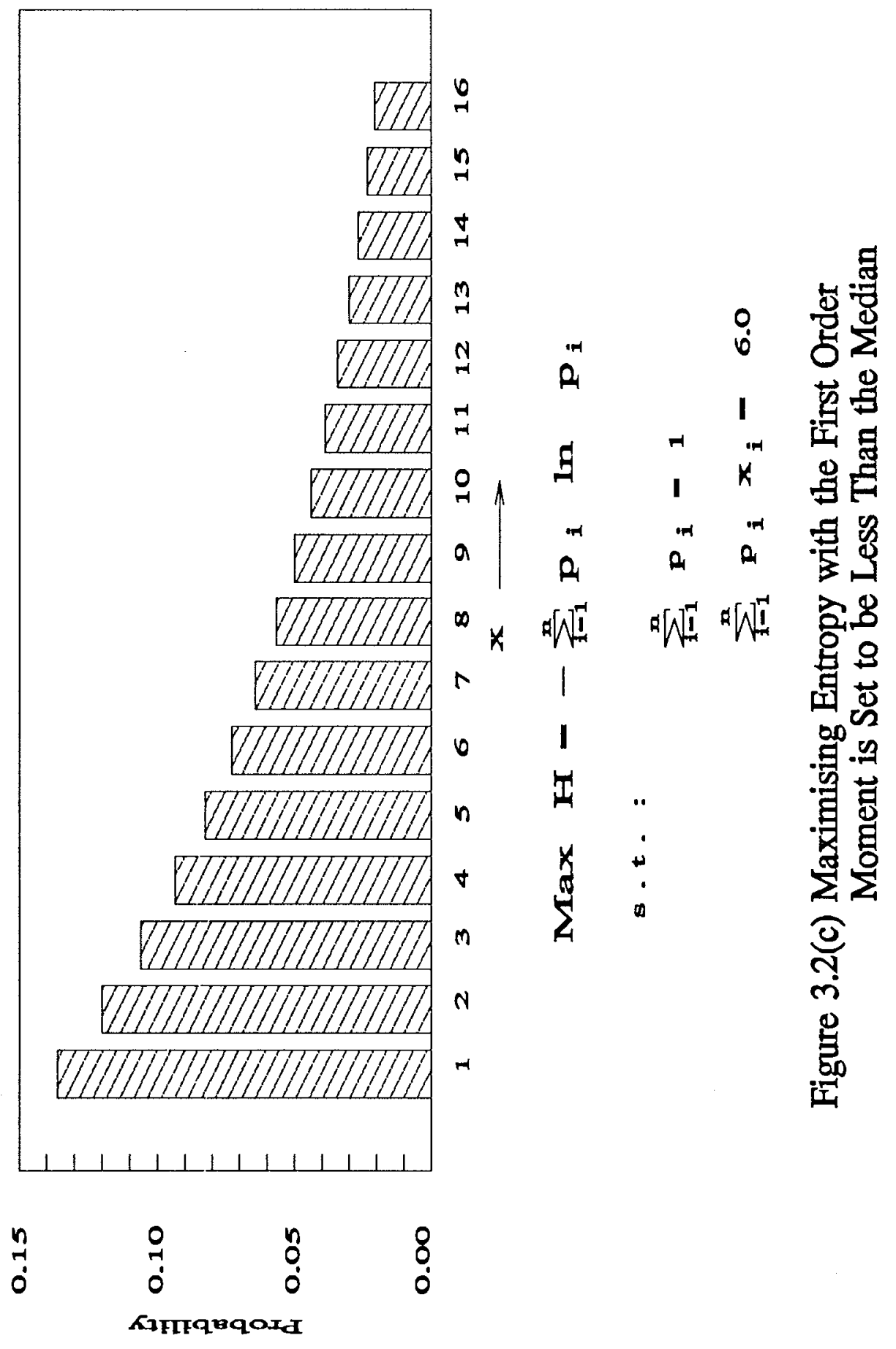




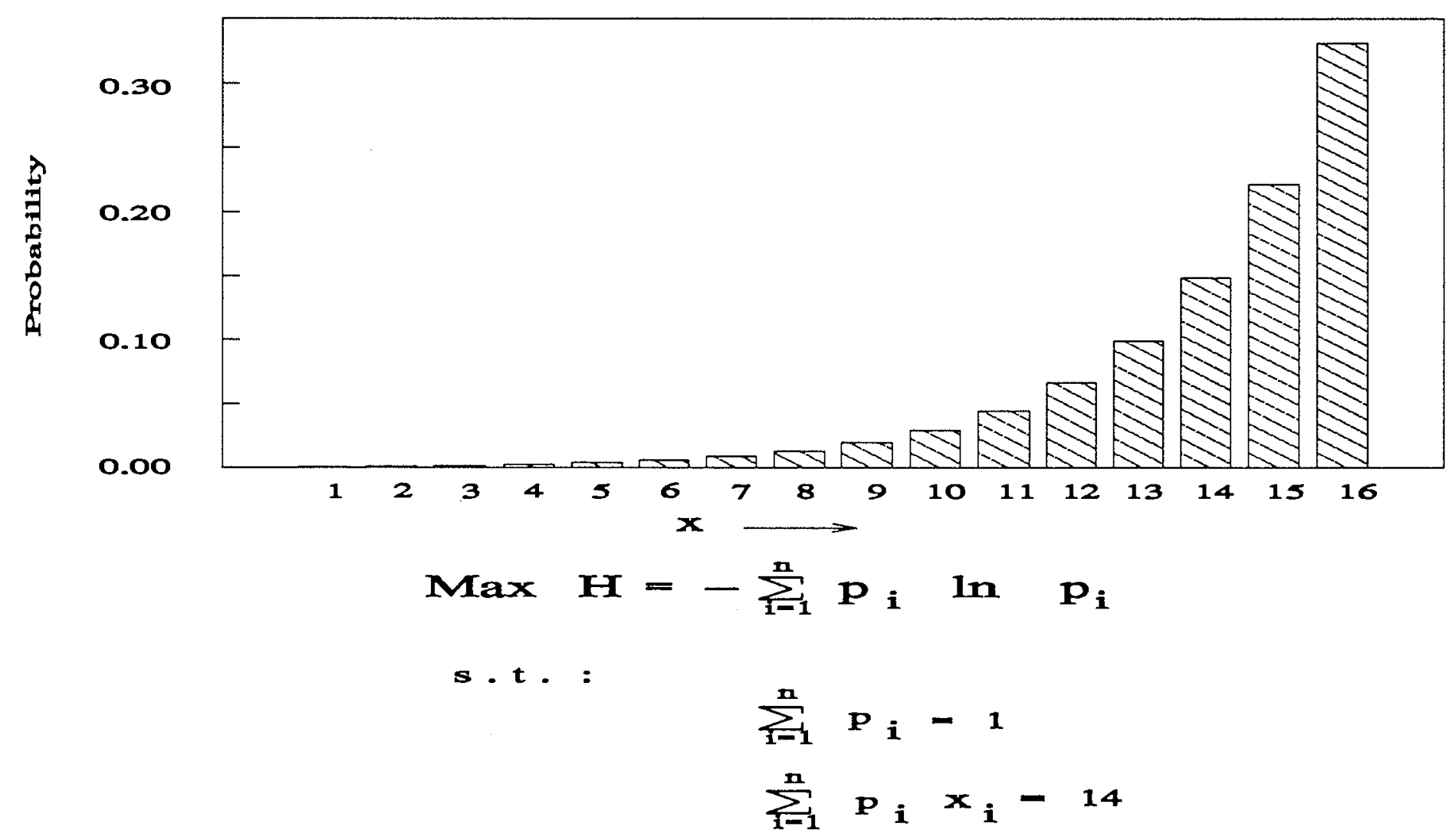

Figure 3.2(d) Maximising Entropy with the First Order Moment is Set to be Greater Than the Median 


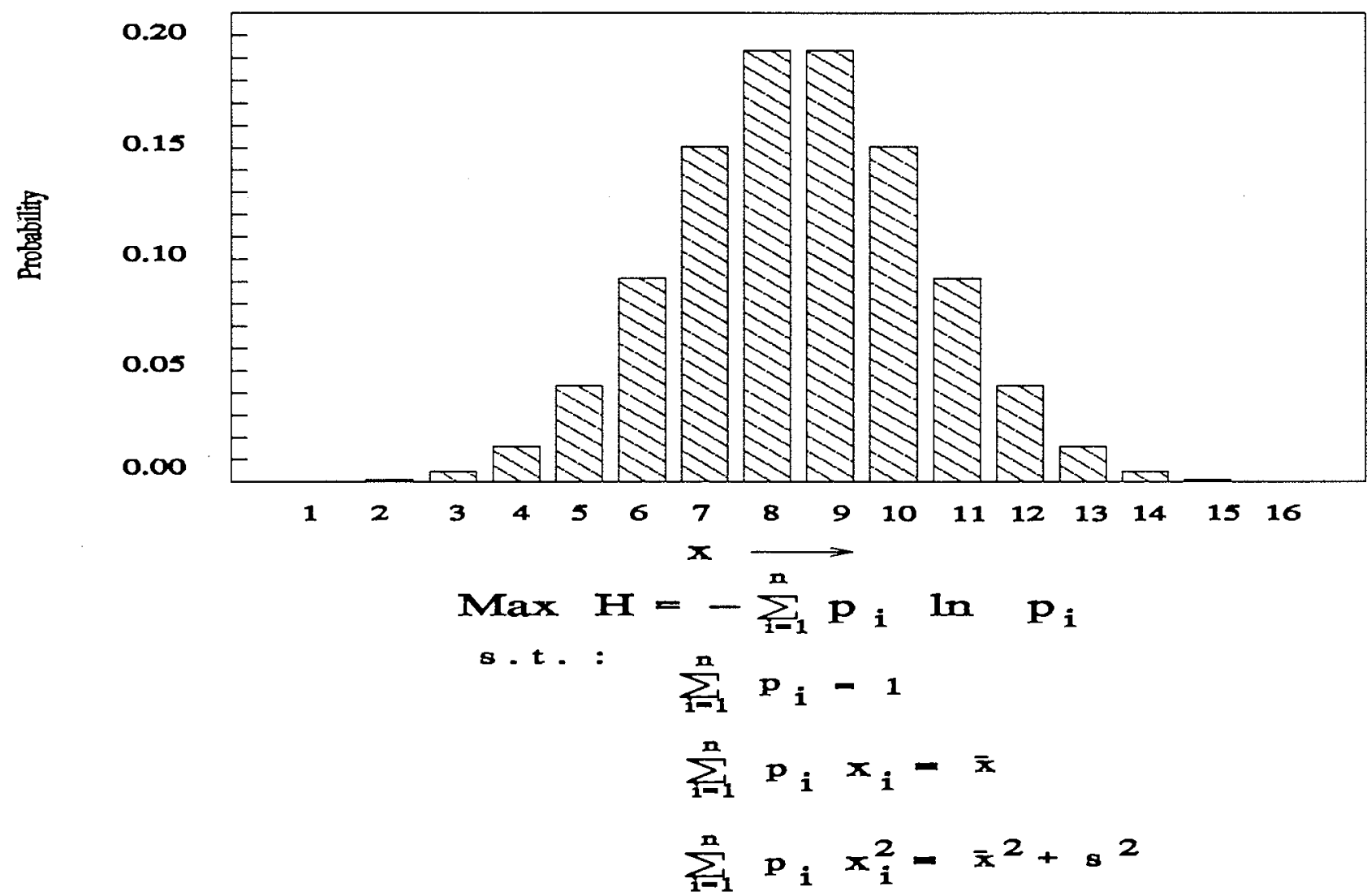

Figure 3.2(e) Maximising Entropy with the First and the Second Order Moments are Specified 
In fact, a range of common probability distributions can also be derived using this principle (Kapur, 1983; Singh and Singh, 1985; Singh et al., 1986). For example, the Gamma distribution can be derived from maximising the entropy function with the following sets of constraints :

$$
\begin{gathered}
\sum_{i=1}^{n} p_{1}=1 \\
\sum_{i=1}^{n} p_{1} x_{1}=\bar{x} \\
\sum_{i=1}^{n} p_{i} \ln x_{i}=E\left[\ln x_{i}\right]
\end{gathered}
$$

on the other hand, the Log-normal distribution may be derived by the same procedure [i.e., maximising the entropy expression (Eq. 3.2)], but with the following set of constraints :

$$
\begin{gathered}
\sum_{i=1}^{n} p_{i}=1 \\
\sum_{i=1}^{n} p_{i} y_{i}=\bar{y} \\
\sum_{i=1}^{n} p_{i} y^{2}=S_{y}^{2}+\bar{y}^{2}
\end{gathered}
$$


where :

$$
\begin{array}{ll}
y_{i} & =\ln x_{i} \\
\bar{y} & =\operatorname{E}\left[y_{i}\right] \\
S_{y} & =\operatorname{Var}\left[y_{i}\right]
\end{array}
$$

In light of the characteristics described above Kapur (1983) suggested that there are other names which may be appropriately given to the Principle of Maximum Entropy (POME), namely, Principle of Maximum objectivity, Principle of Minimum Bias, Principle of Minimum Prejudice, Principle of Maximum Uniformity, Principle of Maximum Spread-out Distribution, and Principle of Maximum Honesty. All such names reflect the nature of the probability distribution derived by application of the principle.

\title{
3.3 THE PRINCIPLE OF MINIMUM DISCRIMINATION INFORMATION (MDI)
}

\begin{abstract}
Kullback and Leibler (1951) introduced a measure of nearness of two probability distributions where nearness is defined as " the mean information for discrimination between probability distributions $P$ and Q". The measure proposed by Kullback and Leibler can be expressed in the following form :
\end{abstract}




$$
I(P: Q)=\sum_{i=1}^{N} p_{1} \ln \frac{p_{i}}{q_{1}}
$$

where :

$$
\begin{aligned}
& \mathrm{p}_{\mathrm{i}}=\text { probability of event } \mathrm{i} \text { from a } \\
& \text { probability distribution P. } \\
& \mathrm{q}_{\mathrm{i}}=\text { probability of event } i \text { from } a \\
& \text { probability distribution } Q \text {. }
\end{aligned}
$$

In this case the probability distributions $\mathrm{P}$ and $\mathrm{Q}$ represent two manifestations or conditions of similar process, e.g., probability distributions of rainfalls monitored at a location, or probability distributions of flows in a river, etc. As the value of $\mathbf{p}_{\mathbf{1}}$ approaches $\mathbf{q}_{1}$, the value of $I(P: Q)$ will become smaller with the value of $I(P: Q)$ becoming equal to 0 when $p_{1}=q_{1}$ for all i.

If $Q$ is a uniform distribution, i.e., $q_{1}=1 / n$, Equation 3.10 becomes :

$$
I(P: Q)=\sum_{i=1}^{n} p_{i} \ln n p_{i}=\sum_{i=1}^{n} p_{i} \ln p_{i}+\ln n \quad(3.11)
$$

This expression is similar to the entropy function described in the POME except for the term in $\mathbf{n}$ which, in the case of a known number of possible outcomes (events), is a constant and has no bearing on the 
result. It can therefore be seen that, due to the absence of the negative sign in the expression for $I(P: Q)$ given by Equation 3.10 , maximising $H$ is equivalent to minimising $I(P: Q)$.

The MDI principle can also be considered as the more general expression of the POME, because the POME expression can be derived from the MDI principle by specifying a uniform distribution for $q_{i}$. In other words, in the special case, where the probability distribution $Q$ is uniform, the MDI principle is the same as the Principle of Maximum Entropy.

The MDI principle can also be interpreted as a way of choosing, in an unbiased fashion, the probability distribution $P$ which is closest to the known (prtor) probability distribution $Q$, subject to information specified as constraints. In a practical application this process is equivalent to choosing a probability distribution for a water quality parameter for a particular location on a river on the basis of some given or observed information at some other location, and also knowing the historical conditions and probability distribution of the water quality at that location for which the distribution is being determined. Note that, under. this interpretation, the prior distribution $Q$ need not be uniform. The PoME, 
through its relationship with MDI, can be interpreted in a similar fashion as a way of choosing the probability distribution which is closest to the uniform probability distribution, subject to information given as constraints.

\subsection{DEMONSTRATION OF THE USE OF ENTROPY BASED PROBABILITY ESTIMATION}

In this section, the use of entropy for probability estimation, as it represents the basis for the proposed method for prediction/estimation of the mean of water quality values at the discontinued monitoring stations, is discussed.

The theory behind probability estimation in this manner can be explained from the following example:

If the head of a coin is given a value of one and the tail is given a value of zero, then, for a fair coin, the expected mean value of tossing the coin $n$ times ( $\mathrm{n}$ is a large number) is 0.5 . Suppose a coin is tossed $n$ times (where $n$ is very large) and the mean value happens not to be equal to 0.5 , as might be expected from a 'fair' coin, but something else, e.g, 0.6. Setting aside other factors relating to sampling theory and probability of that outcome at this time, 
this result indicates that the coin as not likely being fair and also that it is likely that the head and tail occur with probabilities of 0.6 and 0.4 respectively. These probabilities can be seen as the 'new' condition of the coin. In this case, in which only two events are possible, it is relatively easy to calculate the most likely probability for each event of a head or a tail. However, the problem of assigning the probability to the two events could also have been solved using the POME or MDI formulated as :

POME :

$$
\operatorname{Max} H=-\sum_{i=1}^{n} p_{i} \ln p_{i}
$$

or

$$
\operatorname{Min} H=\sum_{i=1}^{n} p_{i} \ln \frac{p_{i}}{1 / n}
$$

subject to :

$$
\sum_{i=1}^{n} p_{i} x_{i}=\bar{x}
$$

where :

$$
\begin{aligned}
& \mathrm{x}_{\mathrm{i}}=\text { possible events }(0 \text { or } 1) \\
& \mathrm{p}_{\mathrm{i}}=\text { probability of event } \mathrm{x}_{\mathrm{i}} \\
& \overline{\mathrm{x}}=\text { the mean value } \\
& \mathrm{n}=\text { number of events }
\end{aligned}
$$

In solving the coin toss problem by this formulation, 
the observed mean value $\bar{x}$ is set equal to 0.6 and $n$ is set equal to 2 . The two $p_{i}$ values defined by the formulation then take on values of 0.4 and 0.6 respectively.

A more complicated problem with similar characteristics is known as 'a die problem' as described by Jaynes (1979). This problem can be illustrated as follows :

Suppose a die is tossed $N=1000$ times and the average number of spots up was observed as 4.5 and was not 3.5 as might be expected from a 'fair' die. Mathematically, the mean value (average number) of spots up can be expressed as :

$$
\sum_{I=1}^{n} p_{i} x_{i}=\bar{x}
$$

where :

$$
\begin{aligned}
& \overline{\mathrm{x}} \quad=\text { mean value } \\
& \mathrm{x}_{\mathrm{i}} \quad=\text { event }(1,2, \ldots, 6) \\
& \mathrm{p}_{\mathrm{i}}=\text { probability of event } \mathrm{x}_{\mathrm{i}} \\
& \mathrm{n} \quad=\text { number of events }
\end{aligned}
$$

Given only this information, what estimate should be assigned to the probability $\left(p_{i}\right)$ of the different faces ? The following statements were made by Jaynes (1968) in respect to this problem: 
- "The probability distribution which maximises the entropy is numerically identical with the frequency distribution which can be realised in the greatest number of ways"

- "If the information incorporated into the maximum entropy analysis includes all the constraints actually operative in the random experiment, then the distribution predicted by maximum entropy is overwhelmingly the most likely to be observed experimentally, because it can be realised in overwhelmingly the greatest number of ways"

Those two statements strongly suggest that the estimation of the probability for the 'die problem' should be undertaken by maximising the entropy value expressed in Equation 3.12, subject to the constraint expressed in Equation 3.15.

Figures $3.3(a)$ to $3.3(d)$ illustrate the above issues in graphical form. Figures $3.3(a)$ and $3.3(b)$ show the result of probability estimation for the coin case by maximising the entropy value, where the mean value, $\bar{x}$, in the Equation 3.14 was set as 0.5 and 0.6 respectively. Figures $3.3(\mathrm{c})$ and $3.3(\mathrm{~d})$ give the results from maximising the entropy function for the die problem, where the mean value, $\bar{x}$, in Equation 


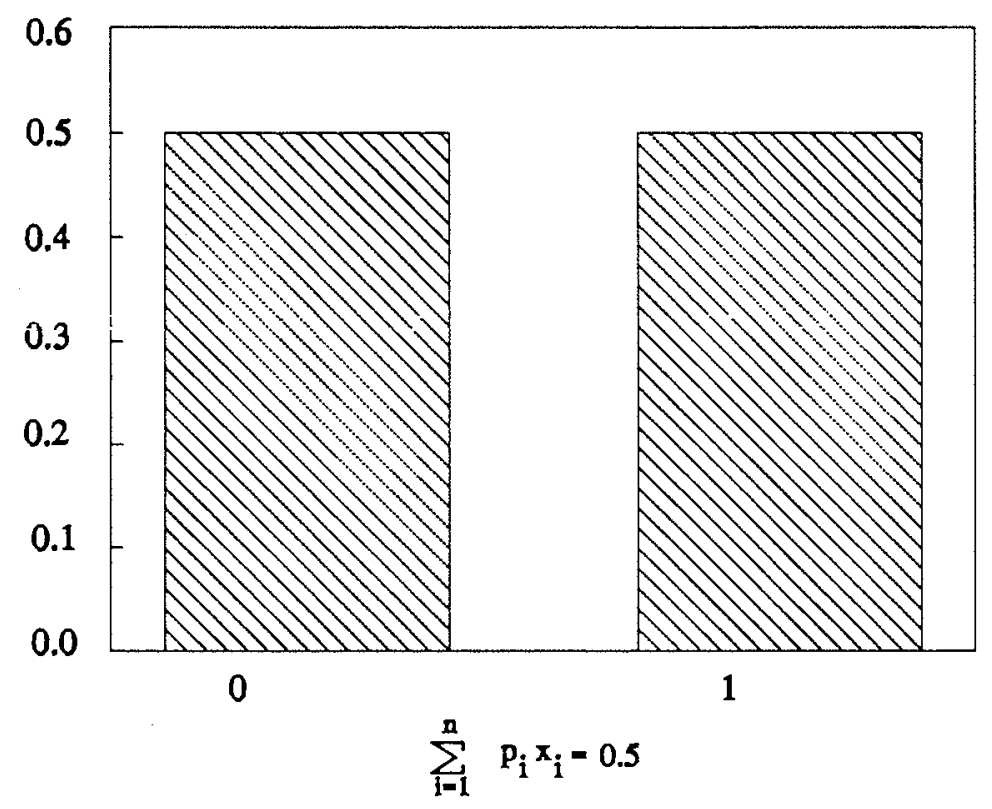

Figure 3.3(a) Probability Assignment for the Coin Problem with the Mean Value $=0.5$

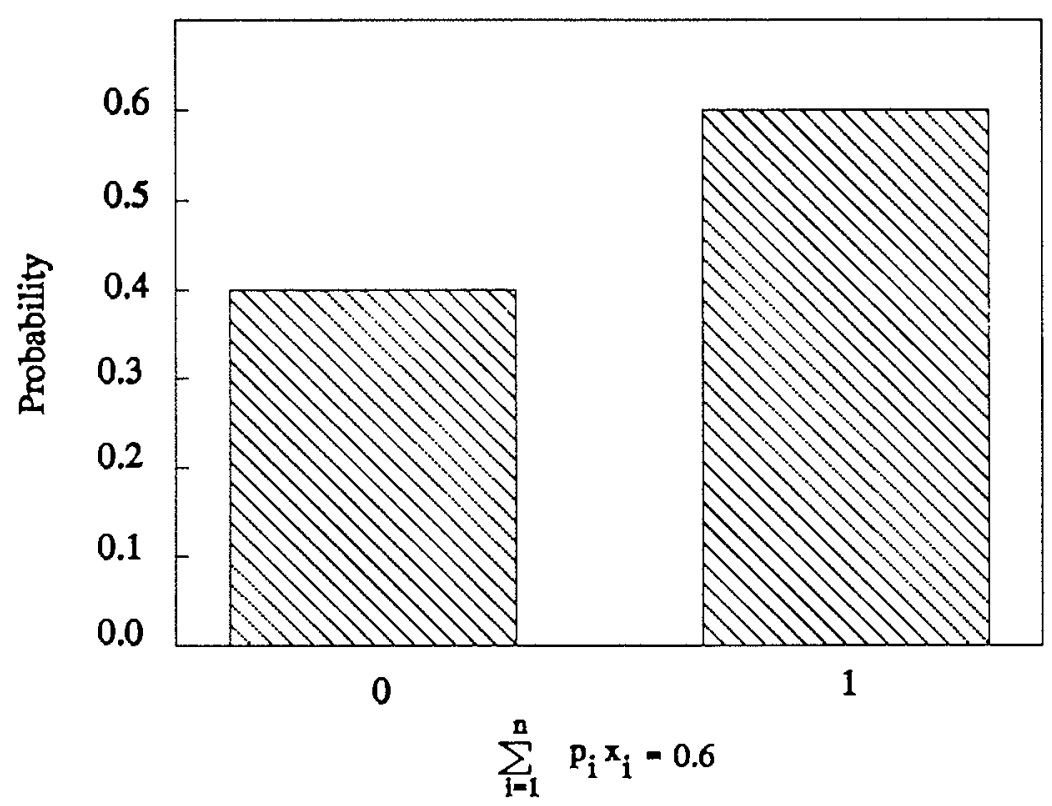

Fifure 3.3(b) Probability Assigoment for the Coin Problem with the Mean Vahue $=0.6$ 


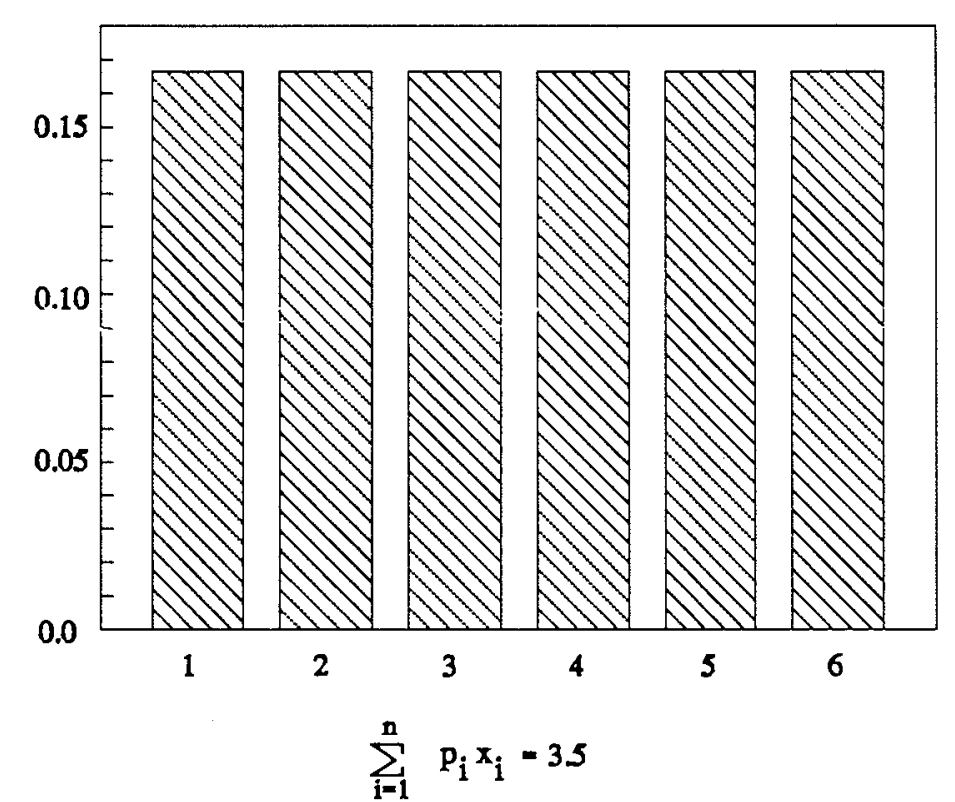

Figure 3.3(c) Probability Assignment for the Die Problem with the Mean Vahue - 3.5

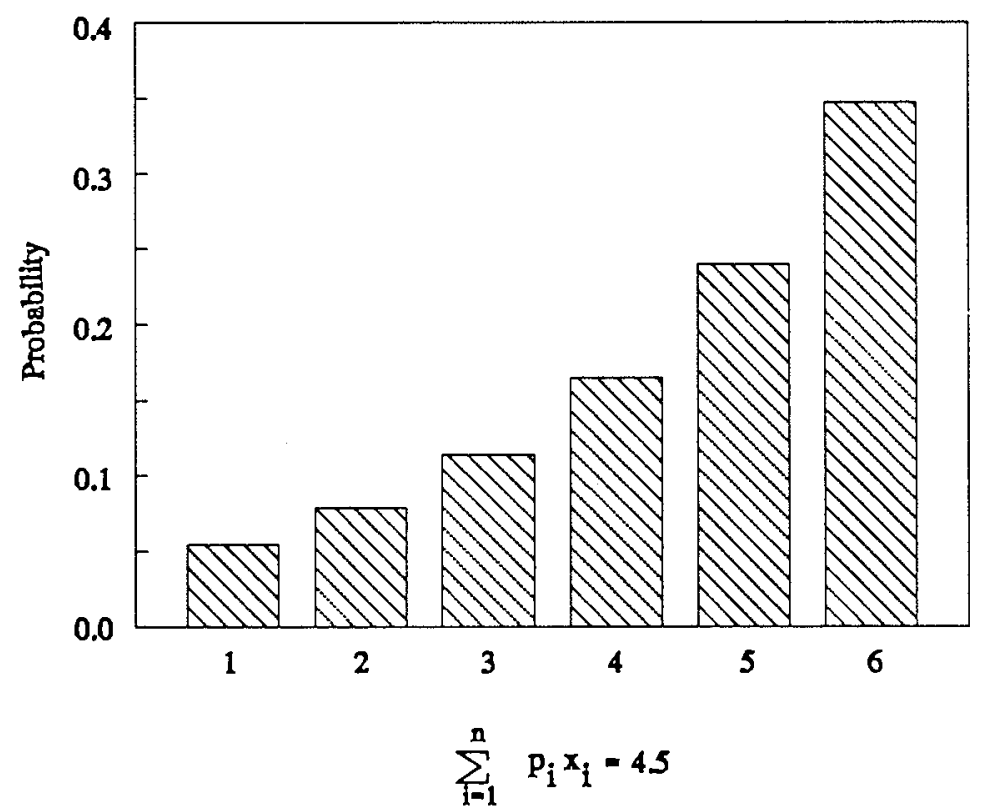

Figure 3.3(d) Probability Assigment for the Die Problem with the Mean Value $=4.5$ 
3.15 was set as 3.5 and 4.5 respectively.

The assignment of the relative frequency (probability) to every event by maximising the entropy value is unbiased, since it only uses the information available and no other assumptions. As discussed previously the method assigns as uniform a distribution as possible. However, as shown in Figure 3.3, the 'new' information provided by the constraints forces the method to assign non uniform distributions.

The problem addressed in this study, which is described in detail in Chapter 4, has characteristics similar to the two problems described above. The fundamental similarity lies in the fact that, in the water quality case being examined in this study only the outcomes, in this case the water quality value(s) on the mainstem of the river at a downstream location, are known. These downstream observed water quality values are to a large degree the result of the water quality values (events) from upstream tributaries. This downstream, mainstem observed value is therefore similar in concept to the observed mean value $\bar{x}$ of a set of experiments discussed earlier in this chapter in relation to the coin and die problems. The problem is, therefore, how to predict the most likely values for the water quality parameters at the upstream stations 
which result in the value observed at the downstream station.

The same basic principle used in assigning the probability distribution to the set of outcomes of experiments discussed previously is employed in this case to assign, in an unbiased manner, the probability distributions of water quality values at the discontinued upstream monitoring stations. The commonality of the features between the water quality estimation problem and the coin and die problems are discussed in more detail in Chapter 4 .

\subsection{SUMMARY AND CONCLUSION}

Entropy theory, through its interpretation as a measure of information and therein uncertainty, is presented as the basic principle for the development of a new approach to predicting water quality values at discontinued stations. The utility of the theory for the problem was argued on the basis of its ability to assign probabilities to every possible event when only the mean value of the outcomes, or its equivalent, from a set of experjments or possibilities is known.

Relatively little theory or applications have been reported for this general case or for the specific case 
of predicting water quality values at discontinued stations. The maximum entropy principle has been shown by Jaynes (1979) to be able to give a solution to this type of problem by not only assigning probability to every possible event but also doing so in an unbiased fashion. Furthermore, when applied in this fashion, the entropy principle uses only the available information and no other assumptions when assigning probability for every event.

The unbiasedness of the entropy principle was emphasised in the discussion, since this attribute is important in predicting the water quality values at discontinued monitoring station(s), when violations to water quality standards are believed to be occurring and it is desired to determine the most likely location of these violations, in the absence of direct monitoring and in the face of limited data at other locations. 


\section{CHAPTER 4}

\section{FORMULATION OF THE ENTROPY APPROACH}

\subsection{PROBLEM DESCRIPTION}

As described in chapter 1, the objective of this thesis is the estimation/prediction of water quality values at discontinued monitoring station(s). More specifically, this study is directed at one aspect of the budgetary issues associated with water quality monitoring, namely, the case where a reduced budget, or a budget not increasing as fast as the cost of monitoring, or where the needs for monitoring are more acute at other locations, has resulted in the discontinuation of existing monitoring stations. In these circumstances, when information is required about conditions at locations where stations have been discontinued, it becomes necessary to predict water quality at those sites. Such predictions are particularly : mportant where water quality conditions appear to be changing at the locations of the discontinued upstream monitoring stations as might be indicated by changes in the observed water quality at a downstream site where monitoring is ongoing. 
The problem can be formulated and illustrated as follows :

Consider a water quality monitoring network which has been established in a river basin for a sufficiently long period of time to define, at each monitoring location, the base-line or historical distributions of the water quality parameters of interest. [The need for, and implications of, knowing the historical (or prior) distributions of water quality values at the discontinued stations are discussed in detail later in this chapter]. Consider, for example, the simplified water quality monitoring network shown schematically in Figure 4.1. This simplified river network is a forked configuration with a mainstem and two upstream channels, one of which might be the mainstream and the other a tributary, or both upstream elements may be tributaries which come together to form a 'new' river.

Consider three water quality monitoring stations in this system, located at points $a, b$, and $c$ respectively as shown in Figure 4.1. The particular situation addressed in this thesis may arise, for example, where the number of operating monitoring stations has to be reduced due to a shortage of funding. Within this scenario, one, two or even three of the sampling stations may have to be discontinued. Suppose it was determined that two stations have to be 


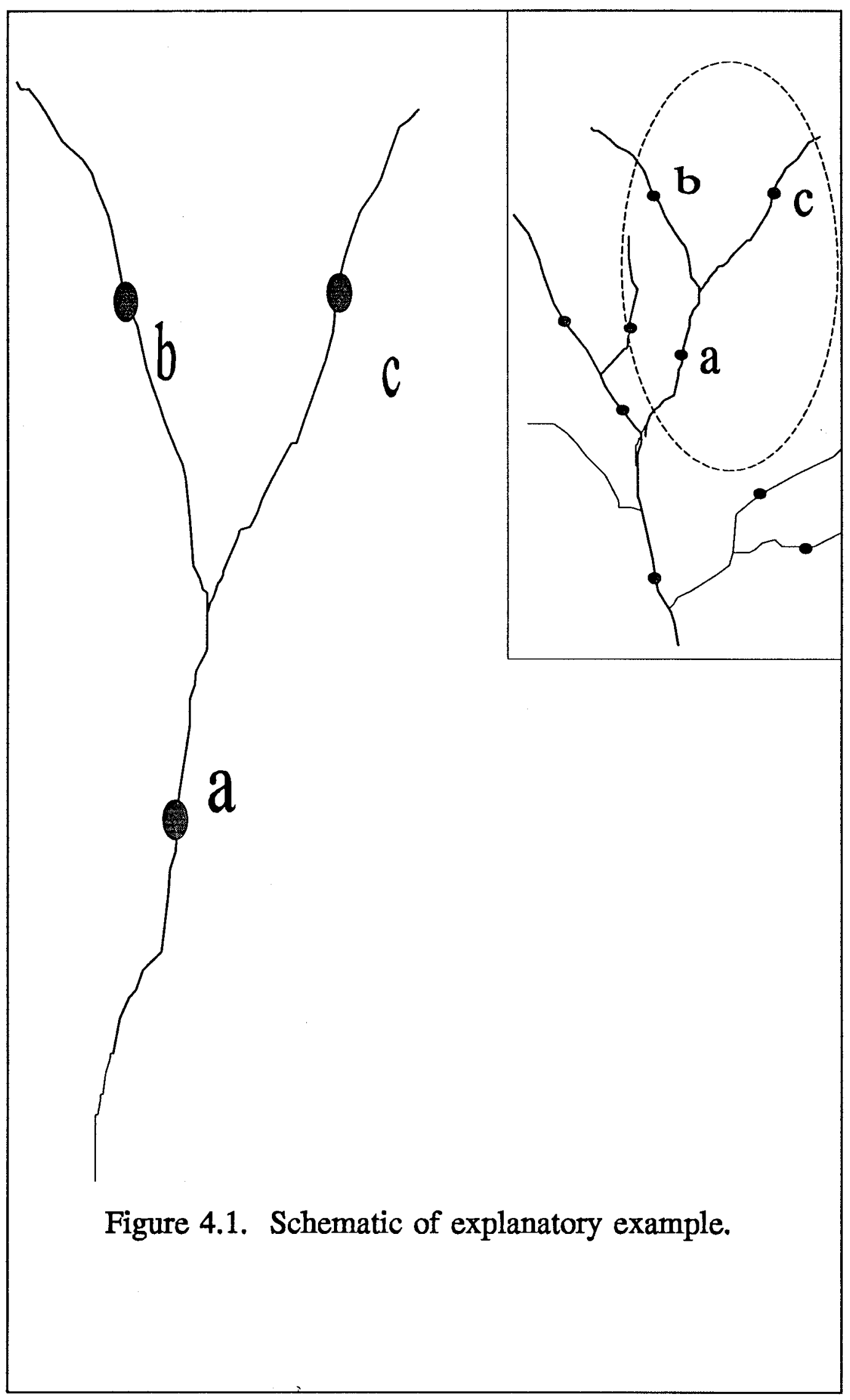


discontinued from the particular section highlighted in Figure 4.1. In such a situation, the most likely decision is to discontinue the operation of stations $b$ and $c$ (upstream), and continue the operation of station a (downstream) which is located on the main stream and therefore captures some of the 'information' available in the records obtained from stations $b$ and $c$. In fact, considerable information about conditions at locations $b$ and $c$ is contained in the records at station a because the water quality at locations $b$ and $c$ contributes significantly to the water quality values recorded at station a. However, even though some of the information contained in the data recorded for stations $b$ and $c$ is incorporated in the record for station a, actual values at those stations are lost when the stations are discontinued. It is generally highly desirable that some specific information about the water quality at those two locations be "maintained".

One of the alternatives for maintaining information about the water quality at those two locations (besides of course actually continuing to take data at those locations which is impossible when the stations are discontinued) is to estimate the water quality values. Such predictions are likely to be based on historical records at stations $a, b$ and $c$ and the current observations at station a and should be as 
accurate as possible.

The quality, or value, of the information obtained from the process of prediction/estimation of the values at the discontinued upstream stations will largely depend on how accurately the values at those stations can be estimated. In other words, the question becomes how to estimate the water quality values at the discontinued monitoring stations when the only available information is the set of values recorded at the downstream monitoring station and the historical records for all three stations. (Recall that in the original statement of the problem, it was assumed that all stations had been in operation for a period of time sufficient to define the distribution of the various water quality values at all the stations and thereby establish the baseline conditions at those stations.)

Obviously, it is not possible to achieve perfect predictions of values for variables such as water quality which are stochastic in nature. However, if a method can be developed to estimate the value within a reasonable level of accuracy, the estimated value will be of use for a number of purposes, e.g.. assistance in enforcing adherence to water quality standards based on the ability to identify suspected source of pollution, detection of Locations that may have caused observed 
changes in water quality at a downstream location, etc. Existing and proposed methods for providing the types of prediction required of this problem are described in the following section together with comments on the general topic of monitoring.

\section{2 EXISTING METHODS}

\subsubsection{REGRESSION ANALYSIS}

One of the most commonly used existing methods for prediction of unknown values on the basis of one or more known parameters is regression analysis. Detailed explanations of this technique can be found in most statistics textbooks. The objective of regression analysis is to exploit an observed relationship between two (or more) variables such that information about one variable can be achieved through knowing the values of the other variable(s). Regression analysis can be defined as follows:

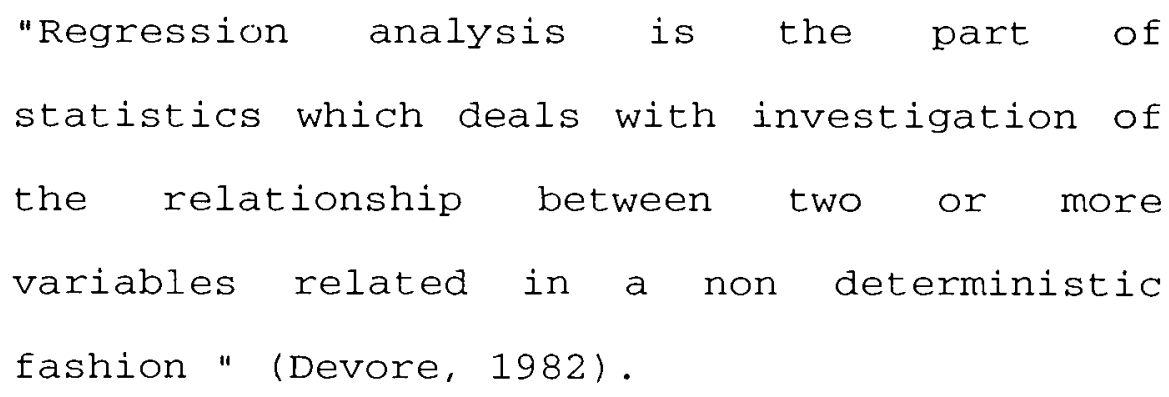

Regression analysis is essentially based on the 
development of a curve (function) which is the best fit to the data from two or more observations, where the value of one observation is considered to be dependent on the value(s) from other observation(s). The curve (function) shows, or embeds, the relationship, derived on the basis of historical data, between one ("unknown") parameter whose value is to be predicted using the expression, and the other known or measurable parameter(s) from which the value of unknown parameter is to be predicted. If this curve (function) can be developed for the water quality prediction problem, the water quality value at one station can be estimated, within a specified range for a certain level of confidence, by using the curve (function) and the water quality value(s) known (observed) at the other station(s).

The simplest and most common regression analysis uses a linear relationship between the data. When a linear function is not an appropriate model of the observed or experimental data, other functions such as polynomial or exponential expressions may be applied. In the simplest case, i.e., for two variables, the linear regression function can be expressed as :

$$
Y=\beta_{0}+\beta_{1} X+e
$$


where :

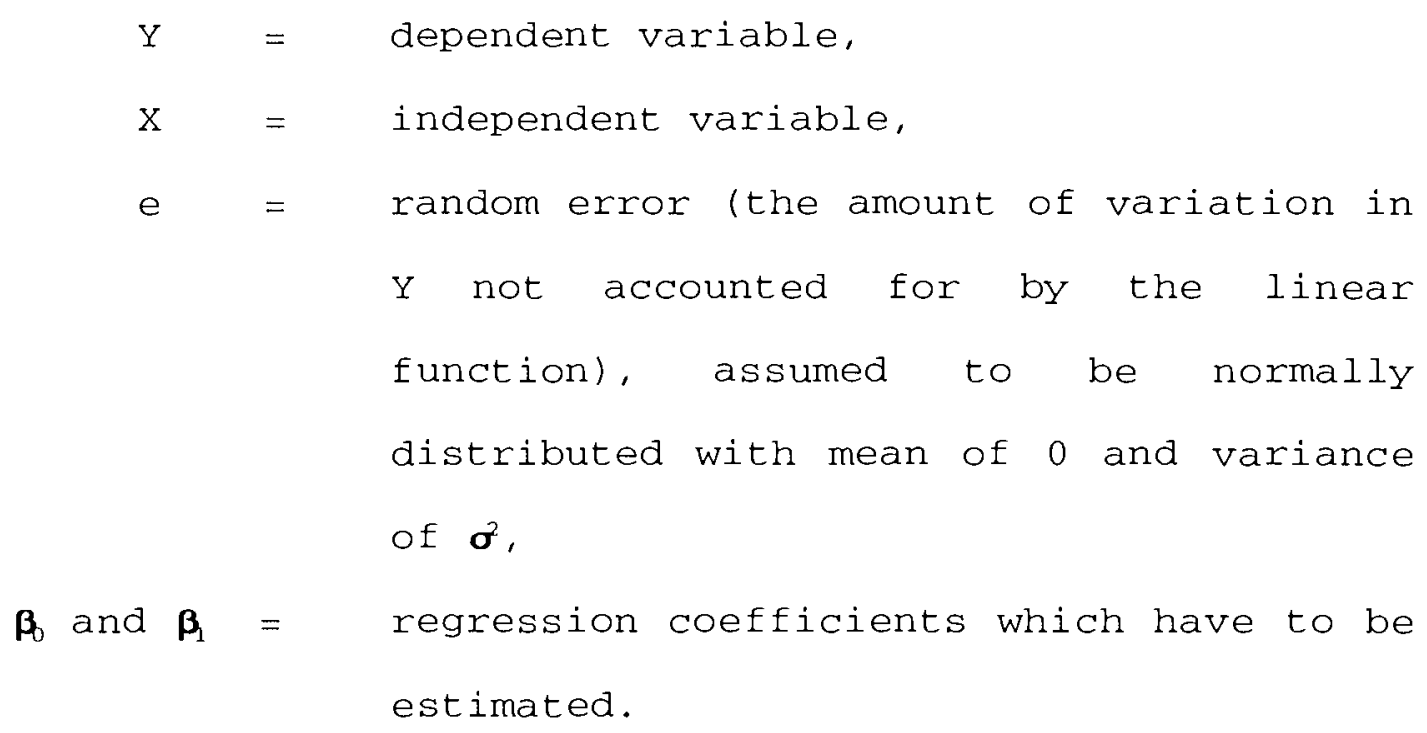

Estimation of the values of $\boldsymbol{\beta}$ and $\boldsymbol{\beta}_{1}$ is usually performed on the principle of least squares which is based on identifying the regression line (function) which minimises the sum of squared deviations (vertical distances) of the observed points from to the corresponding values as indicated by the regression line.

The formulae for estimating the value of $\boldsymbol{\beta}_{0}$ and $\boldsymbol{\beta}_{1}$, derived using the principle of least squares, can be expressed as follows :

$$
\begin{gathered}
\hat{\beta}_{1}=\frac{\sum\left(X_{i}-\bar{X}\right)\left(Y_{i}-\bar{Y}\right)}{\sum\left(X_{i}-\bar{X}\right)^{2}}=\frac{\sum X_{i} Y_{1}-\left(\sum X_{i}\right)\left(\sum Y_{1}\right)}{N \sum X_{i}^{2}-\left(\sum X_{i}\right)^{2}} \\
\hat{\beta}_{0}=\frac{Y_{i}-\beta_{1} \sum Y_{i}}{n}
\end{gathered}
$$

where : 


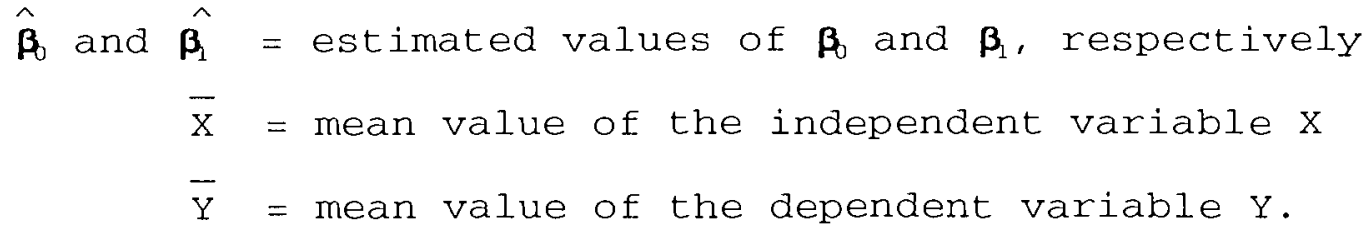
proposed entropy based method.

\subsection{THE PROPOSED ENTROPY BASED METHOD}

\subsubsection{PROBLEM ANALYSIS}

Most, if not "all, water quality values are 
measured and specified as a concentration of a substance within a unit or volume of water (i.e., mg/l, ppm, etc.). Assuming no interaction between water quality variables, a complete mixture of water from two different sources of different quality generally results in a final mixture with a water quality which lies between the two original values in direct proportion to the volumes (flow rates) which give rise to that final mixture.

Consider again Figure 4.1. If, from observation, the mean of the water quality value at station $\mathbf{b}$ (upstream) $=\mathbf{x}$, and the mean of the water quality value at station $c$ (upstream) $=y$, and assuming that the two streams upon which stations $b$ and $c$ are located have the same magnitude of flow, it can reasonably be expected that the mean of water quality value at the downstream station a is the average of the two water quality values at each of the two upstream stations. If the two rivers have significantly different flows, the water quality value at downstream station a can be calculated by weighting the corresponding water quality values from each river in proportion to their respective flows.

This process assumes that the water quality values do not change in passage from locations $b$ or $c$ to 
location a as a result of time of transport or the transportation process itself, or that there are no further inflows of water and associated pollutants between locations $b$ or $c$ and $a$. These assumptions are somewhat unrealistic in a practical context. However, this simple example is being used solely to describe in general terms the situation for which the entropy based prediction model would be used. The implications of changes in water quality arising from time and transport from the upstream to downstream stations and the means for considering those implications are addressed later in this chapter.

Now consider the situation where stations $b$ and $c$ have been discontinued after a number of years in operation and then, at some later time, it was observed that the mean value at the downstream station a had changed significantly from the mean value from a number of years before. The question could then be asked as to "What is the most likely mean value at the upstream stations b and c under this new water quality regime ?" An associated question might be "On which branch, i.e., at which of the two upstream stations $b$ and $c$, did the water quality change causing the significant change observed at the downstream station a most likely occur ?" A new method proposed to answer these two questions on the basis of the entropy principles 
discussed in the previous chapter, is described in the following section.

\subsubsection{THE ENTROPY BASED MODEL}

The fundamental principle of the proposed method is derived from the theory of information entropy, as first introduced by Shannon (1948). This entropy concept was presented in Chapter 3, where its utility for the problem of probability estimation was demonstrated. The proposed method for the prediction of the water quality values at discontinued monitoring stations is based on this same probability estimation principle. The problem of predicting water quality values at discontinued monitoring stations and the proposed solution strategy is logically similar to the problem of estimating probability in the die problem described in section 3.4.

In the die problem, for a fair die, the probability of each of the single events $(1,2, \ldots, 6)$ is likely to be $1 / 6$. In the water quality case, for a particular water quality parameter, the probability (equivalent to the $1 / 6$ probability assigned to each outcome in the fair die problem) of each possible value of that parameter at a particular location is derived from (based on) the probability distribution function 
of the water quality parameter at each of the relevant upstream stations. This probability distribution is determined from the historical data collected during the initial period of the operation of that station. In both the die and water quality case, those probabilities can be considered as the prior probability, i.e., the probability that is believed or known to be true or to exist before any new conflicting evidence is found.

A mean water quality value, observed at the downstream monitoring station in the period following the discontinuation of the upstream monitoring stations, may be different from the mean value for that downstream station, as defined from the historical records collected prior to the discontinuation of the upstream stations. This new mean value can be viewed as being equivalent to the mean value for the die problem, which may not be 3.5 such as expected from a 'fair' die, but some other value. On this basis and with the knowledge of the new mean value at the downstream monitoring station, the new most likely probabilities for each possible water quality values at each of the upstream stations, and thereby the most likely probability distributions of water quality at those upstream stations, can then be generated using the entropy principle. 
The basic entropy formulation needed to derive these probabilities is specified by a set of equations based on Equations 3.13 and 3.14 . However, this set of equations must be modified to reflect the particular conditions of the water quality prediction problem being addressed in this thesis. Prior to describing these modifications, some terms will be defined to avoid confusion in the interpretation of the proposed model.

\subsubsection{DESCRIPTION OF TERMINOLOGY USED IN THE MODEL}

\section{(i) Events}

Events in the case of the die problem were the number of dots facing up, namely, $1,2, \ldots, 6$. These numbers represent all possible events for that example. A similar principle is used for the water quality problem, i.e., the events are defined as the range of possible water quality values that might occur at each of the monitoring stations.

To define the possible range of water quality values (events) for the water quality problem, the records collected prior to the discontinuation of the station(s) must be examined. Suppose the data from that historical record show the water quality values in the 
past to be normally distributed with a mean value of $\mu$ and a standard deviation of $\boldsymbol{\sigma}$. From a statistical view point, and from a historical perspective, it is reasonable to assume that the range of possible water quality values at that location lies between $\mu-4 \boldsymbol{\sigma}$ and $\mu+4 \sigma$. Any values outside these boundaries are very unlikely to happen and therefore can reasonably be eliminated from consideration in the formulation. (Where the water quality values lying within $\mu \pm 4 \sigma$ are negative for a given station, the corresponding distribution is transformed by translation along the relevant axis until all values are positive. The corresponding distributions from the other stations are also transformed with the same magnitude to avoid distortion in the prediction processes. The results of the entropy model are then transformed back by the reverse process. )

It should be noted that the entropy model was developed by Shannon (1948) for discrete rather than continuous functions. The continuous probability distributions that describe the variation in water quality values, and which are derived from the historical data, therefore have to be discretized for use in the entropy model. The procedure for the discretization can be explained as follows. Once the range of possible values has been determined, the 
discrete events are defined by dividing the range of possible values into a specified number of intervals. The 'events' in this model are then defined as the values of the mid-points of every interval arising from application of the discretization procedure to the continuous probability distribution function. Figure 4.2 shows a probability distribution which has been discretized into 24 intervals over the range of possible values $\mu-4 \boldsymbol{\sigma}$ to $\mu+4 \boldsymbol{\sigma}$. Figure 4.2 (b) also shows the events associated with the intervals.

Harmancioglu et al. (1985) and Harmancioglu and Alpaslan (1992) have noted problems in the application of the entropy theory to water quality related problems arising from this discretization process. In particular they found that quite different answers or conclusions could be obtained or drawn depending on the level of discretization, i.e., depending on the size of the intervals of the discretization. However, such problems did not arise in this application. [A more complete discussion of the issues associated with discretization together with evidence that the problems encountered by Harmancioglu et al. (1985) and Harmancioglu and Alpaslan (1992) do not occur in this application of entropy theory is provided in section 5.3.2]. 


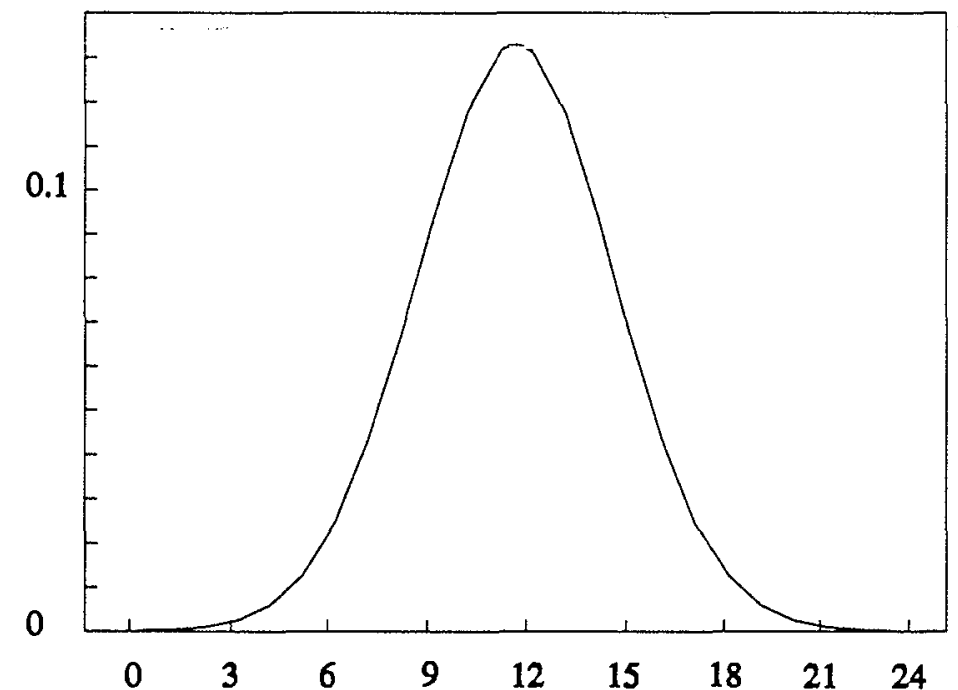

(a) Contimuous Probability Distribution Functions Developed from the Data Recorded at the Station

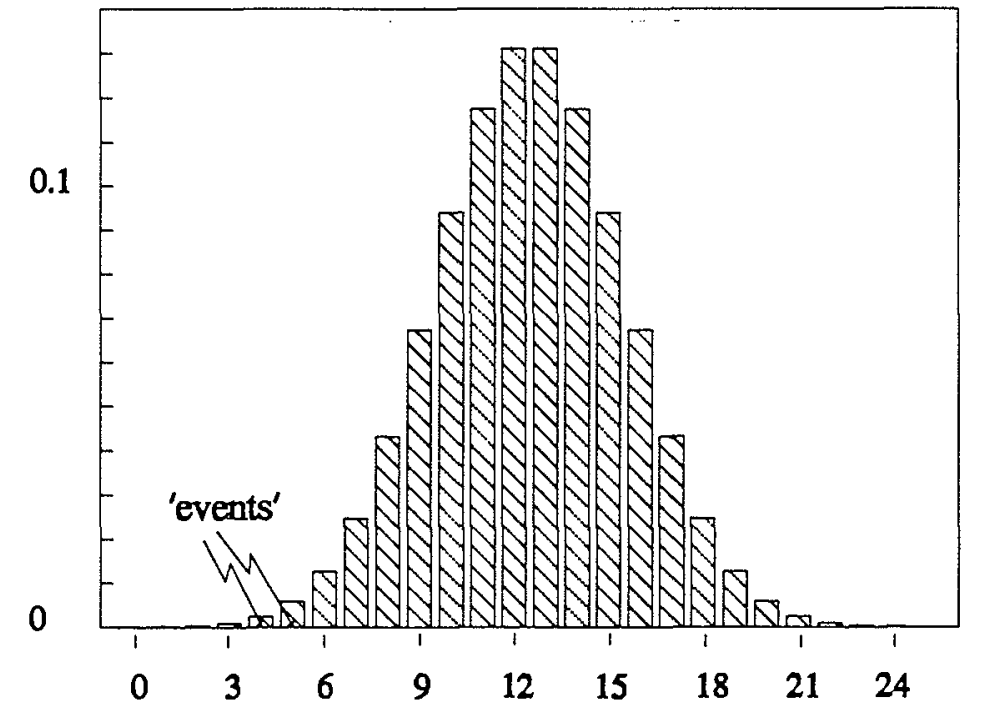

(b) The PDF in (a) Discretized into 24 Intervals

Figure 4.2 Discretization of PDF to Define the Candidate Events 


\section{(i1) Objective Function}

It was noted in section 4.3 .2 that the proposed model is based on the theory of information entropy which was introduced by Jaynes (1957) as the Principle of Maximum Entropy. This principle was demonstrated by Jaynes as being capable of addressing the problem of probability estimation. Recall that the basic concept recognises that the probability distribution with the maximum entropy is the probability distribution that can be realised in the greatest number of ways, and is therefore the most likely to occur. The corollary for the water quality prediction problem, namely, that the distribution which constitutes the maximum entropy should be the one chosen for allocation of probabilities to the specific water quality values defined in the discretization process, is re-emphasised here.

Recall also that maximising entropy using POME is, in fact, the same as minimising cross entropy using MDI under the restriction that the underlying (or prior) distribution of the problem is uniform. Hence for the water quality case, where the prior probability distributions at the discontinued station(s) are highly unlikely to be uniform and the new distributions which occur at these stations are also unlikely to be 
uniform, the MDI, as the generalised case of POME able to consider distributions other than uniform, must form the objective function in the formulation.

The mathematical expression of the objective function for the water quality problem for assignment of probabilities to water quality events at $\mathbf{N}$ stations in this case can therefore be written as follows:

$$
\text { Minimise } \quad H=\sum_{i=1}^{M(1)} \sum_{j=1}^{M(2)} \ldots \sum_{k=1}^{M(N)} p_{1 j \ldots k} \ln \frac{p_{i f \ldots k}}{q_{1 f \ldots k}}
$$

where :

$p_{i j \ldots k}=$ joint probability value to be assigned to joint event $i$ at station 1 , event $j$ at station $2, \ldots$ and event $k$ at station $N$,

$\mathrm{q}_{i j \ldots k}=$ 'prior' joint probability value of joint event $i$ at station 1 , event $j$ at station $2, \ldots$, and event $\mathrm{k}$ at station $\mathrm{N}$, derived from historical records,

$\mathrm{M}(\mathrm{n})$ = number of intervals (discrete water quality values) at station $n$,

N number of upstream stations at which the probabilities of events are to be predicted.

The basic principle for the method proposed in this thesis is therefore the determination of new 
probability distributions at discontinued monitoring station(s) such that the new probability distributions are as close as possible to the prior probability distributions of water quality at the stations and remain consistent with the information given about the system as expressed by the constraints. Note that when a significant change in the environment is known to have occurred, e.g., a change of land use or development of industries that causes a change in pollutant loading into the river system, the 'prior' probability may be modified to incorporate this 'prior' knowledge about the change in the environment into the model .

\section{(iii) Constraints}

Application of the entropy principle to the probability estimation problem through the MDI approach enables information other than the prior probabilities, which are incorporated in the objective function through the $q_{n i}$ values, to be expressed mathematically as constraints within the formulation. This information will govern (constrain) the assignment of the probability to every event. Hence, only relevant and appropriate information on conditions in the system should be included, in the constraints. Any other 
additional information will tend to increase the prejudice of the model, thereby detracting from the unbiased nature of the predictions obtained from the approach. The importance of maintaining a lack of bias in the prediccion relates to the potential use of the method for predicting the likely upstream locations of water quality changes which are the cause(s) of observed water quality changes at the downstream station. (This use of the procedure is discussed in more detail in section 5.4.)

When using the entropy model to predict water quality values, or more precisely, the distribution of the water quality values, at discontinued monitoring stations, the following types of information could reasonably be considered as appropriate for inclusion in the set of constraints. The first piece of information might be the known or observed mean at the downstream station. The value of this mean determines in part the probability distributions, and thereby the mean values, which are assigned to the upstream stations .

Recall from section 4.3 .1 that the means of the water quality values at the upstream stations $\mathbf{b}$ and $\mathbf{c}$ have been defined as $\mathbf{x}$ and $\mathbf{y}$ respectively, and the mean of the water quality value at the downstream station a 
has been similarly defined as $\mathbf{z}$ (where $\mathbf{z}$ is a function of $\mathbf{x}$ and $\mathbf{y}$ ). Considering the water quality values in terms of concentrations of pollutant (and assuming no changes in flow rates, pollutant loadings, water quality values due to time of transport, the transport itself, or mixing of the flows from the two tributaries on which stations $\mathbf{b}$ and $\mathbf{c}$ are located), the value of $\mathbf{z}$ can be looked upon as a proportional mixture of $\mathbf{x}$ and y, expressed as :

$$
z=\frac{Q_{b} \cdot x+Q_{c} \cdot y}{Q_{b}+Q_{c}}
$$

where :

$$
\begin{aligned}
\mathrm{Q}_{\mathrm{b}} \text { and } \mathrm{Q}_{\mathrm{c}}= & \text { discharges at stations } \mathrm{b} \text { and } \mathrm{c} \\
& \text { respectively. }
\end{aligned}
$$

Ideally these discharges $Q_{b}$ and $Q_{c}$ at station $b$ and c should be discharges measured at the same time as the water quality values of interest were measured for those stations. Furthermore, the measurements at stations $b$ and $c$ should be taken at times such that the bodies of water being measured at those separate locations arrive at the downstream station a at the same time. Such situations are rarely practical and occur very rarely, if at all. An approximation is therefore adopted in this study, wherein the values assigned to the flows ("weighting factors") $Q_{b}$ and $Q_{c}$ in 
Equation 4.5 are the mean annual flows on the respective streams.

Now consider more closely the simplifying assumptions used in the derivation of Equation 4.5. In particular consider those assumptions relating to the time and distance of the travel between the stations and any physical processes affecting water quality and flow rates that might occur over this time and distance. In other words, the water quality measured at b or c may have changed before it reaches the confluence of the two streams upon which those stations are located. The water quality resulting from the mixing of those two streams may then change again before reaching a. This process can be quite complicated and a number of simulation models, e.g., Streeter-Phelps model for the BOD processes in a river (Tchobanoglous and Schroeder, 1985), have been developed to predict the values of water quality parameters in these circumstances.

However, the focus of this thesis, is not in the development of similar simulation models, but rather in the prediction of the values of the water quality at discontinued monitoring stations. The consequences of any of the mixing processes at the confluence or which might be occurring during travel down the river are 
addressed through a regression process which relates, at least on a statistical if not on a physical basis, the water quality value at the downstream station a $(=\mathbf{z})$ to the water quality value $\left(=\mathbf{z}^{\prime}\right)$ that occurs from the direct weighted mixing of the values measured at the upstream monitoring stations. Implications of the changes that occur during the mixing process itself can also be recognised and incorporated into the formulation through this regression process.

The mathematical expression of this process can be written as :

$$
z^{\prime}=b_{0}+b_{1} \cdot z
$$

where :

$$
\begin{aligned}
& z^{\prime}=\quad \text { water quality value as a weighted } \\
& \text { mixture of water quality values } \\
& \text { from upstream locations derived } \\
& \text { from Equation } 4.5, \\
& =\quad \text { water quality value observed at the } \\
& \text { downstream station } a, \\
& \text { regression coefficients for the } \\
& \mathrm{b}_{0} \text { and } \mathrm{b}_{1}=\quad \text { relationship between } \mathrm{z} \text { and } \mathrm{z}^{\prime} .
\end{aligned}
$$

The expression given by Equation 4.6 essentially states that the value of the water quality at downstream station a is a function of the water quality at the upstream stations mixed in proportion to the 
flow. An underlying assumption in this approach is that the rate at which a particular water quality value changes is linear with respect to that value and does not depend on the values of other water quality parameters. As such it assumes that the reactions or processes that cause changes during the transport or mixing process do not depend on threshold or ceiling values. For a number of water quality values, e.g., Conductivity, Dissolved Ions, Dissolved Solids, Hardness, etc., this is not an unreasonable assumption. (In future developments of the technique proposed in this thesis, it may be possible to develop an expression for Equation 4.6 that more accurately reflects the transport and mixing processes, in a simulation rather than statistical modelling sense. However, for use in the current formulation such an equation must be sufficiently simple to be incorporated into the non-linear optimisation problem that the formulation already represents without causing the model to become computationally impractical.)

An additional issue which must be considered in the development of the Equation 4.6 is "What values from each station should be used in developing Equation 4.6?"

Consider again, the river system in Figure 4.1. 
Assume all three stations $\mathbf{a}, \mathbf{b}$ and $\mathbf{c}$ were in operation for a period of observation from 1961 to 1975 inclusive. Let the annual mean water quality values recorded at stations $\mathbf{a}, \mathbf{b}$ and $\mathbf{c}$ through this period be denoted by the variables $\mathbf{z}, \mathbf{x}$ and $\mathbf{y}$ respectively. Regression analysis, using Equations 4.5 and 4.6, can be performed to express the relationship between the annual mean water quality values at station $\mathbf{a}$ and the combination (weighted by the associated discharges) of the annual mean water quality values from stations b and $c$.

The problem to be solved, however, is the prediction of specific values at locations $b$ and $c$ corresponding to an observed value at the downstream station a. These values might be the annual value, or if trends are to be identified, time averaged values over specified time intervals such as a specific number of years. The expression of the relationship function derived by Equations 4.5 and 4.6 therefore should also consider, or carry over, the effect of averaging the values over periods of time longer than one year. This situation can be managed by implementing a 'moving average' procedure in developing the basic relationship function.

The steps for implementing a moving average approach 
are as follows :

1. Select the number of years over which the mean value of the water quality is to be predicted, e.g., $\hat{n}$ years.

2. Calculate the mean values over the same number of years $(\hat{n})$ from each stations sequentially, e.g., in the example 1961 to $1961+\hat{n} ; 1962$ to $1962+\hat{n}$; ... i $1975-\hat{n}$ to 1975 .

3. Use the values obtained from step 2 to develop the relationship function using Equations 4.5 and 4.6 .

In this process the time frame used in the calibration phase must be the same as that for which prediction is required. The values predicted by the entropy model using these functions therefore give the probability distributions (and associated means) associated with the selected time averaging period of the water quality values at the upstream stations.

\subsubsection{FORMULATION}

The complete mathematical formulation including constraints which assigns the joint probabilities is as follows :

Maximise $H=-\sum_{i=1}^{M(1)} \sum_{j=1}^{M(2)} \ldots \sum_{k=1}^{M(N)} p_{i j \ldots k} \ln \frac{p_{i j \ldots k}}{q_{i j \ldots k}}$ (4.7.a)

or 


$$
\text { Minimise } \quad H=\sum_{i=1}^{M(1)} \sum_{j=1}^{M(2)} \ldots \sum_{k=1}^{M(M)} p_{i f \ldots k} \ln \frac{p_{i f \ldots k}}{q_{i f \ldots k}} \quad(4.7 . \mathrm{b})
$$

$$
\begin{aligned}
& \text { subject to : } \\
& \sum_{i=1}^{M(1)} \sum_{j=1}^{M(2)} \ldots \sum_{k=1}^{M(N)} p_{i j \ldots k}=1 \\
& \sum_{i=1}^{M(1)} \sum_{j=1}^{M(2)} \ldots \sum_{k=1}^{M(N)} p_{i j \ldots k} x_{11}=\bar{x}_{1} \\
& \sum_{i=1}^{M(1)} \sum_{j=1}^{M(2)} \ldots \sum_{k=1}^{M(N)} p_{i j \ldots k} x_{2 j}=\bar{x}_{2} \\
& \sum_{i=1}^{M(1)} \sum_{j=1}^{M(2)} \ldots \sum_{k=1}^{M(N)} p_{i j \ldots k} x_{N k}=\bar{x}_{N} \\
& \bar{x}=f\left(\bar{x}_{1}, \bar{x}_{2}, \ldots, \bar{x}_{N}\right)
\end{aligned}
$$

$0 \leq p_{i j \ldots k} \leq 1$

$$
\forall_{i} ; \forall_{j} ; \ldots ; \forall_{k}
$$

$0 \leq q_{i j \ldots k} \leq 1$

$$
\forall_{i} ; \forall_{j} ; \ldots ; \forall_{k}
$$

$x_{1 i} ; x_{2 j} ; \ldots ; x_{N k} \geq 0$

$$
\forall_{1} ; \forall_{f} ; \ldots ; \forall_{k}
$$

where :

$\mathrm{x}_{1 \mathrm{i}}, \mathrm{x}_{2 \mathrm{j}}, \ldots, \mathrm{x}_{\mathrm{Nk}}=$ events (water quality values) in the $i^{\text {th }}$ discrete interval at station 1 , in the $j^{\text {th }}$ discrete interval at station $2, \ldots$ and in the $k^{\text {th }}$ 


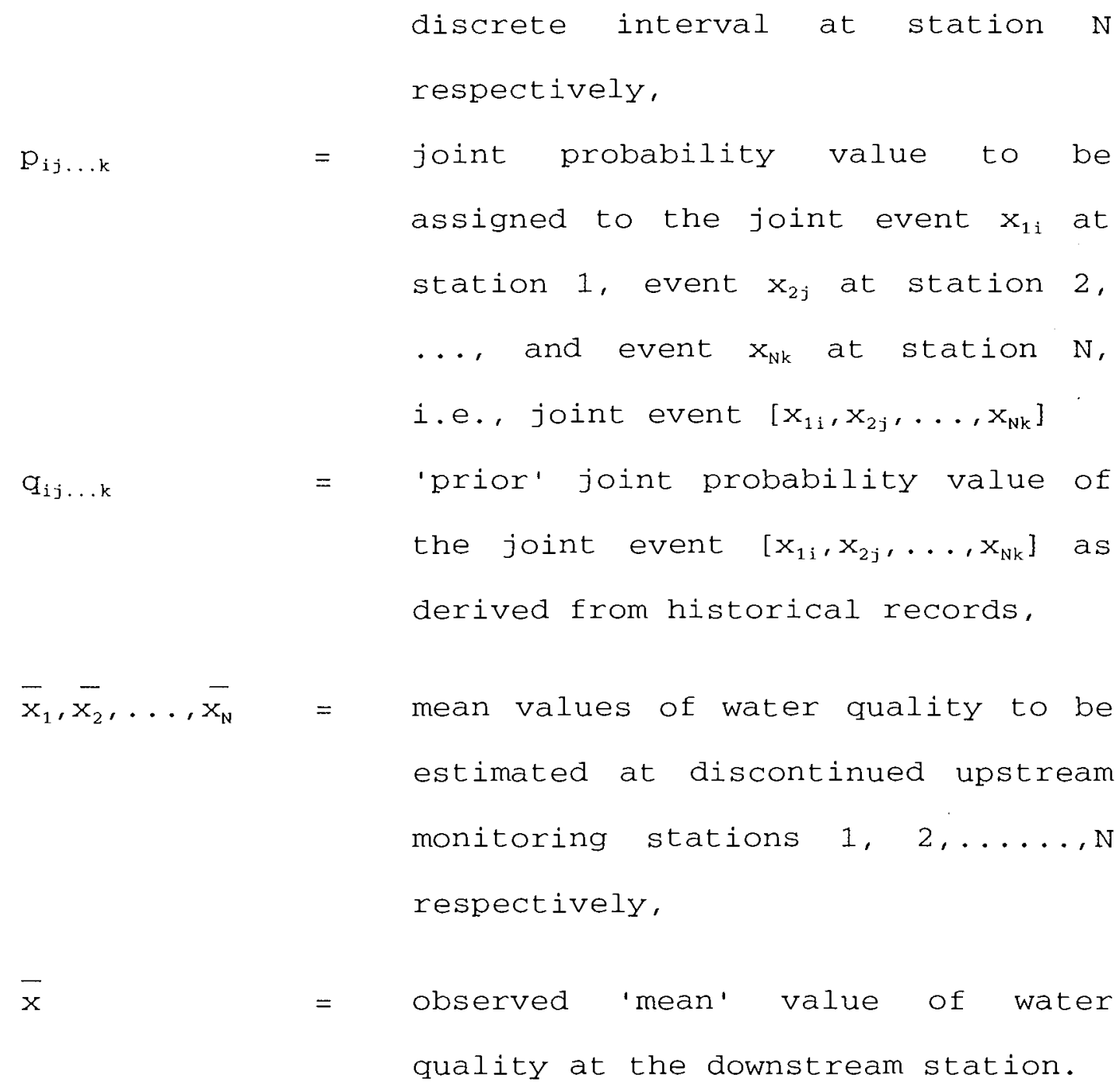

The above formulation can be interpreted as follows :

The objective function (Equation 4.7) minimises the total divergence of joint probability values $\left(p_{i j} \ldots k_{k}\right)$ of event $\left[x_{1 i}, x_{2 j}, \ldots, x_{N k}\right]$ from the known prior joint probability $\left[q_{i j} \ldots k_{k}\right]$ for all combinations of these events. 
The constraints expressed in Equations 4.8 to 4.13

have the following interpretations :

- Equation 4.8 specifies that the sum of the entropy defined probabilities of all the possible events should be equal to one in order to ensure the definition of a complete probability distribution.

- Equation 4.9 defines the first order moments of the encropy defined marginal probability distributions of the water quality values for each upstream station as being equal to the mean value of the water quality for the corresponding station.

- Equation 4.10 ensures that the observed value at the downstream monitoring station upon which the prediction is based is equal to that derived from the historically derived or known function of mean values from the upstream stations.

- Equations 4.11 and 4.12 establish that the joint probability value of every event is between zero and one.

- Equation 4.13 ensures that there are no negative values in the parameters of interest.

It should be noted that application of this formulation to the problem of predicting water quality values at discontinued monitoring stations results in the specification, of a new joint probability 
distribution for the range of combinations of water quality values at the upstream stations. It does not derive the probability distributions at each station directly as is the case when the simplified formulation which is described in the following section is used. The distributions at each of these upstream stations must be derived by calculating, from the new joint distribution determined by the entropy formulation, the marginal probability distributions at those stations.

Due to the non-linear characteristics of the problem, the size of the problem, e.g., number of variables, in the formulation stated in Equations 4.7 to 4.13 can be of concern. Consider the case where there are only two upstream stations and the probability space in both dimensions (one for each of the two stations) is discretized into 24 intervals $[M(i)=24$ for $i=1$ and 2]. The number of variables in this problem is $578 \quad(=24 * 24+2$ where the " $+2 "$ arises from the mean values of the stations). The situation is even more complex when more than two upstream stations are involved; for the same level of discretization, i.e., 24 intervals, more than $24^{3} \quad(=13824)$ variables are needed for three upstream stations. Even this limited size problem can be very demanding on non-linear optimisation algorithms. 
However, the formulation can be easily simplified to improve the: computational efficiency by reduction in the "dimension" of the problem, i.e., a three dimensional problem corresponding to the two station case of Figure 4.1 can be converted into a two dimensional problem. This simplification step, which reduces the number of variables to be solved is based upon the marginal probabilities as depicted in Figure 4.3. (It should be noted that the problem collapses to a two-dimension problem under the proposed simplification no matter how many upstream stations are being considered.)

The 'prior' mean water quality value at a particular station $n$ can be calculated (for the case of two upstream stations) from the 'prior' marginal distribution as follows :

$$
\bar{x}_{n}=\sum_{i=1}^{M(n)} q_{n i}^{*} x_{n i} \quad n=1,2
$$

where :

$\mathrm{q}_{n i}^{*}=$ prior marginal probability of event (water quality value) $i$ at station $n$

$\bar{x}_{\mathrm{n}}=$ 'prior' mean water quality value at station $\mathrm{n}$

$\mathrm{x}_{\mathrm{ni}}=$ event (water quality value) $i$ at station $\mathrm{n}$

The simplification arises from an interpretation 


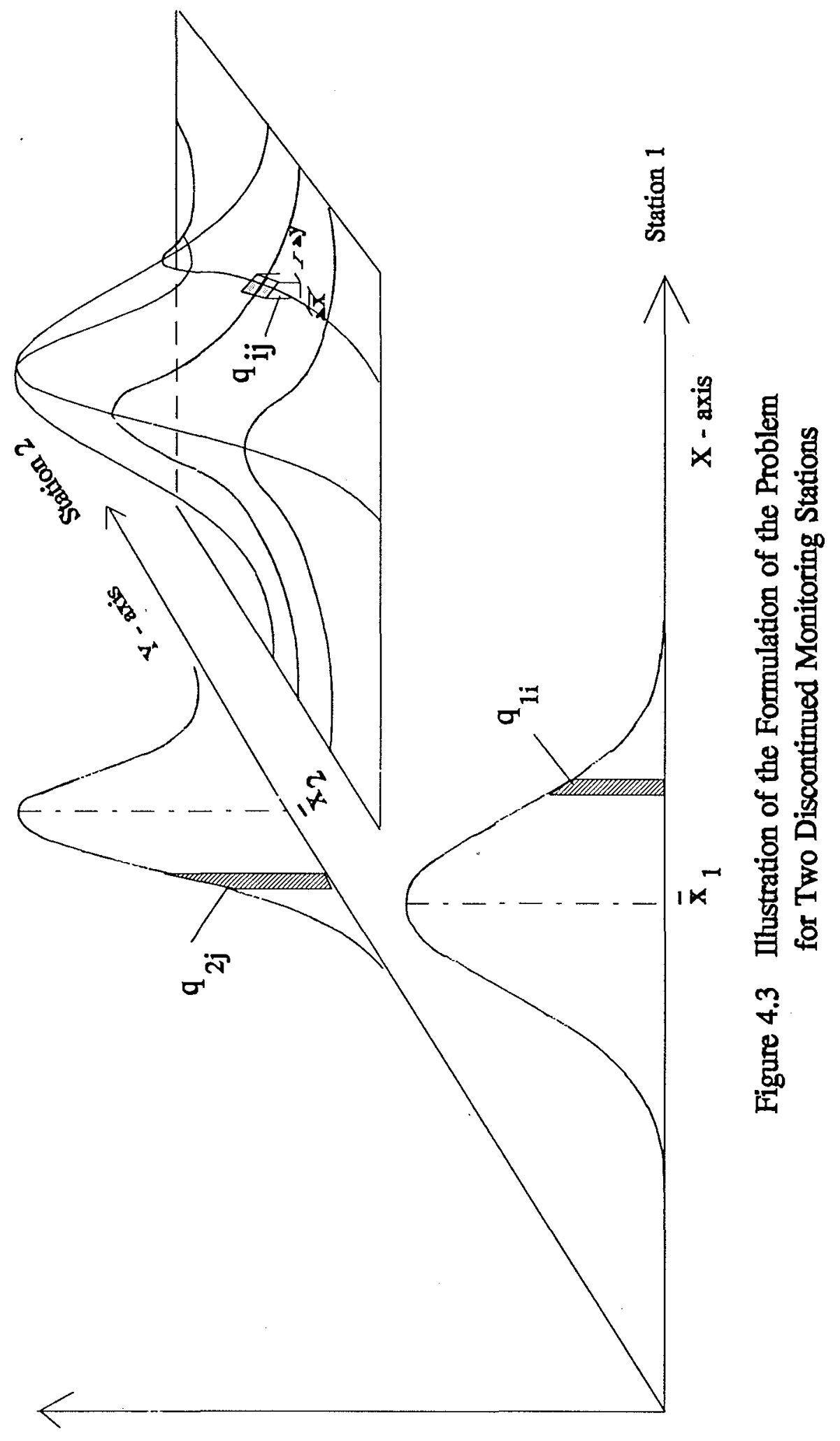


of the nature of the joint probability distribution of water quality at each station as derived by the entropy model. It should be noted that the sum of the probabilities over all water quality values at all stations should be always equal to unity. For the simplified two dimensional formulation illustrated by Figure 4.4, all stations have an 'equal likelihood of existence' with an 'equal total likelihood of the complete range of water quality values at that location'. The total probability of all combinations of water quality values at all stations individually must of course also remain equal to 1 .

The best way to handle the total likelihood of water quality values at a given station, when there are $\mathrm{N}$ stations, is to 'assign' a total probability of $1 / \mathrm{N}$ to the sum of the probabilities of the water quality variables at each station. This 'sum' has some of the characteristics of the marginal distribution in that, for a given monitoring station, it represents the likelihood of the complete range of different water quality values occurring at that station 'relative' to the complete range of water quality values at all the other upstream stations.

Equations 4.8 and 4.9 can be modified to reflect this observation. In the case of Equation 4.8, the 


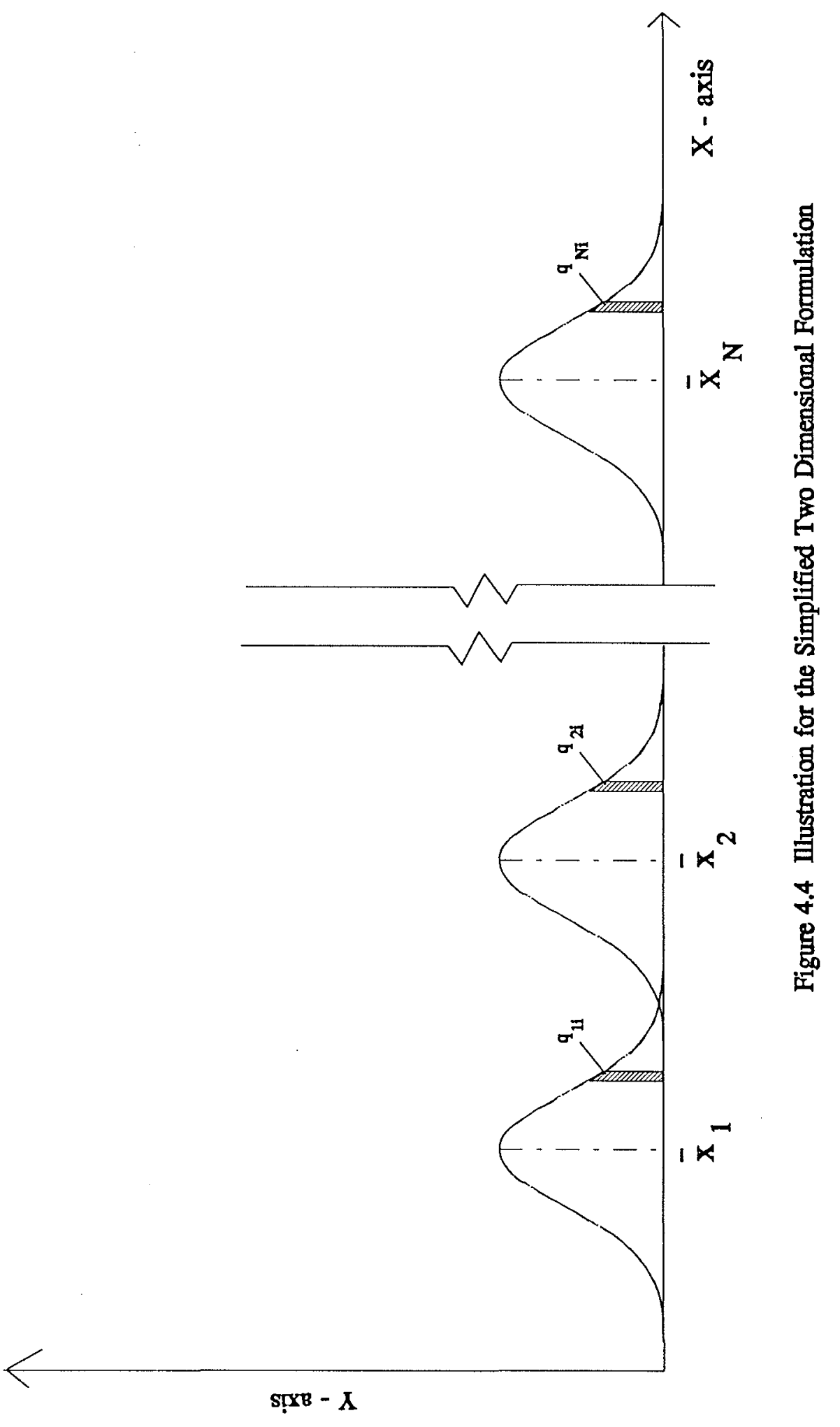


expression is modified to equate the total probability, i.e., likelihood of the water quality values at the station, to $1 / \mathrm{N}$. Equation 4.9 on the other hand must be modified to normalise, or standardise, the probabilities of the values of the water quality values such that the correct mean of the water quality values is defined by the model at each station. This step is achieved by dividing the expected value of the water quality at a station by the total probability of the values at that station, namely, 1/N. (Recall that under the assumptions being used at this time to simplify the problem, the total probability at any of $N$ stations is $1 / N)$.

It should be noted that when the model was run directly as given in the formulation of Equations 4.15 to 4.21 in the following section, but using $\sum_{1=1}^{M(n)} p_{n i}$ rather than $1 / N$ in Equation 4.17 and specifying that sum of all the probabilities is equal to 1 (i.e., $\sum_{n=1}^{N} \sum_{1=1}^{\mathbf{M}(n)} p_{n i}=1$ ) to replace Equation 4.16 , the probability distribution of water quality values at each station at optimality summed to $1 / \mathrm{N}$, confirming the validity of the assumption that the 'total probability' of water quality values at each station is $1 / \mathrm{N}$.

The simplified two dimensional form of the formulation of Equations 4.7 to 4.13 resulting from 
these changes can now be written as:

$$
\text { Maximise } H=-\sum_{n=1}^{N} \sum_{i=1}^{M(n)} p_{n i} \ln \frac{p_{n i}}{\left(\frac{q_{n t}}{N}\right)}
$$

Subject to :

$$
\begin{aligned}
& \sum_{1=1}^{M(n)} p_{n t}=\frac{1}{N} \\
& (n=1,2, \ldots, N) \\
& \bar{x}_{n}=\frac{\sum_{1=1}^{M(n)} p_{n 1} x_{n 1}}{\sum_{1=1}^{M(n)} p_{n 1}}=\frac{\sum_{1=1}^{M(n)} p_{n 1} x_{n 1}}{\frac{1}{N}} \quad(n=1,2, \ldots, N) \\
& \bar{x}=f\left(\bar{x}_{1}, \bar{x}_{2}, \ldots, \bar{x}_{N}\right) \\
& \forall_{n} ; \forall_{i} \\
& 0 \leq q_{n i} \leq 1 \\
& \forall_{n} ; \forall_{i} \\
& 0 \leq \bar{x}_{n i} \\
& \forall_{n} ; \forall_{i}
\end{aligned}
$$

where :

$\mathrm{x}_{\mathrm{ni}}=$ water quality value in the $i^{\text {th }}$ discrete interval at station $n$,

$\mathrm{q}_{\mathrm{n} i}=$ prior probability of event $\mathrm{x}_{\mathrm{ni}}$.

$\bar{x}_{n}=$ mean of the water quality value at station $n$,

$\bar{x}=$ observed (changed) mean of the water quality value at the downstream location. 


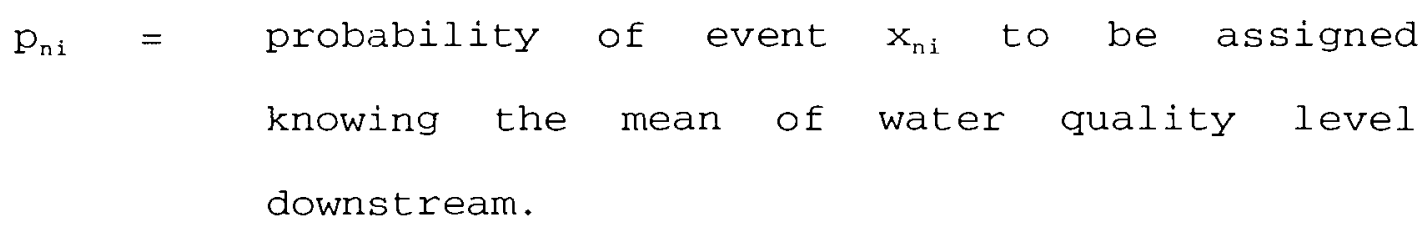

Using this formulation for the two dimensional problem for the case of predicting conditions at two stations and 24 intervals in the discretization, there are only $50 \quad(=24 * 2+2)$ variables to be solved, which is a significant reduction from the 578 variables in the previous formulation. A further advantage of using this simplified formulation lies in the fact that the number of variables to be solved increases linearly with the number of intervals derived from discretization processes, rather than exponentially as in the previous formulation. This reduction in the number of variables is accompanied by a corresponding significant reduction in the processing time. It should also be noted that in addition to the reduction of processing time, the probability distributions of the water quality values at each of the discontinued stations are defined directly by this formulation rather having to be calculated separately through development of the marginal distributions as is the case for the 'multidimensional' formulation defined by Equations 4.7 to 4.14 .

The formulation of Equation 4.15 to 4.21 has been 
verified by comparing the results of this model with those from the formulation for the multi-dimensional case presented in Equations 4.7 to 4.13 . Both formulations give exactly the same values for the same set of defined conditions. It should be noted that this process is valid for situations when there is no dependency between the water quality values at the upstream stations. (The issues related to use of the model when dependency exists among data at the upstream stations are discussed later in this chapter.)

A number of different variations of this basic model can be considered in relation to the application of the proposed method to the problem of estimating water quality values. These variations include consideration of a range of types of possible probability distributions for the water quality values, changes in the environment, and possible statistical or physical relationships among the data from different upstream stations.

In the first instance consider the way in which different distributions might be addressed within the approach. The formulation presented in Equations 4.15 to 4.21 is in fact applicable for general probability distribution functions. Hence, application of the formulation to situations where different probability 
distribution functions for the water quality values are known to exist, only requires that the prior probability distribution values $\mathrm{g}_{n i}$ in the formulation be defined on the basis of these known distributions. In other words, the prior probabilities $\mathrm{q}_{n i}$ should be developed on the basis of the probability distribution that best resembles the known probability distribution of the historical data.

\begin{abstract}
Now consider the case where changes effecting water quality are known to have occurred in the basin. In this situation, the new knowledge can be incorporated by replacing the prior probability, specified in the objective function of the model as $q_{n i}$, with new values estimated, or known, to exist because of these changes. This modification can be accomplished by shifting the prior probability distribution toward the estimated values. The extent to which the $q_{n i}$ values can or should be changed is a matter of judgement and experience and is examined in more detail in Chapter 5 . No matter how difficult it is to determine the extent of the changes in prior probability that can be justified by knowledge of conditions in the basin, the important feature is that the formulation is theoretically capable of handling the issue.
\end{abstract}

The last issue relates to the possibility that 
statistical (and perhaps physical based) relationships between water quality values in the basin, and in particular between values at the upstream stations. If such a relationship exists, it is possible to incorporate this information implicitly in the formulation through the 'prior' probability distribution values. The inclusion of this relationship should theoretically improve the overall prediction process. Inclusion of this issue is quite complex, however, and requires that the multi-dimensional form of the formulation of Equations 4.7 to 4.13 rather than simplified form of Equations 4.15 to 4.21 be used. Inclusion of this relationship also requires the use of a dependent 'prior' probability distribution.

For a situation in which the water quality variables are correlated and normally distributed, i.e., a multivariate normal distribution exists, the 'prior' probability distribution can be expressed as :

$$
q_{i j \ldots k}=\frac{\Delta_{1} \Delta_{2} \ldots \Delta_{N}}{(2 \pi)^{N D / 2}|S|^{1 / 2}} e^{-1 / 2(X-\bar{z})^{/ S} \mathcal{S}^{-1}(X-\bar{x})}
$$

where :

$\begin{aligned} \Delta_{1}, \Delta_{2}, \ldots, \Delta_{N}= & \text { discrete intervals of water quality } \\ & \text { values at stations } 1,2, \ldots, N \\ & \text { respectively, } \\ = & \text { sample covariance matrix of the } \\ & \text { multivąriate normal distribution, }\end{aligned}$




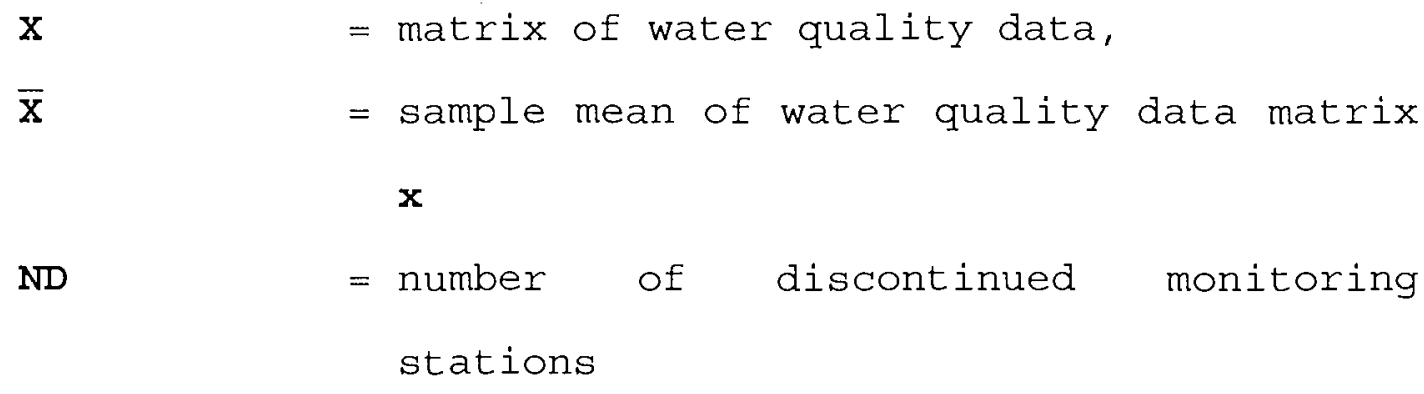

The $q_{i j \ldots k}$ values defined in this manner are inserted into Equation 4.7 of the multi-dimensional formulation.

For the case of two discontinued monitoring stations, the above prior probability becomes :

$$
q_{i j}=\frac{\Delta x_{1} \cdot \Delta x_{2}}{2 \pi . S x_{1 i} S x_{2 j} \sqrt{1-\rho^{2}}} e^{-\left[\left(\frac{x_{1 i}-\bar{x}_{1}}{S x_{1 i}}\right)^{2}-2 \rho\left(\frac{x_{1 i}-\bar{x}_{1}}{S x_{1 i}}\right)\left(\frac{x_{2 j}-\bar{x}_{2}}{S x_{2 j}}\right)+\left(\frac{x_{2 j}-\bar{x}_{2}}{S x_{2 j}}\right)^{2}\right] / 2\left(1-\rho^{2}\right)}
$$

where :

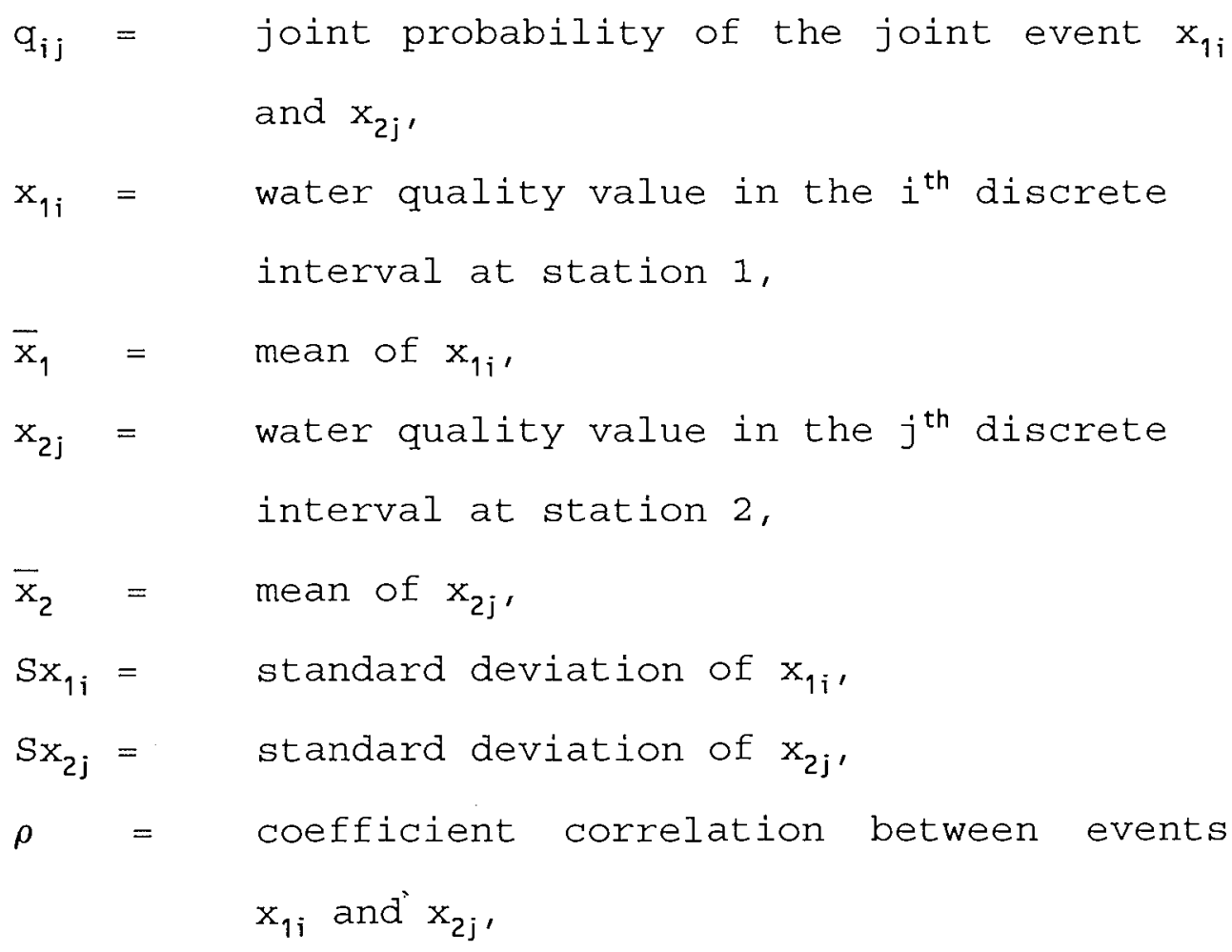




$$
\begin{aligned}
& \Delta \mathrm{x}_{1}=\text { width of interval at station } 1 . \\
& \Delta \mathrm{x}_{2}=\text { width of interval at station } 2 .
\end{aligned}
$$

\subsection{DISCUSSION}

Recall that, given an observed value of water quality at a downstream water quality monitoring station, the proposed method will result in the most likely probability distribution of water quality values being defined for discontinued upstream monitoring stations. If the 'new' or predicted mean values of water quality at the upstream stations derived from those 'new' probability distributions are plotted 'against' the 'prior' probability distributions, the probability of that new mean value, or more precisely the interval containing the mean value, occurring under the historical or original conditions can be calculated.

Application of the method to the case studies described in the following chapter reveals the following phenomenon related to the probability of this 'mean value'. For a given observed downstream water quality value, the product of the probabilities from the original prior probability distribution associated with the intervals containing the means of the entropy 
defined distribution at each of the upstream stations, is greater than the product of the probabilities of any other combination of water quality values at those upstream stations that can give rise to the observed downstream value. Note that these 'upstream' probabilities are again derived from the intervals containing these values in the original prior probability distributions for the corresponding stations.

This phenomenon can be expressed mathematically as:

$$
\prod_{n=1}^{N} p\left(\bar{\Delta} \mu_{n}\right)>\prod_{\substack{n=1 \\ k \in u}}^{N} p\left(\bar{\Delta}_{n k}\right) \quad u \in \bar{u}
$$

where :

$$
\begin{aligned}
\mathrm{p}\left(\bar{\Delta}_{\mathrm{n}}\right)= & \text { probability of the discrete water } \\
& \text { quality interval in the original } \\
& \text { prior distribution at station } \mathrm{n} \\
& \text { containing the new mean of the } \\
& \text { distribution of water quality } \\
& \text { values at station } \mathrm{n} \text { as defined by } \\
& \text { the entropy prediction, } \\
\mathrm{p}\left(\bar{\Delta}_{\mathrm{nk}}\right)= & \text { probability associated with } \\
& \text { discrete water quality interval k } \\
& \text { at station } \mathrm{n} \text { in the original prior } \\
& \text { distribution of water quality }
\end{aligned}
$$




values at that station,
combination of upstream water
quality values, one for each
upstream station, that gives rise
to the observed water quality value
at the downstream station,
$\bar{u}=$ set of all possible u,
$\mathrm{N}=$ number of upstream stations.

The phenomenon can perhaps be described more clearly by reference to Figure 4.5 which reflects a situation in which there are two upstream stations (stations 1 and 2) and one downstream station in the same configuration as in Figure 4.1. Assume that means of the entropy defined distributions are $A$ and $B$ for station 1 and 2 respectively. The values of water quality at the two upstream stations, designated by $A$ and B, combine to produce the observed water quality value $F$ at the downstream station. Now consider two other values of water quality $C$ and $D$ at stations 1 and 2 respectively which can also combine to give the observed water quality value $F$ at the downstream station. The product of the probabilities of the intervals containing $A$ and $B$ in the original prior probability distributions (not the probabilities of the intervals containing the values of $A$ and $B$ in the entropy defined distributions) is greater than the 
Upstream Station 1

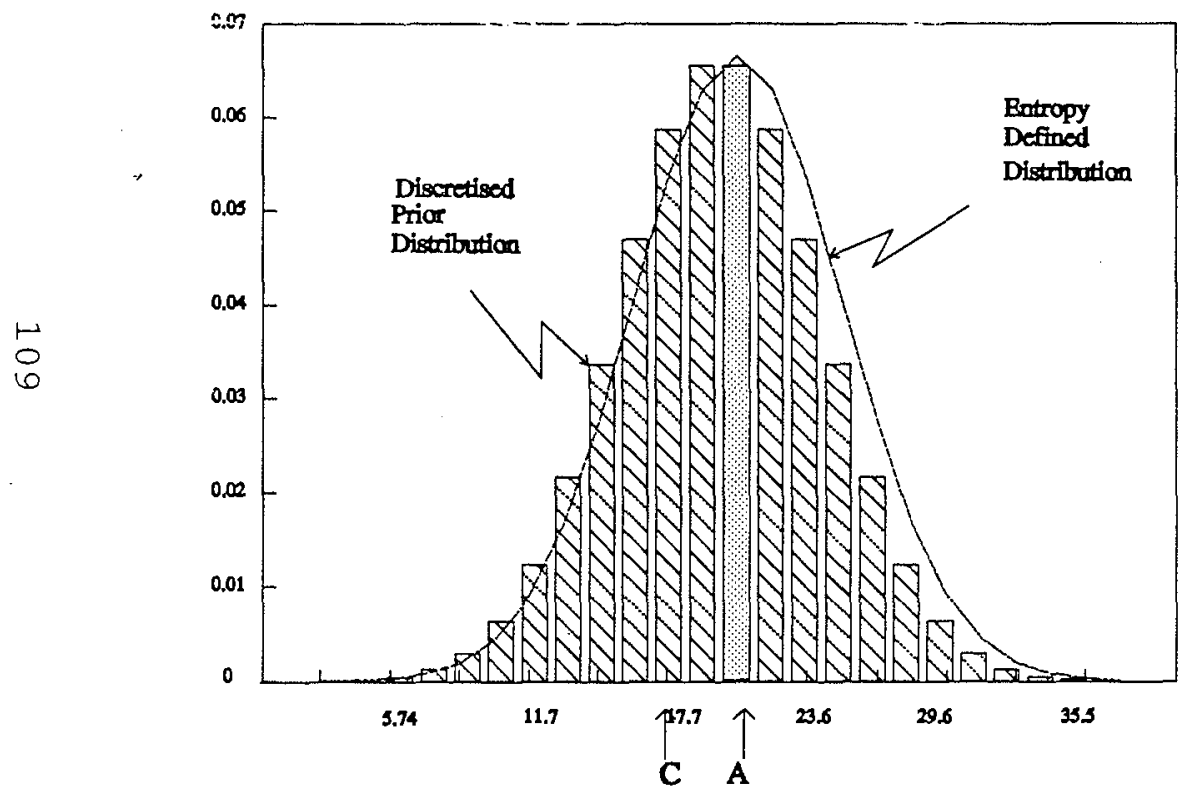

Upstream Station 2

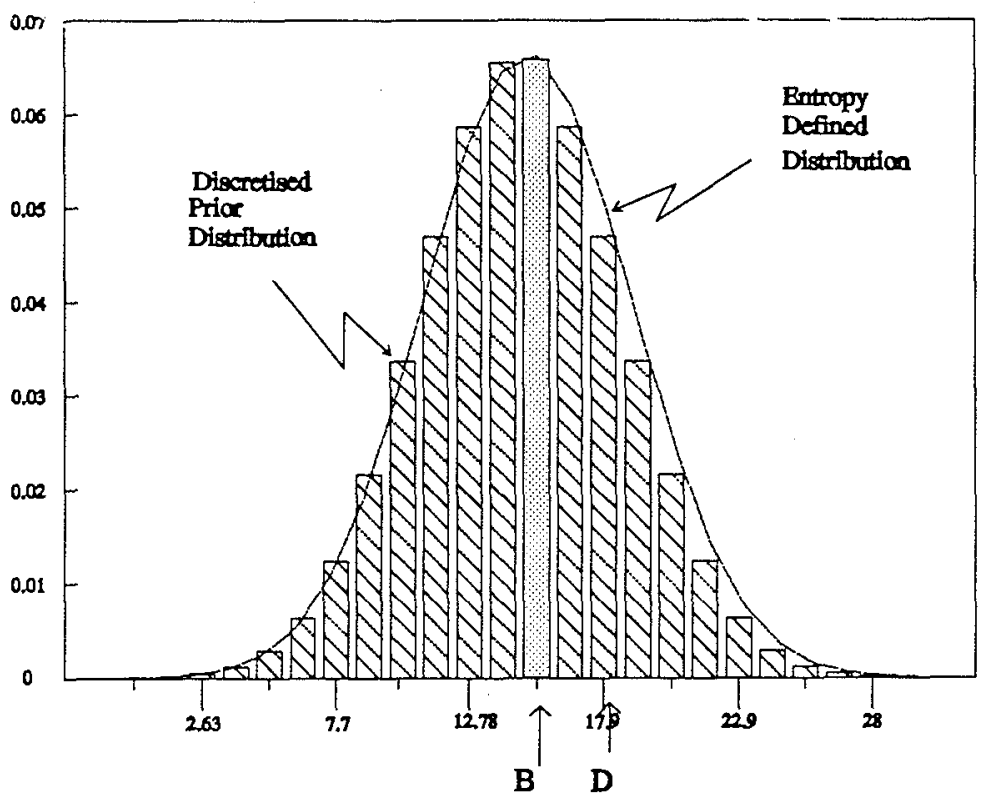

Figure 4.5 Figure for Explanation of Relationship between Products of Probability of Intervals of Water Quality Values that Give Rise to Observed Downstream Values 
product of the probabilities of the intervals in the prior distribution containing the values $C$ and $D$.

(Once again note that the probabilities of the intervals containing $\mathrm{C}$ and $\mathrm{D}$ are taken from the prior probability distributions not the entropy defined distribution). This same phenomenon occurs for any other combination of water quality values at the two upstream stations that give rise to the observed downstream value. This phenomenon was not observed for the upstream water quality values predicted by the regression analysis used to evaluate and compare the technique in Chapter 5.

The phenomenon confirming that the entropy principle defines the combination of 'new' values that is most likely to occur given prior knowledge about the situation provides further evidence that the new values predicted by the entropy principle should be considered the best estimate.

The following chapters describe the application of the technique to a series of case studies, followed by discussion of the results of those applications. 


\section{CHAPTER 5}

\section{APPLICATION OF THE TECHNIQUE}

In this chapter, the entropy model described in the previous chapter is demonstrated by application to observed data from selected water quality monitoring stations in Queensland, Australia. The utility of the approach is then assessed by comparing its performance, measured in terms of the accuracy of the predictions of water quality values at discontinued stations, with that of another prediction approach.

Recall that the entropy expression (Equation 4.15) used to assigr: the probability values to the upstream stations requires the specification of the prior probabilities $q_{n i}$, and the derivation of the relationship between the weighted mixture of flow at the conjunction of a stream and the observed values of water quality at a monitoring station some distance downstream of the mixing point (Section 4.3.3). It is therefore necessary to have a data set on which to 'calibrate' the model. The requirement for prior existence of such a data set is not inconsistent with the nature of the definition of problem being 
addressed in this thesis, namely, how to predict water quality values at discontinued monitoring stations where the discontinued stations have been in operation for a period of time sufficient to define the characteristics of the distribution of water quality data at that station. (It should be noted that similar restrictions apply for other prediction techniques such as regression.!

\subsection{DATABASE DESCRIPTION}

The data used in this study are taken from the Water Quality Data System of the Queensland Water Resources Commission in the state of Queensland, Australia. Examination of this data base showed that recording of those data which are appropriate for demonstrating the proposed model were generally only began in the 1970 's. Furthermore, no continuous monthly records were available for water quality monitoring activities and only a few records are available for each year. While the lack of good data causes some problems for the calibration and verification of the model, it should be recognised that such lack of data is a common problem. Hence use of this model in what might be termed a typical environment of sparse data may in fact be a better test of its true utility. 
The locations of the groupings of stations used to demonstrate the method, and the locations of the stations within those grouping, are shown in Figures $5.1(\mathrm{a})$ to $5.1(\mathrm{~d})$. An example of the data from one of the groupings of stations is presented in Table 5.1 [ The other data sets are presented in Appendix A, Tables A.1(a) to A.1(C) ]. In most cases there is more than one value in each year with the data usually being recorded in different seasons. The annual mean value of the water quality parameter is assumed to be equal to the value calculated by averaging the data values in each annual record. The mean value determined in this fashion is recognised as only being an estimate of the actual mean but is one of the best estimates possible from the available data. However, there are also a few cases when only one value was recorded in a given year. In this situation, that single value is assumed to be the mean value for that particular year.

Where a number of daily records are available within a single month, these values were averaged first and the resulting 'averaged' value taken as the data point for that month when calculating the annual average value. This step was performed to reduce bias in calculating the annual average value. It should be recognised that all prediction methods would suffer from these sane problems with lack of data. Hence a 


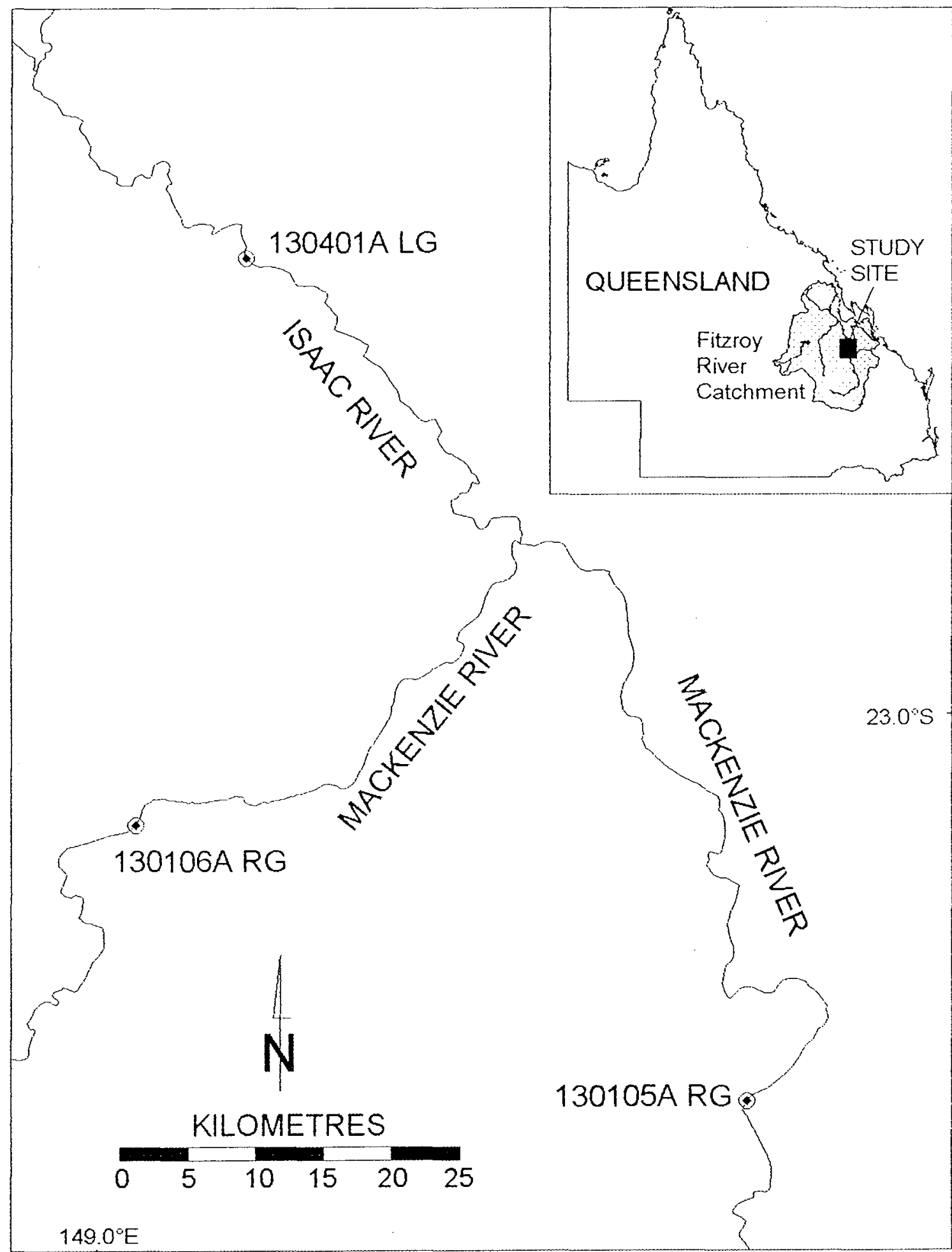

Figure 5.1(a) Location of the Water Quality Monitoring Stations in the MacKenzie River Sub-Basin 


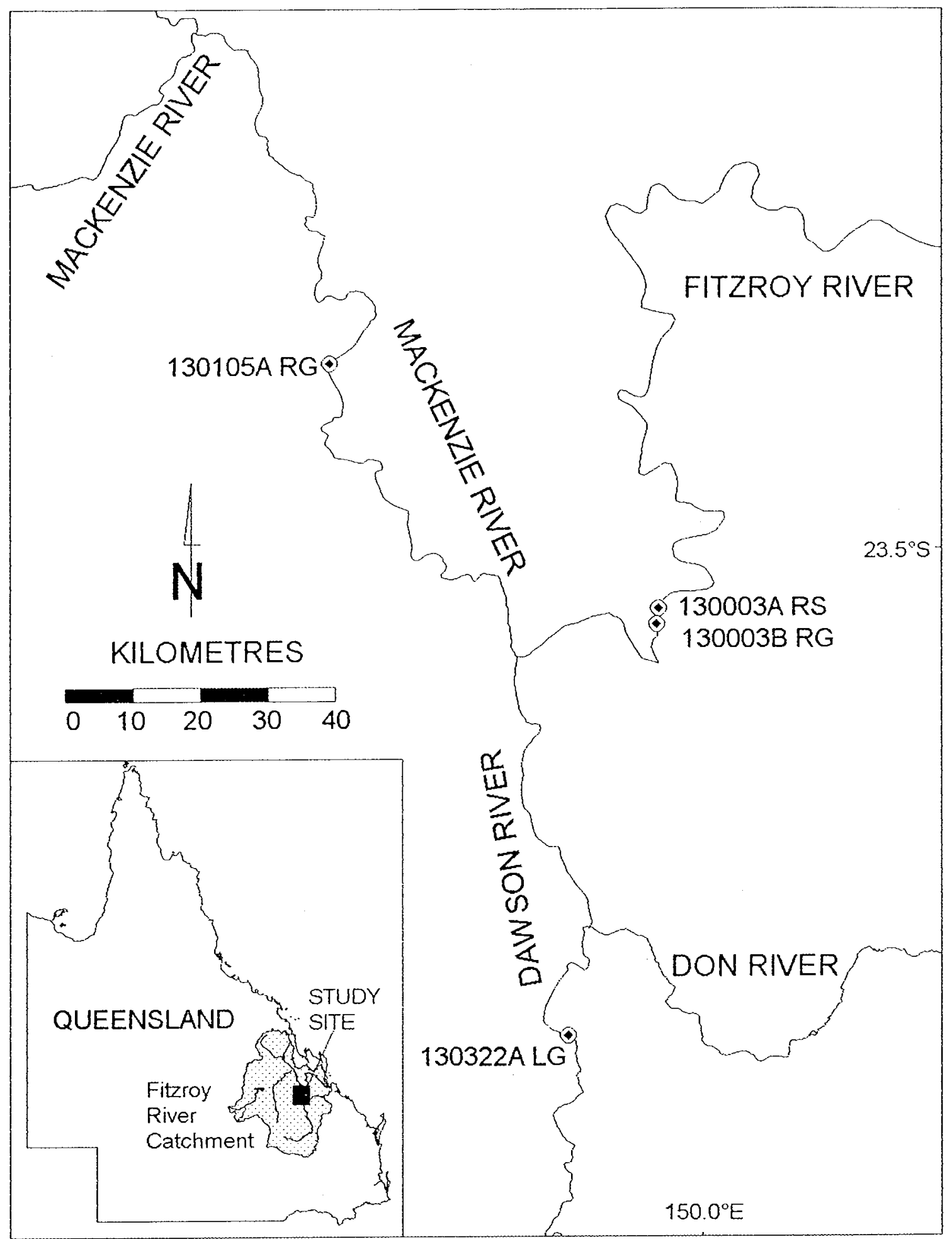

Figure 5.1(b) Location of the Water Quality Monitoring Stations in the Fitzroy River Basin 


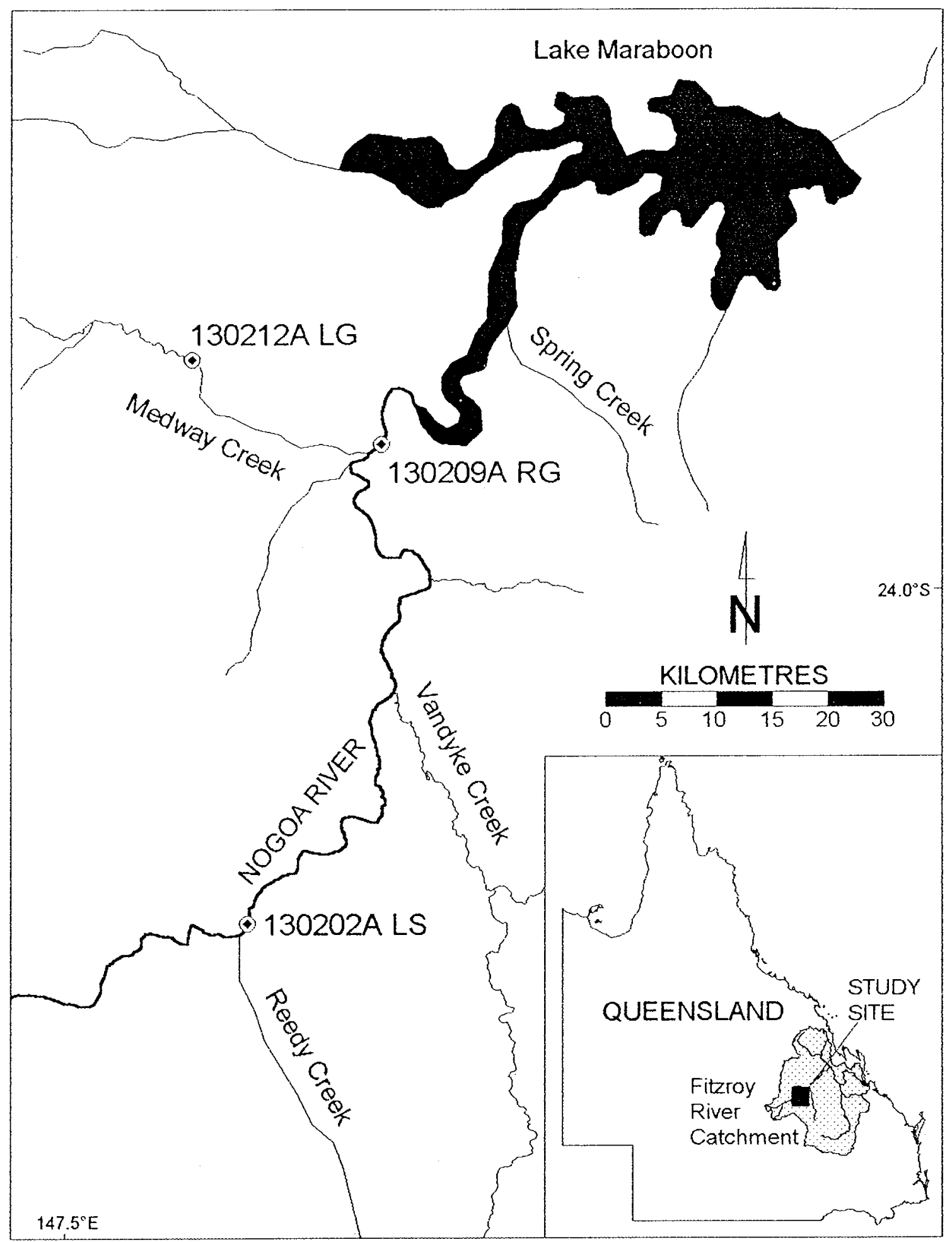

Figure 5.1(c) Location of the Water Quality Monitoring Stations in the Nogoa River Basin 


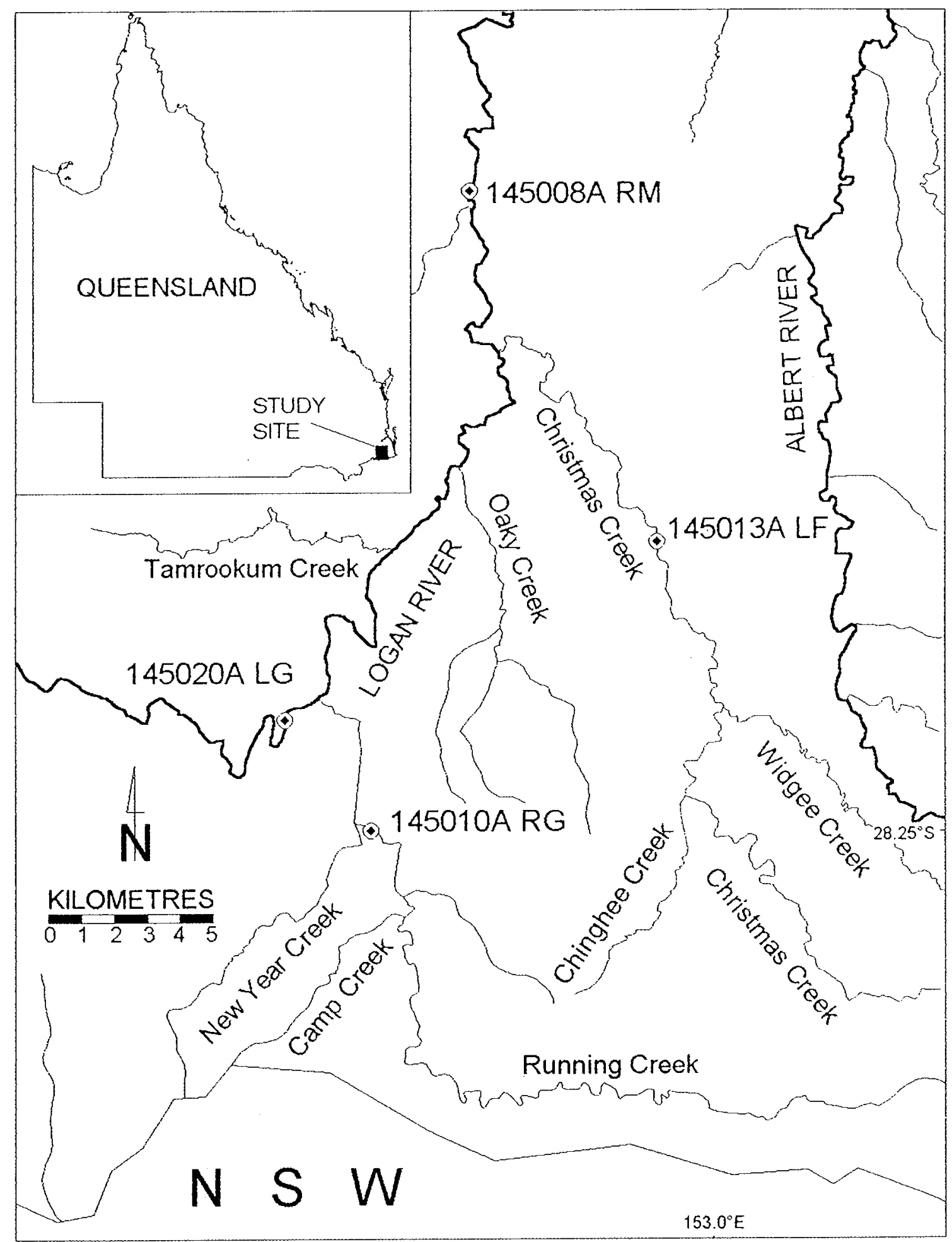

Figure 5.1(d) Location of the Water Quality Monitoring Stations in the Logan River Basin 
Table 5.1 Water Quality Records in the MacKenzie River Sub-Basin

Table 5.1(a) Station 130401

\begin{tabular}{|c|c|c|c|c|c|c|c|c|c|c|c|c|}
\hline \multicolumn{3}{|c|}{$\begin{array}{l}\text { Date } \\
\text { Sampled }\end{array}$} & \multirow[t]{2}{*}{$\begin{array}{c}\text { CONDUCTIVIry } \\
25 \mathrm{C} \\
(\mathrm{mS} / \mathrm{m}) \\
\end{array}$} & \multirow[t]{2}{*}{$\mathrm{PH}$} & \multirow[t]{2}{*}{$\begin{array}{c}\text { OISSOLVED } \\
\text { IONS } \\
\text { (mg/l) }\end{array}$} & \multirow[t]{2}{*}{$\begin{array}{c}\text { DISSOLVED } \\
\text { SOLIDS } \\
\text { (mg/l) }\end{array}$} & \multirow[t]{2}{*}{$\begin{array}{l}\text { HARDNESS } \\
\text { (mgm)as Caco3 } \\
\end{array}$} & \multirow[t]{2}{*}{$\begin{array}{l}\text { ALKALINITY } \\
\text { (myglpas Caco3 }\end{array}$} & \multirow[t]{2}{*}{$\begin{array}{c}\text { NATRIUM } \\
\text { (mg/i) }\end{array}$} & \multirow[t]{2}{*}{$\begin{array}{c}\text { KALIUM } \\
(\mathrm{mg} / \mathrm{l})\end{array}$} & \multirow[t]{2}{*}{$\begin{array}{c}\text { CALCIUM } \\
(\mathrm{mg} / \mathrm{l})\end{array}$} & \multirow[t]{2}{*}{$\begin{array}{c}\text { MAGNESIUM } \\
(\mathrm{mg} / \mathrm{l})\end{array}$} \\
\hline ldd & $\mathrm{mm}$ & yr) & & & & & & & & & & \\
\hline 17 & 6 & 71 & 270 & 7.2 & 184.2 & 0 & 77 & 72 & 27 & 0.0 & 16.0 & 9.0 \\
\hline 2 & 9 & 71 & 175 & 7.9 & 130.2 & 0 & 58 & 56 & 17 & 0.0 & 10.0 & 8.0 \\
\hline 8 & 12 & 71 & 365 & 7.8 & 274.1 & 0 & 99 & 120 & 43 & 0.0 & 20.0 & 12.0 \\
\hline 10 & 4 & 72 & 245 & 7.4 & 198.1 & 0 & 80 & 84 & 29 & 0.0 & 17.0 & 9.0 \\
\hline 4 & 7 & 72 & 320 & 7.8 & 242.1 & 0 & 101 & 100 & 34 & 0.0 & 24.0 & 10.0 \\
\hline 10 & 10 & 72 & 430 & 8.2 & 344.1 & 0 & 130 & 130 & 55 & 0.0 & 34.0 & 11.0 \\
\hline 16 & 12 & 72 & 410 & 8.0 & 279.2 & 0 & 100 & 102 & 48 & 0.0 & 22.0 & 11.0 \\
\hline 17 & 4 & 73 & 217 & 7.6 & 153.8 & 127 & 65 & 62 & 19 & 1.0 & 13.4 & 7.6 \\
\hline 27 & 6 & 73 & 294 & 7.9 & 226.9 & 179 & 105 & 100 & 23.4 & 1.7 & 19.8 & 13.6 \\
\hline 27 & 9 & 73 & 230 & 7.3 & 168.0 & 143 & 60 & 62 & 25.5 & 2.0 & 13.0 & 6.7 \\
\hline 13 & 12 & 73 & 210 & 7.6 & 146.4 & 114 & 64 & 56 & 19 & 2.0 & 14.0 & 7.0 \\
\hline 4 & 7 & 74 & 432 & 8.0 & 283.7 & 244 & 129 & 111 & 36 & 1.2 & 26.0 & 15.6 \\
\hline 18 & 9 & 74 & 510 & 8.6 & 318.2 & 255 & 144 & 120 & 38 & 1.4 & 28.0 & 18.0 \\
\hline 3 & 9 & 75 & 430 & 8.1 & 267.3 & 218 & 116 & 107 & 34 & 1.2 & 25.0 & 13.0 \\
\hline 13 & 11 & 75 & 270 & 8.1 & 155.5 & 134 & 62 & 60 & 20 & 3.1 & 13.0 & 7.2 \\
\hline 22 & 7 & 76 & 540 & 7.8 & 350.9 & 294 & 152 & 120 & 49 & 1.2 & 31.0 & 18.0 \\
\hline 29 & 10 & 76 & 630 & 8.1 & 419.4 & 346 & 162 & 160 & 59 & 1.6 & 40.0 & 20.0 \\
\hline 24 & 11 & 76 & 480 & 8.3 & 307.9 & 269 & 139 & 99 & 40 & 2.2 & 31.0 & 15.0 \\
\hline 5 & 2 & 77 & 105 & 7.5 & 77.0 & 72 & 25 & 33 & 9.6 & 1.8 & 5.9 & 2.5 \\
\hline 28 & 3 & 77 & 330 & 7.6 & 194.8 & 174 & 86 & 80 & 25 & 1.4 & 20.0 & 8.8 \\
\hline 25 & 7 & 77 & 400 & 8.3 & 266.8 & 226 & 111 & 110 & 34 & 1.2 & 23.0 & 13.0 \\
\hline 9 & 9 & 77 & 510 & 8.0 & 351.3 & 285 & 150 & 142 & 44 & 1.4 & 32.0 & 17.0 \\
\hline 9 & 12 & 77 & 210 & 7.8 & 131.6 & 114 & 60 & 50 & 16 & 2.7 & 13.0 & 6.6 \\
\hline 25 & 5 & 78 & 460 & 8 & 315.3 & 271 & 132 & 115 & 42 & 1.4 & 28.0 & 15.0 \\
\hline 24 & 7 & 78 & 455 & 7.7 & 294.5 & 255 & 126 & 98 & 44 & 1.0 & 24.0 & 16.0 \\
\hline 25 & 10 & 79 & 660 & 7.6 & 411.0 & 343 & 181 & 145 & 59 & 2.0 & 36.0 & 22.0 \\
\hline 10 & 3 & 80 & 350 & 7.6 & 226.9 & 199 & 95 & 88 & 30 & 1.5 & 20.0 & 11.0 \\
\hline 6 & 6 & 80 & 335 & 7.2 & 201.9 & 181 & 89 & 70 & 29 & 1.3 & 19.0 & 10.0 \\
\hline 15 & 9 & 80 & 450 & 7.2 & 297.7 & 248 & 127 & 110 & 40 & 1.5 & 26.0 & 15.0 \\
\hline 10 & 11 & 80 & 500 & 7.7 & 311.2 & 264 & 128 & 113 & 44 & 1.7 & 25.0 & 16.0 \\
\hline 9 & 12 & 80 & 510 & 7.7 & 310.5 & 267 & 126 & 116 & 46 & 2.0 & 24.0 & 16.0 \\
\hline 27 & 7 & 81 & 380 & 7.5 & 228.3 & 197 & 95 & 86 & 32 & 1.0 & 20.0 & 11.0 \\
\hline 16 & 10 & 81 & 470 & 8.5 & 173.2 & 240 & 118 & 14 & 41 & 1.6 & 24.0 & 14.0 \\
\hline 5 & 4 & 82 & 235 & 8.4 & 148.9 & 140 & 60 & 57 & 21 & 1.3 & 13.0 & 6.6 \\
\hline 21 & 6 & 82 & 330 & 7.9 & 204.5 & 180 & 88 & 79 & 27 & 1.4 & 19.0 & 9.8 \\
\hline 7 & 9 & 82 & 385 & 8.1 & 248.7 & 200 & 102 & 92 & 35 & 1.3 & 21.0 & 12.0 \\
\hline 1 & 8 & 83 & 340 & 7.5 & 189.7 & 170 & 89 & 56 & 30 & 1.2 & 19.0 & 10.0 \\
\hline 12 & 12 & 83 & 255 & 7.8 & 173.6 & 150 & 66 & 70 & 25 & 2.5 & 14.0 & 7.6 \\
\hline 8 & 3 & 84 & 310 & 8.0 & 200.6 & 170 & 82 & 71 & 27 & 1.7 & 17.0 & 9.6 \\
\hline 25 & 6 & 84 & 355 & 8.0 & 238.0 & 200 & 85 & 95 & 37 & 1.6 & 18.0 & 9.8 \\
\hline 5 & 3 & 85 & 200 & 7.2 & 129.8 & 130 & 51 & 47 & 17 & 2.7 & 11.0 & 5.6 \\
\hline 17 & 6 & 85 & 260 & 7.8 & $145: 8$ & 130 & 61 & 56 & 23 & 1.3 & 13.0 & 6.9 \\
\hline 3 & 10 & 85 & 390 & 7.5 & 254.4 & 210 & 104 & 91 & 35 & 1.8 & 22.0 & 12.0 \\
\hline 17 & 3 & 86 & 220 & 7.7 & 152.3 & 120 & 65 & 67 & 18 & 2.4 & 16.0 & 6.0 \\
\hline 17 & 6 & 86 & 260 & 7.9 & 170.6 & 150 & 69 & 62 & 22 & 1.9 & 15.0 & 7.7 \\
\hline 2 & 10 & 86 & 350 & 7.8 & 225.0 & 180 & 93 & 87 & 32 & 2.2 & 20.0 & 10.5 \\
\hline 29 & 6 & 87 & 265 & 7.4 & $\uparrow 82.3$ & 140 & 75 & 82 & 22 & 3.8 & 17.0 & 7.8 \\
\hline 11 & 12 & 87 & 205 & 7.9 & 144.8 & 120 & 64 & 68 & 14 & 2.9 & 15.5 & 6.1 \\
\hline 20 & 5 & 88 & 395 & 7.5 & 250.2 & 220 & 111 & 87 & 32.5 & 1.9 & 24.0 & 12.5 \\
\hline 8 & 10 & 88 & 320 & 7.3 & 204.1 & 180 & 86 & 74 & 27 & 1.5 & 18.0 & 10.0 \\
\hline 21 & 6 & 89 & 315 & 7.9 & 212.9 & 180 & 86 & 81 & 31 & 1.3 & 18.0 & 10.0 \\
\hline 10 & 10 & 89 & 510 & 7.7 & 332.5 & 280 & 158 & 120 & 46 & 1.7 & 32.0 & 19.0 \\
\hline
\end{tabular}

Source: Queensland Water Resources Commission

Surface Water Resources Branch

Water Quality Data System 
Table 5.1(b) Station 130106

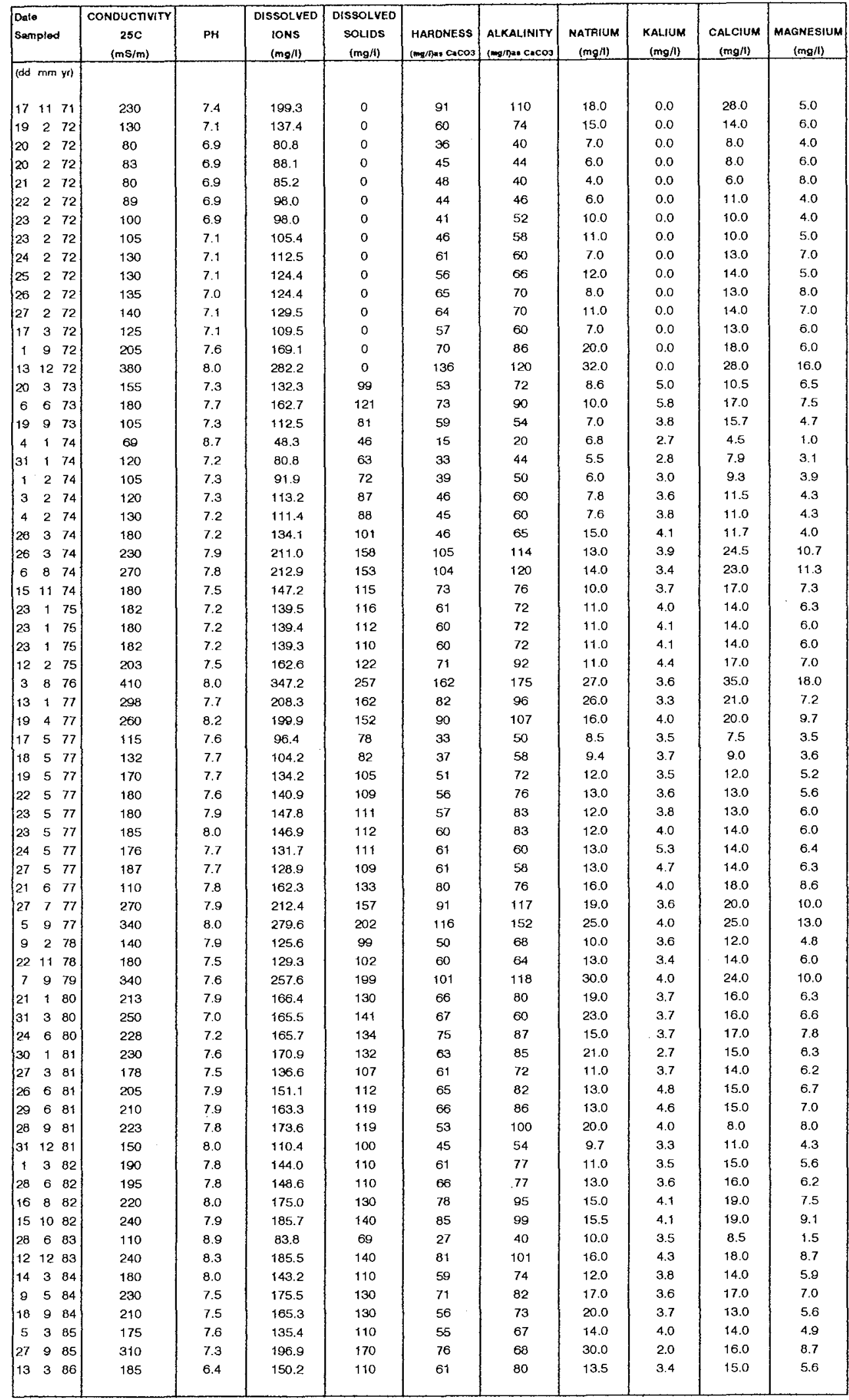

Source: Queensland Water Resources Commission

Surface Water Resources Branch

Water Quality Data System 
Table 5.1(c) Station 130105

\begin{tabular}{|c|c|c|c|c|c|c|c|c|c|c|c|}
\hline \multicolumn{2}{|c|}{$\begin{array}{l}\text { Dete } \\
\text { Sampied }\end{array}$} & $\begin{array}{c}\text { CONDUCTIVITY } \\
25 \mathrm{C} \\
(\mathrm{mS} / \mathrm{m}) \\
\end{array}$ & $\mathrm{PH}$ & $\begin{array}{l}\text { DISSOLVED } \\
\text { IONS } \\
\text { (mg/l) }\end{array}$ & $\begin{array}{c}\text { OISSOLVED } \\
\text { solios } \\
\text { (mg/l) }\end{array}$ & $\begin{array}{l}\text { HARONESS } \\
\text { (mg)/2as Cacos }\end{array}$ & $\mid \begin{array}{l}\text { ALKALINITY } \\
\text { (mp:inas Caco3 }\end{array}$ & $\begin{array}{l}\text { NATRIUM } \\
(\mathrm{mg} / \mathrm{l})\end{array}$ & $\begin{array}{c}\text { KALIUM } \\
\text { (mgR) }\end{array}$ & $\begin{array}{c}\text { CALCIUM } \\
\text { (mg/l) }\end{array}$ & $\begin{array}{c}\text { MAGNESIUM } \\
\text { (mgfl) }\end{array}$ \\
\hline \multicolumn{12}{|c|}{ (dd $\mathrm{rmm} y$ y) } \\
\hline 1 & 972 & 280 & 7.7 & 197.1 & 146 & 75 & 82 & 30.0 & 0.0 & 17.0 & 8.0 \\
\hline & 1272 & 300 & 7.7 & 202.2 & 151 & 86 & 82 & 28.0 & 0.0 & 18.0 & 10.0 \\
\hline 21 & 373 & 175 & 7.7 & 125.3 & 104 & 51 & 60 & 13.9 & 2.9 & 10.5 & 6.0 \\
\hline 27 & 373 & 230 & 7.1 & 154.9 & 136 & 63 & 60 & 20.0 & 1.6 & 12.5 & 7.7 \\
\hline 5 & 673 & 205 & 8.1 & 143.7 & 117 & 60 & 64 & 13.8 & 2.8 & 13.5 & 6.5 \\
\hline 18 & 973 & 250 & 8.1 & 214.4 & 186 & 73 & 72 & 25.0 & 2.5 & 16.0 & 8.0 \\
\hline & 374 & 180 & 7.2 & 123.3 & 105 & 48 & 52 & 14.0 & 2.7 & 10.0 & 5.5 \\
\hline & 874 & 440 & 8.0 & 299.6 & 248 & 129 & 115 & 38.0 & 1.8 & 26.0 & 15.6 \\
\hline & 1174 & 430 & 7.7 & 277.7 & 229 & 114 & 105 & 36.0 & 2.0 & 22.0 & 14.4 \\
\hline 8 & 175 & 155 & 7.1 & 118.0 & 88 & 61 & 54 & 12.0 & 3.5 & 14.0 & 6.3 \\
\hline 8 & 175 & 153 & 7.1 & 113.3 & 87 & 81 & 50 & 12.0 & 3.6 & 14.0 & 6.3 \\
\hline 8 & 175 & 153 & 7.0 & 112.1 & 105 & 57 & 50 & 11.5 & 3.4 & 13.0 & 6.0 \\
\hline 10 & 175 & 147 & 7.0 & 115.6 & 106 & 53 & 56 & 11.0 & 3.7 & 12.0 & 5.7 \\
\hline 12 & 175 & 135 & 7.0 & 104.4 & 96 & 45 & 54 & 9.0 & 3.9 & 11.0 & 4.3 \\
\hline 13 & 175 & 130 & 7.1 & 97.3 & 90 & 43 & 52 & 3.5 & 4.2 & 10.0 & 4.3 \\
\hline 13 & 175 & 130 & 7.0 & 101.8 & 90 & 43 & 52 & 8.0 & 4.2 & 10.0 & 4.3 \\
\hline 13 & 175 & 130 & 6.9 & 98.8 & 88 & 44 & 50 & 8.5 & 4.2 & 10.5 & 4.3 \\
\hline 16 & 175 & 155 & 7.1 & 125.1 & 103 & 60 & 66 & 9.5 & 4.3 & 14.0 & 6.0 \\
\hline 16 & 175 & 155 & 7.0 & 122.8 & 106 & 58 & 66 & 9.0 & 4.0 & 13.5 & 6.0 \\
\hline 16 & 175 & 157 & 7.2 & 134.5 & 119 & 62 & 66 & 9.5 & 3.9 & 14.5 & 0.3 \\
\hline 16 & 175 & 157 & 7.1 & 124.8 & 106 & 62 & 66 & 9.5 & 4.2 & 14.5 & 6.3 \\
\hline 20 & 175 & 142 & 7.1 & 108.4 & 99 & 50 & 54 & 9.5 & 3.9 & 12.0 & 4.8 \\
\hline 20 & 175 & 142 & 7.0 & 106.7 & 95 & 47 & 54 & 9.0 & 3.8 & 11.0 & 4.7 \\
\hline 20 & 175 & 142 & 7.1 & 108.7 & 96 & 47 & 56 & 9.0 & 3.8 & 11.0 & 4.7 \\
\hline 21 & 175 & 160 & 7.1 & 119.6 & 107 & 54 & 62 & 10.0 & 4.2 & 13.0 & 5.2 \\
\hline 21 & 175 & 160 & 7.1 & 121.2 & 104 & 51 & 64 & 10.0 & 4.2 & 11.5 & 5.3 \\
\hline 21 & 175 & 160 & 7.1 & 121.7 & 107 & 52 & 64 & 10.0 & 4.2 & 12.0 & 5.3 \\
\hline & 175 & 172 & 7.1 & 131.2 & 110 & 57 & 68 & 11.0 & 4.0 & 13.0 & .6 .0 \\
\hline 22 & 175 & 175 & 7.2 & 131.0 & 112 & 56 & 68 & 11.0 & 4.1 & 13.0 & 5.7 \\
\hline 22 & 175 & 170 & 7.2 & 133.0 & 112 & 56 & 70 & 11.0 & 4.1 & 13.0 & 5.7 \\
\hline 24 & 175 & 185 & 7.2 & 143.8 & 117 & 60 & 75 & 11.5 & 4.1 & 14.0 & 6.0 \\
\hline 24 & 1 75 & 187 & 7.2 & 145.8 & 121 & 65 & 75 & 11.5 & 4.1 & 16.0 & 6.0 \\
\hline 24 & 175 & 185 & 7.2 & 158.6 & 135 & 65 & 74 & 11.5 & 4.1 & 16.0 & 6.0 \\
\hline & 175 & 197 & 7.2 & 151.4 & 121 & 63 & 80 & 13.0 & 3.9 & 15.0 & 6.3 \\
\hline & 275 & 220 & 7.4 & 162.4 & 131 & 68 & 82 & 16.0 & 3.7 & 15.5 & 7.0 \\
\hline $2 \theta$ & 975 & 370 & 7.6 & 237.4 & 195 & 99 & 102 & 29.0 & 2.2 & 20.0 & 12.0 \\
\hline 15 & 1275 & 115 & 7.6 & 75.4 & 75 & 24 & 28 & 10.0 & 3.1 & 5.3 & 2.7 \\
\hline 5 & 876 & 555 & 8.4 & 351.3 & 295 & 164 & 125 & 50.0 & 1.6 & 36.0 & 18.0 \\
\hline 25 & 1076 & 670 & 8.0 & 409.7 & 342 & 186 & 140 & 60.0 & 2.0 & 38.0 & 22.0 \\
\hline 15 & 1276 & 325 & 8.0 & 247.5 & 185 & 101 & 119 & 26.0 & 4.2 & 24.0 & 10.0 \\
\hline 10 & 977 & 250 & 7.5 & 157.3 & 138 & 67 & 62 & 20.0 & 2.5 & 16.0 & 6.6 \\
\hline 18 & 477 & 350 & 8.1 & 233.2 & 196 & 100 & 100 & 29.0 & 2.0 & 22.0 & 11.0 \\
\hline 26 & 777 & 380 & 8.2 & 256.9 & 206 & 104 & 116 & 30.0 & 2.4 & 22.0 & 12.0 \\
\hline 4 & 1077 & 460 & 8.1 & 346.8 & 276 & 138 & 146 & 40.0 & 2,4 & 29.0 & 16.0 \\
\hline 5 & 178 & 405 & 8.1 & 292.8 & 238 & 122 & 115 & 37.0 & 3.6 & 24.0 & 15.0 \\
\hline 20 & 1178 & 330 & 7.9 & 223.5 & 177 & 99 & 96 & 28.0 & 3.2 & 23.0 & 10.0 \\
\hline 2 & 680 & 375 & 7.3 & 228.7 & 201 & 104 & 80 & 32.0 & 1.4 & 22.0 & 12.0 \\
\hline 18 & 980 & 400 & 7.5 & 253.9 & 217 & 107 & 89 & 38.0 & 1.6 & 23.0 & 12.0 \\
\hline 131 & 1180 & 460 & 7.8 & 284.8 & 242 & 112 & 91 & 45.0 & 2.3 & 20.0 & 15.0 \\
\hline 23 & 781 & 248 & 7.7 & 176.7 & 139 & 71 & 85 & 18.0 & 3.1 & 15.0 & 8.1 \\
\hline 19 & $\begin{array}{ll}8 \quad 82\end{array}$ & 260 & 7.9 & 167.0 & 150 & 63 & 61 & 27.0 & 1.7 & 13.0 & 7.5 \\
\hline 15 & 384 & 165 & 8.2 & 129.0 & 100 & 53 & 60 & 13.0 & 3.9 & 12.0 & 5.6 \\
\hline 18 & $\begin{array}{ll}6 \quad 84\end{array}$ & 290 & 6.9 & 196.9 & 160 & 77 & 82 & 26.0 & 3.5 & 17.0 & 8.4 \\
\hline 17 & $\begin{array}{ll}9 & 84\end{array}$ & 200 & 7.4 & 157.0 & 120 & 65 & 78 & 15.0 & 3.8 & 15.0 & 6.8 \\
\hline 41 & 1284 & 250 & 7.4 & 161.2 & 140 & 61 & 67 & 23.0 & 4.0 & 14.0 & 6.2 \\
\hline 4 & 385 & 265 & 7.4 & 184.0 & 150 & 72 & 77 & 22.0 & 3.8 & 16.0 & 7.8 \\
\hline $\begin{array}{ll}3 & 1\end{array}$ & 1285 & 205 & 7.9 & 137.9 & 130 & 51 & 55 & 18.0 & 4.0 & 12.0 & 5.0 \\
\hline 13 & 386 & 205 & 8.3 & 154 & 120 & 66 & 80 & 13.0 & 4.0 & 16.0 & 8.2 \\
\hline 24 & 686 & 225 & 8.0 & 174.9 & 140 & 72 & 81 & 19.0 & 3.6 & 16.0 & 7.8 \\
\hline 20 & 986 & 335 & 8.3 & 234.9 & 180 & 104 & 105 & 28.0 & 3.8 & 22.0 & 12.0 \\
\hline 7 & 187 & 225 & 7.8 & 267.3 & 130 & 63 & 73 & 18.0 & 4.1 & 15.0 & 6.1 \\
\hline & $\begin{array}{ll}387\end{array}$ & 220 & 7.7 & 185.7 & 140 & 69 & 83 & 17.0 & 4.7 & 16.0 & 7.0 \\
\hline 161 & 1287 & 185 & 7.5 & 118.7 & 99 & 51 & 51 & 12.5 & 3.3 & 12.0 & 5.2 \\
\hline 41 & 1088 & 200 & 7.1 & 128 & 110 & 55 & 51 & 15.5 & 2.8 & 13.0 & 5.5 \\
\hline 26 & $\begin{array}{ll}6 \quad 89\end{array}$ & 330 & 7.8 & 175.6 & 150 & 72 & 76 & 24.0 & 2.2 & 15.0 & 8.4 \\
\hline 81 & 1289 & 210 & 8.0 & 155.5 & 130 & 59 & 65 & 20.0 & 2.8 & 13.0 & 6.4 \\
\hline
\end{tabular}

Source: Queensland Water Resources Commission Surtace Water Resources Branch Water Quality Data System 
comparison, using the same data and assumptions, of the entropy based technique with other estimation techniques on the basis of their performances in prediction as undertaken later in this chapter is valid. Furthermore, the method(s) can be evaluated in an absolute sense, on the basis or in the sense of how well they predict (known) values in a verification step in spite of the problems (shortcomings) in the data used for calibration.

The annual mean values calculated for the data from Table 5.I are presented in Table 5.2 and for the other sets of data are presented in Appendix A, Tables A.2(a) to A.2(C). The choice of which of the water quality parameters measured at each station would be used in this demonstration was based upon the completeness and length of the record for each parameter. Following review of the records at the stations, the following parameters were selected for analysis: Conductivity, PH, Dissolved Ions, Dissolved Solids, Hardness, Alkalinity, Natrium, Kalium, Calcium and Magnesium.

\subsection{APPLICATION OF THE MODEL}

In this section, the steps required to calibrate and then apply the model are described. 
Table 5.2 Annual Mean Values of the Water Quality Parameters from the MacKenzie River Sub-Basin

Table 5.2(a) Station 130401

\begin{tabular}{|c|c|c|c|c|c|c|c|c|c|c|}
\hline YEAR & $\begin{array}{c}\text { CONDUCTIVITY } \\
\text { @ 25C } \\
(\mathrm{mS} / \mathrm{m}) \\
\end{array}$ & $\mathrm{PH}$ & $\begin{array}{c}\text { DISSOLVED } \\
\text { IONS } \\
\text { (mg/l) }\end{array}$ & $\begin{array}{c}\text { DISSOLVED } \\
\text { SOLIDS } \\
\text { (mg/) }\end{array}$ & $\begin{array}{c}\text { HARDNESS } \\
\text { (mgl)as CaCo3 }\end{array}$ & $\begin{array}{c}\text { ALKALINITY } \\
\text { (mg/)as CaCo3 }\end{array}$ & $\begin{array}{l}\text { NATRIUM } \\
\text { (mg/l) }\end{array}$ & $\begin{array}{l}\text { KALIUM } \\
(\mathrm{mg} / \mathrm{l}) \\
\end{array}$ & $\begin{array}{l}\text { CALCIUM } \\
(\mathrm{mg} / \mathrm{l})\end{array}$ & $\begin{array}{c}\text { MAGNESIUM } \\
\text { (mg/l) } \\
\end{array}$ \\
\hline 71 & 270.0 & 7.6 & 196.1 & - & 78.0 & 82.7 & 29.0 & - & 15.3 & 9.7 \\
\hline 72 & 351.3 & 7.9 & 265.9 & - & 102.8 & 104.0 & 41.5 & - & 24.3 & 10.3 \\
\hline 73 & 237.8 & 7.6 & 173.8 & 140.8 & 73.5 & 70.0 & 21.7 & 1.7 & 15.1 & 8.7 \\
\hline 74 & 471.0 & 8.3 & 301.0 & 249.5 & 136.5 & 115.5 & 37.0 & 1.3 & 27.0 & 16.8 \\
\hline 75 & 350.0 & 8.1 & 211.4 & 176.0 & 89.0 & 83.5 & 27.0 & 2.2 & 19.0 & 10.1 \\
\hline 76 & 550.0 & 8.1 & 359.4 & 303.0 & 157.7 & 126.3 & 49.3 & 1.7 & 34.0 & 17.7 \\
\hline 77 & 311.0 & 7.8 & 204.3 & 174.2 & 86.4 & 83.0 & 25.7 & 1.7 & 18.8 & 9.6 \\
\hline 78 & 457.5 & 7.9 & 304.9 & 263.0 & 129.0 & 106.5 & 43.0 & 1.2 & 26.0 & 15.5 \\
\hline 79 & 660.0 & 7.6 & 411.0 & 343.0 & 181.0 & 145.0 & 59.0 & 2.0 & 36.0 & 22.0 \\
\hline 80 & 429.0 & 7.5 & 269.6 & 231.8 & 113.0 & 99.4 & 37.8 & 1.6 & 22.8 & 13.6 \\
\hline 81 & 425.0 & 8.0 & 200.8 & 218.5 & 106.5 & 50.0 & 36.5 & 1.3 & 22.0 & 12.5 \\
\hline 82 & 316.7 & 8.1 & 200.7 & 173.3 & 83.3 & 76.0 & 27.7 & 1.3 & 17.7 & 9.5 \\
\hline 84 & 332.5 & 8.0 & 219.3 & 185.0 & 83.5 & 83.0 & 32.0 & 1.7 & 17.5 & 9.7 \\
\hline 85 & 283.3 & 7.5 & 176.7 & 156.7 & 72.0 & 64.7 & 25.0 & 1.9 & 15.3 & 8.2 \\
\hline 86 & 276.7 & 7.8 & 182.6 & 150.0 & 75.7 & 72.0 & 24.0 & 2.2 & 17.0 & 8.1 \\
\hline
\end{tabular}

Table 5.2(b) Station 130106

\begin{tabular}{|c|c|c|c|c|c|c|c|c|c|c|}
\hline YEAR & $\begin{array}{c}\text { CONDUCTIVITY } \\
\text { @ 25C } \\
(\mathrm{mS} / \mathrm{m})\end{array}$ & $\mathrm{PH}$ & $\begin{array}{c}\text { DISSOLVED } \\
\text { IONS } \\
\text { (mg/l) } \\
\end{array}$ & $\begin{array}{c}\text { DISSOLVED } \\
\text { SOLIDS } \\
(\mathrm{mg} / \mathrm{l})\end{array}$ & $\begin{array}{c}\text { HARDNESS } \\
\text { (mg/)as } \mathrm{CaCO} 3 \\
\end{array}$ & $\begin{array}{c}\text { ALKALINITY } \\
\text { (mg/)as } \mathrm{CaCO} 3\end{array}$ & $\begin{array}{l}\text { NATRIUM } \\
\text { (mg/l) }\end{array}$ & $\begin{array}{l}\text { KALIUM } \\
\text { (mg/i) }\end{array}$ & $\begin{array}{l}\text { CALCIUM } \\
\text { (mg/) }\end{array}$ & $\begin{array}{c}\text { MAGNESIUM } \\
\text { (mg/l) } \\
\end{array}$ \\
\hline 71 & 230.0 & 7.4 & 199.3 & - & 91.0 & 110.0 & 18.0 & - & 28.0 & 5.0 \\
\hline 72 & 204.8 & 7.4 & 167.1 & - & 78.6 & 80.6 & 17.0 & - & 17.5 & 8.5 \\
\hline 73 & 146.7 & 7.4 & 135.8 & 100.3 & 61.7 & 72.0 & 8.5 & 4.9 & 14.4 & 6.2 \\
\hline 74 & 168.6 & 7.8 & 136.1 & 104.2 & 61.7 & 71.8 & 10.3 & 3.4 & 14.5 & 6.2 \\
\hline 75 & 192.2 & 7.4 & 151.0 & 117.3 & 65.7 & 82.0 & 11.0 & 4.2 & 15.5 & 6.6 \\
\hline 76 & 410.0 & 8.0 & 347.2 & 257.0 & 162.0 & 175.0 & 27.0 & 3.6 & 35.0 & 18.0 \\
\hline 77 & 240.6 & 7.9 & 198.6 & 151.4 & 85.2 & 102.6 & 18.9 & 3.8 & 19.3 & 9.0 \\
\hline 78 & 160.0 & 7.7 & 127.5 & 100.5 & 55.0 & 66.0 & 11.5 & 3.5 & 13.0 & 5.4 \\
\hline 79 & 340.0 & 7.6 & 257.6 & 199.0 & 101.0 & 118.0 & 30.0 & 4.0 & 24.0 & 10.0 \\
\hline 80 & 230.3 & 7.4 & 165.9 & 135.0 & 69.3 & 75.7 & 19.0 & 3.7 & 16.3 & 6.9 \\
\hline 81 & 199.3 & 7.8 & 151.0 & 114.8 & 58.8 & 79.8 & 14.6 & 3.9 & 13.0 & 6.4 \\
\hline 82 & 211.3 & 7.9 & 163.3 & 122.5 & 72.5 & 87.0 & 13.6 & 3.8 & 17.3 & 7.1 \\
\hline 84 & 206.7 & 7.7 & 161.3 & 123.3 & 62.0 & 76.3 & 16.3 & 3.7 & 14.7 & 6.2 \\
\hline 85 & 242.5 & 7.5 & 166.2 & 140.0 & 65.5 & 67.5 & 22.0 & 3.0 & 15.0 & 6.8 \\
\hline 86 & 185.0 & 6.4 & 150.2 & 110.0 & 61.0 & 80.0 & 13.5 & 3.4 & 15.0 & 5.6 \\
\hline
\end{tabular}


Table 5.2(c) Station 130105

\begin{tabular}{|c|c|c|c|c|c|c|c|c|c|c|}
\hline YEAR & $\begin{array}{c}\text { CONDUCTIVITY } \\
\text { @ 25C } \\
\text { (ms/m) }\end{array}$ & PH & $\begin{array}{l}\text { DISSOLVED } \\
\text { IONS } \\
(\mathrm{mg} / \mathrm{l})\end{array}$ & $\begin{array}{c}\text { DISSOLVED } \\
\text { SOLIOS } \\
(\mathrm{mg} / \mathrm{l})\end{array}$ & $\begin{array}{l}\text { HARDNESS } \\
\text { (mg/l)as } \mathrm{CaCO} 3\end{array}$ & $\begin{array}{c}\text { ALKALINITY } \\
\text { (mg/)as CaCO3 }\end{array}$ & $\begin{array}{l}\text { Nataium } \\
\text { (mg/l) }\end{array}$ & $\begin{array}{l}\text { KALIUM } \\
\text { (mg/l) }\end{array}$ & $\begin{array}{l}\text { CALCIUM } \\
\text { (mg/L) }\end{array}$ & $\begin{array}{l}\text { MAGNESIUM } \\
\text { (mg/l) }\end{array}$ \\
\hline 71 & - & - & - & - & - & - & - & - & - & - \\
\hline 72 & 290.0 & 7.7 & 199.7 & 148.5 & 80.5 & 82.0 & 29.0 & - & 17.5 & 9.0 \\
\hline 73 & 215.0 & 7.8 & 159.6 & 135.8 & 61.8 & 64.0 & 18.2 & 2.4 & 13.1 & 7.1 \\
\hline 74 & 350.0 & 7.6 & 233.5 & 194.0 & 97.0 & 90.7 & 29.3 & 2.2 & 19.3 & 11.8 \\
\hline 75 & 235.0 & 7.5 & 158.4 & 133.7 & 63.7 & 68.5 & 16.3 & 3.2 & 13.4 & 6.8 \\
\hline 76 & 516.7 & 8.1 & 336.2 & 274.0 & 150.3 & 128.0 & 45.3 & 2.6 & 32.7 & 16.7 \\
\hline 77 & 360.0 & 8.0 & 248.6 & 204.0 & 102.3 & 106.0 & 29.8 & 2.3 & 22.3 & 10.6 \\
\hline 78 & 367.5 & 8.0 & 258.2 & 207.5 & 110.5 & 105.5 & 32.5 & 3.4 & 23.5 & 12.5 \\
\hline 79 & - & - & - & - & - & - & - & - & - & - \\
\hline 80 & 411.7 & 7.5 & 255.8 & 220.0 & 107.7 & 86.7 & 38.3 & 1.8 & 21.7 & 13.0 \\
\hline 81 & 248.0 & 7.7 & 176.7 & 139.0 & 71.0 & 85.0 & 18.0 & 3.1 & 15.0 & 8.1 \\
\hline 82 & 260.0 & 7.9 & 167.0 & 150,0 & 63.0 & 61.0 & 27.0 & 1.7 & 13.0 & 7.5 \\
\hline 84 & 226.3 & 7.5 & 161.0 & 130.0 & 64.0 & 71.8 & 19.3 & 3.8 & 14.5 & 6.8 \\
\hline 85 & 235.0 & 7.7 & 161.0 & 140.0 & 61.5 & 66.0 & 20.0 & 3.9 & 14.0 & 6.4 \\
\hline 86 & 255.0 & 8.2 & 187.9 & 146.7 & 80.7 & 88.7 & 20.0 & 3.8 & 18.0 & 8.7 \\
\hline
\end{tabular}


The data described in the previous section were split into two groups, one to calibrate the model, the other to test how well the model performs. In the calibration phase the data are used to :

i. develop the probability distributions of each of the water quality parameters at each monitoring station, and

ii. develop the relationship or 'information functions' (see Equations 4.18) between the observed downstream values and the upstream values for each parameter as described in section 4.3.3.

An example of how the data from the data set shown in Table 5.2 are split into calibration and verification sets is shown in Table 5.3. In this case, the first group of data contains the records from year 1971 to 1980 and the other, records from 1981 to 1986. It can be seen in Table 5.3 that the data sets for the calibration step are larger than those for the verification or validation step. This choice of relative sizes of data sets for the two steps was based on a decision to have a larger set of data in the calibration step in order to provide a sufficient number of data points for a more reliable development of Equation 4.18 when moving average values are used. 
Table 5.3 Annual Mean Values of the Water Quality Parameters (Grouped) from the Mackenzie River Sub-Basin

Table 5.3(a) Station 130401

(Calibration set)

\begin{tabular}{|c|c|c|c|c|c|c|c|c|c|c|}
\hline YEAR & $\begin{array}{c}\text { CONDUCTIVITY } \\
@ 250 \\
(\mathrm{mS} / \mathrm{m})\end{array}$ & $\mathrm{PH}$ & $\begin{array}{c}\text { DissolvEd } \\
\text { IONS } \\
\text { (mgft }\end{array}$ & $\begin{array}{c}\text { DISSOLVED } \\
\text { SOLIDS } \\
\text { (mg/l) }\end{array}$ & $\begin{array}{l}\text { HARDNESS } \\
\text { (mg/)as } \mathrm{CaCOa}\end{array}$ & $\begin{array}{l}\text { ALKALINITY } \\
\text { (mg/)ea } \mathrm{CaCO} \\
\end{array}$ & $\begin{array}{l}\text { NATHIUA } \\
\text { (mg/l) } \\
\end{array}$ & $\begin{array}{l}\text { KALIUM } \\
\text { (mg/) } \\
\end{array}$ & $\begin{array}{l}\text { CALCIUM } \\
\text { (mgn) }\end{array}$ & $\begin{array}{c}\text { MAQNESIUM } \\
\text { (mg/) } \\
\end{array}$ \\
\hline 71 & 270.0 & 7.6 & 196.1 & - & 78.0 & 82.7 & 29.0 & - & 15.3 & 9.7 \\
\hline 72 & 351.3 & 7.9 & 265.9 & - & 102.8 & 104.0 & 41.5 & - & 24.3 & 10.3 \\
\hline 73 & 237.8 & 7.6 & 173.8 & 140.8 & 73.5 & 70.0 & 21.7 & 1.7 & 15.1 & 8.7 \\
\hline 74 & 471.0 & 8.3 & 301.0 & 249.5 & 136.5 & 115.5 & 37.0 & 1.3 & 27.0 & 16.8 \\
\hline 75 & 350.0 & 8.1 & 211.4 & 176.0 & 89.0 & 83.5 & 27.0 & 2.2 & 19.0 & 10.1 \\
\hline 76 & 550.0 & 8.1 & 359.4 & 303.0 & 157.7 & 126.3 & 49.3 & 1.7 & 34.0 & 17.7 \\
\hline 77 & 311.0 & 7.8 & 204.3 & 174.2 & 86.4 & 83.0 & 25.7 & 1.7 & 18.8 & 9.6 \\
\hline 78 & 457.5 & 7.9 & 304.9 & 263.0 & 129.0 & 106.5 & 43.0 & 1.2 & 26.0 & 15.5 \\
\hline 79 & 660.0 & 7.6 & 411.0 & 343.0 & 181.0 & 145.0 & 59.0 & 2.0 & 36.0 & 22.0 \\
\hline 80 & 429.0 & 7.5 & 269.6 & 231.8 & 113.0 & 99.4 & 37.8 & 1.6 & 22.8 & 13.6 \\
\hline Mean & 408.8 & 7.8 & 269.7 & 235.2 & 114.7 & 101.6 & 37.1 & 1.7 & 23.8 & 13.4 \\
\hline $\begin{array}{l}\text { Standard } \\
\text { Deviation }\end{array}$ & 131.0 & 0.3 & 76.4 & 68.1 & 35.9 & 23.0 & 11.6 & 0.3 & 7.2 & 4.5 \\
\hline
\end{tabular}

(Validation set)

\begin{tabular}{|c|c|c|c|c|c|c|c|c|c|c|}
\hline YEAP & $\begin{array}{c}\text { CONDUCTIVITY } \\
\text { @25C } \\
\text { (mS/m) }\end{array}$ & PH & $\begin{array}{c}\text { DISSOLVEO } \\
\text { IONS } \\
\text { (mgll) }\end{array}$ & $\begin{array}{c}\text { DISSOLVED } \\
\text { SOLIOS } \\
\text { (mgli) }\end{array}$ & $\begin{array}{l}\text { HARONESS } \\
\text { (mg/l)as CaCOB }\end{array}$ & $\begin{array}{l}\text { ALKALINITY } \\
\text { (mg/)as } \mathrm{CACO}_{\mathrm{C}}\end{array}$ & $\begin{array}{l}\text { NATFIUA } \\
\text { (mg/l) }\end{array}$ & $\begin{array}{l}\text { KALIUM } \\
(\mathrm{mg} / \mathrm{l})\end{array}$ & $\begin{array}{l}\text { CALCIUM } \\
\text { (mg/l) }\end{array}$ & $\begin{array}{c}\text { MAGNESIUM } \\
\text { (mgli) }\end{array}$ \\
\hline (1 yearly) & & & & & & & & & & \\
\hline 81 & 425.0 & 8.0 & 200.8 & 218.5 & 106.5 & 50.0 & 36.5 & 1.3 & 22.0 & 12.5 \\
\hline 82 & 316.7 & 8.1 & 200.7 & 173.3 & 83.3 & 76.0 & 27.7 & 1.3 & 17.7 & 9.5 \\
\hline 84 & 332.5 & 8.0 & 219.3 & 185.0 & 83.5 & 83.0 & 32.0 & 1.7 & 17.5 & 9.7 \\
\hline 85 & 283.3 & 7.5 & 176.7 & 156.7 & 72.0 & 64.7 & 25.0 & 1.9 & 15.3 & 8.2 \\
\hline 86 & 276.7 & 7.8 & 182.6 & 150.0 & 75.7 & 72.0 & 24.0 & 2.2 & 17.0 & 8.1 \\
\hline (2 yearly) & & & & & & & & & & \\
\hline Mean \# 1 & 370.8 & 8.1 & 200.7 & 195.9 & 94.9 & 63.0 & 32.1 & 1.3 & 19.8 & 11.0 \\
\hline Mean \#2 & 324.6 & 8.1 & 210.0 & 179.2 & 83.4 & 79.5 & 29.8 & 1.5 & 17.6 & 9.6 \\
\hline Mean \#3 & 307.9 & 7.8 & 198.0 & 170.8 & 77.8 & 73.8 & 28.5 & 1.8 & 16.4 & 8.9 \\
\hline Mean \#4 & 280.0 & 7.7 & 179.7 & 153.3 & 73.8 & 68.3 & 24.5 & 2.1 & 16.2 & 8.1 \\
\hline (3 yesrly) & & & & & & & & & & \\
\hline Mean \#5 & 358.1 & 8.0 & 206.9 & 192.3 & 91.1 & 69.7 & 32.1 & 1.4 & 19.1 & 10.6 \\
\hline Mean \#6 & 310.8 & 7.9 & 198.9 & 171.7 & 79.6 & 74.6 & 28.2 & 1.6 & 16.8 & 9.1 \\
\hline Mean \#7 & 297.5 & 7.8 & 192.9 & 163.9 & 77.1 & 73.2 & 27.0 & 1.9 & 16.6 & 8.6 \\
\hline$\{4$ yearly $\}$ & & & & & & & & & & \\
\hline Mean \#8 & 339.4 & 7.9 & 199.4 & 183.4 & 86.3 & 68.4 & 30.3 & 1.6 & 18.1 & 10.0 \\
\hline Mean \#9 & 302.3 & 7.9 & 194.8 & 166.3 & 78.6 & 73.9 & 27.2 & 1.8 & 16.9 & 8.9 \\
\hline
\end{tabular}

Note: $\quad$ Mean \#1 = Mean of years 81,82 Mean $\# 2=$ Mean of years 82,84 Mean \#3 = Mean of years 84,85 Mean \#4 = Mean of years 85,86 Mean \#5 $=$ Mean of years $81,82,84$
Mean \#6 = Mean of years $82,84,85$ Mean \#7 = Mean of years $84,85,86$ Mean \#8 = Mean of years $81,82,84,85$ Mean \#9 = Mean of years $82,84,85,86$ 
Table 5.3(b) Station 130106

(Calibration set)

\begin{tabular}{|c|c|c|c|c|c|c|c|c|c|c|}
\hline YEAR & $\begin{array}{c}\text { CONDUCTIVITY } \\
\text { @ 25C } \\
(\mathrm{mS} / \mathrm{m})\end{array}$ & PH & $\begin{array}{c}\text { OISSOLVED } \\
\text { IONS } \\
\text { (mg/) }\end{array}$ & $\begin{array}{c}\text { DISSOLVEO } \\
\text { SOLIDS } \\
\text { (mg)) }\end{array}$ & $\begin{array}{l}\text { HARONESS } \\
\text { (mg/)as } \mathrm{CaCO} 3 \\
\end{array}$ & $\begin{array}{l}\text { ALKALINITY } \\
\text { (mg/)as } \mathrm{CaCO} 3 \\
\end{array}$ & $\begin{array}{l}\text { NATRIUM } \\
\text { (mg/l) }\end{array}$ & $\begin{array}{l}\text { KaLIUM } \\
\text { (mg/) } \\
\end{array}$ & $\begin{array}{l}\text { CALCIUM } \\
\text { (mgfl) }\end{array}$ & $\begin{array}{c}\text { MAGNESIUM } \\
(\mathrm{mg} / \mathrm{l}) \\
\end{array}$ \\
\hline 71 & 230.0 & 7.4 & 199.3 & - & 91.0 & 110.0 & 18.0 & - & 28.0 & 5.0 \\
\hline 72 & 204.8 & 7.4 & 167.1 & - & 78.6 & 80.6 & 17.0 & - & 17.5 & 8.5 \\
\hline 73 & 146.7 & 7.4 & 135.8 & 100.3 & 61.7 & 72.0 & 8.5 & 4.9 & 14.4 & 6.2 \\
\hline 74 & 168.6 & 7.8 & 136.1 & 104.2 & 61.7 & 71.8 & 10.3 & 3.4 & 14.5 & 6.2 \\
\hline 75 & 192.2 & 7.4 & 151.0 & 117.3 & 65.7 & 82.0 & 11.0 & 4.2 & 15.5 & 6.6 \\
\hline 76 & 410.0 & 8.0 & 347.2 & 257.0 & 162.0 & 175.0 & 27.0 & 3.6 & 35.0 & 18.0 \\
\hline 77 & 240.6 & 7.9 & 198.6 & 151.4 & 85.2 & 102.6 & 18.9 & 3.8 & 19.3 & 9.0 \\
\hline 78 & 160.0 & 7.7 & 127.5 & 100.5 & 55.0 & 66.0 & 11.5 & 3.5 & 13.0 & 5.4 \\
\hline 79 & 340.0 & 7.6 & 257.6 & 199.0 & 101.0 & 118.0 & 30.0 & 4.0 & 24.0 & 10.0 \\
\hline 80 & 230.3 & 7.4 & 165.9 & 135.0 & 69.3 & 75.7 & 19.0 & 3.7 & 16.3 & 6.9 \\
\hline Mean & 232.3 & 7.6 & 188.6 & 145.6 & 83.1 & 95.4 & 17.1 & 3.9 & 19.8 & 8.2 \\
\hline $\begin{array}{l}\text { Standard } \\
\text { Deviation }\end{array}$ & 83.2 & 0.2 & 68.2 & 56.1 & 31.3 & 33.1 & 7.2 & 0.5 & 7.1 & 3.8 \\
\hline
\end{tabular}

(Validation set)

\begin{tabular}{|c|c|c|c|c|c|c|c|c|c|c|}
\hline YEAR & $\begin{array}{c}\text { CONOUCTIVITY } \\
\text { 25C } \\
(\mathrm{mS} / \mathrm{m})\end{array}$ & $\mathrm{PH}$ & $\begin{array}{c}\text { OISSOLVED } \\
\text { tONS } \\
\text { (mgfl) }\end{array}$ & $\begin{array}{c}\text { OISSOLVED } \\
\text { solids } \\
\text { (mgli) }\end{array}$ & $\begin{array}{l}\text { HARDNESS } \\
\text { (mg/)as CaCO3 }\end{array}$ & $\begin{array}{l}\text { ALKALINITY } \\
\text { (mg/)as CaCO3 }\end{array}$ & $\begin{array}{l}\text { NATAIUM } \\
\text { (mg/l) }\end{array}$ & $\begin{array}{l}\text { KALIUM } \\
\text { (mg/f) }\end{array}$ & $\begin{array}{l}\text { CALCIUM } \\
\text { (mg/l) }\end{array}$ & $(\mathrm{mg} / \mathrm{l})$ \\
\hline (1 yearly) & & & & & & & & & & \\
\hline 81 & 199.3 & 7.8 & 151.0 & 114.8 & 58.8 & 79.8 & 14.6 & 3.9 & 13.0 & 6.4 \\
\hline 82 & 211.3 & 7.9 & 163.3 & 122.5 & 72.5 & 87.0 & 13.6 & 3.8 & 17.3 & 7.1 \\
\hline 84 & 206.7 & 7.7 & 161.3 & 123.3 & 62.0 & 76.3 & 16.3 & 3.7 & 14.7 & 6.2 \\
\hline 85 & 242.5 & 7.5 & 166.2 & 140.0 & 65.5 & 67.5 & 22.0 & 3.0 & 15.0 & 6.8 \\
\hline 86 & 185.0 & 6.4 & 150.2 & 110.0 & 61.0 & 80.0 & 13.5 & 3.4 & 15.0 & 5.6 \\
\hline (2 yeariy) & & & & & & & & & & \\
\hline Mean \#1 & 205.3 & 7.8 & 157.2 & 118.7 & 65.7 & 83.4 & 14.1 & 3.8 & 15.1 & 6.8 \\
\hline Mean \#2 & 209.0 & 7.8 & 162.3 & 122.9 & 67.3 & 81.7 & 15.0 & 3.8 & 16.0 & 6.6 \\
\hline Mean \#3 & 224.6 & 7.6 & 163.7 & 131.7 & 63.8 & 71.9 & 19.2 & 3.4 & 14.8 & 6.5 \\
\hline Mean \#4 & 213.8 & 6.9 & 158.2 & 125.0 & 63.3 & 73.8 & 17.8 & 3.2 & 15.0 & 6.2 \\
\hline (3 yearly) & & & & & & & & & & \\
\hline Mean \#5 & 205.8 & 7.8 & 158.5 & 120.2 & 64.4 & 81.1 & 14.9 & 3.8 & 15.0 & 6.6 \\
\hline Mean \#6 & 220.1 & 7.7 & 163.6 & 128.6 & 66.7 & 76.9 & 17.3 & 3.5 & 15.6 & 6.7 \\
\hline Mean \#7 & 211.4 & 7.2 & 159.2 & 124.4 & 62.8 & 74.6 & 17.3 & 3.4 & 14.9 & 6.2 \\
\hline (4 yeeriy) & & & & & & & & & & \\
\hline Mean \#8 & 214.9 & 7.7 & 160.4 & 125.2 & 64.7 & 77.7 & 16.6 & 3.6 & 15.0 & 6.6 \\
\hline Mean \#9 & 211.4 & 7.3 & 160.3 & 124.0 & 65.3 & 77.7 & 16.4 & 3.5 & 15.5 & 6.4 \\
\hline
\end{tabular}

Note: $\quad$ Mean $\# 1=$ Mean of years 81,82 Mean \#2 = Mean of years 82,84 Mean \#3 = Mean of years 84,85 Mean \#4 = Mean of years 85,86 Mean \#5 = Mean of years $81,82,84$
Mean \#6 = Mean of years $82,84,85$

Mean $\# 7=$ Mean of years $84,85,86$

Mean \#8 = Mean of years $81,82,84,85$

Mean $\# 9=$ Mean of years $82,84,85,86$ 
Table 5.3(c) Station 130105

(Calibration set)

\begin{tabular}{|c|c|c|c|c|c|c|c|c|c|c|}
\hline YEAR & $\begin{array}{c}\text { CONDUCTIVITY } \\
\text { @25C } \\
(\mathrm{mS} / \mathrm{m}) \\
\end{array}$ & PH & $\begin{array}{c}\text { DISSOLVED } \\
\text { IONS } \\
\text { (mg/l) } \\
\end{array}$ & $\begin{array}{c}\text { DISSOLVED } \\
\text { SOLIDS } \\
\text { (mg/) }\end{array}$ & $\begin{array}{c}\text { HARDNESS } \\
\text { (mg/)as } \mathrm{CaCO} 3\end{array}$ & $\begin{array}{c}\text { ALKALINITY } \\
(\mathrm{mg} /) \text { as } \mathrm{CaCO} 3 \\
\end{array}$ & $\begin{array}{l}\text { NATRIUM } \\
\text { (mg/l) }\end{array}$ & $\begin{array}{l}\text { KALIUM } \\
(\mathrm{mg} / \mathrm{l}) \\
\end{array}$ & $\begin{array}{l}\text { CaLcium } \\
\text { (mg/) }\end{array}$ & $\begin{array}{c}\text { MAGNESIUM } \\
\text { (mgll) } \\
\end{array}$ \\
\hline 71 & - & - & - & - & - & - & - & - & - & - \\
\hline 72 & 290.0 & 7.7 & 199.7 & 148.5 & 80.5 & 82.0 & 29.0 & - & 17.5 & 9.0 \\
\hline 73 & 215.0 & 7.8 & 159.6 & 135.8 & 61.8 & 64.0 & 18.2 & 2.4 & 13.1 & 7.1 \\
\hline 74 & 350.0 & 7.6 & 233.5 & 194.0 & 97.0 & 90.7 & 29.3 & 2.2 & 19.3 & 11.8 \\
\hline 75 & 235.0 & 7.5 & 158.4 & 133.7 & 63.7 & 68.5 & 16.3 & 3.2 & 13.4 & 6.8 \\
\hline 76 & 516.7 & 8.1 & 336.2 & 274.0 & 150.3 & 128.0 & 45.3 & 2.6 & 32.7 & 16.7 \\
\hline 77 & 360.0 & 8.0 & 248.6 & 204.0 & 102.3 & 106.0 & 29.8 & 2.3 & 22.3 & 10.6 \\
\hline 78 & 367.5 & 8.0 & 258.2 & 207.5 & 110.5 & 105.5 & 32.5 & 3.4 & 23.5 & 12.5 \\
\hline 79 & - & - & - & - & - & - & - & - & - & - \\
\hline 80 & 411.7 & 7.5 & 255.8 & 220.0 & 107.7 & 86.7 & 38.3 & 1.8 & 21.7 & 13.0 \\
\hline Mean & 343.2 & 7.8 & 231.2 & 189.7 & 96.7 & 91.4 & 29.8 & 2.2 & 20.4 & 10.9 \\
\hline $\begin{array}{l}\text { Standard } \\
\text { Deviation }\end{array}$ & 97.6 & 0.2 & 58.7 & 48.3 & 28.8 & 21.2 & 9.6 & 1.1 & 6.3 & 3.3 \\
\hline
\end{tabular}

(Validation set)

\begin{tabular}{|c|c|c|c|c|c|c|c|c|c|c|}
\hline YEAR & $\begin{array}{c}\text { CONDUCTIVITY } \\
@ 25 \mathrm{C} \\
(\mathrm{mS} / \mathrm{m}) \\
\end{array}$ & $\mathrm{PH}$ & $\begin{array}{c}\text { DISSOLVED } \\
\text { IONS } \\
\text { (mg/) } \\
\end{array}$ & $\begin{array}{c}\text { DISSOLVED } \\
\text { SOLIDS } \\
\text { (mg/i) } \\
\end{array}$ & $\begin{array}{c}\text { HARDNESS } \\
\text { (mg/i)as } \mathrm{CaCO} 3\end{array}$ & $\begin{array}{c}\text { ALKALINITY } \\
\text { (mg/l)as } \mathrm{CaCO} 3\end{array}$ & $\begin{array}{l}\text { NATRIUM } \\
\text { (mg/) }\end{array}$ & $\begin{array}{l}\text { KALIUM } \\
\text { (mg/l) }\end{array}$ & $\begin{array}{l}\text { CALCIUM } \\
\text { (mg/l) }\end{array}$ & $\begin{array}{c}\text { MAGNESIUM } \\
\text { (mg/l) }\end{array}$ \\
\hline (1 yearly) & & & & & & & & & & \\
\hline 81 & 248.0 & 7.7 & 176.7 & 139.0 & 71.0 & 85.0 & 18.0 & 3.1 & 15.0 & 8.1 \\
\hline 82 & 260.0 & 7.9 & 167.0 & 150.0 & 63.0 & 61.0 & 27.0 & 1.7 & 13.0 & 7.5 \\
\hline 84 & 226.3 & 7.5 & 161.0 & 130.0 & 64.0 & 71.8 & 19.3 & 3.8 & 14.5 & 6.8 \\
\hline 85 & 235.0 & 7.7 & 161.0 & 140.0 & 61.5 & 66.0 & 20.0 & 3.9 & 14.0 & 6.4 \\
\hline 86 & 255.0 & 8.2 & 187.9 & 146.7 & 80.7 & 88.7 & 20.0 & 3.8 & 18.0 & 8.7 \\
\hline (2 yearly) & & & & & & & & & & \\
\hline Mean \#1 & 254.0 & 7.8 & 171.9 & 144.5 & 67.0 & 73.0 & 22.5 & 2.4 & 14.0 & 7.8 \\
\hline Mean \#2 & 243.1 & 7.7 & 164.0 & 140.0 & 63.5 & 66.4 & 23.1 & 2.8 & 13.8 & 7.1 \\
\hline Mean $\# 3$ & 230.6 & 7.6 & 161.0 & 135.0 & 62.8 & 68.9 & 19.6 & 3.9 & 14.3 & 6.6 \\
\hline Mean \#4 & 245.0 & 7.9 & 174.4 & 143.3 & 71.1 & 77.3 & 20.0 & 3.9 & 16.0 & 7.5 \\
\hline (3 yearly) & & & & & & & & & & \\
\hline Mean \#5 & 244.8 & 7.7 & 168.2 & 139.7 & 66.0 & 72.6 & 21.4 & 2.9 & 14.2 & 7.5 \\
\hline Mean \#6 & 240.4 & 7.7 & 163.0 & 140.0 & 62.8 & 66.3 & 22.1 & 3.1 & 13.8 & 6.9 \\
\hline Mean \#7 & 238.8 & 7.8 & 170.0 & 138.9 & 68.7 & 75.5 & 19.8 & 3.8 & 15.5 & 7.3 \\
\hline (4 yearly) & & & & & & & & & & \\
\hline Mean $\# 8$ & 242.3 & 7.7 & 166.4 & 139.8 & 64.9 & 70.9 & 21.1 & 3.1 & 14.1 & 7.2 \\
\hline Mean \#9 & 244.1 & 7.8 & 169.2 & 141.7 & 67.3 & 71.9 & 21.6 & 3.3 & 14.9 & 7.3 \\
\hline
\end{tabular}

Note: $\quad$ Mean \#1 = Mean of years 81,82 Mean \#2 = Mean of years 82,84 Mean \#3= Mean of years 84,85 Mean \#4 = Mean of years 85,86 Mean \#5 = Mean of years $81,82,84$
Mean \#6 = Mean of years $82,84,85$

Mean \#7 = Mean of years $84,85,86$

Mean \#8 = Mean of years $81,82,84,85$

Mean \#9= Mean of years $82,84,85,86$ 
Recall that the prior probabilities, $q_{n i}$, reflect the historical conditions and are required as an integral part of the entropy prediction model. Hence the longer period of time in the calibration step is also preferred for obtaining the best picture of historical conditions for incorporation in the prior probabilities.

The missing data evident in the calibration data sets listed in Tables 5.2 and 5.3 did limit the number of data points which could be used for the calibration of the 2-year 3-year and 4-year moving average models. The limited number of points available for calibration does in turn reduce the confidence that can be placed in the calibrated model. The problem cannot be avoided for the data used to demonstrate the model in this thesis and is likely to be an issue in the application of the model to other watersheds. Prediction of water quality values by the approach should therefore be performed with a clear understanding of any limitations on the acuracy of the model imposed by small calibration data sets.

\subsubsection{DATA ANALYSIS}

After the data have been divided into calibration and validation sets, the data set assigned to the calibration step is, used to develop the probability 
density function for each parameter at each location (monitoring station). It should be noted that the model can only be used for estimation of the values of one water quality parameter at a time. Thus, in order to predict the values for different water quality parameters, the procedure has to be repeated using the probability distributions and relationship function associated with that parameter. The number of calculations therefore increases linearly with the number of parameters to be predicted.

\section{a. DETERMINING THE DISTRIBUTION}

After the mean annual average values of the water quality parameters had been determined from the calibration data set, the probability distribution functions for those parameters at each monitoring station were developed. Normality tests using the Saphiro-Wilk W test (Gilbert, 1987) were then conducted to determine whether the data conform to a normal distribution. (The procedure of the Saphiro-Wilk w test is presented in Appendix C). Table 5.4 shows the calculations and results for the normality tests for the water quality parameters listed in Table 5.3.

It can be seen in Table 5.4 that most of the water quality parameters follow normal distributions, and are 
Table 5.4 Normality Test for Data (SAPHIRO-WILK W TEST)

Table 5.4(a) Station 130401

1. Rank of the Data from the Smallest Value

\begin{tabular}{|c|c|c|c|c|c|c|c|c|c|c|}
\hline DATA \# & $\begin{array}{c}\text { CONDUCTVITY } \\
@ 25 \mathrm{C} \\
(\mathrm{mS} / \mathrm{m}) \\
\end{array}$ & $\mathrm{PH}$ & $\begin{array}{l}\text { DISSOLVED } \\
\text { IONS } \\
\text { (mg/) }\end{array}$ & $\begin{array}{c}\text { DISSOLVED } \\
\text { SOLIDS } \\
\text { (mgfl) } \\
\end{array}$ & $\begin{array}{l}\text { HARONESS } \\
\text { (mojlins cacos }\end{array}$ & $\begin{array}{l}\text { AL.KALINIT } \\
\text { Imeq I)as Caco3 }\end{array}$ & $\begin{array}{l}\text { NATRIUM } \\
\text { (mggll) }\end{array}$ & $\begin{array}{l}\text { KaLIUM } \\
\text { (mg/n) }\end{array}$ & $\begin{array}{c}\text { CALCIUM } \\
\text { (mg/li) } \\
\end{array}$ & $\begin{array}{c}\text { MAGNESIUM } \\
\text { (mmg/l) }\end{array}$ \\
\hline$x 1$ & 237.8 & 7.48 & 173.8 & 140.8 & 73.5 & 70.00 & 21.73 & 1,20 & 15.05 & 8.73 \\
\hline$x 2$ & 270.0 & 7.60 & 106.1 & 174.2 & 78.0 & 82.67 & 25.72 & 1.30 & 15.33 & 9.58 \\
\hline$x 3$ & 311.0 & 7.60 & 204.3 & 176.0 & 86.4 & 83.00 & 27.00 & 1.6 & 18.78 & 9.67 \\
\hline$\times 4$ & 350.0 & 7.63 & 211.4 & 231.8 & 89.0 & 83.50 & 29.00 & 1.67 & 19.00 & 10.10 \\
\hline$\times 5$ & 351.3 & 7.84 & 265.9 & 249.5 & 102.8 & 99.4 & 37.00 & 1.68 & 22.8 & 10.25 \\
\hline$\times 6$ & 429.0 & 7.85 & 269.6 & 263.0 & 113.0 & 104.00 & 37.8 & 1.70 & 24.25 & 13.60 \\
\hline$x 7$ & 457.5 & 7.85 & 301.0 & 303.0 & 129.0 & 106.50 & 41.50 & 2.00 & 26.00 & 15.50 \\
\hline$x 8$ & 471.0 & 8.07 & 304.9 & 343.0 & 136.5 & 115.50 & 43.00 & 2.15 & 27.00 & 16.80 \\
\hline$x 9$ & 550.0 & 8.10 & 359.4 & & 157.7 & 126.33 & 49.33 & & 34.00 & 17.67 \\
\hline$\times 10$ & 660.0 & 8.30 & 411.0 & & 181.0 & 145.00 & 59.00 & & 36.00 & 22.00 \\
\hline $\bar{x}$ & 408.8 & 7.8 & 269.7 & 235.2 & 114.7 & 101.6 & 37.1 & 1.7 & 23.8 & 13.4 \\
\hline
\end{tabular}

2. Computation of the Denominator $(=d)$

$d=\operatorname{sum}(x i-\bar{x})^{\wedge} 2$

\begin{tabular}{|c|c|c|c|c|c|c|c|c|c|c|}
\hline & \multicolumn{10}{|c|}{$(x i-x)^{\wedge} 2$} \\
\hline & 19251.56 & 0.04 & 5421.97 & 8912.54 & 1345.54 & 367.36 & 64.50 & 0.00 & 73.99 & 13.85 \\
\hline & 3306.25 & 0.00 & 14.89 & 205.74 & 142.36 & 4.69 & 19.97 & 0.14 & 0.10 & 9.85 \\
\hline & 29241.00 & 0.05 & 9208.13 & 3499.46 & 1695.93 & 1013.36 & 234.27 & 0.23 & 78.94 & 21.75 \\
\hline & 3875.06 & 0.22 & 974.44 & 4602.77 & 476.04 & 186.78 & 0.00 & 0.00 & 9.40 & 11.64 \\
\hline & 3451.56 & 0.07 & 3402.86 & 3715.66 & 659.55 & 336.11 & 100.62 & 0.00 & 24.35 & 10.82 \\
\hline & 19951.56 & 0.06 & 8039.99 & 775.27 & 1847.71 & 600.25 & 151.35 & 0.22 & 101.31 & 18.30 \\
\hline & 9555.06 & 0.00 & 4281.61 & 11630.27 & 799.85 & 354.69 & 127.94 & 0.11 & 26.57 & 14.51 \\
\hline & 2376.56 & 0.00 & 1236.65 & 11.26 & 205.01 & 21.78 & 35.63 & 0.00 & 4.26 & 4.46 \\
\hline & 63126.56 & 0.05 & 19956.08 & & 4398.12 & 1863.36 & 482.64 & & 145.57 & 74.15 \\
\hline & 410.06 & 0.12 & 0.01 & & 2.83 & 5.92 & 0.59 & & 1.29 & 0.04 \\
\hline$d=$ & 154545.25 & 0.62 & 52536.62 & 33353.00 & 11572.95 & 4754.31 & 1217.51 & 0.70 & 465.77 & 179.37 \\
\hline
\end{tabular}

3. Computation of the $W$ values

$w=[\text { sum ai }\{x(n-i+1)-x(i)\}]^{\wedge} 2 / d$

\begin{tabular}{|c|c|c|c|c|c|c|c|c|c|c|}
\hline & & \multicolumn{9}{|c|}{ ai $\{x(n-1+1)-x(i)\}$} \\
\hline & 242.33 & 0.47 & 136.14 & 122.40 & 61.69 & 43.04 & 21.39 & 0.57 & 12.02 & 7.62 \\
\hline & 92.15 & 0.16 & 53.74 & 40.75 & 26.22 & 14.37 & 7.77 & 0.22 & 6.14 & 2.66 \\
\hline & 34.26 & 0.10 & 27.54 & 15.16 & 10.73 & 6.96 & 3.43 & 0.02 & 1.76 & 1.53 \\
\hline & 13.16 & 0.03 & 10.96 & 0.99 & 4.90 & 2.82 & 1.53 & 0.00 & 0.86 & 0.66 \\
\hline & 3.10 & 0.00 & 0.15 & & 0.41 & 0.18 & 0.03 & & 0.06 & 0.13 \\
\hline sum & 384.99 & 0.76 & 222.54 & 179.31 & 103.94 & 67.37 & 34.15 & 0.81 & 20.84 & 12.60 \\
\hline $\operatorname{sum}^{\wedge} 2$ & 148220.00 & 0.58 & 49521.85 & 32152.47 & 10804.34 & 4538.74 & 1166.28 & 0.66 & 434.35 & 158.80 \\
\hline
\end{tabular}

\begin{tabular}{|c|c|c|c|c|c|c|c|c|c|c|}
\hline & $\begin{array}{c}\text { CONDUCTIVIYY } \\
@ 25 \mathrm{C} \\
(\mathrm{mS} / \mathrm{m}) \\
\end{array}$ & $\mathrm{PH}$ & $\begin{array}{l}\text { DISSOLVED } \\
\text { IONS } \\
\text { (mg/i) } \\
\end{array}$ & $\begin{array}{c}\text { DISSOLVED } \\
\text { SOLIDS } \\
\text { (mg/l) }\end{array}$ & $\begin{array}{l}\text { HARDNESS } \\
(\mathrm{mg} / \mathrm{l}) \mathrm{as} \mathrm{CacCO} 3\end{array}$ & $\begin{array}{l}\text { ALKALINITY } \\
\text { Img:1)as } \mathrm{CaCO3}\end{array}$ & $\begin{array}{l}\text { NATRiUM } \\
\text { (mgh) }\end{array}$ & $\begin{array}{l}\text { KALUUM } \\
\text { (mgn) }\end{array}$ & $\begin{array}{l}\text { CALCIUM } \\
\text { (mg/) }\end{array}$ & $\begin{array}{l}\text { MAGNESIUM } \\
\text { (mgn) }\end{array}$ \\
\hline $\begin{array}{c}W= \\
\left(\operatorname{sum}^{\wedge} 2 / d\right)\end{array}$ & 0.9591 & 0.9400 & 0.9426 & 0.9640 & 0.9336 & 0.9547 & 0.9579 & 0.9433 & 0.9325 & 0.8953 \\
\hline$W[0.05]$ & 0.842 & 0.842 & 0.842 & 0.818 & 0.842 & 0.842 & 0.842 & 0.818 & 0.842 & 0.842 \\
\hline$W[0.02]$ & 0.806 & 0.806 & 0.806 & 0.778 & 0.806 & 0.806 & 0.806 & 0.778 & 0.806 & 0.806 \\
\hline$W[0.01]$ & 0.781 & 0.781 & 0.781 & 0.749 & 0.781 & 0.781 & 0.781 & 0.749 & 0.781 & 0.781 \\
\hline
\end{tabular}


Table 5.4(b) Station 130106

t. Rank of the Data trom the Smallest Value

\begin{tabular}{|c|c|c|c|c|c|c|c|c|c|c|}
\hline DATA $F$ & $\begin{array}{c}\text { CONDUCTIVITY } \\
\text { @ 25C } \\
\text { (ms/m) } \\
\end{array}$ & $\mathrm{PH}$ & $\begin{array}{c}\text { DISSOLVED } \\
\text { IONS } \\
\text { (mg/) } \\
\end{array}$ & $\begin{array}{c}\text { DISSOLVED } \\
\text { SOLIDS } \\
\text { (mig/) } \\
\end{array}$ & $\begin{array}{l}\text { HARDNESS } \\
\text { (mgi)as Cacos }\end{array}$ & $\begin{array}{l}\text { ALKALINIT } \\
\text { (mg//)as } \mathrm{CaCO} \\
\end{array}$ & $\begin{array}{l}\text { NATRIUM } \\
\text { (ming/l) }\end{array}$ & $\begin{array}{l}\text { KALIUM } \\
\text { (mg/l) }\end{array}$ & $\begin{array}{l}\text { CALCIUM } \\
\text { (mg/l) } \\
\end{array}$ & $\begin{array}{c}\text { MAGNESIUM } \\
\text { (mg/) } \\
\end{array}$ \\
\hline$\times 1$ & 146.7 & 7.35 & 127.5 & 100.3 & 55.0 & 66.0 & 8.5 & 3.4 & 13.0 & 5 \\
\hline$x 2$ & 160.0 & 7.37 & 135.8 & 100.5 & 61.7 & 71.8 & 10.3 & 3.5 & 14.4 & 5.4 \\
\hline$\times 3$ & 168.6 & 7.40 & 136.1 & 104.2 & 61.7 & 72.0 & 11.0 & 3.6 & 14.5 & 6.2 \\
\hline$x 4$ & 192.2 & 7.43 & 151.0 & 117.3 & 65.7 & 75.7 & 11.5 & 3.7 & 15.5 & 6.2 \\
\hline$\times 5$ & 204.8 & 7.43 & 165.9 & 135.0 & 69.3 & 80.6 & 17.0 & 3.8 & 16.3 & 6.6 \\
\hline$x 6$ & 230.0 & 7.60 & 167.1 & $\$ 51.4$ & 78.6 & 82.0 & 18.0 & 4.0 & 17.5 & 6.9 \\
\hline$x 7$ & 230.3 & 7.70 & 198.6 & 199.0 & 85.2 & 102.6 & 18.9 & 4.2 & 19.3 & 8.5 \\
\hline$x 8$ & 240.6 & 7.76 & 199.3 & 257.0 & 91.0 & 110 & 19.0 & 4.9 & 24.0 & 9.0 \\
\hline$\times 9$ & 340.0 & 7.89 & 257.6 & & 101.0 & 118 & 27.0 & & 28.0 & 10 \\
\hline$\times 10$ & 410.0 & 8.00 & 347.2 & & 162.0 & 175 & 30.0 & & 35.0 & 18 \\
\hline $\bar{x}$ & 232.3 & 7.6 & 188.6 & 145.6 & 83.1 & 95.4 & 17.1 & 3.9 & 19.8 & 8.2 \\
\hline
\end{tabular}

2. Computation of the Denominator $(=d)$

\begin{tabular}{|c|c|c|c|c|c|c|c|c|c|c|}
\hline & \multicolumn{10}{|c|}{$(x i-x)^{\wedge} 2$} \\
\hline & 5.35 & 0.04 & 114.55 & 2048.18 & 62.26 & 214.21 & 0.77 & 0.95 & 67.93 & 10.04 \\
\hline & 756.01 & 0.03 & 462.02 & 1713.14 & 20.21 & 218.25 & 0.03 & 0.22 & 5.10 & 0.08 \\
\hline & 7335.45 & 0.03 & 2784.00 & 798.45 & 459.80 & 545.88 & 73.78 & 0.12 & 28.71 & 3.74 \\
\hline & 4065.84 & 0.03 & 2760.66 & 12412.16 & 460.52 & 555.27 & 46.48 & 0.09 & 27.60 & 3.99 \\
\hline & 1611.80 & 0.06 & 1413.53 & 33.22 & 304.26 & 178.60 & 37.49 & 0.01 & 18.13 & 2.62 \\
\hline & 31572.35 & 0.17 & 25154.92 & 2033.12 & 6223.68 & 6341.88 & 97.56 & 0.15 & 232.31 & 96.67 \\
\hline & 68.73 & 0.09 & 99.31 & 2852.62 & 4.23 & 52.12 & 3.29 & 0.01 & 0.17 & 0.64 \\
\hline & 5229.30 & 0.01 & 3738.95 & 112.15 & 790.16 & 862.25 & 31.62 & 0.04 & 45.67 & 7.66 \\
\hline & 11596.30 & 0.00 & 4761.42 & & 320.06 & 512.38 & 165.82 & & 17.99 & 3.36 \\
\hline & 3.92 & 0.05 & 516.67 & & 189.79 & 387.99 & 3.52 & & 11.73 & 1.61 \\
\hline$d=$ & 62245.05 & 0.49 & 41806.04 & 22003.04 & 8834.97 & 9868.82 & 460.35 & 1.58 & 455.35 & 130.41 \\
\hline
\end{tabular}

3. Computation of the $W$ values

$w=[\operatorname{sum} \text { ai }\{x(n-i+1)-x(i)\}]^{\wedge} 2 / d$

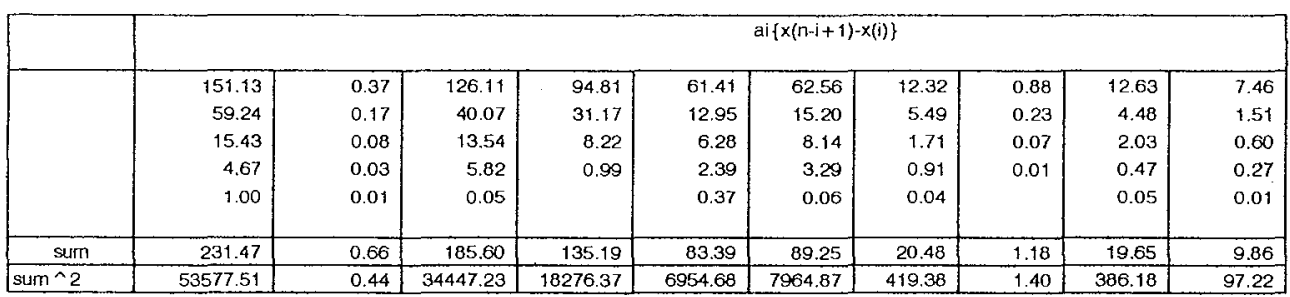

\begin{tabular}{|c|c|c|c|c|c|c|c|c|c|c|}
\hline & $\begin{array}{c}\text { CONDUCTNITY } \\
\text { @ 25C } \\
\text { (mS/m) } \\
\end{array}$ & $\mathrm{PH}$ & $\begin{array}{c}\text { DISSOLVED } \\
\text { IONS } \\
\text { (mgfl) } \\
\end{array}$ & $\begin{array}{c}\text { DISSOLVED } \\
\text { SOUDS } \\
\text { (mgjl) } \\
\end{array}$ & $\begin{array}{l}\text { HARDNESS } \\
\text { (mgry) } \mathrm{CacO}^{2}\end{array}$ & 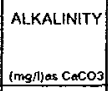 & $\begin{array}{l}\text { NATRIUM } \\
\text { (mgil) } \\
\end{array}$ & $\begin{array}{l}\text { KALIUM } \\
\text { (mg/l) }\end{array}$ & $\begin{array}{l}\text { CALCIUM } \\
\text { (mg/) }\end{array}$ & $\begin{array}{l}\text { MAGNESIUM } \\
(\mathrm{mg} /)\end{array}$ \\
\hline $\begin{array}{c}W= \\
\left(\operatorname{sum} \mathrm{m}^{\wedge} 2 / 0\right)\end{array}$ & 0.8608 & 0.8881 & 0.8240 & 0.8306 & 0.7872 & 0.8071 & 0.9110 & 0.8860 & 0.8481 & 0.7455 \\
\hline$W[0.05]$ & 0.842 & 0.842 & 0.842 & 0.818 & 0.842 & 0.842 & 0.842 & 0.818 & 0.842 & 0.842 \\
\hline$W[0.02]$ & 0.806 & 0.806 & 0.806 & 0.778 & 0.806 & 0.806 & 0.806 & 0.778 & 0.806 & 0.806 \\
\hline$W[0.01]$ & 0.781 & 0.781 & 0.781 & 0.749 & 0.781 & 0.781 & 0.781 & 0.749 & 0.781 & 0.781 \\
\hline
\end{tabular}

Note: $\quad$ reject the normality at i\% significance level if $W<W$ [i] 
not able to be rejected at the 5\% significance level. Only the Dissolved Ions parameter from Station 130106 , the Hardness parameter from Station 130106 require more prescriptive levels of significance, namely, $2 \%$ and $1 \%$ respectively, in order to be rejected, and the Magnesium parameter from station 130106 is the only parameter able to be rejected at the $1 \%$ significant level. All parameters including Magnesium at Station 130106 were therefore assumed to follow normal distributions.

The mean annual average values of the distributions at each station were calculated by :

$$
\bar{x}=\frac{1}{n} \sum_{i=1}^{n} x_{i}
$$

where :

$$
\begin{aligned}
\mathrm{x}_{\mathrm{i}}= & \text { annual 'average' water quality value in } \\
& \text { year } \mathrm{i} \\
\overline{\mathrm{x}}= & \text { mean value of } \mathrm{x}_{\mathrm{i}} \\
\mathrm{n}= & \text { number of data (number of years) }
\end{aligned}
$$

while the variance was calculated as :

$$
s^{2}=\frac{1}{n-1} \sum_{i=1}^{n}\left(x_{i}-\bar{x}\right)^{2}
$$

where :

$$
s^{2}=\text { variance of } x_{i}
$$


Using the results of Equations 5.2 and 5.3 the historical probability distributions of each water quality parameter at each of the monitoring stations were defined. The range of the possible values of each water quality parameter at each of the monitoring stations, e.g., $\bar{x}-4 s$ to $\bar{x}+4 s$, was also defined using the values of $\bar{x}$ and $s$ determined from Equations 5.2 and 5.3 respectively. (When the data are not normally distributed, a common transformation, such as log-normal transformation, may be applied).

\section{b. DISCRETIZATION OF THE VARIABLES}

The method proposed in this thesis uses a discrete form of the entropy principles such as described in Equation 4.13. When applying the principle to actual data, the range for the values of the variables must be discretized. The associated discrete values of the parameters for use in the entropy function is generated by discretizing the range, in this case, from $\bar{x}-4 s$ to $\bar{x}+4 s$, of the 'possible values' derived from the normal distribution developed from the records, into $k$ intervals of the same width. The mid value of each interval is then taken as the input value, $x_{j}$, for the model. An important issue related to this process is how many intervals should be chosen in order to get the best results from the model. This issue is discussed in some 
detail later in the thesis.

\section{c. DEVELOPMENT OF THE 'INFORMATION FUNCTION'}

A critical requirement for the application of the entropy approach is historical information which can be used to define the historical relationship among the data from the various stations. This relationship may be considered as information introduced into the model and as such may be called the 'information function' as expressed in Equation 4.18. A physically based model or approach which models the actual process of the water quality change while the water is transported from upstream tributary stations to the junction of the streams or to the downstream station itself would be ideal. However, unless the physical processes can be expressed in a few relatively simple expressions it cannot be applied in the optimisation framework upon which the entropy method is based. Furthermore, in order to model the physical processes properly it is generally necessary to have a more complete set of data than simply the water quality values and flow rates at relevant stations. For example, additional data on the cross-sectional characteristics of the channel, the level of turbulence etc. are likely to be needed. In this study, since the primary focus is on prediction of values rather than modelling the physical processes in 
the system, a statistical model, in particular a linear regression approach, which expresses the relationship between the values at the downstream station and the mixed values of water quality from the upstream stations, is used for this information function. [The equation and processes for this function have been described in detail in the previous chapter (Equation $4.6) .1$

\section{d. CASES}

A number of cases involving the direct applications of the entropy model to the prediction of water quality values at discontinued monitoring stations, were examined :

\section{CASE I :}

Running the model as described by the formulation in Equations $4.15-4.21$.

\section{CASE II :}

Running the model using non-normal distribution for those water quality parameters which had been identified as having non-normal distribution, e.g., Dissolved Ions, Hardness and Magnesium parameters from station 130106. 


\section{CASE III :}

Running the model with consideration of possible observed changes in the watershed that may have caused changes in water quality values.

\section{CASE IV :}

Running the model with consideration of the statistical or physical dependency that might exist between the data at the upstream stations.

\subsection{RESULTS, DISCUSSION AND COMPUTATIONAL PROBLEMS}

\subsubsection{RESULTS AND DISCUSSION}

In this section the results for each of the four cases described above are presented and discussed.

\section{a. CASE I. Normally Distributed Approximation}

In this case, the model assigns probabilities to mean water quality values at the discontinued monitoring stations for different periods of time averaging, varying from annual (i.e., 1 yearly) mean average values to four yearly averaged annual mean values. The results from the application of the entropy model for this case are summarised in Tables 5.5 to 5.7 . The results obtained from using regression to predict water quality 
Table 5.5 Results of Assignment of Water Quality Values in the Mackenzie River Sub-Basin

Table 5.5(a) 1 yearly

\begin{tabular}{|c|c|c|c|c|c|c|c|c|c|c|c|c|c|c|}
\hline \multirow{4}{*}{$\begin{array}{l}\text { Water Quallity } \\
\text { Parameter }\end{array}$} & \multirow{2}{*}{\multicolumn{2}{|c|}{ Obsorvod Valuog }} & \multirow{2}{*}{\multicolumn{2}{|c|}{$\begin{array}{l}\text { Aosignod Values } \\
\text { (Entropy Melhod) }\end{array}$}} & \multirow{2}{*}{\multicolumn{2}{|c|}{$\begin{array}{c}\text { Aoslgned Values } \\
\text { (Regression Methed) }\end{array}$}} & \multicolumn{8}{|c|}{ Absolute Values of Errors (\%) } \\
\hline & & & & & & & \multicolumn{4}{|c|}{ (Entropy Method) } & \multicolumn{4}{|c|}{ (Regression Method) } \\
\hline & \multicolumn{2}{|c|}{ at Statlon } & \multicolumn{2}{|c|}{ at Station } & \multicolumn{2}{|c|}{ at Slation } & \multirow{2}{*}{\multicolumn{2}{|c|}{$\begin{array}{l}\text { at Slation } \\
130401 \quad 130108\end{array}$}} & \multirow[b]{2}{*}{ Average } & \multirow[b]{2}{*}{ Maximum } & \multicolumn{2}{|c|}{ at Stallon } & \multirow[b]{2}{*}{ Average } & \multirow[b]{2}{*}{ Maximum } \\
\hline & 130401 & 130108 & 130401 & 130108 & 130401 & 130108 & & & & & 130401 & 130108 & & \\
\hline (1) & 12 & & & & 14 & & (5) & & (6) & (?) & & 8) & (9) & $(10)$ \\
\hline $\begin{array}{l}\text { Conductivity } \\
\text { (mS/m) }\end{array}$ & $\begin{array}{l}425.00 \\
316.67 \\
332.50 \\
283.33 \\
276.67\end{array}$ & $\begin{array}{l}199.39 \\
211.25 \\
206.67 \\
242.50 \\
185.00\end{array}$ & $\begin{array}{l}285.63 \\
298.72 \\
261.84 \\
271.43 \\
293.26\end{array}$ & $\begin{array}{l}206.51 \\
209.27 \\
201.46 \\
203.50 \\
208.13\end{array}$ & $\begin{array}{l}312.74 \\
323.02 \\
294.10 \\
301.60 \\
318.74\end{array}$ & $\begin{array}{l}154.19 \\
162.36 \\
139.38 \\
145.34 \\
158.96\end{array}$ & $\begin{array}{r}32.79 \\
5.67 \\
21.25 \\
4.20 \\
6.00\end{array}$ & $\begin{array}{r}3.60 \\
0.94 \\
2.52 \\
16.08 \\
12.50\end{array}$ & 10.56 & 32.79 & $\begin{array}{r}26.42 \\
2.01 \\
11.55 \\
6.45 \\
15.21\end{array}$ & $\begin{array}{l}22.65 \\
23.14 \\
32.56 \\
40.07 \\
14.08\end{array}$ & 19.41 & 40.07 \\
\hline $\mathrm{PH}$ & $\begin{array}{l}8.0 \\
8.1 \\
8.0 \\
7.5 \\
7.8\end{array}$ & $\begin{array}{l}7.8 \\
7.9 \\
7.7 \\
7.5 \\
6.4\end{array}$ & $\begin{array}{l}7.9 \\
7.9 \\
7.8 \\
7.8 \\
8.0\end{array}$ & $\begin{array}{l}7.6 \\
7.6 \\
7.6 \\
7.6 \\
7.7\end{array}$ & $\begin{array}{l}7.9 \\
7.9 \\
7.9 \\
7.9 \\
7.9\end{array}$ & $\begin{array}{l}7.6 \\
7.7 \\
7.4 \\
7.5 \\
8.0\end{array}$ & $\begin{array}{l}1.88 \\
2.50 \\
3.13 \\
4.40 \\
3.08\end{array}$ & $\begin{array}{c}2.23 \\
2.98 \\
1.26 \\
2.01 \\
20.16\end{array}$ & 4.36 & 20.16 & $\begin{array}{l}1.55 \\
3.04 \\
1.69 \\
4.98 \\
1.29\end{array}$ & $\begin{array}{r}2.98 \\
1.94 \\
4.00 \\
0.79 \\
24.64\end{array}$ & 4.69 & 24.64 \\
\hline $\begin{array}{c}\text { Dissolved } \\
\text { lons } \\
\text { (mgin) }\end{array}$ & $\begin{array}{l}200.75 \\
200.70 \\
219.30 \\
176.67 \\
182.63\end{array}$ & $\begin{array}{c}150.98 \\
163.33 \\
161.33 \\
166.15 \\
150.20\end{array}$ & $\begin{array}{l}199.19 \\
188.66 \\
182.16 \\
182.07 \\
211.35\end{array}$ & $\begin{array}{r}159.38 \\
155.00 \\
152.25 \\
152.18 \\
164.45\end{array}$ & $\begin{array}{l}214.62 \\
206.35 \\
201.26 \\
201.20 \\
224.19\end{array}$ & $\begin{array}{l}129.43 \\
120.70 \\
115.32 \\
115.26 \\
139.54\end{array}$ & $\begin{array}{r}0.78 \\
6.00 \\
16.94 \\
3.06 \\
15.72\end{array}$ & $\begin{array}{l}5.56 \\
5.10 \\
5.63 \\
8.41 \\
9.49\end{array}$ & 7.67 & 16.94 & $\begin{array}{r}6.91 \\
2.82 \\
8.22 \\
13.89 \\
22.75\end{array}$ & $\begin{array}{r}14.28 \\
26.10 \\
28.52 \\
30.63 \\
7.10\end{array}$ & 16.12 & 30.63 \\
\hline $\begin{array}{c}\text { Dissolved } \\
\text { Solids } \\
\text { (mgh) }\end{array}$ & $\begin{array}{l}218.50 \\
173.33 \\
185.00 \\
156.67 \\
150.00\end{array}$ & $\begin{array}{l}114.83 \\
122.50 \\
123.33 \\
140.00 \\
110.00\end{array}$ & $\begin{array}{l}149.07 \\
162.58 \\
138.06 \\
160.30 \\
158.40\end{array}$ & $\begin{array}{l}115.91 \\
120.62 \\
111.99 \\
116.34 \\
119.17\end{array}$ & $\begin{array}{l}163.29 \\
174.27 \\
154.31 \\
164.29 \\
170.94\end{array}$ & $\begin{array}{l}88.73 \\
88.30 \\
80.90 \\
89.60 \\
95.40\end{array}$ & $\begin{array}{r}31.78 \\
6.20 \\
25.37 \\
4.06 \\
5.60\end{array}$ & $\begin{array}{r}0.94 \\
1.53 \\
9.20 \\
16.90 \\
8.34\end{array}$ & 10.99 & 31.78 & $\begin{array}{r}25.27 \\
0.54 \\
16.59 \\
4.87 \\
13.96\end{array}$ & $\begin{array}{l}22.73 \\
19.76 \\
34.41 \\
36.00 \\
13.27\end{array}$ & 18.74 & 36.00 \\
\hline $\begin{array}{c}\text { Hardness } \\
\text { (mg/)as } \mathrm{CaCO}\end{array}$ & $\begin{array}{r}106.50 \\
83.33 \\
83.50 \\
72.00 \\
75.67\end{array}$ & $\begin{array}{l}58.83 \\
72.50 \\
62.00 \\
65.50 \\
61.00\end{array}$ & $\begin{array}{l}82.67 \\
74.14 \\
75.20 \\
72.55 \\
92.97\end{array}$ & $\begin{array}{l}70.39 \\
66.98 \\
67.41 \\
66.32 \\
74.50\end{array}$ & $\begin{array}{l}80.57 \\
82.92 \\
83.75 \\
81.68 \\
97.60\end{array}$ & $\begin{array}{l}57.21 \\
50.18 \\
51.06 \\
48.86 \\
65.71\end{array}$ & $\begin{array}{r}22.38 \\
11.03 \\
9.94 \\
0.76 \\
22.87\end{array}$ & $\begin{array}{r}19.64 \\
7.61 \\
8.73 \\
1.25 \\
22.13\end{array}$ & 12.63 & 22.87 & $\begin{array}{r}15.90 \\
0.49 \\
0.30 \\
13.44 \\
28.99\end{array}$ & $\begin{array}{r}2.76 \\
30.79 \\
17.65 \\
25.41 \\
7.71\end{array}$ & 14.34 & 30.79 \\
\hline $\begin{array}{c}\text { Alkalinity } \\
(\mathrm{mg} /)_{\mathrm{as}} \mathrm{C}_{\mathrm{C}} \mathrm{CO} 3\end{array}$ & $\begin{array}{l}50.00 \\
76.00 \\
83.00 \\
64.67 \\
72.00\end{array}$ & $\begin{array}{l}79.83 \\
87.00 \\
76.33 \\
67.50 \\
80.00\end{array}$ & $\begin{array}{l}92.80 \\
73.65 \\
82.27 \\
77.66 \\
95.84\end{array}$ & $\begin{array}{l}85.97 \\
65.10 \\
74.45 \\
69.45 \\
89.14\end{array}$ & $\begin{array}{l}94.45 \\
79.47 \\
86.18 \\
82.59 \\
96.74\end{array}$ & $\begin{array}{l}82.94 \\
53.87 \\
66.89 \\
59.93 \\
87.38\end{array}$ & $\begin{array}{r}85.78 \\
3.09 \\
0.88 \\
20.09 \\
33.11\end{array}$ & $\begin{array}{r}7.69 \\
25.17 \\
2.47 \\
2.89 \\
11.43\end{array}$ & 19.26 & 85.78 & $\begin{array}{r}88.90 \\
4.57 \\
3.83 \\
27.72 \\
34.36\end{array}$ & $\begin{array}{r}3.89 \\
38.08 \\
12.37 \\
11.22 \\
9.22\end{array}$ & 23.42 & 88.90 \\
\hline $\begin{array}{l}\text { Natrium } \\
(m g / h)\end{array}$ & $\begin{array}{l}36.50 \\
27.67 \\
32.00 \\
25.00 \\
24.00\end{array}$ & $\begin{array}{l}14.62 \\
13.63 \\
16.33 \\
22.00 \\
13.50\end{array}$ & $\begin{array}{l}22.98 \\
31.92 \\
24.22 \\
24.96 \\
24.96\end{array}$ & $\begin{array}{l}14.32 \\
16.09 \\
14.57 \\
14.72 \\
14.72\end{array}$ & $\begin{array}{l}27.99 \\
41.99 \\
29.93 \\
31.10 \\
31.10\end{array}$ & $\begin{array}{r}9.10 \\
13.88 \\
9.76 \\
10.16 \\
10.16\end{array}$ & $\begin{array}{r}37.04 \\
15.37 \\
24.31 \\
0.16 \\
4.00\end{array}$ & $\begin{array}{r}2.03 \\
18.09 \\
10.80 \\
33.09 \\
9.04\end{array}$ & 15.39 & 37.04 & $\begin{array}{r}23.32 \\
51.75 \\
6.46 \\
24.40 \\
29.58\end{array}$ & $\begin{array}{r}37.76 \\
1.85 \\
40.23 \\
53.82 \\
24.74\end{array}$ & 29.39 & 53.82 \\
\hline $\begin{array}{l}\text { Kalium } \\
(\mathrm{mg} / \mathrm{l})\end{array}$ & $\begin{array}{l}1.30 \\
1.33 \\
1.65 \\
1.93 \\
2.17\end{array}$ & $\begin{array}{l}3.85 \\
3.83 \\
3.70 \\
3.00 \\
3.40\end{array}$ & $\begin{array}{l}1.60 \\
1.48 \\
1.66 \\
1.66 \\
1.66\end{array}$ & $\begin{array}{l}3.83 \\
3.70 \\
3.90 \\
3.90 \\
3.90\end{array}$ & $\begin{array}{l}1.61 \\
1.58 \\
1.62 \\
1.62 \\
1.62\end{array}$ & $\begin{array}{l}3.82 \\
3.53 \\
3.96 \\
3.98 \\
3.96\end{array}$ & $\begin{array}{r}23.08 \\
11.00 \\
0.61 \\
14.14 \\
23.38\end{array}$ & $\begin{array}{r}0.52 \\
3.27 \\
5.41 \\
30.00 \\
14.71\end{array}$ & 12.61 & 30.00 & $\begin{array}{r}23.67 \\
18.79 \\
1.84 \\
16.14 \\
25.25\end{array}$ & $\begin{array}{r}0.82 \\
7.64 \\
7.06 \\
32.72 \\
16.51\end{array}$ & 15.04 & 32.72 \\
\hline $\begin{array}{l}\text { Calcium } \\
\text { (mg/l) }\end{array}$ & $\begin{array}{l}22.00 \\
17.67 \\
17.50 \\
15.33 \\
17.00\end{array}$ & $\begin{array}{l}13.00 \\
17.25 \\
14.67 \\
15.00 \\
15.00\end{array}$ & $\begin{array}{l}17.52 \\
15.58 \\
17.04 \\
16.55 \\
20.44\end{array}$ & $\begin{array}{l}16.57 \\
15.57 \\
16.32 \\
16.07 \\
18.05\end{array}$ & $\begin{array}{l}19.15 \\
17.60 \\
18.76 \\
18.38 \\
21.47\end{array}$ & $\begin{array}{l}13.43 \\
11.68 \\
12,99 \\
12.56 \\
16.06\end{array}$ & $\begin{array}{r}20.36 \\
11.81 \\
2.63 \\
7.93 \\
20.24\end{array}$ & $\begin{array}{r}27.46 \\
9.74 \\
11.27 \\
7.13 \\
20.33\end{array}$ & 13.89 & 27.46 & $\begin{array}{r}12.95 \\
0.36 \\
7.22 \\
19.85 \\
26.31\end{array}$ & $\begin{array}{r}3.32 \\
32.29 \\
11.40 \\
16.29 \\
7.07\end{array}$ & 13.71 & 32.29 \\
\hline $\begin{array}{l}\text { Magnesium } \\
\text { (mg/s) }\end{array}$ & $\begin{array}{r}12.50 \\
9.47 \\
9.70 \\
8.17 \\
8.07\end{array}$ & $\begin{array}{l}6.42 \\
7.10 \\
6.17 \\
6.80 \\
5.60\end{array}$ & $\begin{array}{r}9.79 \\
9.12 \\
8.28 \\
7.90 \\
10.42\end{array}$ & $\begin{array}{l}6.79 \\
6.54 \\
6.22 \\
6.07 \\
7.03\end{array}$ & $\begin{array}{r}10.16 \\
9.61 \\
8.92 \\
8.60 \\
10.68\end{array}$ & $\begin{array}{l}6.08 \\
5.60 \\
5.00 \\
4.72 \\
6.53\end{array}$ & $\begin{array}{r}21.68 \\
3.66 \\
14.64 \\
3.27 \\
29.17\end{array}$ & $\begin{array}{r}5.82 \\
7.89 \\
0.86 \\
10.74 \\
25.54\end{array}$ & 12.33 & 29.17 & $\begin{array}{r}18.70 \\
1.51 \\
8.05 \\
5.26 \\
32.45\end{array}$ & $\begin{array}{r}5.31 \\
21.16 \\
18.92 \\
30.58 \\
16.56\end{array}$ & 15.85 & 32.45 \\
\hline
\end{tabular}


Table 5.5(b) 2 yearly

\begin{tabular}{|c|c|c|c|c|c|c|c|c|c|c|c|c|c|c|}
\hline \multirow{4}{*}{$\begin{array}{l}\text { Water Quality } \\
\text { Paramater }\end{array}$} & \multirow{2}{*}{\multicolumn{2}{|c|}{ Observed Valuen }} & \multirow{2}{*}{\multicolumn{2}{|c|}{$\begin{array}{l}\text { Assigned Values } \\
\text { (Entropy Method) }\end{array}$}} & \multirow{2}{*}{\multicolumn{2}{|c|}{$\begin{array}{l}\text { Assigned Values } \\
\text { (Regreasion Methad) }\end{array}$}} & \multicolumn{8}{|c|}{ Absolute Values of Errors $(\%)$} \\
\hline & & & & & & & \multicolumn{4}{|c|}{ (Entropy Mothod) } & \multicolumn{4}{|c|}{ (Regression Mothod) } \\
\hline & \multicolumn{2}{|c|}{ at Station } & \multicolumn{2}{|c|}{ at Statlon } & \multirow{2}{*}{\multicolumn{2}{|c|}{$\begin{array}{l}\text { at Station } \\
\text { 130401 } 130108\end{array}$}} & \multicolumn{2}{|c|}{ al Station } & \multirow[b]{2}{*}{ Average } & \multirow[b]{2}{*}{ Maximum } & \multicolumn{2}{|c|}{ at Station } & \multirow[b]{2}{*}{ Average } & \multirow[b]{2}{*}{ Maximum } \\
\hline & 130401 & 130106 & 130401 & 130108 & & 130108 & 130404 & 130106 & & & 130401 & 130108 & & \\
\hline (1) & & & & & & & (5) & & (6) & (7) & & (8) & (9) & (10) \\
\hline $\begin{array}{l}\text { Conductivity } \\
\text { (ms/m) }\end{array}$ & $\begin{array}{l}370.83 \\
324.58 \\
307.92 \\
280.00\end{array}$ & $\begin{array}{l}205.29 \\
208.96 \\
224.58 \\
213.75\end{array}$ & $\begin{array}{l}306.10 \\
295.67 \\
283.70 \\
297.48\end{array}$ & $\begin{array}{l}210.82 \\
208.62 \\
206.10 \\
209.10\end{array}$ & $\begin{array}{l}336.97 \\
329.77 \\
321.49 \\
331.01\end{array}$ & $\begin{array}{r}151.50 \\
143.13 \\
133.50 \\
144.57\end{array}$ & $\begin{array}{r}17.46 \\
8.91 \\
7.86 \\
6.24\end{array}$ & $\begin{array}{l}2.69 \\
0.16 \\
8.23 \\
2.18\end{array}$ & 6.72 & 17.46 & $\begin{array}{r}9.13 \\
1.60 \\
4.41 \\
18.22\end{array}$ & $\begin{array}{l}26.20 \\
31.50 \\
40.55 \\
32.36\end{array}$ & 20.50 & 40.55 \\
\hline $\mathrm{PH}$ & $\begin{array}{l}8.07 \\
8.07 \\
7.75 \\
7.65\end{array}$ & $\begin{array}{l}7.83 \\
7.77 \\
7.56 \\
6.93\end{array}$ & $\begin{array}{l}7.8 \\
7.8 \\
7.8 \\
7.8\end{array}$ & $\begin{array}{l}8.2 \\
8.2 \\
8.2 \\
8.2\end{array}$ & $\begin{array}{l}7.9 \\
8.0 \\
8.0 \\
7.9\end{array}$ & $\begin{array}{l}7.7 \\
7.6 \\
7.5 \\
7.8\end{array}$ & $\begin{array}{l}3.55 \\
3.55 \\
0.39 \\
1.70\end{array}$ & $\begin{array}{r}4.61 \\
5.39 \\
8.36 \\
18.27\end{array}$ & 5.73 & 18.27 & $\begin{array}{l}1.89 \\
1.42 \\
3.16 \\
2.89\end{array}$ & $\begin{array}{r}2.23 \\
2.65 \\
1.24 \\
11.98\end{array}$ & 3.43 & 11.98 \\
\hline $\begin{array}{l}\text { Dissolved } \\
\text { Ions } \\
\text { (mrgil) }\end{array}$ & $\begin{array}{l}200.73 \\
210.00 \\
197.98 \\
179.65\end{array}$ & $\begin{array}{l}157.15 \\
162.33 \\
163.74 \\
158.18\end{array}$ & $\begin{array}{l}208.22 \\
201.70 \\
199.11 \\
210.41\end{array}$ & $\begin{array}{l}163.15 \\
160.44 \\
159.36 \\
164.04\end{array}$ & $\begin{array}{l}229.30 \\
225.24 \\
223.67 \\
230.64\end{array}$ & $\begin{array}{l}122.93 \\
115.41 \\
112.51 \\
125.41\end{array}$ & $\begin{array}{r}3.73 \\
3.95 \\
0.57 \\
17.12\end{array}$ & $\begin{array}{l}3.82 \\
1.16 \\
2.68 \\
3.71\end{array}$ & 4.59 & 17.12 & $\begin{array}{r}14.24 \\
7.26 \\
12.97 \\
28.39\end{array}$ & $\begin{array}{l}21.78 \\
28.91 \\
31.29 \\
20.71\end{array}$ & 20.69 & 31.29 \\
\hline $\begin{array}{l}\text { Dissolved } \\
\text { Solids } \\
\text { (mmgli) }\end{array}$ & $\begin{array}{l}195.92 \\
179.17 \\
170.83 \\
153.33\end{array}$ & $\begin{array}{l}118.67 \\
122.92 \\
131.67 \\
125.00\end{array}$ & $\begin{array}{r}173.57 \\
169.30 \\
164.57 \\
172.43\end{array}$ & $\begin{array}{l}124.40 \\
122.93 \\
121.30 \\
124.02\end{array}$ & $\begin{array}{r}195.68 \\
193.21 \\
190.46 \\
195.04\end{array}$ & $\begin{array}{l}82.21 \\
77.28 \\
71.80 \\
80.93\end{array}$ & $\begin{array}{r}11.41 \\
5.51 \\
3.67 \\
12.45\end{array}$ & $\begin{array}{l}4.83 \\
0.01 \\
7.87 \\
0.78\end{array}$ & 5.82 & 12.45 & $\begin{array}{r}0.12 \\
7.84 \\
11.49 \\
27.20\end{array}$ & $\begin{array}{l}30.73 \\
37.13 \\
45.46 \\
35.26\end{array}$ & 24.40 & 45.46 \\
\hline $\begin{array}{c}\text { Hardness } \\
\text { (mg/)as } \mathrm{CaCO} 3\end{array}$ & $\begin{array}{l}94.92 \\
83.42 \\
77.75 \\
73.83\end{array}$ & $\begin{array}{l}65.67 \\
67.25 \\
63.75 \\
63.25\end{array}$ & $\begin{array}{l}87.18 \\
84.44 \\
83.84 \\
90.39\end{array}$ & $\begin{array}{l}72.20 \\
71.10 \\
70.87 \\
73.48\end{array}$ & $\begin{array}{l}96.62 \\
94.90 \\
94.53 \\
98.63\end{array}$ & $\begin{array}{l}54.24 \\
51.15 \\
50.49 \\
57.83\end{array}$ & $\begin{array}{r}8.15 \\
1.23 \\
7.83 \\
22.42\end{array}$ & $\begin{array}{r}9.95 \\
5.72 \\
11.17 \\
16.17\end{array}$ & 10.33 & 22.42 & $\begin{array}{r}1.80 \\
13.77 \\
21.58 \\
33.58\end{array}$ & $\begin{array}{r}17.41 \\
23.93 \\
20.79 \\
8.57\end{array}$ & 17.68 & 33.68 \\
\hline $\begin{array}{c}\text { Alkalinity } \\
(\mathrm{mg} / \text { /) as } \mathrm{CaCO}\end{array}$ & $\begin{array}{l}63.00 \\
79.50 \\
73.83 \\
68.33\end{array}$ & $\begin{array}{l}83.42 \\
81.67 \\
71.92 \\
73.75\end{array}$ & $\begin{array}{l}86.80 \\
82.86 \\
84.35 \\
89.38\end{array}$ & $\begin{array}{l}79.38 \\
75.13 \\
76.73 \\
82.14\end{array}$ & $\begin{array}{l}92.58 \\
90.71 \\
91.41 \\
93.81\end{array}$ & $\begin{array}{l}68.40 \\
60.18 \\
63.28 \\
73.78\end{array}$ & $\begin{array}{r}37.78 \\
4.23 \\
14.24 \\
30.80\end{array}$ & $\begin{array}{r}4.84 \\
8.00 \\
6.69 \\
11.38\end{array}$ & 14.75 & 37.78 & $\begin{array}{l}46.95 \\
14.10 \\
23.81 \\
37.28\end{array}$ & $\begin{array}{r}18.00 \\
26.31 \\
12.01 \\
0.04\end{array}$ & 22.31 & 46.95 \\
\hline $\begin{array}{c}\text { Natrium } \\
(\mathrm{mg} /)\end{array}$ & $\begin{array}{l}32.08 \\
29.83 \\
28.50 \\
24.50\end{array}$ & $\begin{array}{l}14.12 \\
14.98 \\
19.17 \\
17.75\end{array}$ & $\begin{array}{l}28.22 \\
28.74 \\
25.78 \\
26.09\end{array}$ & $\begin{array}{l}15.36 \\
15.46 \\
14.88 \\
14.94\end{array}$ & $\begin{array}{l}30.78 \\
31.15 \\
29.09 \\
29.31\end{array}$ & $\begin{array}{r}10.47 \\
10.89 \\
8.54 \\
8.79\end{array}$ & $\begin{array}{r}12.04 \\
3.66 \\
9.54 \\
6.19\end{array}$ & $\begin{array}{r}8.78 \\
3.21 \\
22.37 \\
15.83\end{array}$ & 10.24 & 22.37 & $\begin{array}{r}4.07 \\
4.40 \\
2.05 \\
19.62\end{array}$ & $\begin{array}{l}25.86 \\
27.30 \\
55.47 \\
50.49\end{array}$ & 23.66 & 55.47 \\
\hline $\begin{array}{l}\text { Kalium } \\
(\mathrm{mg} /)\end{array}$ & $\begin{array}{l}1.32 \\
1.49 \\
1.79 \\
2.05\end{array}$ & $\begin{array}{l}3.84 \\
3.76 \\
3.35 \\
3.20\end{array}$ & $\begin{array}{l}1.61 \\
1.59 \\
1.62 \\
1.62\end{array}$ & $\begin{array}{l}3.85 \\
3.82 \\
3.85 \\
3.85\end{array}$ & $\begin{array}{l}1.64 \\
1.63 \\
1.57 \\
1.57\end{array}$ & $\begin{array}{l}3.69 \\
3.75 \\
3.94 \\
3.94\end{array}$ & $\begin{array}{r}22.28 \\
6.59 \\
9.58 \\
20.98\end{array}$ & $\begin{array}{r}0.33 \\
1.53 \\
14.93 \\
20.31\end{array}$ & 12.06 & 22.28 & $\begin{array}{r}24.86 \\
9.05 \\
12.23 \\
23.29\end{array}$ & $\begin{array}{r}3.91 \\
0.40 \\
17.49 \\
23.00\end{array}$ & 14.28 & 24.86 \\
\hline $\begin{array}{l}\text { Calcium } \\
\text { (mmg/) }\end{array}$ & $\begin{array}{r}19.83 \\
17.58 \\
16.42 \\
16.17\end{array}$ & $\begin{array}{l}15.13 \\
15.96 \\
14.83 \\
15.00\end{array}$ & $\begin{array}{l}18.11 \\
17.93 \\
18.29 \\
19.56\end{array}$ & $\begin{array}{c}16.87 \\
16.77 \\
16.96 \\
17.60\end{array}$ & $\begin{array}{l}20.26 \\
20.14 \\
20.38 \\
21.20\end{array}$ & $\begin{array}{l}12.76 \\
12.54 \\
12.97 \\
14.47\end{array}$ & $\begin{array}{r}8.69 \\
1.97 \\
11.41 \\
20.99\end{array}$ & $\begin{array}{r}11.54 \\
5.09 \\
14.34 \\
17.33\end{array}$ & 11.42 & 20.99 & $\begin{array}{r}2.15 \\
14.55 \\
24.12 \\
31.12\end{array}$ & $\begin{array}{r}15.65 \\
21.40 \\
12.54 \\
3.50\end{array}$ & 15.63 & 31.12 \\
\hline $\begin{array}{l}\text { Magnesium } \\
(\mathrm{mg} / \mathrm{l})\end{array}$ & $\begin{array}{r}10.98 \\
9.58 \\
8.93 \\
8.12\end{array}$ & $\begin{array}{l}6.76 \\
6.63 \\
6.48 \\
6.20\end{array}$ & $\begin{array}{r}10.39 \\
9.77 \\
9.29 \\
10.14\end{array}$ & $\begin{array}{l}7.01 \\
6.79 \\
6.60 \\
6.92\end{array}$ & $\begin{array}{l}11.05 \\
10.64 \\
10.32 \\
10.89\end{array}$ & $\begin{array}{l}5.72 \\
5.13 \\
4.65 \\
5.48\end{array}$ & $\begin{array}{r}5.40 \\
1.95 \\
3.99 \\
24.93\end{array}$ & $\begin{array}{r}3.72 \\
2.36 \\
1.80 \\
11.61\end{array}$ & 6.97 & 24.93 & $\begin{array}{r}0.57 \\
11.08 \\
15.50 \\
34.14\end{array}$ & $\begin{array}{l}15.44 \\
22.70 \\
28.29 \\
11.56\end{array}$ & 17.41 & 34.14 \\
\hline
\end{tabular}


Table 5.5(c) 3 yearly

\begin{tabular}{|c|c|c|c|c|c|c|c|c|c|c|c|c|c|c|}
\hline \multirow{4}{*}{$\begin{array}{l}\text { Wator Quality } \\
\text { Parametor }\end{array}$} & \multirow{2}{*}{\multicolumn{2}{|c|}{ Obeerved Values }} & \multirow{2}{*}{\multicolumn{2}{|c|}{$\begin{array}{l}\text { Assigned Values } \\
\text { (Entropy Method) }\end{array}$}} & \multirow{2}{*}{\multicolumn{2}{|c|}{$\begin{array}{l}\text { Asstgned Values } \\
\text { (Regresslon Method) }\end{array}$}} & \multicolumn{8}{|c|}{ Absolute Values of Errors (\%) } \\
\hline & & & & & & & \multicolumn{4}{|c|}{ (Entropy Mothod) } & \multicolumn{4}{|c|}{ (Rogression Mathod) } \\
\hline & \multicolumn{2}{|c|}{ at Stallon } & \multicolumn{2}{|c|}{ at Station } & \multicolumn{2}{|c|}{ at Station } & \multicolumn{2}{|c|}{ at Stalton } & \multirow[b]{2}{*}{ Average } & \multirow[b]{2}{*}{ Maximum } & \multicolumn{2}{|c|}{ at Station } & \multirow[b]{2}{*}{ Average } & \multirow[b]{2}{*}{ Maximum } \\
\hline & 130401 & 130108 & 130401 & 130108 & 130401 & 130106 & 130401 & 130108 & & & 130401 & 130108 & & \\
\hline (1) & \multicolumn{2}{|c|}{ (2) } & \multicolumn{2}{|c|}{ (3) } & \multicolumn{2}{|c|}{ (4) } & \multicolumn{2}{|c|}{ (5) } & (6) & $(7)$ & \multicolumn{2}{|c|}{ (8) } & (9) & $(10)$ \\
\hline $\begin{array}{c}\text { Conductivity } \\
\text { (mS/m) }\end{array}$ & $\begin{array}{l}358.10 \\
310.80 \\
297.50\end{array}$ & $\begin{array}{l}205.80 \\
220.10 \\
211.40\end{array}$ & $\begin{array}{l}306.70 \\
302.70 \\
301.20\end{array}$ & $\begin{array}{l}210.90 \\
210.10 \\
209.80\end{array}$ & $\begin{array}{l}336.92 \\
334.18 \\
333.18\end{array}$ & $\begin{array}{l}152.69 \\
149.51 \\
148.35\end{array}$ & $\begin{array}{r}14.35 \\
2.61 \\
1.24\end{array}$ & $\begin{array}{l}2.48 \\
4.54 \\
0.76\end{array}$ & 4.33 & 14.35 & $\begin{array}{r}5.91 \\
7.52 \\
11.99\end{array}$ & $\begin{array}{l}25.81 \\
32.07 \\
29.83\end{array}$ & 18.86 & 32.07 \\
\hline $\mathrm{PH}$ & $\begin{array}{l}8.04 \\
7.88 \\
7.77\end{array}$ & $\begin{array}{l}7.78 \\
7.66 \\
7.17\end{array}$ & $\begin{array}{l}7.96 \\
7.95 \\
7.96\end{array}$ & $\begin{array}{l}7.66 \\
7.66 \\
7.66\end{array}$ & $\begin{array}{l}8.04 \\
8.04 \\
8.02\end{array}$ & $\begin{array}{l}7.59 \\
7.57 \\
7.65\end{array}$ & $\begin{array}{l}1.04 \\
0.93 \\
2.50\end{array}$ & $\begin{array}{l}1.48 \\
0.04 \\
6.80\end{array}$ & 2.13 & 6.80 & $\begin{array}{l}0.05 \\
2.12 \\
3.21\end{array}$ & $\begin{array}{l}2.43 \\
1.17 \\
6.70\end{array}$ & 2.62 & 6.70 \\
\hline $\begin{array}{c}\text { Dissolved } \\
\text { lons } \\
\text { (mg/) }\end{array}$ & $\begin{array}{l}206.90 \\
198.90 \\
192.90\end{array}$ & $\begin{array}{l}158.50 \\
163.60 \\
159.20\end{array}$ & $\begin{array}{l}208.00 \\
203.70 \\
209.50\end{array}$ & $\begin{array}{l}163.00 \\
161.20 \\
163.60\end{array}$ & $\begin{array}{l}226.10 \\
223.27 \\
227.09\end{array}$ & $\begin{array}{l}128.15 \\
123.57 \\
129.74\end{array}$ & $\begin{array}{l}0.53 \\
2.41 \\
8.61\end{array}$ & $\begin{array}{l}2.84 \\
1.47 \\
2.76\end{array}$ & 3.10 & 8.61 & $\begin{array}{r}9.28 \\
12.25 \\
17.72\end{array}$ & $\begin{array}{l}19.15 \\
24.47 \\
18.51\end{array}$ & 16.90 & 24.47 \\
\hline $\begin{array}{l}\text { Dissolved } \\
\text { Solids } \\
\text { (mgf) }\end{array}$ & $\begin{array}{l}192.30 \\
171.70 \\
163.90\end{array}$ & $\begin{array}{l}120.20 \\
128.60 \\
124.40\end{array}$ & $\begin{array}{l}168.10 \\
168.40 \\
167.40\end{array}$ & $\begin{array}{l}122.50 \\
122.60 \\
122.30\end{array}$ & $\begin{array}{l}179.48 \\
179.70 \\
178.89\end{array}$ & $\begin{array}{l}100.72 \\
100.96 \\
100.09\end{array}$ & $\begin{array}{r}12.58 \\
1.92 \\
2.14\end{array}$ & $\begin{array}{l}1.91 \\
4.67 \\
1.69\end{array}$ & 4.15 & 12.58 & $\begin{array}{l}6.67 \\
4.66 \\
9.14\end{array}$ & $\begin{array}{l}16.21 \\
21.50 \\
19.54\end{array}$ & 12.95 & 21.50 \\
\hline $\begin{array}{c}\text { Hardness } \\
(\mathrm{mg} / 1) \text { as } \mathrm{CaCO} 3\end{array}$ & $\begin{array}{l}91.10 \\
79.60 \\
77.10\end{array}$ & $\begin{array}{l}64.40 \\
66.70 \\
62.80\end{array}$ & $\begin{array}{l}88.90 \\
86.50 \\
90.90\end{array}$ & $\begin{array}{l}72.90 \\
71.90 \\
73.70\end{array}$ & $\begin{array}{l}96.92 \\
95.36 \\
98.24\end{array}$ & $\begin{array}{l}57.39 \\
54.80 \\
59.56\end{array}$ & $\begin{array}{r}2.41 \\
8.67 \\
17.90\end{array}$ & $\begin{array}{r}13.20 \\
7.80 \\
17.36\end{array}$ & 11.22 & 17.90 & $\begin{array}{r}6.39 \\
19.80 \\
27.42\end{array}$ & $\begin{array}{r}10.89 \\
17.84 \\
5.15\end{array}$ & 14.58 & 27.42 \\
\hline $\begin{array}{c}\text { Alkalinity } \\
\text { (mg//)as } \mathrm{C}_{\theta} \mathrm{CO} 9\end{array}$ & $\begin{array}{l}69.66 \\
74.55 \\
73.22\end{array}$ & $\begin{array}{l}81.05 \\
76.94 \\
74.61\end{array}$ & $\begin{array}{l}87.89 \\
84.25 \\
89.55\end{array}$ & $\begin{array}{l}80.53 \\
76.61 \\
82.34\end{array}$ & $\begin{array}{l}92.25 \\
90.26 \\
93.16\end{array}$ & $\begin{array}{l}72.12 \\
65.01 \\
75.36\end{array}$ & $\begin{array}{l}26.17 \\
13.01 \\
22.30\end{array}$ & $\begin{array}{r}0.64 \\
0.43 \\
10.36\end{array}$ & 12.15 & 26.17 & $\begin{array}{l}32.43 \\
21.08 \\
27.23\end{array}$ & $\begin{array}{r}11.02 \\
15.51 \\
1.01\end{array}$ & 18.05 & 32.43 \\
\hline $\begin{array}{l}\text { Natrium } \\
\text { (mg/l) }\end{array}$ & $\begin{array}{l}32.05 \\
28.22 \\
27.00\end{array}$ & $\begin{array}{l}14.85 \\
17.31 \\
17.27\end{array}$ & $\begin{array}{l}27.08 \\
27.67 \\
25.61\end{array}$ & $\begin{array}{r}15.14 \\
15.25 \\
14.84\end{array}$ & $\begin{array}{l}29.63 \\
30.05 \\
28.57\end{array}$ & $\begin{array}{r}10.25 \\
10.68 \\
9.19\end{array}$ & $\begin{array}{r}15.51 \\
1.95 \\
5.15\end{array}$ & $\begin{array}{r}1.95 \\
11.90 \\
14.07\end{array}$ & 8.42 & 15.51 & $\begin{array}{l}7.57 \\
6.49 \\
5.82\end{array}$ & $\begin{array}{l}30.97 \\
38.31 \\
46.78\end{array}$ & 22.66 & 46.78 \\
\hline $\begin{array}{c}\text { Kalium } \\
\text { (mgli) }\end{array}$ & $\begin{array}{l}1.43 \\
1.64 \\
1.92\end{array}$ & $\begin{array}{l}3.79 \\
3.51 \\
3.37\end{array}$ & $\begin{array}{l}1.62 \\
1.65 \\
1.70\end{array}$ & $\begin{array}{l}3.85 \\
3.89 \\
3.95\end{array}$ & $\begin{array}{l}1.65 \\
1.66 \\
1.69\end{array}$ & $\begin{array}{l}3.78 \\
3.84 \\
4.01\end{array}$ & $\begin{array}{r}13.52 \\
0.73 \\
11.27\end{array}$ & $\begin{array}{r}1.56 \\
10.89 \\
17.35\end{array}$ & 9.22 & 17.35 & $\begin{array}{r}15.42 \\
1.27 \\
11.81\end{array}$ & $\begin{array}{r}0.26 \\
9.59 \\
19.15\end{array}$ & 9.58 & 19.15 \\
\hline $\begin{array}{l}\text { Calcium } \\
\text { (mg/l) }\end{array}$ & $\begin{array}{l}19.05 \\
16.83 \\
16.61\end{array}$ & $\begin{array}{l}14.97 \\
15.63 \\
14.88\end{array}$ & $\begin{array}{l}18.75 \\
18.51 \\
19.66\end{array}$ & $\begin{array}{l}17.19 \\
17.07 \\
17.65\end{array}$ & $\begin{array}{l}20.41 \\
20.25 \\
21.05\end{array}$ & $\begin{array}{l}13.96 \\
13.71 \\
14.86\end{array}$ & $\begin{array}{r}1.57 \\
9.98 \\
18.36\end{array}$ & $\begin{array}{r}14.83 \\
9.21 \\
18.62\end{array}$ & 12.10 & 18.62 & $\begin{array}{r}7.12 \\
20.31 \\
26.73\end{array}$ & $\begin{array}{r}6.75 \\
12.27 \\
0.55\end{array}$ & 12.29 & 26.73 \\
\hline $\begin{array}{l}\text { Magnesium } \\
\text { (mmgli) }\end{array}$ & $\begin{array}{r}10.55 \\
9.11 \\
8.64\end{array}$ & $\begin{array}{l}6.56 \\
6.69 \\
6.19\end{array}$ & $\begin{array}{r}10.36 \\
9.91 \\
10.20\end{array}$ & $\begin{array}{l}7.01 \\
6.91 \\
6.95\end{array}$ & $\begin{array}{l}11.09 \\
10.78 \\
10.99\end{array}$ & $\begin{array}{l}5.58 \\
5.08 \\
5.43\end{array}$ & $\begin{array}{r}1.80 \\
8.77 \\
18.00\end{array}$ & $\begin{array}{r}6.84 \\
3.32 \\
12.31\end{array}$ & 8.51 & 18.00 & $\begin{array}{r}5.08 \\
18.30 \\
27.13\end{array}$ & $\begin{array}{l}14.90 \\
24.02 \\
12.32\end{array}$ & 16.96 & 27.13 \\
\hline
\end{tabular}


Table 5.5(d) 4 yearly

\begin{tabular}{|c|c|c|c|c|c|c|c|c|c|c|c|c|c|c|}
\hline \multirow{4}{*}{$\begin{array}{l}\text { Wator Qusathy } \\
\text { Paramotor }\end{array}$} & \multirow{2}{*}{\multicolumn{2}{|c|}{ Obestrad Values }} & \multirow{2}{*}{\multicolumn{2}{|c|}{$\begin{array}{l}\text { Aesignod Values } \\
\text { \{Entropy Meltiod) }\end{array}$}} & \multirow{2}{*}{\multicolumn{2}{|c|}{$\begin{array}{c}\text { Asedgnod Valuos } \\
\text { (Ragreston Mathed) }\end{array}$}} & \multicolumn{8}{|c|}{ Absolute Values of Errors (\%) } \\
\hline & & & & & & & \multicolumn{4}{|c|}{ (Entropy Method) } & \multicolumn{4}{|c|}{ (R\&grq*⿻三丨日巾 Mon Mithod) } \\
\hline & \multicolumn{2}{|c|}{ at Station } & \multirow{2}{*}{\multicolumn{2}{|c|}{$\begin{array}{l}\text { at Stailon } \\
130401 \quad 130108\end{array}$}} & \multirow{2}{*}{\multicolumn{2}{|c|}{$\begin{array}{l}\text { of Station } \\
130401 \quad 130106\end{array}$}} & \multicolumn{2}{|c|}{ at Statlon } & \multirow[b]{2}{*}{ Average } & \multirow[b]{2}{*}{ Maximum } & \multicolumn{2}{|c|}{ at Station } & \multirow[b]{2}{*}{ Average } & \multirow[b]{2}{*}{ Maximum } \\
\hline & 130401 & 130106 & & & & & 130401 & 130106 & & & 130401 & 130108 & & \\
\hline (1) & \multicolumn{2}{|c|}{ (2) } & \multicolumn{2}{|c|}{ (3) } & \multicolumn{2}{|c|}{ (4) } & \multicolumn{2}{|c|}{ (5) } & (6) & (7) & \multicolumn{2}{|c|}{ (8) } & (9) & (10) \\
\hline Conduclivity & 332.40 & 214.20 & 318.60 & 212.40 & 341.50 & 169.15 & 6.12 & 0.70 & \multirow[t]{2}{*}{3.45} & \multirow[t]{2}{*}{6.13} & 0.65 & 21.29 & \multirow[t]{2}{*}{13.69} & \multirow[t]{2}{*}{21.29} \\
\hline$(\mathrm{ms} / \mathrm{m})$ & 302.30 & 211.40 & 320.10 & 213.70 & 342.67 & 170.24 & 5.89 & 1.09 & & & 13.36 & 19.47 & & \\
\hline $\mathrm{PH}$ & 7.91 & 7.09 & 7.97 & 7.60 & 3.00 & 7.57 & 0.73 & 0.43 & 1.79 & 4.40 & 1.15 & 1.50 & 2.10 & 4.54 \\
\hline Dissolved & 190.40 & 160.40 & 215.90 & 166.40 & 228.79 & 141.69 & 8.27 & 3.74 & 7.06 & 11.91 & 14.74 & 11.66 & 13.73 & 18.19 \\
\hline $\begin{array}{l}\text { Ions } \\
\text { (ngg)! }\end{array}$ & 184.80 & 160.30 & 218.00 & 167.20 & 230.23 & 143.75 & $\$ 1.91$ & 4.30 & & & 18.19 & 10.32 & & \\
\hline Dissolved & 183.40 & 125.20 & 171.00 & 123.50 & 181.09 & 104.08 & 6.76 & 1.36 & 3.05 & 6.76 & 1.26 & 16.87 & 10.69 & 16.87 \\
\hline $\begin{array}{l}\text { Solids } \\
\{\text { magn }\}\end{array}$ & 168.30 & 124.00 & 172.80 & 124.20 & 182.48 & 105.52 & 3.91 & $\overline{0} .16$ & & & 9.73 & 14.90 & & \\
\hline Hardness & 86.30 & 64.70 & 92.25 & 74.22 & 97.25 & 64.60 & 6.89 & 14.71 & $\$ 3.92$ & 19.43 & 12.69 & 0.15 & 9.83 & 25.19 \\
\hline$(\mathrm{mg} /$ il)as $\mathrm{CaCO}$ & 78.60 & 65.30 & 93.87 & 74.87 & 98.40 & 66.14 & 19.43 & 14.66 & & & 25.19 & 1.28 & & \\
\hline Alkalinity & 68.41 & 77.66 & 89,60 & 82.44 & 92.36 & 77.16 & 30.98 & 6.16 & 16.45 & 30.98 & 35.00 & 0.65 & 15.35 & 35.00 \\
\hline$\langle m g / l)$ & 73.91 & 77.70 & 90.10 & 82.96 & 92.64 & 78.03 & 21.91 & 6.77 & & & 25.34 & 0.42 & & \\
\hline Natrium & 30.29 & 16.64 & 28.12 & 15.34 & 30.44 & 10.88 & 7.16 & 7.81 & 6.41 & 7.81 & 0.48 & 34.62 & 19.98 & 34.62 \\
\hline$(\operatorname{mog} / t)$ & 27.16 & 16.36 & 28.50 & 15.42 & 30.71 & 11.17 & 4.93 & 5.75 & & & 13.06 & 31.75 & & \\
\hline Kalium & 1.55 & 3.59 & 1.64 & 3.88 & 1.66 & 3.83 & 5.53 & 7.99 & 8.01 & 11.75 & 6.85 & 6.69 & 7.61 & 11.22 \\
\hline (mgri) & 1.77 & 3.48 & 1.65 & 3.89 & 1.67 & 3.87 & 6.78 & 11.75 & & & 5.69 & 11.22 & & \\
\hline Calcium & 18.12 & 14.97 & 19.71 & 17.68 & 20.91 & 15.41 & 8.77 & 18.10 & 15.54 & 19.50 & 15.37 & 2.92 & 11.66 & 25.84 \\
\hline$(\mathrm{mg} / \mathrm{l})$ & 16.87 & 15.47 & 20.16 & +7.91 & 21.23 & 15.86 & 19.50 & 15.77 & & & 25.84 & 2.52 & & \\
\hline Magnesium & 9.96 & 6.62 & 10.58 & 7.09 & 10.92 & 6.41 & 6.25 & 7.10 & 11.34 & 20.90 & 9.71 & 3.22 & 9.66 & 24.34 \\
\hline (mg/i) & 8.85 & 6.42 & 10.70 & 7.13 & 11.00 & 6.50 & 20.90 & 11.13 & & & 24.34 & 1.38 & & \\
\hline
\end{tabular}




\section{Table 5.6 Summary of Error Values for Entropy and Regression Methods}

Table 5.6(a) 1 yearly

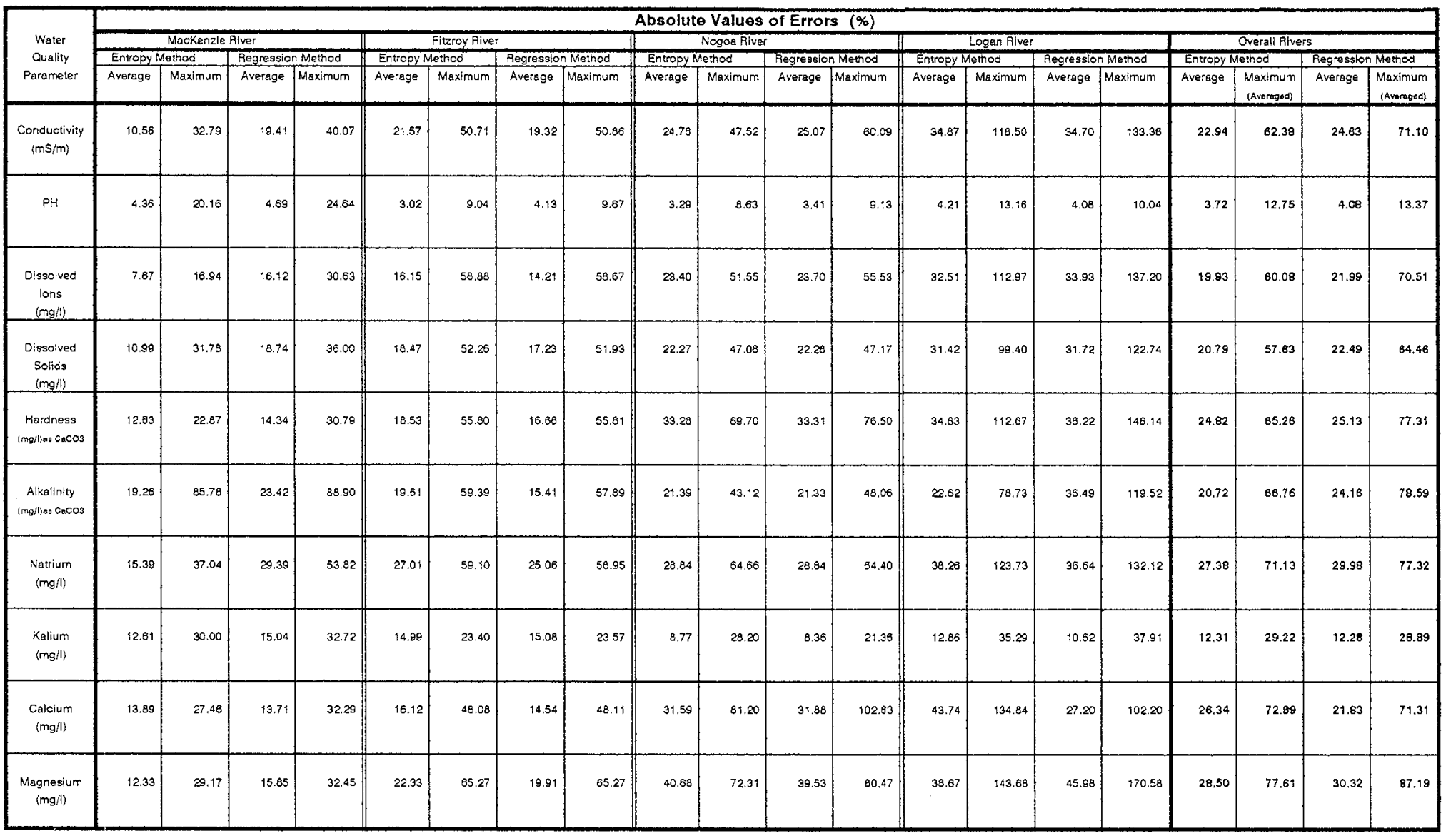


Table 5.6(b) 2 yearly

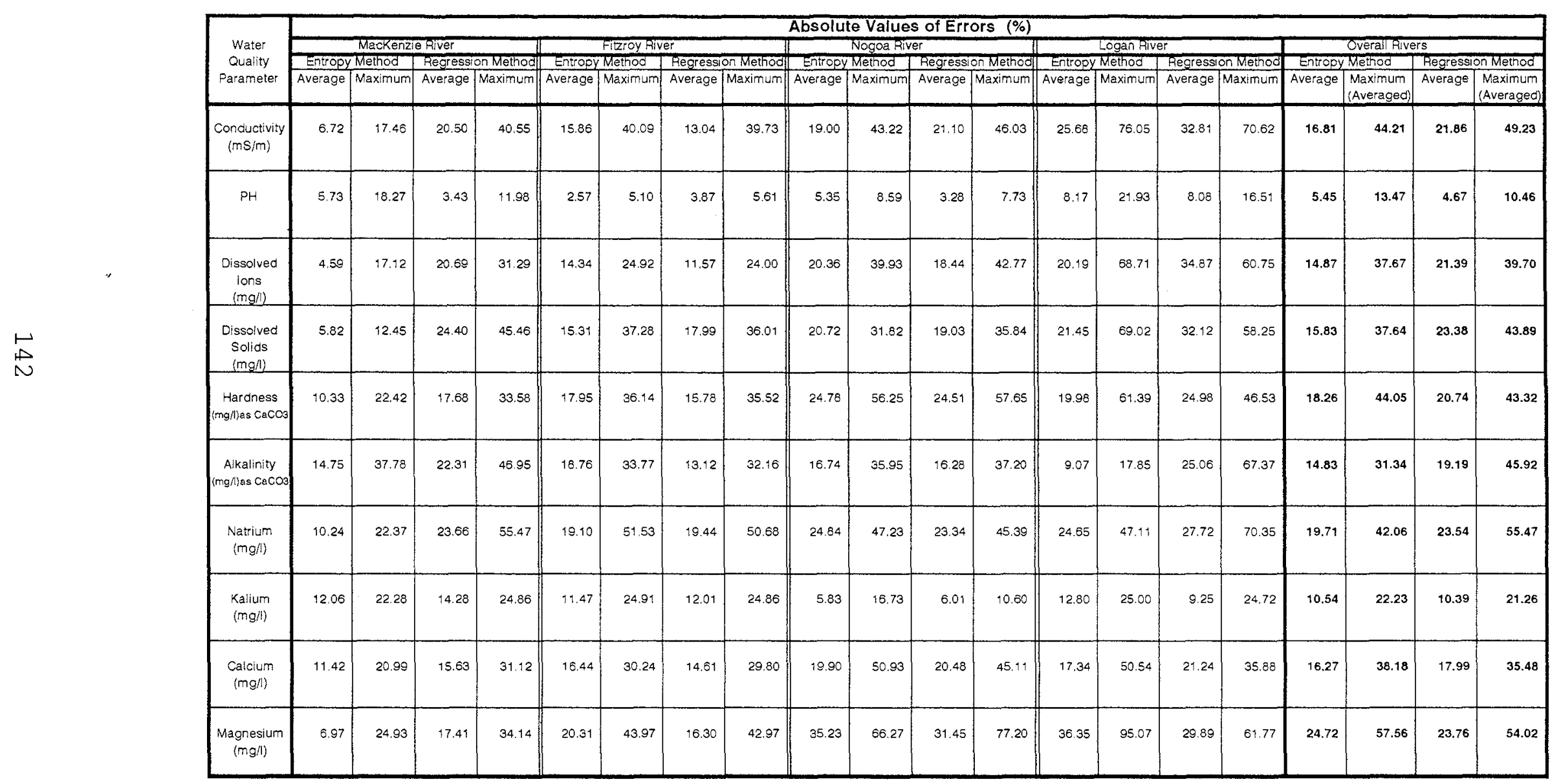


Table 5.6(c) 3 yearly

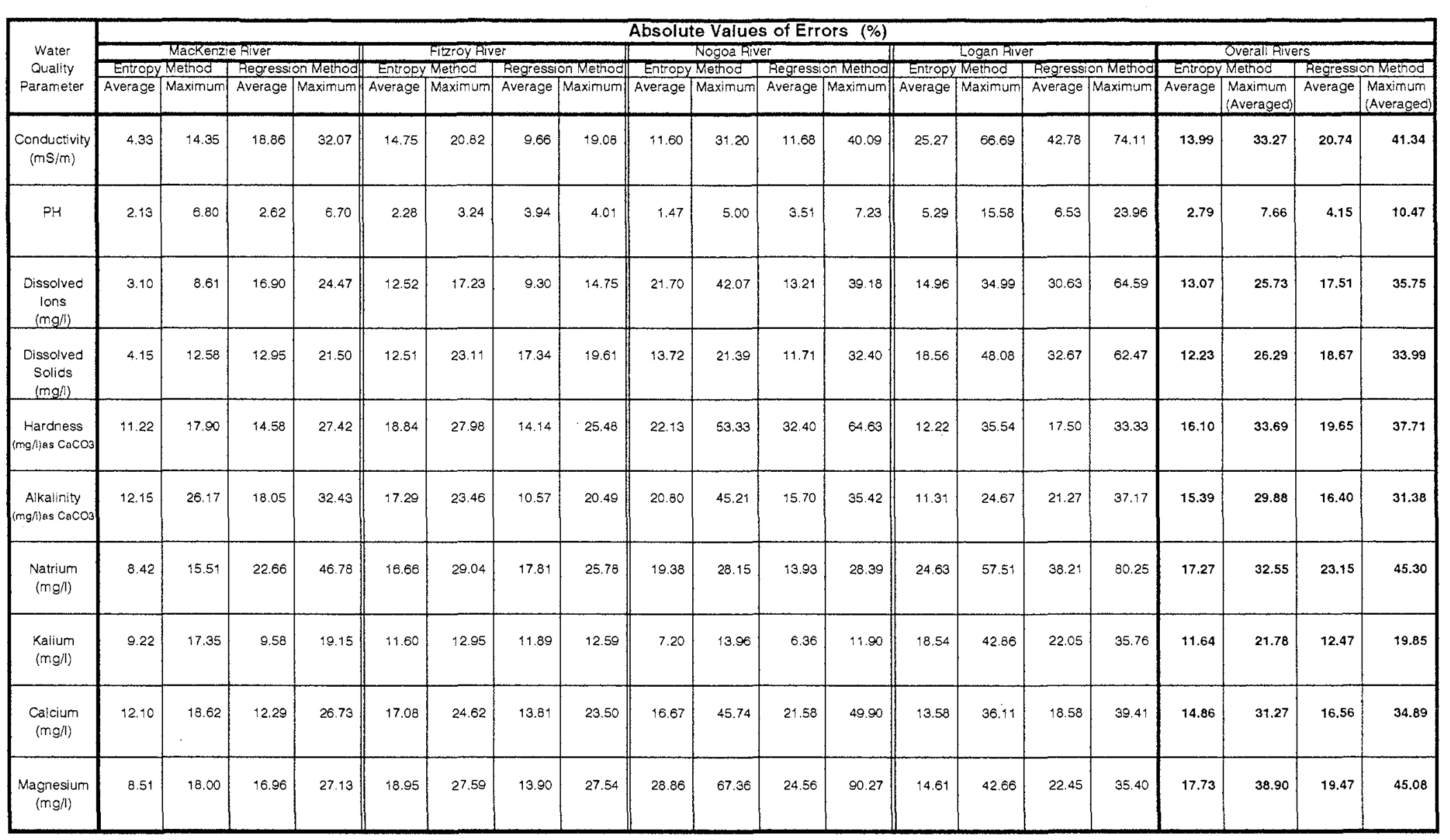


Table 5.6(d) 4 yearly

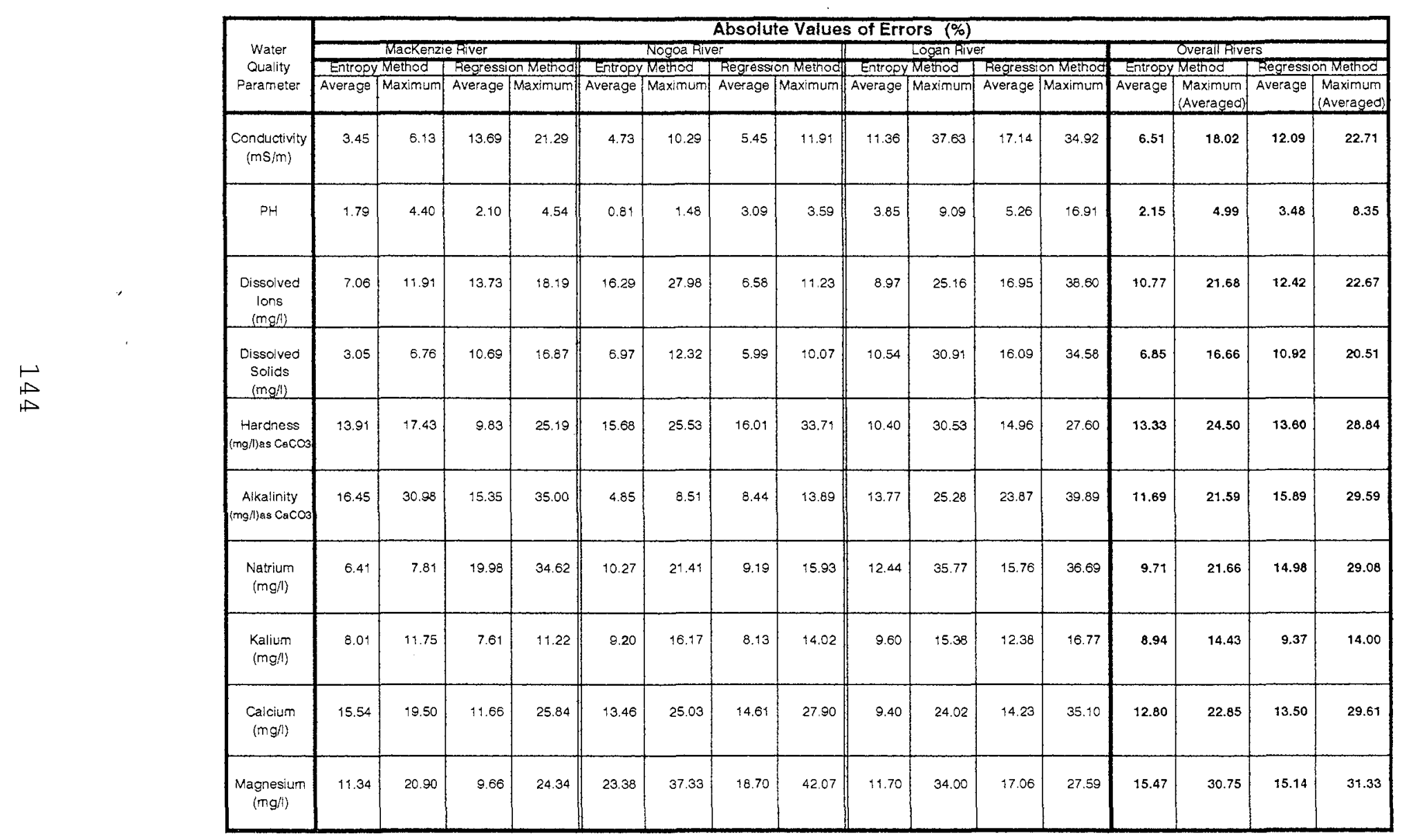


Table 5.7 Summary of the Absolute Errors of the Predicted Values

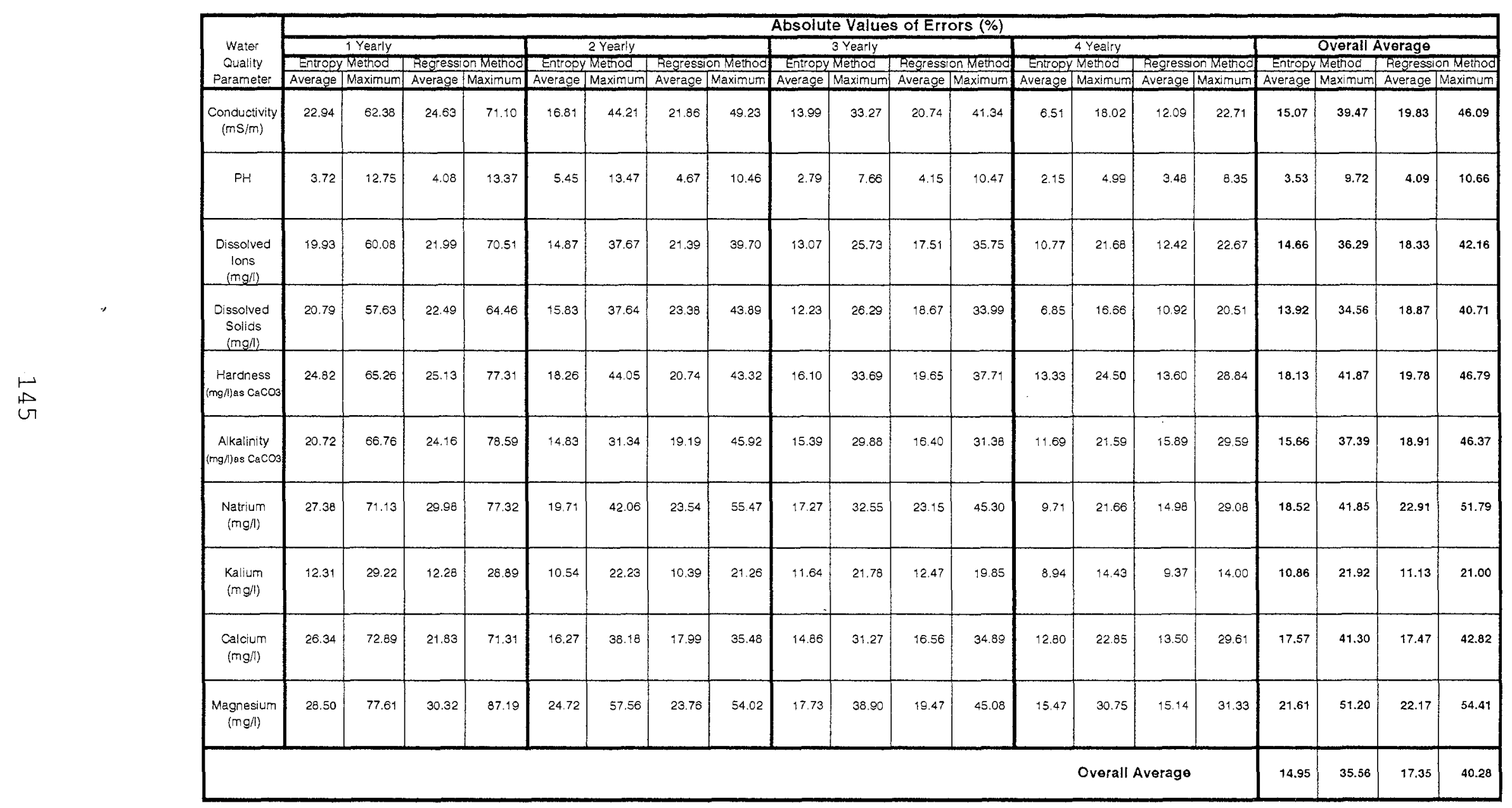


values are also shown in these tables. The regression coefficients used in the calculations for the various cases are shown in Table 5.8 and Tables A.5.1 to A.5.3 in the Appendix A. [ All the data used for this case are assumed to be normally distributed. As noted previously, only a few parameters are not normally distributed at a 5\% rejection level, and can, with the exception of Magnesium at Station 130106, be accepted as normally distributed at the $1 \%$ rejection level].

It can be seen from Tables $5.5(a)$ to 5.5 (d) that, for most of the water quality parameters at Mackenzie River, the entropy method predicts the water quality values at discontinued monitoring stations, more accurately, than the regression method using the same data. (Results for other sets of data at different rivers are presented in Tables $A 4.1$ to $A 4.3$ in Appendix A).

Tables $5.6(a)$ to $5.6(d)$ summarise the results of predicting the values of water quality parameters at discontinued monitoring stations, for each of the four sets of data at the different locations. In particular these tables show the average and maximum errors of the predictions of the entropy or regression methods. The absolute errors in these tables were calculated using the following expression: Error $=(\mathrm{XP}-\mathrm{XO}) / \mathrm{xO}$, where $\mathrm{XP}=$ 
Table 5.8 Regression Coefficients for Various Periods of Time in the MacKenzie River Sub-Basin

Table 5.8(a) Between the Downstream Station 130105 and the Upstream Station 130401

Upstream Value $=B o+B i *$ (Downstream Value)

\begin{tabular}{|c|c|c|c|c|c|}
\hline $\begin{array}{c}\text { Water Quality } \\
\text { Parameter }\end{array}$ & $\begin{array}{l}\text { Regression } \\
\text { Coefficiont }\end{array}$ & 1 Yearly & 2 Yearly & 3 Yeariy & 4 Yearly \\
\hline $\begin{array}{l}\text { Conductivity } \\
\text { (ms/m) }\end{array}$ & $\begin{array}{c}\text { Bo } \\
\text { Bi } \\
\text { Correlation } \\
\text { Coefficient }\end{array}$ & $\begin{array}{c}100.20 \\
0.86 \\
0.83\end{array}$ & $\begin{array}{c}168.70 \\
0.66 \\
0.80\end{array}$ & $\begin{array}{l}184.12 \\
0.62 \\
0.85\end{array}$ & $\begin{array}{c}197.36 \\
0.60 \\
0.97\end{array}$ \\
\hline $\mathrm{PH}$ & $\begin{array}{c}\text { Bo } \\
\text { Bi } \\
\text { Correlation } \\
\text { Coefticient } \\
\end{array}$ & $\begin{array}{l}7.49 \\
0.05 \\
0.04\end{array}$ & $\begin{array}{c}10.57 \\
-0.34 \\
0.32\end{array}$ & $\begin{array}{c}10.27 \\
-0.30 \\
0.32\end{array}$ & $\begin{array}{l}11.07 \\
-0.40 \\
0.32\end{array}$ \\
\hline $\begin{array}{l}\text { Dissolved lons } \\
\text { (mg/l) }\end{array}$ & $\begin{array}{c}\text { Bo } \\
\mathrm{Bi} \\
\text { Correlation } \\
\text { Coefficient } \\
\end{array}$ & $\begin{array}{c}64.07 \\
0.85 \\
0.81\end{array}$ & $\begin{array}{c}140.10 \\
0.52 \\
0.83\end{array}$ & $\begin{array}{c}134.35 \\
0.55 \\
0.83\end{array}$ & $\begin{array}{c}142.94 \\
0.52 \\
0.89\end{array}$ \\
\hline $\begin{array}{c}\text { Dissolved Solids } \\
\text { (mg/) }\end{array}$ & $\begin{array}{c}\text { Bo } \\
\text { Bi } \\
\text { Correlation } \\
\text { Coefficient } \\
\end{array}$ & $\begin{array}{c}24.57 \\
1.00 \\
0.84\end{array}$ & $\begin{array}{c}116.30 \\
0.55 \\
0.81\end{array}$ & $\begin{array}{l}77.80 \\
0.73 \\
0.91\end{array}$ & $\begin{array}{c}78.78 \\
0.73 \\
0.99\end{array}$ \\
\hline $\begin{array}{c}\text { Hardness } \\
\text { (mg/l)as } \mathrm{CaCO} 3\end{array}$ & $\begin{array}{c}\text { Bo } \\
\text { Bi } \\
\text { Correlation } \\
\text { Coefficient } \\
\end{array}$ & $\begin{array}{c}30.57 \\
0.83 \\
0.84\end{array}$ & $\begin{array}{l}63.66 \\
0.49 \\
0.79\end{array}$ & $\begin{array}{l}64.77 \\
0.49 \\
0.78\end{array}$ & $\begin{array}{l}66.04 \\
0.48 \\
0.95\end{array}$ \\
\hline $\begin{array}{c}\text { Alkatinity } \\
\text { (mg/l)as } \mathrm{CaCO} 3\end{array}$ & $\begin{array}{c}\text { Bo } \\
\text { Bi } \\
\text { Correlation } \\
\text { Coefficient }\end{array}$ & $\begin{array}{c}41.41 \\
0.62 \\
0.71\end{array}$ & $\begin{array}{c}71.92 \\
0.28 \\
0.68\end{array}$ & $\begin{array}{c}69.46 \\
0.31 \\
0.67\end{array}$ & $\begin{array}{c}70.51 \\
0.31 \\
0.93\end{array}$ \\
\hline $\begin{array}{l}\text { Natrium } \\
(\mathrm{mg} / \mathrm{l})\end{array}$ & $\begin{array}{c}\text { Bo } \\
\text { Bi } \\
\text { Correlation } \\
\text { Coefficient } \\
\end{array}$ & $\begin{array}{c}10.93 \\
0.82 \\
0.81\end{array}$ & $\begin{array}{l}17.52 \\
0.58 \\
0.88\end{array}$ & $\begin{array}{l}16.03 \\
0.64 \\
0.90\end{array}$ & $\begin{array}{l}19.00 \\
0.54 \\
0.99\end{array}$ \\
\hline $\begin{array}{l}\text { Kalium } \\
\text { (mgn) }\end{array}$ & $\begin{array}{c}\text { Bo } \\
\text { Bi } \\
\text { Correlation } \\
\text { Coefficient }\end{array}$ & $\begin{array}{l}1.56 \\
0.02 \\
0.12\end{array}$ & $\begin{array}{c}1.76 \\
-0.04 \\
0.25\end{array}$ & $\begin{array}{l}1.52 \\
0.04 \\
0.25\end{array}$ & $\begin{array}{l}1.50 \\
0.05 \\
0.47\end{array}$ \\
\hline $\begin{array}{l}\text { Calcium } \\
(\mathrm{mg} /)\end{array}$ & $\begin{array}{c}\text { Bo } \\
\text { Bi } \\
\text { Correlation } \\
\text { Coefficient } \\
\end{array}$ & $\begin{array}{l}7.54 \\
0.77 \\
0.82\end{array}$ & $\begin{array}{l}13.68 \\
0.47 \\
0.83\end{array}$ & $\begin{array}{l}13.61 \\
0.48 \\
0.80\end{array}$ & $\begin{array}{l}14.82 \\
0.43 \\
0.97\end{array}$ \\
\hline $\begin{array}{l}\text { Magnesium } \\
\qquad(\mathrm{mg} / \mathrm{l})\end{array}$ & $\begin{array}{c}\text { Bo } \\
\text { Bi } \\
\text { Correlation } \\
\text { Coefficient }\end{array}$ & $\begin{array}{l}2.70 \\
0.92 \\
0.86\end{array}$ & $\begin{array}{l}6.41 \\
0.59 \\
0.73\end{array}$ & $\begin{array}{l}7.05 \\
0.54 \\
0.77\end{array}$ & $\begin{array}{l}6.90 \\
0.56 \\
0.94\end{array}$ \\
\hline
\end{tabular}


Table 5.8(b) Between the Downstream Station 130105 and the Upstream Station 130106

Upstream Value $=B o+B i *($ Downstream Value $)$

\begin{tabular}{|c|c|c|c|c|c|}
\hline $\begin{array}{c}\text { Water Quality } \\
\text { Parameter }\end{array}$ & $\begin{array}{r}\text { Regression } \\
\text { Coefficient }\end{array}$ & 1 Yearly & 2 Yearly & 3 Yearly & 4 Yearly \\
\hline $\begin{array}{l}\text { Conductivity } \\
(\mathrm{mS} / \mathrm{m})\end{array}$ & $\begin{array}{c}\text { Bo } \\
\text { Bi } \\
\text { Correlation } \\
\text { Coefficient } \\
\end{array}$ & $\begin{array}{c}-14.70 \\
0.68 \\
0.79\end{array}$ & $\begin{array}{c}-44.00 \\
0.77 \\
0.79\end{array}$ & $\begin{array}{c}-24.28 \\
0.72 \\
0.85\end{array}$ & $\begin{array}{c}23.02 \\
0.60 \\
0.95\end{array}$ \\
\hline $\mathrm{PH}$ & $\begin{array}{c}\text { Bo } \\
\text { Bi } \\
\text { Correlation } \\
\text { Coefficient } \\
\end{array}$ & $\begin{array}{l}1.00 \\
0.85 \\
0.83\end{array}$ & $\begin{array}{l}1.41 \\
0.80 \\
0.82\end{array}$ & $\begin{array}{l}1.46 \\
0.80 \\
0.92\end{array}$ & $\begin{array}{l}0.98 \\
0.86 \\
0.90\end{array}$ \\
\hline $\begin{array}{c}\text { Dissolved lons } \\
(\mathrm{mg} / \mathrm{l})\end{array}$ & $\begin{array}{c}\text { Bo } \\
\text { Bi } \\
\text { Correlation } \\
\text { Coefficient } \\
\end{array}$ & $\begin{array}{c}-29.60 \\
0.90 \\
0.73\end{array}$ & $\begin{array}{c}-41.90 \\
0.96 \\
0.71\end{array}$ & $\begin{array}{c}-20.00 \\
0.88 \\
0.79\end{array}$ & $\begin{array}{c}19.12 \\
0.74 \\
0.92\end{array}$ \\
\hline $\begin{array}{c}\text { Dissolved Solid } \\
(\mathrm{mg} / 1)\end{array}$ & $\begin{array}{c}\text { Bo } \\
\text { Bi } \\
\text { Correlation } \\
\text { Coefficient } \\
\end{array}$ & $\begin{array}{c}-32.20 \\
0.87 \\
0.76\end{array}$ & $\begin{array}{c}-76.00 \\
1.09 \\
0.74\end{array}$ & $\begin{array}{c}-33.03 \\
0.90 \\
0.83\end{array}$ & $\begin{array}{l}-2.49 \\
0.76 \\
0.94\end{array}$ \\
\hline $\begin{array}{c}\text { Hardness } \\
(\mathrm{mg} / \mathrm{l}) \text { as } \mathrm{CaCO} 3\end{array}$ & $\begin{array}{c}\text { Bo } \\
\text { Bi } \\
\text { Correlation } \\
\text { Coefficient } \\
\end{array}$ & $\begin{array}{c}-5.20 \\
0.88 \\
0.73\end{array}$ & $\begin{array}{c}-4.76 \\
0.88 \\
0.69\end{array}$ & $\begin{array}{l}4.12 \\
0.81 \\
0.77\end{array}$ & $\begin{array}{c}23.11 \\
0.64 \\
0.90\end{array}$ \\
\hline $\begin{array}{c}\text { Alkalinity } \\
(\mathrm{mg} / \mathrm{l}) \text { as } \mathrm{CaCO} 3\end{array}$ & $\begin{array}{c}\text { Bo } \\
\text { Bi } \\
\text { Correlation } \\
\text { Coefficient } \\
\end{array}$ & $\begin{array}{c}-20.00 \\
1.21 \\
0.72\end{array}$ & $\begin{array}{c}-22.10 \\
1.24 \\
0.71\end{array}$ & $\begin{array}{l}-9.39 \\
1.12 \\
0.78\end{array}$ & $\begin{array}{c}10.20 \\
0.94 \\
0.89\end{array}$ \\
\hline $\begin{array}{l}\text { Natrium } \\
(\mathrm{mg} / \mathrm{l})\end{array}$ & $\begin{array}{c}\mathrm{Bo} \\
\mathrm{Bi} \\
\text { Correlation } \\
\text { Coefficient } \\
\end{array}$ & $\begin{array}{c}-0.46 \\
0.53 \\
0.82\end{array}$ & $\begin{array}{l}-4.66 \\
0.67 \\
0.85\end{array}$ & $\begin{array}{l}-3.43 \\
0.64 \\
0.91\end{array}$ & $\begin{array}{r}-1.21 \\
0.57 \\
0.98\end{array}$ \\
\hline $\begin{array}{l}\text { Kalium } \\
(\mathrm{mg} / \mathrm{l})\end{array}$ & $\begin{array}{c}\mathrm{Bo} \\
\mathrm{Bi} \\
\text { Correlation } \\
\text { Coefficient } \\
\end{array}$ & $\begin{array}{l}3.19 \\
0.20 \\
0.86\end{array}$ & $\begin{array}{l}3.28 \\
0.17 \\
0.86\end{array}$ & $\begin{array}{l}3.10 \\
0.24 \\
0.91\end{array}$ & $\begin{array}{l}3.15 \\
0.22 \\
0.97\end{array}$ \\
\hline $\begin{array}{c}\text { Calcium } \\
(\mathrm{mg} / \mathrm{l})\end{array}$ & $\begin{array}{c}\text { Bo } \\
\text { Bi } \\
\text { Correlation } \\
\text { Coefficient } \\
\end{array}$ & $\begin{array}{l}0.29 \\
0.88 \\
0.78\end{array}$ & $\begin{array}{l}0.75 \\
0.86 \\
0.73\end{array}$ & $\begin{array}{l}3.37 \\
0.75 \\
0.79\end{array}$ & $\begin{array}{l}6.88 \\
0.60 \\
0.90\end{array}$ \\
\hline $\begin{array}{l}\text { Magnesium } \\
(\mathrm{mg} / \mathrm{l})\end{array}$ & $\begin{array}{c}\mathrm{Bo} \\
\mathrm{Bi} \\
\text { Correlation } \\
\text { Coefficient }\end{array}$ & $\begin{array}{l}-0.38 \\
0.80 \\
0.65\end{array}$ & $\begin{array}{r}-1.07 \\
0.87 \\
0.57\end{array}$ & $\begin{array}{l}-1.01 \\
0.89 \\
0.71\end{array}$ & $\begin{array}{l}1.46 \\
0.69 \\
0.88\end{array}$ \\
\hline
\end{tabular}


values predicted by the entropy method and regression method as appropriate, and $\mathrm{XO}=$ observed value.

It can be seen that, in general, the entropy method is 1) a more accurate predictor than the regression method for most of the water quality parameters at the Mackenzie and Logan River; 2) about the same for the Nogoa River, and 3) a little worse for the Fitzroy River. However, the average of over all the rivers, shows that the entropy method is better, overall, than the regression method. It should be recalled that this comparison is very valid in that both the entropy method and regression use the same set of input for their development/calibration and are compared on the basis of the same set of verification data.

It is also important to note that, in general, the maximum errors produced by the entropy method are significantly smaller than the maximum errors produced by the regression technique. Furthermore, as shown in Tables $5.6(a)$ to $5.6(d)$, there is also a general tendency that when the entropy method performs better (in term of the value of the average error), the values of those average errors are significantly smaller than the average errors for the regression technique. On the other hand, when the reverse happens, the average errors from the regression technique are generally only 
slightly smaller than the error obtained by the entropy method. As might be expected from regression theory, the average and maximum errors in the predictions generally decrease as the value of the correlation coefficient increases.

It can also be seen in Tables $5.5(\mathrm{a})$ to $5.5(\mathrm{~d})$, that the predicted values for a number of water quality parameters, namely, Conductivity, PH, Dissolved Ions, Dissolved Solids, Natrium and Kalium, tend to have smaller average errors than other water quality parameters. It is suspected that the normality of the distribution of the historical data plays an important role for this case, since these are the parameters which conform most closely to the normal distribution, such as indicated by relatively high $\mathbf{w}$ values compared to the $\mathbf{w}_{\mathbf{c r}}$ values in the Saphiro-Wilk test for the data sets from both upstream stations.

It is also interesting to note that, in general, the errors tend to be smaller for larger periods of time averaging. This fact is not surprising, since the entropy concept is based on a statistical theory developed on the basis of a large number of experiments, and the prediction of the 'new' mean values is conducted by assigning the most likely 'new' probability distribution. Therefore, prediction of a 'new' mean 
defined in terms of a longer period of time, i.e., from more data points might be expected to be more accurate.

The percentage errors from running the proposed model for CASE I, using observed data from four sets of stations from Queensland described in section 5.1 for the selected water quality parameters and for various time averaging intervals are summarised in Table 5.7. Figures $5.2(\mathrm{a})$ to $5.2(\mathrm{~d})$ are examples of graphical representation of the accuracy of the water quality values observed and assigned by the entropy and regression methods. (Graphs of the similar plots for other water quality parameters are presented in Figures B. 3 Appendix B.)

These results indicate that, in general, the entropy model performs better (predicts the values more closely more often) than the classical regression method in predicting values at the discontinued monitoring stations. The total average absolute error of the prediction using the proposed model (with normal approximation) over all the four data sets from different rivers, and for various time averaging is found to be $14.95 \%$ while the same error using the regression method is $17.35 \%$

Furthermore, unlike the 'classical' linear 


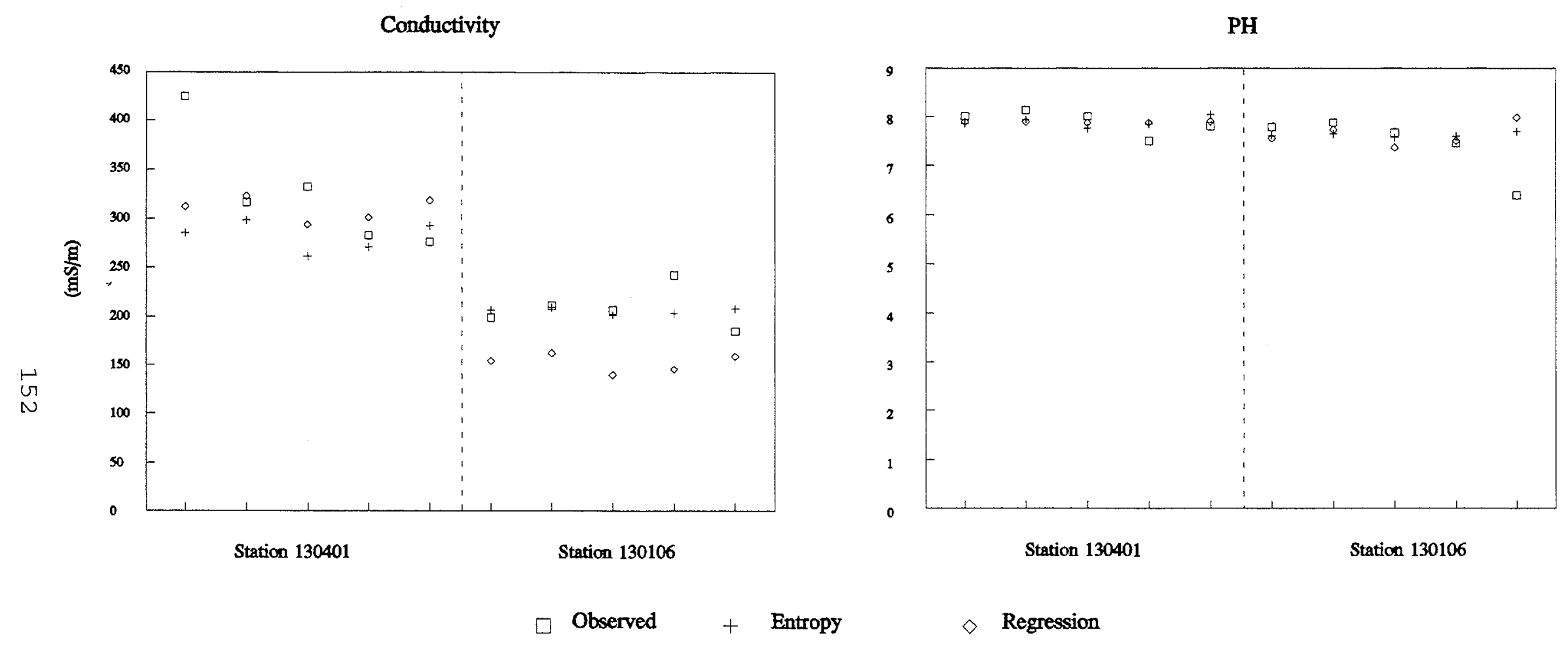

Figure 5.2(a) Plot of Water Quality Values in the MacKenzie River (1 yearly) 


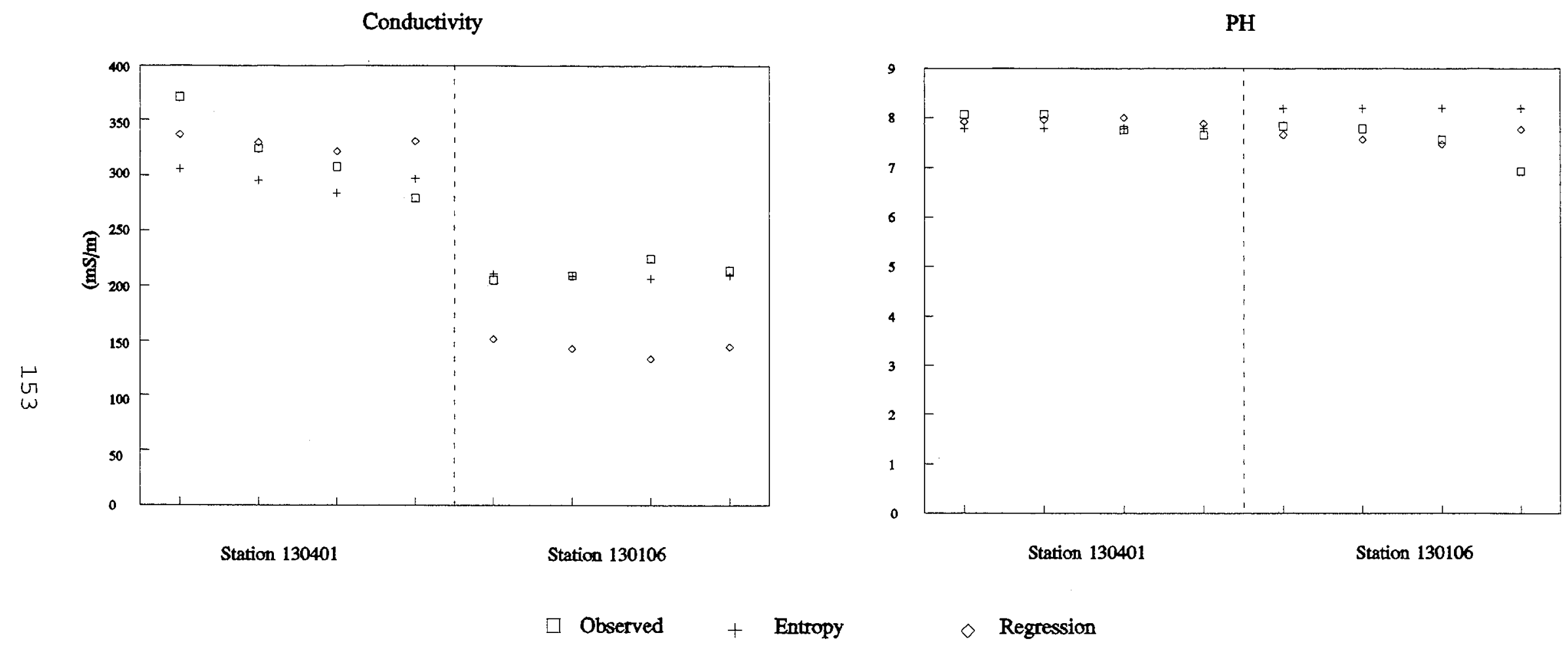

Figure 5.2(b) Plot of Water Quality Values in the MacKenzie River ( 2 yearly ) 


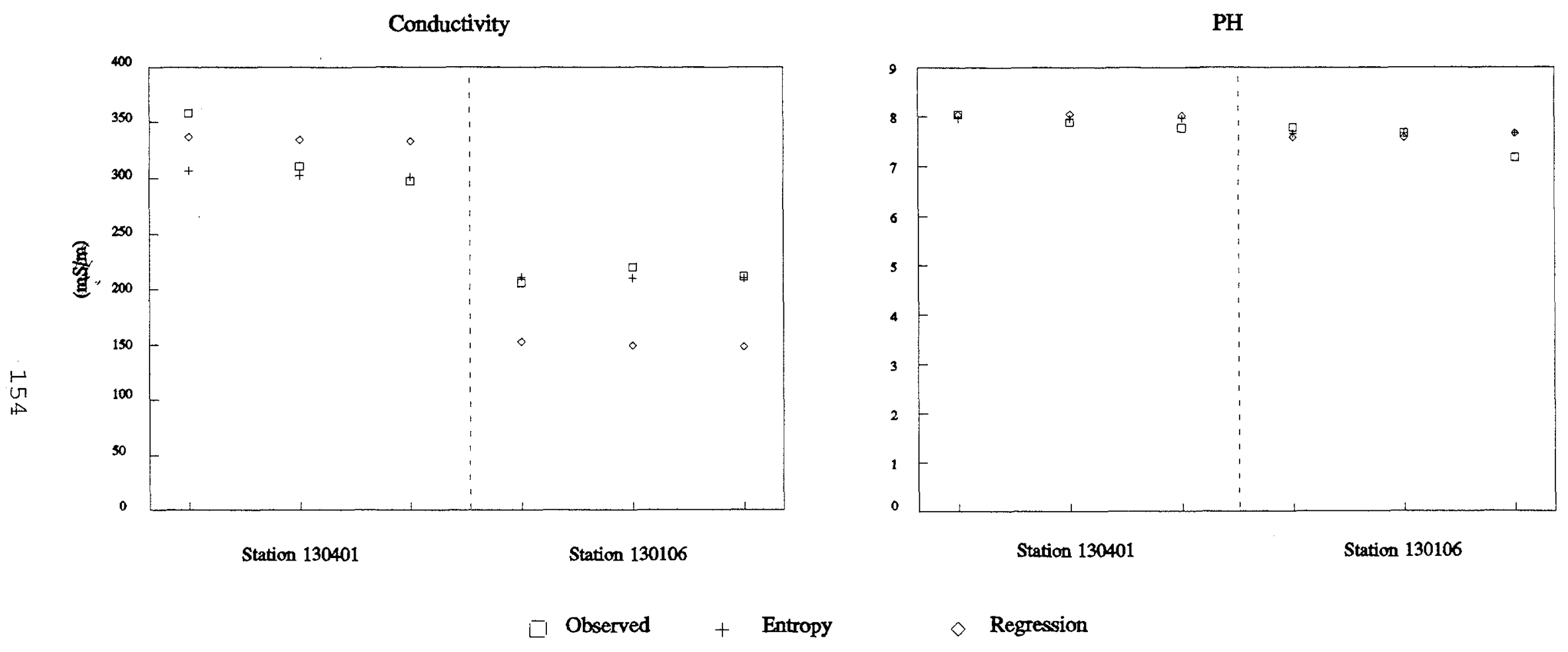

Figure 5.2(c) Plot of Water Quality Values in the MacKenzie River ( 3 yearly ) 


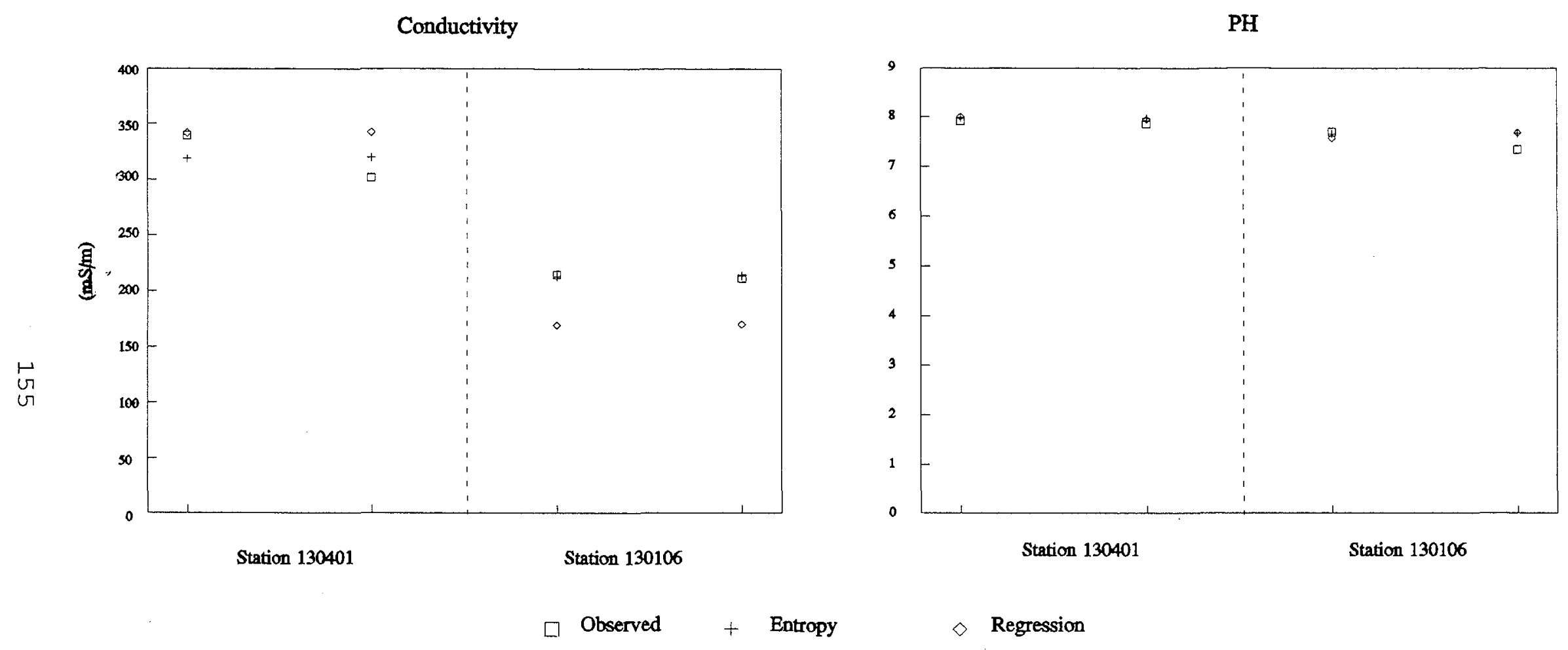

Figure 5.2(d) Plot of Water Quality Values in the MacKenzie River ( 4 yearly ) 
regression technique, the proposed method is able to consider explicitly the probability distribution of the water quality at the discontinued monitoring stations, prior to the closure of the stations, as a reference, while also including the relationship among the upstream and the downstream stations. The capability of the model to include this information may be one reason the results are better than those obtained from the 'classical' linear regression approach.

\section{b. CASE II. Non-normal Distribution}

Non-normality of the data is the issue of concern for this case. If the data are not normal the model can be run with exactly the same formulation, but with an appropriate probability distribution applied through the prior distribution $\left(q_{n i}\right)$. In this case the log-normal transformation was used for those data that did not conform to the normal distribution at the 5\% less significance level in the saphiro-Wilk test. (The results of the tests for normality presented in Table 5.4 and Tables C.3.1 to C.3.3 in Appendix C, show that a number of water quality parameters from the observed data fall within this category.) There are three parameters from the data set from the Mackenzie River, i.e., Dissolved Ions, Hardness and Magnesium at station 130106; three parameters from the data set from the 
Fitzroy River, i.e., Conductivity, Dissolved Ions and Dissolved Solids at Station 130105; four parameters from the data set from the Nogoa River, i.e., Conductivity, Dissolved Ions, Dissolved Solids and Hardness; and five parameters from the data set from the Logan River, i.e., Conductivity, PH, Dissolved Ions, Dissolved Solids and Alkalinity at station 145010. It should be noted that these data did conform to the normal distribution at the 5\% significance level in the Saphiro-Wilk test following their logarithmic transformation.

Comparisons of the results for the data at the Mackenzie river with the normal approximation and the log-normally transformed prior probability are presented in Table 5.9. Results for the sets of transformed data from the other locations are presented in Appendix B, Tables B.1.1 to B.1.3.

Surprisingly, the results presented in these tables show that, even when the log-normal model is a better model of the distribution, use of the log-normal distribution in the prior distribution does not always improve the accuracy of the prediction relative to the results using normal approximation. In some cases the predictions are more accurate while in other cases they are less accurate. It can be seen in Table 5.9 that in the Mackenzie River, use of the log-normal distribution 
Table 5.9 Comparison of the Use of Normal and Log-normal Approach in the MacKenzie River

Tabie 5.9(a) 1 yearly

\begin{tabular}{|c|c|c|c|c|c|c|c|c|c|c|c|c|c|c|}
\hline \multirow{4}{*}{$\begin{array}{l}\text { Wator Quallty } \\
\text { Parameter }\end{array}$} & \multirow{2}{*}{\multicolumn{2}{|c|}{ Observed Valuec }} & \multirow{2}{*}{\multicolumn{2}{|c|}{$\begin{array}{l}\text { Assigred Values } \\
\text { (Normal Distribuilon) }\end{array}$}} & \multirow{2}{*}{\multicolumn{2}{|c|}{$\begin{array}{l}\text { Aeslgned Values } \\
\text { (Log-normal Dlstribution) }\end{array}$}} & \multicolumn{8}{|c|}{ Absolute Values of Errors $(\%)$} \\
\hline & & & & & & & \multicolumn{4}{|c|}{ (Normal Distribution) } & \multicolumn{4}{|c|}{ (Log-normal Oistribution) } \\
\hline & \multicolumn{2}{|c|}{ at Statlon } & \multicolumn{2}{|c|}{ at Station } & \multicolumn{2}{|c|}{ at Station } & \multicolumn{2}{|c|}{ at Slatlon } & \multirow[b]{2}{*}{ Average } & \multirow[b]{2}{*}{ Maximum } & \multicolumn{2}{|c|}{ at Station } & \multirow[b]{2}{*}{ Averago } & \multirow[b]{2}{*}{ Maximum } \\
\hline & $\$ 30401$ & 130106 & 130401 & $130+06$ & 130401 & 130106 & 130401 & 130106 & & & 130401 & 130106 & & \\
\hline \multirow{5}{*}{$\begin{array}{l}\text { Dissolved } \\
\text { (ons } \\
\text { (mg/) }\end{array}$} & 200.8 & 151.0 & 199.2 & 159.4 & 194.8 & 167.9 & 0.8 & 5.6 & \multirow{5}{*}{7.7} & \multirow{5}{*}{16.9} & 3.0 & 11.2 & \multirow{5}{*}{7.5} & \multirow{5}{*}{19.6} \\
\hline & 200.7 & 163.3 & 188.7 & 155.0 & 183.3 & 165.3 & 0.0 & 5.1 & & & 8.7 & 1.2 & & \\
\hline & 219.3 & 161.3 & 182.2 & 152.3 & 176.2 & 163.7 & 16.9 & 5.6 & & & 19.6 & 1.4 & & \\
\hline & 176.7 & 166.2 & 182.1 & 152.2 & 176.1 & 163.7 & 3.1 & 8.4 & & & 0.3 & 1.5 & & \\
\hline & 182.6 & 150.2 & 211.4 & 164.5 & 207.9 & 171.1 & 15.7 & 9.5 & & & 13.8 & 13.9 & & \\
\hline \multirow{5}{*}{$\begin{array}{c}\text { Hardness } \\
\text { (mg/)as } \mathrm{CaCO} 3\end{array}$} & 106.5 & 58.8 & 82.7 & 70.4 & 80.5 & 74.6 & 22.4 & 19.6 & \multirow{5}{*}{12.6} & \multirow{5}{*}{22.9} & 24.4 & 26.7 & \multirow{5}{*}{15.8} & \multirow{5}{*}{26.7} \\
\hline & 83.3 & 72.5 & 74.1 & 67.0 & 71.2 & 72.6 & 11.0 & 7.6 & & & 14.6 & 0.2 & & \\
\hline & 83.5 & 62.0 & 75.2 & 67.4 & 72.4 & 72.9 & 9.9 & 8.7 & & & 13.3 & 17.5 & & \\
\hline & 72.0 & 65.5 & 72.6 & 66.3 & 69.5 & 72.3 & 0.8 & 1.3 & & & 3,5 & 10.3 & & \\
\hline & 75.7 & 61.0 & 93.0 & 74.5 & 91.6 & 77.1 & 22.9 & 22.1 & & & 21.1 & 26.3 & & \\
\hline \multirow{5}{*}{$\begin{array}{l}\text { Magnesium } \\
\qquad(\operatorname{mg} f)\end{array}$} & 12.5 & 6.4 & 9.8 & 6.8 & 9.5 & 7.3 & 21,7 & 5.8 & \multirow{5}{*}{12.3} & \multirow{5}{*}{29.2} & 23.7 & 13.6 & \multirow{5}{*}{14.7} & \multirow{5}{*}{32.5} \\
\hline & 8.5 & 7.1 & 9.1 & 6.5 & 8.8 & 7.2 & 3.7 & 7.9 & & & 7.0 & 0.7 & & \\
\hline & 9.7 & 6.2 & 8.3 & 6.2 & 7.9 & 7.0 & 14.6 & 0.9 & & & 18.8 & 13.5 & & \\
\hline & 8.2 & 6.8 & 7.9 & 6.1 & 7.5 & 6.9 & 3.3 & 10.7 & & & 8.8 & 1.8 & & \\
\hline & 8.1 & 5.6 & 10.4 & 7.0 & 10.2 & 7.4 & 29.2 & 25.5 & & & 26.7 & 32.5 & & \\
\hline
\end{tabular}

Table 5.9(b) 2 yearly

\begin{tabular}{|c|c|c|c|c|c|c|c|c|c|c|c|c|c|c|}
\hline \multirow{4}{*}{$\begin{array}{l}\text { Waler Quallty } \\
\text { Parameter }\end{array}$} & \multirow{2}{*}{\multicolumn{2}{|c|}{ Oboerved Values }} & \multirow{2}{*}{\multicolumn{2}{|c|}{$\begin{array}{l}\text { Aselgned Values } \\
\text { (Normal Distribution) }\end{array}$}} & \multirow{2}{*}{\multicolumn{2}{|c|}{$\begin{array}{c}\text { Aselgned Velues } \\
\text { (Log-normal Dietributlon) }\end{array}$}} & \multicolumn{8}{|c|}{ Absolute Values of Errors (\%) } \\
\hline & & & & & & & \multicolumn{4}{|c|}{ (Normal Distrlbution) } & \multicolumn{4}{|c|}{ (Log-normal Distributtan) } \\
\hline & \multirow{2}{*}{\multicolumn{2}{|c|}{$\begin{array}{l}\text { at Statlon } \\
130401 \quad 130108\end{array}$}} & \multicolumn{2}{|c|}{ at Statlon } & \multicolumn{2}{|c|}{ al Station } & \multicolumn{2}{|c|}{ af Stallon } & \multirow[b]{2}{*}{ Avorage } & \multirow[b]{2}{*}{ Moximum } & \multicolumn{2}{|c|}{ at Slation } & \multirow[b]{2}{*}{ Avorage } & \multirow[b]{2}{*}{ Naximum } \\
\hline & & & 130401 & 130106 & 130401 & 130106 & 13040 & 130108 & & & 13040 & 130106 & & \\
\hline (1) & \multicolumn{2}{|c|}{ (2) } & \multicolumn{2}{|c|}{ (3) } & \multicolumn{2}{|c|}{ (4) } & \multicolumn{2}{|c|}{ (5) } & (6) & (7) & \multicolumn{2}{|c|}{ (8) } & (9) & (10) \\
\hline Dissolved & 200.7 & 157.2 & 208.2 & 163.2 & 204.5 & 170.2 & 3.7 & 3.8 & \multirow{4}{*}{4.6} & \multirow{4}{*}{17.1} & 1.9 & & \multirow{4}{*}{$\mathbf{5 . 9}$} & \multirow{4}{*}{15.2} \\
\hline lons & 210.0 & 162.3 & 201.7 & 160.4 & 197.5 & 168.6 & 4.0 & 1.2 & & & 6.0 & 3.8 & & \\
\hline$(\mathrm{mg} / \mathrm{ll})$ & 198.0 & 163.7 & 199.1 & 159.4 & 194.7 & 167.9 & 0.6 & 2.7 & & & 1.7 & 2.5 & & \\
\hline & 179.7 & 158.2 & 210.4 & 164.0 & 206.9 & 170.8 & 17.1 & 3.7 & & & 16.2 & & & \\
\hline \multirow{4}{*}{$\begin{array}{c}\text { Hardness } \\
\text { (min)as } \mathrm{CaCO}\end{array}$} & 94.9 & 65.7 & 87.2 & 72.2 & 85.4 & 75.6 & 8.2 & 9.9 & \multirow{4}{*}{10.3} & \multirow{4}{*}{22.4} & 10.0 & 15.2 & \multirow{4}{*}{12.7} & \multirow{4}{*}{20.8} \\
\hline & 83.4 & 67.3 & 84.4 & 71.1 & 82.4 & 75.0 & 1.2 & 5.7 & & & 1.2 & 11.5 & & \\
\hline & 77.8 & 63.8 & 83.8 & 70.9 & 81.8 & 74.8 & 7.8 & 11.2 & & & 5.2 & 17.4 & & \\
\hline & 73.8 & 63.3 & 90.4 & 73.5 & 88.9 & 76.4 & 22.4 & 16.2 & & & 20.4 & 20.8 & & \\
\hline \multirow{4}{*}{$\begin{array}{l}\text { Magnesium } \\
\quad(\mathrm{mg} / \mathrm{l})\end{array}$} & 11.0 & 6.8 & 10.4 & 7.0 & 10.2 & 7.4 & 5.4 & 3.7 & \multirow{4}{*}{7.0} & \multirow{4}{*}{24.9} & 7.5 & 9.5 & & \\
\hline & 9.6 & 6.6 & 9.8 & 6.8 & 9.5 & 7.3 & 1.9 & 2.4 & & & 0.8 & 9.7 & 9.9 & 22.0 \\
\hline & 8.9 & 6.5 & 9.3 & 6.6 & 9.0 & 7.2 & 4.0 & 1.8 & & & 0.6 & 10.9 & & \\
\hline & 8.1 & 6.2 & 10.1 & 6.9 & 9.9 & 7.4 & 24.9 & 11.6 & & & 22.0 & 18.5 & & \\
\hline
\end{tabular}


Table 5.9(c) 3 yearly

\begin{tabular}{|c|c|c|c|c|c|c|c|c|c|c|c|c|c|c|}
\hline \multirow{4}{*}{$\begin{array}{l}\text { Water Qualtty } \\
\text { Parameter }\end{array}$} & \multirow{2}{*}{\multicolumn{2}{|c|}{ Observed Values }} & \multirow{2}{*}{\multicolumn{2}{|c|}{$\begin{array}{l}\text { Assignod Values } \\
\text { (Normal Distribution) }\end{array}$}} & \multirow{2}{*}{\multicolumn{2}{|c|}{$\begin{array}{l}\text { Aodgnod Velwe } \\
\text { (Log-normel Distribution) }\end{array}$}} & \multicolumn{8}{|c|}{ Absolute Values of Errors (\%) } \\
\hline & & & & & & & \multicolumn{4}{|c|}{ (Normal Distribution) } & \multicolumn{4}{|c|}{ (Log-normai Dletribution) } \\
\hline & \multicolumn{2}{|c|}{ at Station } & \multicolumn{2}{|c|}{ at Stallon } & \multicolumn{2}{|c|}{ al Simtlon } & \multicolumn{2}{|c|}{ at Station } & \multirow[b]{2}{*}{ Averege } & \multirow[b]{2}{*}{ Maximum } & \multicolumn{2}{|c|}{ ai Stallion } & \multirow[b]{2}{*}{ Average } & \multirow[b]{2}{*}{ Maximum } \\
\hline & 130401 & 130108 & 130401 & 130108 & 130401 & 130106 & 130401 & 130106 & & & 130401 & 130106 & & \\
\hline Dlssolved & 206.9 & 158.5 & 208.0 & 163.0 & 204.2 & 170.2 & 0.5 & 2.8 & \multirow{3}{*}{3.1} & \multirow{3}{*}{8.6} & 1.3 & 7.4 & \multirow{3}{*}{4.5} & \multirow{3}{*}{7.6} \\
\hline lons & 198.9 & 163.6 & 203.7 & 161.2 & 199.5 & 169.0 & 2.4 & 1.5 & & & 3.6 & 6.6 & & \\
\hline$(\mathrm{mg} / \mathrm{l})$ & 192.9 & 159.2 & 209.5 & 163.6 & 205.8 & 170.5 & 8.6 & 2.8 & & & 0.5 & 7.6 & & \\
\hline \multirow{3}{*}{$\begin{array}{l}\text { Herdness } \\
(\mathrm{m} \mathrm{m} / \mathrm{f}) \text { as } \mathrm{CaCO}_{3}\end{array}$} & 94.1 & 64.4 & 88.9 & 72.9 & 87.2 & 76.0 & 2.4 & 13.2 & \multirow{3}{*}{11.2} & \multirow{3}{*}{17.9} & 4.2 & 18.1 & \multirow{3}{*}{13.3} & \multirow{3}{*}{21.9} \\
\hline & 79.6 & 68.7 & 86.5 & 71.9 & 84.7 & 75.5 & 8.7 & 7.8 & & & 6.3 & 13.1 & & \\
\hline & 77.1 & 62.8 & 90.9 & 73.7 & 89.4 & 76.5 & 17.9 & 17.4 & & & 16.0 & 21.9 & & \\
\hline Magnesium & 10.6 & 6.6 & 10.4 & 7.0 & 10.1 & 7.4 & 1.8 & 6.8 & \multirow{3}{*}{8.5} & \multirow{3}{*}{18.0} & 3.9 & 12.8 & \multirow{3}{*}{11.0} & \multirow{3}{*}{19.1} \\
\hline \multirow[t]{2}{*}{$(\mathrm{mg} / \mathrm{l})$} & 9.1 & 6.7 & 9.9 & 6.9 & 9.6 & 7.3 & 8.8 & 3.3 & & & 5.6 & 0.2 & & \\
\hline & 8.6 & 6.2 & 10.2 & 7.0 & 10.0 & 7.4 & 18.0 & 12.3 & & & 15.6 & 19.1 & & \\
\hline
\end{tabular}

Table 5.9(d) 4 yearly

\begin{tabular}{|c|c|c|c|c|c|c|c|c|c|c|c|c|c|c|}
\hline \multirow{3}{*}{$\begin{array}{l}\text { Wator Quallty } \\
\text { Parametor }\end{array}$} & \multirow{2}{*}{\multicolumn{2}{|c|}{ Obeerved Values }} & \multirow{2}{*}{\multicolumn{2}{|c|}{$\begin{array}{l}\text { Acelgnod Values } \\
\text { (Normal Dlairibution) }\end{array}$}} & \multirow{2}{*}{\multicolumn{2}{|c|}{$\begin{array}{c}\text { Aosigned Vatwoe } \\
\text { (Log:normsi Dlstrlbulion) }\end{array}$}} & \multicolumn{8}{|c|}{ Absolute Values of Errors (\%) } \\
\hline & & & & & & & \multicolumn{4}{|c|}{ (Normal Dl stribution) } & \multicolumn{4}{|c|}{ (Log-normal Distribution) } \\
\hline & $\begin{array}{r}\text { at S } \\
130401\end{array}$ & 130106 & $\begin{array}{r}\text { at St } \\
130401\end{array}$ & 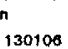 & $\begin{array}{r}\text { at Sh } \\
130401\end{array}$ & 130100 & $\begin{array}{r}\text { at St } \\
130401\end{array}$ & on & Average: & Maximum & $\begin{array}{l}\text { it } 9 \\
130401\end{array}$ & $\begin{array}{l}\text { tallon } \\
130100\end{array}$ & Averago & Maximum \\
\hline $\begin{array}{c}\text { Dissolved } \\
\text { ions } \\
\text { (mng/h) }\end{array}$ & $\begin{array}{l}199.4 \\
194.8\end{array}$ & $\begin{array}{l}160.4 \\
160.3\end{array}$ & $\begin{array}{l}215.9 \\
218.0\end{array}$ & $\begin{array}{l}166.4 \\
167.2\end{array}$ & $\begin{array}{l}212.9 \\
215.1\end{array}$ & $\begin{array}{l}172.3 \\
172.9\end{array}$ & $\begin{array}{r}8.3 \\
11.9\end{array}$ & $\begin{array}{l}3.7 \\
4.3\end{array}$ & 7.1 & $\$ 1.9$ & $\begin{array}{l}2.9 \\
4.0\end{array}$ & $\begin{array}{l}8.7 \\
9.1\end{array}$ & 6.2 & 9.1 \\
\hline $\begin{array}{l}\text { Hardneas } \\
\text { (mgrf) as } \mathrm{CaCO}\end{array}$ & $\begin{array}{l}86.3 \\
78.6\end{array}$ & $\begin{array}{l}64.7 \\
65.3\end{array}$ & $\begin{array}{l}93.9 \\
92.3\end{array}$ & $\begin{array}{l}74.2 \\
74.9\end{array}$ & $\begin{array}{l}90.9 \\
92.6\end{array}$ & $\begin{array}{l}76.9 \\
77.3\end{array}$ & $\begin{array}{l}8.8 \\
17.4\end{array}$ & $\begin{array}{l}14.7 \\
14.7\end{array}$ & 13.9 & 17.4 & $\begin{array}{c}5.3 \\
17.8\end{array}$ & $\begin{array}{l}18.8 \\
18.3\end{array}$ & 15.1 & 18.8 \\
\hline $\begin{array}{l}\text { Magnestum } \\
\text { (mg/) }\end{array}$ & $\begin{array}{l}10.0 \\
8.9\end{array}$ & $\begin{array}{l}6.6 \\
6.4\end{array}$ & $\begin{array}{l}10.6 \\
10.7\end{array}$ & $\begin{array}{l}7.1 \\
7.1\end{array}$ & $\begin{array}{l}10.4 \\
10.5\end{array}$ & $\begin{array}{l}7.5 \\
7.5\end{array}$ & $\begin{array}{c}6.2 \\
20.9\end{array}$ & $\begin{array}{c}7.1 \\
11.1\end{array}$ & 11.3 & 20.9 & $\begin{array}{c}4.3 \\
18.6\end{array}$ & $\begin{array}{l}12.5 \\
16.4\end{array}$ & 13.0 & 18.6 \\
\hline
\end{tabular}


in the prior distribution gives more accurate predictions only for Dissolved Ions and even then only for the 1 and 4 yearly time averaged cases. Better values of predictions for the log-normal data are also achieved for Dissolved Ions in the Nogoa River for the 3 and 4 yearly time averaged cases; Conductivity in the Logan River for the 3 and 4 yearly time averaged cases; Dissolved Ions in the Logan River for the 2, 3 and 4 yearly time averaged cases; Dissolved Solids in the Logan River for the 3 and 4 yearly time averaged cases; and Alkalinity in the Logan River for the 2 and 3 yearly time averaged cases [See Appendix B, Tables B.1.1 to B.1.3].

Furthermore, the results do not reveal any general pattern as to when better predictions can be achieved by using the log-normal distribution for the prior probability values. It should also be recalled in assessing these results that the data were originally quite close to normal distribution and that the number of points in the data sets is relatively limited. For these two reasons, the evaluation of the merits of using either the log-normal and normal approximations in the prior distributions, as performed in this study, may not be sufficient to draw any general conclusions with respect to the advantages or disadvantages that may arise from using probability distributions other than 
normal in the prior probability distribution even when the other distribution may in fact be a better representation of the probability distribution of the parameter of interest.

c. CASE III. Consideration of observed changes in the watershed that are, or may be, the cause of observed changes in water quality levels

The issue for this case relates to changes in the measured water quality values at the downstream station that have occurred since the upstream stations were discontinued and that can be attributed, completely or in part, to observed or known changes in the upstream region of the basin particularly in those sections of the watershed above the discontinued upstream monitoring stations. This knowledge about changes in the system is addressed by modifying the prior probability, as specified in the objective function of the model through $q_{n i}$. The modification itself involves the replacement of the 'original' $q_{n i}$ values, which were initially established on the basis of observed historical data, with 'new' values which best reflect the current known changed conditions. The actual process of modification of the $q_{n i}$ values is generally performed by 'shifting' the prior probability distribution values at a particular monitoring station towards the values which 
best reflect the effects of observed or known changes in that portion of the watershed. It should be recognised that while change of the $q_{n i}$ values in this manner provides the basis for incorporating knowledge about the situation, it also causes the solution to become more biased.

The impact of this process of incorporating knowledge about locations of the causes of observed changes in water quality on the accuracy of the predictions can be demonstrated by applying the formulation with the modified $q_{n i}$ values to a range of water quality parameters in the river systems examined for CASE I. However, detailed information on conditions in these watersheds which might provide specific guidance as to the quantitative extent of changes in water quality caused by modifications in land use and land management practice, etc. was not available. Furthermore the detailed analysis necessary to generate this information lies beyond the scope of this study. In view of these limitations, in order to demonstrate how knowledge of changes in upstream conditions can be addressed using the approach, the mean values of the prior distribution of the water quality parameters at a particular station, were reduced by an arbitrary selected amount, e.g., the water quality parameters at Station 130106 from the MacKenzie River Sub-Basin data 
set were reduced by 10 units.

The magnitude of the change in the $q_{n i}$ values in this demonstration example, namely, a change in the mean of 10 units with an associated equal change in the values of water quality associated with the probability levels across the complete distribution from $\mu-4 \sigma$ to $\mu+4 \sigma$, is relatively 'small' compared to the historical values. Furthermore, the selection of the value of 10 units was made without reference to the magnitude of the differences in the historical record for the upstream stations, as summarised in Tables 5.3(a) and 5.3(b), between the water quality values contained in the calibration data set (the period 1971 to 1980) used to define the distributions and the water quality values contained in the validation data set (the period 1981 to 1986) used to assess the performance of the formulation. The only reference point involved in the choice of the variation to impose on the $q_{n i}$ values was the knowledge that the values of the various water quality parameters had decreased at the downstream station and were therefore likely to have decreased at one or both of the upstream stations. (It should be noted that improvements in water quality arising from enhanced effluent treatment practices or improved land use practices can be accommodated equally easily within the approach by simply increasing, rather than reducing, the water 
quality values by an amount reflecting the effects of those changes.)

The model was then run under the same conditions as for CASE I. The results for this case are presented in Table 5.10 for the Mackenzie River data set, and in Appendix B, Tables B.2.1 to B.2.3 for the data sets from the other river systems.

It can be seen from Table 5.10, that for the Mackenzie River data set, and for the one, two, three yearly time averaged scenarios, the average error of prediction for most of the parameters, with the exception of Hardness actually increased in comparison to CASE I. In the case of the four yearly time averaged data, the average error of prediction decreased for the Dissolved Ions and Hardness. The consistent decrease in error for the Hardness parameter for all time averaging periods indicates that 'shifting' the prior probability for Hardness at Station 130106 appears to have the capacity to improve the accuracy of the prediction for that particular parameter.

Results obtained by testing the case with the data sets from the other river systems, such as presented in Tables B.2.1 to B.2.3, however, do not show any significant improvemęnts, except for Dissolved Ions in 
Table 5.10 Comparison of the Results Obtained by Using Knowledge about Changes in the Watershed

(incorporated by changing the Prlor Probability Distribution at One Upstream Station [Station 130106]) with those Obtained lgnorlng that Knowledge [MacKenzie River ]

Table 5.10 (a) 1 yearly

\begin{tabular}{|c|c|c|c|c|c|c|c|c|c|c|c|c|c|c|}
\hline \multirow{3}{*}{ 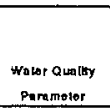 } & \multirow{2}{*}{\multicolumn{2}{|c|}{ Oboorred Hoan Vathes }} & \multicolumn{2}{|c|}{ Pribr Moen Valuas } & \multirow{2}{*}{\multicolumn{2}{|c|}{ 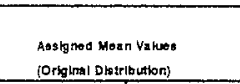 }} & \multirow{2}{*}{\multicolumn{2}{|c|}{ 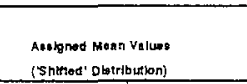 }} & \multicolumn{4}{|c|}{$\%$ Error of Predlection } & \multicolumn{2}{|c|}{$\begin{array}{l}\text { \%. Error of Prodtetion } \\
\text { (Avorago) }\end{array}$} \\
\hline & & & \multirow{2}{*}{ 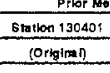 } & \multirow{2}{*}{ 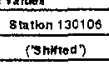 } & & & & & \multirow{2}{*}{\multicolumn{2}{|c|}{ 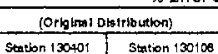 }} & \multicolumn{2}{|c|}{ (Snmed Descrpurtion) } & \multirow{2}{*}{$\begin{array}{c}\text { Oratinat } \\
\text { Destrution }\end{array}$} & \multirow{2}{*}{$\begin{array}{c}\text { Shithed } \\
\text { Daintrantion }\end{array}$} \\
\hline & 5 sotion 130409 & Sation 190108 & & & Satition $130 x+91$ & Statantan 130106 & Ststion 130901 & Station 100108 & & & sation 13040 & $\tan 1300108$ & & \\
\hline \multirow{5}{*}{ 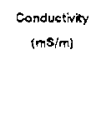 } & 425.0 & 199.3 & 408.8 & 2222,2 & 285.8 & 200.5 & 200.3 & 197.5 & 32.8 & 3.6 & 31.7 & 0.9 & \multirow[t]{5}{*}{10.8} & \multirow{5}{*}{10.8} \\
\hline & 318.6 & 211.3 & & & 288.7 & 209.3 & 303.4 & 200.3 & 5.6 & 1.0 & 4.2 & 5.2 & & \\
\hline & 332.5 & 206.7 & & & 261.8 & 201.5 & 266.5 & 192.5 & 21.3 & 2.5 & 19.8 & 6.9 & & \\
\hline & 283.3 & 2425 & & & 271.4 & 203.5 & 275.1 & 194.5 & 4.2 & 16.1 & 2.5 & 19.8 & & \\
\hline & 278.6 & 185.0 & & & 293.3 & 208.4 & 298.0 & 199.1 & 6.0 & 12.5 & 7.7 & 7.6 & & \\
\hline \multirow{5}{*}{ 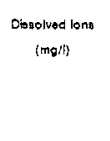 } & 200.7 & 151.0 & 269.7 & 178.6 & 199.2 & 159.4 & 203.5 & 151.2 & 0.8 & 5.5 & 1.4 & 0.1 & \multirow[t]{5}{*}{7.7} & \multirow[t]{5}{*}{8.2} \\
\hline & 200.7 & 163.3 & & & 188.7 & 155.0 & 182.9 & 148.8 & 6.0 & 5.1 & 3.9 & 10.1 & & \\
\hline & 218.3 & 181.3 & & & 182.2 & $\begin{array}{l}152.3 \\
150\end{array}$ & 188.4 & 144.1 & 18.8 & 5.6 & 15.0 & 10.7 & & \\
\hline & 176.8 & 188.2 & & & 182.9 & 152.2 & 186.3 & 144.0 & 3.9 & 8.4 & 5.5 & 13.3 & & \\
\hline & 182.8 & 150.2 & & & 211.4 & 184.5 & 215.5 & 158.2 & 15.7 & 9.5 & 18.9 & 4.0 & & \\
\hline \multirow{5}{*}{$\begin{array}{c}\text { Disao ived Solide } \\
\text { (mall) }\end{array}$} & 218.5 & 114.8 & 235.2 & 135.6 & 149.1 & 115.8 & 153.5 & 107.5 & 31.8 & 1.0 & 2.8 & 6.4 & \multirow[t]{5}{*}{11.0} & \multirow[t]{5}{*}{12.1} \\
\hline & 173.3 & 122.5 & & & 182.6 & 120.6 & 167.0 & 112.1 & 6.2 & 1.5 & 3.6 & 8.5 & & \\
\hline & 185.0 & 123.3 & & & 138.1 & 112.0 & 142.4 & 103.6 & 25.4 & 9.2 & 23.0 & 16.0 & & \\
\hline & 158.6 & 740.0 & & & 150.3 & 118.3 & 154.7 & 107.9 & 4.0 & 16.9 & 1.2 & 22.9 & & \\
\hline & 150.0 & $\$ 10.0$ & & & 158.4 & 119.2 & 162.8 & 110.7 & 5.8 & 8.3 & 8.5 & 0.8 & & \\
\hline \multirow{5}{*}{ 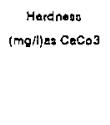 } & 108.5 & 58.8 & $\$ 14.7$ & 73.1 & 82.7 & 70.4 & 87.0 & $\$ 2.1$ & 22,4 & 19.7 & 18.3 & 5.6 & \multirow[t]{5}{*}{12.8} & \multirow[t]{5}{*}{11.3} \\
\hline & 83.3 & 72.5 & & & 74.1 & 67.0 & 78.4 & 58.7 & 11.0 & 7.6 & 5.9 & 19.0 & & \\
\hline & 83.5 & 62.0 & & & 75.2 & 67.4 & 79.5 & 59.1 & 9.9 & 8.7 & 4.8 & 4.6 & & \\
\hline & 72.0 & 65.5 & & & 72.5 & 66.3 & 76.8 & 58.1 & 0.8 & 1.3 & 6.7 & 11.3 & & \\
\hline & 75.7 & 61.0 & & & 83.0 & 74.5 & 87.3 & 86.2 & 22.9 & 22.1 & 28.6 & 8.5 & & \\
\hline
\end{tabular}

Table 5.10(b) 2 yearly

\begin{tabular}{|c|c|c|c|c|c|c|c|c|c|c|c|c|c|c|}
\hline \multirow{3}{*}{$\begin{array}{l}\text { Wasor acality } \\
\text { Paramister }\end{array}$} & \multirow{2}{*}{\multicolumn{2}{|c|}{ Oberved Maen Valuess }} & \multicolumn{2}{|c|}{ Priter Moen Vzatiese } & \multirow{2}{*}{\multicolumn{2}{|c|}{ 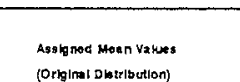 }} & & \multicolumn{4}{|c|}{ \%o Error of Prodiction } & \multicolumn{2}{|c|}{$\begin{array}{l}\text { \% Error of Prediction } \\
\text { (Avorage) }\end{array}$} \\
\hline & & & \multirow{2}{*}{ 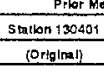 } & \multirow{2}{*}{ 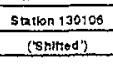 } & & & & & \multicolumn{2}{|c|}{ 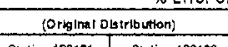 } & \multirow{2}{*}{\multicolumn{2}{|c|}{ 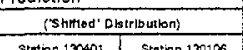 }} & \multirow{2}{*}{ 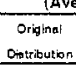 } & \multirow{2}{*}{$\begin{array}{c}\text { Snitited } \\
\text { Onitrivexton }\end{array}$} \\
\hline & sateon 130401 & Sestant 1300108 & & & 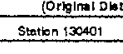 & Samion 130106 & \multicolumn{2}{|c|}{ 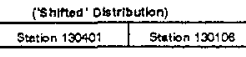 } & & Sultion 130100 & & & & \\
\hline \multirow{4}{*}{$\begin{array}{l}\text { Conducterty } \\
\text { (msim) }\end{array}$} & 370.8 & 205.2 & \multirow{4}{*}{408.8} & \multirow{4}{*}{222.2} & 308.1 & 210.8 & 310.8 & 201.8 & 17.4 & 27 & 16.2 & 1.7 & \multirow{4}{*}{8.71} & \multirow{4}{*}{7.83} \\
\hline & 324.5 & 208.9 & & & 295.7 & 208.6 & 300.4 & 199.6 & 8.9 & 0.1 & 7.4 & 4.5 & & \\
\hline & 307.9 & 224.5 & & & 283.7 & 205.1 & 288.4 & 197.1 & 7.9 & 8.2 & 6.3 & 12.2 & & \\
\hline & 280.0 & 219.7 & & & 27.5 & 209.1 & 302.2 & 200.0 & 8.2 & 2.2 & 7.9 & 6.4 & & \\
\hline \multirow{4}{*}{$\begin{array}{c}\text { Obeolusod lann } \\
\text { (nosin) }\end{array}$} & 200.7 & 157.1 & \multirow[t]{4}{*}{269.7} & \multirow[t]{4}{*}{ :78.8 } & 208.2 & 183.2 & 212.5 & 154.9 & 3.7 & 3.9 & 5.9 & 1.4 & \multirow[t]{4}{*}{4.81} & \multirow[t]{4}{*}{5.85} \\
\hline & 210.0 & 162.3 & & & 201.7 & 180.4 & 206.0 & 152.2 & 4.0 & 1.1 & 1.8 & 8.2 & & \\
\hline & 197.9 & 163.7 & & & 199.1 & 158.4 & 203.4 & 151.1 & 0.6 & 2.7 & 2.8 & 7.7 & & \\
\hline & 179.8 & 158.9 & & & 210.4 & 164.0 & 214.7 & 155.8 & 17.2 & 3.8 & 19.5 & 1.4 & & \\
\hline \multirow{4}{*}{ 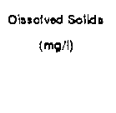 } & 195.8 & 118.6 & \multirow[t]{4}{*}{235.2} & \multirow[t]{4}{*}{135.6} & 173.5 & 124.4 & 178.0 & 115.9 & 11.4 & 4.9 & 9.2 & 2.3 & \multirow[t]{4}{*}{3.82} & \multirow[t]{4}{*}{7,44} \\
\hline & 179.1 & 122.9 & & & $\begin{array}{l}10.0 \\
169.3\end{array}$ & $\begin{array}{l}124.4 \\
122.9\end{array}$ & $\begin{array}{l}173.7 \\
170\end{array}$ & 114.5 & 5.5 & 0.0 & 3.0 & 6.9 & & \\
\hline & 170.8 & 131.6 & & & 164.6 & 121.3 & 159.0 & $1+2.8$ & 3.6 & 7.8 & 1.1 & 14.3 & & \\
\hline & 153.3 & 123.0 & & & 172.4 & 124.0 & 176.8 & $\$ 15.5$ & 12.5 & 0.8 & 15.3 & 7.6 & & \\
\hline \multirow{4}{*}{ 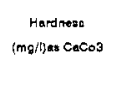 } & 94.8 & 65.7 & 114.7 & 73.1 & 87,2 & 72.2 & 81.5 & $63 .$. & 8.1 & 10.0 & 3.6 & 2.7 & 10.33 & 8.23 \\
\hline & $\begin{array}{l}84.9 \\
83.4\end{array}$ & $\begin{array}{l}0.1 \\
67.3\end{array}$ & & & 84,4 & $\begin{array}{l}7.2 \\
71.1\end{array}$ & 88.7 & $\begin{array}{l}6.8 .8 \\
60.8\end{array}$ & $\begin{array}{l}0.1 \\
1.2\end{array}$ & 5.7 & $\begin{array}{l}5.0 \\
5.4\end{array}$ & 6.6 & & \\
\hline & 77.8 & 63.8 & & & 83.8 & 70.9 & 88.2 & 82.6 & 7.8 & 11.2 & 13.4 & 1.9 & & \\
\hline & 73,8 & 63.3 & & & 90.4 & 73.5 & 94.7 & 85.2 & 22.4 & 16.2 & 28.3 & 3.1 & & \\
\hline
\end{tabular}


Table $5.10(\mathrm{c}) 3$ yearly

\begin{tabular}{|c|c|c|c|c|c|c|c|c|c|c|c|c|c|c|}
\hline \multirow{3}{*}{$\begin{array}{c}\text { Wator Ouality } \\
\text { Parameter }\end{array}$} & \multirow{2}{*}{\multicolumn{2}{|c|}{ Observed Mean Values }} & \multicolumn{2}{|c|}{ Prior Moan Values } & \multirow{2}{*}{\multicolumn{2}{|c|}{$\begin{array}{l}\text { Assigned Mean Values } \\
\text { (Original Dlastibution) }\end{array}$}} & \multirow{2}{*}{\multicolumn{2}{|c|}{$\begin{array}{l}\text { Assigned Moan Values } \\
\text { ('Shliliod' Distribution) }\end{array}$}} & \multicolumn{4}{|c|}{ \% Error of Prediction } & \multicolumn{2}{|c|}{$\begin{array}{l}\text { \%o Error of Prediction } \\
\text { (Average) }\end{array}$} \\
\hline & & & \multirow{2}{*}{$\frac{\text { Station 130401 }}{\text { (Original) }}$} & \multirow{2}{*}{\begin{tabular}{|l} 
Station 130106 \\
('Shilted') \\
\end{tabular}} & & & & & \multicolumn{2}{|c|}{ (Original Distribution) } & \multicolumn{2}{|c|}{ ('Shlfied Distrifbutlon) } & \multirow{2}{*}{$\begin{array}{l}\text { Orlginal } \\
\text { Diatribution }\end{array}$} & \multirow{2}{*}{$\begin{array}{l}\text { Shliftod } \\
\text { Dlatribution }\end{array}$} \\
\hline & Station 130404 & Station 130106 & & & Station 130401 & Station 130106 & S1ation 130401 & Station 130108 & Station 13040:1 & Station 130108 & Stetilion 13040 & Station 130106 & & \\
\hline \multirow{3}{*}{$\begin{array}{c}\text { Conductivity } \\
(\mathrm{mS} / \mathrm{m})\end{array}$} & 358.1 & 205.8 & \multirow[t]{3}{*}{408.8} & \multirow{3}{*}{222.2} & 306.7 & 210.9 & 313.3 & 201.9 & 14.4 & 2.5 & 12.5 & 1.9 & \multirow[t]{3}{*}{4.3} & \multirow{3}{*}{5.3} \\
\hline & 310.8 & 220.1 & & & 302.7 & 210.1 & 307.4 & 201.1 & 2.6 & 4.5 & 1.1 & 8.7 & & \\
\hline & 297.5 & 211.4 & & & 301.2 & 209.8 & 305.9 & 200.8 & 1.2 & 0.8 & 2.8 & 5.0 & & \\
\hline \multirow{3}{*}{$\begin{array}{l}\text { Dissolved lons } \\
\text { (mg/l) }\end{array}$} & 206.9 & 158.5 & \multirow[t]{3}{*}{269.7} & \multirow[t]{3}{*}{178.5} & 208.0 & 163.0 & 212.2 & 154.8 & 0.5 & 2.8 & 2.6 & 2.3 & \multirow[t]{3}{*}{3.1} & \multirow[t]{3}{*}{4.8} \\
\hline & 198.9 & 163.6 & & & 203.7 & 161.2 & 207.9 & 153.0 & 2.4 & 1.5 & 4.5 & 6.5 & & \\
\hline & 192.9 & 159.2 & & & 209.5 & 163.6 & 213.7 & 155.4 & 8.6 & 2.8 & 10.8 & 2.4 & & \\
\hline \multirow{3}{*}{$\begin{array}{l}\text { Dissoived Solids } \\
\text { (mg//) }\end{array}$} & 192.3 & 120.2 & \multirow[t]{3}{*}{235.2} & \multirow[t]{3}{*}{135.5} & 168.1 & 122.5 & 172.5 & 114.1 & 12.6 & 1.9 & 10.3 & 5.1 & \multirow[t]{3}{*}{4.2} & \multirow[t]{3}{*}{6.8} \\
\hline & 171.7 & 128.8 & & & 168.4 & 122.6 & 172.8 & 114.2 & 1.9 & 4.7 & 0.7 & 11.2 & & \\
\hline & 163.9 & 124.4 & & & 167.4 & 122.3 & 171.8 & 113.8 & 2.1 & 1.7 & 4.8 & 8.5 & & \\
\hline \multirow{3}{*}{$\begin{array}{c}\text { Hardness } \\
\text { (mg/)as } \mathrm{CaCO}_{0}\end{array}$} & 91.1 & 64.4 & \multirow[t]{3}{*}{114.7} & \multirow[t]{3}{*}{73.1} & 88.9 & 72.9 & 93.2 & 64.6 & 2.4 & 13.2 & 2.3 & 0.3 & \multirow[t]{3}{*}{11.2} & \multirow{3}{*}{8.1} \\
\hline & 79.6 & 66.7 & & & 86.5 & 71.9 & 90.8 & 63.5 & 8.7 & 7.8 & 14.0 & 4.6 & & \\
\hline & 77.1 & 62.8 & & & 90.9 & 73.7 & 95.2 & 65.4 & 17.9 & 17.4 & 23.5 & 4.1 & & \\
\hline
\end{tabular}

\section{Table 5.10 (d) 4 yearly}

\begin{tabular}{|c|c|c|c|c|c|c|c|c|c|c|c|c|c|c|}
\hline \multirow{3}{*}{$\begin{array}{c}\text { Water Quality } \\
\text { Paramoler }\end{array}$} & \multirow{2}{*}{\multicolumn{2}{|c|}{ Observed Mean Values }} & \multicolumn{2}{|c|}{ Prior Mean Values } & \multirow{2}{*}{\multicolumn{2}{|c|}{$\begin{array}{l}\text { Assigned Moan Values } \\
\text { (Original Distribution) }\end{array}$}} & \multirow{2}{*}{\multicolumn{2}{|c|}{$\begin{array}{l}\text { Asslgnod Mean Vaicos } \\
\text { ('Shifitad' Distributlon) }\end{array}$}} & \multicolumn{4}{|c|}{ \% Error of Prediction } & \multicolumn{2}{|c|}{$\begin{array}{l}\text { \% Error of Prediction } \\
\text { (Average) }\end{array}$} \\
\hline & & & \multirow{2}{*}{\begin{tabular}{|c|} 
Station 130401 \\
(Original) \\
\end{tabular}} & \multirow{2}{*}{\begin{tabular}{|c|} 
Station 130108 \\
('shilted 'i') \\
\end{tabular}} & & & & & \multirow{2}{*}{\multicolumn{2}{|c|}{ 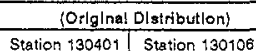 }} & \multicolumn{2}{|c|}{ ('Shifted' Distributlon) } & \multirow{2}{*}{$\begin{array}{c}\text { Orlginat } \\
\text { DAstribution }\end{array}$} & \multirow{2}{*}{$\begin{array}{c}\text { Shitted } \\
\text { Distributlon }\end{array}$} \\
\hline & Station 13040 & Station 130105 & & & \multicolumn{2}{|c|}{$\begin{array}{c}\text { (Orighinal Distributition) } \\
\text { Stestion } 130040 \text { Station } 130106 \\
\end{array}$} & \multicolumn{2}{|c|}{$\begin{array}{c}\text { ('Shifitad' Distribution) } \\
\text { Station } 130401 \text { (Station 130106 }\end{array}$} & & & Station 130401 & Station 130108 & & \\
\hline Conductivity & 339.4 & 214.9 & 408.8 & 222.2 & 318.6 & 213.4 & 323.3 & 204.4 & 6.1 & 0.7 & 4.7 & 4.9 & 3.45 & 5.04 \\
\hline$(m s / m)$ & 302.3 & 211.4 & & & 320.1 & 213.7 & 324.7 & 204.8 & 5.9 & 1.1 & 7.4 & 3.1 & & \\
\hline Dissolved 'ons & 199.4 & 160.4 & 269.7 & 178.6 & 215.9 & 166.4 & 220.2 & 158.1 & 8.3 & 3.7 & 10.4 & 1.4 & 7.06 & 6.70 \\
\hline (mgli) & 194.8 & 160.3 & & & 218.0 & 167.2 & 222.3 & 159.0 & 11.9 & 4.3 & 14,1 & 0.8 & & \\
\hline Dissolved Solids & 183.4 & 125.2 & 235.2 & 135.6 & 171.0 & 123.5 & 175.4 & 115.0 & 6.8 & 1.4 & 4.4 & 8.1 & 3.05 & 6.44 \\
\hline$(\mathrm{mg} /)$ & 166.3 & 124.0 & & & 172.8 & 124.2 & 177.2 & 115.7 & 3.9 & 0.2 & 6.6 & 6.7 & & \\
\hline Herdness & 86,3 & 64.7 & 114.7 & 73.1 & 92.3 & 74.2 & & 65.9 & 6.9 & 14.7 & 12.3 & 1.9 & 13.82 & 10.27 \\
\hline $\mathrm{mg} / \mathrm{f}$ & 78.6 & 65.3 & & & 93.9 & 74.9 & 98.2 & 66.6 & 19.4 & 14.7 & 24.9 & 2.0 & & \\
\hline
\end{tabular}


the Nogoa River for the 3 and 4 yearly time averaging. It appears that changes to the prior distribution in reflection of known changes in the basin do not necessarily improve the accuracy of the predictions available through the entropy method.

From an intuitive basis it might be expected that inclusion of such knowledge would improve the accuracy of the prediction. Part of the problem however, may lie in the problem of determining the magnitude of the change to apply to the 'prior' probability distribution in order to incorporate knowledge of changes in the watershed. Research on how much adjustment should be applied to the prior distribution in light of known or observed changes in conditions, e.g. a change of land use, needs therefore to be undertaken so that the predictions can become more accurate while not compromising the unbiased nature of the predictions through inclusion of such additional information. As the changes in water quality for which this sort of adjustment might be applied are related to physical changes in the basin, this research is likely to involve some work on the physical relationships between basin conditions and water quality values and is outside the scope of this study. 


\section{d. CASE IV. Dependency between the Water Quality at Upstream Discontinued Stations}

It is possible, and perhaps likely, that some level of dependency, at least statistically, exists between the water quality values at the upstream stations. In order to consider this dependency, a 'multi-dimensional' form of the formulation given by Equations 4.7 to 4.13 must be used. A dependent prior probability distribution of the following form (for two discontinued upstream stations) forms the basis for the required modification of the formulation:

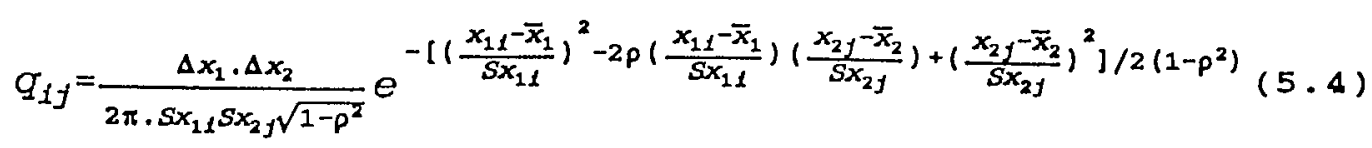

where :

$$
\begin{aligned}
& q_{i j}=\quad \text { joint probability of events } x_{1 i} \text { and } x_{2 j} \\
& x_{1 i}=\text { water quality value in the } i^{\text {th }} \text { discrete } \\
& \text { interval at station } 1 \text {. } \\
& \overline{\mathrm{x}}_{1}=\text { mean of } \mathrm{x}_{1 \mathrm{i}} \\
& x_{2 j}=\text { water quality value in the } j^{\text {th }} \text { discrete } \\
& \text { interval at station } 2 \\
& \bar{x}_{2}=\text { mean of } x_{2 j} \\
& \mathrm{Sx}_{1 \mathrm{i}}=\quad \text { standard deviation of } \mathrm{x}_{1 \mathrm{i}} \\
& \mathrm{Sx}_{2 \mathrm{j}}=\quad \text { standard deviation of } \mathrm{x}_{2 \mathrm{j}} \\
& \rho=\quad \text { coefficient correlation between events } \mathrm{x}_{1 i} \\
& \text { and } \mathrm{x}_{2 \mathrm{j}}
\end{aligned}
$$




$$
\begin{aligned}
& \Delta \mathrm{x}_{1}=\text { width of interval at station } 1 \\
& \Delta \mathrm{x}_{2}=\text { width of interval at station } 2
\end{aligned}
$$

This equation is used to calculate the prior probability $\mathrm{q}_{i j}$, embedded in the entropy formulation. The impacts of including this dependency are demonstrated by application of this multi-dimensional form of the entropy model, with the $q_{i j}$ values calculated using Equation 5.4 to the data on the Mackenzie River used in the previous demonstrations. The results of the application of this multi-dimensional dependency based form of the formulation are shown in the Table 5.11 (Results from application of this multi-dimensional form of the entropy approach to the data sets from the Fitzroy River and Nogoa River data are shown in Tables B.3.1 and B.3.2). It can be seen that, of the water quality parameters selected in these examples to demonstrate consideration of dependency, among the data, the predictions are more accurate only for Hardness parameter from the Mackenzie and the Nogoa River Basins. The predictions for the other parameters are actually less accurate.

These results suggest one or both of two different processes may be in effect. In the first case, the dependency that existed previously in the historical data may no longer hold for the new conditions (except 
Table 5.11 Comparison of the Use of Independent and Dependent Data in the MacKenzle River

Table 5.11(a) 1 yearly

\begin{tabular}{|c|c|c|c|c|c|c|c|c|c|c|c|c|c|}
\hline \multirow{3}{*}{ 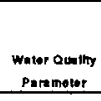 } & \multirow{3}{*}{ 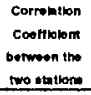 } & \multirow{2}{*}{\multicolumn{2}{|c|}{ 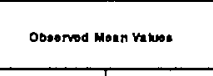 }} & \multirow{3}{*}{\multicolumn{2}{|c|}{ 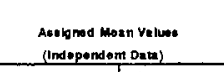 }} & \multirow{2}{*}{\multicolumn{2}{|c|}{ 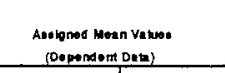 }} & \multicolumn{4}{|c|}{ \& Eroror of Prodictlon } & \multicolumn{2}{|c|}{ 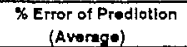 } \\
\hline & & & & & & & & \multirow{2}{*}{\multicolumn{2}{|c|}{ 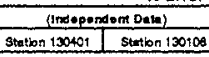 }} & \multirow{2}{*}{\multicolumn{2}{|c|}{ 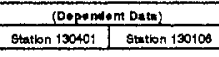 }} & & Depossonen \\
\hline & & $\operatorname{sentibn} 13000$ & Stestion 1300.106 & & $\operatorname{sintition} 1300100$ & & tation 130100 & & & & & Dath & Dot \\
\hline \multirow{5}{*}{ 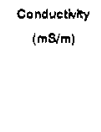 } & 0.574 & 425.0 & 199.3 & 285.6 & 208.5 & 299.4 & 179.8 & 32.8 & 3.6 & 29.6 & 9.8 & 10.6 & 12.9 \\
\hline & & 318.7 & 211.3 & 208.7 & 209.3 & 314.1 & 185.5 & 5.7 & 0.9 & 1.8 & 12,2 & & \\
\hline & & 332.5 & 206.7 & 281.8 & 201.5 & 278.4 & 180.6 & 21.3 & 2.5 & 10.3 & 18.0 & & \\
\hline & & 283.3 & 242.5 & 271.4 & 203.5 & 287.0 & $\$ 73.5$ & 4.2 & 16.1 & 1.3 & 28.5 & & \\
\hline & & 278.7 & 185.0 & 293.3 & 208.1 & 306.3 & 183.0 & 8.0 & 12.5 & 10.7 & 1.1 & & \\
\hline \multirow{4}{*}{$\begin{array}{l}\text { Ohaolvod bone } \\
\text { (mant) }\end{array}$} & 0.530 & 200.8 & 151.0 & 199.2 & 158.4 & 207.1 & 144.1 & 0.8 & 5.8 & 3.2 & 4.6 & 7.7 & 10.4 \\
\hline & & 200.7 & 189.3 & 188.7 & 155.0 & 197.8 & 137.5 & 8.0 & 5.7 & 1.5 & 15.8 & & \\
\hline & & $\begin{array}{l}210.3 \\
-276\end{array}$ & 181.3 & 182.22 & 152.3 & 122.0 & 133.4 & 18.8 & 5.6 & 12.5 & 17.3 & & \\
\hline & & 782.6 & $\begin{array}{l}18.2 \\
150.2 \\
10.2\end{array}$ & $\begin{array}{l}182.1 \\
211.4\end{array}$ & $\begin{array}{l}152.2 \\
184.5\end{array}$ & 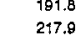 & $\begin{array}{l}13.4 \\
15.9\end{array}$ & $\begin{array}{l}3.1 \\
15.7\end{array}$ & 8.5 & $\begin{array}{l}8.6 \\
10.3\end{array}$ & $\begin{array}{l}18.7 \\
1.1\end{array}$ & & \\
\hline \multirow{5}{*}{ 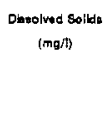 } & 0.542 & 218.5 & 114.8 & 149.1 & 115.8 & 158.0 & 86.9 & 31.8 & 0.8 & 27.3 & 15.6 & 11.0 & 15.5 \\
\hline & & 173.3 & & & & & & 8.2 & 1.5 & & 14.5 & & \\
\hline & & 185 & 12 & & & & 80.7 & 25.4 & 8.2 & 18.4 & 20.4 & & \\
\hline & & 156.7 & 140.0 & 150.3 & 118.3 & & 97.7. & 4.1 & 18.9 & 2.1 & 30.2 & & \\
\hline & & 150.0 & 110.0 & 158.4 & 119.2 & 187,2 & 102.3 & 5,8 & 8.3 & 11.5 & 7.0 & & \\
\hline \multirow{5}{*}{ 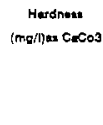 } & 0.545 & 108.5 & 58.8 & 82. & 70.4 & 88.3 & 83.4 & 22.4 & 88.8 & 99.0 & 7.7 & 12.6 & 12.3 \\
\hline & & 83.3 & 72.5 & & 87.0 & 78.8 & 59.1 & 11.0 & 7.0 & 5.5 & 18,8 & & \\
\hline & & 83.5 & 82.0 & 75.2 & 87.4 & 78.7 & 88.8 & 8.8 & 8.7 & 4.6 & 5.2 & & \\
\hline & & 72.0 & 85.5 & 72.8 & 86.3 & 77.4 & 57.0 & 0.8 & 1.3 & 7.5 & 13.0 & & \\
\hline & & 75.7 & 81.0 & 93.0 & 74.5 & 85.7 & 88.7 & 22.9 & 22.1 & 28.5 & 14,2 & & \\
\hline
\end{tabular}

Table 5.11(b) 2 yearly

\begin{tabular}{|c|c|c|c|c|c|c|c|c|c|c|c|c|c|}
\hline \multirow{3}{*}{$\begin{array}{c}\text { Wewr oum my } \\
\text { Panmerer } \\
\end{array}$} & \multirow{3}{*}{ 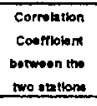 } & \multirow{2}{*}{\multicolumn{2}{|c|}{ 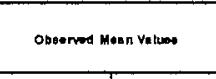 }} & \multirow{2}{*}{\multicolumn{2}{|c|}{ 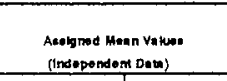 }} & \multirow{2}{*}{\multicolumn{2}{|c|}{ 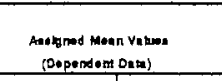 }} & \multicolumn{4}{|c|}{ \% Error of Prodiolion } & \multicolumn{2}{|c|}{$\begin{array}{c}\begin{array}{c}\%_{0} \text { Error of Prodlotion } \\
\text { (Averege) }\end{array}\end{array}$} \\
\hline & & & & & & & & \multirow{2}{*}{\multicolumn{2}{|c|}{ 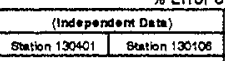 }} & \multirow{2}{*}{\multicolumn{2}{|c|}{ 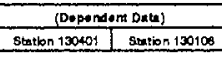 }} & \multirow{2}{*}{ 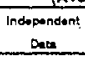 } & \multirow{3}{*}{ 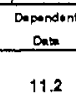 } \\
\hline & & Sallan 1300001 & 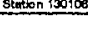 & Station 130401 & Station 130108 & 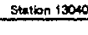 & Station 130000 & & & & & & \\
\hline \multirow{4}{*}{ 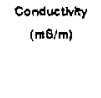 } & 0.814 & 370.8 & 205,3 & 306.1 & 210.8 & 318,4 & 187.2 & 17.5 & & & & \multirow[t]{4}{*}{8.7} & \\
\hline & & 324.6 & & 295.7 & 208.8 & 309.2 & 182.2 & 8.8 & 0.2 & 4.7 & 12.8 & & \\
\hline & & 307.8 & 224.8 & 283.7 & 208.1 & 298.8 & 177.5 & 7.9 & 8.2 & 3.0 & 21.0 & & \\
\hline & & 280.0 & 213.8 & 207.5 & 209.1 & 310.7 & 183.5 & 8.2 & 2.2 & 11.0 & 14,1 & & \\
\hline \multirow{4}{*}{$\begin{array}{l}\text { Denolined bons } \\
\text { (mali) }\end{array}$} & 0.801 & 200.7 & 157.2 & 208.2 & 183.2 & 204.6 & 170.2 & 3.7 & 3.8 & 1.9 & 8.3 & \multirow[t]{4}{*}{4.8} & \multirow{4}{*}{3.3} \\
\hline & & 210.0 & 182.3 & 201.7 & 180.4 & 198.8 & 186.1 & 4.0 & 1,2 & 5.4 & 2.3 & & \\
\hline & & & 183.7 & 199.1 & 159.4 & 180.5 & 184.3 & 0.8 & 2.7 & 0.7 & 0.4 & & \\
\hline & & 179.7 & 158.2 & 210.4 & 184.0 & 206.6 & .171 .3 & 17.1 & 3.7 & 15.0 & 8.3 & & \\
\hline \multirow{4}{*}{ 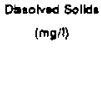 } & 0.613 & 195.8 & 116.7 & 173.8 & 124.4 & 181.3 & 108.6 & 11.4 & 4.8 & 7.5 & & \multirow{4}{*}{3.8} & \multirow{4}{*}{10.2} \\
\hline & & 179.2 & 122.8 & 189.3 & 122.8 & 177.8 & 107.1 & 5.5 & 0.0 & 0.8 & 12.8 & & \\
\hline & & 170.8 & 131.7 & 184.8 & 121.3 & & 104.3 & 3.7 & 7.8 & 1.5 & 20.8 & & \\
\hline & & 153.3 & 125.0 & 172.4 & 124.0 & 180.3 & 108.0 & 12.5 & 0.8 & 17.8 & 12.8 & & \\
\hline \multirow{4}{*}{ 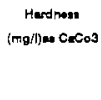 } & 0.533 & 94.8 & 85.7 & 87.2 & 72.2 & 80.2 & 80.3 & 8,2 & 8.9 & 4.8 & 1.0 & \multirow[t]{4}{*}{10.3} & \multirow[t]{4}{*}{7.8} \\
\hline & & & & & & & & & & & & & \\
\hline & & 77.8 & 63.8 & 83.8 & 70.9 & 87.3 & 84.2 & 7.8 & 11.2 & 12.3 & 0.7 & & \\
\hline & & 73.8 & 83.3 & 80.4 & 73.5 & 93,2 & 68.2 & 22.4 & 18.2 & 26.2 & 7.8 & & \\
\hline
\end{tabular}


Table 5.11(c) 3 yearly

\begin{tabular}{|c|c|c|c|c|c|c|c|c|c|c|c|c|c|}
\hline \multirow{3}{*}{$\begin{array}{c}\text { Wator Quallty } \\
\text { Paramotior }\end{array}$} & \multirow{3}{*}{$\begin{array}{l}\text { Corroiation } \\
\text { Cootifliont } \\
\text { batwoon the } \\
\text { two stations }\end{array}$} & \multirow{2}{*}{\multicolumn{2}{|c|}{ Obuerved Moan Values }} & \multirow{2}{*}{\multicolumn{2}{|c|}{$\begin{array}{l}\text { Assignod Mean Values } \\
\text { (Independent Datas) }\end{array}$}} & \multirow{2}{*}{\multicolumn{2}{|c|}{$\begin{array}{c}\text { Asealgned Mean Val ues } \\
\text { (Dependent Data) }\end{array}$}} & \multicolumn{4}{|c|}{ \% Error of Predictlon } & \multicolumn{2}{|c|}{$\begin{array}{l}\text { \% Ertor of Prodiction } \\
\text { (Average) }\end{array}$} \\
\hline & & & & & & & & \multicolumn{2}{|c|}{ (Independent Data) } & \multicolumn{2}{|c|}{ (Dependent Data) } & \multirow{2}{*}{$\begin{array}{c}\text { Independent } \\
\text { Data } \\
\end{array}$} & \multirow{2}{*}{$\begin{array}{c}\text { Dopendent } \\
\text { Data }\end{array}$} \\
\hline & & Station 130401 & Station 130106 & Station 130401 & Stetion 130106 & Station 130401 & Station $\$ 3010 \mathrm{~B}$ & Station 130401 & Station 130108 & Station 130401 & Station 130106 & & \\
\hline \multirow{3}{*}{$\begin{array}{l}\text { Conductivity } \\
(m S / m)\end{array}$} & 0.836 & 358.1 & 205.8 & 306.7 & 210.8 & 321.6 & 182.1 & 14.4 & 2.5 & 10.2 & 11.5 & \multirow[t]{3}{*}{4.3} & \multirow[t]{3}{*}{10.7} \\
\hline & & 310.8 & 220.1 & 302.7 & 210.1 & 318.3 & 180.1 & 2.6 & 4.5 & 2.4 & +8.2 & & \\
\hline & & 297.5 & 211.4 & 301.2 & 209.8 & 317.1 & 179.3 & 1.2 & 0.8 & 6.6 & 15.2 & & \\
\hline \multirow{3}{*}{$\begin{array}{l}\text { Dlssolved lons } \\
\quad(m g / i)\end{array}$} & 0.762 & 206.9 & 158.5 & 208.0 & 163.0 & 246.8 & 146.1 & 0.5 & 2.8 & 4.8 & 7.9 & \multirow{3}{*}{3.1} & \multirow{3}{*}{8.8} \\
\hline & & 198.9 & 163.6 & 203.7 & 161.2 & 213.1 & 143.1 & 2.4 & 1.5 & 7.1 & 12.5 & & \\
\hline & & 192.9 & 159.2 & 209.5 & 163.6 & 218.0 & 147.1 & 8.6 & 2.8 & 13.0 & 7.6 & & \\
\hline \multirow{3}{*}{$\begin{array}{c}\text { Dissolved Solids } \\
\text { (mgik) }\end{array}$} & 0.810 & 192.3 & 120.2 & 168.1 & 122.5 & 178.1 & 103.3 & 12.6 & 1.9 & 7.4 & 14.1 & \multirow[t]{3}{*}{4.2} & \multirow[t]{3}{*}{11.8} \\
\hline & & 171.7 & 128.6 & 168.4 & 122.6 & 178.4 & 103.4 & 1.9 & 4.7 & 3.9 & 19.6 & & \\
\hline & & 163.9 & 124.4 & 167.4 & 122.3 & 177.5 & 102.7 & 2.1 & 1.7 & 8.3 & 17.4 & & \\
\hline \multirow{3}{*}{$\begin{array}{c}\text { Hardness } \\
\text { (ma//)as CaCo3 }\end{array}$} & 0.775 & 91.1 & 64.4 & 88.9 & 72.9 & 92.6 & 65.7 & 2.4 & 13.2 & 1.6 & 2.0 & \multirow[t]{3}{*}{11.2} & \multirow[t]{3}{*}{7.6} \\
\hline & & 79.6 & 66.7 & 86.5 & 71.9 & 90.6 & 64.0 & 8.7 & 7.8 & 13.8 & 4.0 & & \\
\hline & & 77.1 & 62.8 & 90,9 & 73.7 & 92.4 & 65.5 & 17.8 & 17.4 & 19.8 & 4.3 & & \\
\hline
\end{tabular}

Table 5.11(d) 4 yearly

\begin{tabular}{|c|c|c|c|c|c|c|c|c|c|c|c|c|c|}
\hline \multirow{2}{*}{$\begin{array}{c}\text { Water Quality } \\
\text { Paramotor }\end{array}$} & \multirow{2}{*}{$\begin{array}{l}\text { Correlation } \\
\text { coothloiont } \\
\text { sotweon the } \\
\text { two twations }\end{array}$} & \multirow{2}{*}{\multicolumn{2}{|c|}{ Oberrvad Moan Veluss }} & \multirow{2}{*}{\multicolumn{2}{|c|}{$\begin{array}{l}\text { Asslgrood Meani Valuos: } \\
\text { (Indopandent Data) }\end{array}$}} & \multirow{2}{*}{\multicolumn{2}{|c|}{$\begin{array}{l}\text { Asestgnod Mean Values } \\
\text { (Depondent Data) }\end{array}$}} & \multicolumn{4}{|c|}{ \% Error of Prediction } & \multicolumn{2}{|c|}{$\begin{array}{l}\text { \% Ertor of Prodiction } \\
\text { (Average) }\end{array}$} \\
\hline & & & & & & & & (Independ & ant Data] & (Dopende & It Datal & Independent & Dapendent \\
\hline Conduetivity & 0.992 & 339.4 & 214.9 & 318.6 & 213.4 & 333.3 & 185.1 & 6.1 & 0.7 & 1.8 & 13.9 & 3.5 & 9.6 \\
\hline$(m \mathrm{~s} / \mathrm{m})$ & & 302.3 & 211.4 & 320.1 & 213.7 & 334.5 & 186.0 & 5.9 & 1.1 & 10.7 & 12,0 & & \\
\hline Dissolved lons & 0.940 & 199.4 & 160.4 & 215.9 & 166.4 & 224.7 & 149.6 & 8.3 & 3.7 & 12.7 & 6.7 & 7.1 & 10.3 \\
\hline (mgI) & & 194.8 & 160.3 & 218.0 & 167.2 & 226.4 & 151.9 & 11.9 & 4.3 & 16.2 & 5.7 & & \\
\hline Dissolved Sollds & 0.963 & 183.4 & 125.2 & 171.0 & 123.5 & 181.6 & 103.1 & 6.8 & 1.4 & 1.0 & 17.6 & 3.0 & 11.2 \\
\hline$(m g /)$ & & 166.3 & 124.0 & 172.8 & 124.2 & 183.7 & 104.3 & 3.9 & 0.2 & 10.5 & 15.9 & & \\
\hline Hardness & 0.966 & 86.3 & 84.7 & 92.3 & 74.2 & 95.9 & 67.1 & 6.9 & 14.7 & 11.1 & 3.7 & 13.8 & 10.8 \\
\hline (mg/)as $\mathrm{CaCO}_{2}$ & & 78.6 & 65.3 & 93.9 & 74.9 & 97.3 & 68.3 & 19.4 & 14.7 & 23.7 & 4.7 & & \\
\hline
\end{tabular}


in this case, possibly, for the Hardness parameter from the Mackenzie and the Nogoa River Basin). The second possible outcome is that dependency does still exist but its inclusion in the formulation does not improve, and in fact reduces, the accuracy of the predictions.

It should also be recognised that inclusion of dependency in the model actually introduces bias into the solution thereby degrading one of the strengths of the approach, namely, its ability to provide unbiased predictions. It should be similarly noted that the running time for each case with the prior probability calculated by Equation 5.4, and with 24 intervals in the discretization of the probability distributions at each station, takes approximately 7 hours on a Digital VAX 6000-330 with 64 Mbytes memory running VMS. This computational requirement can be contrasted with the approximately 35 seconds needed for the simplified formulation when run on a 486 IBM-Compatible Personal Computer. This very large increase in computational requirement is due mainly to the exponential increase in the number of variables associated with the 'multidimensional' formulation.

Consideration of dependency therefore not only appears to reduce the accuracy of prediction in most cases, but it also increases the running time of the 
model dramatically. It also introduces bias into the solution. The combination of these factors indicate that, although inclusion of dependency in the formulation is intuitively attractive, it should not be undertaken unless there is very strong evidence in support of the decision.

\subsubsection{DISCRETIZATION PROBLEM}

One of the steps required for the procedure is to define the "events" to which the entropy model assigning probabilities. As discussed previously this process is performed by discretizing the range of possible values (in this study the range from $\mu-4 \sigma$ to $\mu+4 \sigma$ ) at each station into a number of discrete values as required for entropy theory. One problem in this discretization process is how to determine (choose) the size of the intervals such that the best, i.e., most accurate predictions are obtained. In their studies of the application of entropy theory for determination of the extent of transfer of information between water quality variables Harmancioglu et al. (1985) and Harmancioglu and Alpaslan (1992) reported that the choice of the level of discretization has a significant effect on the result. This section of the thesis examines the effect in the discretization procedure that the choice of the number of intervals, and thereby the size of the interval, has 
on the performance of the proposed model.

Six different levels of discretization, namely 8, 16, 24, 32, 40 and 48 intervals spread over four standard deviations either side of the mean, were examined for the set of data presented in Table 5.3. This process was undertaken for each of the four water quality parameters of Conductivity, Dissolved Ions, Dissolved Solids and Hardness. The results derived from the MDI formulation for this range of values are presented in Table 5.12 and Figure B.1 in Appendix B (The duration of the interval over which the water quality values were averaged was 4 years for this case. It should be noted that any other duration would have similar results since the only factor to be examined in this case is variation of the number of intervals.)

It is clear from the results shown in Table 5.12 that variation in the level of discretization has very little effect on the value of the entropy $\mathrm{H}_{i}$ doubling the number of intervals from 24 to 48 results in a maximum change of less than $1 \%$ in the value of $H$. Similarly, the variation in the mean values of the water quality values assigned by the entropy function with the different levels of discretization is extremely small with the only changes occurring in the second decimal place. These observations indicate, that unlike the 
Table 5.12 Results of Assignment of Water Quality Values with Varying Levels of Discretisation in the MacKenzie River

(for 4 year averaged data)

\begin{tabular}{|c|c|c|c|c|c|c|c|c|}
\hline \multirow{3}{*}{$\begin{array}{c}\text { Water Quality } \\
\text { Parameter }\end{array}$} & \multirow{3}{*}{$\begin{array}{l}\text { Mean Value at } \\
\text { Station } 130401\end{array}$} & \multirow{3}{*}{$\begin{array}{l}\text { Mean Value at } \\
\text { Station } 130106\end{array}$} & \multicolumn{6}{|c|}{ Number of Intervals } \\
\hline & & & \multicolumn{2}{|c|}{8} & \multicolumn{2}{|c|}{16} & \multicolumn{2}{|c|}{24} \\
\hline & & & $\begin{array}{c}\text { Entropy } \\
\text { Value }\end{array}$ & $\begin{array}{l}\text { Thre to Reach } \\
\text { Solution }\end{array}$ & $\begin{array}{c}\text { Entropy } \\
\text { value }\end{array}$ & $\begin{array}{c}\text { Time to Reach } \\
\text { Soluton }\end{array}$ & $\begin{array}{c}\text { Entropy } \\
\text { value }\end{array}$ & $\begin{array}{c}\text { Time to Reach } \\
\text { Solution }\end{array}$ \\
\hline Conductivity & 318.6 & 213.4 & 0.1314 & $7.74 "$ & 0.1315 & $14.88^{\prime \prime}$ & 0.1315 & $32.08^{\prime \prime}$ \\
\hline$(\mathrm{mS} / \mathrm{m})$ & 320.1 & 213.7 & 0.1271 & $5.05 "$ & 0.1272 & $15.6^{\prime \prime}$ & 0.1273 & $28.29^{\prime \prime}$ \\
\hline Dissolved lons & 215.9 & 166.4 & 0.1506 & $4.23^{\prime \prime}$ & 0.1509 & $18.34^{\prime \prime}$ & 0.1509 & $43.62^{\prime \prime}$ \\
\hline (mg/l) & 218.0 & 167.2 & 0.1392 & $4.62^{\prime \prime}$ & 0.1393 & 16.92" & 0.1394 & $33.56^{\prime \prime}$ \\
\hline Dissolved Solids & 171.0 & 123.5 & 0.2552 & $3.73^{\prime \prime}$ & 0.2554 & $17.25^{\prime \prime}$ & 0.2557 & $26.2^{n}$ \\
\hline (mg/l) & 172.8 & 124.2 & 0.2409 & 3.79" & 0.2411 & $18.5^{\prime \prime}$ & 0.2414 & $27.24^{\prime \prime}$ \\
\hline Hardness & 92.3 & 74.2 & 0.1181 & $6.48^{\prime \prime}$ & 0.1182 & $16.48^{\prime \prime}$ & 0.1183 & $37.46^{\prime \prime}$ \\
\hline$(\mathrm{mg} / \mathrm{h}) \mathrm{as} \mathrm{CaCO}$ & 93.9 & 74.9 & 0.1016 & $5.71 "$ & 0.1016 & $17.41^{\prime \prime}$ & 0.1018 & 26.69 \\
\hline
\end{tabular}

\begin{tabular}{|c|c|c|c|c|c|c|c|c|}
\hline \multirow{3}{*}{$\begin{array}{l}\text { Water Quality } \\
\text { Parameter }\end{array}$} & \multirow{3}{*}{$\begin{array}{l}\text { Mean Value at } \\
\text { Station } 130401\end{array}$} & \multirow{3}{*}{$\begin{array}{l}\text { Mesn Value at } \\
\text { Station } 130106\end{array}$} & \multicolumn{6}{|c|}{ Number of Intervals } \\
\hline & & & \multicolumn{2}{|c|}{32} & \multicolumn{2}{|c|}{40} & \multicolumn{2}{|c|}{48} \\
\hline & & & $\begin{array}{c}\text { Entropy } \\
\text { Valua }\end{array}$ & $\begin{array}{l}\text { Time to Reach } \\
\text { Solution }\end{array}$ & $\begin{array}{c}\text { Entropy } \\
\text { Value }\end{array}$ & $\begin{array}{l}\text { Time to Reach } \\
\text { Solution }\end{array}$ & $\begin{array}{c}\text { Entropy } \\
\text { Value }\end{array}$ & $\begin{array}{c}\text { Time to Raech } \\
\text { Solution }\end{array}$ \\
\hline Conductlvity & 318.6 & 213.4 & 0.1318 & $72.4^{\prime \prime}$ & 0.1320 & $146.10^{\prime \prime}$ & 0.1320 & $242.38^{\prime \prime}$ \\
\hline (mS/m) & 320.1 & 213.7 & 0.1275 & $89.25 "$ & 0.1275 & $173.84^{\prime \prime}$ & 0.1276 & $185.87^{\prime \prime}$ \\
\hline Dissolved lons & 215.9 & 166.4 & 0.1510 & $72.61^{\prime \prime}$ & 0.1511 & $143.85^{\prime \prime}$ & 0.1512 & $270.01 "$ \\
\hline$(m \mathrm{~m} / \mathrm{l})$ & 218.0 & 167.2 & 0.1396 & $73.98^{\prime \prime}$ & 0.1398 & $108.23^{\prime \prime}$ & 0.1399 & 220.48 \\
\hline Dissolved Sollds & 171.0 & 123.5 & 0.2561 & $82.00 "$ & 0.2563 & $132.48^{\prime \prime}$ & 0.2563 & $246.6 t^{\prime \prime}$ \\
\hline (mg/) & 172.8 & 124.2 & 0.2418 & $75.19^{\prime \prime}$ & 0.2418 & $188.03^{\prime \prime}$ & 0.2419 & $270.57^{\prime \prime}$ \\
\hline Hardress & 92.3 & 74.2 & 0.1184 & $172.74^{41}$ & 0.1185 & $117.54^{\prime \prime}$ & 0.1187 & $393.21^{\prime \prime}$ \\
\hline$(\mathrm{mg} / \mathrm{f}) \mathrm{as} \mathrm{CaCo}$ & 93.9 & 74.9 & 0.1019 & $68.44^{\prime \prime}$ & 0.1019 & $142.48^{n}$ & 0.1019 & $246.18^{\prime \prime}$ \\
\hline
\end{tabular}


applications of the entropy function reported by Harmancioglu et al. (1985) and Harmancioglu and Alpaslan (1992), the model is quite insensitive to the level of discretization and therefore very robust in its assignment of water quality values. Hence the level of discretization does not appear to be a significant problem.

As shown in Table 5.12, there are, however, considerable differences in the processing time for different levels of discretization. The times shown in this table are the result of running the model on an IBM-PC Compatible with an Intel 80486 processor, $33 \mathrm{Mhz}$, and using the non-linear programming package GRG2 (Lasdon and Warren, 1986) to solve the model. The results presented in the table were obtained using the same starting values for every variable in the initialisation of variables required by the program. Different initial values may result in different times to reach the solution, and may therefore results in times to solution which are different from those one presented in Table 5.12. However, it is quite clear that the processing time increases rapidly as the discretization interval becomes smaller.

Since the differences in results for the different levels of discretization are very small, the appropriate 
level of discretization can be quite coarse. In this case the level of discretization associated with having only eight intervals would be appear to be quite satisfactory.

It should be noted that the time required to reach solution can be reduced if the starting (initial) values are close to the values expected from the model solution. If small intervals of discretization are required, or if necessary to include dependency in the formulation as described in CASE IV in section 5.3.1, then a careful choice of starting values will overcome, in part, some of the associated computational requirements.

\subsubsection{CHOICE OF THE PERIOD OF TIME AVERAGING}

Recall that the method proposed in this study is intended primarily to predict the mean values of water quality over selected periods of time. In order to observe the effect of the selection of the period of time over which the function expressed in Equation 4.18 is developed, the entropy formulation was solved for a range of different time intervals. The data from the MacKenzie River, as described in Table 5.3, were used to examine this issue. As in the previous cases, the data from 1971 to 1980 were used for the calibration step and 
the data from 1981 on were used in the validation step.

The parameters chosen to examine the effects of the duration over which the values are time averaged are the same as those used in section 5.3 .2 for the examination of the effects of the level of discretization. Due to the limited data (only 8 years of data are available for all stations, except for the Dissolved solids parameter which has only 7 years of data available for the calibration step, and only 5 years of data available for the validation step) only a limited number of variations in the averaging time period were able to be analysed. In this study, 5, 4, 3 and 2 year duration time averaging periods were selected. The 5 year duration averaging period is included in this examination primarily to show that the correlation coefficient becomes smaller beyond the 4 years duration averaging period and to examine the effects of this decrease. From the 8 data points available for calibration, only 4 data points can be used to calculate the regression coefficients for the 5 year moving average; 5 data points for the 4 year moving average; 6 data points for the 3 year moving average and 7 data points for the 2 year moving average.

The regression coefficients for each of the time averaging periods are shown in Table 5.13 with the 
Table 5.13 Regression Coefficients for Various Periods of Time Averaging for MacKenzie River Data

Summation of Weighted Upstream Values $=B o+B i *$ (Downstream Value)

\begin{tabular}{|c|c|c|c|c|}
\hline $\begin{array}{c}\text { Regression } \\
\text { Coefficient }\end{array}$ & $\begin{array}{c}\text { 2 Year } \\
\text { Moving Average }\end{array}$ & $\begin{array}{c}\text { 3 Year } \\
\text { Moving Average }\end{array}$ & $\begin{array}{c}\text { 4 Year } \\
\text { Moving Average }\end{array}$ & $\begin{array}{c}5 \text { Year } \\
\text { Moving Average }\end{array}$ \\
\hline $\mathrm{Bo}$ & 95.96 & 112.82 & 137.72 & 147.89 \\
$\mathrm{Bi}$ & 0.6990 & 0.6580 & 0.5980 & 0.5689 \\
Correlation \\
Coefficient
\end{tabular}

\begin{tabular}{l} 
Dissolved lons \\
\begin{tabular}{|c|c|c|c|c|}
\hline $\begin{array}{c}\text { Regression } \\
\text { Coefficient }\end{array}$ & $\begin{array}{c}2 \text { Year } \\
\text { Moving Average }\end{array}$ & $\begin{array}{c}\text { 3 Year } \\
\text { Moving Average }\end{array}$ & $\begin{array}{c}\text { 4 Year } \\
\text { Moving Average }\end{array}$ & $\begin{array}{c}5 \text { Year } \\
\text { Moving Average }\end{array}$ \\
\hline Bo & 77.88 & 81.55 & 100.58 & 147.23 \\
Bi & 0.6693 & 0.6602 & 0.5914 & 0.3936 \\
Correlation \\
Coefticient
\end{tabular} \\
\hline
\end{tabular}

\begin{tabular}{l} 
Dissolved Solids \\
\begin{tabular}{|c|c|c|c|c|}
\hline $\begin{array}{c}\text { Regression } \\
\text { Coefficient }\end{array}$ & $\begin{array}{c}\text { 2 Year } \\
\text { Moving Average }\end{array}$ & $\begin{array}{c}\text { 3 Year } \\
\text { Moving Average }\end{array}$ & $\begin{array}{c}\text { 4 Year } \\
\text { Moving Average }\end{array}$ & $\begin{array}{c}5 \text { Year } \\
\text { Moving Average }\end{array}$ \\
\hline Bo & 50.59 & 46.68 & 50.98 & 105.98 \\
$\mathrm{Bi}$ & 0.7355 & 0.7577 & 0.7423 & 0.4668 \\
Correlation \\
Coefficient
\end{tabular} \\
\hline
\end{tabular}

\begin{tabular}{|c|c|c|c|c|}
\hline $\begin{array}{c}\text { Regression } \\
\text { Coefficient }\end{array}$ & $\begin{array}{c}\text { 2 Year } \\
\text { Moving Average }\end{array}$ & $\begin{array}{c}\text { 3 Year } \\
\text { Moving Average }\end{array}$ & $\begin{array}{c}4 \text { Year } \\
\text { Moving Average }\end{array}$ & $\begin{array}{c}5 \text { Year } \\
\text { Moving Average }\end{array}$ \\
\hline Bo & 40.27 & 44.02 & 51.36 & 74.37 \\
Bi & 0.6247 & 0.5966 & 0.5351 & 0.3034 \\
Correlation \\
Coefficient
\end{tabular}


graphical presentations of the regression lines being given in Appendix B. [Figure B.2(a) for Conductivity, Figure B.2(b) for Dissolved Ions, Figure B.2(c) for Dissolved Solids and Figure B.2(d) for Hardness.] It can be seen in Table 5.13, that in most cases, the 4 year moving average gives the highest coefficient of correlation between the water quality values at the downstream station and the summation of the water quality values at the two upstream stations, weighted by their average flows.

It was initially expected that the best entropy prediction would occur for those time intervals with the highest correlation coefficients, e.g., the 4 year interval. The results of the prediction step, as shown in Table 5.14, show that it is not always true. For example, as shown in Table 5.13 the correlation coefficient for a four year averaging interval is significantly larger than those for the other three time intervals considered for all water quality parameters. However, it can be seen that the errors in entropy prediction using the four year time interval are not always better, and in some cases worse, than using the other time periods.

This situation appears to be due in part to the variation in the number of points available for a fixed 
Table 5.14 Results of Assignment of Mean of Water Quality Values for the MacKenzie River for Various Time Intervals

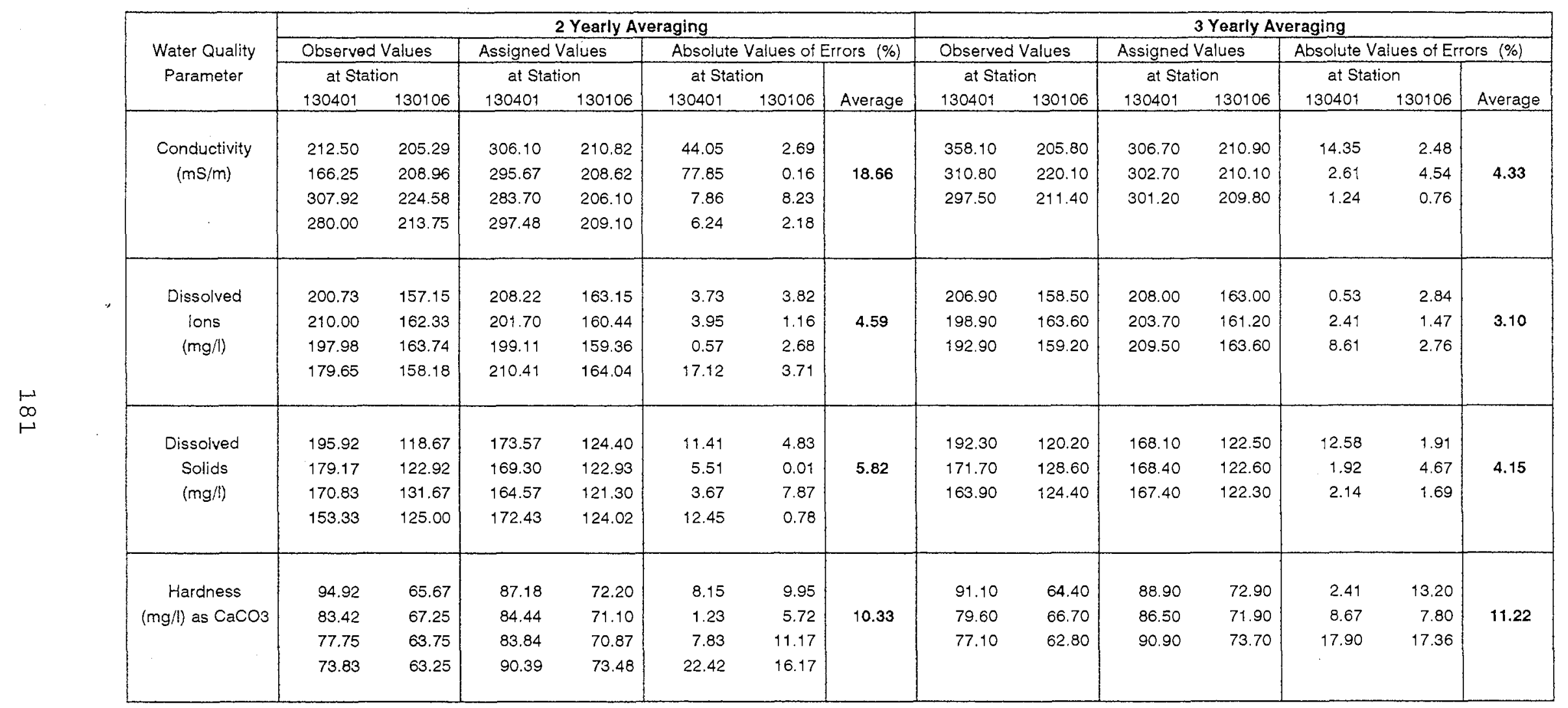




\section{Table 5.14 (continued)}

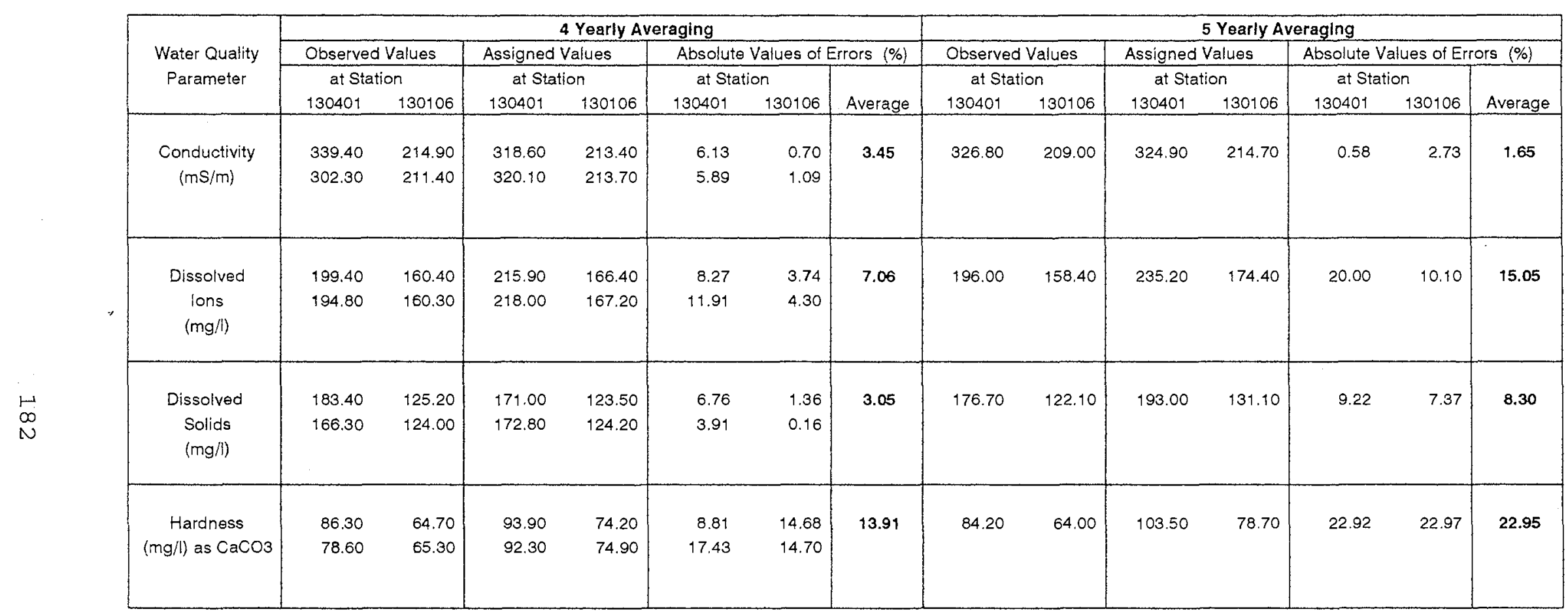


length of record to develop the 'information function' (Equation 4.18 in the formulation) resulting from change in the duration of the intervals over which the water quality values are time averaged. Longer averaging periods result in fewer points for the expression. For example, in the case of a 5 year moving average only 4 data points are available. The smaller numbers of data points may result in good correlation coefficients but, in fact, the resulting expression may not be an accurate or appropriate representation of reality. In the case of smaller intervals over which the values are averaged, the number of points to calculate the regression coefficients will increase, and the resulting expression is likely to be a better reflection of reality. However, the variation of the data in this case may be more evident with a correspondingly smaller correlation coefficient. (It can be noted that, due to the limited numbers of data points suitable for use for the demonstration of the technique, only time averaging up to 4 year duration are chosen for the calculations presented in this thesis.)

These results have some bearing on the issues concerning the appropriate time scale for water quality monitoring analysis identified by Loftis et al. (1991) who indicated that an explicit consideration of time scale in data analysis is important for producing 
meaningful statistical information. The decision of choosing the duration of the averaging interval should, therefore, be made on the basis of the time span over which it is desired to calculate average water quality values rather than on a formal statistical evaluation of what time interval is optimal in terms of accuracy of prediction. The same 'time-averaging' period must of course be used in the calibration and prediction steps.

It should also be recognised that use of time averaged values for water quality damps out the effects of short term transient fluctuations in water quality, which although important at their time of occurrence, do not relate directly to the background water quality conditions and to the long term and possibly permanent variation in those background conditions.

The limited data (as low as 3-4 pieces of data in some cases) referred to earlier with respect to the errors in the predictions by the entropy and regression approaches also have the potential to give rise to concerns as to the confidence that can placed in the predictions of the regression model. Obviously the number of data available for development of the regression model does affect the results of the regressions, and the confidence that can be placed on those results, significantly. However, the degree to 
which the data available for the development of the regression model are dispersed within the range of values important to the analysis is also important. A large number of data which are highly clustered may not be as good for prediction within the range for which prediction is required as a smaller number of data dispersed more uniformly within the range of prediction. It can be seen from Figure B.2 in Appendix B that the raw data used to develop the regression models used in this thesis are reasonably well dispersed within the range of values of interest. Hence while the number of points available for the regression analysis is of some concern with respect to the validity of the regression model and the confidence which was given to the predictions from the regression models and therefore to the validity of the comparisons between the accuracy of the entropy model relative to the regression model, the dispersed nature of the data upon which these regression models were developed does allay some of those concerns.

\subsection{THE USE OF ENTROPY METHOD FOR IDENTIFICATION OF LOCATIONS OF CAUSES OF CHANGES IN OBSERVED WATER QUALITY VALUES}

The entropy formulations described above can also be used for identifying the "most likely" location in the watershed of changes, e.g., new sources of 
pollution, which are causing observed and unaccounted for changes in water quality at the downstream continuing monitoring station. The "locations" which able to be identified in this process are restricted to branches upon which monitoring stations have existed previously but have been discontinued, i.e., the problem has the same "dimensions" as in the use of entropy to predict values at discontinued stations.

Use of the entropy based formulation in this role entails prediction of the water quality values at the discontinued monitoring stations as described in the previous sections. These predicted values are then evaluated as to the extent to which they deviate from the historical mean values, e.g., how many standard deviations are the new values away from the old observed mean [where the distribution of the old mean (specified by a mean and standard deviation) is defined by the historical sampling (observations)].

Recall that according to sampling theory, if a population has a distribution with a standard deviation of $\sigma$, then the mean values of a set of random samples from that population will have a standard deviation of:

$$
\sigma_{n}=\frac{\sigma}{\sqrt{n}}
$$


where :

$$
\begin{aligned}
\sigma_{n} & =\text { standard deviation of the mean value } \\
\sigma & =\text { standard deviation of the population } \\
n & =\text { number of samples }
\end{aligned}
$$

The determination of the most likely locations of changes in water quality which are causing the changes in observed values at the downstream station can be demonstrated by using the 'calibration data sets' (listed in Table 5.3) to define the distribution of the population, and using the values from the 'validation set' as 'samples from the population'.

Consider the 'new' entropy predicted mean values at the upstream stations, as representing values of the mean derived from 'sampling' undertaken at the downstream monitoring station following discontinuation of the upstream stations.

The number of samples used to define the downstream observed mean value for which changes are noted is implicitly the number of samples used to define the predicted mean(s) at the upstream station(s). The standard deviation of the predicted means at the upstream stations derived from the sampled downstream mean can therefore be defined as $\sigma_{\mathrm{us}} / \mathcal{} \mathrm{n}$ where $\sigma_{\mathrm{us}}$ is the standard deviation of the water quality at the upstream station, as defined by the prior (calibration) data set, 
and $\mathrm{n}$ is the number of samples at the downstream station used to define the downstream mean.

Now define distance in terms of the number of standard deviations which the new predicted ('sampled') mean at the upstream station lies away from the "known" mean (as defined from the calibration data set) of the water quality at that upstream station. The greater the distance of the predicted ('sampled') mean from the prior mean for a particular upstream station, i.e., the greater the number of standard deviations the two means are apart, the more likely it is that water quality conditions at that location (or on that branch) have changed and the less likely the difference between the old known and new predicted ('sampled') mean is due to chance alone. For example, if the new value lies outside the range of $\mu \pm 1.96\left(\sigma_{\text {us }} / \sqrt{ } \mathrm{n}\right)$, then it can be reasonably concluded at a 95\% confidence level that changes have occurred at that particular location.

Table 5.15 (and Tables B.4.1 to B.4.3 in the Appendix B), show the results of applying the approach to the data sets used in this thesis. It can be seen in the Table 5.15(c), for the data set from the Mackenzie River Sub-Basin, that the mean value of the water quality as observed at the downstream station (Station 130105) has changed significantly between the 
Table 5.15 Evaluation of the Water Quality Values in the MacKenzie River Sub-Basin

Legend :

Xno $=$ observed water quality values ( $\equiv$ XO in the formula for determination of absolute errors)

Xne $=$ water quality values predicted by the entropy method

$\mathrm{Xh}=$ historical mean water quality values

Table 5.15(a) Station 130401

Historical (prior) Mean Values

\begin{tabular}{|c|c|c|c|c|c|c|c|c|c|c|}
\hline & $\begin{array}{c}\text { Conductivity } \\
\text { (a) } 25 \mathrm{C} \\
\text { (mS/m) }\end{array}$ & PH & $\begin{array}{c}\text { Dissolved } \\
\text { lons } \\
\text { (mgl) }\end{array}$ & $\begin{array}{l}\text { Dissolved } \\
\text { Solids } \\
\text { (mgli) } \\
\end{array}$ & $\begin{array}{c}\text { Hardness } \\
\text { (mgl) as } \mathrm{CaCO} 3\end{array}$ & $\begin{array}{c}\text { Alkalinity } \\
\text { (mg/) as Caco3 }\end{array}$ & $\begin{array}{l}\text { Natrium } \\
\text { (mg/) }\end{array}$ & $\begin{array}{l}\text { Kakium } \\
\text { (mogl) }\end{array}$ & $\begin{array}{l}\text { Calcium } \\
\text { (mgf) }\end{array}$ & $\begin{array}{c}\text { Magnesium } \\
\text { (mgl) } \\
\end{array}$ \\
\hline $\begin{array}{l}\text { Mean (X) } \\
\text { Standard } \\
\text { Deviation }\end{array}$ & $\begin{array}{c}408.8 \\
131\end{array}$ & $\begin{array}{l}7.8 \\
0.3\end{array}$ & $\begin{array}{c}269.7 \\
76.4\end{array}$ & $\begin{array}{c}235.2 \\
68.1\end{array}$ & $\begin{array}{l}114.7 \\
35.9\end{array}$ & $\begin{array}{c}101.6 \\
23\end{array}$ & $\begin{array}{l}37.1 \\
11.6\end{array}$ & $\begin{array}{l}1.7 \\
0.3\end{array}$ & $\begin{array}{c}23.8 \\
7.2\end{array}$ & $\begin{array}{c}13.4 \\
4.5\end{array}$ \\
\hline
\end{tabular}

\section{[ 1 Yearly Averaging]}

New/Predicted Mean Values

\begin{tabular}{|c|c|c|c|c|c|c|c|c|c|c|}
\hline & $\begin{array}{c}\text { Conductivity } \\
\text { (i) } 25 \mathrm{C} \\
\text { (mS/m) }\end{array}$ & PH & $\begin{array}{l}\text { Dissolved } \\
\text { Ions } \\
\text { (mgn) }\end{array}$ & $\begin{array}{l}\text { Dissolved } \\
\text { Solkds } \\
\text { (mg/) }\end{array}$ & $\begin{array}{c}\text { Hardness } \\
\text { (mg/) as } \mathrm{CaCO} 3\end{array}$ & $\begin{array}{c}\text { Alkalinity } \\
\text { (mgl/) as } \mathrm{CaCO}_{3}\end{array}$ & $\begin{array}{l}\text { Natrium } \\
\text { (mgn) }\end{array}$ & $\begin{array}{l}\text { Kalium } \\
\text { (mol) }\end{array}$ & $\begin{array}{l}\text { Calciura } \\
\text { (mgl) }\end{array}$ & $\begin{array}{l}\text { Magnesium } \\
\text { (mg/) }\end{array}$ \\
\hline \multirow[t]{2}{*}{ OBSERVED } & 425.0 & 8.0 & 200.8 & 218.5 & 106.5 & 50.0 & 36.5 & 1.3 & 22.0 & 12.5 \\
\hline & 316.7 & 8.1 & 20.7 & 173.3 & 83.3 & 76.0 & 27.7 & 1.3 & 17.7 & 9.5 \\
\hline \multirow[t]{3}{*}{$\left(X_{n o}\right)$} & 332.5 & 8.0 & 219.3 & 185.0 & 83.5 & 83.0 & 32.0 & 1.7 & 17.5 & 9.7 \\
\hline & 283.3 & 7.5 & 176.7 & 156.7 & 72.0 & 64.7 & 25.0 & 1.9 & 15.3 & 8.2 \\
\hline & 276.7 & 7.8 & 182.6 & 120.0 & 75.7 & 72.0 & 24.0 & 2.2 & 17.0 & 8.1 \\
\hline \multirow[t]{2}{*}{$\left(\overline{X_{n}}\right)$} & 326.8 & 7.9 & 196.0 & 176.7 & 84.2 & 69.1 & 29.0 & 1.7 & 17.9 & 9.6 \\
\hline & $\begin{array}{c}\text { Conductivity } \\
\text { (9) } 25 \mathrm{C} \\
(\mathrm{mS} / \mathrm{m})\end{array}$ & $\mathrm{PH}$ & $\begin{array}{c}\text { Dissolved } \\
\text { lons } \\
\text { (mgl) } \\
\end{array}$ & $\begin{array}{l}\text { Dissolved } \\
\text { Solids } \\
\text { (mgl) }\end{array}$ & $\begin{array}{c}\text { Hardness } \\
\text { (mgl) as } \mathrm{CaCO} 3\end{array}$ & $\begin{array}{c}\text { Alkalinity } \\
\text { (mgn) as } \mathrm{CaCO} 3\end{array}$ & $\begin{array}{l}\text { Natrium } \\
(\mathrm{mg} /)\end{array}$ & $\begin{array}{l}\text { Kalium } \\
\text { (molt) }\end{array}$ & $\begin{array}{l}\text { Calcium } \\
\text { (mg/) }\end{array}$ & $\begin{array}{c}\text { Magnesium } \\
\text { (mg/) }\end{array}$ \\
\hline \multirow[t]{2}{*}{ ENTROPY } & 285.6 & 7.9 & 199,2 & 149.1 & 82.7 & 92.9 & 23.0 & 1.6 & 17.5 & 8.8 \\
\hline & 298.7 & 7.9 & 188.7 & 162.6 & 74.1 & 73.7 & 31.9 & 1.5 & 15.6 & 9.1 \\
\hline \multirow[t]{3}{*}{ (Xne) } & 261.8 & 7.8 & 182.2 & 138.1 & 75.2 & 82.3 & 24.2 & 1.7 & 17.0 & 8.3 \\
\hline & 271.4 & 7.8 & 182.1 & 150.3 & 72.6 & 77.7 & 25.0 & 1.7 & 16.6 & 7.9 \\
\hline & 293.3 & 8.0 & 211.4 & 158.4 & 93.0 & 95.8 & 25.0 & 1.7 & 20.4 & 10.4 \\
\hline (X̄ne) & 282.2 & 7.9 & 192.7 & 151.7 & 79.5 & 84.5 & 25.8 & 1.6 & 17.4 & 9.1 \\
\hline
\end{tabular}

Number of Standard Deviations of the Distribution of Sampled Means by which the New/Predicted Mean Values lies from the Historical Mean Values

\begin{tabular}{|c|c|c|c|c|c|c|c|c|c|c|}
\hline & $\begin{array}{l}\text { Conductivity } \\
\text { (1) } 250 \\
\text { (ms/m) }\end{array}$ & $\mathrm{PH}$ & $\begin{array}{l}\text { Dissoved } \\
\text { lons } \\
\text { (mgf) }\end{array}$ & $\begin{array}{c}\text { Dissolved } \\
\text { Solids } \\
(m g /)\end{array}$ & $\begin{array}{c}\text { Hardness } \\
\text { (mgl) as } \mathrm{CaCO} 3\end{array}$ & $\begin{array}{c}\text { Alkalinity } \\
\text { (mgl) as } \mathrm{CaCO} 3\end{array}$ & $\begin{array}{l}\text { Natrium } \\
\text { (mgl) }\end{array}$ & $\begin{array}{l}\text { Kalium } \\
\text { (mgli) }\end{array}$ & $\begin{array}{l}\text { Calcium } \\
\text { (mgl) }\end{array}$ & $\begin{array}{c}\text { Magnesium } \\
\text { (mgl) }\end{array}$ \\
\hline $\begin{array}{c}\text { OBSERVED } \\
(\bar{X}(n)-\bar{X} h) /[s / N n]\end{array}$ & -1.4 & 0.65 & -2.16 & -1.92 & -1.9 & -3.16 & -1.55 & -0.17 & -1.83 & -1.8 \\
\hline $\begin{array}{c}\text { ENTROPY } \\
(\overline{X n e}-\bar{X} h) /[s N n]\end{array}$ & -2.16 & 0.6 & -2.25 & -2.74 & -2.19 & -1.67 & -2.18 & -0.66 & -1.98 & -2.14 \\
\hline
\end{tabular}


Table 5.15(a) (continued)

[2 Yearly Averaging]

New/Predicted Mean Values

\begin{tabular}{|c|c|c|c|c|c|c|c|c|c|c|}
\hline & $\begin{array}{c}\text { Conductivity } \\
@ 25 \mathrm{C} \\
\text { (ms/m) }\end{array}$ & $\mathrm{PH}$ & $\begin{array}{c}\text { Dissolved } \\
\text { lons } \\
\text { (mg/l) } \\
\end{array}$ & $\begin{array}{c}\text { Dissolved } \\
\text { Solids } \\
\text { (mg/l) }\end{array}$ & $\begin{array}{c}\text { Hardness } \\
\text { (mg/)as } \mathrm{CaCO} 3\end{array}$ & $\begin{array}{c}\text { Alkalinity } \\
\text { (mgn)as } \mathrm{CaCO} 3 \\
\end{array}$ & $\begin{array}{l}\text { Natrium } \\
(\mathrm{mg} / 1)\end{array}$ & $\begin{array}{l}\text { Kalium } \\
\text { (mg/) }\end{array}$ & $\begin{array}{l}\text { Calcium } \\
\text { (mgn) }\end{array}$ & $\begin{array}{l}\text { Magnesium } \\
\text { (mg/) }\end{array}$ \\
\hline $\begin{array}{c}\text { OBSERVED } \\
(X n O)\end{array}$ & $\begin{array}{l}370.8 \\
324.6 \\
307.9 \\
280.0\end{array}$ & $\begin{array}{l}8.1 \\
8.1 \\
7.8 \\
7.7\end{array}$ & $\begin{array}{l}200.7 \\
210.0 \\
198.0 \\
179.7\end{array}$ & $\begin{array}{l}195.9 \\
179.2 \\
170.8 \\
153.3\end{array}$ & $\begin{array}{l}84.9 \\
83.4 \\
77.8 \\
73.8\end{array}$ & $\begin{array}{l}63.0 \\
79.5 \\
73.8 \\
68.3\end{array}$ & $\begin{array}{l}32.1 \\
29.8 \\
28.5 \\
24.5\end{array}$ & $\begin{array}{l}1.3 \\
1.5 \\
1.8 \\
2.1\end{array}$ & $\begin{array}{l}19.8 \\
17.6 \\
16.4 \\
16.2\end{array}$ & $\begin{array}{l}11.0 \\
9.6 \\
8.9 \\
8.1\end{array}$ \\
\hline$(\bar{X} \mathrm{no})$ & 320.8 & 7.9 & 197.1 & 174.8 & 82.5 & 71.2 & 28.7 & 1.7 & 17.5 & 9.4 \\
\hline $\begin{array}{c}\text { ENTROPY } \\
\text { (Xne) }\end{array}$ & $\begin{array}{l}306.1 \\
295.7 \\
283.7 \\
297.5\end{array}$ & $\begin{array}{l}7.8 \\
7.8 \\
7.8 \\
7.8\end{array}$ & $\begin{array}{l}208.2 \\
201.7 \\
199.1 \\
210.4\end{array}$ & $\begin{array}{l}173.6 \\
169.3 \\
164.6 \\
172.4\end{array}$ & $\begin{array}{l}87.2 \\
84.4 \\
83.8 \\
90.4\end{array}$ & $\begin{array}{l}86.8 \\
82.9 \\
84.4 \\
89.4\end{array}$ & $\begin{array}{l}28.2 \\
28.7 \\
25.8 \\
26.1\end{array}$ & $\begin{array}{l}1.6 \\
1.6 \\
1.6 \\
1.6\end{array}$ & $\begin{array}{l}18.1 \\
17.9 \\
18.3 \\
19.6\end{array}$ & $\begin{array}{c}10.4 \\
9.8 \\
9.3 \\
10.1\end{array}$ \\
\hline (रne) & 295.7 & 7.8 & 204.9 & 170.0 & 86.5 & 85.8 & 27.2 & 1.6 & 18.5 & 9.9 \\
\hline
\end{tabular}

Number of Standard Deviations of the Distribution of Sampled Means by which the New/Predicted Mean Values lies from the Historical Mean Values

\begin{tabular}{|c|c|c|c|c|c|c|c|c|c|c|}
\hline & $\begin{array}{c}\text { Conductivity } \\
@ 25 \mathrm{C} \\
(\mathrm{ms} / \mathrm{m}) \\
\end{array}$ & $\mathrm{PH}$ & $\begin{array}{c}\text { Dissolved } \\
\text { lons } \\
\text { (mg/l) } \\
\end{array}$ & $\begin{array}{c}\text { Dissolved } \\
\text { Solids } \\
\text { (mgh) }\end{array}$ & $\begin{array}{c}\text { Hardness } \\
\text { (mg/)as } \mathrm{CaCO} 3\end{array}$ & $\begin{array}{c}\text { Alkalinity } \\
\text { (mg/)as } \mathrm{CaCO}\end{array}$ & $\begin{array}{l}\text { Natrium } \\
(\mathrm{m} g / \mathrm{l})\end{array}$ & $\begin{array}{l}\text { Kalium } \\
(\mathrm{mg} /)\end{array}$ & $\begin{array}{l}\text { Calcium } \\
(\mathrm{mg} /)\end{array}$ & $\begin{array}{l}\text { Magnesium } \\
\text { (mg/) }\end{array}$ \\
\hline $\begin{array}{c}\text { OBSERVED } \\
(\bar{X} n o-\bar{X} h) /[s / \mathrm{Nn}]\end{array}$ & -1.34 & 0.56 & -1.90 & -1.77 & -1.80 & -2.65 & -1.44 & -0.25 & -1.75 & -1.78 \\
\hline $\begin{array}{c}\text { ENTROPY } \\
(\bar{X} \text { (Xne-X̄X } h) /\left[s / N_{n}\right]\end{array}$ & -1.73 & -0.13 & -1.70 & -1.82 & -1.57 & -1.37 & -1.71 & -0.60 & $-1.4 B$ & -1.56 \\
\hline
\end{tabular}

\section{[3 Yearly Averaging]}

New/Predicted Mean Values

\begin{tabular}{|c|c|c|c|c|c|c|c|c|c|c|}
\hline & $\begin{array}{c}\text { Conductivity } \\
@ 25 \mathrm{C} \\
(\mathrm{ms} / \mathrm{m}) \\
\end{array}$ & $\mathrm{PH}$ & $\begin{array}{c}\text { Dissolved } \\
\text { lons } \\
\text { (mgf) } \\
\end{array}$ & $\begin{array}{c}\text { Dissolved } \\
\text { Solids } \\
\text { (mg/l) } \\
\end{array}$ & $\begin{array}{c}\text { Hardness } \\
\text { (mg/)as } \mathrm{CaCO} 3\end{array}$ & $\begin{array}{c}\text { Alkalinity } \\
\text { (mg/l)as } \mathrm{CaCO}_{3} \\
\end{array}$ & $\begin{array}{l}\text { Natrium } \\
\text { (mg/l) }\end{array}$ & Kalium & $\begin{array}{l}\text { Calcium } \\
\text { (mg/i) }\end{array}$ & $\begin{array}{l}\text { Magnesium } \\
\text { (mg/l) }\end{array}$ \\
\hline $\begin{array}{c}\text { OBSERVED } \\
\text { (Xno) }\end{array}$ & $\begin{array}{l}358.10 \\
310.80 \\
297.50\end{array}$ & $\begin{array}{l}8.04 \\
7.88 \\
7.77\end{array}$ & $\begin{array}{l}206.90 \\
198.90 \\
192.90\end{array}$ & $\begin{array}{l}192.30 \\
171.70 \\
163.90\end{array}$ & $\begin{array}{l}91.10 \\
79.60 \\
77.10\end{array}$ & $\begin{array}{l}69.66 \\
74.55 \\
73.22\end{array}$ & $\begin{array}{l}32.05 \\
28.22 \\
27.00\end{array}$ & $\begin{array}{l}1.43 \\
1.64 \\
1.92\end{array}$ & $\begin{array}{l}19.05 \\
16.83 \\
16.61\end{array}$ & $\begin{array}{l}10.55 \\
9.11 \\
8.64\end{array}$ \\
\hline$\left(\overline{x_{n}}\right)$ & 322.1 & 79 & 199.6 & 176.0 & 82.6 & 72.5 & 29.1 & 1.7 & 17.5 & 9.4 \\
\hline $\begin{array}{c}\text { ENTROPY } \\
(\text { Xne })\end{array}$ & $\begin{array}{l}306.70 \\
302.70 \\
301.20\end{array}$ & $\begin{array}{l}7.96 \\
7.95 \\
7.96\end{array}$ & $\begin{array}{l}208.00 \\
203.70 \\
209.50\end{array}$ & $\begin{array}{l}168.10 \\
168.40 \\
167.40\end{array}$ & $\begin{array}{l}88.90 \\
86.50 \\
90.90\end{array}$ & $\begin{array}{l}87.88 \\
84.25 \\
89.55\end{array}$ & $\begin{array}{l}27.08 \\
27.67 \\
25.61\end{array}$ & $\begin{array}{l}1.62 \\
1.65 \\
1.70\end{array}$ & $\begin{array}{l}18.75 \\
18.54 \\
19.66\end{array}$ & $\begin{array}{c}10.36 \\
9.91 \\
10.20\end{array}$ \\
\hline$(\bar{X} \cap \ominus)$ & 303.5 & 8.0 & 207.1 & 168.0 & 88.8 & 87.2 & 26.8 & 1.7 & 19.0 & 10.2 \\
\hline
\end{tabular}

Number of Standard Deviations of the Distribution of Sampled Means by which the New/Predicted Mean Values lies from the Historical Mean Values

\begin{tabular}{|c|c|c|c|c|c|c|c|c|c|c|}
\hline & $\begin{array}{c}\text { Conductivity } \\
@ 25 \mathrm{C} \\
\text { (ms/m) } \\
\end{array}$ & $\mathrm{PH}$ & $\begin{array}{c}\text { Dissolved } \\
\text { Ions } \\
\text { (mg/l) } \\
\end{array}$ & $\begin{array}{c}\text { Dissolved } \\
\text { Solids } \\
\text { (mg/l) }\end{array}$ & $\begin{array}{c}\text { Hardness } \\
\text { (mgl)as } \mathrm{CaCO} 3 \\
\end{array}$ & $\begin{array}{c}\text { Alkalinity } \\
\text { (mg)as } \mathrm{CaCO} 3 \\
\end{array}$ & $\begin{array}{l}\text { Natrium } \\
(\mathrm{mg} /)\end{array}$ & $\begin{array}{l}\text { Kalium } \\
\text { (mg/l) }\end{array}$ & $\begin{array}{l}\text { Calcium } \\
(\mathrm{mg} / \mathrm{l}) \\
\end{array}$ & $\begin{array}{l}\text { Magnesium } \\
\text { (mg/l) }\end{array}$ \\
\hline $\begin{array}{c}\text { OBSERVED } \\
(\overline{\mathrm{X}} \mathrm{n} \cap \overline{\mathrm{X}} \mathrm{n}) /[\mathrm{s} / \mathrm{N} \mathrm{n}]\end{array}$ & -1.15 & 0.55 & -1.59 & -1.51 & -1.55 & -2.19 & -1.20 & -0.23 & -1.52 & -1.53 \\
\hline $\begin{array}{c}\text { ENTROPY } \\
(\bar{X} \text { ne- } \bar{X} h) /[s / \mathrm{Sn}]\end{array}$ & -1.39 & 0.90 & -1.42 & -1.71 & -1.25 & -1.08 & -1.54 & -0.25 & -1.16 & -1.25 \\
\hline
\end{tabular}


Table 5.15(a) (continued)

\section{[4 Yearly Averaging]}

\section{New/Predicted Mean Values}

\begin{tabular}{|c|c|c|c|c|c|c|c|c|c|c|}
\hline & $\begin{array}{c}\text { Conductivity } \\
@ 25 \mathrm{C} \\
\text { (ms/m) }\end{array}$ & $\mathrm{PH}$ & $\begin{array}{c}\text { Dissolved } \\
\text { lons } \\
\text { (mg/l) }\end{array}$ & $\begin{array}{c}\text { Dissolved } \\
\text { Solids } \\
\text { (mg/l) }\end{array}$ & $\begin{array}{c}\text { Hardness } \\
\text { (mg/l)as Caco3 }\end{array}$ & $\begin{array}{c}\text { Alkalinity } \\
\text { (mg/) } a s \mathrm{CaCO} 3\end{array}$ & $\begin{array}{l}\text { Natrium } \\
\text { (mg/) }\end{array}$ & $\begin{array}{l}\text { Kalium } \\
(\mathrm{mg} / \mathrm{l})\end{array}$ & $\begin{array}{l}\text { Calcium } \\
(\mathrm{mg} /)\end{array}$ & $\begin{array}{c}\text { Magnesium } \\
\text { (mg/) }\end{array}$ \\
\hline $\begin{array}{c}\text { OBSERVED } \\
\text { (XПO) }\end{array}$ & $\begin{array}{l}339.4 \\
302.3\end{array}$ & 7.9 & $\begin{array}{l}199.4 \\
194.8\end{array}$ & $\begin{array}{l}183.4 \\
166.3\end{array}$ & 86.3 & $\begin{array}{l}68.4 \\
73.9\end{array}$ & $\begin{array}{l}30.3 \\
27.2\end{array}$ & 1.6 & 18.1 & 10.0 \\
\hline$(X n O)$ & 320.9 & 7.9 & 197.1 & 174.9 & 82.5 & 71.2 & 28.7 & 1.7 & 17.5 & 9.4 \\
\hline $\begin{array}{c}\text { ENTROPY } \\
\text { (Xne) }\end{array}$ & $\begin{array}{l}318.6 \\
320.1\end{array}$ & $\begin{array}{l}8.0 \\
8.0\end{array}$ & $\begin{array}{l}215.9 \\
218.0\end{array}$ & $\begin{array}{l}171.0 \\
172.8\end{array}$ & $\begin{array}{l}92.3 \\
93.9\end{array}$ & $\begin{array}{l}89.6 \\
90.1\end{array}$ & $\begin{array}{l}28.1 \\
28.5\end{array}$ & $\begin{array}{l}1.8 \\
1.7\end{array}$ & $\begin{array}{l}19.7 \\
20.2\end{array}$ & $\begin{array}{l}10.6 \\
10.7\end{array}$ \\
\hline$\overline{(\bar{x} n)}$ & 319.4 & 8.0 & 217.0 & 171.9 & 93.1 & 89.9 & 28.3 & 16 & 19.8 & 10.6 \\
\hline
\end{tabular}

Number of Standard Deviations of the Distribution of Sampled Means by which the New/Predicted Mean Values lies from the Historical Mean Values

\begin{tabular}{|c|c|c|c|c|c|c|c|c|c|c|}
\hline & $\begin{array}{c}\text { Conductivity } \\
@ 25 \mathrm{C} \\
(\mathrm{ms} / \mathrm{m})\end{array}$ & $\mathrm{PH}$ & $\begin{array}{c}\text { Dissolved } \\
\text { lons } \\
\text { (mg/l) } \\
\end{array}$ & $\begin{array}{c}\text { Dissolved } \\
\text { Solids } \\
\text { (mg/) } \\
\end{array}$ & $\begin{array}{c}\text { Hardness } \\
\text { (mgn)as CaCO3 } \\
\end{array}$ & $\begin{array}{c}\text { Alkalinity } \\
\text { (mg/f)as } \mathrm{CaCO}\end{array}$ & $\begin{array}{l}\text { Natrium } \\
\text { (mg/l) }\end{array}$ & $\begin{array}{l}\text { Kalium } \\
\text { (mgl) }\end{array}$ & $\begin{array}{l}\text { Calcium } \\
\text { (mg/) }\end{array}$ & $\begin{array}{l}\text { Magnesium } \\
\text { (mg/l) } \\
\end{array}$ \\
\hline $\begin{array}{c}\text { OBSERVED } \\
\left(\bar{x}_{n o-}-\bar{x} h\right) /[s / \mathrm{s}]\end{array}$ & -0.95 & 0.39 & -1.34 & -1.25 & -1.27 & -1.87 & -1.02 & -0.18 & -1.24 & -1.26 \\
\hline $\begin{array}{c}\text { ENTROPY } \\
\left(\bar{X} n e-\bar{X}(n) /\left[s / N_{n}\right]\right.\end{array}$ & -0.97 & 0.62 & -0.98 & $-1,31$ & -0.85 & -0.72 & $-1,07$ & -0.26 & -0.76 & -0.87 \\
\hline
\end{tabular}


Table 5.15(b) Station 130106

Historical (prior) Mean Values

\begin{tabular}{|c|c|c|c|c|c|c|c|c|c|c|}
\hline & $\begin{array}{l}\text { Conductivity } \\
\text { @ } 25 \mathrm{C} \\
\text { (ms/m) }\end{array}$ & $\mathrm{PH}$ & $\begin{array}{c}\text { Dissolved } \\
\text { Ions } \\
\text { (mg/t) }\end{array}$ & $\begin{array}{c}\text { Dissolved } \\
\text { Solids } \\
\text { (mg/) } \\
\end{array}$ & $\begin{array}{c}\text { Hardness } \\
\text { (mg/)as cacos }\end{array}$ & $\begin{array}{c}\text { Alkalinity } \\
\text { (mg/)as } \mathrm{CaCO} 3\end{array}$ & $\begin{array}{l}\text { Natrium } \\
\text { (mg/i) }\end{array}$ & $\begin{array}{l}\text { Kalium } \\
(\mathrm{mg} / 1)\end{array}$ & $\begin{array}{l}\text { Calcium } \\
(\mathrm{mg} / \mathrm{l})\end{array}$ & $\begin{array}{l}\text { Magnesium } \\
\quad(m g /) \\
\end{array}$ \\
\hline $\begin{array}{ll}\text { Mean } \quad(\vec{X} h) \\
\text { Standard } \\
\text { Deviation }\end{array}$ & $\begin{array}{c}232.3 \\
83.2\end{array}$ & $\begin{array}{l}7.6 \\
0.2\end{array}$ & $\begin{array}{l}188.6 \\
68.2\end{array}$ & $\begin{array}{l}145.6 \\
56.1\end{array}$ & $\begin{array}{l}83.1 \\
31.3\end{array}$ & $\begin{array}{l}95.4 \\
33.1\end{array}$ & $\begin{array}{l}17.1 \\
7.2\end{array}$ & $\begin{array}{l}3.9 \\
0.5\end{array}$ & $\begin{array}{c}19.8 \\
7.1\end{array}$ & $\begin{array}{l}8.2 \\
3.8\end{array}$ \\
\hline
\end{tabular}

\section{[1 Yearly Averaging]}

\section{New/Predicted Mean Values}

\begin{tabular}{|c|c|c|c|c|c|c|c|c|c|c|}
\hline & $\begin{array}{c}\text { Condurctivity } \\
\text { @ 25 C } \\
\text { (ms/m) }\end{array}$ & $\mathrm{PH}$ & $\begin{array}{c}\text { Dissolved } \\
\text { lons } \\
(\mathrm{mg} / \mathrm{l}) \\
\end{array}$ & $\begin{array}{c}\text { Dissolved } \\
\text { Solids } \\
\text { (mg/l) } \\
\end{array}$ & $\begin{array}{c}\text { Hardness } \\
\text { (mofi)as Caco3 }\end{array}$ & $\begin{array}{c}\text { Alkalinity } \\
\text { (mg/i)as } \mathrm{CaCO} 3\end{array}$ & $\begin{array}{l}\text { Natrium } \\
\text { (mg/l) }\end{array}$ & $\begin{array}{l}\text { Kalium } \\
(\mathrm{mg} / \mathrm{l})\end{array}$ & $\begin{array}{l}\text { Calcium } \\
(\mathrm{mg} /)\end{array}$ & $\begin{array}{c}\text { Magnesium } \\
\text { (mgn) }\end{array}$ \\
\hline \multirow[t]{5}{*}{ OBSERVED } & 198.3 & 7.8 & 151.0 & 114.8 & 58.8 & 79.8 & 14.6 & 3.9 & 13.0 & 6.4 \\
\hline & 211.3 & 7.9 & 163.3 & 122.5 & 72.5 & 87.0 & 13.6 & 3.8 & 17.3 & 7.1 \\
\hline & 206.7 & 7.7 & 161.3 & 123.3 & 62.0 & 76.3 & 16.3 & 3.7 & 14.7 & 6.2 \\
\hline & 242.5 & 7.5 & 166.2 & 140.0 & 65.5 & 67.5 & 22.0 & 3.0 & 15.0 & 6.8 \\
\hline & 185.0 & 6.4 & 150.2 & 110.0 & 61.0 & 80.0 & 13.5 & 3.4 & 15.0 & 5.6 \\
\hline$(\overline{x n o})$ & 209.0 & 7.4 & 158.4 & 122.1 & 54.0 & 78.1 & 16.0 & 3.6 & 15.0 & 6.4 \\
\hline \multirow[t]{5}{*}{ ENTROPY } & 206.5 & 7.6 & 159,4 & 115.9 & 70.4 & 86.0 & 14.3 & 3.8 & 16.6 & 6.8 \\
\hline & 209.3 & 7.6 & 155.0 & 120.6 & 67.0 & 65.1 & 16.1 & 3.7 & 15.6 & 6.5 \\
\hline & 201.5 & 7.6 & 152.3 & $\$ 12.0$ & 67.4 & 74.5 & 14.6 & 3.9 & 16.3 & 6.2 \\
\hline & 203.5 & 7.6 & 152.2 & 116.3 & 66.3 & 69.5 & 14.7 & 3.9 & 16.1 & 6.1 \\
\hline & 208.1 & 7.7 & 164.5 & 119.2 & 74.5 & 89.1 & 14.7 & 3.9 & 18.1 & 7.0 \\
\hline$\left(\overline{X_{n}}\right)$ & 205.8 & 7.6 & 156.7 & 116.8 & 69.1 & 76.8 & 14.9 & 3.8 & 16.5 & 6.5 \\
\hline
\end{tabular}

Number of Standard Deviations of the Distribution of Sampled Means by which the New/Predicted Mean Values lies from the Historical Mean Values

\begin{tabular}{|c|c|c|c|c|c|c|c|c|c|c|}
\hline & $\begin{array}{l}\text { Conductivity } \\
\text { @ } 25 \mathrm{C} \\
(\mathrm{ms} / \mathrm{m})\end{array}$ & $\mathrm{PH}$ & $\begin{array}{c}\text { Dissolved } \\
\text { Ions } \\
\text { (mg/l) }\end{array}$ & $\begin{array}{c}\text { Dissolved } \\
\text { Solids } \\
\text { (mg/l) } \\
\end{array}$ & $\begin{array}{c}\text { Hardness } \\
(\mathrm{mg} /) \text { as } \mathrm{CaCO} 3\end{array}$ & $\begin{array}{c}\text { Alkalinity } \\
\text { (mg//)as Caco3 }\end{array}$ & $\begin{array}{l}\text { Natrium } \\
\text { (mg/l) }\end{array}$ & $\begin{array}{l}\text { Kalium } \\
(\mathrm{mg} / \mathrm{l})\end{array}$ & $\begin{array}{l}\text { Calciurn } \\
\text { (mg/l) }\end{array}$ & $\begin{array}{c}\text { Magnesium } \\
(\mathrm{mg} /)\end{array}$ \\
\hline $\begin{array}{c}\text { OBSERVED } \\
(\bar{X} \text { no- }-\bar{X} h) /[s / N n]\end{array}$ & -0.63 & -1.84 & -0.99 & -0.94 & -1.37 & -1.17 & -0.34 & -1.54 & -7.52 & -1.05 \\
\hline $\begin{array}{c}\text { ENTROPY } \\
(\bar{X} n e-\bar{X} h) /[s / V n]\end{array}$ & -0.71 & 0.25 & -1.05 & -1.15 & -1.00 & -1.26 & -0.69 & -0.24 & -1.03 & -0.98 \\
\hline
\end{tabular}


Table 5.15(b) (continued)

[2 Yearly Averaging]

New/Predicted Mean Values

\begin{tabular}{|c|c|c|c|c|c|c|c|c|c|c|}
\hline & $\begin{array}{c}\text { Conductivity } \\
\text { @ } 25 \mathrm{C} \\
\text { (ms/m) } \\
\end{array}$ & $\mathrm{PH}$ & $\begin{array}{c}\text { Dissolved } \\
\text { Ions } \\
\text { (mg/f) } \\
\end{array}$ & $\begin{array}{c}\text { Dissolved } \\
\text { Solids } \\
(\mathrm{mg} / \mathrm{l})\end{array}$ & $\begin{array}{c}\text { Haroness } \\
\text { (mgn)as } \mathrm{CaCO} 3\end{array}$ & $\begin{array}{c}\text { Alkalinity } \\
\text { (mgA)as } \mathrm{CaCO} 3\end{array}$ & $\begin{array}{l}\text { Natrium } \\
\text { (mg/i) }\end{array}$ & $\begin{array}{l}\text { Kalium } \\
\text { (mg/) }\end{array}$ & $\begin{array}{l}\text { Calcium } \\
\text { (mgf) }\end{array}$ & $\begin{array}{l}\text { Magnesium } \\
\text { (mg/) }\end{array}$ \\
\hline $\begin{array}{c}\text { OBSERVED } \\
\left(X_{n O}\right)\end{array}$ & $\begin{array}{l}205.3 \\
209.0 \\
224.6 \\
213.8\end{array}$ & $\begin{array}{l}7.8 \\
7.8 \\
7.6 \\
6.9\end{array}$ & $\begin{array}{c}157.2 \\
162.3 \\
163.7 \\
158.2\end{array}$ & $\begin{array}{l}118.7 \\
122.9 \\
131.7 \\
125.0\end{array}$ & $\begin{array}{l}65.7 \\
67.3 \\
63.8 \\
63.3\end{array}$ & $\begin{array}{l}83.4 \\
81.7 \\
71.9 \\
73.8\end{array}$ & $\begin{array}{l}14.1 \\
15.0 \\
19.2 \\
17.8\end{array}$ & $\begin{array}{l}3.8 \\
3.8 \\
3.4 \\
3.2\end{array}$ & $\begin{array}{l}15.1 \\
16.0 \\
14.8 \\
15.0\end{array}$ & $\begin{array}{l}6.8 \\
6.6 \\
6.5 \\
6.2\end{array}$ \\
\hline$\left(\overrightarrow{X_{n O}}\right)$ & 213.1 & 7.5 & 160.4 & 124.6 & 65.0 & 77.7 & 16.5 & 3.5 & 15.2 & 6.5 \\
\hline $\begin{array}{c}\text { ENTROPY } \\
(X n e)\end{array}$ & $\begin{array}{l}210.8 \\
208.6 \\
206.1 \\
209.1\end{array}$ & $\begin{array}{l}8.2 \\
8.2 \\
8.2 \\
8.2\end{array}$ & $\begin{array}{c}163.2 \\
160.4 \\
159.4 \\
164.0\end{array}$ & $\begin{array}{l}124.4 \\
122.9 \\
121.3 \\
124.0\end{array}$ & $\begin{array}{l}72.2 \\
71.1 \\
70.9 \\
73.5\end{array}$ & $\begin{array}{l}79.4 \\
75.1 \\
76.7 \\
82.1\end{array}$ & $\begin{array}{r}15.4 \\
15.5 \\
14.9 \\
14.9\end{array}$ & $\begin{array}{l}3.9 \\
3.8 \\
3.9 \\
3.9\end{array}$ & $\begin{array}{l}16.9 \\
16.8 \\
17.0 \\
17.6\end{array}$ & $\begin{array}{l}7.0 \\
6.8 \\
6.6 \\
6.9\end{array}$ \\
\hline$\left(\overline{x_{n}}\right)$ & 208.7 & 8.2 & 161.7 & 123.2 & 71.9 & 78.3 & 15.2 & 3.8 & 17.1 & 6.8 \\
\hline
\end{tabular}

Number of Standard Deviations of the Distribution of Sampled Means by which the New/Predicted Mean Values lies from the Historical Mean Values

\begin{tabular}{|c|c|c|c|c|c|c|c|c|c|c|}
\hline & $\begin{array}{c}\text { Conductivity } \\
@ 25 \mathrm{C} \\
\text { (ms/m) }\end{array}$ & $\mathrm{PH}$ & $\begin{array}{c}\text { Dissolved } \\
\text { lons } \\
(\mathrm{mg} / \mathrm{l}) \\
\end{array}$ & $\begin{array}{c}\text { Dissolved } \\
\text { Solids } \\
\text { (mg/f) }\end{array}$ & $\begin{array}{c}\text { Hardiness } \\
(\mathrm{mg} /) \text { as } \mathrm{CaCO} 3\end{array}$ & $\begin{array}{c}\text { Alkalinity } \\
\text { (mg/l)as Cacos }\end{array}$ & $\begin{array}{l}\text { Natrium } \\
\text { (mgil) }\end{array}$ & $\begin{array}{l}\text { Kalium } \\
(\mathrm{mg} / \mathrm{l})\end{array}$ & $\begin{array}{l}\text { Calcium } \\
(\mathrm{mgn})\end{array}$ & $\begin{array}{c}\text { Magnesium } \\
\text { (mgl) }\end{array}$ \\
\hline $\begin{array}{c}\text { OBSERVED } \\
(\bar{X} n o-\bar{X} n) /[s N(n)]\end{array}$ & -0.46 & -0.79 & -0.83 & -0.75 & -1.16 & -1.07 & -0.17 & -1.45 & -1.20 & -0.88 \\
\hline $\begin{array}{c}\text { ENTROPY } \\
(\bar{X} n e-\bar{X} h) /[s / n n]\end{array}$ & -0.57 & 5.90 & -0.79 & -0.80 & -0.71 & -1.03 & -0.54 & -0.23 & -0.77 & -0.72 \\
\hline
\end{tabular}

\section{[3 Yearly Averaging]}

New/Predicted Mean Values

\begin{tabular}{|c|c|c|c|c|c|c|c|c|c|c|}
\hline & $\begin{array}{c}\text { Conductivity } \\
@ 25 \mathrm{C} \\
\text { (ms/m) }\end{array}$ & $\mathrm{PH}$ & $\begin{array}{c}\text { Dissolved } \\
\text { tons } \\
\text { (mg/l) } \\
\end{array}$ & $\begin{array}{c}\text { Dissolved } \\
\text { Solids } \\
\text { (mg/i) }\end{array}$ & $\begin{array}{c}\text { Hardness } \\
\text { (mg/l)as } \mathrm{CaCO} 3 \\
\end{array}$ & $\begin{array}{c}\text { Alkalinity } \\
\text { (mg/l)as CaCO3 }\end{array}$ & $\begin{array}{l}\text { Natrium } \\
\text { (mg/l) }\end{array}$ & $\begin{array}{l}\text { Kalium } \\
\text { (mg/l) }\end{array}$ & $\begin{array}{l}\text { Calcium } \\
\text { (mg/) }\end{array}$ & $\begin{array}{c}\text { Magnesium } \\
\text { (mgn) }\end{array}$ \\
\hline $\begin{array}{c}\text { OBSERVED } \\
(\mathrm{XnO})\end{array}$ & $\begin{array}{l}205.80 \\
220.10 \\
211.40\end{array}$ & $\begin{array}{l}7.78 \\
7.66 \\
7.17\end{array}$ & $\begin{array}{l}158.50 \\
163.60 \\
159.20\end{array}$ & $\begin{array}{l}120.20 \\
128.60 \\
124.40\end{array}$ & $\begin{array}{l}64.40 \\
66.70 \\
62.80\end{array}$ & $\begin{array}{l}81.05 \\
76.94 \\
74.61\end{array}$ & $\begin{array}{l}14.85 \\
17.31 \\
17.27\end{array}$ & $\begin{array}{l}3.79 \\
3.51 \\
3.37\end{array}$ & $\begin{array}{l}14.97 \\
15.63 \\
14.88\end{array}$ & $\begin{array}{l}6.56 \\
6.69 \\
6.19\end{array}$ \\
\hline$(\bar{X} \cap 0)$ & 212.4 & 7.5 & 160.4 & 124.4 & 64.6 & 77.5 & 16.5 & 3.6 & 15.2 & 6.5 \\
\hline $\begin{array}{c}\text { ENTROPY } \\
\text { (Xne) }\end{array}$ & $\begin{array}{l}210.90 \\
210.10 \\
209.80\end{array}$ & $\begin{array}{l}7.66 \\
7.66 \\
7.66\end{array}$ & $\begin{array}{l}163.00 \\
161.20 \\
163.60\end{array}$ & $\begin{array}{l}122.50 \\
122.60 \\
122.30\end{array}$ & $\begin{array}{l}72.90 \\
71.90 \\
73.70\end{array}$ & $\begin{array}{l}80.53 \\
76.61 \\
82.34\end{array}$ & $\begin{array}{r}15.14 \\
15.25 \\
14.84\end{array}$ & $\begin{array}{l}3.85 \\
3.89 \\
3.95\end{array}$ & $\begin{array}{l}17.19 \\
17.07 \\
17.65\end{array}$ & $\begin{array}{l}7.01 \\
6.91 \\
6.95\end{array}$ \\
\hline$(\bar{x} \cap \bar{e})$ & 210.3 & 7.7 & 162.6 & 122.5 & 72.8 & 79.8 & 15.1 & 3.9 & 17.3 & 7.0 \\
\hline
\end{tabular}

Number of Standard Deviations of the Distribution of Sampled Means by which the New/Predicted Mean Values lies from the Historical Mean Values

\begin{tabular}{|c|c|c|c|c|c|c|c|c|c|c|}
\hline & $\begin{array}{c}\text { Conductivity } \\
@ 25 \mathrm{C} \\
(\mathrm{ms} / \mathrm{m}) \\
\end{array}$ & $\mathrm{PH}$ & $\begin{array}{c}\text { Dissolved } \\
\text { lons } \\
(\mathrm{mg} / \mathrm{l}) \\
\end{array}$ & \begin{tabular}{|c|} 
Dissolved \\
Solids \\
(mg/) \\
\end{tabular} & $\begin{array}{c}\text { Hardness } \\
\text { (mg/l)as CaCO3 }\end{array}$ & $\begin{array}{c}\text { Alkalinity } \\
\text { (mg/)as } \mathrm{CaCO} 3\end{array}$ & $\begin{array}{l}\text { Natrium } \\
\text { (mg/) }\end{array}$ & $\begin{array}{l}\text { Kalium } \\
\text { (mg/l) }\end{array}$ & $\begin{array}{l}\text { Calcium } \\
(\mathrm{mg} / \mathrm{l})\end{array}$ & $\begin{array}{l}\text { Magnesium } \\
\text { (mg/) }\end{array}$ \\
\hline $\begin{array}{c}\text { OBSERVED } \\
(\bar{X} \text { no- } \bar{x} h) /[\mathrm{s} / \mathrm{Nn}]\end{array}$ & -0.41 & -0.55 & -0.72 & -0.65 & -1.02 & -0.93 & -0.15 & -1.20 & -1.43 & -0.78 \\
\hline $\begin{array}{c}\text { ENTROPY } \\
(\bar{X} n e-\bar{X} h) /[S N n]\end{array}$ & -0.46 & 0.52 & -0.66 & -0.71 & -0.57 & -0.81 & -0.49 & -0.01 & -0.61 & -0.57 \\
\hline
\end{tabular}


Table 5.15(b) (continued)

\section{[4 Yearly Averaging]}

\section{New/Predicted Mean Values}

\begin{tabular}{|c|c|c|c|c|c|c|c|c|c|c|}
\hline & $\begin{array}{c}\text { Conductivity } \\
\text { @ } 25 \mathrm{C} \\
(\mathrm{ms} / \mathrm{m}) \\
\end{array}$ & PH & $\begin{array}{c}\text { Dissolved } \\
\text { lons } \\
(\mathrm{mg} /) \\
\end{array}$ & $\begin{array}{c}\text { Dissolved } \\
\text { Solids } \\
(\mathrm{mg} / \mathrm{l}) \\
\end{array}$ & $\begin{array}{c}\text { Hardness } \\
\text { (mgl)as } \mathrm{CaCO} 3 \\
\end{array}$ & $\begin{array}{c}\text { Alkalinity } \\
\text { (mgl)as } \mathrm{CaCO} 3 \\
\end{array}$ & $\begin{array}{l}\text { Natrium } \\
(\mathrm{mg} / \mathrm{f})\end{array}$ & $\begin{array}{l}\text { Kalium } \\
\text { (mg/) }\end{array}$ & $\begin{array}{l}\text { Calcium } \\
\text { (mg/) }\end{array}$ & $\begin{array}{c}\text { Magnesium } \\
\text { (mgn) } \\
\end{array}$ \\
\hline OBSERVED & 214.9 & 7.7 & 160.4 & 125.2 & 64.7 & 77.7 & 16.6 & 3.6 & $\begin{array}{l}15.0 \\
15.5\end{array}$ & 6.6 \\
\hline (Xno) & 213.2 & 7.5 & 160.4 & 124.6 & 65.0 & 77.7 & 16.5 & 3.5 & 15.2 & 6.5 \\
\hline $\begin{array}{c}\text { ENTROPY } \\
(\text { Xne) }\end{array}$ & $\begin{array}{l}213.4 \\
213.7\end{array}$ & $\begin{array}{l}7.7 \\
7.7\end{array}$ & $\begin{array}{l}166.4 \\
167.2\end{array}$ & $\begin{array}{l}123.5 \\
124.2\end{array}$ & $\begin{array}{l}74.2 \\
74.9\end{array}$ & $\begin{array}{l}82.4 \\
83.0\end{array}$ & $\begin{array}{l}15.3 \\
15.4\end{array}$ & $\begin{array}{l}3.9 \\
3.9\end{array}$ & $\begin{array}{l}17.7 \\
17.9\end{array}$ & $\begin{array}{l}7.1 \\
7.1\end{array}$ \\
\hline$(\tilde{x} \bar{x})$ & 213.8 & 7.7 & 166.8 & 123.9 & 74.5 & 82.7 & 15.4 & 3.9 & 17.8 & 7.1 \\
\hline
\end{tabular}

Number of Standard Deviations of the Distribution of Sampled Means by which the New/Predicted Mean Values lies from the Historical Mean Values

\begin{tabular}{|c|c|c|c|c|c|c|c|c|c|c|}
\hline & $\begin{array}{l}\text { Conductivity } \\
@ 25 \mathrm{C} \\
(\mathrm{mS} / \mathrm{m}) \\
\end{array}$ & $\mathrm{PH}$ & $\begin{array}{c}\text { Dissolved } \\
\text { lons } \\
\text { (mg/) }\end{array}$ & $\begin{array}{c}\text { Dissolved } \\
\text { Solids } \\
\text { (mg/l) }\end{array}$ & $\begin{array}{c}\text { Hardness } \\
\text { (mg/l)as } \mathrm{CaCO} 3\end{array}$ & $\begin{array}{c}\text { Alkalinity } \\
\text { (mg/)las CaCO3 } \\
\end{array}$ & $\begin{array}{l}\text { Natrium } \\
(\mathrm{mg} / \mathrm{l})\end{array}$ & $\begin{array}{l}\text { Kalium } \\
(\mathrm{mg} / \mathrm{i})\end{array}$ & $\begin{array}{l}\text { Calcium } \\
(m g /)\end{array}$ & $\begin{array}{l}\text { Magnesium } \\
\text { (mgl) }\end{array}$ \\
\hline $\begin{array}{c}\text { OBSERVED } \\
\left(\bar{x}_{n o-}-\bar{x}_{h}\right) /[\mathrm{g} / \mathrm{Nn}]\end{array}$ & -0.33 & -0.57 & -0.59 & -0.53 & -0.82 & -0.76 & -0.12 & -1.03 & $\cdot-0.91$ & -0.63 \\
\hline 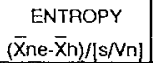 & -0.32 & 0.46 & -0.45 & -0.55 & -0.39 & -0.54 & -0.34 & -0.04 & -0.40 & -0.41 \\
\hline
\end{tabular}


Table $5.15(\mathrm{c})$ Station 130105

Historical (prior) Mean Values

\begin{tabular}{|c|c|c|c|c|c|c|c|c|c|c|}
\hline & $\begin{array}{c}\text { Conductivity } \\
@ 25 \mathrm{C} \\
(\mathrm{ms} / \mathrm{m}) \\
\end{array}$ & $\mathrm{PH}$ & $\begin{array}{c}\text { Dissotved } \\
\text { Ions } \\
\text { (mg/l) } \\
\end{array}$ & $\begin{array}{c}\text { Dissolved } \\
\text { Solids } \\
\text { (mg/l) } \\
\end{array}$ & $\begin{array}{c}\text { Hardness } \\
\text { (mgll)as } \mathrm{CaCO} 3 \\
\end{array}$ & \begin{tabular}{c|} 
Alkalinity \\
(mg/l)as $\mathrm{CaCO} 3$ \\
\end{tabular} & $\begin{array}{l}\text { Natrium } \\
(\mathrm{mg} / \mathrm{l})\end{array}$ & $\begin{array}{l}\text { Kalium } \\
(\mathrm{mg} / \mathrm{h})\end{array}$ & $\begin{array}{l}\text { Calcium } \\
\text { (mg/) }\end{array}$ & $\begin{array}{l}\text { Magnesium } \\
\text { (mg/l) }\end{array}$ \\
\hline Mean $\quad(\bar{x} h)$ & 343.2 & 7.8 & 231.2 & 189.7 & 96.7 & 91.4 & 29.8 & 2.6 & 20.4 & 10.9 \\
\hline $\begin{array}{l}\text { Standard (s) } \\
\text { Deviation }\end{array}$ & 97.6 & 0.2 & 58.7 & 48.3 & 28.8 & 21.2 & 9.6 & 0.6 & 6.3 & 3.3 \\
\hline
\end{tabular}

\section{[1 Yearly Averaging]}

New Mean Values

\begin{tabular}{|c|c|c|c|c|c|c|c|c|c|c|}
\hline & $\begin{array}{c}\text { Conductivity } \\
\text { @ } 25 \mathrm{C} \\
\text { (ms/m) } \\
\end{array}$ & $\mathrm{PH}$ & $\begin{array}{c}\text { Dissolved } \\
\text { Ions } \\
\text { (mgh) } \\
\end{array}$ & $\begin{array}{c}\text { Dissolved } \\
\text { Solids } \\
\text { (mgll) } \\
\end{array}$ & $\begin{array}{c}\text { Hardness } \\
\text { (mg/l)as } \mathrm{CaCO} 3\end{array}$ & $\begin{array}{c}\text { Aikalinity } \\
\text { (mg/l)as } \mathrm{CaCO} 3\end{array}$ & $\begin{array}{l}\text { Natrium } \\
(\mathrm{mg} / \mathrm{l})\end{array}$ & $\begin{array}{l}\text { Kelium } \\
\text { (mg/) }\end{array}$ & $\begin{array}{l}\text { Calcium } \\
\text { (mg/) }\end{array}$ & $\begin{array}{l}\text { Magnesium } \\
\text { (mgl) }\end{array}$ \\
\hline \multirow[t]{5}{*}{ OBSERVED } & 248.0 & 7.7 & 176.7 & 139.0 & 71.0 & 85.0 & 18.0 & 3.1 & 15.0 & 8.1 \\
\hline & 260.0 & 7.9 & 167.0 & 150.0 & 63.0 & 61.0 & 27.0 & 1.7 & 13.0 & 7.5 \\
\hline & 226.3 & 7.5 & 161.0 & 130.0 & 64.0 & 71.8 & 19.3 & 3.8 & 14.5 & 6.8 \\
\hline & 235.0 & 7.7 & 161.0 & 140.0 & 61.5 & 66.0 & 20.0 & 3.9 & 14.0 & 6.4 \\
\hline & 255.0 & 8.2 & 187.9 & 146.7 & 80.7 & 88.7 & 20.0 & 3.8 & 18.0 & 8.7 \\
\hline$(\bar{x}$ no $)$ & 244.9 & 7.8 & 170.7 & 141.1 & 68.0 & 74.5 & 20.9 & 3.3 & 14.9 & 7.5 \\
\hline
\end{tabular}

Number of Standard Deviations of the Distribution of Sampled Means by which the New Mean Values lies from the Historical Mean Values

\begin{tabular}{|c|c|c|c|c|c|c|c|c|c|c|}
\hline & $\begin{array}{l}\text { Conductivity } \\
@ 25 \mathrm{C} \\
\text { (mS/m) }\end{array}$ & $\mathrm{PH}$ & $\begin{array}{c}\text { Dissolved } \\
\text { lons } \\
\text { (mg/l) }\end{array}$ & $\begin{array}{c}\text { Dissolved } \\
\text { Solids } \\
\text { (mg/l) }\end{array}$ & $\begin{array}{c}\text { Hardness } \\
\text { (mg/l)as } \mathrm{CaCO} 3\end{array}$ & $\begin{array}{c}\text { Alkalinity } \\
\text { (mg/)as } \mathrm{CaCO} 3\end{array}$ & $\begin{array}{l}\text { Natrium } \\
\text { (mg/l) }\end{array}$ & $\begin{array}{l}\text { Kalium } \\
\text { (mgl) }\end{array}$ & $\begin{array}{l}\text { Calcium } \\
\text { (mg/) }\end{array}$ & $\begin{array}{l}\text { Magnesium } \\
\text { (mg/i) }\end{array}$ \\
\hline $\begin{array}{c}\text { OBSERVED } \\
\left(\bar{X} \cap \bar{X}_{0}-\bar{X} h\right) /\left[s / V_{n}\right]\end{array}$ & -2.25 & -0.17 & -2.30 & -2.25 & -2.23 & -1.78 & -2.08 & 2.46 & -1.95 & -2.32 \\
\hline
\end{tabular}

\section{[2 Yearly Averaging]}

New Mean Values

\begin{tabular}{|c|c|c|c|c|c|c|c|c|c|c|}
\hline & $\begin{array}{c}\text { Conductivity } \\
@ 25 \mathrm{C} \\
\text { (ms/m) }\end{array}$ & $\mathrm{PH}$ & $\begin{array}{c}\text { Dissolved } \\
\text { Ions } \\
\text { (mg/l) } \\
\end{array}$ & $\begin{array}{c}\text { Dissolved } \\
\text { Solids } \\
(\mathrm{mg} / \mathrm{l}) \\
\end{array}$ & $\begin{array}{c}\text { Hardness } \\
\text { (mg/l)as } \mathrm{CaCO}\end{array}$ & $\begin{array}{c}\text { Alkalinity } \\
\text { (mgn)as } \mathrm{CaCO}\end{array}$ & $\begin{array}{l}\text { Natrium } \\
\text { (mg/l) }\end{array}$ & $\begin{array}{l}\text { Kalium } \\
\text { (mgn) }\end{array}$ & $\begin{array}{l}\text { Calcium } \\
\text { (mg/) }\end{array}$ & $\begin{array}{l}\text { Magnesium } \\
\text { (mg/) }\end{array}$ \\
\hline $\begin{array}{l}\text { OBSERVED } \\
(x \cap O)\end{array}$ & $\begin{array}{l}254.0 \\
243.1 \\
230.6 \\
245.0\end{array}$ & $\begin{array}{l}7.8 \\
7.7 \\
7.6 \\
7.9\end{array}$ & $\begin{array}{l}171.9 \\
164.0 \\
161.0 \\
174.4\end{array}$ & $\begin{array}{l}144.5 \\
140.0 \\
135.0 \\
143.3\end{array}$ & $\begin{array}{l}67.0 \\
63.5 \\
62.8 \\
71.1\end{array}$ & $\begin{array}{l}73.0 \\
66.4 \\
68.9 \\
77.3\end{array}$ & $\begin{array}{l}22.5 \\
23.1 \\
19.6 \\
20.0\end{array}$ & $\begin{array}{l}2.4 \\
2.8 \\
3.9 \\
3.9\end{array}$ & $\begin{array}{l}14.0 \\
13.8 \\
14.3 \\
16.0\end{array}$ & $\begin{array}{l}7.8 \\
7.1 \\
6.6 \\
7.5\end{array}$ \\
\hline$(\bar{x} \cap 0)$ & 243.2 & 7.7 & 167.8 & 140.7 & 66,1 & 71.4 & 21.3 & 3.2 & 14.5 & 7.3 \\
\hline
\end{tabular}

Number of Standard Deviations of the Distribution of Sampled Means by which the New Mean Values lies from the Historical Mean Values

\begin{tabular}{|c|c|c|c|c|c|c|c|c|c|c|}
\hline & $\begin{array}{c}\text { Conductivity } \\
@ 25 \mathrm{C} \\
(\mathrm{ms} / \mathrm{m})\end{array}$ & $\mathrm{PH}$ & $\begin{array}{l}\text { Dissolved } \\
\text { Ions } \\
\text { (mgl) }\end{array}$ & $\begin{array}{c}\text { Dissolved } \\
\text { Solids } \\
\text { (mg/) }\end{array}$ & $\begin{array}{c}\text { Hardness } \\
\text { (mg/)as } \mathrm{CaCO} 3\end{array}$ & \begin{tabular}{|c|} 
Alkalinity \\
(mg/)as $\mathrm{CaCO} 3$ \\
\end{tabular} & $\begin{array}{l}\text { Natrium } \\
(\mathrm{mg} / \mathrm{l})\end{array}$ & $\begin{array}{l}\text { Kalium } \\
\text { (mg/) }\end{array}$ & $\begin{array}{l}\text { Calcium } \\
\text { (mg/) }\end{array}$ & $\begin{array}{l}\text { Magnesium } \\
\text { (mg/) }\end{array}$ \\
\hline $\begin{array}{c}\text { OBSERVED } \\
\left(\bar{X}_{n O-}-\bar{X} n\right) /[s N n]\end{array}$ & $-2,05$ & -0.56 & -2.16 & -2.03 & -2.13 & $-1,89$ & -1.77 & 2.04 & -1.87 & -2.21 \\
\hline
\end{tabular}


Table 5.15 (c) (continued)

\section{[3 Yearly Averaging]}

New Mean Values

\begin{tabular}{|c|c|c|c|c|c|c|c|c|c|c|}
\hline & $\begin{array}{l}\text { Conductivity } \\
@ 25 \mathrm{C} \\
\text { (ms/m) }\end{array}$ & $\mathrm{PH}$ & $\begin{array}{l}\text { Dissolved } \\
\text { Jons } \\
\text { (mg/l) }\end{array}$ & $\begin{array}{l}\text { Dissolved } \\
\text { Solids } \\
\text { (mgn) }\end{array}$ & $\begin{array}{c}\text { Hardness } \\
(\mathrm{mg} / \text { ) } \text { as } \mathrm{CaCO} 3\end{array}$ & $\begin{array}{c}\text { Alkalinity } \\
\text { (mg/l)as } \mathrm{CaCO} 3\end{array}$ & $\begin{array}{l}\text { Natrium } \\
(\mathrm{mg} /)\end{array}$ & $\begin{array}{l}\text { Kalium } \\
\text { (mg/l) }\end{array}$ & $\begin{array}{l}\text { Calcium } \\
\text { (mg/l) }\end{array}$ & $\begin{array}{c}\text { Magnesium } \\
\text { (mg/) }\end{array}$ \\
\hline $\begin{array}{c}\text { OBSEAVED } \\
\left(x_{n O}\right)\end{array}$ & $\begin{array}{l}244.8 \\
240.4 \\
238.8\end{array}$ & $\begin{array}{l}7.7 \\
7.7 \\
7.8\end{array}$ & $\begin{array}{l}168.2 \\
163 \\
170\end{array}$ & $\begin{array}{c}139.7 \\
140 \\
138.9\end{array}$ & $\begin{array}{c}66 \\
62.8 \\
68.7\end{array}$ & $\begin{array}{l}72.6 \\
66.3 \\
75.5\end{array}$ & $\begin{array}{l}21.4 \\
22.1 \\
19.8\end{array}$ & $\begin{array}{l}2.9 \\
3.1 \\
3.8\end{array}$ & $\begin{array}{l}14.2 \\
13.8 \\
15.5\end{array}$ & $\begin{array}{l}7.5 \\
6.9 \\
7.3\end{array}$ \\
\hline$(\bar{X} \cap 0)$ & 241.3 & 7.7 & 167.1 & 139.5 & 65.8 & 71.5 & 21.1 & 3.3 & 14.5 & 7.2 \\
\hline
\end{tabular}

Number of Standard Deviations of the Distribution of Sampled Means by which the New Mean Values lies from the Historical Mean Values

\begin{tabular}{|c|c|c|c|c|c|c|c|c|c|c|}
\hline & $\begin{array}{l}\text { Conductivity } \\
@ 25 \mathrm{C} \\
\text { (ms/m) }\end{array}$ & $\mathrm{PH}$ & $\begin{array}{c}\text { Dissolved } \\
\text { lons } \\
(\mathrm{mg} / \mathrm{h}) \\
\end{array}$ & $\begin{array}{c}\text { Dissolved } \\
\text { Solids } \\
\text { (mgh) } \\
\end{array}$ & $\begin{array}{c}\text { Hardness } \\
\text { (mg/)as } \mathrm{CaCO} 3 \\
\end{array}$ & $\begin{array}{c}\text { Alkalinity } \\
\text { (mg/)as } \mathrm{CaCO} 3 \\
\end{array}$ & $\begin{array}{l}\text { Natrium } \\
\text { (mg/i) }\end{array}$ & $\begin{array}{l}\text { Kalium } \\
\text { (mg/) } \\
\end{array}$ & $\begin{array}{l}\text { Calcium } \\
(\mathrm{mg} / \mathrm{l})\end{array}$ & $\begin{array}{c}\text { Magnesium } \\
\text { (mg/l) }\end{array}$ \\
\hline $\begin{array}{c}\text { OBSERVEO } \\
\left(\vec{X}_{n O}-\bar{X}_{h}\right) /[\mathrm{s} N n]\end{array}$ & -1.81 & -0.58 & -1.89 & -1.80 & -1.86 & -1.63 & -1.57 & 1.92 & -1.62 & -1.92 \\
\hline
\end{tabular}

\section{[4 Yearly Averaging]}

\section{New Mean Values}

\begin{tabular}{|c|c|c|c|c|c|c|c|c|c|c|}
\hline & $\begin{array}{l}\text { Conductivity } \\
\text { @ } 25 \mathrm{C} \\
\text { (ms/m) }\end{array}$ & $\mathrm{PH}$ & $\begin{array}{l}\text { Dissolved } \\
\text { lons } \\
\text { (mg/i) }\end{array}$ & $\begin{array}{c}\text { Dissolved } \\
\text { Solids } \\
\text { (mgl) }\end{array}$ & $\begin{array}{c}\text { Hardness } \\
\text { (mg//)as } \mathrm{CaCO} 3\end{array}$ & $\begin{array}{c}\text { Alkalinity } \\
\text { (mg/)as } \mathrm{CaCO}\end{array}$ & $\begin{array}{l}\text { Natrium } \\
\text { (mgili) }\end{array}$ & $\begin{array}{l}\text { Kalium } \\
\text { (mgl) }\end{array}$ & $\begin{array}{l}\text { Calcium } \\
(\mathrm{mg} / \mathrm{l})\end{array}$ & $\begin{array}{l}\text { Magnesium } \\
\text { (mg/f) }\end{array}$ \\
\hline $\begin{array}{c}\text { OBSERVED } \\
(\text { Xno })\end{array}$ & $\begin{array}{l}242.3 \\
244.1\end{array}$ & $\begin{array}{l}7.7 \\
7.8\end{array}$ & $\begin{array}{l}166.4 \\
169.2\end{array}$ & $\begin{array}{r}139.8 \\
141.7\end{array}$ & $\begin{array}{l}64.9 \\
67.3\end{array}$ & $\begin{array}{l}70.9 \\
71.9\end{array}$ & $\begin{array}{l}21.1 \\
21.6\end{array}$ & $\begin{array}{l}3.1 \\
3.3\end{array}$ & $\begin{array}{l}14.1 \\
14.9\end{array}$ & $\begin{array}{l}7.2 \\
7.3\end{array}$ \\
\hline$(X \cap)$ & 243.2 & 7.7 & 167.8 & 140.7 & 66.1 & 71.4 & 21.3 & 3.2 & 14.5 & 7.3 \\
\hline
\end{tabular}

Number of Standard Deviations of the Distribution of Sampled Means by which the New Mean Values lies from the Historical Mean Values

\begin{tabular}{|c|c|c|c|c|c|c|c|c|c|c|}
\hline & $\begin{array}{c}\text { Conductivity } \\
\text { @25 C } \\
\text { (mS/m) }\end{array}$ & $\mathrm{PH}$ & $\begin{array}{l}\text { Dissolved } \\
\text { lons } \\
\text { (mgl) } \\
\end{array}$ & \begin{tabular}{|c} 
Dissolved \\
Solids \\
(mg/) \\
\end{tabular} & $\begin{array}{c}\text { Hardness } \\
\text { (mg/)as } \mathrm{CaCO} 3\end{array}$ & $\begin{array}{c}\text { Alkalinity } \\
\text { (mg/l)as } \mathrm{CaCO} 3 \\
\end{array}$ & $\begin{array}{l}\text { Natrium } \\
\text { (mg/) }\end{array}$ & $\begin{array}{l}\text { Kalium } \\
\text { (mgll) }\end{array}$ & $\begin{array}{l}\text { Calcium } \\
\text { (mg/) }\end{array}$ & $\begin{array}{c}\text { Magnesium } \\
\text { (nng/) }\end{array}$ \\
\hline $\begin{array}{c}\text { OBSERVEO } \\
(\bar{X} n O-\bar{X} n) /[s / N n]\end{array}$ & -1.45 & -0.40 & -1.53 & -1.43 & -1.50 & -1.33 & -1.25 & 1.44 & -1.32 & -1.56 \\
\hline
\end{tabular}


calibration data set (1971 to 1980) and the verification data set (1981 to 1985) for most of the water quality parameters. In most cases the change is greater than one standard deviation from the mean of the historical data.

The new values derived for the upstream stations from the entropy formulation on the basis at this observed downstream value are also presented in Table 5.15(a) for Station 130401 and Table 5.15(b) for Station 130106

It can be seen that in general the differences between the predicted new mean values and corresponding historical means in Table 5.15(a) for station 130401 are greater, in terms of the standard deviations of the sampled mean, than the differences between the predicted means and corresponding historical means for station 130106. This difference in 'distances' indicates that the changes observed at the downstream stations are most. likely caused by a change in the conditions in the branch upon which station 130401 is located. If the causes of the predicted changes in water quality on that branch are not evident, then the results suggest that, if the water quality changes are critical, then some effort should be directed at verifying that changes have occurred on this branch (recall that the prediction is one of most likely rather than absolute certainty) and 
identifying the causes of the changes. (The results of application of the approach to the other data sets are presented in Tables B.4.1 to B.4.3 in the Appendix B.)

Two other interesting features can be identified in Table 5.15. While significant changes in most of the water quality parameters were identified by sampling at the downstream station 130105, as evident in the 'distances' between the known and sampled means for parameter being greater than 1.96 (i.e., for the 1 and 2 yearly averaging), there is no indication of an equivalent magnitude of change in the predicted values for the upstream stations. The reasons for this phenomenon are not yet clear.

The second and associated feature in Table 5.15 relates to the general magnitude of the differences between the known and sampled means at the downstream station and the known and entropy predicted (sampled) means at the upstream stations. The sum of the distances between the known and predicted means at the upstream stations is not equal to the distance between the known and sampled mean at the downstream station and does not appear to be different in a consistent manner. Once again the reason for this difference is not clear and is suitable area for further investigation. 
It should be noted that the approach to identifying the most likely location in the river system of the source of the observed changes in water quality at the downstream monitoring station described in this section, is based on the assumption that the true (historical) probability distribution of the water quality values is appropriately represented by the data contained in the 'calibration set' in Table 5.3. These data do not necessarily give the true distributions as they are aiso only sampled from the population. It can therefore be argued that the calibration data may not reflect the true distribution of the population and therefore the comparison is invalid. Another statistical test such as hypothesis testing can be undertaken in these circumstances to justify whether there is a change in the mean value from the two groups of sampling.

Now consider the Null hypothesis that the predicted (new) mean $\mu_{\mathrm{n}}$ is equal to the historical mean $\mu_{\mathrm{h}}$, i.e., $\mathrm{H}_{0}: \mu_{\mathrm{h}}-\mu_{\mathrm{n}}=0$. The appropriate test statistic for this case is (Bethea et al., 1985) :

$$
T=\frac{\bar{X}_{h}-\bar{X}_{n e}}{\sqrt{\frac{s_{h}^{2}}{n_{h}}+\frac{s_{n o}{ }^{2}}{n_{n o}}}}
$$

which follows a t-distribution 
where :

$$
\begin{aligned}
\overline{\mathrm{X}}_{\mathrm{h}} \text { and } \overline{\mathrm{X}}_{\mathrm{ne}}= & \begin{array}{l}
\text { sample means for the historical and } \\
\text { predicted (new) values respectively, }
\end{array} \\
\mathrm{n}_{\mathrm{h}} \text { and } \mathrm{n}_{\mathrm{ne}}=\quad & \text { sample sizes for the historical and } \\
& \text { predicted (new) values respectively, } \\
& \text { sample variances for the historical } \\
& \text { and predicted (new) values } \\
& \text { respectively. }
\end{aligned}
$$

The degree of freedom for Equation 5.6 is calculated as follows :

$$
V=\frac{\left(\frac{s_{h}^{2}}{n_{h}}+\frac{s_{n 0}^{2}}{n_{n e}}\right)^{2}}{\frac{\left(\frac{s_{h}^{2}}{n_{h}}\right)^{2}}{n_{h}-1}+\frac{\left(\frac{s_{n 0}^{2}}{n_{n e}}\right)^{2}}{n_{n e}-1}}
$$

On the basis of a t-distribution with $v$ degrees of freedom the Null hypothesis for this case, namely that there is no difference between the predicted mean and the historical mean may therefore be rejected if :

$$
T>t_{v}, 1-\frac{\alpha}{2}
$$

or :

$$
T<-t_{v}, 1-\frac{\alpha}{2}
$$


The use of this test is demonstrated by application to the water quality values data sets used earlier in this thesis. The result of these applications are shown in Table 5.16 (and Tables B.5.1 to B.5.3 in the Appendix B) .

It can be seen in Table 5.16 [which contains the data set from the MacKenzie River, that, based on the historical (calibration) samples and the set of values predicted by the entropy method, there is a significant change in the mean water quality values for most of the parameters of interest at the station 130401, i.e., the Null hypothesis can be rejected at the 5\% level. Therefore, a conclusion similar to that of the previous less complex comparison of means, namely that changes in the water quality values at station 130401 are more likely to be the cause of variations in the water quality values observed downstream, can be drawn.

It should also be recognised that the results of this case using the $T$ statistics are in general very similar to those obtained from use of the more simple statistic, namely the significant changes in the water quality parameters observed at the downstream station 130105, are not reflected in an equivalent magnitude of changes in the predicted values for the upstream stations. However, both cases show, how the entropy 
Table 5.16 Hypothesis Testing for the Water Quality Values in the MacKenzie River Sub-Basin

Table 5.16(a) Station 130401

Historical (prior) Mean Values

\begin{tabular}{|c|c|c|c|c|c|c|c|c|c|c|}
\hline & $\begin{array}{c}\text { Conductivity } \\
@ 25 \mathrm{C} \\
\text { (ms/m) }\end{array}$ & $\mathrm{PH}$ & $\begin{array}{c}\text { Dissolved } \\
\text { lons } \\
\text { (mg/l) }\end{array}$ & $\begin{array}{c}\text { Dissolved } \\
\text { Solids } \\
\text { (mg/l) } \\
\end{array}$ & $\begin{array}{c}\text { Hardness } \\
\text { (mg/)as } \mathrm{CaCO}\end{array}$ & $\begin{array}{c}\text { Alkalinity } \\
\text { (mg/)as } \mathrm{CaCO} 3\end{array}$ & $\begin{array}{l}\text { Natrium } \\
(\mathrm{mg} /)^{2}\end{array}$ & $\begin{array}{l}\text { Kalium } \\
\text { (mgn) }\end{array}$ & $\begin{array}{l}\text { Calcium } \\
(\mathrm{mg} /)\end{array}$ & $\begin{array}{l}\text { Magressium } \\
\text { (mg/) }\end{array}$ \\
\hline Mean $\quad(\bar{X} h)$ & 408.8 & 7.8 & 269.7 & 235.2 & 114.7 & 101.6 & 37.1 & 1.7 & 23.8 & 13.4 \\
\hline $\begin{array}{l}\text { Standard (Sh) } \\
\text { Deviation }\end{array}$ & 131 & 0.3 & 76.4 & 68.1 & 35.9 & 23 & 11.6 & 0.3 & 7.2 & 4.5 \\
\hline
\end{tabular}

\section{[1 Yearly Averaging]}

New Mean Values Predicted by the Entropy Method

\begin{tabular}{|c|c|c|c|c|c|c|c|c|c|c|}
\hline & $\begin{array}{c}\text { Conductivity } \\
\text { @ 25 C } \\
(\mathrm{mS} / \mathrm{m})\end{array}$ & PH & $\begin{array}{c}\text { Dissolved } \\
\text { lons } \\
\text { (mg/h) }\end{array}$ & $\begin{array}{c}\text { Dissolved } \\
\text { Solids } \\
\text { (mg/l) }\end{array}$ & $\begin{array}{c}\text { Hardness } \\
\text { (mg/)as } \mathrm{CaCO} 3\end{array}$ & $\begin{array}{c}\text { Alkalinity } \\
\text { (mgl)as CaCo3 }\end{array}$ & $\begin{array}{l}\text { Natrium } \\
\text { (mgll) }\end{array}$ & $\begin{array}{l}\text { Kalium } \\
\text { (mg/l) }\end{array}$ & $\begin{array}{l}\text { Calcium } \\
(m g n)\end{array}$ & $\begin{array}{l}\text { Magnesium } \\
\text { (mg/t) }\end{array}$ \\
\hline \multirow{5}{*}{ (Xne) } & 285.6 & 7.9 & 199.2 & 149.1 & 82.7 & 92.9 & 23.0 & 1.6 & 17.5 & 9.8 \\
\hline & 298.7 & 7.9 & 188.7 & 162.6 & 74.1 & 73.7 & 31.9 & 1.5 & 15.6 & 9.1 \\
\hline & 261.8 & 7.8 & 182.2 & 138.1 & 75.2 & 82.3 & 24.2 & 1.7 & 17.0 & 8.3 \\
\hline & 271.4 & 7.8 & 182.1 & 150.3 & 72.6 & 77.7 & 25.0 & 1.7 & 16.6 & 7.9 \\
\hline & 293.3 & 8.0 & 211.4 & 158.4 & 93.0 & 85.8 & 25.0 & 1.7 & 20.4 & 10.4 \\
\hline (X̄ne) & 282.2 & 7.9 & 192.7 & 151.7 & 79.5 & 84.5 & 25.8 & 1.6 & 17.4 & 9.1 \\
\hline (Sne) & 15.3 & 0.1 & 12.6 & 9.5 & 8.5 & 9.6 & 3.5 & 0.1 & 1.8 & 1.0 \\
\hline
\end{tabular}

Statistic Test (T), Calculated by Equation $\mathbf{5 . 6}$

\begin{tabular}{|c|c|c|c|c|c|c|c|c|c|c|}
\hline & $\begin{array}{l}\text { Conductivity } \\
@ 25 \mathrm{C} \\
(\mathrm{ms} / \mathrm{m}) \\
\end{array}$ & $\mathrm{PH}$ & $\begin{array}{c}\text { Dissolved } \\
\text { fons } \\
\text { (mg/l) } \\
\end{array}$ & \begin{tabular}{|c|}
$\begin{array}{c}\text { Dissolved } \\
\text { Solids } \\
\text { (mgll) }\end{array}$ \\
\end{tabular} & $\begin{array}{c}\text { Hardness } \\
\text { (mg/l)as } \mathrm{CaCO} 3\end{array}$ & \begin{tabular}{|c|} 
Alkalinity \\
(mgll)as CaCoa \\
\end{tabular} & $\begin{array}{l}\text { Natrium } \\
\text { (mgn) }\end{array}$ & $\begin{array}{l}\text { Kalium } \\
(\mathrm{mgl})\end{array}$ & $\begin{array}{l}\text { Calcium } \\
(\mathrm{mg} / \mathrm{l})\end{array}$ & $\begin{array}{c}\text { Magnesium } \\
(\mathrm{mg} / \mathrm{l}) \\
\end{array}$ \\
\hline$T$ & -3.02 & 0.75 & -3.10 & -3.42 & -2.94 & -2.03 & -2.83 & -0.79 & -2.63 & -2.87 \\
\hline $\begin{array}{l}\text { Degrees of } \\
\text { Freedom (v) }\end{array}$ & 9.48 & 12.46 & 9.93 & 7.43 & 10.81 & 12.85 & 11.72 & 8.43 & 11.06 & 10.75 \\
\hline$t[v, 0.975]$ & 2.246 & 2.170 & 2.230 & 2.340 & 2.206 & 2.163 & 2.185 & 2.287 & 2.200 & 2.208 \\
\hline$t[v, 0.950]$ & 1.823 & 1.777 & 1.813 & 1.880 & 1.799 & 1.773 & 1.786 & 1.848 & 1.795 & 1.800 \\
\hline & & & $\begin{array}{l}T>\|\|\} \\
T<-1 \|\end{array}$ & & & & & & & \\
\hline
\end{tabular}

\section{[2 Yearly Averaging]}

New Mean Values Predicted by the Entropy Method

\begin{tabular}{|c|c|c|c|c|c|c|c|c|c|c|}
\hline & $\begin{array}{c}\text { Conductivity } \\
@ 25 \mathrm{C} \\
(\mathrm{mS} / \mathrm{m})\end{array}$ & $\mathrm{PH}$ & $\begin{array}{c}\text { Dissolved } \\
\text { lons } \\
\text { (mgl) } \\
\end{array}$ & $\begin{array}{c}\text { Dissolved } \\
\text { Solids } \\
\text { (mg/) }\end{array}$ & $\begin{array}{c}\text { Hardness } \\
\text { (mgl) as } \mathrm{CaCO} 3\end{array}$ & $\begin{array}{c}\text { Alkalinity } \\
\text { (mg/l)as Caco3 } \\
\end{array}$ & $\begin{array}{l}\text { Natrium } \\
\text { (mg/) }\end{array}$ & $\begin{array}{l}\text { Kalium } \\
\text { (mg/) }\end{array}$ & $\begin{array}{l}\text { Calcium } \\
(\mathrm{mg} /)\end{array}$ & $\begin{array}{c}\text { Magnesium } \\
\text { (mg/l) }\end{array}$ \\
\hline \multirow{4}{*}{ (Xn日) } & 306.1 & 7.8 & 208.2 & 173.6 & 87.2 & 86.8 & 28.2 & 1.6 & 18.1 & 10.4 \\
\hline & 295.7 & 7.8 & 201.7 & 169.3 & 84.4 & 82.9 & 28.7 & 1.6 & 17.9 & 9.8 \\
\hline & 283.7 & 7.8 & 199.1 & 164.6 & 83.8 & 84.4 & 25.8 & 1.6 & 18.3 & 9.3 \\
\hline & 297.5 & 7.8 & 210.4 & 172.4 & 90.4 & 89.4 & 26.1 & 1.6 & 19.6 & 10.1 \\
\hline (X̃ne) & 295.7 & 7.8 & 204.9 & 170.0 & 86.5 & 85.8 & 27.2 & 1.6 & 18.5 & 9.9 \\
\hline (Sne) & 9.2 & 0.0 & 5.3 & 4.0 & 3.0 & 2.9 & 1.5 & 0.0 & 0.7 & 0.5 \\
\hline
\end{tabular}

Statistic Test (T), Calculated by Equation 5.6

\begin{tabular}{|c|c|c|c|c|c|c|c|c|c|c|}
\hline & $\begin{array}{c}\text { Concuctivity } \\
@ 25 \mathrm{C} \\
(\mathrm{mS} / \mathrm{m}) \\
\end{array}$ & $\mathrm{PH}$ & \begin{tabular}{|c|} 
Dissolved \\
Ions \\
(mg/l) \\
\end{tabular} & \begin{tabular}{|c|}
$\begin{array}{c}\text { Dissolved } \\
\text { Solids } \\
\text { (mgll) }\end{array}$ \\
\end{tabular} & $\begin{array}{c}\text { Hardness } \\
\text { (mg//)as CaCO3 }\end{array}$ & $\begin{array}{c}\text { Alkalinity } \\
\text { (mgl)as } \mathrm{CaCO} 3 \\
\end{array}$ & $\begin{array}{l}\text { Natrium } \\
(\mathrm{mg} / \mathrm{l})\end{array}$ & $\begin{array}{l}\text { Kalium } \\
\text { (mg/l) }\end{array}$ & $\begin{array}{l}\text { Calcium } \\
\text { (mgh) }\end{array}$ & \begin{tabular}{|c|} 
Magnesium \\
(mg/)
\end{tabular} \\
\hline$T$ & -2.71 & -0.21 & -2.67 & -2.70 & -2.47 & -2.13 & -2.64 & -0.85 & -2.31 & -2.43 \\
\hline $\begin{array}{l}\text { Degrees of } \\
\text { Freedom (v) }\end{array}$ & 9.22 & 9.00 & 9.22 & 7.10 & 9.31 & 9.67 & 9.71 & 7.06 & 9.46 & 9.49 \\
\hline$t[v, 0.975]$ & 2.255 & 2.262 & 2.255 & 2.359 & 2.252 & 2.239 & 2.238 & 2.361 & 2.246 & 2.245 \\
\hline$t[v, 0.950]$ & 1.828 & 1.833 & 1.628 & 1.892 & 1.827 & 1.819 & 1.818 & 1.893 & 1.823 & 1.823 \\
\hline
\end{tabular}


Table 5.16(a) (continued)

\section{[3 Yearly Averaging]}

New Mean Values Predicted by the Entropy Method

\begin{tabular}{|c|c|c|c|c|c|c|c|c|c|c|}
\hline & $\begin{array}{c}\text { Conductivity } \\
@ 25 \mathrm{C} \\
\text { (ms/m) } \\
\end{array}$ & $\mathrm{PH}$ & $\begin{array}{c}\text { Oissolved } \\
\text { Ions } \\
\text { (mg/l) } \\
\end{array}$ & \begin{tabular}{|c}
$\begin{array}{c}\text { Dissolved } \\
\text { Solids } \\
\text { (mg/) }\end{array}$ \\
\end{tabular} & $\begin{array}{c}\text { Hardness } \\
\text { (mg/l)as Cacos }\end{array}$ & $\begin{array}{c}\text { Alkalinity } \\
\text { (mgn)as CaCo3 }\end{array}$ & $\begin{array}{l}\text { Natrium } \\
\text { (mgn) }\end{array}$ & $\begin{array}{l}\text { Kalium } \\
\text { (mg/) }\end{array}$ & $\begin{array}{l}\text { Calcium } \\
\text { (mg/) }\end{array}$ & $\begin{array}{c}\text { Magnesium } \\
(\mathrm{mg} \Omega)\end{array}$ \\
\hline$(X n e)$ & $\begin{array}{l}306.7 \\
302.7 \\
301.2\end{array}$ & $\begin{array}{l}8.0 \\
8.0 \\
8.0\end{array}$ & $\begin{array}{l}208.0 \\
203.7 \\
209.5\end{array}$ & $\begin{array}{l}168.1 \\
168.4 \\
167.4\end{array}$ & $\begin{array}{l}88.9 \\
86.5 \\
80.9\end{array}$ & $\begin{array}{l}87.9 \\
84.3 \\
89.6\end{array}$ & $\begin{array}{l}27.1 \\
27.7 \\
25.6\end{array}$ & $\begin{array}{l}1.6 \\
1.7 \\
1.7\end{array}$ & $\begin{array}{l}18.8 \\
18.5 \\
19.7\end{array}$ & $\begin{array}{c}10.4 \\
9.9 \\
10.2\end{array}$ \\
\hline $\begin{array}{l}(\bar{X} n e) \\
\text { (Sne) }\end{array}$ & $\begin{array}{c}303.5 \\
2.8\end{array}$ & $\begin{array}{l}8.0 \\
0.0\end{array}$ & $\begin{array}{c}207.1 \\
3.0\end{array}$ & $\begin{array}{c}168.0 \\
0.5\end{array}$ & $\begin{array}{c}88.8 \\
2.2 \\
\end{array}$ & $\begin{array}{c}87.2 \\
2.7 \\
\end{array}$ & $\begin{array}{c}26.8 \\
1.1 \\
\end{array}$ & $\begin{array}{l}1.7 \\
0.0 \\
\end{array}$ & $\begin{array}{c}19.0 \\
0.6 \\
\end{array}$ & $\begin{array}{c}10.2 \\
0.2 \\
\end{array}$ \\
\hline
\end{tabular}

Statistic Test (T), Calculated by Equation 5.6

\begin{tabular}{|c|c|c|c|c|c|c|c|c|c|c|}
\hline & $\begin{array}{c}\text { Conductivity } \\
@ 25 \mathrm{C} \\
\text { (ms/m) } \\
\end{array}$ & $\mathrm{PH}$ & $\begin{array}{c}\text { Dissolved } \\
\text { Ions } \\
\text { (mgn) }\end{array}$ & \begin{tabular}{|c|} 
Dissolved \\
Solids \\
(mg/l) \\
\end{tabular} & $\begin{array}{c}\text { Hardness } \\
\text { (mg() as Caco3 }\end{array}$ & $\begin{array}{c}\text { Alkalinity } \\
\text { (mgh)as } \mathrm{CacO} 3 \\
\end{array}$ & $\begin{array}{l}\text { Natrium } \\
\text { (mg/) }\end{array}$ & $\begin{array}{l}\text { Kalium } \\
\text { (mg/l) }\end{array}$ & $\begin{array}{l}\text { Calcium } \\
\text { (mg/l) }\end{array}$ & $\begin{array}{c}\text { Magnesium } \\
\text { (mg/ll) } \\
\end{array}$ \\
\hline$T$ & -2.54 & 1.65 & -2.59 & -2.79 & -2.27 & -1.93 & -2.77 & -0.40 & -2.10 & -2.27 \\
\hline $\begin{array}{l}\text { Degrees of } \\
\text { Freedom (v) }\end{array}$ & 9.03 & 9.02 & 9.09 & 7.00 & 9.22 & 9.76 & 9.48 & 7.63 & 8.41 & 9.15 \\
\hline $\mathrm{t}[\mathrm{v}, 0.975]$ & 2.261 & 2.261 & 2.259 & 2.365 & 2.254 & 2.236 & 2.246 & 2.328 & 2.248 & 2.257 \\
\hline$t[v, 0.950]$ & 1.832 & 1.833 & 1.831 & 1.895 & 1.828 & 1.817 & 1.823 & 1.873 & 1.824 & 1.830 \\
\hline of. retort & & & $\begin{array}{l}T>t[] \\
T<-t[1]\end{array}$ & & & & & & & \\
\hline
\end{tabular}

\section{[4 Yearly Averaging]}

New Mean Values Predicted by the Entropy Method

\begin{tabular}{|c|c|c|c|c|c|c|c|c|c|c|}
\hline & $\begin{array}{c}\text { Conductivity } \\
@ 25 \mathrm{C} \\
\text { (ms/m) } \\
\end{array}$ & $\mathrm{PH}$ & $\begin{array}{c}\text { Dissolved } \\
\text { Ions } \\
\text { (mg/) } \\
\end{array}$ & $\begin{array}{l}\text { Dissolved } \\
\text { Solids } \\
\text { (mgl) }\end{array}$ & $\begin{array}{c}\text { Hardness } \\
\text { (mg/l)as Caco3 }\end{array}$ & $\begin{array}{c}\text { Alkalinity } \\
\text { (mgl)as CaCO3 }\end{array}$ & $\begin{array}{l}\text { Natrium } \\
\text { (mgil) }\end{array}$ & $\begin{array}{l}\text { Kalium } \\
\text { (mg/) }\end{array}$ & $\begin{array}{l}\text { Calcium } \\
\text { (mgn) }\end{array}$ & $\begin{array}{l}\text { Magnesium } \\
\text { (mg/) }\end{array}$ \\
\hline (Xne) & $\begin{array}{l}318.6 \\
320.1\end{array}$ & $\begin{array}{l}8.0 \\
8.0\end{array}$ & $\begin{array}{l}215.9 \\
218.0\end{array}$ & $\begin{array}{l}171.0 \\
172.8\end{array}$ & $\begin{array}{l}92.3 \\
93.9\end{array}$ & $\begin{array}{l}89.6 \\
90.1\end{array}$ & $\begin{array}{l}28.1 \\
28.5\end{array}$ & $\begin{array}{l}1.6 \\
1.7\end{array}$ & $\begin{array}{l}19.7 \\
20.2\end{array}$ & $\begin{array}{l}10.6 \\
10.7\end{array}$ \\
\hline $\begin{array}{l}\bar{X} \text { (ne) } \\
\text { (Sne) }\end{array}$ & $\begin{array}{c}319.4 \\
1.1\end{array}$ & $\begin{array}{l}8.0 \\
0.0\end{array}$ & $\begin{array}{c}217.0 \\
1.5\end{array}$ & $\begin{array}{c}171.9 \\
1.3\end{array}$ & $\begin{array}{c}93.1 \\
1.1\end{array}$ & $\begin{array}{c}89.9 \\
0.4\end{array}$ & $\begin{array}{c}28.3 \\
0.3\end{array}$ & $\begin{array}{l}1.6 \\
0.0\end{array}$ & $\begin{array}{c}19.9 \\
0.3\end{array}$ & $\begin{array}{c}10.6 \\
0.7\end{array}$ \\
\hline
\end{tabular}

Statistic Test (T), Calculated by Equation 5.6

\begin{tabular}{|c|c|c|c|c|c|c|c|c|c|c|}
\hline & $\begin{array}{c}\text { Conductivity } \\
@ 25 \mathrm{C} \\
(\mathrm{ms} / \mathrm{m})\end{array}$ & PH & $\begin{array}{c}\text { Dissolved } \\
\text { Ions } \\
\text { (mg/l) }\end{array}$ & $\begin{array}{c}\text { Dissolved } \\
\text { Solids } \\
\text { (mg/l) } \\
\end{array}$ & $\begin{array}{c}\text { Hardness } \\
\text { (mg/)as } \mathrm{CaCO} 3\end{array}$ & $\begin{array}{c}\text { Alkalinity } \\
\text { (mgil)as CaCO3 }\end{array}$ & $\begin{array}{l}\text { Natrium } \\
\text { (mg/) }\end{array}$ & $\begin{array}{l}\text { Kalium } \\
\text { (mg/) }\end{array}$ & $\begin{array}{l}\text { Calcium } \\
(\mathrm{mg} / \mathrm{l})\end{array}$ & $\begin{array}{l}\text { Magnesium } \\
\text { (mg/n) }\end{array}$ \\
\hline$T$ & -2.16 & 1.64 & -2.17 & -2.94 & -1.89 & -1.56 & -2.35 & -0.56 & -1.67 & -1.93 \\
\hline $\begin{array}{l}\text { Degrees of } \\
\text { Freedom (v) }\end{array}$ & 9.01 & 9.05 & 9.03 & 7.02 & 9.09 & 9.02 & 9.05 & 7.03 & 9.17 & 9.03 \\
\hline$i[v, 0.875]$ & 2.262 & 2.260 & 2.261 & 2.364 & 2.259 & 2.261 & 2.260 & 2.363 & 2.256 & 2.261 \\
\hline$t[v, 0.950]$ & 1.833 & 1.832 & 1.832 & 1.894 & 1.831 & 1.833 & 1.832 & 1.894 & 1.829 & 1.832 \\
\hline
\end{tabular}


Table 5.16(b) Station 130106

Historical (prior) Mean Values

\begin{tabular}{|c|c|c|c|c|c|c|c|c|c|c|}
\hline & $\begin{array}{c}\text { Conductivity } \\
\text { @ } 25 \mathrm{C} \\
(\mathrm{ms} / \mathrm{m}) \\
\end{array}$ & $\mathrm{PH}$ & $\begin{array}{c}\text { Dissolved } \\
\text { Ions } \\
(\mathrm{mg} / \mathrm{l}) \\
\end{array}$ & $\begin{array}{c}\text { Dissolved } \\
\text { Solids } \\
(\mathrm{mg} /) \\
\end{array}$ & $\begin{array}{c}\text { Hardness } \\
\text { (mg/)as } \mathrm{CaCO}\end{array}$ & $\begin{array}{c}\text { Alkalinity } \\
(\mathrm{mg} / \mathrm{l}) \mathrm{es} \mathrm{CaCO} 3\end{array}$ & $\begin{array}{l}\text { Natrium } \\
\text { (mgl) } \\
\end{array}$ & $\begin{array}{l}\text { Kalium } \\
(\mathrm{mg} / \mathrm{l})\end{array}$ & $\begin{array}{l}\text { Calcium } \\
(\mathrm{mg} /)\end{array}$ & $\begin{array}{r}\text { Magnesium } \\
\text { (mg/l) } \\
\end{array}$ \\
\hline Mean $\quad(X \bar{h})$ & 232.3 & 7.6 & 188.6 & 145.6 & 83.1 & 95.4 & 17.1 & 3.9 & 19.8 & 8.2 \\
\hline $\begin{array}{l}\text { Standard (Sh) } \\
\text { Deviation }\end{array}$ & 83.2 & 0.2 & 68.2 & 56.1 & 31.3 & 33.1 & 7.2 & 0.5 & 7.1 & 3.8 \\
\hline
\end{tabular}

\section{[1 Yearly Averaging]}

New Mean Values Predicted by the Entropy Method

\begin{tabular}{|c|c|c|c|c|c|c|c|c|c|c|}
\hline & $\begin{array}{c}\text { Conductivity } \\
@ 25 \mathrm{C} \\
\text { (ms/m) }\end{array}$ & $\mathrm{PH}$ & $\begin{array}{c}\text { Dissolved } \\
\text { lons } \\
\text { (mg/l) } \\
\end{array}$ & $\begin{array}{c}\text { Dissolved } \\
\text { Solids } \\
\text { (mgn) } \\
\end{array}$ & $\begin{array}{c}\text { Hardness } \\
\text { (mgfi)as } \mathrm{CaCO} 3\end{array}$ & $\begin{array}{c}\text { Alkalinity } \\
\text { (mg/)as } \mathrm{CaCO} 3\end{array}$ & $\begin{array}{l}\text { Natrium } \\
(\mathrm{mg} / 1)\end{array}$ & $\begin{array}{l}\text { Kalium } \\
\text { (mg/l) }\end{array}$ & $\begin{array}{l}\text { Calcium } \\
(\mathrm{mg} /)\end{array}$ & $\begin{array}{c}\text { Magnesium } \\
\text { (mg/l) }\end{array}$ \\
\hline \multirow{5}{*}{ (Xne) } & 206.5 & 7.6 & 159.4 & 115.9 & 70.4 & 86.0 & 14.3 & 3.8 & 16.6 & 6.8 \\
\hline & 209.3 & 7.6 & 155.0 & 120.6 & 67.0 & 65.1 & 16.1 & 3.7 & 15.6 & 6.5 \\
\hline & 201.5 & 7.6 & 152.3 & 112.0 & 67.4 & 74.5 & 14.6 & 3.9 & 16.3 & 6.2 \\
\hline & 203.5 & 7.6 & 152.2 & 116.3 & 66.3 & 69.5 & 14.7 & 3.9 & 16.1 & 6.1 \\
\hline & 208.1 & 7.7 & 164.5 & 119.2 & 74.5 & 89.1 & 14.7 & 3.9 & 18.1 & 7.0 \\
\hline$(\vec{X} n e)$ & 205.8 & 7.6 & 156.7 & 116.8 & 69.1 & 76.8 & 14.9 & 3.8 & 16.5 & 6.5 \\
\hline (Sne) & 3.2 & 0.0 & 5.3 & 3.3 & 3.4 & 10.4 & 0.7 & 0.1 & 0.9 & 0.4 \\
\hline
\end{tabular}

Statistic Test (T), Calculated by Equation 5.6

\begin{tabular}{|c|c|c|c|c|c|c|c|c|c|c|}
\hline & $\begin{array}{c}\text { Conductivity } \\
@ 25 \mathrm{C} \\
(\mathrm{mS} / \mathrm{m}) \\
\end{array}$ & $\mathrm{PH}$ & $\begin{array}{c}\text { Dissolved } \\
\text { Ions } \\
(\mathrm{mg} / \mathrm{l}) \\
\end{array}$ & $\begin{array}{c}\text { Dissolved } \\
\text { Solids } \\
\text { (mg/l) } \\
\end{array}$ & $\begin{array}{c}\text { Hardness } \\
\text { (mg/l)as CaCO3 }\end{array}$ & $\begin{array}{c}\text { Alkalinity } \\
\text { (mg/)as } \mathrm{CaCO} 3\end{array}$ & $\begin{array}{l}\text { Natrium } \\
\text { (mg/f) }\end{array}$ & $\begin{array}{l}\text { Kalium } \\
(m g /)\end{array}$ & $\begin{array}{l}\text { Calcium } \\
\text { (mg/i) }\end{array}$ & $\begin{array}{c}\text { Magnesium } \\
(\mathrm{mg} / \mathrm{i}) \\
\end{array}$ \\
\hline $\mathrm{T}$ & -1.01 & 0.33 & -1.47 & -1.45 & -1.40 & $-1,62$ & -0.96 & -0.30 & -1.44 & -1.37 \\
\hline $\begin{array}{l}\text { Degrees of } \\
\text { Freedom (v) }\end{array}$ & 9.05 & 10.70 & 9.21 & 7.08 & 9.41 & 11.86 & 9.33 & 7.66 & 9.61 & 9.38 \\
\hline$t[v, 0.975]$ & 2.260 & 2.209 & 2.255 & 2.360 & 2.248 & 2.182 & 2.251 & 2.328 & 2.241 & 2.249 \\
\hline$t[v, 0.850]$ & 1.832 & 1.801 & 1.829 & 1.892 & 1.824 & 1.784 & 1.826 & 1.872 & 1.820 & 1.825 \\
\hline ote: & & & $\begin{array}{l}T>t ! 3 \\
T<-1[\}\end{array}$ & & & & & & & \\
\hline
\end{tabular}

[2 Yearly Averaging]

New Mean Values Predicted by the Entropy Method

\begin{tabular}{|c|c|c|c|c|c|c|c|c|c|c|}
\hline & $\begin{array}{l}\text { Conductivity } \\
@ 25 \mathrm{C} \\
\text { (ms/m) }\end{array}$ & $\mathrm{PH}$ & $\begin{array}{c}\text { Dissolved } \\
\text { tons } \\
\text { (mg/) }\end{array}$ & $\begin{array}{c}\text { Dissolved } \\
\text { Solids } \\
\text { (mg/) }\end{array}$ & $\begin{array}{c}\text { Hardness } \\
\text { (mg/)as } \mathrm{CaCO} 3 \\
\end{array}$ & $\begin{array}{c}\text { Alkalinity } \\
\text { (mg//)as CaCO3 }\end{array}$ & $\begin{array}{l}\text { Natrium } \\
\text { (mg/) }\end{array}$ & $\begin{array}{l}\text { Kalium } \\
\text { (mgl) }\end{array}$ & $\begin{array}{l}\text { Calcium } \\
\text { (mg/l) }\end{array}$ & $\begin{array}{l}\text { Magnesium } \\
(\mathrm{mg} /)\end{array}$ \\
\hline \multirow{4}{*}{ (Xne) } & 210.8 & 8.2 & 163.2 & 124.4 & 72.2 & 79.4 & 15.4 & 3.9 & 16.8 & 7.0 \\
\hline & 208.6 & 8.2 & 160.4 & 122.9 & 71.1 & 75.1 & 15.5 & 3.8 & 16.8 & 6.8 \\
\hline & 206.1 & 8.2 & 159.4 & 121.3 & 70.9 & 76.7 & 14.9 & 3.9 & 17.0 & 6.6 \\
\hline & 209.1 & 8.2 & 164.0 & 124.0 & 73.5 & 82.1 & 14.9 & 3.9 & 17.6 & 6.9 \\
\hline$\left(\overline{X_{n}}\right)$ & 208.7 & 8.2 & 161.7 & 123.2 & 71.9 & 78.3 & 15.2 & 3.8 & 17.1 & 6.8 \\
\hline (Sne) & 2.0 & 0.0 & 2.2 & 1.4 & 1.2 & 3.1 & 0.3 & 0.0 & 0.4 & 0.2 \\
\hline
\end{tabular}

Statistic Test (T), Calculated by Equation 5.6

\begin{tabular}{|c|c|c|c|c|c|c|c|c|c|c|}
\hline & $\begin{array}{c}\text { Conductivity } \\
@ 25 \mathrm{C} \\
(\mathrm{ms} / \mathrm{m}) \\
\end{array}$ & $\mathrm{PH}$ & $\begin{array}{c}\text { Dissolved } \\
\text { Jons } \\
(\mathrm{mg} / \mathrm{l}) \\
\end{array}$ & $\begin{array}{c}\text { Dissolved } \\
\text { Solids } \\
(\mathrm{mg} / \mathrm{l})\end{array}$ & $\begin{array}{c}\text { Hardness } \\
\text { (mg/)as } \mathrm{CaCO} 3\end{array}$ & $\begin{array}{c}\text { Alkalinity } \\
\text { (mgn)as } \mathrm{CaCO} 3\end{array}$ & $\begin{array}{l}\text { Natrium } \\
(\mathrm{mg} /) \\
\end{array}$ & $\begin{array}{l}\text { Kalium } \\
\text { (mgll) }\end{array}$ & $\begin{array}{l}\text { Calcium } \\
\text { (mg/l) }\end{array}$ & $\begin{array}{l}\text { Magnesium } \\
(\mathrm{mg} / \mathrm{l})\end{array}$ \\
\hline$T$ & -0.90 & 9.33 & -1.24 & -1.13 & -1.13 & -1.61 & -0.85 & -0.32 & -1.22 & -1.14 \\
\hline $\begin{array}{l}\text { Degrees of } \\
\text { Freedom }(v)\end{array}$ & 9.02 & 9.00 & 9.05 & 7.02 & 9.07 & 9.38 & 9.07 & 7.03 & 9.12 & 9.10 \\
\hline$t[v, 0.975]$ & 2.261 & 2.262 & 2.260 & 2.364 & 2.260 & 2.249 & 2.259 & 2.364 & 2.258 & 2.259 \\
\hline$t[\mathrm{v}, 0.950\}$ & 1.832 & 1.833 & 1.832 & 1.894 & 1.832 & 1.825 & 1.831 & 1.894 & 1.830 & 1.831 \\
\hline
\end{tabular}


Table 5.16(b) (continued)

\section{[3 Yearly Averaging]}

New Mean Values Predicted by the Entropy Method

\begin{tabular}{|c|c|c|c|c|c|c|c|c|c|c|}
\hline & $\begin{array}{c}\text { Conductivity } \\
@ 25 \mathrm{C} \\
\text { (mSim) }\end{array}$ & $\mathrm{PH}$ & $\begin{array}{c}\text { Dissolved } \\
\text { lons } \\
\text { (mg/l) } \\
\end{array}$ & $\begin{array}{c}\text { Dissolved } \\
\text { Solids } \\
\text { (mg/) } \\
\end{array}$ & $\begin{array}{c}\text { Hardness } \\
\text { (mg/)as Caco3 }\end{array}$ & $\begin{array}{c}\text { Alkalinity } \\
\text { (mgn)as caco3 }\end{array}$ & $\begin{array}{l}\text { Natrium } \\
\text { (mg/f) }\end{array}$ & $\begin{array}{l}\text { Kalium } \\
(\mathrm{mg} / \mathrm{l}) \\
\end{array}$ & $\begin{array}{l}\text { Calcium } \\
(\mathrm{mg} /)\end{array}$ & $\begin{array}{c}\text { Magnesium } \\
(\mathrm{mg} / \mathrm{l})\end{array}$ \\
\hline (Xne) & $\begin{array}{l}210.90 \\
210.10 \\
209.80\end{array}$ & $\begin{array}{l}7.66 \\
7.66 \\
7.66\end{array}$ & $\begin{array}{l}163.00 \\
161.20 \\
163.60\end{array}$ & $\begin{array}{l}122.50 \\
122.60 \\
122.30\end{array}$ & $\begin{array}{l}72.90 \\
71.90 \\
73.70\end{array}$ & $\begin{array}{l}80.53 \\
76.61 \\
82.34\end{array}$ & $\begin{array}{l}15.14 \\
15.25 \\
14.84\end{array}$ & $\begin{array}{l}3.85 \\
3.89 \\
3.95\end{array}$ & $\begin{array}{l}17.19 \\
17.07 \\
17.65\end{array}$ & $\begin{array}{l}7.01 \\
6.91 \\
6.95\end{array}$ \\
\hline $\begin{array}{l}(\bar{X} n e) \\
(\text { Sne })\end{array}$ & $\begin{array}{c}210.3 \\
0.6 \\
\end{array}$ & $\begin{array}{l}7.7 \\
0.0 \\
\end{array}$ & $\begin{array}{c}162.6 \\
1.2 \\
\end{array}$ & $\begin{array}{c}122.5 \\
0.2 \\
\end{array}$ & $\begin{array}{c}72.8 \\
0.9 \\
\end{array}$ & $\begin{array}{r}79.8 \\
2.9 \\
\end{array}$ & $\begin{array}{l}15.1 \\
0.2 \\
\end{array}$ & $\begin{array}{l}3.9 \\
0.1 \\
\end{array}$ & $\begin{array}{c}17.3 \\
0.3 \\
\end{array}$ & $\begin{array}{l}7.0 \\
0.1 \\
\end{array}$ \\
\hline
\end{tabular}

Statistlc Test (T), Calculated by Equation 5.6

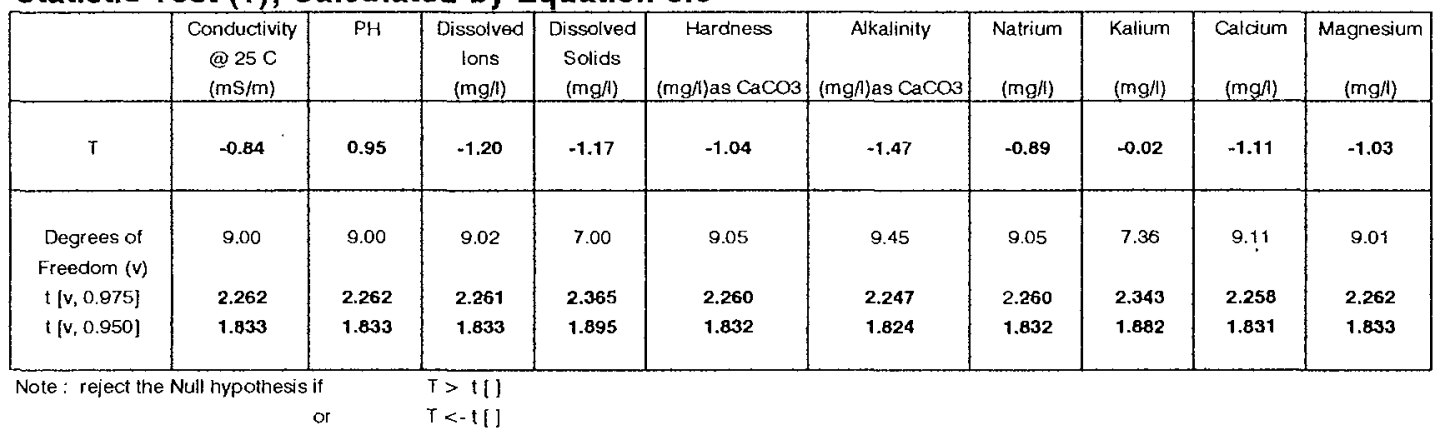

\section{[4 Yearly Averaging]}

New Mean Values Predicted by the Entropy Method

\begin{tabular}{|c|c|c|c|c|c|c|c|c|c|c|}
\hline & $\begin{array}{c}\text { Conductivity } \\
@ 25 \mathrm{C} \\
\text { (ms/m) }\end{array}$ & $\mathrm{PH}$ & $\begin{array}{c}\text { Dissolved } \\
\text { lons } \\
\text { (mg/l) } \\
\end{array}$ & $\begin{array}{c}\text { Dissolved } \\
\text { Solids } \\
\text { (mg/) } \\
\end{array}$ & $\begin{array}{c}\text { Hardness } \\
\text { (mg/l)as } \mathrm{CaCO} 3\end{array}$ & $\begin{array}{c}\text { Alkalinity } \\
\text { (mg/l)as } \mathrm{CaCO} 3\end{array}$ & $\begin{array}{l}\text { Natrium } \\
\text { (mg/l) }\end{array}$ & $\begin{array}{l}\text { Kalium } \\
\text { (mg/l) }\end{array}$ & $\begin{array}{l}\text { Calcium } \\
\text { (mgn) }\end{array}$ & $\begin{array}{l}\text { Magnesium } \\
\text { (mg/l) }\end{array}$ \\
\hline (Xne) & $\begin{array}{l}213.40 \\
213.70\end{array}$ & $\begin{array}{l}7.66 \\
7.67\end{array}$ & $\begin{array}{l}166.40 \\
167.20\end{array}$ & $\begin{array}{l}123.50 \\
124.20\end{array}$ & $\begin{array}{l}74.22 \\
74.87\end{array}$ & $\begin{array}{l}82.44 \\
82.96\end{array}$ & $\begin{array}{l}15.34 \\
15.42\end{array}$ & $\begin{array}{l}3.88 \\
3.89\end{array}$ & $\begin{array}{l}17.68 \\
17.91\end{array}$ & $\begin{array}{l}7.09 \\
7.13\end{array}$ \\
\hline $\begin{array}{l}\text { (X̄ne) } \\
\text { (Sne) }\end{array}$ & $\begin{array}{c}213.6 \\
0.2\end{array}$ & $\begin{array}{l}7.7 \\
0.0\end{array}$ & $\begin{array}{c}166.8 \\
0.6\end{array}$ & $\begin{array}{c}123.9 \\
0.5\end{array}$ & $\begin{array}{c}74.5 \\
0.5\end{array}$ & $\begin{array}{c}82.7 \\
0.4\end{array}$ & $\begin{array}{c}15.4 \\
0.1\end{array}$ & $\begin{array}{l}3.9 \\
0.0\end{array}$ & $\begin{array}{l}17.8 \\
0.2\end{array}$ & $\begin{array}{l}7.1 \\
0.0\end{array}$ \\
\hline
\end{tabular}

Statistic Test (T), Calculated by Equation 5.6

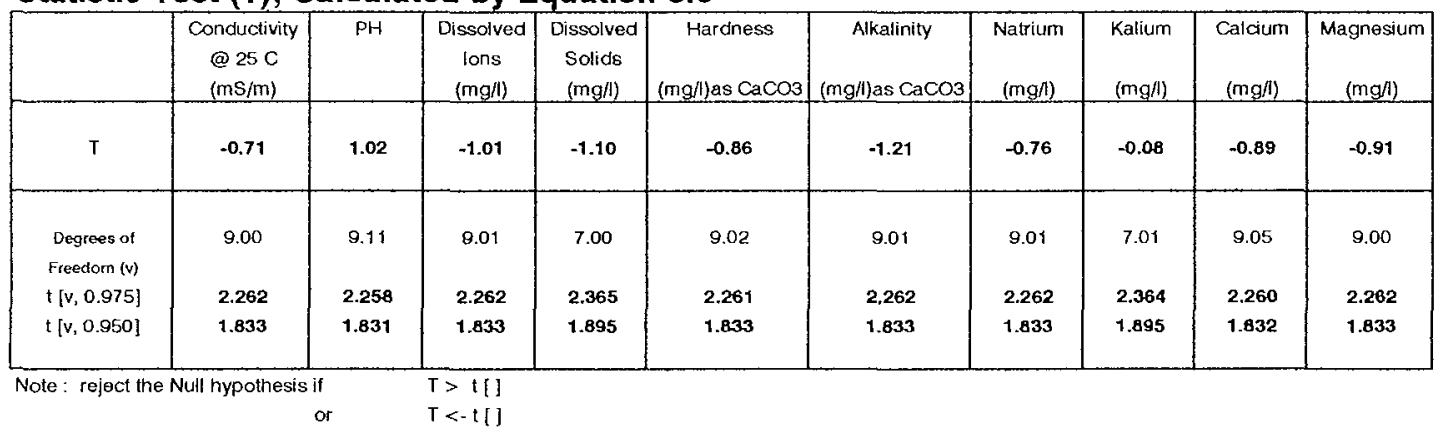


Table 5.16(c) Station 130105

Historical (prior) Mean Values

\begin{tabular}{|c|c|c|c|c|c|c|c|c|c|c|}
\hline & $\begin{array}{l}\text { Conductivity } \\
@ 25 \mathrm{C} \\
(\mathrm{mS} / \mathrm{m})\end{array}$ & $\mathrm{PH}$ & $\begin{array}{c}\text { Dissolved } \\
\text { Ions } \\
\text { (mg/l) } \\
\end{array}$ & $\begin{array}{c}\text { Dissolved } \\
\text { Solids } \\
(\mathrm{mg} / \mathrm{i}) \\
\end{array}$ & $\begin{array}{c}\text { Hardness } \\
\text { (mg/l)as CaCO3 }\end{array}$ & $\begin{array}{c}\text { Alkalinity } \\
\text { (mg/)as } \mathrm{CaCO} 3\end{array}$ & $\begin{array}{l}\text { Natrium } \\
(\mathrm{mg} / \mathrm{l})\end{array}$ & $\begin{array}{l}\text { Kalium } \\
\text { (mgll) }\end{array}$ & $\begin{array}{l}\text { Calcium } \\
(\mathrm{mg} /) \\
\end{array}$ & $\begin{array}{l}\text { Magnesium } \\
(\mathrm{mg} / \mathrm{l})\end{array}$ \\
\hline Mean & 343.2 & 7.8 & 231.2 & 189.7 & 96.7 & 91.4 & 29.8 & 2.6 & 20.4 & 10.9 \\
\hline $\begin{array}{l}\text { Standard (Sh) } \\
\text { Deviation }\end{array}$ & 97.6 & 0.2 & 58.7 & 48.3 & 28.8 & 21.2 & 9.6 & 0.6 & 6.3 & 3.3 \\
\hline
\end{tabular}

\section{[1 Yearly Averaging]}

New Mean Values

\begin{tabular}{|c|c|c|c|c|c|c|c|c|c|c|}
\hline & $\begin{array}{l}\text { Conduclivity } \\
\text { @ } 25 \mathrm{C} \\
\text { (ms/m) }\end{array}$ & $\mathrm{PH}$ & $\begin{array}{c}\text { Dissolved } \\
\text { lons } \\
\text { (mg/l) }\end{array}$ & $\begin{array}{c}\text { Dissolved } \\
\text { Solids } \\
\text { (mg/l) }\end{array}$ & $\begin{array}{c}\text { Hardness } \\
\text { (mg/l)as CaCos }\end{array}$ & $\begin{array}{c}\text { Alkalinity } \\
\text { (mgil)as } \mathrm{CaCO} 3\end{array}$ & $\begin{array}{l}\text { Natrium } \\
(\mathrm{mg} /) \\
\end{array}$ & $\begin{array}{l}\text { Kalium } \\
(\mathrm{mg} / /)\end{array}$ & $\begin{array}{l}\text { Calcium } \\
\text { (mgn) }\end{array}$ & $\begin{array}{l}\text { Magnesium } \\
\text { (mg/h) }\end{array}$ \\
\hline \multirow{5}{*}{ (Xne) } & 248.0 & 7.7 & 176.7 & 139.0 & 71.0 & 85.0 & 18.0 & 3.1 & 15.0 & 8.1 \\
\hline & 260.0 & 7.9 & 167.0 & 150.0 & 63.0 & 61.0 & 27.0 & 1.7 & 13.0 & 7.5 \\
\hline & 226.3 & 7.5 & 161.0 & 130.0 & 64.0 & 71.8 & 19.3 & 3.8 & 14.5 & 6.8 \\
\hline & 235.0 & 7.7 & 161.0 & 140,0 & 61.5 & 66.0 & 20.0 & 3.9 & 14.0 & 6.4 \\
\hline & 255.0 & 8.2 & 187.9 & 146.7 & 80.7 & 88.7 & 20.0 & 3.8 & 18.0 & 8.7 \\
\hline$(\overline{\bar{X}} n \theta)$ & 244.9 & 7.8 & 170.7 & 141.1 & 68.0 & 74.5 & 20.9 & 3.3 & 14.9 & 7.5 \\
\hline (Sne) & 14.0 & 0.3 & 11.6 & 7.7 & 7.9 & 12.0 & 3.5 & 0.9 & 1.9 & 0.9 \\
\hline
\end{tabular}

Statistic Test (T), Calculated by Equation 5.6

\begin{tabular}{|c|c|c|c|c|c|c|c|c|c|c|}
\hline & $\begin{array}{c}\text { Conductivity } \\
@ 25 \mathrm{C} \\
(\mathrm{ms} / \mathrm{m}) \\
\end{array}$ & $\mathrm{PH}$ & $\begin{array}{c}\text { Dissolved } \\
\text { lons } \\
\text { (mg/l) } \\
\end{array}$ & $\begin{array}{c}\text { Dissolved } \\
\text { Solids } \\
\text { (mg/l) } \\
\end{array}$ & $\begin{array}{c}\text { Haroness } \\
(\mathrm{mg} / \text { )as } \mathrm{CaCO} 3\end{array}$ & $\begin{array}{c}\text { Alkalinity } \\
\text { (mg/)as } \mathrm{CaCO} 3\end{array}$ & $\begin{array}{l}\text { Natrium } \\
\text { (mgn) } \\
\end{array}$ & $\begin{array}{r}\text { Kalium } \\
(\mathrm{mg} / \mathrm{l}) \\
\end{array}$ & $\begin{array}{l}\text { Calcium } \\
(m g n) \\
\end{array}$ & $\begin{array}{l}\text { Magnesium } \\
\quad(\mathrm{mg} /)\end{array}$ \\
\hline T & -2.80 & -0.11 & -2.83 & -2.79 & -2.66 & -1.84 & -2.39 & 1.39 & -2.31 & -2.76 \\
\hline $\begin{array}{l}\text { Degrees of } \\
\text { Freedom (v) }\end{array}$ & 7.46 & 6.63 & 7.84 & 7.56 & 8.59 & 10.97 & 9.58 & 6.36 & 8.83 & 8.66 \\
\hline$f[v, 0.975]$ & 2.338 & 2.395 & 2.315 & 2.332 & 2.280 & 2.202 & 2.242 & 2.417 & 2.269 & 2.277 \\
\hline$I[v, 0.950]$ & 1.879 & 1.913 & 1.865 & 1.875 & 1.844 & 1.797 & 1.821 & 1.926 & 1.838 & 1.842 \\
\hline
\end{tabular}

Note: reject the Null hypothesis if
or

$<-11]$

\section{[2 Yearly Averaging]}

\section{New Mean Values}

\begin{tabular}{|c|c|c|c|c|c|c|c|c|c|c|}
\hline & $\begin{array}{c}\text { Conductivity } \\
@ 25 \mathrm{C} \\
\text { (ms/m) }\end{array}$ & $\mathrm{PH}$ & $\begin{array}{c}\text { Dissolved } \\
\text { lons } \\
\text { (mg/l) } \\
\end{array}$ & $\begin{array}{c}\text { Dissolved } \\
\text { Solids } \\
\text { (mgh) } \\
\end{array}$ & $\begin{array}{c}\text { Hardness } \\
\text { (mg/)as CaCO3 }\end{array}$ & $\begin{array}{c}\text { Alkalinity } \\
\text { (mg/)as CaCO3 }\end{array}$ & $\begin{array}{l}\text { Natrium } \\
(\mathrm{mg} / \mathrm{l})\end{array}$ & $\begin{array}{l}\text { Katium } \\
\text { (mgl) }\end{array}$ & $\begin{array}{l}\text { Calcium } \\
(m g /)\end{array}$ & $\begin{array}{l}\text { Magnesium } \\
\text { (mg/) }\end{array}$ \\
\hline \multirow{4}{*}{$(X \cap e)$} & 254.0 & 7.8 & 171.8 & 144.5 & 67.0 & 73.0 & 22.5 & 2.4 & 14.0 & 7.8 \\
\hline & 243.1 & 7.7 & 164.0 & 140.0 & 63.5 & 66.4 & 23.1 & 2.8 & 13.8 & 7.1 \\
\hline & 230.6 & 7.6 & 161.0 & 135.0 & 62.8 & 68.9 & 19.6 & 3.9 & 14.3 & 6.6 \\
\hline & 245.0 & 7.9 & 174.4 & 143.3 & 71.1 & 77.3 & 20.0 & 3.9 & 16.0 & 7.5 \\
\hline$\left(\bar{X}_{n e}\right)$ & 243.2 & 7.7 & 167.8 & 140.7 & 66.1 & 71.4 & 21.3 & 3.2 & 14.5 & 7.3 \\
\hline (Sne) & 9.6 & 0.2 & 6.4 & 4.3 & 3.8 & 4.8 & 1.8 & 0.7 & 1.0 & 0.5 \\
\hline
\end{tabular}

Statistic Test (T), Calculated by Equation 5.6

\begin{tabular}{|c|c|c|c|c|c|c|c|c|c|c|}
\hline & $\begin{array}{c}\text { Conductivity } \\
@ 25 \mathrm{C} \\
(\mathrm{ms} / \mathrm{m}) \\
\end{array}$ & $\mathrm{PH}$ & $\begin{array}{c}\text { Dissolved } \\
\text { Ions } \\
(\mathrm{mg} / \mathrm{l}) \\
\end{array}$ & $\begin{array}{l}\text { Dissolved } \\
\text { Solids } \\
\text { (mgh) }\end{array}$ & $\begin{array}{c}\text { Hardness } \\
\text { (mg//)as CaCO3 }\end{array}$ & $\begin{array}{c}\text { Alkalinity } \\
\text { (mg/l)as } \mathrm{CaCO} 3\end{array}$ & $\begin{array}{l}\text { Natrium } \\
(\mathrm{mg} / \mathrm{)})\end{array}$ & $\begin{array}{l}\text { Kalium } \\
(\mathrm{mg} /)\end{array}$ & $\begin{array}{l}\text { Calcium } \\
(\mathrm{mg} / \mathrm{l})\end{array}$ & $\begin{array}{l}\text { Magnesium } \\
\text { (mg/l) }\end{array}$ \\
\hline $\mathrm{T}$ & -2.87 & -0.54 & -3.02 & -2.85 & -2.96 & -2.54 & -2.42 & 1.40 & -2.5 .8 & -3.04 \\
\hline $\begin{array}{l}\text { Degrees of } \\
\text { Freedom (v) }\end{array}$ & 7.27 & 7.77 & 7.32 & 7.22 & 7.48 & 8.31 & 7.89 & 5.25 & 7.70 & 7.70 \\
\hline$t[v, 0.975\}$ & 2.349 & 2.320 & 2.346 & 2.352 & 2.337 & 2.292 & 2.313 & 2.541 & 2.323 & 2.324 \\
\hline $\mathrm{t}[\mathrm{v}, 0.950]$ & 1.886 & 1.868 & 1.894 & 1.887 & 1.878 & 1.852 & 1.864 & 1.997 & 1.870 & 1.870 \\
\hline & & & $\begin{array}{l}T>t[] \\
T<-t[]\end{array}$ & & & & & & & \\
\hline
\end{tabular}


Table 5.16(c) (continued)

\section{[3 Yearly Averaging]}

New Mean Values

\begin{tabular}{|c|c|c|c|c|c|c|c|c|c|c|}
\hline & $\begin{array}{c}\text { Conductivity } \\
@ 25 \mathrm{C} \\
(\mathrm{mS} / \mathrm{m}) \\
\end{array}$ & $\mathrm{PH}$ & $\begin{array}{c}\text { Dissolved } \\
\text { lons } \\
\text { (mgli) } \\
\end{array}$ & $\begin{array}{c}\text { Dissolved } \\
\text { Solids } \\
\text { (mg/l) }\end{array}$ & $\begin{array}{c}\text { Hardness } \\
\text { (mg/l)as } \mathrm{CaCO} 3 \\
\end{array}$ & $\begin{array}{c}\text { Alkalinity } \\
\text { (mg/)as } \mathrm{CaCO}\end{array}$ & $\begin{array}{l}\text { Natrium } \\
(\mathrm{mg} /)\end{array}$ & $\begin{array}{l}\text { Kalium } \\
\text { (mgn) }\end{array}$ & $\begin{array}{l}\text { Calcium } \\
(\mathrm{mg} /)\end{array}$ & $\begin{array}{c}\text { Magnesium } \\
(\mathrm{mg} \|) \\
\end{array}$ \\
\hline$(X n e)$ & $\begin{array}{l}244.8 \\
240.4 \\
238.8\end{array}$ & $\begin{array}{l}7.7 \\
7.7 \\
7.8\end{array}$ & $\begin{array}{c}168.2 \\
163 \\
170\end{array}$ & $\begin{array}{c}139.7 \\
140 \\
138.9\end{array}$ & $\begin{array}{c}66 \\
62.8 \\
68.7\end{array}$ & $\begin{array}{l}72.6 \\
66.3 \\
75.5\end{array}$ & $\begin{array}{l}21.4 \\
22.1 \\
19.8\end{array}$ & $\begin{array}{l}2.9 \\
3.1 \\
3.8\end{array}$ & $\begin{array}{l}14.2 \\
13.8 \\
15.5\end{array}$ & $\begin{array}{l}7.5 \\
6.9 \\
7.3\end{array}$ \\
\hline $\begin{array}{l}(\bar{X} n e) \\
(S n \theta)\end{array}$ & $\begin{array}{c}241.3 \\
3.1\end{array}$ & $\begin{array}{l}7.7 \\
0.1\end{array}$ & $\begin{array}{c}167.1 \\
3.6\end{array}$ & $\begin{array}{c}139.5 \\
0.6\end{array}$ & $\begin{array}{c}65.8 \\
3.0 \\
\end{array}$ & $\begin{array}{l}71.5 \\
4.7\end{array}$ & $\begin{array}{c}21.1 \\
1.2\end{array}$ & $\begin{array}{l}3.3 \\
0.5 \\
\end{array}$ & $\begin{array}{l}14.5 \\
0.9\end{array}$ & $\begin{array}{l}7.2 \\
0.3\end{array}$ \\
\hline
\end{tabular}

Statistic Test (T), Calculated by Equation 5.6

\begin{tabular}{|c|c|c|c|c|c|c|c|c|c|c|}
\hline & $\begin{array}{c}\text { Conductivity } \\
@ 25 \mathrm{C} \\
(\mathrm{mS} / \mathrm{m}) \\
\end{array}$ & $\mathrm{PH}$ & $\begin{array}{c}\text { Dissolved } \\
\text { lons } \\
\text { (mg/) }\end{array}$ & $\begin{array}{c}\text { Dissolved } \\
\text { Solids } \\
(\mathrm{mg} / \mathrm{l}) \\
\end{array}$ & $\begin{array}{c}\text { Hardness } \\
\text { (mg/has } \mathrm{CaCO} 3\end{array}$ & $\begin{array}{c}\text { Alkalinity } \\
\text { (mgl)as } \mathrm{CaCO} 3\end{array}$ & $\begin{array}{l}\text { Natrium } \\
\text { (mg/l) }\end{array}$ & $\begin{array}{l}\text { Kalium } \\
(m g / l)\end{array}$ & $\begin{array}{l}\text { Calcium } \\
\text { (mg/l) }\end{array}$ & $\begin{array}{c}\text { Magnesium } \\
\text { (mg/) }\end{array}$ \\
\hline T & -2.95 & -0.85 & -3.07 & -2.94 & $-2,99$ & -2.50 & $-2.5 t$ & 1.88 & -2.58 & -3.11 \\
\hline $\begin{array}{l}\text { Degrees of } \\
\text { Freedom (v) }\end{array}$ & 7.04 & 8.92 & 7.14 & 7.01 & 7.38 & 8.45 & 7.53 & 4.69 & 7.69 & 7.31 \\
\hline$t[v, 0.975]$ & 2.363 & 2.266 & 2.357 & 2.365 & 2.343 & 2.286 & 2.334 & 2.640 & 2.324 & 2.347 \\
\hline$t[v, 0.950]$ & 1.894 & 1.835 & 1.890 & 1.895 & 1.882 & 1.848 & 1.876 & 2.055 & 1.871 & 1.884 \\
\hline
\end{tabular}

\section{[4 Yearly Averaging]}

\section{New Mean Values}

\begin{tabular}{|c|c|c|c|c|c|c|c|c|c|c|}
\hline & $\begin{array}{c}\text { Conductivity } \\
@ 25 \mathrm{C} \\
(\mathrm{ms} / \mathrm{m}) \\
\end{array}$ & PH & $\begin{array}{c}\text { Dissolved } \\
\text { Ions } \\
\text { (mg/l) } \\
\end{array}$ & $\begin{array}{c}\text { Dissolved } \\
\text { Solids } \\
\text { (mgA) }\end{array}$ & $\begin{array}{c}\text { Hardness } \\
\text { (mgn)as Caco3 }\end{array}$ & $\begin{array}{c}\text { Alkatinity } \\
\text { (mg/l)as CaCOa } \\
\end{array}$ & $\begin{array}{l}\text { Natrium } \\
(\mathrm{mg} / \mathrm{l})\end{array}$ & $\begin{array}{l}\text { Kalium } \\
\text { (mg/l) }\end{array}$ & $\begin{array}{l}\text { Calcium } \\
\text { (mg/l) }\end{array}$ & $\begin{array}{l}\text { Magnesium } \\
\text { (mgA) }\end{array}$ \\
\hline (Xne) & $\begin{array}{l}242.3 \\
244.1\end{array}$ & $\begin{array}{l}7.7 \\
7.8\end{array}$ & $\begin{array}{l}166.4 \\
169.2\end{array}$ & $\begin{array}{l}139.8 \\
141.7\end{array}$ & $\begin{array}{l}64.9 \\
67.3\end{array}$ & $\begin{array}{l}70.9 \\
71.9\end{array}$ & $\begin{array}{l}21.1 \\
21.6\end{array}$ & $\begin{array}{l}3.1 \\
3.3\end{array}$ & $\begin{array}{l}14.1 \\
14.9\end{array}$ & $\begin{array}{l}7.2 \\
7.3\end{array}$ \\
\hline $\begin{array}{l}\left.\bar{X}_{n e}\right) \\
\text { (Sne) }\end{array}$ & $\begin{array}{c}243.2 \\
1.2\end{array}$ & $\begin{array}{l}7.7 \\
0.1\end{array}$ & $\begin{array}{c}167.8 \\
2.0\end{array}$ & $\begin{array}{c}140.7 \\
1.4\end{array}$ & $\begin{array}{c}66.1 \\
1.7\end{array}$ & $\begin{array}{c}71.4 \\
0.6\end{array}$ & $\begin{array}{c}21.3 \\
0.4\end{array}$ & $\begin{array}{l}3.2 \\
0.1\end{array}$ & $\begin{array}{l}14.5 \\
0.5\end{array}$ & $\begin{array}{l}7.3 \\
0.1\end{array}$ \\
\hline
\end{tabular}

Statistic Test (T), Calculated by Equation 5.6

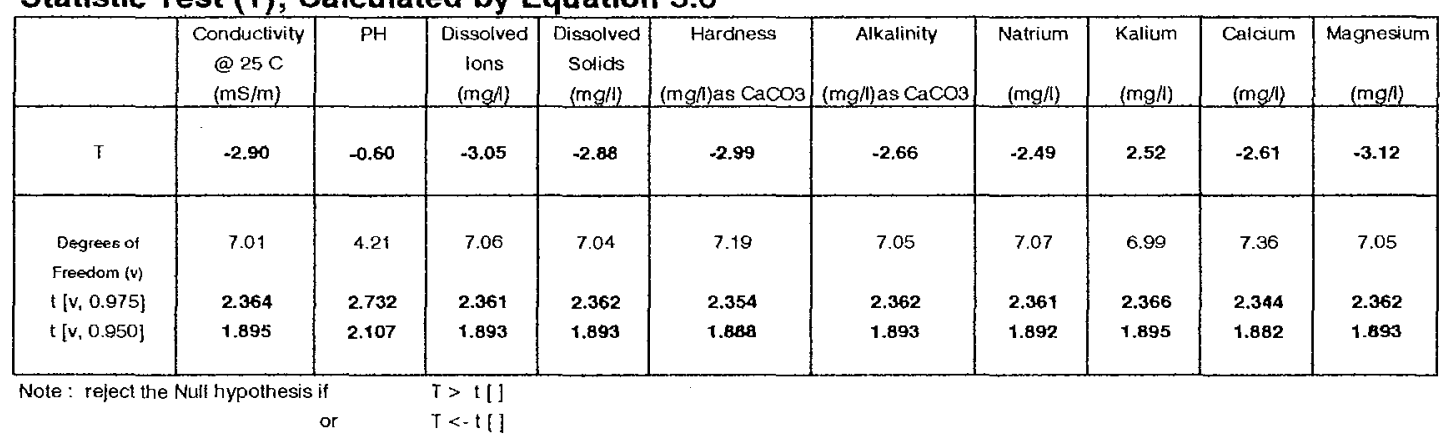


method can be used, not just to predict water quality values at discontinued monitoring station, but also how the results can be used to identify the most likely location(s) of changes which are causing variations in the water quality values being observed at some downstream point. 


\title{
CHAPTER 6
}

\section{SUMMARY AND CONCLUSION}

\begin{abstract}
Efficient water quality monitoring is a very complex problem involving definition of the objectives of monitoring, the amount of information to collect including which parameters to monitor and the value of that information, and the costs associated with the establishment and maintenance of both the monitoring network itself and the monitoring program to be undertaken with that network. While establishment of a water quality monitoring network and program is very costly, the assessment, in economic or quantitative terms, of the benefits accruing as a result of that monitoring is a difficult, if not impossible, task at this time.
\end{abstract}

However, with the current, and increasing, emphasis on the protection and enhancement of the environment, water quality and its monitoring has been, and continues to be, the focus of attention by water authorities, governments, special interest groups and the general public. Optimisation of water quality monitoring networks has therefore been given an 
increasing level of attention by researchers in recent times. Even with the increased emphasis on the environment and the associated consideration of water quality in water resources projects and allocation of budget to monitoring and improving that water quality, in particular cases, when budget is limited, it is not unlikely that discontinuation of existing water quality monitoring stations has to be undertaken.

Reasons for discontinuation of existing stations may be that the cost of operating water quality monitoring is increasing over time with the budget allocated to the monitoring remaining static or not increasing to keep pace with the increasing cost of operation, or monitoring has to be undertaken at another location where the need is more acute. Loss of information due to the discontinuation of existing monitoring stations has the potential to cause decisions, which would have previously been made on the basis of information derived from the discontinued station, to be inappropriate. A new approach to the prediction of water quality values at discontinued monitoring stations has been proposed in this thesis and its value and advantages over a more traditional regression based method demonstrated.

The model has been formulated and validated for 
use for monitoring networks on river systems characterised by a number of monitoring stations located on upstream tributaries or on the upstream portions of the mainstem of the river, and a station located on the mainstem downstream of all these stations. The particular problem for which the technique was developed arises when the upstream stations are discontinued and only the downstream mainstem station remains in operation. Water quality values at the discontinued upstream stations are then predicted on the basis of 1) the observed water quality values at the downstream station and 2) the probability distributions of water quality known to exist at the upstream stations prior to their discontinuation. This process assumes that upstream stations were in operation for a period of time sufficient to define adequately the probability distributions of the water quality parameters at these stations.

The approach is based on entropy 'information' theory and is shown to improve the accuracy of prediction of water quality values under the conditions outlined above. The actual technique of prediction is based on the Principle of Maximum Entropy (POME) as articulated in a non-linear programming formulation in which probability is assigned, in an unbiased manner, to all possible event/outcomes, i.e., values of water 
quality parameters, at discontinued monitoring stations on the basis of information about prior conditions at those stations. The assignment of these probabilities is performed in a manner which maximises the mathematical statement of the entropy function.

The method also utilises the Minimum Discrimination Information principle wherein, since the characteristics of the basin are reflected in the historical observations, the probability regime predicted by the formulation has to fulfil specified constraints as well as making the predicted probability distributions as close as possible to the observed historical (prior) probability distributions.

Application of the model to water quality monitoring networks in Queensland, Australia demonstrates the power of the technique and reveals a number of advantages that complement the inherent unbiased nature of its predictions. In the first instance the model performs better in predicting water quality values at the upstream stations than traditional techniques such as regression (It should be noted that regression analysis also requires the same level of prior data as the entropy formulation). In fact, in the demonstration examples, in comparison with the regression method, using the same data, the entropy 
method makes more accurate predictions in terms of the average error $61 \%$ of the time. The largest error in prediction from the entropy based formulation being $26.90 \%$ smaller than the largest error derived from regression method. Similarly the overall average maximum error in prediction is $4.72 \%$ smaller for the entropy method than that for the regression procedure.

The method is also able to incorporate knowledge about changing conditions in the basin through modification of the 'prior' probability term used in the formulation. Care has to be taken, however, in modifying these prior probability terms in order to avoid eliminating one of the strengths of the technique, namely the unbiased nature of its predictions, by inappropriately prejudicing the results.

In the original formulation of the model the water quality values on each tributary were assumed to be independent of each other. The model was modified to allow for consideration of statistical dependency where such dependency was observed. However, it was found that inclusion of this dependency did not improve the performance of the model in terms of the accuracy of the predictions. Furthermore, inclusion of the dependency increases the size (number of variables) of 
the formulation significantly with, because of the nonlinear nature of the formulation, an associated exponential increase in computational time and effort. For this reason, unless there are overriding reasons, it is not recommended that dependency be included in the formulation.

The entropy function upon which the approach is based assumes discrete probability distributions for the events under consideration. Hence, when the model is applied to prediction of water quality it is necessary to discretize the range of water quality values. Previous application of entropy theory to problems involving continuous variables indicated that the level (fineness) of the discretization had a significant impact on the accuracy of the results and the decisions that would be made on the basis of these results. The particular application described in the thesis appears to be relatively insensitive to the level of discretization as demonstrated by the result that changing the discretization from 48 to 8 intervals caused less than $1 \%$ change to the predicted water quality values.

Furthermore, although the entropy approach assumes a normal distribution for the variables, experience with the model in the case study indicates that the 
model is quite robust, with similar results and in fact better predictions, being obtained when normal distribution is assumed and applied to data which are not strictly normal.

The method was also shown to have the potential for assisting in the identification of the most likely locations of causes of changes to water quality which are being observed at a downstream monitoring station.

The combination of these features indicate that the approach has considerable potential for prediction of water quality values at discontinued monitoring stations in certain spatial configurations and is therefore an important step forward in the area of prediction of water quality values.

There are still a number of areas, however, which require further investigation before the model can be implemented on an operational basis. In the first instance there is a need for an analysis of how prior knowledge about changes in the basin can be most appropriately incorporated into the model. In particular, there is a need to develop some better understanding of the appropriate magnitude of the quantitative changes that should be made to the prior probability in order, to reflect the known changes in 
the system.

Further work is also required to determine how water quality distributions which are very different from normal might be handled by the formulation.

There is also considerable merit in undertaking a more comprehensive range of case studies using different data bases to validate the performance of the technique on a more global basis. 


\section{BIBLIOGRAPHY}

Alexander, R.B. and Smith, R.A. (1988), "Trends in Lead Concentrations in Major U.S. Rivers and Their Relation to Historical Changes in Gasoline-lead Consumption", Water Resources Bulletin, 24(3), pp. 557-569.

Alpaslan, N. and Harmancioglu, N.B. (1990), "Water Quality Monitoring: Site Selection", stuttgart, Seminar Umweltschutz, pp. 185-205.

Alpaslan, N., Harmancioglu, N.B, and Singh, V.P. (1992), "The Role of the Entropy Concept in Design and Evaluation of Water Quality Monitoring Networks", in Entropy and Energy Dissipation in Water Resources, (Ed. by Singh V.P. and Fiorentino. M.), Kluwer Academic Publishers, pp. 283-302.

Amorocho, J. and Espildora, B. (1973), "Entropy in the Assessment of Uncertainty of Hydrologic Systems and Models", Water Resources Research, 9(6), pp. 1515-1522.

Awumah, K., Goulter, I. and Bhatt, S. (1990)," Assessment of Reliability in water Distribution Networks Using Entropy Based Measures ", stochastic Hydrology and Hydraulics, 4, pp. 309-320.

Awumah, K., Goulter, I. and Bhatt, S. (1991), "Entropy Based Redundancy Measures in Water Distribution Network Design", Journal of Hydraulic Engineering, ASCE, 117(10), pp. 595-614.

Belle, G. and Hughes, J.P. (1983), "Monitoring for Water Quality: Fixed Stations versus Intensive Surveys", Journal of the water Pollution Control Federation, 55(4), pp. 400-404.

Belle, G. and Hughes, J.P. (1984), "Nonparametric Tests for Trend in Water Quality", Water Resources Research, 20(1), pp. 127-136.

Berthouex, P.M. and Hau, I. (1991), "A Simple Rule for Judging Compliance Using Highly Censored Samples", Journal of the water Pollution control Federation, 63(6), pp. 880-886. 
Bethea, R.M, Duran, B.S, and Boullion, T.L. (1985), "Statistical Methods for Engineers and Scientists", Marcel Dekker, Inc, New York, $698 \mathrm{p}$.

Bruton, G. (1982), in "Water Quality Sampling and Data Analysis", Edited By Hart, B.T., Melbourne, Water studies Centre, Chisholm Institute of Technology and Australian Society of Limnology, $158 \mathrm{p}$.

Burn, D.H., and Goulter, I.C. (1991), "An approach to the Rationalization of streamflow Data Collection Networks", Journal of Hydrology, 122, pp. 71-91.

Casey, D., Nemetz, P.N., Uyeno, D.H. (1983), "Sampling Frequency for Water Quality Monitoring: Measures of Effectiveness", Water Resources Research, 19(5), pp. 1107-1110.

Caselton, W.F. and Husein, T. (1980), "Hydrologic Networks: Information Transmission", Journal of the Water Resources Planning and Management Division, ASCE, 106(WR2), pp. 503-520.

Chiu, Chao-Lin (1987), "Entropy and Probability Concepts in Hydraulics", Journal of Hydraulics Engineering, ASCE, $113(5)$, pp. 583-600.

Chiu, Chao-Lin (1988), " Entropy and 2-D Velocity Distribution in Open Channels ", Journal of Hydraulics Engineering, ASCE, 114(7), pp. 738-756.

Chiu, Chao-Lin (1989), " Velocity Distribution in Open Channels Flow ", Journal of Hydraulics Engineering, ASCE, 115(5), pp. 576-594.

Chiu, Chao-Lin (1991), " Application of Entropy Concept in Open Channel Flow Study", Journal of Hydraulics Engineering, ASCE, 117(5), pp. 615-628.

Chiu, Chao-Lin and Chiou, J.D. (1986)," "structures of 3-D Flow in Rectangular Open Channels" Journal of Hydraulics Engineering, ASCE, 112(11), pp. 1050-1068.

Devore, J.L. (1982), Probability and statistics for Engineering and the Sciences, Brooks/Cole Publishing Company, Monterey, California, $640 \mathrm{p}$.

Duckstein, L., Kisiel, C.C., Beckman, M. (1976), "Water Quality Control Under Uncertainty : Optimal stopping Rules for Sampling", Journal of Hydrology, 29, pp. 393-406. 
Duckson, Jr. D.W. (1986), "Basin Water Monitoring: Hydrologic Impact or Legal Compliance", Water Resources Bulletin, 22(3), pp. 457-464.

Dunnette, D.A. (1980), "Sampling Frequency Optimization Using a Water Quality Index", Journal of the water pollution Control Federation, 52(11), pp. 2807-2811.

Gambolati, G. and Volpi, G. (1979), "A Conceptual Deterministic Analysis of the Kriging Technique in Hydrology", Water Resources Research, 15(3), pp. 625629 .

Gilbert, R.O. (1987), Statistical Methods for Environmental pollution Monitoring, Van Nostrand Reinhold, New York.

Gilliom, R.J., Hirsch, R.M. and Gilroy, E.J. (1984), "Effect of Censoring Trace Level Water Quality Data on Trend Detection Capability", Environmental Science Technology, 18(7), pp. 530-535.

Harcum, J.B., Loftis, J.C., Ward, R.C. (1992), "Selecting Trend Tests for water Quality Series with Serial Correlation and Missing values", Water Resources Bulletin, 28(3), pp. 469-478.

Harmancioglu, N.B. (1981), "Measuring the Information Content of Hydrological Processes by the Entropy Concept", Centennial of Ataturk's Birth, Journal of the Civil Engineering, Faculty of Ege University, pp. $13-38$.

Harmancioglu, N.B. and Alpaslan, N. (1992), "watè Quality Monitoring Network Design: A Problem of Multi-objective Decision Making", Water Resources Bulletin, 28(3), pp. 179-192.

Harmancioglu, N.B. and Baran, T. (1989), "Effects of Recharge Systems on Hydrological Information Transfer along Rivers", IAHS, Proc. of the Third Scientific Assembly - New Directions for surface water Modelling, IAHS Publ. 181, pp. 223-233.

Harmancioglu, N.B. and Yevjevich, V. (1987), "Transfer of Hydrologic Information Among River Points, Journal of Hydrology, 91, pp. 103-118. 
Harmancioglu, N.B. and Singh, V.P. (1991), "An Information-Based Approach to Monitoring and Evaluation of Water Quality Data", Advances in water Resources Technology, G.Tsakiris (ed.), pp. 377-386.

Harmancioglu, N.B., Yevjevich, V. and Obeysekera, J.T.B. (1985), "Measures of Information Transfer Between Variables", Proceedings of Fourth International Hydrology Symposium, Published by Hsieh Wen Shen, Engineering Research Center, Colorado state University, Fort Collins, Colorado 80523, U.S.A., pp. 481-499.

Heidtke, T.M. and Armstrong, J.M. (1979), "Probabilistic Sampling Model for water Quality Management", Journal of the water pollution Control Federation, 51(12), pp. 2916-2927.

Herricks, E.E., Schaeffer, D.J., Kapsner, J.C. (1985), "Complying with NPDES Permit Limits : When is a Violation a Violation ?", Journal of the water Pollution Control Federation, 57(2), pp. 109-115.

Hirsch, R.M. (1988), "Statistical Methods and Sampling Design for Estimating step Trends in Surface-Water Quality", Water Resources Bulletin, $24(3)$, pp. 493-503.

Hirsch, R.M., Alexander, R.B., Smith R.A. (1991), "Selection of Methods for the Detection and Estimation of Trends in water Quality", Water Resources Research, 27(5), pp. 803-813.

Hirsch, R.M. and Slack, J.R. (1984), "A Nonparametric Trend Test for Seasonal Data With Serial Dependence", Water Resources Research, 20(6), pp. 727-732.

Hirsch, R.M., Slack J.R., Smith R.A. (1982), "Techniques of Trend Analysis for Monthly water Quality Data", Water Resources Research, 18(1), pp. 107-121.

Jaynes, E.T. (1957), "Information Theory and Statistical Mechanics I", Physical Reviews, 106, pp. $620-630$.

Jaynes, E.T. (1979), "Concentration of Distribution at Entropy Maxima", $19^{\text {th }}$ NBER-NSF Seminar on Bayesian Statistics, Montreal, in Papers on Probability, Statistics and Statistical Physics, Edited by Rosenkrantz R.D., D.Reidel Publishing Company, Dordrecht:Holland/ Boston:U.S.A/London:England, pp. $317-336$. 
Jaynes, E.T. (1968), "Prior Probabilities", IEEE Transactions on System Science and Cybernetics, 4(3), pp. 227-241.

Kapur, J.N. (1983), "Twenty Five Years of Maximum Entropy Principle", Journal of Mathematics and Physical Sciences, $17(2)$, pp. 103-156.

Kapur, J.N. (1989), Maximum Entropy Models in Science and Engineering, Wiley Eastern Limited, New Delhi, $635 \mathrm{p}$.

Kullback, S. and Leibler, R.A. (1951), "On Information and Sufficiency", Annual Mathematics and Statistics, (22), pp. 79-86.

Lasdon, L.S. and Waren, A.D. (1986), GRG2 User's Guide, Department of General Business Administration, The University of Texas at Austin, Austin, Texas, 60 p.

Lettenmaier, D.P., Anderson, D.E., Brenner, R.N. (1984), "Consolidation of a Stream Quality Monitoring Network", Water Resources Bulletin, 20(4), pp. 473481 .

Lettenmaier, D.P., Hooper, E.R., Wagoner, C., Faris, K.B. (1991), "Trends in stream Quality in the Continental United States, 1978-1987", Water Resources Research, 27(3), pp. 327-339.

Liebetrau, A.M. (1979), "Water Quality Sampling: Some Statistical Considerations", Water Resources Research, 15(6), pp. 1717-1725.

Loftis, J.C. and Ward, R.C. (1980), "Water quality Monitoring - Some Practical Sampling Frequency Considerations", Environmental Management, 4(6), pp. 521-526.

Loftis, J.C. and Ward, R.C. (1981), "Evaluating Stream Standard Violations Using a Water Quality Data Base", Water Resources Bulletin, 17(6), pp. 10711078 .

Loftis, J.C., McBride, G.B., Ellis, J.C. (1991), "Consideration of Scale in water Quality Monitoring and Data Analysis", Water Resources Bulletin, 27(2), pp. 255-264.

Matalas, N.C. and Langbein, W.B. (1962), "Information Content of the Mean", Journal of Geophysical Research, 67(9), pp. 3441-3448. 
Palmer, R.N., and Mackenzie, M.C. (1985), "Optimization of Water Quality Monitoring Networks", Journal of Water Resources Planning and Management, ASCE, $111(4)$, pp. 478-493.

Perry, J.A, Schaeffer, D.J., and Herricks, E.E. (1987), "Innovative Designs for water Quality Monitoring: Are We Asking the Questions Before the Data are Collected ?, New Approach to Monitoring Aquatic Ecosystems, ASTM STP 940, T.P. Boyle, Ed., American Society for Testing and Materials, Philadelphia, pp. 28-39.

Pinter, J. and Somlyody, L. (1987), "Optimization of Regional Water Quality Monitoring strategies", Water Science and Technology, 19, pp. 721-727.

Sanders, T.G., Adrian D.D. (1978), "Sampling Frequency for River Quality Monitoring", Water Resources Research, 14(4), pp. 569-576

Sanders, T.G., Adrian, D.D., Joyce, J.M. (1977), "Mixing Length for Representative water Quality Sampling", Journal of the water Pollution Control Federation, pp. 2467-2478.

Sanders, T.G., Ward, R.C., Loftis, J.C., Steel, T.D., Adrian D.D., and Yevjevich, V (1983), Design of Networks for Monitoring water Quality, water Resources Publications, Colorado.

Schaeffer, D.J., Janardan, K.G., Kerster, H.W., Shekar, M.S. (1980), "Graphical Effluent Quality Control for Compliance Monitoring: What Is a Violation?", Environmental Management, 4(3), pp. 241245 .

Schilperoort, T. and Groot, S. (1983), "Design and Optimization of Water Quality Monitoring Networks", Publication No. 286, Delft Hydraulics Laboratory, 18 p.

Shannon, C.E. (1948), "A Mathematical Theory of Communication", Bell System Technical Journal, 27(3), pp. 379-423\&623-656.

Singh, V.P., and Singh, K. (1985), "Derivation of the Gamma Distribution by Using the Principle of Maximum Entropy (POME)", water Resources Bulletin, 21(6), pp. $941-949$. 
Singh, V.P. Rajagopal, A.K., Singh, K. (1986), "Derivation of Some Frequency Distributions Using the Principle of Maximum Entropy (POME)", Advances in Water Resources, 9, pp. 91-105.

Sonuga, J.O. (1972), "Principle of Maximum Entropy in Hydrologic Frequency Analysis", Journal of Hydrology, 17, pp. 177-191.

Sonuga, J.O. (1976), "Entropy Principle Applied to the Rainfall Runoff Process", Journal of Hydrology, 30, pp. 81-94.

Steele, T.D. (1987), "Water Quality Monitoring Strategies", Hydrological Sciences Journal, 32(2), pp. 207-213.

Tchobanoglous, G and Schroeder, E.D. (1985), "Water Quality", Addison-Wesley Publishing Company, $767 \mathrm{p}$.

Valiela, D. and Whitfield, P.H. (1989), "Monitoring Strategies to Determine Compliance with Water quality Objectives", Water Resources Bulletin, 25(1), pp. 6369 .

Ward, R.C. and Loftis, J.C. (1989), "Monitoring Systems for water Quality", Critical Reviews in Environmental Control, 19(2), pp. 101-118.

Ward, R.C., Loftis, J.C., McBride, G.B. (1986), "The 'Data-rich but Information-poor' syndrome in Water Quality Monitoring", Environmental Management, 10(3), pp. 291-297.

Ward, R.C., Loftis, J.C., McBride, G.B. (1990), Design of Water Quality Monitoring Systems, Van Nostrand Reinhold, New York, 231 p.

Ward, R.C., Loftis, J.C., Nielsen, K.S., Anderson, R.D. (1979), "Statistical Evaluation of Sampling Frequencies in Monitoring Networks", Journal of the Water Pollution Control Federation, 51(9), pp. 22922300 .

Whitfield, P.H. (1983), "Evaluation of Water quality Sampling Locations on the Yukon River", Water Resources Bulletin, 19(1), pp. 115-121.

Whitfield, P.H. (1983), "Evaluation of Water Quality Sampling Locations on the Yukon River", Water Resources Bulletin, 19(1), pp. 115-121. 
Whitfield, P.H. (1988), "Goals and Data Collection Designs for Water Quality Monitoring", Water Resources Bulletin, 24(4), pp. 775-780.

Whitfield, P.H. and Woods, P.F. (1984), "Intervention Analysis of Water Quality Records", Water Resources Bulletin, 20(5), pp. 657-667.

$\overline{\text { Resources }}^{\prime} \frac{\text { Atlas of Australian Resources }}{\text { Information and Development }}$ Branch), Department of National Development, Australia.

, Queensland Resources Atlas (1980), Australian State Public Relation Bureau, Premiers Department, Brisbane. 


\title{
ENTROPY PRINCIPLES IN THE PREDICTION OF WATER QUALITY VALUES AT DISCONTINUED MONITORING STATIONS
}

\author{
By \\ Agus Suprapto Kusmulyono
}

\begin{abstract}
A Thesis Submitted to
the Central Queensland University

in Partial Fulfilment of the Requirements

for the Degree of
\end{abstract}

DOCTOR OF PHILOSOPHY

VOLUME II

[Appendices]

Department of Civil Engineering and Building James Goldston Faculty of Engineering Central Queensland University Rockhampton, Queensland, Australia

December, 1994 
Appendix $A$ 
Table A.1 (a) Water Quality Records in the Fitzroy River Basin

Station 130322

\begin{tabular}{|c|c|c|c|c|c|c|c|c|c|c|c|c|}
\hline \multicolumn{3}{|c|}{$\begin{array}{l}\text { Date } \\
\text { Sampled }\end{array}$} & $\begin{array}{c}\text { CONDUCTIVITY } \\
@ 25 \mathrm{c} \\
\text { (mS/m) }\end{array}$ & $\mathrm{PH}$ & $\begin{array}{c}\text { DISSOLVED } \\
\text { IONS } \\
\text { (mg/) }\end{array}$ & $\begin{array}{c}\text { DISSOLVED } \\
\text { SOLIDS } \\
\text { (mg/i) }\end{array}$ & 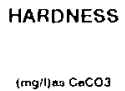 & 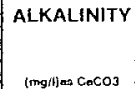 & $\begin{array}{l}\text { NATRIUM } \\
\text { (mg/l) }\end{array}$ & $\begin{array}{l}\text { KALIUM } \\
\text { (mg/l) }\end{array}$ & $\begin{array}{c}\text { CALCIUM } \\
\text { (mgll) }\end{array}$ & $\begin{array}{c}\text { MAGNESIUM } \\
\text { (mg/l) }\end{array}$ \\
\hline (dd & $\min y$ & $y=)$ & & & & & & & & & & \\
\hline 26 & 11 & 64 & 200 & 7.3 & 176.2 & 124 & 65 & 72 & 26.5 & 0.0 & 16.0 & 6.0 \\
\hline 9 & 6 & 65 & 405 & 8 & 279.2 & 274 & 84 & 100 & 54.0 & 0.0 & 24.0 & 5.8 \\
\hline 7 & 1 & 66 & 175 & 8.2 & 165.2 & 105 & 64 & 80 & 23.0 & 0.0 & 14.0 & 7.0 \\
\hline 17 & 5 & 66 & 255 & 8 & 217.2 & 152 & 86 & 104 & 28.0 & 0.0 & 26.0 & 5.0 \\
\hline 29 & 1 & 67 & 190 & 7.6 & 182.1 & 133 & 50 & 80 & 34.0 & 0.0 & 10.0 & 6.0 \\
\hline 29 & 1 & 67 & 202 & 7.7 & 182.1 & 133 & 50 & 80 & 34.0 & 0.0 & 10.0 & 6.0 \\
\hline 30 & 1 & 67 & 266 & 8.2 & 270 & 0 & 100 & 110 & 38.0 & 0.0 & 30.0 & 6.0 \\
\hline 30 & 1 & 67 & 168 & 7.9 & 182 & 0 & 50 & 75 & 31.0 & 0.0 & 18.0 & 6.0 \\
\hline 20 & 2 & 68 & 70 & 8 & 64 & 0 & 12 & 24 & 15.0 & 0.0 & 3.0 & 1.0 \\
\hline 23 & 11 & 69 & 280 & 6.9 & 210.7 & 0 & 65 & 90 & 36.0 & 0.0 & 22.0 & 2.5 \\
\hline 24 & 11 & 69 & 250 & 6.9 & 190.7 & 0 & 65 & 90 & 29.0 & 0.0 & 16.0 & 6.0 \\
\hline 26 & 11 & 69 & 250 & 7 & 174.1 & 0 & 75 & 85 & 20.0 & 0.0 & 20.0 & 6.0 \\
\hline 11 & 12 & 70 & 100 & 7 & 76.3 & 0 & 32 & 36 & 9.0 & 0.0 & 8.0 & 3.0 \\
\hline 12 & 12 & 70 & 114 & 6.9 & 91.3 & 0 & 33 & 46 & 12.0 & 0.0 & 10.0 & 2.0 \\
\hline 15 & 12 & 70 & 127 & 6.8 & 111.3 & 0 & 35 & 52 & 18.0 & 0.0 & 9.0 & 3.0 \\
\hline 16 & 12 & 70 & 123 & 6.8 & 103.3 & 0 & 35 & 52 & 15.0 & 0.0 & 9.0 & 3.0 \\
\hline 18 & 12 & 70 & 130 & 6.8 & 103.3 & 0 & 35 & 52 & 15.0 & 0.0 & 9.0 & 3.0 \\
\hline 19 & 12 & 70 & 140 & 6.8 & 109.3 & 0 & 44 & 58 & 13.0 & 0.0 & 11.0 & 4.0 \\
\hline 20 & 12 & 70 & 140 & 6.9 & 110.3 & 0 & 46 & 58 & 12.0 & 0.0 & 12.0 & 4.0 \\
\hline 21 & 12 & 70 & 150 & 6.9 & 113.3 & 0 & 51 & 58 & 12.0 & 0.0 & 12.0 & 5.0 \\
\hline 9 & 2 & 71 & 100 & 8 & 72.6 & 0 & 26 & 36 & 10.0 & 0.0 & 4.0 & 4.0 \\
\hline 10 & 2 & 71 & 93 & 7.8 & 72.6 & 0 & 26 & 36 & 10.0 & 0.0 & 4.0 & 4.0 \\
\hline 14 & 2 & 71 & 130 & 7.6 & 103.6 & 0 & 49 & 54 & 10.0 & 0.0 & 8.0 & 7 \\
\hline 8 & 6 & 71 & 345 & 7.1 & 237.1 & 0 & 89 & 96 & 37.0 & 0.0 & 24.0 & 7.0 \\
\hline 26 & 11 & 71 & 790 & 7.9 & 491.3 & 0 & 142 & 120 & 110.0 & 0.0 & 32.0 & 15.0 \\
\hline 9 & 4 & 73 & 215 & 8 & 176.1 & 132 & 62 & 88 & 21.3 & 6.6 & 15.0 & 6.0 \\
\hline 3 & 12 & 73 & 300 & 7.9 & 170.5 & 135 & 61 & 82 & 21.0 & 5.8 & 17.0 & 4.6 \\
\hline 2 & 4 & 74 & 170 & 7.8 & 113.9 & 100 & 36 & 44 & 18.0 & 4.6 & 8.0 & 4.0 \\
\hline 3 & 7 & 74 & 225 & 7.6 & 167.9 & 133 & 58 & 76 & 22.0 & 6.8 & 15.0 & 5.0 \\
\hline 5 & 1 & 75 & 145 & 7.1 & 111.6 & 92 & 51 & 54 & 12.0 & 5.1 & 12.5 & 4.7 \\
\hline 30 & 9 & 76 & 230 & 7.5 & 174.7 & 136 & 59 & 80 & 22.0 & 6.3 & 15.0 & 5.2 \\
\hline 5 & 10 & 76 & 190 & 7.5 & 137.9 & 113 & 50 & 55 & 18.0 & 5.6 & 13.0 & 4.2 \\
\hline 9 & 12 & 76 & 150 & 7.6 & 114 & 96 & 43 & 52 & 13.0 & 5.5 & 12.0 & 3.1 \\
\hline 6 & 4 & 77 & 115 & 7.7 & 79.2 & 72 & 33 & 32 & 9.8 & 5.4 & 8.4 & 2.8 \\
\hline 14 & 12 & 77 & 175 & 7.8 & 133.6 & 102 & 41 & 60 & 17.0 & 4.7 & 10.0 & 4.0 \\
\hline 16 & 3 & 78 & 190 & 7.4 & 146.3 & 122 & 49 & 66 & 18.0 & 5.5 & 12.0 & 4.5 \\
\hline 13 & 4 & 81 & 185 & 7.5 & 141.2 & 110 & 57 & 71 & 12.0 & 5.0 & 18.0 & 3.0 \\
\hline 1 & 6 & 84 & 215 & 7.8 & 170.9 & 140 & 64 & 83 & 21.0 & 5.8 & 17.0 & 5.3 \\
\hline 23 & 8 & 84 & 190 & 7.6 & 148.7 & 150 & 47 & 63 & 21.0 & 6.2 & 12.0 & 4.1 \\
\hline 15 & 12 & 84 & 315 & 7.9 & 217.6 & 180 & 77 & 91 & 31.0 & 5.3 & 18.0 & 7.8 \\
\hline 9 & 3 & 85 & 205 & 7.8 & 165 & 140 & 56 & 77 & 17 & 6.7 & 14.0 & 5.2 \\
\hline 21 & 12 & 85 & 285 & 7.6 & 190.9 & 160 & 66 & 77 & 26.0 & 6.0 & 16.0 & 6.2 \\
\hline 16 & 3 & 86 & 265 & 8 & 177.2 & 140 & 58 & 72 & 27.5 & 5.4 & 14.5 & 5.4 \\
\hline 14 & 12 & 86 & 170 & 7.2 & 120.8 & 110 & 44 & 55 & 15.0 & 4.6 & 11.0 & 3.9 \\
\hline 26 & 6 & 87 & 275 & 8 & 196.8 & 150 & 71 & 87 & 25.0 & 5.5 & 17.0 & 7.0 \\
\hline 14 & 12 & 87 & 170 & 7.8 & 122.8 & 100 & 44 & 60 & 14.0 & 4.3 & 11.0 & 4.1 \\
\hline 11 & 4 & 88 & 210 & 7.6 & 154 & 120 & 54 & 75 & 17.5 & 6.3 & 13.5 & 5.0 \\
\hline 23 & 7 & 88 & 180 & 7.5 & 135.1 & 100 & 49 & 69 & 14.0 & 5.1 & 12.5 & 4.2 \\
\hline 29 & 8 & 89 & 275 & 7.6 & 191.4 & 150 & 75 & 82 & 26.0 & 5.0 & 19.0 & 6.6 \\
\hline 7 & 9 & 89 & 260 & 7.8 & 183.4 & 140 & 71 & 79 & 24.0 & 4.6 & 18.0 & 6.2 \\
\hline 7 & 9 & 89 & 245 & 7.8 & 181.5 & 140 & 67 & 79 & 23.5 & 4.4 & 17.0 & 6.0 \\
\hline 301 & 11 & 89 & 215 & 7.3 & 144.9 & 120 & 53 & 69 & 18.5 & 5.0 & 14.0 & 4.3 \\
\hline
\end{tabular}

Source: Queensland Water Resources Commission

Surface Water Resources Branch

Water Quality Data System 
Table A.1 (a) Water Quality Records in the Fitzroy River Basin (continued)

Station 130105

\begin{tabular}{|c|c|c|c|c|c|c|c|c|c|c|c|c|}
\hline \multicolumn{3}{|c|}{$\begin{array}{l}\text { Date } \\
\text { Samplad }\end{array}$} & $\begin{array}{c}\text { CONDUCTIVITY } \\
@ 25 \mathrm{C} \\
(\mathrm{mS} / \mathrm{m})\end{array}$ & \multirow[t]{2}{*}{ PH } & \multirow[t]{2}{*}{$\begin{array}{c}\text { OHSSOLVED } \\
\text { IONS } \\
\text { (mg/) }\end{array}$} & $\begin{array}{c}\text { DISSOLVED } \\
\text { SOLIDS } \\
\text { (mg/l) }\end{array}$ & 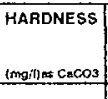 & $\begin{array}{l}\text { ALKALINITY } \\
\text { (mngil)es } \mathrm{CaCO} 03\end{array}$ & \multirow[t]{2}{*}{$\begin{array}{r}\text { NATRIUM } \\
\text { (Ing/) } \\
\end{array}$} & $\begin{array}{r}\text { KALIUM } \\
\text { (mgg/h) } \\
\end{array}$ & $\begin{array}{l}\text { CALCIUM } \\
\text { (rigill) } \\
\end{array}$ & $\begin{array}{c}\text { MAGNESIUM } \\
\text { (mql) }\end{array}$ \\
\hline isd & $\mathrm{mmm} \quad \mathrm{y} n$ & & & & & & & & & & & \\
\hline 1 & 97 & & 280 & 7.7 & 197.1 & 146 & 75 & 82 & 30.0 & - & 17.0 & 8.0 \\
\hline 12 & 127 & & 300 & 7.7 & 202.2 & 151 & 86 & 82 & 28.0 & . & 18.0 & 10.0 \\
\hline 21 & 37 & & 175 & 7.7 & 125.3 & 104 & 51 & 60 & 13.9 & 2.9 & 10.5 & 6.0 \\
\hline 27 & 3 & & 230 & 7.1 & 154.9 & 136 & 63 & 60 & 20.0 & 1.6 & 12.5 & 7.7 \\
\hline 5 & 6 & & 205 & 8.1 & 149.7 & 117 & 60 & 64 & 13.8 & 2.8 & 13.5 & 6.5 \\
\hline 18 & 9 & & 250 & 8.1 & 214.4 & 186 & 73 & 72 & 25.0 & 2.5 & 16.0 & 8.0 \\
\hline 27 & 37 & & 180 & 7.2 & 123.3 & 105 & 48 & 52 & 14.0 & 2.7 & 10.0 & 5.5 \\
\hline 7 & 8 & & 440 & 8.0 & 299.6 & 248 & 129 & 115 & 38.0 & 1.8 & 26.0 & 15.6 \\
\hline 131 & 117 & & 430 & 7.7 & 277.7 & 229 & 114 & 105 & 36.0 & 2.0 & 22.0 & 14.4 \\
\hline 8 & 17 & & 155 & 7.1 . & 118.0 & 88 & 61 & 54 & 12.0 & 3.5 & 14.0 & 6.3 \\
\hline 8 & 1 & & 153 & 7.1 & 113.3 & 87 & 61 & 50 & 12.0 & 3.6 & 14.0 & 6.3 \\
\hline 8 & 1 & & 153 & 7.0 & 112.1 & 105 & 57 & 50 & 11.5 & 3.4 & 13.0 & 6.0 \\
\hline 10 & 1 & & 147 & 7.0 & 115.6 & 106 & 53 & 56 & 11.0 & 3.7 & 12.0 & 5.7 \\
\hline 12 & 1 & & 135 & 7.0 & 104.4 & 06 & 45 & 54 & 9.0 & 3.9 & 11.0 & 4.3 \\
\hline 13 & 1 & & 130 & 7.1 & 97.3 & 90.0 & 43 & 52 & 3.5 & 4.2 & 10.0 & 4.3 \\
\hline 13 & 1 & & 130 & 7.0 & 101.8 & 90.0 & 43 & 52 & 8.0 & 4.2 & 10.0 & 4.3 \\
\hline 13 & 1 & & 130 & 6.9 & 98.8 & 88 & 44 & 50 & 8.5 & 4.2 & 10.5 & 4.3 \\
\hline 16 & 1 & & 155 & 7.1 & 125.1 & 103 & 60 & 66 & 0.5 & 4.3 & 14.0 & 6.0 \\
\hline 16 & 1 & & 155 & 7.0 & 122.8 & 106 & 58 & 66 & 9.0 & 4.0 & 13.5 & 6.0 \\
\hline 16 & 1 & 75 & 157 & 7.2 & 134.5 & 119 & 62 & 66 & 9.5 & 3.9 & 14.5 & 6.3 \\
\hline 16 & 1 & 75 & 157 & 7.1 & 124.8 & 106 & 62 & 66 & 9.5 & 4.2 & 14.5 & 6.3 \\
\hline 20 & 1 & & 142 & 7.1 & 108.4 & 99 & 50 & 54 & 9.5 & 3.9 & 12.0 & 4.8 \\
\hline 20 & 1 & 75 & 142 & 7.0 & 106.7 & 95 & 47 & 54 & 9.0 & 3.8 & 11.0 & 4.7 \\
\hline 20 & 1 & 75 & 142 & 7.1 & 108.7 & 96 & 47 & 56 & 9.0 & 3.8 & 11.0 & 4.7 \\
\hline 21 & 1 & 75 & 160 & 7.1 & 199.6 & 107 & 54 & 62 & 10.0 & 4.2 & 13.0 & 5.2 \\
\hline 21 & 1 & 75 & 160 & 7.1 & 121.2 & 104 & 51 & 64 & 10.0 & 4.2 & 11.5 & 5.3 \\
\hline 21 & 1 & 75 & 160 & 7.1 & 121.7 & 107 & 52 & 64 & 10.0 & 4.2 & 12.0 & 5.3 \\
\hline 22 & 1 & 75 & 172 & 7.1 & 131.2 & 110 & 57 & 68 & 11.0 & 4.0 & 13.0 & 6.0 \\
\hline 22 & 1 & 75 & 175 & 7.2 & 131.0 & 112 & 56 & 68 & 11.0 & 4.1 & 13.0 & 5.7 \\
\hline 22 & 1 & 75 & 170 & 7.2 & 133.0 & 112 & 56 & 70 & 11.0 & 4.1 & 13.0 & 5.7 \\
\hline 24 & 1 & 75 & 185 & 7.2 & 143.8 & 117 & 60 & 75 & 11.5 & 4.1 & 14.0 & 6.0 \\
\hline 24 & 1 & & 187 & 7.2 & 145.8 & 121 & 65 & 75 & 11.5 & 4.1 & 16.0 & 6.0 \\
\hline 24 & 1 & 75 & 185 & 7.2 & 158.6 & 135 & 65 & 74 & 11.5 & 4.1 & 16.0 & 6.0 \\
\hline 28 & 1 & 75 & 197 & 7.2 & 151.4 & 121 & 63 & 80 & 13.0 & 3.9 & 15.0 & 6.3 \\
\hline 11 & 2 & 75 & 220 & 7.4 & 162.4 & 131 & 68 & 82 & 16.0 & 3.7 & 15.5 & 7.0 \\
\hline 29 & 97 & 75 & 370 & 7.6 & 237.4 & 195 & 99 & 102 & 29.0 & 2.2 & 20.0 & 12.0 \\
\hline 151 & 127 & 75 & 115 & 7.6 & 75.4 & 75 & 24 & 28 & 10.0 & 3.1 & 5.3 & 2.7 \\
\hline 5 & 87 & 76 & 555 & 8.4 & 351.3 & 295 & 164 & 125 & 50.0 & 1.6 & 36.0 & 18.0 \\
\hline 251 & 107 & 76 & 670 & 8.0 & 409.7 & 342 & 186 & 140 & 60.0 & 2.0 & 38.0 & 22.0 \\
\hline 151 & 127 & 76 & 325 & 8.0 & 247.5 & 185 & rot & 119 & 20.0 & 4.2 & 24.0 & 10.0 \\
\hline 10 & 17 & 77 & 250 & 7.5 & 157.3 & 138 & 67 & 62 & 20.0 & 2.5 & 16.0 & 6.6 \\
\hline 18 & 4 & 77 & 350 & 8.1 & 233.2 & 196 & 100 & 100 & 29 & 2.0 & 22.0 & 11.0 \\
\hline 26 & 77 & 77 & 380 & 8.2 & 256.9 & 206 & 104 & 116 & 30.0 & 2.4 & 22.0 & 12.0 \\
\hline 41 & 107 & 77 & 460 & 8.1 & 346.8 & 276 & 138 & 146 & 40.0 & 2.4 & 29.0 & 16.0 \\
\hline 5 & 17 & 78 & 405 & 8.1 & 292.8 & 238 & 122 & 115 & 37.0 & 3.6 & 24.0 & 15.0 \\
\hline 20 & 117 & 78 & 330 & 7.9 & 223.5 & 177 & 99 & 96 & 28.0 & 3.2 & 23.0 & 10.0 \\
\hline 2 & 68 & 80 & 375 & 7.3 & 228.7 & 201 & 104 & 80 & 32.0 & 1.4 & 22.0 & 12.0 \\
\hline 18 & 98 & 80 & 400 & 7.5 & 253.9 & 217 & 107 & 89 & 38.0 & 1.6 & 23.0 & 12.0 \\
\hline 13 & 178 & 80 & 460 & 7.8 & 284.8 & 242 & 112 & 91 & 45.0 & 2.3 & 20.0 & 15.0 \\
\hline 23 & 78 & 81 & 248 & 7.7 & 176.7 & 139 & 71 & 85 & 18.0 & 3.1 & 15.0 & 8.1 \\
\hline 19 & 8 & 82 & 260 & 7.9 & 167.0 & 150 & 63 & 61 & 27.0 & 1.7 & 13.0 & 7.5 \\
\hline 15 & 3 & 84 & 165 & 8.2 & 129.0 & 100 & 53 & 60 & 13.0 & 3.9 & 12.0 & 5.6 \\
\hline 18 & 6 & 84 & 290 & 6.9 & 196.9 & 160 & 77 & 82 & 26.0 & 3.5 & 17.0 & 8.4 \\
\hline 17 & 98 & 84 & 200 & 7.4 & 157.0 & 120 & 65 & 78 & 15.0 & 3.8 & 15.0 & 6.8 \\
\hline 41 & 128 & 84 & 250 & 7.4 & 161.2 & 140 & 61 & 67 & 23.0 & 4.0 & 14.0 & 6.2 \\
\hline 4 & 38 & 85 & 265 & 7.4 & 184.0 & 150 & 72 & 77 & 22.0 & 3.8 & 16.0 & 7.8 \\
\hline 31 & 128 & 85 & 205 & 7.9 & 137.9 & 130 & 51 & 55 & 18.0 & 4.0 & 12.0 & 5.0 \\
\hline 13 & 38 & 86 & 205 & 8.3 & 154 & 120 & 66 & 80 & 13.0 & 4.0 & 16.0 & 6.2 \\
\hline 24 & 6 & 86 & 225 & 8 & 174.9 & 140 & 72 & 81 & 19.0 & 3.6 & 16.0 & 7.8 \\
\hline 26 & 9 & 86 & 335 & 8.3 & 234.9 & 180 & 104 & 105 & 28.0 & 3.8 & 22.0 & 12.0 \\
\hline 7 & 18 & & 225 & 7.8 & 267.3 & 130 & 63 & 73 & 18.0 & 4.1 & 15.0 & 6.1 \\
\hline 31 & 38 & 87 & 220 & 7.7 & 165.7 & 140 & 69 & 83 & 17.0 & 4.7 & 16.0 & 7.0 \\
\hline 161 & 128 & 87 & 185 & 7.5 & 118.7 & 99 & 51 & 51 & 12.5 & 3.3 & 12.0 & 5.2 \\
\hline 41 & 108 & 88 & 200 & 7.1 & 128 & 110 & 55 & 51 & 15.5 & 2.8 & 13.0 & 5.5 \\
\hline 26 & 68 & 89 & 330 & 7.8 & 175.6 & 150 & 72 & 76 & 24.0 & 2.2 & 15.0 & 8.4 \\
\hline 81 & 128 & 89 & 210 & 8 & 155.5 & 130 & 59 & 65 & 20.0 & 2.3 & 13.0 & 6.4 \\
\hline
\end{tabular}

Source: Queensland Water Resources Commission

Surface Water Resources Branch

Water Quality Data System 
Table A.1(a) Water Quality Records in the Fitzroy River Basin (continued)

Station 130003

\begin{tabular}{|c|c|c|c|c|c|c|c|c|c|c|c|c|}
\hline \multicolumn{3}{|c|}{$\begin{array}{l}\text { Dale } \\
\text { Sampled }\end{array}$} & $\begin{array}{c}\text { CONOUCTIVITY } \\
\text { (1) } 25 \mathrm{C} \\
(\mathrm{mS} / \mathrm{m}) \\
\end{array}$ & $\mathrm{PH}$ & $\begin{array}{c}\text { DISSOLVED } \\
\text { IONS } \\
\text { (mg//) }\end{array}$ & $\begin{array}{c}\text { DISSOLVED } \\
\text { SOLIDS } \\
\text { (mg/l) }\end{array}$ & $\begin{array}{l}\text { HARDNESS } \\
\text { (mgil)ias CACO3 }\end{array}$ & $\begin{array}{l}\text { ALKALINITY } \\
\text { (mg/l)as CaCO3 }\end{array}$ & $\begin{array}{l}\text { NATRIUM } \\
\text { (mg/l) }\end{array}$ & $\begin{array}{l}\text { KALIUM } \\
\text { (mgl) }\end{array}$ & $\begin{array}{l}\text { CALCIUM } \\
(\mathrm{mg} / \mathrm{l})\end{array}$ & $\begin{array}{l}\text { MAGNE SIUM } \\
(\mathrm{mg} /) \\
\end{array}$ \\
\hline \multicolumn{13}{|c|}{ (dd $\mathrm{mm} \quad \mathrm{yr}$ ) } \\
\hline 22 & 2 & 64 & 225 & 7.6 & 170.4 & 130 & 72 & 69 & 23.0 & 0.0 & 14.0 & 9.0 \\
\hline 246 & 6 & 64 & 246 & 7.3 & 197.1 & 140 & 89 & 75 & 25.0 & 0.0 & 16.0 & 12.0 \\
\hline 19 & 9 & 64 & 370 & 8 & 235.1 & 156 & 92 & 80 & 39.0 & 0.0 & 17.0 & 12.0 \\
\hline 241 & 11 & 64 & 274 & 7.7 & 215.5 & 162 & 111 & 113 & 16.0 & 0.0 & 28.0 & 10.0 \\
\hline 13 & 3 & 65 & 236 & 6.7 & 203.6 & 140 & 65 & 80 & 34.0 & 0.0 & 16.0 & 6.0 \\
\hline 54 & 4 & 65 & 255 & 7.6 & 199.3 & 140 & 112 & 105 & 12.0 & 0.0 & 20.0 & 15.0 \\
\hline $9 \quad 1$ & 12 & 65 & 100 & 7.5 & 104.2 & 0 & 62 & 50 & 6.0 & 0.0 & 10.0 & 9.0 \\
\hline 293 & 3 & 73 & 177 & 7.9 & 134 & 104 & 53 & 66 & 14.2 & 3.6 & 12.0 & 5.5 \\
\hline 267 & 7 & 73 & 190 & 7.8 & 147.2 & 114 & 62 & 66 & 16.0 & 5.5 & 15.7 & 5.6 \\
\hline 21 & 10 & 75 & 430 & 7.5 & 265.4 & 215 & 113 & 105 & 35.0 & 3.0 & 22.0 & 14.0 \\
\hline 68 & 8 & 76 & 790 & 7.9 & 483.2 & 416 & 224 & 135 & 70.0 & 1.8 & 45.0 & 27.0 \\
\hline 141 & 1 & 77 & 280 & 7.8 & 174.6 & 152 & 72 & 65 & 22.0 & 2.9 & 17.0 & 7.1 \\
\hline 224 & 4 & ל & 113 & 8 & 238.6 & 204 & 111 & 95 & 31.0 & 2.5 & 23.0 & 13.0 \\
\hline 257 & 7 & 77 & 450 & 8.2 & 309.8 & 257 & 128 & 112 & 40.0 & 3.0 & 25.0 & 16.0 \\
\hline 31 & 10 & 77 & 510 & 8.1 & 356.2 & 292 & 144 & 130 & 46.0 & 2.6 & 28.0 & 18.0 \\
\hline 4 & 1 & 87 & 405 & 8.1 & 284.2 & 235 & 115 & 102 & 38.0 & 4.0 & 23.0 & 14.0 \\
\hline 163 & 3 & 78 & 310 & 7.7 & 215 & 187 & 86 & 80 & 29.0 & 2.4 & 18.0 & 10.0 \\
\hline 86 & 6 & 78 & 545 & 8.2 & 366.9 & 318 & 157 & 112 & 51.0 & 3.0 & 30.0 & 20.0 \\
\hline 285 & 5 & 80 & 320 & 7.4 & 213.6 & 180 & 93 & 88 & 26.0 & 2.3 & 19.0 & 11.0 \\
\hline 238 & 9 & 80 & 330 & 7.6 & 224.6 & 177 & 89 & 89 & 28.0 & 2.2 & 19.0 & 10.0 \\
\hline 255 & 5 & 82 & 270 & 7.1 & 164.4 & 150 & 70 & 60 & 23.0 & 2.0 & 15.0 & 7.8 \\
\hline 200 & 8 & 82 & 290 & 7.6 & 186.1 & 150 & 73 & 67 & 29.0 & 1.8 & 15.0 & 8.7 \\
\hline 121 & 10 & 84 & 205 & 8.3 & 151.4 & 120 & 51 & 69 & 18.0 & 4.7 & 13.0 & 4.5 \\
\hline 123 & 3 & 85 & 245 & 7.7 & 173.6 & 140 & 68 & 76 & 20.0 & 4.7 & 15.0 & 7.4 \\
\hline 266 & 6 & 85 & 160 & 7.9 & 111.6 & 110 & 47 & 42 & 14.0 & 3.8 & 11.0 & 4.8 \\
\hline 21 & 12 & 85 & 160 & 7.6 & 108.2 & 110 & 46 & 46 & 12.0 & 3.0 & 10.0 & 5.0 \\
\hline 263 & 3 & 86 & 305 & 7.8 & 204.1 & 170 & 85 & 87 & 25.0 & 4.0 & 19.0 & 9.0 \\
\hline 256 & 6 & 86 & 390 & 7.9 & 268 & 210 & 108 & 104 & 35.0 & 5.2 & 22.0 & 13.0 \\
\hline 25 & 9 & 86 & 485 & 8 & 310.7 & 280 & 120 & 95 & 51.0 & 4.4 & 21.5 & 16.0 \\
\hline 6 & 1 & 87 & 230 & 7.8 & 156.3 & 130 & 60 & 65 & 20.0 & 4.4 & 14.0 & 6.1 \\
\hline 113 & 3 & 87 & 335 & 8 & 234.7 & 190 & 80 & 95 & 29.0 & 4.9 & 19.0 & 8.0 \\
\hline 256 & 6 & 87 & 300 & 7.5 & 192.5 & 160 & 73 & 68 & 29.0 & 3.9 & 16.0 & 8.1 \\
\hline 47 & 78 & 88 & 350 & 7.7 & 236.5 & 200 & 103 & 87 & 32.0 & 3.5 & 25.0 & 9.9 \\
\hline 101 & 11 & 88 & 390 & 7.4 & 239.2 & 200 & 102 & 76 & 32.0 & 4.4 & 19.5 & 13.0 \\
\hline 255 & 5 & 89 & 165 & 7.4 & 113.9 & 98 & 48 & 51 & 14.0 & 3.1 & 11.0 & 4.9 \\
\hline 265 & 5 & 89 & 175 & 7.7 & 122.2 & 100 & 52 & 54 & 16.0 & 3.8 & 12.0 & 5.3 \\
\hline 275 & 5 & 89 & 195 & 7.3 & 131.2 & 110 & 57 & 54 & 17.0 & 2.9 & 12.0 & 6.6 \\
\hline 315 & 5 & 89 & 150 & 7.1 & 102.9 & 96 & 42 & 40 & 15.0 & 3.4 & 9.0 & 4.7 \\
\hline 46 & 6 & 89 & 185 & 7.5 & 130.9 & 110 & 50 & 59 & 16.0 & 3.3 & 11.5 & 5.2 \\
\hline 66 & 6 & 89 & 190 & 7.5 & 135.9 & 110 & 53 & 60 & 16.5 & 3.1 & 12.0 & 5.7 \\
\hline
\end{tabular}

Source: Queensland Water Resources Commission

Surface Water Resources Branch

Water Quality Data System 
Table A.1 (b) Water Quality Records in the Nogoa River Basin

Station 130202

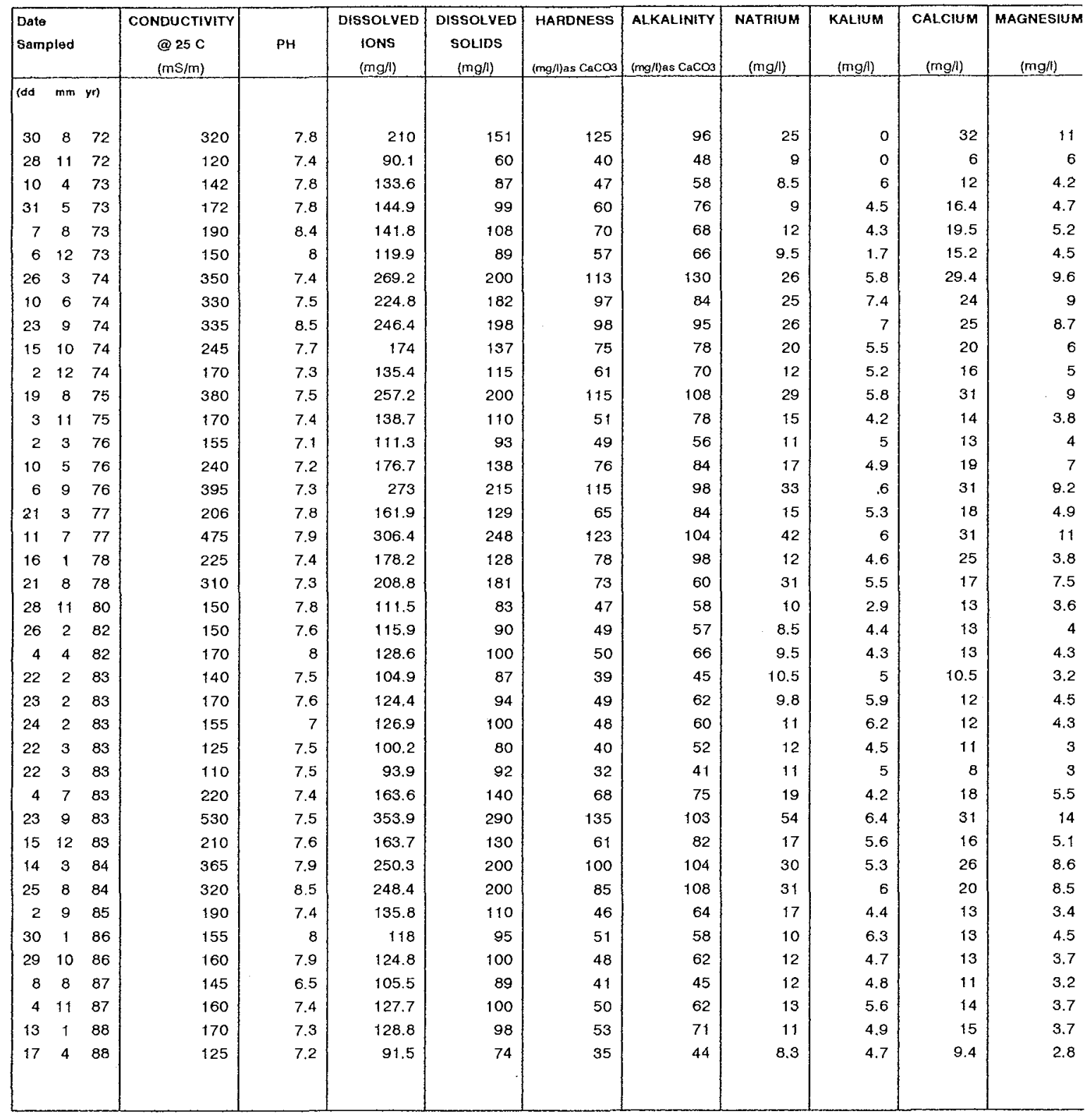

Source:

Queensland Water Resources Commission Surface Water Resources Branch

Water Quality Data System 
Table A.1 (b) Water Quality Records in the Nogoa River Basin (continued)

\section{Station 130212}

\begin{tabular}{|c|c|c|c|c|c|c|c|c|c|c|c|c|}
\hline \multicolumn{3}{|c|}{$\begin{array}{l}\text { Date } \\
\text { Sampled }\end{array}$} & $\begin{array}{c}\text { CONDUCTIVITY } \\
@ 25 \mathrm{C} \\
(\mathrm{mS} / \mathrm{m}) \\
\end{array}$ & \multirow[t]{2}{*}{$\mathrm{PH}$} & \multirow[t]{2}{*}{$\begin{array}{c}\text { DISSOLVED } \\
\text { IONS } \\
\text { (mg/l) } \\
\end{array}$} & \multirow[t]{2}{*}{$\begin{array}{c}\text { DISSOLVEO } \\
\text { SOLIDS } \\
(\mathrm{mg} / 1) \\
\end{array}$} & \multirow[t]{2}{*}{$\begin{array}{l}\text { HARDNESS } \\
\text { (mg/)as CaCO3 }\end{array}$} & \multirow[t]{2}{*}{$\begin{array}{l}\text { ALKALINITY } \\
\text { (mg/)as } \mathrm{CaCO} 3 \\
\end{array}$} & \multirow[t]{2}{*}{$\begin{array}{l}\text { NATRIUM } \\
(\mathrm{mg} / \mathrm{l}) \\
\end{array}$} & \multirow[t]{2}{*}{$\begin{array}{l}\text { KALIUA } \\
\text { (mg/l) }\end{array}$} & \multirow[t]{2}{*}{$\begin{array}{c}\text { CALCIUA } \\
\text { (mg/l) } \\
\end{array}$} & \multirow[t]{2}{*}{$\begin{array}{l}\text { MAGNESIUM } \\
\text { (mg/) }\end{array}$} \\
\hline (dd & $\mathrm{mm}$ & yr) & & & & & & & & & & \\
\hline 4 & 12 & 72 & 290 & 7.5 & 247.1 & 159 & 122 & 142 & 17 & 0 & 39 & 6 \\
\hline 24 & 2 & 73 & 140 & 7.2 & 114.6 & 76 & 44 & 62 & 15 & 0 & 6.4 & 6.8 \\
\hline 17 & 4 & 73 & 140 & 7.5 & 131.4 & 96 & 40 & 62 & 13 & 10 & 11 & 3 \\
\hline 20 & 9 & 73 & 150 & 7.5 & 137.1 & 95 & 51 & 70 & 14.6 & 5.3 & 14 & 4 \\
\hline 1 & 4 & 74 & 130 & 6.9 & 89.9 & 74 & 34 & 43 & 10 & 4.8 & 9 & 2.9 \\
\hline 17 & 10 & 74 & 115 & 7.3 & 93.7 & 81 & 46 & 40 & 10 & 3.7 & 13 & 3.2 \\
\hline 4 & 12 & 74 & 172 & 7.3 & 140.9 & 102 & 56 & 76 & 12 & 5.7 & 15.5 & 4.3 \\
\hline 30 & 1. & 75 & 100 & 7.3 & 76.5 & 71 & 47 & 42 & 0.8 & 3.6 & 13.5 & 3.1 \\
\hline 15 & 4 & 75 & 195 & 7.5 & 151 & 127 & 68 & 82 & 14 & 4.9 & 19 & 5 \\
\hline 121 & 12 & 75 & 120 & 7 & 91.1 & 75 & 38 & 52 & 8.6 & 3.1 & 11 & 2.6 \\
\hline 19 & 2 & 76 & 425 & 7.6 & 314.4 & 236 & 135 & 164 & 35 & 3.6 & 39 & 9 \\
\hline 29 & 6 & 76 & 520 & 7.6 & 386.6 & 275 & 171 & 188 & 42 & 3.6 & 52 & 10 \\
\hline 7 & 1 & 77 & 145 & 7.5 & 115.9 & 89 & 47 & 60 & 11 & 3.9 & 14 & 2.9 \\
\hline 7 & 3 & 77 & 145 & 7.6 & 118.2 & 94 & 51 & 60 & 11 & 4.7 & 15 & 3.2 \\
\hline 26 & 8 & 77 & 820 & 8.3 & 593.6 & 454 & 219 & 240 & 85 & 4.5 & 58 & 18 \\
\hline 20 & 10 & 77 & 855 & 7.9 & 562.2 & 437 & 182 & 209 & 103 & 5 & 40 & 20 \\
\hline 10 & 1 & 78 & 355 & 7.4 & 263.5 & 202 & 115 & 120 & 25 & 5.4 & 36 & 6 \\
\hline 14 & 3 & 78 & 370 & 7.5 & 260.5 & 201 & 102 & 124 & 33 & 3.6 & 29 & 7.2 \\
\hline 6 & 6 & 78 & 530 & 8 & 424.4 & 324 & 157 & 170 & 62 & 5.5 & 43 & 12 \\
\hline 27 & 7 & 78 & 155 & 7.3 & 137.1 & 108 & 55 & 64 & 17 & 3.2 & 15 & 4.2 \\
\hline 24 & 11 & 80 & 144 & 7.8 & 114.3 & 87 & 44 & 59 & 11 & 3.5 & 12 & 3.3 \\
\hline 6 & 1 & 81 & 120 & 7.2 & 118.6 & 104 & 55 & 41 & 8.8 & 9 & 10 & 7.2 \\
\hline 27 & 2 & 83 & 170 & 7.4 & 134.5 & 100 & 54 & 72 & 11 & 5.2 & 15 & 4 \\
\hline 30 & 7 & 83 & 255 & 7.5 & 208 & 170 & 90 & 107 & 22 & 3 & 26 & 6 \\
\hline 20 & 9 & 83 & 250 & 6.8 & 204.2 & 140 & 90 & 111 & 21 & 4.2 & 26 & 6 \\
\hline 18 & 12 & 83 & 210 & 8.3 & 190.6 & 180 & 78 & 96 & 14 & 5.9 & 21 & 6.3 \\
\hline 20 & 2 & 84 & 345 & 8.1 & 276.6 & 200 & 133 & 154 & 18 & 4 & 40 & 8.1 \\
\hline 26 & 8 & 84 & 150 & 6.9 & 115.5 & 94 & 46 & 63 & 11 & 3.6 & 13 & 3.2 \\
\hline 29 & 11 & 84 & 195 & 7.2 & 155.1 & 120 & 61 & 86 & 13 & 5 & 17 & 4.5 \\
\hline 30 & 11 & 85 & 125 & 7.7 & 97.2 & 80 & 37 & 51 & 9.5 & 4.5 & 10 & 2.8 \\
\hline 28 & 1 & 87 & 120 & 7.4 & 95.8 & 71 & 36 & 49 & 10 & 3.6 & 11 & 2 \\
\hline 4 & 11 & 87 & 185 & 7.3 & 154.5 & 110 & 65 & 86 & 14 & 5 & 19 & 4.2 \\
\hline 12 & 1 & 88 & 165 & 7.2 & 133.9 & 110 & 50 & 70 & 11 & 7.8 & 14 & 3.7 \\
\hline 27 & 3 & 88 & 180 & 7.2 & 141.7 & 100 & 59 & 80 & 11 & 4.4 & 17 & 4 \\
\hline
\end{tabular}

Source: Queensland Water Resources Commission

Surface Water Resources Branch

Water Quality Data System 
Table A.1(b) Water Quality Records in the Nogoa River Basin (continued)

Station 130209

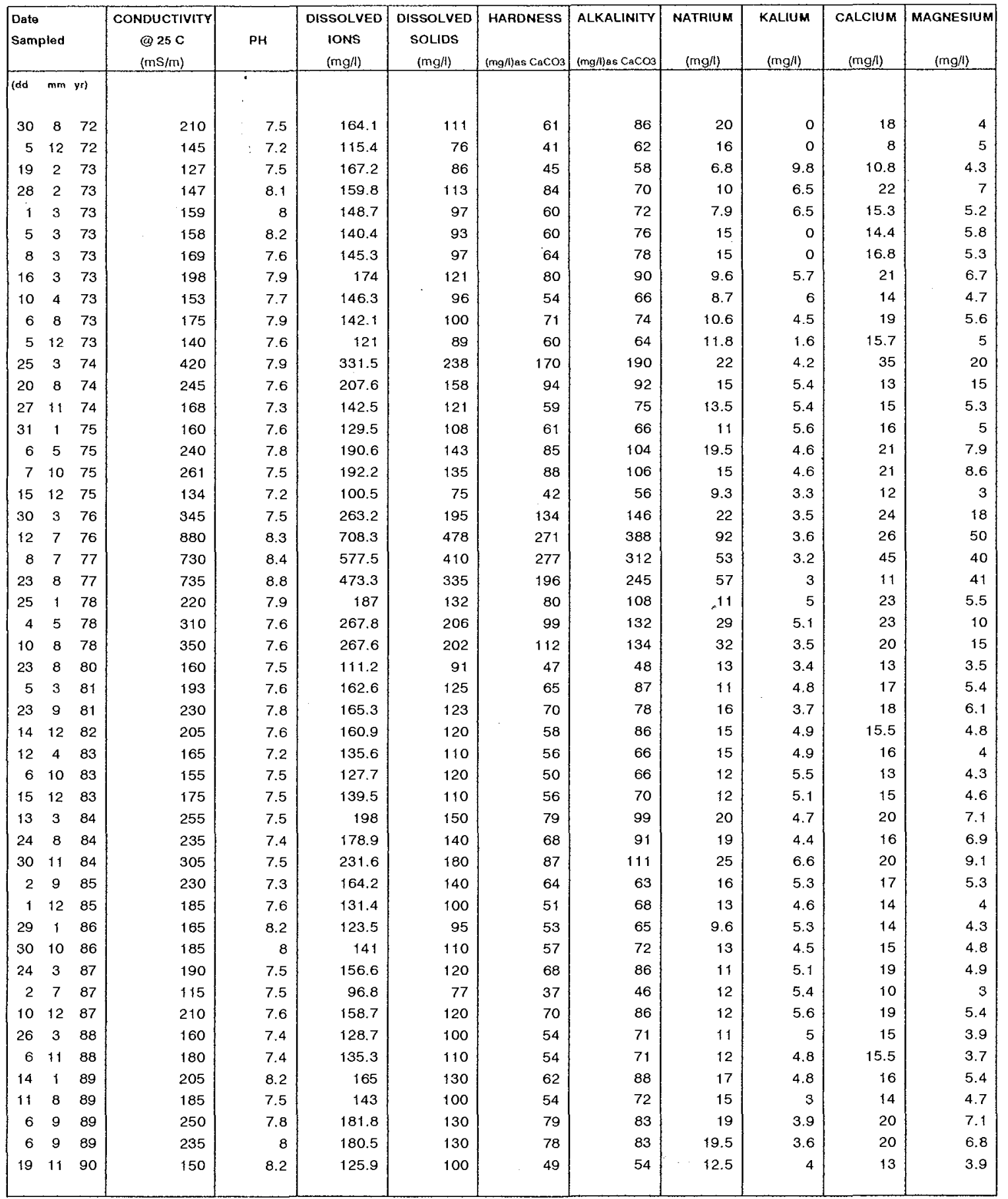

Source: Queensland Water Resources Commission

Surface Water Resources Branch

Water Quality Data System 
Table A.1(c) Water Quality Records in the Logan River Basin

Station 145010

\begin{tabular}{|c|c|c|c|c|c|c|c|c|c|c|c|c|}
\hline \multicolumn{3}{|c|}{\begin{tabular}{|l} 
Date \\
Sompiod
\end{tabular}} & $\begin{array}{c}\text { conoucriYtry } \\
25 c \\
\text { imSimi } \\
\end{array}$ & PH & \multirow[t]{2}{*}{$\begin{array}{c}\text { OISSOLYED } \\
\text { rOAS } \\
\text { Imall } \\
\end{array}$} & \multirow[t]{2}{*}{$\begin{array}{c}\text { Dis SOLVEO } \\
\text { SOUDS } \\
\text { (mgin) } \\
\end{array}$} & \multirow[t]{2}{*}{$\begin{array}{l}\text { MARONESS } \\
\text { (mg/h)as CaCOJ }\end{array}$} & \multirow[t]{2}{*}{$\begin{array}{l}\text { ALKALNATI } \\
\text { imglilies Cocos }\end{array}$} & \multirow[t]{2}{*}{$\begin{array}{l}\text { Nathivi } \\
\text { (mglin) }\end{array}$} & \multirow[t]{2}{*}{$\begin{array}{l}\text { KALLUM } \\
\text { (m) }\end{array}$} & \multirow[t]{2}{*}{$\begin{array}{l}\text { CALCiUn } \\
\text { (mogl) } \\
\end{array}$} & $\begin{array}{l}\text { maumesiv' } \\
\text { (mg,l) }\end{array}$ \\
\hline (dod & $\mathrm{mm}$ & $y r)$ & & & & & & & & & & \\
\hline 12 & 10 & 65 & 425 & 8 & 303.3 & 280 & 141 & 104 & 40 & 0 & 30 & 16 \\
\hline 16 & 2 & 66 & 460 & 8 & 318.9 & 255 & 166 & 117 & 33 & 0 & 41.6 & 15.1 \\
\hline 19 & 5 & 66 & 430 & 8.5 & 286.6 & 232 & 158 & 102 & 26 & 0 & 40,8 & 13.6 \\
\hline 251 & 10 & 66 & 483 & 8.2 & 352.1 & 290 & 167 & 129 & 44 & 0 & 34 & 20 \\
\hline 10 & 11 & 66 & 299 & 6.7 & 228.1 & 171 & 106 & 92 & 28 & 0 & 26 & 10 \\
\hline 28 & 9 & 67 & 750 & 7.5 & 521.2 & 409 & 279 & 180 & 54 & 0 & 54 & 35 \\
\hline 23 & 2 & 68 & 202 & 7.2 & 152.1 & 115 & 72 & 60 & 18 & 0 & 14 & 9 \\
\hline 23 & 4 & 68 & 340 & 7.4 & 225.1 & $\uparrow 72$ & 118 & 84 & 24 & 0 & 24 & 14 \\
\hline 11 & 10 & 68 & 530 & 7.2 & 346.1 & 268 & 242 & 125 & 14 & 0 & 36 & 37 \\
\hline 21 & 4 & 71 & 456 & 8.1 & 312.2 & 244 & 150 & 110 & 39 & 0 & 27 & 20 \\
\hline 18 & 6 & 71 & 530 & 7.9 & 446.1 & 354 & 232 & 148 & 51 & 0 & 40 & 32 \\
\hline 27 & 7 & 71 & 748 & 8 & 502 & 400 & 265 & 165 & 57 & 0 & 40 & 40 \\
\hline 28 & 9 & 71 & 830 & 8 & 535.4 & 419 & 289 & 188 & 52 & 0 & 48 & 41 \\
\hline 10 & $1 t$ & 71 & 865 & 7.5 & 552.4 & 436 & 302 & 188 & 58 & 0 & 50 & 43 \\
\hline 13 & 1 & 72 & 650 & 7.7 & 468.5 & 353 & 250 & 165 & 52 & 0 & 26 & 45 \\
\hline 9 & 3 & 72 & 180 & 7 & 148.4 & 107 & 72 & 66 & 16 & 0 & 14 & 9 \\
\hline 10 & 3 & 72 & 185 & 7.1 & 163.3 & 118 & 76 & 72 & 19 & 0 & 14 & 10 \\
\hline 21 & 6 & 72 & 310 & 7.9 & 202.1 & 157 & 125 & 72 & 15 & 0 & 22 & 17 \\
\hline 9 & 8 & 72 & 405 & 7.3 & 313.2 & 245 & 144 & 110 & 41 & 0 & 28 & 18 \\
\hline 11 & 10 & 72 & 530 & 7.4 & 364.1 & 286 & 199 & 125 & 37 & 0 & 40 & 24 \\
\hline 17 & 1 & 73 & 450 & 7.5 & 330.1 & 252 & 150 & 125 & 43 & 0 & 32 & 17 \\
\hline 8 & 3 & 73 & 194 & 7.8 & 132.1 & 100 & 60 & 52 & 17 & 0 & 11 & 8 \\
\hline 10 & 5 & 73 & 450 & 8.1 & 291.3 & 241 & 170 & 104 & 24.8 & 0.3 & 31.8 & 22 \\
\hline 10 & 7 & 73 & 155 & 7.5 & 113.4 & 102 & 56 & 42 & 11.5 & 1 & 7 & 9.4 \\
\hline 24 & 8 & 73 & 307 & 7.7 & $21 \theta .2$ & 189 & 122 & 80 & 21 & 0.5 & 20.5 & 17.1 \\
\hline 17 & 10 & 73 & 310 & 8.2 & 223.6 & 175 & 114 & 86 & 22 & 1.1 & 21 & 15 \\
\hline 28 & 3 & 74 & 256 & 8.2 & 191.3 & 168 & 94 & 75 & 20 & 1.1 & 16.6 & 12.8 \\
\hline 31 & 7 & 74 & 564 & 8 & 366.1 & 305 & 203 & 135 & 36 & 1 & 36 & 27.5 \\
\hline 11 & 9 & 74 & 655 & 8.1 & 406.5 & 336 & 227 & 150 & 40 & 2 & 40 & 30.8 \\
\hline 5 & 11 & 74 & 455 & 8.3 & 278.3 & 283 & 135 & 108 & 33 & 1.3 & 21 & 20 \\
\hline 14 & 2 & 78 & 360 & 7.8 & 219.4 & 196 & 116 & 87 & 24 & 1.2 & 20 & 16 \\
\hline 4 & 4 & 78 & 310 & 7.9 & 192.9 & 177 & 101 & 74 & 22 & 1.6 & 19 & 13 \\
\hline 12 & 4 & 78 & 370 & 7.5 & 220.3 & 200 & 118 & 76 & 24 & 1.4 & 21 & 16 \\
\hline 4 & 7 & 78 & 530 & 7.4 & 338.7 & 296 & 188 & 105 & 35 & 1.6 & 34 & 25 \\
\hline 26 & 9 & 78 & 560 & 7.7 & 402.3 & 333 & 208 & 148 & 40 & 1.6 & 37 & 28 \\
\hline 30 & 7 & 79 & 155 & 6.8 & 89.9 & 95 & 42 & 23 & 12 & 1.9 & 8.1 & 5.4 \\
\hline 30 & 7 & 79 & 140 & 6.7 & 93.7 & 93 & 42 & 26 & 15 & 1.9 & 7.7 & 5.6 \\
\hline 25 & 2 & 80 & 390 & 8 & 260.4 & 222 & 132 & 106 & 26 & 1.4 & 23 & 18 \\
\hline 15 & 5 & 80 & 150 & 7.8 & 97.2 & 96 & 45 & 35 & 11 & $0 . \theta$ & 8.2 & 6 \\
\hline 29 & 10 & 80 & 540 & 7.7 & 347.4 & 292 & 172 & 135 & 35 & 1.8 & 31 & 23 \\
\hline 2 & 6 & 81 & 380 & 7.8 & 244.3 & 212 & 87 & 86 & 39 & 1.9 & 15 & 12 \\
\hline 27 & 8 & 81 & 406 & 8.4 & 251.8 & 217 & 129 & 93 & 24 & 0.9 & 22 & 18 \\
\hline 12 & 1 & 82 & 480 & 8.2 & 336.2 & 280 & 166 & 142 & 33 & 1.5 & 30 & 22 \\
\hline 17 & 3 & 82 & 180 & 7.7 & 111.7 & 110 & 52 & 49 & 12 & 1 & 9.7 & 6.8 \\
\hline 17 & 8 & 82 & 540 & 8.2 & 336.3 & 280 & 180 & 126 & 35 & 1.1 & 31 & 25 \\
\hline 19 & 10 & 82 & 330 & 8.1 & 229.8 & 200 & 116 & 95 & 20 & 2 & 20 & 16 \\
\hline 18 & 1 & 83 & 315 & 7.6 & 208.2 & 180 & 101 & 91 & 22 & 1,6 & 16.5 & 14.5 \\
\hline 13 & 4 & 83 & 330 & 8.3 & 217.9 & 190 & 112 & 84 & 26 & 2.2 & 20 & 15 \\
\hline 15 & 6 & 83 & 330 & 8.3 & 214.8 & 180 & 109 & 88 & 25 & 0.9 & 19 & 15 \\
\hline 31 & 8 & 83 & 440 & 8.2 & 295.5 & 250 & 147 & 121 & 34 & 1 & 26 & 20 \\
\hline 1 & 11 & 83 & 610 & 7.9 & 414.2 & 340 & 205 & 166 & 40 & 1.6 & 36 & 28 \\
\hline 10 & 11 & 83 & 610 & 7.9 & 413.7 & 340 & 205 & 166 & 40 & 1.6 & 36 & 28 \\
\hline 19 & 1 & 84 & 305 & 7.9 & 206.8 & 180 & 98 & 91 & 21 & 1.2 & 18 & 13 \\
\hline 21 & 3 & 84 & 425 & 7.9 & 291.6 & 240 & 145 & 116 & 29 & 1 & 25 & 20 \\
\hline 9 & 4 & 84 & 115 & 7.5 & 81.7 & 83 & 34 & 31 & 9.1 & 1.6 & 6.4 & 4.3 \\
\hline 21 & 5 & 84 & 345 & 8.0 & 230.0 & 190 & 113 & 108 & 24 & 1.1 & 22 & 14 \\
\hline 22 & 8 & 84 & 480 & 8.2 & 343.8 & 280 & 171 & 138 & 34 & 1 & 29 & 24 \\
\hline
\end{tabular}

Source: Queensland Water Resources Commission

Surface Water Resources Branch

Water Quality Data System 
Station 145010 (continued)

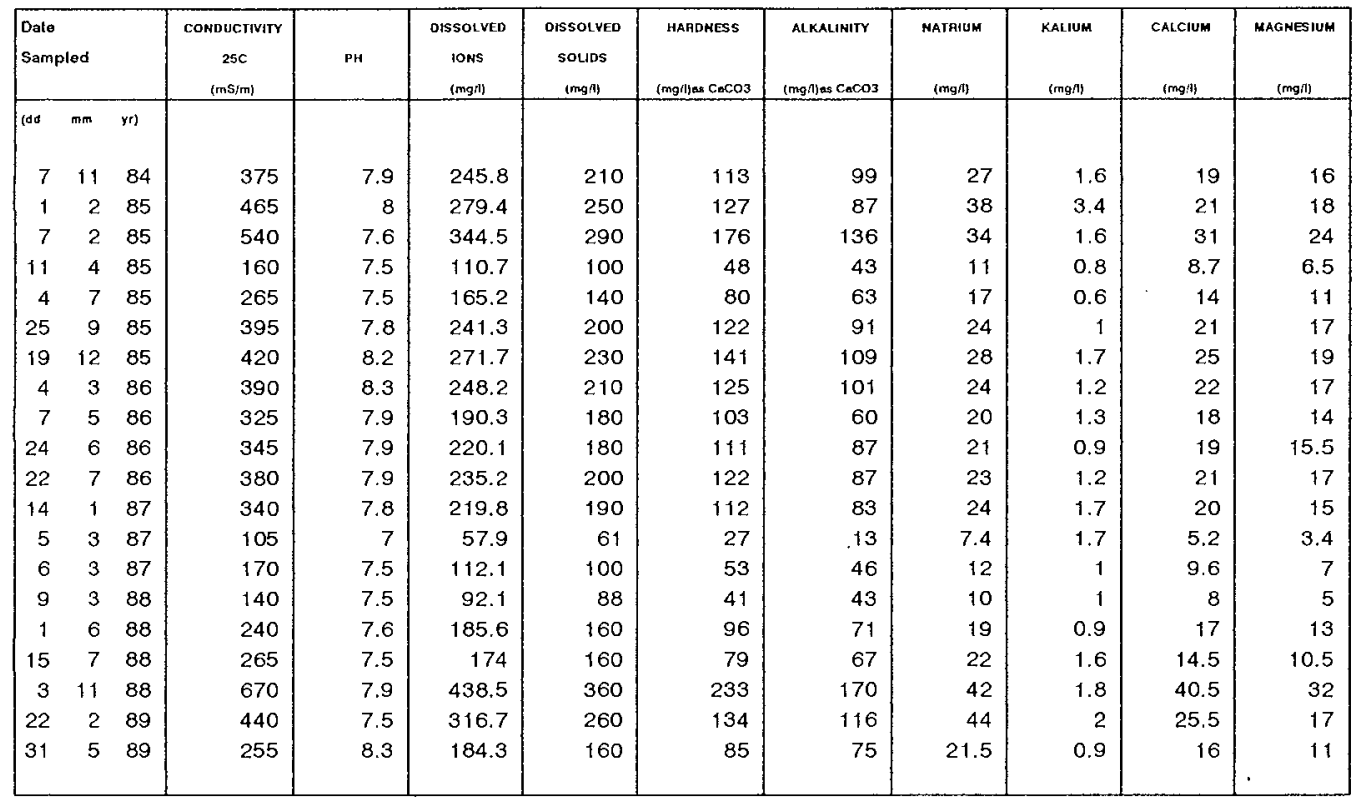

Source: Queensland Water Resources Commission Surface Water Resources Branch Water Quality Data System 
Table A.1(c) Water Quality Records in the Logan River Basin (continued)

\section{Station 145013}

\begin{tabular}{|c|c|c|c|c|c|c|c|c|c|c|c|c|}
\hline \multicolumn{3}{|c|}{$\begin{array}{l}\text { Date } \\
\text { Sampled }\end{array}$} & $\begin{array}{c}\text { CONDUCIIVITY } \\
25 \mathrm{C} \\
(\mathrm{mS} / \mathrm{m})\end{array}$ & \multirow[t]{2}{*}{$\mathrm{PH}$} & \multirow[t]{2}{*}{$\begin{array}{c}\text { DISSOLYED } \\
\text { IONS } \\
\text { (mg/) } \\
\end{array}$} & \multirow[t]{2}{*}{$\begin{array}{c}\text { OISSOLVED } \\
\text { SOLIOS } \\
\text { (mg/) } \\
\end{array}$} & \multirow[t]{2}{*}{$\begin{array}{c}\text { HARDNESS } \\
\text { (mg/)aS } \mathrm{C}_{\mathrm{BCO}}\end{array}$} & \multirow[t]{2}{*}{$\begin{array}{l}\text { ALKALINITY } \\
\text { (mg/)as } \mathrm{CaCO}\end{array}$} & \multirow[t]{2}{*}{$\begin{array}{l}\text { NATRIUM } \\
\text { (mg/i) } \\
\end{array}$} & \multirow[t]{2}{*}{$\begin{array}{l}\text { KALIUM } \\
\text { (ming/i) } \\
\end{array}$} & \multirow[t]{2}{*}{$\begin{array}{l}\text { CALCIUM } \\
\text { (mg/) }\end{array}$} & \multirow[t]{2}{*}{$\begin{array}{r}\text { MAGNESIUM } \\
\text { (mg/li) }\end{array}$} \\
\hline (dd & $\mathrm{mm}$ & yr) & & & & & & & & & & \\
\hline 5 & 11 & 68 & 820 & 7.8 & 582.2 & 427 & 308 & 250 & 54 & 0 & 54 & 42 \\
\hline 8 & 7 & 70 & 495 & 8 & 366.1 & 274 & 180 & 148 & 41 & 0 & 31 & 25 \\
\hline 17 & 6 & 71 & 800 & 7.8 & 705.2 & 533 & 370 & 244 & 78 & 0 & 64 & 51 \\
\hline 29 & 7 & 71 & 1040 & 8.7 & 733.1 & 578 & 379 & 250 & 84 & 0 & 61 & 55 \\
\hline 23 & 9 & 71 & 1000 & 7.9 & 652.2 & 509 & 349 & 230 & 69 & 0 & 54 & 52 \\
\hline 11 & 11 & 71 & 1075 & 7.8 & 749.3 & 563 & 386 & 300 & 78 & 0 & 64 & 55 \\
\hline 12 & 1 & 72 & 810 & 7.8 & 643.3 & 480 & 323 & 250 & 72 & 0 & 52 & 47 \\
\hline 10 & 3 & 72 & 200 & 7.3 & 158.3 & 117 & 68 & 66 & 21 & 0 & 14 & 8 \\
\hline 21 & 6 & 72 & 360 & 7.8 & 233.1 & 180 & 131 & 85 & 22 & 0 & 26 & 16 \\
\hline 9 & 8 & 72 & 620 & 7.8 & 490.1 & 381 & 229 & 175 & 63 & 0 & 44 & 29 \\
\hline 16 & 1 & 73 & 605 & 7.6 & 435.1 & 336 & 200 & 160 & 57 & 0 & 42 & 23 \\
\hline 8 & 3 & 73 & 350 & 7.8 & 236.1 & 177 & 111 & 94 & 28 & 0 & 28 & 10 \\
\hline 10 & 5 & 73 & 632 & 8.2 & 443 & 356 & 253 & 165 & 36.5 & 1.2 & 50 & 31 \\
\hline 22 & 6 & 73 & 695 & 8.2 & 504.8 & 409 & 311 & 185 & 40 & 1.5 & 42 & 50 \\
\hline 4 & 9 & 73 & 700 & 8 & 460.7 & 356 & 277 & 184 & 30 & 1.6 & 55 & 34 \\
\hline 17 & 10 & 73 & 520 & 7.9 & 368.2 & 305 & 189 & 145 & 40 & 1.9 & 36 & 24 \\
\hline 29 & 9 & 74 & 518 & 8.1 & 413.2 & 326 & 202 & 182 & 46 & 1.8 & 34.7 & 28 \\
\hline 10 & 9 & 74 & 986 & 8.3 & 652 & 525 & 336 & 255 & 64 & 2.8 & 62 & 44 \\
\hline 6 & 11 & 74 & 650 & 8 & 471.2 & 395 & 211 & 155 & 64 & 2.2 & 24 & 36.6 \\
\hline 16 & 12 & 77 & 760 & 8.6 & 523.3 & 416 & 286 & 245 & 49 & 1.5 & 52 & 38 \\
\hline 14 & 2 & 78 & 500 & 7.7 & 325.3 & 276 & 166 & 140 & 34 & 2 & 32 & 21 \\
\hline 26 & 4 & 78 & 645 & 8.1 & 431.7 & 362 & 217 & 162 & 47 & 2 & 39 & 29 \\
\hline 5 & 7 & 78 & 650 & 7.9 & 457.6 & 383 & 237 & 164 & 50 & 1.5 & 42 & 32 \\
\hline 1 & 8 & 79 & 450 & 8 & 266.7 & 261 & 130 & 100 & 29 & 2 & 24 & 17 \\
\hline 6 & 2 & 80 & 387 & 7.5 & 256 & 225 & 117 & 102 & 30 & 3.2 & 22 & 15 \\
\hline 26 & 2 & 80 & 373 & 7.7 & 239.2 & 208 & 117 & 98 & 26 & 1.5 & 22 & 15 \\
\hline 22 & 8 & 80 & 510 & 8 & 332.7 & 276 & 161 & 135 & 36 & 1.6 & 30 & 21 \\
\hline 30 & 10 & 80 & 740 & 7 & 507.3 & 407 & 248 & 220 & 52 & 2.5 & 48 & 31 \\
\hline 6 & 1 & 81 & 310 & 7.9 & 203.4 & 182 & 94 & 84 & 24 & 1.8 & 18 & 12 \\
\hline 18 & 3 & 81 & 430 & 7.7 & 270.2 & 231 & 127 & 110 & 29 & 1.7 & 23 & 17 \\
\hline 2 & 6 & 81 & 350 & 8.1 & 226.1 & 196 & 105 & 93 & 25 & 1.2 & 19 & 14 \\
\hline 26 & 8 & 81 & 640 & 8.5 & 405.5 & 343 & 201 & 153 & 43 & 0.8 & 36 & 27 \\
\hline 11 & 1 & 82 & 500 & 7.6 & 346.4 & 290 & 168 & 140 & 36 & 1.9 & 31 & 22 \\
\hline 11 & 1 & 82 & 580 & 7.9 & 212.8 & 350 & 204 & 23 & 45 & 1.5 & 37 & 27 \\
\hline 15 & 3 & 82 & 150 & 8 & 89.2 & 96 & 42 & 31 & 12 & 1.4 & 8.1 & 5.4 \\
\hline 16 & 8 & 82 & 640 & 8.2 & 427.3 & 350 & 222 & 172 & 45 & 1.6 & 41 & 29 \\
\hline 18 & 10 & 82 & 275 & 7.3 & 200.2 & 180 & 96 & 82 & 23 & 1.6 & 17 & 13 \\
\hline 17 & 1 & 83 & 325 & 7.7 & 220 & 0 & 100 & 99 & 23.5 & 1.9 & 18.5 & 13 \\
\hline 11 & 4 & 83 & 380 & 7.4 & 254.5 & 210 & 123 & 107 & 28 & 1.7 & 23 & 16 \\
\hline 14 & 6 & 83 & 425 & 7.8 & 283.2 & 230 & 141 & 124 & 31.5 & 1.4 & 25 & 19 \\
\hline 30 & 8 & 83 & 570 & 7.9 & 388.5 & 310 & 185 & 166 & 45 & 1.6 & 33 & 25 \\
\hline 11 & 11 & 83 & 770 & 7.9 & 490.3 & 410 & 213 & 149 & 68 & 3.2 & 39 & 28 \\
\hline 19 & 1 & 84 & 345 & 8.3 & 240.8 & 200 & 118 & 109 & 26 & 1.5 & 21 & 16 \\
\hline 21 & 3 & 84 & 640 & 8.1 & 436.7 & 360 & 219 & 184 & 45 & 1.8 & 40 & 29 \\
\hline 23 & 5 & 84 & 520 & 8.0 & 340.3 & 280 & 170 & 146 & 37 & 1.3 & 30 & 23 \\
\hline 22 & 8 & 84 & 680 & 8.0 & 511.9 & 400 & 243 & 220 & 52 & 1.9 & 43 & 33 \\
\hline 7 & 11 & 84 & 440 & 7.5 & 287.2 & 240 & 132 & 124 & 32 & 1.7 & 23 & 18 \\
\hline 7 & 2 & 85 & 670 & 8.4 & 460.4 & 370 & 222 & 208 & 44 & 2 & 41 & 29 \\
\hline 11 & 4 & 85 & 290 & 7.6 & 205.2 & 180 & 94 & 86 & 20 & 1.6 & 18 & 12 \\
\hline 12 & 4 & 85 & 1400 & 7.8 & 784.9 & 710 & 298 & 145 & 145 & 5.9 & 55 & 39 \\
\hline 4 & 7 & 85 & 350 & 7.9 & 240.5 & 200 & 119 & 104 & 24 & 1 & 23 & 15 \\
\hline
\end{tabular}

Source: Queensland Water Resources Commission

Surface Water Resources Branch

Water Quality Data System 


\section{Station 145013 (continued)}

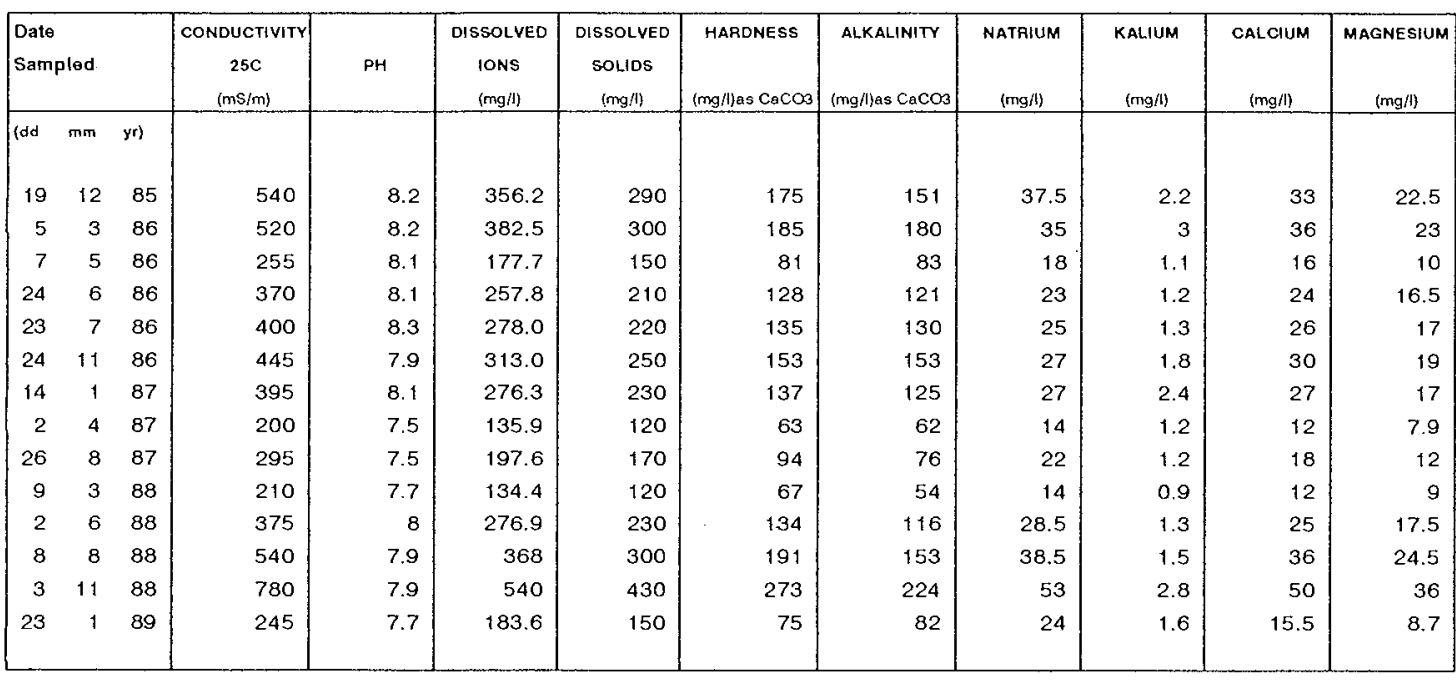

Source: Queensland Water Resources Commission Surface Water Resources Branch Water Quality Data System 
Table A.1(c) Water Quality Records in the Logan River Basin (continued)

Station 145008

\begin{tabular}{|c|c|c|c|c|c|c|c|c|c|c|c|}
\hline \multicolumn{2}{|c|}{$\begin{array}{l}\text { Date } \\
\text { Sampled }\end{array}$} & $\begin{array}{c}\text { CONDUCTIVITY } \\
25 \mathrm{C} \\
(\mathrm{mS} / \mathrm{m})\end{array}$ & $\mathrm{PH}$ & $\begin{array}{c}\text { DISSOLVED } \\
\text { IONS } \\
\text { (mg/h) }\end{array}$ & $\begin{array}{c}\text { DISSOLVED } \\
\text { SOLIDS } \\
\text { (mg/L) }\end{array}$ & $\begin{array}{c}\text { haRONESS } \\
\text { imgilisas CaCOS }\end{array}$ & $\begin{array}{c}\text { ALKaLINITY } \\
\text { (mgil)as CaCO3 } \\
\end{array}$ & $\begin{array}{l}\text { NATRIUM } \\
\text { (mg/L) } \\
\end{array}$ & $\begin{array}{l}\text { KALIUM } \\
(\mathrm{mg} / \mathrm{L}) \\
\end{array}$ & $\begin{array}{l}\text { CALCIUM } \\
\text { (mg/h) }\end{array}$ & $\begin{array}{c}\text { MAGNESIUM } \\
\text { (mg/) }\end{array}$ \\
\hline \multicolumn{12}{|c|}{ (dd $\mathrm{mm}$ yr) } \\
\hline 153 & 61 & 269 & 7.3 & 185.2 & 150 & 76 & 68 & 28 & 0 & 14 & 10 \\
\hline 283 & 63 & 292 & 7.5 & 190.3 & 175 & 68 & 70 & 32 & 0 & 14 & 8 \\
\hline 313 & 363 & 350 & 7.5 & 228.2 & 220 & 90 & 80 & 36 & 0 & 18 & 11 \\
\hline 301 & 64 & 880 & 7.6 & 610.1 & 520 & 265 & 200 & 92 & 0 & 50 & 34 \\
\hline 96 & 64 & 555 & 8.5 & 397.4 & 320 & 173 & 131 & 60 & 0 & 33 & 22 \\
\hline 89 & 364 & 880 & 8.1 & 613.1 & 520 & 282 & 195 & 86 & 0 & 60 & 32 \\
\hline 48 & 65 & 597 & 7.5 & 386.1 & 319 & 181 & 108 & 54 & 0 & 38 & 21 \\
\hline 131 & 66 & 590 & 8.3 & 377.7 & 311 & 188 & 124 & 48.5 & 0 & 48 & 16.5 \\
\hline 299 & 367 & 1050 & 7.9 & 730.3 & 579 & 370 & 244 & 88 & 0 & 69 & 48 \\
\hline $\begin{array}{ll}7 & 12\end{array}$ & 267 & 1030 & 7.6 & 725.3 & 581 & 340 & 230 & 101 & 0 & 62 & 45 \\
\hline $22 \quad 2$ & 68 & 377 & 7.1 & 280.2 & 217 & 121 & 102 & 40 & 0 & 32 & 10 \\
\hline 224 & 68 & 640 & 7.9 & 424.1 & 323 & 204 & 162 & 51 & 0 & 39 & 26 \\
\hline $10 \quad 10$ & 068 & 920 & 7.5 & 606.1 & 471 & 354 & 218 & 53 & 0 & 56 & 52 \\
\hline $5 \quad 11$ & 168 & 900 & 7.8 & 646.2 & 491 & 300 & 250 & 83 & 0 & 54 & 40 \\
\hline 89 & 70 & 630 & 7.7 & 413.2 & 320 & 209 & 150 & 48 & 0 & 36 & 29 \\
\hline 294 & 71 & 890 & 8 & 581.3 & 462 & 275 & 193 & 76 & 0 & 54 & 34 \\
\hline 297 & 71 & 1130 & 8.2 & 785.3 & 636 & 370 & 240 & 109 & 0 & 64 & 51 \\
\hline 168 & 71 & 1320 & 8.3 & 836.4 & 636 & 372 & 236 & 129 & 0 & 70 & 48 \\
\hline 239 & 71 & 1052 & 8 & 692.3 & 562 & 317 & 210 & 101 & 0 & 56 & 43 \\
\hline $11 \quad 11$ & 171 & 1275 & 8.1 & 868.3 & 682 & 408 & 300 & 115 & 0 & 76 & 53 \\
\hline 121 & 72 & 885 & 7.9 & 672.3 & 520 & 342 & 245 & 78 & 0 & 56 & 49 \\
\hline 83 & 72 & 300 & 7.2 & 238.3 & 185 & 123 & 85 & 27 & 0 & 18 & 19 \\
\hline $28 \quad 4$ & 472 & 530 & 7.4 & 392.1 & 315 & 121 & 124 & 78 & 0 & 32 & 10 \\
\hline 216 & 72 & 415 & 7.7 & 270.1 & 211 & 138 & 95 & 31 & 0 & 24 & 19 \\
\hline $12 \quad 10$ & 072 & 820 & 7.5 & 579.1 & 452 & 276 & 205 & 75 & 0 & 48 & 38 \\
\hline 161 & 73 & 625 & 7.5 & 412.2 & 344 & 138 & 110 & 81 & 0 & 34 & 13 \\
\hline 93 & 373 & 390 & 7.4 & 265.1 & 204 & 108 & 98 & 39 & 0 & 30 & 8 \\
\hline 105 & 73 & 820 & 8.1 & 537.9 & 442 & 269 & 175 & 64 & 1.3 & 55 & 32 \\
\hline 107 & 73 & 254 & 7.8 & 168.9 & 149 & 81 & 50 & 22,4 & 2.8 & 10 & 13.6 \\
\hline 49 & 73 & 800 & 8.4 & 477.7 & 413 & 241 & 164 & 68 & 1.6 & 47 & 30 \\
\hline 1510 & 073 & 520 & 7.6 & 342.8 & 289 & 155 & 115 & 50 & 2.3 & 29 & 20 \\
\hline 133 & 874 & 127 & 7 & 98.8 & 92 & 34 & 42 & 12.5 & 2.3 & 6.8 & 4.2 \\
\hline 307 & 74 & 1020 & 8.3 & 698.9 & 574 & 355 & 249 & 84 & 1.6 & 68 & 45 \\
\hline $\begin{array}{ll}6 & 11\end{array}$ & 174 & 450 & 8.7 & 259 & 229 & 89 & 70 & 50 & 2.4 & 12 & 14.4 \\
\hline 122 & 276 & 260 & 7.3 & 174.4 & 155 & 70 & 68 & 22 & 2.5 & 17 & 6.7 \\
\hline 122 & 76 & 230 & 7.4 & 147.8 & 139 & 58 & 54 & 22 & 2.3 & 13 & 6.1 \\
\hline $13 \quad 12$ & 277 & 600 & 8 & 369.2 & 298 & 169 & 150 & 50 & 2 & 33 & 21 \\
\hline 142 & 78 & 630 & 7.9 & 404.1 & 339 & 176 & 145 & 60 & 2.5 & 34 & 22 \\
\hline 264 & 78 & 780 & 7.9 & 486.8 & 417 & 220 & 150 & 69 & 2.5 & 42 & 28 \\
\hline 57 & 78 & 900 & 7.9 & 575.1 & 494 & 260 & 163 & 85 & 2.5 & 48 & 34 \\
\hline 262 & 80 & 540 & 8 & 358.7 & 298 & 160 & 140 & 43 & 2.5 & 31 & 20 \\
\hline 145 & 80 & 300 & 7.7 & 185.3 & 168 & 78 & 62 & 26 & 1.9 & 15 & 9.8 \\
\hline $30 \quad 10$ & 080 & 710 & 8.3 & 465.7 & 377 & 207 & 181 & 60 & 2.8 & 40 & 26 \\
\hline 51 & 81 & 340 & 7.6 & 208.4 & 184 & 88 & 76 & 28 & 2.1 & 17 & 11 \\
\hline 46 & 81 & 690 & 7.3 & 387.5 & 349 & 155 & 90 & 70 & 2.3 & 29 & 20 \\
\hline 268 & 81 & 854 & 8.7 & 535.9 & 447 & 235 & 181 & 75 & 1.5 & 43 & 31 \\
\hline 121 & 82 & 390 & 7.9 & 256.8 & 220 & 102 & 91 & 37 & 2.2 & 21 & 12 \\
\hline 156 & 82 & 480 & 7.9 & 308.7 & 260 & 138 & 116 & 41 & 1.9 & 26.5 & 17.5 \\
\hline 178 & 82 & 720 & 8.1 & 465.3 & 380 & 204 & 171 & 66 & 2 & 39 & 26 \\
\hline 1910 & 082 & 440 & 7.9 & 293.4 & 250 & 123 & 99 & 40 & 7 & 23 & 16 \\
\hline 171 & 83 & 485 & 8.2 & 316.9 & 270 & 133 & 117 & 47 & 2.5 & 24.5 & 17.5 \\
\hline
\end{tabular}

Source: Queensland Water Resources Commission Surface Water Resources Branch Water Quality Data System 
Station 145008 (continued)

\begin{tabular}{|c|c|c|c|c|c|c|c|c|c|c|c|c|}
\hline \multicolumn{3}{|c|}{$\begin{array}{l}\text { Date } \\
\text { Sampled }\end{array}$} & $\begin{array}{c}\text { CONDUCTIVITY } \\
25 \mathrm{C} \\
\text { (ms/m) }\end{array}$ & PH & $\begin{array}{c}\text { DISSOLVED } \\
\text { IONS } \\
\text { (mg/h) }\end{array}$ & $\begin{array}{c}\text { DISSOLVED } \\
\text { SOLIOS } \\
(\mathrm{mg} / \mathrm{L})\end{array}$ & $\begin{array}{l}\text { HARDNESS } \\
\text { (mg/L)as CaCO3 }\end{array}$ & $\begin{array}{l}\text { ALKALINITY } \\
\text { (mg/L)as CaCO3 }\end{array}$ & $\begin{array}{l}\text { NATFlUM } \\
\text { (mg/L) }\end{array}$ & $\begin{array}{l}\text { KaLIUM } \\
\text { (mmg/L) }\end{array}$ & $\begin{array}{l}\text { CALCIUM } \\
\text { (mg/L) }\end{array}$ & $\begin{array}{c}\text { MAGNESIUM } \\
\text { (mg/L) }\end{array}$ \\
\hline \multicolumn{13}{|c|}{ (dd $\mathrm{mm} \quad \mathrm{yr}$ ) } \\
\hline 12 & 48 & 83 & 475 & 7.7 & 298.4 & 250 & 135 & 103 & 44 & 1.9 & 26 & 17 \\
\hline 15 & 6 & 83 & 480 & 7.9 & 308.8 & 260 & 138 & 116 & 41 & 1.9 & 26.5 & 17.5 \\
\hline 1 & $8 \varepsilon$ & 83 & 650 & 7.9 & 418.7 & 350 & 181 & 153 & 61 & 2.1 & 33 & 24 \\
\hline 23 & 38 & 84 & 630 & 8.2 & 407.8 & 340 & 184 & 155 & 51 & 1.8 & 34 & 24 \\
\hline 25 & 5 & 84 & 650 & 7.9 & 402.0 & 330 & 188 & 149 & 52 & 1.5 & 34 & 25 \\
\hline 22 & 8 & 84 & 730 & 8.3 & 522.5 & 430 & 228 & 194 & 68 & 2.1 & 42 & 30 \\
\hline 161 & 118 & 84 & 520 & 7.7 & 338.5 & 290 & 143 & 128 & 48 & 3.5 & 26 & 19 \\
\hline 6 & 28 & 85 & 670 & 7.6 & 443.9 & 360 & 195 & 173 & 54 & 2.4 & 37 & 25 \\
\hline 11 & 4 & 85 & 335 & 7.6 & 221.8 & 190 & 92 & 82 & 28 & 1.7 & 17 & 12 \\
\hline 5 & 78 & 85 & 450 & 8 & 270.5 & 230 & 123 & 100 & 35 & 1.2 & 23 & 1 \\
\hline 171 & 12 & 85 & 395 & 7.6 & 239.4 & 210 & 101 & 80 & 37 & 2 & 19 & 13 \\
\hline 5 & 38 & 86 & 465 & 8.3 & 292.1 & 240 & 122 & 105 & 41 & 2.4 & 24 & 15 \\
\hline 6 & 5 & 86 & 430 & 8.1 & 297 & 240 & 135 & 125 & 32 & 1.7 & 26 & 17 \\
\hline 24 & 6 & 86 & 600 & 8.2 & 401.3 & 320 & 191 & 159 & 44.5 & 1.8 & 37 & 24 \\
\hline 17 & 7 & 86 & 590 & 8.4 & 396.5 & 310 & 180 & 157 & 44 & 2.1 & 34 & 23 \\
\hline 7 & 8 & 86 & 460 & 7.9 & 292.3 & 240 & 126 & 104 & 40 & 1.8 & 24 & 16 \\
\hline 21 & 10 & 86 & 500 & 7.1 & 313.7 & 270 & 102 & 94 & 60 & 1 & 21 & 12 \\
\hline 3 & 108 & 86 & 340 & 6.9 & 200 & 180 & 69 & 49 & 39 & 3.5 & 14 & 8.2 \\
\hline 11 & 12 & 86 & 420 & 8 & 275.7 & 230 & 128 & 108 & 39 & 2.1 & 25 & 16 \\
\hline 5 & 1 & 87 & 250 & 7.5 & 136.8 & 130 & 46 & 37 & 24 & 2.8 & 9.7 & 5.4 \\
\hline 2 & 4 & 87 & 250 & 7.8 & 133.1 & 140 & 70 & 65 & 21 & 1.5 & 14 & 8.4 \\
\hline 29 & 4 & 87 & 210 & 7.5 & 136.5 & 120 & 59 & 54 & 17 & 1.2 & 12 & 7.1 \\
\hline 23 & 2 & 88 & 275 & 8 & 173.4 & 150 & 79 & 69 & 23 & 1.4 & 15 & 10 \\
\hline 11 & 8 & 88 & 730 & 8.5 & 476.5 & 390 & 214 & 166 & 67 & 2 & 42 & 26.5 \\
\hline $31 \quad 1$ & 108 & 88 & 910 & 7.5 & 611,1 & 500 & 281 & 224 & 76 & 3.1 & 53 & 36 \\
\hline 3 & 4 & 89 & 480 & 8.5 & 323.2 & 280 & 146 & 107 & 45.5 & 2,3 & 20.5 & 23 \\
\hline
\end{tabular}

Source: Queensland Water Resources Commission

Surface Water Resources Branch

Water Quality Data System 
Table A.2(a) Annual Mean Values of the Water Quality Parameters from the Fitzroy River Basin

\section{Station 130322}

\begin{tabular}{|c|c|c|c|c|c|c|c|c|c|c|}
\hline YEAR & $\begin{array}{c}\text { CONDUCTIVITY } \\
\text { @ 25C } \\
(\mathrm{mS} / \mathrm{m})\end{array}$ & $\mathrm{PH}$ & $\begin{array}{c}\text { DISSOLVED } \\
\text { IONS } \\
\text { (mg/) }\end{array}$ & $\begin{array}{c}\text { DISSOLVED } \\
\text { SOLIDS } \\
\text { (mmgll) }\end{array}$ & $\begin{array}{l}\text { HARDNESS } \\
\text { (mg/) as CaCO3 }\end{array}$ & $\begin{array}{l}\text { ALKALINITY } \\
\text { (mg/i) as CaCO3 }\end{array}$ & $\begin{array}{l}\text { NATRIUM } \\
\text { (mg/) }\end{array}$ & $(\mathrm{mg} / \mathrm{l})$ & $\begin{array}{l}\text { CALCIUM } \\
\text { (mg/l) }\end{array}$ & $\begin{array}{l}\text { MAGNESIUM } \\
\text { (mg/l) }\end{array}$ \\
\hline 64 & 200.0 & 7.3 & 176.2 & 124.0 & 65.0 & 72.0 & 26.5 & 0.0 & 16.0 & 6.0 \\
\hline 65 & 405.0 & 8.0 & 279.2 & 274.0 & 84.0 & 100.0 & 54.0 & 0.0 & 24.0 & 5.8 \\
\hline 66 & 215,0 & 8.1 & 191.2 & 128.5 & 75.0 & 92.0 & 25.5 & 0.0 & 20.0 & 6.0 \\
\hline 67 & 206.5 & 7.9 & 204.1 & 133.0 & 69.5 & 90.0 & 36.3 & 0.0 & 15.0 & 6.0 \\
\hline 68 & 70.0 & 8.0 & 64.0 & 0.0 & 12.0 & 24.0 & 15.0 & 0.0 & 3.0 & 1.0 \\
\hline 69 & 260.0 & 6.9 & 191.8 & 0.0 & 68.3 & 88.3 & 28.3 & 0.0 & 19.3 & 4.8 \\
\hline 70 & 128.0 & 6.9 & 102.3 & 0.0 & 38.9 & 51.5 & 13.3 & 0.0 & 10.0 & 3.4 \\
\hline 71 & 171.6 & 7.7 & 195.4 & 0.0 & 66.4 & 68.4 & 35.4 & 0.0 & 14.4 & 7.4 \\
\hline 73 & 257.5 & 8.0 & 173.3 & 133.5 & 61.5 & 85.0 & 21.2 & 6.2 & 16.0 & 5.3 \\
\hline 74 & 197.5 & 7.7 & 140.9 & 116.5 & 47.0 & 60.0 & 20.0 & 5.7 & 11.5 & 4.5 \\
\hline 75 & 145.0 & 7.1 & 111.6 & 92.0 & 51.0 & 54.0 & 12.0 & 5.1 & 12.5 & 4.7 \\
\hline 76 & 190.0 & 7.5 & 142.2 & 115.0 & 50.7 & 62.3 & 17.7 & 5.8 & 13.3 & 4.2 \\
\hline 77 & 145.0 & 7.8 & 106.4 & 87.0 & 37.0 & 46.0 & 13.4 & 5.1 & 9.2 & 3.4 \\
\hline 78 & 190.0 & 7.4 & 146.3 & 122.0 & 49.0 & 66.0 & 18.0 & 5.5 & 12.0 & 4.5 \\
\hline 81 & 185.0 & 7.5 & 141.2 & 110.0 & 57.0 & 71.0 & 12.0 & 5.0 & 18.0 & 3.0 \\
\hline 84 & 240.0 & 7.8 & 179.1 & 156.7 & 62.7 & 79.0 & 24.3 & 5.8 & 15.7 & 5.7 \\
\hline 85 & 245.0 & 7.7 & 178.0 & 150.0 & 61.0 & 77.0 & 21.5 & 6.4 & 15.0 & 5.7 \\
\hline 86 & 217.5 & 7.6 & 149.0 & 125.0 & $5 \nmid .0$ & 63.5 & 21.3 & 5.0 & 12.8 & 4.7 \\
\hline 87 & 222.5 & 7.9 & 159.8 & 125.0 & 57.5 & 73.5 & 19.5 & 4.9 & 14.0 & 5.6 \\
\hline 88 & 195.0 & 7.6 & 144.6 & 110.0 & 51.5 & 72.0 & 15.8 & 5.7 & 13.0 & 4.6 \\
\hline 89 & 248.8 & 7.6 & 175.3 & 137.5 & 66.5 & 77.3 & 23.0 & 4.8 & 17.0 & 5.8 \\
\hline
\end{tabular}

\section{Station 130105}

\begin{tabular}{|c|c|c|c|c|c|c|c|c|c|c|}
\hline YEAR & $\left\{\begin{array}{c}\text { CONDUCTIVITY } \\
@ 25 \mathrm{C} \\
(\mathrm{mS} / \mathrm{m})\end{array}\right.$ & $\mathrm{PH}$ & $\begin{array}{c}\text { DISSOLVED } \\
\text { IONS } \\
\text { (mg/l) }\end{array}$ & $\begin{array}{c}\text { DISSOLVED } \\
\text { SOLIOS } \\
\text { (mg/i) }\end{array}$ & $\begin{array}{l}\text { MARDNESS } \\
\text { (mg/)as } \mathrm{CaCO} 3\end{array}$ & $\begin{array}{l}\text { ALKALINITY } \\
\text { (mg/)as } \mathrm{CaCO} 3\end{array}$ & $\begin{array}{l}\text { NATRIUM } \\
\text { (mg/l) }\end{array}$ & $\begin{array}{l}\text { KALIUM } \\
\text { (mg/l) }\end{array}$ & $\begin{array}{c}\text { CALCIUM } \\
\text { (mg/l) }\end{array}$ & $\begin{array}{l}\text { MAGNESIUM } \\
\text { (mig/l) }\end{array}$ \\
\hline 72 & 290.0 & 7.7 & 199.7 & 148.5 & 80.5 & 82.0 & 29.0 & & 17.5 & 9.0 \\
\hline 73 & 215.0 & 7.8 & $\$ 59.6$ & 135.8 & 61.8 & 64.0 & 18.2 & 2.4 & 13.1 & 7.1 \\
\hline 74 & 350.0 & 7.6 & 233.5 & 194.0 & 97.0 & 90.7 & 29.3 & 2.2 & 19.3 & 11.8 \\
\hline 75 & 235.0 & 7.5 & 158.4 & 133.7 & 63.7 & 68.5 & 16.3 & 3.2 & 13.4 & 6.8 \\
\hline 76 & 516.7 & 8.1 & 336.2 & 274.0 & 150.3 & 128.0 & 45.3 & 2.6 & 32.7 & 16.7 \\
\hline 77 & 360.0 & 8.0 & 248.6 & 204.0 & 102.3 & 106.0 & 29.8 & 2.3 & 22.3 & 10.6 \\
\hline 78 & 367.5 & 8.0 & 258.2 & 207.5 & 110.5 & 105.5 & 32.5 & 3.4 & 23.5 & 12.5 \\
\hline 80 & 411.7 & 7.5 & 255.8 & 220.0 & 107.7 & 86.7 & 38.3 & 1.8 & 21.7 & 13.0 \\
\hline 81 & 248.0 & 7.7 & 176.7 & 139.0 & 71.0 & 85.0 & 18.0 & 3.1 & 15.0 & 8.1 \\
\hline 82 & 260.0 & 7.9 & 167.0 & 150.0 & 63.0 & 61.0 & 27.0 & 1.7 & 13.0 & 7.5 \\
\hline 84 & 226.3 & 7.5 & 161.0 & 130.0 & 64.0 & 71.8 & 19.3 & 3.8 & 14.5 & 6.8 \\
\hline 85 & 235.0 & 7.7 & 161.0 & 140.0 & 61.5 & 66.0 & 20.0 & 3.9 & 14.0 & 6.4 \\
\hline 86 & 255.0 & 8.2 & 187.9 & 146.7 & 80.7 & 88.7 & 20.0 & 3.8 & 18.0 & 8.7 \\
\hline 87 & 210.0 & 7.7 & 183.9 & 123.0 & 61.0 & 69.0 & 15.8 & 4.0 & 14.3 & 6.1 \\
\hline 88 & 200.0 & 7.1 & 128.0 & 110.0 & 55.0 & 51.0 & 15.5 & 2.8 & 13.0 & 5.5 \\
\hline 89 & 270.0 & 7.9 & 165.6 & 140.0 & 65.5 & 70.5 & 22.0 & 2.5 & 14.0 & 7.4 \\
\hline
\end{tabular}


Table A.2(a) Annual Mean Values of the Water Quality Parameters from the Fitzroy River Basin (continued)

\section{Station 130003}

\begin{tabular}{|c|c|c|c|c|c|c|c|c|c|c|}
\hline YEAR & $\begin{array}{c}\text { CONDUCTIVITY } \\
\text { @25C } \\
\text { (nTS/m) }\end{array}$ & PH & $\begin{array}{c}\text { DISSOLVED } \\
\text { IONS } \\
\text { (mg/l) }\end{array}$ & $\begin{array}{c}\text { DISSOLVED } \\
\text { SOLIDS } \\
(\mathrm{mg} /)\end{array}$ & $\begin{array}{l}\text { HARDNESS } \\
\text { (ma/)as CaCO3 }\end{array}$ & $\begin{array}{l}\text { ALKALINITY } \\
\text { (mg/)as CaCO3 }\end{array}$ & NATRIUM & $(\mathrm{mg} / 1)$ & $\begin{array}{l}\text { CALCIUM } \\
\text { (ng } /) \\
\end{array}$ & MAGNESIUM \\
\hline 64 & 278.8 & 7.7 & 204.5 & 147.0 & 91.0 & 84.3 & 25.8 & 0.0 & 18.8 & 10.8 \\
\hline 65 & 197.0 & 7.3 & 169.0 & 140.0 & 79.7 & 78.3 & 17.3 & 0.0 & 15.3 & 10.0 \\
\hline 73 & 183.5 & 7.9 & 140.6 & 109.0 & 57.5 & 66.0 & 15.1 & 4.6 & 13.9 & 5.6 \\
\hline 75 & 430.0 & 7.5 & 265.4 & 215.0 & 113.0 & 105.0 & 35.0 & 3.0 & 22.0 & 14.0 \\
\hline 76 & 790.0 & 7.9 & 483.2 & 416.0 & 224.0 & 135.0 & 70.0 & 1.8 & 45.0 & 27.0 \\
\hline 77 & 338.3 & 8.0 & 269.8 & 226.3 & 113.8 & 100.5 & 34.8 & 2.8 & 23.3 & 13.5 \\
\hline 78 & 420.0 & 8.0 & 288.7 & 246.7 & 119.3 & 98.0 & 39.3 & 3.1 & 23.7 & 14.7 \\
\hline 80 & 325.0 & 7.5 & 219.1 & 178.5 & 91.0 & 88.5 & 27.0 & 2.3 & 19.0 & 10.5 \\
\hline 82 & 280.0 & 7.4 & 175.3 & 150.0 & 71.5 & 63.5 & 26.0 & 1.9 & 15.0 & 8.3 \\
\hline 84 & 205.0 & 8.3 & 151.4 & 120.0 & 51.0 & 69.0 & 18.0 & 4.7 & 13.0 & 4.5 \\
\hline 85 & 188.3 & 7.7 & 131.1 & 120.0 & 53.7 & 54.7 & 15.3 & 3.8 & 12.0 & 5.7 \\
\hline 86 & 393.3 & 7.9 & 260.9 & 220.0 & 104.3 & 95,3 & 37.0 & 4.5 & 20,8 & 12.7 \\
\hline 87 & 288.3 & 7.8 & 194.5 & 160.0 & 71.0 & 76.0 & 26.0 & 4.4 & 16.3 & 7.4 \\
\hline 88 & 370.0 & 7.6 & 237.9 & 200.0 & 102.5 & 81.5 & 32.0 & 4.0 & 22.3 & 11.5 \\
\hline 89 & 176.7 & 7.4 & 122.8 & 104.0 & 50.3 & 53.0 & 15.8 & 3.3 & 11.3 & 5.4 \\
\hline
\end{tabular}


Table A.2(b) Annual Mean Values of the Water Quality Parameters from the Nogoa River Basin

\section{Station 130202}

\begin{tabular}{|c|c|c|c|c|c|c|c|c|c|c|}
\hline YEAR & $\begin{array}{c}\text { CONDUCTIVITY } \\
\text { @ } 25 \mathrm{C} \\
(\mathrm{ms} / \mathrm{m})\end{array}$ & $\mathrm{PH}$ & $\begin{array}{c}\text { DISSOLVED } \\
\text { IONS } \\
\text { (mg!l) }\end{array}$ & $\begin{array}{c}\text { DISSOLVED } \\
\text { SOLIDS } \\
\text { (mg } n)\end{array}$ & $\begin{array}{l}\text { HARONESS } \\
\text { (migl)as } \mathrm{CaCO} 3\end{array}$ & $\begin{array}{l}\text { ALKALIN|TY } \\
\text { (mggl)as CaCO3 }\end{array}$ & $\begin{array}{l}\text { NATRIUM } \\
\text { (mg/) }\end{array}$ & $\begin{array}{l}\text { KALIUM } \\
\text { (mgg/) } \\
\end{array}$ & $\begin{array}{l}\text { CALCIUM } \\
\text { (mg/l) }\end{array}$ & $\begin{array}{c}\text { MAGNESIUM } \\
(\mathrm{mg} / \mathrm{l}) \\
\end{array}$ \\
\hline 72 & 220.0 & 7.6 & 150.1 & 105.5 & 82.5 & 72.0 & 17.0 & - & 19.0 & 8.5 \\
\hline 73 & 163.5 & 8.0 & 135.1 & 95.8 & 58.5 & 67.0 & 9.8 & 4.1 & 15.8 & 4.7 \\
\hline 74 & 286.0 & 7.7 & 210.0 & 166.4 & 88.8 & 91.4 & 21.8 & 6.2 & 22.9 & 7.7 \\
\hline 75 & 275.0 & 7.5 & 198.0 & 155.0 & 83.0 & 93.0 & 22.0 & 5.0 & 22.5 & 6.4 \\
\hline 76 & 263.3 & 7.2 & 187.0 & 148.7 & 80.0 & 79.3 & 20.3 & 5.3 & 21.0 & 6.7 \\
\hline 77 & 340.5 & 7.9 & 234.2 & 188.5 & 94.0 & 94.0 & 28.5 & 5.7 & 24.5 & 8.0 \\
\hline 78 & 267.5 & 7.4 & 193.5 & 154.5 & 75.5 & 79.0 & 21.5 & 5.1 & 21.0 & 5.7 \\
\hline 80 & 150.0 & 7.8 & 111.5 & 83.0 & 47.0 & 58.0 & 10.0 & 2.9 & 13.0 & 3.6 \\
\hline 82 & 160.0 & 7.8 & 122.3 & 95.0 & 49.5 & 61.5 & 9.0 & 4.4 & 13.0 & 4.2 \\
\hline 83 & 246.5 & 7.5 & 179.4 & 147.9 & 69.1 & 72.4 & 22.4 & 5.3 & 17.2 & 6.3 \\
\hline 84 & 342.5 & 8.2 & 249.4 & 200.0 & 92.5 & 106.0 & 30.5 & 5.7 & 23.0 & 8.6 \\
\hline 85 & 190.0 & 7.4 & 135.8 & 110.0 & 46.0 & 64.0 & 17.0 & 4.4 & 13.0 & 3.4 \\
\hline 86 & 157.5 & 8.0 & 121.4 & 97.5 & 49.5 & 60.0 & 11.0 & 5.5 & 13.0 & 4.1 \\
\hline 87 & 152.5 & 7.0 & 116.6 & 94.5 & 45.5 & 53.5 & 12.5 & 5.2 & 12.5 & 3.5 \\
\hline 88 & 147.5 & 7.3 & 110.2 & 86.0 & 44.0 & 57.5 & 9.7 & 4.8 & 12.2 & 3.3 \\
\hline
\end{tabular}

\section{Station 130212}

\begin{tabular}{|c|c|c|c|c|c|c|c|c|c|c|}
\hline YEAR & $\begin{array}{c}\text { CONDUCTIVITY } \\
\text { (@25C } \\
\text { (ms/m) }\end{array}$ & $\mathrm{PH}$ & $\begin{array}{c}\text { DISSOLVED } \\
\text { IONS } \\
\text { (mg/l) }\end{array}$ & $\begin{array}{c}\text { DISSOLVED } \\
\text { SOLIDS } \\
\text { (mg/l) }\end{array}$ & $\begin{array}{l}\text { HARDNESS } \\
\text { (mgil)as } \mathrm{CaCO} 3\end{array}$ & $\begin{array}{l}\text { ALKALINITY } \\
\text { (mgg/)as CaCO3 }\end{array}$ & $\begin{array}{c}\text { NATRIUM } \\
\text { (mg/) }\end{array}$ & (mg/l) & $\begin{array}{l}\text { CALCIUM } \\
(\mathrm{mg} / 1)\end{array}$ & MAGNESIUM \\
\hline 72 & 290.0 & 7.5 & 247.1 & 159.0 & 122.0 & 142.0 & 17.0 & - & 39,0 & 6.0 \\
\hline 73 & 143.3 & 7.4 & 127.7 & 89.0 & 45.0 & 64.7 & 14.2 & 5.1 & 10.5 & 4.6 \\
\hline 74 & 139.0 & 7.2 & 108.2 & 85.7 & 45.3 & 53.0 & 10.7 & 4.7 & 12.5 & 3.5 \\
\hline 75 & 138.3 & 7.3 & 106.2 & 91.0 & 51.0 & 58.7 & 7.8 & 3.9 & 14.5 & 3.6 \\
\hline 76 & 472.5 & 7.6 & 350.5 & 255.5 & 153.0 & 176.0 & 38.5 & 3.6 & 45.5 & 9.5 \\
\hline 77 & 491.3 & 7.8 & 347.5 & 268.5 & 124.8 & 142.3 & 52.5 & 4.5 & 31.8 & 11.0 \\
\hline 78 & 352.5 & 7.6 & 271.4 & 208.8 & 107.3 & 119.5 & 34.3 & 4.4 & 30.8 & 7.4 \\
\hline 80 & 144.0 & 7.8 & 114.3 & 87.0 & 44.0 & 59.0 & 11.0 & 3.5 & 12.0 & 3.3 \\
\hline 81 & 120.0 & 7.2 & 118.6 & 104.0 & 55.0 & 41.0 & 8.8 & 9.0 & 10.0 & 7.2 \\
\hline 83 & 221.3 & 7.5 & 184.3 & 147.5 & 78.0 & 96.5 & 17.0 & 4.6 & 22.0 & 5.6 \\
\hline 84 & 230.0 & 7.4 & 182.4 & 138.0 & 80.0 & 101.0 & 14.0 & 4.2 & 23.3 & 5.3 \\
\hline 85 & 125.0 & 7.7 & 97.2 & 80.0 & 37.0 & 51.0 & 9.5 & 4.5 & 10.0 & 2.8 \\
\hline 87 & 152.5 & 7.4 & 125.2 & 90.5 & 50.5 & 67.5 & 12.0 & 4.3 & 15.0 & 3.1 \\
\hline 88 & 172.5 & 7.2 & 137.8 & 105.0 & 54.5 & 75.0 & 11.0 & 6.1 & 15.5 & 3.9 \\
\hline
\end{tabular}


Table A.2(b) Annual Mean Values of the Water Quality Parameters from the Nogoa River Basin (continued)

\section{Station 130209}

\begin{tabular}{|c|c|c|c|c|c|c|c|c|c|c|}
\hline YEAR & $\begin{array}{c}\text { CONDUCTIVITY } \\
\text { @25C } \\
\text { (ms/m) }\end{array}$ & $\mathrm{PH}$ & $\begin{array}{c}\text { DISSOLVED } \\
\text { IONS } \\
\text { (mg/l) }\end{array}$ & $\begin{array}{c}\text { DISSOLVED } \\
\text { SOLIDS } \\
\text { (mg/l) } \\
\end{array}$ & $\begin{array}{l}\text { HARDNESS } \\
\text { (mg//)as } \mathrm{CaCO3} \\
\end{array}$ & $\begin{array}{l}\text { ALKALINITY } \\
\text { (mgg/)as CaCO3 } \\
\end{array}$ & $\begin{array}{l}\text { NATHIUM } \\
\text { (mg/l) }\end{array}$ & $\begin{array}{l}\text { KALIUM } \\
\text { (mg/l) } \\
\end{array}$ & $\begin{array}{l}\text { CaLCIUM } \\
\text { (mg/l) }\end{array}$ & MAGNESIUM \\
\hline 72 & 177.5 & 7.4 & 139.8 & 93.5 & 51.0 & 74.0 & 18.0 & - & 13.0 & 4.5 \\
\hline 73 & 155.2 & 7.8 & 145.0 & 97.3 & 63.1 & 69.4 & 10.3 & 4.7 & 16.4 & 5.3 \\
\hline 74 & 277.7 & 7.6 & 227.2 & 172.3 & 107.7 & 119.0 & 16.8 & 5.0 & 21.0 & 13.4 \\
\hline 75 & 198.8 & 7.5 & 153.2 & 115.3 & 69.0 & 83.0 & 13.7 & 4.5 & 17.5 & 6.1 \\
\hline 76 & 612.5 & 7.9 & 485.8 & 336.5 & 202.5 & 267.0 & 57.0 & 3.6 & 25.0 & 34.0 \\
\hline 77 & 732.5 & 8.6 & 525.4 & 372.5 & 236.5 & 278.5 & 55.0 & 3.1 & 28.0 & 40.5 \\
\hline 78 & 293.3 & 7.7 & 240.8 & 180.0 & 97.0 & 124.7 & 24.0 & 4.5 & 22.0 & 10.2 \\
\hline 80 & 160.0 & 7.5 & 111.2 & 91.0 & 47.0 & 48.0 & 13.0 & 3.4 & 13.0 & 3.5 \\
\hline 81 & 211.5 & 7.7 & 164.0 & 124.0 & 67.5 & 82.5 & 13.5 & 4.3 & 17.5 & 5.8 \\
\hline 82 & 205.0 & 7.6 & 160.9 & 120.0 & 58.0 & 86.0 & 15.0 & 4.9 & 15.5 & 4.8 \\
\hline 83 & 165.0 & 7.4 & 134.3 & 113.3 & 54.0 & 67.3 & 13.0 & 5.2 & 14.7 & 4.3 \\
\hline 84 & 265.0 & 7.5 & 202.8 & 156.7 & 78.0 & 100.3 & 21.3 & 5.2 & 18.7 & 7.7 \\
\hline 85 & 207.5 & 7.5 & 147.8 & 120.0 & 57.5 & 65.5 & 14.5 & 5.0 & 15.5 & 4.7 \\
\hline 86 & / 175.0 & 8.1 & 132.3 & 102.5 & 55.0 & 68.5 & 11.3 & 4.9 & 14.5 & 4.6 \\
\hline 87 & 171.7 & 7.5 & 137.4 & 105.7 & 58.3 & 72.7 & 11.7 & 5.4 & 16.0 & 4.4 \\
\hline 88 & 170.0 & 7.4 & 132.0 & 105.0 & 54.0 & 71.0 & 11.5 & 4.9 & 15.3 & 3.8 \\
\hline 89 & 210.8 & 7.9 & 163.1 & 120.0 & 64.8 & 81.0 & 17.1 & 3.9 & 16.7 & 5.7 \\
\hline 90 & 150.0 & 8.2 & 125.9 & 100.0 & 49.0 & 54.0 & 12.5 & 4.0 & 13.0 & 3.9 \\
\hline
\end{tabular}


Table A.2(c) Annual Mean Values of the Water Quality Parameters from the Logan River Basin

\section{Station 145010}

\begin{tabular}{|c|c|c|c|c|c|c|c|c|c|c|}
\hline YEAR & $\begin{array}{c}\text { CONDUCTIVITY } \\
\text { (9) 25C } \\
\text { (mS/rit) }\end{array}$ & PH & $\begin{array}{l}\text { DISSOLVED } \\
\text { IONS } \\
\text { (mg/l) }\end{array}$ & $\begin{array}{c}\text { DISSOLVED } \\
\text { SOLIDS } \\
\text { (mg/l) }\end{array}$ & $\begin{array}{l}\text { HARONESS } \\
\text { (mgM)as } \mathrm{CaC} O 3\end{array}$ & $\begin{array}{l}\text { ALKALINITY } \\
\text { (mg/)as } \mathrm{CaCO} 3\end{array}$ & $\begin{array}{l}\text { NATAIUM } \\
\text { (mg/l) }\end{array}$ & (mng/l) & $\begin{array}{l}\text { CALCIUM } \\
(\mathrm{mg} / \mathrm{l})\end{array}$ & MAGNESIUM \\
\hline 65 & 425.0 & 8.0 & 303.3 & 280.0 & 141.0 & 104.0 & 40.0 & 0.0 & 30.0 & 16.0 \\
\hline 66 & 418.0 & 7.9 & 296.4 & 237.0 & 149.3 & 110.0 & 32.8 & 0.0 & 35.6 & 14.7 \\
\hline 67 & 750.0 & 7.5 & 521.2 & 409.0 & 279.0 & 180.0 & 54.0 & 0.0 & 54.0 & 35.0 \\
\hline 68 & 357.3 & 7.3 & 241.1 & 185.0 & 144.0 & 89.7 & 18.7 & 0.0 & 24.7 & 20.0 \\
\hline 71 & 685.8 & 7.9 & 469.6 & 370.6 & 247.6 & 159.8 & 51.4 & 0.0 & 41.0 & 35.2 \\
\hline 72 & 376.7 & 7.4 & 276.6 & 211.0 & 144.3 & 101.7 & 30.0 & 0.0 & 24.0 & 20.5 \\
\hline 73 & 311.0 & 7.8 & 218.3 & 176.5 & 112.0 & 81.5 & 23.2 & 0.5 & 20.6 & 14.8 \\
\hline 74 & 482.5 & 8.2 & 310.6 & 273.0 & 164.8 & 117.0 & 32.3 & 1.4 & 28.4 & 22.8 \\
\hline 78 & 426.0 & 7.7 & 274.7 & 240.4 & 146.2 & 98.0 & 29.0 & 1.5 & 26.2 & 19.6 \\
\hline 79 & 147.5 & 6.8 & 91.8 & 94.0 & 42.0 & 24.5 & 13.5 & 1.9 & 7.9 & 5.5 \\
\hline 80 & 360.0 & 7.8 & 235.0 & 203.3 & 116.3 & 92.0 & 24.0 & 1.4 & 20.7 & 15.7 \\
\hline 81 & 393.0 & 8.1 & 248.1 & 214.5 & 108.0 & 89.5 & 31.5 & 1.4 & 18.5 & 15.0 \\
\hline 82 & 382.5 & 8.1 & 253.5 & 217.5 & 128.5 & 103.0 & 25.0 & 1.4 & 22.7 & 17.5 \\
\hline 83 & 439.2 & 8.0 & 294.1 & 246.7 & 146.5 & 119.3 & 31.2 & 1.5 & 25.6 & 20.1 \\
\hline 84 & 340.8 & 7.9 & 233.3 & 197.2 & 112.3 & 97.2 & 24.0 & 1.3 & 19.9 & 15.2 \\
\hline 85 & 348.5 & 7.8 & 220.2 & 188.0 & 108.5 & 83.5 & 53.4 & 1.3 & 10.1 & 16.9 \\
\hline 86 & 360.0 & 8.0 & 223.5 & 192.5 & 115.3 & 83.8 & 22.0 & 1.2 & 20.0 & 15.9 \\
\hline 87 & 205.0 & 7.4 & 129.9 & 117.0 & 64.0 & 47.3 & 14.5 & 1.5 & 11.6 & 8.5 \\
\hline 88 & 328.8 & 7.6 & 222.6 & 192.0 & 112.3 & 87.8 & 23.3 & 1.3 & 20.0 & 15.1 \\
\hline 89 & 347.5 & 7.9 & 250.5 & 210.0 & 109.5 & 95.5 & 32.8 & 1.5 & 20.8 & 14.0 \\
\hline
\end{tabular}

\section{Station 145013}

\begin{tabular}{|c|c|c|c|c|c|c|c|c|c|c|}
\hline YEAR & $\begin{array}{c}\text { CONDUCTVITY } \\
@ 25 \mathrm{C} \\
(\mathrm{mS} / \mathrm{m})\end{array}$ & $\mathrm{PH}$ & $\begin{array}{c}\text { OISSOL.VEO } \\
\text { toNS } \\
\text { (mg/i) }\end{array}$ & $\begin{array}{c}\text { DISSOLVED } \\
\text { SOLIDS } \\
\text { (mg/) }\end{array}$ & $\begin{array}{l}\text { HARDNESS } \\
\text { (mg/)as } \mathrm{CaCO} \\
\end{array}$ & $\begin{array}{l}\text { ALKALINITY } \\
\text { (mg/l)as } \mathrm{CaCO}_{3}\end{array}$ & (mg/l) & $\begin{array}{l}\text { KaLIUM } \\
\text { (mg/l) } \\
\end{array}$ & $\begin{array}{l}\text { CALCIUM } \\
(\mathrm{mg} / \mathrm{l})\end{array}$ & $\begin{array}{l}\text { MAGNE SIUM } \\
\text { (mg/i) }\end{array}$ \\
\hline 68 & 820.0 & 7.8 & 582.2 & 427.0 & 308.0 & 250.0 & 54.0 & 0.0 & 54.0 & 42.0 \\
\hline 70 & 495.0 & 8.0 & 366.1 & 274.0 & 180.0 & 148.0 & 41.0 & 0.0 & 31.0 & 25.0 \\
\hline 71 & 978.8 & 8.1 & 710.0 & 545.8 & 371.0 & 256.0 & 77.3 & 0.0 & 60.8 & 53.3 \\
\hline 72 & 497.5 & 7.7 & 381.2 & 289.5 & 187.8 & 144.0 & 44.5 & 0.0 & 34.0 & 25.0 \\
\hline 73 & 583.7 & 8.0 & 408.0 & 323.2 & 223.5 & 155.5 & 38.6 & 1.0 & 42.2 & 28.7 \\
\hline 74 & 718.0 & 8.1 & 512.1 & 415.3 & 249.7 & 197.3 & 58.0 & 2.3 & 40.2 & 36.2 \\
\hline 77 & 760.0 & 8.6 & 523.3 & 416.0 & 286.0 & 245.0 & 49.0 & 1.5 & 52.0 & 38.0 \\
\hline 78 & 598.3 & 7.9 & 404.9 & 340.3 & 206.7 & 155.3 & 43.7 & 1.8 & 37.7 & 27.3 \\
\hline 79 & 450.0 & 8.0 & 266.7 & 261.0 & 130.0 & 100.0 & 29.0 & 2.0 & 24.0 & 17.0 \\
\hline 80 & 541.0 & 7.6 & 359.7 & 297.0 & 175.3 & 151.0 & 38.0 & 1.9 & 33.3 & 22.3 \\
\hline 81 & 432.5 & 8.1 & 276.3 & 238.0 & 131.8 & 110.0 & 30.3 & 1.4 & 24.0 & 17.5 \\
\hline 82 & 429.0 & 7.8 & 255.2 & 253.2 & 146.4 & 89.6 & 32.2 & 1.6 & 26.8 & 19.3 \\
\hline 83 & 494.0 & 7.7 & 327.3 & 232.0 & 152.4 & 129.0 & 39.2 & 2.0 & 27.7 & 20.2 \\
\hline 84 & 525.0 & 8.0 & 363.4 & 296.0 & 176.4 & 156.6 & 38.4 & 1.6 & 31.4 & 23.8 \\
\hline 85 & 650.0 & 8.0 & 409.4 & 350.0 & 181.6 & 138.8 & 54.1 & 2.5 & 34.0 & 23.5 \\
\hline 86 & 398.0 & 8.1 & 281.8 & 226.0 & 136.4 & 133.4 & 25.6 & 1.7 & 26.4 & 17.1 \\
\hline 87 & 296.7 & 7.7 & 203.3 & 173.3 & 98.0 & 87.7 & 21.0 & 1.6 & 19.0 & 12.3 \\
\hline 88 & 476.3 & 7.9 & 329.8 & 270.0 & 166.3 & 136.8 & 33.5 & 1.6 & 30.8 & 21.8 \\
\hline 89 & 245.0 & 7.7 & 183.6 & 150.0 & 75.0 & 82.0 & 24.0 & 1.6 & 15.5 & 8.7 \\
\hline
\end{tabular}


Table A.2(c) Annual Mean Values of the Water Quality Parameters from the Logan River Basin (continued)

Station 145020

\begin{tabular}{|c|c|c|c|c|c|c|c|c|c|c|}
\hline YEAR & $\begin{array}{c}\text { CONDUCTIVITY } \\
@ 25 \mathrm{C} \\
(\mathrm{m} S / \mathrm{m})\end{array}$ & PH & $\begin{array}{c}\text { OISSOLVED } \\
\text { IONS } \\
\text { (mg/l) }\end{array}$ & $\begin{array}{c}\text { DISSOLVED } \\
\text { SOLIDS } \\
\text { (mg/l) }\end{array}$ & $\begin{array}{l}\text { HARDNESB } \\
\text { (mg/)as CaCO3 }\end{array}$ & $\begin{array}{l}\text { ALKALINITY } \\
\text { (mag/)as CaCO3 }\end{array}$ & $\begin{array}{c}\text { NaTRIUN } \\
\text { (mgI) }\end{array}$ & $\begin{array}{l}\text { KALIUM } \\
\text { (mg/) }\end{array}$ & $\begin{array}{l}\text { CALCIUM } \\
\text { (mg/h) }\end{array}$ & MAGNESIUM \\
\hline 74 & 680.6 & 8.0 & 418.8 & 364.4 & 96.2 & 96.2 & 71.4 & 2.5 & 31.9 & 21.0 \\
\hline 77 & 465.0 & 7.8 & 280.3 & 222.0 & 115.0 & 115.0 & 42.0 & 2.0 & 23.0 & 14.0 \\
\hline 78 & 677.0 & 7.7 & 396.4 & 356.0 & 89.8 & 89.8 & 71.0 & 2.5 & 29.4 & 19.2 \\
\hline 80 & 856.7 & 7.7 & 519.6 & 444.7 & 141.0 & 141.0 & 87.3 & 3.1 & 39.7 & 25.7 \\
\hline 81 & 539.7 & 8.1 & 311.7 & 271.3 & 87.3 & 87.3 & 52.7 & 2.0 & 23.3 & 15.3 \\
\hline 82 & 402.5 & 7.7 & 262.3 & 227.5 & 90.8 & 83.3 & 42.8 & 2.3 & 19.8 & 12.1 \\
\hline 83 & 617.5 & 7.9 & 362.2 & 317.5 & 135.8 & 98.8 & 64.5 & 2.5 & 25.6 & 17.4 \\
\hline 84 & 571.3 & 8.1 & 350.5 & 305.0 & 132.3 & 103.5 & 59.8 & 1.9 & 24.5 & 17.3 \\
\hline 85 & 397.5 & 7.8 & 241.7 & 210.0 & 86.3 & 73.5 & 41.3 & 2.1 & 17.0 & 10.7 \\
\hline 86 & 434.0 & 7.9 & 264.4 & 224.0 & 96.2 & 81.0 & 45.0 & 2.6 & 19.3 & 11.6 \\
\hline 87 & 268.3 & 7.5 & 162.5 & 143.3 & 57.3 & 47.3 & 29.5 & 1.7 & 11.8 & 6.8 \\
\hline 88 & 645.0 & 7.9 & 400.6 & 340.0 & 159.3 & 119.3 & 66.8 & 2.3 & 32.0 & 19.3 \\
\hline 89 & 631.7 & 7.9 & 425.9 & 366.7 & 172.7 & 123.7 & 69.7 & 2.4 & 31.7 & 22.7 \\
\hline
\end{tabular}

Station 145008

\begin{tabular}{|c|c|c|c|c|c|c|c|c|c|c|}
\hline YEAR & $\begin{array}{c}\text { CONDUCTVITY } \\
@ 25 \mathrm{C} \\
(\mathrm{mS} / \mathrm{m})\end{array}$ & $\mathrm{PH}$ & $\begin{array}{c}\text { DISSOLVED } \\
\text { IONS } \\
\text { (mg/L) }\end{array}$ & $\begin{array}{c}\text { DISSOIVED } \\
\text { SOLIDS } \\
\text { (mg/ } /)\end{array}$ & $\begin{array}{l}\text { HARDNESS } \\
\text { (ing/L)as CaCOO }\end{array}$ & $\begin{array}{l}\text { ALKALINITY } \\
\text { (mg/L)as } \mathrm{CaCO}_{3}\end{array}$ & $\begin{array}{l}\text { NATRIUM } \\
\text { (mg/t) } \\
\end{array}$ & $\begin{array}{l}\text { KALlUM } \\
\text { (mg/L) } \\
\end{array}$ & $\begin{array}{l}\text { CALCIUM } \\
\text { (ming) }\end{array}$ & $\begin{array}{c}\text { MAGNESIUM } \\
(\mathrm{mg} / \mathrm{h}) \\
\end{array}$ \\
\hline 61 & 269.0 & 7.3 & 185.2 & 150.0 & 76.0 & 68.0 & 28.0 & 0.0 & 14.0 & 10.0 \\
\hline 63 & 321.0 & 7.5 & 209.3 & 197.5 & 79.0 & 75.0 & 34.0 & 0.0 & 16.0 & 9.5 \\
\hline 64 & 771.7 & 8.1 & 540.2 & 453.3 & 240.0 & 175.3 & 79.3 & 0.0 & 47.7 & 29.3 \\
\hline 65 & 597.0 & 7.5 & 386.1 & 319.0 & 181.0 & 108.0 & 54.0 & 0.0 & 38.0 & 21.0 \\
\hline 66 & 590.0 & 8.3 & 377.7 & 311.0 & 188.0 & 124.0 & 48.5 & 0.0 & 48.0 & 16.5 \\
\hline 67 & 1040.0 & 7.8 & 727.8 & 580.0 & 355.0 & 237.0 & 94.5 & 0.0 & 65.5 & 46.5 \\
\hline 68 & 709.3 & 7.6 & 489.2 & 375.5 & 244.8 & 183.0 & 56.8 & 0.0 & 45.3 & 32.0 \\
\hline 70 & 630.0 & 7.7 & 413.2 & 320.0 & 209.0 & 150.0 & 48.0 & 0.0 & 36.0 & 29.0 \\
\hline 71 & 1133.4 & 8.1 & 752.7 & 595.6 & 348.4 & 235.8 & 106.0 & 0.0 & 64.0 & 45.8 \\
\hline 72 & 590.0 & 7.5 & 430.4 & 336.6 & 200.0 & 150.8 & 57.8 & 0.0 & 35.6 & 27.0 \\
\hline 73 & 567.7 & 7.8 & 367.4 & 306.8 & 165.3 & 118.7 & 54.1 & 1.6 & 34.2 & 19.4 \\
\hline 74 & 532.3 & 8.0 & 352.2 & 298.3 & 159.3 & 120.3 & 48.8 & 2.1 & 28.9 & 21.2 \\
\hline 76 & 245.0 & 7.4 & 161.1 & 147.0 & 64.0 & 61.0 & 22.0 & 2.4 & 15.0 & 6.4 \\
\hline 77 & 600.0 & 8.0 & 369.2 & 298.0 & 169.0 & 150.0 & 50.0 & 2.0 & 33.0 & 21.0 \\
\hline 78 & 770.0 & 7.9 & 488.7 & 416.7 & 218.7 & 152.7 & 71.3 & 2.5 & 41.3 & 28.0 \\
\hline 80 & 516.7 & 8.0 & 336.6 & 281.0 & 148.3 & 127.7 & 43.0 & 2.4 & 28.7 & 18.6 \\
\hline 81 & 628.0 & 7.9 & 377.3 & 326.7 & 159.3 & 115.7 & 57.7 & 2.0 & 29.7 & 20.7 \\
\hline 82 & 546.7 & 8.0 & 355.8 & 296.7 & 155.0 & 128.7 & 49.0 & 3.6 & 899.0 & 19.8 \\
\hline 83 & 535.0 & 7.8 & 342.0 & 286.7 & 151.3 & 124.0 & 48.7 & 2.0 & 28.5 & 19.5 \\
\hline 84 & 633.3 & 8.0 & 421.0 & 350.0 & 186.3 & 157.0 & 56.0 & 2.4 & 34.0 & 24.7 \\
\hline 85 & 393.3 & 7.7 & 243.9 & 210.0 & 105.3 & 87.3 & 33.3 & 1.6 & 19.7 & 8.7 \\
\hline 86 & 475.6 & 7.9 & 308.6 & 253.8 & 131.6 & 112.6 & 42.4 & 2.1 & 25.6 & 16.4 \\
\hline 87 & 236.7 & 7.6 & 135.5 & 130.0 & 58.3 & 52.0 & 20.7 & 1.8 & 11.9 & 7.0 \\
\hline 88 & 638.3 & 8.0 & 420.3 & 346.7 & 191.3 & 153.0 & 55.3 & 2.2 & 36.7 & 24.2 \\
\hline 89 & 480.0 & 8.5 & 323.2 & 280.0 & 146.0 & 107.0 & 45.5 & 2.3 & 20.5 & 23.0 \\
\hline
\end{tabular}


Table A.3(a) Annual Mean Values of the Water Quality Parameters (Grouped) from the Fitzroy River Basin

Station 130105

(Calibration set)

\begin{tabular}{|c|c|c|c|c|c|c|c|c|c|c|}
\hline YEAR & $\begin{array}{c}\text { CONOUCTVITY } \\
@ 25 \mathrm{C} \\
(\mathrm{mS} / \mathrm{m})\end{array}$ & PH & $\begin{array}{c}\text { DISSOLIVED } \\
\text { IONS } \\
\text { (mg/) } \\
\end{array}$ & $\begin{array}{c}\text { DISSOLVEO } \\
\text { SOLIDS } \\
\text { (mg/) } \\
\end{array}$ & $\begin{array}{l}\text { HARONESS } \\
\text { (mg/)as CaCO3 }\end{array}$ & $\begin{array}{l}\text { ALKAL:INITY } \\
\text { (mag/)As CaCO3 } \\
\end{array}$ & $\begin{array}{l}\text { NATRIUM } \\
\text { (mg/) } \\
\end{array}$ & (mg/l) & CALCIUM & MAGNESIUM \\
\hline 73 & 215.0 & 7.8 & 159.6 & 135.8 & 61.8 & 64.0 & 18.2 & 2.4 & 13.1 & 7.1 \\
\hline 75 & 235.0 & 7.5 & 158.4 & 133.7 & 63.7 & 68.5 & 16.3 & 3.2 & 13.4 & 6.8 \\
\hline 76 & 516.7 & 8.1 & 336.2 & 274.0 & 150.3 & 128.0 & 45.3 & 2.6 & 32.7 & 16.7 \\
\hline 77 & 360.0 & 8.0 & 248.6 & 204.0 & 102.3 & 106.0 & 29.8 & 2.3 & 22.3 & 10.6 \\
\hline 78 & 367.5 & 8.0 & 258.2 & 207.5 & 110.5 & 105.5 & 32.5 & 3.4 & 23.5 & 12.5 \\
\hline 84 & 226.3 & 7.5 & 161.0 & 130.0 & 64.0 & 71.8 & 19.3 & 3.8 & 14.5 & 6.8 \\
\hline 85 & 235.0 & 7.7 & 161.0 & 140.0 & 61.5 & 66.0 & 20.0 & 3.9 & 14.0 & 6.4 \\
\hline 86 & 255.0 & 8.2 & 187.9 & 146.7 & 80.7 & 88.7 & 20.0 & 3.8 & 18.0 & 8.7 \\
\hline Mean & 301.3 & 7.8 & 208.8 & 171.4 & 86.8 & 87.3 & 25.2 & 3.2 & 18.9 & 9.4 \\
\hline $\begin{array}{l}\text { Standard } \\
\text { Deviation }\end{array}$ & 105.7 & 0.3 & 65.7 & 52.0 & 32.1 & 23.7 & 10.0 & 0.7 & 6.9 & 3.6 \\
\hline
\end{tabular}

(Validation set)

\begin{tabular}{|c|c|c|c|c|c|c|c|c|c|c|}
\hline YEAR & $\begin{array}{c}\text { CONDUCTIVITY } \\
@ 25 \mathrm{C} \\
(\mathrm{mS} / \mathrm{m}) \\
\end{array}$ & $\mathrm{PHH}$ & $\begin{array}{c}\text { OISSOLVED } \\
\text { IONS } \\
\text { (mg/l) }\end{array}$ & $\begin{array}{c}\text { DISSOLVED } \\
\text { SOLIOS } \\
\text { (mgin) }\end{array}$ & $\begin{array}{l}\text { HARDNESS } \\
\text { (mg/l)as CaCO3 }\end{array}$ & $\begin{array}{l}\text { ALKALINITY } \\
\text { (mgh/)as } \mathrm{CaCO}_{3}\end{array}$ & $\begin{array}{l}\text { NATRIUM } \\
\text { (mg/) } \\
\end{array}$ & $\begin{array}{l}\text { KALIUM } \\
\text { (mg/l) } \\
\end{array}$ & $\begin{array}{l}\text { CALCIUM } \\
\text { (mg/l) } \\
\end{array}$ & $\begin{array}{c}\text { MAGNESIUM } \\
\text { (mg/l) } \\
\end{array}$ \\
\hline (1 yeerly) & & & & & & & & & & \\
\hline 87 & 210.0 & 7.7 & 183.9 & 123.0 & 61.0 & 69.0 & 15.8 & 4.0 & 14.3 & 6.1 \\
\hline 88 & 200.0 & 7.1 & 128.0 & 110.0 & 55.0 & 51.0 & 15.5 & 2.8 & 13.0 & 5.5 \\
\hline 89 & 270.0 & 7.9 & 165.6 & 140.0 & 65.5 & 70.5 & 22.0 & 2.5 & 14.0 & 7.4 \\
\hline \{2 yearly\} & & & & & & & & & & \\
\hline Mean \#1 & 205.0 & 7.4 & 156.0 & 116.5 & 58.0 & 60.0 & 15.7 & 3.4 & 13.7 & 5.8 \\
\hline Mean \#2 & 235.0 & 7.5 & 146.8 & 125.0 & 60.3 & 60.8 & 18.8 & 2.7 & 13.5 & 6.5 \\
\hline (3 yearly) & & & & & & & & & & \\
\hline Mean \#3 & 226.7 & 7.6 & 159.2 & 124.3 & 60.5 & 63.5 & 17.8 & 3.1 & 13.8 & 6.3 \\
\hline
\end{tabular}

Note: $\quad$ Mean \#1 = Mean of years 87,88

Mean \#2 = Mean of years 88,89

Mean \#3 = Mean of years $87,88,89$ 
Table A.3(a) Annual Mean Values of the Water Quality Parameters (Grouped) from the Fitzroy River Basin (continued)

Station 130322

(Calibration set)

\begin{tabular}{|c|c|c|c|c|c|c|c|c|c|c|}
\hline YEAR & $\begin{array}{c}\text { CONDUCTIVITY } \\
\text { 25C } \\
(\mathrm{ms} / \mathrm{m}) \\
\end{array}$ & PH & $\begin{array}{c}\text { DISSOLVED } \\
\text { IONS } \\
\text { (mg } /)\end{array}$ & $\begin{array}{c}\text { OISSOLVED } \\
\text { solids } \\
\text { (mg/li) }\end{array}$ & $\begin{array}{l}\text { HARONESS } \\
\text { (mag/)as CaCO3 }\end{array}$ & $\begin{array}{l}\text { ALKALINITY } \\
\text { (mg/l)as CaCO3 }\end{array}$ & $\begin{array}{l}\text { NATRIUM } \\
\quad(\mathrm{mg} / \mathrm{l}) \\
\end{array}$ & $\begin{array}{l}\text { KALIUM } \\
\text { (mg/i) } \\
\end{array}$ & $\begin{array}{l}\text { CALCIUM } \\
(\mathrm{mg} / \mathrm{l}) \\
\end{array}$ & MAGNESIUM \\
\hline 73 & 257.5 & 8.0 & 173.3 & 133.5 & 61.5 & 85.0 & 21.2 & 6.2 & 16.0 & 5.3 \\
\hline 75 & 145.0 & 7.1 & 111.6 & 92.0 & 51.0 & 54.0 & 12.0 & 5.1 & 12.5 & 4.7 \\
\hline 76 & 190.0 & 7.5 & 142.2 & 115,0 & 50.7 & 62.3 & 17.7 & 5.8 & 13.3 & 4.2 \\
\hline 77 & 145.0 & 7.8 & 106.4 & 87.0 & 37.0 & 46.0 & 13.4 & 5.1 & 9.2 & 3.4 \\
\hline 78 & 190.0 & 7.4 & 146.3 & 122.0 & 49.0 & 66.0 & 18.0 & 5.5 & 12.0 & 4.5 \\
\hline 84 & 240.0 & 7.8 & 179.1 & 156.7 & 62.7 & 79.0 & 24.3 & 5.8 & 15.7 & 5.7 \\
\hline 85 & 245.0 & 7.7 & 178.0 & 150.0 & 61.0 & 77.0 & 21.5 & 6.4 & 15.0 & 5.7 \\
\hline 86 & 217.5 & 7.6 & 149.0 & 125.0 & 51.0 & 63.5 & 21.3 & 5.0 & 12.8 & 4.7 \\
\hline Mean & 203.8 & 7.6 & 148.2 & 122.6 & 53.0 & 66.6 & 18.7 & 5.6 & 13.3 & 4.8 \\
\hline $\begin{array}{l}\text { Standard } \\
\text { Deviation }\end{array}$ & 43.7 & 0.3 & 28.3 & 24.8 & 8.6 & 13.2 & 4.3 & 0.5 & 2.2 & 0.8 \\
\hline
\end{tabular}

(Validation set)

\begin{tabular}{|c|c|c|c|c|c|c|c|c|c|c|}
\hline YEAR & $\begin{array}{c}\text { CONDUCIIVITY } \\
@ 25 \mathrm{C} \\
(\mathrm{mS} / \mathrm{m})\end{array}$ & $\mathrm{PH}$ & $\begin{array}{c}\text { DISSOLVED } \\
\text { IONS } \\
\text { (mg/l) }\end{array}$ & $\begin{array}{c}\text { DISSOLVED } \\
\text { SOLIDS } \\
\text { (mg/i) }\end{array}$ & $\begin{array}{l}\text { HARDNESS } \\
\text { (mg/)as } \mathrm{CaCO} 3\end{array}$ & $\begin{array}{l}\text { ALKALINITY } \\
\text { (mg,il)as } \mathrm{CaCO}_{3}\end{array}$ & $\begin{array}{l}\text { NATRIUM } \\
\text { (mg/l) }\end{array}$ & $\begin{array}{l}\text { KALIUM } \\
\text { (mg/l) }\end{array}$ & $\begin{array}{l}\text { CALCIUM } \\
\text { (mg/l) }\end{array}$ & $\begin{array}{l}\text { MAGNESIUM } \\
\text { (mg/l) }\end{array}$ \\
\hline (Iyearly) & & & & & & & & & & \\
\hline 87 & 222.5 & 7.9 & 159.8 & 125.0 & 57.5 & 73.5 & 19.5 & 4.9 & 14.0 & 5.6 \\
\hline 88 & 195.0 & 7.6 & 144.6 & 110.0 & 51.5 & 72.0 & 15.8 & 5.7 & 13.0 & 4.6 \\
\hline 89 & 248.8 & 7.6 & 175.3 & 137.5 & 66.5 & 77.3 & 23.0 & 4.8 & 17.0 & 5.8 \\
\hline (2 yearly) & & & & & & & & & & \\
\hline Mean \#1 & 208.8 & 7.7 & 152.2 & 117.5 & 54.5 & 72.8 & 17.6 & 5.3 & 13.5 & 5.1 \\
\hline Mean \#2 & 221.9 & 7.6 & 159.9 & 123.8 & 59.0 & 74.6 & 19.4 & 5.2 & 15.0 & 5.2 \\
\hline (3 yearly) & & & & & & & & & & \\
\hline Mean \#3 & 222.1 & 7.7 & 159.9 & 124.2 & 58.5 & 74.3 & 19.4 & 5.1 & 14.7 & 5.3 \\
\hline
\end{tabular}

Note: $\quad$ Mean \#1. = Mean of years 87,88

Mean \#2 = Mean of years 88,89

Mean \#3 = Mean of years $87,88,89$ 
Table A.3(a) Annual Mean Values of the Water Quality Parameters (Grouped) from the Fitzroy River Basin (continued)

\section{Station 130003}

(Calibration set)

\begin{tabular}{|c|c|c|c|c|c|c|c|c|c|c|}
\hline YEAR & $\begin{array}{c}\text { CONDUCTVITY } \\
\text { (95c } \\
(\mathrm{mS} / \mathrm{m})\end{array}$ & $\mathrm{PH}$ & $\begin{array}{l}\text { DISSOLVED } \\
\text { IONS } \\
\text { (mg/) }\end{array}$ & $\begin{array}{c}\text { OISSOLYED } \\
\text { SOLIDS } \\
(\mathrm{m} \cdot \mathrm{g} / \mathrm{l}) \\
\end{array}$ & $\begin{array}{l}\text { MARDNESS } \\
\text { (mg/l)as } \mathrm{CaCO}_{3}\end{array}$ & $\begin{array}{l}\text { ALKALINITY } \\
\text { (mg/l)as } \mathrm{CACO}\end{array}$ & $\begin{array}{l}\text { NATRIUM } \\
\text { (mg } / \text { ) }\end{array}$ & $\begin{array}{l}\text { KALIUM } \\
\text { (mxg/f) } \\
\end{array}$ & $\begin{array}{l}\text { CALCIUM } \\
\text { (mg/l) }\end{array}$ & MAGNESIUM \\
\hline 73 & 183.5 & 7.9 & 140.6 & 109.0 & 57.5 & 66.0 & 15.1 & 4.6 & 13.9 & 5.6 \\
\hline 75 & 430.0 & 7.5 & 265.4 & 215.0 & 113.0 & 105.0 & 35.0 & 3.0 & 22.0 & 14.0 \\
\hline 76 & 790.0 & 7.9 & 483.2 & 416.0 & 224.0 & 135.0 & 70.0 & 1.8 & 45.0 & 27.0 \\
\hline 77 & 338.3 & 8.0 & 269.8 & 226.3 & 113.8 & 100.5 & 34.8 & 2.8 & 23.3 & 13.5 \\
\hline 78 & 420.0 & 8.0 & 288.7 & 246.7 & 119.3 & 98.0 & 39.3 & 3.1 & 23.7 & 14.7 \\
\hline 84 & 205.0 & 8.3 & 151.4 & 120.0 & 51.0 & 69.0 & 18.0 & 4.7 & 13.0 & 4.5 \\
\hline 85 & 188.3 & 7.7 & 131.1 & 120.0 & 53.7 & 54.7 & 15.3 & 3.8 & 12.0 & 5.7 \\
\hline 86 & 393.3 & 7.9 & 260.9 & 220.0 & 104.3 & 95.3 & 37.0 & 4.5 & 20.8 & 12.7 \\
\hline Mean & 368.6 & 7.9 & 248.9 & 209.1 & 104.6 & 90.4 & 33.1 & 3.5 & 21.7 & 12.2 \\
\hline $\begin{array}{l}\text { Standard } \\
\text { Deviation }\end{array}$ & 199.7 & 0.2 & 114.9 & 100.4 & 56.5 & 26.0 & 18.1 & 1.0 & 10.6 & 7.3 \\
\hline
\end{tabular}

(Validation set)

\begin{tabular}{|c|c|c|c|c|c|c|c|c|c|c|}
\hline YEAA & $\begin{array}{c}\text { CONDUCTIVITY } \\
@ 25 \mathrm{C} \\
(\mathrm{mS} / \mathrm{m}) \\
\end{array}$ & $\mathrm{PH}$ & $\begin{array}{c}\text { DISSOLVED } \\
\text { IONS } \\
\text { (mg/) } \\
\end{array}$ & $\begin{array}{c}\text { DISSOLVEO } \\
\text { SOLIDS } \\
\text { (mg/l) }\end{array}$ & $\begin{array}{l}\text { HARDNESS } \\
\text { (mg/) } \mathrm{as} \mathrm{CaCO} 3\end{array}$ & $\begin{array}{l}\text { ALKALINITY } \\
\text { (mag/)as } \mathrm{CaCO} 3\end{array}$ & $\begin{array}{l}\text { NATRIUM } \\
\text { (mg/l) }\end{array}$ & $\begin{array}{l}\text { KALIUM } \\
\text { (mg/l) } \\
\end{array}$ & $\begin{array}{l}\text { CALCIUM } \\
\text { (mg/l) } \\
\end{array}$ & $\begin{array}{l}\text { MAGNESIUM } \\
\text { (mig/l) }\end{array}$ \\
\hline (f yearly) & & & & & & & & & & \\
\hline 87 & 288.3 & 7.8 & 194.5 & 160.0 & 71.0 & 76.0 & 26.0 & 4.4 & 16.3 & 7.4 \\
\hline 88 & 370.0 & 7.6 & 237.9 & 200.0 & 102.5 & 81.5 & 32.0 & 4.0 & 22.3 & 11.5 \\
\hline 89 & 176.7 & 7.4 & 122.8 & 104.0 & 50.3 & 53.0 & 15.8 & 3.3 & 11.3 & 5.4 \\
\hline (2 yeariy) & & & & & & & & & & \\
\hline Mean \#1 & 329.2 & 7.7 & 216.2 & 180.0 & 86.8 & 78.8 & 29.0 & 4.2 & 19.3 & 9.4 \\
\hline Mean \#2 & 273.3 & 7.5 & 180.3 & 152.0 & 76.4 & 67.3 & 23.9 & 3.6 & 16.8 & 8.4 \\
\hline (3 yearly) & & & & & & & & & & \\
\hline Mean $\# 3$ & 278.3 & 7.6 & 185.1 & 154.7 & 74.6 & 70.2 & 24.6 & 3.9 & 16.6 & 8.1 \\
\hline
\end{tabular}

\footnotetext{
Note: $\quad$ Mean \#1 $=$ Mean of years 87,88

Mean \#2 $=$ Mean of years 88,89

Mean \#3 $=$ Mean of years $87,88,89$
} 
Table A.3(b) Annual Mean Values of the Water Quality Parameters (Grouped) from the Nogoa River Basin

\section{Station 130202}

(Calibration set)

\begin{tabular}{|c|c|c|c|c|c|c|c|c|c|c|}
\hline YEAR & $\begin{array}{c}\text { CONDUCTVITY } \\
\text { @25C } \\
(\mathrm{mS} / \mathrm{m})\end{array}$ & $\mathrm{PH}$ & $\begin{array}{c}\text { OISSOLVEO } \\
\text { IONS } \\
\text { (mg/i) }\end{array}$ & $\begin{array}{c}\text { DISSOLVED } \\
\text { SOLIDS } \\
\text { (mgil) }\end{array}$ & $\begin{array}{l}\text { HARONESS } \\
\text { (mgg/)as } \mathrm{CaCO} \\
\end{array}$ & $\begin{array}{l}\text { ALKaLINITY } \\
\text { ing:llas CaCO3 }\end{array}$ & $\begin{array}{l}\text { NATfIUM } \\
\text { (mg/) }\end{array}$ & $\begin{array}{l}\text { KALIUM } \\
\text { (mrg/l) } \\
\end{array}$ & $\begin{array}{l}\text { CALCIUM } \\
(\mathrm{mg} n)\end{array}$ & $\begin{array}{l}\text { MAGNESIUM } \\
(\mathrm{mg} / \mathrm{l}) \\
\end{array}$ \\
\hline 72 & 220.00 & 7.60 & 150.05 & 105.50 & 82.50 & 72.00 & 17.00 & - & 19.00 & 8.50 \\
\hline 73 & 163.50 & 8.00 & 135.05 & 95.75 & 58.50 & 67.00 & 9.75 & 4.13 & 15.78 & 4.65 \\
\hline 74 & 286.00 & 7.68 & 209.96 & 166.40 & 88.80 & 91.40 & 21.80 & 6.18 & 22.88 & 7.66 \\
\hline 75 & 275.00 & 7.45 & 197.95 & 155.00 & 83.00 & 93.00 & 22.00 & 5.00 & 22.50 & 6.40 \\
\hline 76 & 263.33 & 7.20 & 187.00 & 148.67 & 80.00 & 79.33 & 20.33 & 5.30 & 21.00 & 6.73 \\
\hline 77 & 340.50 & 7.85 & 234.15 & 188.50 & 94.00 & 94.00 & 28.50 & 5.65 & 24.50 & 7.95 \\
\hline 78 & 267.50 & 7.35 & 193.50 & 154.50 & 75.50 & 79.00 & 21.50 & 5.05 & 21.00 & 5.65 \\
\hline 80 & 150.00 & 7.80 & 111.50 & 83.00 & 47.00 & 58.00 & 10.00 & 2.90 & 13.00 & 3.60 \\
\hline Mean & 245.73 & 7.62 & 177.40 & 137.16 & 76.16 & 79.22 & 18.86 & 4.28 & 19.96 & 6.39 \\
\hline $\begin{array}{l}\text { Standard } \\
\text { Deviation }\end{array}$ & 64.18 & 0.27 & 41.30 & 37.59 & 15.78 & 13.14 & 6.39 & 2.02 & 3.87 & 1.69 \\
\hline
\end{tabular}

(Validation set)

\begin{tabular}{|c|c|c|c|c|c|c|c|c|c|c|}
\hline YEAR & $\begin{array}{c}\text { CONDUCTIVITY } \\
@ 25 \mathrm{C} \\
(\mathrm{m} \mathrm{s} / \mathrm{m})\end{array}$ & PH & $\begin{array}{c}\text { DISSOLVED } \\
\text { IONS } \\
\text { (mg/l) }\end{array}$ & $\begin{array}{c}\text { DISSOLVED } \\
\text { SOLIDS } \\
\text { (mingl) }\end{array}$ & $\begin{array}{l}\text { HARDNESS } \\
\text { (mig//)as Caco3 }\end{array}$ & $\begin{array}{l}\text { ALKALINITY } \\
\text { (Img) Rlas CaCO3 }\end{array}$ & $\begin{array}{l}\text { NATRIUM } \\
\text { (mg/l) }\end{array}$ & $\begin{array}{l}\text { KALIUAM } \\
(\mathrm{mg} / \mathrm{l})\end{array}$ & $\begin{array}{l}\text { CALCIUM } \\
\text { (rngil) }\end{array}$ & $\begin{array}{l}\text { MAGaNesiuM } \\
\text { (mg/l) }\end{array}$ \\
\hline (f yoarty) & & & & & & & & & & \\
\hline 83 & 246.50 & 7.47 & 179.40 & 147.93 & 69.07 & 72.43 & 22.39 & 5.33 & 17.20 & 6.32 \\
\hline 84 & 342.50 & 8.20 & 249.35 & 200.00 & 92.50 & 106.00 & 30.50 & 5.65 & 23.00 & 8.55 \\
\hline 85 & 190.00 & 7.40 & 135.80 & 110.00 & 46.00 & 64.00 & 17.00 & 4.40 & 13.00 & 3.40 \\
\hline 87 & 152.50 & 6.95 & 116.60 & 94.50 & 45.50 & 53.50 & 12.50 & 5.20 & 12.50 & 3.45 \\
\hline 88 & 147.50 & 7.25 & 110.15 & 86.00 & 44.00 & 57.50 & 9.65 & 4.80 & 12.20 & 3.25 \\
\hline (2 yearly) & & & & & & & & & & \\
\hline Mean \#1 & 294.5 & 7.8 & 214.37 & 173.97 & 80.78 & 89.22 & 26.44 & 5.49 & 20.10 & 7.44 \\
\hline Mean $\# 2$ & 266.3 & 7.8 & 192.58 & 155.00 & 69.25 & 85.00 & 23.75 & 5.03 & 18.00 & 5.98 \\
\hline Mean \#3 & 171.3 & 7.2 & 126.20 & 102.25 & 45.75 & 58.75 & 14.75 & 4.80 & 12.75 & 3.43 \\
\hline Mean \#4 & 150.0 & 7.1 & 113.38 & 90.25 & 44.75 & 55.50 & 11.08 & 5.00 & 12.35 & 3.35 \\
\hline (3 yoarly) & & & & & & & & & & \\
\hline Mean \#5 & 259.67 & 7.69 & 188.18 & 152.64 & 69.19 & 80.81 & 23,30 & 5.13 & 17.73 & 6.09 \\
\hline Mean $\# 6$ & 228.33 & 7.52 & 167.25 & 134.83 & 61.33 & 74.50 & 20.00 & 5.08 & 16.17 & 5.13 \\
\hline Mean \#7 & 163.33 & 7.20 & 120.85 & 96.83 & 45.17 & 58.33 & 13.05 & 4.80 & 12.57 & 3.37 \\
\hline (4 yearly) & & & & & & & & & & \\
\hline Mean $\# 8$ & 232.88 & 7.51 & 170.29 & 138.11 & 63.27 & 73.98 & 20.60 & 5.15 & 16.43 & 5.43 \\
\hline Mean $\# 9$ & 208.13 & 7.45 & 152.98 & 122.63 & 57.00 & 70.25 & 17.41 & 5.01 & 15.18 & 4.66 \\
\hline
\end{tabular}

Note: $\quad$ Mean \#1 = Mean of years 83,84

Mean \#2 = Mean of years 84,85

Mean \#3 = Mean of years 85,87

Mean $\# 4=$ Mean of years 87,88

Mean \#5 = Mean of years $83,84,85$
Mean \#6 $=$ Mean of years $84,85,87$

Mean \#7 = Mean of years $85,87,88$

Mean $\# 8=$ Mean of years $83,84,85,87$

Mean \#9= Mean of years $84,85,87,88$ 
Table A.3(b) Annual Mean Values of the Water Quality Parameters (Grouped) from the Nogoa River Basin (continued)

Station 130212

(Calibration set)

\begin{tabular}{|c|c|c|c|c|c|c|c|c|c|c|}
\hline YEAR & $\begin{array}{c}\text { CONDUCTVITY } \\
\text { @ } 25 C \\
(\mathrm{~m} S / \mathrm{m})\end{array}$ & $\mathrm{PH}$ & $\begin{array}{c}\text { OISSOLVED } \\
\text { IONS } \\
\text { (mm/L) }\end{array}$ & $\begin{array}{c}\text { DISSOLVEO } \\
\text { SOLIOS } \\
\text { (mg/L) }\end{array}$ & $\begin{array}{l}\text { HARUNESS } \\
\text { (mag/L)as } \mathrm{CaCO}\end{array}$ & $\begin{array}{l}\text { ALKALINITY } \\
\text { (mg/L)as } \mathrm{CaCO}^{2}\end{array}$ & $\begin{array}{l}\text { NATRIUM } \\
\text { (migg/L) }\end{array}$ & $\begin{array}{l}\text { KaLIUM } \\
\text { (mxg/L) }\end{array}$ & $\begin{array}{l}\text { CALCIUA } \\
\text { (mg/L) }\end{array}$ & $\begin{array}{c}\text { MAGNESIUM } \\
\text { (mg/h) }\end{array}$ \\
\hline 72 & 290.00 & 7.50 & 247.10 & 159.00 & 122.00 & 142.00 & 17.00 & - & 39.00 & 6.00 \\
\hline 73 & 143.33 & 7.40 & 127.70 & 89.00 & 45.00 & 64.67 & 14.20 & 5.10 & 10.47 & 4.60 \\
\hline 74 & 139.00 & 7.17 & 108.17 & 85.67 & 45.33 & 53.00 & 10.67 & 4.73 & 12.50 & 3.47 \\
\hline 75 & 138.33 & 7.27 & 106.20 & 91.00 & 51.00 & 58.67 & 7.80 & 3.87 & 14.50 & 3.57 \\
\hline 76 & 472.50 & 7.60 & 350.50 & 255.50 & 153.00 & 176.00 & 38.50 & 3.60 & 45.50 & 9.50 \\
\hline 77 & 491.25 & 7.83 & 347.48 & 268.50 & 124.75 & 142.25 & 52.50 & 4.53 & 31.75 & 11.03 \\
\hline 78 & 352.50 & 7.55 & 271.38 & 208.75 & 107.25 & 119.50 & 34.25 & 4.43 & 30.75 & 7.35 \\
\hline 80 & 144.00 & 7.80 & 114.30 & 87.00 & 44.00 & 59.00 & 11.00 & 3.50 & 12.00 & 3.30 \\
\hline Mean & 271.36 & 7.51 & 209.10 & 155.55 & 86.54 & 101.89 & 23.24 & 3.72 & 24.56 & 6.10 \\
\hline $\begin{array}{l}\text { Standard } \\
\text { Deviation }\end{array}$ & 152.86 & 0.23 & 107.47 & 79.07 & 44.82 & 48.59 & 16.38 & 1.62 & 13.84 & 2.95 \\
\hline
\end{tabular}

(Validation set)

\begin{tabular}{|c|c|c|c|c|c|c|c|c|c|c|}
\hline YEAR & $\begin{array}{c}\text { CONDUCTIV!TY } \\
\text { (925C } \\
\text { (ms/m) }\end{array}$ & PH & $\begin{array}{c}\text { DISSOLVED } \\
\text { IONS } \\
\text { (mg/h) }\end{array}$ & $\begin{array}{c}\text { DISSOLVED } \\
\text { SOLIDS } \\
\text { (mg/L) }\end{array}$ & $\begin{array}{l}\text { HARDNESS } \\
\text { (mag)as } \mathrm{CaCO}_{3}\end{array}$ & $\begin{array}{l}\text { ALKALINITY } \\
\text { (mg/L)as } \mathrm{CaCO} 3\end{array}$ & $\begin{array}{l}\text { NATRIUM } \\
\text { (mg/L) }\end{array}$ & $\begin{array}{l}\text { KALIUM } \\
\text { (mg/L) } \\
\end{array}$ & $\begin{array}{l}\text { CALCIUM } \\
\text { (mg/L) }\end{array}$ & $\begin{array}{l}\text { MAGNE SIUM } \\
\text { (mgR) }\end{array}$ \\
\hline (f yearly) & & & & & & & & & & \\
\hline 83 & 221.25 & 7.50 & 184.33 & 147.50 & 78.00 & 96.50 & 17.00 & 4.58 & 22.00 & 5.58 \\
\hline 84 & 230.00 & 7.40 & 182.40 & 138.00 & 80.00 & 101.00 & 14.00 & 4.20 & 23,33 & 5.27 \\
\hline 85 & 125.00 & 7.70 & 97.20 & 80.00 & 37.00 & 51.00 & 9.50 & 4.50 & 10.00 & 2.80 \\
\hline 87 & 152.50 & 7.35 & 125.15 & 90.50 & 50.50 & 67.50 & 12.00 & 4.30 & 15.00 & 3.10 \\
\hline 88 & 172.50 & 7.20 & 137.80 & 105.00 & 54.50 & 75.00 & 11.00 & 6.10 & 15.50 & 3.85 \\
\hline (2 yearly) & & & & & & & & & & \\
\hline Mean \#1 & 225.6 & 7.5 & 183.4 & 142.8 & 79.0 & 98.8 & 15.5 & 4.4 & 22.7 & 5.4 \\
\hline Mean \#2 & 177.5 & 7.6 & 139.8 & 109.0 & 58.5 & 76.0 & 11.8 & 4.4 & 16.7 & 4.0 \\
\hline Mean \#3 & 138.8 & 7.5 & 111.2 & 85.3 & 43.8 & 59.3 & 10.8 & 4.4 & 12.5 & 3.0 \\
\hline Mean $\# 4$ & 162.5 & 7.3 & 131.5 & 97.8 & 52.5 & 71.3 & 11.5 & 5.2 & 15.3 & 3.5 \\
\hline (3 yearly) & & & & & & & & & & \\
\hline Mean $\# 5$ & 192.08 & 7.53 & 154.64 & 121.83 & 65.00 & 82.83 & 13.50 & 4.43 & 18.44 & 4.55 \\
\hline Mean \#6 & 169.17 & 7.48 & 134.92 & 102.83 & 55.83 & 73.17 & 11.83 & 4.33 & 16.11 & 3.72 \\
\hline Mean \#7 & 150.00 & 7.42 & 120.05 & 91.83 & 47.33 & 64.50 & 10.83 & 4.97 & 13.50 & 3.25 \\
\hline (4 yearty) & & & & & & & & & & \\
\hline Mean \#8 & 182.19 & 7.49 & 147.27 & 114.00 & 61.38 & 79.00 & 13.13 & 4.39 & 17.58 & 4.19 \\
\hline Mean $\# 9$ & 170.00 & 7.41 & 135.64 & 103.38 & 55.50 & 73.63 & 11.63 & 4.78 & 15.96 & 3.75 \\
\hline
\end{tabular}

Note: $\quad$ Mean \#1 = Mean of years 83,84 Mean \#2 = Mean of years 84,85 Mean \#3 $=$ Mean of years 85,87 Mean \#4 $=$ Mean of years 87,88 Mean \#5 = Mean of years $83,84,85$
Mean $\# 6=$ Mean of years $84,85,87$ Mean \#7 = Mean of years $85,87,88$ Mean \#8= Mean of years $83,84,85,87$ Mean \#9 $=$ Mean of years $84,85,87,88$ 
Table A.3(b) Annual Mean Values of the Water Quality Parameters (Grouped) from the Nogoa River Basin (continued)

\section{Station 130209}

(Calibration set)

\begin{tabular}{|c|c|c|c|c|c|c|c|c|c|c|}
\hline YEAR & $\begin{array}{c}\text { CONOUCTIVITY } \\
\text { @ } 25 \mathrm{C} \\
(\mathrm{n} \mathrm{S} / \mathrm{m})\end{array}$ & PH & $\begin{array}{c}\text { DISSOLYED } \\
\text { IONS } \\
\text { (mg/l) } \\
\end{array}$ & $\begin{array}{c}\text { DISSOLVED } \\
\text { SOLIDS } \\
\text { (mg/i) }\end{array}$ & $\begin{array}{l}\text { HARDNESS } \\
\text { (mag//)as CaCO3 }\end{array}$ & $\begin{array}{l}\text { ALKaLinity } \\
\text { (mgg/l)as CaCO3 }\end{array}$ & NATRIUM & $\begin{array}{l}\text { KaLIUM } \\
\text { (mgll) } \\
\end{array}$ & (mg/li) & MAGNESIUM \\
\hline 72 & 177.50 & 7.35 & 139.75 & 93.50 & 51.00 & 74.00 & 18.00 & - & 13.00 & 4.50 \\
\hline 73 & 155.20 & 7.79 & 145.00 & 97.30 & 63.10 & 69.40 & 10.28 & 4.66 & 16.40 & 5.34 \\
\hline 74 & 277.67 & 7.60 & 227.20 & 172.33 & 107.67 & 119.00 & 16.83 & 5.00 & 21.00 & 13.43 \\
\hline 75 & 198.75 & 7.53 & 153.20 & 115.25 & 69.00 & 83.00 & 13.70 & 4.53 & 17.50 & 6.13 \\
\hline 76 & 612.50 & 7.90 & 485.75 & 336.50 & 202.50 & 267.00 & 57.00 & 3.55 & 25.00 & 34.00 \\
\hline 77 & 732.50 & 8.60 & 525.40 & 372.50 & 236.50 & 278.50 & 55.00 & 3.10 & 28.00 & 40.50 \\
\hline 78 & 293.33 & 7.70 & 240.80 & 180.00 & 97.00 & 124.67 & 24.00 & 4.53 & 22.00 & 10.17 \\
\hline 80 & 160.00 & 7.50 & 111.20 & 91.00 & 47.00 & 48.00 & 13.00 & 3.40 & 13.00 & 3.50 \\
\hline Mean & 325.93 & 7.75 & 253.54 & 182.30 & 109.22 & 132.95 & 25.98 & 3.60 & 19.49 & 14.70 \\
\hline $\begin{array}{l}\text { Standard } \\
\text { Deviation }\end{array}$ & 222.23 & 0.39 & 162.02 & 112.12 & 71.77 & 89.95 & 18.98 & 1.62 & 5.47 & 14.40 \\
\hline
\end{tabular}

(Validation set)

\begin{tabular}{|c|c|c|c|c|c|c|c|c|c|c|}
\hline YEAF & $\begin{array}{c}\text { CONDUCTIVITY } \\
\text { @25C } \\
(\mathrm{mS} / \mathrm{m})\end{array}$ & PH & $\begin{array}{c}\text { DISSOLVED } \\
\text { IONS } \\
\text { (mg/) }\end{array}$ & $\begin{array}{c}\text { DISSOLVED } \\
\text { SOLIDS } \\
\text { (mg/l) }\end{array}$ & $\begin{array}{l}\text { HARDNESS } \\
\text { (mg/l)as CaCO3 }\end{array}$ & $\begin{array}{l}\text { ALKALINITY } \\
\text { (mgfl)as CaCO3 }\end{array}$ & $\begin{array}{l}\text { NATRIUM } \\
\text { (mg/) }\end{array}$ & $\begin{array}{l}\text { KALIUM } \\
\text { (mg/h) }\end{array}$ & $\begin{array}{l}\text { CALCIUM } \\
\text { (mng/l) }\end{array}$ & $\begin{array}{c}\text { MAGNESIUM } \\
\text { (mg/l) }\end{array}$ \\
\hline (1 yearly) & & & & & & & & & & \\
\hline 83 & 165.00 & 7.40 & 134.27 & 113.33 & 54.00 & 67.33 & 13.00 & 5.17 & 14.67 & 4.30 \\
\hline 84 & 265.00 & 7.47 & 202.83 & 156.67 & 78.00 & 100.33 & 21.33 & 5.23 & 18.67 & 7.70 \\
\hline 85 & 207.50 & 7.45 & 147.80 & 120.00 & 57.50 & 65.50 & 14.50 & 4.95 & 15.50 & 4.65 \\
\hline 87 & 171.67 & 7.53 & 137.37 & 105.67 & 58.33 & 68.50 & 11.30 & 4.90 & 14.50 & 4.55 \\
\hline 88 & 170.00 & 7.40 & 132.00 & 105.00 & 54.00 & 72.67 & 11.67 & 5.37 & 16.00 & 4.43 \\
\hline (2 yearily) & & & & & & & & & & \\
\hline Mean \#1 & 215.0 & 7.4 & 168.6 & 135.0 & 66.0 & 83.8 & 17.2 & 5.2 & 16.7 & 6.0 \\
\hline Mean \#2 & 236.3 & 7.5 & 175.3 & 138.3 & 67.8 & 82.9 & 17.9 & 5.1 & 17.1 & 6.2 \\
\hline Mean $\sharp 3$ & 189.6 & 7.5 & 142.6 & 112.8 & 57.9 & 67.0 & 12.9 & 4.9 & 15.0 & 4.6 \\
\hline Mean $\# 4$ & 170.8 & 7.5 & 134.7 & 105.3 & 56.2 & 70.6 & 11.5 & 5.1 & 15.3 & 4.5 \\
\hline (3 yeerly) & & & & & & & & & & \\
\hline Mean \#5 & 212.50 & 7.44 & 161.63 & 130.00 & 63.17 & 77.72 & 16.28 & 5.12 & 16.28 & 5.55 \\
\hline Mean \#6 & 214.72 & 7.48 & 162.67 & 127.44 & 64.61 & 78.11 & 15.71 & 5.03 & 16.22 & 5.63 \\
\hline Mean \#7 & 183.06 & 7.46 & 139.06 & $1+0.22$ & 56.61 & 68.89 & 12.49 & 5.07 & 15.33 & 4.54 \\
\hline (4 yearly) & & & & & & & & & & \\
\hline Mean $\# 8$ & 202.29 & 7.46 & 155.57 & 123.92 & 61.96 & 75.42 & 15.03 & 5.06 & 15.83 & 5.30 \\
\hline Mean $\# 9$ & 203.54 & 7.46 & 155.00 & 121.83 & 61.96 & 76.75 & 14.70 & 5.11 & 16.17 & 5.33 \\
\hline
\end{tabular}

Note: $\quad$ Mean \#1 = Mean of years 83,84

Mean \#2 = Mean of years 84,85

Mean \#3 = Mean of years 85,87

Mean \#4 = Mean of years 87,88

Mean \#5 = Mean of years $83,84,85$
Mean \#6 = Mean of years $84,85,87$

Mean \#7 = Mean of years $85,87,88$

Mean \#8 = Mean of years $83,84,85,87$

Mean $\# 9=$ Mean of years $84,85,87,88$ 


\section{Table A.3(c) Annual Mean Values of the Water Quality Parameters (Grouped) from the Logan River Basin}

\section{Station 145010}

(Calibration set)

\begin{tabular}{|c|c|c|c|c|c|c|c|c|c|c|}
\hline YEAH & $\begin{array}{c}\text { CONOUCTVITY } \\
@ 25 \mathrm{C} \\
(\pi \mathrm{S} / \mathrm{m})\end{array}$ & $\mathrm{PH}$ & $\begin{array}{c}\text { DISSOLVED } \\
\text { IONS } \\
\text { (mg/i) }\end{array}$ & $\begin{array}{c}\text { DISSOLVED } \\
\text { sOLIDS } \\
\text { (mg/l) }\end{array}$ & $\begin{array}{l}\text { HARDNESS } \\
\text { \{mg//\}as } \mathrm{CACO}_{3}\end{array}$ & $\begin{array}{l}\text { ALKALINITY } \\
\text { (mgg/)as CaCO3 }\end{array}$ & $\begin{array}{l}\text { NATRIUM } \\
\text { (mgid) }\end{array}$ & $\begin{array}{l}\text { KALIUM } \\
\text { (mag/) }\end{array}$ & $\begin{array}{l}\text { CALCIUA } \\
\text { (mggh) }\end{array}$ & $\begin{array}{c}\text { MAGNESIUM } \\
\text { (mg/l) }\end{array}$ \\
\hline 78 & 426,0 & 7.7 & 274.7 & 240.4 & 146.2 & 98.0 & 29.0 & 1.5 & 26.2 & 19.6 \\
\hline 79 & 147.5 & 6.8 & 91.8 & 94.0 & 42.0 & 24.5 & 13.5 & 1.9 & 7.9 & 5.5 \\
\hline 80 & 360.0 & 7.8 & 235.0 & 203.3 & 116.3 & 92.0 & 24.0 & 1.4 & 20.7 & 15.7 \\
\hline 81 & 393.0 & 8.1 & 248.1 & 214.5 & 108.0 & 89.5 & 31.5 & 1.4 & 18.5 & 15.0 \\
\hline 82 & 382.5 & 8.1 & 253.5 & 217.5 & 128.5 & 103.0 & 25.0 & 1.4 & 22.7 & 17.5 \\
\hline 83 & 439.2 & 8.0 & 294.1 & 246.7 & 146.5 & 119.3 & 31.2 & 1.5 & 25.6 & 20.1 \\
\hline 84 & 340.8 & 7.9 & 233.3 & 197.2 & 112.3 & 97.2 & 24.0 & 1.3 & 19.9 & 15.2 \\
\hline Mean & 355.6 & 7.8 & 232.9 & 201.9 & 114.3 & 89.1 & 25.5 & 1.5 & 20.2 & 15.5 \\
\hline $\begin{array}{l}\text { Standard } \\
\text { Deviation }\end{array}$ & 98.0 & 0.5 & 65.9 & 50.9 & 35.4 & 30.1 & 6.2 & 0.2 & 6.1 & 4.9 \\
\hline
\end{tabular}

(Validation set)

\begin{tabular}{|c|c|c|c|c|c|c|c|c|c|c|}
\hline YEAR & $\begin{array}{c}\text { CONDUCTIVITY } \\
\text { @25C } \\
(\mathrm{ms} / \mathrm{m})\end{array}$ & $\mathrm{PH}$ & $\begin{array}{c}\text { DISSOLVED } \\
\text { IONS } \\
\text { (mg/A) }\end{array}$ & $\begin{array}{c}\text { DISSOLVED } \\
\text { SOLIDS } \\
\text { (mg/l) }\end{array}$ & $\begin{array}{l}\text { HAADNESS } \\
\text { (mg/)aa } \mathrm{CBCO}_{3}\end{array}$ & $\begin{array}{l}\text { ALKALINITY } \\
\text { (mg/)as CaCO3 }\end{array}$ & NATFIUM & $\begin{array}{l}\text { KALIUM } \\
\text { (mg/t) } \\
\end{array}$ & $\begin{array}{l}\text { CaLcIUM } \\
\text { (mgf) } \\
\end{array}$ & MAGNESIUM \\
\hline (i yearly) & & & & & & & & & & \\
\hline 85 & 348.5 & 7.8 & 220.2 & 188.0 & 108.5 & 83.5 & 53.4 & 1.3 & 10.1 & 16.9 \\
\hline 86 & 360.0 & 8.0 & 223.5 & 192.5 & 115.3 & 83.8 & 22.0 & 1.2 & 20.0 & 15.9 \\
\hline 87 & 205.0 & 7.4 & 129.9 & 117.0 & 64.0 & 47.3 & 14.5 & 1.5 & 11.6 & 8.5 \\
\hline 88 & 328.8 & 7.6 & 222.6 & 192.0 & 112.3 & 87.8 & 23.3 & 1.3 & 20.0 & 15.1 \\
\hline 89 & 347.5 & 7.9 & 250.5 & 210.0 & 109.5 & 95.5 & 32.8 & 1.5 & 20.8 & 14.0 \\
\hline (2 yearly) & & & & & & & & & & \\
\hline Mean \#1 & 354.3 & 7.9 & 221.8 & 190.3 & 111.9 & 83.6 & 37.7 & 1.2 & 15.1 & 16.4 \\
\hline Mean $\# 2$ & 282.5 & 7.7 & 176.7 & 154.8 & 89.6 & 65.5 & 18.2 & 1.3 & 15.8 & 12.2 \\
\hline Mean \#3 & 266.9 & 7.5 & 176.2 & 154.5 & 88.1 & 67.5 & 18.9 & 1.4 & 15.8 & 11.8 \\
\hline Mean \#4 & 338.1 & 7.8 & 236.5 & 201.0 & 110.9 & 91.6 & 28.0 & 1.4 & 20.4 & 14.6 \\
\hline (3 yeatly) & & & & & & & & & & \\
\hline Mean \#5 & 304.5 & 7.7 & 191.2 & 165.8 & 95.9 & 71.5 & 29.9 & 1.3 & 13.9 & 13.8 \\
\hline Mean $\# 6$ & 297.9 & 7.7 & 192.0 & 167.2 & 97.2 & 72.9 & 19.9 & 1.3 & 17.2 & 13.2 \\
\hline Mean \#7 & 293.8 & 7.7 & 201.0 & 173.0 & 95.3 & 76.9 & 23.5 & 1.4 & 17.5 & 12.5 \\
\hline (4 yeariy) & & & & & & & & & & \\
\hline Mean \#8 & 310.6 & 7.7 & 199.0 & 172.4 & 100.0 & 75.6 & 28.3 & 1.3 & 15.4 & 14.1 \\
\hline Mean \#9 & 310.3 & 7.7 & 206.6 & 177.9 & 100.3 & 78.6 & 23.1 & 1.3 & 18.1 & 13.4 \\
\hline
\end{tabular}

Note: $\quad$ Mean \#1 = Mean of years 85,86 Mean \#2 = Mean of years 86,87 Mean \#3 $=$ Mean of years 87,88 Mean \#4 = Mean of years 88,89 Mean \#5 = Mean of years $85,86,87$
Mean \#6 = Mean of years $86,87,88$

Mean $\# 7=$ Mean of years $87,88,89$

Mean \#8 = Mean of years $85,86,87,88$

Mean $\# 9=$ Mean of years $86,87,88,89$ 
Table A.3(c) Annual Mean Values of the Water Quality Parameters (Grouped) from the Logan River Basin (Continued)

Station 145013

(Calibration set)

\begin{tabular}{|c|c|c|c|c|c|c|c|c|c|c|}
\hline YEAR & $\begin{array}{c}\text { CONDUCTIVITY } \\
@ 25 \mathrm{C} \\
(\mathrm{ms} / \mathrm{m})\end{array}$ & PH & $\begin{array}{c}\text { OISSOLVED } \\
\text { IONS } \\
\text { (mg } h) \\
\end{array}$ & $\begin{array}{c}\text { DISSOLVED } \\
\text { SOLIDS } \\
\text { (mg/l) } \\
\end{array}$ & $\begin{array}{l}\text { HARDNESS } \\
\text { (mg/)as CaCO } 3 \\
\end{array}$ & $\begin{array}{l}\text { ALKALINITY } \\
\text { (mgi/l)as CaCOB }\end{array}$ & NATRIUM & KALIUM & CALCIUM & MAGNESIUM \\
\hline 78 & 598.3 & 7.9 & 404.9 & 340.3 & 206.7 & 155.3 & 43.7 & 1.8 & 37.7 & 27.3 \\
\hline 79 & 450.0 & 8.0 & 266.7 & 261.0 & 130.0 & 100.0 & 29.0 & 2.0 & 24.0 & 17.0 \\
\hline 80 & 541.0 & 7.6 & 359.7 & 297.0 & 175.3 & 151.0 & 38.0 & 1.9 & 33.3 & 22.3 \\
\hline 81 & 432.5 & 8.1 & 276.3 & 238.0 & 131.8 & 110.0 & 30.3 & 1.4 & 24.0 & 17.5 \\
\hline 82 & 429.0 & 7.8 & 255.2 & 253.2 & 146.4 & 89.6 & 32.2 & 1.6 & 26.8 & 19.3 \\
\hline 83 & 494.0 & 7.7 & 327.3 & 232.0 & 152.4 & 129.0 & 39.2 & 2.0 & 27.7 & 20.2 \\
\hline 84 & 525.0 & 8.0 & 363.4 & 296.0 & 176.4 & 156.6 & 38.4 & 1.6 & 31.4 & 23.8 \\
\hline Mean & 495.7 & 7.9 & 321.9 & 273.9 & 159.9 & 127.4 & 35.8 & 1.8 & 29.3 & 21.1 \\
\hline $\begin{array}{l}\text { Standard } \\
\text { Deviation }\end{array}$ & 63.2 & 0.2 & 57.2 & 38.9 & 27.8 & 27.9 & 5.4 & 0.2 & 5.1 & 3.7 \\
\hline
\end{tabular}

(Validation set)

\begin{tabular}{|c|c|c|c|c|c|c|c|c|c|c|}
\hline YEAR & $\begin{array}{c}\text { CONDUCTIVITY } \\
@ 25 \mathrm{C} \\
\text { (ms/m) }\end{array}$ & PH & $\begin{array}{c}\text { DISSOLVED } \\
\text { IONS } \\
\text { (mg/l) }\end{array}$ & $\begin{array}{c}\text { DISSOLVED } \\
\text { SOLIOS } \\
\text { (mg/l) }\end{array}$ & $\begin{array}{l}\text { HARDNESS } \\
\text { (mg/l)as CaCOS }\end{array}$ & $\begin{array}{l}\text { ALKALINITY } \\
\text { (mg/I)as CaCO3 }\end{array}$ & $\begin{array}{l}\text { NATRIUM } \\
\text { (mg/l) }\end{array}$ & $\begin{array}{l}\text { KaLIUM } \\
\text { (mgg/l) }\end{array}$ & $\begin{array}{l}\text { CALCIUM } \\
\text { (mg/1) }\end{array}$ & $\begin{array}{c}\text { MAGNESIUM } \\
\text { (mgli) }\end{array}$ \\
\hline (1 yearly) & & & & & & & & & & \\
\hline 85 & 650.0 & 8.0 & 409.4 & 350.0 & 181.6 & 138.8 & 54.1 & 2.5 & 34.0 & 23.5 \\
\hline 86 & 398.0 & 8.1 & 281.8 & 226.0 & 136.4 & 133.4 & 25.6 & 1.7 & 26.4 & 17.1 \\
\hline 87 & 296.7 & 7.7 & 203.3 & 173.3 & 98.0 & 87.7 & 21.0 & 1.6 & 19.0 & 12.3 \\
\hline 88 & 476.3 & 7.9 & 329.8 & 270.0 & 166.3 & 136.8 & 33.5 & 1.6 & 30.8 & 21.8 \\
\hline 89 & 245.0 & 7.7 & 183.6 & 150.0 & 75.0 & 82.0 & 24.0 & 1.6 & 15.5 & 8.7 \\
\hline (2 yeariy) & & & & & & & & & & \\
\hline Mean \#1 & 524.0 & 8.1 & 345.6 & 288.0 & 159.0 & 136.1 & 39.9 & 2.1 & 30.2 & 20.3 \\
\hline Mean \#2 & 347.3 & 7.9 & 242.5 & 199.7 & 117.2 & 110.5 & 23.3 & 1.6 & 22.7 & 14.7 \\
\hline Mean \#3 & 386.5 & 7.8 & 266.5 & 221.7 & 132.1 & 112.2 & 27.3 & 1.6 & 24.9 & 17.0 \\
\hline Mean \#4 & 360.6 & 7.8 & 256.7 & 210.0 & 120.6 & 109.4 & 28.8 & 1.6 & 23.1 & 15.2 \\
\hline (3 yearly) & & & & & & & & & & \\
\hline Mean \#5 & 448.2 & 7.9 & 298.2 & 249.8 & 138.7 & 120.0 & 33.6 & 1.9 & 26.5 & 17.6 \\
\hline Mean \#6 & 390.3 & 7.9 & 271.6 & 223.1 & 133.6 & 119.3 & 26.7 & 1.6 & 25.4 & 17.1 \\
\hline Mean $\# 7$ & 339.3 & 7.8 & 238.9 & 197.8 & 113.1 & 102.1 & 26.2 & 1.6 & 21.8 & 14.3 \\
\hline (4 yearly) & & & & & & & & & & \\
\hline Mean \#8 & 455.2 & 7.9 & 306.1 & 254.8 & 145.6 & 124.2 & 33.6 & 1.9 & 27.5 & 18.7 \\
\hline Mean $\# 9$ & 354.0 & 7.8 & 249.6 & 204.8 & 118.9 & 110.0 & 26.0 & 1.6 & 22.9 & 15.0 \\
\hline
\end{tabular}

Note: $\quad$ Mean \#1 = Mean of years 85,86 Mean $\# 2=$ Mean of years 86,87 Mean \#3 = Mean of years 87,88 Mean $\# 4=$ Mean of years 88,89 Mean $\# 5=$ Mean of years $85,86,87$
Mean \#6 = Mean of years $86,87,88$

Mean $\# 7=$ Mean of years $87,88,89$

Mean \#8 = Mean of years $85,86,87,88$

Mean $\# 9=$ Mean of years $86,87,88,89$ 
Table A.3(c) Annual Mean Values of the Water Quality Parameters (Grouped) from the Logan River Basin (Continued)

\section{Station 145020}

(Calibration set)

\begin{tabular}{|c|c|c|c|c|c|c|c|c|c|c|}
\hline YEAR & $\begin{array}{l}\text { CONDUCTIVITY } \\
\text { @ } 25 \mathrm{C} \\
\text { (mS/m) }\end{array}$ & $\mathrm{PH}$ & $\begin{array}{c}\text { DISSOLVED } \\
\text { IONS } \\
\text { (mg/) }\end{array}$ & $\begin{array}{c}\text { DISSOLVEO } \\
\text { SOLIDS } \\
\text { (mg/l) }\end{array}$ & $\begin{array}{l}\text { HARDNESS } \\
\text { (mg//)as CaCO3 }\end{array}$ & $\begin{array}{l}\text { ALKALINITY } \\
\text { (mg//)as } \mathrm{CaCO3}\end{array}$ & $\begin{array}{l}\text { NATRIUM } \\
\text { (mg/l) }\end{array}$ & $\begin{array}{l}\text { KALIUM } \\
\text { (mg/) } \\
\end{array}$ & CALCIUM & MAGNESIUM \\
\hline 78 & 677.0 & 7.7 & 396.4 & 356.0 & 89.8 & 89.8 & 71.0 & 2.5 & 29.4 & 19.2 \\
\hline 79 & - & - & - & - & - & . & - & - & - & - \\
\hline 80 & 856.7 & 7.7 & 519.6 & 444,7 & 141.0 & 141.0 & 87.3 & 3.1 & 39.7 & 25.7 \\
\hline 81 & 539.7 & 8.1 & 311.7 & 271.3 & 87.3 & 87.3 & 52.7 & 2.0 & 23.3 & 15.3 \\
\hline 82 & 402.5 & 7.7 & 262.3 & 227.5 & 90.8 & 83.3 & 42.8 & 2.3 & 19.8 & 12.1 \\
\hline 83 & 617.5 & 7.9 & 362.2 & 317.5 & 135.8 & 98.8 & 64.5 & 2.5 & 25.6 & 17.4 \\
\hline 84 & 571.3 & 8.1 & 350.5 & 305.0 & 132.3 & 103.5 & 59.8 & 1.9 & 24.5 & 17.3 \\
\hline Mean & 523.5 & 6.7 & 314.7 & 274.6 & 96.7 & 86.2 & 54.0 & 2.0 & 23.2 & 15.3 \\
\hline $\begin{array}{l}\text { Standard } \\
\text { Deviation }\end{array}$ & 273.0 & 3.0 & 162.5 & 141.0 & 49.5 & 43.3 & 28.0 & 1.0 & 12.2 & 8.0 \\
\hline
\end{tabular}

(Validation set)

\begin{tabular}{|c|c|c|c|c|c|c|c|c|c|c|}
\hline YEAH & $\begin{array}{c}\text { CONDUCTIVITY } \\
\text { @ } 25 \mathrm{C} \\
(\mathrm{mS} / \mathrm{m})\end{array}$ & $\mathrm{PH}$ & $\begin{array}{c}\text { DISSOLVED } \\
\text { IONS } \\
\text { (mgl) } \\
\end{array}$ & $\begin{array}{c}\text { DISSOLVED } \\
\text { SOLIDS } \\
(\mathrm{mg} /) \\
\end{array}$ & $\begin{array}{l}\text { HARDNESS } \\
\text { (mg/)as CaCO3 }\end{array}$ & $\begin{array}{l}\text { ALKALINITY } \\
\text { (mg/l)as } \mathrm{CaCO} 3\end{array}$ & $\begin{array}{l}\text { NATRIUM } \\
(\mathrm{mg} / \mathrm{l}) \\
\end{array}$ & $\begin{array}{l}\text { KALIUM } \\
\text { (mg/f) } \\
\end{array}$ & $\begin{array}{l}\text { CALCIUM } \\
\text { (ming/l) }\end{array}$ & $\begin{array}{l}\text { MAGNESIUM } \\
\text { (mg/l) }\end{array}$ \\
\hline (1 yoarly) & & & & & & & & & & \\
\hline 85 & 397.5 & 7.8 & 241.7 & 210.0 & 86.3 & 73.5 & 41.3 & 2.1 & 17.0 & 10.7 \\
\hline 86 & 434.0 & 7.9 & 264.4 & 224.0 & 96.2 & 81.0 & 45.0 & 2.6 & 19.3 & 11.6 \\
\hline 87 & 268.3 & 7.5 & 162.5 & 143.3 & 57.3 & 47.3 & 29.5 & 1.7 & 11.8 & 6.8 \\
\hline 88 & 645.0 & 7.9 & 400.6 & 340.0 & 159.3 & 119.3 & 66.8 & 2.3 & 32.0 & 19.3 \\
\hline 89 & 631.7 & 7.9 & 425.9 & 366.7 & 172.7 & 123.7 & 69.7 & 2.4 & 31.7 & 22.7 \\
\hline (2 yeariy) & & & & & & & & & & \\
\hline Mean \#1 & 415.8 & 7.9 & 253.0 & 217.0 & 91.2 & 77.3 & 43.1 & 2.4 & 18.2 & 11.1 \\
\hline Mean \#2 & 351.2 & 7.7 & 213.5 & 183.7 & 76.8 & 64.2 & 37.3 & 2.2 & 15.6 & 9.2 \\
\hline Mean \#3 & 456.7 & 7.7 & 281.5 & 241.7 & 108.3 & 83.3 & 48.1 & 2.0 & 21.9 & 13.0 \\
\hline Mean \#4 & 638.3 & 7.9 & 413.2 & 353.3 & 166.0 & 121.5 & 68.2 & 2.3 & 31.8 & 21.0 \\
\hline (3 yearly) & & & & & & & & & & \\
\hline Mean \#5 & 366.6 & 7.7 & 222.9 & 192.4 & 79.9 & 67.3 & 38.6 & 2.1 & 16.0 & 9.7 \\
\hline Mean $\# 6$ & 449.1 & 7.8 & 275.8 & 235.8 & 104.3 & 82.5 & 47.1 & 2.2 & 21.0 & 12.5 \\
\hline Mean \#7 & 515.0 & 7.7 & 329.6 & 283.3 & 129.8 & 96.8 & 55.3 & 2.1 & 25.2 & 16.3 \\
\hline (4 yearly) & & & & & & & & & & \\
\hline Mean $\# 8$ & 436.2 & 7.8 & 267.3 & 229.3 & 99.8 & 80.3 & 45.6 & 2.2 & 20.0 & 12.1 \\
\hline Mean \#9 & 494.8 & 7.8 & 313.3 & 268.5 & 121.4 & 92.8 & 52.7 & 2.2 & 23.7 & 15.1 \\
\hline
\end{tabular}

Note: $\quad$ Mean \#1 = Mean of years 85,86 Mean \#2 = Mean of years 86,87 Mean \#3 = Mean of years 87,88 Mean \#4 = Mean of years 88,89 Mean $\# 5=$ Mean of years $85,86,87$
Mean \#6 = Mean of years $86,87,88$

Mean \#7 = Mean of years $87,88,89$

Mean $\# 8=$ Mean of years $85,86,87,88$

Mean $\# 9=$ Mean of years $86,87,88,89$ 
Table A.3(c) Annual Mean Values of the Water Quality Parameters (Grouped) from the Logan River Basin (Continued)

\section{Station 145008}

(Calibration set)

\begin{tabular}{|c|c|c|c|c|c|c|c|c|c|c|}
\hline YEAF & $\begin{array}{c}\text { CONOUCTIVITY } \\
\text { @ 25C } \\
(\mathrm{mS} / \mathrm{m})\end{array}$ & $\mathrm{PH}$ & $\begin{array}{c}\text { DISSOLVED } \\
\text { IONS } \\
\text { (mg } n \text { ) }\end{array}$ & $\begin{array}{c}\text { DISSOLVED } \\
\text { SOLIDS } \\
\text { (rrag/) }\end{array}$ & $\begin{array}{l}\text { HARDNESS } \\
\text { (ngg/l)as } \mathrm{CaCO} 3\end{array}$ & $\begin{array}{l}\text { ALKALINITY } \\
\text { (mag/)as CaCo }\end{array}$ & NATRIUM & KALIUM & CALCIUM & MAGNESIUM \\
\hline 78 & 770.0 & 7.9 & 488.7 & 416.7 & 218.7 & 152.7 & 71.3 & 2.5 & 41.3 & 28.0 \\
\hline 79 & - & - & - & - & - & - & - & - & - & - \\
\hline 80 & 516.7 & 8.0 & 336.6 & 281.0 & 148.3 & 127.7 & 43.0 & 2.4 & 28.7 & 18.6 \\
\hline 81 & 628.0 & 7.9 & 377.3 & 326.7 & 159.3 & 115.7 & 57.7 & 2.0 & 29.7 & 20.7 \\
\hline 82 & 546.7 & 8.0 & 355.8 & 296.7 & 155.0 & 128.7 & 49.0 & 3.6 & 899.0 & 19.8 \\
\hline 83 & 535.0 & 7.8 & 342.0 & 286.7 & 151.3 & 124.0 & 48.7 & 2.0 & 28.5 & 19.5 \\
\hline 84 & 633.3 & 8.0 & 421.0 & 350.0 & 186.3 & 157.0 & 56.0 & 2.4 & 34.0 & 24.7 \\
\hline Mean & 518.5 & 6.8 & 331.6 & 279.7 & 145.6 & 115.1 & 46.5 & 2.1 & 151.6 & 18.8 \\
\hline $\begin{array}{l}\text { Standard } \\
\text { Deviation }\end{array}$ & 247.9 & 3.0 & 157.9 & 133.8 & 69.9 & 53.7 & 22.7 & 1.1 & 334.5 & 9.0 \\
\hline
\end{tabular}

(Validation set)

\begin{tabular}{|c|c|c|c|c|c|c|c|c|c|c|}
\hline YEAR & $\begin{array}{c}\text { CONDUCTIVITY } \\
\text { @ 25C } \\
(\mathrm{mS} / \mathrm{m}) \\
\end{array}$ & $\mathrm{PH}$ & $\begin{array}{c}\text { DISSOLVED } \\
\text { IONS } \\
\text { (mgil) }\end{array}$ & $\begin{array}{c}\text { DISSOLVED } \\
\text { SOLIDS } \\
\text { (mg/) }\end{array}$ & $\begin{array}{l}\text { HARDNESS } \\
\text { (mg/)as CaCOB } \\
\end{array}$ & $\begin{array}{l}\text { ALKALINITY } \\
\text { (mg/)as CaCOS }\end{array}$ & $\begin{array}{l}\text { NATHIUM } \\
\text { (mg/f) }\end{array}$ & $\begin{array}{l}\text { KALIUM } \\
\text { (mingll) } \\
\end{array}$ & $\begin{array}{l}\text { CALCIUM } \\
\text { (mg/i) } \\
\end{array}$ & $\begin{array}{l}\text { MAGNESIUM } \\
\text { (ming/l) }\end{array}$ \\
\hline$(1$ yearly) & & & & & & & & & & \\
\hline 85 & 393.3 & 7.7 & 243.9 & 210.0 & 105.3 & 87.3 & 33.3 & 1.6 & 19.7 & 8.7 \\
\hline 86 & 475.6 & 7.9 & 308.6 & 253.8 & 131.6 & 112.6 & 42.4 & 2.1 & 25.6 & 16.4 \\
\hline 87 & 236.7 & 7.6 & 135.5 & 130.0 & 58.3 & 52.0 & 20.7 & 1.8 & 11.9 & 7.0 \\
\hline 88 & 638.3 & 8.0 & 420.3 & 346.7 & 191.3 & 153.0 & 55.3 & 2.2 & 36.7 & 24.2 \\
\hline 89 & 480.0 & 8.5 & 323.2 & 280.0 & 146.0 & 107.0 & 45.5 & 2.3 & 20.5 & 23.0 \\
\hline (2 yearly) & & & & & & & & & & \\
\hline Mean \#1 & 434.5 & 7.8 & 276.2 & 231.9 & 118.5 & 100.0 & 37.9 & 1.8 & 22.6 & 12.5 \\
\hline Mean \#2 & 356.1 & 7.7 & 222.0 & 191.9 & 95.0 & 82.3 & 31.6 & 1.9 & 18.8 & 11.7 \\
\hline Mean \#3 & 437.5 & 7.8 & 277.9 & 238.3 & 124.8 & 102.5 & 38.0 & 2.0 & 24.3 & 15.6 \\
\hline Mean \#4 & 559.2 & 8.3 & 371.8 & 313.3 & 168.7 & 130.0 & 50.4 & 2.2 & 28.6 & 23.6 \\
\hline (3 yearly) & & & & & & & & & & \\
\hline Mean \#5 & 368.5 & 7.7 & 229.3 & 197.9 & 98.4 & 84.0 & 32.1 & 1.8 & 19.1 & 10.7 \\
\hline Mean $\# 6$ & 450.2 & 7.8 & 288.1 & 243.5 & 127.1 & 105.9 & 39.5 & 2.0 & 24.7 & 15.8 \\
\hline Mean \#7 & 451.7 & 8.0 & 293.0 & 252.2 & 131.9 & 104.0 & 40.5 & 2.1 & 23.0 & 18.0 \\
\hline (4 yearfy) & & & & & & & & & & \\
\hline Mean \#8 & 436.0 & 7.8 & 277.1 & 235.1 & 121.7 & 101.2 & 37.9 & 1.9 & 23.5 & 14.1 \\
\hline Mean \#9 & 457.7 & 8.0 & 296.9 & 252.6 & 131.8 & 106.2 & 41.0 & 2.1 & 23.7 & 17.6 \\
\hline
\end{tabular}

Note: $\quad$ Mean \#1 = Mean of years 85,86 Mean \#2 = Mean of years 86,87 Mean \#3 $=$ Mean of years 87,88 Mean \#4 = Mean of years 88,89 Mean \#5 = Mean of years 85,86,87
Mean \#6 = Mean of years $86,87,88$ Mean $\# 7=$ Mean of years $87,88,89$ Mean \#8 $=$ Mean of years $85,86,87,88$ Mean $\# 9=$ Mean of years $86,87,88,89$ 
Table A.4.1 Results of Assignment of Water Quality Values in the Fitzroy River Basin

Table A.4.1(a) 1 yearly

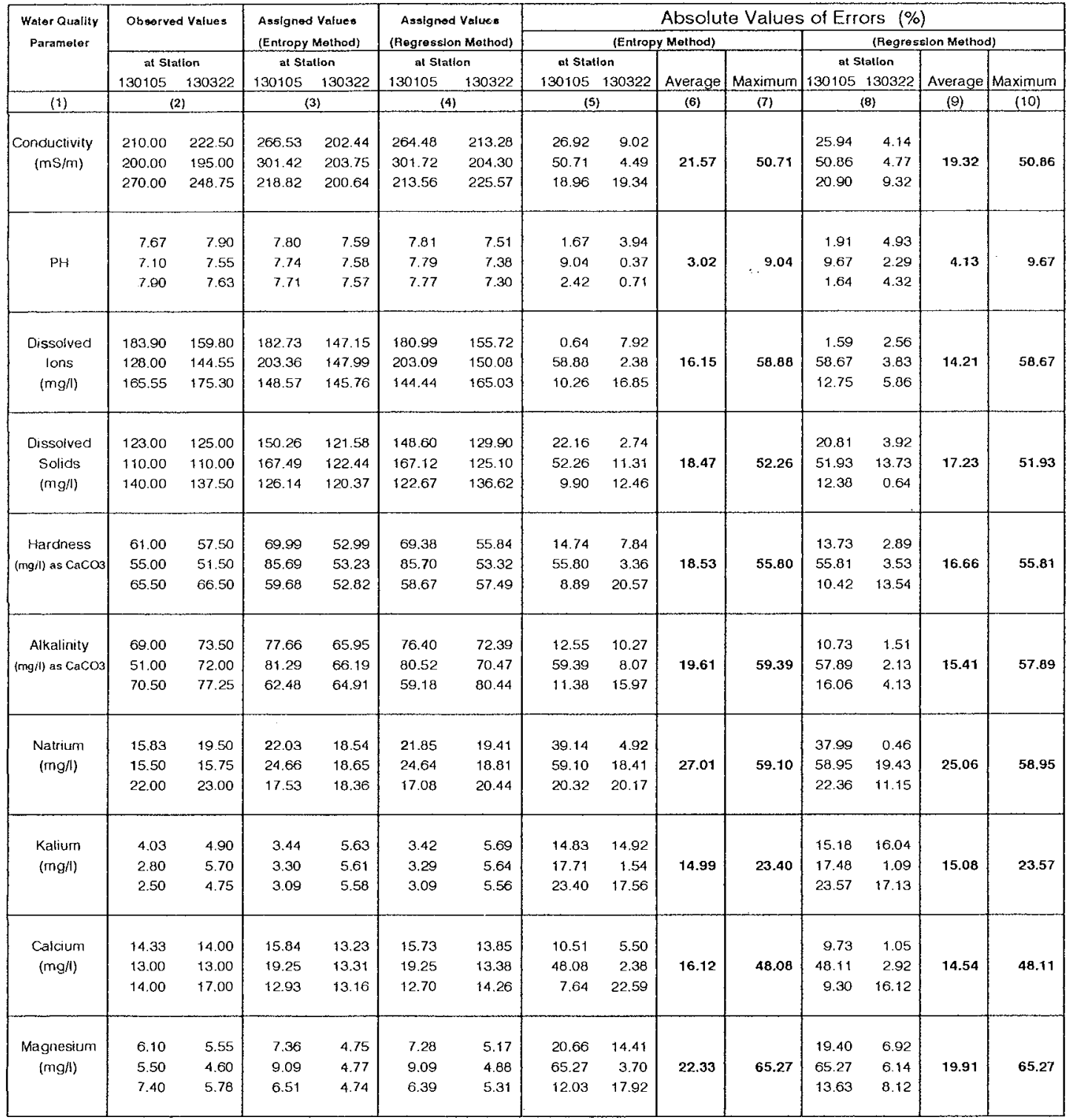


Table A.4.1(b) 2 yearly

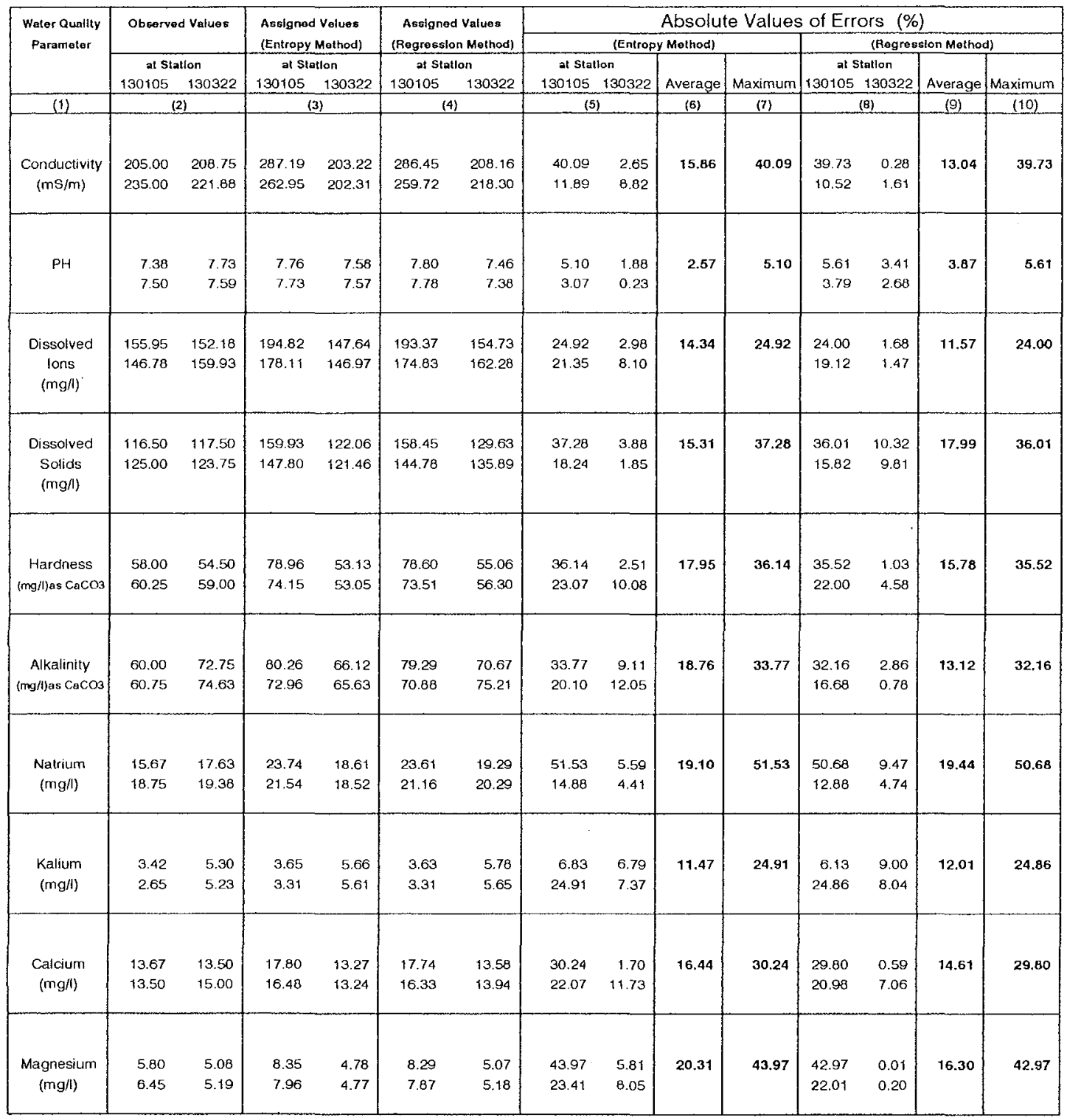


Table A.4.1(c) 3 yearly

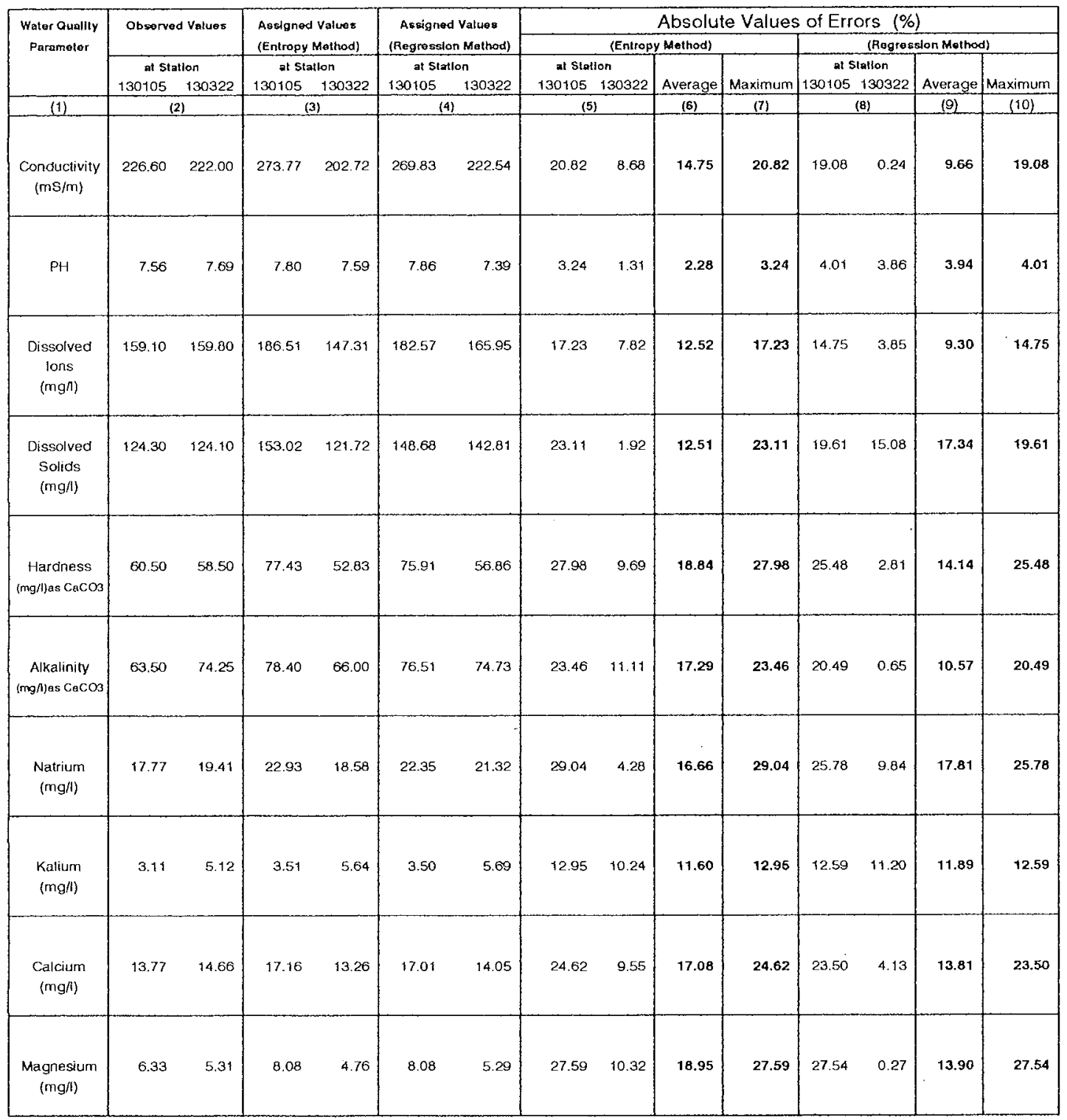


Table A.4.2 Results of Assignment of Water Quality Values in the Nogoa River Basin

Table A.4.2(a) 1 yearly

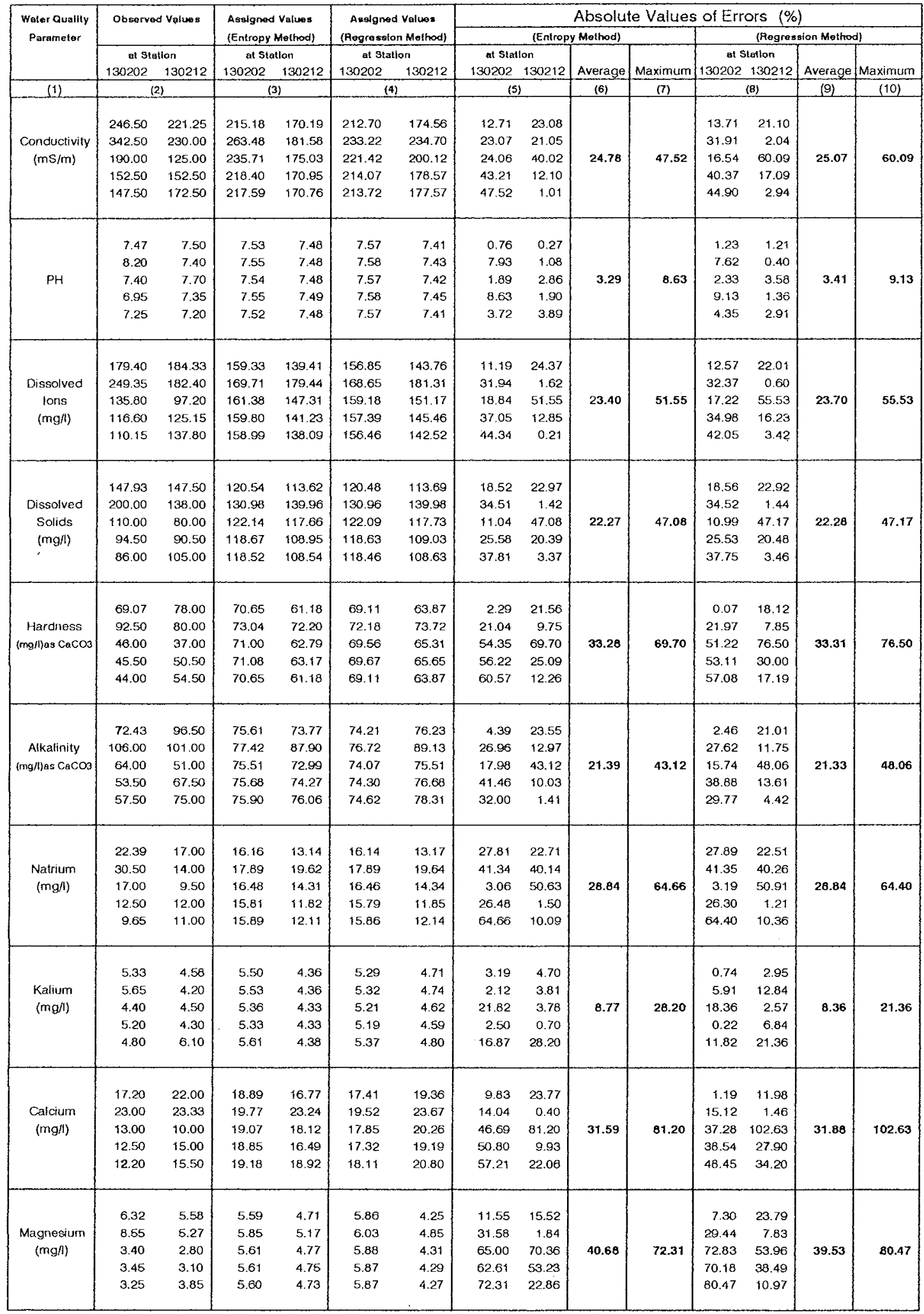


Table A.4.2(b) 2 yearly

\begin{tabular}{|c|c|c|c|c|c|c|c|c|c|c|c|c|c|c|}
\hline \multirow{4}{*}{$\begin{array}{l}\text { Water Quality } \\
\text { Paramater }\end{array}$} & \multirow{2}{*}{\multicolumn{2}{|c|}{ Observed Values }} & \multirow{2}{*}{\multicolumn{2}{|c|}{$\begin{array}{l}\text { Assigned Values } \\
\text { (Eniropy Method) }\end{array}$}} & \multirow{2}{*}{\multicolumn{2}{|c|}{$\begin{array}{c}\text { Assigned Values } \\
\text { (Regression Method) }\end{array}$}} & \multicolumn{8}{|c|}{ Absolute Values of Errors $(\%)$} \\
\hline & & & & & & & \multicolumn{4}{|c|}{ (Entropy Mothod) } & \multicolumn{4}{|c|}{ (Ragression Mathod) } \\
\hline & \multicolumn{2}{|c|}{ at Statlon } & \multicolumn{2}{|c|}{ at Statlon } & \multicolumn{2}{|c|}{ at Statton } & \multicolumn{2}{|c|}{ at Station } & \multirow[b]{2}{*}{ Average } & \multirow[b]{2}{*}{ Maximum } & \multicolumn{2}{|c|}{ at Station } & \multirow[b]{2}{*}{ Average } & \multirow[b]{2}{*}{ Maximum } \\
\hline & 130202 & 130212 & 130202 & 130212 & 130202 & 130212 & 130202 & 130212 & & & 130202 & 130212 & & \\
\hline (1) & \multicolumn{2}{|c|}{ (2) } & \multicolumn{2}{|c|}{ (3) } & \multicolumn{2}{|c|}{ (4) } & \multicolumn{2}{|c|}{ (5) } & (6) & (7) & \multicolumn{2}{|c|}{ (8) } & (9) & (10) \\
\hline $\begin{array}{c}\text { Conductivity } \\
\text { (ms/m) }\end{array}$ & $\begin{array}{l}294.50 \\
266.25 \\
171.25 \\
150.00\end{array}$ & $\begin{array}{l}225.63 \\
177.50 \\
138.75 \\
162.50\end{array}$ & $\begin{array}{l}237.12 \\
247.85 \\
224.30 \\
214.83\end{array}$ & $\begin{array}{l}175.36 \\
177.90 \\
172.37 \\
170.10\end{array}$ & $\begin{array}{l}227.84 \\
232.07 \\
222.78 \\
219.04\end{array}$ & $\begin{array}{l}191.72 \\
205.65 \\
175.07 \\
162.78\end{array}$ & $\begin{array}{r}19.48 \\
6.91 \\
30.99 \\
43.22\end{array}$ & $\begin{array}{r}22.28 \\
0.23 \\
24.23 \\
4.68\end{array}$ & 19.00 & 43.22 & $\begin{array}{l}22.64 \\
12.84 \\
30.09 \\
46.03\end{array}$ & $\begin{array}{r}15.03 \\
15.86 \\
26.18 \\
0.17\end{array}$ & 21.10 & 46.03 \\
\hline $\mathrm{PH}$ & $\begin{array}{l}7.84 \\
7.80 \\
7.18 \\
7.10\end{array}$ & $\begin{array}{l}7.45 \\
7.55 \\
7.53 \\
7.28\end{array}$ & $\begin{array}{l}7.48 \\
7.48 \\
7.49 \\
7.48\end{array}$ & $\begin{array}{l}7.90 \\
7.90 \\
7.91 \\
7.90\end{array}$ & $\begin{array}{l}7.65 \\
7.65 \\
7.65 \\
7.65\end{array}$ & $\begin{array}{l}7.32 \\
7.34 \\
7.35 \\
7.34\end{array}$ & $\begin{array}{l}4.55 \\
4.10 \\
4.39 \\
5.35\end{array}$ & $\begin{array}{l}6.04 \\
4.64 \\
5.12 \\
8.59\end{array}$ & 5.35 & 8.59 & $\begin{array}{l}2.33 \\
1.92 \\
6.56 \\
7.73\end{array}$ & $\begin{array}{l}1.68 \\
2.83 \\
2.29 \\
0.90\end{array}$ & 3.28 & 7.73 \\
\hline $\begin{array}{c}\text { Dissolved } \\
\text { lons } \\
\text { (mg/) }\end{array}$ & $\begin{array}{l}214.37 \\
192.58 \\
126.20 \\
113.38\end{array}$ & $\begin{array}{l}141.10 \\
139.80 \\
111.18 \\
131.48\end{array}$ & $\begin{array}{l}163.98 \\
165.04 \\
159.90 \\
158.65\end{array}$ & $\begin{array}{l}157.33 \\
161.43 \\
141.61 \\
136.82\end{array}$ & $\begin{array}{r}167.34 \\
168.44 \\
163.14 \\
161.86\end{array}$ & $\begin{array}{l}151.44 \\
155.48 \\
135.92 \\
131.20\end{array}$ & $\begin{array}{l}23.51 \\
14.30 \\
26.70 \\
39.93\end{array}$ & $\begin{array}{r}11.50 \\
15.47 \\
27.38 \\
4.07\end{array}$ & 20.36 & 39.93 & $\begin{array}{l}21.94 \\
12.53 \\
29.27 \\
42.77\end{array}$ & $\begin{array}{r}7.33 \\
11.22 \\
22.26 \\
0.21\end{array}$ & 18.44 & 42.77 \\
\hline $\begin{array}{l}\text { Dissolved } \\
\text { Solids } \\
\text { (mg/l) }\end{array}$ & $\begin{array}{r}173.97 \\
155.00 \\
102.25 \\
90.25\end{array}$ & $\begin{array}{r}142.75 \\
109.00 \\
85.25 \\
97.75\end{array}$ & $\begin{array}{l}125.62 \\
126.46 \\
120.04 \\
118.15\end{array}$ & $\begin{array}{r}126.44 \\
128.55 \\
112.38 \\
107.62\end{array}$ & $\begin{array}{r}129.43 \\
130.20 \\
124.32 \\
122.60\end{array}$ & $\begin{array}{r}119.77 \\
122.01 \\
104.87 \\
99.83\end{array}$ & $\begin{array}{l}27.79 \\
18.41 \\
17.40 \\
30.91\end{array}$ & $\begin{array}{l}11.43 \\
17.94 \\
31.82 \\
10.10\end{array}$ & 20.72 & 31.82 & $\begin{array}{l}25.60 \\
16.00 \\
21.59 \\
35.84\end{array}$ & $\begin{array}{r}16.10 \\
11.94 \\
23.02 \\
2.13\end{array}$ & 19.03 & 35.84 \\
\hline $\begin{array}{c}\text { Hardness } \\
\left(\mathrm{mg} / \mathrm{flas}_{\mathrm{CaC}} \mathrm{Ca}\right.\end{array}$ & $\begin{array}{l}80.78 \\
69.25 \\
45.75 \\
44.75\end{array}$ & $\begin{array}{l}79.00 \\
58.50 \\
43.75 \\
52.50\end{array}$ & $\begin{array}{l}71.00 \\
71.19 \\
70.11 \\
69.92\end{array}$ & $\begin{array}{l}62.80 \\
63.70 \\
58.74 \\
57.86\end{array}$ & $\begin{array}{l}71.71 \\
71.91 \\
70.76 \\
70.55\end{array}$ & $\begin{array}{l}61.60 \\
62.46 \\
57.63 \\
56.77\end{array}$ & $\begin{array}{r}12.11 \\
2.80 \\
53.25 \\
56.25\end{array}$ & $\begin{array}{r}20.51 \\
8.89 \\
34.26 \\
10.21\end{array}$ & 24.78 & 56.25 & $\begin{array}{r}11.24 \\
3.84 \\
54.66 \\
57.65\end{array}$ & $\begin{array}{r}22.03 \\
6.77 \\
31.73 \\
8.13\end{array}$ & 24.51 & 57.65 \\
\hline $\begin{array}{c}\text { Alkatinity } \\
\text { (mg/l)as } \mathrm{CaCO} 3\end{array}$ & $\begin{array}{l}89.22 \\
85.00 \\
58.75 \\
55.50\end{array}$ & $\begin{array}{l}98.75 \\
76.00 \\
59.25 \\
71.25\end{array}$ & $\begin{array}{l}76.21 \\
76.16 \\
75.25 \\
75.45\end{array}$ & $\begin{array}{l}78.46 \\
78.08 \\
70.97 \\
72.57\end{array}$ & $\begin{array}{l}77.08 \\
77.01 \\
75.90 \\
76.15\end{array}$ & $\begin{array}{l}76.96 \\
76.58 \\
69.84 \\
71.36\end{array}$ & $\begin{array}{r}14.58 \\
10.40 \\
28.09 \\
35.95\end{array}$ & $\begin{array}{r}20.55 \\
2.74 \\
19.78 \\
1.85\end{array}$ & 16.74 & 35.95 & $\begin{array}{r}13.61 \\
9.40 \\
29.19 \\
37.20\end{array}$ & $\begin{array}{r}22.06 \\
0.76 \\
17.88 \\
0.15\end{array}$ & 16.28 & 37.20 \\
\hline $\begin{array}{l}\text { Natrium } \\
(\mathrm{mg} / 1)\end{array}$ & $\begin{array}{l}26.44 \\
23.75 \\
14.75 \\
11.08\end{array}$ & $\begin{array}{l}15.50 \\
11.75 \\
10.75 \\
11.50\end{array}$ & $\begin{array}{l}17.11 \\
17.27 \\
16.19 \\
15.88\end{array}$ & $\begin{array}{l}16.69 \\
17.30 \\
13.23 \\
12.08\end{array}$ & $\begin{array}{r}17.35 \\
17.52 \\
16.41 \\
16.10\end{array}$ & $\begin{array}{l}16.26 \\
16.87 \\
12.83 \\
11.69\end{array}$ & $\begin{array}{r}35.30 \\
27.28 \\
9.76 \\
43.39\end{array}$ & $\begin{array}{r}7.68 \\
47.23 \\
23.07 \\
5.04\end{array}$ & 24.84 & 47.23 & $\begin{array}{l}34.37 \\
26.23 \\
11.28 \\
45.39\end{array}$ & $\begin{array}{r}4.93 \\
43.55 \\
19.34 \\
1.64\end{array}$ & 23.34 & 45.39 \\
\hline $\begin{array}{l}\text { Kalium } \\
(\mathrm{mg} / \mathrm{l})\end{array}$ & $\begin{array}{l}5.49 \\
5.03 \\
4.80 \\
5.00\end{array}$ & $\begin{array}{l}4.30 \\
4.35 \\
4.40 \\
5.20\end{array}$ & $\begin{array}{l}5.40 \\
5.36 \\
5.33 \\
5.37\end{array}$ & $\begin{array}{l}4.34 \\
4.33 \\
4.33 \\
4.33\end{array}$ & $\begin{array}{l}5.21 \\
5.20 \\
5.19 \\
5.20\end{array}$ & $\begin{array}{l}4.68 \\
4.63 \\
4.56 \\
4.65\end{array}$ & $\begin{array}{r}1.64 \\
6.67 \\
11.04 \\
7.40\end{array}$ & $\begin{array}{r}1.08 \\
0.46 \\
1.59 \\
16.73\end{array}$ & 5.83 & 16.73 & $\begin{array}{l}5.11 \\
3.49 \\
8.03 \\
4.08\end{array}$ & $\begin{array}{r}6.56 \\
6.48 \\
3.74 \\
10.60\end{array}$ & 6.01 & 10.60 \\
\hline $\begin{array}{l}\text { Calcium } \\
(\mathrm{mg} / \mathrm{l})\end{array}$ & $\begin{array}{l}20.10 \\
18.00 \\
12.75 \\
12.35\end{array}$ & $\begin{array}{l}22.67 \\
16.67 \\
12.50 \\
15.25\end{array}$ & $\begin{array}{l}19.03 \\
19.14 \\
18.58 \\
18.64\end{array}$ & $\begin{array}{l}17.82 \\
18.63 \\
14.51 \\
15.00\end{array}$ & $\begin{array}{l}18.63 \\
18.84 \\
17.80 \\
17.92\end{array}$ & $\begin{array}{l}18.51 \\
19.17 \\
15.88 \\
16.28\end{array}$ & $\begin{array}{r}5.32 \\
6.33 \\
45.73 \\
50.93\end{array}$ & $\begin{array}{r}21.38 \\
11.78 \\
16.08 \\
1.64\end{array}$ & 19.90 & 50.93 & $\begin{array}{r}7.29 \\
4.69 \\
39.57 \\
45.11\end{array}$ & $\begin{array}{r}18.32 \\
15.02 \\
27.07 \\
6.74\end{array}$ & 20.48 & 45.11 \\
\hline $\begin{array}{l}\text { Magnesium } \\
(\mathrm{mg} / \mathrm{l})\end{array}$ & $\begin{array}{l}7.44 \\
5.98 \\
3.43 \\
3.35\end{array}$ & $\begin{array}{l}5.42 \\
4.03 \\
2.95 \\
3.48\end{array}$ & $\begin{array}{l}5.68 \\
5.70 \\
5.58 \\
5.57\end{array}$ & $\begin{array}{l}4.87 \\
4.89 \\
4.68 \\
4.67\end{array}$ & $\begin{array}{l}6.00 \\
6.01 \\
5.94 \\
5.94\end{array}$ & $\begin{array}{l}4.32 \\
4.35 \\
4.04 \\
4.02\end{array}$ & $\begin{array}{r}23.60 \\
4.60 \\
62.92 \\
66.27\end{array}$ & $\begin{array}{l}10.16 \\
21.24 \\
58.64 \\
34.39\end{array}$ & 35.23 & 66.27 & $\begin{array}{r}19.29 \\
0.56 \\
73.45 \\
77.20\end{array}$ & $\begin{array}{r}20.36 \\
7.88 \\
37.09 \\
15.77\end{array}$ & 31.45 & 77.20 \\
\hline
\end{tabular}


Table A.4.2(c) 3 yearly

\begin{tabular}{|c|c|c|c|c|c|c|c|c|c|c|c|c|c|c|}
\hline \multirow{4}{*}{$\begin{array}{l}\text { Water Quality } \\
\text { Parameter }\end{array}$} & \multirow{2}{*}{\multicolumn{2}{|c|}{ Observed Values }} & \multirow{2}{*}{\multicolumn{2}{|c|}{$\begin{array}{l}\text { Assigned Values } \\
\text { (Entropy Method) }\end{array}$}} & \multirow{2}{*}{\multicolumn{2}{|c|}{$\begin{array}{c}\text { Aselgnod Values } \\
\text { (Regresston Method) }\end{array}$}} & \multicolumn{8}{|c|}{ Absolute Values of Errors (\%) } \\
\hline & & & & & & & \multicolumn{4}{|c|}{ (Entropy Mothod) } & \multicolumn{4}{|c|}{ (Regresslon Method) } \\
\hline & \multicolumn{2}{|c|}{ at Stalion } & \multicolumn{2}{|c|}{ at Slation } & \multicolumn{2}{|c|}{ at Station } & \multicolumn{2}{|c|}{ at Station } & \multirow[b]{2}{*}{ Average } & \multirow[b]{2}{*}{ Maximum } & \multicolumn{2}{|c|}{ at Station } & \multirow[b]{2}{*}{ Average } & \multirow[b]{2}{*}{ Maximum } \\
\hline & 130202 & 130212 & 130202 & 130212 & 130202 & 130212 & 130202 & 130212 & & & 130202 & 130212 & & \\
\hline (1) & $(2$ & & & & 1 & & (5) & & (6) & (7) & & (8) & (9) & $(10)$ \\
\hline $\begin{array}{l}\text { Conductivity } \\
\text { (m) } \mathrm{m} / \mathrm{m})\end{array}$ & $\begin{array}{l}259.67 \\
228.33 \\
163.33\end{array}$ & $\begin{array}{l}192.08 \\
169.17 \\
150.00\end{array}$ & $\begin{array}{l}229.99 \\
231.18 \\
214.20\end{array}$ & $\begin{array}{l}173.68 \\
173.95 \\
169.98\end{array}$ & $\begin{array}{l}234.06 \\
234.46 \\
228.80\end{array}$ & $\begin{array}{l}166.59 \\
168.25 \\
144.56\end{array}$ & $\begin{array}{r}11.43 \\
1.25 \\
31.20\end{array}$ & $\begin{array}{r}9.58 \\
2.83 \\
13.32\end{array}$ & 11.60 & 31.20 & $\begin{array}{r}9.86 \\
2.68 \\
40.09\end{array}$ & $\begin{array}{r}13.27 \\
0.55 \\
3.63\end{array}$ & 11.68 & 40.09 \\
\hline $\mathrm{PH}$ & $\begin{array}{l}7.69 \\
7.52 \\
7.20\end{array}$ & $\begin{array}{l}7.53 \\
7.48 \\
7.42\end{array}$ & $\begin{array}{l}7.56 \\
7.56 \\
7.56\end{array}$ & $\begin{array}{l}7.49 \\
7.49 \\
7.49\end{array}$ & $\begin{array}{l}7.73 \\
7.71 \\
7.72\end{array}$ & $\begin{array}{l}7.19 \\
7.22 \\
7.21\end{array}$ & $\begin{array}{l}1.69 \\
0.53 \\
5.00\end{array}$ & $\begin{array}{l}0.53 \\
0.13 \\
0.94\end{array}$ & 1.47 & 5.00 & $\begin{array}{l}0.49 \\
2.57 \\
7.23\end{array}$ & $\begin{array}{l}4.49 \\
3.43 \\
2.87\end{array}$ & 3.51 & 7.23 \\
\hline $\begin{array}{c}\text { Dissolved } \\
\text { lons } \\
\text { (mg/) }\end{array}$ & $\begin{array}{l}188.18 \\
167.25 \\
120.85\end{array}$ & $\begin{array}{l}154.64 \\
134.92 \\
120.05\end{array}$ & $\begin{array}{l}145.34 \\
145.82 \\
134.90\end{array}$ & $\begin{array}{l}173.52 \\
173.66 \\
170.56\end{array}$ & $\begin{array}{l}171.37 \\
171.51 \\
168.20\end{array}$ & $\begin{array}{l}127.87 \\
128.59 \\
112.14\end{array}$ & $\begin{array}{l}22.77 \\
12.81 \\
11.63\end{array}$ & $\begin{array}{l}12.21 \\
28.71 \\
42.07\end{array}$ & 21.70 & 42.07 & $\begin{array}{r}8.93 \\
2.55 \\
39.18\end{array}$ & $\begin{array}{r}17.31 \\
4.69 \\
6.59\end{array}$ & 13.21 & 39.18 \\
\hline $\begin{array}{l}\text { Dissolved } \\
\text { Solids } \\
\text { (mgil) }\end{array}$ & $\begin{array}{r}152.64 \\
134.83 \\
96.83\end{array}$ & $\begin{array}{r}121.83 \\
102.83 \\
91.83\end{array}$ & $\begin{array}{l}122.84 \\
122.15 \\
117.54\end{array}$ & $\begin{array}{l}119.43 \\
117.72 \\
106.10\end{array}$ & $\begin{array}{l}132.25 \\
131.72 \\
128.20\end{array}$ & $\begin{array}{r}102.93 \\
100.92 \\
87.40\end{array}$ & $\begin{array}{r}19.52 \\
9.40 \\
21.39\end{array}$ & $\begin{array}{r}1.97 \\
14.48 \\
15.54\end{array}$ & 13.72 & 21.39 & $\begin{array}{r}13.36 \\
2.30 \\
32.40\end{array}$ & $\begin{array}{r}15.51 \\
1.85 \\
4.82\end{array}$ & 11.71 & 32.40 \\
\hline $\begin{array}{c}\text { Hardness } \\
\text { (mg/h)as } \mathrm{CaCO}^{2}\end{array}$ & $\begin{array}{l}69.19 \\
61.33 \\
45.17\end{array}$ & $\begin{array}{l}82.83 \\
73.17 \\
64.50\end{array}$ & $\begin{array}{l}70.03 \\
70.21 \\
69.26\end{array}$ & $\begin{array}{l}58.37 \\
59.14 \\
54.80\end{array}$ & $\begin{array}{l}74.87 \\
74.98 \\
74.36\end{array}$ & $\begin{array}{l}49.88 \\
50.77 \\
45.85\end{array}$ & $\begin{array}{r}1.21 \\
14.48 \\
53.33\end{array}$ & $\begin{array}{l}29.53 \\
19.17 \\
15.04\end{array}$ & 22.13 & 53.33 & $\begin{array}{r}8.21 \\
22.26 \\
64.63\end{array}$ & $\begin{array}{l}39.77 \\
30.61 \\
28.92\end{array}$ & 32.40 & 64.63 \\
\hline $\begin{array}{c}\text { Alkalinity } \\
\text { (ming/)as } \mathrm{CaCO} 3\end{array}$ & $\begin{array}{l}80.81 \\
74.50 \\
58.33\end{array}$ & $\begin{array}{l}65.00 \\
55.83 \\
47.33\end{array}$ & $\begin{array}{l}75.49 \\
75.52 \\
74.96\end{array}$ & $\begin{array}{l}72.92 \\
73.10 \\
68.73\end{array}$ & $\begin{array}{l}79.42 \\
79.44 \\
78.99\end{array}$ & $\begin{array}{l}66.02 \\
66.21 \\
61.65\end{array}$ & $\begin{array}{r}6.58 \\
1.37 \\
28.51\end{array}$ & $\begin{array}{l}12.18 \\
30.93 \\
45.21\end{array}$ & 20.80 & $45.2 !$ & $\begin{array}{r}1.72 \\
6.63 \\
35.42\end{array}$ & $\begin{array}{r}1.57 \\
18.60 \\
30.25\end{array}$ & 15.70 & 35.42 \\
\hline $\begin{array}{l}\text { Natrium } \\
(\mathrm{mg} /)\end{array}$ & $\begin{array}{l}23.30 \\
20.00 \\
13.05\end{array}$ & $\begin{array}{l}13.50 \\
11.83 \\
10.83\end{array}$ & $\begin{array}{l}16.74 \\
16.61 \\
15.87\end{array}$ & $\begin{array}{l}15.29 \\
14.80 \\
12.04\end{array}$ & $\begin{array}{l}17.50 \\
17.45 \\
16.75\end{array}$ & $\begin{array}{l}13.81 \\
13.31 \\
10.50\end{array}$ & $\begin{array}{l}28.15 \\
16.95 \\
21.61\end{array}$ & $\begin{array}{l}13.26 \\
25.11 \\
11.17\end{array}$ & 19.38 & 28.15 & $\begin{array}{l}24.55 \\
12.73 \\
28.39\end{array}$ & $\begin{array}{r}2.29 \\
12.52 \\
3.09\end{array}$ & 13,93 & 28.39 \\
\hline $\begin{array}{l}\text { Kalium } \\
\text { (mg/l) }\end{array}$ & $\begin{array}{l}5.13 \\
5.08 \\
4.80\end{array}$ & $\begin{array}{l}4.43 \\
4.33 \\
4.97\end{array}$ & $\begin{array}{l}5.48 \\
5.47 \\
5.47\end{array}$ & $\begin{array}{l}4.35 \\
4.35 \\
4.35\end{array}$ & $\begin{array}{l}5.38 \\
5.36 \\
5.37\end{array}$ & $\begin{array}{l}4.55 \\
4.52 \\
4.53\end{array}$ & $\begin{array}{r}6.82 \\
7.68 \\
13.96\end{array}$ & $\begin{array}{r}1.81 \\
0.46 \\
12.47\end{array}$ & 7.20 & 13.96 & $\begin{array}{r}4.90 \\
5.56 \\
11.90\end{array}$ & $\begin{array}{l}2.63 \\
4.32 \\
8.85\end{array}$ & 6.36 & 11.90 \\
\hline $\begin{array}{c}\text { Calcium } \\
(\text { mgl) }\end{array}$ & $\begin{array}{l}17.73 \\
16.17 \\
12.57\end{array}$ & $\begin{array}{l}18.44 \\
16.11 \\
13.50\end{array}$ & $\begin{array}{l}18.63 \\
18.62 \\
18.32\end{array}$ & $\begin{array}{l}14.91 \\
14.76 \\
12.62\end{array}$ & $\begin{array}{l}19.21 \\
19.19 \\
18.84\end{array}$ & $\begin{array}{l}13.90 \\
13.76 \\
11.69\end{array}$ & $\begin{array}{r}5.08 \\
15.15 \\
45.74\end{array}$ & $\begin{array}{r}19.14 \\
8.38 \\
6.52\end{array}$ & 16.67 & 45.74 & $\begin{array}{r}8.34 \\
18.65 \\
49.80\end{array}$ & $\begin{array}{l}24.61 \\
14.57 \\
13.39\end{array}$ & 21.58 & 49.90 \\
\hline $\begin{array}{l}\text { Magnesium } \\
\text { (mg/) }\end{array}$ & $\begin{array}{l}6.09 \\
5.13 \\
3.37\end{array}$ & $\begin{array}{l}4.55 \\
3.72 \\
3.25\end{array}$ & $\begin{array}{l}5.71 \\
5.72 \\
5.64\end{array}$ & $\begin{array}{l}4.92 \\
4.93 \\
4.79\end{array}$ & $\begin{array}{l}6.43 \\
6.43 \\
6.41\end{array}$ & $\begin{array}{l}3.66 \\
3.68 \\
3.44\end{array}$ & $\begin{array}{r}6.24 \\
11.50 \\
67.36\end{array}$ & $\begin{array}{r}8.13 \\
32.53 \\
47.38\end{array}$ & 28.86 & 67.36 & $\begin{array}{r}5.53 \\
25.30 \\
90.27\end{array}$ & $\begin{array}{r}19.50 \\
1.05 \\
5.69\end{array}$ & 24.56 & 90.27 \\
\hline
\end{tabular}


Table A.4.2(d) 4 yearly

\begin{tabular}{|c|c|c|c|c|c|c|c|c|c|c|c|c|c|c|}
\hline \multirow{4}{*}{$\begin{array}{c}\text { Waler Quallty } \\
\text { Parameter }\end{array}$} & \multirow{2}{*}{\multicolumn{2}{|c|}{ Obsorvad Valuos }} & \multirow{2}{*}{\multicolumn{2}{|c|}{$\begin{array}{l}\text { Asslgnod Valuas } \\
\text { (Entropy Method) }\end{array}$}} & \multirow{2}{*}{\multicolumn{2}{|c|}{$\begin{array}{c}\text { Assigned Values } \\
\text { (Regresston Method) }\end{array}$}} & \multicolumn{8}{|c|}{ Absolute Values of Errors (\%) } \\
\hline & & & & & & & \multicolumn{4}{|c|}{ (Entropy Method) } & \multicolumn{4}{|c|}{ (Regression Method) } \\
\hline & \multicolumn{2}{|c|}{ at Station } & \multicolumn{2}{|c|}{ at Station } & \multicolumn{2}{|c|}{ at Stalion } & \multicolumn{2}{|c|}{ at Station } & \multirow[b]{2}{*}{ Average } & \multirow[b]{2}{*}{ Maximum } & \multicolumn{2}{|c|}{ at Statlon } & \multirow[b]{2}{*}{ Average } & \multirow[b]{2}{*}{ Maximum } \\
\hline & 130202 & 130212 & 130202 & 130212 & 130202 & 130212 & 130202 & 130212 & & & 130202 & 130212 & & \\
\hline (1) & \multicolumn{2}{|c|}{ (2) } & \multicolumn{2}{|c|}{ (3) } & \multicolumn{2}{|c|}{ (4) } & \multicolumn{2}{|c|}{ (5) } & (6) & (7) & \multicolumn{2}{|r|}{ (8) } & (9) & \multirow{3}{*}{11.91} \\
\hline Conductivity & 232.88 & 182.19 & 228.90 & 173.43 & 232.69 & 166.80 & 1.71 & 4.81 & \multirow[t]{2}{*}{4.73} & \multirow[t]{2}{*}{10.29} & 0.0801 & 8.4479 & \multirow[t]{2}{*}{5.45} & \\
\hline$(m S / m)$ & 208.13 & 170.00 & 229.55 & 173.58 & 232.91 & 167.67 & 10.29 & 2.11 & & & 11.908 & 1.3687 & & \\
\hline \multirow[t]{2}{*}{$\mathrm{PH}$} & 7.51 & 7.49 & 7.56 & 7.49 & 7.71 & 7.22 & 0.67 & 0.01 & \multirow[t]{2}{*}{0.81} & \multirow[t]{2}{*}{1.48} & 2.7012 & 3.59 & \multirow[t]{2}{*}{3.09} & 3.59 \\
\hline & 7.45 & 7.41 & 7.56 & 7.49 & 7.71 & 7.22 & 1.48 & 1.07 & & & 3.5283 & 2.5491 & & \\
\hline Dissolved & 170.29 & $\{47.27$ & 145.79 & 173.66 & 170.24 & 130.78 & 14.39 & 17.92 & 16.29 & 27.98 & 0.0275 & 11.195 & 6.58 & 11.23 \\
\hline $\begin{array}{c}\text { tons } \\
(\mathrm{mg} / \mathrm{l})\end{array}$ & 152.98 & $\$ 35.84$ & 145.55 & 173.59 & 170.16 & 130.42 & 4.85 & 27.98 & & & 11.232 & 3.8488 & & \\
\hline Dissolved & $\{38.11$ & $\$ 14,00$ & 122.07 & 117.47 & 130.59 & 102.53 & $\$ 1.01$ & 3.04 & 6.97 & 12.32 & 5.4475 & 10.065 & 5,99 & 10.07 \\
\hline $\begin{array}{l}\text { Solids } \\
\text { (mgfl) }\end{array}$ & 122.63 & 103.38 & 121.53 & 116.12 & 130.15 & 101.00 & 0.00 & 12.32 & & & 6.1315 & 2.2981 & & \\
\hline Hardness & 63.27 & 61.38 & 71.55 & 65.32 & 76.21 & 57.14 & 13.09 & 6.42 & 15.68 & 25.53 & 20.457 & 6.91 & 16.01 & 33.71 \\
\hline (mmg/l)@s $\mathrm{CaCO}_{3}$ & 57.00 & 55.50 & 71.55 & 65.32 & 76.21 & 57.14 & 25.53 & 17.69 & & & 33.707 & 2.9525 & & \\
\hline Alkatinity & 73.98 & 79.00 & 76.16 & 78.10 & 79.95 & 71.44 & 2.95 & 1.14 & 4.85 & 8.51 & 8.0711 & 9.5682 & 8.44 & 13.89 \\
\hline (trigf/)as $\mathrm{CaCO} 3$ & 70.25 & 73.63 & 76.23 & 78.63 & 80.01 & 72.00 & 8.51 & 6.79 & & & 13.89 & 2.2195 & & \\
\hline Natrium & 20.60 & 13.13 & 16.19 & 13.24 & 17.32 & 11.27 & 21.41 & 0.84 & 10.27 & 21.41 & 15.935 & 14.172 & 9.19 & 15.93 \\
\hline$(\mathrm{mg} / \mathrm{i})$ & 17.41 & 11.63 & 16.11 & 12.95 & 17.25 & 10.96 & 7.47 & 11.35 & & & 0.936 & 5.7201 & & \\
\hline Kalium & 5.15 & 4.39 & 5.79 & 4.41 & 5.69 & 4.58 & 12.43 & 0.46 & 9.20 & 16.17 & 10.432 & 4.2659 & 8.13 & 14.02 \\
\hline$(\mathrm{mg} / \mathrm{l})$ & 5.01 & 4.78 & 5.82 & 4.41 & 5.71 & 4.60 & 16.17 & 7.74 & & & 14.016 & 3.8197 & & \\
\hline Calcium & 16.43 & 17.58 & 18.89 & 16.79 & 19.30 & 16.09 & 14.97 & 4.49 & 13.46 & 25.03 & 17,452 & 8.5004 & 14.61 & 27.90 \\
\hline$(\mathrm{mg} / 1)$ & 15.18 & 15.96 & 18.90 & 17.45 & 19.42 & 16.69 & 25.03 & 9.34 & & & 27.899 & 4.5963 & & \\
\hline Magnesium & 5.43 & 4.19 & 5.85 & 5.15 & 6.62 & 3.80 & 7.73 & 22.91 & 23.38 & 37.33 & 21.928 & 9.3735 & 18.70 & 42.07 \\
\hline (mg/l) & 4.66 & 3.75 & 5.85 & 5.15 & 6.62 & 3.80 & 25.54 & 37.33 & & & 42.074 & 1.426 & & \\
\hline
\end{tabular}


Table A.4.3 Results of Assignment of Water Quality Values in the Logan River Basin

Table A.4.3(a) 1 yearly

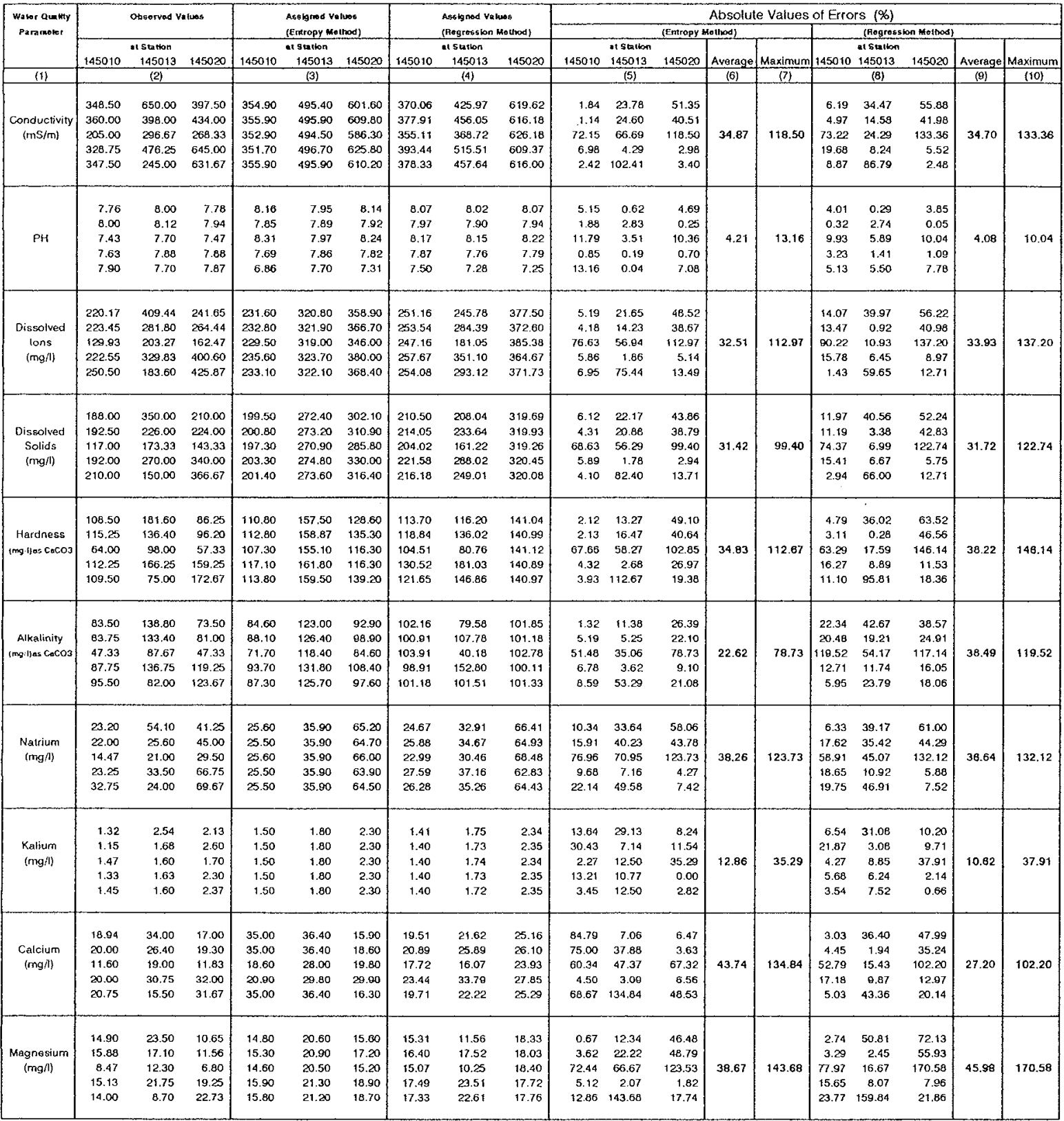


Table A.4.3(b) 2 yearly

\begin{tabular}{|c|c|c|c|c|c|c|c|c|c|c|c|c|c|c|c|c|c|c|c|}
\hline \multirow{3}{*}{$\begin{array}{c}\text { Water Quasithy } \\
\text { paramiotor }\end{array}$} & \multirow{2}{*}{\multicolumn{3}{|c|}{ observed values }} & \multirow{2}{*}{\multicolumn{3}{|c|}{$\begin{array}{l}\text { Assigned Vatuces } \\
\text { (Emropy Metitod) }\end{array}$}} & \multirow{2}{*}{\multicolumn{3}{|c|}{$\begin{array}{l}\text { Assigned Vatues } \\
\text { (Regressiken Me thod) }\end{array}$}} & \multicolumn{10}{|c|}{ Absolute Values of Errors (\%) } \\
\hline & & & & & & & & & & & & (Entropy 1) & Meithod) & & & (Regres: & in Marthod) & & \\
\hline & 145010 & $\begin{array}{l}\text { al SLAton } \\
145013\end{array}$ & 145020 & 145010 & $\begin{array}{l}\text { al Santon } \\
145013\end{array}$ & 145020 & 145010 & $\begin{array}{l}\text { al Station } \\
145013\end{array}$ & 145020 & 145010 & $\begin{array}{l}\text { at Station } \\
145013\end{array}$ & 145020 & Average & Maximum & $\begin{array}{l}145010 \\
\end{array}$ & $\begin{array}{l}\text { a1 sution } \\
145013\end{array}$ & 145020 & Aversge & Maximum \\
\hline (1) & & (2) & & & (3) & & & (4) & & & (5) & & (6) & (7) & & (8) & & (9) & (10) \\
\hline $\begin{array}{c}\text { Conduclivity } \\
\text { (mS } / m)\end{array}$ & $\begin{array}{l}354.25 \\
282.50 \\
266.88 \\
338.13\end{array}$ & $\begin{array}{l}524.00 \\
347.33 \\
386.46 \\
360.63\end{array}$ & $\begin{array}{l}115.75 \\
351.17 \\
456.67 \\
638.33\end{array}$ & $\begin{array}{l}310.40 \\
261.00 \\
311.70 \\
349.10\end{array}$ & $\begin{array}{l}474.80 \\
451.70 \\
475.30 \\
492.70\end{array}$ & $\begin{array}{r}258.30 \\
84.10 \\
265.30 \\
554.00\end{array}$ & $\begin{array}{l}407.62 \\
415.91 \\
407.30 \\
394.42\end{array}$ & $\begin{array}{l}333.13 \\
250.97 \\
336.30 \\
463.91\end{array}$ & $\begin{array}{l}275.55 \\
103.17 \\
282.19 \\
549.92\end{array}$ & $\begin{array}{r}12.38 \\
7.61 \\
16.80 \\
3.25\end{array}$ & $\begin{array}{r}9.39 \\
30.05 \\
22,99 \\
36.62\end{array}$ & $\begin{array}{l}37.87 \\
76.05 \\
41.91 \\
13.21\end{array}$ & 25.68 & 76.05 & $\begin{array}{l}15.06 \\
47.22 \\
52.62 \\
16.65\end{array}$ & $\begin{array}{l}36.43 \\
27.74 \\
12.98 \\
28.64\end{array}$ & $\begin{array}{l}33.72 \\
70.62 \\
38.21 \\
13.85\end{array}$ & 32.81 & 70.62 \\
\hline PH & $\begin{array}{l}7.88 \\
7.72 \\
7.53 \\
7.76\end{array}$ & $\begin{array}{l}8.06 \\
7.91 \\
7.79 \\
7.79\end{array}$ & $\begin{array}{l}7.86 \\
7.70 \\
7.67 \\
7.87\end{array}$ & $\begin{array}{l}8.36 \\
8.75 \\
8.36 \\
6.06\end{array}$ & $\begin{array}{l}7.98 \\
8.06 \\
7.98 \\
7.19\end{array}$ & $\begin{array}{l}8.27 \\
8.46 \\
8.27 \\
7.11\end{array}$ & $\begin{array}{l}8.51 \\
8.80 \\
8.50 \\
6.48\end{array}$ & $\begin{array}{l}8.01 \\
8.11 \\
8.00 \\
7.31\end{array}$ & $\begin{array}{l}8.23 \\
8.42 \\
8.22 \\
6.90\end{array}$ & $\begin{array}{r}6.09 \\
13.39 \\
11.03 \\
21.93\end{array}$ & $\begin{array}{l}0.99 \\
1.90 \\
2.47 \\
7.67\end{array}$ & $\begin{array}{l}5.25 \\
9.82 \\
7.81 \\
9.67\end{array}$ & 8.17 & 21.93 & $\begin{array}{r}7.95 \\
34.10 \\
12.85 \\
16.51\end{array}$ & $\begin{array}{l}0.66 \\
2.52 \\
2.78 \\
6.11\end{array}$ & $\begin{array}{r}4.70 \\
9.32 \\
7.16 \\
12.29\end{array}$ & 8.08 & 16.51 \\
\hline $\begin{array}{c}\text { Dissolved } \\
\text { lons } \\
\text { (mg/l) }\end{array}$ & $\begin{array}{l}221.81 \\
176.69 \\
776.24 \\
236.53\end{array}$ & $\begin{array}{l}345.62 \\
242.53 \\
266.55 \\
256.71\end{array}$ & $\begin{array}{l}253.05 \\
213.45 \\
281.53 \\
413.23\end{array}$ & $\begin{array}{l}199.20 \\
164.10 \\
199.90 \\
233.20\end{array}$ & $\begin{array}{l}293.70 \\
264.20 \\
234.30 \\
322.10\end{array}$ & $\begin{array}{r}170.50 \\
66.80 \\
173.80 \\
368.80\end{array}$ & $\begin{array}{l}262.44 \\
265.52 \\
202.35 \\
257.01\end{array}$ & $\begin{array}{r}175.95 \\
95.19 \\
178.43 \\
318.26\end{array}$ & $\begin{array}{r}190.00 \\
91.77 \\
193.02 \\
363.09\end{array}$ & $\begin{array}{r}10.19 \\
7.13 \\
13.42 \\
1.41\end{array}$ & $\begin{array}{r}15.02 \\
8.93 \\
10.41 \\
25.47\end{array}$ & $\begin{array}{l}32.62 \\
68.71 \\
38.27 \\
10.75\end{array}$ & 20.19 & 68.71 & $\begin{array}{r}18.32 \\
50.28 \\
48.86 \\
8.66\end{array}$ & $\begin{array}{l}49.09 \\
60.75 \\
33.06 \\
20.98\end{array}$ & $\begin{array}{l}24.91 \\
57.01 \\
31.44 \\
\{2.14\end{array}$ & $\mathbf{3 4 . 8 7}$ & 60.75 \\
\hline $\begin{array}{c}\text { Dissolved } \\
\text { Solids } \\
\text { (mg/il) }\end{array}$ & $\begin{array}{l}190.25 \\
154.75 \\
154.50 \\
201.00\end{array}$ & $\begin{array}{l}288.00 \\
199.67 \\
221.67 \\
210.00\end{array}$ & $\begin{array}{l}217.00 \\
183.67 \\
241.67 \\
353.33\end{array}$ & $\begin{array}{l}175.90 \\
148.40 \\
178.30 \\
201.60\end{array}$ & $\begin{array}{l}257.00 \\
239.20 \\
258.60 \\
273.70\end{array}$ & $\begin{array}{r}137.90 \\
56.90 \\
152.00 \\
318.10\end{array}$ & $\begin{array}{l}223.56 \\
225.19 \\
223.29 \\
220.22\end{array}$ & $\begin{array}{l}160.38 \\
108.67 \\
168.73 \\
265.69\end{array}$ & $\begin{array}{r}155.26 \\
76.67 \\
167.94 \\
315.29\end{array}$ & $\begin{array}{r}7.54 \\
4.50 \\
15.40 \\
0.30\end{array}$ & $\begin{array}{l}10.76 \\
19.80 \\
16.66 \\
30.33\end{array}$ & $\begin{array}{r}36.45 \\
69.02 \\
37.10 \\
9.97\end{array}$ & 21.45 & 69.02 & $\begin{array}{r}17.51 \\
45.52 \\
44.53 \\
0.56\end{array}$ & $\begin{array}{l}44.31 \\
45.58 \\
23.88 \\
26.52\end{array}$ & $\begin{array}{l}28.45 \\
58.25 \\
30.51 \\
10.77\end{array}$ & 32.12 & 58.25 \\
\hline $\begin{array}{c}\text { Hardness } \\
\text { (magithas } \\
\mathrm{CaCOCO}\end{array}$ & $\begin{array}{r}111.68 \\
89.63 \\
88.13 \\
110.88\end{array}$ & $\begin{array}{l}159.00 \\
117.20 \\
132.13 \\
120.63\end{array}$ & $\begin{array}{r}91.23 \\
76.77 \\
108.29 \\
165.86\end{array}$ & $\begin{array}{r}92.85 \\
76.53 \\
96.22 \\
117.56\end{array}$ & $\begin{array}{l}145.28 \\
134.10 \\
147.53 \\
162.09\end{array}$ & $\begin{array}{r}67.19 \\
28.64 \\
77.88 \\
152.61\end{array}$ & $\begin{array}{l}113.17 \\
106.59 \\
114.85 \\
127.22\end{array}$ & $\begin{array}{r}95.97 \\
62.67 \\
104.97 \\
167.09\end{array}$ & $\begin{array}{r}77.20 \\
43.96 \\
86.19 \\
148.20\end{array}$ & $\begin{array}{r}17.01 \\
14.61 \\
9.19 \\
6.03\end{array}$ & $\begin{array}{r}8.63 \\
14.42 \\
11.66 \\
34.38\end{array}$ & $\begin{array}{r}20.35 \\
81.39 \\
28.08 \\
8.04\end{array}$ & 19.98 & 61.39 & $\begin{array}{r}1.15 \\
18.92 \\
30.44 \\
14.74\end{array}$ & $\begin{array}{l}39.64 \\
46.53 \\
20.55 \\
38.52\end{array}$ & $\begin{array}{l}15.37 \\
42.74 \\
20.41 \\
10.70\end{array}$ & 24.98 & 48.53 \\
\hline $\begin{array}{c}\text { Alkalinity } \\
\text { (masiffos } \operatorname{Coc} \operatorname{Cos}\end{array}$ & $\begin{array}{l}83.63 \\
65.54 \\
67.54 \\
91.63\end{array}$ & $\begin{array}{l}136.10 \\
110.53 \\
112.21 \\
109.38\end{array}$ & $\begin{array}{r}77.25 \\
64.17 \\
83.29 \\
121.46\end{array}$ & $\begin{array}{l}74.40 \\
64.40 \\
75.80 \\
90.70\end{array}$ & $\begin{array}{l}113.30 \\
103.80 \\
114.60 \\
128.90\end{array}$ & $\begin{array}{r}75.70 \\
59.60 \\
70.00 \\
103.40\end{array}$ & $\begin{array}{r}91.75 \\
86.76 \\
92.47 \\
100.24\end{array}$ & $\begin{array}{r}69.68 \\
36.06 \\
74.47 \\
126.80\end{array}$ & $\begin{array}{r}84.74 \\
74.99 \\
86.13 \\
101.30\end{array}$ & $\begin{array}{r}11.03 \\
1.74 \\
12.23 \\
1.01\end{array}$ & $\begin{array}{r}16.75 \\
6.09 \\
2.13 \\
17.85\end{array}$ & $\begin{array}{r}2.01 \\
7.12 \\
15.96 \\
14.87\end{array}$ & 9.07 & 17.85 & $\begin{array}{r}9.72 \\
32.38 \\
36.90 \\
9.40\end{array}$ & $\begin{array}{l}48.81 \\
67.37 \\
33.63 \\
15.93\end{array}$ & $\begin{array}{r}9.70 \\
16.87 \\
3.41 \\
16.59\end{array}$ & 25.06 & 67.37 \\
\hline $\begin{array}{c}\text { Natrium } \\
\text { (mg/l) }\end{array}$ & $\begin{array}{l}22.60 \\
18.23 \\
18.86 \\
28.00\end{array}$ & $\begin{array}{l}39.85 \\
23.30 \\
27.25 \\
28.75\end{array}$ & $\begin{array}{l}43.13 \\
37.25 \\
48.13 \\
68.21\end{array}$ & $\begin{array}{l}24.00 \\
23.20 \\
24.00 \\
25.30\end{array}$ & $\begin{array}{l}34.60 \\
33.90 \\
34.60 \\
35.70\end{array}$ & $\begin{array}{l}32.80 \\
19.70 \\
33.10 \\
59.10\end{array}$ & $\begin{array}{l}30.02 \\
31.06 \\
30.00 \\
27.98\end{array}$ & $\begin{array}{l}27.79 \\
24.15 \\
27.86 \\
35.00\end{array}$ & $\begin{array}{l}33.27 \\
20.50 \\
33.50 \\
58.53\end{array}$ & $\begin{array}{r}6.19 \\
27.24 \\
27.26 \\
9.64\end{array}$ & $\begin{array}{l}13.17 \\
45.49 \\
26.97 \\
24.17\end{array}$ & $\begin{array}{l}23.94 \\
47.11 \\
31.22 \\
13.35\end{array}$ & 24.65 & 47.11 & $\begin{array}{r}32.83 \\
70.35 \\
59.09 \\
0.14\end{array}$ & $\begin{array}{r}30.26 \\
3.64 \\
2.22 \\
21.73\end{array}$ & $\begin{array}{l}22.86 \\
44.97 \\
30.39 \\
14.19\end{array}$ & 27.72 & 70.35 \\
\hline $\begin{array}{l}\text { Kalium } \\
(\mathrm{mg} /)\end{array}$ & $\begin{array}{l}1.24 \\
1.31 \\
1.40 \\
1.39\end{array}$ & $\begin{array}{l}2.11 \\
1.64 \\
1.61 \\
1.61\end{array}$ & $\begin{array}{l}2.36 \\
2.15 \\
2.00 \\
2.33\end{array}$ & $\begin{array}{l}1.50 \\
1.50 \\
1.50 \\
1.50\end{array}$ & $\begin{array}{l}1.80 \\
1.80 \\
1.80 \\
1.80\end{array}$ & $\begin{array}{l}2.50 \\
2.50 \\
2.50 \\
2.50\end{array}$ & $\begin{array}{l}1.36 \\
1.36 \\
1.37 \\
1.39\end{array}$ & $\begin{array}{l}1.80 \\
1.78 \\
1.77 \\
1.74\end{array}$ & $\begin{array}{l}2.53 \\
2.51 \\
2.49 \\
2.44\end{array}$ & $\begin{array}{r}21.46 \\
14.65 \\
7.46 \\
8.11\end{array}$ & $\begin{array}{r}14.69 \\
9.76 \\
11.63 \\
11.63\end{array}$ & $\begin{array}{r}5.82 \\
16.28 \\
25.00 \\
7.14\end{array}$ & 12.80 & 25.00 & $\begin{array}{l}9.91 \\
4.29 \\
1.95 \\
0.15\end{array}$ & $\begin{array}{r}14.84 \\
8.71 \\
10.06 \\
8.04\end{array}$ & $\begin{array}{r}7.06 \\
16.61 \\
24.72 \\
4.70\end{array}$ & 9.25 & 24.72 \\
\hline $\begin{array}{l}\text { Calcium } \\
\text { (mg/n) }\end{array}$ & $\begin{array}{l}19.47 \\
15.80 \\
15.80 \\
20.38\end{array}$ & $\begin{array}{l}30.20 \\
22.70 \\
24.88 \\
23.13\end{array}$ & $\begin{array}{l}18.15 \\
15.57 \\
21.92 \\
31.83\end{array}$ & $\begin{array}{l}17.20 \\
15.30 \\
17.90 \\
19.60\end{array}$ & $\begin{array}{l}27.00 \\
25.50 \\
27.50 \\
28.80\end{array}$ & $\begin{array}{r}14.20 \\
7.70 \\
17.00 \\
24.40\end{array}$ & $\begin{array}{l}20.30 \\
19.39 \\
20.68 \\
21.69\end{array}$ & $\begin{array}{l}19.48 \\
14.56 \\
21.56 \\
27.01\end{array}$ & $\begin{array}{l}15.74 \\
10.06 \\
18.14 \\
24.44\end{array}$ & $\begin{array}{r}11.66 \\
3.16 \\
13.29 \\
3.80\end{array}$ & $\begin{array}{l}10.60 \\
12.33 \\
10.55 \\
24.54\end{array}$ & $\begin{array}{l}21.70 \\
50.54 \\
22.43 \\
23.35\end{array}$ & 17.34 & 50.54 & $\begin{array}{r}4.25 \\
22.70 \\
30.89 \\
6.45\end{array}$ & $\begin{array}{l}35.50 \\
35.88 \\
13.34 \\
16.79\end{array}$ & $\begin{array}{l}13.26 \\
35.40 \\
17.22 \\
23.22\end{array}$ & 21.24 & 35.88 \\
\hline $\begin{array}{l}\text { Magnesium } \\
\{\text { mg/l })\end{array}$ & $\begin{array}{l}15.39 \\
12.17 \\
11.80 \\
14.56\end{array}$ & $\begin{array}{l}20.30 \\
14.70 \\
17.03 \\
15.23\end{array}$ & $\begin{array}{r}11.11 \\
9.18 \\
13.03 \\
20.99\end{array}$ & $\begin{array}{l}10.80 \\
10.10 \\
12.80 \\
27.00\end{array}$ & $\begin{array}{l}18.10 \\
17.60 \\
19.30 \\
29.70\end{array}$ & $\begin{array}{r}5.10 \\
4.00 \\
9.70 \\
16.70\end{array}$ & $\begin{array}{l}15.00 \\
14.79 \\
15.76 \\
17.77\end{array}$ & $\begin{array}{r}9.08 \\
7.88 \\
13.35 \\
24.63\end{array}$ & $\begin{array}{r}6.83 \\
5.73 \\
10.74 \\
21.07\end{array}$ & $\begin{array}{r}29.81 \\
17.01 \\
8.51 \\
85.41\end{array}$ & $\begin{array}{l}10.84 \\
19.73 \\
13.36 \\
95.07\end{array}$ & $\begin{array}{l}54.07 \\
56.43 \\
25.53 \\
20.44\end{array}$ & 36.35 & 95.07 & $\begin{array}{r}2.49 \\
21.53 \\
33.64 \\
22.04\end{array}$ & $\begin{array}{l}55.27 \\
46.37 \\
21.59 \\
61.77\end{array}$ & $\begin{array}{r}38.50 \\
37.53 \\
17.56 \\
0.35\end{array}$ & 28.89 & 61.77 \\
\hline
\end{tabular}


Table A.4.3(c) 3 yearly

\begin{tabular}{|c|c|c|c|c|c|c|c|c|c|c|c|c|c|c|c|c|c|c|c|}
\hline \multirow{3}{*}{$\begin{array}{l}\text { Walter Ounithy } \\
\text { Parameistor }\end{array}$} & \multirow{2}{*}{\multicolumn{3}{|c|}{ Observed values }} & \multirow{3}{*}{\multicolumn{3}{|c|}{$\begin{array}{l}\text { Asstyned Vakeses } \\
\text { (Emropy Me thes) }\end{array}$}} & \multirow{2}{*}{\multicolumn{3}{|c|}{ 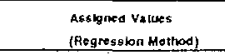 }} & \multicolumn{10}{|c|}{ Absolute Values of Errors $(\%)$} \\
\hline & & & & & & & & & & \multicolumn{5}{|c|}{ (Emrrapy Method) } & \multicolumn{5}{|c|}{ (Regression Method) } \\
\hline & 145010 & at Station & 4.00 & & & & & is stition & 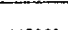 & 115010 & al station & & Average & Mrimon & 145010 & or Station & & aromol & Mrim \\
\hline (1) & & (2) & & & (3) & & & (4) & & & $(5)$ & & (6) & (7) & & (a) & & (9) & $(10)$ \\
\hline $\begin{array}{c}\text { Conducivity } \\
\text { (mS/m) }\end{array}$ & $\begin{array}{l}304.50 \\
297.90 \\
293.80\end{array}$ & $\begin{array}{l}448.22 \\
390.31 \\
339.31\end{array}$ & $\begin{array}{l}366.61 \\
449.11 \\
515.00\end{array}$ & $\begin{array}{l}280.60 \\
317.90 \\
318.30\end{array}$ & $\begin{array}{l}460.70 \\
478.30 \\
478.60\end{array}$ & $\begin{array}{l}122.10 \\
306.70 \\
310.20\end{array}$ & $\begin{array}{l}530.17 \\
464.83 \\
463.66\end{array}$ & $\begin{array}{l}303.54 \\
370.67 \\
371.87\end{array}$ & $\begin{array}{r}96.87 \\
294.51 \\
298.04\end{array}$ & $\begin{array}{l}7.85 \\
6.71 \\
8.34\end{array}$ & $\begin{array}{r}2.78 \\
22.54 \\
41.05\end{array}$ & $\begin{array}{l}66.69 \\
31.71 \\
39.77\end{array}$ & 25.27 & 66.69 & $\begin{array}{l}74.11 \\
56.04 \\
57.82\end{array}$ & $\begin{array}{r}32.28 \\
5.03 \\
9.60\end{array}$ & $\begin{array}{l}73.58 \\
34.42 \\
42.13\end{array}$ & 42.78 & 74.11 \\
\hline $\mathrm{PH}$ & $\begin{array}{l}7.70 \\
7.70 \\
7.70\end{array}$ & $\begin{array}{l}7.90 \\
7.90 \\
7.80\end{array}$ & $\begin{array}{l}7.70 \\
7.80 \\
7.70\end{array}$ & $\begin{array}{l}8.90 \\
8.30 \\
7.43\end{array}$ & $\begin{array}{l}8.10 \\
7.98 \\
7.81\end{array}$ & $\begin{array}{l}8.50 \\
8.26 \\
7.64\end{array}$ & $\begin{array}{l}9.54 \\
8.78 \\
7.26\end{array}$ & $\begin{array}{l}8.00 \\
7.93 \\
7.79\end{array}$ & $\begin{array}{l}8.37 \\
8.14 \\
7.70\end{array}$ & $\begin{array}{r}15.58 \\
7.79 \\
3.51\end{array}$ & $\begin{array}{l}2.53 \\
1.01 \\
0.13\end{array}$ & $\begin{array}{r}10.39 \\
5.80 \\
0.78\end{array}$ & 5.29 & 15.58 & $\begin{array}{r}23.96 \\
14.05 \\
5.75\end{array}$ & $\begin{array}{l}1.31 \\
0.39 \\
0.18\end{array}$ & $\begin{array}{l}8.66 \\
4.41 \\
0.03\end{array}$ & 6.53 & 23.96 \\
\hline $\begin{array}{c}\text { Dissolved } \\
\text { Tons } \\
\text { \{mgl/) }\end{array}$ & $\begin{array}{l}191.20 \\
192.00 \\
201.00\end{array}$ & $\begin{array}{l}298.20 \\
271.60 \\
238.90\end{array}$ & $\begin{array}{l}222.90 \\
275.80 \\
329.80\end{array}$ & $\begin{array}{l}193.80 \\
211.50 \\
212.90\end{array}$ & $\begin{array}{l}289.10 \\
304.00 \\
305.10\end{array}$ & $\begin{array}{l}144.90 \\
237.40 \\
245.20\end{array}$ & $\begin{array}{l}314.69 \\
281.76 \\
279.02\end{array}$ & $\begin{array}{l}182.93 \\
234.85 \\
238.18\end{array}$ & $\begin{array}{l}144.40 \\
239.71 \\
247.65\end{array}$ & $\begin{array}{r}1.36 \\
10.16 \\
5.92\end{array}$ & $\begin{array}{r}3.05 \\
11.93 \\
27.71\end{array}$ & $\begin{array}{l}34.99 \\
13.92 \\
25.61\end{array}$ & 14.96 & 34.99 & $\begin{array}{l}64.59 \\
46.75 \\
38.82\end{array}$ & $\begin{array}{r}38.65 \\
13.53 \\
0.12\end{array}$ & $\begin{array}{l}35.22 \\
13.09 \\
29.86\end{array}$ & 30.63 & 64.59 \\
\hline $\begin{array}{c}\text { Dissolved } \\
\text { Solid's } \\
\text { (mgh) }\end{array}$ & $\begin{array}{l}165.80 \\
167.20 \\
173.00\end{array}$ & $\begin{array}{l}249.80 \\
223,10 \\
197.80\end{array}$ & $\begin{array}{l}192.40 \\
235.80 \\
233.30\end{array}$ & $\begin{array}{l}167.80 \\
183.70 \\
186.10\end{array}$ & $\begin{array}{l}251.70 \\
262.10 \\
263.60\end{array}$ & $\begin{array}{r}99.90 \\
186.90 \\
203.80\end{array}$ & $\begin{array}{l}269.38 \\
243.84 \\
238.97\end{array}$ & $\begin{array}{l}158.23 \\
200.92 \\
209.06\end{array}$ & $\begin{array}{l}100.10 \\
188.79 \\
205.71\end{array}$ & $\begin{array}{l}1.23 \\
9.87 \\
7.57\end{array}$ & $\begin{array}{r}0.76 \\
17.48 \\
39.27\end{array}$ & $\begin{array}{l}48.08 \\
20.74 \\
28.06\end{array}$ & 18.56 & 48.08 & $\begin{array}{l}62.47 \\
45.84 \\
38.13\end{array}$ & $\begin{array}{r}36.66 \\
9.94 \\
5.69\end{array}$ & $\begin{array}{l}47.97 \\
19.94 \\
27.39\end{array}$ & 32.67 & 62.47 \\
\hline $\begin{array}{c}\text { Hardness } \\
\text { img thos Cocos }\end{array}$ & $\begin{array}{l}95.90 \\
97.17 \\
85.25\end{array}$ & $\begin{array}{l}138.70 \\
133.60 \\
113.10\end{array}$ & $\begin{array}{r}79.93 \\
104.30 \\
129.80\end{array}$ & $\begin{array}{r}92.90 \\
103.00 \\
104.60\end{array}$ & $\begin{array}{l}145.40 \\
152.20 \\
153.30\end{array}$ & $\begin{array}{r}67.50 \\
100.90 \\
106.50\end{array}$ & $\begin{array}{l}127.86 \\
121.27 \\
120.16\end{array}$ & $\begin{array}{l}101.09 \\
124.77 \\
128.74\end{array}$ & $\begin{array}{r}71.80 \\
104.63 \\
110.13\end{array}$ & $\begin{array}{l}3.13 \\
6.00 \\
9.82\end{array}$ & $\begin{array}{r}4.83 \\
13.92 \\
35.54\end{array}$ & $\begin{array}{r}\mathbf{1 5 . 5 5} \\
3.26 \\
17.95\end{array}$ & 12.22 & 35.54 & $\begin{array}{l}33.33 \\
24.80 \\
26.16\end{array}$ & $\begin{array}{r}27.11 \\
6.61 \\
13.83\end{array}$ & $\begin{array}{r}10.17 \\
0.32 \\
15.16\end{array}$ & 17.50 & 33.33 \\
\hline 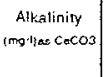 & $\begin{array}{l}71.50 \\
72.90 \\
76.90\end{array}$ & $\begin{array}{l}120.00 \\
119.30 \\
102.10\end{array}$ & $\begin{array}{l}67.30 \\
82.50 \\
95.80\end{array}$ & $\begin{array}{l}79.20 \\
84.30 \\
83.80\end{array}$ & $\begin{array}{l}118.00 \\
122.80 \\
122.40\end{array}$ & $\begin{array}{l}83.90 \\
92.40 \\
91.70\end{array}$ & $\begin{array}{l}94.62 \\
91.99 \\
92.22\end{array}$ & $\begin{array}{l}77.97 \\
99.10 \\
97.27\end{array}$ & $\begin{array}{l}92.31 \\
97.81 \\
97.33\end{array}$ & $\begin{array}{r}10.77 \\
15.64 \\
8.97\end{array}$ & $\begin{array}{r}1.67 \\
2.93 \\
19.88\end{array}$ & $\begin{array}{r}24.67 \\
12.00 \\
5.27\end{array}$ & 11.31 & 24.67 & $\begin{array}{l}32.34 \\
26.19 \\
19.82\end{array}$ & $\begin{array}{r}35.03 \\
16.93 \\
4.73\end{array}$ & $\begin{array}{r}37.17 \\
18.56 \\
0.55\end{array}$ & 21.27 & 37.17 \\
\hline $\begin{array}{l}\text { Nattium } \\
\text { (mgit) }\end{array}$ & $\begin{array}{l}19.90 \\
19.90 \\
23.50\end{array}$ & $\begin{array}{l}33.60 \\
26.70 \\
26.20\end{array}$ & $\begin{array}{l}38.60 \\
47.10 \\
55.30\end{array}$ & $\begin{array}{l}22.90 \\
24.10 \\
24.20\end{array}$ & $\begin{array}{l}33.60 \\
34.60 \\
34.70\end{array}$ & $\begin{array}{l}16.40 \\
33.80 \\
36.10\end{array}$ & $\begin{array}{l}35.87 \\
32.10 \\
31.59\end{array}$ & $\begin{array}{l}28.14 \\
28.65 \\
29.13\end{array}$ & $\begin{array}{l}15.44 \\
33.39 \\
35.81\end{array}$ & $\begin{array}{r}15.08 \\
21.11 \\
2.88\end{array}$ & $\begin{array}{r}0.00 \\
29.59 \\
32.44\end{array}$ & $\begin{array}{l}57.51 \\
28.24 \\
34.72\end{array}$ & 24.63 & 57.51 & $\begin{array}{l}80.25 \\
61.28 \\
34.40\end{array}$ & $\begin{array}{r}25.17 \\
7.31 \\
11.17\end{array}$ & $\begin{array}{l}59.99 \\
20.11 \\
35.24\end{array}$ & 38.21 & 80.25 \\
\hline $\begin{array}{l}\text { Kalium } \\
\text { (mg:t) }\end{array}$ & $\begin{array}{l}1.30 \\
1.30 \\
1.40\end{array}$ & $\begin{array}{l}1.90 \\
1.60 \\
1.60\end{array}$ & $\begin{array}{l}2.10 \\
2.20 \\
2.10\end{array}$ & $\begin{array}{l}1.50 \\
1.50 \\
1.50\end{array}$ & $\begin{array}{l}1.80 \\
1.80 \\
1.80\end{array}$ & $\begin{array}{l}3.00 \\
2.80 \\
2.70\end{array}$ & $\begin{array}{l}1.76 \\
1.68 \\
1.64\end{array}$ & $\begin{array}{l}1.89 \\
1.85 \\
1.82\end{array}$ & $\begin{array}{l}2.85 \\
2.74 \\
2.68\end{array}$ & $\begin{array}{r}15.38 \\
15.38 \\
7.14\end{array}$ & $\begin{array}{r}5.26 \\
12.50 \\
12.50\end{array}$ & $\begin{array}{l}42.86 \\
27.27 \\
28.57\end{array}$ & 18.54 & 42.86 & $\begin{array}{l}35.00 \\
29.00 \\
17.00\end{array}$ & $\begin{array}{r}0.53 \\
15.37 \\
14.00\end{array}$ & $\begin{array}{l}35.76 \\
24.32 \\
27.48\end{array}$ & 22.05 & 35.76 \\
\hline $\begin{array}{l}\text { Calcium } \\
\text { (mglit) }\end{array}$ & $\begin{array}{l}16.20 \\
17.20 \\
17.50\end{array}$ & $\begin{array}{l}26.50 \\
25.40 \\
21.80\end{array}$ & $\begin{array}{l}16.00 \\
21.00 \\
25.20\end{array}$ & $\begin{array}{l}16.50 \\
18.20 \\
17.70\end{array}$ & $\begin{array}{l}26.40 \\
27.70 \\
27.40\end{array}$ & $\begin{array}{l}11.30 \\
18.30 \\
16.10\end{array}$ & $\begin{array}{l}23.42 \\
21.66 \\
22.20\end{array}$ & $\begin{array}{l}20.33 \\
24.35 \\
23.13\end{array}$ & $\begin{array}{l}13.64 \\
20.84 \\
18.65\end{array}$ & $\begin{array}{l}1.79 \\
5.81 \\
1.14\end{array}$ & $\begin{array}{r}0.38 \\
9.06 \\
25.69\end{array}$ & $\begin{array}{l}29.37 \\
12.86 \\
36.11\end{array}$ & 13.58 & 36.11 & $\begin{array}{l}39.41 \\
25.94 \\
26.83\end{array}$ & $\begin{array}{r}23.27 \\
4.13 \\
6.11\end{array}$ & $\begin{array}{r}14.78 \\
0.75 \\
25.98\end{array}$ & 18.58 & 39.41 \\
\hline $\begin{array}{c}\text { Magnesium } \\
\text { (nug:(1) }\end{array}$ & $\begin{array}{l}13.10 \\
13.20 \\
12.50\end{array}$ & $\begin{array}{l}17.60 \\
17.10 \\
14.30\end{array}$ & $\begin{array}{r}9.70 \\
82.50 \\
16.30\end{array}$ & $\begin{array}{l}11.80 \\
13.80 \\
14.50\end{array}$ & $\begin{array}{l}18.70 \\
20.00 \\
20.40\end{array}$ & $\begin{array}{r}7.20 \\
12.60 \\
14.90\end{array}$ & $\begin{array}{l}17.28 \\
16.31 \\
15.89\end{array}$ & $\begin{array}{l}11.37 \\
15.82 \\
17.74\end{array}$ & $\begin{array}{l}11.37 \\
15.82 \\
17.74\end{array}$ & $\begin{array}{r}9.92 \\
4.55 \\
16.00\end{array}$ & $\begin{array}{r}6.25 \\
16.96 \\
42.66\end{array}$ & $\begin{array}{r}25.77 \\
0.80 \\
8.59\end{array}$ & 14.61 & 42.66 & $\begin{array}{l}31.89 \\
23.55 \\
27.12\end{array}$ & $\begin{array}{r}35.40 \\
7.50 \\
24.03\end{array}$ & $\begin{array}{r}17.22 \\
26.54 \\
8.81\end{array}$ & 22.45 & 35.40 \\
\hline
\end{tabular}


Table A.4.3(d) 4 yearly

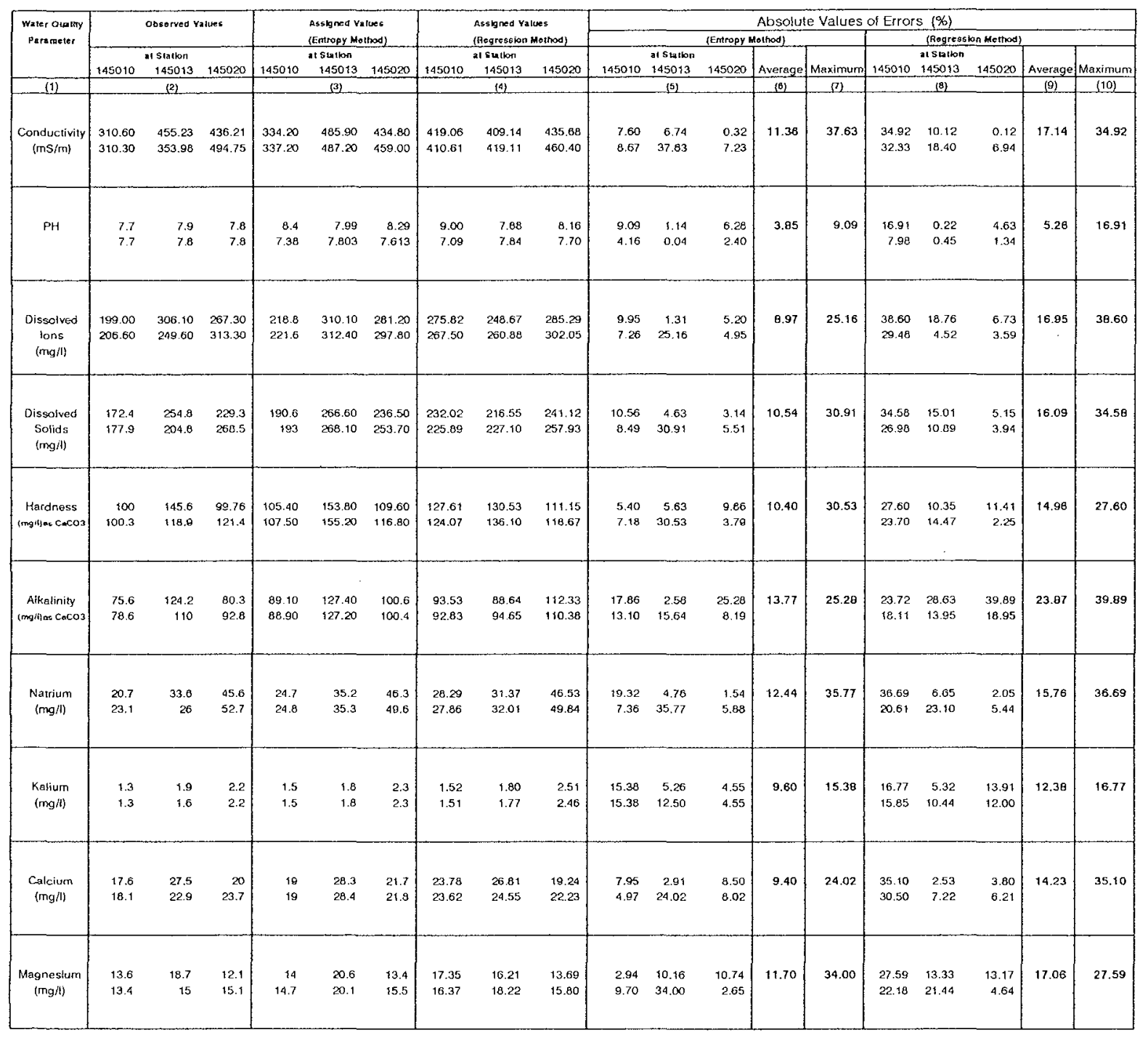


Table A.5.1 Regression Coefficients for Various Periods of Time in the Fitzroy River Basin

Table A.5.1(a) Between the Downstream Station 130003 and the Upstream Station 130105

Upstream Value $=B o+B i *($ Downstream Value $)$

\begin{tabular}{|c|c|c|c|c|}
\hline $\begin{array}{c}\text { Water Quality } \\
\text { Parameter }\end{array}$ & $\begin{array}{l}\text { Regression } \\
\text { Coetficient }\end{array}$ & 1 Yearly & 2 Yearly & 3 Yearly \\
\hline Conductivity & $\begin{array}{c}\text { Bo } \\
\text { Bi } \\
\text { Correlation } \\
\text { Coefficient }\end{array}$ & $\begin{array}{c}133.00 \\
0.46 \\
0.86\end{array}$ & $\begin{array}{c}128.80 \\
0.48 \\
0.87\end{array}$ & $\begin{array}{c}140.70 \\
0.46 \\
0.89\end{array}$ \\
\hline PH & $\begin{array}{c}\text { Bo } \\
\text { 8i } \\
\text { Correlation } \\
\text { Coefficient }\end{array}$ & $\begin{array}{l}6.87 \\
0.12 \\
0.10\end{array}$ & $\begin{array}{l}7.23 \\
0.07 \\
0.07\end{array}$ & $\begin{array}{c}8.24 \\
-0.05 \\
0.08\end{array}$ \\
\hline Dissolved Ions & $\begin{array}{c}\text { 8o } \\
\text { Bi } \\
\text { Corretation } \\
\text { Coefficient }\end{array}$ & $\begin{array}{l}81.79 \\
0.51 \\
0.89\end{array}$ & $\begin{array}{l}81.52 \\
0.52 \\
0.91\end{array}$ & $\begin{array}{c}91.73 \\
0.49 \\
0.92\end{array}$ \\
\hline Dissolved Solids & $\begin{array}{c}\text { Bo } \\
\text { Bi } \\
\text { Correiation } \\
\text { Coefficient }\end{array}$ & $\begin{array}{l}74.52 \\
0.46 \\
0.90\end{array}$ & $\begin{array}{l}70.58 \\
0.49 \\
0.93\end{array}$ & $\begin{array}{l}74.16 \\
0.48 \\
0.94\end{array}$ \\
\hline Hardness & $\begin{array}{c}\text { Bo } \\
\text { Bi } \\
\text { Correlation } \\
\text { Coefficient }\end{array}$ & $\begin{array}{c}32.60 \\
0.52 \\
0.91\end{array}$ & $\begin{array}{c}35.81 \\
0.49 \\
0.90\end{array}$ & $\begin{array}{c}42.04 \\
0.45 \\
0.91\end{array}$ \\
\hline Afkalinity & $\begin{array}{c}\text { Bo } \\
\text { Bi } \\
\text { Correlation } \\
\text { Coefficient }\end{array}$ & $\begin{array}{l}19.48 \\
0.75 \\
0.82\end{array}$ & $\begin{array}{c}21.69 \\
0.73 \\
0.83\end{array}$ & $\begin{array}{c}30.77 \\
0.65 \\
0.85\end{array}$ \\
\hline Natrium & $\begin{array}{c}\text { Bo } \\
\text { Bi } \\
\text { Correlation } \\
\text { Coefficient }\end{array}$ & $\begin{array}{l}9.76 \\
0.47 \\
0.84\end{array}$ & $\begin{array}{l}9.79 \\
0.48 \\
0.89\end{array}$ & $\begin{array}{l}11.29 \\
0.45 \\
0.89\end{array}$ \\
\hline Kalium & $\begin{array}{c}\text { Bo } \\
\text { Bi } \\
\text { Correlation } \\
\text { Coefficient }\end{array}$ & $\begin{array}{l}2.13 \\
0.29 \\
0.45\end{array}$ & $\begin{array}{l}1.29 \\
0.56 \\
0.83\end{array}$ & $\begin{array}{l}1.01 \\
0.64 \\
0.94\end{array}$ \\
\hline Calcium & $\begin{array}{c}\text { 8o } \\
\text { Bi } \\
\text { Correlation } \\
\text { Coefficient }\end{array}$ & $\begin{array}{l}5.99 \\
0.60 \\
0.92\end{array}$ & $\begin{array}{l}7.05 \\
0.55 \\
0.89\end{array}$ & $\begin{array}{l}8.80 \\
0.49 \\
0.90\end{array}$ \\
\hline Magnesium & $\begin{array}{c}\text { 8o } \\
\text { Bi } \\
\text { Correlation } \\
\text { Coefficiert }\end{array}$ & $\begin{array}{l}3.98 \\
0.45 \\
0.90\end{array}$ & $\begin{array}{l}4.31 \\
0.42 \\
0.91\end{array}$ & $\begin{array}{l}4.98 \\
0.40 \\
0.92\end{array}$ \\
\hline
\end{tabular}


Table A.5.1 (b) Between the Downstream Station 130003 and the Upstream Station 130322

Upstream Value $=B o+B i{ }^{\star}$ (Downstream Value)

\begin{tabular}{|c|c|c|c|c|}
\hline $\begin{array}{c}\text { Water Quality } \\
\text { Parameter }\end{array}$ & $\begin{array}{c}\text { Regression } \\
\text { Coefficient }\end{array}$ & 1 Yearly & 2 Yearly & 3 Yearly \\
\hline Conductivity & $\begin{array}{c}\text { Bo } \\
\mathrm{Bi} \\
\text { Correlation } \\
\text { Coefficient }\end{array}$ & $\begin{array}{c}245.00 \\
-0.11 \\
0.51\end{array}$ & $\begin{array}{c}267.90 \\
-0.18 \\
0.86\end{array}$ & $\begin{array}{c}278.20 \\
-0.20 \\
0.88\end{array}$ \\
\hline $\mathrm{PH}$ & $\begin{array}{c}\text { Bo } \\
\text { Bi } \\
\text { Correlation } \\
\text { Coefficient } \\
\end{array}$ & $\begin{array}{l}2.73 \\
0.62 \\
0.54\end{array}$ & $\begin{array}{l}4.08 \\
0.44 \\
0.58\end{array}$ & $\begin{array}{l}3.58 \\
0.50 \\
0.76\end{array}$ \\
\hline Dissolved lons & $\begin{array}{c}\text { Bo } \\
\text { Bi } \\
\text { Correlation } \\
\text { Coefficient }\end{array}$ & $\begin{array}{c}181.00 \\
-0.13 \\
0.54\end{array}$ & $\begin{array}{c}200.20 \\
-0.21 \\
0.82\end{array}$ & $\begin{array}{c}212.20 \\
-0.25 \\
0.94\end{array}$ \\
\hline Dissolved Solid & $\begin{array}{c}\text { Bo } \\
\text { Bi } \\
\text { Correlation } \\
\text { Coefficient } \\
\end{array}$ & $\begin{array}{c}149.10 \\
-0.12 \\
0.51\end{array}$ & $\begin{array}{c}169.80 \\
-0.22 \\
0.82\end{array}$ & $\begin{array}{l}186.10 \\
-0.28 \\
0.95\end{array}$ \\
\hline Hardness & $\begin{array}{c}\text { Bo } \\
\text { Bi } \\
\text { Correlation } \\
\text { Coefficient } \\
\end{array}$ & $\begin{array}{c}61.52 \\
-0.08 \\
0.54\end{array}$ & $\begin{array}{c}65.47 \\
-0.11 \\
0.78\end{array}$ & $\begin{array}{c}65.81 \\
-0.12 \\
0.83\end{array}$ \\
\hline Alkalinity & $\begin{array}{c}\text { Bo } \\
\text { Bi } \\
\text { Correlation } \\
\text { Coefficient } \\
\end{array}$ & $\begin{array}{c}98.99 \\
-0.35 \\
0.71\end{array}$ & $\begin{array}{c}101.70 \\
-0.39 \\
0.92\end{array}$ & $\begin{array}{c}103.50 \\
-0.41 \\
0.92\end{array}$ \\
\hline Natrium & $\begin{array}{c}\mathrm{Bo} \\
\mathrm{Bi} \\
\text { Correlation } \\
\text { Coefficient } \\
\end{array}$ & $\begin{array}{c}22.01 \\
-0.10 \\
0.43\end{array}$ & $\begin{array}{c}24.95 \\
-0.19 \\
0.81\end{array}$ & $\begin{array}{c}27.71 \\
-0.26 \\
0.95\end{array}$ \\
\hline Kalium & $\begin{array}{c}\text { Bo } \\
\text { Bi } \\
\text { Correlation } \\
\text { Coefficient } \\
\end{array}$ & $\begin{array}{l}5.21 \\
0.11 \\
0.22\end{array}$ & $\begin{array}{l}4.81 \\
0.23 \\
0.78\end{array}$ & $\begin{array}{l}4.90 \\
0.20 \\
0.71\end{array}$ \\
\hline Calcium & $\begin{array}{c}\text { Bo } \\
\text { Bi } \\
\text { Correlation } \\
\text { Coefficient } \\
\end{array}$ & $\begin{array}{c}15.16 \\
-0.08 \\
0.40\end{array}$ & $\begin{array}{c}16.32 \\
-0.14 \\
0.71\end{array}$ & $\begin{array}{c}16.38 \\
-0.14 \\
0.75\end{array}$ \\
\hline Magnesium & $\begin{array}{c}\text { Bo } \\
\text { Bi } \\
\text { Correlation } \\
\text { Coefficient }\end{array}$ & $\begin{array}{c}5.68 \\
-0.07 \\
0.69\end{array}$ & $\begin{array}{c}6.04 \\
-0.10 \\
0.86\end{array}$ & $\begin{array}{c}6.10 \\
-0.10 \\
0.92\end{array}$ \\
\hline
\end{tabular}


Table A.5.2 Regression Coefficients for Various Periods of Time in the Nogoa River Basin

Table A.5.2(a) Between the Downstream Station 130209 and the Upstream Station 130202

Upstream Value $=B o+B i *($ Downstream Value $)$

\begin{tabular}{|c|c|c|c|c|c|}
\hline $\begin{array}{c}\text { Water Quality } \\
\text { Parameter }\end{array}$ & $\begin{array}{l}\text { Regression } \\
\text { Coefficient }\end{array}$ & 1 Yearly & 2 Yoariy & 3 Yearly & 4 Yoarly \\
\hline Conductivity & $\begin{array}{c}\text { Bo } \\
\text { Bi } \\
\text { Correlation } \\
\text { Coefficient }\end{array}$ & $\begin{array}{c}178.84 \\
0.21 \\
0.71\end{array}$ & $\begin{array}{c}185.01 \\
0.20 \\
0.82\end{array}$ & $\begin{array}{c}196.11 \\
0.18 \\
0.92\end{array}$ & $\begin{array}{c}197.05 \\
0.18 \\
0.83\end{array}$ \\
\hline $\mathrm{PH}$ & $\begin{array}{c}\text { Bo } \\
\text { Bi } \\
\text { Correlation } \\
\text { Coefficient }\end{array}$ & $\begin{array}{l}5.19 \\
0.30 \\
0.21\end{array}$ & $\begin{array}{c}8.68 \\
-0.14 \\
0.23\end{array}$ & $\begin{array}{c}10.42 \\
-0.36 \\
0.56\end{array}$ & $\begin{array}{l}10.92 \\
-4.30 \\
0.20\end{array}$ \\
\hline Dissolved lons & $\begin{array}{c}\mathrm{Bo} \\
\mathrm{Bi} \\
\text { Correlation } \\
\text { Coefficient } \\
\end{array}$ & $\begin{array}{c}133.76 \\
0.17 \\
0.68\end{array}$ & $\begin{array}{c}140.07 \\
0.16 \\
0.76\end{array}$ & $\begin{array}{c}148.69 \\
0.14 \\
0.88\end{array}$ & $\begin{array}{c}148.23 \\
0.14 \\
0.78\end{array}$ \\
\hline Dissolved Solids & $\begin{array}{c}\text { Bo } \\
\text { Bi } \\
\text { Corretation } \\
\text { Coefficient }\end{array}$ & $\begin{array}{c}93.07 \\
0.24 \\
0.72\end{array}$ & $\begin{array}{c}98.33 \\
0.23 \\
0.80\end{array}$ & $\begin{array}{c}105.65 \\
0.20 \\
0.90\end{array}$ & $\begin{array}{c}104.65 \\
0.21 \\
0.85\end{array}$ \\
\hline Hardness & $\begin{array}{c}\mathrm{Bo} \\
\mathrm{Bi} \\
\text { Correlation } \\
\text { Coefficient }\end{array}$ & $\begin{array}{c}62.22 \\
0.13 \\
0.58\end{array}$ & $\begin{array}{c}63.95 \\
0.12 \\
0.72\end{array}$ & $\begin{array}{c}69.99 \\
0.08 \\
0.63\end{array}$ & $\begin{array}{l}72.71 \\
0.06 \\
0.41\end{array}$ \\
\hline Aikalinity & $\begin{array}{c}\text { Bo } \\
\text { Bi } \\
\text { Correlation } \\
\text { Coefficient }\end{array}$ & $\begin{array}{l}69.09 \\
0.08 \\
0.52\end{array}$ & $\begin{array}{l}71.19 \\
0.07 \\
0.57\end{array}$ & $\begin{array}{l}75.66 \\
0.05 \\
0.54\end{array}$ & $\begin{array}{l}76.72 \\
0.04 \\
0.41\end{array}$ \\
\hline Natrium & $\begin{array}{c}\text { Bo } \\
\text { Bi } \\
\text { Correlation } \\
\text { Coefficient }\end{array}$ & $\begin{array}{l}13.42 \\
0.21 \\
0.62\end{array}$ & $\begin{array}{l}13.57 \\
0.22 \\
0.78\end{array}$ & $\begin{array}{l}14.04 \\
0.22 \\
0.96\end{array}$ & $\begin{array}{l}14.11 \\
0.21 \\
0.84\end{array}$ \\
\hline Kalium & $\begin{array}{c}\mathrm{Bo} \\
\mathrm{Bi} \\
\text { Correlation } \\
\text { Coefficient }\end{array}$ & $\begin{array}{l}3.31 \\
0.38 \\
0.26\end{array}$ & $\begin{array}{l}4.75 \\
0.09 \\
0.09\end{array}$ & $\begin{array}{l}4.31 \\
0.21 \\
0.27\end{array}$ & $\begin{array}{l}3.16 \\
0.50 \\
0.49\end{array}$ \\
\hline Calcium & $\begin{array}{c}\text { Bo } \\
\text { Bi } \\
\text { Correlation } \\
\text { Coefficient }\end{array}$ & $\begin{array}{l}9.64 \\
0.53 \\
0.75\end{array}$ & $\begin{array}{l}10.24 \\
0.50 \\
0.82\end{array}$ & $\begin{array}{l}12.94 \\
0.38 \\
0.79\end{array}$ & $\begin{array}{l}13.82 \\
0.35 \\
0.68\end{array}$ \\
\hline Magnesium & $\begin{array}{c}\text { Bo } \\
\text { Bi } \\
\text { Correlation } \\
\text { Coefficient }\end{array}$ & $\begin{array}{l}5.64 \\
0.05 \\
0.44\end{array}$ & $\begin{array}{l}5.74 \\
0.04 \\
0.58\end{array}$ & $\begin{array}{l}6.35 \\
0.01 \\
0.25\end{array}$ & $\begin{array}{c}6.63 \\
-0.001 \\
0.02\end{array}$ \\
\hline
\end{tabular}


Table A.5.2(b) Between the Downstream Station 130209 and the Upstream Station 130212

Upstream Value $=B o+B i$ * (Downstream Value)

\begin{tabular}{|c|c|c|c|c|c|}
\hline $\begin{array}{c}\text { Water Quality } \\
\text { Parameter }\end{array}$ & $\begin{array}{c}\text { Regression } \\
\text { Coefficient }\end{array}$ & 1 Yearly & 2 Yearly & 3 Yearly & 4 Yearly \\
\hline Conductivity & $\begin{array}{c}\text { Bo } \\
\text { Bi } \\
\text { Correlation } \\
\text { Coefficient }\end{array}$ & $\begin{array}{c}75.33 \\
0.60 \\
0.71\end{array}$ & $\begin{array}{c}50.83 \\
0.66 \\
0.82\end{array}$ & $\begin{array}{l}7.61 \\
0.75 \\
0.97\end{array}$ & $\begin{array}{c}25.30 \\
0.70 \\
0.95\end{array}$ \\
\hline $\mathrm{PH}$ & $\begin{array}{c}\mathrm{Bo} \\
\mathrm{Bi} \\
\text { Correlation } \\
\text { Coefficient }\end{array}$ & $\begin{array}{l}5.19 \\
0.30 \\
0.21\end{array}$ & $\begin{array}{l}3.81 \\
0.47 \\
0.23\end{array}$ & $\begin{array}{l}1.35 \\
0.79 \\
0.89\end{array}$ & $\begin{array}{l}1.60 \\
0.75 \\
0.83\end{array}$ \\
\hline Dissolved Ions & $\begin{array}{c}\text { Bo } \\
\mathrm{Bi} \\
\text { Correlation } \\
\text { Coefficlent }\end{array}$ & $\begin{array}{c}70.22 \\
0.55 \\
0.68\end{array}$ & $\begin{array}{c}50.72 \\
0.60 \\
0.76\end{array}$ & $\begin{array}{l}15.21 \\
0.70 \\
0.94\end{array}$ & $\begin{array}{c}31.58 \\
0.64 \\
0.93\end{array}$ \\
\hline Dissolved Solid & $\begin{array}{c}\mathrm{Bo} \\
\mathrm{Bi} \\
\text { Correlation } \\
\text { Coefficient }\end{array}$ & $\begin{array}{c}44.92 \\
0.61 \\
0.72\end{array}$ & $\begin{array}{c}29.05 \\
0.67 \\
0.80\end{array}$ & $\begin{array}{l}0.86 \\
0.79 \\
0.96\end{array}$ & $\begin{array}{c}12.31 \\
0.73 \\
0.94\end{array}$ \\
\hline Hardness & $\begin{array}{c}\mathrm{Bo} \\
\mathrm{Bi} \\
\text { Correlation } \\
\text { Coefficient }\end{array}$ & $\begin{array}{c}41.71 \\
0.41 \\
0.58\end{array}$ & $\begin{array}{c}29.19 \\
0.49 \\
0.72\end{array}$ & $\begin{array}{l}10.99 \\
0.62 \\
0.94\end{array}$ & $\begin{array}{c}25.92 \\
0.50 \\
0.90\end{array}$ \\
\hline Alkalinity & $\begin{array}{c}\text { Bo } \\
\text { Bi } \\
\text { Correlation } \\
\text { Coefficient }\end{array}$ & $\begin{array}{c}49.90 \\
0.39 \\
0.52\end{array}$ & $\begin{array}{l}41.50 \\
0.42 \\
0.57\end{array}$ & $\begin{array}{c}27.53 \\
0.50 \\
0.93\end{array}$ & $\begin{array}{c}39.99 \\
0.42 \\
0.90\end{array}$ \\
\hline Natrium & $\begin{array}{c}\text { Bo } \\
\text { Bi } \\
\text { Correlation } \\
\text { Coefficient }\end{array}$ & $\begin{array}{l}3.09 \\
0.78 \\
0.62\end{array}$ & $\begin{array}{l}2.45 \\
0.80 \\
0.78\end{array}$ & $\begin{array}{l}-0.43 \\
0.87 \\
0.94\end{array}$ & $\begin{array}{l}-2.60 \\
0.92 \\
0.97\end{array}$ \\
\hline Kalium & $\begin{array}{c}\text { Bo } \\
\text { Bi } \\
\text { Correlation } \\
\text { Coefficient }\end{array}$ & $\begin{array}{l}2.46 \\
0.44 \\
0.26\end{array}$ & $\begin{array}{l}2.58 \\
0.40 \\
0.09\end{array}$ & $\begin{array}{l}2.86 \\
0.33 \\
0.71\end{array}$ & $\begin{array}{l}2.54 \\
0.40 \\
0.99\end{array}$ \\
\hline Calcium & $\begin{array}{c}\text { Bo } \\
\mathrm{Bi} \\
\text { Correlation } \\
\text { Coefficient }\end{array}$ & $\begin{array}{l}3.56 \\
1.08 \\
0.75\end{array}$ & $\begin{array}{l}-7.78 \\
1.58 \\
0.82\end{array}$ & $\begin{array}{c}-23.96 \\
2.33 \\
0.88\end{array}$ & $\begin{array}{c}-12.22 \\
1.79 \\
0.87\end{array}$ \\
\hline Magnesium & $\begin{array}{c}\text { Bo } \\
\text { Bi } \\
\text { Correlation } \\
\text { Coefficient }\end{array}$ & $\begin{array}{l}3.48 \\
0.18 \\
0.44\end{array}$ & $\begin{array}{l}3.15 \\
0.19 \\
0.58\end{array}$ & $\begin{array}{l}2.41 \\
0.23 \\
0.95\end{array}$ & $\begin{array}{l}2.70 \\
0.21 \\
0.93\end{array}$ \\
\hline
\end{tabular}


Table A.5.3 Regression Coefficients for Various Periods of time in the Logan River Basin

Table A.5.3(a) Between the Downstream Station 145008 and the Upstream Station 145010

Upstream Value $=B o+B i *($ Downstream Value $)$

\begin{tabular}{|c|c|c|c|c|c|}
\hline $\begin{array}{c}\text { Water Quality } \\
\text { Parameter }\end{array}$ & $\begin{array}{r}\text { Regression } \\
\text { Coefficient }\end{array}$ & 1 Yearly & 2 Yearly & 3 Yearly & 4 Yearly \\
\hline Conductivity & $\begin{array}{c}\text { Bo } \\
\text { Bi } \\
\text { Correlation } \\
\text { Coefficient }\end{array}$ & $\begin{array}{c}332.52 \\
0.10 \\
0.24\end{array}$ & $\begin{array}{c}453.61 \\
-0.11 \\
0.32\end{array}$ & $\begin{array}{c}825.03 \\
-0.80 \\
0.56\end{array}$ & $\begin{array}{c}589.17 \\
-0.39 \\
0.38\end{array}$ \\
\hline PH & $\begin{array}{c}\text { Bo } \\
\text { Bi } \\
\text { Correlation } \\
\text { Coefficient }\end{array}$ & $\begin{array}{c}13.88 \\
-0.75 \\
0.30\end{array}$ & $\begin{array}{c}43.44 \\
-4.48 \\
0.76\end{array}$ & $\begin{array}{l}68.62 \\
-7.63 \\
0.62\end{array}$ & $\begin{array}{c}83.76 \\
-9.58 \\
0.67\end{array}$ \\
\hline Dissolved lons & $\begin{array}{c}\text { Bo } \\
\text { Bi } \\
\text { Correlation } \\
\text { Coefficient }\end{array}$ & $\begin{array}{c}242.15 \\
0.04 \\
0.09\end{array}$ & $\begin{array}{c}278.15 \\
-0.06 \\
0.12\end{array}$ & $\begin{array}{c}443.13 \\
-0.57 \\
0.40\end{array}$ & $\begin{array}{c}392.20 \\
-0.43 \\
0.34\end{array}$ \\
\hline Dissolved Solids & $\begin{array}{c}\text { Bo } \\
\text { Bi } \\
\text { Correlation } \\
\text { Coefficient }\end{array}$ & $\begin{array}{c}193.47 \\
0.08 \\
0.21\end{array}$ & $\begin{array}{c}233.05 \\
-0.04 \\
0.10\end{array}$ & $\begin{array}{c}380.21 \\
-0.57 \\
0.45\end{array}$ & $\begin{array}{c}314.37 \\
-0.36 \\
0.35\end{array}$ \\
\hline Hardness & $\begin{array}{c}\text { Bo } \\
\text { Bi } \\
\text { Correlation } \\
\text { Coefficient }\end{array}$ & $\begin{array}{c}93.10 \\
0.20 \\
0.32\end{array}$ & $\begin{array}{l}79.98 \\
0.28 \\
0.35\end{array}$ & $\begin{array}{c}150.58 \\
-0.23 \\
0.17\end{array}$ & $\begin{array}{c}170.27 \\
-0.36 \\
0.27\end{array}$ \\
\hline Alkalinity & $\begin{array}{c}\text { Bo } \\
\text { Bi } \\
\text { Correlation } \\
\text { Coefficient }\end{array}$ & $\begin{array}{c}106.47 \\
-0.05 \\
0.08\end{array}$ & $\begin{array}{c}63.51 \\
0.28 \\
0.30\end{array}$ & $\begin{array}{c}104.71 \\
-0.12 \\
0.06\end{array}$ & $\begin{array}{c}107.72 \\
-0.15 \\
0.04\end{array}$ \\
\hline Natrium & $\begin{array}{c}\text { Bo } \\
\text { Bi } \\
\text { Correlation } \\
\text { Coefficient }\end{array}$ & $\begin{array}{c}20.25 \\
0.13 \\
0.37\end{array}$ & $\begin{array}{l}36.25 \\
-0.16 \\
0.76\end{array}$ & $\begin{array}{c}52.25 \\
-0.51 \\
0.51\end{array}$ & $\begin{array}{c}33.65 \\
-0.15 \\
0.23\end{array}$ \\
\hline Kalium & $\begin{array}{c}\text { Bo } \\
\text { Bi } \\
\text { Correlation } \\
\text { Coefficient }\end{array}$ & $\begin{array}{r}1.43 \\
-0.01 \\
0.08\end{array}$ & $\begin{array}{l}1.23 \\
0.07 \\
0.74\end{array}$ & $\begin{array}{r}2.46 \\
-0.40 \\
0.82\end{array}$ & $\begin{array}{c}1.63 \\
-0.07 \\
0.14\end{array}$ \\
\hline Calcium & $\begin{array}{c}\text { Bo } \\
\text { Bi } \\
\text { Correlation } \\
\text { Coefticient }\end{array}$ & $\begin{array}{l}14.98 \\
0.23 \\
0.39\end{array}$ & $\begin{array}{l}14.99 \\
0.23 \\
0.35\end{array}$ & $\begin{array}{c}29.42 \\
-0.31 \\
0.29\end{array}$ & $\begin{array}{c}29.32 \\
-0.32 \\
0.31\end{array}$ \\
\hline Magnesium & $\begin{array}{c}\text { Bo } \\
\text { Bi } \\
\text { Corretation } \\
\text { Coefficient }\end{array}$ & $\begin{array}{l}14.09 \\
0.14 \\
0.23\end{array}$ & $\begin{array}{l}11.87 \\
0.25 \\
0.30\end{array}$ & $\begin{array}{c}19.31 \\
-0.19 \\
0.12\end{array}$ & $\begin{array}{c}21.31 \\
-0.29 \\
0.20\end{array}$ \\
\hline
\end{tabular}


Table A.5.3(b) Between the Downstream Station 145008 and the Upstream Station 145013

Upstream Value $=B o+B i *($ Downstream Value $)$

\begin{tabular}{|c|c|c|c|c|c|}
\hline $\begin{array}{l}\text { Water Quality } \\
\text { Parameter }\end{array}$ & $\begin{array}{l}\text { Regression } \\
\text { Coefficient }\end{array}$ & 1 Yearly & 2 Yearly & 3 Yearly & 4 Yearly \\
\hline Conductivity & $\begin{array}{c}\text { Bo } \\
\text { Bi } \\
\text { Correlation } \\
\text { Coefficient }\end{array}$ & $\begin{array}{c}282.22 \\
0.37 \\
0.53\end{array}$ & $\begin{array}{c}-122.50 \\
1.05 \\
0.74\end{array}$ & $\begin{array}{l}0.60 \\
0.82 \\
0.93\end{array}$ & $\begin{array}{c}208.51 \\
0.46 \\
0.91\end{array}$ \\
\hline $\mathrm{PH}$ & $\begin{array}{c}\text { Bo } \\
\text { Bi } \\
\text { Corretation } \\
\text { Coefficient }\end{array}$ & $\begin{array}{c}15.56 \\
-0.97 \\
0.36\end{array}$ & $\begin{array}{c}20.00 \\
-1.54 \\
0.44\end{array}$ & $\begin{array}{c}13.58 \\
-0.72 \\
0.63\end{array}$ & $\begin{array}{c}9.74 \\
-0.24 \\
0.08\end{array}$ \\
\hline Dissolved lons & $\begin{array}{c}\text { Bo } \\
\text { Bi } \\
\text { Correlation } \\
\text { Coefficient }\end{array}$ & $\begin{array}{c}100.19 \\
0.60 \\
0.62\end{array}$ & $\begin{array}{c}-235.50 \\
1.49 \\
0.82\end{array}$ & $\begin{array}{c}-19.54 \\
0.88 \\
0.95\end{array}$ & $\begin{array}{c}77.73 \\
0.62 \\
0.88\end{array}$ \\
\hline Dissolved Solids & $\begin{array}{c}\mathrm{Bo} \\
\mathrm{Bi} \\
\text { Correlation } \\
\text { Coefficient }\end{array}$ & $\begin{array}{c}85.14 \\
0.59 \\
0.71\end{array}$ & $\begin{array}{c}-139.30 \\
1.29 \\
0.91\end{array}$ & $\begin{array}{c}-27.97 \\
0.94 \\
0.89\end{array}$ & $\begin{array}{c}74.84 \\
0.60 \\
0.87\end{array}$ \\
\hline Hardness & $\begin{array}{c}\text { Bo } \\
\text { Bı } \\
\text { Correlation } \\
\text { Coefficient }\end{array}$ & $\begin{array}{c}36.78 \\
0.75 \\
0.78\end{array}$ & $\begin{array}{c}-71.92 \\
1.42 \\
0.92\end{array}$ & $\begin{array}{l}19.80 \\
0.83 \\
0.95\end{array}$ & $\begin{array}{c}63.41 \\
0.55 \\
0.90\end{array}$ \\
\hline Alkalinity & $\begin{array}{c}\text { Bo } \\
\text { Bi } \\
\text { Correlation } \\
\text { Coefficient }\end{array}$ & $\begin{array}{c}-17.80 \\
1.12 \\
0.67\end{array}$ & $\begin{array}{c}-120.50 \\
1.90 \\
0.80\end{array}$ & $\begin{array}{l}-3.09 \\
0.97 \\
0.86\end{array}$ & $\begin{array}{c}-33.00 \\
1.20 \\
0.79\end{array}$ \\
\hline Natrium & $\begin{array}{c}\text { Bo } \\
\text { Bi } \\
\text { Correlation } \\
\text { Coefficient }\end{array}$ & $\begin{array}{c}26.47 \\
0.19 \\
0.39\end{array}$ & $\begin{array}{l}6.00 \\
0.58 \\
0.48\end{array}$ & $\begin{array}{l}9.93 \\
0.47 \\
0.70\end{array}$ & $\begin{array}{c}23.52 \\
0.21 \\
0.55\end{array}$ \\
\hline Kalium & $\begin{array}{c}\mathrm{Bo} \\
\mathrm{Bi} \\
\text { Correlation } \\
\text { Coefficient }\end{array}$ & $\begin{array}{c}1.82 \\
-0.05 \\
0.13\end{array}$ & $\begin{array}{c}2.05 \\
-0.14 \\
0.29\end{array}$ & $\begin{array}{c}2.29 \\
-0.22 \\
0.39\end{array}$ & $\begin{array}{c}2.10 \\
-0.16 \\
0.48\end{array}$ \\
\hline Calcium & $\begin{array}{c}\text { Bo } \\
\text { Bi } \\
\text { Correlation } \\
\text { Coefficient }\end{array}$ & $\begin{array}{l}7.56 \\
0.72 \\
0.76\end{array}$ & $\begin{array}{c}-9.23 \\
1.27 \\
0.95\end{array}$ & $\begin{array}{r}6.62 \\
0.72 \\
0.94 \\
.\end{array}$ & $\begin{array}{c}13.34 \\
0.49 \\
0.91\end{array}$ \\
\hline Magnesium & $\begin{array}{c}\text { Bo } \\
\text { Bi } \\
\text { Correlation } \\
\text { Coefficient }\end{array}$ & $\begin{array}{l}4.88 \\
0.77 \\
0.80\end{array}$ & $\begin{array}{l}8.56 \\
1.47 \\
0.91\end{array}$ & $\begin{array}{l}2.04 \\
0.87 \\
0.95\end{array}$ & $\begin{array}{l}8.11 \\
0.57 \\
0.91\end{array}$ \\
\hline
\end{tabular}


Table A.5.3(c) Between the Downstream Station 145008 and the Upstream Station 145020

Upstream Value $=B o+B i *($ Downstream Value $)$

\begin{tabular}{|c|c|c|c|c|c|}
\hline $\begin{array}{c}\text { Water Quality } \\
\text { Parameter }\end{array}$ & $\begin{array}{l}\text { Regression } \\
\text { Coefficient }\end{array}$ & 1 Yearly & 2 Yearly & 3 Yearly & 4 Yearly \\
\hline Conductivity & $\begin{array}{c}\text { Bo } \\
\text { Bi } \\
\text { Correlation } \\
\text { Coeficient }\end{array}$ & $\begin{array}{c}636.09 \\
-0.04 \\
0.03\end{array}$ & $\begin{array}{l}-6.80 \\
2.20 \\
0.66\end{array}$ & $\begin{array}{c}-795.90 \\
2.43 \\
0.75\end{array}$ & $\begin{array}{c}-61.62 \\
1.14 \\
0.65\end{array}$ \\
\hline $\mathrm{PH}$ & $\begin{array}{c}\text { Bo } \\
\text { Bi } \\
\text { Correlation } \\
\text { Coefficient }\end{array}$ & $\begin{array}{c}16.34 \\
-1.07 \\
0.38\end{array}$ & $\begin{array}{c}31.05 \\
-2.93 \\
0.59\end{array}$ & $\begin{array}{c}25.54 \\
-2.23 \\
0.65\end{array}$ & $\begin{array}{c}26.31 \\
-2.33 \\
0.71\end{array}$ \\
\hline Dissolved tons & $\begin{array}{c}\text { Bo } \\
\text { Bi } \\
\text { Correlation } \\
\text { Coefficient }\end{array}$ & $\begin{array}{c}395.22 \\
-0.07 \\
0.05\end{array}$ & $\begin{array}{c}-310.40 \\
1.81 \\
0.64\end{array}$ & $\begin{array}{c}-227.30 \\
1.62 \\
0.63\end{array}$ & $\begin{array}{c}50.73 \\
0.85 \\
0.52\end{array}$ \\
\hline Dissolved Solids & $\begin{array}{c}\text { Bo } \\
\text { Bi } \\
\text { Correlation } \\
\text { Coefficient }\end{array}$ & $\begin{array}{c}318.54 \\
0.01 \\
0.00\end{array}$ & $\begin{array}{c}-300.20 \\
1.96 \\
0.68\end{array}$ & $\begin{array}{c}-284.80 \\
1.95 \\
0.73\end{array}$ & $\begin{array}{l}15.18 \\
0.96 \\
0.60\end{array}$ \\
\hline Hardness & $\begin{array}{c}\text { Bo } \\
\text { Bi } \\
\text { Correlation } \\
\text { Coefficient }\end{array}$ & $\begin{array}{c}141.22 \\
-0.00 \\
0.00\end{array}$ & $\begin{array}{c}-90.39 \\
1.41 \\
0.62\end{array}$ & $\begin{array}{c}-40.97 \\
1.15 \\
0.56\end{array}$ & $\begin{array}{c}20.48 \\
0.75 \\
0.50\end{array}$ \\
\hline Alkalinity & $\begin{array}{c}\text { Bo } \\
\text { Bi } \\
\text { Correlation } \\
\text { Coefficient }\end{array}$ & $\begin{array}{c}104.15 \\
-0.03 \\
0.02\end{array}$ & $\begin{array}{c}29.58 \\
0.55 \\
0.39\end{array}$ & $\begin{array}{l}71.23 \\
0.25 \\
0.19\end{array}$ & $\begin{array}{c}151.88 \\
-0.39 \\
0.30\end{array}$ \\
\hline Natrium & $\begin{array}{c}\text { Bo } \\
\text { Bi } \\
\text { Correlation } \\
\text { Coefficient }\end{array}$ & $\begin{array}{c}71.84 \\
-0.16 \\
0.10\end{array}$ & $\begin{array}{c}-43.10 \\
2.02 \\
0.51\end{array}$ & $\begin{array}{c}-62.49 \\
2.43 \\
0.67\end{array}$ & $\begin{array}{l}6.17 \\
1.07 \\
0.60\end{array}$ \\
\hline Kalium & $\begin{array}{c}\text { Bo } \\
\text { Bi } \\
\text { Correlation } \\
\text { Coefficient }\end{array}$ & $\begin{array}{l}2.32 \\
0.01 \\
0.02\end{array}$ & $\begin{array}{c}2.93 \\
-0.22 \\
0.25\end{array}$ & $\begin{array}{c}3.90 \\
-0.59 \\
0.47\end{array}$ & $\begin{array}{c}2.91 \\
-0.21 \\
0.19\end{array}$ \\
\hline Calcium & $\begin{array}{c}\text { Bo } \\
\text { Bi } \\
\text { Correlation } \\
\text { Coefficient }\end{array}$ & $\begin{array}{c}22.04 \\
0.16 \\
0.12\end{array}$ & $\begin{array}{c}-17.42 \\
1.46 \\
0.74\end{array}$ & $\begin{array}{c}-10.94 \\
1.29 \\
0.69\end{array}$ & $\begin{array}{l}3.09 \\
0.80 \\
0.57\end{array}$ \\
\hline Magnesium & $\begin{array}{c}\text { Bo } \\
\text { Bi } \\
\text { Correlation } \\
\text { Coefficient }\end{array}$ & $\begin{array}{c}18.68 \\
-0.04 \\
0.03\end{array}$ & $\begin{array}{c}-9.32 \\
1.29 \\
0.56\end{array}$ & $\begin{array}{l}-2.74 \\
1.01 \\
0.49\end{array}$ & $\begin{array}{l}5.21 \\
0.60 \\
0.43\end{array}$ \\
\hline
\end{tabular}


Appendix $B$ 
Table B.1.1 Comparison of the Use of Normal and Log-normal Approach in the Fitzroy River

Table B.1.1(a) 1 yearly

\begin{tabular}{|c|c|c|c|c|c|c|c|c|c|c|c|c|c|c|}
\hline \multirow{4}{*}{$\begin{array}{l}\text { Water Quality } \\
\text { Paramoler }\end{array}$} & \multirow{2}{*}{\multicolumn{2}{|c|}{ Observed Values }} & \multirow{2}{*}{\multicolumn{2}{|c|}{$\begin{array}{l}\text { Asslgned Values } \\
\text { [Normal Dlstribution) }\end{array}$}} & \multirow{2}{*}{\multicolumn{2}{|c|}{$\begin{array}{c}\text { Asslgned Values } \\
\text { (Log-normal Distribution) }\end{array}$}} & \multicolumn{8}{|c|}{ Absolute Values of Errors (\%) } \\
\hline & & & & & & & \multicolumn{4}{|c|}{ (Normal Distribution) } & \multicolumn{4}{|c|}{ (Log-normal Distributlon) } \\
\hline & \multicolumn{2}{|c|}{ at Stalion } & \multicolumn{2}{|c|}{ at Stalton } & \multicolumn{2}{|c|}{ at Statlon } & \multicolumn{2}{|c|}{ at Station } & \multirow[b]{2}{*}{ Averáge } & \multirow[b]{2}{*}{ Maximum } & \multicolumn{2}{|c|}{ at Statlon } & \multirow[b]{2}{*}{ Average } & \multirow[b]{2}{*}{ Maximum } \\
\hline & 130105 & 130322 & 130105 & 130322 & 130105 & 130322 & 130105 & 130322 & & & 130105 & 130322 & & \\
\hline (1) & \multicolumn{2}{|c|}{ (2) } & \multicolumn{2}{|c|}{ (3) } & \multicolumn{2}{|c|}{ (4) } & \multicolumn{2}{|c|}{ (5) } & (6) & (7) & & (8) & (9) & $(10)$ \\
\hline \multirow{3}{*}{$\begin{array}{l}\text { Conductivity } \\
(\mathrm{mS} / \mathrm{m})\end{array}$} & 210.00 & 222.50 & 266.53 & 202.44 & 266.66 & 201.82 & 26.92 & 9.02 & \multirow{3}{*}{21.57} & \multirow{3}{*}{50.71} & 26.98 & 9.29 & \multirow{3}{*}{21.78} & \multirow{3}{*}{50.72} \\
\hline & 200.00 & 195.00 & 301.42 & 203.75 & 301.43 & 203.72 & 50.71 & 4.49 & & & 50.72 & 4.47 & & \\
\hline & 270.00 & 248.75 & 218.82 & 200.64 & 219.45 & 197.77 & 18.96 & 19.34 & & & 18.72 & 20.49 & & \\
\hline Dissolved & 183.90 & 159.80 & 182.73 & 147.15 & 182.83 & 146.70 & 0.64 & 7.92 & \multirow{3}{*}{16.15} & \multirow{3}{*}{58.88} & 0.58 & 8.20 & \multirow{3}{*}{16.34} & \multirow{3}{*}{58.88} \\
\hline Ions & 128.00 & 144.55 & 203.36 & 147.99 & 203.37 & 147.92 & 58.88 & 2.38 & & & 58.88 & 2.33 & & \\
\hline$(\mathrm{mg} A)$ & 165.55 & 175.30 & 148.57 & 145.76 & 149.05 & 143.56 & 10.26 & 16.85 & & & 9.97 & 18.11 & & \\
\hline Dissolved & 123.00 & 125.00 & 150.26 & 121.58 & 150.35 & 121.12 & 22.16 & 2.74 & & & 22.24 & 3.10 & & \\
\hline Solids & 110.00 & 110.00 & 167.49 & 122.44 & 167.51 & 122.37 & 52.26 & 11.31 & 18.47 & 52.26 & 52.28 & 11.25 & 18.72 & 52.28 \\
\hline (mg/i) & 140.00 & 137.50 & 126.14 & 120.37 & 126.55 & 118.49 & 9.90 & 12,46 & & & 9.61 & 13.83 & & \\
\hline
\end{tabular}

Table B.1.1(b) 2 yearly

\begin{tabular}{|c|c|c|c|c|c|c|c|c|c|c|c|c|c|c|}
\hline \multirow{4}{*}{$\begin{array}{l}\text { Water Quallty } \\
\text { Perrameter }\end{array}$} & \multirow{3}{*}{\multicolumn{2}{|c|}{ Oboerved Values }} & \multirow{2}{*}{\multicolumn{2}{|c|}{$\begin{array}{l}\text { Asslgned Values } \\
\text { (Normal Distribulton) }\end{array}$}} & \multirow{3}{*}{\multicolumn{2}{|c|}{$\begin{array}{c}\text { Asetgned Values } \\
\text { (Log-normal Distribution) }\end{array}$}} & \multicolumn{8}{|c|}{ Absolute Values of Errors (\%) } \\
\hline & & & & & & & \multicolumn{4}{|c|}{ (Normal Distribution) } & \multicolumn{4}{|c|}{ (Log-normal Distribulion) } \\
\hline & & at Slatton & \multirow{2}{*}{\multicolumn{2}{|c|}{$\begin{array}{l}\text { at Station } \\
130105 \quad 130322\end{array}$}} & & & \multicolumn{2}{|c|}{ at Slation } & \multirow[b]{2}{*}{ Average } & \multirow[b]{2}{*}{ Maximum } & \multicolumn{2}{|c|}{ at Station } & \multirow[b]{2}{*}{ Average } & \multirow[b]{2}{*}{ Maximum } \\
\hline & 130105 & 130322 & & & \multicolumn{2}{|c|}{$\begin{array}{l}\text { at Station } \\
130105 \\
130322\end{array}$} & 130105 & 130322 & & & 13010 & 130322 & & \\
\hline (1) & \multicolumn{2}{|c|}{ (2) } & \multicolumn{2}{|c|}{ (3) } & \multicolumn{2}{|c|}{ (4) } & \multicolumn{2}{|c|}{ (5) } & (6) & (7) & \multicolumn{2}{|c|}{$(8)$} & (9) & (10) \\
\hline $\begin{array}{l}\text { Conduclivity } \\
\text { (ms/m) }\end{array}$ & 205.00 & 208.75 & 287.19 & 203.22 & 287.23 & 203.04 & 40.09 & 2.65 & 15.88 & 40.09 & 40.11 & 2.74 & 15.99 & 40.11 \\
\hline \multirow{2}{*}{$\begin{array}{l}\text { Dissolved } \\
\text { Ions } \\
(\mathrm{mg} / \mathrm{l})\end{array}$} & 155.95 & 152.18 & 194.82 & 147.64 & 194.86 & 147.46 & 24.92 & 2.98 & \multirow[t]{2}{*}{14.34} & \multirow[t]{2}{*}{24.92} & 24.95 & 3.10 & \multirow[t]{2}{*}{14.49} & \multirow[t]{2}{*}{24.95} \\
\hline & 146.78 & 159.93 & 178.11 & 146.97 & 178.24 & 146.37 & 21.35 & 8.10 & & & 21.44 & 8.48 & & \\
\hline \multirow{2}{*}{$\begin{array}{l}\text { Dissolved } \\
\text { Solids } \\
\text { (mgl) }\end{array}$} & 116.50 & 117.50 & 159.93 & 122.06 & 159.97 & 121.87 & 37.28 & 3.88 & \multirow[t]{2}{*}{15.31} & \multirow[t]{2}{*}{37.28} & 37.31 & 3.72 & \multirow[t]{2}{*}{15.42} & \multirow[t]{2}{*}{37.31} \\
\hline & 125.00 & 123.75 & 147.80 & 121.46 & 147.92 & 120.90 & 18.24 & 1.85 & & & 18.34 & 2.30 & & \\
\hline
\end{tabular}

Table B.1.1(c) 3 yearly

\begin{tabular}{|c|c|c|c|c|c|c|c|c|c|c|c|c|c|c|}
\hline \multirow{4}{*}{$\begin{array}{l}\text { Water Quallty } \\
\text { Parameter }\end{array}$} & \multirow{2}{*}{\multicolumn{2}{|c|}{ Observed Values }} & \multirow{2}{*}{\multicolumn{2}{|c|}{$\begin{array}{l}\text { Assigned Values } \\
\text { (Normal Distribution) }\end{array}$}} & \multirow{2}{*}{\multicolumn{2}{|c|}{$\begin{array}{c}\text { Assigned Values } \\
\text { (Log-normat Dlatribution) }\end{array}$}} & \multicolumn{8}{|c|}{ Absolute Values of Errors (\%) } \\
\hline & & & & & & & \multicolumn{4}{|c|}{ (Normal Diotributlon) } & \multicolumn{4}{|c|}{ (Log-normal Distribution) } \\
\hline & \multicolumn{2}{|c|}{ at Station } & \multicolumn{2}{|c|}{ at Stallon } & \multicolumn{2}{|c|}{ at Station } & \multicolumn{2}{|c|}{ at Station } & \multirow[b]{2}{*}{ Average } & \multirow[b]{2}{*}{ Maximum } & \multicolumn{2}{|c|}{ at Station } & \multirow[b]{2}{*}{ Average } & \multirow[b]{2}{*}{ Maximum } \\
\hline & 13010 & 130322 & 130105 & 130322 & 130105 & 130322 & 130105 & 130322 & & & 130105 & 130322 & & \\
\hline (1) & \multicolumn{2}{|c|}{ (2) } & \multicolumn{2}{|c|}{ (3) } & \multicolumn{2}{|c|}{ (4) } & \multicolumn{2}{|c|}{ (5) } & \multirow{2}{*}{$\frac{(6)}{14.75}$} & \multirow{2}{*}{$\begin{array}{l}71 \\
20.82\end{array}$} & \multicolumn{2}{|c|}{ (8) } & (9) & $(10)$ \\
\hline $\begin{array}{l}\text { Conductivity } \\
(\mathrm{ms} / \mathrm{m})\end{array}$ & 226.6 & 222.00 & 273.77 & 202.72 & 273.86 & 202.29 & 20.82 & 8.68 & & & 20.86 & 8.88 & 14.87 & 20.86 \\
\hline $\begin{array}{c}\text { Dissolved } \\
\text { Ions } \\
\text { (mg/l) }\end{array}$ & 159.1 & 159.80 & 186.51 & 147.31 & 186.59 & 146.96 & 17.23 & 7.82 & 12.52 & 17.23 & 17.28 & 8.04 & 12.65 & 17.28 \\
\hline $\begin{array}{l}\text { Dissolved } \\
\text { Solids } \\
\text { (mg/l) }\end{array}$ & 124.30 & 124.10 & 153.02 & 121.72 & 153.10 & 121.35 & 23.11 & 1.92 & 12.51 & 23.11 & 23.17 & 2.22 & 12.69 & 23.17 \\
\hline
\end{tabular}


Table B.1.2 Comparison of the Use of Normal and Log-normal Approach in the Nogoa River

Table B.1.2(a) 1 yearly

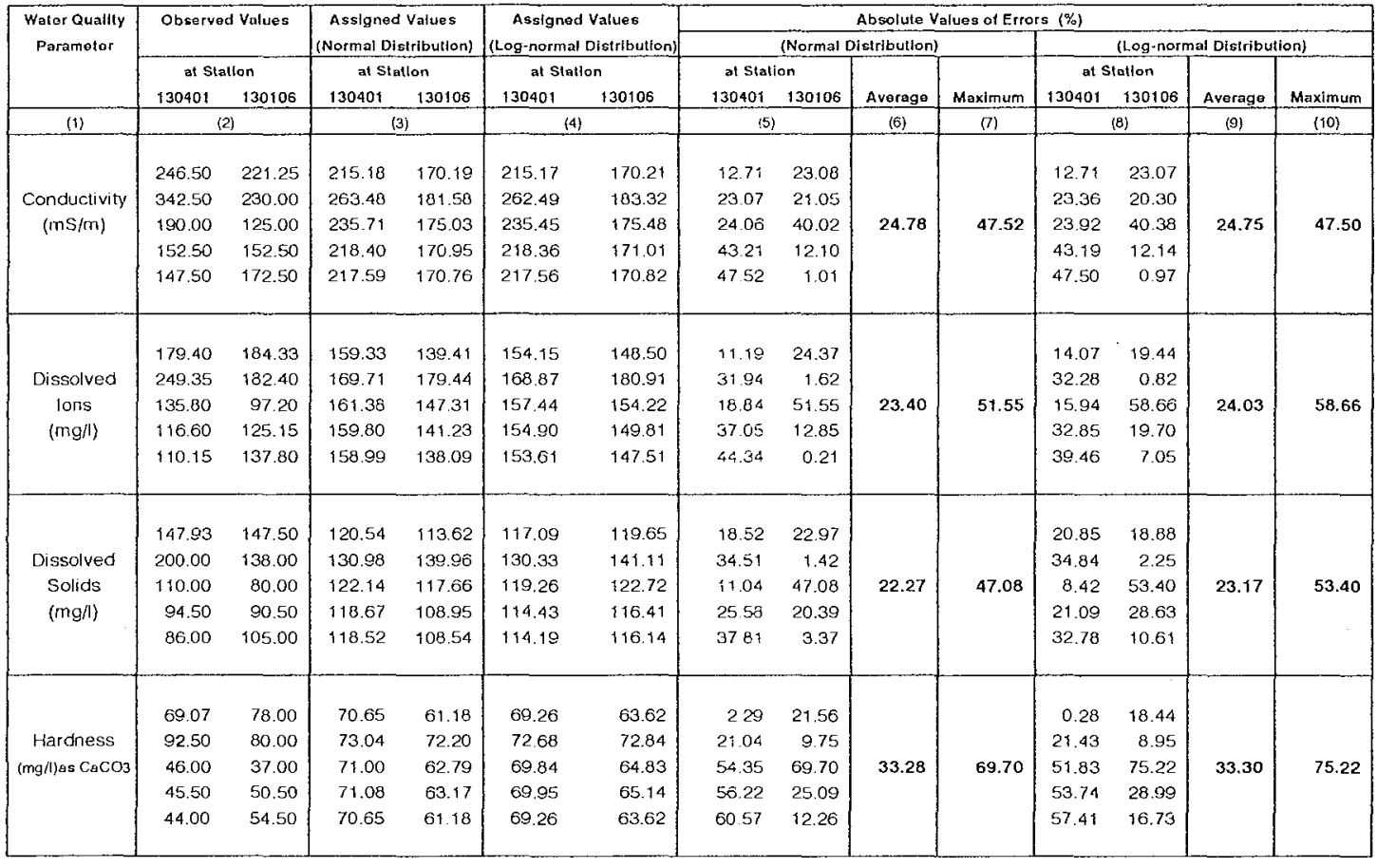

Table B.1.2(b) 2 yearly

\begin{tabular}{|c|c|c|c|c|c|c|c|c|c|c|c|c|c|c|}
\hline \multirow{3}{*}{$\begin{array}{l}\text { Water Quallty } \\
\text { Parametor }\end{array}$} & \multirow{2}{*}{\multicolumn{2}{|c|}{ Observed Values }} & \multirow{2}{*}{\multicolumn{2}{|c|}{$\begin{array}{c}\text { Assigned Values } \\
\text { (Normal Distributlon) }\end{array}$}} & \multirow{2}{*}{\multicolumn{2}{|c|}{$\begin{array}{c}\text { Assigned Values } \\
\text { (Log-normal Distribution }\end{array}$}} & \multicolumn{8}{|c|}{ Absoluto Values of Errors $(\%)$} \\
\hline & & & & & & & \multicolumn{4}{|c|}{ (Normal Distrfbution) } & \multicolumn{4}{|c|}{ (Log-normal Dlstribution) } \\
\hline & \multicolumn{2}{|c|}{$\begin{array}{c}\text { ai Station } \\
130401 \quad 130106 \\
\end{array}$} & \multicolumn{2}{|c|}{$\begin{array}{c}\text { at Station } \\
130401 \quad 130108\end{array}$} & \multicolumn{2}{|c|}{\begin{tabular}{|c|}
\multicolumn{2}{c}{ at Station } \\
$130401 \quad 130106$ \\
\end{tabular}} & \multicolumn{2}{|c|}{$\begin{array}{l}\text { at Station } \\
130401 \quad 130106\end{array}$} & Average & Maximum & \multicolumn{2}{|c|}{ at Station } & Average & Maximum \\
\hline (1) & $(2$ & & 13 & & & & (5) & & (6) & (7) & & (8) & (9) & $(10)$ \\
\hline $\begin{array}{l}\text { Conductivity } \\
\text { (ms/m) }\end{array}$ & $\begin{array}{c}294.50 \\
266.25 \\
171.25 \\
150.00\end{array}$ & $\begin{array}{l}225.63 \\
177.50 \\
138.75 \\
162.50\end{array}$ & $\begin{array}{l}237.12 \\
247.85 \\
224.30 \\
214.83\end{array}$ & $\begin{array}{l}175.36 \\
177.90 \\
172.37 \\
170.10\end{array}$ & $\begin{array}{l}236.84 \\
247.33 \\
224.20 \\
214.81\end{array}$ & $\begin{array}{l}175.85 \\
178.80 \\
172.49 \\
170.13\end{array}$ & $\begin{array}{r}19.48 \\
6.91 \\
30.98 \\
43.22\end{array}$ & $\begin{array}{r}22.28 \\
0.23 \\
24.23 \\
4.68\end{array}$ & 19.00 & 43.22 & $\begin{array}{r}10.58 \\
7.11 \\
30.92 \\
43.21\end{array}$ & $\begin{array}{r}22.06 \\
0.73 \\
24.32 \\
4.70\end{array}$ & 19.08 & 43.21 \\
\hline $\begin{array}{c}\text { Dissolved } \\
\text { tons } \\
\text { (mg/l) }\end{array}$ & $\begin{array}{l}214.37 \\
192.58 \\
126.20 \\
113.38\end{array}$ & $\begin{array}{l}141.10 \\
139.80 \\
111.18 \\
131.48\end{array}$ & $\begin{array}{r}163.98 \\
165.04 \\
159.90 \\
158.65\end{array}$ & $\begin{array}{l}157.33 \\
161.43 \\
141.61 \\
136.82\end{array}$ & $\begin{array}{l}161.37 \\
162.88 \\
155.13 \\
153.01\end{array}$ & $\begin{array}{l}161.91 \\
165.22 \\
149.97 \\
146.72\end{array}$ & $\begin{array}{l}23.51 \\
14.30 \\
26.70 \\
39.93\end{array}$ & $\begin{array}{r}11.50 \\
15.47 \\
27.38 \\
4.07\end{array}$ & 20.36 & 39.93 & $\begin{array}{l}24.72 \\
15.42 \\
22.92 \\
34.96\end{array}$ & $\begin{array}{l}14.75 \\
18.18 \\
34.90 \\
11.60\end{array}$ & 22.18 & 34.96 \\
\hline $\begin{array}{l}\text { Dissolved } \\
\text { Solids } \\
\text { (mg/l) }\end{array}$ & $\begin{array}{r}173.97 \\
155.00 \\
102.25 \\
90.25\end{array}$ & $\begin{array}{r}142.75 \\
109.00 \\
85.25 \\
97.75\end{array}$ & $\begin{array}{l}125.62 \\
126.46 \\
120.04 \\
118.15\end{array}$ & $\begin{array}{l}126.44 \\
128.55 \\
112.38 \\
107.62\end{array}$ & $\begin{array}{l}123.85 \\
124.98 \\
116.31 \\
113.64\end{array}$ & $\begin{array}{l}129.55 \\
131.15 \\
118.92 \\
115.53\end{array}$ & $\begin{array}{l}27.70 \\
18.41 \\
17.40 \\
30.91\end{array}$ & $\begin{array}{l}11.43 \\
17.94 \\
31.82 \\
10.10\end{array}$ & 20.72 & 31.82 & $\begin{array}{l}28.81 \\
19.37 \\
13.75 \\
25.92\end{array}$ & $\begin{array}{r}9.25 \\
20.32 \\
39.50 \\
18.19\end{array}$ & 21.89 & 39.50 \\
\hline $\begin{array}{c}\text { Hardness } \\
\text { (mg//)as } \mathrm{CaCO} 3\end{array}$ & $\begin{array}{l}80.78 \\
69.25 \\
45.75 \\
44.75\end{array}$ & $\begin{array}{l}79.00 \\
58.50 \\
43.75 \\
52.50\end{array}$ & $\begin{array}{l}71.00 \\
71.19 \\
70.11 \\
69.92\end{array}$ & $\begin{array}{l}62.80 \\
63.70 \\
58.74 \\
57.86\end{array}$ & $\begin{array}{l}69.82 \\
70.14 \\
68.38 \\
68.09\end{array}$ & $\begin{array}{l}64.90 \\
65.55 \\
61.78 \\
61.04\end{array}$ & $\begin{array}{r}12.11 \\
2.80 \\
53.25 \\
56.25\end{array}$ & $\begin{array}{r}20.51 \\
8.89 \\
34.26 \\
10.21\end{array}$ & 24.78 & 56.25 & $\begin{array}{r}13.57 \\
\{.29 \\
49.46 \\
52.16\end{array}$ & $\begin{array}{l}17.85 \\
12.05 \\
41.21 \\
16.27\end{array}$ & 25.48 & 52.16 \\
\hline
\end{tabular}


Table B.1.2(c) 3 yearly

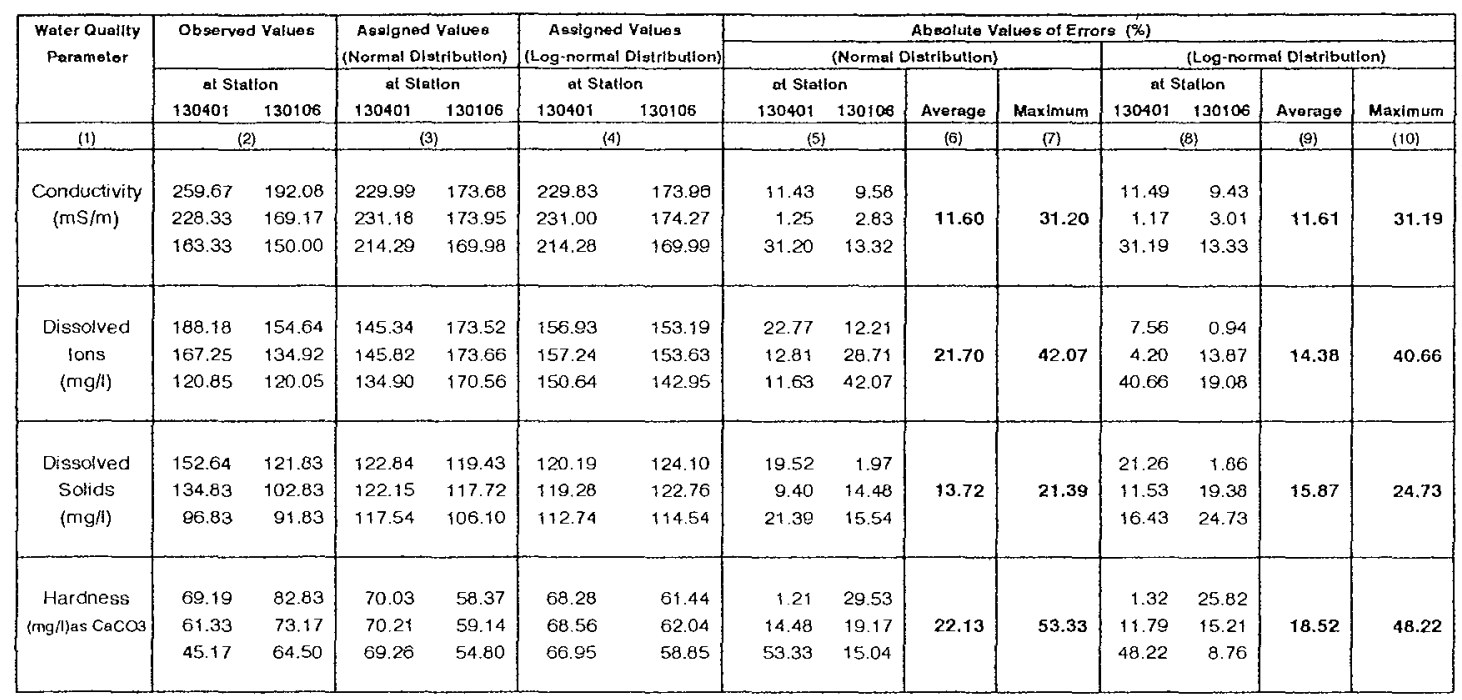

Table B.1.2(d) 4 yearly

\begin{tabular}{|c|c|c|c|c|c|c|c|c|c|c|c|c|c|c|}
\hline \multirow{4}{*}{$\begin{array}{l}\text { Water Qualily } \\
\text { Parameter }\end{array}$} & \multirow{2}{*}{\multicolumn{2}{|c|}{ Observod Valuos }} & \multirow{2}{*}{\multicolumn{2}{|c|}{$\begin{array}{l}\text { Asslgned Values } \\
\text { (Normal Distribution) }\end{array}$}} & \multirow{2}{*}{\multicolumn{2}{|c|}{$\begin{array}{c}\text { Asolgned Values } \\
\text { (Log-normal Oistribullon) }\end{array}$}} & \multicolumn{8}{|c|}{ Absolute Values of Errors (\%) } \\
\hline & & & & & & & \multicolumn{4}{|c|}{ (Normal Distribution) } & \multicolumn{4}{|c|}{ (Log-normal Otsirfbulton) } \\
\hline & \multicolumn{2}{|c|}{ et Station } & \multicolumn{2}{|c|}{ at Stalton } & \multicolumn{2}{|c|}{ at Slation } & \multicolumn{2}{|c|}{ at Station } & \multirow[b]{2}{*}{ Average } & \multirow[b]{2}{*}{ Maximum } & \multicolumn{2}{|c|}{ at Station } & \multirow[b]{2}{*}{ Average } & \multirow[b]{2}{*}{ Maximum } \\
\hline & 130401 & 130106 & 130401 & 130108 & 130401 & 130106 & 130401 & 130106 & & & 130401 & 130108 & & \\
\hline (i) & \multicolumn{2}{|c|}{ (2) } & \multicolumn{2}{|c|}{ (3) } & \multicolumn{2}{|c|}{ (4) } & \multicolumn{2}{|c|}{ (\$) } & (6) & (7) & \multicolumn{2}{|r|}{ (8) } & (9) & (10) \\
\hline $\begin{array}{c}\text { Conductivity } \\
(\mathrm{mS} / \mathrm{m})\end{array}$ & $\begin{array}{l}232.88 \\
208.13\end{array}$ & $\begin{array}{l}182.19 \\
170.00\end{array}$ & $\begin{array}{l}228.90 \\
229.55\end{array}$ & $\begin{array}{l}173.43 \\
173.58\end{array}$ & $\begin{array}{l}228.76 \\
229.30\end{array}$ & $\begin{array}{l}173.69 \\
173.86\end{array}$ & $\begin{array}{r}1.71 \\
10.20\end{array}$ & $\begin{array}{l}4.81 \\
2.11\end{array}$ & 4.73 & 10.29 & $\begin{array}{r}1.77 \\
10.21\end{array}$ & $\begin{array}{l}4.67 \\
2.27\end{array}$ & 4.73 & $\{0.21$ \\
\hline Dissolved & 170.28 & 147.27 & 145.79 & 173.66 & 157.19 & 153.67 & 14.39 & 17.92 & 16.29 & 27.88 & 7.69 & 4.35 & 5.11 & 7.69 \\
\hline $\begin{array}{c}\text { lons } \\
\text { (mg/l) }\end{array}$ & 152.98 & 135.64 & 145.55 & 173.59 & 157.04 & 143.42 & 4.86 & 27.98 & & & 2.65 & 5.74 & & \\
\hline Dissolved & 138.11 & 114.00 & 122.07 & 117.47 & 119,14 & 122.62 & 11.61 & 3,04 & 6.97 & 12.32 & 13.74 & 7.56 & 10.59 & 17.63 \\
\hline $\begin{array}{l}\text { Solids } \\
\text { (mg/l) }\end{array}$ & 122.63 & 103.38 & 121.53 & 116.12 & 118.41 & 121.61 & 0.90 & 12.32 & & & 3.44 & 17.63 & & \\
\hline Hardness & 63.27 & 61.38 & 71.55 & 65.32 & 70.63 & 66.93 & 13.09 & 6.42 & 15.68 & 25.53 & 11.63 & 9.04 & 16.30 & 23.91 \\
\hline (mg/t)as $\mathrm{CaCO}$ & 57.00 & 55.50 & 71.55 & 65.32 & 70.63 & 65.93 & 25.53 & 17.69 & & & 23.91 & 20.59 & & \\
\hline
\end{tabular}


Table B.1.3 Comparison of the Use of Normal and Log-normal Approach in the Logan River

Table B.1.3(a) 1 yearly

\begin{tabular}{|c|c|c|c|c|c|c|c|c|c|c|c|c|c|c|c|c|c|c|c|}
\hline \multirow{3}{*}{$\begin{array}{l}\text { Water Questily } \\
\text { Paramelar }\end{array}$} & \multirow{2}{*}{\multicolumn{3}{|c|}{ Otserved values }} & \multirow{2}{*}{\multicolumn{3}{|c|}{$\begin{array}{r}\text { Ass igned Values } \\
\text { (Normas Orstribution) }\end{array}$}} & \multirow{2}{*}{\multicolumn{3}{|c|}{$\begin{array}{c}\text { Assigned Values } \\
\text { (Log-normal Dsiribution) }\end{array}$}} & \multicolumn{10}{|c|}{ Absolute Values of Errors (\%) } \\
\hline & & & & & & & & & & \multicolumn{5}{|c|}{ (Normal Distribunton) } & \multicolumn{5}{|c|}{ (Log-normal Okstriburison) } \\
\hline & 145010 & $\begin{array}{l}\text { t5 stathon } \\
145013\end{array}$ & 145020 & 145010 & $\begin{array}{l}\text { Statiton } \\
145013\end{array}$ & 145020 & 145010 & $\begin{array}{l}\text { sution } \\
145013\end{array}$ & 145020 & 145010 & $\begin{array}{l}\text { at 9ution } \\
145013\end{array}$ & 145020 & Average & Maximum & 145010 & $\begin{array}{l}\text { at Staton } \\
145013\end{array}$ & 145020 & Average & Maximum \\
\hline (1) & & (2) & & & (3) & & & $(4)$ & & & (5) & & $(6)$ & (7) & & (8) & & (9) & $(10)$ \\
\hline $\begin{array}{c}\text { Conductivity } \\
(\mathrm{mS} / \mathrm{m})\end{array}$ & $\begin{array}{l}348.50 \\
360.00 \\
205.00 \\
328.75 \\
347.50\end{array}$ & $\begin{array}{l}650.00 \\
308.00 \\
298.67 \\
476.25 \\
245.00\end{array}$ & $\begin{array}{l}397.50 \\
434.00 \\
268.33 \\
645.00 \\
631.67\end{array}$ & $\begin{array}{l}354.90 \\
355.90 \\
352.90 \\
351.70 \\
355.90\end{array}$ & $\begin{array}{l}495.40 \\
495.90 \\
494.50 \\
496.70 \\
495.90\end{array}$ & $\begin{array}{l}601.60 \\
609.80 \\
586.30 \\
625.80 \\
610.20\end{array}$ & $\begin{array}{l}361.70 \\
363.80 \\
358.40 \\
367.59 \\
363.70\end{array}$ & $\begin{array}{l}495.20 \\
495.80 \\
494.50 \\
496.60 \\
495.70\end{array}$ & $\begin{array}{l}599.70 \\
607.40 \\
584.70 \\
623.00 \\
608.00\end{array}$ & $\begin{array}{r}1.84 \\
1.14 \\
7.15 \\
6.98 \\
2.42\end{array}$ & $\begin{array}{r}23.78 \\
24.60 \\
66.69 \\
4.29 \\
102.41\end{array}$ & $\begin{array}{r}51.35 \\
40.51 \\
118.50 \\
2.98 \\
3.40\end{array}$ & 34.87 & 118.50 & $\begin{array}{r}3.79 \\
1.06 \\
74.83 \\
11.81 \\
4.66\end{array}$ & $\begin{array}{r}23.82 \\
24.57 \\
66.69 \\
4.27 \\
102.33\end{array}$ & $\begin{array}{r}50.87 \\
39.95 \\
117.90 \\
3.41 \\
3.75\end{array}$ & 35.58 & 117.90 \\
\hline PH & $\begin{array}{l}7.76 \\
8.00 \\
7.43 \\
7.63 \\
7.90\end{array}$ & $\begin{array}{l}8.00 \\
8.12 \\
7.70 \\
7.88 \\
7.70\end{array}$ & $\begin{array}{l}7.78 \\
7.94 \\
7.47 \\
7.88 \\
7.87\end{array}$ & $\begin{array}{l}8.16 \\
7.85 \\
8.31 \\
7.69 \\
6.86\end{array}$ & $\begin{array}{l}7.95 \\
7.89 \\
7.97 \\
7.86 \\
7.70\end{array}$ & $\begin{array}{l}8.14 \\
7.92 \\
8.24 \\
7.82 \\
7.31\end{array}$ & $\begin{array}{l}8.21 \\
8.10 \\
8.40 \\
8.14 \\
6.90\end{array}$ & $\begin{array}{l}7.94 \\
7.49 \\
7.97 \\
7.49 \\
7.70\end{array}$ & $\begin{array}{l}8.12 \\
7.97 \\
8.21 \\
7.81 \\
7.30\end{array}$ & $\begin{array}{r}5.15 \\
1.88 \\
11.79 \\
0.85 \\
13.16\end{array}$ & $\begin{array}{l}0.62 \\
2.83 \\
3.51 \\
0.19 \\
0.04\end{array}$ & $\begin{array}{r}4.69 \\
0.25 \\
10.36 \\
0.70 \\
7.08\end{array}$ & 4.21 & 13.16 & $\begin{array}{r}5.80 \\
1.25 \\
13.00 \\
6.75 \\
12.66\end{array}$ & $\begin{array}{l}0.75 \\
7.76 \\
3.51 \\
4.89 \\
0.00\end{array}$ & $\begin{array}{l}4.44 \\
0.38 \\
9.96 \\
0.83 \\
7.20\end{array}$ & 5.28 & 13.00 \\
\hline $\begin{array}{l}\text { Dissolved } \\
\text { lons } \\
\text { (mg/l) }\end{array}$ & $\begin{array}{l}220.97 \\
223.45 \\
129.93 \\
222.55 \\
250.50\end{array}$ & $\begin{array}{l}409.44 \\
281.80 \\
203.27 \\
329.83 \\
183.60\end{array}$ & $\begin{array}{r}241.65 \\
264.44 \\
162.47 \\
400.60 \\
425.87\end{array}$ & $\begin{array}{l}231.60 \\
232.80 \\
229.50 \\
235.60 \\
233.10\end{array}$ & $\begin{array}{l}320.80 \\
321.90 \\
319.00 \\
323.70 \\
322.10\end{array}$ & $\begin{array}{l}358.90 \\
366.70 \\
346.00 \\
380.00 \\
368.40\end{array}$ & $\begin{array}{l}235.50 \\
238.10 \\
231.30 \\
242.80 \\
238.70\end{array}$ & $\begin{array}{l}320.70 \\
321.70 \\
319.00 \\
323.40 \\
321.90\end{array}$ & $\begin{array}{l}357.90 \\
365.20 \\
345.50 \\
377.00 \\
366.90\end{array}$ & $\begin{array}{r}5.19 \\
4.18 \\
7.63 \\
5.86 \\
6.95\end{array}$ & $\begin{array}{r}21.65 \\
14.23 \\
56.94 \\
1.86 \\
75.44\end{array}$ & $\begin{array}{r}48.52 \\
38.67 \\
112.97 \\
5.14 \\
13.49\end{array}$ & 32.51 & 112.97 & $\begin{array}{r}6.96 \\
6.56 \\
78.01 \\
9.10 \\
4.71\end{array}$ & $\begin{array}{r}21.67 \\
14.16 \\
56.94 \\
1.95 \\
75.33\end{array}$ & $\begin{array}{r}48.11 \\
38.10 \\
112.66 \\
5.67 \\
13.85\end{array}$ & 32.92 & 112.66 \\
\hline $\begin{array}{l}\text { Dissolved } \\
\text { Solids } \\
\text { (mg/h) }\end{array}$ & $\begin{array}{l}188.00 \\
192.50 \\
117.00 \\
192.00 \\
210.00\end{array}$ & $\begin{array}{l}350.00 \\
226.00 \\
173.33 \\
270.00 \\
150.00\end{array}$ & $\begin{array}{l}210.00 \\
224.00 \\
143.33 \\
340.00 \\
366.67\end{array}$ & $\begin{array}{l}199.50 \\
200.80 \\
197.30 \\
203.30 \\
201.40\end{array}$ & $\begin{array}{l}272.40 \\
273.20 \\
270.90 \\
274.80 \\
273.60\end{array}$ & $\begin{array}{l}302.10 \\
310.90 \\
285.80 \\
330.00 \\
316.40\end{array}$ & $\begin{array}{l}200.60 \\
202.80 \\
197.10 \\
207.30 \\
204.00\end{array}$ & $\begin{array}{l}272.30 \\
273.10 \\
270.90 \\
274.70 \\
273.50\end{array}$ & $\begin{array}{l}301.80 \\
310.50 \\
285.90 \\
328.90 \\
315.70\end{array}$ & $\begin{array}{r}6.12 \\
4.31 \\
68.63 \\
5.89 \\
4.10\end{array}$ & $\begin{array}{r}22.17 \\
20.88 \\
56.29 \\
1.78 \\
82.40\end{array}$ & $\begin{array}{r}43.86 \\
38.79 \\
99.40 \\
2.94 \\
13.71\end{array}$ & 31.42 & 99.40 & $\begin{array}{r}5.70 \\
5.35 \\
68.46 \\
7.97 \\
2.86\end{array}$ & $\begin{array}{r}22.20 \\
20.84 \\
56.29 \\
1.74 \\
82.33\end{array}$ & $\begin{array}{r}43.71 \\
38.62 \\
99.47 \\
3.20 \\
13.90\end{array}$ & 31.58 & 99.47 \\
\hline $\begin{array}{c}\text { Afkalinity } \\
\text { (mgs il)as } \mathrm{C}_{\mathrm{COC}} \mathrm{O3}\end{array}$ & $\begin{array}{l}83.50 \\
83.75 \\
47.33 \\
87.75 \\
85.50\end{array}$ & $\begin{array}{r}138.80 \\
133.40 \\
87.67 \\
136.75 \\
82.00\end{array}$ & $\begin{array}{r}73.50 \\
81.00 \\
47.33 \\
119.25 \\
123.67\end{array}$ & $\begin{array}{l}84.60 \\
88.10 \\
71.70 \\
93.70 \\
87.30\end{array}$ & $\begin{array}{l}123.00 \\
126.40 \\
118.40 \\
131.80 \\
125.70\end{array}$ & $\begin{array}{r}92.90 \\
98.90 \\
84.60 \\
108.40 \\
97.60\end{array}$ & $\begin{array}{r}82.80 \\
90.10 \\
74.50 \\
105.30 \\
88.40\end{array}$ & $\begin{array}{r}123.30 \\
126.10 \\
119.10 \\
130.10 \\
125.50\end{array}$ & $\begin{array}{r}93.40 \\
98.40 \\
85.90 \\
105.50 \\
97.30\end{array}$ & $\begin{array}{r}1.32 \\
5.19 \\
51.48 \\
6.78 \\
8.59\end{array}$ & $\begin{array}{r}11.38 \\
5.25 \\
35.06 \\
3.62 \\
53.28\end{array}$ & $\begin{array}{r}20.39 \\
22.10 \\
78.73 \\
9.10 \\
21.09\end{array}$ & 22.62 & 78.73 & $\begin{array}{r}0.84 \\
7.58 \\
57.39 \\
20.00 \\
7.43\end{array}$ & $\begin{array}{r}11.17 \\
5.47 \\
35.86 \\
4.86 \\
53.05\end{array}$ & $\begin{array}{l}27.07 \\
21.48 \\
81.48 \\
11.53 \\
21.32\end{array}$ & 24.44 & 81.48 \\
\hline
\end{tabular}

Table B.1.3(b) 2 yearly

\begin{tabular}{|c|c|c|c|c|c|c|c|c|c|c|c|c|c|c|c|c|c|c|c|}
\hline \multirow{3}{*}{$\begin{array}{l}\text { Waier Oualty } \\
\text { Parameter }\end{array}$} & \multirow{2}{*}{\multicolumn{3}{|c|}{ observed values }} & \multirow{2}{*}{\multicolumn{3}{|c|}{$\begin{array}{l}\text { Ass shred Yalues } \\
\text { (Mormal Dtiributhon) }\end{array}$}} & \multirow{2}{*}{\multicolumn{3}{|c|}{ 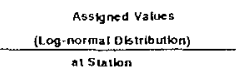 }} & \multicolumn{10}{|c|}{ Absolute Values of Errors $(\%)$} \\
\hline & & & & & & & & & & \multicolumn{5}{|c|}{ (Normal Distribulion) } & \multicolumn{5}{|c|}{ (Log rarmal Distribution) } \\
\hline & 145010 & $\begin{array}{l}\text { at Station } \\
145013\end{array}$ & 145020 & 14501 & $\begin{array}{l}\text { 15 Statibn } \\
145013\end{array}$ & 145020 & 145010 & $\begin{array}{c}1 \text { Sun ton } \\
145013\end{array}$ & 145020 & 145010 & $\begin{array}{l}\text { 21 Stotho } \\
145013\end{array}$ & 145020 & Average & Maximum & 145010 & $\begin{array}{l}\text { nt Station } \\
145013\end{array}$ & 145020 & Average & Maximum \\
\hline (I) & & (2) & & & $(3)$ & & & (4) & & & (5) & & (6) & $(7)$ & & (8) & & (9) & (10) \\
\hline $\begin{array}{l}\text { Conductivity } \\
\text { (ms/m) }\end{array}$ & $\begin{array}{r}354.25 \\
282.50 \\
266.88 \\
338.13\end{array}$ & $\begin{array}{l}524.00 \\
347.33 \\
386.46 \\
360.63\end{array}$ & $\begin{array}{l}415.75 \\
351.17 \\
456.67 \\
638.33\end{array}$ & $\begin{array}{l}310.4 \\
261.0 \\
311.7 \\
349.1\end{array}$ & $\begin{array}{l}474.80 \\
451.70 \\
475.30 \\
492.70\end{array}$ & $\begin{array}{r}258.30 \\
84.10 \\
265.30 \\
554.00\end{array}$ & $\begin{array}{l}297.00 \\
253.10 \\
298.60 \\
351.30\end{array}$ & $\begin{array}{l}474.50 \\
451.40 \\
475.20 \\
492.70\end{array}$ & $\begin{array}{r}262.20 \\
86.00 \\
260.10 \\
553.30\end{array}$ & $\begin{array}{r}12.38 \\
7.69 \\
16.79 \\
3.24\end{array}$ & $\begin{array}{r}9.39 \\
30.05 \\
22.99 \\
36.62\end{array}$ & $\begin{array}{l}37.87 \\
76.05 \\
41.91 \\
13.21\end{array}$ & 25.68 & 76.05 & $\begin{array}{r}16.16 \\
10.41 \\
11.89 \\
3.89\end{array}$ & $\begin{array}{r}9.45 \\
29.96 \\
22.06 \\
36.62\end{array}$ & $\begin{array}{l}36.93 \\
75.51 \\
41.07 \\
13.32\end{array}$ & 25.68 & 75.51 \\
\hline $\mathrm{PH}$ & $\begin{array}{l}7.88 \\
7.72 \\
7.53 \\
7.76\end{array}$ & $\begin{array}{l}8.06 \\
7.91 \\
7.79 \\
7.79\end{array}$ & $\begin{array}{l}7.86 \\
7.70 \\
7.67 \\
7.87\end{array}$ & $\begin{array}{l}8.3 \\
8.7 \\
8.3 \\
6.0\end{array}$ & $\begin{array}{l}7.98 \\
8.06 \\
7.08 \\
7.19\end{array}$ & $\begin{array}{l}3.27 \\
8.46 \\
8.27 \\
7.11\end{array}$ & $\begin{array}{l}8.46 \\
8.92 \\
8.46 \\
6.16\end{array}$ & $\begin{array}{l}7.97 \\
8.03 \\
7.97 \\
7.18\end{array}$ & $\begin{array}{l}8.24 \\
8.41 \\
8.24 \\
7.11\end{array}$ & $\begin{array}{r}6.09 \\
13.39 \\
11.03 \\
21.91\end{array}$ & $\begin{array}{l}0.99 \\
1.90 \\
2.47 \\
7.70\end{array}$ & $\begin{array}{l}5.25 \\
9.82 \\
7.81 \\
9.66\end{array}$ & 8.17 & 21.91 & $\begin{array}{r}7.36 \\
15.59 \\
12.36 \\
20.62\end{array}$ & $\begin{array}{l}1.12 \\
1.52 \\
2.34 \\
7.83\end{array}$ & $\begin{array}{l}4.87 \\
9.17 \\
7.42 \\
9.66\end{array}$ & 8.32 & 20.62 \\
\hline $\begin{array}{l}\text { Dissolved } \\
\text { lons } \\
(\mathrm{mg} / /)\end{array}$ & $\begin{array}{l}221.81 \\
176.69 \\
176.24 \\
236.53\end{array}$ & $\begin{array}{l}345.62 \\
242.53 \\
266.55 \\
256.71\end{array}$ & $\begin{array}{r}53.05 \\
213.45 \\
281.53 \\
413.23\end{array}$ & $\begin{array}{c}199.2 \\
164.1 \\
199.9 \\
233.2\end{array}$ & $\begin{array}{l}293.70 \\
264.20 \\
294.30 \\
322.10\end{array}$ & $\begin{array}{r}170.50 \\
66.80 \\
173.80 \\
368.80\end{array}$ & $\begin{array}{l}188.10 \\
158.40 \\
188.80 \\
239.00\end{array}$ & $\begin{array}{r}294.20 \\
265.00 \\
294.80 \\
321.90\end{array}$ & $\begin{array}{r}173.50 \\
68.20 \\
176.90 \\
367.20\end{array}$ & $\begin{array}{r}10.19 \\
7.13 \\
13.42 \\
\mathbf{1 . 4 1}\end{array}$ & $\begin{array}{r}15.02 \\
8.93 \\
10.44 \\
25.47\end{array}$ & $\begin{array}{l}32.62 \\
68.70 \\
38.27 \\
10.75\end{array}$ & 20.19 & 68.70 & $\begin{array}{r}15.20 \\
10.35 \\
7.13 \\
1.04\end{array}$ & $\begin{array}{r}14.88 \\
9.26 \\
10.60 \\
25.38\end{array}$ & $\begin{array}{l}31.44 \\
68,05 \\
37.17 \\
11.14\end{array}$ & 20.14 & 68.05 \\
\hline $\begin{array}{l}\text { Dissolved } \\
\text { Solids } \\
\text { (mgfl) }\end{array}$ & $\begin{array}{l}190.25 \\
154.75 \\
154.50 \\
201.00\end{array}$ & $\begin{array}{l}288.00 \\
199.67 \\
221.67 \\
210.00\end{array}$ & $\begin{array}{l}217.00 \\
183.67 \\
244.67 \\
353.33\end{array}$ & $\begin{array}{l}175.9 \\
148.4 \\
178.3 \\
201.6\end{array}$ & $\begin{array}{l}257.00 \\
239.20 \\
258.60 \\
273.70\end{array}$ & $\begin{array}{r}137.00 \\
56.90 \\
152.00 \\
318.10\end{array}$ & $\begin{array}{l}169.70 \\
146.00 \\
171.10 \\
204.40\end{array}$ & $\begin{array}{r}57.30 \\
239.50 \\
258.90 \\
273.70\end{array}$ & $\begin{array}{r}139.60 \\
57.50 \\
154.00 \\
377.30\end{array}$ & $\begin{array}{r}7.54 \\
4.10 \\
15.40 \\
0.30\end{array}$ & $\begin{array}{l}10.76 \\
19.80 \\
16.66 \\
30.33\end{array}$ & $\begin{array}{r}36.45 \\
69.02 \\
37.10 \\
9.97\end{array}$ & 21.45 & 69.02 & $\begin{array}{r}10.80 \\
5.65 \\
10.74 \\
1.69\end{array}$ & $\begin{array}{l}10.66 \\
19.95 \\
16.80 \\
30.33\end{array}$ & $\begin{array}{l}35.67 \\
68.69 \\
36.28 \\
10.20\end{array}$ & 21.46 & 68.69 \\
\hline 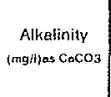 & $\begin{array}{l}83.63 \\
65.54 \\
67.54 \\
91.63\end{array}$ & $\begin{array}{l}138.10 \\
110.53 \\
112.25 \\
109.38\end{array}$ & $\begin{array}{r}77.25 \\
64.17 \\
83.29 \\
121.46\end{array}$ & $\begin{array}{l}74.4 \\
64.4 \\
75.8 \\
90.7\end{array}$ & $\begin{array}{l}113.30 \\
103.80 \\
114.60 \\
128.90\end{array}$ & $\begin{array}{r}75.70 \\
59.60 \\
70.00 \\
103.40\end{array}$ & $\begin{array}{l}67.80 \\
58.20 \\
69.50 \\
96.90\end{array}$ & $\begin{array}{l}114.30 \\
104.80 \\
115.60 \\
128.20\end{array}$ & $\begin{array}{r}77.40 \\
61.20 \\
79.70 \\
102.00\end{array}$ & $\begin{array}{r}11.03 \\
1.74 \\
12.23 \\
1.01\end{array}$ & $\begin{array}{r}16.75 \\
6.09 \\
2.13 \\
17.85\end{array}$ & $\begin{array}{r}2.01 \\
7.12 \\
15.96 \\
14.87\end{array}$ & 9.07 & 17.85 & $\begin{array}{r}18.92 \\
11.20 \\
2.90 \\
5.75\end{array}$ & $\begin{array}{r}16.02 \\
5.19 \\
3.02 \\
17.21\end{array}$ & $\begin{array}{r}0.19 \\
4.62 \\
4.31 \\
16.02\end{array}$ & 8.78 & 18.92 \\
\hline
\end{tabular}


Table B.1.3(c) 3 yearly

\begin{tabular}{|c|c|c|c|c|c|c|c|c|c|c|c|c|c|c|c|c|c|c|c|}
\hline \multirow{3}{*}{$\begin{array}{l}\text { Water Quality } \\
\text { Parameler }\end{array}$} & \multirow{2}{*}{\multicolumn{3}{|c|}{ Obeervad Values }} & \multirow{2}{*}{\multicolumn{3}{|c|}{$\begin{array}{l}\text { Asskgnod Values } \\
\text { (Harsial Dstribution) }\end{array}$}} & \multirow{2}{*}{\multicolumn{3}{|c|}{ 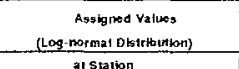 }} & \multicolumn{10}{|c|}{ Absolute Values of Errors (\%) } \\
\hline & & & & & & & & & & \multicolumn{5}{|c|}{ (Normal Dstribution) } & \multicolumn{5}{|c|}{ (Log-norma1 Dketribitution). } \\
\hline & 145010 & t station & $1450 \% 0$ & 145010 & $\begin{array}{l}\text { Statlon } \\
\text { 195013 }\end{array}$ & 145020 & 145010 & $\begin{array}{l}\text { Istation } \\
145013\end{array}$ & 145070 & 145010 & $\begin{array}{l}\text { at Station } \\
14501+3\end{array}$ & 145020 & Average & Maximum & 145010 & $\begin{array}{l}\text { at Stations } \\
145013\end{array}$ & 145020 & Ayerage & Meximum \\
\hline (1) & & (2) & & & (3) & & & (4) & & & (5) & & (6) & (7) & & (8) & & (9) & $110)$ \\
\hline $\begin{array}{l}\text { Conductivity } \\
\text { (mS/m) }\end{array}$ & $\begin{array}{l}304.50 \\
297.90 \\
293.80\end{array}$ & $\begin{array}{l}448.22 \\
390.31 \\
339.31\end{array}$ & $\begin{array}{l}366.61 \\
449.11 \\
515.00\end{array}$ & $\begin{array}{r}280.60 \\
317.90 \\
318.30\end{array}$ & $\begin{array}{l}460.70 \\
478.30 \\
478.60\end{array}$ & $\begin{array}{r}122.10 \\
306.70 \\
310.20\end{array}$ & $\begin{array}{l}268.70 \\
306.10 \\
306.90\end{array}$ & $\begin{array}{l}461.30 \\
478.40 \\
478.70\end{array}$ & $\begin{array}{r}125.40 \\
310.10 \\
313.40\end{array}$ & $\begin{array}{l}7.85 \\
6.71 \\
8.34\end{array}$ & $\begin{array}{r}2.78 \\
22.54 \\
41.05\end{array}$ & $\begin{array}{l}66.69 \\
31.71 \\
39.77\end{array}$ & 25.27 & 66.69 & $\begin{array}{r}11.76 \\
2.75 \\
4.46\end{array}$ & $\begin{array}{r}2.92 \\
22.57 \\
41.08\end{array}$ & $\begin{array}{l}65.79 \\
30.95 \\
39.15\end{array}$ & 24.60 & 65.79 \\
\hline PH & $\begin{array}{l}7.70 \\
7.70 \\
7.70\end{array}$ & $\begin{array}{l}7.90 \\
7.90 \\
7.80\end{array}$ & $\begin{array}{l}7.70 \\
7.80 \\
7.70\end{array}$ & $\begin{array}{l}8.90 \\
8.30 \\
7.43\end{array}$ & $\begin{array}{l}8.10 \\
7.88 \\
7.81\end{array}$ & $\begin{array}{l}8.50 \\
8.26 \\
7.64\end{array}$ & $\begin{array}{l}9.11 \\
8.43 \\
7.42\end{array}$ & $\begin{array}{l}8.07 \\
7.87 \\
7.81\end{array}$ & $\begin{array}{l}8.47 \\
8.23 \\
7.64\end{array}$ & $\begin{array}{r}15.58 \\
7.79 \\
3.51\end{array}$ & $\begin{array}{l}2.53 \\
1.01 \\
0.13\end{array}$ & $\begin{array}{r}10.39 \\
5.90 \\
0.78\end{array}$ & 5.29 & 15.58 & $\begin{array}{r}18.31 \\
9.48 \\
3.64\end{array}$ & $\begin{array}{l}2.15 \\
0.89 \\
0.13\end{array}$ & $\begin{array}{r}10.00 \\
5.51 \\
0.78\end{array}$ & 5.65 & 18.31 \\
\hline $\begin{array}{c}\text { Dissolved } \\
\text { ions } \\
(\mathrm{ming} / \mathrm{i})\end{array}$ & $\begin{array}{l}191.20 \\
192.00 \\
201.00\end{array}$ & $\begin{array}{l}298.20 \\
271.60 \\
238.90\end{array}$ & $\begin{array}{l}222.90 \\
275.80 \\
329.60\end{array}$ & $\begin{array}{l}193.80 \\
211.50 \\
212.90\end{array}$ & $\begin{array}{l}289.10 \\
304.00 \\
305.10\end{array}$ & $\begin{array}{l}144.90 \\
237.40 \\
245.20\end{array}$ & $\begin{array}{l}182.80 \\
202.80 \\
204.60\end{array}$ & $\begin{array}{l}289.70 \\
304.30 \\
305.40\end{array}$ & $\begin{array}{l}147.90 \\
239.80 \\
247.50\end{array}$ & $\begin{array}{r}1.36 \\
10.16 \\
5.92\end{array}$ & $\begin{array}{r}3.05 \\
11.93 \\
27.71\end{array}$ & $\begin{array}{l}34.99 \\
13.92 \\
25.61\end{array}$ & 14.96 & 34.99 & $\begin{array}{l}4.39 \\
5.63 \\
1.79\end{array}$ & $\begin{array}{r}2.85 \\
12.04 \\
27.84\end{array}$ & $\begin{array}{l}33.65 \\
13.05 \\
24.91\end{array}$ & 14.02 & 33.85 \\
\hline $\begin{array}{l}\text { Dissolved } \\
\text { Solids } \\
\text { (mg } / l)\end{array}$ & $\begin{array}{l}165.80 \\
167.20 \\
173.00\end{array}$ & $\begin{array}{l}249.80 \\
223.10 \\
197.80\end{array}$ & $\begin{array}{l}192.40 \\
235.80 \\
283.30\end{array}$ & $\begin{array}{r}167.80 \\
183.70 \\
186.10\end{array}$ & $\begin{array}{l}251.70 \\
262.10 \\
253.60\end{array}$ & $\begin{array}{r}99.90 \\
186.90 \\
203.80\end{array}$ & $\begin{array}{l}161.30 \\
178.10 \\
181.10\end{array}$ & $\begin{array}{l}252.00 \\
262.30 \\
263.80\end{array}$ & $\begin{array}{l}101.70 \\
188.50 \\
205.20\end{array}$ & $\begin{array}{l}1.21 \\
8.87 \\
7.57\end{array}$ & $\begin{array}{r}0.76 \\
17.48 \\
33.27\end{array}$ & $\begin{array}{l}48.08 \\
20.74 \\
28.06\end{array}$ & 18.56 & 48.08 & $\begin{array}{l}2.71 \\
8.52 \\
4.68\end{array}$ & $\begin{array}{r}0.88 \\
17.57 \\
93.37\end{array}$ & $\begin{array}{l}47.14 \\
20.06 \\
27.57\end{array}$ & 17.83 & 97.14 \\
\hline $\begin{array}{l}\text { Alkalinity } \\
\text { (magilios cocos }\end{array}$ & $\begin{array}{l}71.50 \\
72.90 \\
76.90\end{array}$ & $\begin{array}{l}120.00 \\
\$ 19.30 \\
102.10\end{array}$ & $\begin{array}{l}67.30 \\
82.50 \\
96.80\end{array}$ & $\begin{array}{l}79.20 \\
84.30 \\
83.80\end{array}$ & $\begin{array}{l}118.00 \\
122.80 \\
122.40\end{array}$ & $\begin{array}{l}83.90 \\
92.40 \\
91.70\end{array}$ & $\begin{array}{l}74.00 \\
82.20 \\
81.40\end{array}$ & $\begin{array}{l}118.70 \\
123.00 \\
122.70\end{array}$ & $\begin{array}{l}85.10 \\
92.90 \\
92.30\end{array}$ & $\begin{array}{r}10.77 \\
15.64 \\
8.97\end{array}$ & $\begin{array}{r}1.67 \\
2.93 \\
+9.88\end{array}$ & $\begin{array}{r}24.67 \\
12.00 \\
5.27\end{array}$ & 11.31 & 24.67 & $\begin{array}{r}3.50 \\
12.76 \\
5.85\end{array}$ & $\begin{array}{r}1.08 \\
3.10 \\
20.18\end{array}$ & $\begin{array}{r}26.45 \\
12.61 \\
4.65\end{array}$ & 10.02 & 26.45 \\
\hline
\end{tabular}

Table B.1.3(d) 4 yearly

\begin{tabular}{|c|c|c|c|c|c|c|c|c|c|c|c|c|c|c|c|c|c|c|c|}
\hline \multirow{3}{*}{$\begin{array}{l}\text { Water Quality } \\
\text { Parameter }\end{array}$} & \multirow{2}{*}{\multicolumn{3}{|c|}{ Observod Values }} & \multirow{2}{*}{\multicolumn{3}{|c|}{$\begin{array}{l}\text { Assignod Va unes } \\
\text { (Morrasl Distribution) }\end{array}$}} & \multirow{3}{*}{\multicolumn{3}{|c|}{ 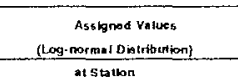 }} & \multicolumn{10}{|c|}{ Absolute Values of Errors $(\%)$} \\
\hline & & & & & & & & & & \multicolumn{5}{|c|}{ (Normal Distribution) } & \multicolumn{5}{|c|}{ (log-tormad Distrbution) } \\
\hline & 145010 & isation & 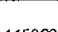 & trar & $\operatorname{sinsibn}$ & 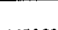 & 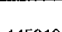 & & & & a1 Suation & 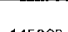 & A Arom & s & & at station & 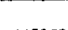 & & \\
\hline (i) & 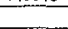 & (2) & & & (3) & & & (4) & & & (5) & & (6) & (7) & & (8) & & (g) & $(10)$ \\
\hline $\begin{array}{c}\text { Conductivity } \\
\text { (mSim) }\end{array}$ & $\begin{array}{l}310.60 \\
310.30\end{array}$ & $\begin{array}{l}455.23 \\
353.98\end{array}$ & $\begin{array}{l}436.21 \\
494.75\end{array}$ & $\begin{array}{l}334.20 \\
337.20\end{array}$ & $\begin{array}{l}485.90 \\
487.20\end{array}$ & $\begin{array}{l}434.80 \\
459.00\end{array}$ & $\begin{array}{l}327.60 \\
332.40\end{array}$ & $\begin{array}{l}485.70 \\
487.40\end{array}$ & $\begin{array}{l}436.80 \\
460.30\end{array}$ & $\begin{array}{l}7.60 \\
8.67\end{array}$ & $\begin{array}{r}6.74 \\
37.63\end{array}$ & $\begin{array}{l}0.32 \\
7.23\end{array}$ & 11.36 & 37.63 & $\begin{array}{l}5.47 \\
7.12\end{array}$ & $\begin{array}{r}6.69 \\
37.69\end{array}$ & $\begin{array}{l}0.14 \\
6.96\end{array}$ & 10.68 & 37.69 \\
\hline PH & $\begin{array}{l}7.7 \\
7.7\end{array}$ & $\begin{array}{l}7.9 \\
7.8\end{array}$ & $\begin{array}{l}7.8 \\
7.8\end{array}$ & $\begin{array}{r}8.4 \\
7.38\end{array}$ & $\begin{array}{r}7.99 \\
7.809\end{array}$ & $\begin{array}{r}8.29 \\
7.613\end{array}$ & $\begin{array}{l}8.51 \\
7.38\end{array}$ & $\begin{array}{l}7.98 \\
7.80\end{array}$ & $\begin{array}{l}8.26 \\
7.61\end{array}$ & $\begin{array}{l}9.09 \\
4.16\end{array}$ & $\begin{array}{l}1.14 \\
0.04\end{array}$ & $\begin{array}{l}6.28 \\
2.40\end{array}$ & 3.85 & 9.09 & $\begin{array}{r}10.52 \\
4.16\end{array}$ & $\begin{array}{l}1.01 \\
0.04\end{array}$ & $\begin{array}{l}5.90 \\
2.38\end{array}$ & 4.00 & 10.52 \\
\hline $\begin{array}{l}\text { Dissolved } \\
\text { ions }\end{array}$ & $\begin{array}{l}199.00 \\
206.60\end{array}$ & $\begin{array}{l}306.10 \\
249.60\end{array}$ & $\begin{array}{l}267.30 \\
313.30\end{array}$ & $\begin{array}{l}218.8 \\
221.6\end{array}$ & $\begin{array}{l}310.10 \\
312.40\end{array}$ & $\begin{array}{l}281.20 \\
297.80\end{array}$ & $\begin{array}{l}213.10 \\
217.50\end{array}$ & $\begin{array}{l}310.30 \\
312.60\end{array}$ & $\begin{array}{l}282.70 \\
299.00\end{array}$ & $\begin{array}{l}9.95 \\
7.26\end{array}$ & $\begin{array}{r}1.31 \\
25.16\end{array}$ & $\begin{array}{l}5.20 \\
4.95\end{array}$ & 8.97 & 25.16 & $\begin{array}{l}7.09 \\
5.28\end{array}$ & $\begin{array}{r}1.37 \\
25.24\end{array}$ & $\begin{array}{l}5.76 \\
4.56\end{array}$ & 8.22 & 25.24 \\
\hline $\begin{array}{l}\text { Oissolved } \\
\text { Solids } \\
\text { (mig/l) }\end{array}$ & $\begin{array}{l}172.4 \\
177.9\end{array}$ & $\begin{array}{l}254.8 \\
204.8\end{array}$ & $\begin{array}{l}229.3 \\
268.5\end{array}$ & $\begin{array}{r}190.6 \\
193\end{array}$ & $\begin{array}{l}206.60 \\
268.10\end{array}$ & $\begin{array}{l}236.50 \\
253.70\end{array}$ & $\begin{array}{l}187.10 \\
190.40\end{array}$ & $\begin{array}{l}266.70 \\
268.20\end{array}$ & $\begin{array}{l}237.50 \\
254.40\end{array}$ & $\begin{array}{r}10.56 \\
8.49\end{array}$ & $\begin{array}{r}4.63 \\
30.91\end{array}$ & $\begin{array}{l}3.14 \\
5.51\end{array}$ & 10.54 & 30.91 & $\begin{array}{l}8.53 \\
7.03\end{array}$ & $\begin{array}{r}4.67 \\
30.96\end{array}$ & $\begin{array}{l}3.58 \\
5.25\end{array}$ & 10.00 & 30.96 \\
\hline $\begin{array}{c}\text { Alkalinity } \\
\text { (mgit)as } \mathrm{CaCO}_{3}\end{array}$ & 75.6 & 124.2 & 80,3 & 89.10 & 127.40 & 100.6 & 92.50 & 126.90 & 99.70 & 17.86 & 2.58 & 25.28 & 13.77 & 25.28 & 22,35 & 2.17 & 24.16 & 14.77 & 29.16 \\
\hline (mg:l)as $\mathrm{CaCO}$ & 78.6 & 110 & 92.8 & 88.90 & 127.20 & 100.4 & 92.20 & 126.80 & 99.60 & 13.10 & 15.64 & 8.19 & & & 17.30 & 15.27 & 7.33 & & \\
\hline
\end{tabular}


Table B.2.1 Comparison of the Results Obtained by Using Knowledge about Changes in the Watershed

(incorporated by changing the Prior Probability Distribution at One Upstream Station [Station 130105])

with those Obtained Ignoring that Knowledge [Fitzroy River]

Table B.2.1(a) 1 yearly

\begin{tabular}{|c|c|c|c|c|c|c|c|c|c|c|c|c|c|c|}
\hline \multirow{3}{*}{$\begin{array}{c}\text { Water Quality } \\
\text { Paramelor }\end{array}$} & \multirow{2}{*}{\multicolumn{2}{|c|}{ Obrorryod Moan Valuos }} & \multicolumn{2}{|c|}{\begin{tabular}{|c} 
Prior Moan Values \\
\end{tabular}} & \multirow{2}{*}{\multicolumn{2}{|c|}{$\begin{array}{l}\text { Assigned Moan Values } \\
\text { Oarlignal Dilstribution) }\end{array}$}} & \multirow{2}{*}{\multicolumn{2}{|c|}{$\begin{array}{c}\text { Assigned Moan Values } \\
\text { ('Shilfted' Dlstributlon) } \\
\end{array}$}} & \multicolumn{4}{|c|}{ \% Error of Prediction } & \multicolumn{2}{|c|}{$\begin{array}{l}\text { \% Error of Predictlon } \\
\text { (Average) }\end{array}$} \\
\hline & & & \begin{tabular}{|l|l|} 
Station 130105 \\
\end{tabular} & Station 130322 & & & & & \multirow{2}{*}{\multicolumn{2}{|c|}{ 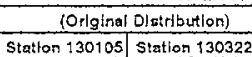 }} & \multicolumn{2}{|c|}{ ('Shlffod' Digtcllbution\} } & \multirow{2}{*}{$\begin{array}{l}\text { Orginal } \\
\text { Distrlbution }\end{array}$} & \multirow{2}{*}{$\begin{array}{c}\text { Shitted } \\
\text { Distribution }\end{array}$} \\
\hline & Statlon $1301 \mathrm{C}$ & Stat: 130 130322 & ('Shilted') & (Orlgina 1 ) & Statton 130105 & Statition 130322 & Statlon 130105 & Station 130322 & & & Staxion 13010 & Statlon 130322 & & \\
\hline \multirow{3}{*}{$\begin{array}{l}\text { Conductivity } \\
(m S / m)\end{array}$} & 210.00 & 222.50 & 291.3 & 203.7 & 266.53 & 202.44 & 266.4 & 202.8 & 26.9 & 9.0 & 26.9 & 8.8 & \multirow[t]{3}{*}{21.6} & \multirow[t]{3}{*}{21.5} \\
\hline & 200.00 & 195.00 & & & 304.42 & 203.75 & 301.3 & 204.1 & 50.7 & 4.5 & 50.7 & 4.7 & & \\
\hline & 270.00 & 246.75 & & & 218.82 & 200.64 & 218.7 & 201.0 & 19.0 & 19.3 & 19.0 & 19.2 & & \\
\hline \multirow{3}{*}{$\begin{array}{l}\text { Dissolved ions } \\
\text { (mg })\end{array}$} & 183.90 & 159.80 & 198.8 & 148.2 & 182.73 & 147.15 & 182.5 & 147.6 & 0.6 & 7.9 & 0.7 & 7.7 & \multirow[t]{3}{*}{16.2} & \multirow[t]{3}{*}{18.2} \\
\hline & 128.00 & 144.55 & & & 203.36 & 147.99 & 203.3 & 143.4 & 58.9 & 2,4 & 58.8 & 2.7 & & \\
\hline & 165.55 & 175.30 & & & 148.57 & 145.78 & 148.5 & 124.2 & 10.3 & 16.9 & 10.3 & 29.2 & & \\
\hline \multirow{3}{*}{$\begin{array}{l}\text { Dissolved Solids } \\
\text { (mg//) }\end{array}$} & 123.00 & 125.00 & 161.4 & 122.6 & 150.26 & 121.58 & 150.2 & 122.1 & 22.2 & 2.7 & 22.1 & 2.3 & \multirow[t]{3}{*}{18.5} & \multirow[t]{3}{*}{18.4} \\
\hline & 110.00 & 110.00 & & & 187.49 & 122.44 & 167.4 & 122.9 & 52.3 & 11.3 & 52.2 & 11.8 & & \\
\hline & 140.00 & 137.50 & & & 126,14 & 120.37 & 126.0 & 120.9 & 9.9 & 12.5 & 10.0 & 12,1 & & \\
\hline \multirow{3}{*}{ 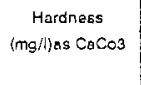 } & 61.00 & 57.50 & 76.82 & 53.0 & 69.99 & 52.99 & 70.0 & 52.9 & 14.7 & 7.8 & 14.8 & 8.1 & \multirow[t]{3}{*}{18.5} & \multirow[t]{3}{*}{18.6} \\
\hline & 55.00 & 51.50 & & & 85.69 & 53.23 & 85.7 & 53.1 & 55.8 & 3.4 & 55.8 & 3.1 & & \\
\hline & 65.50 & 66.50 & & & 59.68 & 52.82 & 59.7 & 52.7 & 8.9 & 20.6 & 8.8 & 20.7 & & \\
\hline
\end{tabular}


Table B.2.1(b) 2 yearly

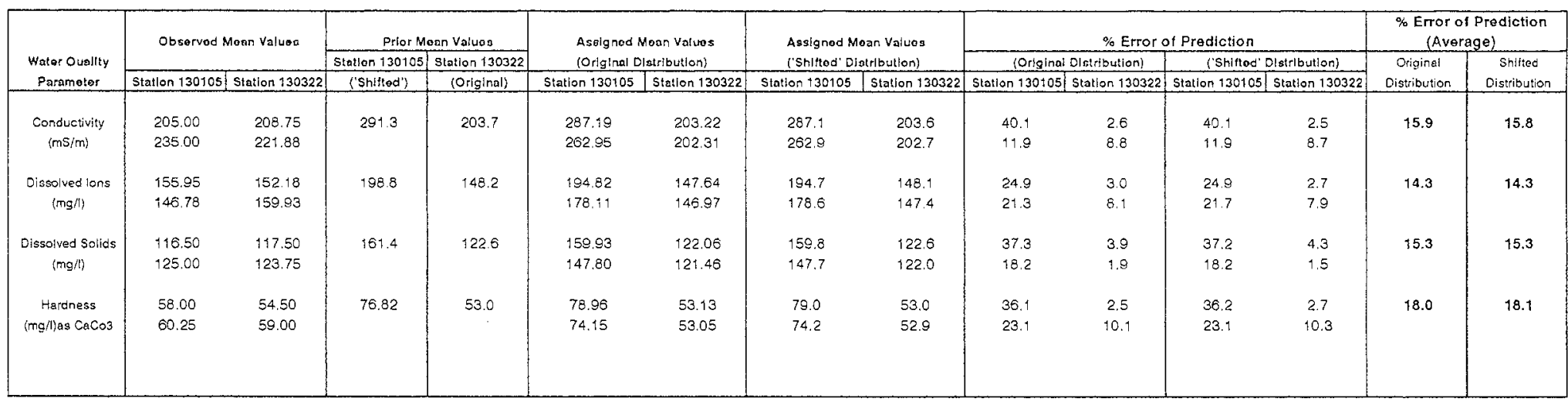

Table B.2.1(c) 3 yearly

\begin{tabular}{|c|c|c|c|c|c|c|c|c|c|c|c|c|c|c|}
\hline \multirow{2}{*}{$\begin{array}{c}\text { Watar Quality } \\
\text { Paramater }\end{array}$} & \multirow{2}{*}{\multicolumn{2}{|c|}{ Obsarved Moan Yalues }} & \multicolumn{2}{|c|}{ Prior Mean Values } & \multirow{2}{*}{\multicolumn{2}{|c|}{$\begin{array}{l}\text { Asslgnod Moan Values } \\
\text { Original Diatribution) }\end{array}$}} & \multirow{2}{*}{\multicolumn{2}{|c|}{$\begin{array}{l}\text { Assignod Moan Values } \\
\text { ('Shifled ' Oistribution) } \\
\end{array}$}} & \multicolumn{4}{|c|}{$\%$ Error of Prediction } & \multicolumn{2}{|c|}{$\begin{array}{l}\text { \% Error of Prediction } \\
\text { (Average) }\end{array}$} \\
\hline & & & \begin{tabular}{|l} 
Station 130105 \\
('Stifted')
\end{tabular} & \begin{tabular}{|l|} 
Station 130322 \\
$(01031)$
\end{tabular} & & & & & $\frac{\text { OOrigln }}{\text { Stration }+3010}$ & 12al Olstributlon) & $\begin{array}{l}\text { C'Shilito } \\
\text { Station } 13010\end{array}$ & 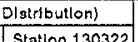 & Original & 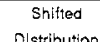 \\
\hline $\begin{array}{c}\text { Conductivity } \\
(m \mathrm{~m} / \mathrm{m})\end{array}$ & 226.60 & 222.00 & 291.3 & 203.7 & 273.77 & 202.72 & 255.2 & 202.4 & 20.8 & 8.7 & 12.6 & 8.8 & 14.8 & 10.7 \\
\hline $\begin{array}{l}\text { Dissolved lons } \\
\text { (mg/) }\end{array}$ & 159.10 & 159.80 & 198.8 & 148.2 & 186.51 & 147.31 & 180.4 & 147.7 & 17.2 & 7.8 & 17.2 & 7.6 & 12.5 & 12.4 \\
\hline $\begin{array}{l}\text { Dissolved Sol ids } \\
\qquad(\mathrm{mg} / \mathrm{l})\end{array}$ & 124.30 & 124.10 & 161.4 & 122.6 & 153.02 & 121.72 & 152.9 & 122.2 & 23.1 & 1.9 & 23.0 & 1.5 & 12.5 & 12.3 \\
\hline $\begin{array}{c}\text { Hardnass } \\
\text { (mgl/)as } \mathrm{CaCo} 3\end{array}$ & 60.50 & 58.50 & 76.82 & 53.0 & 77.43 & 52.83 & 76.6 & 53.0 & 28.0 & 9.7 & 26.7 & 9.4 & 18.8 & 18.0 \\
\hline
\end{tabular}


Table B.2.2 Comparison of the Results Obtained by Using Knowledge about Changes in the Watershed (incorporated by changing the Prior Probability Distribution at One Upstream Station [Station 130212]) with those Obtained Ignoring that Knowledge [ Nogoa River ]

Table B.2.2(a) 1 yearly

\begin{tabular}{|c|c|c|c|c|c|c|c|c|c|c|c|c|c|c|}
\hline \multirow{3}{*}{$\begin{array}{c}\text { Wator Qunity } \\
\text { Dexame:or } \\
\end{array}$} & \multirow{2}{*}{\multicolumn{2}{|c|}{ Obsorved Mtan Ynivess }} & \multicolumn{2}{|c|}{ Prot Maan yathes } & \multirow{2}{*}{\multicolumn{2}{|c|}{ 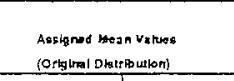 }} & \multirow{2}{*}{\multicolumn{2}{|c|}{ 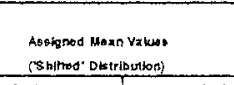 }} & \multicolumn{4}{|c|}{ \% Error of Prodiotion } & \multicolumn{2}{|c|}{$\begin{array}{l}\text { \% Error of Prodiolion } \\
\text { (Averago) } \\
\end{array}$} \\
\hline & & & Statsen 13020 & smimini 130212 & & & & & \multicolumn{2}{|c|}{ 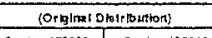 } & \multicolumn{2}{|c|}{ 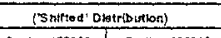 } & \multirow{2}{*}{ 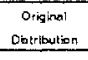 } & \multirow{2}{*}{$\begin{array}{l}\text { Shimed } \\
\text { Dharitiontion }\end{array}$} \\
\hline & 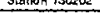 & 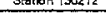 & (Orgitanh) & (Snitod $)$ & Station 19020202 & & Station 132002 & & & 3utron on 190212 & Samion 13020202 & Spation 190212 & & \\
\hline \multirow{5}{*}{$\begin{array}{l}\text { conductsky } \\
\text { (ms } /(m)\end{array}$} & 246.50 & 221.26 & 245.73 & 281.4 & 215.18 & 170.18 & 220.2 & 161.4 & 12.7 & 23.1 & 10.7 & 27.1 & \multirow{5}{*}{24.8} & \multirow[t]{5}{*}{25.4} \\
\hline & 342.50 & 230.00 & & & 283.43 & 191.58 & 268.5 & 172.8 & 23.1 & 21.1 & 21.6 & 24.9 & & \\
\hline & & 125.00 & & & 235.71 & 175.03 & 240.7 & 166.2 & 24.9 & 40.0 & 26.7 & 33.0 & & \\
\hline & & 152.50 & & & 218.40 & 170.95 & 223.4 & 182.1 & 43.2 & 12.1 & & 6.3 & & \\
\hline & & & & & 217.59 & 170.76 & 222.5 & 181.9 & 47.5 & 1.0 & 50.8 & 6.1 & & \\
\hline \multirow{5}{*}{ 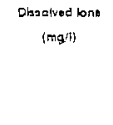 } & 179.40 & 184.33 & 177.4 & 199.1 & 159.33 & 139.41 & 181.1 & 136.3 & 11.2 & 24.4 & 10.2 & 26.1 & \multirow{5}{*}{23.4} & \multirow{5}{*}{23.0} \\
\hline & 249.35 & 182.40 & & & 169.71 & 178.44 & 171.5 & 176.3 & 31.8 & 1.6 & 31.2 & 3.3 & & \\
\hline & & & & & 181.38 & 147.31 & 183.2 & 144.2 & 18.8 & 51.6 & & 48.3 & & \\
\hline & & 125.15 & & & 159.80 & 141.23 & 161.6 & 130.1 & 37.0 & 12.8 & 38.5 & 3.9 & & \\
\hline & 110.15 & 137.80 & & & 156.99 & 138.09 & 180.8 & 135.0 & 44.3 & 0.2 & 45,9 & 2.1 & & \\
\hline \multirow{5}{*}{ 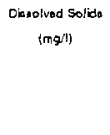 } & 147.93 & 747.50 & 137.18 & 145.6 & 120.54 & 119.62 & 122.6 & 108.9 & 19.5 & 23.0 & 17.4 & 25.5 & \multirow{5}{*}{22.3} & \multirow{5}{*}{21.8} \\
\hline & 200.00 & 138.00 & & & 130.98 & 139.96 & 133.3 & 135.9 & 34.5 & 1.4 & 33.3 & 1.6 & & \\
\hline & 110.00 & 80.00 & & & 122.14 & 117.66 & 124.5 & 113.6 & 11.0 & 47.1 & 13.2 & $\$ 2.0$ & & \\
\hline & 94.50 & 90.50 & & & $\begin{array}{l}118.57 \\
10.6\end{array}$ & 108.95 & $\begin{array}{l}121.0 \\
\end{array}$ & 104.9 & $\begin{aligned} 25.6 \\
27.6\end{aligned}$ & 20.4 & 28.7 & 15.9 & & \\
\hline & & & & & 110.36 & 160.24 & 180.9 & 104,4 & 37,0 & .... & & & & \\
\hline \multirow{5}{*}{ 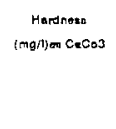 } & 69.07 & 78.00 & 76.18 & 88.5 & 70.65 & 61.18 & 72.2 & 58.5 & 2.3 & 21.5 & 4.5 & 25.0 & \multirow{5}{*}{ э3.3 } & \multirow{5}{*}{35.3} \\
\hline & 92. & 80. & & & 73.04 & & & 69 & 21.0 & s.7 & 19.3 & 13.2 & & \\
\hline & 46. & 37,09 & & & 71,00 & & & 50.0 & 54.3 & 69.7 & 57.8 & 62.2 & & \\
\hline & 45.50 & 50.50 & & & 71.08 & 63.17 & 72.7 & 80.4 & 56.2 & 25.7 & 59.7 & 18.6 & & \\
\hline & 44.00 & 54.50 & & & 70.85 & 61.11 & 72.2 & 58.5 & $\infty 0,8$ & 12,3 & 64.0 & 7.4 & & \\
\hline
\end{tabular}

Table B.2.2(b) 2 yearly

\begin{tabular}{|c|c|c|c|c|c|c|c|c|c|c|c|c|c|c|}
\hline \multirow{3}{*}{$\begin{array}{l}\text { Wacer acullity } \\
\text { Paramerot }\end{array}$} & \multirow{2}{*}{\multicolumn{2}{|c|}{ Otsorred Mat Valueses }} & \multicolumn{2}{|c|}{ Pribr Mean vaitios } & \multirow{2}{*}{\multicolumn{2}{|c|}{ 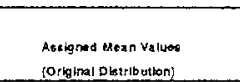 }} & \multirow{2}{*}{\multicolumn{2}{|c|}{ 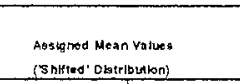 }} & \multicolumn{4}{|c|}{ \% Error of Prodiotion } & \multicolumn{2}{|c|}{$\begin{array}{l}\text { \%o Error of Proditotion } \\
\text { (Avoragge) }\end{array}$} \\
\hline & & & Statition 130802 & stalion 130212 & & & & & \multicolumn{2}{|c|}{ 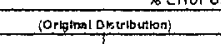 } & \multicolumn{2}{|c|}{ 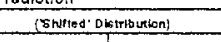 } & \multirow{2}{*}{$\begin{array}{l}\text { Ongininal } \\
\text { Oetribution }\end{array}$} & \multirow{2}{*}{$\begin{array}{l}\text { Shilibed } \\
\text { Oobrtibution }\end{array}$} \\
\hline & Sation 13040101 & Stataton 1300106 & (Origianali. & (Shitioa? & $\operatorname{sintion} 330<-21$ & Statoon 1300100 & sestion $130+09$ & 1 Semition: 30106 & station 13008: & Station 130106 & $\operatorname{sintion} 130401$ & Satation 100106 & & \\
\hline \multirow{4}{*}{ 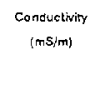 } & 294.50 & 285.63 & 245.73 & 261.4 & 237.12 & 175.36 & 242.2 & 166.6 & 19.5 & 22.3 & 17.8 & 20.2 & \multirow{4}{*}{18.0} & \multirow{4}{*}{19.4} \\
\hline & 266.25 & 177.50 & & & 247.85 & 177.90 & 252.0 & 168.1 & 6.9 & 0.2 & 5.4 & 4.7 & & \\
\hline & 171.25 & 138.75 & & & 224.30 & 172.37 & $2 \% .3$ & 163.5 & 31.0 & 24,2 & 33.8 & 17.9 & & \\
\hline & 150.00 & 962.50 & & & 214.83 & 170.10 & 219.9 & 181.3 & 43.2 & 4.7 & 48.6 & 0.8 & & \\
\hline \multirow{4}{*}{$\begin{array}{l}\text { Cissoived lona } \\
\text { (mgli) }\end{array}$} & 214.37 & 141,10 & 177.4 & 199.1 & 183.96 & 157.33 & 165.8 & 154.2 & 23.5 & 11.5 & 22.7 & 9.3 & \multirow{4}{*}{20.4} & \multirow{4}{*}{20.5} \\
\hline & 182.58 & 139.80 & & & 165.04 & 151.43 & 168.8 & 158.3 & 14.3 & 15.5 & 13.4 & 13.2 & & \\
\hline & & 111.16 & & & 159.90 & 142.61 & 161.7 & 138.5 & 28.7 & 27.4 & 28.1 & 24.8 & & \\
\hline & 113.38 & 131.48 & & & 158.65 & 136.82 & 160.4 & 193.8 & 39.9 & 4.1 & 41.4 & 1.8 & & \\
\hline \multirow{4}{*}{ 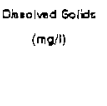 } & 173.97 & 142.75 & 197,16 & 145.6 & 125.62 & 128.44 & 128.0 & 122.3 & 27.9 & 19.4 & 26.4 & 14.3 & \multirow[t]{4}{*}{20.7} & \multirow[t]{4}{*}{21.0} \\
\hline & 155.00 & 109.00 & & & 126.46 & 128.55 & 128.8 & 124.5 & 18.4 & 17.9 & 15.8 & 14.2 & & \\
\hline & 102.25 & 85.25 & & & 120,04 & 112.38 & 122.4 & 108.3 & 17.4 & 39.8 & 19.7 & 27.0 & & \\
\hline & 90.25 & 97.75 & & & 188,15 & 107.62 & 120.5 & 103.5 & 30.8 & 10.1 & 33.5 & 5.9 & & \\
\hline \multirow{4}{*}{ 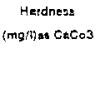 } & 80.78 & 79.00 & 75.16 & 56.5 & 71.00 & 82.80 & 72.6 & 60.1 & 12.1 & 20.5 & 10.2 & 24.0 & \multirow[t]{4}{*}{24.8} & \multirow[t]{4}{*}{25.7} \\
\hline & 59.25 & 58.50 & & & 71.18 & 63.70 & 72.8 & 60.9 & 2.8 & 8.8 & 5.1 & & & \\
\hline & 45.75 & 43.75 & & & 70.11 & 58,74 & 71.7 & 56.0 & 53.2 & 34.3 & 56.7 & 27.9 & & \\
\hline & 44.75 & 52.50 & & & 69.92 & 57.86 & 71.5 & 55.1 & 56.2 & 10.2 & 59.8 & 5.0 & & \\
\hline
\end{tabular}


Table B.2.2(c) 3 yearly

\begin{tabular}{|c|c|c|c|c|c|c|c|c|c|c|c|c|c|c|}
\hline \multirow{2}{*}{$\begin{array}{c}\text { Water Quality } \\
\text { Parameter }\end{array}$} & \multirow{2}{*}{\multicolumn{2}{|c|}{ Observed Mean Values }} & \multicolumn{2}{|c|}{ Prlor Mean Values } & \multirow{2}{*}{\multicolumn{2}{|c|}{$\begin{array}{l}\text { Assigned Moan Valuos } \\
\text { (Origlinat Distributilon) }\end{array}$}} & \multirow{2}{*}{\multicolumn{2}{|c|}{$\begin{array}{l}\text { Assignod Moan Vaicus } \\
\text { ('Shittod' Distribution) }\end{array}$}} & \multicolumn{4}{|c|}{$\%$ Error of Prediction } & \multicolumn{2}{|c|}{$\begin{array}{l}\text { \% Error of Prediction } \\
\text { (Average) }\end{array}$} \\
\hline & & & \begin{tabular}{|c|} 
Station 130202 \\
(Orrginal) \\
\end{tabular} & $\begin{array}{c}\text { Stattion } 130212 \\
\text { ('shlited') } \\
\end{array}$ & & & & & Corlgina & al Distribution & I (shiltoc & 8lotribution) & Original & Shilited \\
\hline Conductivity & 259.67 & 192.08 & 245.73 & 261.4 & 229.99 & 173.68 & 235.0 & 1649 & 11.4 & 9.6 & 9.5 & 142 & 11.6 & 11.9 \\
\hline$(\mathrm{ms} i \mathrm{~m})$ & 228.33 & 169.17 & & & 231,18 & 173.95 & 236.2 & 165.2 & 1.2 & 2.8 & 3.4 & 2.4 & & \\
\hline Dissolved lans & 188.18 & 154.64 & 177.4 & 199.1 & 145.34 & 173.52 & 161.0 & 146.0 & 22.8 & 12.2 & 14.4 & 5.6 & 21.7 & 12.0 \\
\hline$(\mathrm{mg} / \mathrm{l})$ & 167.25 & 134.92 & & & 145.82 & 173.66 & 161.2 & 146.6 & 12.8 & 28.7 & 3.6 & 8.7 & & \\
\hline & 120.85 & 120.05 & & & 134.90 & 170.56 & 157.2 & 131.4 & 11.6 & 42.1 & 30.1 & 0.5 & & \\
\hline & 96.83 & 91.83 & & & 117.54 & 106.10 & 119.9 & 102.0 & 21.4 & 15.5 & 23.8 & 11.1 & & \\
\hline Herdness & 69.19 & 82.83 & 76.16 & 86.5 & 70.03 & 53.37 & 71.6 & 55.6 & 1.2 & 295 & 3.5 & 32.9 & 22.1 & 25.3 \\
\hline (ma///as $\mathrm{CaC}$ & 61,33 & 73.17 & & & 70.21 & 59.14 & 71.8 & 56.4 & 14.5 & 19.2 & 17.0 & 23.0 & & \\
\hline & 45.17 & 64.50 & & & 69.26 & 54.80 & 70.7 & 52.3 & 53.3 & 15.0 & 56.5 & 190 & & \\
\hline
\end{tabular}

Table B.2.2(d) 4 yearly

\begin{tabular}{|c|c|c|c|c|c|c|c|c|c|c|c|c|c|c|}
\hline \multirow{2}{*}{$\begin{array}{l}\text { Water Quallity } \\
\text { Parameter }\end{array}$} & \multirow{2}{*}{\multicolumn{2}{|c|}{ Oboorvod Moan Valuos }} & \multirow{2}{*}{\multicolumn{2}{|c|}{$\begin{array}{l}\text { Prior Moan Valuos } \\
\text { Statlon } 1302021 / \operatorname{station} 13021\end{array}$}} & \multirow{2}{*}{\multicolumn{2}{|c|}{$\begin{array}{l}\text { Aoselgnod Moan Voluar } \\
\text { (Original Dlatitibution) }\end{array}$}} & \multirow{2}{*}{\multicolumn{2}{|c|}{$\begin{array}{l}\text { Astignod Moan Valuos } \\
\text { ('Shilfted' Distrflutlion) }\end{array}$}} & \multicolumn{4}{|c|}{$\%$ Error of Prodiction } & \multicolumn{2}{|c|}{$\begin{array}{c}\text { \% Error of Prediction } \\
\text { (Average) }\end{array}$} \\
\hline & & & & & & & & & \begin{tabular}{|r} 
|Origlnal \\
Station 130401 \\
\end{tabular} & \begin{tabular}{|l|} 
Distriluution) \\
Sterion 130106
\end{tabular} & \begin{tabular}{|l|} 
('Shll:tod' \\
Station 130401 \\
\end{tabular} & 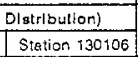 & $\begin{array}{l}\text { Original } \\
\text { Distribution }\end{array}$ & $\begin{array}{c}\text { Shlithed } \\
\text { Distribution }\end{array}$ \\
\hline $\begin{array}{c}\text { Conductivity } \\
(\mathrm{mS} / \mathrm{m})\end{array}$ & $\begin{array}{l}232.88 \\
208.13\end{array}$ & $\begin{array}{l}182.19 \\
170.00\end{array}$ & 245.73 & 261.4 & $\begin{array}{l}228.90 \\
229.55\end{array}$ & $\begin{array}{l}173.43 \\
173.58\end{array}$ & $\begin{array}{l}233.9 \\
234.6\end{array}$ & $\begin{array}{l}164.6 \\
164.8\end{array}$ & $\begin{array}{l}1.7 \\
10.3\end{array}$ & $\begin{array}{l}4.8 \\
2.1\end{array}$ & $\begin{array}{l}0.5 \\
12.7\end{array}$ & $\begin{array}{l}9.6 \\
3.1\end{array}$ & 4.7 & 6.5 \\
\hline $\begin{array}{l}\text { Dissolved lons } \\
\text { (mg//) }\end{array}$ & $\begin{array}{l}170.29 \\
152.98\end{array}$ & $\begin{array}{l}147.27 \\
135.64\end{array}$ & 177,4 & 199.1 & $\begin{array}{l}145.79 \\
145.55\end{array}$ & $\begin{array}{l}173.66 \\
173.59\end{array}$ & $\begin{array}{l}161.2 \\
161.1\end{array}$ & $\begin{array}{l}146.5 \\
146.3\end{array}$ & $\begin{array}{c}14.4 \\
4.9\end{array}$ & $\begin{array}{l}17.9 \\
28.0\end{array}$ & $\begin{array}{l}5.3 \\
5.3\end{array}$ & $\begin{array}{l}0.4 \\
7.8\end{array}$ & 16.3 & 4.7 \\
\hline $\begin{array}{c}\text { Hardness } \\
\text { (mag/)es } \mathrm{CaCo3}\end{array}$ & $\begin{array}{l}63.27 \\
57.00\end{array}$ & $\begin{array}{l}61.38 \\
55.50\end{array}$ & 76.16 & 85.5 & $\begin{array}{l}71.55 \\
71.55\end{array}$ & $\begin{array}{l}65.32 \\
65.32\end{array}$ & $\begin{array}{l}73.1 \\
73.1\end{array}$ & $\begin{array}{l}62.6 \\
62.6\end{array}$ & $\begin{array}{l}13.1 \\
25.5\end{array}$ & $\begin{array}{c}6.4 \\
17.7\end{array}$ & $\begin{array}{l}15.6 \\
28.3\end{array}$ & $\begin{array}{l}1.9 \\
12.7\end{array}$ & 15.7 & 14.6 \\
\hline
\end{tabular}


Table B.2.3 Comparison of the Results Obtained by Using Knowledge about Changes in the Watershed (incorporated by changing the Prior Probability Distribution at One Upstream Station [Station 145020]) with those Obtained Ignoring that Knowledge [Logan River ]

Table B.2.3(a) 1 yearly

\begin{tabular}{|c|c|c|c|c|c|c|c|c|c|c|c|c|c|c|c|c|c|c|c|c|}
\hline \multirow{3}{*}{$\begin{array}{l}\text { Water Ounutiki } \\
\text { Paramolor }\end{array}$} & \multirow{2}{*}{\multicolumn{3}{|c|}{ Oboorved Moan valloos }} & \multicolumn{3}{|c|}{ Pror Masn Valuat } & \multirow{2}{*}{\multicolumn{3}{|c|}{ 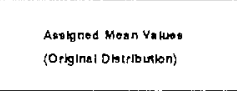 }} & \multirow{2}{*}{\multicolumn{3}{|c|}{ 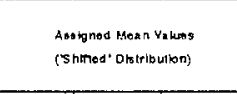 }} & \multicolumn{6}{|c|}{ \% Etror of Prodlotion } & \multicolumn{2}{|c|}{$\begin{array}{l}\text { \% Error of Prodletion } \\
\text { (Averago) }\end{array}$} \\
\hline & & & & \multirow{2}{*}{ 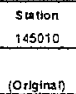 } & \multirow{2}{*}{$\begin{array}{l}\text { Station } \\
445013 \\
\text { SOrgitran } \\
\end{array}$} & \multirow{2}{*}{ 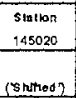 } & & & & & & & \multicolumn{3}{|c|}{ 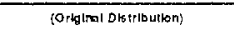 } & \multicolumn{3}{|c|}{ 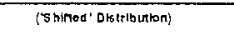 } & \multirow{2}{*}{$\begin{array}{c}\text { Original } \\
\text { Dusrbution }\end{array}$} & \multirow{2}{*}{$\begin{array}{l}\text { shithed } \\
\text { Dartibution }\end{array}$} \\
\hline & $\begin{array}{l}\text { Swation } \\
1.45010 \\
\end{array}$ & $\begin{array}{l}\text { Slation } \\
1.45013 \\
\end{array}$ & $\begin{array}{l}5 \mathrm{Station} \\
145020 \\
\end{array}$ & & & & $\begin{array}{l}5.41100 \\
1.5010 \\
\end{array}$ & $\begin{array}{ll}\text { Stration } \\
1.50013\end{array}$ & $\begin{array}{l}\text { Satilon } \\
145020 \\
\end{array}$ & $\begin{array}{l}\text { Station } \\
1.50910\end{array}$ & $\begin{array}{l}\text { Sasiton } \\
\text { 145013 }\end{array}$ & $\begin{array}{l}\text { Staton } \\
145020 \\
\end{array}$ & $\begin{array}{l}\text { Stantilon } \\
795010\end{array}$ & $\begin{array}{l}\text { Sation } \\
\text { 1asolis }\end{array}$ & $\begin{array}{l}\text { Station } \\
\text { iasszon }\end{array}$ & 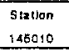 & 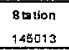 & $\begin{array}{l}\text { Sation } \\
\text { 1.45020 } \\
\end{array}$ & & \\
\hline 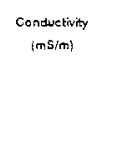 & $\begin{array}{l}348.5 \\
360.0 \\
205.0 \\
328.8 \\
347.5\end{array}$ & $\begin{array}{l}650.0 \\
328.0 \\
296.7 \\
476.3 \\
245.0\end{array}$ & $\begin{array}{l}397.5 \\
434.0 \\
258.3 \\
645.0 \\
631.7\end{array}$ & 355.6 & 495.7 & 513.5 & $\begin{array}{l}354.9 \\
355.9 \\
352.9 \\
351.7 \\
355.9\end{array}$ & $\begin{array}{l}495.4 \\
495.9 \\
494.5 \\
496.7 \\
495.9\end{array}$ & $\begin{array}{l}601.5 \\
609.8 \\
586.3 \\
625.8 \\
610.2\end{array}$ & $\begin{array}{r}356.0 \\
357.0 \\
354.2 \\
358.9 \\
356,9\end{array}$ & $\begin{array}{l}496.0 \\
486.4 \\
495.1 \\
497.3 \\
496.3\end{array}$ & $\begin{array}{l}601.1 \\
609.2 \\
585.7 \\
825.2 \\
608.6\end{array}$ & $\begin{array}{c}1.8 \\
1.1 \\
72.1 \\
7.0 \\
2.4\end{array}$ & $\begin{array}{c}23.8 \\
24.8 \\
56.7 \\
4.3 \\
102.4\end{array}$ & $\begin{array}{l}51.3 \\
40.5 \\
111.5 \\
3.0 \\
3.4\end{array}$ & $\begin{array}{c}2.2 \\
0.8 \\
72.8 \\
9.2 \\
2.7\end{array}$ & $\begin{array}{c}23.7 \\
24.7 \\
66.9 \\
4.4 \\
102.5\end{array}$ & $\begin{array}{l}51.2 \\
40.4 \\
118.3 \\
3.1 \\
3.7\end{array}$ & 34.9 & 35.1 \\
\hline $\begin{array}{l}\text { Dinsolved lono } \\
\left(m \theta^{\prime \prime \prime}\right)\end{array}$ & $\begin{array}{l}220.2 \\
223.5 \\
123.9 \\
2222.6 \\
250.5\end{array}$ & $\begin{array}{l}409.4 \\
291.8 \\
203.3 \\
329.8 \\
183.6\end{array}$ & $\begin{array}{l}241,7 \\
264.4 \\
162.5 \\
400.6 \\
425.9\end{array}$ & 232.9 & 321.9 & 304.7 & $\begin{array}{l}231.6 \\
232.8 \\
229.5 \\
235.6 \\
233.1\end{array}$ & $\begin{array}{l}320.8 \\
321.8 \\
319.0 \\
323.7 \\
322.1\end{array}$ & $\begin{array}{l}358.9 \\
386.7 \\
346.0 \\
380.0 \\
368.4\end{array}$ & $\begin{array}{l}233,1 \\
234.3 \\
230.9 \\
239.5 \\
234.6\end{array}$ & $\begin{array}{l}322.1 \\
323.1 \\
3220.3 \\
32224 \\
322.4\end{array}$ & $\begin{array}{l}358.1 \\
365.9 \\
345.2 \\
380.9 \\
367.6\end{array}$ & $\begin{array}{c}5.2 \\
4.2 \\
76.8 \\
5.9 \\
6.9\end{array}$ & $\begin{array}{c}21.6 \\
14.2 \\
56.9 \\
1.9 \\
75.4\end{array}$ & $\begin{array}{c}48.5 \\
38.7 \\
113.0 \\
5.1 \\
13.5\end{array}$ & $\begin{array}{c}5.9 \\
4.9 \\
77.7 \\
4.9 \\
6.3\end{array}$ & $\begin{array}{r}21.3 \\
14.7 \\
57.6 \\
2.2 \\
76.1\end{array}$ & $\begin{array}{c}48.2 \\
38.3 \\
112.4 \\
4.9 \\
13.7\end{array}$ & 32.5 & 32.5 \\
\hline 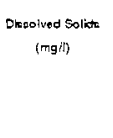 & $\begin{array}{l}188.0 \\
182.5 \\
117.0 \\
192.0 \\
210.0\end{array}$ & $\begin{array}{l}350.0 \\
226.0 \\
173.3 \\
270.0 \\
150.0\end{array}$ & $\begin{array}{l}210.0 \\
224.0 \\
143.3 \\
340.0 \\
368.7\end{array}$ & 201.8 & 273.9 & 264.6 & $\begin{array}{l}199.5 \\
200.8 \\
197.3 \\
203.3 \\
201.4\end{array}$ & $\begin{array}{l}272.4 \\
273.2 \\
270.9 \\
274.8 \\
273.6\end{array}$ & $\begin{array}{l}302.1 \\
30.1 \\
30.95 \\
285.8 \\
330.0 \\
316.4\end{array}$ & $\begin{array}{l}200.8 \\
201.9 \\
198.6 \\
20.0 \\
200.2\end{array}$ & $\begin{array}{l}273.2 \\
273.9 \\
27.9 .8 \\
27.0 \\
272.8\end{array}$ & $\begin{array}{l}301.5 \\
310.5 \\
235.2 \\
330.7 \\
217.1\end{array}$ & $\begin{array}{l}5.1 \\
4.3 \\
68.6 \\
5.9 \\
4.1\end{array}$ & $\begin{array}{l}22.2 \\
20.9 \\
58.3 \\
1.9 \\
98.4 \\
9 . .4\end{array}$ & $\begin{array}{l}43.9 \\
38.8 \\
99.4 \\
2.9 \\
13.7\end{array}$ & $\begin{array}{c}6.8 \\
4.9 \\
69.7 \\
5.2 \\
4.7\end{array}$ & $\begin{array}{l}22.0 \\
21.2 \\
58.5 \\
1.5 \\
81.9\end{array}$ & $\begin{array}{c}43.6 \\
38.6 \\
99.0 \\
2.7 \\
40.8\end{array}$ & 31.4 & 33.4 \\
\hline 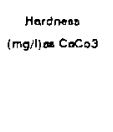 & $\begin{array}{l}108.5 \\
115.3 \\
64.0 \\
112.3 \\
109.5\end{array}$ & $\begin{array}{l}181.6 \\
136.4 \\
98.0 \\
166.3 \\
75.0\end{array}$ & $\begin{array}{l}86.3 \\
96.2 \\
57.3 \\
179.3 \\
172.7\end{array}$ & 14.3 & 159.9 & 86.7 & $\begin{array}{l}110.8 \\
112.8 \\
107.3 \\
117.1 \\
113.8\end{array}$ & $\begin{array}{l}157.5 \\
158.9 \\
155.1 \\
161.8 \\
159.5\end{array}$ & $\begin{array}{l}128.6 \\
135.5 \\
118.3 \\
111.3 \\
139.2 \\
19.2\end{array}$ & $\begin{array}{l}113.2 \\
111.2 \\
109.8 \\
114.6 \\
; 16.2\end{array}$ & $\begin{array}{l}159.2 \\
160.5 \\
156.8 \\
160.1 \\
161.2\end{array}$ & $\begin{array}{l}127.3 \\
134.9 \\
115.0 \\
152.2 \\
137.9\end{array}$ & $\begin{array}{c}2.1 \\
2.1 \\
67.7 \\
4.3 \\
3.9\end{array}$ & $\begin{array}{c}13.3 \\
15.5 \\
58.3 \\
2.7 \\
112.7\end{array}$ & $\begin{array}{l}49.1 \\
40.6 \\
102.8 \\
27.0 \\
19.4\end{array}$ & $\begin{array}{c}4.3 \\
0.0 \\
71.6 \\
2.1 \\
6.1\end{array}$ & $\begin{array}{c}12.3 \\
17.7 \\
60.0 \\
3.7 \\
114.9\end{array}$ & $\begin{array}{c}47.6 \\
39.4 \\
100.6 \\
4.4 \\
20.1\end{array}$ & 34.8 & 33.7 \\
\hline
\end{tabular}

Table B.2.3(b) 2 yearly

\begin{tabular}{|c|c|c|c|c|c|c|c|c|c|c|c|c|c|c|c|c|c|c|c|c|}
\hline \multirow{3}{*}{$\begin{array}{l}\text { Water OLeally } \\
\text { Prrametos }\end{array}$} & \multirow{2}{*}{\multicolumn{3}{|c|}{ Obsorvod Mean Vatioss }} & \multicolumn{3}{|c|}{ Pror Mean valuest } & \multirow{2}{*}{\multicolumn{3}{|c|}{ 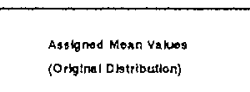 }} & \multirow{2}{*}{\multicolumn{3}{|c|}{ 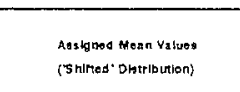 }} & \multicolumn{6}{|c|}{$\%_{0}$ Error of Prodicllon } & \multicolumn{2}{|c|}{$\begin{array}{l}\text { \% Erroor of Prodition } \\
\text { (Avoragas) }\end{array}$} \\
\hline & & & & $\begin{array}{l}\text { Statition } \\
\text {.145010 } \\
\end{array}$ & \multirow{2}{*}{ 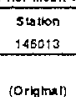 } & \multirow{2}{*}{ 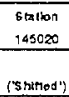 } & & & & & & & \multicolumn{3}{|c|}{ 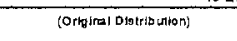 } & \multicolumn{3}{|c|}{ 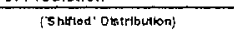 } & \multirow{2}{*}{$\begin{array}{c}\text { Original } \\
\text { Ointribustion }\end{array}$} & \multirow{2}{*}{$\begin{array}{l}\text { Shixitod } \\
\text { Saltributer }\end{array}$} \\
\hline & $\begin{array}{l}8 \operatorname{sint10n} \\
1450: 0\end{array}$ & $\begin{array}{l}\text { Siation } \\
1.55013\end{array}$ & $\begin{array}{l}545009 \\
145020\end{array}$ & Oratinal & & & $\begin{array}{l}\text { Sturtion } \\
145010\end{array}$ & $\begin{array}{l}\text { Stalkn } \\
\text { 145013 }\end{array}$ & $\begin{array}{l}\text { Sa:ion } \\
\text { ias5020 }\end{array}$ & $\begin{array}{l}\text { Station } \\
145010\end{array}$ & $\begin{array}{l}\text { sration } \\
\text { 195013 }\end{array}$ & $\begin{array}{l}\text { ststiton } \\
145020\end{array}$ & $\begin{array}{l}\text { station } \\
145010\end{array}$ & $\begin{array}{l}\text { Statiton } \\
145013\end{array}$ & $\begin{array}{l}\text { Stration } \\
145020\end{array}$ & $\begin{array}{l}\text { Stanton } \\
145010\end{array}$ & $\begin{array}{l}\text { Slation } \\
1<5013\end{array}$ & $\begin{array}{l}\text { Station } \\
145020\end{array}$ & & \\
\hline \multirow{3}{*}{ 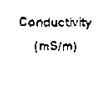 } & 354,3 & 524.0 & 415.9 & \multirow{3}{*}{355.5} & \multirow[t]{3}{*}{495.7} & \multirow[t]{3}{*}{513.5} & 310.4 & 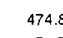 & 258.3 & 311.8 & 475.5 & 257.6 & 12.4 & 9.4 & 37.9 & 12.0 & 0.3 & 38.0 & \multirow[t]{3}{*}{25.7} & \multirow[t]{3}{*}{25.7} \\
\hline & 282.5 & 347.3 & 351.2 & & & & 261.0 & 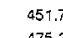 & 84.9 & 283.6 & 452.7 & 82.5 & 7.6 & 30.0 & 76.1 & 6.7 & 30.3 & 76.5 & & \\
\hline & $\begin{array}{l}236.9 \\
333 .\end{array}$ & $\begin{array}{l}338.5 \\
360.6\end{array}$ & $\begin{array}{l}456.7 \\
638.3\end{array}$ & & & & $\begin{array}{l}31.7 \\
349.1\end{array}$ & 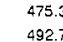 & 255.3 & 312.9 & $\begin{array}{l}476,0.0 \\
493.2\end{array}$ & $\begin{aligned} 264.7 \\
553.5\end{aligned}$ & 18.8 & $\begin{aligned} 23.0 \\
36.5\end{aligned}$ & 41,9 & $\begin{array}{r}17.2 \\
3.5\end{array}$ & 23.2 & 42.0 & & \\
\hline \multirow{4}{*}{ 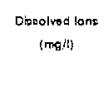 } & & & & \multirow{4}{*}{232.9} & \multirow{4}{*}{$32: .8$} & \multirow{4}{*}{304.7} & & & & & & & & & & & & & \multirow{4}{*}{20.2} & \multirow{4}{*}{20.3} \\
\hline & 227.8 & 345.6 & $\begin{array}{l}253.0 \\
2313.5\end{array}$ & & & & 199.2 & 293.7 & 170.5 & 2010.0 & 2005.2 & 169.5 & 10.8 & 15.0 & 32.6 & 9.4 & 14.6 & 33.0 & & \\
\hline & (170. & (26) & 21315 & & & & 1090 & 年 & 66.8 & $\begin{array}{l}1684 \\
2017\end{array}$ & . & (7.5 & 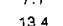 & 109 & 年, & 4.5 & 10 & 年 & & \\
\hline & 238.5 & 256.7 & 413.2 & & & & 233.2 & 322. & 368.8 & 231.7 & $\begin{array}{ll}3230.9 \\
320.9\end{array}$ & 369.7 & $\begin{array}{l}1.44 \\
1.4\end{array}$ & 25.5 & 10.8 & 2.0 & 25.0 & $\begin{array}{l}38.6 \\
10.5\end{array}$ & & \\
\hline \multirow{4}{*}{ 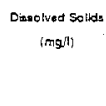 } & 1903 & 2880 & 2170 & \multirow{4}{*}{201.9} & \multirow{4}{*}{273.9} & \multirow{4}{*}{254.6} & 1759 & 3570 & 1379 & 1775 & & .277 & 75 & 108 & 365 & 67 & 104 & 358 & 215 & 215 \\
\hline & 154.8 & 199.7 & 183.7 & & & & 148,4 & 239. & 58.9 & 153.3 & 242,4 & 54.4 & 4.1 & 19.8 & & 0.9 & 21.4 & 70.4 & & \\
\hline & 154.5 & 221.7 & 241.7 & & & & 178.3 & $25 a$. & 152.0 & 179.7 & 259.6 & 151.3 & 15.4 & 16.7 & 37.1 & 16.3 & 17.1 & 37.4 & & \\
\hline & 201.0 & 210.0 & 353.3 & & & & 201.6 & 273.7 & $3 \div 8.1$ & 200.4 & 272.9 & $3+9.7$ & 0.3 & 30.3 & 10.0 & 0.3 & 30.0 & 9.8 & & \\
\hline Hardmax & 111.8 & 155 & 91.2 & 144.3 & 159.9 & 86.7 & 82 & 145. & 67.2 & 95.6 & & 55.8 & 17.0 & 8.5 & 26.3 & 14.6 & 75 & 27.9 & 20.0 & 20.0 \\
\hline 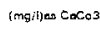 & 89.6 & 117.2 & 76.8 & & & & 76.5 & 134. & 29.5 & 81.0 & 137.2 & 27.3 & 14.5 & 14.4 & 61.4 & 9.8 & 17.0 & & & \\
\hline & 88. & 132. & 108.3 & & & & 96.2 & 147. & 77.9 & 98.8 & 149.3 & 76.8 & 9.2 & & 28.1 & 12.1 & 13.0 & 29.3 & & \\
\hline & 110.9 & 120.6 & 168.0 & & & & 117.5 & 182. & 152.8 & 115.1 & 160.4 & 153.9 & 8.0 & 34.4 & 8.0 & э.8 & 33.0 & 7.3 & & \\
\hline
\end{tabular}


Table B.2.3(c) 3 yearly

\begin{tabular}{|c|c|c|c|c|c|c|c|c|c|c|c|c|c|c|c|c|c|c|c|c|}
\hline \multirow{3}{*}{$\begin{array}{l}\text { water auathy } \\
\text { Poramelor }\end{array}$} & \multirow{2}{*}{\multicolumn{3}{|c|}{ Obourred Marn Valuear }} & \multicolumn{3}{|c|}{ Prear Hoan Valies } & \multirow{2}{*}{\multicolumn{3}{|c|}{ 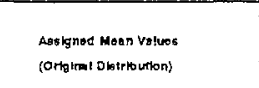 }} & \multirow{2}{*}{\multicolumn{3}{|c|}{ 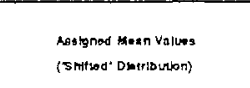 }} & \multicolumn{6}{|c|}{$\%$ Error of Prodiction } & \multicolumn{2}{|c|}{ 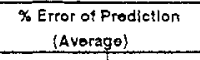 } \\
\hline & & & & \multirow{2}{*}{$\begin{array}{l}\text { Slatition } \\
196010 \\
\text { COrrgiran }\end{array}$} & \multirow{2}{*}{ 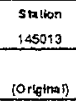 } & \multirow{2}{*}{ 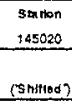 } & & & & & & & \multicolumn{3}{|c|}{ 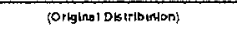 } & \multicolumn{3}{|c|}{ 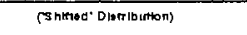 } & \multirow{2}{*}{$\begin{array}{l}\text { Orighal } \\
\text { Dratrituritan }\end{array}$} & \multirow{2}{*}{$\begin{array}{c}\text { Shuted of } \\
\text { Distribusion }\end{array}$} \\
\hline & $\begin{array}{l}\text { Stanton } \\
1465010\end{array}$ & $\begin{array}{l}\text { sintion } \\
105013\end{array}$ & $\begin{array}{l}\text { stritom } \\
145020\end{array}$ & & & & $\begin{array}{l}\text { spation } \\
1450010\end{array}$ & $\begin{array}{l}\text { sution } \\
\text { insoit }\end{array}$ & $\begin{array}{l}8 \text { station } \\
145020\end{array}$ & $\begin{array}{l}\text { Station } \\
\text { iasorot }\end{array}$ & $\begin{array}{l}85 \text { saton } \\
\text { i.45013 }\end{array}$ & 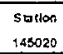 & $\begin{array}{l}\text { Sputon } \\
\text { i4so10 }\end{array}$ & $\begin{array}{l}\text { sulton } \\
1480073\end{array}$ & $\begin{array}{l}\text { Sitation } \\
\text { insosozo }\end{array}$ & $\begin{array}{l}\text { Sositon } \\
14501010\end{array}$ & $\begin{array}{l}\text { snition } \\
\text {.196013 }\end{array}$ & $\begin{array}{l}88 \text { mition } \\
145020\end{array}$ & & \\
\hline $\begin{array}{c}\text { Conductinary } \\
\text { (mS }(m)\end{array}$ & $\begin{array}{l}304.5 \\
297.90 \\
293.30\end{array}$ & $\begin{array}{l}448.22 \\
390.31 \\
338.31\end{array}$ & $\begin{array}{l}365.87 \\
449.11 \\
515.00\end{array}$ & 355.5 & 495.7 & 513.5 & $\begin{array}{l}280.80 \\
317.20 \\
318.30\end{array}$ & $\begin{array}{l}460.70 \\
478.30 \\
478.60\end{array}$ & $\begin{array}{l}12210 \\
308.70 \\
310.20\end{array}$ & $\begin{array}{l}282.5 \\
318.2 \\
318.1\end{array}$ & $\begin{array}{l}461.8 \\
478.5 \\
47.7\end{array}$ & $\begin{array}{l}119.9 \\
305.2 \\
30.8\end{array}$ & $\begin{array}{l}7.8 \\
6.7 \\
8.3\end{array}$ & $\begin{array}{l}2.8 \\
22.5 \\
44.1\end{array}$ & $\begin{array}{l}86.7 \\
31.7 \\
39.8\end{array}$ & $\begin{array}{l}7.2 \\
8.8 \\
8.6\end{array}$ & $\begin{array}{l}3.0 \\
22.6 \\
41.1\end{array}$ & $\begin{array}{l}67.3 \\
32.1 \\
40.1\end{array}$ & 25.3 & 25.4 \\
\hline $\begin{array}{c}\text { Oibalved lont } \\
\text { (magn }\end{array}$ & $\begin{array}{l}191.20 \\
192.00\end{array}$ & $\begin{array}{l}288.20 \\
271.50\end{array}$ & $\begin{array}{l}222.50 \\
275.30 \\
20050\end{array}$ & 232.9 & 321.9 & 304.7 & $\begin{array}{l}183.80 \\
211.50\end{array}$ & $\begin{array}{l}288.10 \\
304.00\end{array}$ & $\begin{array}{l}144.90 \\
237.40 \\
205\end{array}$ & $\begin{array}{l}181.6 \\
208.9\end{array}$ & $\begin{array}{l}287.3 \\
302.5\end{array}$ & $\begin{array}{l}146.1 \\
238.3\end{array}$ & $\begin{array}{l}1.4 \\
10.2 \\
5.9\end{array}$ & $\begin{array}{l}3.1 \\
11.9\end{array}$ & $\begin{array}{r}35.0 \\
13.9\end{array}$ & $\begin{array}{l}0.2 \\
9.3\end{array}$ & $\begin{array}{l}3.7 \\
11.4\end{array}$ & $\begin{array}{l}34.5 \\
13.6\end{array}$ & 15.0 & 14.5 \\
\hline $\begin{array}{l}\text { Dinsoneded Solide } \\
\text { (mgat) }\end{array}$ & $\begin{array}{l}165.80 \\
167.20 \\
173.00\end{array}$ & $\begin{array}{l}249.80 \\
223.10 \\
197.80\end{array}$ & $\begin{array}{l}192.40 \\
235.80 \\
233.30 \\
233 .\end{array}$ & 201.9 & 273.9 & 264.5 & $\begin{array}{l}187.90 \\
183.70 \\
186.10\end{array}$ & $\begin{array}{l}251.70 \\
262.10 \\
253.50\end{array}$ & $\begin{array}{r}99.90 \\
186.90 \\
203.80\end{array}$ & $\begin{array}{l}169.7 \\
184.9 \\
107.3\end{array}$ & $\begin{array}{l}253.7 \\
262.9 \\
264.4\end{array}$ & $\begin{array}{r}87.9 \\
185.3 \\
202.2\end{array}$ & $\begin{array}{l}1.2 \\
9.9 \\
7.6\end{array}$ & $\begin{array}{l}0.8 \\
17.5 \\
33.3\end{array}$ & $\begin{array}{l}48.1 \\
20.7 \\
28.1\end{array}$ & $\begin{array}{l}2.4 \\
10.6 \\
3.3\end{array}$ & $\begin{array}{r}1.3 \\
17.8 \\
33.7\end{array}$ & $\begin{array}{l}48.1 \\
27.4 \\
28.6\end{array}$ & 18.8 & 19.2 \\
\hline 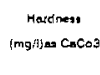 & $\begin{array}{l}95.90 \\
97.17 \\
95.25\end{array}$ & $\begin{array}{l}139.70 \\
133.60 \\
113.10\end{array}$ & $\begin{array}{r}79.93 \\
104.30 \\
129.80\end{array}$ & 114.3 & 159.9 & 86.7 & $\begin{array}{r}92.90 \\
103.00 \\
104.60\end{array}$ & $\begin{array}{l}145.40 \\
152.20 \\
153.30\end{array}$ & $\begin{array}{r}67.50 \\
100.80 \\
10.50\end{array}$ & $\begin{array}{l}85.7 \\
105.5 \\
10.7\end{array}$ & $\begin{array}{l}147.2 \\
153.9 \\
155.0\end{array}$ & $\begin{array}{c}86.2 \\
09.8 \\
105.4\end{array}$ & $\begin{array}{l}3.1 \\
6.0 \\
.8 .8\end{array}$ & $\begin{array}{l}4.8 \\
13.9 \\
35.5\end{array}$ & $\begin{array}{l}15.8 \\
3.3 \\
18.0\end{array}$ & $\begin{array}{l}0.2 \\
8.6 \\
12.4\end{array}$ & $\begin{array}{l}0.1 \\
15.2 \\
37.0\end{array}$ & $\begin{array}{l}17.2 \\
4.3 \\
18.8\end{array}$ & 12.2 & 13.3 \\
\hline
\end{tabular}

Table B.2.3(d) 4 yearly

\begin{tabular}{|c|c|c|c|c|c|c|c|c|c|c|c|c|c|c|c|c|c|c|c|c|}
\hline \multirow{3}{*}{ 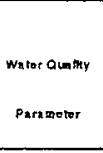 } & \multirow{2}{*}{\multicolumn{3}{|c|}{ 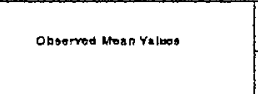 }} & \multicolumn{3}{|c|}{ Prfor Mean Vustuses. } & \multirow{2}{*}{\multicolumn{3}{|c|}{ 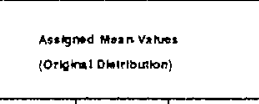 }} & \multirow{2}{*}{\multicolumn{3}{|c|}{ 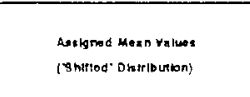 }} & \multicolumn{6}{|c|}{$\%$ Error of Prediction } & \multicolumn{2}{|c|}{$\begin{array}{r}\begin{array}{c}\text { \% Error of Prodiction } \\
\text { (Avoreggo) }\end{array} \\
\end{array}$} \\
\hline & & & & station & sulkn & sutian & & & & & & & \multicolumn{3}{|c|}{ 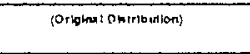 } & \multicolumn{3}{|c|}{ 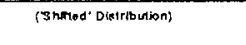 } & \multirow{2}{*}{$\begin{array}{c}\text { Oitionat } \\
\text { Dhertibution }\end{array}$} & \multirow{2}{*}{$\begin{array}{c}\text { Sritito } \\
\text { Sntriburion }\end{array}$} \\
\hline & $\begin{array}{c}\text { sention } \\
1.45010 \\
1\end{array}$ & 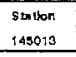 & \begin{tabular}{|l} 
Sriton \\
1945020 \\
\end{tabular} & Sorriman & (orgima) & rshotedy) & 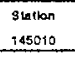 & $\begin{array}{c}\text { Statron } \\
\text { tasolis } \\
\end{array}$ & $\begin{array}{l}\text { sation } \\
\text { s. } 145020 \\
\end{array}$ & $\begin{array}{c}\text { Snalon } \\
145010 \\
\end{array}$ & 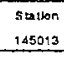 & $\begin{array}{l}5 \text { Sation } \\
\text { 1asoso20 } \\
\end{array}$ & 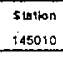 & 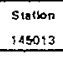 & $\begin{array}{l}51424000 \\
1.45020 \\
\end{array}$ & $\begin{array}{l}\text { stmilion } \\
\text { a. } 145010 \\
\end{array}$ & $\begin{array}{l}\text { 8:tation } \\
\text { 145013 } \\
\end{array}$ & $\begin{array}{r}\text { snation } \\
\text { iaso2020 }\end{array}$ & & \\
\hline $\begin{array}{l}\text { Conducthyty } \\
\text { (ms:min) }\end{array}$ & $\begin{array}{l}310.80 \\
310.30\end{array}$ & $\begin{array}{l}455.23 \\
353.98\end{array}$ & $\begin{array}{l}436.21 \\
494.75\end{array}$ & 355.6 & 495.7 & 513.5 & $\begin{array}{l}334.20 \\
337.20\end{array}$ & $\begin{array}{l}485.90 \\
487.20\end{array}$ & $\begin{array}{l}434.80 \\
459.00\end{array}$ & $\begin{array}{l}335.2 \\
338.1\end{array}$ & $\begin{array}{l}486.3 \\
487.8\end{array}$ & $\begin{array}{l}434.7 \\
458.9\end{array}$ & $\begin{array}{l}7.6 \\
8.7\end{array}$ & $\begin{array}{l}6.7 \\
37.6\end{array}$ & $\begin{array}{l}0.3 \\
7.2\end{array}$ & $\begin{array}{l}7.9 \\
8.9\end{array}$ & $\begin{array}{l}6.8 \\
37.8\end{array}$ & $\begin{array}{l}0.3 \\
7.2\end{array}$ & 11.4 & 11.5 \\
\hline 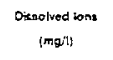 & $\begin{array}{l}199.00 \\
206.80\end{array}$ & $\begin{array}{l}308.10 \\
249.50\end{array}$ & $\begin{array}{r}287.30 \\
313.30\end{array}$ & 23.9 & 221.9 & 304.7 & $\begin{array}{l}218.8 \\
221.6\end{array}$ & $\begin{array}{l}310.10 \\
312.40\end{array}$ & $\begin{array}{l}281.20 \\
297.80\end{array}$ & $\begin{array}{l}217.3 \\
2 \geq 0.1\end{array}$ & $\begin{array}{l}308.9 \\
311.2\end{array}$ & $\begin{array}{l}282.2 \\
\approx 88.9\end{array}$ & $\begin{array}{l}9.9 \\
7.3\end{array}$ & $\begin{array}{l}1.3 \\
25.2\end{array}$ & $\begin{array}{l}5.2 \\
4.9\end{array}$ & $\begin{array}{l}9.2 \\
8.5\end{array}$ & $\begin{array}{l}0.9 \\
24.7\end{array}$ & $\begin{array}{l}5.6 \\
4.6\end{array}$ & 9.0 & 8.6 \\
\hline 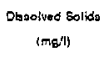 & $\begin{array}{l}172.4 \\
177.9\end{array}$ & $\begin{array}{l}254.8 \\
204.8\end{array}$ & $\begin{array}{l}228.3 \\
268.5\end{array}$ & 201.8 & 273.9 & 264.6 & $\begin{array}{r}190.6 \\
193\end{array}$ & $\begin{array}{l}266.50 \\
268.10\end{array}$ & $\begin{array}{l}236.50 \\
253.70\end{array}$ & $\begin{array}{l}191.9 \\
194.2\end{array}$ & $\begin{array}{l}267.4 \\
269.0\end{array}$ & $\begin{aligned} 235.9 \\
263.2\end{aligned}$ & $\begin{array}{l}10.6 \\
8.5\end{array}$ & $\begin{array}{c}4.6 \\
30.8\end{array}$ & $\begin{array}{l}3.1 \\
5.5\end{array}$ & $\begin{array}{l}11.3 \\
8.2\end{array}$ & $\begin{array}{l}5.0 \\
31.3\end{array}$ & $\begin{array}{l}2.9 \\
2.0\end{array}$ & 10.5 & 10.3 \\
\hline 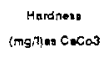 & $\begin{array}{r}100 \\
100.3\end{array}$ & $\begin{array}{l}145.6 \\
118.9\end{array}$ & $\begin{array}{l}99.78 \\
121.4\end{array}$ & $\$ 14.3$ & 159.9 & 86.7 & $\begin{array}{l}105.40 \\
107.50\end{array}$ & $\begin{array}{l}153.80 \\
155.20\end{array}$ & $\begin{array}{l}109.60 \\
116.80\end{array}$ & $\begin{array}{l}108.0 \\
110.0\end{array}$ & $\begin{array}{l}155.6 \\
156.9\end{array}$ & $\begin{array}{l}108.6 \\
115.6\end{array}$ & $\begin{array}{l}5.4 \\
7.2\end{array}$ & $\begin{array}{c}5.6 \\
30.5\end{array}$ & $\begin{array}{l}9.9 \\
3.8\end{array}$ & $\begin{array}{l}8.0 \\
9.7\end{array}$ & $\begin{array}{l}8.2 \\
32.0\end{array}$ & $\begin{array}{l}8.9 \\
4.6\end{array}$ & 10.4 & 11.7 \\
\hline
\end{tabular}


Table B.3.1 Comparison of the Use of Independent and Dependent Data in the Fitzroy River

Table B.3.1(a) 1 yearly

\begin{tabular}{|c|c|c|c|c|c|c|c|c|c|c|c|c|c|}
\hline \multirow{2}{*}{$\begin{array}{c}\text { Wator Quatlly } \\
\text { Paramotor }\end{array}$} & \multirow{2}{*}{$\begin{array}{l}\text { Correlation } \\
\text { Coefitioiont } \\
\text { botwan the } \\
\text { two stations }\end{array}$} & \multirow{2}{*}{\multicolumn{2}{|c|}{ Oboorvod Mann Values }} & \multirow{2}{*}{\multicolumn{2}{|c|}{$\begin{array}{l}\text { Assigned Moen Values } \\
\text { (Independent Data) }\end{array}$}} & \multirow{2}{*}{\multicolumn{2}{|c|}{$\begin{array}{c}\text { Aseignod Moan Yaluos } \\
\text { (Dependent Data) }\end{array}$}} & \multicolumn{4}{|c|}{$\%$ Error of Prediction } & \multicolumn{2}{|c|}{$\begin{array}{c}\text { \% Error of Prediction } \\
\text { (Average) }\end{array}$} \\
\hline & & & & & & & & \multicolumn{2}{|c|}{ (Indepondent Data) } & \multicolumn{2}{|c|}{ (Dopendent Data) } & $\begin{array}{c}\text { Incependent } \\
\text { Date }\end{array}$ & \begin{tabular}{|c|c|} 
Dependent \\
Oata
\end{tabular} \\
\hline \multirow{2}{*}{$\begin{array}{c}\text { Conductivity } \\
(m S / m)\end{array}$} & 0.437 & 210.00 & 222.50 & 256.53 & 202.44 & 267.7 & 196.8 & 26.9 & 9.0 & 27.5 & 11.6 & \multirow[t]{2}{*}{21.6} & \multirow[t]{2}{*}{22.8} \\
\hline & & 270.00 & 248.75 & 218.82 & 200.64 & 221.8 & 187.0 & 19.0 & 19.3 & 17.8 & 24.8 & & \\
\hline \multirow{3}{*}{$\begin{array}{l}\text { Dissolved lons } \\
\text { (mgl) }\end{array}$} & 0.371 & 183.90 & 159.80 & 182.73 & 147.15 & 183.6 & 143.3 & 0.5 & 7.9 & 0.2 & 10.3 & \multirow[t]{3}{*}{16.2} & \multirow[t]{3}{*}{17.1} \\
\hline & & 128.00 & 144.55 & 203.36 & 147.99 & 203.5 & 147.2 & 58.9 & 2.4 & 59.0 & 1.8 & & \\
\hline & & 165.55 & 175.30 & 148.57 & 145.76 & 150.5 & 136.9 & 10.3 & 16.9 & 9.1 & 21.9 & & \\
\hline \multirow{2}{*}{$\begin{array}{c}\text { Dissolved Solids } \\
(\mathrm{mg} / \mathrm{l})\end{array}$} & & 110.00 & 110.00 & 167.49 & 122.44 & 167.6 & 121.8 & 52.3 & 11.3 & 52.4 & 10.7 & \multirow{2}{*}{18.5} & \multirow{2}{*}{19.7} \\
\hline & & 140.00 & 137.50 & 126.14 & 120.37 & 127.8 & 112.8 & 9.9 & 12.5 & 8.7 & 18.0 & & \\
\hline \multirow{3}{*}{$\begin{array}{c}\text { Marreness } \\
\text { (mg/h)as } \mathrm{CaCO3}\end{array}$} & 0.533 & 01.00 & 57.50 & 69.99 & 52.99 & 70.5 & 50.4 & 14.7 & 7.8 & 15.6 & 12.3 & \multirow[t]{3}{*}{18.5} & \multirow[t]{3}{*}{20.1} \\
\hline & & 55.00 & 59.50 & 85.69 & 53.23 & 85.8 & 52.8 & 55.8 & 3.4 & 56.0 & 2.5 & & \\
\hline & & 65.50 & 66.50 & 59.68 & 52.82 & 60.6 & 48.8 & 8.9 & 20.6 & 7.5 & 26.6 & & \\
\hline
\end{tabular}


Table B.3.1(b) 2 yearly

\begin{tabular}{|c|c|c|c|c|c|c|c|c|c|c|c|c|c|}
\hline \multirow{3}{*}{$\begin{array}{c}\text { Woter Qunalty } \\
\text { Parameator } \\
\end{array}$} & \multirow{3}{*}{$\begin{array}{l}\text { Corrolation } \\
\text { Coofflioiont } \\
\text { botwoon tho } \\
\text { two stations }\end{array}$} & \multirow{2}{*}{\multicolumn{2}{|c|}{ Observod Maan Valuos }} & \multirow{2}{*}{\multicolumn{2}{|c|}{$\begin{array}{l}\text { Assigned Moant Values } \\
\text { (Indopendont Data) }\end{array}$}} & \multirow{2}{*}{\multicolumn{2}{|c|}{$\begin{array}{l}\text { Assignod Mean Vaitus } \\
\text { (Dopondont Data) } \\
\end{array}$}} & \multicolumn{4}{|c|}{ \%o Error of Pradiction } & \multicolumn{2}{|c|}{$\begin{array}{l}\text { \% Error of Prediction } \\
\text { (Average) }\end{array}$} \\
\hline & & & & & & & & \multicolumn{2}{|c|}{ (indopendont Data) } & \multicolumn{2}{|c|}{ (Dependon! Data) } & \multirow{2}{*}{$\begin{array}{c}\text { Independent } \\
\text { Dete }\end{array}$} & \multirow{2}{*}{$\begin{array}{c}\text { Dependent } \\
\text { Data }\end{array}$} \\
\hline & & Station 130105 & Station 130202 & Station 130105 & Stetton 130202 & Station 130105 & Station 130202 & Stetion 130105 & Station 130208 & Station 130105 & Station 130202 & & \\
\hline $\begin{array}{c}\text { Conductivlyy } \\
\text { (ms } / m)\end{array}$ & 0.437 & $\begin{array}{l}205.00 \\
235.00\end{array}$ & $\begin{array}{l}208.75 \\
221.88\end{array}$ & $\begin{array}{l}287.19 \\
262.95\end{array}$ & $\begin{array}{l}203.22 \\
202.31\end{array}$ & $\begin{array}{l}288.1 \\
265.5\end{array}$ & $\begin{array}{l}199.0 \\
190.7\end{array}$ & $\begin{array}{l}40.1 \\
11.9\end{array}$ & $\begin{array}{l}2.6 \\
\delta .8\end{array}$ & $\begin{array}{l}40.5 \\
13.0\end{array}$ & $\begin{array}{c}4.7 \\
14.0\end{array}$ & 15.9 & 18.1 \\
\hline $\begin{array}{l}\text { Dissolved ions } \\
\text { (mgh) }\end{array}$ & 0.371 & $\begin{array}{l}155.95 \\
146.78\end{array}$ & $\begin{array}{l}152.18 \\
159.93\end{array}$ & $\begin{array}{l}194.82 \\
178.11\end{array}$ & $\begin{array}{l}147.64 \\
146.97\end{array}$ & $\begin{array}{l}195.7 \\
180.1\end{array}$ & $\begin{array}{l}143.6 \\
138.1\end{array}$ & $\begin{array}{l}24.9 \\
21.3\end{array}$ & $\begin{array}{l}3.0 \\
8.1\end{array}$ & $\begin{array}{l}25.5 \\
22.7\end{array}$ & $\begin{array}{c}5.6 \\
13.7\end{array}$ & 14.3 & $16.9^{\circ}$ \\
\hline $\begin{array}{c}\text { Dissolvet Solids } \\
\text { (mg } / /)\end{array}$ & 0.391 & $\begin{array}{l}116.50 \\
125.00\end{array}$ & $\begin{array}{l}117.50 \\
123.75\end{array}$ & $\begin{array}{l}159.93 \\
147.80\end{array}$ & $\begin{array}{l}122.06 \\
121.46\end{array}$ & $\begin{array}{l}150.7 \\
149.4\end{array}$ & $\begin{array}{l}118.6 \\
114.4\end{array}$ & $\begin{array}{l}37.3 \\
18.2\end{array}$ & $\begin{array}{l}3.9 \\
1.9\end{array}$ & $\begin{array}{l}37.9 \\
19.5\end{array}$ & $\begin{array}{l}1.0 \\
7.6\end{array}$ & 15.3 & 16.5 \\
\hline 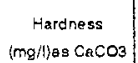 & 0.533 & $\begin{array}{l}58.00 \\
60.25\end{array}$ & $\begin{array}{l}54.50 \\
58.00\end{array}$ & $\begin{array}{l}78.96 \\
74.15\end{array}$ & $\begin{array}{l}53.13 \\
53.05\end{array}$ & $\begin{array}{l}79.4 \\
74.8\end{array}$ & $\begin{array}{l}51.2 \\
50.1\end{array}$ & $\begin{array}{l}36.1 \\
23.1\end{array}$ & $\begin{array}{r}2.5 \\
10.1\end{array}$ & $\begin{array}{l}36.9 \\
24.2\end{array}$ & $\begin{array}{c}6.0 \\
15.1\end{array}$ & 18.0 & 20.5 \\
\hline
\end{tabular}

Table B.3.1(c) 3 yearly

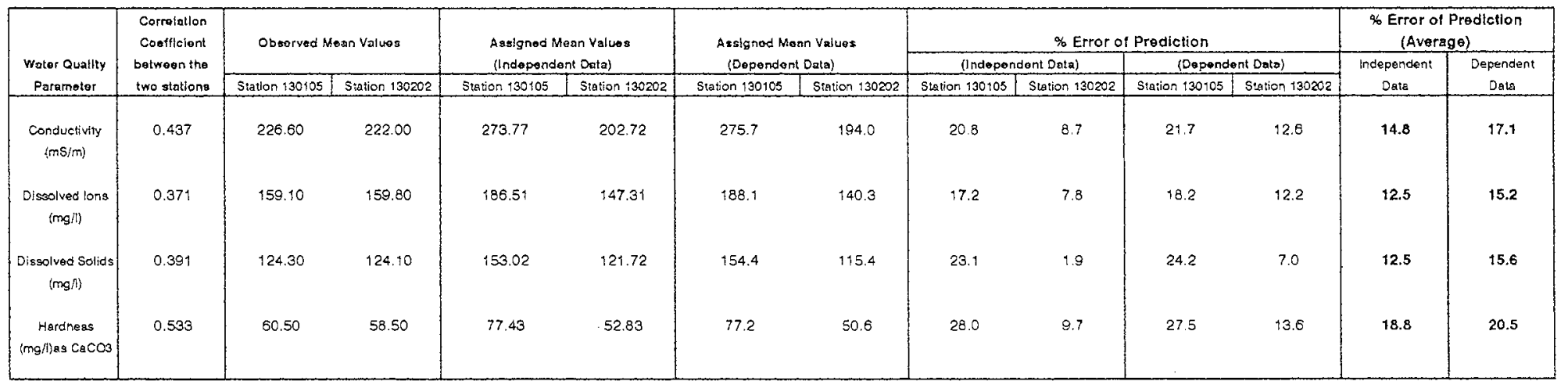


Table B.3.2 Comparison of the Use of Independent and Dependent Data in the Nogoa River

Table B.3.2(a) 1 yearly

\begin{tabular}{|c|c|c|c|c|c|c|c|c|c|c|c|c|c|}
\hline \multirow{3}{*}{$\begin{array}{c}\text { Waver Ouwility } \\
\text { Patramerior }\end{array}$} & \multirow{3}{*}{ 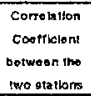 } & \multicolumn{2}{|c|}{ oboerved masan valueas } & \multirow{2}{*}{\multicolumn{2}{|c|}{ 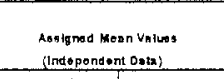 }} & \multirow{2}{*}{\multicolumn{2}{|c|}{ 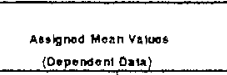 }} & \multicolumn{4}{|c|}{$\%$ Error of Prodlation } & \multicolumn{2}{|c|}{$\begin{array}{l}\text { \% Error of Prodiction } \\
\text { A4vorgage) }\end{array}$} \\
\hline & & & & & & & & \multirow{2}{*}{\multicolumn{2}{|c|}{ 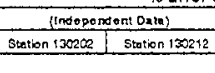 }} & \multirow{2}{*}{\multicolumn{2}{|c|}{ 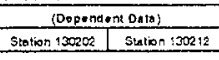 }} & \multirow{2}{*}{$\begin{array}{l}\text { Indopondiden } \\
\text { Date } \\
\end{array}$} & \multirow{2}{*}{ 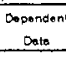 } \\
\hline & & & & & & & & & & & & & \\
\hline \multirow{5}{*}{$\begin{array}{l}\text { Conductinty } \\
\text { (mSIm) }\end{array}$} & 0.570 & 425.0 & 199.3 & 285.6 & 208.5 & 210.0 & 179.9 & 32.8 & 3.5 & 50.6 & & \multirow{5}{*}{10.8} & \multirow{5}{*}{21.0} \\
\hline & & 318.7 & 211.3 & 298.7 & 209.3 & 232.2 & 236.4 & 5.7 & 0.9 & 26.7 & 11.9 & & \\
\hline & & 332.5 & 206.7 & 261.8 & 201.5 & 219.5 & 203.5 & 21.3 & 2.5 & 34.0 & 1.5 & & \\
\hline & & 283.3 & 242.5 & 271.4 & 203.5 & 211.6 & 1829 & 4.2 & 16.1 & 25.3 & 24.6 & & \\
\hline & & 276.7 & 185.0 & 203.3 & 208.1 & 211,2 & 182.0 & 8.0 & 12.5 & 23.7 & 1.5 & & \\
\hline \multirow{5}{*}{$\begin{array}{c}\text { Dincoivod lono } \\
\text { (matl) }\end{array}$} & 0.433 & 200.8 & 151.0 & 199.2 & 159.4 & 156.2 & 144.9 & 0.8 & 5.6 & 22.2 & 4.1 & \multirow{5}{*}{7.7} & \multirow{5}{*}{11.3} \\
\hline & & 200.7 & 163,3 & 188.7 & 155.0 & 178.4 & 163.9 & 6.0 & 5.1 & 11.3 & 0.4 & & \\
\hline & & 219.3 & 161.3 & 182.2 & 152.3 & 158.6 & 152.2 & 16.9 & 5.6 & 27.7 & 5.7 & & \\
\hline & & $\begin{array}{l}176.7 \\
182.6\end{array}$ & $\begin{array}{l}166.2 \\
160.2\end{array}$ & $\begin{array}{l}182.1 \\
214.4\end{array}$ & $\begin{array}{l}152,2 \\
156,5\end{array}$ & $\begin{array}{l}158.8 \\
155.8\end{array}$ & 146.6 & 3.1 & 8.4 & 11.3 & 11.8 & & \\
\hline & & & & & & & 143.7 & 15.7 & 9.5 & 14.7 & 4.4 & & \\
\hline \multirow{5}{*}{$\begin{array}{l}\text { Denolived solitas } \\
\text { (minsil) }\end{array}$} & 0.530 & 218.5 & 114.8 & 149.1 & 115.9 & 119.3 & 115.8 & 31,8 & 0.9 & 45,4 & 0.8 & \multirow{5}{*}{11.0} & \multirow{5}{*}{19.2} \\
\hline & & 173.3 & 122.5 & 162.5 & 120.6 & & 140.9 & 6.2 & 1.5 & 24.8 & 15.1 & & \\
\hline & & 185.0 & 123.3 & 138.1 & 112.0 & 121.0 & 19.6 & 25.4 & 9.2 & 34.6 & 3.0 & & \\
\hline & & 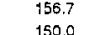 & $\begin{array}{l}140.0 \\
1100\end{array}$ & $\begin{array}{l}150,3 \\
150.4\end{array}$ & $\begin{array}{l}116.3 \\
1119\end{array}$ & $\begin{array}{l}117.2 \\
1110\end{array}$ & 111.5 & $\begin{array}{l}4.1 \\
56\end{array}$ & $\begin{array}{l}16.9 \\
8.3\end{array}$ & $\begin{array}{l}25.2 \\
220\end{array}$ & $\begin{array}{l}20.4 \\
0.9\end{array}$ & & \\
\hline & & 150.0 & 110.0 & 158.4 & 119.2 & 117.0 & 111.0 & 5.6 & 8.3 & 22.0 & 0.9 & & \\
\hline \multirow{5}{*}{ 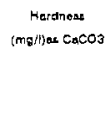 } & 0.478 & 106.5 & 58.8 & 82.7 & 70.4 & 68.3 & 63.6 & 22.4 & 19.5 & 34.8 & 8.0 & \multirow{5}{*}{12.6} & \multirow{5}{*}{9.5} \\
\hline & & 83.3 & 72.5 & 74.1 & 67.0 & 72.3 & 73.6 & 11.0 & 7.6 & 13.3 & 1.5 & & \\
\hline & & 83.5 & 82.0 & 75.2 & 67.4 & 69.7 & 65.0 & 9.9 & 8.7 & 16.5 & 4.8 & & \\
\hline & & 72.0 & 65.5 & 72.6 & 66.3 & 69.9 & 65.3 & 0.8 & 1.3 & 3.0 & 0.3 & & \\
\hline & & 75.7 & 51.0 & 93.0 & 74.5 & 69.3 & 63.6 & 22.9 & 22.7 & 8.4 & 4,2 & & \\
\hline
\end{tabular}

Table B.3.2(b) 2 yearly

\begin{tabular}{|c|c|c|c|c|c|c|c|c|c|c|c|c|c|}
\hline \multirow{3}{*}{ 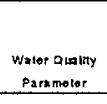 } & \multirow{3}{*}{ 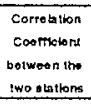 } & \multirow{2}{*}{\multicolumn{2}{|c|}{ 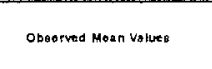 }} & \multirow{2}{*}{\multicolumn{2}{|c|}{ 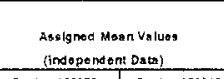 }} & \multirow{2}{*}{\multicolumn{2}{|c|}{ 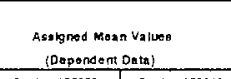 }} & \multicolumn{4}{|c|}{ \% Error of Prodletion } & \multicolumn{2}{|c|}{$\begin{array}{l}\text { \% Error of Proditectlon } \\
\text { (Avoragso) }\end{array}$} \\
\hline & & & & & & & & \multicolumn{2}{|c|}{ 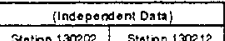 } & \multirow{2}{*}{\multicolumn{2}{|c|}{ 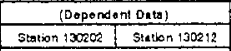 }} & \multirow{2}{*}{ 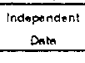 } & \multirow{2}{*}{ 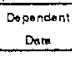 } \\
\hline & & Station 130202 & Station 100012 & Statibr: 130202 & Siation 1300212 & & I station 130212 12 & Sataton 130202 & Lstation 13002 t2 & & & & \\
\hline \multirow{4}{*}{$\begin{array}{l}\text { Conductiny } \\
\text { (nsim) }\end{array}$} & 0.628 & 370.8 & 205.3 & 306.1 & 210.8 & 219.9 & 205.6 & 17.5 & 2.7 & 40.7 & 0.2 & \multirow{4}{*}{6.7} & \multirow{4}{*}{20.4} \\
\hline & & 324.6 & 209.0 & 295.7 & 208.6 & 224.9 & 218.1 & 8.8 & 0.2 & 30.7 & 4.4 & & \\
\hline & & 307.8 & 224.6 & 289.7 & 206.1 & 214.0 & 190.4 & 7.9 & 8.2 & 30.5 & 15.2 & & \\
\hline & & 280.0 & 213.8 & 297.5 & 209.1 & 200.5 & 179.2 & 6.2 & 2.2 & 25.1 & 16.2 & & \\
\hline \multirow{4}{*}{$\begin{array}{c}\text { Disootived lons } \\
\text { ima?i] }\end{array}$} & 0.468 & 200.7 & 157.2 & 208.2 & 163.2 & 161.6 & 161.6 & 3.7 & 3.8 & 19.5 & 2.8 & \multirow{4}{*}{4.6} & \multirow{4}{*}{12.6} \\
\hline & & 210.0 & 152.3 & 201.7 & 160.4 & 162.8 & 165.4 & 4.0 & 1.2 & 22.5 & 1.9 & & \\
\hline & & 198.0 & 163.7 & 198.1 & 150.4 & 156.7 & 147.2 & 0.6 & 2.7 & 20.9 & 10.1 & & \\
\hline & & 179.7 & 158.2 & 210.4 & 184.0 & 155.2 & 142.8 & 17.1 & 3.7 & 13.6 & 9.7 & & \\
\hline \multirow{4}{*}{ 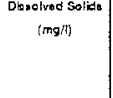 } & 0.570 & 195.8 & 118.7 & 173.6 & 124,4 & 124.7 & 188.0 & 11.4 & 4.8 & 38.3 & 7.9 & \multirow{4}{*}{5.8} & \multirow{4}{*}{18.9} \\
\hline & & & :22.9 & 169.3 & 122.9 & 155.6 & 130.1 & 5.5 & 0.0 & 29.9 & 5.8 & & \\
\hline & & 170.8 & & 164.6 & 121.3 & 118.7 & 114.7 & 3.7 & 7.9 & 30.5 & 12.8 & & \\
\hline & & 153.3 & $\{25.0$ & 172.4 & 124.0 & 116.7 & 110,2 & 12.5 & 0.8 & 23.9 & 11.8 & & \\
\hline \multirow{4}{*}{ 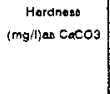 } & 0.404 & 94.9 & 65.7 & 97.2 & 72.2 & 59.9 & 64.8 & 8.2 & 9.9 & 26.4 & 1.4 & \multirow{4}{*}{10.3} & \multirow{4}{*}{9.2} \\
\hline & & 83.4 & 87.3 & 84.4 & 71.1 & 70.9 & 65.6 & 1.2 & 5.7 & 15.9 & 2.5 & & \\
\hline & & 77.8 & 63.8 & 83.8 & 70.9 & 68.8 & 81.0 & 7.8 & 112 & 11.5 & & & \\
\hline & & 73.8 & 63.3 & 90.4 & 73.5 & 68.6 & 60.2 & 22.4 & 16.2 & 7,1 & 4.8 & & \\
\hline
\end{tabular}


Table B.3.2(c) 3 yearly

\begin{tabular}{|c|c|c|c|c|c|c|c|c|c|c|c|c|c|}
\hline \multirow{3}{*}{$\begin{array}{c}\text { Wator Quallty } \\
\text { Parameter }\end{array}$} & \multirow{3}{*}{ 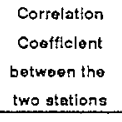 } & \multirow{2}{*}{\multicolumn{2}{|c|}{ Observed Mean Values }} & \multirow{2}{*}{\multicolumn{2}{|c|}{$\begin{array}{l}\text { Assigned Mean Values } \\
\text { (Independent Data) }\end{array}$}} & \multirow{2}{*}{\multicolumn{2}{|c|}{$\begin{array}{c}\text { Asslgned Moan Va:ues } \\
\text { (Dependent Data) }\end{array}$}} & \multicolumn{4}{|c|}{ \% Error of Prediction } & \multicolumn{2}{|c|}{$\begin{array}{l}\text { \% Error of Prediction } \\
\text { (Average) }\end{array}$} \\
\hline & & & & & & & & \multicolumn{2}{|c|}{ (Independent Data) } & \multicolumn{2}{|c|}{ (Dopendent Data) } & \multirow{2}{*}{$\begin{array}{c}\text { Independent } \\
\text { Data } \\
\end{array}$} & \multirow{2}{*}{$\begin{array}{c}\text { Dependen } \\
\text { Data } \\
\end{array}$} \\
\hline & & Station 130202 & Station 130212 & Station 130202 & Station 130212 & Station 130202 & Stetion 130212 & Station 130202 & Station 130212 & Station 130202 & Station 130212 & & \\
\hline \multirow{3}{*}{$\begin{array}{l}\text { Conductivity } \\
\text { (ms }(m)\end{array}$} & 0.802 & 358.1 & 205.8 & 306.7 & 210.9 & 216.0 & 198.2 & 14.4 & 2.5 & 39.7 & 3.7 & \multirow{3}{*}{4.3} & \multirow{3}{*}{21.3} \\
\hline & & 310.8 & 220.1 & 302.7 & 210.1 & $210 \hat{0}$ & 199.5 & 2.6 & 4.5 & 30.3 & 9.4 & & \\
\hline & & 297.5 & 211.4 & 301.2 & 209.8 & 208.6 & 179.9 & 1.2 & 0.8 & 28.9 & 14.9 & & \\
\hline \multirow{3}{*}{$\begin{array}{l}\text { Dissolved lons } \\
\quad(\mathrm{mg} / \mathrm{l})\end{array}$} & 0.669 & 206.9 & 158.5 & 208.0 & 163.0 & 157.3 & 152.5 & 0.5 & 2.8 & 24.0 & 3.8 & \multirow{3}{*}{3.1} & \multirow{3}{*}{14.7} \\
\hline & & 198.9 & 163.6 & 203.7 & 161.2 & 157.5 & 153.2 & 2.4 & 1.5 & 20.8 & 6.4 & & \\
\hline & & 192.9 & 159.2 & 209.5 & 163.6 & 152.6 & 139.5 & 8.6 & 2.8 & 20.9 & 12.4 & & \\
\hline \multirow{3}{*}{$\begin{array}{c}\text { Dissolved Solids } \\
\text { (mg;"l) }\end{array}$} & 0.746 & 192.3 & 120.2 & 168.1 & 122.5 & 121.5 & 121.9 & 12.6 & 1.9 & 36.8 & 1.4 & \multirow{3}{*}{4.2} & \multirow{3}{*}{19.3} \\
\hline & & 171.7 & 128.6 & 168.4 & 122.6 & 120.8 & 120.2 & 1.9 & 4.7 & 29.7 & 6.6 & & \\
\hline & & 163.9 & 124.4 & 167.4 & 122.3 & 115.7 & 109.3 & 2.1 & 1.7 & 29.4 & 12.2 & & \\
\hline \multirow{3}{*}{$\begin{array}{c}\text { Hardness } \\
\left(\mathrm{mg} / \text { /)as } \mathrm{C}_{\mathrm{B}} \mathrm{CO}_{\mathrm{O}}\right.\end{array}$} & 0.515 & 91.1 & 64.4 & 88.9 & 72.9 & 68.5 & 61.1 & 2.4 & 13.2 & 24.8 & 5.2 & \multirow{3}{*}{11.2} & \multirow{3}{*}{11.9} \\
\hline & & 79.6 & 66.7 & 86.5 & 71.9 & 68.7 & 61.9 & 8.7 & 7.8 & 13.7 & 7.3 & & \\
\hline & & 77.1 & 62.8 & 90.9 & 73.7 & 67.5 & 57.9 & 17.9 & 17.4 & 12.5 & 7.8 & & \\
\hline
\end{tabular}

Table B.3.2(d) 4 yearly

\begin{tabular}{|c|c|c|c|c|c|c|c|c|c|c|c|c|c|}
\hline \multirow{3}{*}{$\begin{array}{l}\text { Wator Quallty } \\
\text { Parameter }\end{array}$} & \multirow{3}{*}{$\begin{array}{c}\text { Corroiation } \\
\text { Coofflciont } \\
\text { betweon the } \\
\text { iwo stations }\end{array}$} & \multirow{2}{*}{\multicolumn{2}{|c|}{ Observed Mean Values }} & \multirow{2}{*}{\multicolumn{2}{|c|}{$\begin{array}{l}\text { Assigned Moan Valuos } \\
\text { (IIndopendert Data) }\end{array}$}} & \multirow{2}{*}{\multicolumn{2}{|c|}{$\begin{array}{c}\text { Assignod Moan Values } \\
\text { (Dopondent Data) }\end{array}$}} & \multicolumn{4}{|c|}{$\%$ Error of Prediction } & \multicolumn{2}{|c|}{$\begin{array}{l}\text { \% Error of Prediction } \\
\text { (Average) }\end{array}$} \\
\hline & & & & & & & & \multicolumn{2}{|c|}{ (Indopondent Data) } & \multicolumn{2}{|c|}{ (Dapandont Data) } & \multirow{2}{*}{$\begin{array}{c}\text { Independent } \\
\text { Data }\end{array}$} & \multirow{2}{*}{$\begin{array}{c}\text { Dependen } \\
\text { Disia } \\
\end{array}$} \\
\hline & & Station 130202 & Station 130212 & Station 130202 & Steticn 130212 & Station: 130202 & Station 130212 & Station 130202 & Station 130212 & Station 130202 & Station 1302:2 & & \\
\hline Conductivity & 0.705 & 339.4 & 214.8 & 318.6 & 213.4 & 216.1 & 195.8 & 6.1 & 0.7 & 36.3 & 8.9 & 3.5 & 20.1 \\
\hline$(m S / m)$ & & 302.3 & 211.4 & 320.1 & 213.7 & 216.1 & 197.2 & 5.9 & 1.1 & 28.5 & 6.7 & & \\
\hline Dissolved lons & 0.578 & 199.4 & 160.4 & 215.9 & 165.4 & 157.7 & 152.8 & 8.3 & 3.7 & 209 & 4.7 & 7.1 & 12.5 \\
\hline$(\mathrm{mg} / /)$ & & 194.8 & 160.3 & 218.0 & 167.2 & 157.6 & 152.2 & 11.9 & 4.3 & 19.1 & 5.1 & & \\
\hline Dissolved Solids & 0.700 & 183.4 & 125.2 & 171.0 & 123.5 & 120.7 & 119.9 & 6.8 & 1.4 & 34.2 & 4.2 & 3.0 & 17.6 \\
\hline$(\mathrm{mg} n)$ & & 166.3 & 124.0 & 172.8 & 124.2 & 120.1 & 118.6 & 3.9 & 0.2 & 27.8 & 4.4 & & \\
\hline Mardness & 0.168 & 86.3 & 64.7 & 92.3 & 74.2 & 71.1 & 66.2 & 6.9 & 14.7 & 17.7 & 2.3 & 13.9 & 7.7 \\
\hline (mg/l): $\mathrm{as} \mathrm{CaCO}_{3}$ & & 78.6 & 65.3 & 93.9 & 74.9 & 71.1 & 66.2 & 19.4 & 14.7 & 9.6 & 1.3 & & \\
\hline
\end{tabular}


Table B.4.1 Evaluation of the Water Quality Values in the Fitzroy River Basin

Table B.4.1(a) Station 130105

Historical (prior) Mean Values

\begin{tabular}{|c|c|c|c|c|c|c|c|c|c|c|}
\hline & $\begin{array}{c}\text { Conductivity } \\
@ 25 \mathrm{C} \\
(\mathrm{ms} / \mathrm{m}) \\
\end{array}$ & $\mathrm{PH}$ & $\begin{array}{c}\text { Dissolved } \\
\text { lons } \\
\text { (mgn) } \\
\end{array}$ & $\begin{array}{c}\text { Dissolved } \\
\text { Solids } \\
\text { (mg/l) } \\
\end{array}$ & $\begin{array}{c}\text { Hardness } \\
\text { (mg/l)as } \mathrm{CaCO} 3 \\
\end{array}$ & $\begin{array}{c}\text { Alkalinity } \\
\text { (mgf)as } \mathrm{CaCO} 3 \\
\end{array}$ & $\begin{array}{l}\text { Natrium } \\
\text { (mgfl) }\end{array}$ & $\begin{array}{l}\text { Kalium } \\
(m g /)\end{array}$ & $\begin{array}{l}\text { Calcium } \\
(\mathrm{mg} /)\end{array}$ & $\begin{array}{l}\text { Magnesium } \\
\text { (mg/i) }\end{array}$ \\
\hline Mean $\quad(\bar{X} n)$ & 301.3 & 7.8 & 208.8 & 171.4 & 86.8 & 87.3 & 25.2 & 3.2 & 18.9 & 9.4 \\
\hline $\begin{array}{l}\text { Standard (s) } \\
\text { Deviation }\end{array}$ & 105.7 & 0.3 & 65.7 & 52.0 & 32.1 & 23.7 & 10.0 & 0.7 & 6.9 & 3.6 \\
\hline
\end{tabular}

[1 Yearly Averaging]

New/Predicted Mean Values

\begin{tabular}{|c|c|c|c|c|c|c|c|c|c|c|}
\hline & $\begin{array}{c}\text { Conductivity } \\
\text { (a) } 25 \mathrm{C} \\
\text { (msim) }\end{array}$ & $\mathrm{PH}$ & $\begin{array}{c}\text { Dissolved } \\
\text { lans } \\
(\mathrm{mg} / \mathrm{l})\end{array}$ & $\begin{array}{l}\text { Dissolved } \\
\text { Solids } \\
\text { (mg/I) }\end{array}$ & $\begin{array}{c}\text { Hardness } \\
\text { (mg/l)as CaCO3 }\end{array}$ & $\begin{array}{c}\text { Alkalinity } \\
\text { (mg/)as } \mathrm{CaCO}\end{array}$ & $\begin{array}{l}\text { Natrium } \\
\text { (mgi) }\end{array}$ & $\begin{array}{l}\text { Kalium } \\
(\mathrm{mg} / \mathrm{l})\end{array}$ & $\begin{array}{l}\text { Calcium } \\
(\mathrm{mg} / 1) \\
\end{array}$ & $\begin{array}{l}\text { Magnesium } \\
\text { (mg/i) }\end{array}$ \\
\hline $\begin{array}{c}\text { OBSERVED } \\
\text { (Xno) }\end{array}$ & $\begin{array}{l}210.0 \\
200.0 \\
270.0\end{array}$ & $\begin{array}{l}7.7 \\
7.1 \\
7.9\end{array}$ & $\begin{array}{l}183.9 \\
128.0 \\
165.6\end{array}$ & $\begin{array}{l}123.0 \\
110.0 \\
140.0\end{array}$ & $\begin{array}{l}61.0 \\
55.0 \\
65.5\end{array}$ & $\begin{array}{l}69.0 \\
51.0 \\
70.5\end{array}$ & $\begin{array}{l}15.8 \\
15.5 \\
22.0\end{array}$ & $\begin{array}{l}4.0 \\
2.8 \\
2.5\end{array}$ & $\begin{array}{r}14.3 \\
13.0 \\
14.0\end{array}$ & $\begin{array}{l}6.1 \\
5.5 \\
7.4\end{array}$ \\
\hline (xno) & 228.7 & 7.6 & 159.2 & 124.3 & 60.5 & 63.5 & 17.8 & 3.1 & 13.8 & 6.3 \\
\hline $\begin{array}{c}\text { ENTROPY } \\
\text { (Xne) }\end{array}$ & $\begin{array}{l}266.5 \\
301.4 \\
218.8\end{array}$ & $\begin{array}{l}7.8 \\
7.7 \\
7.7\end{array}$ & $\begin{array}{l}182.7 \\
203.4 \\
148.6\end{array}$ & $\begin{array}{l}150.3 \\
167.5 \\
126.1\end{array}$ & $\begin{array}{l}70.0 \\
85.7 \\
59.7\end{array}$ & $\begin{array}{l}77.7 \\
81.3 \\
62.5\end{array}$ & $\begin{array}{l}22.0 \\
24.7 \\
17.5\end{array}$ & $\begin{array}{l}3.4 \\
3.3 \\
3.1\end{array}$ & $\begin{array}{r}15.8 \\
19.3 \\
12.9\end{array}$ & $\begin{array}{l}7.4 \\
9.1 \\
6.5\end{array}$ \\
\hline$(\bar{X} n e)$ & 262.3 & 7.7 & 178.2 & 148.0 & 71.8 & 73.8 & 21.4 & 3.3 & 16.0 & 7.7 \\
\hline
\end{tabular}

Number of Standard Deviations of the Distribution of Sampled Means by which the New/Predicted Mean Values lies from the Historical Mean Values

\begin{tabular}{|c|c|c|c|c|c|c|c|c|c|c|}
\hline & $\begin{array}{c}\text { Conductivity } \\
@ 25 \mathrm{C} \\
\text { (ms/m) }\end{array}$ & $\mathrm{PH}$ & $\begin{array}{c}\text { Dissolved } \\
\text { lons } \\
\text { (mg/i) }\end{array}$ & $\begin{array}{c}\text { Dissolved } \\
\text { Solids } \\
(\mathrm{mg} /) \\
\end{array}$ & $\begin{array}{c}\text { Hardhess } \\
\text { (mg/h)as } \mathrm{CaCO} 3 \\
\end{array}$ & $\begin{array}{c}\text { Alkalinity } \\
\text { (mg/)as } \mathrm{CaCO} 3\end{array}$ & $\begin{array}{l}\text { Natrium } \\
\text { (ing/f) }\end{array}$ & $\begin{array}{l}\text { Kalium } \\
(\mathrm{mg} n)\end{array}$ & $\begin{array}{l}\text { Calcium } \\
(m g /)\end{array}$ & $\begin{array}{c}\text { Magnesium } \\
\text { (mgfi) } \\
\end{array}$ \\
\hline $\begin{array}{c}\text { OBSERVED } \\
(\bar{X} \cap \overline{-}-\bar{X} h) /[s / N n]\end{array}$ & -1.22 & -1.79 & -1.31 & -1.57 & -1.42 & -1.74 & -1.28 & -0.19 & -1.30 & -1.47 \\
\hline $\begin{array}{c}\text { ENTROPY } \\
\left(\bar{X}_{n} n-\bar{X} n\right) /[s / \mathrm{Nn} \mid\end{array}$ & -0.64 & -0.56 & -0.81 & -0.78 & -0.81 & -0.99 & -0.65 & 0.23 & -0.74 & -0.84 \\
\hline
\end{tabular}


Table B.4.1(a) (continued)

\section{[2 Yearly Averaging]}

New/Predicted Mean Values

\begin{tabular}{|c|c|c|c|c|c|c|c|c|c|c|}
\hline & $\begin{array}{c}\text { Conductivity } \\
@ 25 \mathrm{C} \\
(\mathrm{ms} / \mathrm{m}) \\
\end{array}$ & $\mathrm{PH}$ & $\begin{array}{c}\text { Dissolved } \\
\text { Ions } \\
\text { (mgn) } \\
\end{array}$ & $\begin{array}{c}\text { Dissolved } \\
\text { Solids } \\
\text { (mg/) } \\
\end{array}$ & $\begin{array}{c}\text { Hardness } \\
\text { (mg/l)as } \mathrm{CaCO} 3\end{array}$ & $\begin{array}{c}\text { Alkalinity } \\
\text { (mg/)as } \mathrm{CaCO} 3\end{array}$ & $\begin{array}{l}\text { Natrium } \\
(\mathrm{mg} / \mathrm{h})\end{array}$ & $\begin{array}{l}\text { Kalium } \\
(\mathrm{mg} / \mathrm{l})\end{array}$ & $\begin{array}{l}\text { Calcium } \\
\text { (mgli) }\end{array}$ & $\begin{array}{c}\text { Magnesium } \\
(\mathrm{mg} / \mathrm{t})\end{array}$ \\
\hline $\begin{array}{c}\text { OBSERVED } \\
(X n O)\end{array}$ & $\begin{array}{l}205.0 \\
235.0\end{array}$ & $\begin{array}{l}7.4 \\
7.5\end{array}$ & $\begin{array}{l}156.0 \\
146.8\end{array}$ & $\begin{array}{l}116.5 \\
125.0\end{array}$ & $\begin{array}{l}58.0 \\
60.3\end{array}$ & $\begin{array}{l}60.0 \\
60.8\end{array}$ & $\begin{array}{l}15.7 \\
18.8\end{array}$ & $\begin{array}{l}3.4 \\
2.7\end{array}$ & $\begin{array}{l}13.7 \\
13.5\end{array}$ & $\begin{array}{l}5.8 \\
6.5\end{array}$ \\
\hline$(\bar{X} \cap 0)$ & 220.0 & 7.4 & 151.4 & 120.8 & 59.1 & 60.4 & 17.2 & 3.0 & 13.6 & 6.1 \\
\hline $\begin{array}{c}\text { ENTROPY } \\
(X n e)\end{array}$ & $\begin{array}{l}287.2 \\
263.0\end{array}$ & $\begin{array}{l}7.8 \\
7.7\end{array}$ & $\begin{array}{l}194.8 \\
178.1\end{array}$ & $\begin{array}{l}159.9 \\
147.8\end{array}$ & $\begin{array}{l}79.0 \\
74.2\end{array}$ & $\begin{array}{l}80.3 \\
73.0\end{array}$ & $\begin{array}{l}23.7 \\
21.5\end{array}$ & $\begin{array}{l}3.7 \\
3.3\end{array}$ & $\begin{array}{l}17.8 \\
16.5\end{array}$ & $\begin{array}{l}8.4 \\
8.0\end{array}$ \\
\hline$\left(\overline{x_{n} \mathrm{e}}\right)$ & 275.1 & 7.7 & 186.5 & 153.9 & 76.6 & 76.6 & 22.6 & 3.5 & 17.1 & 8.2 \\
\hline
\end{tabular}

Number of Standard Deviations of the Distribution of Sampled Means by which the New/Predicted Mean Values lies from the Historical Mean Values

\begin{tabular}{|c|c|c|c|c|c|c|c|c|c|c|}
\hline & $\begin{array}{l}\text { Conductivity } \\
@ 25 \mathrm{C} \\
(\mathrm{ms} / \mathrm{m})\end{array}$ & $\mathrm{PH}$ & $\begin{array}{c}\text { Dissolved } \\
\text { Ions } \\
\text { (mg/l) }\end{array}$ & $\begin{array}{c}\text { Dissolved } \\
\text { Solids } \\
\text { (mg/) } \\
\end{array}$ & $\begin{array}{c}\text { Hardness } \\
\text { (mg/i)as Caco3 }\end{array}$ & $\begin{array}{c}\text { Alkalinity } \\
\text { (mg/)as Caco3 }\end{array}$ & $\begin{array}{l}\text { Natrlum } \\
(\mathrm{mg} /)\end{array}$ & $\begin{array}{l}\text { Kalium } \\
\text { (mg/l) }\end{array}$ & $\begin{array}{l}\text { Calcium } \\
(\mathrm{mg} / \mathrm{h})\end{array}$ & $\begin{array}{c}\text { Magnesium } \\
\text { (mg/l) }\end{array}$ \\
\hline $\begin{array}{c}\text { OBSEAVED } \\
\left(\bar{x}_{n} \cap-\bar{x} h\right) /[\mathrm{s} / \mathrm{Vn})\end{array}$ & -1.09 & -2.06 & -1.24 & -1.38 & -1.22 & -1.61 & -1.13 & -0.32 & -1.10 & -1.28 \\
\hline $\begin{array}{c}\text { ENTROPY } \\
(\bar{X} n e-\bar{X} h) /[s N n]\end{array}$ & -0.50 & -0.67 & -0.68 & -0.68 & -0.64 & $-0,90$ & -0.50 & 0.90 & -0.52 & -0.70 \\
\hline
\end{tabular}

\section{[3 Yearly Averaging]}

New/Predicted Mean Values

\begin{tabular}{|c|c|c|c|c|c|c|c|c|c|c|}
\hline & $\begin{array}{c}\text { Conductivity } \\
025 \mathrm{C} \\
\text { (ms/m) } \\
\end{array}$ & $\mathrm{PH}$ & $\begin{array}{c}\text { Dissolved } \\
\text { lons } \\
\text { (mg/i) } \\
\end{array}$ & $\begin{array}{c}\text { Dissolved } \\
\text { Solids } \\
\text { (mg/l) }\end{array}$ & $\begin{array}{c}\text { Hardness } \\
\text { (mg/l)as CaCO3 }\end{array}$ & $\begin{array}{c}\text { Alkalinity } \\
\text { (mg/l)as } \mathrm{CaCO} 3\end{array}$ & $\begin{array}{l}\text { Natrium } \\
(\mathrm{mg} / \mathrm{l}) \\
\end{array}$ & $\begin{array}{l}\text { Kalium } \\
\text { (mg/l) }\end{array}$ & $\begin{array}{l}\text { Calcium } \\
(\mathrm{mg} /)\end{array}$ & $\begin{array}{l}\text { Magriesium } \\
\text { (mg/l) }\end{array}$ \\
\hline $\begin{array}{c}\text { OBSERVED } \\
(X n O)\end{array}$ & 226.7 & 7.6 & 159.2 & 124.3 & 60.5 & 63.5 & 17.8 & 3.1 & 13.8 & 6.3 \\
\hline (Xno) & 226.7 & 7.6 & 159.2 & 124.3 & 60.5 & 63.5 & 17.8 & 3.1 & 13.8 & 6.3 \\
\hline $\begin{array}{c}\text { ENTROPY } \\
\text { (Xne) }\end{array}$ & 273.8 & 7.8 & 186.5 & 153.0 & 77.4 & 78.4 & 22.9 & 3.5 & 17.2 & 8.1 \\
\hline$(\bar{x}$ ne $)$ & 273.8 & 7.8 & 186.5 & 153.0 & 77.4 & 78.4 & 22.9 & 3.5 & 17.2 & 8.1 \\
\hline
\end{tabular}

Number of Standard Deviations of the Distribution of Sampled Means by which the New/Predicted Mean Values lies from the Historical Mean Values

\begin{tabular}{|c|c|c|c|c|c|c|c|c|c|c|}
\hline & $\begin{array}{c}\text { Conductivity } \\
@ 25 \mathrm{c} \\
(\mathrm{ms} / \mathrm{m}) \\
\end{array}$ & $\mathrm{PH}$ & $\begin{array}{c}\text { Dissolved } \\
\text { tons } \\
\text { (mgil) } \\
\end{array}$ & $\begin{array}{c}\text { Dissolved } \\
\text { Solids } \\
\text { (mg/) } \\
\end{array}$ & $\begin{array}{c}\text { Hardness } \\
\text { (mg/l)as CaCO3 }\end{array}$ & $\begin{array}{c}\text { Alkalinity } \\
\text { (mg/)as } \mathrm{CaCO} 3 \\
\end{array}$ & $\begin{array}{l}\text { Natrium } \\
\text { (mgll) }\end{array}$ & $\begin{array}{l}\text { Kalium } \\
\text { (mg/i) }\end{array}$ & $\begin{array}{l}\text { Calcium } \\
(\mathrm{mg} / \mathrm{l})\end{array}$ & $\begin{array}{c}\text { Magnesium } \\
\text { (mg/i) }\end{array}$ \\
\hline $\begin{array}{c}\text { OBSERVED } \\
\left(\bar{X}_{\mathrm{n}} \mathrm{n}-\overline{\mathrm{X}} h\right) /[\mathrm{s} / \mathrm{Nn}]\end{array}$ & -0.71 & -1.03 & -0.76 & -0.91 & -0.82 & -1.00 & -0.74 & -0.11 & -0.75 & -0.85 \\
\hline $\begin{array}{c}\text { ENTROPY } \\
\left(\bar{X}_{n e-\bar{X}} h\right) /[s / N n]\end{array}$ & -0.26 & -0.13 & -0.34 & -0.35 & -0.29 & -0.38 & -0.22 & 0.50 & -0.26 & -0.37 \\
\hline
\end{tabular}


Table B.4.1(b) Station 130322

Historical (prior) Mean Values

\begin{tabular}{|c|c|c|c|c|c|c|c|c|c|c|}
\hline & $\begin{array}{l}\text { Conductivity } \\
\text { @ } 25 \mathrm{C} \\
\text { (ms/m) }\end{array}$ & $\mathrm{PH}$ & $\begin{array}{l}\text { Dissolved } \\
\text { lons } \\
\text { (mg/l) }\end{array}$ & $\begin{array}{l}\text { Dissolved } \\
\text { Solids } \\
\text { (mgn) }\end{array}$ & $\begin{array}{c}\text { Herdness } \\
\text { (mg/)as } \mathrm{CaCO} 3\end{array}$ & $\begin{array}{c}\text { Alkalinity } \\
(m g n) a s \mathrm{CaCO} 3\end{array}$ & $\begin{array}{l}\text { Natrium } \\
(\mathrm{mg} /)\end{array}$ & $\begin{array}{l}\text { Kalium } \\
(\mathrm{mg} /)\end{array}$ & $\begin{array}{l}\text { Calcium } \\
\text { (mg/) }\end{array}$ & $\begin{array}{l}\text { Magnesium } \\
\text { (mgn) }\end{array}$ \\
\hline Mean & 203.8 & 7.6 & 148.2 & 122.6 & 53.0 & 66.8 & 18.7 & 5.6 & 13.3 & 4.8 \\
\hline $\begin{array}{l}\text { Standard (s) } \\
\text { Deviation }\end{array}$ & 43.7 & 0.3 & 28.3 & 24.8 & 8.6 & 13.2 & 4.3 & 0.5 & 2.2 & 0.8 \\
\hline
\end{tabular}

[1 Yearly Averaging]

New/Predicted Mean Values

\begin{tabular}{|c|c|c|c|c|c|c|c|c|c|c|}
\hline & $\begin{array}{c}\text { Conductivity } \\
\text { @ } 25 \mathrm{C} \\
\text { (ms/m) }\end{array}$ & $\mathrm{PH}$ & $\begin{array}{c}\text { Dissolved } \\
\text { Ions } \\
\text { (mg/) }\end{array}$ & $\begin{array}{l}\text { Dissolved } \\
\text { Solids } \\
\text { (mg/i) } \\
\end{array}$ & $\begin{array}{c}\text { Hardness } \\
\text { (mgi)as } \mathrm{CaCO} 3\end{array}$ & $\begin{array}{c}\text { Alkalinity } \\
\text { (mg/l)as } \mathrm{CaCO}\end{array}$ & $\begin{array}{l}\text { Natrium } \\
\text { (mgll) }\end{array}$ & $\begin{array}{l}\text { Kalium } \\
\text { (mgf) }\end{array}$ & $\begin{array}{l}\text { Calcium } \\
\text { (mg/) }\end{array}$ & $\begin{array}{l}\text { Magnesium } \\
\text { (mg/) }\end{array}$ \\
\hline $\begin{array}{c}\text { OBSERVED } \\
(X \cap \circ)\end{array}$ & $\begin{array}{l}222.5 \\
195.0 \\
248.8\end{array}$ & $\begin{array}{l}7.9 \\
7.6 \\
7.6\end{array}$ & $\begin{array}{l}159.8 \\
144.6 \\
175.3\end{array}$ & $\begin{array}{l}125.0 \\
110.0 \\
137.5\end{array}$ & $\begin{array}{l}57.5 \\
51.5 \\
66.5\end{array}$ & $\begin{array}{l}73.5 \\
72.0 \\
77.3\end{array}$ & $\begin{array}{l}19.5 \\
15.8 \\
23.0\end{array}$ & $\begin{array}{l}4.9 \\
5.7 \\
4.8\end{array}$ & $\begin{array}{l}14.0 \\
13.0 \\
17.0\end{array}$ & $\begin{array}{l}5.6 \\
4.6 \\
5.8\end{array}$ \\
\hline$\left(\bar{x}_{\cap \circ}\right)$ & 222.1 & 7.7 & 159.9 & 124.2 & 58.5 & 74.3 & 19.4 & 5.1 & 14.7 & 5.3 \\
\hline $\begin{array}{c}\text { ENTROPY } \\
\text { (Xne) }\end{array}$ & $\begin{array}{l}202.4 \\
203.8 \\
200.6\end{array}$ & $\begin{array}{l}7.6 \\
7.6 \\
7.6\end{array}$ & $\begin{array}{l}147.2 \\
148.0 \\
145.8\end{array}$ & $\begin{array}{l}121.6 \\
122.4 \\
120.4\end{array}$ & $\begin{array}{l}53.0 \\
53.2 \\
52.8\end{array}$ & $\begin{array}{l}66.0 \\
66.2 \\
64.9\end{array}$ & $\begin{array}{l}18.5 \\
18.7 \\
18.4\end{array}$ & $\begin{array}{l}5.6 \\
5.6 \\
5.6\end{array}$ & $\begin{array}{l}13.2 \\
13.3 \\
13.2\end{array}$ & $\begin{array}{l}4.8 \\
4.8 \\
4.7\end{array}$ \\
\hline$(\bar{X} n e)$ & 202.3 & 7.6 & 147.0 & 121.5 & 53.0 & 65.7 & 18.5 & 5.6 & 13.2 & 4.8 \\
\hline
\end{tabular}

Number of Standard Deviations of the Distribution of Sampled Means by which the New/Predicted Mean Values lies from the Historical Mean Values

\begin{tabular}{|c|c|c|c|c|c|c|c|c|c|c|}
\hline & $\begin{array}{c}\text { Conductivity } \\
@ 25 \mathrm{C} \\
\text { (mS/m) }\end{array}$ & $\mathrm{PH}$ & $\begin{array}{c}\text { Dissolved } \\
\text { lons } \\
\text { (mg/l) } \\
\end{array}$ & $\begin{array}{c}\text { Dissolved } \\
\text { Solids } \\
\text { (mg/) }\end{array}$ & $\begin{array}{c}\text { Hardness } \\
\text { (mg/)as } \mathrm{CaCO}\end{array}$ & $\begin{array}{c}\text { Akalinity } \\
\text { (mg/)as CaCO3 }\end{array}$ & $\begin{array}{l}\text { Natrium } \\
\text { (mg/) }\end{array}$ & $\begin{array}{l}\text { Kalium } \\
\text { (mg/) }\end{array}$ & $\begin{array}{l}\text { Calcium } \\
\text { (mg/l) }\end{array}$ & $\begin{array}{c}\text { Magriesium } \\
\text { (mg/) }\end{array}$ \\
\hline $\begin{array}{c}\text { OBSERVED } \\
\left(\bar{X}_{n \cap-\bar{X}}\right) /\left[\mathrm{s}: \bar{s}_{n}\right]\end{array}$ & 0.73 & 0.63 & 0.71 & 0.11 & 1.11 & 1.01 & 0.31 & -1.59 & 1.05 & 1.17 \\
\hline $\begin{array}{c}\text { ENTROPY } \\
(\bar{X} n e-\bar{X}(h) /[\mathrm{s} / \mathrm{Nn}]\end{array}$ & -0.06 & -0.11 & -0.08 & -0.08 & 0.01 & -0.12 & -0.06 & 0.04 & -0.05 & -0.04 \\
\hline
\end{tabular}


Table B.4.1(b) (continued)

\section{[2 Yearly Averaging]}

New/Predicted Mean Values

\begin{tabular}{|c|c|c|c|c|c|c|c|c|c|c|}
\hline & $\begin{array}{l}\text { Conductivity } \\
@ 25 \mathrm{C} \\
\text { (ms/m) }\end{array}$ & $\mathrm{PH}$ & $\begin{array}{c}\text { Dissolved } \\
\text { Ions } \\
\text { (mg/l) } \\
\end{array}$ & $\begin{array}{c}\text { Dissolved } \\
\text { Solids } \\
\text { (mg/i) } \\
\end{array}$ & $\begin{array}{c}\text { Hardness } \\
\text { (mg//)as CaCO3 }\end{array}$ & $\begin{array}{c}\text { Alkalinity } \\
\text { (mg//)as } \mathrm{CaCO} 3\end{array}$ & $\begin{array}{l}\text { Natrium } \\
(\mathrm{mg} / 1) \\
\end{array}$ & $\begin{array}{l}\text { Kalium } \\
\text { (mg/l) }\end{array}$ & $\begin{array}{l}\text { Calcium } \\
(\mathrm{mg} / \mathrm{l})\end{array}$ & $\begin{array}{l}\text { Magnesium } \\
\text { (mg/) }\end{array}$ \\
\hline $\begin{array}{c}\text { OBSERVED } \\
\left(X_{n o}\right)\end{array}$ & $\begin{array}{l}208.8 \\
221.9\end{array}$ & $\begin{array}{l}7.7 \\
7.6\end{array}$ & $\begin{array}{l}152.2 \\
159.9\end{array}$ & $\begin{array}{l}117.5 \\
123.8\end{array}$ & $\begin{array}{l}54.5 \\
59.0\end{array}$ & $\begin{array}{l}72.8 \\
74.6\end{array}$ & $\begin{array}{l}17.6 \\
19.4\end{array}$ & $\begin{array}{l}5.3 \\
5.2\end{array}$ & $\begin{array}{l}13.5 \\
15.0\end{array}$ & $\begin{array}{l}5.1 \\
5.2\end{array}$ \\
\hline$(\bar{x}$ no $)$ & 215.3 & 7.7 & 156.1 & 120.6 & 56.8 & 73.7 & 18.5 & 5.3 & 14.3 & 5.1 \\
\hline $\begin{array}{c}\text { ENTROPY } \\
\text { (Xne) }\end{array}$ & $\begin{array}{l}203.2 \\
202.3\end{array}$ & $\begin{array}{l}7.6 \\
7.6\end{array}$ & $\begin{array}{l}147.6 \\
147.0\end{array}$ & $\begin{array}{l}122.1 \\
121.5\end{array}$ & $\begin{array}{l}53.1 \\
53.1\end{array}$ & $\begin{array}{l}66.1 \\
65.6\end{array}$ & $\begin{array}{l}18.6 \\
18.5\end{array}$ & $\begin{array}{l}5.7 \\
5.6\end{array}$ & $\begin{array}{l}13.3 \\
13.2\end{array}$ & $\begin{array}{l}4.8 \\
4.8\end{array}$ \\
\hline (X̄ne) & 202.8 & 7.6 & 147.3 & 121.8 & 53.1 & 65.9 & 18.6 & 5.6 & 13.3 & 4.8 \\
\hline
\end{tabular}

Number of Standard Deviations of the Distribution of Sampled Means by which the New/Predicted Mean Values lies from the Historical Mean Values

\begin{tabular}{|c|c|c|c|c|c|c|c|c|c|c|}
\hline & $\begin{array}{c}\text { Conductivity } \\
@ 25 \mathrm{C} \\
(\mathrm{mS} / \mathrm{m})\end{array}$ & $\mathrm{PH}$ & $\begin{array}{c}\text { Dissolved } \\
\text { lons } \\
\text { (mg/l) }\end{array}$ & $\begin{array}{c}\text { Dissolved } \\
\text { Solids } \\
\text { (mgA) }\end{array}$ & $\begin{array}{c}\text { Hardness } \\
\text { (mg/)as } \mathrm{CaCO} 3 \\
\end{array}$ & $\begin{array}{c}\text { Alkalinity } \\
\text { (mg/)as } \mathrm{CaCO} 3 \\
\end{array}$ & $\begin{array}{l}\text { Natrium } \\
(\mathrm{mg} /)\end{array}$ & $\begin{array}{l}\text { Kalium } \\
(\mathrm{mg} / \mathrm{l})\end{array}$ & $\begin{array}{l}\text { Calcium } \\
\text { (mg/) }\end{array}$ & $\begin{array}{l}\text { Magnesium } \\
\text { (mg/) }\end{array}$ \\
\hline $\begin{array}{c}\text { OBSERVED } \\
{\left[\bar{X}_{n \cap-}-\bar{X} h\right) /(\mathrm{s} N \mathrm{~N}]}\end{array}$ & 0.37 & 0.33 & 0.39 & -0.12 & 0.62 & 0.76 & -0.06 & -0.90 & 0.60 & 0.64 \\
\hline $\begin{array}{c}\text { ENTROPY } \\
(\bar{X} n e-\bar{X}(h) /[s / N n]\end{array}$ & -0.03 & -0.11 & -0.05 & -0.05 & 0.02 & -0.08 & -0.03 & 0.11 & -0.03 & 0.00 \\
\hline
\end{tabular}

\section{[3 Yearly Averaging]}

\section{New/Predicted Mean Values}

\begin{tabular}{|c|c|c|c|c|c|c|c|c|c|c|}
\hline & $\begin{array}{l}\text { Conduclivity } \\
@ 25 \mathrm{C} \\
(\mathrm{mS} / \mathrm{m})\end{array}$ & $\mathrm{PH}$ & $\begin{array}{c}\text { Dissolved } \\
\text { lons } \\
\text { (mg//) }\end{array}$ & $\begin{array}{c}\text { Dissolved } \\
\text { Solids } \\
\text { (mg/l) }\end{array}$ & $\begin{array}{c}\text { Hardness } \\
\text { (mgll)as } \mathrm{CaCO} 3\end{array}$ & $\begin{array}{c}\text { Alkalinity } \\
\text { (mg/)as } \mathrm{CaCO} 3\end{array}$ & $\begin{array}{l}\text { Natrium } \\
(\mathrm{mg} / \mathrm{l})\end{array}$ & $\begin{array}{l}\text { Kalium } \\
(\mathrm{mg} / \mathrm{l})\end{array}$ & $\begin{array}{l}\text { Calcium } \\
(\mathrm{mg} / \mathrm{d})\end{array}$ & $\begin{array}{l}\text { Magnesium } \\
\text { (mg/l) }\end{array}$ \\
\hline $\begin{array}{c}\text { OBSERVED } \\
\left(x_{n O}\right)\end{array}$ & 222.1 & 7.7 & 159.9 & 124.2 & 58.5 & 74.3 & 19.4 & 5.1 & 14.7 & 5.3 \\
\hline$(\bar{x} \cap 0)$ & 222.1 & 7.7 & 159.9 & 124.2 & 58.5 & 74.3 & 19.4 & 5.1 & 14.7 & 5.3 \\
\hline $\begin{array}{c}\text { ENTROPY } \\
\text { (Xne) }\end{array}$ & 202.7 & 7.6 & 147.3 & 121.7 & 52.8 & 66.0 & 18.6 & 5.6 & 13.3 & 4.8 \\
\hline$\left(\bar{x}_{n}\right)$ & 202.7 & 7.6 & 147.3 & 121.7 & 52.8 & 66.0 & 18.6 & 5.6 & 13.3 & 4.8 \\
\hline
\end{tabular}

Number of Standard Deviations of the Distribution of Sampled Means by which the New/Predicted Mean Values lies from the Historical Mean Values

\begin{tabular}{|c|c|c|c|c|c|c|c|c|c|c|}
\hline & $\begin{array}{c}\text { Conductivity } \\
@ 25 \mathrm{C} \\
\text { (ms/m) } \\
\end{array}$ & $\mathrm{PH}$ & $\begin{array}{c}\text { Dissolved } \\
\text { lons } \\
\text { (mg/) }) \\
\end{array}$ & $\begin{array}{l}\text { Dissolved } \\
\text { Solids } \\
\text { (mg/) } \\
\end{array}$ & $\begin{array}{c}\text { Hardness } \\
\text { (mg/)as } \mathrm{CaCO}\end{array}$ & $\begin{array}{c}\text { Alkalinity } \\
\text { (mg/l)as } \mathrm{CaCO} 3\end{array}$ & $\begin{array}{l}\text { Natrium } \\
\text { (mg/) }\end{array}$ & $\begin{array}{l}\text { Kalium } \\
\text { (mg/i) }\end{array}$ & $\begin{array}{l}\text { Calcium } \\
\text { (mgl) }\end{array}$ & $\begin{array}{l}\text { Magnesium } \\
\quad(m g /) \\
\end{array}$ \\
\hline $\begin{array}{c}\text { OBSERVED } \\
\left(\bar{X}_{n o-}-\bar{X}_{h}\right) /[s / N n]\end{array}$ & 0.42 & 0.36 & 0.41 & 0.06 & 0.64 & 0.58 & 0.18 & -0.92 & 0.61 & 0.68 \\
\hline $\begin{array}{c}\text { ENTROPY } \\
\left(\bar{X}_{n e-}-\bar{X} h\right) /[s / V n]\end{array}$ & -0.02 & -0.02 & -0.03 & -0.04 & -0.02 & -0.05 & -0.02 & 0.08 & -0.02 & -0.02 \\
\hline
\end{tabular}


Table B.4.1(c) Station 130003

Historical (prior) Mean Values

\begin{tabular}{|c|c|c|c|c|c|c|c|c|c|c|}
\hline & $\begin{array}{l}\text { Conductivity } \\
@ 25 \mathrm{C} \\
\text { (ms/m) }\end{array}$ & $\mathrm{PH}$ & $\begin{array}{c}\text { Dissolved } \\
\text { Ions } \\
\text { (mg/i) }\end{array}$ & $\begin{array}{c}\text { Dissolved } \\
\text { Solids } \\
\text { (mg/) }\end{array}$ & \begin{tabular}{|c|} 
Hardness \\
(mg/)as $\mathrm{CaCO} 3$ \\
\end{tabular} & $\begin{array}{c}\text { Alkalinity } \\
\text { (mgn)as } \mathrm{CaCO} 3 \\
\end{array}$ & $\begin{array}{l}\text { Natriurn } \\
\text { (mg/) }\end{array}$ & $\begin{array}{l}\text { Kalium } \\
\text { (mg/) }\end{array}$ & $\begin{array}{l}\text { Calciunn } \\
\text { (mgn) }\end{array}$ & $\begin{array}{c}\text { Magnesium } \\
\text { (mg/l) }\end{array}$ \\
\hline Mean $\left.\quad \overline{X_{h}}\right)$ & 368.6 & 7.9 & 248.9 & 209.1 & 104.6 & 90.4 & 33.1 & 3.5 & 21.7 & 12.2 \\
\hline $\begin{array}{l}\text { Standard (s) } \\
\text { Deviation }\end{array}$ & 199.7 & 0.2 & 114.9 & 100.4 & 56.5 & 26.0 & 18.1 & 1.0 & 10.6 & 7.3 \\
\hline
\end{tabular}

[1 Yearly Averaging]

New Mean Values

\begin{tabular}{|c|c|c|c|c|c|c|c|c|c|c|}
\hline & $\begin{array}{l}\text { Conductivity } \\
@ 25 \mathrm{C} \\
\text { (ms/m) }\end{array}$ & $\mathrm{PH}$ & $\begin{array}{c}\text { Dissolved } \\
\text { ions } \\
\text { (mg/i) } \\
\end{array}$ & \begin{tabular}{|c|} 
Dissolved \\
Solids \\
(mg/l) \\
\end{tabular} & $\begin{array}{c}\text { Hardness } \\
\text { (mg//)as } \mathrm{CaCO} 3 \\
\end{array}$ & $\begin{array}{c}\text { Alkalinity } \\
\text { (mg/)as } \mathrm{CaCO} 3 \\
\end{array}$ & $\begin{array}{l}\text { Natrium } \\
\text { (mgf) }\end{array}$ & $\begin{array}{l}\text { Kalium } \\
\text { (mg/l) }\end{array}$ & $\begin{array}{l}\text { Calcium } \\
(\mathrm{mg} / \mathrm{l})\end{array}$ & $\begin{array}{l}\text { Magnesium } \\
\text { (mg/) }\end{array}$ \\
\hline \multirow{3}{*}{$\begin{array}{c}\text { OBSERVED } \\
(X n O)\end{array}$} & 288.3 & 7.8 & 194.5 & 160.0 & 71.0 & 76.0 & 26.0 & 4.4 & 16.3 & 7.4 \\
\hline & 370.0 & 7.6 & 237.9 & 200.0 & 102.5 & 81.5 & 32.0 & 4.0 & 22.3 & 11.5 \\
\hline & 176.7 & 7.4 & 122.8 & 104.0 & 50.3 & 53.0 & 15.8 & 3.3 & 11.3 & 5.4 \\
\hline$\left(\vec{X}_{n \circ)}\right.$ & 278.3 & 7.6 & 185.1 & 154.7 & 74.6 & 70.2 & 24.6 & 3.9 & 16.6 & 8.1 \\
\hline
\end{tabular}

Number of Standard Deviations of the Distribution of Sampled Means by which the New Mean Values lies from the Historical Mean Values

\begin{tabular}{|c|c|c|c|c|c|c|c|c|c|c|}
\hline & $\begin{array}{c}\text { Conductivity } \\
@ 25 \mathrm{C} \\
(\mathrm{mS} / \mathrm{m}) \\
\end{array}$ & $\mathrm{PH}$ & $\begin{array}{c}\text { Dissolved } \\
\text { lons } \\
\text { (mg/) } \\
\end{array}$ & $\begin{array}{c}\text { Dissolved } \\
\text { Solids } \\
\text { (mg/l) } \\
\end{array}$ & $\begin{array}{c}\text { Hardness } \\
\text { (mg/)as } \mathrm{CaCO} 3 \\
\end{array}$ & $\begin{array}{c}\text { Alkalinity } \\
\text { (mgf)as } \mathrm{CaCO} 3\end{array}$ & $\begin{array}{l}\text { Natrium } \\
\text { (mgl) }\end{array}$ & $\begin{array}{l}\text { Kaliurn } \\
(\mathrm{mg} / \mathrm{l})\end{array}$ & $\begin{array}{l}\text { Calciurn } \\
\text { (mg/) }\end{array}$ & $\begin{array}{c}\text { Magnesium } \\
(\mathrm{mg} / \mathrm{l})\end{array}$ \\
\hline $\begin{array}{c}\text { OBSERVED } \\
(\bar{X} n o-\bar{X} h) /[s / N n]\end{array}$ & -0.78 & -2.42 & -0.96 & -0.94 & -0.92 & -1.35 & -0.81 & 0.56 & -0.83 & -0.97 \\
\hline
\end{tabular}

\section{[2 Yearly Averaging]}

New Mean Values

\begin{tabular}{|c|c|c|c|c|c|c|c|c|c|c|}
\hline & \begin{tabular}{|c|} 
Conductivity \\
$@ 25 \mathrm{C}$ \\
$(\mathrm{ms} / \mathrm{m})$ \\
\end{tabular} & $\overrightarrow{P H}$ & \begin{tabular}{|c|} 
Dissolved \\
lons \\
(mg/l) \\
\end{tabular} & \begin{tabular}{|c|} 
Dissolved \\
' Solids \\
(mg/l) \\
\end{tabular} & $\begin{array}{c}\text { Hardness } \\
\text { (mg/)as } \mathrm{CaCO} 3\end{array}$ & $\begin{array}{c}\text { Alkalinity } \\
\text { (mgll)as } \mathrm{CaCO} 3 \\
\end{array}$ & $\begin{array}{l}\text { Natrium } \\
(m g / l) \\
\end{array}$ & $\begin{array}{l}\text { Kalium } \\
\text { (mg/) }\end{array}$ & $\begin{array}{l}\text { Calcium } \\
(\mathrm{mg} /)\end{array}$ & $\begin{array}{l}\text { Magnesium } \\
\text { (mg/l) }\end{array}$ \\
\hline $\begin{array}{c}\text { OBSEAVED } \\
\text { (XnO) }\end{array}$ & $\begin{array}{l}329.2 \\
273.3\end{array}$ & $\begin{array}{l}7.7 \\
7.5\end{array}$ & $\begin{array}{l}216.2 \\
180.3\end{array}$ & $\begin{array}{r}180.0 \\
+52.0\end{array}$ & $\begin{array}{l}86.8 \\
76.4\end{array}$ & $\begin{array}{l}78.8 \\
67.3\end{array}$ & $\begin{array}{l}29.0 \\
23.9\end{array}$ & $\begin{array}{l}4.2 \\
3.6\end{array}$ & $\begin{array}{l}19.3 \\
16.8\end{array}$ & $\begin{array}{l}9.4 \\
8.4\end{array}$ \\
\hline 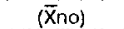 & 301.3 & 7.6 & 198.3 & 166.0 & 81.6 & 73.0 & 26.4 & 3.9 & 18.0 & 8.9 \\
\hline
\end{tabular}

Number of Standard Deviations of the Distribution of Sampled Means by which the New Mean Values lies from the Historical Mean Values

\begin{tabular}{|c|c|c|c|c|c|c|c|c|c|c|}
\hline & $\begin{array}{l}\text { Conductivity } \\
@ 25 \mathrm{C} \\
(\mathrm{ms} / \mathrm{m})\end{array}$ & $\mathrm{PH}$ & \begin{tabular}{|c|} 
Dissolved \\
tons \\
(mg/l) \\
\end{tabular} & \begin{tabular}{|c|}
$\begin{array}{c}\text { Dissolved } \\
\text { Solids } \\
\text { (mg/l) }\end{array}$ \\
\end{tabular} & $\begin{array}{c}\text { Hardness } \\
\text { (mg/l)as } \mathrm{CaCO} 3 \\
\end{array}$ & $\begin{array}{c}\text { Alkalinity } \\
\text { (mg/l)as } \mathrm{CaCO} 3 \\
\end{array}$ & $\begin{array}{l}\text { Natrium } \\
\text { (mg/l) }\end{array}$ & $\begin{array}{l}\text { Kalium } \\
\text { (mgl) }\end{array}$ & $\begin{array}{l}\text { Calcium } \\
(\mathrm{mg} / 1)\end{array}$ & $\begin{array}{c}\text { Magnesium } \\
\text { (mg/l) }\end{array}$ \\
\hline 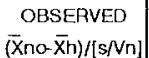 & -0.48 & -2.02 & -0.62 & -0.61 & -0.58 & -0.95 & -0.52 & 0.48 & -0.49 & -0.63 \\
\hline
\end{tabular}

[3 Yearly Averaging]

New Mean Values

\begin{tabular}{|c|c|c|c|c|c|c|c|c|c|c|}
\hline & $\begin{array}{c}\text { Conductivity } \\
@ 25 \mathrm{C} \\
(\mathrm{ms} / \mathrm{m}) \\
\end{array}$ & $\mathrm{PH}$ & $\begin{array}{c}\text { Dissolved } \\
\text { lons } \\
(\mathrm{mg} / \mathrm{l}) \\
\end{array}$ & $\begin{array}{c}\begin{array}{c}\text { Dissolved } \\
\text { Solids } \\
\text { (mg/l) }\end{array} \\
\end{array}$ & $\begin{array}{c}\text { Hardness } \\
\text { (mg//)as } \mathrm{CaCO} 3 \\
\end{array}$ & $\begin{array}{c}\text { Alkalinity } \\
\text { (mg/l)as } \mathrm{CaCO} 3 \\
\end{array}$ & $\begin{array}{l}\text { Natrium } \\
(\mathrm{mg} /)\end{array}$ & $\begin{array}{l}\text { Kalium } \\
\text { (mg/) }\end{array}$ & $\begin{array}{l}\text { Calcium } \\
(\mathrm{mg} /) \\
\end{array}$ & $\begin{array}{c}\text { Magnesium } \\
\text { (mg/l) } \\
\end{array}$ \\
\hline $\begin{array}{c}\text { OBSERVED } \\
\text { (XnO) }\end{array}$ & 244.8 & 7.7 & 168.2 & 139.7 & 66 & 72.6 & 21.4 & 2.9 & 14.2 & 7.5 \\
\hline$(\bar{x}$ no $)$ & 244.8 & 7.7 & 168.2 & 139.7 & 66.0 & 72.6 & 21.4 & 2.9 & 14.2 & 7.5 \\
\hline
\end{tabular}

Number of Standard Deviations of the Distribution of Sampled Means by which the New Mean Values lies from the Historical Mean Values

\begin{tabular}{|c|c|c|c|c|c|c|c|c|c|c|}
\hline & $\begin{array}{c}\text { Conductivity } \\
@ 25 \mathrm{C} \\
\text { (mS/m) }\end{array}$ & $\mathrm{PH}$ & $\begin{array}{c}\text { Dissolved } \\
\text { lons } \\
\text { (mg } /)\end{array}$ & $\begin{array}{c}\text { Dissolved } \\
\text { Solids } \\
\text { (mg/l) }\end{array}$ & $\begin{array}{c}\text { Hardness } \\
\text { (mg/)as } \mathrm{CaCO} 3\end{array}$ & $\begin{array}{c}\text { Aikalinity } \\
\text { (mgl)as } \mathrm{CaCO} 3\end{array}$ & $\begin{array}{l}\text { Natrium } \\
\text { (mg/l) }\end{array}$ & $\begin{array}{l}\text { Kalium } \\
\text { (mg/) }\end{array}$ & $\begin{array}{l}\text { Calcium } \\
\text { (mg/) }\end{array}$ & $\begin{array}{l}\text { Magnesium } \\
\text { (mgfl) }\end{array}$ \\
\hline $\begin{array}{c}\text { OBSERVED } \\
(\bar{X} \cap 0 \cdot \bar{X} n) /[s / N n]]\end{array}$ & -0.62 & -0.87 & -0.70 & -0.69 & -0.68 & -0.69 & -0.64 & -0.61 & -0.71 & -0.64 \\
\hline
\end{tabular}


Table B.4.2 Evaluation of the Water Quality Values in the Nogoa River Basin

Table B.4.2(a) Station 130202

Historical (prior) Mean Values

\begin{tabular}{|c|c|c|c|c|c|c|c|c|c|c|}
\hline & $\begin{array}{c}\text { Conductivity } \\
@ 25 \mathrm{C} \\
\text { (ms/m) } \\
\end{array}$ & $\mathrm{PH}$ & $\begin{array}{c}\text { Dissolved } \\
\text { Ions } \\
\text { (mg/l) } \\
\end{array}$ & $\begin{array}{c}\text { Dissolved } \\
\text { Solids } \\
(m g /) \\
\end{array}$ & $\begin{array}{c}\text { Hardness } \\
\text { (mgh)as } \mathrm{CaCO} 3\end{array}$ & $\begin{array}{c}\text { Alkalinity } \\
\text { (mg/)as } \mathrm{CaCO} 3\end{array}$ & $\begin{array}{l}\text { Natrium } \\
(\mathrm{mg} / \mathrm{l}) \\
\end{array}$ & $\begin{array}{l}\text { Kalium } \\
(\mathrm{mg} /)\end{array}$ & $\begin{array}{l}\text { Calcium } \\
(\mathrm{mg} /) \\
\end{array}$ & $\begin{array}{c}\text { Magnesium } \\
\text { (mg/f) }\end{array}$ \\
\hline Mean $\quad(\bar{X} h)$ & 245.7 & 7.6 & 177.4 & 137.2 & 76.2 & 79.2 & 18.9 & $4 . \overline{3}$ & 20.0 & 6.4 \\
\hline $\begin{array}{l}\text { Standard (s) } \\
\text { Deviation }\end{array}$ & 64.2 & 0.3 & 41.3 & 37.6 & 15.8 & 13.1 & 6.4 & 20 & 3.9 & 1.7 \\
\hline
\end{tabular}

[1 Yearly Averaging]

New/Predicted Mean Values

\begin{tabular}{|c|c|c|c|c|c|c|c|c|c|c|}
\hline & $\begin{array}{c}\text { Conductivity } \\
@ 25 \mathrm{C} \\
(\mathrm{ms} / \mathrm{m}) \\
\end{array}$ & $\mathrm{PH}$ & $\begin{array}{c}\text { Dissolved } \\
\text { lons } \\
(\mathrm{mg} /)\end{array}$ & $\begin{array}{c}\text { Dissolved } \\
\text { Solids } \\
\text { (mg/l) } \\
\end{array}$ & $\begin{array}{c}\text { Hardness } \\
\text { (mg/l)as } \mathrm{CaCO} 3\end{array}$ & $\begin{array}{c}\text { Alkalinity } \\
\text { (mg/)as } \mathrm{CaCO} 3\end{array}$ & $\begin{array}{l}\text { Natrium } \\
\text { (mgl) }\end{array}$ & $\begin{array}{l}\text { Kalium } \\
(\mathrm{mg} / \mathrm{l})\end{array}$ & $\begin{array}{l}\text { Calcium } \\
(\mathrm{mg} / \mathrm{l})\end{array}$ & $\begin{array}{l}\text { Magnesium } \\
\text { (mgf) }\end{array}$ \\
\hline \multirow[t]{5}{*}{ OBSERVED } & 246.5 & 7.5 & 179.4 & 147.9 & 69.1 & 72.4 & 22.4 & 5.3 & 17.2 & 6.3 \\
\hline & 342.5 & 8.2 & 249.4 & 200.0 & 92.5 & 106.0 & 30.5 & 5.7 & 23,0 & 8.6 \\
\hline & 190.0 & 7.4 & 135.8 & 110.0 & 46.0 & 64.0 & 17.0 & 4.4 & 13.0 & 3.4 \\
\hline & 152.5 & 7.0 & 116.6 & 94.5 & 45.5 & 53.5 & 12.5 & 5.2 & 12.5 & 3.5 \\
\hline & 147.5 & 7.3 & 110.2 & 86.0 & 44.0 & 57.5 & 9.7 & 4.8 & 12.2 & 3.3 \\
\hline$(\overline{x n o})$ & 215.8 & 7.5 & 158.3 & 127.7 & 59.4 & 70.7 & 18.4 & 5.1 & 15.6 & 5.0 \\
\hline \multirow[t]{2}{*}{ ENTROPY } & 215.2 & 7.5 & 159.3 & 120.5 & 70.7 & 75.6 & 16.2 & 5.5 & 18.9 & 5.6 \\
\hline & 263.5 & 7.6 & 169.7 & 131.0 & 73.0 & 77.4 & 17.9 & 5.5 & 19.8 & 5.9 \\
\hline \multirow[t]{3}{*}{ (Xne) } & 235.7 & 7.5 & 161.4 & 122.1 & 71.0 & 75.5 & 16.5 & 5.4 & 19.1 & 5.6 \\
\hline & 218.4 & 7.6 & 159.8 & 118.7 & 71.1 & 75.7 & 15.8 & 5.3 & 18.9 & 5.6 \\
\hline & 217.6 & 7.5 & 159.0 & 118.5 & 70.7 & 75.9 & 15.9 & 5.6 & 19.2 & 5.6 \\
\hline$\left(\overline{X_{n}} \mathrm{e}\right)$ & 230.1 & 7.5 & 161.8 & 122.2 & 71.3 & 76.0 & 16.4 & 5.5 & 19.2 & 5.7 \\
\hline
\end{tabular}

Number of Standard Deviations of the Distribution of Sampled Means by which the New/Predicted Mean Values lies from the Historical Mean Values

\begin{tabular}{|c|c|c|c|c|c|c|c|c|c|c|}
\hline & $\begin{array}{c}\text { Conductivity } \\
@ 25 \mathrm{C} \\
(\mathrm{ms} / \mathrm{m}) \\
\end{array}$ & $\mathrm{PH}$ & $\begin{array}{c}\text { Dissolved } \\
\text { tons } \\
(\mathrm{mg} / \mathrm{l}) \\
\end{array}$ & $\begin{array}{c}\text { Dissolved } \\
\text { Solids } \\
\text { (mg/l) } \\
\end{array}$ & $\begin{array}{c}\text { Hardness } \\
\text { (mg/l)as } \mathrm{CaCO} 3 \\
\end{array}$ & $\begin{array}{c}\text { Alkalinity } \\
\text { (mg//)as } \mathrm{CaCO} 3 \\
\end{array}$ & $\begin{array}{l}\text { Natrium } \\
(\mathrm{mg} / \mathrm{l}) \\
\end{array}$ & $\begin{array}{l}\text { Kalium } \\
(\mathrm{mg} / \mathrm{l})\end{array}$ & $\begin{array}{l}\text { Calcium } \\
(\mathrm{mg} / \mathrm{l})\end{array}$ & $\begin{array}{c}\text { Magnesium } \\
\text { (mg/l) }\end{array}$ \\
\hline $\begin{array}{c}\text { OBSERVED } \\
(\bar{X} \text { no-X̄ } h) /[s / \mathrm{sn}]\end{array}$ & -1.04 & $-f .34$ & -1.04 & -0.56 & -2.37 & -1.45 & -0.16 & 0.89 & -2.53 & -1.85 \\
\hline $\begin{array}{c}\text { ENTROPY } \\
\left(\bar{X}_{n \in-}-\bar{X} h\right) /[s / N n]\end{array}$ & -0.55 & -0.65 & -0.84 & -0.89 & -0.69 & -0.54 & -0.85 & 1.32 & -0.47 & -0.98 \\
\hline
\end{tabular}


Table B.4.2(a) (continued)

[2 Yearly Averaging]

New/Predicted Mean Values

\begin{tabular}{|c|c|c|c|c|c|c|c|c|c|c|}
\hline & $\begin{array}{c}\text { Conductivity } \\
@ 25 \mathrm{C} \\
(\mathrm{ms} / \mathrm{m}) \\
\end{array}$ & $\mathrm{PH}$ & $\begin{array}{c}\text { Dissolved } \\
\text { lons } \\
(\mathrm{mg} / 1) \\
\end{array}$ & $\begin{array}{c}\text { Dissolved } \\
\text { Solids } \\
\text { (mg/) }\end{array}$ & $\begin{array}{c}\text { Hardness } \\
\text { (mg/)as } \mathrm{Caco} 3\end{array}$ & \begin{tabular}{|c|} 
Alkalinity \\
(mg/l)as CaCO3 \\
\end{tabular} & $\begin{array}{l}\text { Natrium } \\
(\mathrm{mg} / \mathrm{l})\end{array}$ & $\begin{array}{l}\text { Kalium } \\
\text { (mg/l) }\end{array}$ & $\begin{array}{l}\text { Calcium } \\
(\mathrm{mg} / \mathrm{l})\end{array}$ & $\begin{array}{l}\text { Magnesium } \\
\text { (mg/l) }\end{array}$ \\
\hline $\begin{array}{c}\text { OBSERVED } \\
\text { (Xno) }\end{array}$ & $\begin{array}{l}294.5 \\
266.3 \\
171.3 \\
150.0\end{array}$ & $\begin{array}{l}7.8 \\
7.8 \\
7.2 \\
7.1\end{array}$ & $\begin{array}{l}214.4 \\
192.6 \\
126.2 \\
113.4\end{array}$ & $\begin{array}{c}174.0 \\
155.0 \\
102.3 \\
90.3\end{array}$ & $\begin{array}{l}80.8 \\
69.3 \\
45.8 \\
44.8\end{array}$ & $\begin{array}{l}89.2 \\
85.0 \\
58.8 \\
55.5\end{array}$ & $\begin{array}{l}26.4 \\
23.8 \\
14.8 \\
11.1\end{array}$ & $\begin{array}{l}5.5 \\
5.0 \\
4.8 \\
5.0\end{array}$ & $\begin{array}{l}20.1 \\
18.0 \\
12.8 \\
12.4\end{array}$ & $\begin{array}{l}7.4 \\
6.0 \\
3.4 \\
3.4\end{array}$ \\
\hline$(\vec{x} \times)$ & 220.5 & 7.5 & 161.6 & 130.4 & 60.1 & 72.1 & 19.0 & 5.1 & 15.8 & 5.0 \\
\hline $\begin{array}{c}\text { ENTROPY } \\
\left(X_{n e}\right)\end{array}$ & $\begin{array}{l}237.1 \\
247.9 \\
224.3 \\
214.8\end{array}$ & $\begin{array}{l}7.5 \\
7.5 \\
7.5 \\
7.5\end{array}$ & $\begin{array}{l}164.0 \\
165.0 \\
159.9 \\
158.7\end{array}$ & $\begin{array}{l}125.6 \\
126.5 \\
120.0 \\
118.2\end{array}$ & $\begin{array}{l}71.0 \\
71.2 \\
70.1 \\
69.9\end{array}$ & $\begin{array}{l}76.2 \\
76.2 \\
75.3 \\
75.5\end{array}$ & $\begin{array}{l}17.1 \\
17.3 \\
16.2 \\
15.9\end{array}$ & $\begin{array}{l}5.4 \\
5.4 \\
5.3 \\
5.4\end{array}$ & $\begin{array}{l}19.0 \\
19.1 \\
18.6 \\
18.6\end{array}$ & $\begin{array}{l}5.7 \\
5.7 \\
5.6 \\
5.6\end{array}$ \\
\hline 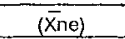 & 231.0 & 7.5 & 161.9 & 122.6 & 70.6 & 75.8 & 16.6 & 5.4 & 18.8 & 5.6 \\
\hline
\end{tabular}

Number of Standard Deviations of the Distribution of Sampled Means by which the New/Predicted Mean Values lies from the Historical Mean Values

\begin{tabular}{|c|c|c|c|c|c|c|c|c|c|c|}
\hline & $\begin{array}{c}\text { Conductivity } \\
@ 25 \mathrm{C} \\
\text { (ms/m) }\end{array}$ & PH & $\begin{array}{c}\text { Dissolved } \\
\text { Ions } \\
\text { (mg/l) }\end{array}$ & $\begin{array}{c}\text { Dissolved } \\
\text { Solids } \\
\text { (mg/l) }\end{array}$ & $\begin{array}{c}\text { Hardness } \\
\text { (mg/h)as } \mathrm{CaCO} 3\end{array}$ & $\begin{array}{c}\text { Alkalinity } \\
\text { (mg/)as } \mathrm{CaCO} 3\end{array}$ & $\begin{array}{l}\text { Natrium } \\
\text { (mg/l) }\end{array}$ & $\begin{array}{l}\text { Kalium } \\
(\mathrm{mg} / \mathrm{l})\end{array}$ & $\begin{array}{l}\text { Calcium } \\
(\mathrm{mg} / \mathrm{l})\end{array}$ & $\begin{array}{c}\text { Magnesium } \\
\text { (mg/l) }\end{array}$ \\
\hline $\begin{array}{c}\text { OBSERVED } \\
(\bar{X} \text { (Xo-X̄ } h) /[s / V n]\end{array}$ & -0.79 & -1.02 & -0.76 & -0.36 & -2.03 & -1.08 & 0.05 & 0.80 & -2.15 & -1.59 \\
\hline $\begin{array}{c}\text { ENTROPY } \\
(\bar{X} n e-\bar{X} h) /[s / N n]\end{array}$ & -0.46 & -0.99 & -0.75 & -0.78 & -0.71 & -0.53 & -0.70 & 1.08 & -0.57 & -0.90 \\
\hline
\end{tabular}

\section{[3 Yearly Averaging]}

New/Predicted Mean Values

\begin{tabular}{|c|c|c|c|c|c|c|c|c|c|c|}
\hline & $\begin{array}{c}\text { Conductivity } \\
\text { @ } 25 \mathrm{C} \\
\text { (ms/m) }\end{array}$ & $\mathrm{PH}$ & $\begin{array}{c}\text { Dissolved } \\
\text { lons } \\
\text { (mg/) }\end{array}$ & $\begin{array}{c}\text { Dissolved } \\
\text { Solids } \\
\text { (mg/l) }\end{array}$ & $\begin{array}{c}\text { Hardness } \\
(\mathrm{mg} / \text { )as } \mathrm{CaCO} 3\end{array}$ & $\begin{array}{c}\text { Alkalinity } \\
\text { (mg/)as } \mathrm{CaCO} 3\end{array}$ & $\begin{array}{l}\text { Natrium } \\
(\mathrm{mg} / \mathrm{l})\end{array}$ & $\begin{array}{l}\text { Kalium } \\
\text { (mg/l) }\end{array}$ & $\begin{array}{l}\text { Calcium } \\
\text { (mg/l) }\end{array}$ & $\begin{array}{c}\text { Magnesium } \\
\text { (mg/i) }\end{array}$ \\
\hline $\begin{array}{l}\text { OBSERVED } \\
(x \text { (X) })\end{array}$ & $\begin{array}{l}259.7 \\
228.3 \\
163.3\end{array}$ & $\begin{array}{l}7.7 \\
7.5 \\
7.2\end{array}$ & $\begin{array}{l}188.2 \\
167.3 \\
120.9\end{array}$ & $\begin{array}{l}152.6 \\
134.8 \\
96.8\end{array}$ & $\begin{array}{l}69.2 \\
61.3 \\
45.2\end{array}$ & $\begin{array}{l}80.8 \\
74.5 \\
58.3\end{array}$ & $\begin{array}{l}23.3 \\
20.0 \\
13.1\end{array}$ & $\begin{array}{l}5.1 \\
5.1 \\
4.8\end{array}$ & $\begin{array}{l}17.7 \\
16.2 \\
12.6\end{array}$ & $\begin{array}{l}6.1 \\
5.1 \\
3.4\end{array}$ \\
\hline$(\bar{x} \cap 0)$ & 217.1 & 7.5 & 158.8 & 128.1 & 58.6 & 71.2 & 18.8 & 5.0 & 15.5 & 4.9 \\
\hline $\begin{array}{c}\text { ENTROPY } \\
(X n e)\end{array}$ & $\begin{array}{l}230.0 \\
231.2 \\
214.3\end{array}$ & $\begin{array}{l}7.6 \\
7.6 \\
7.6\end{array}$ & $\begin{array}{l}145.3 \\
145.8 \\
134.9\end{array}$ & $\begin{array}{l}122.8 \\
122.2 \\
117.5\end{array}$ & $\begin{array}{l}70.0 \\
70.2 \\
69.3\end{array}$ & $\begin{array}{l}75.5 \\
75.5 \\
75.0\end{array}$ & $\begin{array}{l}16.7 \\
16.6 \\
15.9\end{array}$ & $\begin{array}{l}5.5 \\
5.5 \\
5.5\end{array}$ & $\begin{array}{l}18.6 \\
18.6 \\
18.3\end{array}$ & $\begin{array}{l}5.7 \\
5.7 \\
5.6\end{array}$ \\
\hline$\left(\overline{x_{n}} \mathrm{e}\right)$ & 225.2 & 7.6 & 142.0 & 120.8 & 69.8 & 75.3 & 16.4 & 5.5 & 18.5 & 5.7 \\
\hline
\end{tabular}

Number of Standard Deviations of the Distribution of Sampled Means by which the New/Predicted Mean Values lies from the Historical Mean Values

\begin{tabular}{|c|c|c|c|c|c|c|c|c|c|c|}
\hline & $\begin{array}{c}\text { Conductivity } \\
\text { @ } 25 \mathrm{C} \\
\text { (ms/m) }\end{array}$ & $\mathrm{PH}$ & $\begin{array}{c}\text { Dissolved } \\
\text { Ions } \\
\text { (ming/) } \\
\end{array}$ & $\begin{array}{c}\text { Dissolved } \\
\text { Solids } \\
\text { (ming) }\end{array}$ & $\begin{array}{c}\text { Hardness } \\
\text { (mgfl)as CaCO3 }\end{array}$ & $\begin{array}{c}\text { Alkalinity } \\
\text { (mgl)as } \mathrm{CaCO} 3\end{array}$ & $\begin{array}{l}\text { Natrium } \\
(\mathrm{mg} / \mathrm{l})\end{array}$ & $\begin{array}{l}\text { Kalium } \\
\text { (mg/l) }\end{array}$ & $\begin{array}{l}\text { Calcium } \\
\text { (mg/) }\end{array}$ & $\begin{array}{l}\text { Magnesium } \\
(\mathrm{mg} / \mathrm{l})\end{array}$ \\
\hline $\begin{array}{c}\text { OBSERVED } \\
\left(\bar{X}_{n} \cap-\bar{X} h\right) /[s / V n]\end{array}$ & -0.77 & -0.94 & -0.78 & -0.42 & -1.93 & -1.05 & -0.02 & 0.63 & -2.00 & -1.57 \\
\hline $\begin{array}{c}\text { ENTROPY } \\
\left(\bar{X}_{n e}-\bar{X} h\right) /[\mathrm{s} / \mathrm{N} n]\end{array}$ & -0.56 & -0.36 & -1.48 & -0.75 & -0.69 & -0.51 & -0.67 & 1.03 & -0.64 & -0.72 \\
\hline
\end{tabular}


Table B.4.2(a) (continued)

[4 Yearly Averaging]

New/Predicted Mean Values

\begin{tabular}{|c|c|c|c|c|c|c|c|c|c|c|}
\hline & $\begin{array}{c}\text { Conductivity } \\
@ 25 \mathrm{C} \\
(\mathrm{mS} / \mathrm{m}) \\
\end{array}$ & $\mathrm{PH}$ & $\begin{array}{c}\text { Dissolved } \\
\text { lons } \\
\text { (mg/l) }\end{array}$ & $\begin{array}{c}\text { Dissolved } \\
\text { Solids } \\
\text { (mg/) }\end{array}$ & $\begin{array}{c}\text { Hardness } \\
\text { (mg/l)as } \mathrm{CaCO}\end{array}$ & $\begin{array}{c}\text { Alkalinity } \\
\text { (mgll)as } \mathrm{CaCO} 3\end{array}$ & $\begin{array}{l}\text { Natrium } \\
(\mathrm{mg} /)\end{array}$ & $\begin{array}{l}\text { Kalium } \\
\text { (mgi) }\end{array}$ & $\begin{array}{l}\text { Calcium } \\
(\mathrm{mg} / \mathrm{l})\end{array}$ & $\begin{array}{l}\text { Magnesium } \\
\text { (mgn) }\end{array}$ \\
\hline $\begin{array}{c}\text { OBSERVED } \\
\text { (Xno) }\end{array}$ & $\begin{array}{l}232.9 \\
208.1\end{array}$ & $\begin{array}{l}7.5 \\
7.5\end{array}$ & $\begin{array}{l}170.3 \\
153.0\end{array}$ & $\begin{array}{l}138.1 \\
122.6\end{array}$ & $\begin{array}{l}63.3 \\
57.0\end{array}$ & $\begin{array}{l}74.0 \\
70.3\end{array}$ & $\begin{array}{l}20.6 \\
17.4\end{array}$ & $\begin{array}{l}5.1 \\
5.0\end{array}$ & $\begin{array}{l}16.4 \\
15.2\end{array}$ & $\begin{array}{l}5.4 \\
4.7\end{array}$ \\
\hline$\left(x_{1}\right)$ & 220.5 & 7.5 & 161.6 & 130.4 & 60.1 & 72.1 & 19.0 & 5.1 & 15.8 & 5.0 \\
\hline $\begin{array}{c}\text { ENTROPY } \\
\text { (Xne) }\end{array}$ & $\begin{array}{l}228.9 \\
229.6\end{array}$ & $\begin{array}{l}7.6 \\
7.6\end{array}$ & $\begin{array}{l}145.8 \\
145.6\end{array}$ & $\begin{array}{l}122.1 \\
121.5\end{array}$ & $\begin{array}{l}71.6 \\
71.6\end{array}$ & $\begin{array}{l}76.2 \\
76.2\end{array}$ & $\begin{array}{l}16.2 \\
16.9\end{array}$ & $\begin{array}{l}5.8 \\
5.8\end{array}$ & $\begin{array}{l}18.9 \\
19.0\end{array}$ & $\begin{array}{l}5.9 \\
5.9\end{array}$ \\
\hline$\left(\overline{X_{n}}\right)$ & 229.2 & 7.6 & 145.7 & 121.8 & 71.6 & 76.2 & 16.2 & 5.8 & 18.9 & 5.9 \\
\hline
\end{tabular}

Number of Standard Deviations of the Distribution of Sampled Means by which the New/Predicted Mean Values lies from the Historical Mean Values

\begin{tabular}{|c|c|c|c|c|c|c|c|c|c|c|}
\hline & $\begin{array}{l}\text { Conductivity } \\
@ 25 \mathrm{C} \\
\text { (ms/m) }\end{array}$ & $\mathrm{PH}$ & $\begin{array}{c}\text { Dissolved } \\
\text { Ions } \\
\text { (mg/) }\end{array}$ & \begin{tabular}{|c|} 
Dissolved \\
Solids \\
(mg/l)
\end{tabular} & $\begin{array}{c}\text { Hardness } \\
\text { (mg/)as } \mathrm{CaCO} 3\end{array}$ & $\begin{array}{c}\text { Alkalinity } \\
\text { (mg/)as CaCO3 }\end{array}$ & $\begin{array}{l}\text { Natrium } \\
\text { (mg/i) }\end{array}$ & $\begin{array}{l}\text { Kalium } \\
\text { (mg/l) }\end{array}$ & $\begin{array}{l}\text { Calcium } \\
\text { (mg/) }\end{array}$ & $\begin{array}{l}\text { Magnesium } \\
\text { (mg/l) }\end{array}$ \\
\hline $\begin{array}{c}\text { OBSERVED } \\
(\overline{\mathrm{X}} \cap 0-\overline{\mathrm{X}} \mathrm{h}) /[\mathrm{s} / \mathrm{Nn}]\end{array}$ & -0.56 & -0.72 & -0.54 & -0.26 & $\begin{array}{r}-1.44 \\
.\end{array}$ & -0.76 & 0.03 & 0.56 & -1.52 & -1.13 \\
\hline $\begin{array}{c}\text { ENTROPY } \\
(\overline{\mathrm{X}} \mathrm{ne}-\overline{\mathrm{X}} \mathrm{n}) /[\mathrm{s} N \mathrm{Nn}]\end{array}$ & -0.36 & -0.29 & -1.09 & -0.58 & -0.41 & -0.33 & -0.60 & 1.07 & -0.37 & -0.45 \\
\hline
\end{tabular}


Table B.4.2(b) Station 130212

Historical (prior) Mean Values

\begin{tabular}{|c|c|c|c|c|c|c|c|c|c|c|}
\hline & $\begin{array}{l}\text { Conductivity } \\
\text { @ } 25 \mathrm{C} \\
\text { (ms/m) }\end{array}$ & $\mathrm{PH}$ & $\begin{array}{c}\text { Dissolved } \\
\text { ions } \\
\text { (mg } /)\end{array}$ & $\begin{array}{c}\text { Dissolved } \\
\text { Solids } \\
\text { (mg/l) }\end{array}$ & $\begin{array}{c}\text { Hardness } \\
\text { (mg/l)as } \mathrm{CaCO} 3\end{array}$ & $\begin{array}{c}\text { Alkalinity } \\
\text { (mg/)as } \mathrm{CaCO} 3\end{array}$ & $\begin{array}{l}\text { Natrium } \\
\text { (mg/l) }\end{array}$ & $\begin{array}{l}\text { Kalium } \\
\text { (mg/l) }\end{array}$ & $\begin{array}{l}\text { Calcium } \\
\text { (mgh) }\end{array}$ & $\begin{array}{c}\text { Magnesium } \\
\text { (mg/i) }\end{array}$ \\
\hline Mean $\quad(\bar{X} h)$ & 271.4 & 7.5 & 209.1 & 155.6 & 86.5 & 101.9 & 23.2 & 3.7 & 24.6 & 6.1 \\
\hline $\begin{array}{l}\text { Standard (s) } \\
\text { Deviation }\end{array}$ & 152.8 & 0.2 & 107.5 & 79.1 & 44.8 & 48.6 & 16.4 & 1.6 & 13.8 & 2.9 \\
\hline
\end{tabular}

\section{[1 Yearly Averaging]}

New/Predicted Mean Values

\begin{tabular}{|c|c|c|c|c|c|c|c|c|c|c|}
\hline & $\begin{array}{c}\text { Conductivity } \\
\text { @ } 25 \mathrm{C} \\
(\mathrm{ms} / \mathrm{m}) \\
\end{array}$ & $\mathrm{PH}$ & $\begin{array}{c}\text { Dissolved } \\
\text { lons } \\
\text { (mg/) } \\
\end{array}$ & $\begin{array}{c}\text { Dissolved } \\
\text { Sotids } \\
\text { (mg/) } \\
\end{array}$ & $\begin{array}{c}\text { Hardness } \\
\text { (mg/)as } \mathrm{CaCO} 3\end{array}$ & $\begin{array}{c}\text { Alkalınity } \\
\text { (mgl)as } \mathrm{CaCO} 3\end{array}$ & $\begin{array}{l}\text { Natrium } \\
(\mathrm{mg} /)\end{array}$ & $\begin{array}{l}\text { Kafium } \\
\text { (mgA) }\end{array}$ & $\begin{array}{l}\text { Calcium } \\
\text { (mg/) }\end{array}$ & $\begin{array}{l}\text { Magnesium } \\
\text { (mg/l) }\end{array}$ \\
\hline \multirow[t]{5}{*}{ OBSERVED } & 221.3 & 7.5 & 184.3 & 147.5 & 78.0 & 96.5 & 17.0 & 4.6 & 22.0 & 5.6 \\
\hline & 230.0 & 7.4 & 182.4 & 138.0 & 80.0 & 104.0 & 14.0 & 4.2 & 23.3 & 5.3 \\
\hline & 125.0 & 7.7 & 97.2 & 80.0 & 37.0 & 510 & 9.5 & 4.5 & 10.0 & 2.8 \\
\hline & 152.5 & 7.4 & 125.2 & 80.5 & 50.5 & 67.5 & 12.0 & 4.3 & 15.0 & 3.1 \\
\hline & 172.5 & 7.2 & 137.8 & 105.0 & 54.5 & 75.0 & 11.0 & 6.1 & 15.5 & 3.9 \\
\hline$(\bar{x} \cap 0)$ & 180.3 & 7.4 & 145.4 & 112.2 & 60.0 & 78.2 & 12.7 & 4.7 & 17.2 & 4.1 \\
\hline \multirow[t]{2}{*}{ ENTROPY } & 170.2 & 7.5 & 139.4 & 113.6 & 61.2 & 73.8 & 13.1 & 4.4 & 16.8 & 4.7 \\
\hline & 181.6 & 7.5 & 179.4 & 140.0 & 72.2 & 87.9 & 19.6 & 4.4 & 23.2 & 5.2 \\
\hline \multirow[t]{3}{*}{$(X n e)$} & 175.0 & 7.5 & 147.3 & $\{17.7$ & 62.8 & 73.0 & 14.3 & 4.3 & 18.1 & 4.8 \\
\hline & 171.0 & 7.5 & 141.2 & 109.0 & 63.2 & 74.3 & 11.8 & 4.3 & 16.5 & 4.8 \\
\hline & 170.8 & 7.5 & 138.1 & 108.5 & 61.2 & 76.1 & 12.1 & 4.4 & 18.9 & 4.7 \\
\hline (X̄ne) & 173.7 & 7.5 & 149.1 & 117.7 & 64.1 & 77.0 & 14.2 & 4.4 & 18.7 & 4.8 \\
\hline
\end{tabular}

Number of Standard Deviations of the Distribution of Sampled Means by which the New/Predicted Mean Values lies from the Historical Mean Values

\begin{tabular}{|c|c|c|c|c|c|c|c|c|c|c|}
\hline & $\begin{array}{c}\text { Conductivity } \\
@ 25 \mathrm{C} \\
\text { (ms/m) }\end{array}$ & $\mathrm{PH}$ & $\begin{array}{c}\text { Dissolved } \\
\text { lons } \\
\text { (mg/) } \\
\end{array}$ & $\begin{array}{c}\text { Dissolved } \\
\text { Solids } \\
\text { (mg/l) } \\
\end{array}$ & $\begin{array}{c}\text { Hardness } \\
\text { (mg/)as } \mathrm{CaCO} 3 \\
\end{array}$ & $\begin{array}{c}\text { Alkalinity } \\
\text { (mg/l)as } \mathrm{CaCO} 3 \\
\end{array}$ & $\begin{array}{l}\text { Natrium } \\
(\mathrm{mg} / \mathrm{l}) \\
\end{array}$ & $\begin{array}{l}\text { Kalium } \\
(\mathrm{mg} / 1)\end{array}$ & $\begin{array}{l}\text { Calcium } \\
\text { (mg/l) }\end{array}$ & $\begin{array}{l}\text { Magnesium } \\
\text { (mgl) }\end{array}$ \\
\hline $\begin{array}{c}\text { OBSERVED } \\
\left(\bar{X}_{n} \cap-\bar{X}(n) /[\mathrm{s} / \mathrm{N}]\right.\end{array}$ & -1.33 & -0.80 & -1.33 & -1.23 & -1.32 & -1.09 & -1.44 & 1.40 & -1.19 & -1.50 \\
\hline $\begin{array}{c}\text { ENTROPY } \\
(\bar{X} \cap \overline{\mathrm{X}}-\overline{\mathrm{X}} h) /[\mathrm{s} / \mathrm{Nn}]\end{array}$ & -1.43 & -0.30 & -1.25 & -1.07 & -1.12 & -1.15 & -1.23 & 0.87 & -0.95 & -0.97 \\
\hline
\end{tabular}


Table B.4.2(b) (continued)

[2 Yearly Averaging]

New/Predicted Mean Values

\begin{tabular}{|c|c|c|c|c|c|c|c|c|c|c|}
\hline & $\begin{array}{c}\text { Conductivity } \\
@ 25 \mathrm{C} \\
(\mathrm{ms} / \mathrm{m})\end{array}$ & $\mathrm{PH}$ & $\begin{array}{c}\text { Dissolved } \\
\text { lons } \\
(\mathrm{mg} / \mathrm{l}) \\
\end{array}$ & $\begin{array}{l}\text { Dissolved } \\
\text { Solids } \\
\text { (mg/i) }\end{array}$ & $\begin{array}{c}\text { Hardness } \\
\text { (mg/)as caco3 }\end{array}$ & $\begin{array}{c}\text { Alkalinity } \\
\text { (mg/)as } \mathrm{CaCO} 3\end{array}$ & $\begin{array}{l}\text { Natrium } \\
(\mathrm{mg} /)\end{array}$ & $\begin{array}{l}\text { Kalium } \\
(\mathrm{mg} / \mathrm{l})\end{array}$ & $\begin{array}{l}\text { Calcium } \\
\text { (mg/l) }\end{array}$ & $\begin{array}{l}\text { Magnesium } \\
(\mathrm{mg} / \mathrm{l})\end{array}$ \\
\hline $\begin{array}{c}\text { OBSERVED } \\
(\mathrm{XnO})\end{array}$ & $\begin{array}{l}225.6 \\
177.5 \\
138.8 \\
162.5\end{array}$ & $\begin{array}{l}7.5 \\
7.6 \\
7.5 \\
7.3\end{array}$ & $\begin{array}{l}183.4 \\
139.8 \\
111.2 \\
131.5\end{array}$ & $\begin{array}{c}142.8 \\
109.0 \\
85.3 \\
97.8\end{array}$ & $\begin{array}{l}79.0 \\
58.5 \\
43.8 \\
52.5\end{array}$ & $\begin{array}{l}98.8 \\
76.0 \\
59.3 \\
71.3\end{array}$ & $\begin{array}{l}15.5 \\
11.8 \\
10.8 \\
11.5\end{array}$ & $\begin{array}{l}4.4 \\
4.4 \\
4.4 \\
5.2\end{array}$ & $\begin{array}{l}22.7 \\
16.7 \\
12.5 \\
15.3\end{array}$ & $\begin{array}{l}5.4 \\
4.0 \\
3.0 \\
3.5\end{array}$ \\
\hline$(\vec{X} n o)$ & 176.1 & 7.5 & 141.5 & 108.7 & 58.4 & 76.3 & 12.4 & 4.6 & 16.8 & 4.0 \\
\hline $\begin{array}{c}\text { ENTROPY } \\
\text { (Xne) }\end{array}$ & $\begin{array}{l}175.4 \\
177.9 \\
172.4 \\
170.1\end{array}$ & $\begin{array}{l}7.9 \\
7.9 \\
7.9 \\
7.9\end{array}$ & $\begin{array}{l}157.3 \\
161.4 \\
141.6 \\
136.8\end{array}$ & $\begin{array}{l}126.4 \\
128.6 \\
112.4 \\
107.6\end{array}$ & $\begin{array}{l}62.8 \\
63.7 \\
58.7 \\
57.9\end{array}$ & $\begin{array}{l}78.5 \\
78.1 \\
71.0 \\
72.6\end{array}$ & $\begin{array}{l}16.7 \\
17.3 \\
13.2 \\
12.1\end{array}$ & $\begin{array}{l}4.3 \\
4.3 \\
4.3 \\
4.3\end{array}$ & $\begin{array}{l}17.8 \\
18.6 \\
14.5 \\
15.0\end{array}$ & $\begin{array}{l}4.9 \\
4.9 \\
4.7 \\
4.7\end{array}$ \\
\hline$\overline{(\bar{x} \cap e)}$ & 173.9 & 7.9 & 149.3 & 118.7 & 60.8 & 75.0 & 14.8 & 4.3 & 16.5 & 4.8 \\
\hline
\end{tabular}

Number of Standard Deviations of the Distribution of Sampled Means by which the New/Predicted Mean Values lies from the Historical Mean Values

\begin{tabular}{|c|c|c|c|c|c|c|c|c|c|c|}
\hline & $\begin{array}{c}\text { Conductivity } \\
@ 25 \mathrm{C} \\
(\mathrm{ms} / \mathrm{m})\end{array}$ & $\mathrm{PH}$ & $\begin{array}{c}\text { Dissolved } \\
\text { lons } \\
\text { (mg/l) }\end{array}$ & $\begin{array}{c}\text { Dissolved } \\
\text { Solids } \\
\text { (mg/l) }\end{array}$ & $\begin{array}{c}\text { Hardness } \\
\text { (mg/)as } \mathrm{CaCO} 3\end{array}$ & $\begin{array}{c}\text { Alkalinity } \\
\text { (mg/l)as } \mathrm{CaCO}\end{array}$ & $\begin{array}{l}\text { Natrium } \\
\text { (mg/it) }\end{array}$ & $\begin{array}{l}\text { Kalium } \\
\text { (mg/l) }\end{array}$ & $\begin{array}{l}\text { Calcium } \\
\text { (mg/l) }\end{array}$ & $\begin{array}{c}\text { Magnesium } \\
\text { (mg/) }\end{array}$ \\
\hline 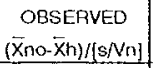 & -1.25 & -0.54 & -1.26 & -1.19 & -1.25 & -1.05 & -1.33 & 1.07 & -1.13 & -1.45 \\
\hline $\begin{array}{c}\text { ENTROPY } \\
\{\bar{X} n e-\bar{X} n) /\left[s / N_{n}\right]\end{array}$ & -1.27 & 3.33 & -1.11 & -0.93 & -1.15 & -1.11 & -1.03 & 0.76 & -1.17 & -0.90 \\
\hline
\end{tabular}

\section{[3 Yearly Averaging]}

New/Predicted Mean Values

\begin{tabular}{|c|c|c|c|c|c|c|c|c|c|c|}
\hline & $\begin{array}{c}\text { Conductivity } \\
@ 25 \mathrm{C} \\
(\mathrm{ms} / \mathrm{m})\end{array}$ & $\mathrm{PH}$ & $\begin{array}{c}\text { Dissolved } \\
\text { lons } \\
(\mathrm{mg} /) \\
\end{array}$ & $\begin{array}{c}\text { Dissolved } \\
\text { Solids } \\
\text { (mg/) } \\
\end{array}$ & $\begin{array}{c}\text { Hardness } \\
\text { (mg/l)as CaCO3 }\end{array}$ & $\begin{array}{c}\text { Alkalinity } \\
\text { (mg//)as CaCO3 } \\
\end{array}$ & $\begin{array}{l}\text { Natrium } \\
\text { (mg/) }\end{array}$ & $\begin{array}{l}\text { Kalium } \\
(\mathrm{mg} / \mathrm{l})\end{array}$ & $\begin{array}{l}\text { Calcium } \\
\text { (mg/l) }\end{array}$ & $\begin{array}{l}\text { Magnesium } \\
\text { (mg/l) }\end{array}$ \\
\hline $\begin{array}{c}\text { OBSERVED } \\
(X n o)\end{array}$ & $\begin{array}{l}192.1 \\
169.2 \\
150.0\end{array}$ & $\begin{array}{l}7.5 \\
7.5 \\
7.4\end{array}$ & $\begin{array}{l}154.6 \\
134.9 \\
120.1\end{array}$ & $\begin{array}{l}121.8 \\
102.8 \\
91.8\end{array}$ & $\begin{array}{l}65.0 \\
55.8 \\
47.3\end{array}$ & $\begin{array}{l}82.8 \\
73.2 \\
64.5\end{array}$ & $\begin{array}{l}13.5 \\
11.8 \\
10.8\end{array}$ & $\begin{array}{l}4.4 \\
4.3 \\
5.0\end{array}$ & $\begin{array}{l}18.4 \\
16.1 \\
13.5\end{array}$ & $\begin{array}{l}4.5 \\
3.7 \\
3.3\end{array}$ \\
\hline$\left(\bar{X}_{\cap 0}\right)$ & 170.4 & 7.5 & 136.5 & 105.5 & 56.1 & 73.5 & 12.1 & 4.6 & 16.0 & 3.8 \\
\hline $\begin{array}{c}\text { ENTROPY } \\
(X n e)\end{array}$ & $\begin{array}{l}173.7 \\
174.0 \\
170.0\end{array}$ & $\begin{array}{l}7.5 \\
7.5 \\
7.5\end{array}$ & $\begin{array}{l}173.5 \\
173.7 \\
170.6\end{array}$ & $\begin{array}{l}119.4 \\
117.7 \\
106.1\end{array}$ & $\begin{array}{l}58.4 \\
59.1 \\
54.8\end{array}$ & $\begin{array}{l}72.9 \\
73.1 \\
68.7\end{array}$ & $\begin{array}{l}15.3 \\
14.8 \\
12.0\end{array}$ & $\begin{array}{l}4.4 \\
4.4 \\
4.4\end{array}$ & $\begin{array}{l}14.9 \\
14.8 \\
12.6\end{array}$ & $\begin{array}{l}4.9 \\
4.9 \\
4.8\end{array}$ \\
\hline$\left(\mathrm{X}_{n e}\right)$ & 172.5 & 7.5 & 172.6 & 114.4 & 57.4 & 71.8 & 14.0 & 4.4 & 14.1 & 4.9 \\
\hline
\end{tabular}

Number of Standard Deviations of the Distribution of Sampled Means by which the New/Predicted Mean Values lies from the Historical Mean Values

\begin{tabular}{|c|c|c|c|c|c|c|c|c|c|c|}
\hline & $\begin{array}{c}\text { Conductivity } \\
@ 25 \mathrm{C} \\
\text { (ms/m) } \\
\end{array}$ & $\mathrm{PH}$ & $\begin{array}{c}\text { Dissolved } \\
\text { lons } \\
\text { (mg/l) }\end{array}$ & $\begin{array}{c}\text { Dissolved } \\
\text { Solids } \\
\text { (mg/l) } \\
\end{array}$ & $\begin{array}{c}\text { Hardness } \\
\text { (mg/l)as } \mathrm{CaCO} 3\end{array}$ & $\begin{array}{c}\text { Alkalinity } \\
\text { (mg/f)as } \mathrm{CaCO} 3\end{array}$ & $\begin{array}{l}\text { Natrium } \\
(\mathrm{mg} / \mathrm{l})\end{array}$ & $\begin{array}{l}\text { Kalium } \\
\text { (mg/) }\end{array}$ & $\begin{array}{l}\text { Calcium } \\
\text { (mg/l) }\end{array}$ & $\begin{array}{l}\text { Magnesium } \\
\text { (mg/) }\end{array}$ \\
\hline $\begin{array}{c}\text { OBSERVED } \\
(\bar{X} \mathrm{Xn}-\overline{\mathrm{X}} \mathrm{h}) /[\mathrm{s} N \mathrm{~N}]\end{array}$ & -1.14 & -0.27 & -1.17 & -1.10 & -1.18 & -1.01 & -1.18 & 0.92 & -1.07 & -1.33 \\
\hline $\begin{array}{c}\text { ENTROPY } \\
(\bar{X} n e-\bar{X} h) /[s / N n]\end{array}$ & -1.12 & -0.17 & -0.59 & -0.90 & -1.12 & -1.08 & -0.97 & 0.67 & -1.31 & -0.72 \\
\hline
\end{tabular}


Table B.4.2(b) (continued)

[4 Yearly Averaging]

New/Predicted Mean Values

\begin{tabular}{|c|c|c|c|c|c|c|c|c|c|c|}
\hline & $\begin{array}{c}\text { Conductivity } \\
\text { @ } 25 \mathrm{C} \\
\text { (ms/m) } \\
\end{array}$ & $\mathrm{PH}$ & $\begin{array}{c}\text { Dissolved } \\
\text { tons } \\
\text { (mg/l) } \\
\end{array}$ & $\begin{array}{c}\text { Dissolved } \\
\text { Solids } \\
\text { (mg/) } \\
\end{array}$ & $\begin{array}{c}\text { Hardness } \\
\text { (mg/)as } \mathrm{CaCO} 3\end{array}$ & $\begin{array}{c}\text { Alkalinity } \\
\text { (mg/l)as CaCo3 }\end{array}$ & $\begin{array}{l}\text { Natrium } \\
\text { (mgl) }\end{array}$ & $\begin{array}{l}\text { Kalium } \\
\text { (mg/) }\end{array}$ & $\begin{array}{l}\text { Calcium } \\
\text { (mg/l) }\end{array}$ & $\begin{array}{l}\text { Magnesiurn } \\
\text { (mg/l) }\end{array}$ \\
\hline OBSERVEO & 182.2 & 7.5 & 147.3 & 114.0 & 61.4 & 79.0 & 13.1 & 4.4 & 17.6 & 4.2 \\
\hline (Xno) & 170.0 & 7.4 & 135.6 & 103.4 & 55.5 & 73.6 & 11.6 & 4.8 & 15.0 & 3.8 \\
\hline$\left(X_{n O}\right)$ & 176.1 & 7.5 & 141.5 & 108.7 & 58.4 & 76.3 & 12.4 & 4.6 & 16.8 & 4.0 \\
\hline ENTROPY & 173.4 & 7.5 & 173.7 & 117.5 & 65.3 & 78.1 & 13.2 & 4.4 & 16.8 & 5.2 \\
\hline (Xne) & 173.6 & 7.5 & 173.6 & 116.1 & 65.3 & 78.6 & 13.0 & 4.4 & 17.5 & 5.2 \\
\hline$\left(\bar{X}_{n e}\right)$ & 173.5 & 7.5 & 173.6 & 116.8 & 65.3 & 78.4 & 13.1 & 4.4 & 17.1 & 5.2 \\
\hline
\end{tabular}

Number of Standard Deviations of the Distribution of Sampled Means by which the New/Predicted Mean Values lies from the Historical Mean Values

\begin{tabular}{|c|c|c|c|c|c|c|c|c|c|c|}
\hline & $\begin{array}{c}\text { Conductivity } \\
\text { @ } 25 \mathrm{c} \\
\text { (ms/m) }\end{array}$ & $\mathrm{PH}$ & $\begin{array}{c}\text { Dissolved } \\
\text { lons } \\
(\mathrm{mg} / \mathrm{l}) \\
\end{array}$ & $\begin{array}{c}\text { Dissolved } \\
\text { Solids } \\
(\mathrm{mg} A) \\
\end{array}$ & $\begin{array}{c}\text { Hardness } \\
\text { (mgn)as } \mathrm{CaCO} 3 \\
\end{array}$ & $\begin{array}{c}\text { Alkalinity } \\
\text { (mgl)as } \mathrm{CaCO} 3\end{array}$ & $\begin{array}{l}\text { Natrium } \\
(\mathrm{mg} / \mathrm{l}) \\
\end{array}$ & $\begin{array}{l}\text { Kalium } \\
\text { (mg/l) }\end{array}$ & $\begin{array}{l}\text { Calcium } \\
\text { (mg/) }\end{array}$ & $\begin{array}{c}\text { Magnesium } \\
(\mathrm{mg} / \Omega)\end{array}$ \\
\hline $\begin{array}{c}\text { OBSERVED } \\
(\bar{X} \cap \cap-\bar{X} h) /[s / N n]\end{array}$ & -0.88 & -0.38 & -0.89 & -0.84 & -0.89 & -0.74 & -0.94 & 0.76 & -0.80 & -1.02 \\
\hline $\begin{array}{c}\text { ENTROPY } \\
(\bar{X} n \mathrm{e}-\overline{\mathrm{X}} h) /[\mathrm{s} / \mathrm{N})\end{array}$ & -0.91 & -0.15 & -0.47 & -0.69 & -0.67 & -0.68 & -0.88 & 0.60 & -0.76 & -0.46 \\
\hline
\end{tabular}


Table B.4.2(c) Station 130209

Historical (prior) Mean Values

\begin{tabular}{|c|c|c|c|c|c|c|c|c|c|c|}
\hline & $\begin{array}{l}\text { Conducivity } \\
@ 25 \mathrm{C} \\
\text { (msim) }\end{array}$ & $\mathrm{PH}$ & $\begin{array}{c}\text { Oissolved } \\
\text { Ions } \\
\text { (mgn) }\end{array}$ & $\begin{array}{c}\text { Dissolved } \\
\text { Solids } \\
\text { (mg/) } \\
\end{array}$ & $\begin{array}{c}\text { Hardness } \\
\text { (mgl)as } \mathrm{CaCO} 3\end{array}$ & $\begin{array}{c}\text { Aikalinity } \\
\text { (mgll)as Cacos }\end{array}$ & $\begin{array}{l}\text { Nantum } \\
\text { (mgl) }\end{array}$ & $\begin{array}{l}\text { Kallum } \\
\text { (mgl) }\end{array}$ & $\begin{array}{l}\text { Calcium } \\
(\mathrm{mg} /)\end{array}$ & $\begin{array}{l}\text { Magnesium } \\
\text { (mg/) } \\
\end{array}$ \\
\hline Mean $\quad(\bar{X} h)$ & 325.9 & 7.7 & 253.5 & 182.3 & 109.2 & 132.9 & 250 & 3.ิे & 19.5 & 14.7 \\
\hline $\begin{array}{l}\text { Standard (s) } \\
\text { Deviation }\end{array}$ & 222.2 & 0.4 & 152.0 & 112.1 & 71.8 & 90.0 & 19.0 & 1.5 & 5.5 & 14.4 \\
\hline
\end{tabular}

\section{[1 Yearly Averaging]}

New Mean Values

\begin{tabular}{|c|c|c|c|c|c|c|c|c|c|c|}
\hline & $\begin{array}{c}\text { Conductivity } \\
@ 25 \mathrm{C} \\
(\mathrm{mS} / \mathrm{m})\end{array}$ & PH & $\begin{array}{c}\text { Oissolved } \\
\text { lons } \\
\text { (mg/) }\end{array}$ & $\begin{array}{c}\text { Dissolved } \\
\text { Solids } \\
\text { (mg/) }\end{array}$ & $\begin{array}{c}\text { Haroness } \\
\text { (mgh)as } \mathrm{CaCO} 3\end{array}$ & $\begin{array}{c}\text { Alkalinity } \\
\text { (mgn)as Caccal }\end{array}$ & $\begin{array}{l}\text { Natrum } \\
\text { (mgl) }\end{array}$ & $\begin{array}{l}\text { Xalium } \\
\text { (m:gn) }\end{array}$ & $\begin{array}{l}\text { Calcium } \\
\text { (mg/) }\end{array}$ & $\begin{array}{c}\text { Magnesium } \\
\text { (mgn) } \\
\end{array}$ \\
\hline \multirow[t]{2}{*}{ OBSERVED } & 155.0 & 7.4 & 134.3 & 113.3 & 54.0 & 67.3 & 13.0 & 5.2 & 14.7 & 4.3 \\
\hline & 255.0 & 7.5 & 202.8 & 150.7 & 78.0 & 100.3 & 21.3 & 5.2 & 18.7 & 7.7 \\
\hline \multirow[t]{3}{*}{$(X n \cap)$} & 207.5 & 7.5 & 147.8 & 120.0 & 57.5 & 65.5 & 14.5 & 5.0 & 15.5 & 4.7 \\
\hline & 171.7 & 7.5 & 137.4 & 105.7 & 50.3 & 68.5 & 11.3 & 4.9 & 14.5 & 4.6 \\
\hline & 170.0 & 7.4 & 132.0 & 105.0 & 54.0 & 72.7 & 11.7 & 5.4 & 15.0 & 4.4 \\
\hline$\left(\bar{x}_{n o}\right)$ & 195.3 & 7.5 & 150.9 & 120.1 & 50.4 & 74.9 & 144 & 5.1 & 15.9 & 5.1 \\
\hline
\end{tabular}

Number of Standard Deviations of the Distribution of Sampled Means by which the New Mean Values lies from the Historical Mean Values

\begin{tabular}{|c|c|c|c|c|c|c|c|c|c|c|}
\hline & $\begin{array}{l}\text { Conductjity } \\
@ 25 \mathrm{C} \\
\text { (mSim) }\end{array}$ & $\mathrm{PH}$ & $\begin{array}{l}\text { Oissolved } \\
\text { lons } \\
\text { (mg/) }\end{array}$ & $\begin{array}{l}\text { Dssoived } \\
\text { Solids } \\
\text { (mgi) }\end{array}$ & $\begin{array}{c}\text { Hardness } \\
\text { (mg/)as Caco } 3\end{array}$ & $\begin{array}{c}\text { Alkalinity } \\
\text { (mgin)as Caca }\end{array}$ & $\begin{array}{l}\text { Natrum } \\
\text { (mgi) }\end{array}$ & $\begin{array}{l}\text { Kalium } \\
\text { (mgy) }\end{array}$ & $\begin{array}{l}\text { Calaum } \\
\text { (mgn) }\end{array}$ & $\begin{array}{l}\text { Maçesium } \\
\text { (mg/l) }\end{array}$ \\
\hline 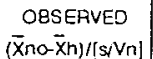 & -1.31 & -1.71 & $-1,42$ & -1.24 & -1.52 & -1.44 & -1.37 & 2.10 & -1.48 & -1.49 \\
\hline
\end{tabular}

\section{[2 Yearly Averaging]}

New Mean Values

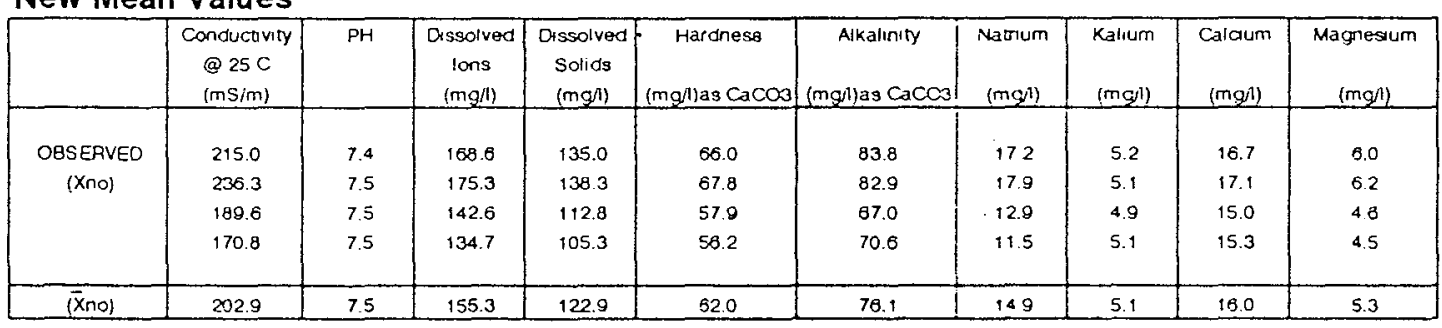

Number of Standard Deviations of the Distribution of Sampled Means by which the New Mean Values lies from the Historical Mean Values

\begin{tabular}{|c|c|c|c|c|c|c|c|c|c|c|}
\hline & $\begin{array}{l}\text { Conductuty } \\
\text { (1) } 25 \mathrm{C} \\
\text { (ms/m) }\end{array}$ & $\mathrm{PH}$ & $\begin{array}{l}\text { Dissolved } \\
\text { Ions } \\
\text { (mg/l) }\end{array}$ & $\begin{array}{c}\text { Diesolved } \\
\text { Soltds } \\
\text { (mgll) }\end{array}$ & $\begin{array}{c}\text { Harchess } \\
\text { (mgh)as } \mathrm{CaCO}\end{array}$ & $\begin{array}{c}\text { Alkalınty } \\
\text { (mgl)as CaCCa }\end{array}$ & $\begin{array}{l}\text { Natrum } \\
\text { (mgi) }\end{array}$ & $\begin{array}{l}\text { Kalium } \\
\text { (mg/) }\end{array}$ & $\begin{array}{l}\text { Calaum } \\
\text { (mgy) }\end{array}$ & $\begin{array}{l}\text { Magnesuum } \\
\text { (mgii) }\end{array}$ \\
\hline $\begin{array}{c}\text { OBSERVED } \\
(\bar{x} \cap-\bar{x} n) /[(\xi / V \cap]\end{array}$ & -1.11 & -1.46 & -1.21 & -1.06 & -1.32 & -1.28 & -1.17 & 1.84 & -1.20 & -1.30 \\
\hline
\end{tabular}


Table B.4.2(c) (continued)

[3 Yearly Averaging]

New Mean Values

\begin{tabular}{|c|c|c|c|c|c|c|c|c|c|c|}
\hline & $\begin{array}{c}\text { Conductivity } \\
@ 25 \mathrm{C} \\
\text { (ms/m) } \\
\end{array}$ & $\mathrm{PH}$ & $\begin{array}{c}\text { Dissolved } \\
\text { lons } \\
\text { (mg/) }\end{array}$ & $\begin{array}{c}\text { Dissolved } \\
\text { Solids } \\
\text { (mgl) } \\
\end{array}$ & $\begin{array}{c}\text { Hardness } \\
\text { (mg/)as Caco3 }\end{array}$ & $\begin{array}{c}\text { Alkalinity } \\
\text { (mg/l)as } \mathrm{CaCO} 3 \\
\end{array}$ & $\begin{array}{l}\text { Natrium } \\
(\mathrm{mg} / \mathrm{l}) \\
\end{array}$ & $\begin{array}{l}\text { Kalium } \\
\text { (mg/) }\end{array}$ & $\begin{array}{l}\text { Calcium } \\
(\mathrm{mg} / \mathrm{l})\end{array}$ & $\begin{array}{c}\text { Magnesium } \\
\text { (mg//) }\end{array}$ \\
\hline $\begin{array}{c}\text { OBSERVED } \\
(X n O)\end{array}$ & $\begin{array}{l}212.5 \\
214.7 \\
183.1\end{array}$ & $\begin{array}{l}7.4 \\
7.5 \\
7.5\end{array}$ & $\begin{array}{l}161.6 \\
162.7 \\
139.1\end{array}$ & $\begin{array}{l}130.0 \\
127.4 \\
110.2\end{array}$ & $\begin{array}{l}63.2 \\
64.6 \\
56.6\end{array}$ & $\begin{array}{l}77.7 \\
78.1 \\
68.9\end{array}$ & $\begin{array}{l}16.3 \\
15.7 \\
12.5\end{array}$ & $\begin{array}{l}5.1 \\
5.0 \\
5.1\end{array}$ & $\begin{array}{l}16.3 \\
16.2 \\
15.3\end{array}$ & $\begin{array}{l}5.6 \\
5.6 \\
4.5\end{array}$ \\
\hline$\left(\bar{x}_{n \circ}\right)$ & 203.4 & 7.5 & 154.5 & 122.6 & 61.5 & 74.9 & 14.8 & 5.1 & 15.9 & 5.2 \\
\hline
\end{tabular}

Number of Standard Deviations of the Distribution of Sampled Means by which the New Mean Values lies from the Historical Mean Values

\begin{tabular}{|c|c|c|c|c|c|c|c|c|c|c|}
\hline & $\begin{array}{c}\text { Conductivity } \\
@ 25 \mathrm{C} \\
\text { (ms/m) }\end{array}$ & $\mathrm{PH}$ & $\begin{array}{c}\text { Dissolved } \\
\text { Ions } \\
\text { (mgh) } \\
\end{array}$ & $\begin{array}{c}\text { Dissolved } \\
\text { Solids } \\
\text { (mg/l) }\end{array}$ & $\begin{array}{c}\text { Hardness } \\
\text { (mg/has CaCO3 }\end{array}$ & $\begin{array}{c}\text { Alkalinity } \\
\text { (mg//)as } \mathrm{CaCO} 3\end{array}$ & $\begin{array}{l}\text { Natrium } \\
(\mathrm{mg} / \mathrm{l})\end{array}$ & $\begin{array}{l}\text { Kalium } \\
\text { (mg/l) }\end{array}$ & $\begin{array}{l}\text { Calcium } \\
(\mathrm{mg} / \mathrm{l})\end{array}$ & $\begin{array}{l}\text { Magnesium } \\
\text { (mg/li) }\end{array}$ \\
\hline $\begin{array}{c}\text { OBSERVED } \\
\left(\bar{X} \text { no- } \bar{X}_{n} h\right) /[s / \mathrm{s} n]\end{array}$ & -0.95 & -1.27 & -1.06 & -0.92 & -1.15 & -1.12 & -1.02 & 1.58 & -1.12 & -1.14 \\
\hline
\end{tabular}

\section{[4 Yearly Averaging]}

New Mean Values

\begin{tabular}{|c|c|c|c|c|c|c|c|c|c|c|}
\hline & $\begin{array}{c}\text { Conductivity } \\
@ 25 \mathrm{C} \\
\text { (ms/m) }\end{array}$ & $\mathrm{PH}$ & $\begin{array}{c}\text { Dissolved } \\
\text { lons } \\
\text { (mg/l) } \\
\end{array}$ & $\begin{array}{c}\text { Dissolved } \\
\text { Solids } \\
\text { (mg/l) } \\
\end{array}$ & $\begin{array}{c}\text { Hardness } \\
\text { (mg/)as } \mathrm{CaCO} 3 \\
\end{array}$ & $\begin{array}{c}\text { Alkalinity } \\
\text { (mgf)as } \mathrm{CaCO} \\
\end{array}$ & $\begin{array}{l}\text { Natrium } \\
\text { (mg/i) } \\
\end{array}$ & $\begin{array}{l}\text { Kalium } \\
\text { (mgid) }\end{array}$ & $\begin{array}{l}\text { Calcium } \\
\text { (mg/l) } \\
\end{array}$ & $\begin{array}{c}\text { Magnesium } \\
\text { (mg/l) }\end{array}$ \\
\hline $\begin{array}{c}\text { OBSERVED } \\
\left(x_{n \circ}\right)\end{array}$ & $\begin{array}{l}202.3 \\
203.5\end{array}$ & $\begin{array}{l}7.5 \\
7.5\end{array}$ & $\begin{array}{l}155.6 \\
155.0\end{array}$ & $\begin{array}{l}123.9 \\
121.8\end{array}$ & $\begin{array}{l}62.0 \\
62.0\end{array}$ & $\begin{array}{l}75.4 \\
76.8\end{array}$ & $\begin{array}{l}15.0 \\
14.7\end{array}$ & $\begin{array}{l}5.1 \\
5.1\end{array}$ & $\begin{array}{l}15.8 \\
16.2\end{array}$ & $\begin{array}{l}5.3 \\
5.3\end{array}$ \\
\hline (X̄no) & 202.9 & 7.5 & 155.3 & 122.9 & 62.0 & 76.1 & 14.9 & 5.1 & 16.0 & 5.3 \\
\hline
\end{tabular}

Number of Standard Deviations of the Distribution of Sampled Means by which the New Mean Values lies from the Historical Mean Values

\begin{tabular}{|c|c|c|c|c|c|c|c|c|c|c|}
\hline & $\begin{array}{l}\text { Conductivity } \\
\text { @ } 25 \mathrm{C} \\
\text { (mS/m) }\end{array}$ & $\mathrm{PH}$ & $\begin{array}{l}\text { Dissolved } \\
\text { lons } \\
(\mathrm{mg} /)\end{array}$ & $\begin{array}{c}\text { Dissolved } \\
\text { Solids } \\
(\mathrm{mg} /)\end{array}$ & $\begin{array}{c}\text { Hardness } \\
\text { (mg/l)as } \mathrm{CaCO} 3\end{array}$ & $\begin{array}{c}\text { Alkalinity } \\
\text { (mg/)as } \mathrm{CaCO} 3\end{array}$ & $\begin{array}{l}\text { Natrium } \\
\text { (mg/l) }\end{array}$ & $\begin{array}{l}\text { Kalium } \\
(\mathrm{mg} / \mathrm{l})\end{array}$ & $\begin{array}{l}\text { Calcium } \\
\text { (mg/l) }\end{array}$ & $\begin{array}{l}\text { Magnesium } \\
(\mathrm{mg} / \mathrm{l})\end{array}$ \\
\hline $\begin{array}{c}\text { OBSERVED } \\
(\bar{X} n o-\bar{X} h) /[s / V n]\end{array}$ & -0.78 & -1.03 & -0.86 & -0.75 & -0.93 & -0.89 & -0.83 & 1.30 & -0.90 & -0.92 \\
\hline
\end{tabular}


Table B.4.3 Evaluation of the Water Quality Values in the Logan River Basin

Table B.4.3(a) Station 145010

Historical (prior) Mean Values

\begin{tabular}{|c|c|c|c|c|c|c|c|c|c|c|}
\hline & $\begin{array}{c}\text { Conduclivity } \\
\text { @ 25 C } \\
\text { (ms/m) }\end{array}$ & $\mathrm{PH}$ & $\begin{array}{c}\text { Dissolved } \\
\text { lons } \\
(\mathrm{mg} / \mathrm{l}) \\
\end{array}$ & $\begin{array}{c}\text { Dissolved } \\
\text { Solids } \\
\text { (mg/l) } \\
\end{array}$ & $\begin{array}{c}\text { Hardness } \\
\text { (mg/)as Caco3 } \\
\end{array}$ & $\begin{array}{c}\text { Alkalinity } \\
\text { (mg/l)as CaCO3 } \\
\end{array}$ & $\begin{array}{l}\text { Natrium } \\
(\mathrm{mg} / \mathrm{l})\end{array}$ & $\begin{array}{l}\text { Kalium } \\
\text { (mg/l) }\end{array}$ & $\begin{array}{l}\text { Calcium } \\
\text { (mg/l) }\end{array}$ & $\begin{array}{l}\text { Magnesium } \\
\quad(\mathrm{mg} / 1) \\
\end{array}$ \\
\hline Mean $\quad(\bar{X} h)$ & 355.6 & 7.8 & 232.9 & 201.9 & 114.3 & 89.1 & 25.5 & 1.5 & 20.2 & 15.5 \\
\hline $\begin{array}{l}\text { Standard (s) } \\
\text { Deviation }\end{array}$ & 98.0 & 0.5 & 65.9 & 50.9 & 35.4 & 30.1 & 6.2 & 0.2 & 6.1 & 4.9 \\
\hline
\end{tabular}

\section{[1 Yearly Averaging]}

New/Predicted Mean Values

\begin{tabular}{|c|c|c|c|c|c|c|c|c|c|c|}
\hline & $\begin{array}{c}\text { Conductivity } \\
@ 25 \mathrm{C} \\
\text { (mS/m) }\end{array}$ & $\mathrm{PH}$ & $\begin{array}{c}\text { Dissolved } \\
\text { lons } \\
\text { (mg/l) }\end{array}$ & $\begin{array}{c}\text { Dissolved } \\
\text { Solids } \\
(\mathrm{mg} /)\end{array}$ & $\begin{array}{c}\text { Hardness } \\
\text { (mg/l)as } \mathrm{CaCO} 3\end{array}$ & $\begin{array}{c}\text { Alkalinity } \\
(\mathrm{mg} / \text { ) as } \mathrm{CaCO} 3\end{array}$ & $\begin{array}{l}\text { Natrium } \\
\langle\mathrm{mg} h\rangle\end{array}$ & $\begin{array}{l}\text { Kalium } \\
(\mathrm{mg} /)\end{array}$ & $\begin{array}{l}\text { Calcium } \\
(\mathrm{mg} / \mathrm{l})\end{array}$ & $\begin{array}{c}\text { Magnesium } \\
\text { (mg/i) }\end{array}$ \\
\hline \multirow[t]{5}{*}{ OBSERVEO } & 348.5 & 7.8 & 220.2 & 188.0 & 108.5 & 83.5 & 53.4 & 1.3 & 10.1 & 16.9 \\
\hline & 360.0 & 8.0 & 223.5 & 192.5 & 115.3 & 83.8 & 22.0 & 1.2 & 20.0 & 15.9 \\
\hline & 205.0 & 7.4 & 129.9 & 117.0 & 64.0 & 47.3 & 14.5 & 1.5 & 11.6 & 8.5 \\
\hline & 328.8 & 7.6 & 222.6 & 192.0 & 112.3 & 87.8 & 23.3 & 1.3 & 20.0 & 15.1 \\
\hline & 347.5 & 7.9 & 250.5 & 210.0 & 109.5 & 95.5 & 32.8 & 1.5 & 20.8 & 14.0 \\
\hline (Xno) & 318.0 & 7.7 & 209.3 & 179.9 & 101.9 & 79.6 & 29.2 & 1.3 & 16.5 & 14.1 \\
\hline \multirow[t]{2}{*}{ ENTROPY } & 354.9 & 8.2 & 231.6 & 199.5 & 110.8 & 84.6 & 25.6 & 1.5 & 35.0 & 14.8 \\
\hline & 355.9 & 7.9 & 232.8 & 200.8 & 112.8 & 88.1 & 25.5 & 1.5 & 35.0 & 15.3 \\
\hline \multirow[t]{3}{*}{ (Xne) } & 352.9 & 8.3 & 229.5 & 197.3 & 107.3 & 71.7 & 25.6 & 1.5 & 18.6 & 14.6 \\
\hline & 351.7 & 7.7 & 235.6 & 203.3 & 117.1 & 93.7 & 25.5 & 1.5 & 20.9 & 15.9 \\
\hline & 355.9 & 6.9 & 233.1 & 201.4 & 113.8 & 87.3 & 25.5 & 1.5 & 35.0 & 15.8 \\
\hline$(\overline{\mathrm{X} n e})$ & 354.3 & 7.8 & 232.5 & 200.5 & $\{12.4$ & 85.1 & 25.5 & 1.5 & 28.9 & 15.3 \\
\hline
\end{tabular}

Number of Standard Deviations of the Distribution of Sampled Means by which the New/Predicted Mean Values lies from the Historical Mean Values

\begin{tabular}{|c|c|c|c|c|c|c|c|c|c|c|}
\hline & $\begin{array}{c}\text { Conductivity } \\
\text { @ } 25 \mathrm{C} \\
\text { (ms/m) } \\
\end{array}$ & $\mathrm{PH}$ & $\begin{array}{c}\text { Dissolved } \\
\text { Ions } \\
\text { (mg/) }\end{array}$ & $\begin{array}{c}\text { Dissolved } \\
\text { Solids } \\
\text { (mg/) }\end{array}$ & $\begin{array}{c}\text { Hardness } \\
\text { (mg/l)as } \mathrm{CaCO} 3\end{array}$ & $\begin{array}{c}\text { Alkalinity } \\
\text { (mg/l)as } \mathrm{CaCO}\end{array}$ & $\begin{array}{l}\text { Natrium } \\
\text { (mg/l) }\end{array}$ & $\begin{array}{l}\text { Kalium } \\
\text { (mg/l) }\end{array}$ & $\begin{array}{l}\text { Calcium } \\
\text { (mg/h) }\end{array}$ & $\begin{array}{l}\text { Magnesium } \\
\text { (mg/l) }\end{array}$ \\
\hline $\begin{array}{c}\text { OBSERVED } \\
(\bar{X} n o-\bar{X} h) /[s / V n]\end{array}$ & -0.86 & -0.08 & -0.80 & -0.97 & -0.78 & -0.71 & 1.34 & -1.42 & -1.36 & -0.66 \\
\hline $\begin{array}{c}\text { ENTROPY } \\
(\bar{X} n e-\bar{X} h) /[s / N n]\end{array}$ & -0.03 & 0.06 & -0.01 & -0.06 & -0.12 & -0.30 & 0.03 & 0.34 & 3.17 & -0.10 \\
\hline
\end{tabular}


Table B.4.3(a) (continued)

\section{[2 Yearly Averaging]}

New/Predicted Mean Values

\begin{tabular}{|c|c|c|c|c|c|c|c|c|c|c|}
\hline & $\begin{array}{c}\text { Conductivity } \\
\text { @ } 25 \mathrm{C} \\
\text { (mS } / \mathrm{m}) \\
\end{array}$ & $\mathrm{PH}$ & $\begin{array}{c}\text { Dissolved } \\
\text { Ions } \\
\text { (mg/f) } \\
\end{array}$ & $\begin{array}{c}\text { Dissolved } \\
\text { Solids } \\
\text { (mg/l) }\end{array}$ & $\begin{array}{c}\text { Hardness } \\
\text { (mg/)as CaCo3 } \\
\end{array}$ & $\begin{array}{c}\text { Alkalinity } \\
\text { (mg/l)as } \mathrm{CaCO} 3 \\
\end{array}$ & $\begin{array}{l}\text { Natrium } \\
\text { (mgf) }\end{array}$ & $\begin{array}{l}\text { Kalium } \\
\text { (mg/l) }\end{array}$ & $\begin{array}{l}\text { Calcium } \\
\text { (mgn) }\end{array}$ & $\begin{array}{c}\text { Magnesium } \\
\text { (mg/) }\end{array}$ \\
\hline $\begin{array}{c}\text { OBSERVED } \\
\left(X_{10}\right)\end{array}$ & $\begin{array}{l}354.3 \\
282.5 \\
266.9 \\
338.1\end{array}$ & $\begin{array}{l}7.9 \\
7.7 \\
7.5 \\
7.8\end{array}$ & $\begin{array}{l}221.8 \\
176.7 \\
176.2 \\
236.5\end{array}$ & $\begin{array}{l}190.3 \\
154.8 \\
154.5 \\
201.0\end{array}$ & $\begin{array}{c}111.9 \\
89.6 \\
88.1 \\
110.9\end{array}$ & $\begin{array}{l}83.6 \\
65.5 \\
67.5 \\
91.6\end{array}$ & $\begin{array}{l}37.7 \\
18.2 \\
18.9 \\
28.0\end{array}$ & $\begin{array}{l}1.2 \\
1.3 \\
1.4 \\
1.4\end{array}$ & $\begin{array}{l}15.1 \\
15.8 \\
15.8 \\
20.4\end{array}$ & $\begin{array}{l}16.4 \\
12.2 \\
11.8 \\
14.6\end{array}$ \\
\hline$\left(\overline{x_{n}}\right)$ & 310.4 & 7.7 & 202.8 & 175.1 & 100.1 & 77.1 & 25.7 & 1.3 & 15.8 & 13.7 \\
\hline $\begin{array}{c}\text { ENTROPY } \\
\left(X_{n e}\right)\end{array}$ & $\begin{array}{l}310.4 \\
261.0 \\
311.7 \\
349.1\end{array}$ & $\begin{array}{l}8.4 \\
8.8 \\
8.4 \\
6.1\end{array}$ & $\begin{array}{c}199.2 \\
164.1 \\
199.9 \\
233.2\end{array}$ & $\begin{array}{l}175.9 \\
148.4 \\
178.3 \\
201.6\end{array}$ & $\begin{array}{c}92.9 \\
76.5 \\
96.2 \\
117.6\end{array}$ & $\begin{array}{l}74.4 \\
64.4 \\
75.8 \\
90.7\end{array}$ & $\begin{array}{l}24.0 \\
23.2 \\
24.0 \\
25.3\end{array}$ & $\begin{array}{l}1.5 \\
1.5 \\
1.5 \\
1.5\end{array}$ & $\begin{array}{l}17.2 \\
15.3 \\
17.8 \\
19.6\end{array}$ & $\begin{array}{l}10.8 \\
10.1 \\
12.8 \\
27.0\end{array}$ \\
\hline (Xne) & 308.1 & 7.9 & 199,1 & 176.1 & 95.8 & 76.3 & 24.1 & 1.5 & 17.5 & 15.2 \\
\hline
\end{tabular}

Number of Standard Deviations of the Distribution of Sampled Means by which the New/Predicted Mean Values lies from the Historical Mean Values

\begin{tabular}{|c|c|c|c|c|c|c|c|c|c|c|}
\hline & $\begin{array}{c}\text { Conductivity } \\
@ 25 \mathrm{C} \\
\text { (ms/m) }\end{array}$ & $\mathrm{PH}$ & \begin{tabular}{|c|} 
Dissolved \\
tons \\
(mg/h) \\
\end{tabular} & $\begin{array}{c}\text { Dissolved } \\
\text { Solids } \\
\text { (mg/l) }\end{array}$ & $\begin{array}{c}\text { Hardness } \\
\text { (mg/l)as } \mathrm{CaCO} 3\end{array}$ & \begin{tabular}{|c|} 
Alkalinity \\
(mg/l)as $\mathrm{CaCO} 3$ \\
\end{tabular} & $\begin{array}{l}\text { Natrium } \\
\text { (mg/l) }\end{array}$ & $\begin{array}{l}\text { Kalium } \\
\text { (mg/l) }\end{array}$ & $\begin{array}{l}\text { Calcium } \\
\text { (mg/i) }\end{array}$ & $\begin{array}{l}\text { Magnesium } \\
\text { (mg/i) }\end{array}$ \\
\hline $\begin{array}{c}\text { OBSERVED } \\
\left(\bar{X}_{n}(\overline{\mathrm{X}} \mathrm{h} h) /[\mathrm{s} N \mathrm{~N}]\right.\end{array}$ & -0.92 & -0.17 & -0.91 & -1.05 & -0.80 & -0.80 & 0.08 & -1.35 & -1.13 & -0.73 \\
\hline $\begin{array}{c}\text { ENTROPY } \\
\left(\bar{X}_{n e-\bar{X}}(h) /[s / N n]\right.\end{array}$ & -0.97 & 0.52 & -1.03 & -1.02 & -1.04 & -0.85 & -0.43 & 0.31 & -0.88 & -0.13 \\
\hline
\end{tabular}

\section{[3 Yearly Averaging]}

New/Predicted Mean Values

\begin{tabular}{|c|c|c|c|c|c|c|c|c|c|c|}
\hline & $\begin{array}{c}\text { Conductivity } \\
\text { @ } 25 \mathrm{C} \\
\text { (mS/m) }\end{array}$ & $\mathrm{PH}$ & $\begin{array}{c}\text { Dissolved } \\
\text { lons } \\
\text { (mill) }\end{array}$ & $\begin{array}{c}\text { Dissolved } \\
\text { Solids } \\
\text { (mg/l) }\end{array}$ & $\begin{array}{c}\text { Hardness } \\
\text { (mg/l)as } \mathrm{CaCO} 3\end{array}$ & $\begin{array}{c}\text { Alkalinity } \\
\text { (mg/)as } \mathrm{CaCO} 3\end{array}$ & $\begin{array}{l}\text { Natrium } \\
\text { (mgl) }\end{array}$ & $\begin{array}{l}\text { Kalium } \\
\text { (mg/l) }\end{array}$ & $\begin{array}{l}\text { Calcium } \\
\text { (mg/) }\end{array}$ & $\begin{array}{c}\text { Magnesium } \\
\text { (mg/ll) }\end{array}$ \\
\hline $\begin{array}{c}\text { OBSERVED } \\
\text { (XnO) }\end{array}$ & $\begin{array}{l}304.5 \\
297.9 \\
293.8\end{array}$ & $\begin{array}{l}7.7 \\
7.7 \\
7.7\end{array}$ & $\begin{array}{l}191.2 \\
192.0 \\
201.0\end{array}$ & $\begin{array}{l}165.8 \\
167.2 \\
173.0\end{array}$ & $\begin{array}{l}95.9 \\
97.2 \\
95.3\end{array}$ & $\begin{array}{l}71.5 \\
72.9 \\
76.9\end{array}$ & $\begin{array}{l}29.9 \\
19.9 \\
23.5\end{array}$ & $\begin{array}{l}1.3 \\
1.3 \\
1.4\end{array}$ & $\begin{array}{l}13.9 \\
17.2 \\
17.5\end{array}$ & $\begin{array}{r}13.8 \\
13.2 \\
12.5\end{array}$ \\
\hline$(\overline{x n o})$ & 298.7 & 7.7 & 194.7 & 168.7 & 96.1 & 73.8 & 24.4 & 1.3 & 16.2 & 13.1 \\
\hline $\begin{array}{c}\text { ENTROPY } \\
\text { (Xne) }\end{array}$ & $\begin{array}{l}280.6 \\
317.8 \\
318.3\end{array}$ & $\begin{array}{l}8.9 \\
8.3 \\
7.4\end{array}$ & $\begin{array}{l}193.8 \\
211.5 \\
212.9\end{array}$ & $\begin{array}{l}167.8 \\
183.7 \\
186.1\end{array}$ & $\begin{array}{c}92.9 \\
103.0 \\
104.6\end{array}$ & $\begin{array}{l}79.2 \\
84.3 \\
83.8\end{array}$ & $\begin{array}{l}22.8 \\
24.1 \\
24.2\end{array}$ & $\begin{array}{l}1.5 \\
1.5 \\
1.5\end{array}$ & $\begin{array}{l}16.5 \\
18.2 \\
17.7\end{array}$ & $\begin{array}{l}11.8 \\
13.8 \\
14.5\end{array}$ \\
\hline$\left(\overline{x_{n}}\right)$ & 305.6 & 8.2 & 206.1 & 179.2 & 100.2 & 82.4 & 23.7 & 1.5 & 17.5 & 13.4 \\
\hline
\end{tabular}

Number of Standard Deviations of the Distribution of Sampled Means by which the New/Predicted Mean Values lies from the Historical Mean Values

\begin{tabular}{|c|c|c|c|c|c|c|c|c|c|c|}
\hline & $\begin{array}{c}\text { Conouctivity } \\
@ 25 \mathrm{C} \\
\text { (ms/m) } \\
\end{array}$ & $\mathrm{PH}$ & 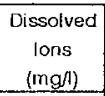 & $\begin{array}{c}\text { Dissolved } \\
\text { Solios } \\
\text { (mg/l) } \\
\end{array}$ & $\begin{array}{c}\text { Hardness } \\
\text { (mgll)as } \mathrm{CaCO} 3 \\
\end{array}$ & \begin{tabular}{|c|} 
Alkalinily \\
(mg/)as Caco3 \\
\end{tabular} & $\begin{array}{l}\text { Natrium } \\
(\mathrm{mg} / \mathrm{l})\end{array}$ & $\begin{array}{l}\text { Kalium } \\
\text { (mg/l) }\end{array}$ & $\begin{array}{l}\text { Calcium } \\
(\mathrm{mg} / \mathrm{l})\end{array}$ & $\begin{array}{c}\text { Magnesium } \\
\text { (mg/l) }\end{array}$ \\
\hline $\begin{array}{c}\text { OBSERVED } \\
(\bar{X} n \circ-\bar{X} h) /[s / V n]\end{array}$ & -1.00 & -0.26 & -1.00 & -1.13 & -0.89 & -0.88 & -0.28 & -1.04 & -1.14 & -0.84 \\
\hline $\begin{array}{c}\text { ENTROPY } \\
\left(\vec{X}_{n e}-\bar{X} h\right) /[s / \mathrm{Vn}]\end{array}$ & -0.88 & 1.65 & -0.71 & -0.77 & -0.69 & -0.38 & -0.48 & 0.26 & -0.78 & -0.76 \\
\hline
\end{tabular}


Table B.4.3(a) (continued)

[4 Yearly Averaging]

New/Predicted Mean Values

\begin{tabular}{|c|c|c|c|c|c|c|c|c|c|c|}
\hline & $\begin{array}{c}\text { Conductivity } \\
@ 25 \mathrm{C} \\
\text { (mS/m) } \\
\end{array}$ & $\mathrm{PH}$ & $\begin{array}{c}\text { Dissolved } \\
\text { Ions } \\
\text { (mg/l) } \\
\end{array}$ & $\begin{array}{c}\text { Dissolved } \\
\text { Solids } \\
\text { (mg/l) } \\
\end{array}$ & $\begin{array}{c}\text { Hardness } \\
\text { (mg/)as CaCO3 } \\
\end{array}$ & $\begin{array}{c}\text { Alkalinity } \\
(\mathrm{mg} / \mathrm{l}) \text { as } \mathrm{CaCO} 3\end{array}$ & $\begin{array}{l}\text { Natrium } \\
\text { (mg/l) }\end{array}$ & $\begin{array}{l}\text { Kalium } \\
(\mathrm{mg} /)\end{array}$ & $\begin{array}{l}\text { Calcium } \\
\text { (mgf) }\end{array}$ & $\begin{array}{l}\text { Magnesium } \\
\text { (mg/l) }\end{array}$ \\
\hline OBSERVED & 310.6 & 7.7 & 199.0 & 172.4 & 100.0 & 75.6 & 28.3 & 1.3 & 15.4 & 14.1 \\
\hline (Xno) & 310.3 & 7.7 & 206.6 & 177.9 & 100.3 & 78.6 & 23.1 & 1.3 & 18.1 & 13.4 \\
\hline$(X n \cap)$ & 310.4 & .7 .7 & 202.8 & 175.1 & 100.1 & 77.1 & 25.7 & 1.3 & 16.8 & 13.7 \\
\hline ENIROPY & 334.2 & 8.4 & 218.8 & 190.6 & 105.4 & 89.1 & 24.7 & 1.5 & 19.0 & 14.0 \\
\hline (Xne) & 337.2 & 7.4 & 221.6 & 193.0 & 107.5 & 88.9 & 24.8 & 1.5 & 19.0 & 14.7 \\
\hline$\left(\overline{x_{n}}\right)$ & 335.7 & 7.9 & 220.2 & 191.8 & 106.5 & 89.0 & 24.8 & 1.5 & 19.0 & 14.4 \\
\hline
\end{tabular}

Number of Standard Deviations of the Distribution of Sampled Means by which the New/Predicted Mean Values lies from the Historical Mean Values

\begin{tabular}{|c|c|c|c|c|c|c|c|c|c|c|}
\hline & $\begin{array}{c}\text { Conductivity } \\
@ 25 \mathrm{C} \\
(\mathrm{ms} / \mathrm{m}) \\
\end{array}$ & $\mathrm{PH}$ & $\begin{array}{c}\begin{array}{c}\text { Dissolved } \\
\text { lons } \\
(\mathrm{mg} / \mathrm{l})\end{array} \\
\end{array}$ & $\begin{array}{c}\text { Dissolved } \\
\text { Solids } \\
(\mathrm{mg} / \mathrm{l}) \\
\end{array}$ & $\begin{array}{c}\text { Hardness } \\
\text { (mg/l)as CaCO3 }\end{array}$ & $\begin{array}{c}\text { Alkalinity } \\
\text { (mg/)as CaCO3 }\end{array}$ & $\begin{array}{l}\text { Natrium } \\
\text { (mg/l) }\end{array}$ & $\begin{array}{l}\text { Kalium } \\
(\mathrm{mg} / \mathrm{l})\end{array}$ & $\begin{array}{l}\text { Calcium } \\
(\mathrm{mg} /) \\
\end{array}$ & $\begin{array}{l}\text { Magnesium } \\
\text { (mg/l) }\end{array}$ \\
\hline $\begin{array}{c}\text { OBSERVED } \\
(\bar{X} n o-\bar{X} h) /[s N n]\end{array}$ & -0.65 & -0.12 & -0.65 & -0.74 & -0.56 & -0.56 & 0.05 & -0.96 & -0.80 & -0.51 \\
\hline $\begin{array}{c}\text { ENTROPY } \\
(\bar{X} \text { ne- } \bar{X} h) /[s / N n]\end{array}$ & -0.29 & 0.39 & -0.27 & -0.28 & -0.31 & -0.00 & -0.16 & 0.22 & -0.28 & -0.34 \\
\hline
\end{tabular}


Table B.4.3(b) Station 145013

Historical (prior) Mean Values

\begin{tabular}{|c|c|c|c|c|c|c|c|c|c|c|}
\hline & $\begin{array}{c}\text { Conductivity } \\
@ 25 \mathrm{C} \\
\text { (ms/m) } \\
\end{array}$ & $\mathrm{PH}$ & $\begin{array}{c}\text { Dissolved } \\
\text { lons } \\
\text { (mg/l) } \\
\end{array}$ & $\begin{array}{c}\text { Dissolved } \\
\text { Solids } \\
\text { (mgn) } \\
\end{array}$ & $\begin{array}{c}\text { Hardness } \\
(\mathrm{mg} /) \text { as CaCO3 }\end{array}$ & $\begin{array}{c}\text { Alkalinity } \\
\text { (mg/l)as CaCO3 }\end{array}$ & $\begin{array}{l}\text { Natrium } \\
\text { (mg/) }\end{array}$ & $\begin{array}{l}\text { Kalium } \\
(\mathrm{mg} /) \text { ) }\end{array}$ & $\begin{array}{l}\text { Calcium } \\
\text { (mg/) }\end{array}$ & $\begin{array}{l}\text { Magnesium } \\
\quad(\mathrm{mg} / \mathrm{i})\end{array}$ \\
\hline Mean $(\bar{X} h)$ & 495.7 & 7.9 & 321.9 & 273.9 & 159.9 & 127.4 & 35.8 & 1.8 & 29.3 & 21.1 \\
\hline $\begin{array}{l}\text { Standard (s) } \\
\text { Deviation }\end{array}$ & 63.2 & 0.2 & 57.2 & 38.9 & 27.8 & 27.9 & 5.4 & 0.2 & 5.1 & 3.7 \\
\hline
\end{tabular}

\section{[1 Yearly Averaging]}

New/Predicted Mean Values

\begin{tabular}{|c|c|c|c|c|c|c|c|c|c|c|}
\hline & $\begin{array}{c}\text { Conductivity } \\
@ 25 \mathrm{C} \\
(\mathrm{mS} / \mathrm{m})\end{array}$ & $\mathrm{PH}$ & $\begin{array}{c}\text { Dissolved } \\
\text { Ions } \\
\text { (mg/) }\end{array}$ & $\begin{array}{l}\text { Dissolved } \\
\text { Solids } \\
\text { (mg/i) }\end{array}$ & $\begin{array}{c}\text { Hardness } \\
\text { (mg/)as CaCo3 }\end{array}$ & $\begin{array}{c}\text { Alkalinity } \\
\text { (mg/i)as } \mathrm{CaCO} 3 \\
\end{array}$ & $\begin{array}{l}\text { Natrium } \\
\left.(\mathrm{mg} /)^{2}\right)\end{array}$ & $\begin{array}{l}\text { Kalium } \\
\text { (mg/l) }\end{array}$ & $\begin{array}{l}\text { Calcium } \\
\text { (mgil) }\end{array}$ & $\begin{array}{l}\text { Magnesum } \\
\quad(\mathrm{mg} / \mathrm{l}) \\
\end{array}$ \\
\hline \multirow[t]{5}{*}{ OBSERVED } & 650.0 & 8.0 & 409.4 & 350.0 & 181.6 & 138.8 & 54.1 & 2.5 & 34.0 & 23.5 \\
\hline & 398.0 & 8.1 & 281.8 & 226.0 & 136.4 & 133.4 & 25.6 & 1.7 & 26.4 & 17.9 \\
\hline & 296.7 & 7.7 & 203.3 & 173.3 & 98.0 & 87.7 & 21.0 & 1.6 & 19.0 & 12.3 \\
\hline & 476.3 & 7.9 & 329.8 & 270.0 & 166.3 & 136.8 & 33.5 & 1.6 & 30.8 & 21.8 \\
\hline & 245.0 & 7.7 & 183.6 & 150.0 & 75.0 & 82.0 & 24.0 & 1.6 & 15.5 & 8.7 \\
\hline$\left(\bar{X}_{n 0}\right)$ & 413.2 & 7.9 & 281.6 & 233.9 & 131.5 & 115.7 & 31.6 & 1.8 & 25.1 & 16.7 \\
\hline \multirow[t]{2}{*}{ ENTROPY } & 495.4 & 8.0 & 320.8 & 272.4 & 157.5 & 123.0 & 35.9 & 1.8 & 36.4 & 20.6 \\
\hline & 495.9 & 7.9 & 321.9 & 273.2 & 158.9 & 126.4 & 35.9 & 1.8 & 36.4 & 209 \\
\hline \multirow[t]{3}{*}{ (Xne) } & 494.5 & 8.0 & 319.0 & 270.9 & 155.1 & 118.4 & 35.9 & 1.8 & 28.0 & 20.5 \\
\hline & 496.7 & 7.9 & 323.7 & 274.8 & 161.8 & 131.8 & 35.9 & 1.8 & 29.8 & 21.3 \\
\hline & 495.9 & 7.7 & 322.1 & 273.6 & 159.5 & 125.7 & 35.9 & 1.8 & 36.4 & 21.2 \\
\hline$\overline{(\bar{X} n \theta)}$ & 495.7 & 7.9 & 321.5 & 273.0 & 158.6 & 125.1 & 35.9 & 1.8 & 33.4 & 20.9 \\
\hline
\end{tabular}

Number of Standard Deviations of the Distribution of Sampled Means by which the New/Predicted Mean Values lies from the Historical Mean Values

\begin{tabular}{|c|c|c|c|c|c|c|c|c|c|c|}
\hline & $\begin{array}{c}\text { Conductivity } \\
@ 25 \mathrm{C} \\
(\mathrm{mS} / \mathrm{m})\end{array}$ & $\mathrm{PH}$ & $\begin{array}{c}\text { Dissolved } \\
\text { lons } \\
\text { (mg/l) }\end{array}$ & $\begin{array}{c}\text { Dissolved } \\
\text { Solids } \\
\text { (mg/i) }\end{array}$ & \begin{tabular}{|c|} 
Hardness \\
(mg/l)as Caco3
\end{tabular} & \begin{tabular}{|c|} 
Alkalinity \\
(mg/)as $\mathrm{CaCO}$ \\
\end{tabular} & $\begin{array}{l}\text { Natrium } \\
(\mathrm{mg} / \mathrm{l})\end{array}$ & $\begin{array}{l}\text { Kalium } \\
(\mathrm{mg} /)\end{array}$ & $\begin{array}{l}\text { Calcium } \\
(\mathrm{mg} / \mathrm{l})\end{array}$ & $\begin{array}{c}\text { Magnesium } \\
(\mathrm{mg} / \mathrm{i})\end{array}$ \\
\hline $\begin{array}{c}\text { OBSERVED } \\
(\overline{\mathrm{X}} \mathrm{n} \mathrm{O}-\overline{\mathrm{X}} \mathrm{h}) /\left[\mathrm{s} / \mathrm{V}_{\mathrm{n}}\right]\end{array}$ & -2.92 & 0.22 & -1.58 & -2.30 & -2.29 & -0.93 & -1.73 & 0.55 & -1.82 & -2.66 \\
\hline $\begin{array}{c}\text { ENTROPY } \\
(\bar{X} n \overline{-}-\bar{X} n) /[\mathrm{s} / \mathrm{NnI}\end{array}$ & -0.00 & 0.16 & -0.02 & -0.05 & -0.10 & -0.18 & 0.03 & 0.46 & 1.81 & -0.10 \\
\hline
\end{tabular}


Table B.4.3(b) (continued)

\section{[2 Yearly Averaging]}

New/Predicted Mean Values

\begin{tabular}{|c|c|c|c|c|c|c|c|c|c|c|}
\hline & $\begin{array}{c}\text { Conductivity } \\
\text { @ } 25 \mathrm{C} \\
\text { (ms/m) } \\
\end{array}$ & $\mathrm{PH}$ & $\begin{array}{c}\text { Dissolved } \\
\text { Ions } \\
(\mathrm{mg} / \mathrm{h}) \\
\end{array}$ & $\begin{array}{c}\text { Dissolved } \\
\text { Solids } \\
\text { (mg/l) } \\
\end{array}$ & $\begin{array}{c}\text { Hardness } \\
\text { (mg//)as } \mathrm{CaCO} 3\end{array}$ & $\begin{array}{c}\text { Alkalinity } \\
\text { (mg/l)as } \mathrm{CaCO} 3\end{array}$ & $\begin{array}{l}\text { Natrium } \\
\text { (mgl) }\end{array}$ & $\begin{array}{l}\text { Kalium } \\
\text { (mg/l) }\end{array}$ & $\begin{array}{l}\text { Calcium } \\
\text { (mg/t) }\end{array}$ & $\begin{array}{l}\text { Magnesium } \\
\text { (mg/) }\end{array}$ \\
\hline $\begin{array}{c}\text { OBSERVED } \\
\text { (Xno) }\end{array}$ & $\begin{array}{l}524.0 \\
347.3 \\
386.5 \\
360.6\end{array}$ & $\begin{array}{l}8.1 \\
7.9 \\
7.8 \\
7.8\end{array}$ & $\begin{array}{l}345.6 \\
242.5 \\
265.5 \\
256.7\end{array}$ & $\begin{array}{l}288.0 \\
199.7 \\
221.7 \\
210.0\end{array}$ & $\begin{array}{l}159.0 \\
117.2 \\
132.1 \\
120.6\end{array}$ & $\begin{array}{l}136.1 \\
110.5 \\
112.2 \\
109.4\end{array}$ & $\begin{array}{l}39.9 \\
23.3 \\
27.3 \\
28.8\end{array}$ & $\begin{array}{l}2.1 \\
1.6 \\
1.6 \\
1.6\end{array}$ & $\begin{array}{l}30.2 \\
22.7 \\
24.9 \\
23.1\end{array}$ & $\begin{array}{l}20.3 \\
14.7 \\
17.0 \\
15.2\end{array}$ \\
\hline$(\bar{X} \cap 0)$ & 404.6 & 7.9 & 277.9 & 229.8 & 132.2 & 117.1 & 29.8 & 1.7 & 25.2 & 16.8 \\
\hline $\begin{array}{c}\text { ENTROPY } \\
\text { (Xne) }\end{array}$ & $\begin{array}{l}474.8 \\
451.7 \\
475.3 \\
492.7\end{array}$ & $\begin{array}{l}8.0 \\
8.1 \\
8.0 \\
7.2\end{array}$ & $\begin{array}{l}293.7 \\
264.2 \\
294.3 \\
322.1\end{array}$ & $\begin{array}{l}257.0 \\
239.2 \\
258.6 \\
273.7\end{array}$ & $\begin{array}{l}145.3 \\
134.1 \\
147.5 \\
162.1\end{array}$ & $\begin{array}{l}113.3 \\
103.8 \\
114.6 \\
128.9\end{array}$ & $\begin{array}{l}34.6 \\
33.9 \\
34.6 \\
35.7\end{array}$ & $\begin{array}{l}1.8 \\
1.8 \\
1.8 \\
1.8\end{array}$ & $\begin{array}{l}27.0 \\
25.5 \\
27.5 \\
28.8\end{array}$ & $\begin{array}{l}18.1 \\
17.6 \\
19.3 \\
29.7\end{array}$ \\
\hline (Xnne) & 473.6 & 7.8 & 293.6 & 257.1 & 147.3 & 115.2 & 34.7 & 1.8 & 27.2 & 21.2 \\
\hline
\end{tabular}

Number of Standard Deviations of the Distribution of Sampled Means by which the New/Predicted Mean Values lies from the Historical Mean Values

\begin{tabular}{|c|c|c|c|c|c|c|c|c|c|c|}
\hline & $\begin{array}{c}\text { Conductivity } \\
\text { @ } 25 \mathrm{C} \\
(\mathrm{ms} / \mathrm{m}) \\
\end{array}$ & $\mathrm{PH}$ & $\begin{array}{c}\text { Dissolved } \\
\text { lons } \\
\text { (mg/l) } \\
\end{array}$ & $\begin{array}{c}\text { Dissolved } \\
\text { Solids } \\
\text { (mg/l) }\end{array}$ & $\begin{array}{c}\text { Hardness } \\
(\mathrm{mg} / \mathrm{l}) \mathrm{as} \mathrm{CaCO} 3\end{array}$ & $\begin{array}{c}\text { Alkalinity } \\
\text { (mgf)as } \mathrm{CaCO} 3 \\
\end{array}$ & $\begin{array}{l}\text { Natrium } \\
\text { (mg/l) }\end{array}$ & $\begin{array}{l}\text { Kalium } \\
(\mathrm{mg} / \mathrm{l})\end{array}$ & $\begin{array}{l}\text { Calcium } \\
\text { (mg/l) }\end{array}$ & $\begin{array}{l}\text { Magnesium } \\
\text { (mg/l) }\end{array}$ \\
\hline $\begin{array}{c}\text { OBSERVED } \\
(\bar{X} n o-\bar{X} h) /[s / N n]\end{array}$ & -2.88 & 0.28 & -1.54 & $-2,27$ & -1.99 & -0.74 & -2.23 & $-0.09^{\circ}$ & -1.59 & -2.31 \\
\hline $\begin{array}{c}\text { ENTROPY } \\
(\bar{X} n \mathrm{e}-\bar{X} h) /(s / \mathrm{s})]\end{array}$ & -0.70 & -0.70 & -0.99 & -0.86 & -0.91 & -0.88 & -0.41 & 0.41 & -0.81 & 0.06 \\
\hline
\end{tabular}

\section{[3 Yearly Averaging]}

\section{New/Predicted Mean Values}

\begin{tabular}{|c|c|c|c|c|c|c|c|c|c|c|}
\hline & $\begin{array}{c}\text { Conductivity } \\
@ 25 \mathrm{C} \\
\text { (ms/m) }\end{array}$ & $\mathrm{PH}$ & $\begin{array}{c}\text { Dissolved } \\
\text { lons } \\
(m g / l) \\
\end{array}$ & $\begin{array}{c}\text { Dissolved } \\
\text { Solids } \\
\text { (mg/) } \\
\end{array}$ & $\begin{array}{c}\text { Hardness } \\
\text { (mg/)as } \mathrm{CaCO} 3\end{array}$ & $\begin{array}{c}\text { Alkalinity } \\
\text { (mg/l)as Caco3 }\end{array}$ & $\begin{array}{l}\text { Natrium } \\
(\mathrm{mg} /)\end{array}$ & $\begin{array}{l}\text { Kalium } \\
\text { (mg/) }\end{array}$ & $\begin{array}{l}\text { Calcium } \\
\text { (mg/l) }\end{array}$ & $\begin{array}{c}\text { Magnesium } \\
(\mathrm{mg} / \mathrm{l})\end{array}$ \\
\hline $\begin{array}{l}\text { OBSERVED } \\
(x, 0)\end{array}$ & $\begin{array}{l}448.2 \\
390.3 \\
339.3\end{array}$ & $\begin{array}{l}7.9 \\
7.9 \\
7.8\end{array}$ & $\begin{array}{l}298.2 \\
271.6 \\
238.9\end{array}$ & $\begin{array}{l}249.8 \\
223.1 \\
197.8\end{array}$ & $\begin{array}{l}138.7 \\
133.6 \\
113.1\end{array}$ & $\begin{array}{l}120.0 \\
119.3 \\
102.1\end{array}$ & $\begin{array}{l}33.6 \\
26.7 \\
26.2\end{array}$ & $\begin{array}{l}1.9 \\
1.6 \\
1.6\end{array}$ & $\begin{array}{l}26.5 \\
25.4 \\
21.8\end{array}$ & $\begin{array}{l}17.6 \\
17.1 \\
14.3\end{array}$ \\
\hline$\left(\bar{x}_{\text {no }}\right.$ & 392.6 & 7.9 & 269.6 & 223.6 & 128.4 & 113.8 & 28.8 & 1.7 & 24.5 & 16.3 \\
\hline $\begin{array}{c}\text { ENTROPY } \\
(X n e)\end{array}$ & $\begin{array}{l}460.7 \\
478.3 \\
478.6\end{array}$ & $\begin{array}{l}8.1 \\
8.0 \\
7.8\end{array}$ & $\begin{array}{l}289.1 \\
304.0 \\
305.1\end{array}$ & $\begin{array}{l}251.7 \\
262.1 \\
263.6\end{array}$ & $\begin{array}{l}145.4 \\
152.2 \\
153.3\end{array}$ & $\begin{array}{r}118.0 \\
122.8 \\
122.4\end{array}$ & $\begin{array}{l}33.6 \\
34.6 \\
34.7\end{array}$ & $\begin{array}{l}1.8 \\
1.8 \\
1.8\end{array}$ & $\begin{array}{l}26.4 \\
27.7 \\
27.4\end{array}$ & $\begin{array}{l}18.7 \\
20.0 \\
20.4\end{array}$ \\
\hline$(\bar{X}$ ne) & 472.5 & 8.0 & 299.4 & 259.1 & 150.3 & 121.1 & 34.3 & 1.8 & 27.2 & 19.7 \\
\hline
\end{tabular}

Number of Standard Deviations of the Distribution of Sampled Means by which the New/Predicted Mean Values lies from the Historical Mean Values

\begin{tabular}{|c|c|c|c|c|c|c|c|c|c|c|}
\hline & $\begin{array}{c}\text { Conductivity } \\
@ 25 \mathrm{C} \\
(\mathrm{ms} / \mathrm{m}) \\
\end{array}$ & $\mathrm{PH}$ & $\begin{array}{c}\text { Dissolved } \\
\text { lons } \\
(\mathrm{mg} / \mathrm{h}) \\
\end{array}$ & $\begin{array}{c}\text { Dissolved } \\
\text { Solids } \\
\text { (mg/l) }\end{array}$ & $\begin{array}{c}\text { Hardness } \\
\text { (mg/)as } \mathrm{CaCO} 3 \\
\end{array}$ & \begin{tabular}{|c|} 
Alkalinity \\
(mg/l)as $\mathrm{CaCO} 3$ \\
\end{tabular} & $\begin{array}{l}\text { Natrium } \\
(\mathrm{mg} / \mathrm{l})\end{array}$ & $\begin{array}{l}\text { Kalium } \\
\text { (mg/l) }\end{array}$ & $\begin{array}{l}\text { Calcium } \\
(\mathrm{mg} /)\end{array}$ & $\begin{array}{l}\text { Magnesium } \\
\text { (mg/l) }\end{array}$ \\
\hline $\begin{array}{c}\text { OBSERVED } \\
(\bar{X} \text { no- } \bar{X} h) /[\mathrm{s} / \mathrm{Nn}]\end{array}$ & -2.82 & 0.03 & -1.58 & $-2,24$ & -1.96 & -0.84 & -2.25 & -0.20 & -1.61 & -2.23 \\
\hline $\begin{array}{c}\text { ENTROPY } \\
(\bar{X} n e-\bar{X}(h) /[s / N n]\end{array}$ & -0.63 & 1.02 & -0.68 & -0.66 & -0.60 & -0.39 & -0.49 & 0.36 & -0.72 & -0.64 \\
\hline
\end{tabular}


Table B.4.3(b) (continued)

\section{[4 Yearly Averaging]}

New/Predicted Mean Values

\begin{tabular}{|c|c|c|c|c|c|c|c|c|c|c|}
\hline & $\begin{array}{c}\text { Conductivity } \\
@ 25 \mathrm{C} \\
\text { (ms/m) } \\
\end{array}$ & $\mathrm{PH}$ & $\begin{array}{c}\text { Dissolved } \\
\text { lons } \\
\text { (mg/l) } \\
\end{array}$ & $\begin{array}{c}\text { Dissolved } \\
\text { Solids } \\
\text { (mg/) } \\
\end{array}$ & $\begin{array}{c}\text { Hardness } \\
\text { (mg/l)as } \mathrm{CaCO} 3\end{array}$ & $\begin{array}{c}\text { Alkalinity } \\
\text { (mg/l)as } \mathrm{CaCO} 3\end{array}$ & $\begin{array}{l}\text { Natrium } \\
(\mathrm{mg} \Omega)\end{array}$ & $\begin{array}{l}\text { Kalium } \\
\text { (mg/) }\end{array}$ & $\begin{array}{l}\text { Calcium } \\
\text { (mg/l) }\end{array}$ & $\begin{array}{l}\text { Magnesium } \\
\text { (mgli) }\end{array}$ \\
\hline $\begin{array}{c}\text { OBSERVED } \\
\text { (XnO) }\end{array}$ & $\begin{array}{l}455.2 \\
354.0\end{array}$ & $\begin{array}{l}7.9 \\
7.8\end{array}$ & $\begin{array}{l}306.1 \\
249.6\end{array}$ & $\begin{array}{l}254.8 \\
204.8\end{array}$ & $\begin{array}{l}145.6 \\
118.9\end{array}$ & $\begin{array}{l}124.2 \\
110.0\end{array}$ & $\begin{array}{l}33.6 \\
26.0\end{array}$ & $\begin{array}{l}1.9 \\
1.6\end{array}$ & $\begin{array}{l}27.5 \\
22.9\end{array}$ & $\begin{array}{l}18.7 \\
15.0\end{array}$ \\
\hline$(x \cap 0)$ & 404.6 & 7.9 & 277.9 & 229.8 & 132.2 & 117.1 & 29.8 & 1.7 & 25.2 & 16.8 \\
\hline $\begin{array}{c}\text { ENTROPY } \\
\text { (Xne) }\end{array}$ & $\begin{array}{l}485.9 \\
487.2\end{array}$ & $\begin{array}{l}8.0 \\
7.8\end{array}$ & $\begin{array}{l}310.1 \\
312.4\end{array}$ & $\begin{array}{l}266.6 \\
268.1\end{array}$ & $\begin{array}{l}153.8 \\
155.2\end{array}$ & $\begin{array}{l}127.4 \\
127.2\end{array}$ & $\begin{array}{l}35.2 \\
35.3\end{array}$ & $\begin{array}{l}1.8 \\
1.8\end{array}$ & $\begin{array}{l}28.3 \\
28.4\end{array}$ & $\begin{array}{l}20.6 \\
20.1\end{array}$ \\
\hline $\bar{x}_{n e}$ & 486.6 & 7.9 & 311.3 & 267.4 & 154.5 & 127.3 & 35.3 & 1.8 & 28.4 & 20.4 \\
\hline
\end{tabular}

Number of Standard Deviations of the Distribution of Sampled Means by which the New/Predicted Mean Values lies from the Historical Mean Values

\begin{tabular}{|c|c|c|c|c|c|c|c|c|c|c|}
\hline & $\begin{array}{c}\text { Conductivity } \\
@ 25 \mathrm{C} \\
\text { (ms/m) }\end{array}$ & $\mathrm{PH}$ & $\begin{array}{c}\text { Dissolved } \\
\text { lons } \\
\text { (mgh) }\end{array}$ & $\begin{array}{c}\text { Dissolved } \\
\text { Solids } \\
\text { (mg/l) }\end{array}$ & $\begin{array}{c}\text { Hardness } \\
\text { (mg/l)as Cacos }\end{array}$ & $\begin{array}{c}\text { Alkalinity } \\
\text { (mg/)as } \mathrm{CaCO} 3\end{array}$ & $\begin{array}{l}\text { Natrium } \\
(\mathrm{mg} / \mathrm{l})\end{array}$ & $\begin{array}{l}\text { Kalium } \\
\text { (mg/l) }\end{array}$ & $\begin{array}{l}\text { Calcium } \\
\text { (mg/l) }\end{array}$ & $\begin{array}{c}\text { Magnesium } \\
\text { (mg/l) }\end{array}$ \\
\hline $\begin{array}{c}\text { OBSERVED } \\
(\bar{X} \cap 0-\bar{X} h) /[s / \mathrm{s} n]\end{array}$ & -2.04 & 0.20 & -1.09 & -1.60 & -1.41 & -0.52 & -1.58 & -0.06 & -1.12 & -1.63 \\
\hline $\begin{array}{c}\text { ENTROPY } \\
\left(\bar{X} \cap \bar{X}-\bar{X}(h) /\left[s / V_{n}\right]\right.\end{array}$ & -0.20 & 0.28 & -0.26 & -0.24 & -0.27 & -0.00 & -0.15 & 0.29 & -0.26 & -0.27 \\
\hline
\end{tabular}


Table B.4.3(c) Station 145020

Historical (prior) Mean Values

\begin{tabular}{|c|c|c|c|c|c|c|c|c|c|c|}
\hline & $\begin{array}{c}\text { Conductivity } \\
@ 25 \mathrm{C} \\
\text { (ms/m) }\end{array}$ & $\mathrm{PH}$ & $\begin{array}{c}\begin{array}{c}\text { Dissolved } \\
\text { lons } \\
\text { (mg/) }\end{array} \\
\end{array}$ & $\begin{array}{c}\text { Dissolved } \\
\text { Solids } \\
\text { (mg/) }\end{array}$ & $\begin{array}{c}\text { Hardness } \\
\text { (mg/)as } \mathrm{CaCO} 3\end{array}$ & $\begin{array}{c}\text { Alkalinity } \\
\text { (mg/l)as } \mathrm{CaCO} 3\end{array}$ & $\begin{array}{l}\text { Natrium } \\
(m g /)\end{array}$ & $\begin{array}{l}\text { Kalium } \\
\text { (mg/l) }\end{array}$ & $\begin{array}{l}\text { Calcium } \\
\text { (mgh) }\end{array}$ & $\begin{array}{c}\text { Magnesium } \\
\text { (mgf) }\end{array}$ \\
\hline Mean $\quad(\bar{X} h)$ & 523.5 & 6.7 & 314.7 & 274.6 & 96.7 & 86.2 & 54.0 & 2.0 & 23.2 & 15.3 \\
\hline $\begin{array}{l}\text { Standard (s) } \\
\text { Deviation }\end{array}$ & 273.0 & 3.0 & 162.5 & 141.0 & 49.5 & 43.3 & 28.0 & 1.0 & 12.2 & 8.0 \\
\hline
\end{tabular}

\section{[1 Yearly Averaging]}

New/Predicted Mean Values

\begin{tabular}{|c|c|c|c|c|c|c|c|c|c|c|}
\hline & $\begin{array}{c}\text { Conductivity } \\
@ 25 \mathrm{C} \\
(\mathrm{ms} / \mathrm{m})\end{array}$ & $\mathrm{PH}$ & $\begin{array}{c}\text { Dissolved } \\
\text { lons } \\
\text { (mg/l) } \\
\end{array}$ & $\begin{array}{c}\text { Dissolved } \\
\text { Solids } \\
\text { (mg/) }\end{array}$ & $\begin{array}{c}\text { Hardness } \\
\text { (mgh)as } \mathrm{CaCO} 3 \\
\end{array}$ & $\begin{array}{c}\text { Alkalinity } \\
\text { (mg/l)as } \mathrm{CaCO} 3 \\
\end{array}$ & $\begin{array}{l}\text { Natrium } \\
\text { (mgh) }\end{array}$ & $\begin{array}{l}\text { Kalium } \\
\text { (mgfl) }\end{array}$ & $\begin{array}{l}\text { Calcium } \\
(\mathrm{mg} /)\end{array}$ & $\begin{array}{c}\text { Magnesium } \\
\text { (mg/l) }\end{array}$ \\
\hline \multirow[t]{5}{*}{ OBSERVED } & 397.5 & 7.8 & 241.7 & 210.0 & 86.3 & 73.5 & 41.3 & 2.1 & 17.0 & 10.7 \\
\hline & 434.0 & 7.9 & 264.4 & 224.0 & 96.2 & 81.0 & 45,0 & 2.6 & 19.3 & 11.6 \\
\hline & 268.3 & 7.5 & 162.5 & 143.3 & 57.3 & 47.3 & 29.5 & 1.7 & 11.8 & 6.8 \\
\hline & 645.0 & 7.9 & 400.6 & 340.0 & 159.3 & 119.3 & 86.8 & 2.3 & 32.0 & 19.3 \\
\hline & 631.7 & 7.9 & 425.9 & 366.7 & 172.7 & 123.7 & 69.7 & 2.4 & 31.7 & 22.7 \\
\hline (X̄no) & 475.3 & 7.8 & 299.0 & 256.8 & 114.3 & 89.0 & 50.4 & 2.2 & 22.4 & 14.2 \\
\hline \multirow{5}{*}{ ENTROPY } & 601.6 & 8.1 & 358.9 & 302.1 & 128.6 & 92.9 & 65.2 & 2.3 & 15.9 & 15.6 \\
\hline & 609.8 & 7.9 & 366.7 & 310.9 & 135.3 & 98.9 & 64.7 & 23 & 18.6 & 17.2 \\
\hline & 586.3 & 8.2 & 346.0 & 285.8 & 116.3 & 84.6 & 66.0 & 2.3 & 19.8 & 15.2 \\
\hline & 625.8 & 7.8 & 380.0 & 330.0 & 116.3 & 108.4 & 63.9 & 2.3 & 29.9 & 18.9 \\
\hline & 610.2 & 7.3 & 368.4 & 316.4 & 139.2 & 97.6 & 64.5 & 2.3 & 16.3 & 18.7 \\
\hline (X̄ne) & 606.7 & 7.9 & 364.0 & 309.0 & 127.1 & 96.5 & 64.9 & 2.3 & 20.1 & 17.1 \\
\hline
\end{tabular}

Number of Standard Deviations of the Distribution of Sampled Means by which the New/Predicted Mean Values lies from the Historical Mean Values

\begin{tabular}{|c|c|c|c|c|c|c|c|c|c|c|}
\hline & $\begin{array}{l}\text { Conductivity } \\
\text { @ } 25 \mathrm{C} \\
\text { (ms/m) }\end{array}$ & $\mathrm{PH}$ & $\begin{array}{c}\text { Dissolved } \\
\text { ions } \\
(\mathrm{mg} / \mathrm{l})\end{array}$ & $\begin{array}{c}\text { Dissolved } \\
\text { Solids } \\
\text { (mg/) }\end{array}$ & $\begin{array}{c}\text { Hardness } \\
\text { (mgll)as Cacos }\end{array}$ & $\begin{array}{c}\text { Alkalinity } \\
\text { (mg/) } 1 \text { as } \mathrm{CaCO} 3\end{array}$ & $\begin{array}{l}\text { Natrium } \\
\left.(\mathrm{mg} /)^{\prime}\right)\end{array}$ & $\begin{array}{l}\text { Kalium } \\
(\mathrm{mg} n)\end{array}$ & $\begin{array}{l}\text { Calcium } \\
(\mathrm{mg} / \mathrm{l})\end{array}$ & $\begin{array}{l}\text { Magnesium } \\
\text { (mg/l) }\end{array}$ \\
\hline $\begin{array}{c}\text { OBSERVED } \\
(\bar{X} n O-\bar{X} h) /[s / N n]\end{array}$ & -0.39 & 0.77 & -0.22 & -0.28 & 0.80 & 0.14 & -0.28 & 0.45 & -0.15 & -0.30 \\
\hline $\begin{array}{c}\text { ENTROPY } \\
(\bar{X} n \overline{-X} \text { X } h) /[s / N n]\end{array}$ & 0.68 & 0.84 & 0.68 & 0.55 & 1.38 & 0.53 & 0.87 & 0.64 & -0.57 & 0.52 \\
\hline
\end{tabular}


Table B.4.3(c) (continued)

[2 Yearly Averaging]

New/Predicted Mean Values

\begin{tabular}{|c|c|c|c|c|c|c|c|c|c|c|}
\hline & $\begin{array}{c}\text { Conductivity } \\
@ 25 \mathrm{C} \\
\text { (mS/m) }\end{array}$ & $\mathrm{PH}$ & $\begin{array}{c}\text { Dissolved } \\
\text { lons } \\
\text { (mg/l) } \\
\end{array}$ & $\begin{array}{c}\text { Dissolved } \\
\text { Solids } \\
\text { (mg/l) } \\
\end{array}$ & $\begin{array}{c}\text { Hardness } \\
\text { (mg//)as CaCO3 }\end{array}$ & $\begin{array}{c}\text { Alkalinity } \\
\text { (mg/)as } \mathrm{CaCO} 3 \\
\end{array}$ & $\begin{array}{l}\text { Natrium } \\
\text { (mg/l) }\end{array}$ & $\begin{array}{l}\text { Kalium } \\
\text { (mg/l) }\end{array}$ & $\begin{array}{l}\text { Calcium } \\
\text { (mg/) }\end{array}$ & $\begin{array}{l}\text { Magnesium } \\
\text { (mg/) }\end{array}$ \\
\hline $\begin{array}{c}\text { OBSERVED } \\
(\mathrm{XnO})\end{array}$ & $\begin{array}{l}415.8 \\
351.2 \\
456.7 \\
638.3\end{array}$ & $\begin{array}{l}7.9 \\
7.7 \\
7.7 \\
7.9\end{array}$ & $\begin{array}{l}253.0 \\
213.5 \\
281.5 \\
413.2\end{array}$ & $\begin{array}{l}217.0 \\
183.7 \\
241.7 \\
353.3\end{array}$ & $\begin{array}{c}91.2 \\
76.8 \\
108.3 \\
166.0\end{array}$ & $\begin{array}{c}77.3 \\
64.2 \\
83.3 \\
121.5\end{array}$ & $\begin{array}{l}43.1 \\
37.3 \\
48.1 \\
68.2\end{array}$ & $\begin{array}{l}2.4 \\
2.2 \\
2.0 \\
2.3\end{array}$ & $\begin{array}{l}18.2 \\
15.6 \\
21.9 \\
31.8\end{array}$ & $\begin{array}{c}11.1 \\
9.2 \\
13.0 \\
21.0\end{array}$ \\
\hline$(\bar{X} \cap 0)$ & 465.5 & 7.8 & 290.3 & 248.9 & 110.6 & 86.5 & 49.2 & 2.2 & 21.9 & 13.6 \\
\hline $\begin{array}{c}\text { ENTROPY } \\
\text { (Xn日) }\end{array}$ & $\begin{array}{c}258.3 \\
84.1 \\
265.3 \\
554.0\end{array}$ & $\begin{array}{l}8.3 \\
8.5 \\
8.3 \\
7.1\end{array}$ & $\begin{array}{c}170.5 \\
66.8 \\
173.8 \\
368.8\end{array}$ & $\begin{array}{c}137.9 \\
56.9 \\
152.0 \\
318.1\end{array}$ & $\begin{array}{c}67.2 \\
29.6 \\
77.9 \\
152.6\end{array}$ & $\begin{array}{c}75.7 \\
59.6 \\
70.0 \\
103.4\end{array}$ & $\begin{array}{l}32.8 \\
19.7 \\
33.1 \\
59.1\end{array}$ & $\begin{array}{l}2.5 \\
2.5 \\
2.5 \\
2.5\end{array}$ & $\begin{array}{c}14.2 \\
7.7 \\
17.0 \\
24.4\end{array}$ & $\begin{array}{c}5.1 \\
4.0 \\
9.7 \\
16.7\end{array}$ \\
\hline (Xne) & 290.4 & 8.0 & 195.0 & 166.2 & 81.8 & 77.2 & 36.2 & 2.5 & 15.8 & 8.9 \\
\hline
\end{tabular}

Number of Standard Deviations of the Distribution of Sampled Means by which the New/Predicted Mean Values lies from the Historical Mean Values

\begin{tabular}{|c|c|c|c|c|c|c|c|c|c|c|}
\hline & $\begin{array}{c}\text { Conductivity } \\
@ 25 \mathrm{C} \\
(\mathrm{ms} / \mathrm{m})\end{array}$ & $\mathrm{PH}$ & $\begin{array}{c}\text { Dissolved } \\
\text { lons } \\
\text { (mg/l) }\end{array}$ & $\begin{array}{c}\text { Dissolved } \\
\text { Solids } \\
\text { (mg/l) }\end{array}$ & $\begin{array}{c}\text { Hardness } \\
\text { (mg//)as CaCO3 }\end{array}$ & $\begin{array}{c}\text { Alkalinity } \\
\text { (mg/f)as CaCO3 }\end{array}$ & $\begin{array}{l}\text { Natrium } \\
\langle\mathrm{mg} / \mathrm{l}\rangle\end{array}$ & $\begin{array}{l}\text { Kalium } \\
\text { (mg/l) }\end{array}$ & $\begin{array}{l}\text { Calcium } \\
(\mathrm{mg} / \mathrm{l})\end{array}$ & $\begin{array}{l}\text { Magnesium } \\
\text { (mg/l) }\end{array}$ \\
\hline $\begin{array}{c}\text { OBSERVED } \\
(\bar{X} n a-\bar{X} h) /(s / \mathrm{s} n]\}\end{array}$ & -0.43 & 0.68 & -0.30 & -0.36 & 0.56 & 0.01 & -0.34 & 0.39 & -0.22 & -0.42 \\
\hline $\begin{array}{c}\text { ENTROPY } \\
\left(\bar{X}_{\text {ne }}-\bar{X} h\right) /[s / \mathrm{V} n]\end{array}$ & -1.71 & 0.85 & -1.47 & -1.54 & -0.60 & -0.42 & -1.27 & 0.97 & -1.21 & -1.59 \\
\hline
\end{tabular}

\section{[3 Yearly Averaging]}

\section{New/Predicted Mean Values}

\begin{tabular}{|c|c|c|c|c|c|c|c|c|c|c|}
\hline & $\begin{array}{c}\text { Conductivity } \\
@ 25 \mathrm{C} \\
\text { (ms/m) } \\
\end{array}$ & $\mathrm{PH}$ & $\begin{array}{c}\text { Dissolved } \\
\text { lons } \\
\text { (mg/l) } \\
\end{array}$ & $\begin{array}{c}\text { Dissolved } \\
\text { Solids } \\
\text { (mg/) }\end{array}$ & $\begin{array}{c}\text { Hardness } \\
\text { (mg/)as } \mathrm{CaCO} 3 \\
\end{array}$ & $\begin{array}{c}\text { Alkalinity } \\
\text { (mgl)as } \mathrm{CaCO} 3\end{array}$ & $\begin{array}{l}\text { Natrium } \\
(m g n)\end{array}$ & $\begin{array}{l}\text { Kalium } \\
\text { (mg/) }\end{array}$ & $\begin{array}{l}\text { Calcium } \\
\text { (mg/l) }\end{array}$ & $\begin{array}{l}\text { Magnesium } \\
\text { (mg/l) }\end{array}$ \\
\hline $\begin{array}{c}\text { OBSERVED } \\
\text { (Xno) }\end{array}$ & $\begin{array}{l}366.6 \\
449.1 \\
515.0\end{array}$ & $\begin{array}{l}7.7 \\
7.8 \\
7.7\end{array}$ & $\begin{array}{l}222.9 \\
275.8 \\
329.6\end{array}$ & $\begin{array}{l}192.4 \\
235.8 \\
283.3\end{array}$ & $\begin{array}{c}79.9 \\
104.3 \\
129.8\end{array}$ & $\begin{array}{l}67.3 \\
82.5 \\
96.8\end{array}$ & $\begin{array}{l}38.6 \\
47.1 \\
55.3\end{array}$ & $\begin{array}{l}2.1 \\
2.2 \\
2.1\end{array}$ & $\begin{array}{l}16.0 \\
21.0 \\
25.2\end{array}$ & $\begin{array}{c}9.7 \\
12.5 \\
16.3\end{array}$ \\
\hline$(\bar{x} \cap 0)$ & 443.6 & 7.7 & 276.1 & 237.2 & 104.6 & 82.2 & 47.0 & 2.2 & 20.8 & 12.8 \\
\hline $\begin{array}{c}\text { ENTROPY } \\
\text { (Xne) }\end{array}$ & $\begin{array}{l}122.1 \\
306.7 \\
310.2\end{array}$ & $\begin{array}{l}8.5 \\
8.3 \\
7.6\end{array}$ & $\begin{array}{l}144.9 \\
237.4 \\
245.2\end{array}$ & $\begin{array}{c}90.9 \\
186.9 \\
203.8\end{array}$ & $\begin{array}{c}67.5 \\
100.9 \\
106.5\end{array}$ & $\begin{array}{l}83.9 \\
92.4 \\
91.7\end{array}$ & $\begin{array}{l}16.4 \\
33.8 \\
36.1\end{array}$ & $\begin{array}{l}3.0 \\
2.8 \\
2.7\end{array}$ & $\begin{array}{l}11.3 \\
18.3 \\
16.1\end{array}$ & $\begin{array}{c}7.2 \\
12.6 \\
14.9\end{array}$ \\
\hline$(\bar{x}$ ne $)$ & 246.3 & 8.1 & 209.2 & 163.5 & 91.6 & 89.3 & 28.8 & 2.8 & 15.2 & 11.6 \\
\hline
\end{tabular}

Number of Standard Deviations of the Distribution of Sampled Means by which the New/Predicted Mean Values lies from the Historical Mean Values

\begin{tabular}{|c|c|c|c|c|c|c|c|c|c|c|}
\hline & $\begin{array}{c}\text { Conductivity } \\
@ 25 \mathrm{C} \\
\text { (ms/m) }\end{array}$ & $\mathrm{PH}$ & $\begin{array}{c}\text { Dissolved } \\
\text { tons } \\
\text { (mg/) } \\
\end{array}$ & $\begin{array}{c}\text { Dissolved } \\
\text { Solids } \\
\text { (mg/l) } \\
\end{array}$ & $\begin{array}{c}\text { Hardness } \\
\text { (mg/l)as } \mathrm{CaCO} 3\end{array}$ & $\begin{array}{c}\text { Alkalinity } \\
\text { (mg/l)as } \mathrm{CaCO} 3 \\
\end{array}$ & $\begin{array}{l}\text { Natrium } \\
(\mathrm{mg} / \mathrm{l})\end{array}$ & $\begin{array}{l}\text { Kalium } \\
\text { (mg/l) }\end{array}$ & $\begin{array}{l}\text { Calcium } \\
(\mathrm{mg} /) \\
\end{array}$ & $\begin{array}{c}\text { Magnesium } \\
\text { (mg/i) }\end{array}$ \\
\hline $\begin{array}{c}\text { OBSEFVED } \\
\left(\overline{\mathrm{X}}_{\mathrm{nO}}-\overline{\mathrm{X}}_{\mathrm{h}}\right) /\left[\mathrm{s} / \mathrm{N}_{\mathrm{n}] \mathrm{l}}\right]\end{array}$ & -0.51 & 0.57 & -0.41 & -0.46 & 0.28 & -0.16 & -0.43 & 0.24 & -0.35 & -0.53 \\
\hline $\begin{array}{c}\text { ENTROPY } \\
\left(\bar{X}_{n e}-\bar{X}_{h}\right) /[\mathrm{s} N \mathrm{Nn}]\end{array}$ & -1.76 & 0.79 & -1.12 & $-1,36$ & -0.18 & 0.12 & -1.56 & 1.43 & -1.13 & -0.80 \\
\hline
\end{tabular}


Table B.4.3(c) (continued)

\section{[4 Yearly Averaging]}

New/Predicted Mean Values

\begin{tabular}{|c|c|c|c|c|c|c|c|c|c|c|}
\hline & $\begin{array}{c}\text { Conductivity } \\
@ 25 \mathrm{C} \\
(\mathrm{ms} / \mathrm{m}) \\
\end{array}$ & $\mathrm{PH}$ & $\begin{array}{c}\text { Dissolved } \\
\text { lons } \\
\text { (mg/) }\end{array}$ & $\begin{array}{c}\text { Dissolved } \\
\text { Solids } \\
\text { (mg } / 1)\end{array}$ & $\begin{array}{c}\text { Mardness } \\
\text { (mg/l)as CaCos }\end{array}$ & $\begin{array}{c}\text { Alkalinity } \\
\text { (mg/)as } \mathrm{CaCO} 3\end{array}$ & $\begin{array}{l}\text { Natrium } \\
\text { (mg/l) }\end{array}$ & $\begin{array}{l}\text { Kalium } \\
\text { (mg/) }\end{array}$ & $\begin{array}{l}\text { Calcium } \\
(\mathrm{mg} / \mathrm{l})\end{array}$ & $\begin{array}{l}\text { Magnesium } \\
\text { (mgfl) }\end{array}$ \\
\hline $\begin{array}{c}\text { OBSERVED } \\
\left(X_{n O}\right)\end{array}$ & $\begin{array}{l}436.2 \\
494.8\end{array}$ & $\begin{array}{l}7.8 \\
7.8\end{array}$ & $\begin{array}{l}267.3 \\
313.3\end{array}$ & $\begin{array}{l}229.3 \\
268.5\end{array}$ & $\begin{array}{l}99.8 \\
121.4\end{array}$ & $\begin{array}{l}80.3 \\
92.8\end{array}$ & $\begin{array}{l}45.6 \\
52.7\end{array}$ & $\begin{array}{l}2.2 \\
2.2\end{array}$ & $\begin{array}{l}20.0 \\
23.7\end{array}$ & $\begin{array}{l}12.1 \\
15.1\end{array}$ \\
\hline$(x \cap 0)$ & 465.5 & 7.8 & 290.3 & 248.8 & 110.6 & 86.5 & 49.2 & 2.2 & 21.9 & 13.6 \\
\hline $\begin{array}{c}\text { ENTROPY } \\
\text { (Xne) }\end{array}$ & $\begin{array}{l}434.8 \\
459.0\end{array}$ & $\begin{array}{l}8.3 \\
7.6\end{array}$ & $\begin{array}{l}281.2 \\
297.8\end{array}$ & $\begin{array}{l}236.5 \\
253.7\end{array}$ & $\begin{array}{r}109.6 \\
116.8\end{array}$ & $\begin{array}{c}100.6 \\
100.4\end{array}$ & $\begin{array}{l}46.3 \\
49.6\end{array}$ & $\begin{array}{l}2.3 \\
2.3\end{array}$ & $\begin{array}{l}21.7 \\
21.8\end{array}$ & $\begin{array}{r}13.4 \\
15.5\end{array}$ \\
\hline$(\bar{x} \cap n)$ & 446.9 & 8.0 & 289.5 & 245.1 & 113.2 & 100.5 & 48.0 & 2.3 & 21.8 & 14.5 \\
\hline
\end{tabular}

Number of Standard Deviations of the Distribution of Sampled Means by which the New/Predicted Mean Values lies from the Historical Mean Values

\begin{tabular}{|c|c|c|c|c|c|c|c|c|c|c|}
\hline & $\begin{array}{c}\text { Conductivity } \\
\text { @ 25 C } \\
\text { (ms/m) } \\
\end{array}$ & $\mathrm{PH}$ & $\begin{array}{c}\text { Dissolved } \\
\text { Ions } \\
\text { (mg/) } \\
\end{array}$ & $\begin{array}{c}\text { Dissolved } \\
\text { Solids } \\
\text { (mg/h) } \\
\end{array}$ & $\begin{array}{c}\text { Hardness } \\
\text { (mg/l)as CaCO3 }\end{array}$ & $\begin{array}{c}\text { Alkalinity } \\
\text { (mg/h)as } \mathrm{CaCO} 3\end{array}$ & $\begin{array}{l}\text { Natrium } \\
\text { (mg/) }\end{array}$ & $\begin{array}{l}\text { Kalium } \\
(\mathrm{mg} / \mathrm{l})\end{array}$ & $\begin{array}{l}\text { Calcium } \\
\text { (ingi) }\end{array}$ & $\begin{array}{l}\text { Magnesium } \\
(m g /) \\
\end{array}$ \\
\hline $\begin{array}{c}\text { OBSERVED } \\
\left(\bar{X}_{n \circ}-\bar{X}_{h}\right) /\left[\mathrm{s} / N_{n}\right]\end{array}$ & -0.30 & 0.48 & -0.21 & -0.26 & 0.40 & 0.01 & -0.24 & 0.28 & -0.15 & -0.30 \\
\hline $\begin{array}{c}\text { ENTROPY } \\
\left(\bar{X}_{n e-\bar{X}_{n}}\right) /[\mathrm{s} N \mathrm{Nn}]\end{array}$ & -0.40 & 0.56 & -0.22 & -0.30 & 0.47 & 0.47 & -0.31 & 0.40 & -0.17 & -0.14 \\
\hline
\end{tabular}


Table B.4.3(d) Station 145008

Historical (prior) Mean Values

\begin{tabular}{|c|c|c|c|c|c|c|c|c|c|c|}
\hline & $\begin{array}{c}\text { Conductivity } \\
@ 25 \mathrm{C} \\
\text { (ms/m) }\end{array}$ & $\mathrm{PH}$ & $\begin{array}{c}\text { Dissolved } \\
\text { lons } \\
\text { (mg/l) } \\
\end{array}$ & $\begin{array}{c}\text { Dissolved } \\
\text { Solids } \\
\text { (mg/i) }\end{array}$ & $\begin{array}{c}\text { Hardness } \\
\text { (mg/)as } \mathrm{CaCO} 3\end{array}$ & $\begin{array}{c}\text { Alkalinity } \\
\text { (mg/l)as } \mathrm{CaCO}\end{array}$ & $\begin{array}{l}\text { Natrium } \\
(\mathrm{mg} /)\end{array}$ & $\begin{array}{l}\text { Kalium } \\
\text { (mg/i) }\end{array}$ & $\begin{array}{l}\text { Calcium } \\
(\mathrm{mg} / \mathrm{l})\end{array}$ & $\begin{array}{l}\text { Magnesium } \\
(\mathrm{mg} /)\end{array}$ \\
\hline Mean $\quad(\bar{X} h)$ & 518.5 & 6.8 & 331.6 & 279.7 & 145.6 & 115.1 & 46.5 & 2.1 & 151.6 & 18.8 \\
\hline $\begin{array}{l}\text { Standard (s) } \\
\text { Deviation }\end{array}$ & 247.9 & 3.0 & 157.9 & 133.8 & 69.9 & 53.7 & 22.7 & 1.1 & 334.5 & 9.0 \\
\hline
\end{tabular}

\section{[1 Yearly Averaging]}

New Mean Values

\begin{tabular}{|c|c|c|c|c|c|c|c|c|c|c|}
\hline & $\begin{array}{c}\text { Conductivity } \\
\text { @ } 25 \mathrm{C} \\
\text { (mS/m) }\end{array}$ & $\mathrm{PH}$ & $\begin{array}{c}\text { Dissolved } \\
\text { lons } \\
\text { (mg/l) } \\
\end{array}$ & $\begin{array}{c}\text { Dissolved } \\
\text { Solids } \\
(\mathrm{mg} / \mathrm{l}) \\
\end{array}$ & $\begin{array}{c}\text { Haróness } \\
\text { (mg/l)as CaCO3 }\end{array}$ & $\begin{array}{c}\text { Alkalinity } \\
\text { (mg/)as } \mathrm{CaCO}\end{array}$ & $\begin{array}{l}\text { Natrium } \\
(\mathrm{mg} / 1)\end{array}$ & $\begin{array}{l}\text { Kalium } \\
\text { (mgli) }\end{array}$ & $\begin{array}{l}\text { Calcium } \\
\text { (mg/) }\end{array}$ & $\begin{array}{c}\text { Magnesium } \\
\text { (mg/) }\end{array}$ \\
\hline \multirow[t]{2}{*}{ OBSERVED } & 393.3 & 7.7 & 243.9 & 210.0 & 105.3 & 87.3 & 33.3 & 1.6 & $\{9.7$ & 8.7 \\
\hline & 475.6 & 7.9 & 308.6 & 253.8 & 131.6 & 112.6 & 42.4 & 2.1 & 25.6 & 16.4 \\
\hline \multirow[t]{3}{*}{$(x n o)$} & 236.7 & 7.6 & 135.5 & 130.0 & 58.3 & 52.0 & 20.7 & 1.8 & $\$ 1.9$ & 7.0 \\
\hline & 638.3 & 8.0 & 420.3 & 346.7 & 191.3 & 153.0 & 55.3 & 2.2 & 36.7 & 24.2 \\
\hline & 480.0 & 8.5 & 323.2 & 280.0 & 146.0 & 107.0 & 45.5 & 2.3 & 20.5 & 23.0 \\
\hline$(\bar{X}$ no $)$ & 444.8 & 7.9 & 286.3 & 244.1 & 126.5 & 902.4 & 39.5 & 2.0 & 22.9 & 15.8 \\
\hline
\end{tabular}

Number of Standard Deviations of the Distribution of Sampled Means by which the New Mean Values lies from the Historical Mean Values

\begin{tabular}{|c|c|c|c|c|c|c|c|c|c|c|}
\hline & $\begin{array}{c}\text { Conductivity } \\
@ 25 \mathrm{C} \\
\text { (ms/m) }\end{array}$ & $\mathrm{PH}$ & $\begin{array}{c}\text { Dissolved } \\
\text { lons } \\
(\mathrm{mg} /) \\
\end{array}$ & $\begin{array}{c}\text { Dissolved } \\
\text { Solids } \\
\text { (mg/) }\end{array}$ & $\begin{array}{c}\text { Haraness } \\
\text { (mg/l)as CaCO3 }\end{array}$ & $\begin{array}{c}\text { Alkalinity } \\
\text { (mg/l)as } \mathrm{CaCO} 3 \\
\end{array}$ & $\begin{array}{l}\text { Natrium } \\
\text { (mg/l) }\end{array}$ & $\begin{array}{l}\text { Kalium } \\
\text { (mg/l) }\end{array}$ & $\begin{array}{l}\text { Calcium } \\
\text { (mg/l) }\end{array}$ & $\begin{array}{l}\text { Magnesium } \\
\text { (mg/l) }\end{array}$ \\
\hline $\begin{array}{c}\text { OBSERVED } \\
(\bar{X} \text { no- } \bar{X} n) /\left(s / V_{n}\right]\end{array}$ & -0.67 & 0.85 & -0.64 & -0.59 & -0.61 & -0.53 & -0.70 & -0.25 & -0.86 & -0.72 \\
\hline
\end{tabular}

\section{[2 Yearly Averaging]}

New Mean Values

\begin{tabular}{|c|c|c|c|c|c|c|c|c|c|c|}
\hline & $\begin{array}{c}\text { Conductivity } \\
@ 25 \mathrm{c} \\
(\mathrm{ms} / \mathrm{m}) \\
\end{array}$ & $\mathrm{PH}$ & $\begin{array}{c}\text { Dissolved } \\
\text { Ions } \\
(\mathrm{mg} / \mathrm{l}) \\
\end{array}$ & $\begin{array}{c}\text { Dissolved } \\
\text { Solids } \\
\text { (mg/) }\end{array}$ & $\begin{array}{c}\text { Hardness } \\
\text { (mg/)as } \mathrm{CaCO} 3 \\
\end{array}$ & $\begin{array}{c}\text { Alkalinity } \\
\text { (mg/)as } \mathrm{CaCO} 3 \\
\end{array}$ & $\begin{array}{l}\text { Natrium } \\
\cdot \\
\text { (mg/i) }\end{array}$ & $\begin{array}{l}\text { Kalium } \\
\text { (mg/i) }\end{array}$ & $\begin{array}{l}\text { Calcium } \\
(\mathrm{mg} /)\end{array}$ & $\begin{array}{l}\text { Magnesium } \\
\text { (mg/li) }\end{array}$ \\
\hline \multirow{4}{*}{$\begin{array}{l}\text { OBSERVED } \\
(X n \cap)\end{array}$} & 434.5 & 7.8 & 276.2 & 231.9 & 118.5 & 100.0 & 37.9 & 1.8 & 22.6 & 12.5 \\
\hline & 356.1 & 7.7 & 222.0 & 191.9 & 95.0 & 82.3 & 31.6 & 1.9 & 18.8 & 11.7 \\
\hline & 437.5 & 7.8 & 277.9 & 238.3 & 124.8 & 102.5 & 38.0 & 2.0 . & 24.3 & 15.6 \\
\hline & 559.2 & 8.3 & 371.8 & 313.3 & 168.7 & 130.0 & 50.4 & 2.2 & 28.6 & 23.6 \\
\hline $\bar{X}(\bar{n})$ & 446.8 & 7.9 & 287.0 & 243.9 & 126.7 & 103.7 & 39.5 & 2.0 & 23.6 & 15.8 \\
\hline
\end{tabular}

Number of Standard Deviations of the Distribution of Sampled Means by which the New Mean Values lies from the Historical Mean Values

\begin{tabular}{|c|c|c|c|c|c|c|c|c|c|c|}
\hline & $\begin{array}{c}\text { Conductivity } \\
@ 25 \mathrm{C} \\
\text { (mS/m) }\end{array}$ & $\mathrm{PH}$ & $\begin{array}{c}\text { Dissolved } \\
\text { lons } \\
(\mathrm{mg} / \mathrm{l})\end{array}$ & $\begin{array}{c}\text { Dissolved } \\
\text { Solids } \\
\text { (mg/i) }\end{array}$ & $\begin{array}{c}\text { Hardness } \\
\text { (mg/l)as } \mathrm{CaCO} 3 \\
\end{array}$ & $\begin{array}{c}\text { Alkalinity } \\
\text { (mg/)as } \mathrm{CaCO} 3\end{array}$ & $\begin{array}{l}\text { Natrium } \\
(\mathrm{mg} / \mathrm{l})\end{array}$ & $\begin{array}{l}\text { Kalium } \\
\text { (mg/l) }\end{array}$ & $\begin{array}{l}\text { Calcium } \\
(\mathrm{mg} /)\end{array}$ & $\begin{array}{c}\text { Magnesium } \\
\text { (mg/) }\end{array}$ \\
\hline $\begin{array}{c}\text { OBSERVED } \\
(\bar{X} n O \cdot \vec{X} h) /[s / N n]\end{array}$ & -0.58 & 0.73 & -0.57 & -0.54 & -0.54 & -0.42 & -0.62 & -0.21 & -0.77 & -0.64 \\
\hline
\end{tabular}


Table B.4.3(d) (continued)

\section{[3 Yearly Averaging]}

\section{New Mean Values}

\begin{tabular}{|c|c|c|c|c|c|c|c|c|c|c|}
\hline & $\begin{array}{l}\text { Conductivity } \\
@ 25 \mathrm{C} \\
\text { (ms/m) }\end{array}$ & $\mathrm{PH}$ & $\begin{array}{c}\text { Dissolved } \\
\text { lons } \\
\text { (mg/t) }\end{array}$ & $\begin{array}{c}\text { Dissofved } \\
\text { Solids } \\
\text { (mg/l) }\end{array}$ & $\begin{array}{c}\text { Hardness } \\
\text { (mgl)as } \mathrm{CaCO} 3\end{array}$ & $\begin{array}{c}\text { Alkalinity } \\
\text { (mg/l)as } \mathrm{CaCO} 3\end{array}$ & $\begin{array}{l}\text { Natrium } \\
(\mathrm{mg} / \mathrm{l})\end{array}$ & $\begin{array}{l}\text { Kalium } \\
\text { (mg/i) }\end{array}$ & $\begin{array}{l}\text { Calcium } \\
(\mathrm{mg} /)\end{array}$ & $\begin{array}{l}\text { Magnesium } \\
\text { (mg/l) }\end{array}$ \\
\hline $\begin{array}{c}\text { OBSERVED } \\
\left(X_{\text {no }}\right)\end{array}$ & $\begin{array}{l}368.5 \\
450.2 \\
451.7\end{array}$ & $\begin{array}{l}7.7 \\
7.8 \\
8.0\end{array}$ & $\begin{array}{l}229.3 \\
288.1 \\
293.0\end{array}$ & $\begin{array}{l}197.9 \\
243.5 \\
252.2\end{array}$ & $\begin{array}{r}98.4 \\
127.1 \\
131.9\end{array}$ & $\begin{array}{c}84.0 \\
105.9 \\
104.0\end{array}$ & $\begin{array}{l}32.1 \\
39.5 \\
40.5\end{array}$ & $\begin{array}{l}1.8 \\
2.0 \\
2.1\end{array}$ & $\begin{array}{l}19.1 \\
24.7 \\
23.0\end{array}$ & $\begin{array}{l}10.7 \\
15.8 \\
18.0\end{array}$ \\
\hline$(\bar{X} n o)$ & 423.5 & 7.9 & 270.1 & 231.2 & 119.1 & 98.0 & 37.4 & 2.0 & 22.3 & 14.9 \\
\hline
\end{tabular}

Number of Standard Deviations of the Distribution of Sampled Means by which the New Mean Values lies from the Historical Mean Values

\begin{tabular}{|c|c|c|c|c|c|c|c|c|c|c|}
\hline & $\begin{array}{c}\text { Conductivity } \\
\text { @ } 25 \mathrm{C} \\
(\mathrm{mS} / \mathrm{m})\end{array}$ & $\mathrm{PH}$ & $\begin{array}{c}\text { Dissolved } \\
\text { Ions } \\
\text { (mg/l) } \\
\end{array}$ & $\begin{array}{c}\text { Dissolved } \\
\text { Solids } \\
\text { (mg!) }\end{array}$ & $\begin{array}{c}\text { Hardness } \\
\text { (mg/l)as } \mathrm{CaCO} 3\end{array}$ & $\begin{array}{c}\text { Alkalinity } \\
\text { (mgll)as } \mathrm{CaCO} 3\end{array}$ & $\begin{array}{l}\text { Natrium } \\
(\mathrm{mg} n)\end{array}$ & $\begin{array}{l}\text { Kalium } \\
\text { (mgh) }\end{array}$ & $\begin{array}{l}\text { Calcium } \\
(\mathrm{mg} / \mathrm{l})\end{array}$ & $\begin{array}{l}\text { Magnesium } \\
\text { (mg/l) }\end{array}$ \\
\hline $\begin{array}{c}\text { OBSERVED } \\
(\bar{X} \text { no- } \bar{X}(n) /[\mathrm{s} / \mathrm{V} n)\end{array}$ & -0.66 & 0.61 & -0.67 & -0.63 & -0.65 & -0.55 & -0.70 & -0.21 & -0.67 & -0.75 \\
\hline
\end{tabular}

\section{[4 Yearly Averaging]}

New Mean Values

\begin{tabular}{|c|c|c|c|c|c|c|c|c|c|c|}
\hline & $\begin{array}{c}\text { Conductivity } \\
\text { @ } 25 \mathrm{C} \\
(\mathrm{mS} / \mathrm{m}) \\
\end{array}$ & PH & $\begin{array}{c}\text { Dissolved } \\
\text { lons } \\
\text { (mg/) } \\
\end{array}$ & $\begin{array}{c}\text { Dissolved } \\
\text { Solids } \\
\text { (mg/l) } \\
\end{array}$ & $\begin{array}{c}\text { Hardness } \\
\text { (mg/) as CaCO3 }\end{array}$ & $\begin{array}{c}\text { Alkalinity } \\
\text { (mg/l)as } \mathrm{CaCO} 3\end{array}$ & $\begin{array}{l}\text { Natrium } \\
\text { (mg/l) }\end{array}$ & $\begin{array}{l}\text { Kalium } \\
\text { (mg/l) }\end{array}$ & $\begin{array}{l}\text { Calcium } \\
(\mathrm{mg} /)\end{array}$ & $\begin{array}{l}\text { Magnesium } \\
\text { (mg/l) }\end{array}$ \\
\hline $\begin{array}{c}\text { OBSERVED } \\
(\mathrm{XnO})\end{array}$ & $\begin{array}{l}436.0 \\
457.7\end{array}$ & $\begin{array}{l}7.8 \\
8.0\end{array}$ & $\begin{array}{l}277.1 \\
296.9\end{array}$ & $\begin{array}{l}235.1 \\
252.6\end{array}$ & $\begin{array}{l}121.7 \\
131.8\end{array}$ & $\begin{array}{l}101.2 \\
106.2\end{array}$ & $\begin{array}{l}37.9 \\
41.0\end{array}$ & $\begin{array}{l}1.9 \\
2.1\end{array}$ & $\begin{array}{l}23.5 \\
23.7\end{array}$ & $\begin{array}{l}14.1 \\
17.6\end{array}$ \\
\hline$(\bar{X} \cap 0)$ & 446.8 & 7.9 & 287.0 & 243.9 & 126.7 & 103.7 & 39.5 & 2.0 & 23.6 & 15.8 \\
\hline
\end{tabular}

Number of Standard Deviations of the Distribution of Sampled Means by which the New Mean Values lies from the Historical Mean Values

\begin{tabular}{|c|c|c|c|c|c|c|c|c|c|c|}
\hline & $\begin{array}{c}\text { Conductivity } \\
@ 25 \mathrm{C} \\
\text { (ms/m) }\end{array}$ & $\mathrm{PH}$ & $\begin{array}{c}\text { Dissolved } \\
\text { Ions } \\
\text { (mg/ })\end{array}$ & $\begin{array}{c}\text { Dissolved } \\
\text { Solids } \\
\text { (mg/l) }\end{array}$ & $\begin{array}{c}\text { Hardness } \\
\text { (mg/) as } \mathrm{CaCO}\end{array}$ & $\begin{array}{c}\text { Alkalinity } \\
\text { (mg/)as } \mathrm{CaCO} 3\end{array}$ & $\begin{array}{l}\text { Natrium } \\
(\mathrm{mg} / \mathrm{l})\end{array}$ & $\begin{array}{l}\text { Kalium } \\
(\mathrm{mg} / \mathrm{l})\end{array}$ & $\begin{array}{l}\text { Calcium } \\
(\mathrm{mg} / \mathrm{l})\end{array}$ & $\begin{array}{l}\text { Magnesium } \\
\text { (mg/l) }\end{array}$ \\
\hline $\begin{array}{c}\text { OBSERVED } \\
(\bar{X} n \circ-\bar{X} h) /[s / \mathrm{Vn}]\end{array}$ & -0.41 & 0.51 & -0.40 & -0.38 & -0.38 & -0.30 & -0.44 & -0.15 & -0.54 & -0.45 \\
\hline
\end{tabular}


Table B.5.1 Hypothesis Testing for the Water Quality Values in the Fitzroy River Basin

Table B.5.1(a) Station 130105

Historical (prior) Mean Values

\begin{tabular}{|c|c|c|c|c|c|c|c|c|c|c|}
\hline & $\begin{array}{c}\text { Condurtivity } \\
@ 25 \mathrm{C} \\
(\mathrm{ms} / \mathrm{m}) \\
\end{array}$ & $\mathrm{PH}$ & $\begin{array}{c}\text { Dissolved } \\
\text { Jons } \\
(\mathrm{mg} / \mathrm{l}) \\
\end{array}$ & $\begin{array}{c}\text { Dissolved } \\
\text { Solids } \\
\text { (mg/) }\end{array}$ & $\begin{array}{c}\text { Hardness } \\
\text { (mgl)as CaCO3 }\end{array}$ & $\begin{array}{c}\text { Alkalinity } \\
\text { (mg/l)as Caco3 }\end{array}$ & $\begin{array}{l}\text { Natrium } \\
\text { (mg/) }\end{array}$ & $\begin{array}{l}\text { Kalium } \\
(\mathrm{mg} / \mathrm{l})\end{array}$ & $\begin{array}{l}\text { Calcium } \\
\text { (mg/i) }\end{array}$ & $\begin{array}{c}\text { Magnesium } \\
\text { (mg/l) }\end{array}$ \\
\hline Mean $\quad(\vec{X} h)$ & 301.3 & 7.8 & 208.8 & 171.4 & 86.8 & 87.3 & 25.2 & 3.2 & 18.9 & 0.4 \\
\hline $\begin{array}{l}\text { Standard (Sh) } \\
\text { Deviation }\end{array}$ & 105.7 & 0.3 & 65.7 & 52.0 & 32.1 & 23.7 & 10.0 & 0.7 & 6.9 & 3.6 \\
\hline
\end{tabular}

[1 Yearly Averaging]

New Mean Values Predicted by the Entropy Method

\begin{tabular}{|c|c|c|c|c|c|c|c|c|c|c|}
\hline & $\begin{array}{c}\text { Conductivity } \\
@ 25 \mathrm{C} \\
(\mathrm{ms} / \mathrm{m})\end{array}$ & $\mathrm{PH}$ & $\begin{array}{c}\text { Dissolved } \\
\text { lons } \\
\text { fingll } \\
\end{array}$ & $\begin{array}{c}\text { Dissolved } \\
\text { Solids } \\
(\mathrm{mg} / 1) \\
\end{array}$ & $\begin{array}{c}\text { Hardness } \\
\text { (ming/lyas CaCO3 }\end{array}$ & $\begin{array}{c}\text { Alkalinity } \\
\text { (mg/l)as CaCO3 }\end{array}$ & $\begin{array}{l}\text { Natrium } \\
(\mathrm{mg} /)\end{array}$ & $\begin{array}{l}\text { Kalium } \\
\text { (mg/l) }\end{array}$ & $\begin{array}{l}\text { Calcium } \\
\text { (mg/) }\end{array}$ & $\begin{array}{l}\text { Magnesium } \\
(\mathrm{mg} / \mathrm{l})\end{array}$ \\
\hline (Xne) & $\begin{array}{l}266.5 \\
301.4 \\
218.8\end{array}$ & $\begin{array}{l}7.8 \\
7.7 \\
7.7\end{array}$ & $\begin{array}{l}182.7 \\
203.4 \\
148.6\end{array}$ & $\begin{array}{l}150.3 \\
167.5 \\
126.1\end{array}$ & $\begin{array}{l}70.0 \\
85.7 \\
59.7\end{array}$ & $\begin{array}{l}77.7 \\
81.3 \\
62.5\end{array}$ & $\begin{array}{l}22.0 \\
24.7 \\
17.5\end{array}$ & $\begin{array}{l}3.4 \\
3.3 \\
3.1\end{array}$ & $\begin{array}{l}15.8 \\
19.3 \\
12.9\end{array}$ & $\begin{array}{l}7.4 \\
9.1 \\
6.5\end{array}$ \\
\hline $\begin{array}{l}(\bar{X} \text { (ne) } \\
\text { (Sne) }\end{array}$ & $\begin{array}{c}262.3 \\
41.5\end{array}$ & $\begin{array}{l}7.7 \\
0.0\end{array}$ & $\begin{array}{c}178.2 \\
27.7\end{array}$ & $\begin{array}{c}148.0 \\
20.8\end{array}$ & $\begin{array}{l}71.8 \\
13.1\end{array}$ & $\begin{array}{l}73.8 \\
10.0\end{array}$ & $\begin{array}{c}21.4 \\
3.6\end{array}$ & $\begin{array}{l}3.3 \\
0.2\end{array}$ & $\begin{array}{c}16.0 \\
3.2\end{array}$ & $\begin{array}{l}7.7 \\
1.3\end{array}$ \\
\hline
\end{tabular}

Statistic Test (T), Calculated by Equation 5.6

\begin{tabular}{|c|c|c|c|c|c|c|c|c|c|c|}
\hline & $\begin{array}{c}\text { Conductivity } \\
@ 25 \mathrm{C} \\
(\mathrm{ms} / \mathrm{m}) \\
\end{array}$ & $\mathrm{PH}$ & $\begin{array}{c}\text { Dissolved } \\
\text { Ions } \\
(\mathrm{mg} / \mathrm{l}) \\
\end{array}$ & $\begin{array}{c}\text { Dissolved } \\
\text { Solids } \\
\text { (mg/l) } \\
\end{array}$ & $\begin{array}{c}\text { Hardness } \\
\text { (mgil)as Caco3 }\end{array}$ & $\begin{array}{c}\text { Alkalinity } \\
\text { (mgll)as } \mathrm{CaCO} 3\end{array}$ & $\begin{array}{l}\text { Natrium } \\
\text { (mgii) }\end{array}$ & $\begin{array}{l}\text { Kalium } \\
\text { (mgII) }\end{array}$ & $\begin{array}{l}\text { Calcium } \\
(\mathrm{mg} / \mathrm{l})\end{array}$ & $\begin{array}{c}\text { Magnesium } \\
\text { (mg/l) }\end{array}$ \\
\hline$T$ & -0.88 & -0.8 .8 & -1.09 & -1.07 & -1.10 & -1.33 & -0.92 & 0.35 & -0.96 & -1.19 \\
\hline $\begin{array}{l}\text { Degrees of } \\
\text { Freedom (v) }\end{array}$ & 8.76 & 7.86 & 8.52 & 8.70 & 8.63 & 8.52 & 8.93 & 8.81 & 8.10 & 8.94 \\
\hline $\mathrm{t}[\mathrm{v}, 0.975]$ & 2.273 & 2.314 & 2.283 & 2.275 & 2.278 & 2.283 & 2.265 & 2.270 & 2.302 & 2.265 \\
\hline$\{[v, 0.950]$ & 1.839 & 1.865 & 1.846 & 1.841 & 1.843 & 1.846 & 1.835 & 1.838 & 1.857 & 1.235 \\
\hline
\end{tabular}

\section{[2 Yearly Averaging]}

New Mean Values Predicted by the Entropy Method

\begin{tabular}{|c|c|c|c|c|c|c|c|c|c|c|}
\hline & $\begin{array}{c}\text { Conductivity } \\
@ 25 \mathrm{C} \\
\text { (ms/m) } \\
\end{array}$ & $\mathrm{PH}$ & $\begin{array}{c}\text { Dissolved } \\
\text { lons } \\
(\mathrm{mg} /) \\
\end{array}$ & $\begin{array}{c}\text { Dissolvad } \\
\text { Solids } \\
\text { (mg/) } \\
\end{array}$ & $\begin{array}{c}\text { Hardness } \\
\text { (mg/h)as } \mathrm{CaCO} 3\end{array}$ & $\begin{array}{c}\text { Alkalinity } \\
\text { (mg/l)as CaCO3 }\end{array}$ & $\begin{array}{l}\text { Natrium } \\
\text { (mg/l) }\end{array}$ & $\begin{array}{l}\text { Kalium } \\
\text { (mg/) }\end{array}$ & $\begin{array}{l}\text { Calcium } \\
\text { (mgn) }\end{array}$ & $\begin{array}{c}\text { Magnesium } \\
\text { (mg/) }\end{array}$ \\
\hline$\left(X_{n e}\right)$ & $\begin{array}{l}287.2 \\
263.0 \\
.\end{array}$ & $\begin{array}{l}7.8 \\
7.7\end{array}$ & $\begin{array}{l}194.8 \\
178.1\end{array}$ & $\begin{array}{l}159.9 \\
147.8\end{array}$ & $\begin{array}{l}79.0 \\
74.2\end{array}$ & $\begin{array}{l}80.3 \\
73.0\end{array}$ & $\begin{array}{l}23.7 \\
21.5\end{array}$ & $\begin{array}{l}3.7 \\
3.3\end{array}$ & $\begin{array}{l}17.8 \\
16.5\end{array}$ & $\begin{array}{l}8.4 \\
8.0\end{array}$ \\
\hline $\begin{array}{l}(\bar{X} n e) \\
\text { (Sne) }\end{array}$ & $\begin{array}{c}275.1 \\
17.1\end{array}$ & $\begin{array}{l}7.7 \\
0.0\end{array}$ & $\begin{array}{c}186.5 \\
11.8\end{array}$ & $\begin{array}{c}153.9 \\
8.6\end{array}$ & $\begin{array}{c}76.6 \\
3.4\end{array}$ & $\begin{array}{c}76.6 \\
5.2\end{array}$ & $\begin{array}{c}22.6 \\
1.6\end{array}$ & $\begin{array}{l}3.5 \\
0.2\end{array}$ & $\begin{array}{c}17.1 \\
0.9\end{array}$ & $\begin{array}{l}8.2 \\
0.3\end{array}$ \\
\hline
\end{tabular}

Statistic Test (T), Calculated by Equation 5.6

\begin{tabular}{|c|c|c|c|c|c|c|c|c|c|c|}
\hline & $\begin{array}{c}\text { Conductivity } \\
\text { (@ } 25 \mathrm{C} \\
\text { (mS/m) } \\
\end{array}$ & $\mathrm{PH}$ & \begin{tabular}{|c|}
$\begin{array}{c}\text { Dissolved } \\
\text { lons } \\
(\mathrm{mg} / \mathrm{l})\end{array}$ \\
\end{tabular} & \begin{tabular}{|c|}
$\begin{array}{c}\text { Dissolved } \\
\text { Solids } \\
\text { (mg/l) }\end{array}$ \\
\end{tabular} & $\begin{array}{c}\text { Hardness } \\
\text { (mg/l)as } \mathrm{CaCO}\end{array}$ & $\begin{array}{c}\text { Alkalinity } \\
\text { (mg/l)as } \mathrm{CaCO} 3\end{array}$ & $\begin{array}{l}\text { Natrium } \\
(\mathrm{mg} / \mathrm{l})\end{array}$ & $\begin{array}{l}\text { Kalium } \\
\text { (mg/) }\end{array}$ & $\begin{array}{l}\text { Calcium } \\
(\mathrm{mg} / \mathrm{l})\end{array}$ & $\begin{array}{c}\text { Magnesium } \\
\text { (mg/l) }\end{array}$ \\
\hline $\mathrm{T}$ & -0.67 & -0.93 & -0.91 & -0.91 & -0.89 & -1.17 & -0.68 & 1.03 & -0.71 & -0.98 \\
\hline $\begin{array}{l}\text { Degrees of } \\
\text { Freedom (v) }\end{array}$ & 7.94 & 7.32 & 7.99 & 7.95 & 7.54 & 7.91 & 7.90 & 5.48 & 7.78 & 7.30 \\
\hline $\mathrm{t}[\mathrm{v}, 0.975]$ & 2.310 & 2.346 & 2.306 & 2.309 & 2.333 & 2.311 & 2.312 & 2.511 & 2.319 & 2.347 \\
\hline$t[v, 0.950]$ & 1.862 & 1.884 & 1.860 & 1.862 & 1.876 & 1.863 & 1.863 & 1.980 & 1.868 & 1.885 \\
\hline
\end{tabular}


Table B.5.1 (a) continued

\section{[3 Yearly Averaging]}

New Mean Values Predicted by the Entropy Method

\begin{tabular}{|c|c|c|c|c|c|c|c|c|c|c|}
\hline & $\begin{array}{c}\text { Conductivity } \\
@ 25 \mathrm{C} \\
(\mathrm{ms} / \mathrm{m}) \\
\end{array}$ & $\mathrm{PH}$ & $\begin{array}{c}\text { Dissolved } \\
\text { lons } \\
\text { (mg/) }\end{array}$ & $\begin{array}{c}\text { Dissolved } \\
\text { Solids } \\
\text { (mign) }\end{array}$ & $\begin{array}{c}\text { Hardness } \\
\text { (mgh)as } \mathrm{CaCO} 3\end{array}$ & $\begin{array}{c}\text { Alkalinity } \\
\text { (mg/l)as Caco3 }\end{array}$ & $\begin{array}{l}\text { Natrium } \\
\text { (mgi) }\end{array}$ & $\begin{array}{l}\text { Kalium } \\
\text { (mg/) }\end{array}$ & $\begin{array}{l}\text { Calcium } \\
\text { (mgh) }\end{array}$ & $\begin{array}{c}\text { Magnesium } \\
\text { (mg/) }\end{array}$ \\
\hline (Xne) & 273.8 & 7.8 & 186.5 & 153.0 & 77.4 & 78.4 & 22.9 & 3.5 & 17.2 & 8.1 \\
\hline $\begin{array}{l}\text { (Xne) } \\
\text { (Sne) }\end{array}$ & $\begin{array}{c}273.8 \\
0\end{array}$ & $\begin{array}{c}7.8 \\
0\end{array}$ & $\begin{array}{c}186.5 \\
0\end{array}$ & $\begin{array}{c}153.0 \\
0\end{array}$ & $\begin{array}{c}77.4 \\
0\end{array}$ & $\begin{array}{c}78.4 \\
0\end{array}$ & $\begin{array}{c}22.9 \\
0\end{array}$ & $\begin{array}{c}3.5 \\
0\end{array}$ & $\begin{array}{c}17.2 \\
0\end{array}$ & $\begin{array}{c}8.1 \\
0\end{array}$ \\
\hline
\end{tabular}

Statistic Test (T), Calculated by Equation 5.6

\begin{tabular}{|c|c|c|c|c|c|c|c|c|c|c|}
\hline & $\begin{array}{c}\text { Conductivity } \\
\text { @ } 25 \mathrm{C} \\
\text { (ms } / \mathrm{m}) \\
\end{array}$ & $\mathrm{PH}$ & $\begin{array}{c}\text { Dissolved } \\
\text { lons } \\
\text { (mg/l) }\end{array}$ & $\begin{array}{c}\text { Dissolved } \\
\text { Solids } \\
\text { (mg/) } \\
\end{array}$ & $\begin{array}{c}\text { Hardness } \\
\text { (mg/) }\end{array}$ & $\begin{array}{c}\text { Alkalinity } \\
\text { (mgf)as Caco3 }\end{array}$ & $\begin{array}{l}\text { Natrium } \\
\text { (mgd) }\end{array}$ & $\begin{array}{l}\text { Kalium } \\
\text { (mg/l) }\end{array}$ & $\begin{array}{l}\text { Calciurn } \\
\text { (mg/l) }\end{array}$ & $\begin{array}{c}\text { Magnesium } \\
\text { (mg/) }\end{array}$ \\
\hline $\mathrm{T}$ & -0.74 & -0.37 & -0.96 & -1.00 & -0.83 & -1.06 & -0.63 & 1.42 & -0.73 & -1.05 \\
\hline $\begin{array}{l}\text { Degrees of } \\
\text { Freedom (v) }\end{array}$ & 7.00 & 7.00 & 7.00 & 7.00 & 7.00 & 7.00 & 7.00 & 7.00 & 7.00 & 7.00 \\
\hline$t[v, 0.975]$ & 2.365 & 2.365 & 2.365 & 2.365 & 2.365 & 2.365 & 2.365 & 2.365 & 2.365 & 2.365 \\
\hline$t[v, 0.950]$ & 1.895 & 1.895 & 1.895 & 1.895 & 1.895 & 1.895 & 1.895 & 1.895 & 1.895 & 1.895 \\
\hline
\end{tabular}


Table B.5.1(b) Station 130322

Historical (prior) Mean Values

\begin{tabular}{|c|c|c|c|c|c|c|c|c|c|c|}
\hline & $\begin{array}{c}\text { Conductivity } \\
@ 25 \mathrm{C} \\
(\mathrm{ms} / \mathrm{m}) \\
\end{array}$ & $\mathrm{PH}$ & $\begin{array}{c}\text { Dissolved } \\
\text { lons } \\
\text { (mg/l) } \\
\end{array}$ & $\begin{array}{c}\text { Dissolved } \\
\text { Solids } \\
\text { (mg/) } \\
\end{array}$ & $\begin{array}{c}\text { Hardness } \\
\text { (mgll)as CaCO3 }\end{array}$ & $\begin{array}{c}\text { Alkalinity } \\
\text { (mg/l)as CaCo3 }\end{array}$ & $\begin{array}{l}\text { Natrium } \\
(\mathrm{mg} / \mathrm{l}) \\
\end{array}$ & $\begin{array}{l}\text { Kalium } \\
\text { (mg/) }\end{array}$ & $\begin{array}{l}\text { Calcium } \\
(\mathrm{mg} /)\end{array}$ & $\begin{array}{l}\text { Magnesium } \\
\text { (mg/) }\end{array}$ \\
\hline Mean & 203.8 & 7.6 & 148.2 & 122.6 & 53.0 & 66.6 & 18.7 & 5.6 & 13.3 & 4.8 \\
\hline $\begin{array}{l}\text { Standard (Sh) } \\
\text { Deviation }\end{array}$ & 43.7 & 0.3 & 28.3 & 24.8 & 8.6 & 13.2 & 4.3 & 0.5 & 2.2 & 0.8 \\
\hline
\end{tabular}

\section{[1 Yearly Averaging]}

New Mean Values Predicted by the Entropy Method

\begin{tabular}{|c|c|c|c|c|c|c|c|c|c|c|}
\hline & $\begin{array}{c}\text { Conductivity } \\
\text { @ } 25 \mathrm{C} \\
\text { (ms/m) } \\
\end{array}$ & $\mathrm{PH}$ & $\begin{array}{c}\begin{array}{c}\text { Dissolved } \\
\text { fons } \\
\text { (mg/l) }\end{array} \\
\end{array}$ & $\begin{array}{c}\text { Dissolved } \\
\text { Solids } \\
(\mathrm{mg} /) \\
\end{array}$ & $\begin{array}{c}\text { Hardness } \\
\text { (mg/) } / \text { as } \mathrm{CaCO} 3\end{array}$ & $\begin{array}{c}\text { Alkalinity } \\
\text { (mg/)as } \mathrm{CaCO}\end{array}$ & $\begin{array}{l}\text { Natrium } \\
\text { (mg/l) }\end{array}$ & $\begin{array}{l}\text { Kalium } \\
\text { (mg/l) }\end{array}$ & $\begin{array}{l}\text { Calcium } \\
\text { (mg/) }\end{array}$ & $\begin{array}{c}\text { Magnesium } \\
(\mathrm{mg} / \mathrm{l})\end{array}$ \\
\hline (Xne) & $\begin{array}{l}202.4 \\
203.8 \\
200.6\end{array}$ & $\begin{array}{l}7.6 \\
7.6 \\
7.6\end{array}$ & $\begin{array}{l}147.2 \\
148.0 \\
145.8\end{array}$ & $\begin{array}{l}121.6 \\
122.4 \\
120.4\end{array}$ & $\begin{array}{l}53.0 \\
53.2 \\
52.8\end{array}$ & $\begin{array}{l}66.0 \\
66.2 \\
64.9\end{array}$ & $\begin{array}{l}18.5 \\
18.7 \\
18.4\end{array}$ & $\begin{array}{l}5.6 \\
5.6 \\
5.6\end{array}$ & $\begin{array}{l}13.2 \\
13.3 \\
13.2\end{array}$ & $\begin{array}{l}4.8 \\
4.8 \\
4.7\end{array}$ \\
\hline $\begin{array}{l}(\bar{X} n e) \\
(\text { Sne }) \\
\end{array}$ & $\begin{array}{r}202.3 \\
1.6 \\
\end{array}$ & $\begin{array}{l}7.6 \\
0.0 \\
\end{array}$ & $\begin{array}{c}147.0 \\
1.1 \\
\end{array}$ & $\begin{array}{c}121.5 \\
1.0 \\
\end{array}$ & $\begin{array}{l}53.0 \\
0.2 \\
\end{array}$ & $\begin{array}{r}65.7 \\
0.7 \\
\end{array}$ & $\begin{array}{c}18.5 \\
0.1 \\
\end{array}$ & $\begin{array}{l}5.6 \\
0.0 \\
\end{array}$ & $\begin{array}{c}13.2 \\
0.1 \\
\end{array}$ & $\begin{array}{l}4.8 \\
0.0 \\
\end{array}$ \\
\hline
\end{tabular}

Statistic Test (T), Calculated by Equation 5.6

\begin{tabular}{|c|c|c|c|c|c|c|c|c|c|c|}
\hline & $\begin{array}{c}\text { Conductivity } \\
@ 25 \mathrm{C} \\
(\mathrm{mS} / \mathrm{m})\end{array}$ & $\mathrm{PH}$ & $\begin{array}{c}\text { Dissolved } \\
\text { tons } \\
\text { (mg/l) } \\
\end{array}$ & $\begin{array}{c}\text { Dissolved } \\
\text { Solids } \\
(\mathrm{mg} /) \\
\end{array}$ & $\begin{array}{c}\text { Hardness } \\
\text { (mg/l)as } \mathrm{CaCO} 3 \\
\end{array}$ & $\begin{array}{c}\text { Alkalinity } \\
\text { (mg/l)as } \mathrm{CaCO} 3\end{array}$ & $\begin{array}{l}\text { Natrium } \\
\text { (mg/) } \\
\end{array}$ & $\begin{array}{l}\text { Kalium } \\
\text { (mg/) }\end{array}$ & $\begin{array}{l}\text { Calcium } \\
\text { (mg/) }\end{array}$ & $\begin{array}{l}\text { Magnesium } \\
\text { (mg/) }\end{array}$ \\
\hline $\mathrm{T}$ & -0.10 & -0.18 & -0.13 & -0.13 & 0.01 & -0.20 & -0.10 & 0.07 & -0.09 & -0.07 \\
\hline $\begin{array}{l}\text { Degreess of } \\
\text { Freedom (v) }\end{array}$ & 7.05 & 7.04 & 7.06 & 7.07 & 7.02 & 7.10 & 7.04 & 7.08 & 7.04 & 7.01 \\
\hline $\mathrm{t}[\mathrm{v}, 0.975]$ & 2.382 & 2.362 & 2.362 & 2.361 & 2.364 & 2.359 & 2.362 & 2.361 & 2.363 & 2.364 \\
\hline$t[v, 0.950\}$ & 1.893 & 1.893 & 1.893 & 1.893 & 1.894 & 1.892 & 1.893 & 1.892 & 1.894 & 1.895 \\
\hline 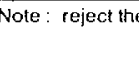 & 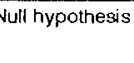 & & $\begin{array}{l}T>t[] \\
T<-t[]\end{array}$ & & & & & & & \\
\hline
\end{tabular}

\section{[2 Yearly Averaging]}

New Mean Values Predicted by the Entropy Method

\begin{tabular}{|c|c|c|c|c|c|c|c|c|c|c|}
\hline & $\begin{array}{c}\text { Conductivity } \\
\text { @ } 25 \mathrm{C} \\
\text { (ms/m) }\end{array}$ & $\mathrm{PH}$ & $\begin{array}{c}\text { Dissolved } \\
\text { lons } \\
\text { (mgll) }\end{array}$ & $\begin{array}{c}\text { Dissolved } \\
\text { Solids } \\
\text { (mgh) } \\
\end{array}$ & $\begin{array}{c}\text { Hardness } \\
\text { (mgl)as } \mathrm{CaCO}\end{array}$ & $\begin{array}{c}\text { Aikalinity } \\
(\mathrm{mg} / \mathrm{f}) \text { as } \mathrm{CaCO} 3\end{array}$ & $\begin{array}{l}\text { Natrium } \\
\text { (mg/l) }\end{array}$ & $\begin{array}{l}\text { Kalium } \\
\langle\mathrm{mg} / \mathrm{l}\rangle\end{array}$ & $\begin{array}{l}\text { Calcium } \\
(\mathrm{mg} / \mathrm{l})\end{array}$ & $\begin{array}{c}\text { Magnesium } \\
\text { (mg/l) } \\
\end{array}$ \\
\hline$(X n e)$ & $\begin{array}{l}203.2 \\
202.3\end{array}$ & $\begin{array}{l}7.6 \\
7.6\end{array}$ & $\begin{array}{l}147.6 \\
147.0\end{array}$ & $\begin{array}{l}122.1 \\
121.5\end{array}$ & $\begin{array}{l}53.1 \\
53.1\end{array}$ & $\begin{array}{l}66.1 \\
65.6\end{array}$ & $\begin{array}{l}18.6 \\
18.5\end{array}$ & $\begin{array}{l}5.7 \\
5.6\end{array}$ & $\begin{array}{l}13.3 \\
13.2\end{array}$ & $\begin{array}{l}4.8 \\
4.8\end{array}$ \\
\hline $\begin{array}{l}(\bar{X} \text { ne) } \\
\text { (Sne) }\end{array}$ & $\begin{array}{c}202.8 \\
0.6 \\
\end{array}$ & $\begin{array}{l}7.6 \\
0.0 \\
\end{array}$ & $\begin{array}{c}147.3 \\
0.5 \\
\end{array}$ & $\begin{array}{c}121.8 \\
0.4 \\
\end{array}$ & $\begin{array}{c}53.1 \\
0.1 \\
\end{array}$ & $\begin{array}{c}65.9 \\
0.3 \\
\end{array}$ & $\begin{array}{c}18.6 \\
0.1 \\
\end{array}$ & $\begin{array}{l}5.6 \\
0.0\end{array}$ & $\begin{array}{c}13.3 \\
0.0 \\
\end{array}$ & $\begin{array}{l}4.8 \\
0.0 \\
\end{array}$ \\
\hline
\end{tabular}

Statistic Test (T), Calculated by Equation 5.6

\begin{tabular}{|c|c|c|c|c|c|c|c|c|c|c|}
\hline & $\begin{array}{c}\text { Conductivity } \\
@ 25 \mathrm{C} \\
(\mathrm{ms} / \mathrm{m})\end{array}$ & $\mathrm{PH}$ & $\begin{array}{c}\text { Dissolved } \\
\text { lons } \\
\text { (mg/l) } \\
\end{array}$ & $\begin{array}{c}\text { Dissolved } \\
\text { Solids } \\
\text { (mg/l) } \\
\end{array}$ & $\begin{array}{c}\text { Hardness } \\
\text { (mg/l)as } \mathrm{CaCO} 3\end{array}$ & $\begin{array}{c}\text { Alkalinity } \\
\text { (mg/l)as } \mathrm{CaCO} 3\end{array}$ & $\begin{array}{l}\text { Natrium } \\
(\mathrm{mg} /)\end{array}$ & $\begin{array}{l}\text { Kalium } \\
\text { (mg/l) }\end{array}$ & $\begin{array}{l}\text { Calcium } \\
(\mathrm{mg} / \mathrm{l})\end{array}$ & $\begin{array}{c}\text { Magnesium } \\
(\mathrm{mg} / 4)\end{array}$ \\
\hline$T$ & -0.06 & -0.22 & -0.09 & -0.10 & 0.04 & -0.16 & -0.07 & 0.21 & -0.06 & 0.01 \\
\hline $\begin{array}{l}\text { Degrees of } \\
\text { Freedom (v) }\end{array}$ & 7.01 & 7.04 & 7.02 & 7.02 & 7.00 & 7.04 & 7.01 & 7.24 & 7.01 & 7.00 \\
\hline $\mathrm{t}[\mathrm{v}, 0.975]$ & 2.364 & 2.363 & 2.364 & 2.364 & 2.365 & 2.363 & 2.364 & 2.293 & 2.365 & 2.365 \\
\hline$t[v, 0,950]$ & 1.695 & 1.894 & 1.694 & 1.894 & 1.895 & 1.894 & 1.695 & 1.854 & 1.895 & 1.895 \\
\hline
\end{tabular}


Table B.5.1(b) (continued)

[3 Yearly Averaging]

New Mean Values Predicted by the Entropy Method

\begin{tabular}{|c|c|c|c|c|c|c|c|c|c|c|}
\hline & $\begin{array}{l}\text { Conductivity } \\
\text { @ 25 C } \\
\text { (ms/m) }\end{array}$ & $\mathrm{PH}$ & $\begin{array}{l}\text { Dissolved } \\
\text { lons } \\
\text { (mg/l) }\end{array}$ & $\begin{array}{c}\text { Dissolved } \\
\text { Solids } \\
\text { (mg/l) }\end{array}$ & $\begin{array}{c}\text { Hardness } \\
\text { (mg/l)as } \mathrm{CaCO}\end{array}$ & $\begin{array}{c}\text { Alkalinity } \\
\text { (mgll)as Cacos }\end{array}$ & $\begin{array}{l}\text { Natrium } \\
\text { (mgl) }\end{array}$ & $\begin{array}{l}\text { Kalium } \\
\text { (mgl) }\end{array}$ & $\begin{array}{l}\text { Calcium } \\
\text { (mg/i) }\end{array}$ & $\begin{array}{l}\text { Magnesium } \\
\text { (mg/l) }\end{array}$ \\
\hline (Xne) & 202.7 & 7.6 & 147.3 & 121.7 & 52.8 & 66.0 & 18.6 & 5.6 & 13.3 & 4.8 \\
\hline $\begin{array}{l}(\bar{X} \text { ne) } \\
\text { (Sne) }\end{array}$ & $\begin{array}{c}202.7 \\
0\end{array}$ & $\begin{array}{c}7.6 \\
0 \\
\end{array}$ & $\begin{array}{c}147.3 \\
0 \\
\end{array}$ & $\begin{array}{c}121.7 \\
0 \\
\end{array}$ & $\begin{array}{c}52.8 \\
0 \\
\end{array}$ & $\begin{array}{c}66.0 \\
0 \\
\end{array}$ & $\begin{array}{c}18.6 \\
0 \\
\end{array}$ & $\begin{array}{c}5.6 \\
0 \\
\end{array}$ & $\begin{array}{c}13.3 \\
0 \\
\end{array}$ & $\begin{array}{c}4.8 \\
0 \\
\end{array}$ \\
\hline
\end{tabular}

Statistic Test (T), Calculated by Equation 5.6

\begin{tabular}{|c|c|c|c|c|c|c|c|c|c|c|}
\hline & $\begin{array}{c}\text { Conductivity } \\
@ 25 \mathrm{C} \\
\text { (ms/m) } \\
\end{array}$ & $\mathrm{PH}$ & $\begin{array}{c}\text { Dissolved } \\
\text { lons } \\
(\mathrm{mg} / \mathrm{l})\end{array}$ & $\begin{array}{c}\text { Dissolved } \\
\text { Solids } \\
\text { (mg/i) } \\
\end{array}$ & $\begin{array}{c}\text { Hardness } \\
\text { (mg/l)as CaCO3 }\end{array}$ & $\begin{array}{c}\text { Alkalinity } \\
\text { (mg/l)as caco3 }\end{array}$ & $\begin{array}{l}\text { Natrium } \\
\text { (mg/i) }\end{array}$ & $\begin{array}{l}\text { Kaliurn } \\
\text { (mg/t) }\end{array}$ & $\begin{array}{l}\text { Calcium } \\
(\mathrm{mg} / \mathrm{l})\end{array}$ & $\begin{array}{l}\text { Magnesium } \\
(m g l) \\
\end{array}$ \\
\hline $\mathrm{T}$ & -0.07 & -0.06 & -0.09 & -0.11 & -0.05 & -0.13 & -0.06 & 0.24 & -0.05 & -0.05 \\
\hline $\begin{array}{l}\text { Degrees of } \\
\text { Freedom (v) }\end{array}$ & 7.00 & 7.00 & 7.00 & 7.00 & 7.00 & 7.00 & 7.00 & 7.00 & 7.00 & 7.00 \\
\hline$t[v, 0.975]$ & 2.365 & 2.365 & 2.365 & 2.365 & 2.365 & 2.365 & 2.365 & 2.365 & 2.365 & 2.365 \\
\hline$t[v, 0.950]$ & 1.895 & 1.895 & 1.895 & 1.895 & 1.895 & 1.895 & 1.895 & 1.895 & 1.895 & 1.895 \\
\hline
\end{tabular}


Table B.5.1(c) Station 130003

Historical (prior) Mean Values

\begin{tabular}{|c|c|c|c|c|c|c|c|c|c|c|}
\hline & $\begin{array}{c}\text { Conductivity } \\
@ 25 \mathrm{C} \\
\text { (ms/m) }\end{array}$ & $\mathrm{PH}$ & $\begin{array}{c}\text { Dissolved } \\
\text { Ions } \\
\text { (mg/) } \\
\end{array}$ & $\begin{array}{c}\text { Dissolved } \\
\text { Solids } \\
\text { (mgh) } \\
\end{array}$ & $\begin{array}{c}\text { Hardness } \\
\text { (mg/l)as CaCO3 }\end{array}$ & $\begin{array}{c}\text { Alkalinily } \\
\text { (mg/)as } \mathrm{CaCO} 3\end{array}$ & $\begin{array}{l}\text { Natrium } \\
(\mathrm{mg} / \mathrm{l})\end{array}$ & $\begin{array}{l}\text { Kalium } \\
\text { (mg/) }\end{array}$ & $\begin{array}{l}\text { Catcium } \\
\text { (mg/l) }\end{array}$ & $\begin{array}{c}\text { Magnesium } \\
\text { (mg/) }\end{array}$ \\
\hline Mean $\quad(\bar{X} \bar{h})$ & 368.6 & 7.9 & 248.8 & 209.1 & 104.6 & 90.4 & 33.1 & 3.5 & 21.7 & 12.2 \\
\hline $\begin{array}{l}\text { Standard (Sh) } \\
\text { Deviation }\end{array}$ & 199.7 & 0.2 & 114.8 & 100.4 & 56.5 & 26.0 & 18.1 & 1.0 & 10.6 & 7.3 \\
\hline
\end{tabular}

\section{[1 Yearly Averaging]}

\section{New Mean Values}

\begin{tabular}{|c|c|c|c|c|c|c|c|c|c|c|}
\hline & $\begin{array}{c}\text { Conductivity } \\
@ 25 \mathrm{C} \\
(\mathrm{ms} / \mathrm{m}) \\
\end{array}$ & $\mathrm{PH}$ & $\begin{array}{c}\text { Dissolved } \\
\text { Ions } \\
(\mathrm{mg} /)\end{array}$ & $\begin{array}{c}\text { Dissolved } \\
\text { Solids } \\
(\mathrm{mg} / \mathrm{l}) \\
\end{array}$ & $\begin{array}{c}\text { Hardness } \\
\text { (mgi)as } \mathrm{CaCO} 3\end{array}$ & $\begin{array}{c}\text { Alkalinity } \\
\text { (mg/)as CaCos }\end{array}$ & $\begin{array}{l}\text { Natrium } \\
\text { (mg/l) }\end{array}$ & $\begin{array}{l}\text { Kalium } \\
\text { (mg/) } \\
\end{array}$ & $\begin{array}{l}\text { Calcium } \\
(\mathrm{mg} /)\end{array}$ & $\begin{array}{l}\text { Magnesium } \\
(m g /) \\
\end{array}$ \\
\hline$(X n e)$ & $\begin{array}{l}288.3 \\
370.0 \\
176.7\end{array}$ & $\begin{array}{l}7.8 \\
7.6 \\
7.4\end{array}$ & $\begin{array}{r}194.5 \\
237.9 \\
122.8\end{array}$ & $\begin{array}{l}160.0 \\
200.0 \\
104.0\end{array}$ & $\begin{array}{c}71.0 \\
102.5 \\
50.3\end{array}$ & $\begin{array}{l}76.0 \\
81.5 \\
53.0\end{array}$ & $\begin{array}{l}26.0 \\
32.0 \\
15.8\end{array}$ & $\begin{array}{l}4.4 \\
4.0 \\
3.9\end{array}$ & $\begin{array}{l}16.3 \\
22.3 \\
11.3\end{array}$ & $\begin{array}{c}7.4 \\
11.5 \\
5.4\end{array}$ \\
\hline $\begin{array}{l}\bar{X} \text { (ne) } \\
\text { (Sne) }\end{array}$ & $\begin{array}{r}278.3 \\
97.1 \\
\end{array}$ & $\begin{array}{l}7.6 \\
0.2 \\
\end{array}$ & $\begin{array}{c}185.1 \\
58.1 \\
\end{array}$ & $\begin{array}{r}154.7 \\
48.2 \\
\end{array}$ & $\begin{array}{l}74.6 \\
26.3 \\
\end{array}$ & $\begin{array}{l}70.2 \\
15.1 \\
\end{array}$ & $\begin{array}{r}24.6 \\
8.2 \\
\end{array}$ & $\begin{array}{l}3.9 \\
0.6 \\
\end{array}$ & $\begin{array}{c}16.6 \\
5.5 \\
\end{array}$ & $\begin{array}{l}8.1 \\
3.1 \\
\end{array}$ \\
\hline
\end{tabular}

Statistic Test (T), Calculated by Equation 5.6

\begin{tabular}{|c|c|c|c|c|c|c|c|c|c|c|}
\hline & $\begin{array}{c}\text { Conductivity } \\
@ 25 \mathrm{C} \\
(\mathrm{ms} / \mathrm{m})\end{array}$ & $\mathrm{PH}$ & $\begin{array}{c}\text { Dissolved } \\
\text { Ions } \\
(\mathrm{mg} /) \\
\end{array}$ & $\begin{array}{c}\text { Dissolved } \\
\text { Solids } \\
(\mathrm{mg} /)\end{array}$ & $\begin{array}{c}\text { Hardness } \\
\text { (mg/)as CaCO3 }\end{array}$ & $\begin{array}{c}\text { Alkalinily } \\
\text { (mgll)as } \mathrm{CaCO} 3\end{array}$ & $\begin{array}{l}\text { Natrium } \\
\text { (mgl) }\end{array}$ & $\begin{array}{l}\text { Kalium } \\
(\mathrm{mg} /)\end{array}$ & $\begin{array}{l}\text { Calcium } \\
\text { (mgll) }\end{array}$ & $\begin{array}{l}\text { Magnasium } \\
\text { (mg/) }\end{array}$ \\
\hline $\mathrm{T}$ & -1.00 & -2.47 & -1.21 & -1.21 & -1.20 & -1.60 & -1.07 & 0.68 & -1.04 & -1.31 \\
\hline $\begin{array}{l}\text { Degrees of } \\
\text { Freedom (v) }\end{array}$ & 7.78 & 4.84 & 7.54 & 7.86 & 8.04 & 6.57 & 8.17 & 6.98 & 7.34 & 8.52 \\
\hline$t[v, 0.975]$ & 2.319 & 2.604 & 2.333 & 2.314 & 2.304 & 2.400 & 2.299 & 2.367 & 2.345 & 2.283 \\
\hline$t\{v, 0.950\}$ & 1.868 & 2.034 & 1.876 & 1.865 & 1.859 & 1.916 & 1.856 & 1.896 & 1.883 & 1.846 \\
\hline & & & $\begin{array}{l}T>t[1] \\
T<-t[]\end{array}$ & & & & & & & \\
\hline
\end{tabular}

\section{[2 Yearly Averaging]}

New Mean Values

\begin{tabular}{|c|c|c|c|c|c|c|c|c|c|c|}
\hline & $\begin{array}{c}\text { Conductivity } \\
@ 25 \mathrm{C} \\
\text { (ms/m) }\end{array}$ & $\mathrm{PH}$ & $\begin{array}{l}\text { Dissolved } \\
\text { lons } \\
\text { (mg/l) }\end{array}$ & $\begin{array}{c}\text { Dissolved } \\
\text { Solids } \\
\text { (mg/l) } \\
\end{array}$ & $\begin{array}{c}\text { Hardness } \\
\text { (mg/)as } \mathrm{CaCO} 3\end{array}$ & $\begin{array}{c}\text { Alkalinity } \\
\text { (mg/l)as CaCO3 }\end{array}$ & $\begin{array}{l}\text { Natrium } \\
(\mathrm{mg} / \mathrm{l})\end{array}$ & $\begin{array}{l}\text { Kalium } \\
\text { (mg/l) }\end{array}$ & $\begin{array}{l}\text { Calcium } \\
(\mathrm{mg} / \mathrm{l})\end{array}$ & $\begin{array}{l}\text { Magnesium } \\
\text { (mg/l) }\end{array}$ \\
\hline (Xne) & $\begin{array}{l}329.2 \\
273.3\end{array}$ & $\begin{array}{l}7.7 \\
7.5\end{array}$ & $\begin{array}{l}216.2 \\
180.3\end{array}$ & $\begin{array}{l}180.0 \\
152.0\end{array}$ & $\begin{array}{l}86.8 \\
76.4\end{array}$ & $\begin{array}{l}78.8 \\
67.3\end{array}$ & $\begin{array}{l}29.0 \\
23.9\end{array}$ & $\begin{array}{l}4.2 \\
3.6\end{array}$ & $\begin{array}{l}19.3 \\
16.8\end{array}$ & $\begin{array}{l}9.4 \\
8.4\end{array}$ \\
\hline $\begin{array}{l}\bar{X}(\mathrm{X} e) \\
\text { (Sne) }\end{array}$ & $\begin{array}{c}301.3 \\
39.5\end{array}$ & $\begin{array}{l}7.6 \\
0.1\end{array}$ & $\begin{array}{l}108.3 \\
25.3\end{array}$ & $\begin{array}{c}166.0 \\
19.8\end{array}$ & $\begin{array}{c}81.6 \\
7.3\end{array}$ & $\begin{array}{c}73.0 \\
8.1\end{array}$ & $\begin{array}{c}26.4 \\
3.6\end{array}$ & $\begin{array}{l}3.9 \\
0.4\end{array}$ & $\begin{array}{c}18.0 \\
1.8\end{array}$ & $\begin{array}{l}8.9 \\
0.7\end{array}$ \\
\hline
\end{tabular}

Statistic Test (T), Calculated by Equation 5.6

\begin{tabular}{|c|c|c|c|c|c|c|c|c|c|c|}
\hline & $\begin{array}{c}\text { Conductivity } \\
@ 25 \mathrm{C} \\
\text { (ms/m) } \\
\end{array}$ & $\mathrm{PH}$ & $\begin{array}{c}\text { Dissolved } \\
\text { Ions } \\
\text { (mg/l) } \\
\end{array}$ & $\begin{array}{c}\text { Dissolved } \\
\text { Solids } \\
\text { (mgh) } \\
\end{array}$ & $\begin{array}{c}\text { Hardness } \\
\text { (mgil)as Cacos }\end{array}$ & $\begin{array}{c}\text { Alkalinity } \\
\text { (mgfl)as } \mathrm{CaCO} \\
\end{array}$ & $\begin{array}{l}\text { Natrium } \\
\text { (mg/) }\end{array}$ & $\begin{array}{l}\text { Kalium } \\
\text { (mgli) }\end{array}$ & $\begin{array}{l}\text { Calcium } \\
\text { (mg/l) }\end{array}$ & $\begin{array}{l}\text { Magnesium } \\
\text { (mg/) }\end{array}$ \\
\hline $\mathrm{T}$ & -0.89 & -2.75 & -1.14 & -1.13 & -1.11 & -1.61 & -0.96 & 0.76 & -0.93 & -1.24 \\
\hline $\begin{array}{l}\text { Degrees of } \\
\text { Freedom (v) }\end{array}$ & 7.99 & 3,17 & 7.90 & 7,99 & 7.73 & 6.53 & 7.99 & 5.12 & 7.97 & 7.46 \\
\hline$t(v, 0.975\}$ & 2,306 & 3.112 & 2.312 & 2.306 & 2.322 & 2.404 & 2307 & 2.557 & 2.300 & 2.338 \\
\hline$t[v, 0.950]$ & 1.860 & 2.315 & 1.864 & 1.860 & 1.870 & 1.918 & 1.860 & 2.007 & 1.861 & 1.879 \\
\hline
\end{tabular}


Table B.5.1(c) (continued)

\section{[3 Yearly Averaging]}

New Mean Values

\begin{tabular}{|c|c|c|c|c|c|c|c|c|c|c|}
\hline & $\begin{array}{c}\text { Conductivity } \\
\text { (a) } 25 \mathrm{C} \\
\text { (ms/m) }\end{array}$ & $\mathrm{PH}$ & $\begin{array}{c}\text { Dissolved } \\
\text { lons } \\
\text { (mgh) } \\
\end{array}$ & $\begin{array}{c}\text { Dissolved } \\
\text { Solids } \\
\text { (mg/) }\end{array}$ & $\begin{array}{c}\text { Hardness } \\
\text { (mg/l)as CaCO3 }\end{array}$ & $\begin{array}{c}\text { Alkalinity } \\
\text { (mg/)as } \mathrm{CaCO} 3\end{array}$ & $\begin{array}{l}\text { Natrium } \\
\text { (mg/l) }\end{array}$ & $\begin{array}{l}\text { Kalium } \\
(\mathrm{mg} /) \\
\end{array}$ & $\begin{array}{l}\text { Calcium } \\
(\mathrm{mg} / \mathrm{l})\end{array}$ & $\begin{array}{c}\text { Magnesium } \\
\text { (mg/) }\end{array}$ \\
\hline (Xne) & 278.3 & 7.6 & 185.1 & 154.7 & 74.6 & 70.2 & 24.6 & 3.9 & 16.6 & 8.1 \\
\hline $\begin{array}{l}\left(\bar{X}_{n e}\right) \\
\text { (Sne) }\end{array}$ & $\begin{array}{c}278.3 \\
0.0\end{array}$ & $\begin{array}{l}7.6 \\
0.0\end{array}$ & $\begin{array}{c}185.1 \\
0.0\end{array}$ & $\begin{array}{c}154.7 \\
0.0\end{array}$ & $\begin{array}{c}74.6 \\
0.0\end{array}$ & $\begin{array}{c}70.2 \\
0.0\end{array}$ & $\begin{array}{c}24.6 \\
0.0\end{array}$ & $\begin{array}{l}3.9 \\
0.0\end{array}$ & $\begin{array}{c}16.6 \\
0.0\end{array}$ & $\begin{array}{l}8.1 \\
0.0\end{array}$ \\
\hline
\end{tabular}

Statistic Test (T), Calculated by Equation 5.6

\begin{tabular}{|c|c|c|c|c|c|c|c|c|c|c|}
\hline & $\begin{array}{c}\text { Conductivity } \\
@ 25 \mathrm{C} \\
(\mathrm{ms} / \mathrm{m}) \\
\end{array}$ & $\mathrm{PH}$ & $\begin{array}{c}\text { Dissolved } \\
\text { [ons } \\
\text { (mg/) } \\
\end{array}$ & $\begin{array}{c}\text { Dissolved } \\
\text { Solids } \\
\text { (mg/l) } \\
\end{array}$ & $\begin{array}{c}\text { Hardness } \\
(\mathrm{mg} / \mathrm{l}) \text { as } \mathrm{CaCO} 3 \\
\end{array}$ & $\begin{array}{c}\text { Alkalinity } \\
\text { (mg) } 1 \text { )as } \mathrm{CaCO} 3\end{array}$ & $\begin{array}{l}\text { Natrium } \\
\text { (mg/) }\end{array}$ & $\begin{array}{l}\text { Kalium } \\
(\mathrm{mg} / \mathrm{l})\end{array}$ & $\begin{array}{l}\text { Calcium } \\
(\mathrm{mg} / \mathrm{l})\end{array}$ & $\begin{array}{l}\text { Magnesium } \\
\text { (mg/n) }\end{array}$ \\
\hline$T$ & -1.28 & -3.95 & -1.57 & -1.53 & -1.50 & -2.21 & -7.33 & 0.91 & -1.36 & -1.59 \\
\hline $\begin{array}{l}\text { Degrees of } \\
\text { Freedom }(v)\end{array}$ & 7.00 & 7.00 & 7.00 & 7.00 & 7.00 & 7.00 & 7.00 & 7.00 & 7.00 & 7.00 \\
\hline$t[v, 0.975]$ & 2.365 & 2.365 & 2.365 & 2.365 & 2.365 & 2.365 & 2.365 & 2.365 & 2.365 & 2.365 \\
\hline$t[v, 0.950]$ & 1.895 & 1.895 & 1.895 & 1.895 & 1.895 & 1.895 & 1.895 & 1.895 & 1.895 & 1.895 \\
\hline
\end{tabular}


Table B.5.2 Hypothesis Testing for the Water Quality Values in the Nogoa River Basin

Table B.5.2(a) Station 130202

Historical (prior) Mean Values

\begin{tabular}{|c|c|c|c|c|c|c|c|c|c|c|}
\hline & $\begin{array}{c}\text { Conductivity } \\
@ 25 \mathrm{C} \\
(\mathrm{mS} / \mathrm{m}) \\
\end{array}$ & $\mathrm{PH}$ & $\begin{array}{l}\text { Dissolved } \\
\text { lons } \\
\text { (mgl) }\end{array}$ & $\begin{array}{l}\text { Dissolved } \\
\text { Solids } \\
\text { (mgll) } \\
\end{array}$ & $\begin{array}{c}\text { Hardness } \\
\text { (mg/)as } \mathrm{CaCO} 3 \\
\end{array}$ & $\begin{array}{c}\text { Alkalinity } \\
\text { (mgl)as } \mathrm{CaCO} 3 \\
\end{array}$ & $\begin{array}{l}\text { Natrium } \\
(\mathrm{mg} / \mathrm{h})\end{array}$ & $\begin{array}{l}\text { Kalium } \\
\text { (mg/l) }\end{array}$ & $\begin{array}{l}\text { Calcium } \\
\text { (mgf) }\end{array}$ & $\begin{array}{c}\text { Magnesium } \\
(\mathrm{mg} / \mathrm{l}) \\
\end{array}$ \\
\hline Mean $(\bar{X} h)$ & 245.7 & 7.6 & 177.4 & 137.2 & 76.2 & 79.2 & 18.9 & 4.3 & 20.0 & 6.4 \\
\hline $\begin{array}{l}\text { Standard (Sh) } \\
\text { Deviation }\end{array}$ & 64.2 & 0.3 & 41.3 & 37.6 & 15.8 & 13.1 & 6.4 & 2.0 & 3.9 & 1.7 \\
\hline
\end{tabular}

\section{[1 Yearly Averaging]}

New Mean Values Predicted by the Entropy Method

\begin{tabular}{|c|c|c|c|c|c|c|c|c|c|c|}
\hline & $\begin{array}{c}\text { Conductivity } \\
@ 25 \mathrm{C} \\
(\mathrm{ms} / \mathrm{m})\end{array}$ & $\mathrm{PH}$ & $\begin{array}{c}\text { Dissolved } \\
\text { lons } \\
\text { (mg//) }\end{array}$ & $\begin{array}{c}\text { Dissolved } \\
\text { Solids } \\
\text { (mg/l) }\end{array}$ & $\begin{array}{c}\text { Hardness } \\
\text { (mgll)as } \mathrm{CaCO} 3\end{array}$ & $\begin{array}{c}\text { Alkalinity } \\
\text { (mgij)as } \mathrm{CaCO} 3\end{array}$ & $\begin{array}{l}\text { Natrium } \\
(\mathrm{mg} / \mathrm{l})\end{array}$ & $\begin{array}{l}\text { Kalium } \\
\text { (mg/l) }\end{array}$ & $\begin{array}{l}\text { Calcium } \\
\text { (mg:) }\end{array}$ & $\begin{array}{l}\text { Magnesium } \\
\quad(\mathrm{mg} / 1)\end{array}$ \\
\hline \multirow{5}{*}{ (Xne) } & 215.2 & 7.5 & 159.3 & 120.5 & 70.7 & 75.6 & 16.2 & 5.5 & 18.9 & 5.6 \\
\hline & 263.5 & 7.6 & 169.7 & 131.0 & 73.0 & 77.4 & 17.9 & 5.5 & 19.8 & 5.9 \\
\hline & 235.7 & 7.5 & 161.4 & 122.1 & 71.0 & 75.5 & 16.5 & 5.4 & 19.1 & 5.6 \\
\hline & 218.4 & 7.6 & 159.8 & 118.7 & 71.1 & 75.7 & 15.8 & 5.3 & 18.9 & 5.6 \\
\hline & 217.6 & 7.5 & 159.0 & 118.5 & 70.7 & 75.9 & 15.9 & 5.6 & 19.2 & 5.6 \\
\hline (Xne) & 230.1 & 7.5 & 161.8 & 122.2 & 71.3 & 76.0 & 16.4 & 5.5 & 19.2 & 5.7 \\
\hline (Sne) & 20.4 & 0.0 & 4.5 & 5.1 & 1.0 & 0.8 & 0.8 & 0.1 & 0.4 & 0.1 \\
\hline
\end{tabular}

Statistic Test (T), Calculated by Equation 5.6

\begin{tabular}{|c|c|c|c|c|c|c|c|c|c|c|}
\hline & $\begin{array}{c}\text { Conductivity } \\
@ 25 \mathrm{c} \\
\text { (ms/m) } \\
\end{array}$ & $\mathrm{PH}$ & $\begin{array}{c}\text { Dissolved } \\
\text { lons } \\
(\mathrm{mg} / \mathrm{l}) \\
\end{array}$ & \begin{tabular}{|c|} 
Dissolved \\
Solids \\
(mg/l)
\end{tabular} & $\begin{array}{c}\text { Hardness } \\
\text { (mg/l)as } \mathrm{CaCO} 3\end{array}$ & $\begin{array}{c}\text { Alkalinity } \\
\text { (mgn)as } \mathrm{CaCO} 3\end{array}$ & $\begin{array}{l}\text { Natrium } \\
\text { (mgn) }\end{array}$ & $\begin{array}{l}\text { Kalium } \\
\text { (mg/) }\end{array}$ & $\begin{array}{l}\text { Calcium } \\
\text { (mg/) }\end{array}$ & $\begin{array}{c}\text { Magnesium } \\
\text { (mgfl) } \\
\end{array}$ \\
\hline $\mathrm{T}$ & -0.64 & -0.82 & -1.06 & -1.11 & -0.87 & -0.69 & -1.05 & 1.56 & -0.58 & -1.24 \\
\hline $\begin{array}{l}\text { Degreess of } \\
\text { Freedom (v) }\end{array}$ & 9.03 & 7.05 & 7.26 & 7.41 & 7.09 & 7.08 & 7.39 & 6.06 & 7.20 & 7.10 \\
\hline$t \mid v, 0.975\}$ & 2.261 & 2.362 & 2.349 & 2.341 & 2,360 & 2.360 & 2.342 & 2.442 & 2.353 & 2359 \\
\hline$t[v, 0.950]$ & 1.832 & 1.893 & 1.886 & 1.881 & 1.892 & 1.892 & 1.881 & 1.940 & 1.888 & 1.892 \\
\hline
\end{tabular}

\section{[2 Yearly Averaging]}

New Mean Values Predicted by the Entropy Method

\begin{tabular}{|c|c|c|c|c|c|c|c|c|c|c|}
\hline & $\begin{array}{c}\text { Conductivity } \\
\text { @ } 25 \mathrm{C} \\
\text { (ms/m) }\end{array}$ & $\mathrm{PH}$ & $\begin{array}{c}\text { Dissolved } \\
\text { Ions } \\
\text { (mgil) } \\
\end{array}$ & $\begin{array}{c}\text { Dissolved } \\
\text { Sollds } \\
\text { (mgh) } \\
\end{array}$ & $\begin{array}{c}\text { Hardness } \\
\text { (mg/l)as CaCO3 }\end{array}$ & $\begin{array}{c}\text { Alkalinity } \\
\text { (mg//)as } \mathrm{CaCO} 3 \\
\end{array}$ & $\begin{array}{l}\text { Natrium } \\
\text { (mg/l) }\end{array}$ & $\begin{array}{l}\text { Kallum } \\
\text { (mgl) }\end{array}$ & $\begin{array}{l}\text { Calcium } \\
\text { (mg/l) }\end{array}$ & $\begin{array}{c}\text { Magnesium } \\
(\mathrm{mg} / \mathrm{l})\end{array}$ \\
\hline \multirow{4}{*}{ (Xne) } & 237.1 & 7.5 & 164.0 & 125.6 & 71.0 & 76.2 & 17.1 & 5.4 & 19.0 & 5.7 \\
\hline & 247.9 & 7.5 & 165.0 & 126.5 & 71.2 & 76.2 & 17.3 & 5.4 & 19.1 & 5.7 \\
\hline & 224.3 & 7.5 & 159.9 & 120.0 & 70.1 & 75.3 & 16.2 & 5.3 & 18.6 & 5.6 \\
\hline & 214.8 & 7.5 & 158.7 & 118.2 & 69.9 & 75.5 & 15.9 & 5.4 & 18.6 & 5.6 \\
\hline$\left(\bar{X}_{n e}\right)$ & 231.0 & 7.5 & 161.9 & 122.6 & 70.6 & 75.8 & 16.6 & 5.4 & 18.8 & 5.8 \\
\hline (Sne) & 14.5 & 0.0 & 3.1 & 4.1 & 0.6 & 0.5 & 0.7 & 0.0 & 0.3 & 0.1 \\
\hline
\end{tabular}

Statistic Test (T), Calculated by Equation 5.6

\begin{tabular}{|c|c|c|c|c|c|c|c|c|c|c|}
\hline & $\begin{array}{c}\text { Conductivity } \\
@ 25 \mathrm{C} \\
\text { (ms/m) } \\
\end{array}$ & $\mathrm{PH}$ & $\begin{array}{c}\text { Dissolved } \\
\text { Ions } \\
\text { (mg/) } \\
\end{array}$ & $\begin{array}{c}\text { Dissolved } \\
\text { Solids } \\
\text { (mg/) }\end{array}$ & $\begin{array}{c}\text { Hardness } \\
\text { (mg/l)as CaCO3 }\end{array}$ & $\begin{array}{c}\text { Alkalinity } \\
\text { (mg/n)as } \mathrm{CaCO} 3\end{array}$ & $\begin{array}{l}\text { Natrlum } \\
(\mathrm{mg} / \mathrm{l})\end{array}$ & $\begin{array}{l}\text { Kalium } \\
\text { (mg/t) }\end{array}$ & $\begin{array}{l}\text { Calcium } \\
(\mathrm{mg} n)\end{array}$ & $\begin{array}{c}\text { Magnesium } \\
\text { (mg/ } / \text { ) }\end{array}$ \\
\hline T & -0.62 & -1.40 & -1.06 & -1.09 & -1.00 & -0.74 & -0.98 & 1.43 & -0.81 & -1.27 \\
\hline $\begin{array}{c}\text { Degrees of } \\
\text { Freadom (v) }\end{array}$ & 8.29 & 7.01 & 7.16 & 7.33 & 7.04 & 7.04 & 7.31 & 6.00 & 7.14 & 7.04 \\
\hline$t[v, 0.975]$ & 2.293 & 2.364 & 2.356 & 2,346 & 2.362 & 2.363 & 2,346 & 2.447 & 2.356 & 2.362 \\
\hline$t[v, 0.950]$ & 1.852 & 1.695 & 1.890 & 1.884 & 1.893 & 1.894 & 1.884 & 1.943 & 1.890 & 1.893 \\
\hline
\end{tabular}


Table B.5.2(a) (continued)

[3 Yearly Averaging]

New Mean Values Predicted by the Entropy Method

\begin{tabular}{|c|c|c|c|c|c|c|c|c|c|c|}
\hline & $\begin{array}{l}\text { Conductivity } \\
@ 25 \mathrm{C} \\
(\mathrm{ms} / \mathrm{m})\end{array}$ & $\mathrm{PH}$ & $\begin{array}{c}\text { Dissolved } \\
\text { lons } \\
\text { (mg/l) }\end{array}$ & $\begin{array}{c}\text { Dissolved } \\
\text { Solids } \\
\text { (mg/) }\end{array}$ & $\begin{array}{c}\text { Hardness } \\
\text { (mg/)as CaCO3 }\end{array}$ & $\begin{array}{c}\text { Alkalinity } \\
\text { (mgf)as } \mathrm{CaCO} 3 \\
\end{array}$ & $\begin{array}{l}\text { Natrium } \\
(\mathrm{mg} / \mathrm{B})\end{array}$ & $\begin{array}{l}\text { Kalium } \\
\text { (mgn) }\end{array}$ & $\begin{array}{l}\text { Calcium } \\
\text { (mg/) }\end{array}$ & $\begin{array}{c}\text { Magnesium } \\
\text { (mg/ } / 4\end{array}$ \\
\hline (Xne) & $\begin{array}{l}230.0 \\
231.2 \\
214.3\end{array}$ & $\begin{array}{l}7.6 \\
7.6 \\
7.6\end{array}$ & $\begin{array}{l}145.3 \\
145.8 \\
134.9\end{array}$ & $\begin{array}{l}122.8 \\
122.2 \\
117.5\end{array}$ & $\begin{array}{l}70.0 \\
70.2 \\
69.3\end{array}$ & $\begin{array}{l}75.5 \\
75.5 \\
75.0\end{array}$ & $\begin{array}{l}16.7 \\
16.6 \\
15.9\end{array}$ & $\begin{array}{l}5.5 \\
5.5 \\
5.5\end{array}$ & $\begin{array}{r}18.6 \\
18.6 \\
18.3\end{array}$ & $\begin{array}{l}5.7 \\
5.7 \\
5.6\end{array}$ \\
\hline $\begin{array}{l}\text { (X) } \\
\text { (Sne) }\end{array}$ & $\begin{array}{c}225.2 \\
9.4\end{array}$ & $\begin{array}{l}7.6 \\
0.0\end{array}$ & $\begin{array}{c}142.0 \\
6.2\end{array}$ & $\begin{array}{c}120.8 \\
2.9\end{array}$ & $\begin{array}{c}69.8 \\
0.5\end{array}$ & $\begin{array}{c}75.3 \\
0.3\end{array}$ & $\begin{array}{c}16.4 \\
0.5\end{array}$ & $\begin{array}{l}5.5 \\
0.0\end{array}$ & $\begin{array}{c}18.5 \\
0.2\end{array}$ & $\begin{array}{l}5.7 \\
0.0\end{array}$ \\
\hline
\end{tabular}

Statistic Test (T), Calculated by Equation 5.6

\begin{tabular}{|c|c|c|c|c|c|c|c|c|c|c|}
\hline & $\begin{array}{c}\text { Conductivity } \\
\text { @ } 25 \mathrm{C} \\
\text { (ms/m) } \\
\end{array}$ & $\mathrm{PH}$ & $\begin{array}{c}\text { Dissolved } \\
\text { lons } \\
\text { (mg/ }) \\
\end{array}$ & $\begin{array}{c}\text { Dissolved } \\
\text { Solids } \\
\text { (mg/l) } \\
\end{array}$ & $\begin{array}{c}\text { Hardness } \\
\text { (mgl)as } \mathrm{CaCO} 3 \\
\end{array}$ & $\begin{array}{c}\text { Alkalinity } \\
\text { (mg/l)as CaCo3 }\end{array}$ & $\begin{array}{l}\text { Natrium } \\
(\mathrm{mg} /)\end{array}$ & $\begin{array}{l}\text { Kalium } \\
\text { (mg/l) }\end{array}$ & $\begin{array}{l}\text { Calcium } \\
(\mathrm{mg} / \mathrm{l})\end{array}$ & $\begin{array}{l}\text { Magnesium } \\
\text { (mg/) }\end{array}$ \\
\hline ז & -0.88 & -0.59 & -2.35 & -1.22 & -1.13 & -0.84 & -1.08 & 1.57 & -1.05 & -1.18 \\
\hline $\begin{array}{l}\text { Degrees of } \\
\text { Freedom (v) }\end{array}$ & 7.74 & 7.00 & 7.76 & 7.21 & 7.04 & 7.02 & 7.20 & 6.00 & 7.08 & 7.02 \\
\hline$t[v, 0.975]$ & 2.321 & 2,365 & 2.320 & 2.352 & 2.363 & 2.364 & 2.353 & 2.447 & 2.360 & 2.364 \\
\hline$t[v, 0.950]$ & 1.869 & 1.895 & 1.868 & 1.887 & 1.894 & 1.894 & 1.888 & 1.943 & 1.892 & 1.894 \\
\hline
\end{tabular}

[4 Yearly Averaging]

New Mean Values Predicted by the Entropy Method

\begin{tabular}{|c|c|c|c|c|c|c|c|c|c|c|}
\hline & $\begin{array}{c}\text { Conductivity } \\
@ 25 \mathrm{C} \\
(\mathrm{ms} / \mathrm{m})\end{array}$ & $\mathrm{PH}$ & $\begin{array}{c}\text { Dissolved } \\
\text { lons } \\
\text { (mg/) }\end{array}$ & $\begin{array}{c}\text { Dissolved } \\
\text { Solids } \\
\text { (mg/l) }\end{array}$ & $\begin{array}{c}\text { Hardness } \\
\text { (mg/)as } \mathrm{CaCO}\end{array}$ & $\begin{array}{c}\text { Alkalinity } \\
\text { (mg/l)as } \mathrm{CaCO}\end{array}$ & $\begin{array}{l}\text { Natrium } \\
\text { (mg/l) }\end{array}$ & $\begin{array}{l}\text { Kalium } \\
\text { (mgl) }\end{array}$ & $\begin{array}{l}\text { Calcium } \\
(\mathrm{mg} / \mathrm{i})\end{array}$ & $\begin{array}{c}\text { Magnesium } \\
(\mathrm{mg} / \mathrm{l})\end{array}$ \\
\hline$(X \cap \theta)$ & $\begin{array}{l}228.9 \\
229.6\end{array}$ & $\begin{array}{l}7.6 \\
7.6\end{array}$ & $\begin{array}{l}145.8 \\
145.6\end{array}$ & $\begin{array}{l}122.7 \\
121.5\end{array}$ & $\begin{array}{l}71.6 \\
71.6\end{array}$ & $\begin{array}{l}76.2 \\
76.2\end{array}$ & $\begin{array}{l}16.2 \\
16.1\end{array}$ & $\begin{array}{l}5.8 \\
5.8\end{array}$ & $\begin{array}{l}18.9 \\
19.0\end{array}$ & $\begin{array}{l}5.9 \\
5.9\end{array}$ \\
\hline $\begin{array}{l}(\bar{X} n e) \\
\text { (Sne) }\end{array}$ & $\begin{array}{c}229.2 \\
0.5\end{array}$ & $\begin{array}{l}7.6 \\
0.0\end{array}$ & $\begin{array}{c}145.7 \\
0.2\end{array}$ & $\begin{array}{c}121.8 \\
0.4\end{array}$ & $\begin{array}{c}71.6 \\
0.0\end{array}$ & $\begin{array}{c}76.2 \\
0.0\end{array}$ & $\begin{array}{c}16.2 \\
0.1\end{array}$ & $\begin{array}{l}5.8 \\
0.0\end{array}$ & $\begin{array}{c}16.9 \\
0.1\end{array}$ & $\begin{array}{l}5.9 \\
0.0\end{array}$ \\
\hline
\end{tabular}

Statistic Test (T), Calculated by Equation 5.6

\begin{tabular}{|c|c|c|c|c|c|c|c|c|c|c|}
\hline & $\begin{array}{c}\text { Conductivity } \\
@ 25 \mathrm{C} \\
(\mathrm{ms} / \mathrm{m}) \\
\end{array}$ & $\mathrm{PH}$ & $\begin{array}{c}\text { Dissolved } \\
\text { lons } \\
\text { (mg/l) } \\
\end{array}$ & $\begin{array}{c}\text { Dissolved } \\
\text { Solids } \\
\text { (mg/) } \\
\end{array}$ & $\begin{array}{c}\text { Hardness } \\
\text { (mg/)as CaCO3 }\end{array}$ & $\begin{array}{c}\text { Alkalinity } \\
\text { (mgf)as } \mathrm{CaCO} 3 \\
\end{array}$ & $\begin{array}{l}\text { Natrium } \\
(\mathrm{mg} /)\end{array}$ & $\begin{array}{l}\text { Kalium } \\
\text { (mgl) }\end{array}$ & $\begin{array}{l}\text { Calcium } \\
\text { (mg/l) }\end{array}$ & $\begin{array}{c}\text { Magnegium } \\
\text { (mgn) }\end{array}$ \\
\hline$T$ & -0.70 & -0.59 & -2.08 & -1.14 & -0.83 & -0.65 & -1.19 & 2.01 & -0.74 & -0.91 \\
\hline $\begin{array}{l}\text { Deggrees of } \\
\text { Freadom (v) }\end{array}$ & 7.00 & 7.00 & 7.00 & 7.01 & 7.00 & 7.00 & 7.00 & 6.00 & 7.02 & 7.00 \\
\hline $\mathrm{t}[\mathrm{v}, 0.975]$ & 2.365 & 2.365 & 2,365 & 2.365 & 2.365 & 2.365 & 2.385 & 2.447 & 2.364 & 2.365 \\
\hline$t[v, 0.950]$ & 1.895 & 1.895 & 1.895 & 1.895 & 1.695 & 1.895 & 1.895 & 1.843 & 1.894 & 1.895 \\
\hline : rejec & & & $\begin{array}{l}T>t[] \\
T<-t[]\end{array}$ & & & & & & & \\
\hline
\end{tabular}


Table B.5.2(b) Station 130212

Historical (prior) Mean Values

\begin{tabular}{|c|c|c|c|c|c|c|c|c|c|c|}
\hline & $\begin{array}{c}\text { Conductivity } \\
@ 25 \mathrm{C} \\
(\mathrm{ms} / \mathrm{m})\end{array}$ & $\mathrm{PH}$ & $\begin{array}{c}\text { Dissolved } \\
\text { lons } \\
(\mathrm{mg} / \mathrm{l}) \\
\end{array}$ & $\begin{array}{c}\text { Dissolved } \\
\text { Solids } \\
\text { (mg/) } \\
\end{array}$ & $\begin{array}{c}\text { Hardness } \\
\text { (mg/l)as Cacos }\end{array}$ & $\begin{array}{c}\text { Alkalinity } \\
\text { (mg/l)as } \mathrm{CacO} 3\end{array}$ & $\begin{array}{l}\text { Natrium } \\
(\mathrm{mg} / \mathrm{l})\end{array}$ & $\begin{array}{l}\text { Kalium } \\
(\mathrm{mg} /)\end{array}$ & $\begin{array}{l}\text { Calcium } \\
\text { (mgil) }\end{array}$ & $\begin{array}{l}\text { Magnesium } \\
(\mathrm{mg} / \mathrm{l}) \\
\end{array}$ \\
\hline Mean $(\overline{x h})$ & 271.4 & 7.5 & 209.1 & 155.6 & 86.5 & 101.9 & 23.2 & 3.7 & 24.6 & 6.1 \\
\hline $\begin{array}{l}\text { Slanctard (Sh) } \\
\text { Deviation }\end{array}$ & 152.9 & 0.2 & 107.5 & 79.1 & 44.8 & 48.6 & 16.4 & 1.6 & 13.8 & 2.9 \\
\hline
\end{tabular}

\section{[1 Yearly Averaging]}

New Mean Values Predicted by the Entropy Method

\begin{tabular}{|c|c|c|c|c|c|c|c|c|c|c|}
\hline & $\begin{array}{c}\text { Conductivity } \\
@ 25 \mathrm{C} \\
\text { (ms/m) }\end{array}$ & $\mathrm{PH}$ & $\begin{array}{c}\text { Dissolved } \\
\text { Ions } \\
(\mathrm{mg} /)\end{array}$ & $\begin{array}{c}\text { Dissolved } \\
\text { Solids } \\
\text { (mg/l) }\end{array}$ & $\begin{array}{c}\text { Hardness } \\
\text { (mg/)as } \mathrm{CaCO} 3\end{array}$ & $\begin{array}{c}\text { Alkalinity } \\
\text { (mgi)as } \mathrm{CaCO} 3\end{array}$ & $\begin{array}{l}\text { Natrium } \\
(\mathrm{mg} / \mathrm{l})\end{array}$ & $\begin{array}{l}\text { Kalium } \\
(\mathrm{mg} /)\end{array}$ & $\begin{array}{l}\text { Calcium } \\
(\mathrm{mg} / \mathrm{l})\end{array}$ & $\begin{array}{l}\text { Magnesium } \\
\text { (mg/) }\end{array}$ \\
\hline \multirow{5}{*}{$\left(X_{n e}\right)$} & 170.2 & 7.5 & 139.4 & 113.6 & 61.2 & 73.8 & 13.1 & 4.4 & 16.8 & 4.7 \\
\hline & 181.6 & 7.5 & 179.4 & 140.0 & 72.2 & 87.9 & 19.6 & 4.4 & 23.2 & 5.2 \\
\hline & 175.0 & 7.5 & 147.3 & 117.7 & 62.8 & 73.0 & 14.3 & 4.3 & 18.1 & 4.8 \\
\hline & 171.0 & 7.5 & 141.2 & 109.0 & 63.2 & 74.3 & 11.8 & 4.3 & 16.5 & 4.8 \\
\hline & 170.8 & 7.5 & 138.1 & 108.5 & 61.2 & 76.1 & 12.1 & 4.4 & 18.9 & 4.7 \\
\hline$\left(\bar{X}_{n e}\right)$ & 173.7 & 7.5 & 149.1 & 117.7 & 64.1 & 77.0 & 14.2 & 4.4 & 18.7 & 4.8 \\
\hline (Sne) & 4.8 & 0.0 & 17.3 & 13.0 & 4.6 & 6.2 & 3.2 & 0.0 & 2.7 & 0.2 \\
\hline
\end{tabular}

Statistic Test (T), Calculated by Equation 5.6

\begin{tabular}{|c|c|c|c|c|c|c|c|c|c|c|}
\hline & $\begin{array}{c}\text { Conductivity } \\
@ 25 \mathrm{C} \\
\text { (ms/m) } \\
\end{array}$ & $\mathrm{PH}$ & $\begin{array}{c}\text { Dissolved } \\
\text { Ions } \\
\text { (mgl) } \\
\end{array}$ & $\begin{array}{c}\text { Dissolved } \\
\text { Solids } \\
\text { (mg/l) }\end{array}$ & $\begin{array}{c}\text { Hardness } \\
\text { (mg/)as } \mathrm{CaCO} 3\end{array}$ & $\begin{array}{c}\text { Alkalinity } \\
\text { (mg/)as } \mathrm{CaCO} 3 \\
\end{array}$ & $\begin{array}{l}\text { Natrium } \\
(\mathrm{mg} / \mathrm{l})\end{array}$ & $\begin{array}{l}\text { Kalium } \\
\text { (mgl) }\end{array}$ & $\begin{array}{l}\text { Calcium } \\
\text { (mg/) }\end{array}$ & $\begin{array}{l}\text { Magnesium } \\
(\mathrm{mg} / 1) \\
\end{array}$ \\
\hline$T$ & -1.81 & -0.38 & -1.55 & -1.32 & -1.40 & -1.43 & -1.52 & 1.03 & -1.16 & -1.22 \\
\hline $\begin{array}{l}\text { Degrees of } \\
\text { Freedon (v) }\end{array}$ & 7.02 & 7.01 & 7.57 & 7.59 & 7.24 & 7.36 & 7.82 & 6.00 & 7.84 & 7.10 \\
\hline$t[v, 0.975]$ & 2.364 & 2.365 & 2.331 & 2.330 & 2.351 & 2.344 & 2.316 & 2.447 & 2.315 & 2.359 \\
\hline$t[v, 0.950]$ & 1.894 & 1.895 & 1.875 & 1.874 & 1.887 & 1.882 & 1.866 & 1.943 & 1.866 & 1.892 \\
\hline - & & & $\begin{array}{l}T>t \mid\} \\
T<-\{1\}\end{array}$ & & & & & & & \\
\hline
\end{tabular}

\section{[2 Yearly Averaging]}

New Mean Values Predicted by the Entropy Method

\begin{tabular}{|c|c|c|c|c|c|c|c|c|c|c|}
\hline & $\begin{array}{c}\text { Conductivity } \\
\text { @ 25c } \\
\text { (ms/m) } \\
\end{array}$ & $\mathrm{PH}$ & $\begin{array}{c}\text { Dissolved } \\
\text { lons } \\
\text { (mg/li) } \\
\end{array}$ & $\begin{array}{c}\text { Dissolved } \\
\text { Solids } \\
\text { (mgl) } \\
\end{array}$ & $\begin{array}{c}\text { Hardness } \\
\text { (mgf)as Caco3 }\end{array}$ & $\begin{array}{c}\text { Alkatinity } \\
\text { (mg/l)as } \mathrm{CaCO} 3\end{array}$ & $\begin{array}{l}\text { Natrium } \\
(\mathrm{mg} / \mathrm{l})\end{array}$ & $\begin{array}{l}\text { Kalium } \\
\text { (mg/l) }\end{array}$ & $\begin{array}{l}\text { Calcium } \\
\text { (mg/i) }\end{array}$ & $\begin{array}{l}\text { Magnesium } \\
\text { (mg/l) }\end{array}$ \\
\hline \multirow{4}{*}{ (Xne) } & 175.4 & 7.9 & 157.3 & 126.4 & 62.8 & 78.5 & 16.7 & 4.3 & 17.8 & 4.9 \\
\hline & 177.9 & 7.9 & 161.4 & 128.6 & 63.7 & 78.1 & 17.3 & 4.3 & 18.6 & 4.9 \\
\hline & 172.4 & 7.9 & 141.6 & 112.4 & 58.7 & 71.0 & 13.2 & 4.3 & 14.5 & 4.7 \\
\hline & 170.1 & 7.9 & 135.8 & 107.6 & 57.9 & 72.6 & 12.1 & 4.3 & 15.0 & 4.7 \\
\hline (X̄ne) & 173.9 & 7.9 & 149.3 & 118.7 & 60.8 & 75.0 & 14.8 & 4.3 & 16.5 & 4.8 \\
\hline (Sne) & 3.4 & 0.0 & 11.9 & 10.3 & 2.9 & 3.8 & 2.6 & 0.0 & 2.0 & 0.1 \\
\hline
\end{tabular}

Statistic Test (T), Calculated by Equation 5.6

\begin{tabular}{|c|c|c|c|c|c|c|c|c|c|c|}
\hline & $\begin{array}{c}\text { Conductivity } \\
@ 25 \mathrm{C} \\
(\mathrm{ms} / \mathrm{m}) \\
\end{array}$ & $\mathrm{PH}$ & $\begin{array}{c}\text { Dissolved } \\
\text { lons } \\
\text { (mg/l) }\end{array}$ & $\begin{array}{c}\text { Dissolved } \\
\text { Solids } \\
\text { (mg/) }\end{array}$ & $\begin{array}{c}\text { Hardness } \\
\text { (mg/)as CaCos }\end{array}$ & $\begin{array}{c}\text { Alkalinity } \\
\text { (mg/)as } \mathrm{CaCO} 3\end{array}$ & $\begin{array}{l}\text { Natrium } \\
(\mathrm{mg} /) \\
\end{array}$ & $\begin{array}{l}\text { Kallium } \\
(\mathrm{mg} / \mathrm{l})\end{array}$ & $\begin{array}{l}\text { Calcium } \\
\text { (mgl) }\end{array}$ & $\begin{array}{c}\text { Magnesium } \\
(\mathrm{mg} / \mathrm{l}) \\
\end{array}$ \\
\hline$T$ & -1.80 & 4.71 & -1.55 & -1.29 & -1.62 & -1.65 & -1.42 & 1.00 & -1.61 & -1.27 \\
\hline $\begin{array}{l}\text { Degrees of } \\
\text { Freedom (v) }\end{array}$ & 7.01 & 7.01 & 7.34 & 7.47 & 7.12 & 7.17 & 7.66 & 6.00 & 7.59 & 7.05 \\
\hline $\mathrm{t}[\mathrm{v}, 0.975]$ & 2.364 & 2.364 & 2.345 & 2.338 & 2.358 & 2.355 & 2.326 & 2.447 & 2.330 & 2.362 \\
\hline $\mathrm{t}[\mathrm{v}, 0.950]$ & 1.895 & 1.895 & 1.883 & 1.879 & 1.891 & 1.889 & 1.872 & 1.943 & 1.874 & 1.893 \\
\hline
\end{tabular}


Table B.5.2(b) (continued)

\section{[3 Yearly Averaging]}

New Mean Values Predicted by the Entropy Method

\begin{tabular}{|c|c|c|c|c|c|c|c|c|c|c|}
\hline & $\begin{array}{c}\text { Conductivity } \\
\text { @ } 25 \mathrm{C} \\
\text { (ms/m) }\end{array}$ & $\mathrm{PH}$ & $\begin{array}{c}\text { Dissolved } \\
\text { Ions } \\
\text { (mg/l) }\end{array}$ & $\begin{array}{c}\text { Dissolved } \\
\text { Solids } \\
\text { (mg/) } \\
\end{array}$ & $\begin{array}{c}\text { Hardness } \\
\text { (mgl)as } \mathrm{CaCO} 3\end{array}$ & $\begin{array}{c}\text { Alkatinity } \\
\text { (mg/)as } \mathrm{CaCO}\end{array}$ & $\begin{array}{l}\text { Natrium } \\
\text { (mgll) }\end{array}$ & $\begin{array}{l}\text { Kalium } \\
\text { (mg/l) }\end{array}$ & $\begin{array}{l}\text { Calcium } \\
(\mathrm{mg} / \mathrm{l})\end{array}$ & $\begin{array}{l}\text { Magnesium } \\
\text { (mgl) }\end{array}$ \\
\hline (Xne) & $\begin{array}{l}173.7 \\
174.0 \\
170.0\end{array}$ & $\begin{array}{l}7.5 \\
7.5 \\
7.5\end{array}$ & $\begin{array}{l}173.5 \\
173.7 \\
170.6\end{array}$ & $\begin{array}{l}119.4 \\
117.7 \\
106.1\end{array}$ & $\begin{array}{l}58.4 \\
59.1 \\
54.8\end{array}$ & $\begin{array}{l}72.9 \\
73.1 \\
68.7\end{array}$ & $\begin{array}{l}15.3 \\
14.8 \\
12.0\end{array}$ & $\begin{array}{l}4.4 \\
4.4 \\
4.4\end{array}$ & $\begin{array}{l}14.9 \\
14.8 \\
12.6\end{array}$ & $\begin{array}{l}4.9 \\
4.9 \\
4.8\end{array}$ \\
\hline $\begin{array}{l}(\bar{X} \text { (ne) } \\
\text { (Sne) }\end{array}$ & $\begin{array}{c}172.5 \\
2.2\end{array}$ & $\begin{array}{l}7.5 \\
0.0\end{array}$ & $\begin{array}{c}172.6 \\
1.8\end{array}$ & $\begin{array}{c}114.4 \\
7.3\end{array}$ & $\begin{array}{c}57.4 \\
2.3\end{array}$ & $\begin{array}{c}71.6 \\
2.5\end{array}$ & $\begin{array}{c}14.0 \\
1.8\end{array}$ & $\begin{array}{l}4.4 \\
0.0\end{array}$ & $\begin{array}{c}14.1 \\
1.3\end{array}$ & $\begin{array}{l}4.9 \\
0.1\end{array}$ \\
\hline
\end{tabular}

Statistic Test (T), Calculated by Equation 5.6

\begin{tabular}{|c|c|c|c|c|c|c|c|c|c|c|}
\hline & $\begin{array}{c}\text { Conductivity } \\
@ 25 \mathrm{C} \\
(\mathrm{mS} / \mathrm{m}) \\
\end{array}$ & $\mathrm{PH}$ & $\begin{array}{c}\text { Dissolved } \\
\text { Ions } \\
(\mathrm{mg} /) \\
\end{array}$ & $\begin{array}{c}\text { Dissolved } \\
\text { Solids } \\
\text { (mg/) }\end{array}$ & $\begin{array}{c}\text { Hardness } \\
\text { (mgl)as } \mathrm{CaCOa}\end{array}$ & $\begin{array}{c}\text { Alkalinity } \\
\text { (mg/l)as } \mathrm{CaCO} 3\end{array}$ & $\begin{array}{l}\text { Natrium } \\
\text { (mg/) }\end{array}$ & $\begin{array}{l}\text { Kalium } \\
\text { (mg/) }\end{array}$ & $\begin{array}{l}\text { Calcium } \\
\text { (mg/) }\end{array}$ & $\begin{array}{c}\text { Magnesium } \\
\text { (mg/) } \\
\end{array}$ \\
\hline T & -1.83 & -0.28 & -0.96 & -1.46 & -1.83 & -1.76 & -1.56 & 1.03 & -2.11 & -1.17 \\
\hline $\begin{array}{l}\text { Degrees of } \\
\text { Freedom (v) }\end{array}$ & 7.01 & 7.00 & 7.01 & 7.30 & 7.10 & 7.10 & 7.41 & 6.00 & 7.31 & 7.03 \\
\hline$t[v, 0.975]$ & 2.365 & 2.365 & 2.364 & 2.347 & $2.35 \theta$ & 2.359 & 2.341 & 2.447 & 2.347 & 2.363 \\
\hline$t[v, 0.950]$ & 1.895 & 1.895 & 1.895 & 1.884 & 1.892 & 1.892 & 1.881 & 1.943 & 1.884 & 1.894 \\
\hline
\end{tabular}

\section{[4 Yearly Averaging]}

New Mean Values Predicted by the Entropy Method

\begin{tabular}{|c|c|c|c|c|c|c|c|c|c|c|}
\hline & $\begin{array}{c}\text { Conductivity } \\
@ 25 \mathrm{C} \\
\text { (ms/m) }\end{array}$ & $\mathrm{PH}$ & $\begin{array}{c}\text { Dissolved } \\
\text { Ions } \\
\text { (moll) }\end{array}$ & $\begin{array}{c}\text { Dissolved } \\
\text { Solids } \\
\text { (mg/l) }\end{array}$ & $\begin{array}{c}\text { Hardness } \\
\text { (mg/)as Caco3 }\end{array}$ & $\begin{array}{c}\text { Alkalinity } \\
\text { (mg/l)as } \mathrm{CaCO} 3\end{array}$ & $\begin{array}{l}\text { Natrium } \\
\text { (mgil) }\end{array}$ & $\begin{array}{l}\text { Kalium } \\
(\mathrm{mg} / \mathrm{l})\end{array}$ & $\begin{array}{l}\text { Calcium } \\
\text { (mg/) }\end{array}$ & $\begin{array}{l}\text { Magnesium } \\
\text { (mg/l) }\end{array}$ \\
\hline (Xne) & $\begin{array}{l}173.4 \\
173.6\end{array}$ & $\begin{array}{l}7.5 \\
7.5\end{array}$ & $\begin{array}{l}173.7 \\
173.6\end{array}$ & $\begin{array}{l}117.5 \\
116.1\end{array}$ & $\begin{array}{l}65.3 \\
85.3\end{array}$ & $\begin{array}{l}78.1 \\
78.6\end{array}$ & $\begin{array}{l}13.2 \\
13.0\end{array}$ & $\begin{array}{l}4.4 \\
4.4\end{array}$ & $\begin{array}{l}16.8 \\
17.5\end{array}$ & $\begin{array}{l}5.2 \\
5.2\end{array}$ \\
\hline $\begin{array}{l}\bar{X} \text { (Xe) } \\
\text { (Sne) }\end{array}$ & $\begin{array}{c}173.5 \\
0.1\end{array}$ & $\begin{array}{l}7.5 \\
0.0\end{array}$ & $\begin{array}{c}173.6 \\
0.0\end{array}$ & $\begin{array}{c}116.8 \\
1.0\end{array}$ & $\begin{array}{l}65.3 \\
0.0\end{array}$ & $\begin{array}{l}78.4 \\
0.4\end{array}$ & $\begin{array}{l}13.1 \\
0.2\end{array}$ & $\begin{array}{l}4.4 \\
0.0\end{array}$ & $\begin{array}{l}17.1 \\
0.5\end{array}$ & $\begin{array}{l}5.2 \\
0.0\end{array}$ \\
\hline
\end{tabular}

Statistic Test (T), Calculated by Equation $\mathbf{5 . 6}$

\begin{tabular}{|c|c|c|c|c|c|c|c|c|c|c|}
\hline & $\begin{array}{c}\text { Conductivity } \\
@ 25 \mathrm{C} \\
(\mathrm{ms} / \mathrm{m}) \\
\end{array}$ & $\mathrm{PH}$ & $\begin{array}{c}\text { Dissoived } \\
\text { Ions } \\
\text { (mg/l) } \\
\end{array}$ & $\begin{array}{c}\text { Dissolved } \\
\text { Solids } \\
\text { (mg/l) }\end{array}$ & $\begin{array}{l}\text { Hardness } \\
\text { (moll)as } \mathrm{CaCO} 3\end{array}$ & $\begin{array}{c}\text { Alkalinity } \\
\text { (mg/)as } \mathrm{CaCO} 3\end{array}$ & $\begin{array}{l}\text { Natrium } \\
\text { (mgl) }\end{array}$ & $\begin{array}{l}\text { Kalium } \\
\text { (mg/) }\end{array}$ & $\begin{array}{l}\text { Calcium } \\
(\mathrm{mg} / \mathrm{l})\end{array}$ & $\begin{array}{l}\text { Magnesium } \\
(m g /)\end{array}$ \\
\hline $\mathbf{T}$ & -1.81 & -0.30 & -0.93 & -1.39 & -1.34 & -1.37 & -1.75 & 1.13 & -1.52 & -0.91 \\
\hline $\begin{array}{l}\text { Degrees of } \\
\text { Freedom (v) }\end{array}$ & 7.00 & 7.00 & 7.00 & 7.01 & 7.00 & 7.00 & 7.01 & 6.00 & 7.06 & 7.00 \\
\hline$t[v, 0.975]$ & 2.365 & 2.365 & 2.365 & 2.365 & 2.365 & 2.365 & 2.364 & 2.447 & 2.361 & 2.365 \\
\hline$t[v, 0.950]$ & 1.895 & 1.895 & 1.895 & 1.895 & 1.895 & 1.895 & 1.895 & 1.943 & 1.893 & 1.895 \\
\hline
\end{tabular}


Table B.5.2(c) Station 130209

Historical (prior) Mean Values

\begin{tabular}{|c|c|c|c|c|c|c|c|c|c|c|}
\hline & $\begin{array}{c}\text { Conductivity } \\
@ 25 \mathrm{C} \\
(\mathrm{ms} / \mathrm{m}) \\
\end{array}$ & $\mathrm{PH}$ & $\begin{array}{c}\text { Dissolved } \\
\text { Ions } \\
\text { (mgl) }\end{array}$ & $\begin{array}{c}\text { Dissolved } \\
\text { Solids } \\
\text { (mgl) } \\
\end{array}$ & $\begin{array}{c}\text { Hardness } \\
\text { (mg/l)as CaCO3 }\end{array}$ & $\begin{array}{c}\text { Alkalinity } \\
\text { (mg/l)as } \mathrm{CaCO} 3 \\
\end{array}$ & $\begin{array}{l}\text { Natrium } \\
(\mathrm{mg} / \mathrm{l})\end{array}$ & $\begin{array}{l}\text { Katium } \\
(\mathrm{mg} / \mathrm{l})\end{array}$ & $\begin{array}{l}\text { Calcium } \\
\text { (mg/) }\end{array}$ & $\begin{array}{c}\text { Magnesium } \\
(\mathrm{mg} /) \\
\end{array}$ \\
\hline Mean $\quad(\overline{X h})$ & 325.9 & 7.7 & 253.5 & 182.3 & 109.2 & 132.9 & 20.0 & 3.6 & 19.5 & 14.7 \\
\hline $\begin{array}{l}\text { Standard (Sh) } \\
\text { Deviation }\end{array}$ & 222.2 & 0.4 & 162.0 & 112.1 & 71.8 & 90.0 & 19.0 & 1.0 & 5.5 & 14.4 \\
\hline
\end{tabular}

\section{[1 Yearly Averaging]}

\section{New Mean Values}

\begin{tabular}{|c|c|c|c|c|c|c|c|c|c|c|}
\hline & $\begin{array}{c}\text { Conductivity } \\
@ 25 \mathrm{C} \\
(\mathrm{ms} / \mathrm{m}) \\
\end{array}$ & $\mathrm{PH}$ & $\begin{array}{c}\text { Dissolved } \\
\text { Ions } \\
\text { (mgfl) }\end{array}$ & $\begin{array}{l}\text { Dissotved } \\
\text { Solids } \\
\text { (mg/) }\end{array}$ & \begin{tabular}{|c|} 
Hardness \\
(mg/l)as $\mathrm{CaCO}$ \\
\end{tabular} & $\begin{array}{c}\text { Alkalinity } \\
\text { (mog/i)as } \mathrm{CaCO} 3 \\
\end{array}$ & $\begin{array}{l}\text { Natrium } \\
\text { (mg/i) }\end{array}$ & $\begin{array}{l}\text { Kalium } \\
\text { (mg/l) }\end{array}$ & $\begin{array}{l}\text { Calcium } \\
(\mathrm{mg} / \mathrm{l})\end{array}$ & $\begin{array}{l}\text { Magnesium } \\
\quad(m g /)\end{array}$ \\
\hline \multirow{5}{*}{ (Xne) } & 165.0 & 7.4 & 134.3 & 113.3 & 54.0 & 67.3 & 13.0 & 5.2 & 14.7 & 4.3 \\
\hline & 265.0 & 7.5 & 202.8 & 156.7 & 78.0 & 100.3 & 21.3 & 5.2 & 18.7 & 7.7 \\
\hline & 207.5 & 7.5 & 147.8 & 120.0 & 57.5 & 65.5 & 14.5 & 5.0 & 15.5 & 4.7 \\
\hline & 171.7 & 7.5 & 137.4 & 105.7 & 58.3 & 68.5 & 11.3 & 4.9 & 14.5 & 4.6 \\
\hline & 170.0 & 7.4 & 132.0 & 105.0 & 54.0 & 72.7 & 11.7 & 5.4 & 16.0 & 4.4 \\
\hline$(\bar{x} \cap \bar{n})$ & 195.8 & 7.5 & 150.9 & 120.1 & 60.4 & 74.9 & 14.4 & 5.1 & 15.9 & 5.1 \\
\hline (Sne) & 42.2 & 0.1 & 29.7 & 21.3 & 10.1 & 14.5 & 4.1 & 0.2 & 1.7 & 1.4 \\
\hline
\end{tabular}

Statistic Test (T), Calculated by Equation 5.6

\begin{tabular}{|c|c|c|c|c|c|c|c|c|c|c|}
\hline & $\begin{array}{c}\text { Conductivity } \\
@ 25 \mathrm{C} \\
\text { (ms/m) } \\
\end{array}$ & $\mathrm{PH}$ & $\begin{array}{c}\text { Dissolved } \\
\text { lons } \\
(\mathrm{mg} /) \\
\end{array}$ & $\begin{array}{c}\text { Dissolved } \\
\text { Solids } \\
\text { (mg/) } \\
\end{array}$ & $\begin{array}{c}\text { Hardness } \\
\text { (mg/l)as } \mathrm{CaCO} 3 \\
\end{array}$ & $\begin{array}{c}\text { Alkalinity } \\
\text { (mng/f)as } \mathrm{CaCO} 3\end{array}$ & $\begin{array}{l}\text { Natrium } \\
\text { (mg/l) }\end{array}$ & $\begin{array}{l}\text { Kalium } \\
(\mathrm{mg} / \mathrm{l})\end{array}$ & $\begin{array}{l}\text { Calcium } \\
\text { (ming) }\end{array}$ & $\begin{array}{l}\text { Magnesium } \\
\text { (mgh) }\end{array}$ \\
\hline T & -1.61 & -2.13 & -1.75 & -1.52 & -1.90 & -1.79 & -1.67 & 2.46 & -1.75 & -1.86 \\
\hline $\begin{array}{l}\text { Degrees of } \\
\text { Freedom (v) }\end{array}$ & 7.79 & 7.45 & 7.73 & $7.7 \theta$ & 7.43 & 7.57 & 8.00 & 6.24 & 8.92 & 7.22 \\
\hline$t[v, 0.975]$ & 2.319 & 2.338 & 2.322 & 2.318 & 2.339 & 2.331 & 2.306 & 2.427 & 2.265 & 2.352 \\
\hline$t[v, 0.950]$ & 1.868 & 1.879 & 1.869 & 1.867 & 1.880 & 1.875 & 1.860 & 1.931 & 1.835 & 1.887 \\
\hline
\end{tabular}

\section{[2 Yearly Averaging]}

New Mean Values

\begin{tabular}{|c|c|c|c|c|c|c|c|c|c|c|}
\hline & $\begin{array}{c}\text { Conductivity } \\
@ 25 \mathrm{C} \\
\text { (ms/m) }\end{array}$ & $\mathrm{PH}$ & $\begin{array}{c}\text { Dissolved } \\
\text { lons } \\
(\mathrm{mg} / \mathrm{l})\end{array}$ & $\begin{array}{c}\text { Dissolved } \\
\text { Solids } \\
\text { (mg/l) } \\
\end{array}$ & $\begin{array}{c}\text { Hardness } \\
\text { (mg/l)as } \mathrm{CaCO} 3\end{array}$ & $\begin{array}{c}\text { Atkalinity } \\
\text { (mng/)as } \mathrm{CaCO} 3 \\
\end{array}$ & $\begin{array}{l}\text { Natrium } \\
\text { (mg/l) }\end{array}$ & $\begin{array}{l}\text { Kalium } \\
(\mathrm{mg} / \mathrm{h})\end{array}$ & $\begin{array}{l}\text { Calcium } \\
\text { (mgl) }\end{array}$ & $\begin{array}{c}\text { Magnesium } \\
\text { (mgn) }\end{array}$ \\
\hline \multirow{4}{*}{ (Xпе) } & 215.0 & 7.4 & 168.6 & 135.0 & 66.0 & 83.8 & 17.2 & 5.2 & 16.7 & 6.0 \\
\hline & 236.3 & 7.5 & $\uparrow 75.3$ & 138.3 & 67.8 & 82.9 & 17.9 & 5.1 & 17.1 & 6.2 \\
\hline & 189.6 & 7.5 & 142.6 & 112.8 & 57.9 & 67.0 & 12.9 & 4.9 & 15.0 & 4.6 \\
\hline & 170.8 & 7.5 & 134.7 & 105.3 & 56.2 & 70.6 & 11.5 & 5.1 & 15.3 & 4.5 \\
\hline (X)ne) & 202.9 & 7.5 & 155.3 & 122.9 & 62.0 & 76.1 & 14.9 & 5.1 & 16.0 & 5.3 \\
\hline (Sne) & 28.7 & 0.0 & 19.7 & 16.3 & 5.8 & 8.6 & 3.2 & 0.1 & 1.0 & 0.9 \\
\hline
\end{tabular}

Statistic Test (T), Calculated by Equation 5.6

\begin{tabular}{|c|c|c|c|c|c|c|c|c|c|c|}
\hline & $\begin{array}{c}\text { Conductivity } \\
@ 25 \mathrm{C} \\
(\mathrm{ms} / \mathrm{m}) \\
\end{array}$ & PH & $\begin{array}{c}\text { Dissolved } \\
\text { lons } \\
\text { (mg/f) } \\
\end{array}$ & $\begin{array}{c}\text { Dissolved } \\
\text { Solids } \\
\text { (mgת) }\end{array}$ & $\begin{array}{c}\text { Hardness } \\
\text { (mg/l)as } \mathrm{CaCO} 3\end{array}$ & $\begin{array}{c}\text { Alkalinity } \\
\text { (mg/)as } \mathrm{CaCO} 3\end{array}$ & $\begin{array}{l}\text { Natrium } \\
\text { (mg/) }\end{array}$ & $\begin{array}{l}\text { Kalium } \\
\text { (mg/) }\end{array}$ & $\begin{array}{l}\text { Calcium } \\
\text { (mgit) }\end{array}$ & $\begin{array}{l}\text { Magnesium } \\
\text { (mg/l) } \\
\end{array}$ \\
\hline$T$ & -1.54 & $-2,06$ & -1.69 & -1.47 & -1.85 & -1.77 & -1.61 & 2.42 & -1.74 & -1.84 \\
\hline $\begin{array}{l}\text { Degrees of } \\
\text { Freedom (v) }\end{array}$ & 7.45 & 7.11 & 7.40 & 7.57 & 7.18 & 7.25 & 7.74 & 6.11 & 7.94 & 7.11 \\
\hline$t[v, 0.975]$ & 2.338 & 2.359 & 2.341 & 2.331 & 2.354 & 2.350 & 2.321 & 2.438 & 2.310 & 2.359 \\
\hline$t[v, 0.950]$ & 1.879 & 1.891 & 1.881 & 1.875 & 1.889 & 1.886 & 1.869 & 1.938 & 1.862 & 1.891 \\
\hline
\end{tabular}


Table B.5.2(c) (continued)

\section{[3 Yearly Averaging]}

New Mean Values

\begin{tabular}{|c|c|c|c|c|c|c|c|c|c|c|}
\hline & $\begin{array}{c}\text { Conductivity } \\
@ 25 \mathrm{C} \\
(\mathrm{ms} / \mathrm{m})\end{array}$ & $\mathrm{PH}$ & $\begin{array}{c}\text { Dissolved } \\
\text { lons } \\
\text { (mg/l) } \\
\end{array}$ & $\begin{array}{c}\text { Dissolved } \\
\text { Solids } \\
\text { (mg/i) }\end{array}$ & $\begin{array}{c}\text { Hardness } \\
\text { (mg/l)as CaCo3 }\end{array}$ & $\begin{array}{c}\text { Alkalinity } \\
\text { (mon)as Cacos }\end{array}$ & $\begin{array}{l}\text { Natrium } \\
(\mathrm{mg} / \mathrm{l})\end{array}$ & $\begin{array}{l}\text { Kalium } \\
\text { (mg/) }\end{array}$ & $\begin{array}{l}\text { Calcium } \\
(\mathrm{mg} /)\end{array}$ & $\begin{array}{l}\text { Magnesium } \\
\text { (mg/) }\end{array}$ \\
\hline$(X n \in)$ & $\begin{array}{l}212.5 \\
214.7 \\
183.1\end{array}$ & $\begin{array}{l}7.4 \\
7.5 \\
7.5\end{array}$ & $\begin{array}{l}161.6 \\
162.7 \\
139.1\end{array}$ & $\begin{array}{l}130.0 \\
127.4 \\
110.2\end{array}$ & $\begin{array}{l}63.2 \\
64.6 \\
56.6\end{array}$ & $\begin{array}{l}77.7 \\
78.1 \\
68.9\end{array}$ & $\begin{array}{l}16.3 \\
15.7 \\
12.5\end{array}$ & $\begin{array}{l}5.1 \\
5.0 \\
5.1\end{array}$ & $\begin{array}{l}16.3 \\
16.2 \\
15.3\end{array}$ & $\begin{array}{l}5.6 \\
5.6 \\
4.5\end{array}$ \\
\hline $\begin{array}{l}\text { (X̄ne) } \\
\text { (Sne) }\end{array}$ & $\begin{array}{r}203.4 \\
17.7 \\
\end{array}$ & $\begin{array}{l}7.5 \\
0.0 \\
\end{array}$ & $\begin{array}{c}154.5 \\
13.3 \\
\end{array}$ & $\begin{array}{c}122.6 \\
10.8 \\
\end{array}$ & $\begin{array}{c}61.5 \\
4.3 \\
\end{array}$ & $\begin{array}{c}74.9 \\
5.2 \\
\end{array}$ & $\begin{array}{c}14.8 \\
2.0 \\
\end{array}$ & $\begin{array}{l}5.1 \\
0.0 \\
\end{array}$ & $\begin{array}{c}15.9 \\
0.5 \\
\end{array}$ & $\begin{array}{l}5.2 \\
0.6 \\
\end{array}$ \\
\hline
\end{tabular}

Statistic Test (T), Calculated by Equation 5.6

\begin{tabular}{|c|c|c|c|c|c|c|c|c|c|c|}
\hline & $\begin{array}{c}\text { Conductivity } \\
(@ 25 \mathrm{C} \\
(\mathrm{ms} / \mathrm{m}) \\
\end{array}$ & PH & $\begin{array}{l}\text { Dissolved } \\
\text { Ions } \\
\text { (mg/f) }\end{array}$ & $\begin{array}{c}\text { Dissolved } \\
\text { Solids } \\
\text { (mg/l) } \\
\end{array}$ & $\begin{array}{c}\text { Hardness } \\
\text { (mg/i)as } \mathrm{CaCO} 3\end{array}$ & $\begin{array}{c}\text { Alkalinity } \\
\text { (mg) } 1 \text { as } \mathrm{CaCO} 3 \\
\end{array}$ & $\begin{array}{l}\text { Natrium } \\
(\mathrm{mg} / \mathrm{l})\end{array}$ & $\begin{array}{l}\text { Kalium } \\
(\mathrm{mg} / \mathrm{f})\end{array}$ & $\begin{array}{l}\text { Calcium } \\
(\mathrm{mg} / 2)\end{array}$ & $\begin{array}{c}\text { Magnosium } \\
\text { (mg/) }\end{array}$ \\
\hline$r$ & -1.55 & -2.07 & -1.71 & -1.49 & -1.87 & -1.82 & -1.64 & 2.40 & -1.81 & -1.85 \\
\hline $\begin{array}{l}\text { Degraes of } \\
\text { Freedom (v) }\end{array}$ & 7.23 & 7.12 & 7.25 & 7.33 & 7.13 & 7.12 & 7.41 & 6.02 & 7.34 & 7.07 \\
\hline$t[v, 0.975]$ & 2.351 & 2.358 & 2.350 & 2.345 & 2.357 & 2.358 & 2.341 & 2.445 & 2.345 & 2.361 \\
\hline$t[v, 0.850]$ & 1.887 & 1.891 & 1.886 & 1.883 & 1.890 & 1.891 & 1.880 & t.942 & 1.883 & 1.893 \\
\hline
\end{tabular}

\section{[4 Yearly Averaging]}

New Mean Values

\begin{tabular}{|c|c|c|c|c|c|c|c|c|c|c|}
\hline & $\begin{array}{c}\text { Conductivity } \\
\text { @ } 25 \mathrm{C} \\
(\mathrm{mS} / \mathrm{m}) \\
\end{array}$ & $\mathrm{PH}$ & $\begin{array}{c}\text { Dissolved } \\
\text { Ions } \\
\text { (mg/l) } \\
\end{array}$ & $\begin{array}{c}\text { Dissolved } \\
\text { Solids } \\
\text { (mgh) } \\
\end{array}$ & $\begin{array}{c}\text { Hardness } \\
\text { (mg/l)as } \mathrm{CaCO} 3\end{array}$ & $\begin{array}{c}\text { Alkalinity } \\
\text { (mg/)as } \mathrm{CaCO} 3\end{array}$ & $\begin{array}{l}\text { Natrium } \\
(m g /)\end{array}$ & $\begin{array}{l}\text { Kalium } \\
\text { (mg/) }\end{array}$ & $\begin{array}{l}\text { Calcium } \\
\text { (mg/l) }\end{array}$ & $\begin{array}{c}\text { Magnesium } \\
\text { (mg/) }\end{array}$ \\
\hline$\left(X_{n \in}\right)$ & $\begin{array}{l}202.3 \\
203.5\end{array}$ & $\begin{array}{l}7.5 \\
7.5\end{array}$ & $\begin{array}{l}155.6 \\
155.0\end{array}$ & $\begin{array}{l}123.9 \\
121.8\end{array}$ & $\begin{array}{l}62.0 \\
62.0\end{array}$ & $\begin{array}{l}75.4 \\
76.8\end{array}$ & $\begin{array}{l}15.0 \\
14.7\end{array}$ & $\begin{array}{l}5.1 \\
5.1\end{array}$ & $\begin{array}{l}15.8 \\
16.2\end{array}$ & $\begin{array}{l}5.3 \\
5.3\end{array}$ \\
\hline $\begin{array}{l}\left(\bar{X}_{n e}\right) \\
(S n \theta)\end{array}$ & $\begin{array}{c}202.9 \\
0.9\end{array}$ & $\begin{array}{l}7.5 \\
0.0\end{array}$ & $\begin{array}{c}155.3 \\
0.4\end{array}$ & $\begin{array}{c}122.9 \\
1.5\end{array}$ & $\begin{array}{c}62.0 \\
0.0 \\
\end{array}$ & $\begin{array}{c}76.1 \\
0.9\end{array}$ & $\begin{array}{c}14.9 \\
0.2\end{array}$ & $\begin{array}{l}5.1 \\
0.0 \\
\end{array}$ & $\begin{array}{c}16.0 \\
0.2 \\
\end{array}$ & $\begin{array}{l}5.3 \\
0.0\end{array}$ \\
\hline
\end{tabular}

Statistic Test (T), Calculated by Equation 5.6

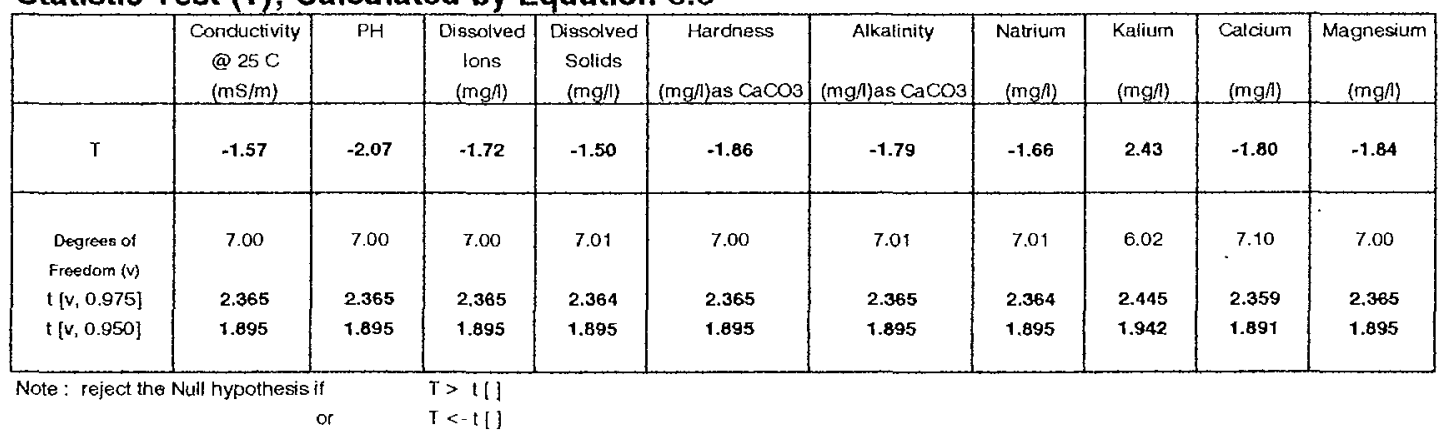


Table B.5.3 Hypothesis Testing for the Water Quality Values in the Logan River Basin

Table B.5.3(a) Station 145010

Historical (prior) Mean Values

\begin{tabular}{|c|c|c|c|c|c|c|c|c|c|c|}
\hline & $\begin{array}{c}\text { Conductivity } \\
@ 25 \mathrm{C} \\
(\mathrm{ms} / \mathrm{m}) \\
\end{array}$ & $\mathrm{PH}$ & $\begin{array}{c}\text { Dissolved } \\
\text { Ions } \\
(\mathrm{mg} /) \\
\end{array}$ & $\begin{array}{l}\text { Dissolved } \\
\text { Solids } \\
\text { (mgn) }\end{array}$ & $\begin{array}{c}\text { Hardness } \\
\text { (mg/h)as } \mathrm{CaCO} 3 \\
\end{array}$ & $\begin{array}{c}\text { Alkalinity } \\
\text { (mg/) as CaCO3 }\end{array}$ & $\begin{array}{l}\text { Natrium } \\
(\mathrm{mg} / \mathrm{l})\end{array}$ & $\begin{array}{l}\text { Kálium } \\
\text { (mg/) }\end{array}$ & $\begin{array}{l}\text { Calciurm } \\
(\mathrm{mg} / \mathrm{l})\end{array}$ & $\begin{array}{c}\text { Magnesium } \\
\text { (mg/) }\end{array}$ \\
\hline Mean $\quad(\bar{X} h)$ & 355.6 & 7.8 & 232.9 & 201.9 & 114.3 & 89.1 & 25.5 & 1.5 & 20.2 & 15.5 \\
\hline $\begin{array}{l}\text { Standard (Sh) } \\
\text { Deviation }\end{array}$ & 98.0 & 0.5 & 65.9 & 50.9 & 35.4 & 30.1 & 6.2 & 0.2 & 6.1 & 4.9 \\
\hline
\end{tabular}

\section{[1 Yearly Averaging]}

New Mean Values Predicted by the Entropy Method

\begin{tabular}{|c|c|c|c|c|c|c|c|c|c|c|}
\hline & $\begin{array}{c}\text { Conductivity } \\
@ 25 \mathrm{C} \\
\text { (ms/m) } \\
\end{array}$ & $\mathrm{PH}$ & $\begin{array}{c}\text { Dissolved } \\
\text { tons } \\
\text { (mg/) } \\
\end{array}$ & $\begin{array}{c}\text { Dissolved } \\
\text { Solids } \\
\text { (ming) } \\
\end{array}$ & $\begin{array}{c}\text { Hardness } \\
\text { (mg/)as } \mathrm{CaCO} 3\end{array}$ & $\begin{array}{c}\text { Alkatinity } \\
\text { (mrg/l)as } \mathrm{CaCO} 3\end{array}$ & $\begin{array}{l}\text { Natrium } \\
(m g / l) \\
\end{array}$ & $\begin{array}{l}\text { Kalium } \\
\text { (mg/) }\end{array}$ & $\begin{array}{l}\text { Calcium } \\
\text { (mgil) }\end{array}$ & $\begin{array}{l}\text { Magnesium } \\
\text { (mg/l) }\end{array}$ \\
\hline \multirow{5}{*}{ (Xne) } & 354.9 & 8.2 & 231.6 & 199.5 & 190.8 & 84.6 & 25.6 & 1.5 & 35.0 & 14.8 \\
\hline & 355.9 & 7.9 & 232.8 & 200.8 & 112.8 & 88.1 & 25.5 & 1.5 & 35.0 & 15.3 \\
\hline & 352.9 & 8.3 & 229.5 & 197.3 & 107.3 & 71.7 & 25.6 & 1.5 & 18.6 & 14.6 \\
\hline & 351.7 & 7.7 & 235.6 & 203.3 & 117.1 & 93.7 & 25.5 & 1.5 & 20.9 & 15.9 \\
\hline & 355.9 & 6.9 & 233.1 & 201.4 & 113.8 & 87.3 & 25.5 & 1.5 & 35.0 & 15.8 \\
\hline (X̄ne) & 354.3 & 7.8 & 232.5 & 200.5 & 112.4 & 85.1 & 25.5 & 1.5 & 28.9 & 15.3 \\
\hline (Sne) & 1.9 & 0.6 & 2.2 & 2.2 & 3.6 & 8.2 & 0.1 & 0.0 & 8.4 & 0.6 \\
\hline
\end{tabular}

Statistic Test (T), Calculatod by Equation 5.6

\begin{tabular}{|c|c|c|c|c|c|c|c|c|c|c|}
\hline & $\begin{array}{c}\text { Conductivily } \\
@ 25 \mathrm{C} \\
\text { (ms/m) }\end{array}$ & $\mathrm{PH}$ & $\begin{array}{c}\text { Dissolved } \\
\text { lons } \\
\text { (mg/l) } \\
\end{array}$ & $\begin{array}{c}\text { Dissolved } \\
\text { Solids } \\
(\mathrm{mg} / 1) \\
\end{array}$ & $\begin{array}{c}\text { Hardness } \\
\text { (mgli)as CaCOB }\end{array}$ & $\begin{array}{c}\text { Aikalinity } \\
\text { (mgn)as Caco3 }\end{array}$ & $\begin{array}{l}\text { Natrium } \\
\text { (mgn) }\end{array}$ & $\begin{array}{l}\text { Kalium } \\
\text { (mgn) }\end{array}$ & $\begin{array}{l}\text { Calcium } \\
\text { (mg/) }\end{array}$ & $\begin{array}{l}\text { Magnesium } \\
\text { (mg/) }\end{array}$ \\
\hline$T$ & -0.04 & 0.04 & -0.02 & -0.08 & -0.14 & -0.33 & 0,04 & 0.40 & 1.97 & -0.12 \\
\hline $\begin{array}{l}\text { Degrees of } \\
\text { Freedom (v) }\end{array}$ & 6.01 & 7.67 & 6.02 & 6.03 & 6.18 & 7.19 & 6.00 & 6.00 & 6.96 & 6.24 \\
\hline$t[v, 0.975\}$ & 2.446 & 2.326 & 2.445 & 2.444 & 2.433 & 2.354 & 2.447 & 2.447 & 2.368 & 2.427 \\
\hline$t\{v .0 .950\}$ & 1.943 & 1.871 & 1.942 & 1.941 & 1.835 & 1.088 & 1.943 & 1.943 & 1.897 & $t .932$ \\
\hline
\end{tabular}

[2 Yearly Averaging]

Now Mean Values Predicted by the Entropy Method

\begin{tabular}{|c|c|c|c|c|c|c|c|c|c|c|}
\hline & $\begin{array}{c}\text { Conductivity } \\
@ 25 \mathrm{C} \\
\text { (ms/m) }\end{array}$ & $\mathrm{PH}$ & $\begin{array}{c}\text { Dissolved } \\
\text { lons } \\
\text { (mgl) }\end{array}$ & $\begin{array}{c}\text { Dissolved } \\
\text { Solids } \\
\text { (mgfi) }\end{array}$ & $\begin{array}{c}\text { Hardness } \\
\text { (mg/l)as } \mathrm{CaCO3}\end{array}$ & $\begin{array}{c}\text { Akalinity } \\
\text { (mg/i)as } \mathrm{CaCO} 3\end{array}$ & $\begin{array}{l}\text { Natrium } \\
(\mathrm{mg} / \mathrm{l})\end{array}$ & $\begin{array}{l}\text { Kalium } \\
(\mathrm{mg} / 1)\end{array}$ & $\begin{array}{l}\text { Calcium } \\
\text { (mgl) }\end{array}$ & $\begin{array}{c}\text { Magnesium } \\
\text { (mg/) }\end{array}$ \\
\hline \multirow{4}{*}{$(x n e)$} & 310.4 & 8.4 & 199.2 & 175.9 & 92.9 & 74.4 & 24.0 & 1.5 & 17.2 & 10.8 \\
\hline & 261.0 & 8.8 & 164.1 & 148.4 & 76.5 & 64.4 & 23.2 & 1.5 & 15.3 & 10.1 \\
\hline & 311.7 & 8.4 & 199.9 & 178.3 & 96.2 & 75.8 & 24.0 & 1.5 & 17.9 & 12.8 \\
\hline & 349.1 & 6.1 & 233.2 & 201.6 & 117.6 & 90.7 & 25.3 & 1.5 & 19.6 & 27.0 \\
\hline$(\bar{X} n \theta)$ & 308.1 & 7.9 & 199.1 & 176.1 & 95.8 & 76.3 & 24.1 & 1.5 & 17.5 & 15.2 \\
\hline (Sne) & 36.1 & 1.2 & 28.2 & 21.8 & 16.9 & 10.8 & 0.9 & 0.0 & 1.8 & 8.0 \\
\hline
\end{tabular}

Statistic Test (T), Calculated by Equation 5.6

\begin{tabular}{|c|c|c|c|c|c|c|c|c|c|c|}
\hline & $\begin{array}{c}\text { Conductivity } \\
@ 25 \mathrm{C} \\
(\mathrm{mS} / \mathrm{m}) \\
\end{array}$ & $\mathrm{PH}$ & $\begin{array}{c}\text { Dissolved } \\
\text { lons } \\
\text { (mig/l) }\end{array}$ & $\begin{array}{c}\text { Dissolved } \\
\text { Solids } \\
\text { (mgh) } \\
\end{array}$ & $\begin{array}{c}\text { Hardrees } \\
\text { (mg/l)as } \mathrm{CaCO} 3\end{array}$ & $\begin{array}{c}\text { Alkalinity } \\
\text { (mg/)as CaCO3 }\end{array}$ & $\begin{array}{l}\text { Natrium } \\
\text { (mg/) }\end{array}$ & $\begin{array}{l}\text { Kalium } \\
\text { (mg/1) }\end{array}$ & $\begin{array}{l}\text { Calcium } \\
\text { (mgn) }\end{array}$ & $\begin{array}{l}\text { Magnesium } \\
\text { (mig/) }\end{array}$ \\
\hline$T$ & -1.15 & 0.19 & -1.18 & $\cdot 1.17$ & -1.17 & -1.01 & -0.56 & 0.40 & -1.09 & -0.07 \\
\hline $\begin{array}{l}\text { Degrees of } \\
\text { Freedom (v) }\end{array}$ & 8.26 & 3.51 & 8.68 & 8.68 & 8.90 & 8.19 & 6.41 & 6.00 & 7.57 & 4.32 \\
\hline I $[v, 0.975]$ & 2.295 & 2.974 & 2.276 & 2.276 & 2.266 & 2.298 & 2.414 & 2.447 & 2.331 & 2.711 \\
\hline$t[v, 0.950]$ & 1.853 & 2.240 & 1.842 & 1.842 & 1.836 & 1.855 & 1.923 & 1.943 & 1.875 & 2.095 \\
\hline
\end{tabular}


Table B.5.3(a) (continued)

[3 Yearly Averaging]

New Mean Values Predicted by the Entropy Method

\begin{tabular}{|c|c|c|c|c|c|c|c|c|c|c|}
\hline & $\begin{array}{c}\text { Conductivity } \\
@ 25 \mathrm{C} \\
\text { (mS/m) }\end{array}$ & $\mathrm{PH}$ & $\begin{array}{c}\text { Dissolved } \\
\text { lons } \\
\text { (mg/l) } \\
\end{array}$ & $\begin{array}{c}\text { Dissolved } \\
\text { Solids } \\
(\mathrm{mg} / \mathrm{l}) \\
\end{array}$ & $\begin{array}{c}\text { Hardness } \\
\text { (mg/)as } \mathrm{CaCO} 3\end{array}$ & $\begin{array}{c}\text { Alkalinity } \\
\text { (mg/) } 3 \text { as } \mathrm{CaCO} 3\end{array}$ & $\begin{array}{l}\text { Natrium } \\
\text { (mgf) }\end{array}$ & $\begin{array}{l}\text { Kalium } \\
\text { (mgn) }\end{array}$ & $\begin{array}{l}\text { Calcium } \\
\text { (mg/n) }\end{array}$ & $\begin{array}{l}\text { Magnesium } \\
\text { (mg/) } \\
\end{array}$ \\
\hline (Xne) & $\begin{array}{l}280.6 \\
317.9 \\
318.3\end{array}$ & $\begin{array}{l}8.9 \\
8.3 \\
7.4\end{array}$ & $\begin{array}{l}193.8 \\
211.5 \\
212.9\end{array}$ & $\begin{array}{l}167.8 \\
183.7 \\
186.1\end{array}$ & $\begin{array}{c}92.9 \\
103.0 \\
104.6\end{array}$ & $\begin{array}{l}79.2 \\
84.3 \\
83.8\end{array}$ & $\begin{array}{l}22.9 \\
24.1 \\
24.2\end{array}$ & $\begin{array}{l}1.5 \\
1.5 \\
1.5\end{array}$ & $\begin{array}{l}16.5 \\
18.2 \\
17.7\end{array}$ & $\begin{array}{l}11.8 \\
13.8 \\
14.5\end{array}$ \\
\hline $\begin{array}{l}\left(\bar{X}_{n e}\right) \\
\text { (Sne) }\end{array}$ & $\begin{array}{c}305.6 \\
21.7\end{array}$ & $\begin{array}{l}8.2 \\
0.7 \\
\end{array}$ & $\begin{array}{c}206.1 \\
10.6 \\
\end{array}$ & $\begin{array}{c}179.2 \\
9.9\end{array}$ & $\begin{array}{c}100.2 \\
6.3\end{array}$ & $\begin{array}{c}82.4 \\
2.8 \\
\end{array}$ & $\begin{array}{c}23.7 \\
0.7 \\
\end{array}$ & $\begin{array}{l}1.5 \\
0.0 \\
\end{array}$ & $\begin{array}{c}17.5 \\
0.9 \\
\end{array}$ & $\begin{array}{c}13.4 \\
1.4 \\
\end{array}$ \\
\hline
\end{tabular}

Statistic Test (T), Calculated by Equation 5.6

\begin{tabular}{|c|c|c|c|c|c|c|c|c|c|c|}
\hline & $\begin{array}{c}\text { Conductivity } \\
@ 25 \mathrm{C} \\
\text { (ms/m) }\end{array}$ & $\mathrm{PH}$ & $\begin{array}{c}\text { Dissolved } \\
\text { lons } \\
\text { (mg/l) }\end{array}$ & $\begin{array}{c}\text { Dissolved } \\
\text { Solids } \\
\text { (mg/) }\end{array}$ & $\begin{array}{c}\text { Hardness } \\
\text { (mgl)as } \mathrm{CaCO} 3\end{array}$ & $\begin{array}{c}\text { Aikalinity } \\
\text { (mg/l)as Cacos }\end{array}$ & $\begin{array}{l}\text { Natrium } \\
\text { (mg/l) }\end{array}$ & $\begin{array}{l}\text { Kalium } \\
\langle\mathrm{mg} / \mid\rangle\end{array}$ & $\begin{array}{l}\text { Calcium } \\
(\mathrm{mg} /)\end{array}$ & $\begin{array}{c}\text { Magnesium } \\
\text { (mg/l) }\end{array}$ \\
\hline$T$ & -1.28 & 0.97 & -1.05 & -1.13 & -1.02 & -0.58 & -0.73 & 0.40 & -1.16 & -1.06 \\
\hline $\begin{array}{l}\text { Degrees of } \\
\text { Freedom (v) }\end{array}$ & 7.17 & 2.73 & 6.68 & 6.95 & 6.82 & 6.24 & 6.37 & 6.00 & 6.54 & 7.68 \\
\hline$t[v, 0.975]$ & 2.355 & 3.487 & 2.391 & 2.369 & 2.380 & 2.427 & 2.417 & 2.447 & 2.403 & 2.325 \\
\hline$t\{v, 0.950\}$ & 1.889 & 2.507 & 1.910 & 1.897 & 1.904 & 1.932 & 1.925 & 1.943 & 1.917 & 1.871 \\
\hline
\end{tabular}

\section{[4 Yearly Averaging]}

New Mean Values Predicted by the Entropy Method

\begin{tabular}{|c|c|c|c|c|c|c|c|c|c|c|}
\hline & $\begin{array}{c}\text { Conductivity } \\
@ 25 \mathrm{C} \\
(\mathrm{ms} / \mathrm{m}) \\
\end{array}$ & $\mathrm{PH}$ & $\begin{array}{c}\text { Dissolved } \\
\text { lons } \\
\text { (mg/) }\end{array}$ & $\begin{array}{c}\text { Dissolved } \\
\text { Solids } \\
\text { (mgn) }\end{array}$ & $\begin{array}{c}\text { Hardness } \\
\text { (mg/t)as } \mathrm{CaCO} 3\end{array}$ & $\begin{array}{c}\text { Alkalinity } \\
\text { (mg/)as } \mathrm{CaCO}\end{array}$ & $\begin{array}{l}\text { Natrium } \\
(\mathrm{mgll})\end{array}$ & $\begin{array}{l}\text { Kalium } \\
\text { (mg/l) }\end{array}$ & $\begin{array}{l}\text { Calcium } \\
\text { (mg/) }\end{array}$ & $\begin{array}{c}\text { Magnesium } \\
(m g / l) \\
\end{array}$ \\
\hline \multirow[t]{2}{*}{$\left(x_{n e}\right)$} & 334.2 & 8.4 & 218.8 & 190.6 & 105.4 & 89.1 & 24.7 & 1.5 & 19.0 & 14.0 \\
\hline & 337.2 & 7.4 & 221.6 & 193.0 & 107.5 & 88.9 & 24.8 & 1.5 & 19.0 & 14.7 \\
\hline$\left(\bar{x}_{\Omega e}\right)$ & 335.7 & 7.9 & 220.2 & 191,8 & 106.5 & 89.0 & 24.8 & 1.5 & 19.0 & 14.4 \\
\hline (Sne) & 2.1 & 0.7 & 2.0 & 1.7 & 1.5 & 0.1 & 0.1 & 0.0 & 0.0 & 0.5 \\
\hline
\end{tabular}

Statistic Test (T), Calculated by Equation 5.6

\begin{tabular}{|c|c|c|c|c|c|c|c|c|c|c|}
\hline & $\begin{array}{c}\text { Conductivity } \\
@ 25 \mathrm{C} \\
(\mathrm{ms} / \mathrm{m}) \\
\end{array}$ & $\mathrm{PH}$ & $\begin{array}{c}\text { Dissolved } \\
\text { lons } \\
\text { (mg/l) } \\
\end{array}$ & $\begin{array}{c}\text { Dissolved } \\
\text { Solids } \\
\text { (mg/l) }\end{array}$ & $\begin{array}{c}\text { Hardness } \\
(\mathrm{mg} / \mathrm{f}) \mathrm{as} \mathrm{CaCO} 3 \\
\end{array}$ & $\begin{array}{c}\text { Alkalinity } \\
\text { (mgl)as } \mathrm{CaCO} 3 \\
\end{array}$ & $\begin{array}{l}\text { Natrium } \\
\text { (mg/) } \\
\end{array}$ & $\begin{array}{l}\text { Kalium } \\
\text { (mg/n) }\end{array}$ & $\begin{array}{l}\text { Calcium } \\
(\mathrm{mg} / 1) \\
\end{array}$ & $\begin{array}{l}\text { Magnesium } \\
\text { (mgit) }\end{array}$ \\
\hline$T$ & -0.50 & 0.23 & .0 .49 & -0.49 & -0.55 & -0.01 & -0.29 & 0.40 & -0.51 & -0.55 \\
\hline $\begin{array}{l}\text { Degres of } \\
\text { Freedom (v) }\end{array}$ & 6.02 & 1.26 & 6.04 & 6.05 & 6.07 & 6.00 & 6.01 & 6.00 & 6.00 & 6.39 \\
\hline $\mathrm{t}[\mathrm{v}, 0.975]$ & 2.445 & 10.562 & 2.444 & 2.443 & 2.441 & 2.447 & 2.447 & 2.447 & 2.447 & 2.415 \\
\hline$t[v, 0.950)$ & 1.942 & 5.448 & 1.941 & 1.941 & 1.940 & 1.943 & 1.943 & 1.943 & 1.943 & 1.92 .4 \\
\hline
\end{tabular}


Table B.5.3(b) Station 145013

Historical (prior) Mean Values

\begin{tabular}{|c|c|c|c|c|c|c|c|c|c|c|}
\hline & $\begin{array}{c}\text { Conductivity } \\
@ 25 \mathrm{C} \\
\text { (ms/m) }\end{array}$ & $\mathrm{PH}$ & $\begin{array}{c}\text { Dissolved } \\
\text { Ions } \\
(\mathrm{mg} / 1) \\
\end{array}$ & $\begin{array}{c}\text { Dissolved } \\
\text { Solids } \\
(\mathrm{mg} / \mathrm{h}) \\
\end{array}$ & $\begin{array}{c}\text { Hardness } \\
\text { (mg/)as } \mathrm{CaCO} \\
\end{array}$ & $\begin{array}{c}\text { Alkalinity } \\
\text { (mg/)as } \mathrm{CaCO} 3\end{array}$ & $\begin{array}{l}\text { Natrium } \\
\text { (mgn) }\end{array}$ & $\begin{array}{l}\text { Kalium } \\
\text { (mg/) }\end{array}$ & $\begin{array}{l}\text { Calcium } \\
(\mathrm{mg} / \mathrm{f})\end{array}$ & $\begin{array}{l}\text { Magnesium } \\
(\mathrm{mg} /)\end{array}$ \\
\hline Mean $\quad\left(\bar{x}_{h}\right)$ & 495.7 & 7.9 & 321.9 & 273.9 & 159.9 & 127.4 & 35.8 & 1.8 & 29.3 & 21.1 \\
\hline $\begin{array}{l}\text { Standard (Sh) } \\
\text { Deviation }\end{array}$ & 63.2 & 0.2 & 57.2 & 38.9 & 27.8 & 27.9 & 5.4 & 0.2 & 5.1 & 3.7 \\
\hline
\end{tabular}

\section{[1 Yearly Averaging]}

New Mean Values Predicted by the Entropy Method

\begin{tabular}{|c|c|c|c|c|c|c|c|c|c|c|}
\hline & $\begin{array}{c}\text { Conduclivity } \\
@ 25 \mathrm{C} \\
(\mathrm{mS} / \mathrm{m})\end{array}$ & $\mathrm{PH}$ & $\begin{array}{c}\text { Dissolved } \\
\text { Ions } \\
\text { (mg/) } \\
\end{array}$ & $\begin{array}{c}\text { Dissolved } \\
\text { Solids } \\
(\mathrm{mg} /)\end{array}$ & $\begin{array}{c}\text { Hardness } \\
\text { (mg/l)as CaCO3 }\end{array}$ & $\begin{array}{c}\text { Alkalinity } \\
\text { (mg/l)as } \mathrm{CacO} 3\end{array}$ & $\begin{array}{l}\text { Nätrium } \\
(\mathrm{mg} / \mathrm{l})\end{array}$ & $\begin{array}{l}\text { Kalium } \\
(\mathrm{mg} / \mathrm{i})\end{array}$ & $\begin{array}{l}\text { Calcium } \\
\text { (mgl) }\end{array}$ & $\begin{array}{c}\text { Magnesium } \\
\text { (mg/l) }\end{array}$ \\
\hline \multirow{5}{*}{ (Xne) } & 495.4 & 8.0 & 320.8 & 272.4 & 157.5 & 123.0 & 35.9 & 1.8 & 36.4 & 20.6 \\
\hline & 495.9 & 7.9 & 321.9 & 273.2 & 158.9 & 126.4 & 35.9 & 1.8 & 36.4 & 20.9 \\
\hline & 494.5 & 8.0 & 318.0 & 270.9 & 155.1 & 118.4 & 35.9 & 1.8 & 28.0 & 20.5 \\
\hline & 496.7 & 7.9 & 323.7 & 274.8 & 161.8 & 131.8 & 35.9 & 1.8 & 29.8 & 21.3 \\
\hline & 495.9 & 7.7 & 322.1 & 273.6 & 159.5 & 125.7 & 35.9 & 1.8 & 36.4 & 21.2 \\
\hline \{Х్Xne) & 495.7 & 7.9 & 321.5 & 273.0 & 158.6 & 125.1 & 35.9 & 1.8 & 33.4 & 20.9 \\
\hline (Sne) & 0.8 & 0.1 & 1.7 & 1.4 & 2.5 & 4.9 & 0.0 & 0.0 & 4.2 & 0.4 \\
\hline
\end{tabular}

Statistic Test (T), Calculated by Equation 5.6

\begin{tabular}{|c|c|c|c|c|c|c|c|c|c|c|}
\hline & $\begin{array}{c}\text { Conductivity } \\
(025 \mathrm{C} \\
(\mathrm{ms} / \mathrm{m}) \\
\end{array}$ & $\mathrm{PH}$ & $\begin{array}{c}\text { Dissoived } \\
\text { lons } \\
\text { (mg/l) }\end{array}$ & $\begin{array}{c}\text { Dissolved } \\
\text { Solids } \\
(\mathrm{mg} / \mathrm{l}) \\
\end{array}$ & $\begin{array}{c}\text { Hardness } \\
\text { (mg/l)as } \mathrm{CaCO} 3\end{array}$ & $\begin{array}{c}\text { Alkalinity } \\
(\mathrm{mg} / \mathrm{l}) \text { as } \mathrm{CaCO} 3\end{array}$ & $\begin{array}{l}\text { Natrium } \\
(\mathrm{mg} / \mathrm{l})\end{array}$ & $\begin{array}{l}\text { Kalium } \\
\text { (mg/) }\end{array}$ & $\begin{array}{l}\text { Calcium } \\
(\mathrm{mg} /)\end{array}$ & $\begin{array}{c}\text { Magnesium } \\
(\mathrm{mg} / \mathrm{l})\end{array}$ \\
\hline$T$ & -0.00 & 0.15 & -0.02 & -0.06 & -0.12 & -0.21 & 0.04 & 0.55 & 1.54 & -0.12 \\
\hline $\begin{array}{l}\text { Degrees of } \\
\text { Freedom (v) }\end{array}$ & 6.00 & 9.89 & 6.02 & 6.02 & 6.13 & 6.51 & 6.00 & 6.00 & 9.72 & 6.15 \\
\hline$t[v, 0.975]$ & 2.447 & 2.232 & 2.446 & 2.445 & 2.436 & 2.405 & 2.447 & 2.447 & 2.237 & 2.434 \\
\hline $\mathrm{I}[\mathrm{v}, 0.950]$ & 1.943 & 1.814 & 1.942 & 1.942 & 1.937 & 1.918 & 1.943 & 1.943 & 1.818 & 1.936 \\
\hline & & & $>t[]$ & & & & & & & \\
\hline
\end{tabular}

\section{[2 Yearly Averaging]}

New Mean Values Predicted by the Entropy Method

\begin{tabular}{|c|c|c|c|c|c|c|c|c|c|c|}
\hline & $\begin{array}{c}\text { Conductivity } \\
@ 25 \mathrm{C} \\
(\mathrm{mS} / \mathrm{m}) \\
\end{array}$ & $\mathrm{PH}$ & $\begin{array}{c}\text { Dissolved } \\
\text { lons } \\
\text { (mgll) }\end{array}$ & $\begin{array}{c}\text { Dissolved } \\
\text { Solids } \\
\text { (mg/l) }\end{array}$ & $\begin{array}{c}\text { Hardness } \\
\text { (mg/)as } \mathrm{CaCO} 3\end{array}$ & $\begin{array}{c}\text { Alkalinity } \\
\text { (mg/l)as } \mathrm{CaCO} 3\end{array}$ & $\begin{array}{l}\text { Natrium } \\
\text { (mg/) }\end{array}$ & $\begin{array}{l}\text { Kalium } \\
\text { (mg/l) }\end{array}$ & $\begin{array}{l}\text { Calcium } \\
(\mathrm{mg} / \mathrm{l})\end{array}$ & $\begin{array}{c}\text { Magnesium } \\
\text { (mg/l) }\end{array}$ \\
\hline \multirow{4}{*}{ (Xne) } & 474.8 & 8.0 & 293.7 & 257.0 & 145.3 & 113.3 & 34.6 & 1.8 & 27.0 & 18.1 \\
\hline & 451.7 & 8.1 & 264.2 & 239.2 & 134.1 & 103.8 & 33.9 & 1.8 & 25.5 & 17.6 \\
\hline & 475.3 & 8.0 & 294.3 & 258.6 & 147.5 & 114.6 & 34.6 & 1.8 & 27.5 & 19.3 \\
\hline & 492.7 & 7.2 & 322.1 & 273.7 & 162.1 & 128.9 & 35.7 & 1.8 & 28.8 & 20.7 \\
\hline$\overline{(\bar{X} \text { ne })}$ & 473.8 & 7.8 & 293.6 & 257.1 & 147.3 & 115.2 & 34.7 & 1.8 & 27.2 & 21.2 \\
\hline (Sne) & 16.8 & 0.4 & 23.6 & 14.1 & 11.5 & 10.4 & 0.7 & 0.0 & 1.4 & 5.7 \\
\hline
\end{tabular}

Statistic Test (T), Calculated by Equation 5.6

\begin{tabular}{|c|c|c|c|c|c|c|c|c|c|c|}
\hline & $\begin{array}{c}\text { Conductivity } \\
@ 25 \mathrm{C} \\
(\mathrm{ms} / \mathrm{m}) \\
\end{array}$ & $\mathrm{PH}$ & $\begin{array}{c}\text { Dissolved } \\
\text { lons } \\
(\mathrm{mg} / \mathrm{l}) \\
\end{array}$ & $\begin{array}{c}\text { Dissolved } \\
\text { Solids } \\
\text { (mg/l) } \\
\end{array}$ & $\begin{array}{c}\text { Hardness } \\
\text { (mg/i)as } \mathrm{CaCO} 3\end{array}$ & $\begin{array}{c}\text { Alkalinity } \\
\text { (mg/l)as } \mathrm{CaCO}\end{array}$ & $\begin{array}{l}\text { Natrium } \\
(\mathrm{mg} / \mathrm{l})\end{array}$ & $\begin{array}{l}\text { Kalium } \\
\text { (mg/l) }\end{array}$ & $\begin{array}{l}\text { Calcium } \\
\text { (mgf) }\end{array}$ & $\begin{array}{c}\text { Magnesium } \\
\text { (mg/l) }\end{array}$ \\
\hline$T$ & -0.87 & -0.28 & -1.15 & -1.03 & -1.05 & -1.04 & -0.54 & 0.55 & -1.02 & 0.03 \\
\hline $\begin{array}{l}\text { Degrees of } \\
\text { Freedom (v) }\end{array}$ & 7.35 & 3.61 & 8.59 & 8.21 & 8.60 & 8.28 & 6.39 & 6.00 & 7.37 & 4.46 \\
\hline$t[v, 0.975]$ & 2.344 & 2.935 & 2.280 & 2.297 & 2.280 & 2.294 & 2.415 & 2.447 & 2.343 & 2.681 \\
\hline$t[y, 0.950]$ & 1.803 & 2.218 & 1.844 & 1.854 & 1.844 & 1.853 & 1.924 & 1.943 & 1.882 & 2.078 \\
\hline
\end{tabular}


Table B.5.3(b) (continued)

\section{[3 Yearly Averaging]}

New Mean Values Predicted by the Entropy Method

\begin{tabular}{|c|c|c|c|c|c|c|c|c|c|c|}
\hline & $\begin{array}{l}\text { Conductivity } \\
@ 25 \mathrm{C} \\
\text { (ms/m) }\end{array}$ & $\mathrm{PH}$ & $\begin{array}{c}\text { Dissolved } \\
\text { Ions } \\
\text { (mg/n) }\end{array}$ & $\begin{array}{c}\text { Dissolved } \\
\text { Solids } \\
(\mathrm{mg} / \mathrm{l})\end{array}$ & $\begin{array}{c}\text { Hardness } \\
\text { (mg/l)as } \mathrm{CaCO} 3 \\
\end{array}$ & $\begin{array}{c}\text { Alkalinity } \\
(\mathrm{mg} /) \text { as } \mathrm{CaCO} 3\end{array}$ & $\begin{array}{l}\text { Natrium } \\
\text { (mg/l) }\end{array}$ & $\begin{array}{l}\text { Kalium } \\
\text { (mg/l) }\end{array}$ & $\begin{array}{l}\text { Calcium } \\
\text { (mg/l) }\end{array}$ & $\begin{array}{c}\text { Magnesium } \\
\text { (mg/) }\end{array}$ \\
\hline$(X n e)$ & $\begin{array}{l}460.7 \\
478.3 \\
478.6\end{array}$ & $\begin{array}{l}8.1 \\
8.0 \\
7.8\end{array}$ & $\begin{array}{l}289.1 \\
304.0 \\
305.1\end{array}$ & $\begin{array}{l}251.7 \\
262.1 \\
263.6\end{array}$ & $\begin{array}{l}145.4 \\
152.2 \\
153.3\end{array}$ & $\begin{array}{l}118.0 \\
122.8 \\
122.4\end{array}$ & $\begin{array}{l}33.6 \\
34.6 \\
34.7\end{array}$ & $\begin{array}{l}1.8 \\
1.8 \\
1.8\end{array}$ & $\begin{array}{l}26.4 \\
27.7 \\
27.4\end{array}$ & $\begin{array}{l}18.7 \\
20.0 \\
20.4\end{array}$ \\
\hline $\begin{array}{l}(\bar{X} \text { (ne) } \\
\text { (Sne) }\end{array}$ & $\begin{array}{c}472.5 \\
10.2 \\
\end{array}$ & $\begin{array}{l}8.0 \\
0.1 \\
\end{array}$ & $\begin{array}{c}299.4 \\
8.8 \\
\end{array}$ & $\begin{array}{c}259.1 \\
6.5 \\
\end{array}$ & $\begin{array}{c}150.3 \\
4.3\end{array}$ & $\begin{array}{c}121.1 \\
2.7 \\
\end{array}$ & $\begin{array}{c}34.3 \\
0.6 \\
\end{array}$ & $\begin{array}{l}1.8 \\
0.0\end{array}$ & $\begin{array}{c}27.2 \\
0.7 \\
\end{array}$ & $\begin{array}{c}19.7 \\
0.9 \\
\end{array}$ \\
\hline
\end{tabular}

Statistic Test (T), Calculated by Equation 5.6

\begin{tabular}{|c|c|c|c|c|c|c|c|c|c|c|}
\hline & $\begin{array}{c}\text { Conductivity } \\
@ 25 \mathrm{C} \\
\text { (ms/m) } \\
\end{array}$ & $\mathrm{PH}$ & $\begin{array}{c}\text { Dissolved } \\
\text { Ions } \\
\text { (mg/l) } \\
\end{array}$ & $\begin{array}{c}\text { Dissolved } \\
\text { Solids } \\
\text { (mg/l) }\end{array}$ & $\begin{array}{c}\text { Hardness } \\
\text { (mg//)as } \mathrm{CaCO} 3\end{array}$ & $\begin{array}{c}\text { Alkalinity } \\
\text { (mg/l)as } \mathrm{CaCO} 3 \\
\end{array}$ & $\begin{array}{l}\text { Natrium } \\
\text { (mgn) }\end{array}$ & $\begin{array}{l}\text { Kalium } \\
\text { (mgl) }\end{array}$ & $\begin{array}{l}\text { Calcium } \\
\text { (mg/) }\end{array}$ & $\begin{array}{l}\text { Magnesium } \\
(\mathrm{mg} / \mathrm{i})\end{array}$ \\
\hline $\mathrm{T}$ & -0.94 & 0.95 & -1.01 & -0.98 & -0.89 & -0.59 & -0.73 & 0.55 & -1.07 & -0.92 \\
\hline $\begin{array}{l}\text { Degrees of } \\
\text { Freedom (v) }\end{array}$ & 6.68 & 4.53 & 6.64 & 6.72 & 6.62 & 6.25 & 6.34 & 6.00 & 6.48 & 7.33 \\
\hline t $[v .0 .975]$ & 2.391 & 2.666 & 2.395 & 2.388 & 2.396 & 2.427 & 2.419 & 2.447 & 2.400 & 2.345 \\
\hline$t[v, 0.950]$ & 1.910 & 2.069 & 1.912 & 1.909 & 1.913 & 1.931 & 1.927 & 1.943 & 1.920 & 1.883 \\
\hline
\end{tabular}

\section{[4 Yearly Averaging]}

New Mean Values Predicted by the Entropy Method

\begin{tabular}{|c|c|c|c|c|c|c|c|c|c|c|}
\hline & $\begin{array}{c}\text { Conductivity } \\
@ 25 \mathrm{C} \\
(\mathrm{ms} / \mathrm{m}) \\
\end{array}$ & $\mathrm{PH}$ & $\begin{array}{c}\text { Dissolved } \\
\text { lons } \\
\text { (mg/l) } \\
\end{array}$ & $\begin{array}{c}\text { Dissolved } \\
\text { Solids } \\
\text { (mg/l) }\end{array}$ & $\begin{array}{c}\text { Hardness } \\
\text { (mgil)as } \mathrm{CaCO} 3\end{array}$ & $\begin{array}{c}\text { Alkalinity } \\
\text { (mgll)as } \mathrm{CaCO} 3\end{array}$ & $\begin{array}{l}\text { Natrium } \\
(\mathrm{mg} / \mathrm{l})\end{array}$ & $\begin{array}{l}\text { Kalium } \\
\text { (mg/l) }\end{array}$ & $\begin{array}{l}\text { Calcium } \\
\text { (mgl) }\end{array}$ & $\begin{array}{l}\text { Magnesium } \\
\text { (mg/) }\end{array}$ \\
\hline (Xne) & $\begin{array}{l}485.9 \\
487.2\end{array}$ & $\begin{array}{l}8.0 \\
7.8\end{array}$ & $\begin{array}{l}310.1 \\
312.4\end{array}$ & $\begin{array}{l}266.6 \\
268.1\end{array}$ & $\begin{array}{l}153.8 \\
155.2\end{array}$ & $\begin{array}{l}127.4 \\
127.2\end{array}$ & $\begin{array}{l}35.2 \\
35.3\end{array}$ & $\begin{array}{l}1.8 \\
1.8\end{array}$ & $\begin{array}{l}28.3 \\
28.4\end{array}$ & $\begin{array}{l}20.6 \\
20.1\end{array}$ \\
\hline $\begin{array}{l}\left(\bar{X}_{n e}\right) \\
\text { (Sne) }\end{array}$ & $\begin{array}{c}486.6 \\
0.9\end{array}$ & $\begin{array}{l}7.9 \\
0.1\end{array}$ & $\begin{array}{c}311.3 \\
1.6\end{array}$ & $\begin{array}{c}267.4 \\
1.1\end{array}$ & $\begin{array}{c}154.5 \\
1.0\end{array}$ & $\begin{array}{c}127.3 \\
0.1\end{array}$ & $\begin{array}{c}35.3 \\
0.1\end{array}$ & $\begin{array}{l}1.8 \\
0.0\end{array}$ & $\begin{array}{c}28.4 \\
0.1\end{array}$ & $\begin{array}{c}20.4 \\
0.4\end{array}$ \\
\hline
\end{tabular}

Statistic Test (T), Calculated by Equation 5.6

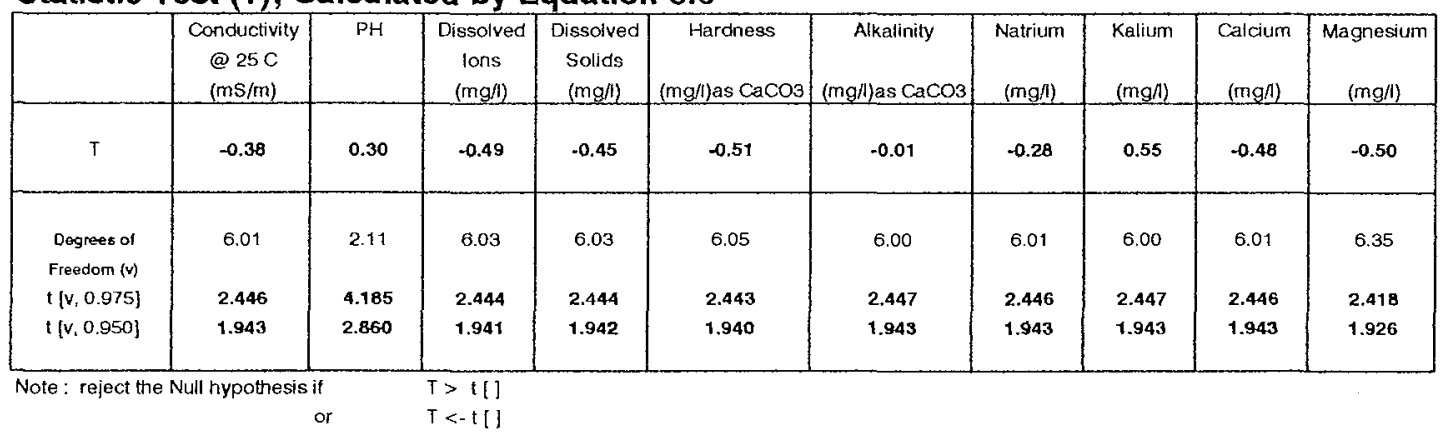


Table B.5.3(c) Station 145020

Historical (prior) Mean Values

\begin{tabular}{|c|c|c|c|c|c|c|c|c|c|c|}
\hline & $\begin{array}{l}\text { Conductivity } \\
@ 25 \mathrm{C} \\
\text { (ms/m) }\end{array}$ & $\mathrm{PH}$ & $\begin{array}{l}\text { Dissolved } \\
\text { lons } \\
\text { (mg/) }\end{array}$ & $\begin{array}{c}\text { Dissolved } \\
\text { Solids } \\
\text { (mgl) }\end{array}$ & $\begin{array}{c}\text { Hardness } \\
\text { (mg/)as } \mathrm{CaCO}\end{array}$ & $\begin{array}{c}\text { Alkalinity } \\
\text { (mg/)as } \mathrm{CaCO}\end{array}$ & $\begin{array}{l}\text { Natrium } \\
\text { (mgn) }\end{array}$ & $\begin{array}{l}\text { Kalium } \\
\text { (mgn) }\end{array}$ & $\begin{array}{l}\text { Calcium } \\
\text { (mgn) }\end{array}$ & $\begin{array}{l}\text { Magnesium } \\
\text { (mgn) }\end{array}$ \\
\hline Mean $\quad(\bar{X} h)$ & 523.5 & 6.7 & 314.7 & 274.8 & 96.7 & 86.2 & 54.0 & 2.0 & 23.2 & 15.3 \\
\hline $\begin{array}{l}\text { Standard (Sh) } \\
\text { Deviation }\end{array}$ & 273.0 & 3.0 & 162.5 & 141.0 & 49.5 & 43.3 & 28.0 & 1.0 & 12.2 & 8.0 \\
\hline
\end{tabular}

\section{[1 Yearly Averaging]}

New Mean Values Predicted by the Entropy Method

\begin{tabular}{|c|c|c|c|c|c|c|c|c|c|c|}
\hline & $\begin{array}{c}\text { Conducivity } \\
@ 25 \mathrm{C} \\
\text { (mS/m) } \\
\end{array}$ & $\mathrm{PH}$ & $\begin{array}{c}\text { Dissolved } \\
\text { Ions } \\
\text { (mgl) } \\
\end{array}$ & $\begin{array}{c}\text { Dissolved } \\
\text { Solids } \\
\text { (mg/l) } \\
\end{array}$ & $\begin{array}{c}\text { Hardness } \\
\text { (mg/)as } \mathrm{CaCO}\end{array}$ & $\begin{array}{c}\text { Alkalinity } \\
\text { (mg/)as CaCOS }\end{array}$ & $\begin{array}{l}\text { Natrium } \\
\text { (mgl) }\end{array}$ & $\begin{array}{l}\text { Kalium } \\
\text { (mgl) }\end{array}$ & $\begin{array}{l}\text { Catcium } \\
\text { (mg/) }\end{array}$ & $\begin{array}{l}\text { Magnesium } \\
\text { (mgly) }\end{array}$ \\
\hline \multirow{5}{*}{ (Xne) } & 601.6 & 8.1 & 358.9 & 302,1 & 128.8 & $\$ 2.9$ & 65.2 & 2.3 & 15.9 & 15.6 \\
\hline & 609.8 & 7.9 & 368.7 & 310.9 & 135.3 & 98.9 & 84.7 & 2.3 & 18.6 & 17.2 \\
\hline & 580.3 & 8.2 & 346.0 & 285.8 & 118.3 & 84.6 & 66.0 & 2.3 & 19.8 & 15.2 \\
\hline & 625.8 & 7.8 & 380.0 & 330.0 & 116.3 & 108.4 & 63.9 & 2.3 & 29.9 & 18.9 \\
\hline & 010.2 & 7.3 & 368.4 & 310.4 & 139.2 & 97.8 & 84.5 & 2.3 & 16.3 & 18.7 \\
\hline$\left(\bar{x}_{n \theta}\right)$ & 606.7 & 7.9 & 364.0 & 309.0 & 127.1 & $\$ 6.5$ & 64.9 & 2.3 & 20.1 & 17.1 \\
\hline (Sne) & 14.4 & 0.4 & 12.6 & 16.5 & 10.6 & 8.7 & 0.8 & 0.0 & 5.7 & 1.7 \\
\hline
\end{tabular}

Statistic Test (T), Calculated by Equation 5.6

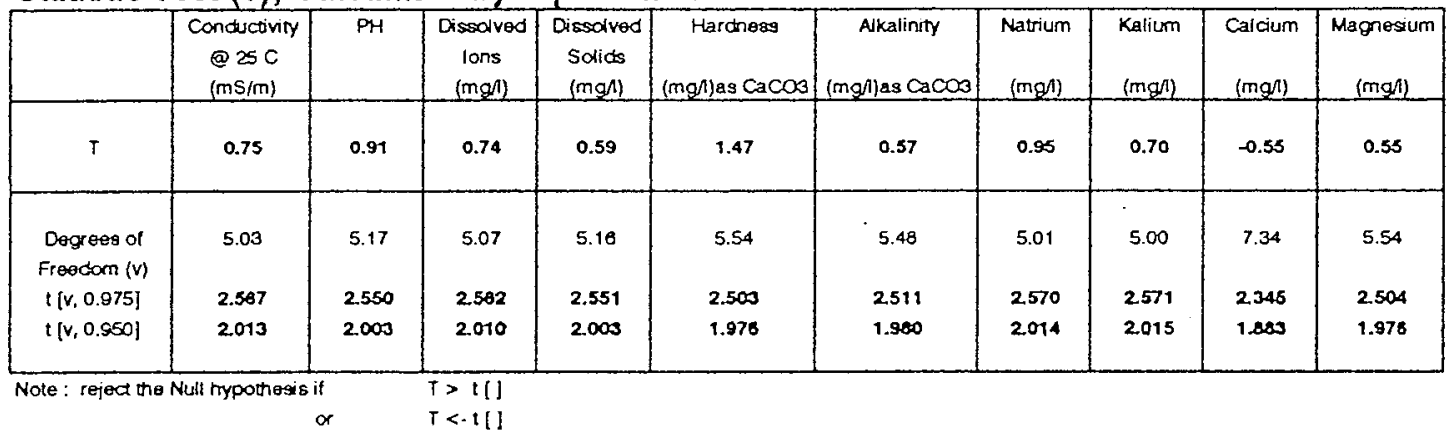

\section{[2 Yearly Averaging]}

New Mean Values Predicted by the Entropy Method

\begin{tabular}{|c|c|c|c|c|c|c|c|c|c|c|}
\hline & $\begin{array}{c}\text { Conductivity } \\
925 \mathrm{C} \\
(\mathrm{mS} / \mathrm{m}) \\
\end{array}$ & $\mathrm{PH}$ & $\begin{array}{c}\text { Dissolved } \\
\text { lons } \\
\text { (mgn) }\end{array}$ & $\begin{array}{c}\text { Dissolved } \\
\text { Solids } \\
\text { (mgl) }\end{array}$ & $\begin{array}{c}\text { Hardness } \\
\text { (mg/)as } \mathrm{CaCOB}\end{array}$ & $\begin{array}{c}\text { Alkatinity } \\
\text { (mgn)as } \mathrm{CaCO}\end{array}$ & $\begin{array}{l}\text { Natrium } \\
\text { (mql) }\end{array}$ & $\begin{array}{l}\text { Kalium } \\
\text { (mgl) }\end{array}$ & $\begin{array}{l}\text { Calcium } \\
(\mathrm{mg} /) .\end{array}$ & $\begin{array}{l}\text { Magnesium } \\
\text { (mg/) }\end{array}$ \\
\hline \multirow{4}{*}{$(X \cap 0)$} & 258.3 & 8.3 & 170.5 & 137.8 & 07.2 & 75.7 & 32.0 & 2.5 & 14.2 & 5.1 \\
\hline & 84.1 & 8.5 & 60.8 & 50.9 & 29.6 & 50.6 & 10.7 & 2.5 & 7.7 & 4.0 \\
\hline & 265.3 & 8.3 & 173.8 & 152.0 & 77.8 & 70.0 & 33.1 & 2.5 & 17.0 & 0.7 \\
\hline & 564.0 & 7.1 & 308.8 & 318.1 & 152.0 & 103.4 & 50.1 & 2.5 & 24.4 & 10.7 \\
\hline (X) & 290.4 & 8.0 & 180.0 & 168.2 & 81.8 & 77.2 & 38.2 & 2.5 & 15.8 & $8 . \theta$ \\
\hline (Sne) & 184.7 & 0.0 & 120.1 & 100.0 & 51,5 & 18.7 & 10.5 & 0.0 & 0.0 & 5.8 \\
\hline
\end{tabular}

Statistic Test (T), Calculated by Equation 5.6

\begin{tabular}{|c|c|c|c|c|c|c|c|c|c|c|}
\hline & $\begin{array}{l}\text { Conductuity } \\
\text { Q25C } \\
(\mathrm{mS} / \mathrm{m})\end{array}$ & $\mathrm{PH}$ & $\begin{array}{l}\text { Dlesolved } \\
\text { lons } \\
\text { (mol) }\end{array}$ & $\begin{array}{l}\text { Drseolved } \\
\text { Sollds } \\
\text { (mgli) }\end{array}$ & $\begin{array}{l}\text { Hardnese } \\
\text { (mgri)as CaCO3 }\end{array}$ & $\begin{array}{c}\text { Alkalinty } \\
\text { (molyas Cacos }\end{array}$ & $\begin{array}{l}\text { Natrium } \\
(m g)\end{array}$ & $\begin{array}{l}\text { Kalium } \\
\text { (mgn) }\end{array}$ & $\begin{array}{l}\text { Calcum } \\
\text { (mg) }\end{array}$ & $\begin{array}{l}\text { Megreaum } \\
\text { (mgd) }\end{array}$ \\
\hline$T$ & -1.50 & 1.01 & $-1.5 y$ & -1.26 & -0.46 & -0.46 & -1.28 & 1.19 & -1.27 & -1.46 \\
\hline $\begin{array}{l}\text { Dogroos of } \\
\text { Froocom (v) }\end{array}$ & 7.80 & 5.01 & 7.07 & 7.07 & 0.38 & 7.25 & 7.00 & 5.00 & 7.82 & 7.87 \\
\hline$l[v, 0.075]$ & 2.513 & 2408 & 2.525 & 2.528 & 2.418 & 2.280 & 2.500 & 2.571 & $2,3: 1$ & 2.314 \\
\hline$[(v, 0.050]$ & 1.064 & 1.871 & 1.871 & 1.872 & 1.825 & 1.006 & 1.061 & 2.016 & 1.800 & 1.004 \\
\hline & & & $\begin{array}{l}T>\|\| \\
T<-\|\|\}\end{array}$ & & & & & & & \\
\hline
\end{tabular}


Table B.5.3(c) (continued)

[3 Yearly Averaging]

New Mean Values Predicted by the Entropy Method

\begin{tabular}{|c|c|c|c|c|c|c|c|c|c|c|}
\hline & $\begin{array}{c}\text { Conousctivity } \\
@ 25 \mathrm{C} \\
(\mathrm{mS} / \mathrm{m})\end{array}$ & $\mathrm{PH}$ & $\begin{array}{c}\text { Dissolved } \\
\text { lons } \\
(\mathrm{mg} /) \\
\end{array}$ & $\begin{array}{c}\text { Dissolved } \\
\text { Solids } \\
\text { (mg/l) }\end{array}$ & $\begin{array}{c}\text { Hardness } \\
\text { (mg/)as Caco3 }\end{array}$ & $\begin{array}{c}\text { Nkalinity } \\
\text { (mg/)as } \mathrm{CaCO} 3\end{array}$ & $\begin{array}{l}\text { Nalrium } \\
\text { (mig/) }\end{array}$ & $\begin{array}{l}\text { Kalium } \\
\text { (mgl) }\end{array}$ & $\begin{array}{l}\text { Calcium } \\
(\mathrm{mg} /)\end{array}$ & $\begin{array}{c}\text { Magnesium } \\
\text { (mg/) }\end{array}$ \\
\hline (Xne) & $\begin{array}{l}122.1 \\
306.7 \\
310.2\end{array}$ & $\begin{array}{l}8.5 \\
8.3 \\
7.6\end{array}$ & $\begin{array}{l}144.9 \\
237.4 \\
245.2\end{array}$ & $\begin{array}{l}99.9 \\
186.9 \\
203.8\end{array}$ & $\begin{array}{c}67.5 \\
100.9 \\
106.5\end{array}$ & $\begin{array}{l}83.9 \\
92.4 \\
91.7\end{array}$ & $\begin{array}{l}16.4 \\
33.8 \\
36.1\end{array}$ & $\begin{array}{l}3.0 \\
2.8 \\
2.7\end{array}$ & $\begin{array}{l}11.3 \\
18.3 \\
16.1\end{array}$ & $\begin{array}{c}7.2 \\
12.0 \\
14.9\end{array}$ \\
\hline $\begin{array}{l}(\bar{X} \text { ne) } \\
\text { (Sne) }\end{array}$ & $\begin{array}{l}246.3 \\
107.6\end{array}$ & $\begin{array}{l}8.1 \\
0.4\end{array}$ & $\begin{array}{c}209.2 \\
55.8 \\
\end{array}$ & $\begin{array}{c}163.5 \\
55.8\end{array}$ & $\begin{array}{l}91.6 \\
21.1\end{array}$ & $\begin{array}{c}89.3 \\
4.7\end{array}$ & $\begin{array}{l}28.8 \\
10.8 \\
\end{array}$ & $\begin{array}{l}2.8 \\
0.2\end{array}$ & $\begin{array}{c}15.2 \\
3.6\end{array}$ & $\begin{array}{c}11.6 \\
4.0\end{array}$ \\
\hline
\end{tabular}

Statistic Test (T), Calculated by Equation 5.6

\begin{tabular}{|c|c|c|c|c|c|c|c|c|c|c|}
\hline & $\begin{array}{c}\text { Conductivity } \\
@ 25 \mathrm{C} \\
(\mathrm{mS} / \mathrm{m})\end{array}$ & PH & $\begin{array}{c}\text { Dissolved } \\
\text { lons } \\
\text { (mgll) } \\
\end{array}$ & $\begin{array}{c}\text { Dissolved } \\
\text { Solids } \\
\text { (mg/l) }\end{array}$ & $\begin{array}{c}\text { Hardness } \\
(\mathrm{mg} / \text { ) as } \mathrm{CaCO} 3\end{array}$ & $\begin{array}{c}\text { Alkalinity } \\
\text { (mgfl)as } \mathrm{CaCO}\end{array}$ & $\begin{array}{l}\text { Natrium } \\
\text { (mgh) }\end{array}$ & $\begin{array}{l}\text { Kalium } \\
\text { (mgfi) }\end{array}$ & $\begin{array}{l}\text { Calcium } \\
(\mathrm{mg} / \mathrm{l})\end{array}$ & $\begin{array}{c}\text { Magnesium } \\
\text { (mg/) }\end{array}$ \\
\hline$T$ & -2.17 & 1.10 & -1.43 & -1.68 & -0.21 & 0.17 & -1.94 & 1.87 & -1.47 & -0.93 \\
\hline $\begin{array}{l}\text { Degrees of } \\
\text { Freedom (v) }\end{array}$ & 6.92 & 5.42 & 6.70 & 6.92 & 6.99 & 5.23 & 6.89 & 5.46 & 6.40 & 6.94 \\
\hline$t\{v, 0.975\}$ & 2.372 & 2.520 & 2.389 & 2.371 & 2.366 & 2.542 & 2.374 & 2,514 & 2.414 & 2.370 \\
\hline$t[v, 0.950)$ & 1.899 & 1.985 & 1.909 & 1.899 & 1.896 & 1.998 & 1.800 & 1.982 & 1.924 & 1.898 \\
\hline - & & & $\begin{array}{l}T>t[] \\
T<-t[]\end{array}$ & & & & & & & \\
\hline
\end{tabular}

\section{[4 Yearly Averaging]}

New Mean Values Predicted by the Entropy Method

\begin{tabular}{|c|c|c|c|c|c|c|c|c|c|c|}
\hline & $\begin{array}{c}\text { Conductivity } \\
@ 25 \mathrm{C} \\
\text { (ms/m) }\end{array}$ & $\mathrm{PH}$ & $\begin{array}{l}\text { Dissolved } \\
\text { lons } \\
\text { (mgl) }\end{array}$ & $\begin{array}{l}\text { Dissolved } \\
\text { Solids } \\
\text { (mg/l) }\end{array}$ & $\begin{array}{c}\text { Hardness } \\
\text { (mg/l)as CaCO3 }\end{array}$ & $\begin{array}{c}\text { Alkalinity } \\
\text { (mg/d)as } \mathrm{CaCO} 3\end{array}$ & $\begin{array}{l}\text { Natrium } \\
\text { (mg/) }\end{array}$ & $\begin{array}{l}\text { Kalium } \\
\text { (mg/l) }\end{array}$ & $\begin{array}{l}\text { Calcium } \\
\text { (mg/) }\end{array}$ & $\begin{array}{l}\text { Magnesium } \\
(\mathrm{mg} /)\end{array}$ \\
\hline (Xne) & $\begin{array}{l}434.8 \\
459.0\end{array}$ & $\begin{array}{l}8.3 \\
7.6\end{array}$ & $\begin{array}{l}281.2 \\
297.8\end{array}$ & $\begin{array}{l}236.5 \\
253.7\end{array}$ & $\begin{array}{l}109.6 \\
116.8\end{array}$ & $\begin{array}{l}100.6 \\
100.4\end{array}$ & $\begin{array}{l}46.3 \\
49.6\end{array}$ & $\begin{array}{l}2.3 \\
2.3\end{array}$ & $\begin{array}{l}21.7 \\
21.8\end{array}$ & $\begin{array}{r}13.4 \\
15.5\end{array}$ \\
\hline $\begin{array}{l}\overline{(\bar{X} n e)} \\
\text { (Sne) }\end{array}$ & $\begin{array}{c}446.9 \\
17.1\end{array}$ & $\begin{array}{l}8.0 \\
0.5\end{array}$ & $\begin{array}{c}289.5 \\
11.7\end{array}$ & $\begin{array}{c}245.1 \\
12.2\end{array}$ & $\begin{array}{c}113.2 \\
5.1\end{array}$ & $\begin{array}{c}100.5 \\
0.1\end{array}$ & $\begin{array}{c}48.0 \\
2.3\end{array}$ & $\begin{array}{l}2.3 \\
0.0\end{array}$ & $\begin{array}{c}21.8 \\
0.1\end{array}$ & $\begin{array}{c}14.5 \\
1.5\end{array}$ \\
\hline
\end{tabular}

Statistic Test (T), Calculated by Equation 5.6

\begin{tabular}{|c|c|c|c|c|c|c|c|c|c|c|}
\hline & $\begin{array}{c}\text { Conductivity } \\
@ 25 \mathrm{C} \\
\text { (ms/m) } \\
\end{array}$ & $\mathrm{PH}$ & $\begin{array}{c}\text { Dissolved } \\
\text { lons } \\
\text { (mg/l) }\end{array}$ & $\begin{array}{c}\text { Dissolved } \\
\text { Solids } \\
\text { (mg/l) } \\
\end{array}$ & $\begin{array}{c}\text { Hardness } \\
\text { (mg/l)as } \mathrm{CaCO} 3\end{array}$ & $\begin{array}{c}\text { Atkalinity } \\
\text { (mg/l)as } \mathrm{CaCO} 3\end{array}$ & $\begin{array}{l}\text { Natrium } \\
(\mathrm{mg} / \mathrm{l})\end{array}$ & $\begin{array}{l}\text { Kalium } \\
\text { (mgi) }\end{array}$ & $\begin{array}{l}\text { Calcium } \\
(\mathrm{mg} / \mathrm{l})\end{array}$ & $\begin{array}{c}\text { Magnesium } \\
\text { (mg/l) }\end{array}$ \\
\hline$T$ & -0.68 & 0.94 & -0.38 & -0.51 & 0.80 & 0.81 & -0.52 & 0.70 & -0.29 & -0.24 \\
\hline $\begin{array}{l}\text { Degrees of } \\
\text { Freedom ( } v \text { ) }\end{array}$ & 5.12 & 5.62 & 5.15 & 5.21 & 5.30 & 5.00 & 5.20 & 5.00 & 5.00 & 5.78 \\
\hline$f(v, 0.975]$ & 2.557 & 2.494 & 2.552 & 2.545 & 2.534 & 2.571 & 2,546 & 2.571 & 2.571 & 2.475 \\
\hline$t[v, 0.950]$ & 2.007 & 1.970 & 2.004 & 2.000 & 1.994 & 2.015 & 2.001 & 2.015 & 2.015 & 1.959 \\
\hline & & & $\begin{array}{l}T>t ! I \\
T<-t ! U\end{array}$ & & & & & & & \\
\hline
\end{tabular}


Table B.5.3(d) Station 145008

Historical (prior) Mean Values

\begin{tabular}{|c|c|c|c|c|c|c|c|c|c|c|}
\hline & $\begin{array}{l}\text { Conductivity } \\
@ 25 \mathrm{C} \\
\text { (ms/m) }\end{array}$ & $\mathrm{PH}$ & $\begin{array}{c}\text { Dissolved } \\
\text { Ions } \\
\text { (mg/l) }\end{array}$ & $\begin{array}{c}\text { Dissolved } \\
\text { Solids } \\
\text { (mg/l) } \\
\end{array}$ & $\begin{array}{c}\text { Hardness } \\
\text { (mg/l)as } \mathrm{CaCO} 3\end{array}$ & $\begin{array}{c}\text { Alkalinity } \\
\text { (mg/l)as } \mathrm{CaCO} 3\end{array}$ & $\begin{array}{l}\text { Natrium } \\
(\mathrm{mg} / \mathrm{f})\end{array}$ & $\begin{array}{l}\text { Kalium } \\
(\mathrm{mg} / \mathrm{l})\end{array}$ & $\begin{array}{l}\text { Calcium } \\
(\mathrm{mg} / \mathrm{l})\end{array}$ & $\begin{array}{c}\text { Magnesium } \\
(\mathrm{mg} /)\end{array}$ \\
\hline Mean $\quad(\bar{X} h)$ & 518.5 & 6.8 & 331.6 & 279.7 & 145.6 & 115.1 & 46.5 & 2.1 & 151.6 & 18.8 \\
\hline $\begin{array}{l}\text { Standard (Sh) } \\
\text { Deviation }\end{array}$ & 247.9 & 3.0 & 157.9 & 133.8 & 69.9 & 53.7 & 22.7 & 1.1 & 334.5 & 9.0 \\
\hline
\end{tabular}

\section{[1 Yearly Averaging]}

\section{New Mean Values}

\begin{tabular}{|c|c|c|c|c|c|c|c|c|c|c|}
\hline & $\begin{array}{c}\text { Conductivity } \\
@ 25 \mathrm{C} \\
(\mathrm{mS} / \mathrm{m})\end{array}$ & $\mathrm{PH}$ & $\begin{array}{c}\text { Dissolved } \\
\text { lons } \\
(\mathrm{mg} / \mathrm{l})\end{array}$ & $\begin{array}{c}\text { Dissolved } \\
\text { Solids } \\
\text { (mgh) } \\
\end{array}$ & $\begin{array}{c}\text { Hardness } \\
\text { (mg/l)as } \mathrm{CaCO} 3\end{array}$ & $\begin{array}{c}\text { Alkalinity } \\
\text { (mgn)as } \mathrm{CaCO} 3\end{array}$ & $\begin{array}{l}\text { Natrium } \\
\text { (mg/l) }\end{array}$ & $\begin{array}{l}\text { Kalium } \\
\text { (mgin) }\end{array}$ & $\begin{array}{l}\text { Calcium } \\
(\mathrm{mg} / \mathrm{l})\end{array}$ & $\begin{array}{l}\text { Magnesium } \\
\text { (mg/l) }\end{array}$ \\
\hline \multirow{5}{*}{ (Xne) } & 393.3 & 7.7 & 243.9 & 210.0 & 105.3 & 87.3 & 33.3 & 1.6 & 19.7 & 8.7 \\
\hline & 475.6 & 7.9 & 308.6 & 253.8 & 131.6 & 112.6 & 42.4 & 2.1 & 25.6 & 16.4 \\
\hline & 236.7 & 7.6 & 135.5 & 130.0 & 58.3 & 52.0 & 20.7 & 1.8 & 11.9 & 7.0 \\
\hline & 638.3 & 8.0 & 420.3 & 346.7 & 191.3 & 153.0 & 55.3 & 2.2 & 36.7 & 24.2 \\
\hline & 480.0 & 8.5 & 323.2 & 280.0 & 146.0 & 107.0 & 45.5 & 2.3 & 20.5 & 23.0 \\
\hline$(\bar{X}$ ne) & 444.8 & 7.9 & 286.3 & 244.1 & 126.5 & 102.4 & 39.5 & 2.0 & 22.9 & 15.8 \\
\hline (Sne) & 146.3 & 0.3 & 105.3 & 80.8 & 49.3 & 36.9 & 13.1 & 0.3 & 9.1 & 7.9 \\
\hline
\end{tabular}

Statistic Test (T), Calculated by Equation 5.6

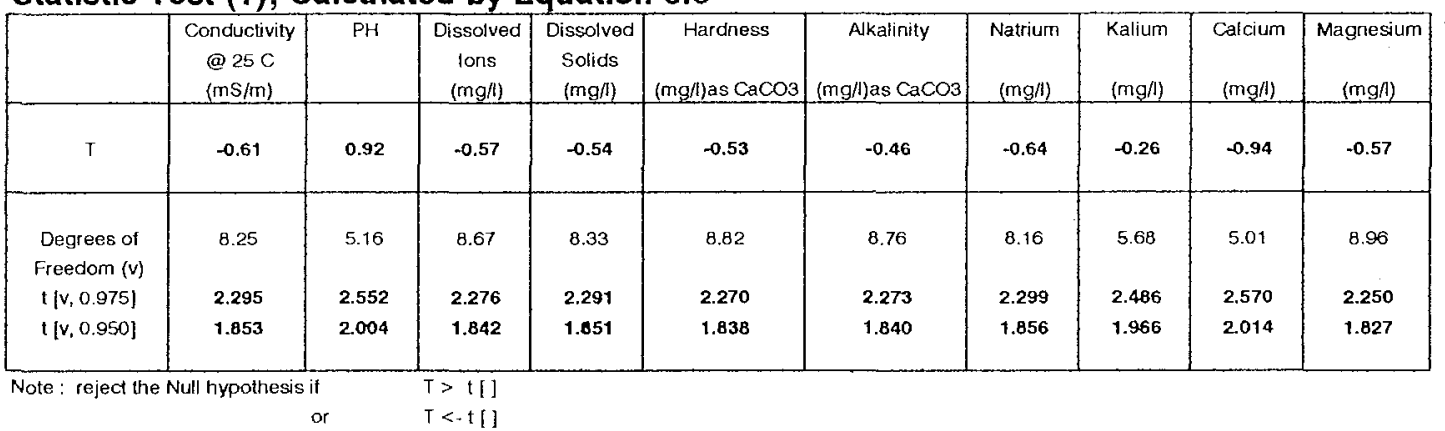

\section{[2 Yearly Averaging]}

New Mean Values

\begin{tabular}{|c|c|c|c|c|c|c|c|c|c|c|}
\hline & $\begin{array}{c}\text { Conductivity } \\
@ 25 \mathrm{C} \\
(\mathrm{ms} / \mathrm{m}) \\
\end{array}$ & $\mathrm{PH}$ & $\begin{array}{c}\text { Dissolved } \\
\text { Ions } \\
\text { (mg/i) } \\
\end{array}$ & $\begin{array}{c}\text { Dissolved } \\
\text { Solids } \\
\text { (mg/li) }\end{array}$ & $\begin{array}{c}\text { Hardness } \\
\text { (mg/l)as Caco3 }\end{array}$ & $\begin{array}{c}\text { Alkalinity } \\
\text { (mg/)as Cacos }\end{array}$ & $\begin{array}{l}\text { Natrium } \\
(\mathrm{mg} / \mathrm{l})\end{array}$ & $\begin{array}{l}\text { Kaliurn } \\
\text { (mg/n) }\end{array}$ & $\begin{array}{l}\text { Calcium } \\
(\mathrm{mg} / \mathrm{l})\end{array}$ & $\begin{array}{l}\text { Magnesium } \\
\text { (mg/l) }\end{array}$ \\
\hline \multirow{4}{*}{ (Xne) } & 434.5 & 7.8 & 276.2 & 231.9 & 118.5 & 100.0 & 37.9 & 1.8 & 22.6 & 12.5 \\
\hline & 356.1 & 7.7 & 222.0 & 191.9 & 95.0 & 82.3 & 31.8 & 1.9 & 18.8 & 11.7 \\
\hline & 437.5 & 7.8 & 277.9 & 238.3 & 124.8 & 102.5 & 38.0 & 2.0 & 24.3 & 15.6 \\
\hline & 559.2 & 8.3 & 371.8 & 313.3 & 168.7 & 130.0 & 50.4 & 2.2 & 28.6 & 23.6 \\
\hline$(\bar{X} n e)$ & 446.8 & 7.9 & 287.0 & 243.8 & 126.7 & 103.7 & 39.5 & 2.0 & 23.6 & 15.8 \\
\hline (Sne) & 83.8 & 0.2 & 62.2 & 50.7 & 30.8 & 19.7 & 7.9 & 0.2 & 4.1 & 5.4 \\
\hline
\end{tabular}

Statistic Test (T), Calculated by Equation 5.6

\begin{tabular}{|c|c|c|c|c|c|c|c|c|c|c|}
\hline & $\begin{array}{c}\text { Conductivity } \\
@ 25 \mathrm{C} \\
(\mathrm{ms} / \mathrm{m}) \\
\end{array}$ & PH & $\begin{array}{c}\text { Dissolved } \\
\text { Ions } \\
\text { (mg/l) } \\
\end{array}$ & $\begin{array}{c}\text { Dissolved } \\
\text { Solids } \\
\text { (mgf) } \\
\end{array}$ & $\begin{array}{c}\text { Hardness } \\
\text { (mg/l)as } \mathrm{CaCO} 3\end{array}$ & $\begin{array}{c}\text { Alkalinity } \\
\text { (mgll)as } \mathrm{CaCO}\end{array}$ & $\begin{array}{l}\text { Natrium } \\
\text { (mgli) }\end{array}$ & $\begin{array}{l}\text { Kaliurn } \\
\text { (mg/n) }\end{array}$ & $\begin{array}{l}\text { Calcium } \\
(\mathrm{mg} / \mathrm{l})\end{array}$ & $\begin{array}{l}\text { Magnesium } \\
\text { (mg/l) } \\
\end{array}$ \\
\hline $\mathrm{T}$ & -0.65 & 0.89 & -0.62 & -0.59 & -0.58 & -0.47 & -0.70 & -0.25 & -0.94 & -0.64 \\
\hline $\begin{array}{c}\text { Degrees of } \\
\text { Freedom }(v)\end{array}$ & 6.54 & 5.09 & 6.97 & 6.85 & 7.30 & 6.76 & 6.61 & 5.34 & 5.00 & 7.98 \\
\hline$t[v, 0.975]$ & 2.403 & 2,560 & 2.368 & 2.377 & 2.347 & 2.385 & 2.397 & 2.529 & 2.571 & 2.307 \\
\hline$t[v, 0,950]$ & 1.917 & 2.000 & 1.896 & 1.902 & 1.885 & 1.906 & 1.914 & 1.991 & 2.015 & 1.881 \\
\hline
\end{tabular}


Table B.5.3(d) (continued)

\section{[3 Yearly Averaging]}

New Mean Values

\begin{tabular}{|c|c|c|c|c|c|c|c|c|c|c|}
\hline & $\begin{array}{c}\text { Conductivity } \\
@ 25 \mathrm{C} \\
(\mathrm{ms} / \mathrm{m})\end{array}$ & $\mathrm{PH}$ & $\begin{array}{c}\text { Dissolved } \\
\text { lons } \\
\text { (mg/l) } \\
\end{array}$ & $\begin{array}{c}\text { Dissolved } \\
\text { Solids } \\
\text { (mg/f) } \\
\end{array}$ & $\begin{array}{c}\text { Hardness } \\
\text { (mg//)as CaCO3 }\end{array}$ & $\begin{array}{c}\text { Alkatinity } \\
\text { (mg/)as } \mathrm{CaCO} 3\end{array}$ & $\begin{array}{l}\text { Natrium } \\
(\mathrm{mg} /)\end{array}$ & $\begin{array}{l}\text { Kalium } \\
\text { (mg/) }\end{array}$ & $\begin{array}{l}\text { Calcium } \\
(\mathrm{mg} / \mathrm{l})\end{array}$ & $\begin{array}{c}\text { Magnesium } \\
(\mathrm{mg} / \mathrm{l})\end{array}$ \\
\hline (Xne) & $\begin{array}{l}368.5 \\
450.2 \\
451.7\end{array}$ & $\begin{array}{l}7.7 \\
7.8 \\
8.0\end{array}$ & $\begin{array}{l}229.3 \\
288.1 \\
293.0\end{array}$ & $\begin{array}{l}197.9 \\
243.5 \\
252.2\end{array}$ & $\begin{array}{c}98.4 \\
127.1 \\
131.9\end{array}$ & $\begin{array}{c}84.0 \\
105.9 \\
104.0\end{array}$ & $\begin{array}{l}32.1 \\
39.5 \\
40.5\end{array}$ & $\begin{array}{l}1.8 \\
2.0 \\
2.1\end{array}$ & $\begin{array}{l}19.1 \\
24.7 \\
23.0\end{array}$ & $\begin{array}{l}10.7 \\
15.8 \\
18.0\end{array}$ \\
\hline $\begin{array}{l}\text { (X̄ne) } \\
\text { (Sne) }\end{array}$ & $\begin{array}{c}423.5 \\
47.6 \\
\end{array}$ & $\begin{array}{l}7.9 \\
0.2 \\
\end{array}$ & $\begin{array}{r}270.1 \\
35.4 \\
\end{array}$ & $\begin{array}{c}231.2 \\
29.2\end{array}$ & $\begin{array}{c}119.1 \\
18.1\end{array}$ & $\begin{array}{l}38.0 \\
12.1\end{array}$ & $\begin{array}{c}37.4 \\
4.6 \\
\end{array}$ & $\begin{array}{l}2.0 \\
0.1\end{array}$ & $\begin{array}{c}22.3 \\
2.9 \\
\end{array}$ & $\begin{array}{c}14.9 \\
3.8\end{array}$ \\
\hline
\end{tabular}

Statistic Test (T), Calculated by Equation 5.6

\begin{tabular}{|c|c|c|c|c|c|c|c|c|c|c|}
\hline & $\begin{array}{c}\text { Conductivity } \\
@ 25 \mathrm{c} \\
\text { (ms/m) }\end{array}$ & $\mathrm{PH}$ & $\begin{array}{c}\text { Dissolved } \\
\text { ions } \\
\text { (mg/l) } \\
\end{array}$ & $\begin{array}{c}\text { Dissolved } \\
\text { Solids } \\
\text { (mg/l) } \\
\end{array}$ & $\begin{array}{c}\text { Hardness } \\
\text { (mg/has } \mathrm{CaCO} 3\end{array}$ & $\begin{array}{c}\text { Alkalinity } \\
\text { (mg/)as } \mathrm{CaCO} 3\end{array}$ & $\begin{array}{l}\text { Natrium } \\
(\mathrm{mg} / \mathrm{l})\end{array}$ & $\begin{array}{l}\text { Kalium } \\
\text { (mgn) }\end{array}$ & $\begin{array}{l}\text { Catcium } \\
\text { (mg/l) }\end{array}$ & $\begin{array}{c}\text { Magnesiurn } \\
\text { (mg/l) }\end{array}$ \\
\hline $\mathbf{T}$ & -0.91 & 0.86 & -0.91 & -0.85 & -0.87 & -0.74 & -0.95 & -0.29 & -0.95 & -0.91 \\
\hline $\begin{array}{l}\text { Degrees of } \\
\text { Freedom (v) }\end{array}$ & 5.69 & 5.05 & 5.91 & 5.86 & 6.15 & 5.92 & 5.74 & 5.28 & 5.00 & 6.98 \\
\hline$t[v, 0.975]$ & 2.486 & 2.565 & 2.458 & 2.464 & 2.434 & 2.457 & 2.479 & 2.536 & 2.571 & 2.387 \\
\hline $\mathrm{t}[\mathrm{v}, 0.950]$ & 1.966 & 2.011 & 1.850 & 1.953 & 1.936 & 1.949 & 1.962 & 1.995 & 2.015 & 1.896 \\
\hline Jote : reject th & h holt & & $\begin{array}{l}T>t[] \\
T<-t[]\end{array}$ & & & & & & & \\
\hline
\end{tabular}

\section{[4 Yearly Averaging]}

New Mean Values

\begin{tabular}{|c|c|c|c|c|c|c|c|c|c|c|}
\hline & $\begin{array}{c}\text { Conductivity } \\
@ 25 \mathrm{C} \\
\text { (ms/m) }\end{array}$ & $\mathrm{PH}$ & $\begin{array}{c}\text { Dissolved } \\
\text { lons } \\
\text { (mg/) } \\
\end{array}$ & $\begin{array}{c}\text { Dissolved } \\
\text { Solids } \\
\text { (mg/) }\end{array}$ & $\begin{array}{c}\text { Hardness } \\
\text { (mgh)as Caco3 }\end{array}$ & $\begin{array}{c}\text { Alkalinity } \\
\text { (mg/l)as } \mathrm{CaCO}\end{array}$ & $\begin{array}{l}\text { Natriurn } \\
\text { (mg/) }\end{array}$ & $\begin{array}{l}\text { Kalium } \\
\text { (mg/l) }\end{array}$ & $\begin{array}{l}\text { Calcium } \\
\text { (mgn) }\end{array}$ & $\begin{array}{l}\text { Magnesium } \\
\text { (mg/l) }\end{array}$ \\
\hline$(x \cap e)$ & $\begin{array}{l}436.0 \\
457.7\end{array}$ & $\begin{array}{l}7.8 \\
8.0\end{array}$ & $\begin{array}{l}277.1 \\
296.9\end{array}$ & $\begin{array}{l}235.1 \\
252.6\end{array}$ & $\begin{array}{l}121.7 \\
131.8\end{array}$ & $\begin{array}{l}101.2 \\
106.2\end{array}$ & $\begin{array}{l}37.9 \\
41.0\end{array}$ & $\begin{array}{l}1.9 \\
2.9\end{array}$ & $\begin{array}{l}23.5 \\
23.7\end{array}$ & $\begin{array}{l}14.1 \\
17.6\end{array}$ \\
\hline $\begin{array}{l}\left(\bar{X}_{n e}\right) \\
\text { (Sne) }\end{array}$ & $\begin{array}{c}448.8 \\
15.3\end{array}$ & $\begin{array}{l}7.9 \\
0.1\end{array}$ & $\begin{array}{c}287.0 \\
14.0\end{array}$ & $\begin{array}{c}243.9 \\
12.4\end{array}$ & $\begin{array}{c}126.7 \\
7.2\end{array}$ & $\begin{array}{c}103.7 \\
3.5\end{array}$ & $\begin{array}{c}39.5 \\
2.2\end{array}$ & $\begin{array}{l}2.0 \\
0.1\end{array}$ & $\begin{array}{c}23 . \widehat{0} \\
0.1\end{array}$ & $\begin{array}{c}15.8 \\
2.5\end{array}$ \\
\hline
\end{tabular}

Statistic Test (T), Calculated by Equation 5.6

\begin{tabular}{|c|c|c|c|c|c|c|c|c|c|c|}
\hline & $\begin{array}{c}\text { Conductivity } \\
@ 25 \mathrm{C} \\
(\mathrm{mS} / \mathrm{m}) \\
\end{array}$ & $\mathrm{PH}$ & $\begin{array}{c}\text { Dissoived } \\
\text { lons } \\
(\mathrm{mg} / \mathrm{l}) \\
\end{array}$ & $\begin{array}{c}\text { Dissolved } \\
\text { Solids } \\
(\mathrm{mg} / \mathrm{l}) \\
\end{array}$ & $\begin{array}{c}\text { Hardness } \\
\text { (mg/l)as } \mathrm{CaCO} 3\end{array}$ & $\begin{array}{c}\text { Alkalinity } \\
\text { (mg/l)as } \mathrm{CaCO} 3\end{array}$ & $\begin{array}{l}\text { Natrium } \\
(\mathrm{mg} / \mathrm{l})\end{array}$ & $\begin{array}{l}\text { Kalium } \\
(\mathrm{mg} / \mathrm{l})\end{array}$ & $\begin{array}{l}\text { Calcium } \\
\text { (mgll) }\end{array}$ & $\begin{array}{l}\text { Magnesium } \\
(\mathrm{mg} /)\end{array}$ \\
\hline T & -0.70 & 0.89 & -0.68 & -0.65 & -0.65 & -0.52 & -0.75 & -0.25 & -0.94 & -0.71 \\
\hline $\begin{array}{l}\text { Degrees of } \\
\text { Freedom (v) }\end{array}$ & 5.11 & 5.06 & 5.22 & 5.24 & 5.30 & 5.12 & 5.25 & 5.32 & 5.00 & 5.98 \\
\hline$t[v, 0.975]$ & 2.557 & 2.564 & 2.543 & 2.541 & 2.534 & 2.556 & 2.540 & 2.532 & 2.571 & 2.450 \\
\hline$t[v, 0.950]$ & 2.007 & 2.011 & 1.999 & 1.988 & 1.994 & 2.006 & 1.997 & 1.992 & 2.015 & 1.945 \\
\hline 8. refecio & & & $\begin{array}{l}T>t \|] \\
T<-t \|\}\end{array}$ & & & & & & & \\
\hline
\end{tabular}



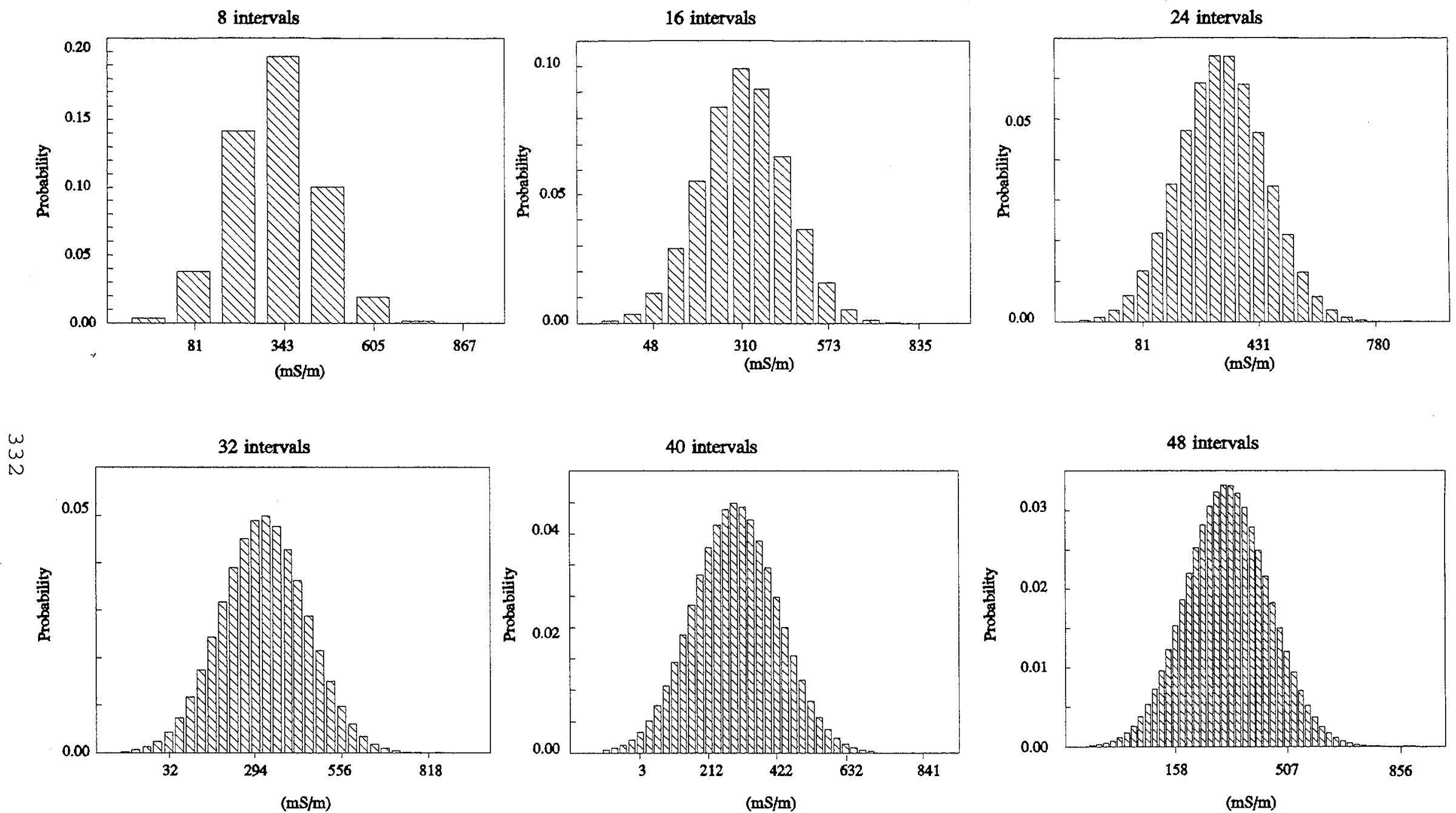

Figure B.1(a) Assigned Probabilities at Station 130401 (Conductivity) 

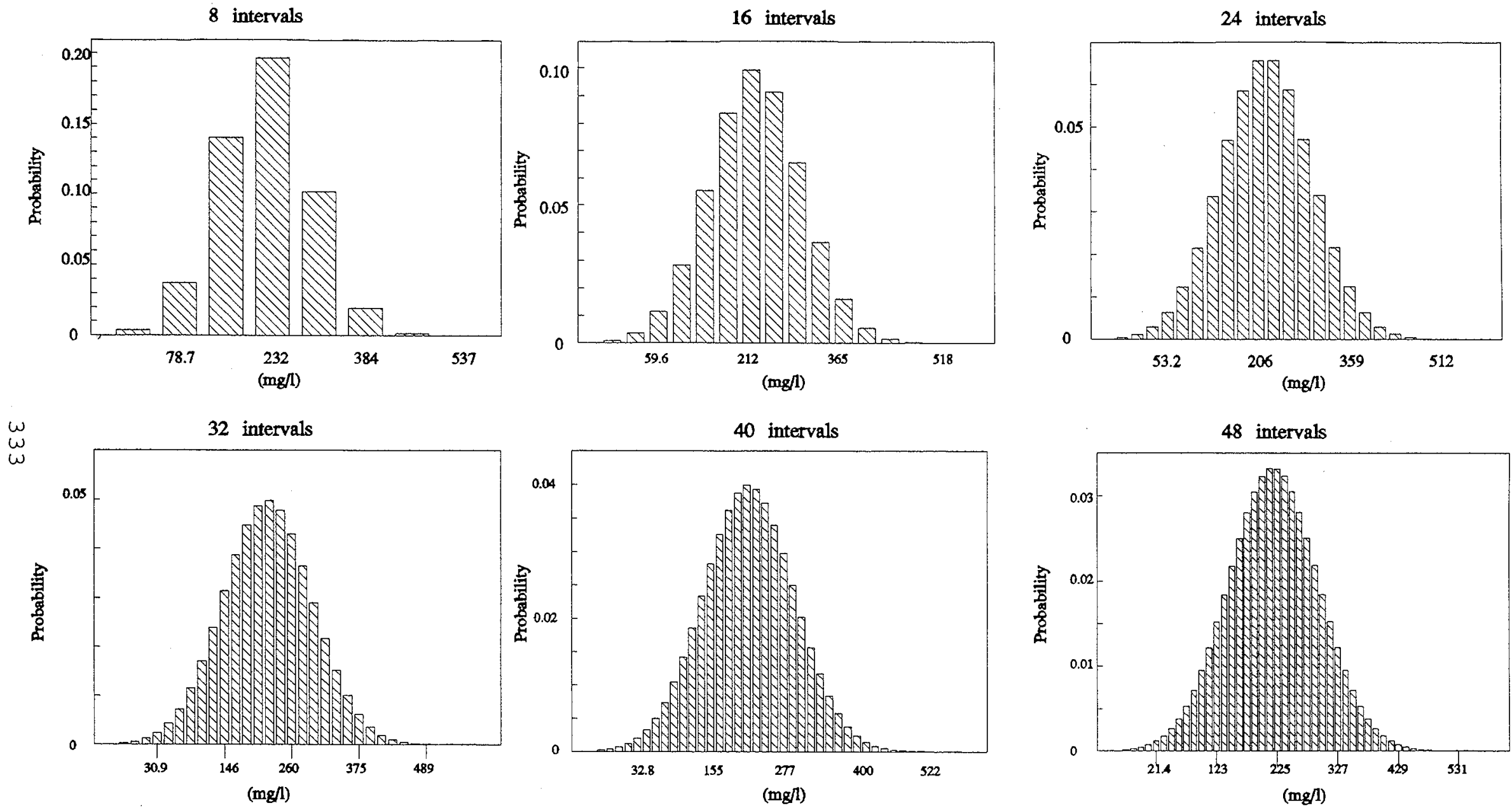

Figure B.1(b) Assigned Probabilities at Station 130401 (Dissolved Ions) 

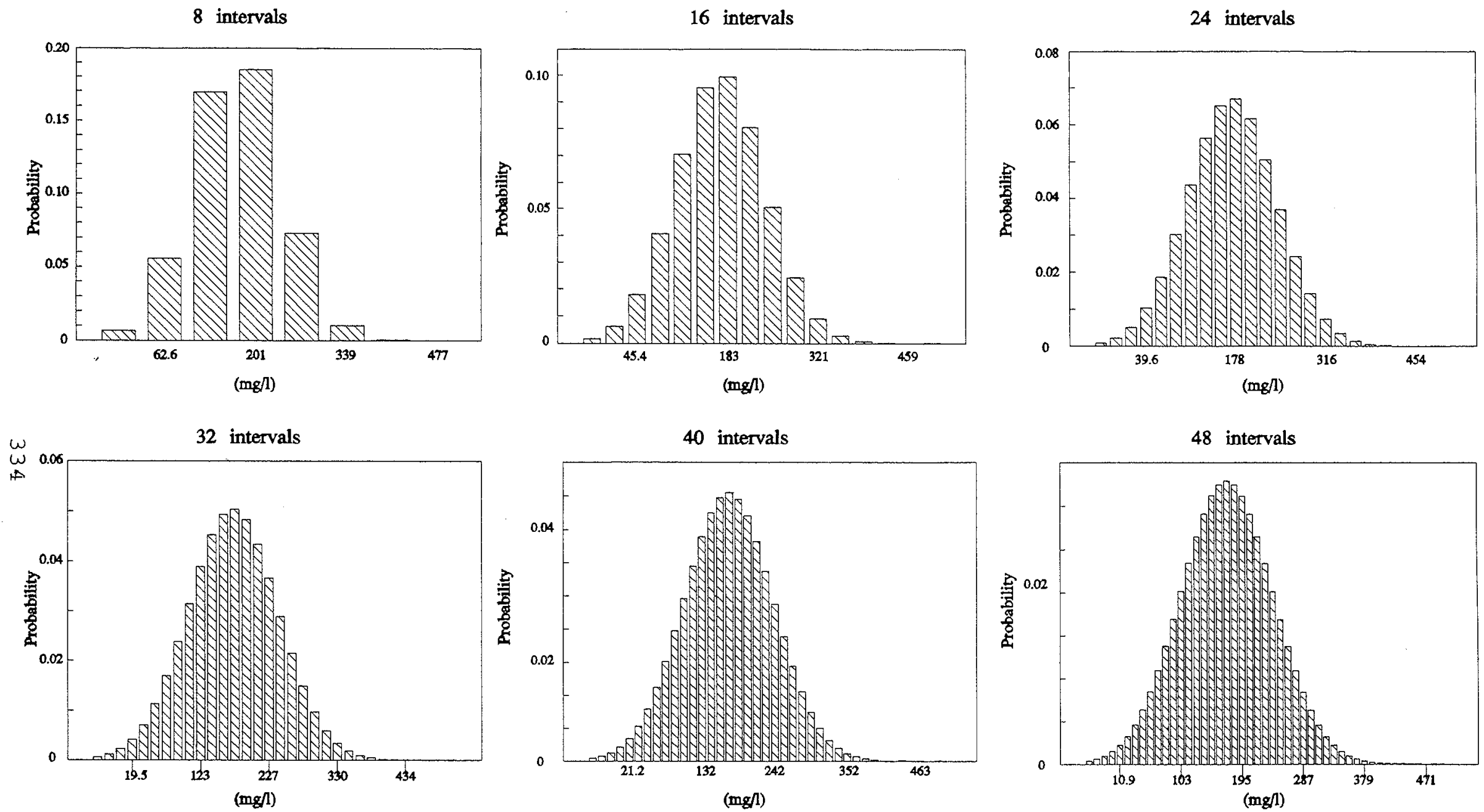

Figure B.1(c) Assigned Probabilities at Station 130401 (Dissolved Solids) 

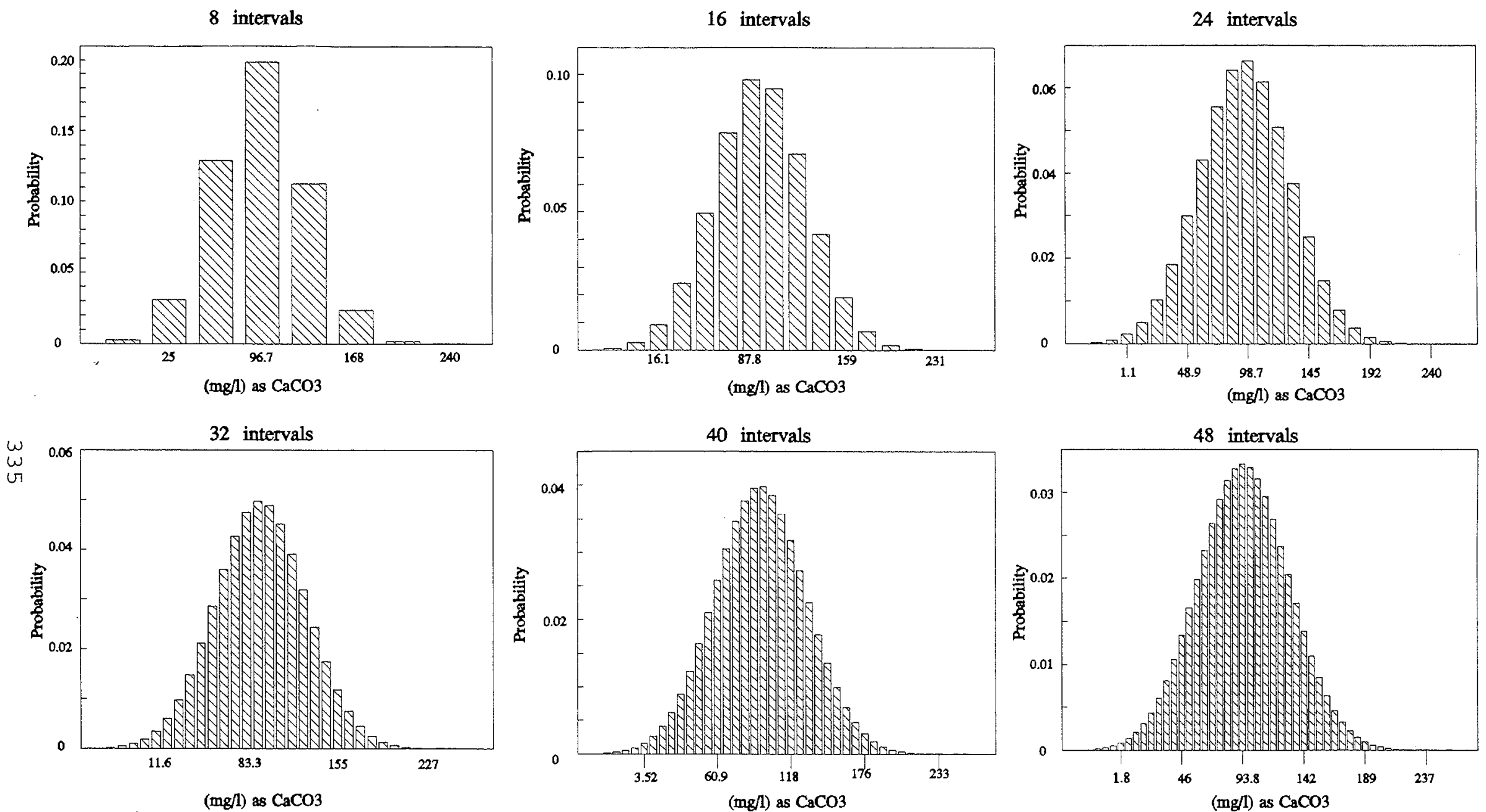

Figure B.1(d) Assigned Probabilities at Station 130401 (Hardness) 

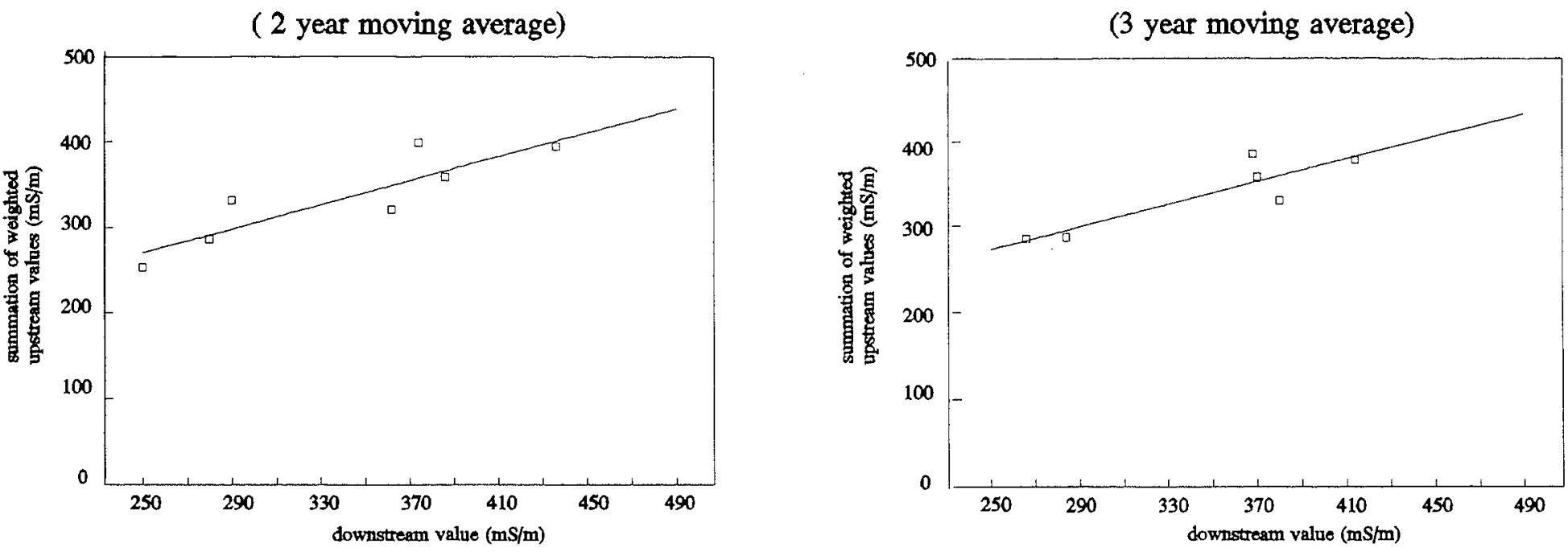

$\stackrel{\omega}{\omega}$
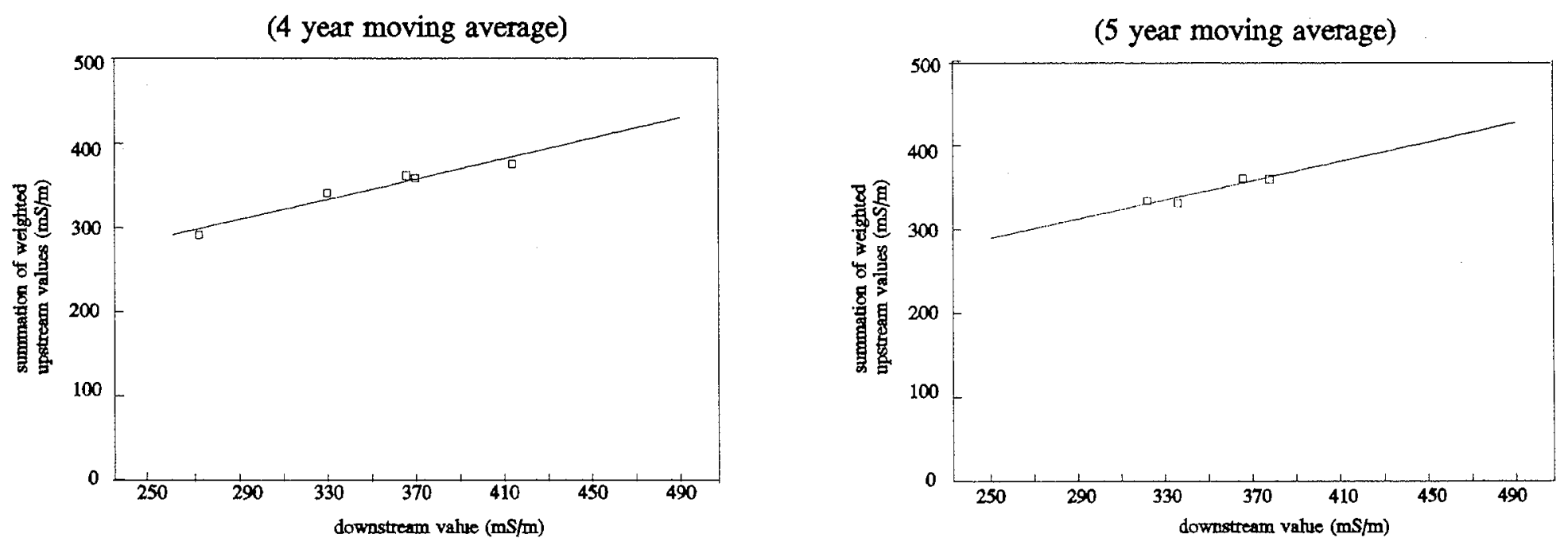

Figure B.2(a) Plot of Regression Lines for Different Periods of Time over which the Conductivity is Averaged 

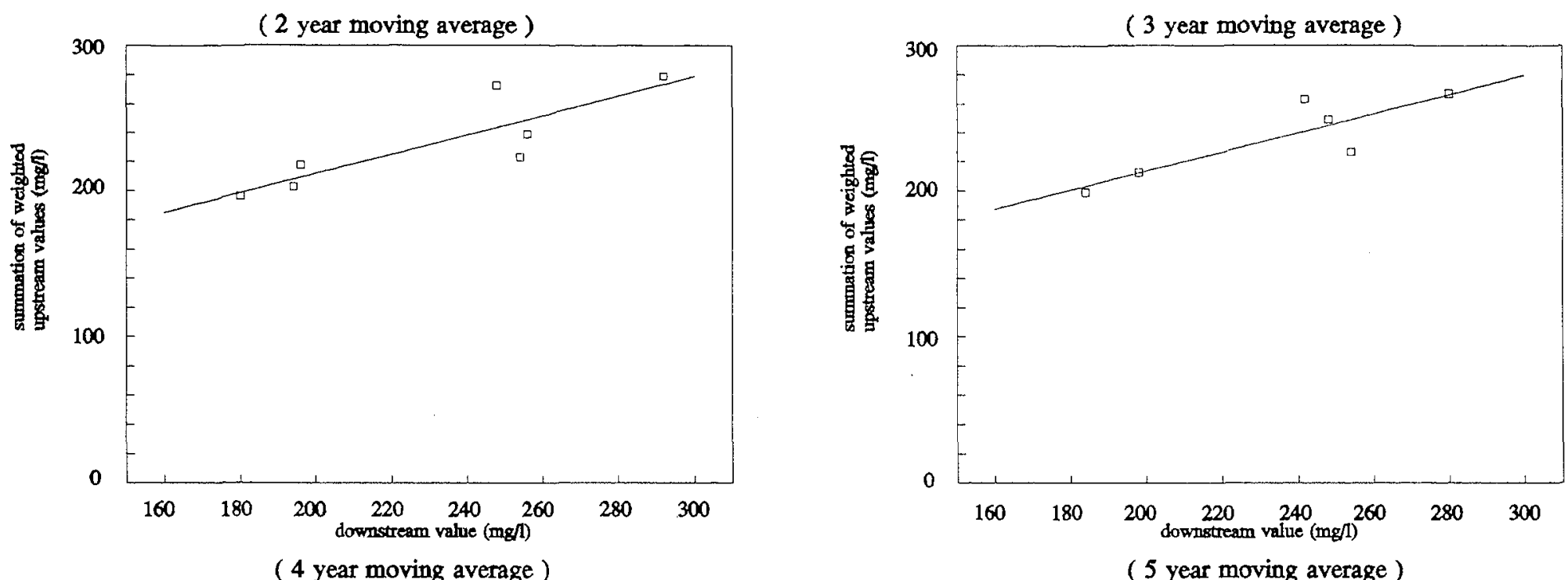

$\underset{w}{\omega}$
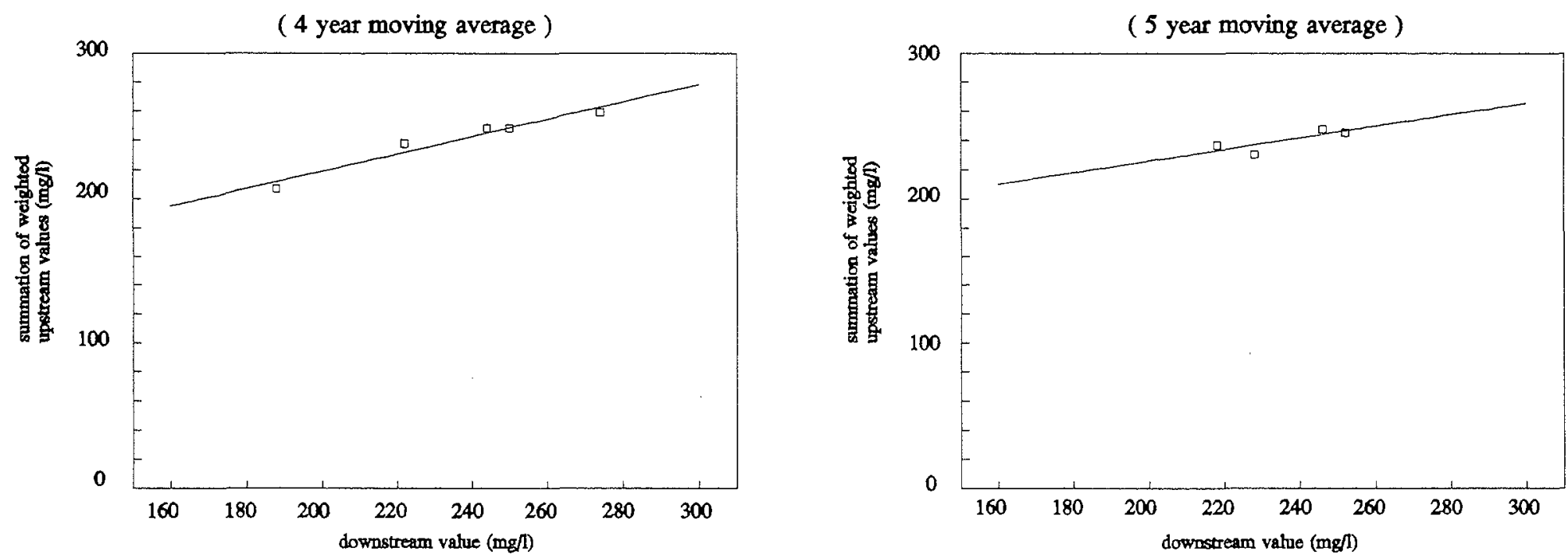

Figure B.2(b) Plot of Regression Lines for Different Periods of Time over which the Dissolved Ions Concentration is Averaged 

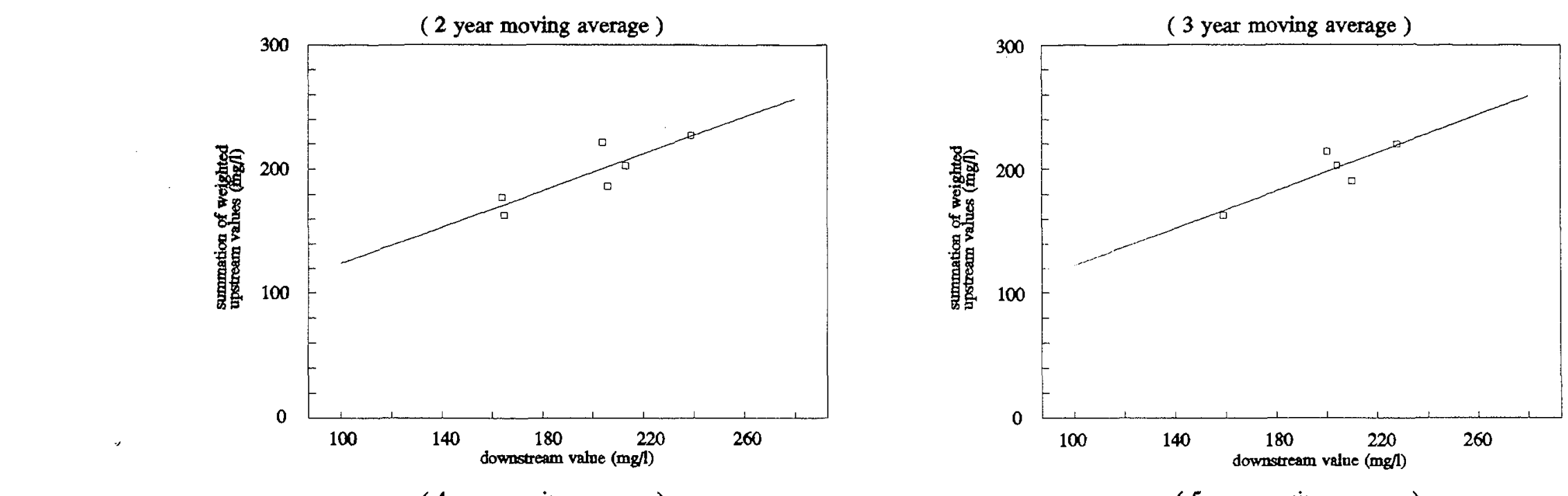

$\omega$
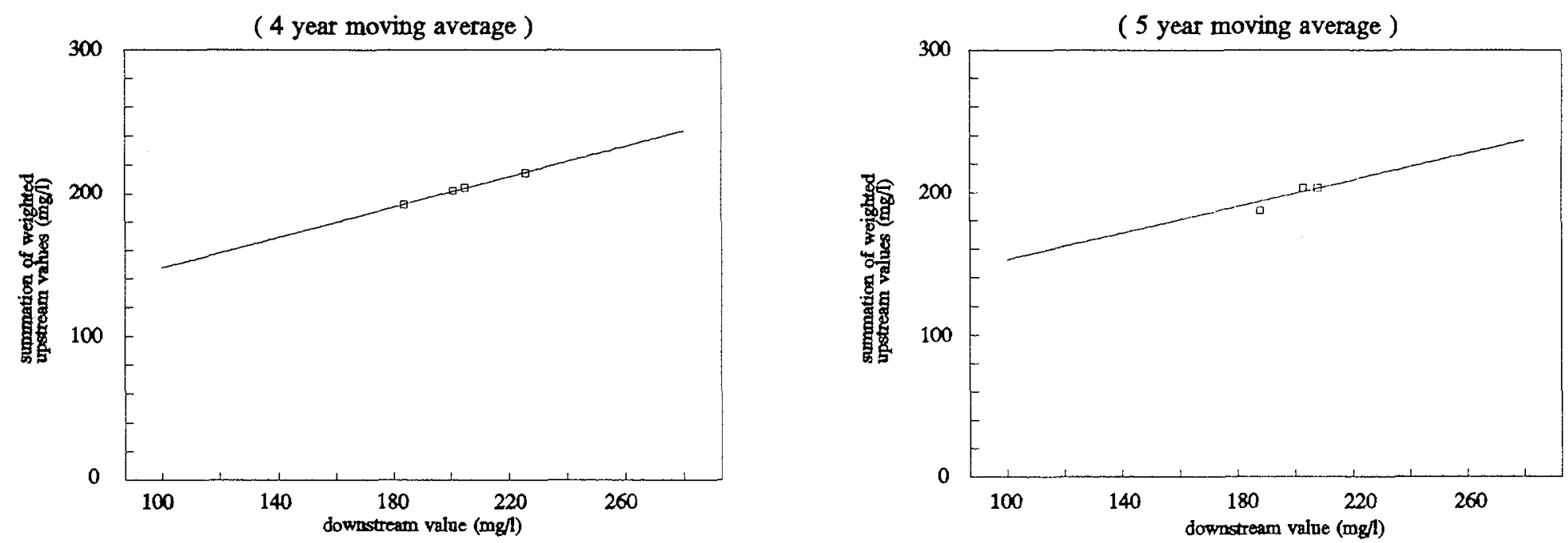

Figure B.2(c) Plot of Regression Lines for Different Periods of Time over which the Dissolved Solids Concentration is Averaged 

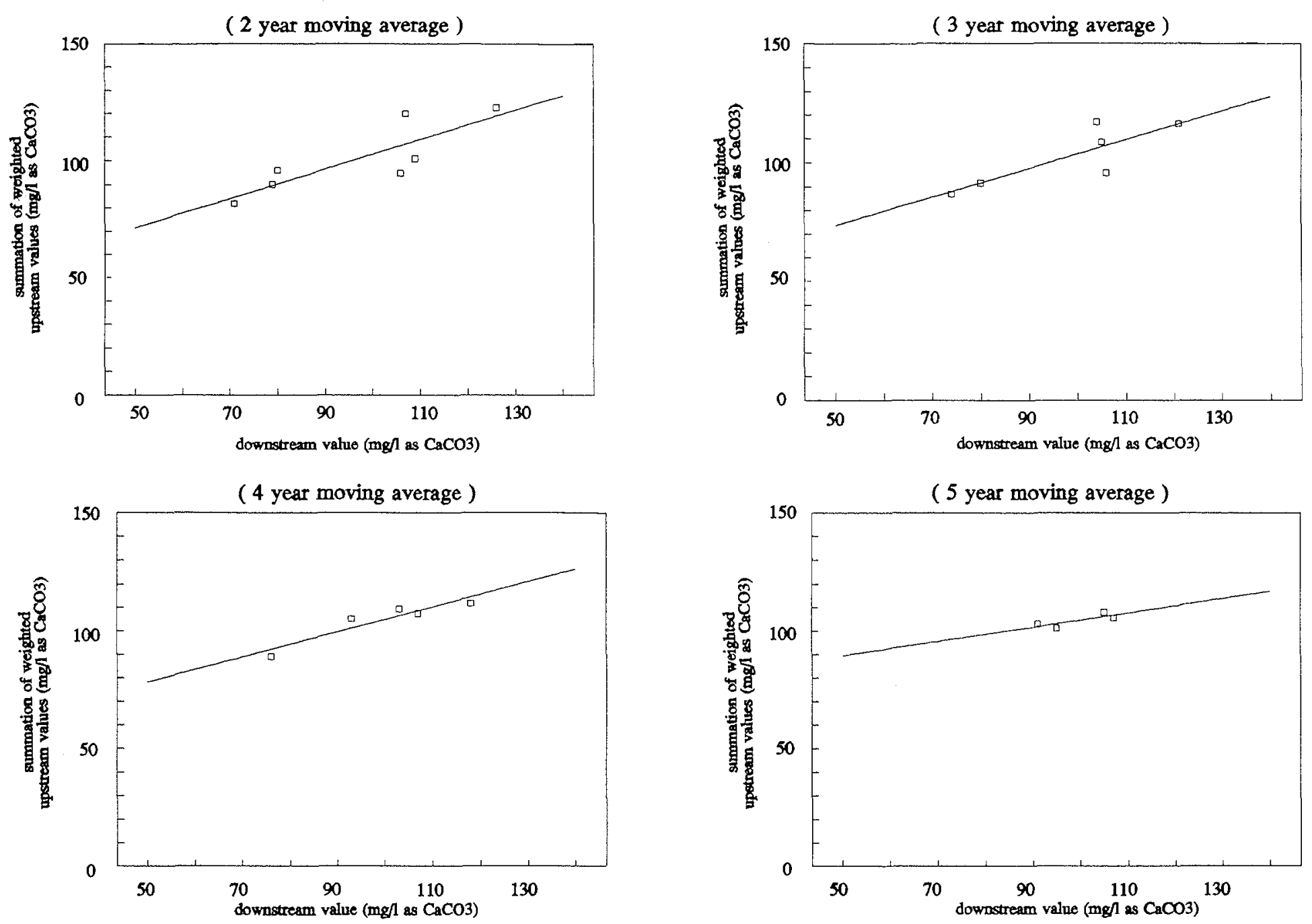

Figure B.2(d) Plot of Regression Lines for Different Periods of Time over which the Hardness is Averaged 

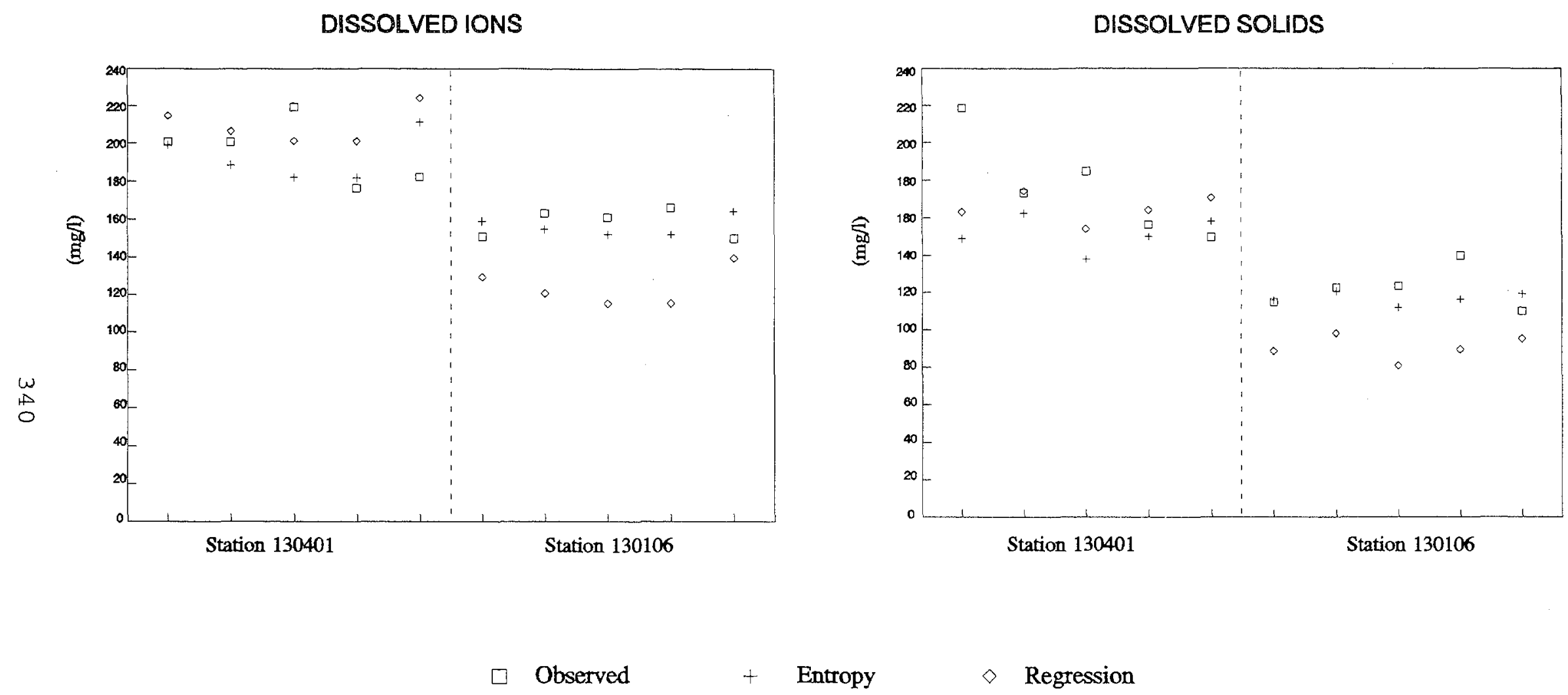

Figure B.3(a) Plot of Water Quality Values in the Mackenzie River ( 1 Yearly Averaging ) 

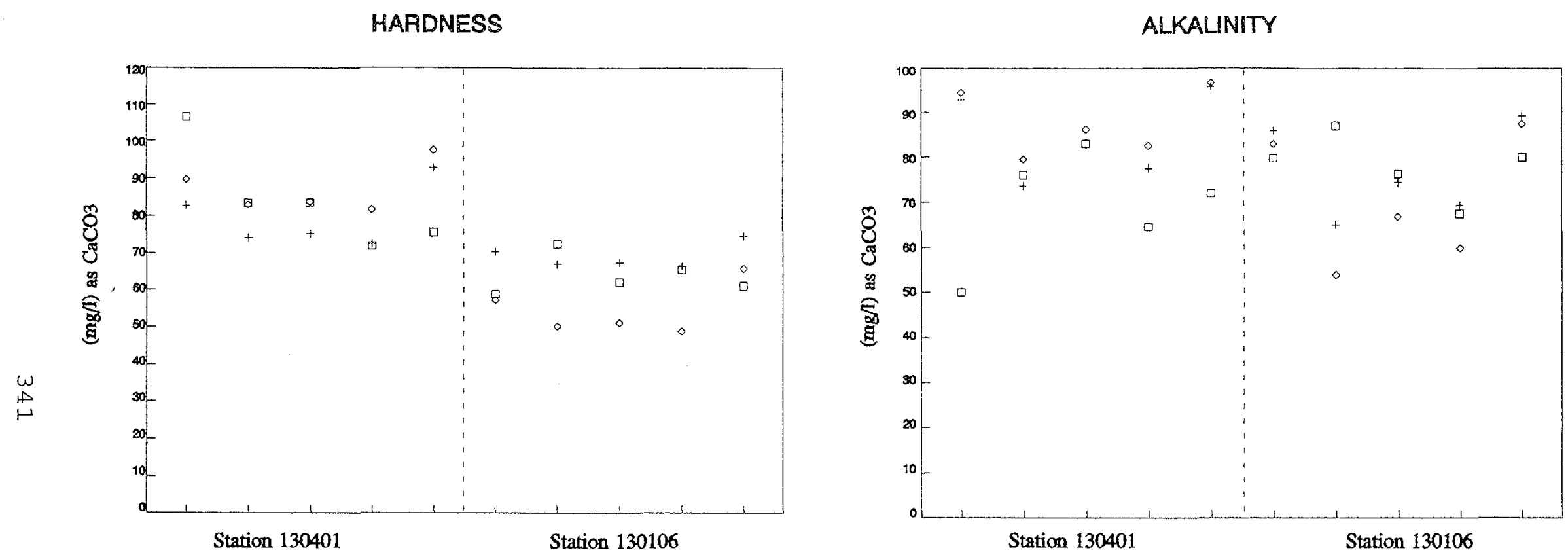

$\square$ Observed + Entropy $\diamond$ Regression

Figure B.3(a) Plot of Water Quality Values in the MacKenzie River ( 1 Yearly Averaging ) (continued) 

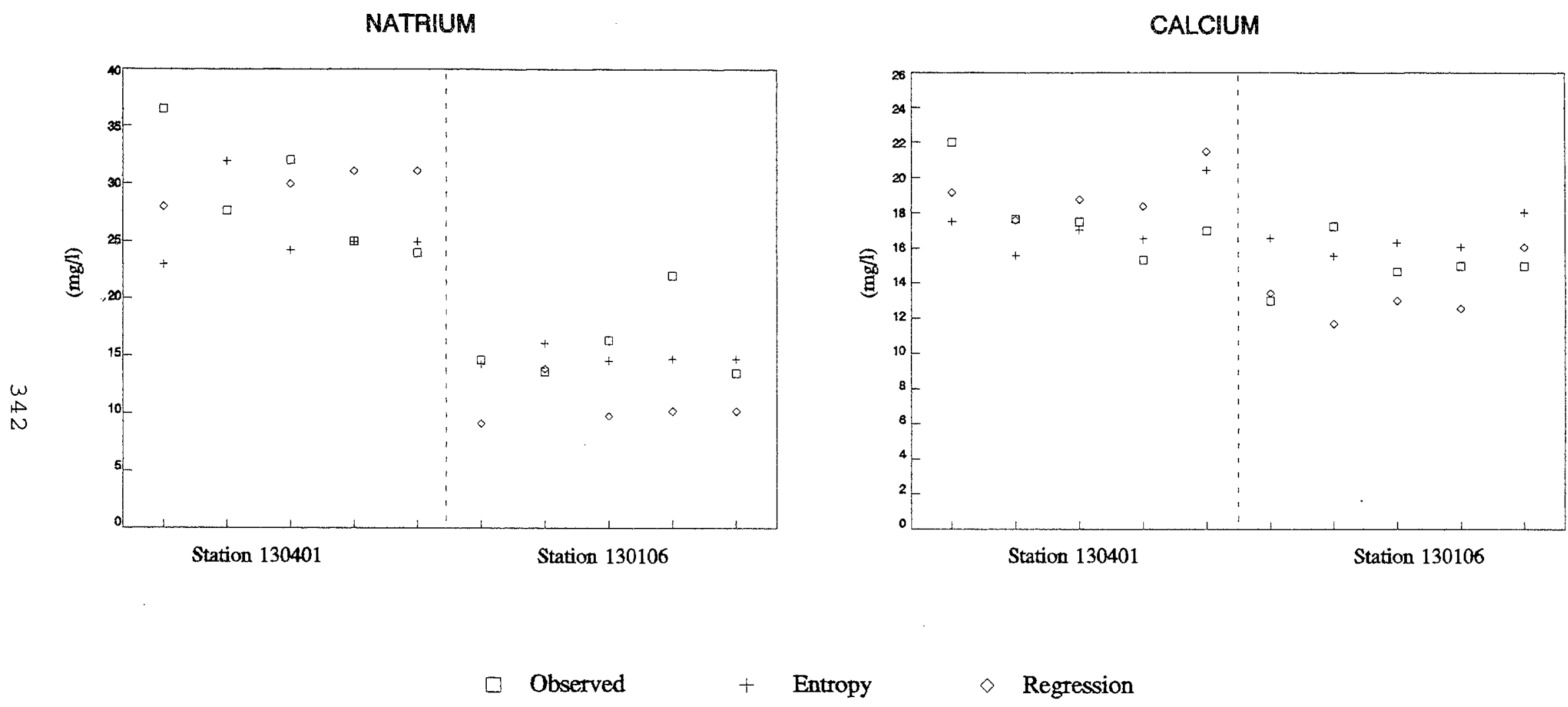

Figure B.3(a) Plot of Water Quality Values in the MacKenzie River ( 1 Yearly Averaging ) (continued) 

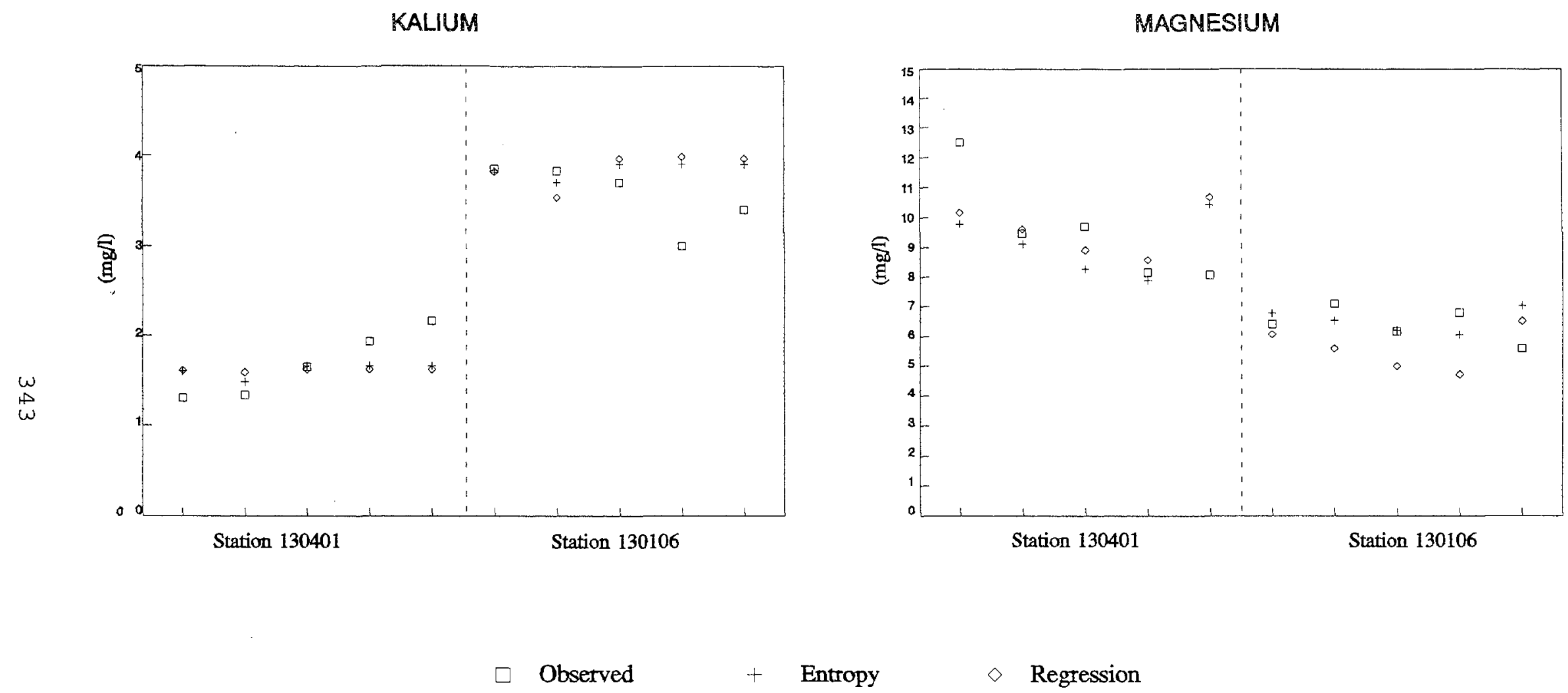

Figure B.3(a) Plot of Water Quality Values in the MacKenzie River ( 1 Yearly Averaging ) (continued) 

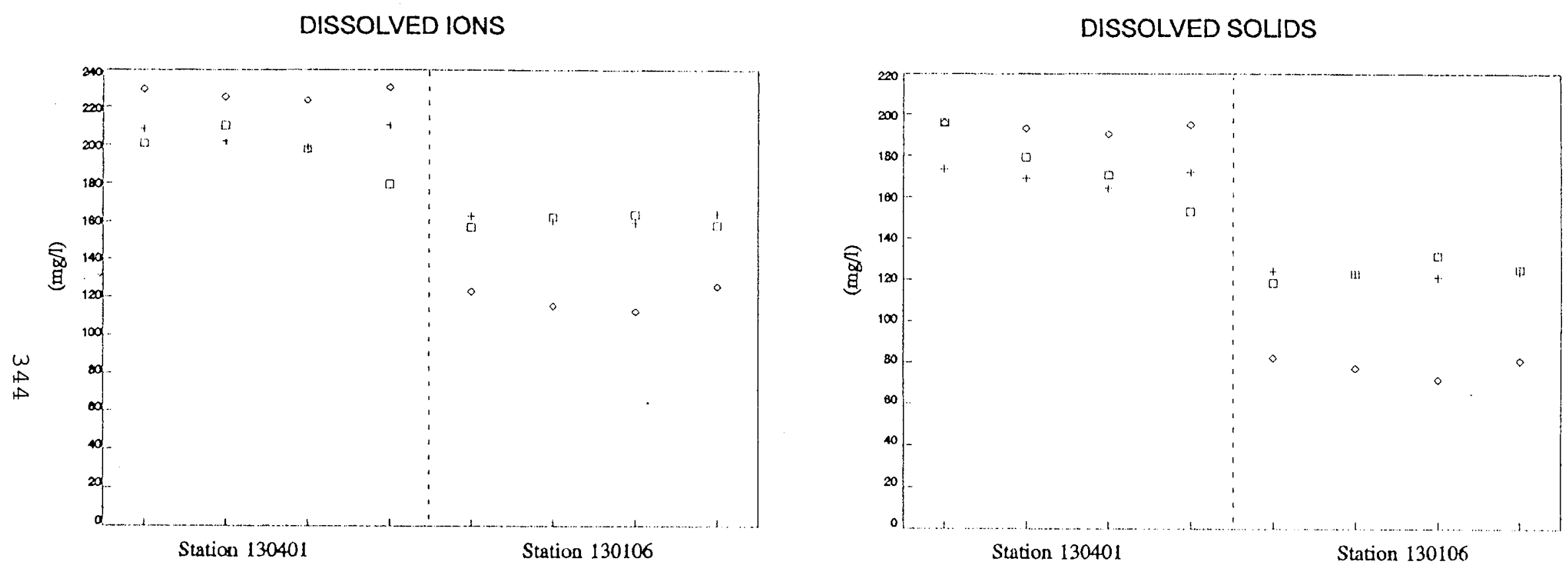

L) Observed $\quad$ Entropy Regression

Figurre B.3(b) Plot of Water Quality Values in the MacKenzie River ( 2 Yearly Averaging) 

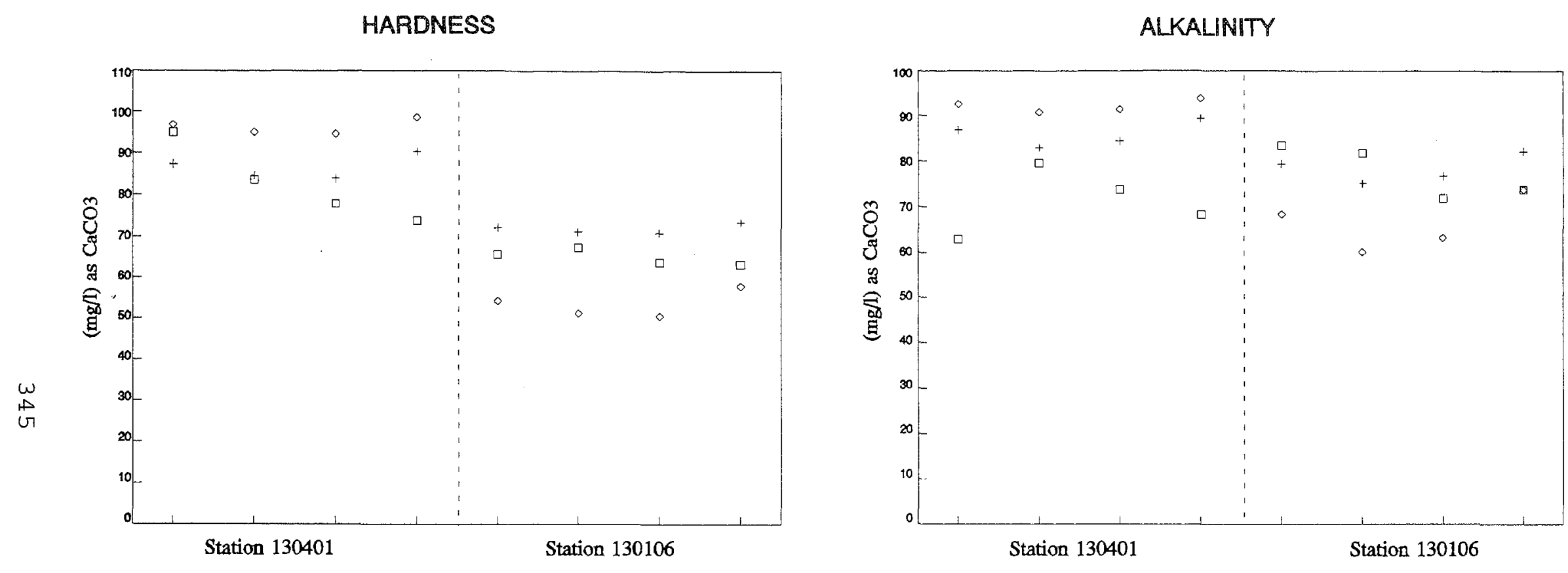

$\square$ Observed + Entropy $\diamond$ Regression

Figurre B.3(b) Plot of Water Quality Values in the MacKenzie River ( 2 Yearly Averaging ) (continued) 

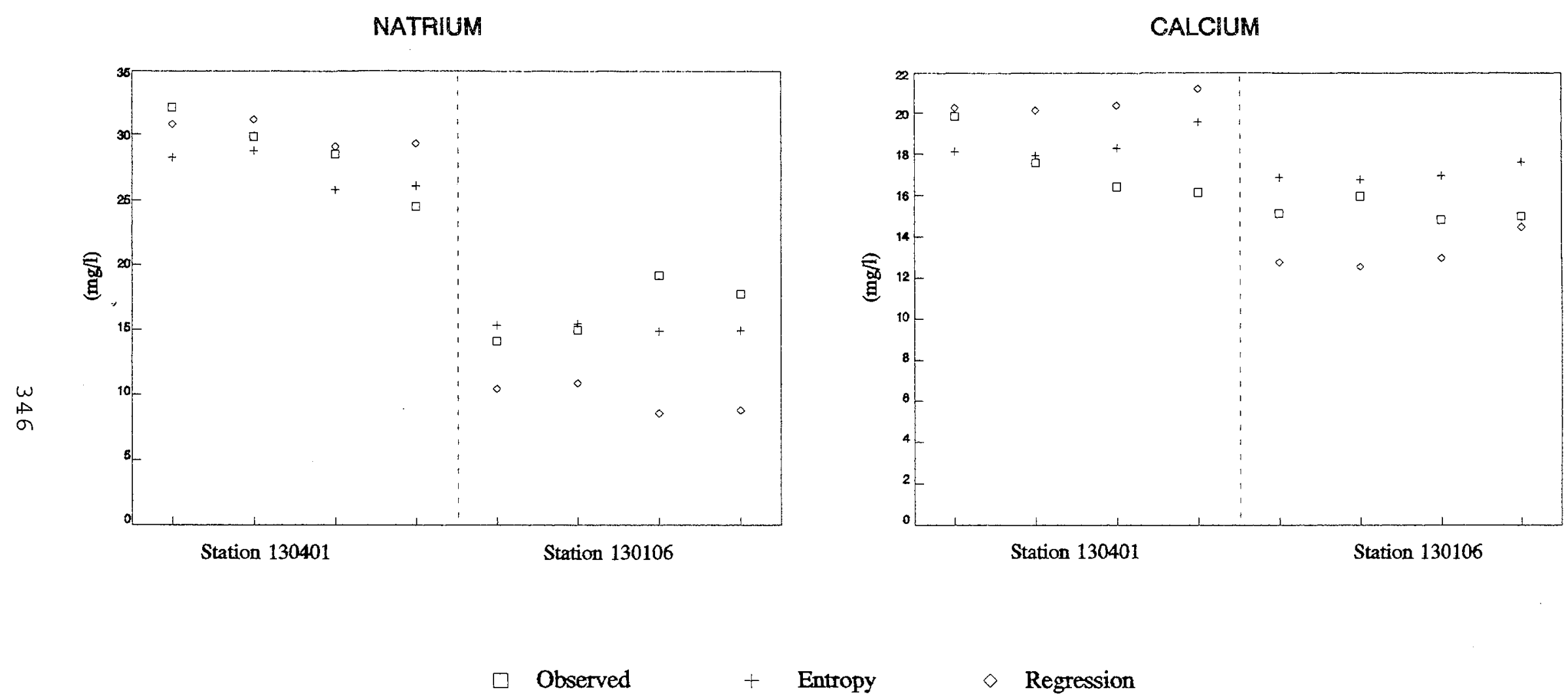

Figurre B.3(b) Plot of Water Quality Values in the MacKenzie River ( 2 Yearly Averaging ) (continued) 
KALIUM

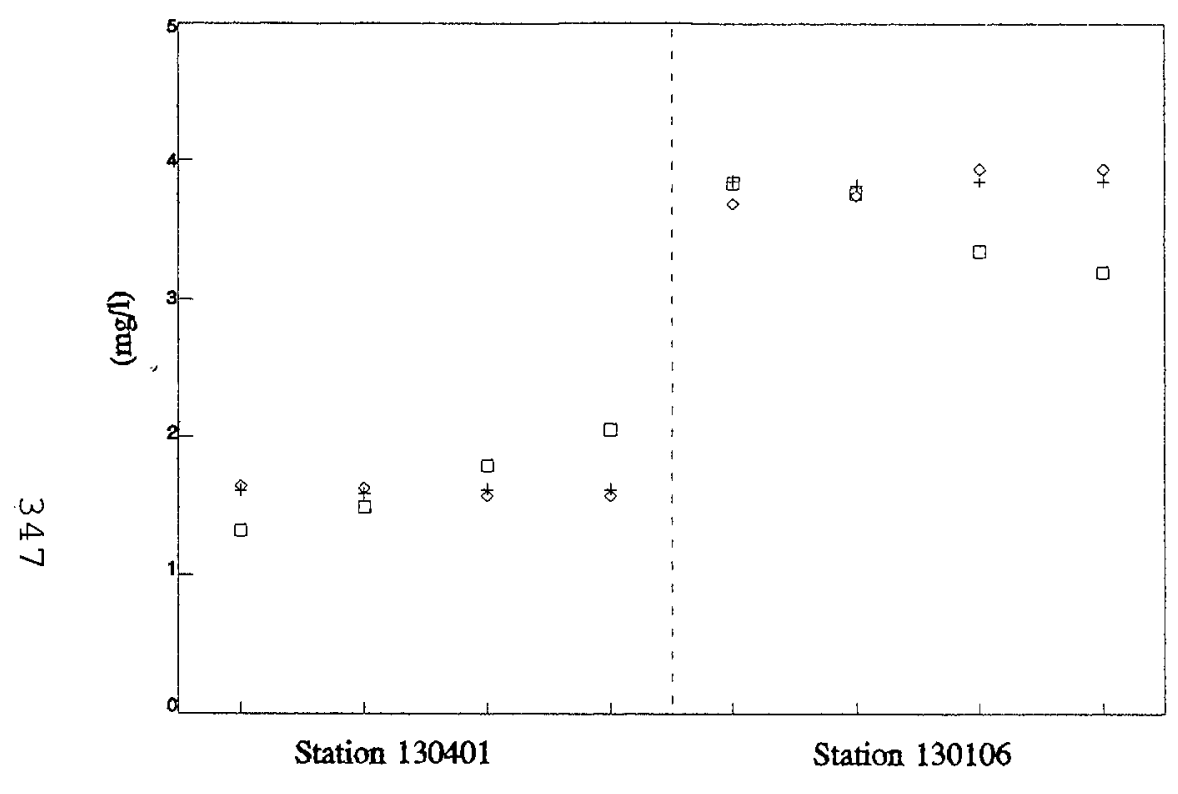

MAGNESIUM

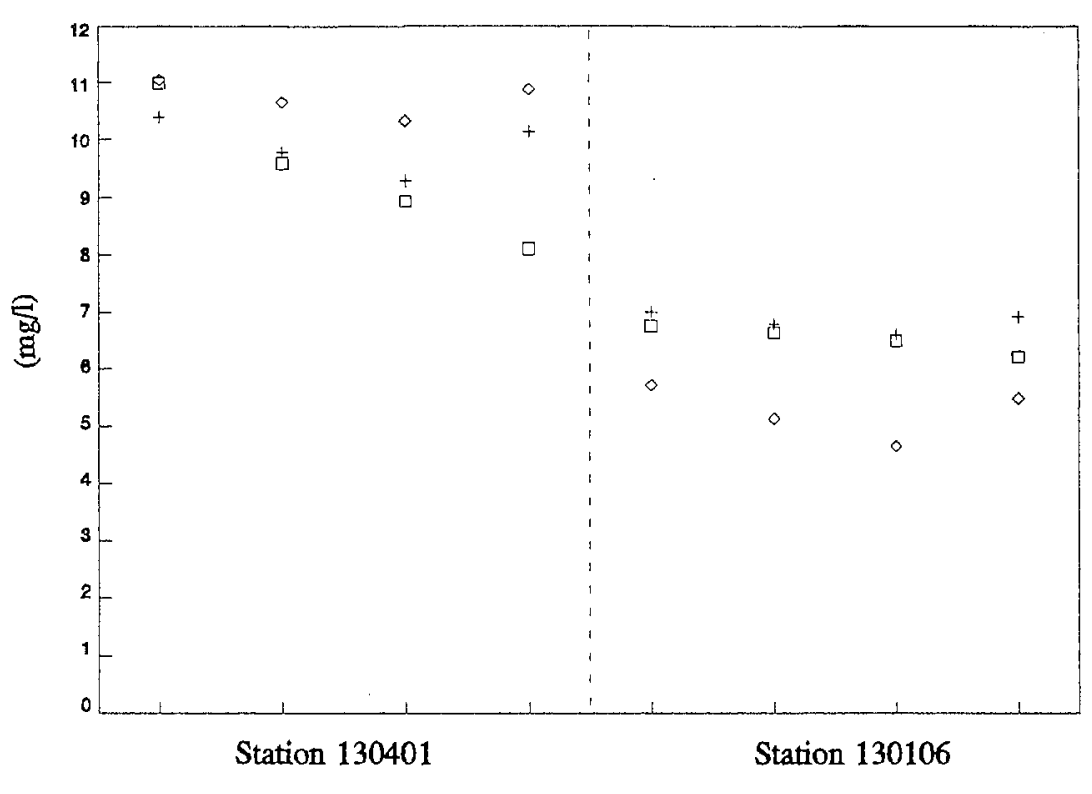

$\diamond$ Regression

Figurre B.3(b) Plot of Water Quality Values in the MacKenzie River ( 2 Yearly Averaging ) (continued) 

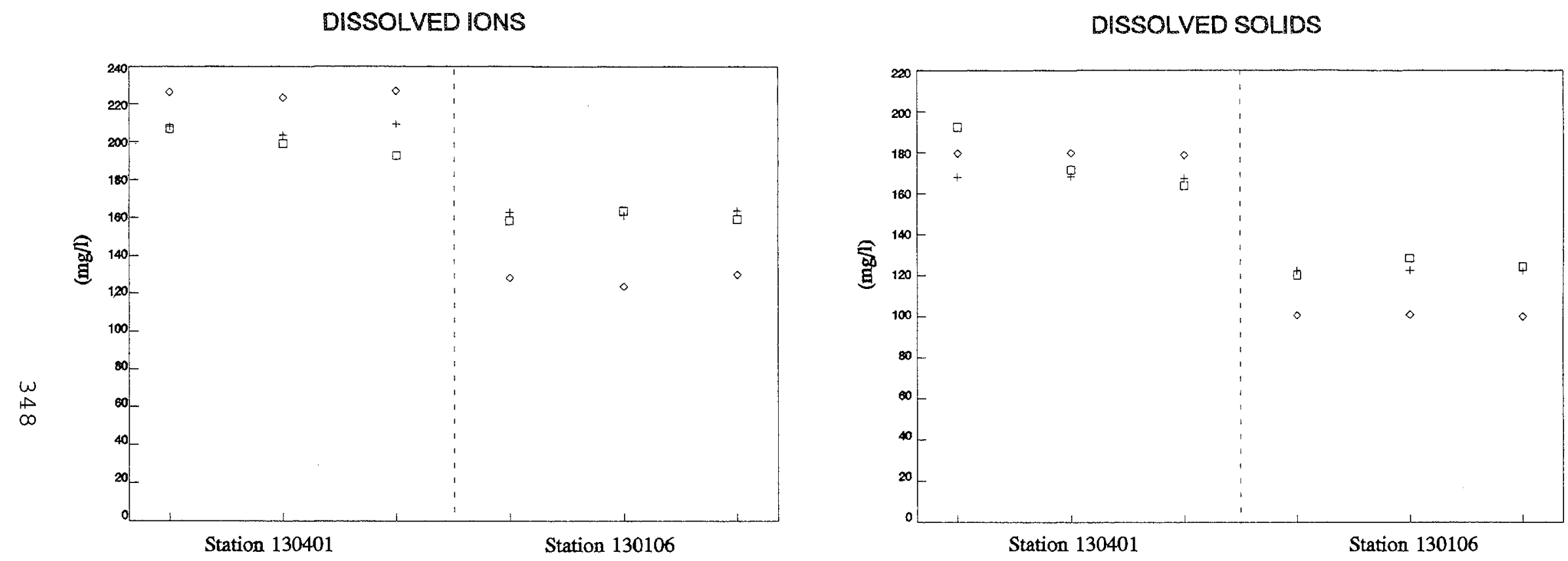

$\square$ Observed + Entropy $\diamond$ Regressión

Figure B.3(c) Plot of Water Quality Values in the MacKenzie River ( 3 Yearly Averaging ) 

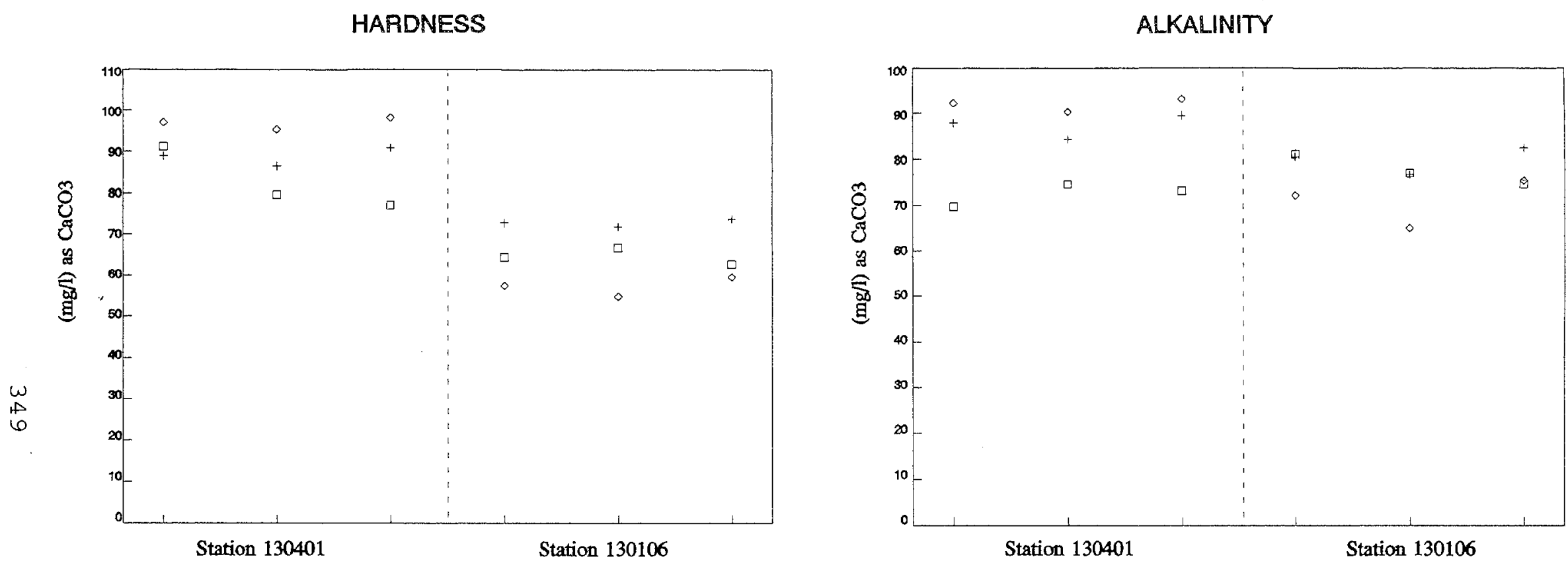

$\square$ Observed + Entropy $\diamond$ Regression

Figure B.3(c) Plot of Water Quality Values in the MacKenzie River ( 3 Yearly Averaging ) (continued) 

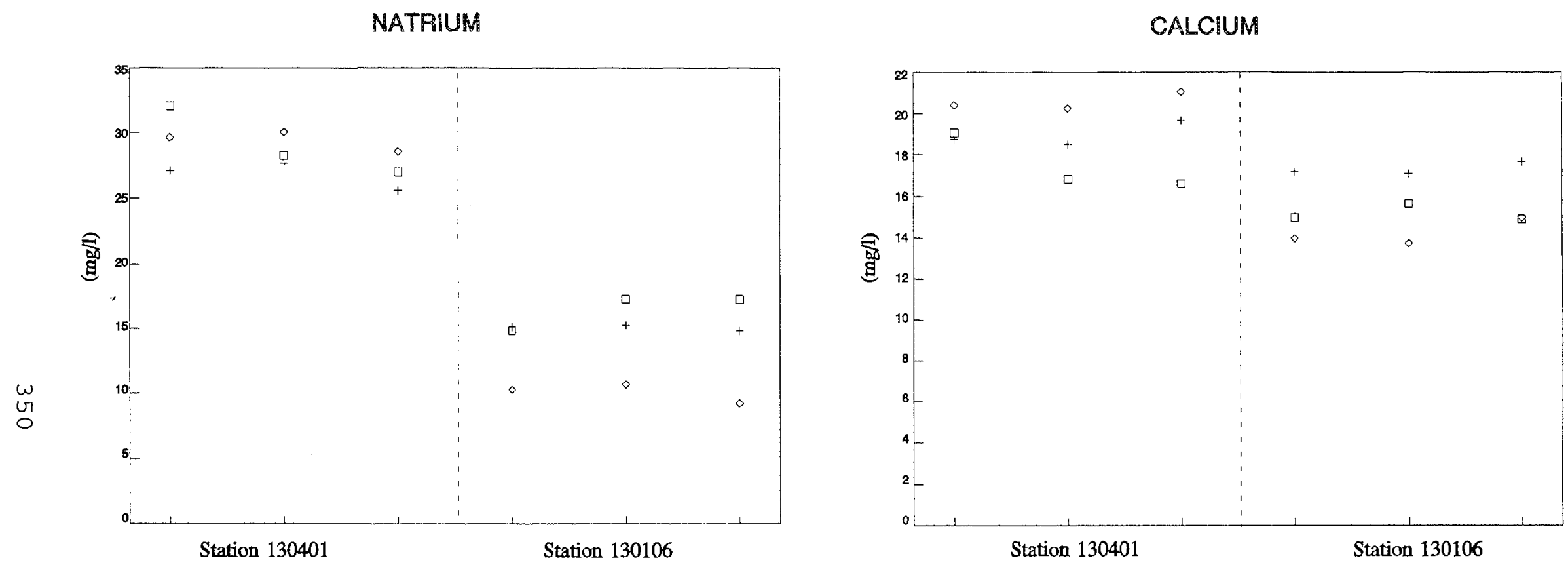

$\square$ Observed $\quad+$ Entropy $\diamond$ Regression

Figure B.3(c) Plot of Water Quality Values in the MacKenzie River ( 3 Yearly Averaging ) (continued) 

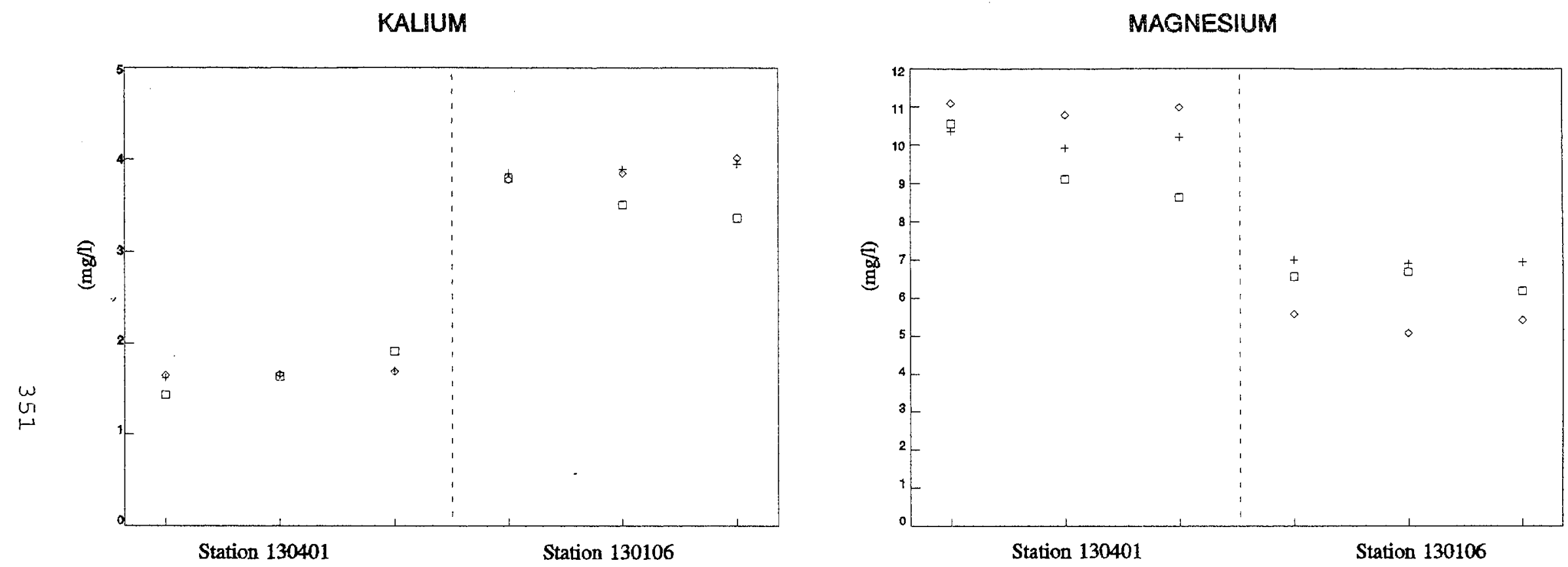

$\square$ Observed $\quad+$ Entropy $\diamond$ Regression

Figure B.3(c) Plot of Water Quality Values in the MacKenzie River ( 3 Yearly Averaging ) (continued) 

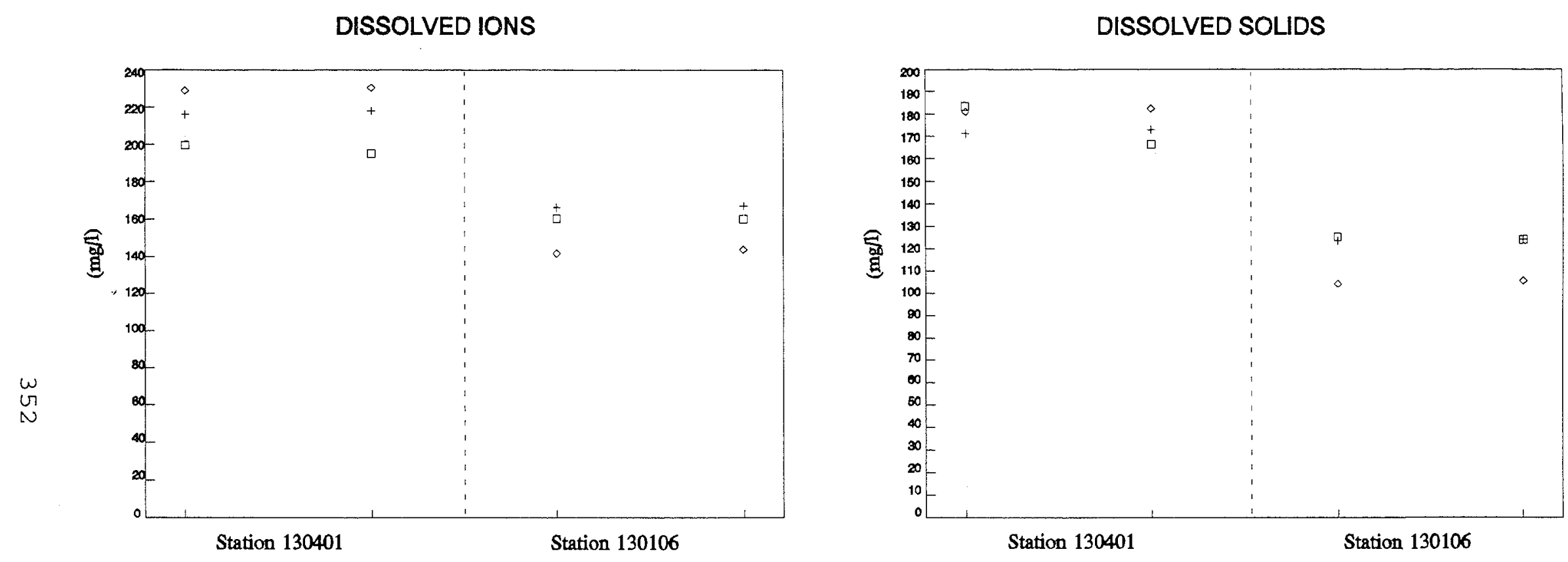

$\square$ Observed $\quad+$ Entropy $\diamond$ Regression

Figure B.3(d) Plot of Water Quality Values in the MacKenzie River ( 4 Yearly Averaging ) 

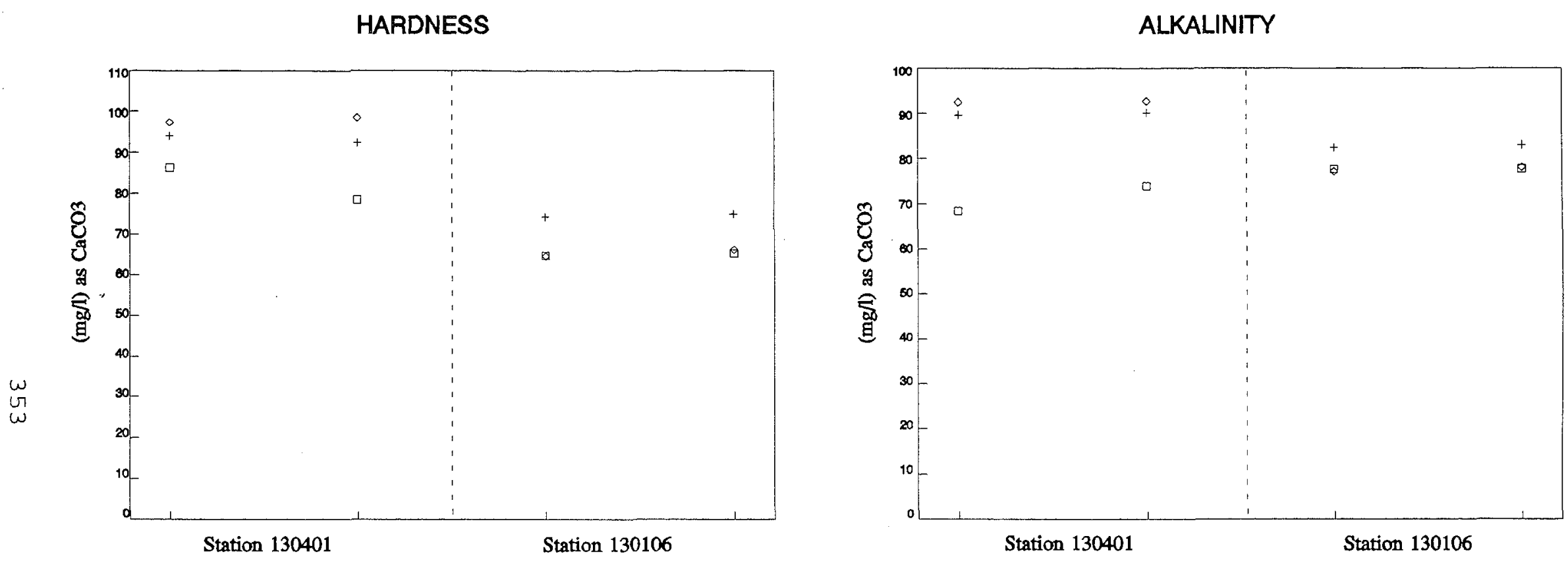

$\square$ Observed $\quad+$ Entropy $\diamond$ Regression

Figure B.3(d) Plot of Water Quality Values in the MacKenzie River ( 4 Yearly Averaging ) (continued) 

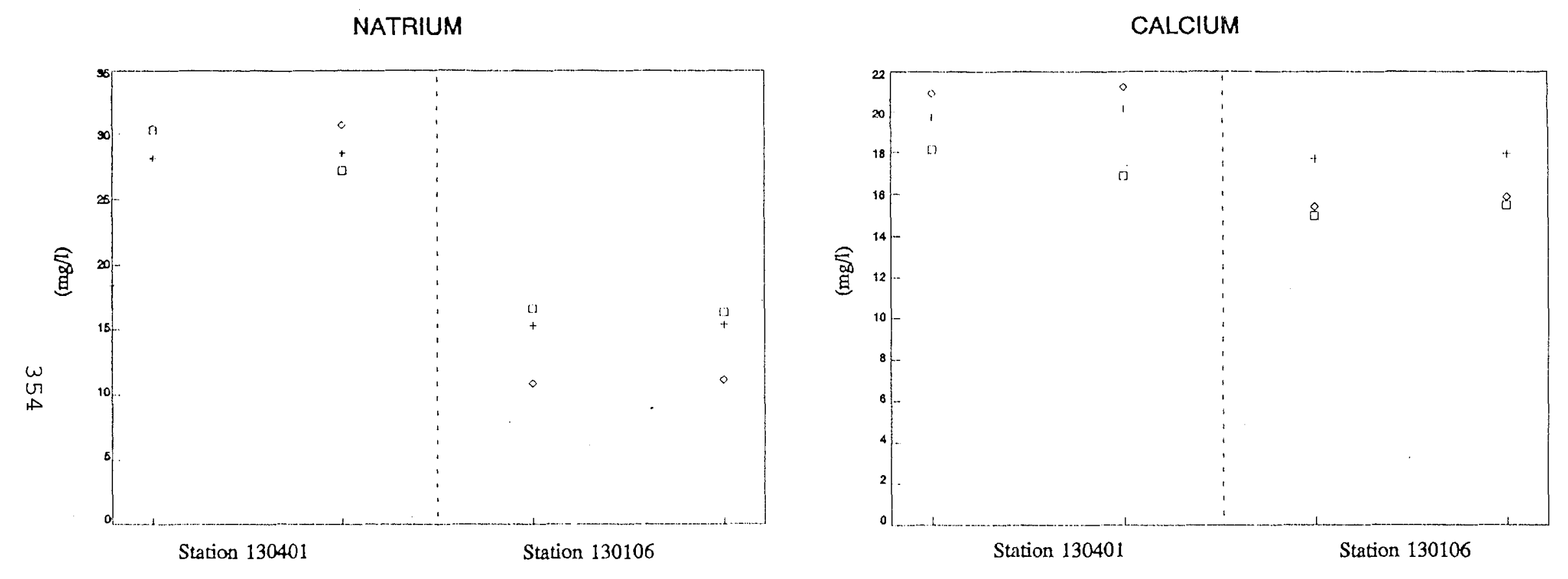

0 Observed $\quad+$ Entropy $\diamond$ Regression

Figure B.3(d) Plot of Water Quality Values in the MacKenzie River ( 4 Yearly Averaging ) (continued) 


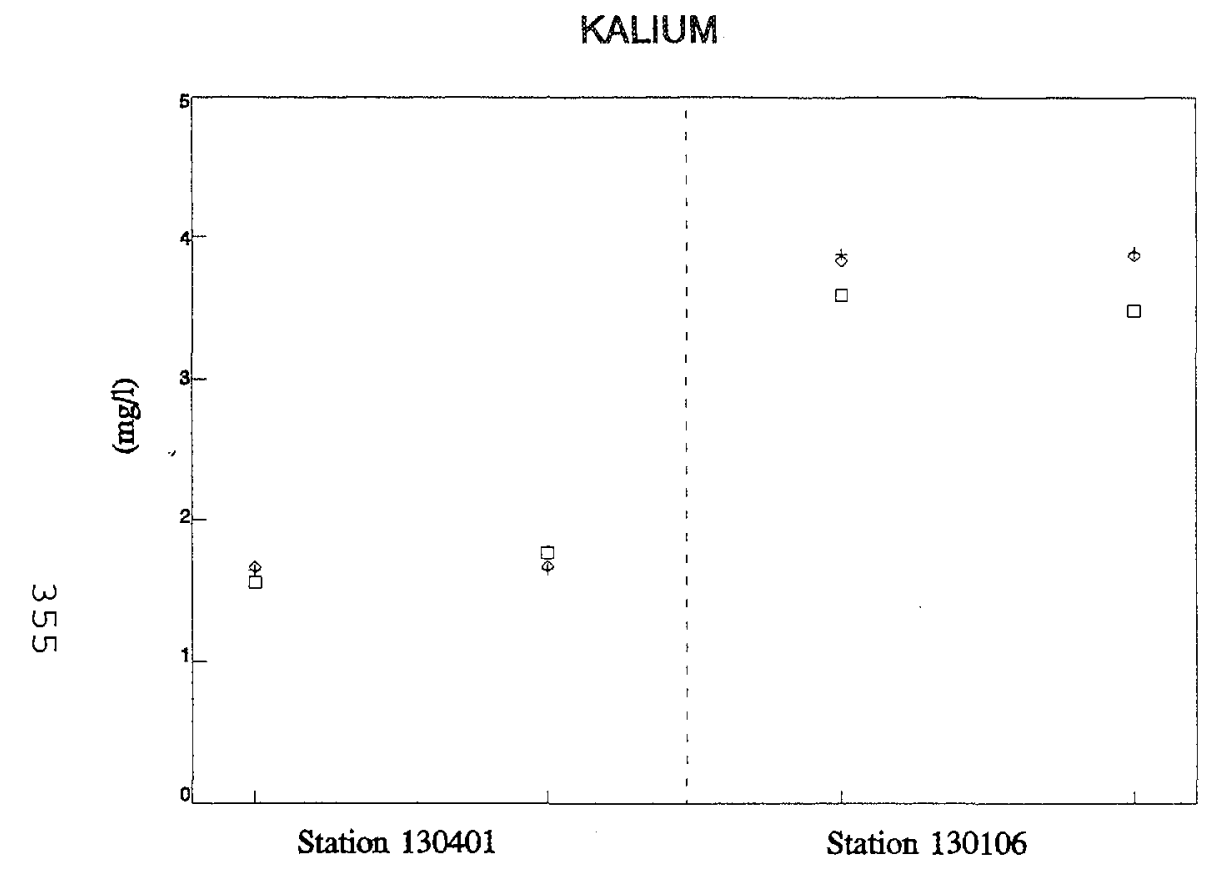

$\square$ Observed

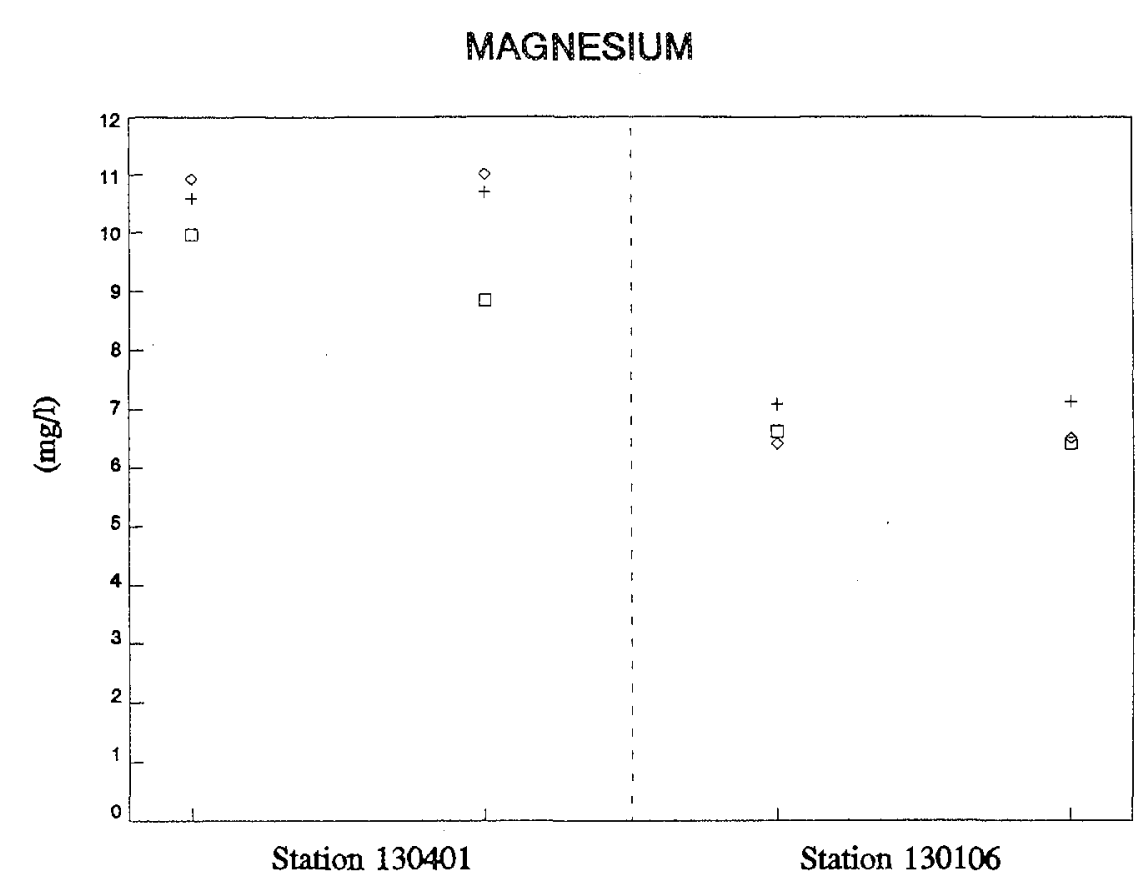

$+\quad$ Entropy

$\diamond$ Regression

Figure B.3(d) Plot of Water Quality Values in the MacKenzie River ( 4 Yearly Averaging ) (continued) 
Appendix $C$ 


\section{The Saphiro-Wilk w test}

This procedure was developed by Saphiro and Wilk (Gilbert, 1987) and was intended as a test of whether a data set had been drawn from a population with normal distribution and can be explained as follows:

Suppose that a set of values $x_{1}, x_{2}, \ldots, x_{n}$ have been drawn randomly from a population. The following hypothesis will be tested :

$\mathbf{H}_{\mathbf{0}}$ : The population has a normal distribution. versus

$\mathbf{H}_{\mathbf{A}}$ : The population does not have a normal distribution.

The procedure for the test is as follows:

1. Compute the denominator $d$ of the $w$ test statistic, using the $\mathrm{n}$ data.

$$
d=\sum_{i=1}^{n}\left(x_{i}-\bar{x}\right)^{2}
$$

2. Order the $n$ data from smallest to largest to obtain the sample order statistics $x_{[1]} \leq x_{[2]} \leq$ $\cdots \leq x_{[n]}$ 
3. Compute $k$, where

$$
k=\frac{n}{2} \quad \text { if } n \text { is even }
$$

$$
k=\frac{n-1}{2} \text { if } n \text { is odd }
$$

4. Find the relevant coefficients $a_{1}, a_{2}, \ldots, a_{k}$ in Table C.1.

5. Compute :

$$
W=\frac{1}{d}\left[\sum_{i=1}^{k} a_{i}\left(x_{[n-i+1]}-x_{i}\right]^{2}\right.
$$

6. Reject $\mathrm{H}_{0}$ at the $\alpha$ significance level if $W$ is less than the relevant quantile given in Table C.2. 
Table C.1 Coefficients a[i] for the Saphiro-Wilk W Test for Normailty

\begin{tabular}{|c|c|c|c|c|c|c|c|c|c|}
\hline$i^{n}$ & 2 & 3 & 4 & 5 & 6 & 7 & 8 & 9 & 10 \\
\hline $\begin{array}{l}1 \\
2 \\
3 \\
4 \\
5\end{array}$ & 0.7071 & $\begin{array}{r}0.7071 \\
0\end{array}$ & $\begin{array}{l}0.6872 \\
0.1677\end{array}$ & $\begin{array}{r}0.6646 \\
0.2413 \\
0\end{array}$ & $\begin{array}{l}0.6431 \\
0.2806 \\
0.0875\end{array}$ & $\begin{array}{r}0.6233 \\
0.3031 \\
0.1401 \\
0\end{array}$ & $\begin{array}{l}0.6052 \\
0.3164 \\
0.1743 \\
0.0561\end{array}$ & $\begin{array}{r}0.5888 \\
0.3244 \\
0.1976 \\
0.0947 \\
0\end{array}$ & $\begin{array}{l}0.5739 \\
0.3291 \\
0.2141 \\
0.1224 \\
0.0399\end{array}$ \\
\hline
\end{tabular}

\begin{tabular}{|c|c|c|c|c|c|c|c|c|c|c|}
\hline$i^{n}$ & 11 & 12 & 13 & 14 & 15 & 16 & 17 & 18 & 19 & 20 \\
\hline 1 & 0.5601 & 0.5475 & 0.5359 & 0.5251 & 0.515 & 0.5056 & 0.4968 & 0.4886 & 0.4808 & 0.4734 \\
\hline 2 & 0.3315 & 0.3325 & 0.3325 & 0.3318 & 0.3306 & 0.329 & 0.3273 & 0.3253 & 0.3232 & 0.3211 \\
\hline 3 & 0.226 & 0.2347 & 0.2412 & 0.246 & 0.2495 & 0.2521 & 0.254 & 0.2553 & 0.2561 & 0.2565 \\
\hline 4 & 0.1429 & 0.1586 & 0.1707 & 0.1802 & 0.1878 & 0.1939 & 0.1988 & 0.2027 & 0.2059 & 0.2085 \\
\hline 5 & 0.0695 & 0.0922 & 0.1099 & 0.124 & 0.1353 & 0.1447 & 0.1524 & 0.1587 & 0.1641 & 0.1686 \\
\hline 6 & 0 & 0.0303 & 0.0539 & 0.0727 & 0.088 & 0.1005 & 0.1109 & 0.1197 & 0.1271 & 0.1334 \\
\hline 7 & & & 0 & 0.024 & 0.0433 & 0.0593 & 0.0725 & 0.0837 & 0.0932 & 0.1013 \\
\hline 8 & & & & & 0 & 0.0196 & 0.0359 & 0.0496 & 0.0612 & 0.0711 \\
\hline 9 & & & & & & & 0 & 0.0163 & 0.0303 & 0.0422 \\
\hline 10 & & & & & & & & & 0 & 0.014 \\
\hline
\end{tabular}

Source : Statistical Methods for Environmental Pollution Monitoring, by Richard O.Gilbert. 1987 
Table C.2 Quantiles of the Saphiro-Wilk W Test for Normality (Values of W such that 100p\% of the Distribution of $W$ is less than $W p$ )

\begin{tabular}{|r|r|r|r|r|r|}
\hline$n$ & $W[0.01]$ & $W[0.02]$ & $W[0.05]$ & $W[0.10]$ & $W[0.50]$ \\
\hline 3 & 0.753 & 0.756 & 0.767 & 0.789 & 0.959 \\
4 & 0.687 & 0.707 & 0.748 & 0.792 & 0.935 \\
5 & 0.686 & 0.715 & 0.762 & 0.806 & 0.927 \\
6 & 0.713 & 0.743 & 0.788 & 0.826 & 0.927 \\
7 & 0.730 & 0.760 & 0.803 & 0.838 & 0.928 \\
8 & 0.749 & 0.778 & 0.818 & 0.851 & 0.932 \\
9 & 0.764 & 0.791 & 0.829 & 0.859 & 0.935 \\
10 & 0.781 & 0.806 & 0.842 & 0.869 & 0.938 \\
11 & 0.792 & 0.817 & 0.850 & 0.876 & 0.940 \\
12 & 0.805 & 0.828 & 0.859 & 0.883 & 0.943 \\
13 & 0.814 & 0.837 & 0.866 & 0.889 & 0.945 \\
14 & 0.825 & 0.846 & 0.874 & 0.895 & 0.947 \\
15 & 0.835 & 0.855 & 0.881 & 0.901 & 0.950 \\
16 & 0.844 & 0.863 & 0.887 & 0.906 & 0.952 \\
17 & 0.851 & 0.869 & 0.892 & 0.910 & 0.956 \\
18 & 0.858 & 0.874 & 0.897 & 0.914 & 0.957 \\
19 & 0.863 & 0.879 & 0.901 & 0.917 & 0.959 \\
20 & 0.868 & 0.884 & 0.905 & 0.920 & 0.960 \\
& & & & \\
\hline
\end{tabular}

Source : Statistical Methods for Environmental Pollution Monitoring, by Richard O.Gilbert, 1987 
Table C.3.1 Normality Test for Data from the Fitzroy River Basin (SAPHIRO-WILK W TEST)

Table C.3.1(a) Station 130105

1. Rank of the Data from the Smallest Value

\begin{tabular}{|c|c|c|c|c|c|c|c|c|c|c|}
\hline DATA * & $\begin{array}{c}\text { CONDUCTIVITY } \\
@ 25 \mathrm{C} \\
\text { (mS } / \mathrm{m}) \\
\end{array}$ & PH & $\begin{array}{c}\text { DISSOLVED } \\
\text { IONS } \\
\text { (mgn) } \\
\end{array}$ & $\begin{array}{c}\text { DISSOLVED } \\
\text { SOLIDS } \\
\text { (mg/l) } \\
\end{array}$ & $\begin{array}{l}\text { HARDNEBS } \\
\text { (mg!) as } C<03\end{array}$ & $\begin{array}{l}\text { ALKALINITY } \\
\text { Impitides CoCOS }\end{array}$ & $\begin{array}{l}\text { NATRIUM } \\
(\mathrm{mg} / \mathrm{li}) \\
\end{array}$ & $\begin{array}{l}\text { KALIUM } \\
\text { (mgil) }\end{array}$ & $\begin{array}{l}\text { CALCIUM } \\
(\text { mg } /) \\
\end{array}$ & $\begin{array}{l}\text { MAGNESHUM } \\
\text { (mgN) } \\
\end{array}$ \\
\hline$x 1$ & 215.00 & 7.48 & 158.40 & 130.00 & 61.50 & 64.00 & 16.26 & 2.30 & 13.13 & 6.40 \\
\hline$\times 2$ & 226.25 & 7.53 & 159.58 & 133.67 & 61.75 & 86.00 & 18.18 & 2.33 & 13.42 & 6.75 \\
\hline$x 3$ & 235.00 & 7.65 & 160.95 & 135.75 & 63.67 & 68.46 & 19.25 & 2.60 & 14.00 & 6.80 \\
\hline$x 4$ & 235.00 & 7.75 & 161.03 & 140.00 & 64.00 & 71.75 & 20.00 & 3.25 & 14.50 & 7.05 \\
\hline$x 5$ & 255.00 & 7.98 & 187.93 & 146.67 & 80.67 & 88.67 & 20.00 & 3.40 & 18.00 & 8.67 \\
\hline$x 6$ & 360.00 & 8.00 & 248.55 & 204.00 & 102.25 & 105.50 & 29.75 & 3.80 & 22.25 & 10.58 \\
\hline$x 7$ & 367.50 & 8.10 & 258.15 & 207.50 & 110.50 & 106.00 & 32.50 & 3.80 & 23.50 & 12.50 \\
\hline$x 8$ & 516.70 & 8.20 & 336.20 & 274.00 & 150.30 & 128.00 & 45.30 & 3.90 & 32.70 & 16.70 \\
\hline$x$ & 301.31 & 7.84 & 208.85 & 171.45 & 86.83 & 87.30 & 25.15 & 3.17 & 18.94 & 9.43 \\
\hline
\end{tabular}

2. Computation of the Denominator [d]

$$
d=\operatorname{sum}(x i-x)^{\wedge} 2
$$

\begin{tabular}{|c|c|c|c|c|c|c|c|c|c|c|}
\hline & \multicolumn{10}{|c|}{$(x i-x)^{\wedge} 2$} \\
\hline & 7448.77 & 0.13 & 2544.99 & 1717.93 & 641.57 & $\$ 42.75$ & 79.11 & 0.76 & 33.77 & 8.18 \\
\hline & 5633.44 & 0.09 & 2427.82 & 1427.42 & 628.96 & 453.57 & 48.71 & 0.72 & 30.48 & 7.19 \\
\hline & 4396.52 & 0.03 & 2294.21 & 1274.34 & 536.50 & 354.84 & 34.86 & 0.33 & 24.37 & 6.90 \\
\hline & 4398.52 & 0.01 & 2287.03 & 988.87 & 521.17 & 241.71 & 26.57 & 0.01 & 19.68 & 5.67 \\
\hline & 2144.27 & 0.02 & 437.42 & 614.11 & 37.98 & 1.88 & 26.57 & 0.05 & 0.88 & 0.58 \\
\hline & 3444.96 & 0.03 & 1576.26 & 1059.64 & 237.80 & 931.35 & 21.12 & 0.40 & 10.93 & 1.31 \\
\hline & 4381.61 & 0.07 & 2430.70 & 1299.75 & 560.31 & 349.80 & 53.96 & 0.40 & 20.83 & 9.42 \\
\hline & 46394.47 & 0.13 & 16218.55 & 10516.93 & 4028.55 & 1656.73 & 405.85 & 0.53 & 189.44 & 52.84 \\
\hline$d=$ & 78240.55 & 0.51 & 30216.98 & 18899.10 & 7192.84 & 3932.62 & 696.74 & 3.18 & 330.43 & 03.10 \\
\hline
\end{tabular}

\section{Computation of the $W$ values}

$w=[\operatorname{sum} a i\{x(n-i+1)-x(i)\}]^{\wedge} 2 / d$

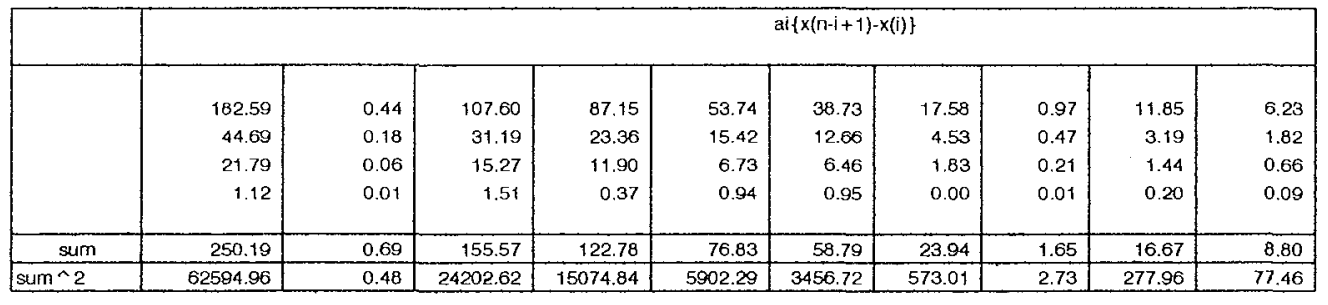

\begin{tabular}{|c|c|c|c|c|c|c|c|c|c|c|}
\hline YEAA & $\begin{array}{c}\text { CONDUCTIVITY } \\
@ 25 \mathrm{C} \\
(\mathrm{ms} / \mathrm{m})\end{array}$ & PH & $\begin{array}{c}\text { DISSOLVED } \\
\text { IONS } \\
\text { (mgg/) } \\
\end{array}$ & $\begin{array}{c}\text { OISSOLVED } \\
\text { SOLIDS } \\
\text { (migh) } \\
\end{array}$ & 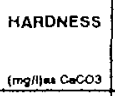 & 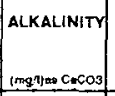 & $\begin{array}{l}\text { NATRIUM } \\
\text { (mg/i) } \\
\end{array}$ & $\begin{array}{l}\text { KaLIUNA } \\
\text { (mg/) }\end{array}$ & $\begin{array}{l}\text { CALCIUM } \\
\text { (mgdi) } \\
\end{array}$ & $\begin{array}{c}\text { MAGNESIUM } \\
(\mathrm{mg} A) \\
\end{array}$ \\
\hline $\begin{array}{c}W= \\
(\operatorname{sum} \sim 2 / d)\end{array}$ & 0.800 & 0.934 & 0.801 & 0.798 & 0.821 & $0.87 \theta$ & 0.822 & 0.859 & 0.841 & 0.832 \\
\hline$w\{0.05\}$ & 0.803 & 0.803 & 0.803 & 0.803 & 0.803 & 0.803 & 0.803 & 0.803 & 0.803 & 0.803 \\
\hline$W[0.02]$ & 0.76 & 0.76 & 0.76 & 0.76 & 0.76 & 0.76 & 0.76 & 0.76 & 0.76 & 0.76 \\
\hline$w[0.01]$ & 0.73 & 0.73 & 0.73 & 0.73 & 0.73 & 0.73 & 0.73 & 0.73 & 0.73 & 0.73 \\
\hline
\end{tabular}

\footnotetext{
Note : reject the normality at i\% significance level if $W<W$ [i]
} 
Table C.3.1(b) Station 130322

1. Rank of the Data from the Smallest Value

\begin{tabular}{|c|c|c|c|c|c|c|c|c|c|c|}
\hline DATA & $\begin{array}{c}\text { CONDUCTIVITY } \\
(\mathrm{O} 25 \mathrm{C} \\
(\mathrm{mS} / \mathrm{m}) \\
\end{array}$ & PH & $\begin{array}{c}\text { DISSOLVED } \\
\text { IONS } \\
\text { (mg/i) } \\
\end{array}$ & $\begin{array}{l}\text { DISSOLVED } \\
\text { SOLIDS } \\
\text { (mg/) } \\
\end{array}$ & $\begin{array}{l}\text { HAADNNESS } \\
\text { ims; } 4 \text { ass } \mathrm{CoCO} 3 \\
\end{array}$ & 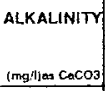 & $\begin{array}{l}\text { NATRIUM } \\
\text { (trg/ll) } \\
\end{array}$ & $\begin{array}{l}\text { KALUUM } \\
\text { (mg/i) }\end{array}$ & $\begin{array}{l}\text { CALCIUM } \\
\text { (ring/i) } \\
\end{array}$ & $\begin{array}{l}\text { MAGNESIUM } \\
\text { (mgg/) } \\
\end{array}$ \\
\hline$x y$ & 145.00 & 7.10 & 106.40 & 87.00 & 37.00 & 46.00 & 12.00 & 5.00 & 9.20 & 3.40 \\
\hline$x 2$ & 145.00 & 7.40 & 111.60 & 92.00 & 49.00 & 54.00 & 13.40 & 5.05 & 12.00 & 4.20 \\
\hline$\times 3$ & 190.00 & 7.50 & 142.20 & 115.00 & 50.70 & 62.30 & 17.70 & 5.10 & 12.50 & 4.50 \\
\hline$\times 4$ & 190.00 & 7.60 & 146.30 & 122.00 & 51.00 & 63.50 & 18.00 & 5.50 & 12.75 & 4.65 \\
\hline$\times 5$ & 217.50 & 7.70 & 149.00 & 125.00 & 51.00 & 66.00 & 21.15 & 5.77 & 13.30 & 4.70 \\
\hline$x 6$ & 240.00 & 7.75 & 173.30 & 133.50 & 61.00 & 77.00 & 21.25 & 5.80 & 15.00 & 5.30 \\
\hline$x 7$ & 245.00 & 7.77 & 177.95 & 150.00 & 61.50 & 79.00 & 21.50 & 6.20 & 15.67 & 5.70 \\
\hline$\times 8$ & 257.50 & 7.95 & 179.07 & 156.67 & 62.67 & 85.00 & 24.33 & 6.35 & 16.00 & 5.73 \\
\hline$x$ & 203.75 & 7.60 & 148.23 & 122.65 & 52.98 & 66.60 & 18.67 & 5.60 & 13.30 & 4.77 \\
\hline
\end{tabular}

2. Computation of the Denominator [d]

$d=\operatorname{sum}(x i-x)^{\sim 2}$

\begin{tabular}{|c|c|c|c|c|c|c|c|c|c|c|}
\hline & & \multicolumn{9}{|c|}{$(x i-x)^{\wedge} 2$} \\
\hline \multirow{8}{*}{. } & 3451.56 & 0.25 & $\{749.50$ & 1270.63 & 255.47 & 424.36 & 44.44 & 0.36 & 16.83 & 1.88 \\
\hline & 3451.56 & 0.04 & 1341.54 & 939.17 & 15.87 & 158.76 & 27.74 & 0.30 & 1.70 & 0.33 \\
\hline & 189.06 & 0.01 & 36.33 & 58.46 & 5.21 & 18.49 & 0.93 & 0.25 & 0.64 & 0.07 \\
\hline & 189.06 & 0.00 & 3.71 & 0.42 & 3.93 & 9.61 & 0.44 & 0.01 & 0.30 & 0.02 \\
\hline & 189.06 & 0.01 & 0.60 & 5.54 & 3.93 & 0.36 & 6.17 & 0.03 & 0.00 & 0.01 \\
\hline & 1314.06 & 0.02 & 628.65 & 117.81 & 64.27 & 108.16 & 6.67 & 0.04 & 2.88 & 0.28 \\
\hline & 1701.56 & 0.03 & 883.45 & 748.25 & 72.53 & 153.76 & 8.03 & 0.37 & 5.50 & 0.56 \\
\hline & 2889.06 & 0.13 . & 951.08 & 1157.42 & 93.77 & 338.56 & 32.11 & 0.57 & 7.28 & $0.9 ?$ \\
\hline$d=$ & 13375.00 & 0.48 & 5594.87 & 4297.69 & 514.98 & 1212.06 & 126.54 & 1.91 & 35.22 & 4.37 \\
\hline
\end{tabular}

\section{Computation of the $W$ values}

$w=[\operatorname{sum} \text { ai }\{x(n-i+t)-x(i)\}]^{\wedge} 2 / d$

\begin{tabular}{|c|c|c|c|c|c|c|c|c|c|c|}
\hline & & & & & & $i\{x(n-i+1)$ & & & & \\
\hline & 68.09 & 0.51 & 43.98 & 42.16 & 15.53 & 23.60 & 7.46 & 0.82 & 4.12 & 1.41 \\
\hline & 31.64 & 0.12 & 20.99 & 18.35 & 3.90 & 7.91 & 2.56 & 0.36 & 1.16 & 0.47 \\
\hline & 8.72 & 0.04 & 5.42 & 3.22 & 1.80 & 2.56 & 0.62 & 0.12 & 0.44 & 0.14 \\
\hline & 1.54 & 0.01 & 0.15 & 0.17 & 0.00 & 0.14 & 0.18 & 0.01 & 0.03 & 0.00 \\
\hline sum & 109.98 & 0.68 & 70.54 & 63.91 & 21.28 & 34.22 & 10.82 & 1.32 & 5.74 & 2.03 \\
\hline $\operatorname{sum}^{\wedge} 2$ & 12096.21 & 0.46 & 4976.34 & 4084.02 & 453.00 & 1770.68 & 117.13 & 1.74 & 32.97 & 4.12 \\
\hline
\end{tabular}

\begin{tabular}{|c|c|c|c|c|c|c|c|c|c|c|}
\hline YEAR & $\begin{array}{c}\text { CONDUCTIVITY } \\
\text { @25c } \\
(\mathrm{m} S \mathrm{~m} / \mathrm{m}) \\
\end{array}$ & $\mathrm{PH}$ & $\begin{array}{c}\text { DISSOL.VED } \\
\text { IONS } \\
\text { (mgh) }\end{array}$ & $\begin{array}{c}\text { DISSOIVED } \\
\text { SOLIDS } \\
\text { (mgh) }\end{array}$ & $\begin{array}{l}\text { HAFDNESS } \\
\text { (mg//)as Cocos }\end{array}$ & $\begin{array}{l}\text { ALKALINITY } \\
\text { (mgin)es Cocos }\end{array}$ & $\begin{array}{l}\text { NATRIUM } \\
\text { (mg/l) }\end{array}$ & $\begin{array}{l}\text { KaLIUM } \\
\text { (mgf) }\end{array}$ & $\begin{array}{l}\text { CALCIUM } \\
\text { (migll) }\end{array}$ & $\begin{array}{c}\text { MAQNESIUM } \\
\text { (mg/l) }\end{array}$ \\
\hline $\begin{array}{c}W= \\
\left(\operatorname{sum}^{\wedge} 2 / d\right)\end{array}$ & 0.904 & 0.957 & 0.889 & 0.950 & 0.880 & 0.966 & 0.926 & 0.908 & 0.936 & 0.943 \\
\hline$W[0.05]$ & 0.803 & 0.803 & 0.803 & 0.803 & 0.803 & 0.803 & 0.803 & 0.803 & 0.803 & 0.803 \\
\hline$w[0.02]$ & 0.76 & 0.76 & 0.76 & 0.76 & 0.76 & 0.76 & 0.76 & 0.76 & 0.76 & 0.76 \\
\hline I $[0.01]$ & 0.73 & 0.73 & 0.73 & 0.73 & 0.73 & 0.73 & 0.73 & 0.73 & 0.73 & 0.73 \\
\hline
\end{tabular}

Note: $\quad$ reject the normality at i\% significance level it $W<W[i]$ 
Table C.3.2 Normality Test for Data from the Nogoa River Basin (SAPHIRO-WILK W TEST)

Table C.3.2(a) Station 130202

1. Rank of the Data from the Smallest Value

\begin{tabular}{|c|c|c|c|c|c|c|c|c|c|c|}
\hline DATA & $\begin{array}{c}\text { CONOUCTVITY } \\
\text { (9 25C } \\
(\mathrm{mS} / \mathrm{m}) \\
\end{array}$ & $\mathrm{PH}$ & $\begin{array}{c}\text { DISSOLVED } \\
\text { IONS } \\
\text { (mg/) } \\
\end{array}$ & $\begin{array}{c}\text { DISSOLVED } \\
\text { sOLIDS } \\
\text { (mg }) \\
\end{array}$ & 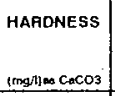 & $\begin{array}{l}\text { ALKALINITY } \\
\text { (mga) }\end{array}$ & $\begin{array}{l}\text { NATFILM } \\
\text { (mon) }\end{array}$ & $\begin{array}{l}\text { KALIUM } \\
\text { (mgn) }\end{array}$ & $\begin{array}{l}\text { CALCIUM } \\
\text { (mgg/n) } \\
\end{array}$ & $\begin{array}{c}\text { MAGNESIUM } \\
\text { (IIMGI) }\end{array}$ \\
\hline$x 1$ & 150.00 & 7.20 & 111.50 & 83.00 & 47.00 & 58.00 & 9.75 & 2.90 & 13.00 & 3.60 \\
\hline $\mathrm{x} 2$ & 163.50 & 7.35 & 135.05 & 95.75 & 58.50 & 67.00 & 10.00 & 4.13 & 15.78 & 4.65 \\
\hline$x^{3}$ & 220.00 & 7.45 & 150.05 & 105.50 & 75,50 & 72.00 & 17.00 & 5.00 & 19.00 & 5.65 \\
\hline$x 4$ & 263.33 & 7.60 & 187.00 & 148.67 & 80.00 & 79.00 & 20.33 & 5.05 & 21.00 & 6.40 \\
\hline$\times 5$ & 267.50 & 7.68 & 193.50 & 154.50 & 82.50 & 79.33 & 21.50 & 5.30 & 21.00 & 6.73 \\
\hline$x 6$ & 275.00 & 7.80 & 197.95 & 155.00 & 83.00 & 91.40 & 21.80 & 5.65 & 22.50 & 7.66 \\
\hline$x 7$ & 286.00 & 7.85 & 209.96 & 166.40 & 88.80 & 93.00 & 22.00 & 6.18 & 22.88 & 7.95 \\
\hline$\times 8$ & 340.50 & 8.00 & 234.15 & 188.50 & 94.00 & 94.00 & 28.50 & & 24.50 & 8.50 \\
\hline$x$ & 245.73 & 7.62 & 177.40 & 137.16 & 76.16 & 79.22 & 18.86 & 4.89 & 19.96 & 6.39 \\
\hline
\end{tabular}

2. Computation of the Denominator $[d]$

$d=\operatorname{sum}(x i-x)^{\wedge} 2$

\begin{tabular}{|c|c|c|c|c|c|c|c|c|c|c|}
\hline & \multicolumn{10}{|c|}{$(x i-x)^{\wedge} 2$} \\
\hline & 9164.07 & 0.17 & 4342.15 & 2933.80 & 850.45 & 450.15 & 83.00 & 3.95 & 48.40 & 7.80 \\
\hline & 6761.64 & 0.07 & 1783,10 & 1715.17 & 311.96 & 149.25 & 78.51 & 0.58 & 17.49 & 3.04 \\
\hline & 661.99 & 0.03 & 747.75 & 1002.65 & 0.44 & 52.08 & 3.46 & 0.01 & 0.92 & 0.55 \\
\hline & 309.91 & 0.00 & 92.26 & 132.30 & 14.73 & 0.05 & 2.17 & 0.03 & 1.09 & 0.00 \\
\hline & 473.97 & 0.00 & 259.37 & 300.52 & 40.16 & 0.01 & 6.97 & 0.17 & 1.09 & 0.12 \\
\hline & 856.78 & 0.03 & 422.51 & 318.10 & 46.75 & 148.43 & 8.64 & 0.58 & 6.47 & 1.61 \\
\hline & 1621.74 & 0.05 & 1060.48 & 854.71 & 159.71 & 189.98 & 9.86 & 1.67 & 8.54 & 2.42 \\
\hline & 8981.51 & 0.15 & 3221.13 & 2635.33 & 318.18 & 218.55 & 92.92 & & 20.64 & 4.44 \\
\hline$d=$ & 28831.61 & 0.51 & 11938.74 & 9892.57 & 1742.38 & 1208.50 & 285.52 & 6.99 & 104.63 & 19.98 \\
\hline
\end{tabular}

3. Computation of the $W$ values

$w=[\operatorname{sum}$ ai $\{x(n-i+1)-x(i)\}] \wedge 2 / d$

\begin{tabular}{|c|c|c|c|c|c|c|c|c|c|c|}
\hline & & & & & & $i f(n)-i+1$ & & & & \\
\hline & $\$ 15.29$ & 0.48 & 74.23 & 63.85 & 28.44 & 21.79 & 11.35 & 2.04 & 6.96 & 2.97 \\
\hline & 38,76 & 0.16 & 23.70 & 22.35 & 9.59 & 8.23 & 3.80 & 0.46 & 2.25 & 1.04 \\
\hline & 9.59 & 0.06 & 8.35 & 8.63 & 1.31 & 3.38 & 0.84 & 0.04 & 0.61 & 0.35 \\
\hline & 0.23 & 0.00 & 0.36 & 0.33 & 0.14 & 0.02 & 0.07 & 0.00 & 0.00 & 0.02 \\
\hline sum & 163.87 & 0.71 & 106.64 & 95.16 & 39.48 & 33.41 & 16.05 & 2.55 & 9.82 & 4.38 \\
\hline $\operatorname{sum}^{\wedge} 2$ & 26853.33 & 0.50 & 11372.71 & 9054.92 & 1558.58 & 1116.48 & 257.49 & 6.50 & 96.39 & 19.17 \\
\hline
\end{tabular}

\begin{tabular}{|c|c|c|c|c|c|c|c|c|c|c|}
\hline YEAR & $\begin{array}{c}\text { CONDUCTIVITY } \\
@ 25 \mathrm{C} \\
(\mathrm{mS} / \mathrm{m}) \\
\end{array}$ & $\mathrm{PH}$ & $\begin{array}{c}\text { DISSOLVED } \\
\text { IONS } \\
\text { (mg/l) } \\
\end{array}$ & $\begin{array}{c}\text { DISSOLVED } \\
\text { SOLIDS } \\
\text { (mg/l) }\end{array}$ & 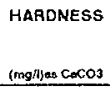 & $\begin{array}{c}\text { ALKALINITY } \\
\text { (my!) } \mathrm{CaCOO}_{3}\end{array}$ & $\begin{array}{l}\text { NATRIUM } \\
\text { (mggh) } \\
\end{array}$ & $\begin{array}{l}\text { KALIUM } \\
\text { (mg/h) }\end{array}$ & $\begin{array}{l}\text { CALCIUM } \\
\text { (mgli) }\end{array}$ & $\begin{array}{c}\text { MAGNESIUM } \\
\text { (mg/l) }\end{array}$ \\
\hline $\begin{array}{c}W= \\
\left(\operatorname{sum}^{\wedge} 2 / d\right)\end{array}$ & 0.931 & 0.879 & 0.953 & 0.915 & 0.895 & 0.924 & 0.902 & 0.929 & 0.921 & 0.960 \\
\hline$W[0.05]$ & 0.842 & 0.842 & 0.842 & 0.818 & 0.842 & 0.842 & 0.842 & 0.818 & 0.842 & 0.842 \\
\hline$W[0.02]$ & 0.806 & 0.806 & 0.806 & 0.778 & 0.806 & 0.806 & 0.806 & 0.778 & 0.806 & 0.806 \\
\hline$W[0.01]$ & 0.781 & 0.781 & 0.781 & 0.749 & 0.781 & 0.781 & 0.781 & 0.749 & 0.781 & 0.781 \\
\hline
\end{tabular}

Note:

reject the normality at i\% significance level if $W<W[i]$ 
Table C.3.2(b) Station 130212

1. Rank of the Data from the Smallest Value

\begin{tabular}{|c|c|c|c|c|c|c|c|c|c|c|}
\hline DATA \# & $\begin{array}{c}\text { CONDUCTVITY } \\
\text { @ } 25 \mathrm{C} \\
\text { (ms/m) } \\
\end{array}$ & $\mathrm{PH}$ & $\begin{array}{c}\text { OISSOLVED } \\
\text { IONS } \\
\text { (mg/l) } \\
\end{array}$ & $\begin{array}{c}\text { DISSOLVED } \\
\text { SOLIDS } \\
\text { (rRg/l) } \\
\end{array}$ & $\begin{array}{l}\text { HARDNESS } \\
\text { Imgil)es Coco3 }\end{array}$ & $\begin{array}{c}\text { ALKALINITY } \\
\text { Imanjeas caco3 }\end{array}$ & $\begin{array}{l}\text { NATRIUM } \\
\text { (mig/l) } \\
\end{array}$ & $\begin{array}{l}\text { KALIUM } \\
\text { (mKgn) }\end{array}$ & $\begin{array}{l}\text { CALCIUM } \\
\text { (mgli) }\end{array}$ & $\begin{array}{c}\text { MAGNESIUM } \\
\text { (mgIl) }\end{array}$ \\
\hline$\times 1$ & 138.33 & 7.17 & 106.20 & 85.67 & 44.00 & 53.00 & 7.80 & 3.50 & 10.47 & 3.30 \\
\hline$\times 2$ & 139.00 & 7.27 & 108.17 & 87.00 & 45.00 & 58.67 & 10.67 & 3.60 & 12.00 & 3.47 \\
\hline$x 3$ & 143.33 & 7.40 & 114.30 & 89.00 & 45.33 & 59.00 & 11.00 & 3.87 & 12.50 & 3.57 \\
\hline$x 4$ & 144.00 & 7.50 & 127.70 & 91.00 & 51.00 & 64.67 & 14.20 & 4.43 & 14.50 & 4.60 \\
\hline$\times 5$ & 290.00 & 7.55 & 247.10 & 159.00 & 107.25 & 119.50 & 17.00 & 4.53 & 30.75 & 6.00 \\
\hline$x 6$ & 352.50 & 7.60 & 271.38 & 208.75 & 122.00 & 142.00 & 34.25 & 4.73 & 31.75 & 7.35 \\
\hline$x 7$ & 472.50 & 7.80 & 347.48 & 255.50 & 124.75 & 142.25 & 38.50 & 5.10 & 39.00 & 9.50 \\
\hline$x 8$ & 491.25 & 7.83 & 350.50 & 268.50 & 153.00 & 176.00 & 52.50 & & 45.50 & 11.03 \\
\hline$x$ & 271.36 & 7.51 & 209.10 & 155.55 & 86.54 & 101.89 & 23.24 & 4.25 & 24.56 & 6.10 \\
\hline
\end{tabular}

2. Computation of the Denominator [d]

$d=\operatorname{sum}(x i-x) \wedge 2$

\begin{tabular}{|c|c|c|c|c|c|c|c|c|c|c|}
\hline & & & & & & $(x \mid-x)^{\wedge} 2$ & & & & \\
\hline & 17697.31 & 0.12 & 10588.84 & 4883.97 & 1809.79 & 2389.78 & 238.38 & 0.56 & 198,58 & 7.85 \\
\hline & 17520.38 & 0.06 & 10187.96 & 4699.39 & 1725.71 & 1867.86 & 158.08 & 0.42 & 157.71 & 6.94 \\
\hline & 16392.00 & 0.01 & 8087.44 & 4429.18 & 1698.13 & 1839.16 & 149.81 & 0.15 & 145.40 & 6.42 \\
\hline & 16221.74 & 0.00 & 6626.30 & 4166.97 & 1263.21 & 1385.24 & 81.71 & 0.03 & 101.17 & 2.25 \\
\hline & 347.28 & 0.00 & 1443.84 & 11.89 & 428.84 & 310.27 & 38.93 & 0.08 & 38.34 & 0.01 \\
\hline & 6582.96 & 0.01 & 3877.92 & 2830.02 & 1257.29 & 1609.18 & 121.23 & 0.23 & 51.72 & 1.56 \\
\hline & 40455.46 & 0.08 & 19147.06 & 9989.59 & 1459.88 & 1629.30 & 232.88 & 0.72 & 208.56 & 11.55 \\
\hline & 48349.60 & 0.10 & 19993.37 & 12757.23 & 4416.71 & 5492.97 & 856.17 & & 438.55 & 24.25 \\
\hline$d=$ & 1635666.72 & 0.38 & 80852.72 & 43768.24 & 14059.56 & 16523.76 & 1877.19 & 2.18 & 1340.03 & 60.83 \\
\hline
\end{tabular}

3. Computation of the $W$ values

$w=[\text { sum } \operatorname{ai}\{x(n-i+1)-x(i)\}]^{\wedge} 2 / d$

\begin{tabular}{|c|c|c|c|c|c|c|c|c|c|c|}
\hline & & \multicolumn{9}{|c|}{$a i\{x(n-i+1)-x(i)\}$} \\
\hline & 213.59 & 0.40 & 147.85 & 110.65 & 65.97 & 74.44 & 27.05 & 1.00 & 24.20 & 4.68 \\
\hline & 105.52 & 0.17 & 75.72 & 53.37 & 25.23 & 26.45 & 8.81 & 0.34 & 8.54 & 1.91 \\
\hline & 36.46 & 0.03 & 27.38 & 20.87 & 13.36 & 14.47 & 4.05 & 0.09 & 3.36 & 0.66 \\
\hline & 8.19 & 0.00 & 6.70 & 3.81 & 3.16 & 3.08 & 0.16 & 0.00 & 0.91 & 0.08 \\
\hline sum & 363.75 & 0.60 & 257.64 & 188.65 & 107.72 & 118.43 & 40.07 & 1.43 & 34.01 & 7.32 \\
\hline sumn 2 & 132316.18 & 0.37 & 66380.45 & 35589.34 & 1160324 & 14025.29 & 1005.48 & 2.05 & 1156.81 & 53.61 \\
\hline
\end{tabular}

\begin{tabular}{|c|c|c|c|c|c|c|c|c|c|c|}
\hline DATA \# & $\begin{array}{c}\text { CONOUCTIVITY } \\
\text { @ 25C } \\
\text { (mS/m) }\end{array}$ & $\mathrm{PH}$ & $\begin{array}{c}\text { OISSOLVED } \\
\text { IONS } \\
\text { (mg/l) } \\
\end{array}$ & $\begin{array}{c}\text { OISSOLVEO } \\
\text { SOLIDS } \\
\text { (mgR) } \\
\end{array}$ & $\begin{array}{l}\text { HARONESS } \\
\text { (mgan)us cocosos }\end{array}$ & $\begin{array}{l}\text { ALKALINITH } \\
\text { (mgli)as Caco3 } \\
\end{array}$ & $\begin{array}{l}\text { NATRIUM } \\
\text { (mg/l) } \\
\end{array}$ & $\begin{array}{l}\text { KaLIUM } \\
\text { (mglil) } \\
\end{array}$ & $\begin{array}{l}\text { CALCIUM } \\
\ldots(\mathrm{mg} / \mathrm{l}) \\
\end{array}$ & $\begin{array}{c}\text { MAGNESIUM } \\
\text { (mgfl) } \\
\end{array}$ \\
\hline $\begin{array}{c}W= \\
\left(\operatorname{sum}^{\wedge} 2 / d\right)\end{array}$ & 0.809 & 0.957 & 0.821 & 0.813 & 0.825 & 0.849 & 0.855 & 0.936 & 0.863 & 0.881 \\
\hline$w[0.05]$ & 0.842 & 0.842 & 0.842 & 0.818 & 0.842 & 0.842 & 0.842 & 0.818 & 0.842 & 0.842 \\
\hline$W[0.02]$ & 0.806 & 0.806 & 0.806 & 0.778 & 0.806 & 0.806 & 0.806 & 0.778 & 0.806 & 0.806 \\
\hline$w[0,01]$ & 0.781 & 0.781 & 0.781 & 0.749 & 0.781 & 0.781 & 0.781 & 0.749 & 0.781 & 0.781 \\
\hline
\end{tabular}


Table C.3.3 Normality Test for Data from the Logan River Basin (SAPHIRO-WILK W TEST)

Table C.3.3(a) Station 145010

1. Rank of the Data from the Smallest Value

\begin{tabular}{|c|c|c|c|c|c|c|c|c|c|c|}
\hline DATA & $\begin{array}{c}\text { CONDUCTIVITY } \\
\text { @ 25C } \\
\text { (ms/m) }\end{array}$ & $\mathrm{PH}$ & $\begin{array}{l}\text { DISSOLVEO } \\
\text { IONS } \\
\text { (mg/) }\end{array}$ & $\begin{array}{l}\text { DISSOL.VED } \\
\text { SOLIDS } \\
(\mathrm{mmg} / \mathrm{l})\end{array}$ & 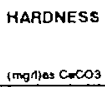 & ALKALINITY & $\begin{array}{l}\text { NATRIUM } \\
\text { (mgA) }\end{array}$ & $\begin{array}{l}\text { KALIUM } \\
\text { (mg/l) }\end{array}$ & $\begin{array}{l}\text { CALCIUM } \\
\text { (mg/) }\end{array}$ & $\begin{array}{c}\text { MAONESIUM } \\
\text { (mg/) }\end{array}$ \\
\hline$x 1$ & 147.50 & 6.75 & 91.80 & 94.00 & 42.00 & 24.50 & 13.50 & 1.25 & 7.90 & 5.50 \\
\hline$\times 2$ & 340.83 & 7.66 & 233.28 & 197.17 & 108.00 & 89.50 & 24.00 & 1.37 & 18.50 & 15.00 \\
\hline$x 3$ & 360.00 & 7.83 & 235.00 & 203.33 & 112.33 & 92.00 & 24.02 & 1.40 & 18.90 & 15.22 \\
\hline$x 4$ & 382.50 & 7.90 & 248.05 & 214.50 & 116.33 & 97.17 & 25.00 & 1.40 & 20.73 & 15.67 \\
\hline$x 5$ & 393.00 & 8.03 & 253.50 & 217.50 & 128.50 & 98.00 & 29.00 & 1.48 & 22.68 & 17.45 \\
\hline$x 6$ & 426.00 & 8.05 & 274.72 & 240.40 & 146.20 & 103.00 & 31.17 & 1.48 & 25.58 & 19.60 \\
\hline$x 7$ & 439.17 & 8.10 & 294.05 & 246.67 & 146.50 & 119.33 & 31.50 & 1.90 & 26.20 & 20.08 \\
\hline$x$ & 355.57 & 7.76 & 232.91 & 201.94 & 114.27 & 89.07 & 25.45 & 1.47 & 20.21 & 15.50 \\
\hline
\end{tabular}

2. Computation of the Denominator [d]

$$
d=\operatorname{sum}(x i-x)^{\wedge} 2
$$

\begin{tabular}{|c|c|c|c|c|c|c|c|c|c|c|}
\hline & & \multicolumn{9}{|c|}{$(x i-x)^{\wedge} 2$} \\
\hline & 43293.72 & 1.02 & 19913.38 & 11650.63 & 5222.47 & 4169.47 & 142.92 & 0.05 & 151.61 & 100.05 \\
\hline & 217.21 & 0.01 & 0.14 & 22.77 & 39.27 & 0.18 & 2.12 & 0.01 & 2.93 & 0.25 \\
\hline & 19.81 & 0.01 & 4.35 & 1.95 & 3.74 & 8.58 & 2.07 & 0.00 & 0.10 & 0.08 \\
\hline & 725.15 & 0.02 & 229.08 & 157.80 & 4.27 & 85.53 & 0.21 & 0.00 & 0.27 & 0.03 \\
\hline & 1400.90 & 0.07 & 423.75 & 242.17 & 202.59 & 79.72 & 12.57 & 0.00 & 6.06 & 3.79 \\
\hline & 4960.18 & 0.08 & 1747,68 & 1479.32 & 1019.74 & 194.01 & 32.63 & 0.00 & 28.84 & 16.79 \\
\hline & 6968.16 & 0.11 & 3737.52 & 2000.65 & 1038.99 & 915.78 & 36.54 & 0.19 & 35.84 & 20.99 \\
\hline$d=$ & 57604.94 & 1.33 & 26055.88 & 15555.28 & 7531.06 & 5433.27 & 229.05 & 0.25 & 225.60 & 141.98 \\
\hline
\end{tabular}

3. Computation of the $W$ values

$w=[\operatorname{sum} \operatorname{ai}\{x(n-i+1)-x(i)\}]^{\wedge} 2 / d$

\begin{tabular}{|r|r|r|r|r|r|r|r|r|r|r|r|}
\hline & \multicolumn{9}{|c|}{ ai $\{\times(n-i+1)-\times(i)\}$} \\
& 181.80 & 0.84 & 126.06 & 95.16 & 65.13 & 59.11 & 11.22 & 0.41 & 11.41 & 9.09 \\
& 25.87 & 0.12 & 12.56 & 13.10 & 11.58 & 4.09 & 2.17 & 0.04 & 2.15 & 1.39 \\
& 4.62 & 0.03 & 2.59 & 1.98 & 2.26 & 0.84 & 0.70 & 0.01 & 0.39 & 0.31 \\
& 0.00 & 0.00 & 0.00 & 0.00 & 0.00 & 0.00 & 0.00 & 0.00 & 0.00 & 0.00 \\
& & & & & & & & & & \\
\hline sum & 212.23 & 0.99 & 141.21 & 110.25 & 78.98 & 64.04 & 14.09 & 0.45 & 13.94 & 10.80 \\
\hline $\operatorname{sum}^{\wedge} 2$ & 45042.91 & 0.98 & 19941.32 & 12154.16 & 6237.56 & 4101.39 & 198.52 & 0.20 & 194.38 & 116.57 \\
\hline
\end{tabular}

\begin{tabular}{|c|c|c|c|c|c|c|c|c|c|c|}
\hline YEAR & $\begin{array}{c}\text { CONDUCTIVTY } \\
@ 25 \mathrm{C} \\
\text { (mS/m) } \\
\end{array}$ & $\mathrm{PH}$ & $\begin{array}{c}\text { DISSOLVED } \\
\text { IONS } \\
\text { (mg/) } \\
\end{array}$ & $\begin{array}{c}\text { DISSOLVED } \\
\text { SOLIDS } \\
\text { (mg/h) }\end{array}$ & $\begin{array}{l}\text { MARDNESS } \\
\text { (mgn) }) \text { a cacos }\end{array}$ & $\begin{array}{l}\text { ALKALINITY } \\
\text { (mgitiles CaCOS }\end{array}$ & $\begin{array}{l}\text { NATRIUM } \\
\text { (mg/) }\end{array}$ & $\begin{array}{l}\text { KALIUM } \\
\text { (mg/) }\end{array}$ & $\begin{array}{c}\text { CALCIUM } \\
\text { (mg } /)\end{array}$ & $\begin{array}{c}\text { MAGNESIUM } \\
\text { (mgn) } \\
\end{array}$ \\
\hline $\begin{array}{c}W= \\
\left(\operatorname{sum}^{\wedge} 2 / d\right)\end{array}$ & 0.782 & 0.734 & 0.765 & 0.781 & 0.828 & 0.755 & 0.867 & 0.803 & 0.861 & 0.821 \\
\hline$W[0.05]$ & 0.803 & 0.803 & 0.803 & 0.803 & 0.803 & 0.803 & 0.803 & 0.803 & 0.803 & 0.803 \\
\hline W [0.02] & 0.760 & 0.760 & 0.760 & 0.760 & 0.760 & 0.760 & 0.760 & 0.760 & 0.760 & 0.780 \\
\hline$\left[\begin{array}{l}w \\
{[0.01]}\end{array}\right.$ & 0.730 & 0.730 & 0.730 & 0.730 & 0.730 & 0.730 & 0.730 & 0.730 & 0.730 & 0.730 \\
\hline
\end{tabular}

Note : $\quad$ reject the normality at i\% significance level if $W<W$ [i] 
Table C.3.3(b) Station 145013

1. Rank of the Data from the Smallest Value

\begin{tabular}{|c|c|c|c|c|c|c|c|c|c|c|}
\hline DATA * & $\begin{array}{c}\text { CONDUCTIVITT } \\
\text { @ } 25 \mathrm{C} \\
(\mathrm{mS} / \mathrm{m})\end{array}$ & PH & $\begin{array}{l}\text { DISSOLVED } \\
\text { IONS } \\
\text { (mig) }\end{array}$ & $\begin{array}{c}\text { DISSOLVED } \\
\text { SOLIDS } \\
\text { (mig/) }\end{array}$ & $\begin{array}{l}\text { HAADNESS } \\
\text { Imgilites Cacos }\end{array}$ & $\mid \begin{array}{l}\text { ALKALINITY } \\
\text { ImgHllas CoCOS }\end{array}$ & $\begin{array}{l}\text { NATRIUM } \\
\text { (mg/) }\end{array}$ & $\begin{array}{l}\text { KALsUM } \\
\text { (mgn) }\end{array}$ & $\begin{array}{l}\text { CALCIUM } \\
\text { (mg/i) }\end{array}$ & $\begin{array}{c}\text { MAGNESIUN } \\
\text { (mg/) } \\
\end{array}$ \\
\hline$\times 1$ & 429.00 & 7.57 & 255.18 & 232.00 & 130.00 & 89.60 & 29.00 & 1.38 & 24.00 & $\$ 7.00$ \\
\hline$\times 2$ & 432.50 & 7.74 & 266.70 & 238.00 & 131.75 & 100.00 & 30.25 & 1.60 & 24.00 & 17.50 \\
\hline$x 3$ & 450.00 & 7.80 & 276.30 & 253.20 & 146.40 & 110.00 & 32.20 & 1.64 & 26.82 & 19.28 \\
\hline$x 4$ & 494.00 & 7.90 & 327.30 & 261.00 & 152.40 & 129.00 & 38.00 & 1.83 & 27.70 & 20.20 \\
\hline$x 5$ & 525.00 & 7.98 & 359.73 & 296.00 & 175.33 & 151.00 & 38.40 & 1.87 & 31.40 & 22.33 \\
\hline$x 6$ & 541.00 & 8.00 & 363.38 & 297.00 & 176.40 & 155.33 & 39.20 & 1.96 & 33.33 & 23.80 \\
\hline$x 7$ & 598.33 & 8.05 & 404.87 & 340.33 & 206.67 & 156.60 & 43.67 & 2.00 & 37.67 & 27.33 \\
\hline$x$ & 495.69 & 7.86 & 321.92 & 273.93 & 159.85 & 127.36 & 35.82 & 1.75 & 29.27 & 21.06 \\
\hline
\end{tabular}

2. Computation of the Denominator [d]

$$
d=\operatorname{sum}(x i-x)^{\wedge} 2
$$

\begin{tabular}{|c|c|c|c|c|c|c|c|c|c|c|}
\hline & & \multicolumn{9}{|c|}{$(x i-x)^{\wedge} 2$} \\
\hline & 4447.62 & 0.09 & 4454.61 & 1758.40 & 891.02 & 1425.96 & 46.47 & 0.14 & 27.82 & 16.51 \\
\hline & 3903.04 & 0.01 & 3049.56 & 1291.20 & 789.61 & 748.67 & 30.99 & 0.02 & 27.82 & 12.70 \\
\hline & 2087.62 & 0.00 & 2081.45 & 429.87 & 180.90 & 301.44 & 13.08 & 0.01 & 6.02 & 3.18 \\
\hline & 2.86 & 0.00 & 28.91 & 167.27 & 55.50 & 2.68 & 4.77 & 0.01 & 2.48 & 0.75 \\
\hline & 859.05 & 0.01 & 1429.63 & 486.94 & 239.73 & 558.76 & 6.67 & 0.01 & 4.52 & 1.61 \\
\hline & 2052.95 & 0.02 & 1718.69 & 532.07 & 273,90 & 782.40 & 11.45 & 0.04 & 16.48 & 7.49 \\
\hline & 10535.56 & 0.04 & 6879.68 & 4408.96 & 2191.80 & 854.87 & 61.62 & 0.06 & 70.43 & 39.31 \\
\hline$d=$ & 23978.69 & 0.18 & 19642.53 & 9074.72 & 4622.47 & 4674.78 & 175.04 & 0.30 & 155.56 & 81.55 \\
\hline
\end{tabular}

\section{Computation of the $W$ values}

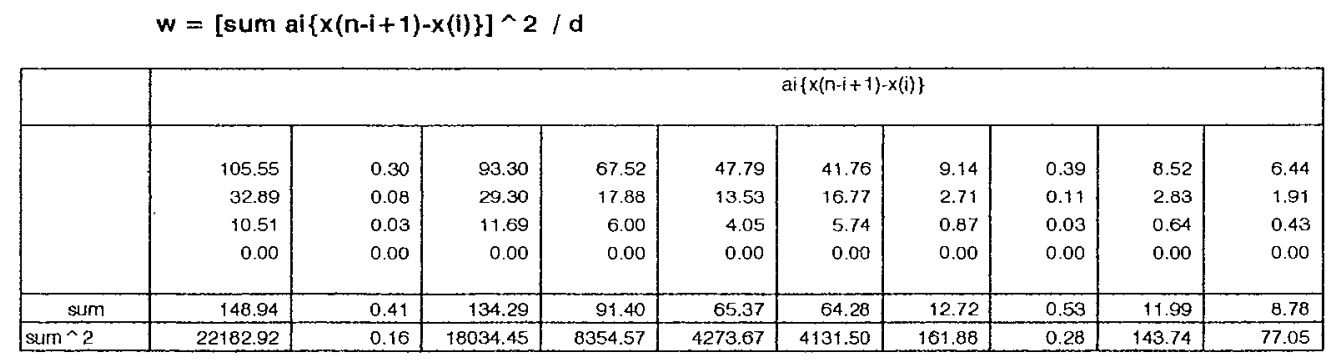

\begin{tabular}{|c|c|c|c|c|c|c|c|c|c|c|}
\hline DATA F & $\begin{array}{c}\text { CONDUCTIVITY } \\
@ 25 \mathrm{C} \\
\langle\mathrm{mS} / \mathrm{m}) \\
\end{array}$ & $\mathrm{PH}$ & $\begin{array}{c}\text { DISSOLVED } \\
\text { IONS } \\
\text { (ming } / \text { ) } \\
\end{array}$ & $\begin{array}{l}\text { DISSOLVED } \\
\text { SOLIDS } \\
\text { (mg/) } \\
\end{array}$ & $\begin{array}{l}\text { HARDNESS } \\
\text { (mg/)as } \mathrm{Coc} \mathrm{CO}_{3} \\
\end{array}$ & $\begin{array}{l}\text { ALKALINITY } \\
\text { (mgilyes Cacos } \\
\end{array}$ & $\begin{array}{l}\text { NATRIUM } \\
\text { (mghl) } \\
\end{array}$ & $\begin{array}{l}\text { KALIUM } \\
\text { (rrag/l) } \\
\end{array}$ & $\begin{array}{l}\text { CALCIUM } \\
\text { (mg/t) }\end{array}$ & $\begin{array}{c}\text { MAGNESIUM } \\
\text { (mg/il) } \\
\end{array}$ \\
\hline $\begin{array}{c}W= \\
\left(\operatorname{sum}^{\wedge} 2 / d\right)\end{array}$ & 0.925 & 0.935 & 0.918 & 0.921 & 0.925 & 0.884 & 0.925 & 0.931 & 0.924 & 0.945 \\
\hline$W[0.05]$ & 0.803 & 0.803 & 0.803 & 0.803 & 0.803 & 0.803 & 0.803 & 0.803 & 0.803 & 0.803 \\
\hline$w[0.02]$ & 0.760 & 0.760 & 0.760 & 0.760 & 0.760 & 0.760 & 0.760 & 0.760 & 0.760 & 0.760 \\
\hline$w[0.01]$ & 0.730 & 0.730 & 0.730 & 0.730 & 0.730 & 0.730 & 0.730 & 0.730 & 0.730 & 0.730 \\
\hline
\end{tabular}

Note: $\quad$ reject the normality at $i \%$ significance level if $W<W$ [i] 
Table C.3.3(c) Station 145020

1. Rank of the Data from the Smallest Value

\begin{tabular}{|c|c|c|c|c|c|c|c|c|c|c|}
\hline DATA \# & $\begin{array}{c}\text { CONOUCTIVIT } \\
\text { (1) 25C } \\
\text { [mS/m] }\end{array}$ & PH & $\begin{array}{c}\text { OISSOLVED } \\
\text { IONS } \\
\text { (mgil) }\end{array}$ & $\begin{array}{c}\text { OISSOLVED } \\
\text { SOLIOS } \\
\text { (mgg) }\end{array}$ & $\begin{array}{l}\text { MARDNESS } \\
\text { (migl)es Cacos }\end{array}$ & $\begin{array}{l}\text { ALKALINITY } \\
\text { (mogli)es Cacos }\end{array}$ & $\begin{array}{l}\text { NATRIUM } \\
\text { (mg/f) }\end{array}$ & $\begin{array}{l}\text { KALIUM } \\
\text { (migh) }\end{array}$ & $\begin{array}{l}\text { CALCIUM } \\
\text { (mgfi) }\end{array}$ & $\begin{array}{l}\text { MAGNESIUM } \\
\text { (mgl) }\end{array}$ \\
\hline$x 1$ & 402.50 & 7.70 & 262.30 & 227.50 & 98.75 & 83.25 & 42.75 & 1.88 & 19.75 & 12.05 \\
\hline$x 2$ & 539.67 & 7.70 & 311.70 & 271.33 & 121.33 & 87.33 & 52.67 & 1.97 & 23.33 & 15.27 \\
\hline$\times 3$ & 571.25 & 7.73 & 350.45 & 305.00 & 132.25 & 89.80 & 59.75 & 2.25 & 24.50 & 17.25 \\
\hline$\times 4$ & 617.50 & 7.93 & 362,20 & 347.50 & 135.75 & 98.75 & 64.50 & 2.45 & 25.63 & 17.38 \\
\hline$\times 5$ & 677.00 & 8.08 & 396.42 & 356.00 & 152.80 & 103.50 & 71.00 & 2.48 & 29.40 & 19.24 \\
\hline$x 6$ & 856.67 & 8.10 & 519.57 & 444.67 & 204.67 & 141.00 & 87.33 & 3.10 & 39.67 & 25.67 \\
\hline$x$ & 610.76 & 7.87 & 367.11 & 320.33 & 140.93 & 100.61 & 63.00 & 2.35 & 27.05 & 17.81 \\
\hline
\end{tabular}

2. Computation of the Denominator [d]

$d=\operatorname{sum}(x i-x) \wedge 2$

\begin{tabular}{|c|c|c|c|c|c|c|c|c|c|c|}
\hline & \multicolumn{10}{|c|}{$(x i-x)^{\wedge} 2$} \\
\hline & 43373.85 & 0.03 & 10984.32 & 8618.03 & 1778.73 & 301.22 & 410.06 & 0.23 & 53.23 & 33.16 \\
\hline & 5054.82 & 0.03 & 3069.84 & 2401.00 & 383.83 & 176.15 & 106.78 & 0.15 & 13.78 & 6.46 \\
\hline & 1561.35 & 0.02 & 277.43 & 235.11 & 75.26 & 116.76 & 10.56 & 0.01 & 6.48 & 0.31 \\
\hline & 45.38 & 0.00 & 24.07 & 8.03 & 26.78 & 3.44 & 2.25 & 0.01 & 2.02 & 0.19 \\
\hline & 4387.22 & 0.04 & 859.30 & 1272.11 & 141.02 & 8.38 & 64.00 & 0.02 & 5.54 & 2.05 \\
\hline & 60468.18 & 0.05 & 23244.22 & 15458.78 & 4063.00 & 1631.71 & 592.11 & 0.56 & 159.29 & 61.76 \\
\hline$d=$ & 114890.78 & 0.17 & 36459.18 & 27993.06 & 6468.62 & 2237.66 & 1185.76 & 0.97 & 240.34 & 103.92 \\
\hline
\end{tabular}

3. Computation of the $W$ values

$w=[\operatorname{sum}$ ai $\{x(n-i+1)-x(i)\}] \bumpeq 2 / d$

\begin{tabular}{|c|c|c|c|c|c|c|c|c|c|c|}
\hline & & & & & & $x(n-i+1)-x$ & & & & \\
\hline & 292.07 & 0.26 & 165.45 & 139.66 & 68.12 & 37.14 & 28.67 & 0.79 & 12.81 & 8.76 \\
\hline & 38.54 & 0.11 & 23.77 & 23.76 & 8.83 & 4.54 & 5.14 & 0.14 & 1.70 & 1.11 \\
\hline & 4.05 & 0.02 & 1.03 & 1.09 & 0.31 & 0.78 & 0.42 & 0.02 & 0.10 & 0.01 \\
\hline & 0.00 & 0.00 & 0.00 & 0.00 & 0.00 & 0.00 & 0.00 & 0.00 & 0.00 & 0.00 \\
\hline sum & 334.66 & 0.38 & 190.25 & 164.51 & 77.25 & 42.46 & 34.23 & 0.95 & 14.61 & 9.88 \\
\hline $\operatorname{sum}^{\wedge} 2$ & 111995.44 & 0.14 & 36194.59 & 27063.90 & 5967.69 & 1802.73 & 1771.80 & 0.90 & 213.43 & 97.67 \\
\hline
\end{tabular}

\begin{tabular}{|c|c|c|c|c|c|c|c|c|c|c|}
\hline DATA \# & $\begin{array}{c}\text { CONDUCTIVIT } \\
\text { @25C } \\
(\mathrm{mS} / \mathrm{m})\end{array}$ & PH & $\begin{array}{l}\text { DISSOLVED } \\
\text { IONS } \\
\text { (mg/l) }\end{array}$ & $\begin{array}{c}\text { DISSOLVED } \\
\text { SOLIOS } \\
\text { (mg/l) }\end{array}$ & $\begin{array}{l}\text { HARDNESS } \\
(\operatorname{mg} / \mathrm{f}) \mathrm{ar} \mathrm{CaCOB}\end{array}$ & $\begin{array}{l}\text { ALKALINITY } \\
\text { (mig/itias } \mathrm{CaCO} 3\end{array}$ & $\begin{array}{l}\text { NATRIUM } \\
\text { (mgil) }\end{array}$ & $\begin{array}{l}\text { KALIUM } \\
\text { (mgif) }\end{array}$ & $\begin{array}{l}\text { CALCIUM } \\
\text { (mg/l) }\end{array}$ & $\begin{array}{l}\text { MAGNESIUM } \\
\text { (mg/l) }\end{array}$ \\
\hline $\begin{array}{c}w= \\
\left(\operatorname{sum}^{\sim} \sim 2 / d\right)\end{array}$ & 0.975 & 0.825 & 0.941 & 0.967 & 0.923 & 0.806 & 0.988 & 0.927 & 0.888 & 0.940 \\
\hline$w[0.05]$ & 0.788 & 0.788 & 0.788 & 0.788 & 0.788 & 0.788 & 0.788 & 0.788 & 0.788 & 0.788 \\
\hline$w[0.02]$ & 0.743 & 0.743 & 0.743 & 0.743 & 0.743 & 0.743 & 0.743 & 0.743 & 0.743 & 0.743 \\
\hline$w[0.01]$ & 0.713 & 0.713 & 0.713 & 0.713 & 0.713 & 0.713 & 0.713 & 0.713 & 0.713 & 0.713 \\
\hline
\end{tabular}

Note: $\quad$ reject the normality at $i \%$ significance level if $\mathrm{W}<\mathrm{W}[\mathrm{i}]$ 